Internationales Recht der Gegenwart

Stephan Riegger

\title{
Die zeitliche Wirkung von Urteilen des EuGH
}

Maßgaben des Unionsrechts und Reaktionsmöglichkeiten mitgliedstaatlicher Gerichte 
Internationales Recht der Gegenwart

herausgegeben von

Prof. Dr. Norman Weiß,

MenschenRechtsZentrum der Universität Potsdam Prof. Dr. Andreas Haratsch,

FernUniversität in Hagen

Band 6 


\section{Stephan Riegger \\ Die zeitliche Wirkung von Urteilen des EuGH}

Maßgaben des Unionsrechts und Reaktionsmöglichkeiten mitgliedstaatlicher Gerichte 
The book processing charge was funded by the Baden-Württemberg Ministry of Science, Research and Arts in the funding programme Open Access Publishing and the Universität Konstanz.

Die Deutsche Nationalbibliothek verzeichnet diese Publikation in der Deutschen Nationalbibliografie; detaillierte bibliografische Daten sind im Internet über http://dnb.d-nb.de abrufbar.

Zugl.: Konstanz, Univ., Diss., 2020

1. Auflage 2021

(c) Stephan Riegger

Publiziert von

Nomos Verlagsgesellschaft $\mathrm{mbH} \& \mathrm{Co}$. KG Waldseestraße 3-5 | 76530 Baden-Baden www.nomos.de

Gesamtherstellung: Nomos Verlagsgesellschaft $\mathrm{mbH} \& \mathrm{Co}$. KG Waldseestraße 3-5 | 76530 Baden-Baden

ISBN (Print): 978-3-8487-8101-0

ISBN (ePDF): 978-3-7489-2519-4

DOI: https://doi.org/10.5771/9783748925194

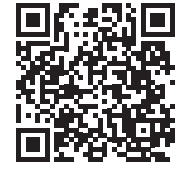

Onlineversion Nomos elibrary

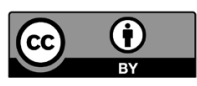

Dieses Werk ist lizensiert unter einer Creative Commons Namensnennung 4.0 International Lizenz. 


\section{Vorwort}

Die vorliegende Arbeit wurde im Wintersemester 2020/2021 vom Fachbereich Rechtswissenschaft der Universität Konstanz als Dissertation angenommen; die mündliche Prüfung erfolgte am 8.12.2020. Für die Veröffentlichung konnten Rechtsprechung und Literatur punktuell noch bis Ende 2020 Berücksichtigung finden.

Ganz besonders möchte ich mich bei meinem Doktorvater Prof. Dr. Marten Breuer für die Unterstützung bedanken, die er mir auf dem gesamten Weg bis zur Veröffentlichung der Arbeit zuteilwerden ließ. Seine große Hilfsbereitschaft gerade auch in schwierigen Zeiten war für mich von unschätzbarem Wert. Ein herzlicher Dank gilt auch Prof. Dr. Philipp Reimer für die sehr zügige Erstellung des Zweitgutachtens und Prof. Dr. Daniel Thym für die Bereitschaft, den Vorsitz der mündlichen Prüfung zu übernehmen. Prof. Dr. Andreas Haratsch und Prof. Dr. Norman Weiß danke ich für die Aufnahme der Arbeit in die Schriftenreihe „Internationales Recht der Gegenwart“. Für die getroffene Vereinbarung zur Übernahme der Kosten der Veröffentlichung danke ich der Universität Konstanz, dem Konsortium Baden-Württemberg und dem Nomos Verlag sehr.

Herzlich bedanke ich mich bei meinen ehemaligen Kolleginnen Dr. Annika Schreiber, Dr. Henrike Schulte und Elisa Stotz, die mir mit offenem Ohr und stets gutem Rat zur Seite standen. Einen herzlichen Dank möchte ich auch der Sekretärin des Lehrstuhls Christiane Richter und allen anderen Lehrstuhlangehörigen aussprechen, die ein sehr angenehmes Umfeld für die Anfertigung der Arbeit geschaffen haben.

Zutiefst dankbar bin ich meinen Eltern. Ihrer Unterstützung darf ich immer gewiss sein. 


\section{Inhaltsverzeichnis}

Abkürzungsverzeichnis

Einführung 25

I. Problemaufriss und Aktualität der Fragestellung 25

II. Gedankengang der Arbeit $\quad 30$

III. Begrenzung des Untersuchungsgegenstands 33

Erster Teil: Die zeitliche Dimension der Rechtsprechung des EuGH

A. Bindungswirkung der Auslegung als Wirkung der ausgelegten

Norm $\quad 38$

I. Verknüpfung mit der zeitlichen Wirkung der Auslegung $\quad 38$

II. Bindungswirkung als Norm- oder Urteilswirkung 40

1. Auslegung im Rahmen der Auslegungsvorabentscheidung $\quad 41$

a) Bindungswirkung im Ausgangsverfahren 41

b) Bindungswirkung außerhalb des Ausgangsverfahrens 46

aa) Kein entscheidender Unterschied zwischen letztinstanzlichen und nicht-letztinstanzlichen Gerichten

bb) Hinweis in der Rechtsprechung zur Begrenzung der zeitlichen Wirkungen 50

cc) Deklaratorisches Auslegungsverständnis und Bindungswirkung

(1) Verhältnis von Rechtsetzung und Rechtsprechung im Unionsrecht 51

(2) Zwischenergebnis 56

dd) Kein Präjudiziensystem 56

c) Ergebnis 61

2. Auslegung im Rahmen anderer Verfahren 63

B. Der Grundsatz der ex tunc-Wirkung der Auslegung 65

I. Auslegung im Rahmen der Auslegungsvorabentscheidung 65

1. Deklaratorisches Auslegungsverständnis und ex tuncWirkung 
2. Ex tunc-Wirkung der Erstauslegung und

Auslegungsbefugnis mitgliedstaatlicher Gerichte $\quad 70$

3. Ex tunc-Wirkung und Rechtsfortbildung $\quad 73$

4. Zeitliche Wirkung der Rechtsprechungsänderung 74

a) Zulässigkeit von Rechtsprechungsänderungen $\quad 75$

b) Zeitliche Wirkung der geänderten Rechtsprechung $\quad 77$

II. Auslegung im Rahmen anderer Verfahren 81

C. Modifikationen der zeitlichen Wirkungen 84

I. Zuständigkeit des Gerichtshofs $\quad 85$

1. Bestehen einer Zuständigkeit 86

2. Ausschließlichkeit dieser Zuständigkeit 87

3. Folgen für eine fehlende Begrenzung der ex tuncWirkung

4. Befugnis zur Prüfung von Amts wegen 92

a) Bestehen eines Antragserfordernisses in der Rechtsprechung des Gerichtshofs?

b) Begründung der Befugnis zur Prüfung von Amts wegen

c) Folgen 96

5. Anwendung des Art. 264 II AEUV? 98

a) Art. 264 II AEUV als Ausgangspunkt der Überlegungen

b) Analoge Anwendung auf die Ungültigkeitsvorabentscheidung aa) Rechtsprechung des Gerichtshofs 100 bb) Kein Entgegenstehen der Unterschiede 102

c) Keine analoge Anwendung auf die Auslegungsvorabentscheidung

d) Grundsatz der Rechtssicherheit 111

e) Vertragsverletzungsverfahren $\quad 116$

6. „Art" der Befugnis 118

7. Ergebnis 121

II. Voraussetzungen einer zeitlichen Beschränkung bei

Auslegungsentscheidungen

1. Kumulatives Vorliegen der Tatbestandsvoraussetzungen und die Rechtssache UNIS

2. Guter Glaube 128
a) Betroffene
129
b) Bezugspunkt des guten Glaubens
130
c) Objektivierter Maßstab 
d) Scheinbare Eindeutigkeit

e) Bildung einer Überzeugung vom Inhalt des Unionsrechts

aa) Veranlassung 138

bb) Berücksichtigungsfähiges Verhalten $\quad 140$

(1) Kommission

(a) Begründung der Beachtlichkeit von Verhalten der Kommission

(b) Beispiele aus der Rechtsprechung des Gerichtshofs

(2) Mitgliedstaaten

(a) Fehlender Anknüpfungspunkt auf Unionsebene

(b) Rechtsschein der Unionsrechtskonformität nationalen Rechts?

(aa) Gültigkeitsvermutung für Unionsrechtsakte

(bb) Keine Übertragbarkeit auf mitgliedstaatliches Recht

(c) Beachtlichkeit von Äußerungen nationaler Gerichte zum Inhalt des Unionsrechts?

(d) Erforderlichkeit eines Bezugs zur Unionsebene

(3) Zwischenergebnis und Schlussfolgerungen 161

(4) Gerichtshof

(a) Erstauslegung

(b) Rechtsprechungsänderung

(c) Anschein einer Rechtsprechungsänderung

(d) Obiter dicta

(e) Untätigkeit des Gerichtshofs /

Schlussanträge

(f) Ausschluss guten Glaubens durch

Rechtsprechung

(g) Unvorhergesehene Einschlägigkeit der Rechtsprechung

(5) Unionsgesetzgeber

(6) Sonstige Rechtsansichten 
cc) Ergebnis 178

f) Zeitpunkt/Zeitraum des guten Glaubens 179

g) Ergebnis 180

3. Gefahr schwerwiegender Störungen 181

a) „Störungen“ als Oberbegriff 181

b) Intention des Kriteriums 183

c) Bestehen einer Gefahr 186

d) Wirtschaftliche und finanzielle Auswirkungen $\quad 187$

e) Maßgeblichkeit der Auswirkungen auf alle Rechtsunterworfenen 191

f) Schwerwiegende Auswirkungen 194

aa) Betroffenheit von „Subsystemen“ 194

bb) Relativität der Auswirkungen 196

cc) Fazit 199

g) Ermittlung der Auswirkungen 199

aa) Schwierigkeiten und Besonderheiten der

bb) Abwälzung der Lasten 201

cc) Mitgliedstaatliche Verfahrensautonomie 204

h) Kohärenz mit den übrigen Aspekten der

Begrenzungsrechtsprechung 205

aa) Rückausnahme und Gefahr schwerwiegender Störungen 205

bb) Präklusion und Gefahr schwerwiegender Störungen 207

i) Ergebnis 209

4. Fragen der „Beweislast“ 209

a) Feststellungslast 210

b) Anforderungen in der Rechtsprechung 211

c) Urteilsfolgenverantwortung des EuGH 215

5. Präklusion / Konnexität 216

a) Begründung und Folgen der Konnexität 217

b) „Bestimmtes Rechtsproblem" 218

c) Präklusion nur bei Auslegungsvorabentscheidungen? 220

d) Verwerfungen? 221

aa) Verhältnis zum guten Glauben 221

bb) Begrenzung der zeitlichen Wirkungen im nachfolgenden Urteil 224

(1) Keine Begrenzung auf den Zeitpunkt des späteren Urteils 
(2) Begrenzung auf den Zeitpunkt des ersten Urteils?

(a) Akzessorische Beschränkungen

(b) Konstitutive Beschränkungen

(aa) Ausgangslage

(bb) Vergleichbarkeit mit einer

Rechtsprechungsänderung?

(cc) Schlussfolgerung

e) Zurückweisung weiterer Einwände gegen das Konnexitätskriterium

f) Ergebnis

III. Voraussetzungen einer Fortwirkungsanordnung in den

Unwirksamkeitsverfahren

1. Rechtssicherheitserwägungen im öffentlichen Interesse

237

a) Vermeidung einer Regelungslücke

b) Wahrung des institutionellen Gleichgewichts / Verstöße gegen den Gleichheitsgrundsatz

c) Vermeidung von Wettbewerbsverzerrungen

d) Haushaltsplan der EU

e) Vermeidung jeglicher Unsicherheit im völkerrechtlichen Verkehr

2. Rechtssicherheitserwägungen im Interesse Privater 247

3. Präklusion / Nachholbarkeit 249

4. Zusammenfassung 251

IV. Rechtsfolgen einer Begrenzung der zeitlichen Wirkungen 251

1. Auslegungsentscheidungen 252

a) Räumliche Erstreckung 252

aa) Eingehen auf mitgliedstaatliche Bedürfnisse 253

bb) Einwand: unionsweit einheitliche Maßstäbe 253

cc) Entgegenstehen des Konnexitätskriteriums 259

dd) Vergleich mit den Unwirksamkeitsverfahren 260

ee) Ergebnis 260

b) Sachliche Erstreckung 261

c) Zeitliche Erstreckung 265

aa) Tag der Urteilsverkündung 265

bb) Zukünftiger Zeitpunkt? 266

d) Persönliche Erstreckung - Rückausnahme für

Rechtsbehelfsführer?

aa) Begriff des Rechtsbehelfsführers 270 
bb) Begründungsansätze $\quad 270$

(1) Effektiver Rechtsschutz 271

(2) Praktische Wirksamkeit des Vorabentscheidungsverfahrens

(3) Rückausnahme und Entscheidungserheblichkeit

cc) Andere Rechtsbehelfsführer 275

dd) Ausnahmen von der Rückausnahme? 275

(1) Rein wirtschaftliche Überlegungen 276

(2) Trittbrettfahrerproblematik 276

ee) Vergleich mit den Unwirksamkeitsentscheidungen 280

(1) Ungültigkeitsvorabentscheidung 280

(2) Nichtigkeitsklage 281

ff) Fazit 281

2. Unwirksamkeitsverfahren 282

a) "Art“ der Befugnis 282

aa) Nichtigkeitsklage 282

bb) Ungültigkeitsvorabentscheidung 284

cc) Abgrenzungen 286

b) Sachliche Erstreckung 288

c) Zeitliche Erstreckung 290

aa) Aufrechterhaltung bis zum Urteil 291

bb) Aufrechterhaltung bis zu einem zukünftigen Zeitpunkt

A. Einordnung der Defrenne-Rechtsprechung in den Kontext des nationalen Verfahrens

I. Grundsatz der Verfahrensautonomie der Mitgliedstaaten 297

1. Bedeutung nationaler Verfahrensmodalitäten 297

2. Schranke der Bestands- und Rechtskraft 301

3. Reaktionen mitgliedstaatlicher Gerichte als Ausfluss nationaler Verfahrensautonomie?

II. Eigenständige Bindungswirkung der Vornahme bzw.

Ablehnung einer zeitlichen Begrenzung?

1. Vornahme einer zeitlichen Begrenzung

2. Unterbleiben einer Begrenzung

3. Rechtskraft und Begrenzung der zeitlichen Wirkungen 
B. Die „Durchsetzungsdimension“

I. Zusammenhang zwischen Auslegung und Anwendung des Unionsrechts

II. Trennung von Auslegung und Durchsetzungsdimension?

III. Folgerungen für die Frage „nationalen Vertrauensschutzes“

I. Stellenwert des Vorrangs im Unionsrecht und Einführung in die Problematik

II. Einschränkbarkeit des Vorrangs

III. Konturierung der Voraussetzungen und der Zuständigkeitsverteilung bei einer Suspendierung des Anwendungsvorrangs

1. Kein Anknüpfen an den Kollisionsbegriff

2. Rechtsgrundlage einer vorübergehenden Aussetzung der Verdrängungswirkung

3. Die Winner Wetten-Rechtsprechung

4. Nähere Konturierung der Voraussetzungen in der Rechtsprechung des EuGH

a) Die Rechtssache Inter-Environnement Wallonie und Terre wallonne

b) Die Rechtssache Association France Nature Environnement

c) Einordnung

aa) Taugliche Ziele

bb) Bestehen einer Vorlagepflicht

cc) Auswirkungen auf den Vorrang

IV. Suspendierung des Vorrangs im Hinblick auf Vertrauen in nationales Recht?

1. Unterschiede und Gemeinsamkeiten mit der

Begrenzung der ex tunc-Wirkung

2. Irrelevanz nationaler Vertrauensumstände

a) Verletzung der zeitlichen Wirkungen eines EuGH-

Urteils durch „nationalen Vertrauensschutz“?

b) „Sperrwirkung“ der Defrenne-Rechtsprechung

aa) Das Urteil in der Rechtssache DI 385

bb) Abbildung im deutschen Recht 394

cc) Ergebnis 396

3. Vergleich zur Winner Wetten-Rechtsprechung 397 
V. Besonderheiten bei individuellen Rechtspositionen gegenüber dem Mitgliedstaat

1. Defrenne-Rechtsprechung und Verwaltungsrecht

2. Nationales Recht als Anknüpfungspunkt für Vertrauensschutz

3. Ergebnis

VI. Begrenzung des Vorrangs durch Zulassung der Anwendung nationaler Grundrechte?

1. Die Taricco-Problematik

a) Verpflichtung zur Nichtanwendung der italienischen Verjährungsregeln

b) „Konkretisierung“ dieser Pflicht im „Dialog“ mit dem italienischen Verfassungsgerichtshof

2. Einordnung des Taricco II-Urteils in die (bisherige) Systematik des Grundrechtsschutzes

a) Bestimmung des Verhältnisses der Grundrechtsebenen

b) Anwendung des Art. 53 GRCh?

3. Nationaler Grundrechtsstandard als Grenze des Vorrangs?

4. Ergebnis

VII. Zusammenfassung 435

D. Mittelbar wirkendes Unionsrecht 436

I. Einführung 436

II. Unterscheidung von unmittelbar und mittelbar wirkendem Unionsrecht wegen ihrer unterschiedlichen Wirkungsweise?

1. Unmittelbare Geltung von Richtlinien 439

2. Vorrang von Richtlinien 444

a) Keine Hierarchie 446

b) Bedeutung der unmittelbaren Wirkung 448

c) Anklänge einer „entkoppelten“ Ausschlusswirkung $\quad 449$ aa) Die Rechtssache Link Logistik N\&N 450

bb) Verdrängung des verfassungsrechtlichen

Prüfungsmaßstabs

d) Unzertrennlichkeit von Vorrang und unmittelbarer Wirkung

e) Ablehnung der Horizontalwirkung von Richtlinien durch den Gerichtshof

3. Fazit 
III. Richtlinienkonforme Auslegung

1. Verpflichtung zu richtlinienkonformer Auslegung als Ausfluss des Vorrangs?

2. Vertrauensschutz gegen Rechtsprechung im deutschen Recht

a) Rechtsprechung als Anknüpfungspunkt für Vertrauensschutz

b) Unterschiede zwischen Erstauslegung und Rechtsprechungsänderung

aa) Erstauslegung

bb) Rechtsprechungsänderung

c) Zusammenfassung

3. Übertragung der Grundsätze des „nationalen Vertrauensschutzes" auf die richtlinienkonforme Auslegung durch Fruchtbarmachung ihrer Grenzen?

a) Keine Unterscheidung zwischen einfach- und verfassungsrechtlichem Vertrauensschutz

b) Die Grenzen richtlinienkonformer Auslegung

c) Ausformung der Grenze der allgemeinen Rechtsgrundsätze in der Rechtsprechung des EuGH

aa) Strafrecht und umgekehrt vertikale Verhältnisse

bb) Vertrauensschutz und „immediate applicability“

cc) Beachtung der Rechtskraft

dd) Horizontalverhältnisse

d) Berücksichtigung nationaler Vertrauensumstände im Rahmen der contra legem-Grenze?

aa) Zuständigkeit für die Bestimmung der contra legem-Grenze

bb) Vertrauensschutz als Methodenregel?

(1) Keine Anerkennung im Impact-Urteil

(2) Verpflichtung zur Abänderung einer richtlinienwidrigen Rechtsprechung

(3) Zeitliche Dimension der Pflicht zu richtlinienkonformer Auslegung

cc) Vertrauensschutz als Reflex der contra legemGrenze

(1) Verpflichtung auch zur Rechtsfortbildung

(2) Teleologische Reduktion (auf Null)

(3) Überspielen der Wertentscheidung des Gesetzgebers 
(4) Zwischenfazit

dd) Bedeutung der Äußerungen nationaler Gerichte zur contra legem-Grenze

ee) Ergebnis

e) Berücksichtigung nationaler Vertrauensumstände im Rahmen der Grenze der allgemeinen Rechtsgrundsätze?

aa) Ausschluss der Berücksichtigung nationaler

Vertrauensumstände im Horizontalverhältnis?

(1) Begrenzte Aussagekraft des Urteils in den verbundenen Rechtssachen Gutiérrez Naranjo u.a.

(2) Deutlicher Hinweis im Urteil in der Rechtssache DI

(3) Rechtssicherheit und Vertrauensschutz
(a) Rechtssicherheit
(b) Vertrauensschutz
(c) Fazit

(4) Vergleichbarkeit mit den Erwägungen zum Anwendungsvorrang

bb) Verhältnis zu Art. 53 GRCh

f) Ergebnis

IV. Zusammenfassung

E. Verfassungsrechtliche Integrationsgrenzen und zeitliche

Dimension der EuGH-Rechtsprechung

I. Einführung

II. Verfassungsrechtliche Grenzen des „Anwendungsvorrangs“

1. Vorbehalt hinreichend wirksamen Grundrechtsschutzes

a) Schicksal des Solange II-Vorbehalts

b) Ex tunc-Wirkung und Solange II-Rechtsprechung

c) Grundrechtsprüfung durch das Bundesverfassungsgericht

2. Identitäts- und Ultra-vires-Kontrolle

a) Identitätskontrolle

aa) Ex tunc-Wirkung im Lichte von Art. 1 GG und Art. $20 \mathrm{GG}$

(1) Menschenwürde

(2) Rechtsstaatsprinzip / Gewaltenteilung

(3) Haushaltspolitische Gesamtverantwortung / Budgetrecht des Deutschen Bundestages 
(4) Ergebnis

bb) Bedeutung für die richtlinienkonforme

Auslegung

b) Ultra-vires-Kontrolle

3. Ergebnis

Schlussbetrachtung und Ausblick

Literaturverzeichnis
587

579

580

583

585

593 


\section{Abkürzungsverzeichnis}

$\begin{array}{ll}\text { a.A. } & \text { anderer Ansicht } \\ \text { a.a.O. } & \text { am angegebenen Ort } \\ \text { a.F. } & \text { alte Fassung } \\ \text { AB } & \text { Administratiefrechtelijke Beslissingen } \\ \text { ABl. } & \text { Amtsblatt der Europäischen Union } \\ \text { Abs. } & \text { Absatz } \\ \text { AEL } & \text { Academy of European Law } \\ \text { AEUV } & \text { Vertrag über die Arbeitsweise der Europäischen Union } \\ \text { AGB } & \text { Allgemeine Geschäftsbedingungen } \\ \text { AJCL } & \text { The American Journal of Comparative Law } \\ \text { AJDA } & \text { L'actualité juridique. Droit administratif } \\ \text { Alt. } & \text { Alternative } \\ \text { Anm. } & \text { Anmerkung } \\ \text { AöR } & \text { Archiv des öffentlichen Rechts } \\ \text { AP } & \text { Arbeitsrechtliche Praxis } \\ \text { ArbG } & \text { Arbeitsgericht } \\ \text { ArbR } & \text { Arbeitsrecht } \\ \text { Art. } & \text { Artikel } \\ \text { Aufl. } & \text { Auflage } \\ \text { AuR } & \text { Arbeit und Recht } \\ \text { B.T.R. } & \text { British Tax Review } \\ \text { BAG } & \text { Bundesarbeitsgericht } \\ \text { BAGE } & \text { Entscheidungen des Bundesarbeitsgerichts } \\ \text { BB } & \text { Betriebs-Berater } \\ \text { BeckOK } & \text { Beck'scher Online-Kommentar } \\ \text { BGB } & \text { Bürgerliches Gesetzbuch } \\ \text { BGBl. } & \text { Bundesgesetzblatt } \\ \text { BGH } & \text { Bundesgerichtshof } \\ \text { BGHZ } & \text { BSG }\end{array}$




\begin{tabular}{|c|c|}
\hline Buchst. & Buchstabe \\
\hline BUrlG & Bundesurlaubsgesetz \\
\hline BVerfG & Bundesverfassungsgericht \\
\hline BVerfGE & Entscheidungen des Bundesverfassungsgerichts \\
\hline BVerfGG & Bundesverfassungsgerichtsgesetz \\
\hline BVerfGK & Kammerentscheidungen des Bundesverfassungsgerichts \\
\hline BVerwG & Bundesverwaltungsgericht \\
\hline BVerwGE & Entscheidungen des Bundesverwaltungsgerichts \\
\hline BVwG & Bundesverwaltungsgericht (Österreich) \\
\hline bzw. & beziehungsweise \\
\hline C.D.E. & Cahiers de Droit Européen \\
\hline C.L.J. & The Cambridge Law Journal \\
\hline CMLRev. & Common Market Law Review \\
\hline CR & $\begin{array}{l}\text { Computer und Recht, Zeitschrift für die Praxis des Rechts der } \\
\text { Informationstechnologie }\end{array}$ \\
\hline CYELS & Cambridge Yearbook of European Legal Studies \\
\hline d.h. & das heißt \\
\hline DB & Der Betrieb \\
\hline DEHSt & Deutsche Emissionshandelsstelle \\
\hline DÖV & Die Öffentliche Verwaltung \\
\hline DStR & Deutsches Steuerrecht \\
\hline DStZ & Deutsche Steuer-Zeitung \\
\hline DVBl. & Deutsches Verwaltungsblatt \\
\hline ecolex & Fachzeitschrift für Wirtschaftsrecht \\
\hline EG & $\begin{array}{l}\text { Europäische Gemeinschaft/Vertrag zur Gründung der Europä- } \\
\text { ischen Gemeinschaft (in der Fassung des Vertrags von Amster- } \\
\text { dam) }\end{array}$ \\
\hline EGMR & Europäischer Gerichtshof für Menschenrechte \\
\hline EGV & $\begin{array}{l}\text { Vertrag zur Gründung der Europäischen Gemeinschaft (in der } \\
\text { Fassung des Vertrags von Maastricht) }\end{array}$ \\
\hline EGVVG & Einführungsgesetz zum Versicherungsvertragsgesetz \\
\hline ELJ & European Law Journal \\
\hline ELRep. & European Law Reporter \\
\hline ELRev. & European Law Review \\
\hline EMRK & $\begin{array}{l}\text { Europäische Konvention zum Schutz der Menschenrechte und } \\
\text { Grundfreiheiten }\end{array}$ \\
\hline
\end{tabular}




\begin{tabular}{ll} 
endg. & endgültig \\
ERCL & European Review of Contract Law \\
EU & Europäische Union \\
EuCML & Journal of European Consumer and Market Law \\
eucrim & The European Criminal Law Associations' Forum \\
EuG & Gericht (vor Inkrafttreten des Vertrags von Lissabon: Gericht \\
& erster Instanz) \\
EuGH & Gerichtshof (der Europäischen Union) \\
EuGH-VerfO & Verfahrensordnung des Gerichtshofs \\
EuGRZ & Europäische Grundrechte-Zeitschrift \\
EUI & European University Institute \\
EuLF & The European Legal Forum \\
EuR & Europarecht \\
EUV & Vertrag über die Europäische Union \\
EuZ & Zeitschrift für Europarecht \\
EuZA & Europäische Zeitschrift für Arbeitsrecht \\
EuZW & Europäische Zeitschrift für Wirtschaftsrecht \\
EWG & Europäische Wirtschaftsgemeinschaft \\
EWGV & Vertrag zur Gründung der Europäischen Wirtschaftsgemein- \\
& schaft \\
EWiR & Entscheidungen zum Wirtschaftsrecht \\
EWS & Europäisches Wirtschafts- und Steuerrecht \\
EZB & Europäische Zentralbank \\
f., ff. & folgende (Singular/Plural) \\
FA & Fachanwalt Arbeitsrecht \\
Fn. & Fußnote(n) \\
FR & Finanz-Rundschau \\
FS & Festschrift \\
GA & Generalanwalt/Generalanwältin \\
GewArch & Zeitschrift für Gewerbe- und Wirtschaftsverwaltungsrecht \\
GG & Grundgesetz \\
GLJ & German Law Journal \\
GPR & Zeitschrift für Gemeinschaftsprivatrecht \\
GRCh & Charta der Grundrechte der Europäischen Union \\
GS & Gedächtnisschrift \\
Hrsg. & Herausgeber \\
\hline &
\end{tabular}


HStR Handbuch des Staatsrechts der Bundesrepublik Deutschland

i.V.m. in Verbindung mit

IJEL Irish Journal of European Law

insb. insbesondere

Intertax International Tax Review

IR Infrastrukturrecht

IStR Internationales Steuerrecht

IWB Internationale Wirtschafts-Briefe

IYIL The Italian Yearbook of International Law

J.T. Journal des tribunaux

JbArbR Jahrbuch des Arbeitsrechts

JB1. Juristische Blätter

JOR Jahrbuch für Ostrecht

jurisPR-ArbR juris PraxisReport Arbeitsrecht

JuS Juristische Schulung

JZ Juristenzeitung

KOM Europäische Kommission

KSchG Kündigungsschutzgesetz

LAG Landesarbeitsgericht

LG Landgericht

lit. litera

LMK Lindenmaier-Möhring, Kommentierte BGH-Rechtsprechung

LSG Landessozialgericht

m.w.N. mit weiteren Nachweisen

MDR Monatsschrift für Deutsches Recht

MwStR Mehrwertsteuerrecht

NJOZ Neue Juristische Online-Zeitschrift

NJW Neue Juristische Wochenschrift

NJW-RR NJW-Rechtsprechungsreport

no. Numéro/number

Nr. Nummer

$\mathrm{NtEr} \quad$ Nederlands tijdschrift voor Europees recht

NVwZ Neue Zeitschrift für Verwaltungsrecht

NZA Neue Zeitschrift für Arbeitsrecht

NZA-RR NZA-Rechtsprechungsreport 
NZWiSt Neue Zeitschrift für Wirtschafts-, Steuer- und Unternehmensstrafrecht

ÖJZ

OLG

OMT

OVG

PSPP

R.A.E.

RabelsZ

RCJB

$\operatorname{RdA}$

RIW

RL

Rn.

Rs.

RTDEur.

S.

SAE

SchiedsVZ

SEW

Slg.

SR

StGB

StuW

SUP

TRIPS

TzBfG

u.a.

UAbs.

UR

UVP

VbR
Österreichische Juristen-Zeitung

Oberlandesgericht

Outright Monetary Transaction

Oberverwaltungsgericht

Public Sector Purchase Programme

Revue des Affaires Européennes

Rabels Zeitschrift für ausländisches und internationales Privatrecht

Revue critique de jurisprudence belge

Recht der Arbeit

Recht der Internationalen Wirtschaft - Betriebs-Berater International

Richtlinie

Randnummer(n)

Rechtssache(n)

Revue trimestrielle de droit européen

Seite(n), Satz

Sammlung Arbeitsrechtlicher Entscheidungen

Zeitschrift für Schiedsverfahren

Sociaal Economische wetgeving (Tijdschrift voor Europees en economisch recht)

Amtliche Sammlung des EuGH

Soziales Recht (Wissenschaftliche Zeitschrift für Arbeits- und Sozialrecht)

Strafgesetzbuch

Steuer und Wirtschaft

Strategische Umweltprüfung

Trade-Related Aspects of Intellectual Property Rights

Teilzeit- und Befristungsgesetz

und andere/unter anderem

Unterabsatz

Umsatzsteuer-Rundschau

Umweltverträglichkeitsprüfung

Zeitschrift für Verbraucherrecht 
verb.

VG

vgl.

$\mathrm{VO}$

VVG

$\mathrm{VwVfG}$

WM

WuB

YEL

z.B.

ZaöRV

ZESAR

ZEuP

ZEuS

ZfA

ZfPW

ZfWG

ZIP

ZJS

ZöR

ZTR

ZZP verbundene(n)

Verwaltungsgericht

vergleiche

Verordnung

Versicherungsvertragsgesetz

Verwaltungsverfahrensgesetz

Wertpapier-Mitteilungen - Zeitschrift für Wirtschafts- und Bankrecht

Entscheidungsanmerkungen zum Wirtschafts- und Bankrecht

Yearbook of European Law

zum Beispiel

Zeitschrift für ausländisches öffentliches Recht und Völkerrecht

Zeitschrift für europäisches Sozial- und Arbeitsrecht

Zeitschrift für Europäisches Privatrecht

Zeitschrift für Europarechtliche Studien

Zeitschrift für Arbeitsrecht

Zeitschrift für die gesamte Privatrechtswissenschaft

Zeitschrift für Wett- und Glücksspielrecht

Zeitschrift für Wirtschaftsrecht

Zeitschrift für das Juristische Studium

Zeitschrift für öffentliches Recht

Zeitschrift für Tarifrecht

Zeitschrift für Zivilprozess 


\section{Einführung}

\section{Problemaufriss und Aktualität der Fragestellung}

Nach dem vom Gerichtshof $(\mathrm{EuGH})^{1}$ in ständiger Rechtsprechung vertretenen Verständnis „erläutert und verdeutlicht" er bei der Auslegung, „in welchem Sinne und mit welcher Tragweite“ eine Bestimmung des Unionsrechts „seit ihrem Inkrafttreten zu verstehen und anzuwenden ist oder gewesen wäre", sodass die nationalen Gerichte die Vorschrift in der vom Gerichtshof vorgenommenen Auslegung bei Vorliegen der nationalen Verfahrensvoraussetzungen „auch auf Rechtsverhältnisse, die vor Erlass des auf das Ersuchen um Auslegung ergangenen Urteils entstanden sind, anwenden können und müssen“. ${ }^{2}$ Bis zum Zeitpunkt der Auslegung des Unionsrechts durch den hierfür nach Art. 19 I UAbs. 1 S. 2 und III lit. b EUV sowie Art. 267 AEUV zuständigen Gerichtshof kann in den Mitgliedstaaten zum Teil bereits über Jahre hinweg eine Rechtsanwendung erfolgt sein, die sich dann mit dem vom EuGH festgestellten Inhalt des Unionsrechts als unvereinbar erweist. In diesem Fall drängt sich die im Rahmen dieser Arbeit näher zu beleuchtende Frage auf, ob ein auf nationaler Ebene vertretenes und sich mit der Entscheidung des Gerichtshofs als unionsrechtswidrig herausstellendes Rechtsverständnis eine schützenswerte Rechtsposition der durch die Auslegung des EuGH negativ Betroffenen begründet hat und wie diese gegebenenfalls zu schützen ist.

Allgemeiner gesprochen geht es um die Beantwortung der Frage, ob und wenn ja welche Reaktionsmöglichkeiten sich mitgliedstaatlichen Gerichten im Hinblick auf die zeitliche Dimension der Auslegungsentscheidungen des EuGH bieten. Angesprochen ist damit ein gegebenenfalls bestehendes Bedürfnis nach Gewährung von - schlagwortartig bezeichnet - „nationalem Vertrauensschutz“ für in der Vergangenheit begründete Rechtsverhältnisse. In den Blick zu nehmen ist darüber hinaus ein mögliches mitgliedstaatliches Interesse daran, die Wirkung des Unionsrechts

1 Nach Art. 19 I UAbs. 1 S. 1 EUV umfasst der Gerichtshof der Europäischen Union den Gerichtshof, das Gericht und Fachgerichte. Mit EuGH wird vorliegend der Gerichtshof bezeichnet.

2 Siehe aus jüngerer Zeit nur EuGH, Urteil vom 13.12.2018, Rs. C-385/17 (Hein), Rn. 56. 
bis zu einem Zeitpunkt in der Zukunft hinauszuzögern, um etwa eine Anpassung des mitgliedstaatlichen Rechts an unionsrechtliche Vorgaben zu ermöglichen.

In Rechnung zu stellen ist bei der vorliegenden Untersuchung, dass EuGH und nationale Gerichte im Rahmen des europäischen Mehrebenensystems gemeinsam Verantwortung dafür tragen, dass bei der Betroffenheit von Unionsrecht berechtigte Erwartungen geschützt werden. Zu erfolgen hat dies im Rahmen ihrer jeweiligen Befugnisse zur Auslegung und Anwendung des Unionsrechts ${ }^{3}$, weshalb die hier zu diskutierende Fragestellung auch grundlegende Fragen des Verhältnisses von Unionsrecht und nationalem Recht aufwirft.

Ihre Aktualität zeigt nicht zuletzt ein im Jahr 2017 an den EuGH gerichtetes (und von diesem Ende 2018 hinsichtlich der hier interessierenden Problematik nur zum Teil beantwortetes) Vorabentscheidungsersuchen des Arbeitsgerichts Verden. ${ }^{4}$ Dieses fragt den EuGH zunächst danach, ob Art. 31 GRCh und Art. 7 I der Richtlinie 2003/88/EG („Arbeitszeitrichtlinie $^{\text {(") }} 5$ dahin auszulegen sind, dass sie einer nationalen gesetzlichen Regelung entgegenstehen, nach der in Tarifverträgen bestimmt werden kann, dass Verdienstkürzungen, die im Berechnungszeitraum infolge von Kurzarbeit eintreten, auf die Berechnung des Urlaubsentgeltes Einfluss haben, was, verglichen mit der Zugrundelegung des durchschnittlichen Arbeitsverdiensts, zu einer geringeren Urlaubsvergütung bzw. -abgeltung führt. ${ }^{6}$

$\mathrm{Da}$ der EuGH zu dem Ergebnis gelangt, dass das Unionsrecht der in Rede stehenden nationalen Regelung entgegensteht ${ }^{7}$, erlangt die zweite Vorlagefrage des Arbeitsgerichts Verden Bedeutung, die sich im Anschluss an diese Feststellung stellt und in Erfahrung bringen möchte, wie mit ihr in zeitlicher Hinsicht umzugehen ist.

In Erwägung zu ziehen ist insoweit zunächst die zeitliche Beschränkung der Möglichkeit, sich auf die vom EuGH im vorliegenden Vorabentscheidungsverfahren vorgenommene Auslegung zu berufen, mit Wirkung

3 Siehe insoweit auch den Ansatz bei Düsterhaus, YEL 36 (2017), 237; Düsterhaus, EuR 2017, 30.

4 Siehe EuGH, Urteil vom 13.12.2018, Rs. C-385/17 (Hein).

5 Richtlinie 2003/88/EG des Europäischen Parlaments und des Rates vom 4. November 2003 über bestimmte Aspekte der Arbeitszeitgestaltung, ABl. L 299 vom 18.11.2003, S. 9.

6 Vorlagefrage 1 in der Rs. C-385/17 (Hein).

7 EuGH, Urteil vom 13.12.2018, Rs. C-385/17 (Hein), Tenor Nr. 1 und Rn. 53. 
für alle Betroffenen. ${ }^{8}$ Eine solche auf den allgemeinen unionsrechtlichen Grundsatz der Rechtssicherheit gestützte Beschränkung erkennt der EuGH seit seinem Defrenne II-Urteil ${ }^{9}$ an, mit der er den praktischen Folgen seiner Auslegung Rechnung trägt. Sie kann allerdings, wie im Verlauf der Arbeit noch näher zu zeigen sein wird, nur vom EuGH selbst vorgenommen werden und ist an enge Voraussetzungen geknüpft. Die in jenem Urteil begründete Rechtsprechung („Defrenne-Rechtsprechung“) wird zu Recht als eine der bedeutendsten richterrechtlichen Entwicklungen im Rahmen des Art. 267 AEUV bezeichnet. ${ }^{10}$

$\mathrm{Ob}$ die Voraussetzungen der Defrenne-Rechtsprechung erfüllt sind, möchte das Arbeitsgericht Verden daher konsequenterweise zunächst in Erfahrung bringen und fragt in diesem Zusammenhang, ob die von ihm angeführten Urteile des BAG einen für die Defrenne-Rechtsprechung relevanten Gesichtspunkt darstellen. ${ }^{11}$

Allgemeiner gesprochen steht damit die Frage im Raum, ob von mitgliedstaatlichen Stellen im Hinblick auf den Inhalt des Unionsrechts geäußerte Rechtsansichten bei der vom Gerichtshof vorzunehmenden Begrenzung der zeitlichen Wirkungen seiner Rechtsprechung Berücksichtigung finden können. Sollte dies nicht der Fall sein und aus diesem Grund eine Begrenzung im Sinne der Defrenne-Rechtsprechung ausscheiden, ist nach anderen, nunmehr im Verfahren vor dem nationalen Gericht bestehenden Möglichkeiten zu deren Berücksichtigung zu fragen. Das Arbeitsgericht Verden interessiert sich in dieser Hinsicht für die unionsrechtliche Zulässigkeit der Gewährung von Vertrauensschutz durch die nationalen Gerichte „auf der Grundlage nationalen Rechts“. ${ }^{12}$ Auch insoweit führt das Arbeitsgericht Verden Vertrauen der Arbeitgeber auf den Fortbestand einer nationalen höchstrichterlichen Rechtsprechung an. ${ }^{13}$

8 In aller Regel werden hiervon diejenigen ausgenommen, die bereits Klage erhoben oder einen entsprechenden Rechtsbehelf eingelegt haben („Rückausnahme für Rechtsbehelfsführer“), siehe z.B. EuGH, Urteil vom 9.3.2000, Rs. C-437/97 (EKW und Wein \& Co.), Tenor Nr.3 und Rn.60. Näher dazu unten bei Fn. $1102 \mathrm{ff}$.

9 EuGH, Urteil vom 8.4.1976, Rs. 43/75 (Defrenne), schlagwortartig als „Defrenne II" bezeichnet, so auch etwa von GA Kokott, Schlussanträge vom 30.6.2016 in der Rs. C-443/15 (Parris), Fn. 85.

10 Düsterhaus, YEL 36 (2017), 237; Düsterhaus, EuR 2017, 30.

11 ArbG Verden, Vorlagebeschluss vom 19.6.2017, 1 Ca 142/16, Rn. 90 ff., insb. Rn. 92 - juris.

12 ArbG Verden, Vorlagebeschluss vom 19.6.2017, 1 Ca 142/16, Rn. 93 - juris.

13 Vorlagefrage 2 in der Rs. C-385/17 (Hein). 
Die hier angesprochenen beiden Problemkreise sind in der Literatur bereits zum Teil ausführlicher Untersuchung unterzogen worden. ${ }^{14}$ Nicht zuletzt das Vorabentscheidungsersuchen des Arbeitsgerichts Verden und die Antwort des EuGH zeigen aber, dass sie noch keineswegs einer abschließenden Klärung zugeführt werden konnten. Die Frage der Reaktionsmöglichkeiten mitgliedstaatlicher Gerichte auf die zeitliche Dimension der Rechtsprechung des Gerichtshofs erneut aufzuwerfen, ermöglicht es auch, neuere Entscheidungen des EuGH ${ }^{15}$ und Reaktionen mitgliedstaatlicher Gerichte ${ }^{16} \mathrm{zu}$ dieser Problemstellung in die Betrachtung miteinzubeziehen. An ihnen zeigt sich, dass auch und insbesondere im Bereich der zeitlichen Wirkung der Rechtsprechung ein grundlegendes Ringen zwischen der nationalen und der europäischen Ebene um die Eigenständigkeit der Mitgliedstaaten im europäischen Einigungsprozess stattfindet.

In den Blick zu nehmen sind auch die Institute des Anwendungsvorrangs und der richtlinienkonformen Auslegung, die zwar bereits seit Jahrzehnten sowohl in der Rechtsprechung des Gerichtshofs als auch derjenigen mitgliedstaatlicher Gerichte fest etabliert sind, an deren zeitlicher Komponente sich aber immer wieder Fragen der Letztentscheidungsbefugnis in unionsrechtlichen Fragestellungen entzünden. Vor dem Hintergrund, dass der EuGH die Wirkung der Auslegung des Unionsrechts in aller Regel zeitlich nicht begrenzt, ist in letzter Zeit sogar eine Zunahme des Begehrens nationaler Gerichte zur Berücksichtigung nationaler

14 Siehe aus jüngerer Zeit etwa Rosenkranz, Die Beschränkung der Rückwirkung von Entscheidungen des Europäischen Gerichtshofs, 2015, der sich insbesondere auch dem Verhältnis der Defrenne-Rechtsprechung zum mitgliedstaatlichen Recht widmet. $\mathrm{Zu}$ nennen sind auch die Arbeiten von Schaer, Rechtssicherheit und Vertrauensschutz als Grenzen rückwirkender Rechtsprechung im europäischen Arbeitsrecht, 2010; Ludewig, Die zeitliche Beschränkung der Wirkung von Urteilen des EuGH im Vorabentscheidungsverfahren, 2012; Kovács, Die temporale Wirkung von Urteilen des EuGH im Vorabentscheidungsverfahren, 2014; Müller, Die Begrenzung der zeitlichen Wirkungen von EuGH-Entscheidungen, 2009 und Wusterhausen, Die Wirkungen der Urteile des EuGH in der Zeit Ein Beitrag zur Problematik der zeitlichen Beschränkung von Urteilswirkungen durch den Gerichtshof der Europäischen Union, 2016. Aus der Perspektive des Staatshaftungsrechts betrachtet die Problematik Frantzen, Staatshaftung für das Vertrauen auf unionsrechtswidrige Gesetze, 2018.

15 Z.B. EuGH, Urteil vom 19.4.2016, Rs. C-441/14 (DI).

16 Z.B. Højesteret, Urteil vom 6.12.2016, 15/2014, englische Übersetzung abrufbar unter https://domstol.dk/media/2udgvvvb/judgment-15-2014.pdf. Auch das Bundesverfassungsgericht hat zu der hier interessierenden Problematik Stellung genommen, siehe insb. BVerfG, Beschluss vom 10.12.2014, 2 BvR 1549/07 - NZA 2015,375 . 
Vertrauensumstände zu verzeichnen. In diesem Zusammenhang spricht etwa Coutron von einem umstrittenen, ja sogar bedrohten Monopol des $\mathrm{EuGH}$, eine Auslegungsvorabentscheidung zeitlich zu begrenzen. ${ }^{17} \mathrm{Um}$ diese Entwicklungen einordnen zu können, wird zu klären sein, worauf sich dieses „Monopol“ tatsächlich erstreckt und welche Möglichkeiten mitgliedstaatlichen Gerichten zur Gestaltung der zeitlichen Wirkung ihrer eigenen Rechtsprechung verbleiben.

Die neuere Rechtsprechungsentwicklung lässt es auch zu, die in weiten Teilen der Literatur im Hinblick auf die Gewährung von Vertrauensschutz vorgenommene Grenzziehung zwischen unmittelbar und mittelbar wirkendem Unionsrecht kritisch zu hinterfragen, nach der es entscheidend darauf ankommt, ob ein Sachverhalt den Anwendungsvorrang oder die Pflicht zu richtlinienkonformer Auslegung nationalen Rechts betrifft. Während Grenzen des Anwendungsvorrangs sehr restriktiv bestimmt werden, werden die Grenzen der richtlinienkonformen Auslegung großzügiger umrissen. Zugrunde liegt dabei eine Unterscheidung zwischen der unionalen Beschränkung der zeitlichen Wirkungen und der Gewährung „nationalen Vertrauensschutzes“. Nach dieser Konzeption erfolgt erstere nach den Grundsätzen der Defrenne-Rechtsprechung durch den EuGH und damit auf Ebene des Unionsrechts und betrifft alle Mitgliedstaaten; „nationaler Vertrauensschutz“ wird dagegen nach (unter Umständen modifizierten) nationalen Grundsätzen gewährt und erstreckt sich nur auf den jeweiligen Mitgliedstaat. Anerkennung findet zwar die Überlegung, dass es sich - wie auch bei der Verpflichtung zur Nichtanwendung unionsrechtswidrigen nationalen Rechts infolge des unionsrechtlichen Anwendungsvorrangs - auch bei der Pflicht zur richtlinienkonformen Auslegung nationalen Rechts um einen unionsrechtlichen „Einwirkungsmechanismus" handelt, eine „Durchsetzungsdimension“, die nur unionsrechtlich begrenzt werden kann. Einer Ausfüllung dieser Grenze durch nationale Umstände des Einzelfalls soll dies aber deshalb grundsätzlich nicht entgegenstehen, da ein Verweis des Unionsrechts auf diese Umstände anzunehmen bzw. jedenfalls nicht auszuschließen sei. Dass der Rechtsprechung des Gerichtshofs ein entsprechendes Verständnis zugrunde liegt, ist allerdings alles andere als klar. ${ }^{18}$ Hier kann die vorliegende Untersuchung ansetzen.

17 Coutron, RTDEur. 2017, $400(401,408)$.

18 Siehe zum Stand der Forschung etwa den Überblick bei Rosenkranz, ZESAR 2018, 24 (25). 


\section{Gedankengang der Arbeit}

Ihren Ausgangspunkt nehmen muss die Arbeit daher bei der Frage der vom Gerichtshof selbst vorzunehmenden Beschränkung der zeitlichen Wirkungen der Auslegung mit Wirkung für alle Betroffenen im Sinne der Defrenne-Rechtsprechung. Deren Berechtigung sowie die in ihrem Rahmen vom EuGH angelegten Maßstäbe sind dementsprechend im ersten Teil dieser Arbeit näher zu beleuchten. Vor dem Hintergrund, dass der EuGH ein deklaratorisches Auslegungsverständnis vertritt, stellt sich die Frage, ob insoweit überhaupt eine Begrenzung in zeitlicher Hinsicht in Betracht kommt und wenn ja, weshalb sie vom EuGH formuliert werden kann. In erster Linie geht es an dieser Stelle darum, die Rechtsprechung des EuGH nachzuzeichnen und einzuordnen, um aus ihr die im zweiten Teil getroffenen Schlussfolgerungen ziehen zu können.

Die von ihm zur Konkretisierung des hinter der Defrenne-Rechtsprechung stehenden Grundsatzes der Rechtssicherheit für eine Begrenzung der zeitlichen Wirkungen entwickelten Kriterien („guter Glaube“/„Gefahr schwerwiegender Störungen“) wendet der Gerichtshof recht schematisch an. Dies kann allerdings nicht darüber hinwegtäuschen, dass er Wertungen vornehmen muss ${ }^{19}$, wenn er die Grundsätze der Rechtssicherheit und der einheitlichen Anwendung des Unionsrechts im Rahmen seiner Entscheidung, ob die zeitlichen Wirkungen zu begrenzen sind, von Fall zu Fall gegeneinander abwägt. ${ }^{20}$ Seine Bereitschaft, in Einzelfällen materiellen Gesichtspunkten mehr Raum zu geben, hat er dadurch signalisiert, dass er in einer neueren Entscheidung unter Verzicht auf die Prüfung der genannten Kriterien eine zeitliche Begrenzung vorgenommen hat. ${ }^{21}$ Ein solches Vorgehen erinnert an seine flexiblere Rechtsprechung zu Art. 264 II AEUV im Rahmen der Nichtigkeitsklage und der Ungültigkeitsvorabentscheidung („Unwirksamkeitsverfahren“), die daher als Vergleichsfolie dienen kann. Art. 264 II AEUV verleiht dem Gerichtshof die Befugnis, im Falle der Nichtigerklärung einer mit der Nichtigkeitsklage nach Art. 263 AEUV angefochtenen Handlung diejenigen Wirkungen der Handlung zu bezeichnen, die als fortgeltend zu betrachten sind, falls der Gerichtshof dies für notwendig hält. Da er Art. 264 II AEUV nur auf die Ungültigkeitsvorabentscheidung entsprechend anwendet, dies aber für die Auslegungs-

19 Siehe auch Düsterhaus, YEL 36 (2017), 237 (274).

20 Lenaerts/Maselis/Gutman, EU Procedural Law, 2014, Rn. 6.34.

$21 \mathrm{EuGH}$, Urteil vom 17.12.2015, verb. Rs. C-25/14 und C-26/14 (UNIS und Beaudout Père et Fils). 
vorabentscheidung ablehnt, lässt die Rechtsprechung zu Art. 264 II AEUV die Besonderheiten der Rechtsprechung des Gerichtshofs bei Auslegungsim Vergleich zu Unwirksamkeitsentscheidungen hervortreten. ${ }^{22}$

Eine Befassung mit Art. 264 II AEUV erscheint zudem vor dem Hintergrund angezeigt, dass der EuGH in seinem Urteil in der Rechtssache Winner Wetten eine analoge Anwendung der zu dieser Vorschrift ergangenen Rechtsprechung auf die Frage einer vorübergehenden Aussetzung der Verdrängungswirkung des unmittelbar anwendbaren Unionsrechts angedacht hat. ${ }^{23}$ Im konkreten Fall sah er dafür zwar keinen Anlass; im Jahr 2016 hat er diesen Gedanken aber wieder aufgegriffen. ${ }^{24}$ Deutlich wird an dieser Überlegung des Gerichtshofs auch, dass er eine Unterscheidung zwischen der Begrenzung der ex tunc-Wirkung seiner Auslegung (Defrenne-Rechtsprechung) und der vorübergehenden Aussetzung der Verdrängungswirkung unmittelbar anwendbaren Unionsrechts (Winner Wetten-Rechtsprechung) trifft. Was dies für die Frage bedeutet, ob nationalen Gerichten die Berücksichtigung nationaler Vertrauensumstände bei der Entscheidung des konkreten Falles gestattet ist, wird im zweiten Teil der Arbeit näher untersucht. Sie stellt sich insbesondere dann, wenn der EuGH eine Aktivierung der Defrenne-Rechtsprechung ausdrücklich oder stillschweigend ablehnt. Für ihre Beantwortung kommt es entscheidend darauf an, welche Folgen sich aus der ausschließlichen Zuständigkeit, die der Gerichtshof im Hinblick auf die Begrenzung der zeitlichen Wirkungen der Auslegung des Unionsrechts für sich beansprucht, ergeben.

Soll etwa eine langjährige nationale unionsrechtswidrige Rechtsprechung als nationaler Vertrauensumstand Berücksichtigung finden, bedarf es eines Anknüpfungspunktes, der dies als gerechtfertigt erscheinen lässt. Zunächst ist an eine Verankerung im Unionsrecht selbst zu denken. Erwiese sich eine solche Verankerung als möglich, hätte dies den Vorteil, dass eine im Einklang mit dem Unionsrecht gebildete Grenze entwickelt werden könnte. In diesem Zusammenhang stellt sich insbesondere die Frage, ob das nach traditionellem Begriffsverständnis unmittelbar bzw. mittelbar wirkende Unionsrecht unterschiedlichen Mechanismen folgt oder ob trotz

22 Siehe zu diesen Fragestellungen näher unten bei Fn. 334 ff. und Fn. 950 ff.

23 EuGH, Urteil vom 8.9.2010, Rs. C-409/06 (Winner Wetten), Rn. 67.

24 EuGH, Urteil vom 28.7.2016, Rs. C-379/15 (Association France Nature Environnement), Rn. 33. Siehe auch EuGH, Urteil vom 29.7.2019, Rs. C-411/17 (Inter-Environnement Wallonie und Bond Beter Leefmilieu Vlaanderen), Rn. 177 und EuGH, Urteil vom 27.6.2019, Rs. C-597/17 (Belgisch Syndicaat van Chiropraxie u.a.), Rn. 59. 
ihrer unterschiedlichen Konzeption im Hinblick auf die Berücksichtigung nationaler Vertrauensumstände eine Gleichbehandlung erfolgen kann.

Angesprochen ist damit zunächst die Frage, ob der Anwendungsvorrang, der jedenfalls (und zumindest nach der traditionellen Rechtsprechung des Gerichtshofs ausschließlich) dem unmittelbar anwendbaren Unionsrecht zukommt, in zeitlicher Hinsicht Grenzen unterliegen kann. Sollte dies der Fall sein, gilt es zu klären, in welchem Verhältnis mögliche Grenzen des Anwendungsvorrangs zu einer Begrenzung im Sinne der Defrenne-Rechtsprechung stehen und damit die Frage, ob die beiden Mechanismen nicht letztlich auf dasselbe hinauslaufen und sich eine unterschiedliche Behandlung damit verbietet. ${ }^{25}$ Eng damit verbunden ist die Frage, ob in diesem Zusammenhang eine Unterscheidung zwischen vergangenheits- und zukunftsbezogenen Wirkungen des Unionsrechts zu treffen ist. Abzugrenzen sind die in diesem Bereich gefundenen Ergebnisse von Entscheidungen des EuGH zu vertrauensschutzrelevanten Rechtspositionen des Einzelnen etwa in verwaltungsrechtlichen Fallgestaltungen. Daneben ist noch das Taricco II-Urteil des Gerichtshofs in den Blick zu nehmen, in dem dieser es italienischen Gerichten gestattete, bei einem Verstoß gegen das italienische Verständnis des Legalitätsgrundsatzes von der Nichtanwendung der unionsrechtswidrigen italienischen Verjährungsregeln abzusehen. Insoweit ist der Versuch zu unternehmen, den Gedankengang des Gerichtshofs offenzulegen und eine Aussage über die Verallgemeinerbarkeit dieser Entscheidung im Hinblick auf die Möglichkeiten der Berücksichtigung nationaler Vertrauensumstände durch eine Anwendung nationaler Grundrechte zu treffen. $\mathrm{Zu}$ erörtern ist insbesondere, ob der Gerichtshof in diesem Urteil eine Begrenzung des Anwendungsvorrangs durch nationale Grundrechtsstandards anerkannt hat. ${ }^{26}$

Wird der Blick sodann auf mittelbar wirkendes Unionsrecht gerichtet, so ist zunächst in Erinnerung zu rufen, dass der EuGH hinsichtlich des Instruments der richtlinien- (bzw. rahmenbeschluss)konformen Auslegung anerkennt, dass diese Verpflichtung „durch die allgemeinen Rechtsgrundsätze und insbesondere durch den Grundsatz der Rechtssicherheit und das Rückwirkungsverbot begrenzt [wird] und [...] auch nicht als Grundlage

25 Diese Frage ist u.a. in EuGH, Urteil vom 19.4.2016, Rs. C-441/14 (DI) aufgeworfen.

26 EuGH, Urteil vom 5.12.2017, Rs. C-42/17 (M.A.S. und M.B.), schlagwortartig als "Taricco II" bezeichnet; siehe in diesem Zusammenhang auch EuGH, Urteil vom 26.2.2013, Rs. C-399/11 (Melloni). 
für eine Auslegung contra legem des nationalen Rechts dienen [darf]“.27 Werden gegen die Pflicht zu richtlinienkonformer Auslegung nationale Vertrauensumstände ins Feld geführt, geht es also um den Versuch, diese als Grenze der richtlinienkonformen Auslegung zu formulieren, sei es als Bestandteil der contra legem-Grenze oder der Grenze der allgemeinen Rechtsgrundsätze. Die unterschiedliche Wirkungsweise von unmittelbar und mittelbar wirkendem Unionsrecht, von Anwendungsvorrang und richtlinienkonformer Auslegung, legt hinsichtlich letzterer zunächst weitergehende Möglichkeiten der mitgliedstaatlichen Gerichte nahe, nationalen Vertrauensumständen Rechnung zu tragen. Die Rechtsprechung des EuGH lässt insoweit aber keine eindeutige Antwort zu; vereinzelt lässt sie sogar ein dem unmittelbar anwendbaren Unionsrecht vergleichbares Vorgehen vermuten, das es kritisch zu hinterfragen gilt. In diesem $\mathrm{Zu}$ sammenhang ist nicht zuletzt die Entscheidung des Gerichtshofs in den verbundenen Rechtssachen Gutiérrez Naranjo u.a. näher zu beleuchten. ${ }^{28}$

Erscheinen die durch das Unionsrecht gebotenen Anknüpfungspunkte für eine Berücksichtigung nationaler Anliegen aus mitgliedstaatlicher Perspektive als unzureichend, ist eine Anknüpfung an die der europäischen Integration durch das nationale Verfassungsrecht gezogenen Grenzen und damit eine Einordnung als Ausfluss dieser Schranken zu erwägen. Damit ist für die deutsche Rechtsordnung die „Trias“29 aus Identitätskontrolle, Ultra-vires-Kontrolle und Solange II-Vorbehalt daraufhin zu untersuchen, ob sie der zeitlichen Dimension der unionsgerichtlichen Rechtsprechung bzw. der mit ihr einhergehenden Vorgaben Grenzen zieht.

\section{Begrenzung des Untersuchungsgegenstands}

Die Arbeit untersucht also zunächst die vom Unionsrecht anerkannten Grenzen der Berufung auf eine vom Gerichtshof ausgelegte Norm des Unionsrechts. Im Anschluss daran beleuchtet sie die Grenzen der vorrangigen Anwendbarkeit einer unionsrechtlichen Norm bzw. der Pflicht, das nationale Recht in ihrem Sinne auszulegen. Abschließend betrachtet sie die Grenzen der mitgliedstaatlichen Anerkennung des Unionsrechts. Damit

27 Siehe nur EuGH, Urteil vom 15.4.2008, Rs. C-268/06 (Impact), Rn. 100 (Kursivschrift im Original).

28 EuGH, Urteil vom 21.12.2016, verb. Rs. C-154/15, C-307/15 und C-308/15 (Gutiérrez Naranjo u.a.).

29 Begriff bei Dederer, JZ 2014, 313. 
widmet sich die Arbeit den unions- und verfassungsrechtlichen Schranken, die für ein nationales Gericht Bedeutung erlangen können, wenn vor ihm die Frage der zeitlichen Dimension der Anwendung des Unionsrechts aufgeworfen ist.

Um die umfassende Fragestellung dieser Arbeit handhabbar zu gestalten, ist eine gewisse Begrenzung des Untersuchungsgegenstands erforderlich.

Was die zeitlichen Wirkungen richterlicher Erkenntnisse anbelangt, so bestehen grundsätzlich drei Möglichkeiten ihrer Ausgestaltung: Ihnen kann eine Wirkung ex tunc, ex nunc oder pro futuro beigelegt werden. Jedes der Konzepte bringt dabei Rechtssicherheit und Gesetzmäßigkeit in unterschiedlicher Weise zum Ausgleich. ${ }^{30}$ Dementsprechend unterschiedlich fallen die in den Mitgliedstaaten der Europäischen Union entwickelten Lösungen aus. Auf Ebene des Unionsrechts kommt, wie noch näher zu zeigen sein wird, der Rechtsprechung des Gerichtshofs sowohl im Rahmen von Unwirksamkeits- als auch von Auslegungsentscheidungen ex tunc-Wirkung zu.

Der Praxis der Mitgliedstaaten zur zeitlichen Wirkung einer Normverwerfung entnehmen Stimmen in der Literatur zum Teil einen allgemeinen Rechtsgrundsatz, wonach Gerichte bei Normverwerfungen dazu befugt sind, den Eintritt der Urteilswirkungen zu verschieben, um unangemessene Auswirkungen einer ex tunc-Wirkung zu vermeiden oder Gemeinwohlbelangen Rechnung zu tragen. In der Zusammenschau mit Art. 220 I EGV (nunmehr Art.19 I EUV) leiten sie daraus eine Pflicht zur Beachtung dieses Grundsatzes im Rahmen des Vorabentscheidungsverfahrens und der Defrenne-Rechtsprechung ab und nehmen eine Pflicht zur stärkeren Berücksichtigung mitgliedstaatlicher Belange an. ${ }^{31}$ Damit verbunden sind Vorschläge einer Neuausrichtung der unionsgerichtlichen Rechtsprechung hin zu einer ex nunc- bzw. sogar prospektiven Wirkung der Auslegung. ${ }^{32}$

30 Vgl. Verstraelen, GLJ 14 (2013), 1687 (1690).

31 In diesem Sinne Schmitz/Krasniqi, EuR 2010, 189 (204 ff.).

32 Hufen/Nörr Stiefenhofer Lutz, Beschränkung von Urteilswirkungen, Rechtsgutachten, Teil 1, 2008, S.14. Gewichtige mitgliedstaatliche Interessen und Belange sollen danach bei der Gestaltung der Urteilswirkungen Berücksichtigung finden: "Zur Berücksichtigung dieser Belange bietet sich die Beschränkung der Wirkungen der Entscheidungen auf den Zeitpunkt ex nunc an. Daneben besteht auch die Möglichkeit einer Verschiebung des Wirkungseintritts in die Zukunft oder die Aufforderung an den Gesetzgeber, eine Korrektur des europarechtswidrigen Zustandes vorzunehmen." (Kursivschrift im Original). 
Kovács geht davon aus, dass der EuGH die Rechtsprechung des Bundesverfassungsgerichts zur Unvereinbarkeitserklärung bei Gleichheitsverstößen (als Abweichung von der Nichtigerklärung der in Rede stehenden Norm) berücksichtigt, „wenn nicht gar übernommen hat“. Hinsichtlich der Rückausnahme für Rechtsbehelfsführer von der Begrenzung der ex tunc-Wirkung spricht er vom „Verdacht einer Inspiration des EuGH durch das österreichische Verfassungsprozessrecht“. ${ }^{33}$ Ludewig sieht die Rechtsprechung des EuGH zur Begrenzung der zeitlichen Wirkung seiner Urteile „durchaus als eine Fortentwicklung aus den mitgliedstaatlichen Grundsätzen".34

Nicht in Abrede gestellt werden kann zwar, dass sich eine ähnliche Problematik wie die, vor der der EuGH im Hinblick auf die zeitlichen Wirkungen seiner Rechtsprechung steht, letztlich in allen Rechtsordnungen stellt. Die in den Mitgliedstaaten beschrittenen Wege sind allerdings zu vielfältig, als dass der Gerichtshof hier eine Lösung vorfände, die er als allgemeinen Rechtsgrundsatz seiner Rechtsprechung zugrunde zu legen hätte. ${ }^{35}$ Ein vom EuGH zu übernehmender unionsweit einheitlicher Standard lässt sich insoweit nicht begründen. Es erscheint daher zulässig, im Rahmen der Herausarbeitung der vom EuGH gefundenen Antworten auf einen vertieften Blick auf die nationalen Rechtsordnungen und die in ihnen gefundenen Lösungen zur Modifikation der zeitlichen Wirkungen nationaler Rechtsprechung zu verzichten. Daran ändert nichts, dass der Gerichtshof für die Frage der Begrenzung der zeitlichen Wirkungen seiner Rechtsprechung den Grundsatz der Rechtssicherheit als allgemeinen Grundsatz des Unionsrechts bemüht. Entscheidend für den Fortgang der Arbeit ist demnach die Aufdeckung der vom Gerichtshof selbst gefundenen Ergebnisse, sodass seine Rechtsprechung auf die ihr zu entnehmenden Grundsätze zu untersuchen ist.

Trotz dieser Begrenzung auf die Rechtsprechung des Gerichtshofs kann das Unionsrecht natürlich nicht isoliert betrachtet werden. Wenn in der vorliegenden Arbeit die Frage nach den Möglichkeiten mitgliedstaatlicher Gerichte zur Reaktion auf die zeitliche Dimension unionsgerichtlicher Rechtsprechung gestellt wird, müssen deren Auswirkungen auf das nationale Recht mit in den Blick genommen werden. Erst in ihrer Bedeutung

33 Kovács, Temporale Wirkung, 2014, S. 211, 239 f.

34 Ludewig, Zeitliche Beschränkung, 2012, S. 53.

35 Ludewig, Zeitliche Beschränkung, 2012, S. 52; siehe hierzu auch Rosenkranz, Beschränkung der Rückwirkung, 2015, S. 1. 
für das nationale Recht lässt sich die Wirkung einer (abgelehnten) Begrenzung der ex tunc-Wirkung durch den EuGH verdeutlichen. ${ }^{36}$

Dass diese Arbeit vorrangig nach den Reaktionsmöglichkeiten mitgliedstaatlicher Gerichte fragt, erklärt sich nicht zuletzt aus der überragend großen Bedeutung des Vorabentscheidungsverfahrens ${ }^{37}$ als eines Dialogs der Gerichte, der die mitgliedstaatlichen Gerichte unmittelbar mit den Wirkungen unionsgerichtlicher Rechtsprechung konfrontiert. Mit ihnen wird daher die Instanz in den Blick genommen, die den hier untersuchten Konflikt unmittelbar zu entscheiden hat: Haben sich mitgliedstaatliche Legislative oder Exekutive unionsrechtswidrig verhalten, ist es für die dem Unionsrecht Unterworfenen in ihrem konkreten Rechtsstreit ausschlaggebend, wie das mitgliedstaatliche Gericht entscheidet. Für den Ausgang dieses Rechtsstreits kommt es also darauf an, wie das mitgliedstaatliche Gericht mit einer vom EuGH mit ex tunc-Wirkung vorgenommenen Auslegung umzugehen hat, was ihm also aus unionsrechtlicher oder auch national(verfassungs)rechtlicher Perspektive gestattet oder untersagt ist. In einer Situation, in der das nationale Recht sich als unionsrechtswidrig darstellt, kommt es damit gewissermaßen vor den nationalen Gerichten zum Schwur, welche Folgen sich aus der Unionsrechtswidrigkeit mitgliedstaatlichen Verhaltens in zeitlicher Hinsicht ergeben.

Ist dem mitgliedstaatlichen Gericht die Herstellung eines unionsrechtskonformen Zustands nicht möglich, kommt für die davon negativ betroffene Partei gegebenenfalls ein unionsrechtlicher Staatshaftungsanspruch in Betracht. Um die unionsrechtswidrige Rechtslage an sich zu beseitigen, bedarf es eines Tätigwerdens des nationalen Gesetzgebers. Dessen Verpflichtung betont auch der EuGH, wenn er hervorhebt, dass zur Herstellung eines unionsrechtskonformen Zustands „zuvörderst“ der nationale Gesetzgeber berufen sei, der gegebenenfalls die Rechtslage ändern und eine „systemische Gefahr" einer Verletzung des Unionsrechts verhindern müsse. Allerdings ändert dies nichts daran, dass auch die nationalen Gerichte, „ohne die Änderung der in Rede stehenden nationalen Regelung auf gesetzgeberischem Wege oder durch ein anderes verfassungsrechtliches Verfahren abzuwarten“, die volle Wirksamkeit der unionsrechtlichen Verpflichtungen

36 Ähnlich Schaer, Grenzen rückwirkender Rechtsprechung, 2010, S. 155 ff.; Rosenkranz, Beschränkung der Rückwirkung, 2015, S. $1 \mathrm{f}$.

37 Rund zwei Drittel der im Jahr 2019 beim EuGH neu eingegangenen Rechtssachen sind demnach Vorlagen zur Vorabentscheidung, vgl. Gerichtshof der Europäischen Union, Jahresüberblick, Jahresbericht 2019, S. 54. 
gewährleisten müssen. ${ }^{38}$ Beim mitgliedstaatlichen Gesetzgeber handelt es sich aus diesem Blickwinkel also um eine „nachgelagerte“ Instanz zur Auflösung des Konflikts zwischen Unions- und nationalem Recht, weswegen auf ihn an den entsprechenden Stellen zwar verwiesen wird, er aber nicht im Mittelpunkt der Betrachtung steht. Stärker in den Blickpunkt geraten ist er etwa im Taricco II-Urteil, in dem der Gerichtshof die Pflichten des mitgliedstaatlichen Gesetzgebers zur Herstellung eines unionsrechtskonformen Zustands stärker betont und die mitgliedstaatlichen Gerichte auf diese Weise von einer eigentlich bestehenden unionsrechtlichen Verpflichtung entbunden hat. ${ }^{39}$

Der Blick auf die Frage der Staatshaftung erfolgt angesichts der Begrenzung des Untersuchungsgegenstands auf die Primärebene lediglich im Rahmen eines Ausblicks. Nur angedeutet wird daher die auf Sekundärebene bestehende Besonderheit des Kriteriums des hinreichend qualifizierten Verstoßes als Voraussetzung eines unionsrechtlichen Staatshaftungsanspruchs. ${ }^{40}$ Aus diesem Grund ist auch die Problematik der vom Bundesverfassungsgericht in seinem Honeywell-Beschluss in Betracht gezogenen Gewährung eines Vertrauensschadensersatzes ${ }^{41}$ lediglich kurz zu erwähnen. Die unionsrechtliche Bewertung eines Ersatzanspruchs des in seinem Vertrauen auf das nationale Recht Enttäuschten bleibt einer eigenständigen Untersuchung vorbehalten.

38 Siehe etwa EuGH, Urteil vom 5.6.2018, Rs. C-612/15 (Kolev u.a.), Rn. 65 f.

39 EuGH, Urteil vom 5.12.2017, Rs. C-42/17 (M.A.S. und M.B.), Rn. 61 und $41 \mathrm{f}$.

40 Angesprochen ist damit nicht zuletzt das Vorgehen des BGH bei der Verneinung der hinreichenden Qualifizierung eines Unionsrechtsverstoßes, BGH, Urteil vom 18.10.2012, III ZR 196/11 - EuZW 2013, 194.

41 BVerfG, Beschluss vom 6.7.2010, 2 BvR 2661/06 - BVerfGE 126, 286 (314f.). 


\section{Erster Teil: Die zeitliche Dimension der Rechtsprechung des EuGH}

Ausgangspunkt der Überlegungen ist wie bereits dargestellt die zeitliche Dimension der unionsgerichtlichen Normauslegung. Es gilt daher, die der Rechtsprechung des Gerichtshofs zu dieser Frage zu entnehmenden Aussagen näher zu beleuchten, denen in Ermangelung einer ausdrücklichen Normierung dieser Frage in den Verträgen entscheidende Bedeutung zukommt. In einem zweiten Schritt wird es dann möglich sein, der Frage nachzugehen, welche Vorgaben sich dieser zeitlichen Dimension hinsichtlich der Zulässigkeit der „zeitlichen Modulation“ durch mitgliedstaatliche Gerichte entnehmen lassen. Dieser Schritt ist im zweiten Teil der Arbeit zu gehen.

\section{A. Bindungswirkung der Auslegung als Wirkung der ausgelegten Norm}

Angesichts der engen Verbindung zwischen der zeitlichen Wirkung und der Bindungswirkung von Rechtsprechung kann eine Untersuchung der zeitlichen Dimension der Rechtsprechung des EuGH nicht ohne Auseinandersetzung mit deren Bindungswirkung erfolgen. ${ }^{42}$

\section{Verknüpfung mit der zeitlichen Wirkung der Auslegung}

Entfaltet eine Auslegungsentscheidung/eine ausgelegte Norm Bindungswirkung, ist damit noch nicht gesagt, in welcher zeitlichen Dimension sie wirkt. Ähnliches gilt in umgekehrter Richtung: Ist von ex tunc-Wirkung auszugehen, erscheint es nicht ausgeschlossen, dass sich diese Wirkung auf das Verfahren beschränkt, das Anlass zu dieser Auslegung gab. Eine Aussage darüber, ob die ex tunc-Wirkung auch in weiteren Fällen Beachtung verlangt, lässt sich allein daraus noch nicht ableiten. Zeitliche Wirkung und Bindungswirkung können also nicht gleichgesetzt werden, sondern

42 Den engen Zusammenhang von zeitlicher Wirkung und Bindungswirkung betonen auch Kovács, Temporale Wirkung, 2014, S. 53 f. und Rosenkranz, Beschränkung der Rückwirkung, 2015, S. 19. 
sind voneinander zu unterscheiden, auch wenn es sich bei ihnen um zwei aus demselben Urteil bzw. derselben Norm fließende Wirkungen handelt.

Fest steht aber auch, dass die zeitliche Dimension von Rechtsprechung ihr besonderes Gewicht nur erlangt, wenn eine vom Gerichtshof in einem unionsgerichtlichen Verfahren getroffene Aussage über den Ausgangsfall hinaus Bedeutung hat. ${ }^{43}$ Je größer die Bindungswirkung, desto stärker erscheint das Bedürfnis nach einer zeitlichen Begrenzung der Wirkung von Rechtsprechung. ${ }^{44}$

Wie sich zeigen wird, trägt der EuGH diesem Zusammenhang auch bei der Ausgestaltung der Voraussetzungen einer zeitlichen Begrenzung Rechnung. Die Bindungswirkung hat also auch Bedeutung für die Ausgestaltung der zeitlichen Begrenzung in ihrer jetzigen Form. ${ }^{45}$

Auch zur Frage der Reaktionsmöglichkeiten mitgliedstaatlicher Gerichte besteht jedenfalls nach Auffassung des Bundesverfassungsgerichts ein Zusammenhang. So hatte ein im zweiten Teil dieser Arbeit noch näher $\mathrm{zu}$ beleuchtender Beschluss des Bundesverfassungsgerichts eine Verletzung des Art. 101 I 2 GG zum Gegenstand. Darin wirft das Bundesverfassungsgericht dem BAG einen Entzug des EuGH als gesetzlicher Richter wegen Gewährung nationalen Vertrauensschutzes ohne vorheriges Vorabentscheidungsersuchen vor und macht hierbei unter anderem geltend, das BAG habe sich nicht mit der Bindungswirkung von Vorabentscheidungen auseinandergesetzt, als es Vertrauensschutz gewährt habe. ${ }^{46}$ Für die Frage der Zulässigkeit der Gewährung nationalen Vertrauensschutzes ist die Bindungswirkung einer im Vorabentscheidungsverfahren ergangenen Entscheidung nach Auffassung des Bundesverfassungsgerichts also ein mitentscheidender Gesichtspunkt.

Vor dem Hintergrund der vorstehenden Überlegungen ist an dieser Stelle nach der Verbindlichkeit der in der jeweiligen Entscheidung durch den Gerichtshof getroffenen Aussagen („Bindungswirkung“47) zu fragen. Die zur Frage der Bindungswirkung vertretenen Auffassungen sind mannigfaltig und sollen hier nicht vollumfänglich nachgezeichnet werden. Aufgezeigt werden soll vielmehr, wie eine Bindung an die vom Gerichtshof zur Auslegung des Unionsrechts getroffenen Aussagen begründet wer-

43 Vgl. Waldhoff, EuR 2006, 615 (620) und Kovács, Temporale Wirkung, 2014, S. 54.

44 Vgl. Düsterhaus, YEL 36 (2017), 237 (239).

45 Zum Zusammenhang und den Unterschieden zwischen beiden Wirkungen siehe auch Rosenkranz, Beschränkung der Rückwirkung, 2015, S. 19.

46 BVerfG, Beschluss vom 10.12.2014, 2 BvR 1549/07, Rn. 42 - NZA 2015, 375.

47 Ähnliche Begrifflichkeit bei Kovács, Temporale Wirkung, 2014, S. 56. 
den kann. Hierzu bedarf es insbesondere auch einer Bestimmung des Gegenstands der Bindungswirkung. Insoweit kommen vorrangig zwei Anknüpfungspunkte in Betracht: einerseits das Urteil des Gerichtshofs selbst und andererseits die von ihm ausgelegte Norm. Geklärt werden muss demzufolge, ob es sich bei der Bindungswirkung um eine Urteils- oder eine Normwirkung handelt.

Die Antwort auf die Frage nach dem Bestehen und der Ausgestaltung einer Bindungswirkung ist dem Unionsrecht selbst zu entnehmen. ${ }^{48}$ Dass der Antwort des Gerichtshofs auf ein Vorabentscheidungsersuchen nicht eine bloße Funktion als unverbindliches Gutachten zukommt, steht außer Zweifel. ${ }^{49}$

\section{Bindungswirkung als Norm- oder Urteilswirkung}

Zunächst ist darauf hinzuweisen, dass mehrere Dimensionen einer Bindungswirkung unterschieden werden können: Neben der Bindung des Gerichts (EuG) an die Rechtsprechung des Gerichtshofs, der an dieser Stelle nicht weiter nachgegangen wird ${ }^{50}$, sind die Bindung mitgliedstaatlicher Gerichte und des Gerichtshofs selbst angesprochen. Letzteres erlangt für die Frage des Präjudizcharakters von EuGH-Entscheidungen Bedeutung ${ }^{51}$ und wirft die Frage auf, wie der Gerichtshof mit seiner eigenen Rechtsprechung umgeht. ${ }^{52}$

48 Vgl. Ehricke, Bindungswirkung, 1997, S. 39.

49 Siehe nur Kovács, Temporale Wirkung, 2014, S. 59 f.

50 Das EuG ist an eine Entscheidung des Gerichtshofs nur nach Maßgabe des Art. 61 II der Satzung des Gerichtshofs sowie im Rahmen der Rechtskraft gebunden. Einen „bindende[n] Präzedenzfall“ stellt ein EuGH-Urteil für das EuG also nicht dar, vgl. EuG, Urteil vom 12.12.1996, verb. Rs. T-177/94 und T-377/94 (Altmann u.a./Kommission), Rn. 80 i.V.m. Rn. 50. Auch außerhalb einer formalen Bindung lassen es aber "der Grundgedanke des Rechtsmittels selbst und die daraus resultierende hierarchische Struktur der Gerichte es dem Gericht grundsätzlich ratsam erscheinen [...], die in der Entscheidung des Gerichtshofs vorgenommene rechtliche Beurteilung nicht selbst in Frage zu stellen“, EuG, Urteil vom 30.9.2010, Rs. T-85/09 (Kadi/Kommission), Rn. 121.

51 Vgl. Düsterhaus, YEL 36 (2017), 237 (241).

52 Siehe zu diesen Aspekten der Bindungswirkung auch Tridimas, in: Dickson/Eleftheriadis (Hrsg.), Philosophical Foundations of European Union Law, 2012, S. $307 \mathrm{f}$. 
1. Auslegung im Rahmen der Auslegungsvorabentscheidung

An den Anfang gestellt ist angesichts der überragend großen Bedeutung dieses Verfahrens für mitgliedstaatliche Gerichte ${ }^{53}$ eine Untersuchung der Bindungswirkung im Rahmen der Auslegungsvorabentscheidung nach Art. 267 I lit. a und lit. b Alt. 2 AEUV.

a) Bindungswirkung im Ausgangsverfahren

Wird die Bindung nationaler Gerichte untersucht, gerät zunächst das Gericht in den Blick, das den Gerichtshof durch die Einleitung des Vorabentscheidungsverfahrens um Auslegung des Unionsrechts ersucht hat und an das die Antwort des Gerichtshofs gerichtet ist. Ebenfalls in die Betrachtung miteinzubeziehen sind die weiteren mit dem Ausgangsrechtsstreit befassten innerstaatlichen Gerichte.

Überlegt werden könnte zunächst, eine Bindung an die vom Gerichtshof getroffenen Aussagen aus der Rechtskraft eines Vorabentscheidungsurteils abzuleiten. Ihre Grundlage findet die Rechtskraft zwar nicht in Art.91 I EuGH-VerfO ${ }^{54}$, auch wenn die Bestimmung in der deutschen Sprachfassung davon spricht, dass ein Urteil des Gerichtshofs mit dem Tage seiner Verkündung rechtskräftig wird, da andere Sprachfassungen des Art. 91 I EuGH-VerfO nicht die der Rechtskraft in der jeweiligen Sprache entsprechenden Begrifflichkeiten gebrauchen, wie z.B. die Verwendung der Formulierung „shall be binding“ oder "force obligatoire“ in der englischen bzw. französischen Sprachfassung zeigt. ${ }^{55}$ Als allgemeiner Rechtsgrundsatz des Unionsrechts ist die Rechtskraft aber jedenfalls anerkannt. ${ }^{56}$

Nach den Ausführungen des Gerichtshofs in der Rechtssache Wünsche „entscheidet ein Urteil, in dem der Gerichtshof im Wege der Vorabentscheidung über die Auslegung oder die Gültigkeit einer Handlung eines

53 Siehe dazu bereits oben bei Fn. 37.

54 Verfahrensordnung des Gerichtshofs vom 25. September 2012 (ABl. L 265 vom 29.9.2012, S. 1) in der Fassung der Änderungen vom 18. Juni 2013 (ABl. L 173 vom 26.6.2013, S. 65), vom 19. Juli 2016 (ABl. L 217 vom 12.8.2016, S. 69), vom 9. April 2019 (ABl. L 111 vom 25.4.2019, S. 73) und vom 26. November 2019 (ABl. L 316 vom 6.12.2019, S. 103).

55 Näher Ionescu, Innerstaatliche Wirkungen, 2016, S. 148 ff.; siehe auch Toth, YEL 4 (1984), 1 (6).

56 Germelmann, EuR 2009, 254 (257 mit Fn. 16); Ionescu, Innerstaatliche Wirkungen, 2016, S. 151. 
Gemeinschaftsorgans befindet, mit Rechtskraft über eine oder mehrere Fragen des Gemeinschaftsrechts und bindet das nationale Gericht bei seiner Entscheidung des Ausgangsrechtsstreits". In der französischen Urteilsfassung ist ebenfalls von Rechtskraft („autorité de la chose jugée“) die Rede, die englische spricht zwar nicht von res judicata, aber immerhin von „conclusively determines“. .57

Dass auch Vorabentscheidungsurteile in Rechtskraft erwachsen, wird zum Teil mit der Erwägung bestritten, dass diese nicht über den Streitgegenstand des Ausgangsrechtsstreits entscheiden. ${ }^{58}$ Diesem Einwand lässt sich allerdings entgegenhalten, dass der Gerichtshof durch seine Auslegung abschließend über eine Rechtsfrage entscheidet, deren Beantwortung für das Ausgangsverfahren maßgeblich ist. ${ }^{59}$ Wird gegen die Rechtskraft die Parteilosigkeit des Vorabentscheidungsverfahrens ins Feld geführt ${ }^{60}$, so trifft es in der Tat zu, dass der Vorabentscheidung das Ersuchen eines nationalen Gerichts und kein Parteiantrag zugrunde liegt und die Parteien des Ausgangsverfahrens nicht Parteien des Vorabentscheidungsverfahrens sind. Dieses ist vielmehr parteilos ${ }^{61}$, weswegen es nicht zutreffend erscheint, von einer Rechtskraftwirkung zwischen den Parteien des Ausgangsverfahrens zu sprechen. ${ }^{62}$ Für die Parteien des Ausgangsverfahrens ist nur das innerstaatliche Urteil ihnen gegenüber rechtlich verbindlich. Aus der Auslegungsentscheidung des Gerichtshofs ergeben sich für sie also „nur mittelbare und rein tatsächliche“, durch das innerstaatliche Urteil vermittelte Folgen. ${ }^{63}$

57 EuGH, Beschluss vom 5.3.1986, Rs. 69/85 (Wünsche), Rn. 13.

58 In diesem Sinne Tomuschat, Vorabentscheidung, 1964, S. 172 f.

59 Germelmann, EuR 2009, 254 (258f.) meint, diese Funktion des Vorabentscheidungsverfahrens habe eigenständige Bedeutung, sodass ihr eine eigenständige Bindungswirkung zukomme; Heß, ZZP 108 (1995), 59 (68) spricht von einer Befriedungsfunktion im Hinblick auf einzelne Rechtsfragen.

60 Siehe etwa Trabucchi, RTDEur. 1974, $56(71,82)$.

61 EuGH, Urteil vom 27.3.1963, verb. Rs. 28 bis 30/62 (Da Costa en Schaake N.V. u.a.), Slg. 1963, S. 81, wonach es „keine Parteien im eigentlichen Wortsinne“ gibt.

62 Vgl. GA Warner, Schlussanträge vom 20.9.1977 in der Rs.112/76 (Manzoni), Slg. 1977, S. 1662. Ionescu, Innerstaatliche Wirkungen, 2016, S. 111 spricht vor diesem Hintergrund davon, dass die Rechtskraft nur inter partes wirke, obwohl es an Parteien fehle.

63 GA Mancini, Schlussanträge vom 17.3.1987 in der Rs. 14/86 (Pretore di Salò/X), Slg. 1987, S. 2558 f.; Hakenberg, EuR 2008, Beiheft 3, 163 (172) spricht daher von indirekter Betroffenheit der Parteien des Ausgangsverfahrens durch das Vorabentscheidungsurteil. 
Urteile im Vorabentscheidungsverfahren können daher konsequenterweise nur das vorlegende Gericht einschließlich sämtlicher in diesem Verfahren entscheidender Gerichte binden. ${ }^{64}$ Dementsprechend wird auch von der Rechtskraft und der daraus folgenden Bindungswirkung inter partes des vorlegenden Gerichts und der mit diesem Rechtsstreit befassten Instanzgerichte gesprochen. ${ }^{65} \mathrm{Ob}$ es sich hierbei allerdings tatsächlich um eine Folge der Rechtskraft handelt, wird nicht einheitlich beurteilt.

Wer betont, dass die Rechtskraft das vom Gerichtshof gefundene Ergebnis für Folgeprozesse zwischen den am Vorabentscheidungsverfahren Beteiligten festschreibt ${ }^{66}$, muss sich nämlich die Frage stellen, ob es sich beim Ausgangsverfahren um ein dem Vorabentscheidungsverfahren nachfolgendes Verfahren handelt. Je nach Einschätzung wird die Bindung des vorlegenden Gerichts im Ausgangsverfahren mit der Rechtskraft ${ }^{67}$ oder um ihn nicht seines Sinns zu entleeren - mit dem Sinn und Zweck des Art. 267 AEUV $^{68}$ bzw. der praktischen Wirksamkeit des Art. 267 AEUV, dem Sinn und Zweck des Vorabentscheidungsverfahrens und damit der Sicherstellung einer einheitlichen Anwendung des Unionsrechts in den Mitgliedstaaten sowie dem Grundsatz der loyalen Zusammenarbeit nach Art. 4 III EUV begründet. ${ }^{69}$

Aus der Sicht der Parteien des Ausgangsverfahrens handelt es sich beim Vorabentscheidungsverfahren um einen Zwischenstreit in ihrem beim vorlegenden Gericht anhängigen Rechtsstreit. ${ }^{70}$ Aus der Sicht des

64 Toth, YEL 4 (1984), 1 (56); Broberg/Fenger, Vorabentscheidungsverfahren, 2014, S. 389.

65 Lohse, Rechtsangleichungsprozesse, 2017, S. 266; siehe auch Düsterhaus, YEL 36 (2017), 237 (241).

66 Weth/Kerwer, in: Oetker/Preis/Rieble (Hrsg.), 50 Jahre Bundesarbeitsgericht, 2004, S. 1383 (1384f.); Althammer, in: Gsell/Hau (Hrsg.), Zivilgerichtsbarkeit, 2012, S. 37 (39f.).

67 Germelmann, Rechtskraft, 2009, S. 440; Rosenkranz, Beschränkung der Rückwirkung, 2015, S. $26 \mathrm{f}$.

68 Smit, in: Smit/Herzog (Hrsg.), The Law of The European Economic Community, Volume 4, 1976, Art. 177, S. 5-485 (177.26); siehe hierzu auch Ebricke, Bindungswirkung, 1997, S. 40.

69 In diesem Sinne Althammer, in: Gsell/Hau (Hrsg.), Zivilgerichtsbarkeit, 2012, S. 37 (39f.); Heß, ZZP 108 (1995), 59 (69 f.); Weth/Kerwer, in: Oetker/Preis/Rieble (Hrsg.), 50 Jahre Bundesarbeitsgericht, 2004, S. 1383 (1386).

70 Hierauf verweist der Gerichtshof stets im Zusammenhang mit der Feststellung, dass die Kostenentscheidung Sache des vorlegenden Gerichts ist, vgl. nur EuGH, Urteil vom 7.8.2018, Rs. C-123/17 (Yön), Rn. 90. Hakenberg, EuR 2008, Beiheft 3, 163 (171) etwa bezeichnet das Vorabentscheidungsverfahren dementsprechend als „nicht streitentscheidendes Zwischenverfahren in einem nationalen Rechts- 
Unionsrechts - und diese ist hier maßgeblich - handelt es sich beim Ausgangsverfahren dagegen insoweit um einen nachfolgenden Rechtsstreit, als es in diesem um die Sicherstellung des vom Gerichtshof gefundenen Ergebnisses geht. Unerheblich erscheint insoweit, in welcher Instanz der Rechtsstreit anhängig ist.

Auf der Grundlage dieser Erwägung kann die Bindung des vorlegenden Gerichts und der weiteren mit diesem Rechtsstreit befassten Gerichte mit der Rechtskraft begründet werden. Für diese Zwecke scheint es allerdings erforderlich, das vorlegende Gericht als Verfahrenspartei einzuordnen, da es sonst angesichts der Parteilosigkeit des Vorabentscheidungsverfahrens an einer subjektiven Dimension der Rechtskraft fehlte. ${ }^{71}$ Bei einer Argumentation mit der Rechtskraft wäre auch klargestellt, dass ihre Bedeutung auf das Ausgangsverfahren begrenzt ist und eine Rechtskraftwirkung erga omnes ausscheiden muss. Eine solche ist angesichts der Starrheit des Konzepts der Rechtskraft jedenfalls abzulehnen. ${ }^{72}$ Dass nach Art. 23 II der Satzung des Gerichtshofs die Möglichkeit zur Einreichung von Schriftsätzen und zur Abgabe schriftlicher Erklärungen für die dort Genannten besteht, führt nicht zu deren Parteistellung im Vorabentscheidungsverfahren und kann ihre Bindung im Sinne der Rechtskraft nicht begründen. Daran ändert sich auch nichts dadurch, dass in Art. 23 I und II der Satzung von „beteiligten Parteien“ bzw. „Parteien“ die Rede ist. Damit sind die Personen gemeint, die im Verfahren vor dem nationalen Gericht Parteistellung haben. ${ }^{73}$ Eine Parteistellung im Vorabentscheidungsverfahren wird hiermit nicht begründet.

Lehnt man eine aus der Rechtskraft fließende Bindung des vorlegenden Gerichts angesichts der soeben aufgezeigten argumentativen Schwierigkei-

streit“. Dass lediglich ein Zwischenstreit beendet wird, gibt der Gerichtshof auch dadurch zu erkennen, dass nur „für Recht erkannt“ („dit pour droit“) und nicht "für Recht erkannt und entschieden“ („déclare et décide“) wird, siehe auch Kadelbach, in: Holoubek/Lang (Hrsg.), Das EuGH-Verfahren in Steuersachen, 2000, S. 119 (122).

71 Schlücke, Umsetzung, 2014, S. 75 f. spricht ebenfalls von einer inter partes-Wirkung, ohne diese allerdings ausdrücklich als Ausfluss der Rechtskraft einzuordnen. Das vorlegende Gericht ist nach ihrer Auffassung Verfahrenspartei.

72 Vgl. GA Lagrange, Schlussanträge vom 13.3.1963 in den verb. Rs. 28 bis 30/62 (Da Costa en Schaake N.V. u.a.), Slg. 1963, S. 91; siehe auch Hay, 12 AJCL (1963), 404 (407), der bei einer erga omnes wirkenden Rechtskraft den erforderlichen Dialog der Gerichte in Gefahr sieht.

$73 \mathrm{EuGH}$, Urteil vom 12.5.2011, Rs. C-391/09 (Runevič-Vardyn und Wardyn), Rn.31. Dies hängt vom nationalen Verfahrensrecht ab, vgl. Barents, Remedies and Procedures Before the EU Courts, 2. Aufl. 2020, Rn. 10.88. 
ten $\mathrm{ab}$, besteht eine Bindung natürlich dennoch. Überzeugend erscheint es dann, von einer Bindung auszugehen, die daraus fließt, dass Art. 267 AEUV dem Vorabentscheidungsverfahren einen Charakter als verbindlicher Entscheidung zuweist. ${ }^{74}$

Bejaht man eine Bindung des vorlegenden Gerichts als Ausfluss der Rechtskraft des Vorabentscheidungsurteils, ist eine Besonderheit hinsichtlich der negativen Rechtskraftwirkung zu beachten. Mit ihr ist die Vorstellung verbunden, dass eine neue Klage mit demselben Streitgegenstand gesperrt ist. ${ }^{75} \mathrm{Im}$ Vorabentscheidungsverfahren ist eine erneute Vorlage derselben Frage durch das Gericht des Ausgangsverfahrens dagegen nicht schlechthin unzulässig; die Rechtskraft unterliegt im Vorabentscheidungsverfahren also besonderen Regeln. ${ }^{76}$ Die Gerichte des Ausgangsverfahrens dürfen den Gerichtshof vor der Entscheidung des Ausgangsrechtsstreits daher grundsätzlich erneut anrufen. Als Gründe für eine solche erneute Vorlage erkennt der Gerichtshof Schwierigkeiten beim Verständnis oder der Anwendung des Urteils, das Stellen einer neuen Rechtsfrage und die Unterbreitung neuer Gesichtspunkte, die eine abweichende Beurteilung einer bereits gestellten Frage rechtfertigen könnten, an. ${ }^{77}$ Diese sehr weitgehende Zulässigkeit einer erneuten Vorlage lässt lediglich das bloße Stellen einer identischen Frage ohne Vorbringen neuer Gesichtspunkte als ausgeschlossen erscheinen.

Für die Frage der Bindungswirkung bei einer Auslegungsvorabentscheidung bleibt unabhängig vom Begründungsansatz festzuhalten, dass die Entscheidung des Gerichtshofs das vorlegende Gericht und die weiteren mit dem Ausgangsverfahren befassten Gerichte bei der Entscheidung des

74 In diesem Sinne etwa Ulsamer/Müller-Terpitz, in: Maunz/Schmidt-Bleibtreu/Klein/ Bethge, BVerfGG, $\ 81$ BVerfGG, Rn. 26 (Stand: Januar 2017) für das in der Ausgangskonstellation mit dem Vorabentscheidungsverfahren vergleichbare konkrete Normenkontrollverfahren. Danach ergibt sich die Bindung des vorlegenden Gerichts zwanglos aus dem „Charakter des Vorlageverfahrens als Zwischenverfahren zur bindenden Entscheidung über eine für das Ausgangsverfahren entscheidungserhebliche Rechtsfrage".

75 Vgl. Germelmann, Rechtskraft, 2009, S. 414, 423.

76 Germelmann, Rechtskraft, 2009, S. 417 ff., 422.

77 EuGH, Beschluss vom 30.6.2016, Rs. C-634/15 (Sokoll-Seebacher und Naderhirn), Rn. 19; EuGH, Urteil vom 6.3.2003, Rs. C-466/00 (Kaba), Rn.39; EuGH, Beschluss vom 5.3.1986, Rs. 69/85 (Wünsche), Rn. 15. 
Ausgangsrechtsstreits bindet. ${ }^{78}$ Eine Abweichungsmöglichkeit für das vorlegende Gericht besteht nicht. ${ }^{79}$

b) Bindungswirkung außerhalb des Ausgangsverfahrens

Steht eine Bindung der Gerichte des Ausgangsverfahrens, wenn auch unter Heranziehung unterschiedlicher Begründungsansätze, aus der Perspektive des Unionsrechts außer Zweifel ${ }^{80}$, ist die Bindungswirkung außerhalb des Ausgangsverfahrens umstritten. ${ }^{81}$ Geltend gemacht wird in diesem Zusammenhang etwa, zu bejahen sei jedenfalls eine Präjudizienwirkung der Entscheidungen des EuGH und damit eine faktische erga omnes-Bindung; ob es sich hier um eine echte erga omnes-Wirkung handle, könne daher dahinstehen. ${ }^{82}$ Zum Teil heißt es, es bestehe lediglich eine Bindungswirkung im Sinne einer Leitfunktion nach Art. 4 III EUV. ${ }^{83}$ Klarheit vermag hier letztlich nur eine Auseinandersetzung mit der Frage zu verschaffen,

78 Vgl. u.a. EuGH, Urteil vom 24.6.1969, Rs. 29/68 (Milch-, Fett- und Eierkontor), Rn.2f.; EuGH, Urteil vom 3.2.1977, Rs. 52/76 (Benedetti), Rn. 26; EuGH, Beschluss vom 5.3.1986, Rs.69/85 (Wünsche), Rn. 13; EuGH, Urteil vom 14.12.2000, Rs. C-446/98 (Fazenda Pública), Rn. 49; EuGH, Urteil vom 5.10.2010, Rs. C-173/09 (Elchinov), Rn. 29; Pechstein, EU-Prozessrecht, 4. Aufl. 2011, Rn. 864; Frenz, Handbuch Europarecht, Band 5, 2010, Rn. 3395; Ebricke, in: Streinz (Hrsg.), EUV/AEUV, 3. Aufl. 2018, Art. 267 AEUV, Rn.68; Wegener, in: Calliess/Ruffert (Hrsg.), EUV/AEUV, 5. Aufl. 2016, Art. 267 AEUV, Rn. 48; Dauses, Vorabentscheidungsverfahren, 2. Aufl. 1995, S. $148 \mathrm{f}$.

79 EuGH, Urteil vom 16.6.2015, Rs. C-62/14 (Gauweiler u.a.), Rn. 11 ff., 16. Siehe auch Wendel, ZaöRV 74 (2014), 615 (650 f.), der hervorhebt, dass das vorlegende Gericht die Auslegung des EuGH umfassend akzeptieren muss.

80 Mitgliedstaatliche Verfassungsgerichte mögen insoweit zum Teil auf einem anderen Standpunkt stehen, wie etwa das Urteil des Bundesverfassungsgerichts zum Anleihekaufprogramm der EZB zeigt, vgl. BVerfG, Urteil vom 5.5.2020, 2 BvR 859/15, 2 BvR 1651/15, 2 BvR 2006/15, 2 BvR 980/16, Rn. 118 f., 163 - NJW 2020, 1647. An dieser Stelle steht aber allein die Bindungswirkung aus unionsrechtlicher Sicht in Rede.

$81 \mathrm{Zu}$ den insoweit vertretenen Auffassungen siehe etwa Ehricke, Bindungswirkung, 1997, S. $44 \mathrm{f}$.

82 Schlücke, Umsetzung, 2014, S.77. Für erga omnes-Wirkung etwa Barents, Remedies and Procedures Before the EU Courts, 2. Aufl. 2020, Rn.10.226. Siehe auch Wollenschläger, NJW 2018, 2532 (2534): aus Art. 4 III EUV folgende erga omnes-Wirkung für den Gesetzgeber.

83 Hakenberg, EuR 2008, Beiheft 3, 163 (172): Präjudizwirkung gemäß Art. 4 III EUV; Kadelbach, in: Holoubek/Lang (Hrsg.), Das EuGH-Verfahren in Steuersachen, 2000, S. 119 (126); Ionescu, Innerstaatliche Wirkungen, 2016, S. 167. 
ob es sich bei der Bindungswirkung um eine Urteils- oder Normwirkung handelt.

Weitgehend anerkannt ist zunächst, dass die Bindungswirkung nicht strenger sein kann als im Ausgangsverfahren. Die Möglichkeit zur Anrufung des EuGH durch andere Gerichte als das Vorlagegericht muss daher bestehen. ${ }^{84}$ Eine Bindungswirkung ohne Vorlagemöglichkeit scheidet dementsprechend von vornherein aus.

aa) Kein entscheidender Unterschied zwischen letztinstanzlichen und nicht-letztinstanzlichen Gerichten

In der Regel wird im vorliegenden Zusammenhang zwischen der Bindung letztinstanzlicher Gerichte, also solchen im Sinne des Art. 267 III AEUV, und der Bindung nicht-letztinstanzlicher Gerichte im Sinne des Art. 267 II AEUV differenziert. ${ }^{85}$ Für erstere wird eine Bindung an das Vorabentscheidungsurteil über Art. 267 III AEUV begründet. Wenn für ein letztinstanzlich entscheidendes Gericht eine Vorlageverpflichtung u.a. nur dann nicht besteht, wenn die betroffene Unionsrechtsvorschrift bereits Gegenstand einer Auslegung durch den EuGH war ${ }^{86}$, wird daraus zu Recht abgeleitet, dass es die Frage erneut vorlegen muss, wenn es von der Auslegung abweichen möchte. Dann ist es aber im Grundsatz - von der Möglichkeit einer erneuten Vorlage einmal abgesehen - an die vom Gerichtshof vorgenommene Auslegung gebunden. ${ }^{87}$

Hinsichtlich der nicht-letztinstanzlichen Gerichte wird vor dem Hintergrund der Begründung der Bindungswirkung für die letztinstanzlichen Gerichte vielfach eine rechtliche Bindung verneint: Da für die Bindung der letztinstanzlichen Gerichte Art.267 III AEUV ausschlaggebend sei,

84 Vgl. Weth/Kerwer, in: Oetker/Preis/Rieble (Hrsg.), 50 Jahre Bundesarbeitsgericht, 2004, S. 1383 (1388).

85 Weth/Kerwer, in: Oetker/Preis/Rieble (Hrsg.), 50 Jahre Bundesarbeitsgericht, 2004, S. 1383 (1389 ff.); Althammer, in: Gsell/Hau (Hrsg.), Zivilgerichtsbarkeit, 2012, S. 37 (47 ff.); Kovács, Temporale Wirkung, 2014, S. 74 ff.; Rosenkranz, Beschränkung der Rückwirkung, 2015, S. 29 ff. Aus der einschlägigen Kommentarliteratur beispielhaft Gaitanides, in: von der Groeben/Schwarze/Hatje (Hrsg.), Unionsrecht, 7. Aufl. 2015, Art. 267 AEUV, Rn. 92.

86 Vgl. EuGH, Urteil vom 6.10.1982, Rs. 283/81 (CILFIT u.a.), Rn. 21.

87 Vgl. statt vieler Frenz, Handbuch Europarecht, Band 5, 2010, Rn. 3405: „im Umkehrschluss“; Schwarze/Wunderlich, in: Schwarze/Becker/Hatje/Schoo (Hrsg.), EU-Kommentar, 4. Aufl. 2019, Art. 267 AEUV, Rn. 72. 
mangele es bei den nicht-letztinstanzlichen Gerichten an einer vergleichbaren Ausgangslage. Für diese bestehe nach Art. 267 II AEUV ja gerade keine Vorlagepflicht. ${ }^{88}$ Auf Grundlage dieser Auffassung ist es konsequent, einen Erst-recht-Schluss von der Bindung der letztinstanzlichen Gerichte auf diejenige der nicht-letztinstanzlichen ${ }^{89}$ abzulehnen. ${ }^{90}$

Nicht übersehen werden darf aber, dass auch nicht-letztinstanzliche Gerichte das Unionsrecht in vollem Umfang beachten müssen. Art. 267 II AEUV nimmt daher gegen das Unionsrecht verstoßende Entscheidungen keineswegs hin. ${ }^{91}$ Zudem dürfen die Fragen nach der Vorlagepflicht und der Bindungswirkung nicht miteinander vermengt werden. ${ }^{92}$ So lässt sich die in Art. 267 II und III AEUV vorgenommene Unterscheidung zwischen letztinstanzlichen und nicht-letztinstanzlichen Gerichten auch damit erklären, dass sie nur so lange von Bedeutung ist, bis der Gerichtshof die entsprechende Vorschrift ausgelegt hat. Existiert noch keine einschlägige Rechtsprechung des EuGH, dürfen die nicht-letztinstanzlichen Gerichte die Vorschrift des Unionsrechts selbst auslegen. Ist die Vorschrift dagegen einmal vom Gerichtshof ausgelegt worden, sind auch diese zur Befolgung der Rechtsprechung verpflichtet. ${ }^{93}$ Dies widerspricht Art. 267 II AEUV nicht, da dieser insoweit gerade keine Aussage trifft. ${ }^{94}$ Ebenfalls in die Richtung einer Gleichbehandlung von letztinstanzlichen und nicht-letztinstanzlichen Gerichten deutet die Tatsache, dass auch der EuGH in seiner zur ständigen Rechtsprechung gewordenen Formulierung hinsichtlich der

88 Weth/Kerwer, in: Oetker/Preis/Rieble (Hrsg.), 50 Jahre Bundesarbeitsgericht, 2004, S. 1383 (1391); Althammer, in: Gsell/Hau (Hrsg.), Zivilgerichtsbarkeit, 2012, S. 37 (49); siehe auch Wollenschläger, NJW 2018, 2532 (2536 mit Fn. 45).

89 In diesem Sinne GA Reischl, Schlussanträge vom 21.1.1981 in der Rs. 66/80 (International Chemical Corporation), Slg. 1981, S. 1228.

90 Ausdrücklich Althammer, in: Gsell/Hau (Hrsg.), Zivilgerichtsbarkeit, 2012, S. 37 (50 f.). Vgl. auch Weth/Kerwer, in: Oetker/Preis/Rieble (Hrsg.), 50 Jahre Bundesarbeitsgericht, 2004, S. 1383 (1391) mit Fn. 27.

91 Breuer, EuZW 2004, 199 (201) unter Verweis auf EuGH, Urteil vom 14.7.1994, Rs. C-91/92 (Faccini Dori), Rn.26. Siehe auch Düsterhaus, YEL 36 (2017), 237 (241), der darauf hinweist, dass Art. 267 AEUV durch die Begrenzung der Vorlagepflicht auf letztinstanzliche Gerichte den nationalen Gerichtsaufbau achte.

92 Davor warnt auch Schröder, Gesetzesbindung, 2010, S. 140.

93 Ist eine Bestimmung des Unionsrechts einmal ausgelegt, bindet diese Auslegung alle Gerichte, GA Wathelet, Schlussanträge vom 25.7.2018 in der Rs. C-416/17 (Kommission/Frankreich), Rn.92. Siehe auch Wildemeersch, J.T. 2018, 256.

94 Ebenso Kruis, Anwendungsvorrang, 2013, S. 137; Lenaerts/Arts/Maselis, Procedural Law, 2. Aufl. 2006, Rn. 2-058. 
zeitlichen Wirkung der Auslegung/Auslegungsurteile ${ }^{95}$ keine entsprechende Differenzierung vornimmt. ${ }^{96}$

Gegen eine rechtliche Bindung der nicht-letztinstanzlichen Gerichte spricht auch nicht, dass in einem Vertragsverletzungsverfahren zwar zu berücksichtigen ist, wie die nationalen Gerichte die nationalen Rechtsund Verwaltungsvorschriften auslegen, um über das Vorliegen einer Vertragsverletzung entscheiden zu können, dabei aber ,isolierte gerichtliche Entscheidungen" ebenso wie solche, die in der Minderheit sind, außer Betracht bleiben - im Gegensatz zu einer vom obersten nationalen Gericht nicht verworfenen oder gar bestätigten richterlichen Auslegung. ${ }^{97}$ Auch wenn eine Vertragsverletzung eines Mitgliedstaats mit diesen isolierten Entscheidungen nicht begründet werden kann, ändert dies nichts daran, dass ein Berufungsgericht sie verwerfen muss. ${ }^{98}$ Auch die nicht-letztin-

95 EuGH, Urteil vom 27.3.1980, verb. Rs. 66/79, 127/79 und 128/79 (Salumi u.a.), Rn. 9: „Durch die Auslegung einer Vorschrift des Gemeinschaftsrechts [...] wird erläutert und erforderlichenfalls verdeutlicht, in welchem Sinn und mit welcher Tragweite diese Vorschrift seit ihrem Inkrafttreten zu verstehen und anzuwenden ist oder gewesen wäre. Darauf folgt, daß die Gerichte die Vorschrift in dieser Auslegung auch auf Rechtsverhältnisse, die vor Erlaß des auf das Ersuchen um Auslegung ergangenen Urteils entstanden sind, anwenden können und müssen, wenn alle sonstigen Voraussetzungen für die Anrufung der zuständigen Gerichte in einem die Anwendung dieser Vorschriften betreffenden Streit vorliegen."

96 Darauf weist Frenz, Handbuch Europarecht, Band 5, 2010, Rn. 3406 zu Recht hin; ebenso Frenz/Kübl, DStZ 2009, 432 (434). Dass sich diese Aussage als Argument für eine rechtliche Bindung heranziehen lässt, bezweifelt etwa Althammer, in: Gsell/Hau (Hrsg.), Zivilgerichtsbarkeit, 2012, S. 37 (45). Auch Franzen, Privatrechtsangleichung, 1999, S. 276 meint, hier gehe es nur um die zeitliche Wirkung von Urteilen. Ablehnend auch Rosenkranz, Beschränkung der Rückwirkung, 2015, S. $35 \mathrm{f}$.

97 EuGH, Urteil vom 9.12.2003, Rs. C-129/00 (Kommission/Italien), Rn. 30 ff. Siehe auch das im Vorabentscheidungsverfahren ergangene Urteil des Gerichtshofs EuGH, Urteil vom 15.3.2018, Rs. C-431/16 (Blanco Marqués), Rn. 47 zu der Frage, ob die von einem obersten Gericht vorgenommene Auslegung einer Rechtsvorschrift zu den Rechtsvorschriften im Sinne von Art. 1 Buchst.j der Verordnung Nr. 1408/71 gezählt werden muss.

98 Zutreffend Düsterhaus, YEL 36 (2017), 237 (241). Sein Verweis in Fn. 29 auf EuGH, Urteil vom 19.4.2016, Rs. C-441/14 (DI) ist in diesem Zusammenhang allerdings insoweit irreführend, als es dort um eine ständige höchstrichterliche nationale Rechtsprechung geht, die gegebenenfalls abzuändern ist, um eine unionsrechtskonforme Auslegung zu ermöglichen, vgl. Urteil DI, Rn. 33 f. Auch die Rechtsprechung unterinstanzlicher Gerichte ist aber natürlich im Falle ihrer Unionsrechtswidrigkeit im Instanzenzug zu korrigieren. 
stanzlichen Gerichte sind also rechtlich an die Auslegung des Unionsrechts durch den Gerichtshof gebunden.

bb) Hinweis in der Rechtsprechung zur Begrenzung der zeitlichen Wirkungen

Die sich hier andeutende erga omnes-Wirkung findet einen weiteren Anhaltspunkt in der Rechtsprechung des EuGH zur zeitlichen Begrenzung der Wirkungen seiner Auslegungstätigkeit. Wenn der Gerichtshof ausführt, die zeitliche Begrenzung könne nur im erstauslegenden Urteil erfolgen, um die Gleichbehandlung der Mitgliedstaaten und der Einzelnen sicherzustellen ${ }^{99}$, so zeigt dies, dass diese Auslegung auf alle Mitgliedstaaten und Einzelnen anzuwenden ist. ${ }^{100}$

\section{cc) Deklaratorisches Auslegungsverständnis und Bindungswirkung}

Zudem ist der Gerichtshof der Auffassung, eine Vorabentscheidung sei deklaratorischer Natur ${ }^{101}$, geht also von der Vorstellung deklaratorischer Rechtserkenntnis aus. Danach stimmt die Bindungswirkung der Auslegung mit der Bindungswirkung der ausgelegten Vorschrift überein; die vom Gerichtshof vorgenommene Auslegung ist dann Bestandteil der unionsrechtlichen Vorschrift, welche für alle mitgliedstaatlichen Gerichte verbindlich ist. ${ }^{102}$ Die Auslegungsentscheidungen sind also gewissermaßen in die ausgelegte Norm „inkorporiert“; die Auslegung des Unionsrechts durch den EuGH setzt sich daher mit der Kraft der ausgelegten Norm

99 EuGH, Urteil vom 6.3.2007, Rs. C-292/04 (Meilicke u.a.), Rn. 37. Siehe hierzu ausführlich unten bei Fn. $881 \mathrm{ff}$.

100 Lenaerts, CMLRev. 44 (2007), 1625 (1642 f., Fn. 102); Broberg/Fenger, Vorabentscheidungsverfahren, 2014, S. 390 f. Kritisch zur Brauchbarkeit dieses Arguments Rosenkranz, Beschränkung der Rückwirkung, 2015, S. 33.

101 So ausdrücklich EuGH, Urteil vom 12.2.2008, Rs. C-2/06 (Kempter), Rn. 35; EuGH, Urteil vom 8.9.2011, verb. Rs. C-89/10 und C-96/10 (Q-Beef und Bosschaert), Rn. 48; EuGH, Urteil vom 16.1.2014, Rs. C-429/12 (Pohl), Rn.30; EuGH, Urteil vom 28.1.2015, Rs. C-417/13 (Starjakob), Rn. 63.

102 Lenaerts, CMLRev. 44 (2007), 1625 (1642); Broberg/Fenger, Vorabentscheidungsverfahren, 2014, S. 390. Siehe auch Schröder, Gesetzesbindung, 2010, S. 134 und Koenig, EWS 2010, 449 (452). 
durch. ${ }^{103}$ Wenn die Norm in ihrer Auslegung durch den EuGH wirkt, bedeutet dies im Übrigen zugleich, dass die Bindungswirkung der Rechtsprechung nicht über die Bindungswirkung der Norm hinausgehen kann. ${ }^{104}$

Die Vorstellung des EuGH von der deklaratorischen Rechtserkenntnis wird zum Teil kritisiert. ${ }^{105}$ Von vornherein nicht zu überzeugen vermag allerdings der Einwand, dass neue Mitgliedstaaten den acquis, zu dem auch die Rechtsprechung des EuGH gehört, übernehmen müssen, da dies nicht zwingend für eine rechtsetzende Tätigkeit des Gerichtshofs spricht. ${ }^{106}$ Dass die Rechtsprechung des EuGH als Bestandteil des acquis zu übernehmen ist, liegt daran, dass die Norm wie gesehen in ihrer Auslegung durch den EuGH wirkt, diese also zu deren Verständnis herangezogen werden muss.

Zutreffend ist dagegen zwar der Hinweis darauf, dass die Rechtsprechung auch Lücken füllen muss und dabei mit den Auslegungsmethoden ein Instrumentarium an der Hand hat, das ihr gewisse Spielräume eröffnet. Richter sind demnach nicht nur „la bouche qui prononce les paroles de la loi“ im Sinne Montesquieus. ${ }^{107}$ Dennoch ist es möglich, im Ergebnis davon zu sprechen, dass der Gerichtshof den Inhalt einer unionsrechtlichen Norm lediglich „findet“. Hierfür sind allerdings nähere Überlegungen zum Verhältnis von Rechtsetzung und Rechtsprechung im Unionsrecht erforderlich.

(1) Verhältnis von Rechtsetzung und Rechtsprechung im Unionsrecht

Für das deutsche Recht führt das Bundesverfassungsgericht aus, es bestehe keine Befugnis des Gesetzgebers zur authentischen Interpretation gesetz-

103 Vandersanden, RCJB 1972, 508 (518ff.). Siehe auch Lenaerts/Gutiérrez-Fons, EUI Working Paper AEL 2013/9, die bereits im Titel ihres Beitrags die Bedeutung des Gerichtshofs in diesem Zusammenhang zum Ausdruck bringen ("To Say What the Law of the EU Is: Methods of Interpretation and the European Court of Justice").

104 Nach Ansicht von Lepsius, JZ 2019, 793 (796) haben die Entscheidungen des Gerichtshofs dagegen mittlerweile „die Bindungsfunktion des Unionsrechts übernommen".

105 Grundsätzlich kritisch zur Bestimmung des Verhältnisses „von Recht und Rechtsprechung" mit einem Ansatz wie der deklaratorischen Theorie Payandeh, Judikative Rechtserzeugung, 2017, S. 478.

106 So aber Levits, SR 2015, 121 (124).

107 Verstraelen, GLJ 14 (2013), 1687 (1689). Darauf, dass rechtliche Normen die Rechtsanwendung nicht vollständig determinieren können, weist insbesondere auch Payandeh, Judikative Rechtserzeugung, 2017, S. 26, 205 hin. 
licher Vorschriften. ${ }^{108}$ Der Gesetzgeber habe es für die Vergangenheit grundsätzlich hinzunehmen, dass die Gerichte das damals geltende Gesetzesrecht in den verfassungsrechtlichen Grenzen richterlicher Gesetzesauslegung und Rechtsfortbildung verbindlich auslegten. ${ }^{109}$ Für das Bundesverfassungsgericht gehört die Vergangenheit demnach den Gerichten. ${ }^{110}$ Derartige Überlegungen können auch im Unionsrecht fruchtbar gemacht werden, wenn das Verhältnis von Rechtsetzung und Rechtsprechung im Unionsrecht dies gestattet.

In der Literatur findet sich in diesem Zusammenhang die Auffassung, der Gerichtshof dürfe grundsätzlich in den Kompetenzbereich der Legislative übergreifen. Der Judikative wird dabei eine konkurrierende Kompetenz zur Normsetzung zugesprochen, wenn der Gesetzgeber seiner Verpflichtung zur Gestaltung der Rechtsordnung aus sachlich nicht gerechtfertigten Gründen nicht nachkommt. ${ }^{111}$ Eine solche Rechtsetzungskompetenz des Gerichtshofs ist aber unvereinbar mit der Beschränkung des Gerichtshofs auf die Wahrung des Rechts bei der Auslegung und Anwendung der Verträge nach Art. 19 I UAbs. 1 S. 2 EUV. ${ }^{112}$ Eine derartige Ausweitung der Befugnisse des Gerichtshofs ist daher abzulehnen.

Betrachtet man die grundsätzliche zeitliche Wirkung von Rechtsetzung und Rechtsprechung, werden unterschiedliche Ausgangspunkte deutlich. Unionsrechtsakte wirken in der Regel nicht zurück. Insoweit gilt der Grundsatz der Nichtrückwirkung. Demnach sind die Vorschriften des materiellen Unionsrechts „so auszulegen, dass sie für vor ihrem Inkrafttreten abgeschlossene Sachverhalte nur gelten, soweit aus ihrem Wortlaut, ihrer Zielsetzung oder ihrem Aufbau eindeutig hervorgeht, dass ihnen eine solche Wirkung beizumessen ist“ ${ }^{\text {" }}{ }^{113}$ Die Wirkung in die Vergangenheit ist

108 BVerfG, Beschluss vom 17.12.2013, 1 BvL 5/08, Rn. 45 - BVerfGE 135, 1.

109 BVerfG, Beschluss vom 17.12.2013, 1 BvL 5/08, Rn. 52 - BVerfGE 135, 1.

110 So auch die Einschätzung von Osterloh, StuW 2015, 201 (202).

111 Borchardt, in: GS Grabitz, 1995, S. 29 (38 f.).

112 Riesenhuber, in: Riesenhuber (Hrsg.), Europäische Methodenlehre, 3. Aufl. 2015, $\$ 10$, Rn. 9 .

$113 \mathrm{EuGH}$, Urteil vom 12.9.2013, Rs. C-614/11 (Kuso), Rn. 24; EuGH, Urteil vom 6.10.2015, Rs. C-303/13 P (Kommission/Andersen), Rn. 50; EuGH, Urteil vom 29.1.2002, Rs. C-162/00 (Pokrzeptowicz-Meyer), Rn. 49; EuGH, Urteil vom 11.12.2008, Rs. C-334/07 P (Kommission/Freistaat Sachsen), Rn. 44. EuGH, Urteil vom 10.2.1982, Rs. 21/81 (Bout), Rn. 13 spricht noch von vor dem Inkrafttreten „entstandenen“ Sachverhalten; dieses Urteil wird aber auch in den nachfolgenden Urteilen zitiert, in denen von „abgeschlossenen“ Sachverhalten die Rede ist, sodass damit keine inhaltliche Änderung verbunden ist. 
Rechtsakten daher nicht wesenseigen; sie muss vielmehr gesondert begründet werden.

Dagegen ist die Wirkung in die Vergangenheit wegen des notwendigen Zeitablaufs zwischen Inkrafttreten einer Norm und erstmaliger Auslegung konstituierendes Merkmal der Rechtsprechung. Sie muss daher nicht gesondert begründet werden. ${ }^{114}$ Hier besteht vielmehr ein Interesse am Ausschluss dieser Wirkung. Vor diesem Hintergrund ist bei der Vergleichbarkeit von Rechtsetzung und Rechtsprechung also Vorsicht geboten.

Sie besteht am ehesten bei sogenannter authentischer Auslegung einer Vorschrift durch den Gesetzgeber. Interpretiert der Gesetzgeber eine Norm „authentisch“, so erlässt er in seiner Vorstellung eine deklaratorische Vorschrift, die nur das wiedergibt, was die interpretierte Vorschrift schon immer zum Ausdruck gebracht hat.

Für deklaratorische Vorschriften erkennt der Gerichtshof eine Ausnahme vom Rückwirkungsverbot für den Unionsgesetzgeber an. ${ }^{115}$ So betrachtete er in der Rechtssache Osram Sätze, die dem Gemeinsamen Zolltarif mit Wirkung vom 1.1.1972 angefügt worden waren, als Auslegungsregeln, die rechtlich keine Neuerung darstellten, sodass sie auch auf vor dem 1.1.1972 getätigte Einfuhren anwendbar waren. ${ }^{116}$ Dahinter steht die Überlegung, dass die interpretierende Bestimmung erläutert und verdeutlicht, in welchem Sinn und mit welcher Tragweite die interpretierte Rechtsvorschrift seit ihrem Inkrafttreten zu verstehen und anzuwenden ist bzw. gewesen wäre. ${ }^{17}$ Die Anwendbarkeit seit Inkrafttreten der interpretierten Vorschrift ist einer derartigen interpretierenden Vorschrift damit immanent und muss nicht gesondert angeordnet werden. Insoweit findet also eine sinngemäße Übertragung der vom Gerichtshof in ständiger Rechtsprechung verwendeten Formulierung hinsichtlich seiner Auslegungsurteile statt. ${ }^{118}$

Die Entscheidung über den deklaratorischen bzw. konstitutiven Charakter der interpretierenden unionsrechtlichen Norm ist eine Frage der Auslegung, für die der Gerichtshof zuständig ist. Eine Einordnung einer Vorschrift als deklaratorisch nimmt der Gerichtshof nur ausnahmsweise

114 Höpfner, RdA 2006, 156 (157) spricht insoweit von einem notwendigen Charakteristikum der richterlichen Tätigkeit; Waldhoff, Rückwirkung, 2006, S. 13 f. bezeichnet den Vergangenheitsbezug als „zum ,Wesen“ von Rechtsprechung“ gehörend.

115 Schermers/Waelbroeck, Judicial Protection, 6. Aufl. 2001, $\mathbb{} 142$.

116 EuGH, Urteil vom 8.5.1974, Rs. 183/73 (Osram), Rn. 8.

117 Vgl. Heukels, Intertemporales Gemeinschaftsrecht, 1990, S. 85.

$118 \mathrm{Zu}$ dieser näher unten bei Fn. $174 \mathrm{ff}$. 
vor. ${ }^{119}$ Sie setzt voraus, dass der in der deklaratorischen Vorschrift ermittelte Gehalt mit den Vorgaben der ursprünglichen Vorschrift übereinstimmt. ${ }^{120}$ Die neue Norm darf also die sich aus der ursprünglichen Vorschrift ergebende Rechtslage nicht verändern. Ist eine Regelung dagegen rechtsgestaltend, kann sie keine rückwirkende Kraft entfalten. ${ }^{121}$

Die bloße Bezeichnung der neuen Norm als Interpretationsnorm bindet den Gerichtshof bei seiner Entscheidung nicht, da sich die Unionsorgane ansonsten selbst eine Ausnahme vom Rückwirkungsverbot schaffen könnten. $\mathrm{Zu}$ Recht wies der Gerichtshof deshalb ein Vorbringen der Kommission zurück, wonach sich aus einer Begründungserwägung ergebe, dass die in Rede stehende Verordnung lediglich die bereits vor ihrem Inkrafttreten bestehende Rechtslage bestätigen und klarstellen wolle. ${ }^{122}$

Sieht der Unionsgesetzgeber eine Vorschrift als deklaratorisch an, kann der Gerichtshof diese also immer noch als konstitutiv einordnen. Entscheidende Bedeutung kommt insoweit der Frage zu, welches Verständnis des Begriffs „konstitutiv“ zugrunde gelegt wird. Ist unklar, wie die ursprüngliche Norm auszulegen ist, ist ebenso unklar, ob die neue Norm konstitutiv oder deklaratorisch ist. Bewegt sie sich im Rahmen möglicher Auslegungen der alten Norm, kann sie beides sein. Das jedenfalls konstitutive Element einer klarstellenden Regelung ist die Veränderung des Normtextes, d.h. des Gegenstands der Auslegung. Ob auch das Ergebnis der Auslegung konstitutiv verändert wird, lässt sich dagegen vor einer Konkretisierung der alten Norm durch die Rechtsprechung nicht sagen. Über ein weites Verständnis des Begriffs „konstitutiv“ kann die Rechtsprechung damit die

119 Heukels, Intertemporales Gemeinschaftsrecht, 1990, S. 86; Schermers/Waelbroeck, Judicial Protection, 6. Aufl. 2001, $\$ 142$.

120 EuGH, Urteil vom 16.12.1976, verb. Rs. 36/76 und 37/76 (Foral u.a.), Rn.9.

121 Ausdrücklich festgestellt wurde der rechtsgestaltende Charakter etwa für Verordnungen, die die Voraussetzungen für die Einreihung in eine Position oder Unterposition des Zolltarifs festlegen, siehe EuGH, Urteil vom 28.3.1979, Rs. 158/78 (Biegi), Rn. 11; EuGH, Urteil vom 1.10.1981, Rs. 196/80 (Anglo-Irish Meat), Rn. 25; EuGH, Urteil vom 7.6.2001, Rs. C-479/99 (CBA Computer), Rn. 31; EuGH, Urteil vom 27.11.2008, Rs. C-403/07 (Metherma), Rn. 39; EuGH, Urteil vom 18.6.2009, Rs. C-173/08 (Kloosterboer Services), Rn. 21; EuGH, Urteil vom 16.12.2010, Rs. C-339/09 (Skoma-Lux), Rn. 27.

122 EuGH, Urteil vom 12.7.1984, Rs. 49/83 (Luxemburg/Kommission), Rn. 11, 14. Der dritte Erwägungsgrund der Verordnung (EWG) Nr. 2206/77 der Kommission vom 5. Oktober 1977 zur Änderung der Verordnung (EWG) Nr. 2015/76 über Lagerverträge für Tafelwein, Traubenmost und konzentrierten Traubenmost, ABl. L 255 vom 6.10.1977, S. 13 besagte, es erscheine „eine Bestätigung der Tatsache erforderlich, daß $[\ldots]$ “. 
Befugnisse des Gesetzgebers begrenzen, indem sie auch dann von einer unzulässigen Rückwirkung ausgeht, wenn die neue Norm nur potentiell konstitutiv ist, eine Auslegung der alten Norm also erst noch zeigen muss, ob die neue Norm tatsächlich konstitutiv ist. ${ }^{123}$ Dies zeigt, dass es authentische Auslegung durch den Gesetzgeber im Ergebnis nicht geben kann, da letztlich immer die Rechtsprechung letztverbindlich über den Norminhalt entscheidet. ${ }^{124}$

Im Unterschied zur Situation bei interpretierenden Vorschriften des Gesetzgebers erscheinen die Ergebnisse, wenn die Rechtsprechung eine Norm auslegt, immer als deklaratorisch. Das liegt daran, dass es keine Instanz gibt, die die Auslegung durch den EuGH als konstitutiv bezeichnen könnte. Dass der Gerichtshof insoweit mehr als deklaratorisch bezeichnen darf als er es dem Gesetzgeber zugesteht, folgt aus der Funktionsverteilung zwischen Rechtsprechung und Gesetzgebung, nach der ausweislich Art. 19 I UAbs. 1 S. 2 EUV und Art. 267 AEUV dem Gerichtshof die Zuständigkeit für die Auslegung zugewiesen worden ist.

Diese Funktionsverteilung hat auch zur Folge, dass der Gesetzgeber nicht einfach gegen aus seiner Sicht unliebsame Rechtsprechung ein rückwirkendes Nichtanwendungsgesetz erlassen kann. Möchte er dies tun, ist er an das Legislativrückwirkungsverbot gebunden ${ }^{125}$, da anderenfalls Möglichkeiten eröffnet würden, die Konkretisierungskompetenz der Rechtsprechung zu konterkarieren. $\mathrm{Zu}$ bejahen ist damit letztlich ein Verlust der Konkretisierungskompetenz des Gesetzgebers für die von ihm geschaffenen Normen. ${ }^{126}$

Im Hinblick auf den deklaratorischen Charakter ihrer Tätigkeit fehlt es Rechtsprechung und Gesetzgebung also an Vergleichbarkeit. Dies ändert allerdings nichts daran, dass in einem bestimmten Fall eine Gleichbehandlung erfolgen sollte. Angesprochen ist die Beschränkung der ex tunc-Wirkung der Rechtsprechung einerseits und die Beschränkung der Ausnahme vom Rückwirkungsverbot für den Gesetzgeber andererseits. Der Gerichtshof sollte also die Ausnabme von der Wirkung seiner Rechtsprechung in die Vergangenheit und die Ausnahme von der Wirkung tatsächlich deklaratorischer Vorschriften des Gesetzgebers in die Vergangenheit gleichbehandeln: Erkennt der Gerichtshof bei einer interpretierenden Vorschrift des Gesetzgebers keinen Unterschied zu der von ihm ermittelten Rechtslage

123 Siehe hierzu näher Osterloh, StuW 2015, 201 (202 f.).

124 Vgl. auch Schnapp, JZ 2011, 1125 (1129).

125 Vgl. Hey, JZ 2014, 500 (506 f.).

126 Anders Rosenkranz, Beschränkung der Rückwirkung, 2015, S. 106. 
nach der ursprünglichen Norm, ist die Vorschrift des Gesetzgebers wie gesehen - ebenso wie eine entsprechende Entscheidung des EuGH - „tatsächlich" als deklaratorisch einzuordnen. Sie wirkt seit Inkrafttreten der interpretierten Vorschrift. Da der Gerichtshof bei der von ihm vorgenommenen Erstauslegung einer Vorschrift (ohne Hinzutreten einer interpretierenden Vorschrift des Gesetzgebers) eine Ausnahme von der ex tunc-Wirkung für möglich erachtet ${ }^{127}$, sollte er daher auch für die von ihm bei deklaratorischen Vorschriften des Gesetzgebers angenommene Ausnahme vom Rückwirkungsverbot eine Beschränkungsmöglichkeit vorsehen. Die Rückwirkung dieser Art von Normen geht ja letztlich auf die Anerkennung der Vorschrift als deklaratorisch durch den Gerichtshof zurück.

\section{(2) Zwischenergebnis}

Die vorangehenden Überlegungen haben gezeigt, dass entscheidende Unterschiede zwischen Rechtsetzung und Rechtsprechung hinsichtlich des deklaratorischen Charakters der jeweiligen Tätigkeit bestehen. Im Ergebnis ist es daher zulässig, davon zu sprechen, dass ein Gericht wie der EuGH den Sinn einer Norm lediglich findet. Dass andere einen anderen Normsinn finden könnten, ist unerheblich. Bloße Fiktion wäre es allerdings, dabei davon auszugehen, dass die richterliche Meinung den Willen des Gesetzgebers widerspiegelt. Das Ergebnis der Auslegung in diesem Sinne als Willen des Gesetzgebers und nicht des Gerichts darzustellen, setzte nämlich voraus, dass man zwischen der richterlichen Meinung vom Inhalt des Gesetzes und seinem „tatsächlichen“ Inhalt unterscheiden könnte. Dies ist aber mit den Auslegungsmethoden nicht möglich. ${ }^{128}$ Entscheidend ist daher auf die besondere Stellung des für die Auslegung der jeweiligen Norm zuständigen Gerichts abzustellen. Nur dieses ist dazu berufen, den Sinn und Zweck des Gesetzes zu finden.

dd) Kein Präjudiziensystem

Abzusichern ist das hier gefundene Ergebnis der Bindungswirkung als Normwirkung noch gegen Überlegungen, dem Unionsrecht liege ein Präjudiziensystem zugrunde. So heißt es etwa in Teilen der Literatur, es

127 Siehe hierzu näher bei Fn. $647 \mathrm{ff}$.

128 Levits, SR 2015, 121 (123). 
gebe "some doctrine of precedent", wenn sie auch nicht mit stare decisis oder precedent bezeichnet werde. ${ }^{129}$ Zum Teil wird dort auch von einer gelockerten stare decisis-Doktrin ${ }^{130}$ oder von einem „binding precedent system", das den mitgliedstaatlichen Gerichten eine gewisse Autonomie belasse ${ }^{131}$, gesprochen.

Eine Präjudizienbindung hat eine andere Stoßrichtung als eine Rechtskraftbindung, sodass zwischen einer präjudiziellen Wirkung infolge der Rechtskraft und der mit der stare decisis-Doktrin einhergehenden Präjudizienbindung zu unterscheiden ist. ${ }^{132}$ Diese Unterscheidung hat auch zur Folge, dass der Gerichtshof aufgrund einer Regel wie der stare decisis-Doktrin verpflichtet sein könnte, einer früheren Entscheidung zu folgen, während die Rechtskraft ihn nicht daran hindert, sich bei fehlender Identität der Parteien, des Klagegrundes oder des Klagebegehrens inhaltlich mit einer identischen Frage zu befassen und diese abweichend zu beantworten. ${ }^{133}$ Beide Konzepte können daher nebeneinander bestehen. ${ }^{134}$

Zur begrifflichen Klärung ist hervorzuheben, dass ein Präjudiz („precedent“) zunächst einmal eine frühere gerichtliche Entscheidung bezeichnet. Stare decisis bedeutet demgegenüber, dass ein Gericht ein Präjudiz aufgrund einer rechtlichen Verpflichtung befolgen muss. ${ }^{135}$ Bei Präjudizien geht es um die Beantwortung abstrakter Rechtsfragen und die Schaffung abstrakter Rechtsregeln, die dann verbindliches Recht sind, sodass ein Zusammenhang zur Rechtsfortbildung besteht. ${ }^{136}$

129 Komárek, CYELS 11 (2009), 399 (400), der u.a. auf EuGH, Urteil vom 30.9.2003, Rs. C-224/01 (Köbler), Rn. 56 verweist.

130 Ehricke, in: Streinz (Hrsg.), EUV/AEUV, 3. Aufl. 2018, Art. 267 AEUV, Rn. 69.

131 Silveira/Perez Fernandes, Revista de Derecho Comunitario Europeo 54 (2016), 631 (642f.).

$132 \mathrm{Zu}$ diesen Begrifflichkeiten und der Unterscheidung siehe auch Ionescu, Innerstaatliche Wirkungen, 2016, S. 162, 167; ähnlich Plouvier, Décisions, 1975, S. 37 f. Die Rechtskraft geht dann nicht in der Bindungswirkung auf, da nur die Rechtskraft die Endgültigkeit der Entscheidung im konkreten Fall sicherstellen kann, siehe Germelmann, Rechtskraft, 2009, S. 404 ff. Siehe auch Payandeh, Judikative Rechtserzeugung, 2017, S. 40 f., 45.

133 Vgl. GA Lagrange, Schlussanträge vom 13.3.1963 in den verb. Rs. 28 bis 30/62 (Da Costa en Schaake N.V. u.a.), Slg. 1963, S. 88.

134 Siehe Toth, YEL 4 (1984), 1 (19): „no contradiction in principle“; „not mutually exclusive".

135 Toth, YEL 4 (1984), 1 (20, 44). Siehe in diesem Zusammenhang auch Payandeh, Judikative Rechtserzeugung, 2017, S. 46 ff., der dem Begriff des Präjudizes noch sein Konzept der judikativen Rechtserzeugung hinzufügt.

136 Germelmann, Rechtskraft, 2009, S. 406. 
Bedingungen für das Entstehen eines Präjudiziensystems sieht Koopmans zum einen darin, dass die wichtigsten Regeln des Rechtssystems in ungeschriebenen Regeln bestehen und zum anderen in der Bedeutung der Rolle der Gerichte als einigende Kraft und dem Abstützen von Gerichtsentscheidungen auf allgemeine Grundsätze. Diese Bedingungen sieht er auch im Unionsrecht als erfüllt an. ${ }^{137}$

Für das Bestehen eines Präjudiziensystems könnte auf den ersten Blick sprechen, dass der Gerichtshof trotz der Betonung der deklaratorischen Natur des Vorabentscheidungsverfahrens im Zusammenhang mit den Möglichkeiten des vorlegenden Gerichts zu einer erneuten Vorlage von der „Bindungswirkung eines im Vorabentscheidungsverfahren ergangenen Urteils“ (in der englischen Urteilsfassung von „the authority of a preliminary ruling“, in der französischen von „l'autorité dont est revêtu un arrêt rendu en matière préjudicielle“) spricht; von der unionsrechtlichen Bestimmung in dem Sinne, in dem sie vom EuGH ausgelegt wurde, ist dagegen nicht die Rede. ${ }^{138}$ Aufgrund der in dieser Aussage erfolgenden Bezugnahme auf das vorlegende Gericht, für das hinsichtlich der Bindungswirkung wie gesehen Besonderheiten bestehen, kann aus ihr für die Frage der Abgrenzung von Norm- und Urteilswirkung aber nichts abgeleitet werden.

Ebenso wenig kann angenommen werden, dass der Gerichtshof in einer vereinzelt gebliebenen Entscheidung, in der er in der niederländischen Verfahrenssprache vom „rechtskader van dat precedent" und in anderen Sprachfassungen vom „legal context of that precedent“ bzw. „cadre juridique de ce précédent" spricht, ein Präjudiziensystem etablieren wollte. In der deutschen Fassung ist dann auch bereits unverdächtiger von einem ,in dieser Vorläuferentscheidung vorgegebenen Rechtsrahmen“ die Rede. ${ }^{139}$

Präjudizienbindung hat in einer Rechtsordnung, in der ein deklaratorisches Verständnis besteht, letztlich keinen Platz. ${ }^{140}$ Rechtsquelle sind die

137 Koopmans, in: O’Keeffe/Schermers (Hrsg.), Essays, 1982, S. 11 (14 ff.).

138 EuGH, Beschluss vom 30.6.2016, Rs. C-634/15 (Sokoll-Seebacher und Naderhirn), Rn. 19; EuGH, Urteil vom 6.3.2003, Rs. C-466/00 (Kaba), Rn. 39; EuGH, Beschluss vom 5.3.1986, Rs. 69/85 (Wünsche), Rn. 15. Siehe hierzu auch Düsterhaus, YEL 36 (2017), 237 (240).

$139 \mathrm{EuGH}$, Urteil vom 12.6.2014, verb. Rs. C-39/13 bis C-41/13 (SCA Group Holding u.a.), Rn. 36 .

140 Tridimas, in: Dickson/Eleftheriadis (Hrsg.), Philosophical Foundations of European Union Law, 2012, S. 307 (308), der auch darauf verweist, dass eine kurze und bündige Argumentationsweise, wie der EuGH sie praktiziert, dem stare decisis eher abträglich ist. Siehe auch den Hinweis von Payandeh, Judikative 
Verträge und die vom Unionsgesetzgeber erlassenen Rechtsakte. In Rechnung zu stellen ist insbesondere auch die nicht-hierarchische Beziehung zwischen den Gerichten in der EU. Zwischen dem EuGH und nationalen Gerichten besteht kein hierarchisches Verhältnis; der EuGH ist kein Berufungsgericht, das die nationalen Gerichte zur Befolgung seiner Entscheidungen zwingen könnte. ${ }^{141}$

In der Rechtsprechung des Gerichtshofs zur auf das Unionsrecht gestützten Staatshaftung wird der EuGH-Rechtsprechung zwar beinahe Rechtsquelleneigenschaft zugesprochen. So spricht der Gerichtshof seinen Urteilen Bedeutung für die Frage der Qualifizierung des Unionsrechtsverstoßes zu, da der Verstoß gegen Unionsrecht bei Fortbestehen eines Verstoßes trotz einschlägiger Rechtsprechung als offenkundig hinreichend qualifiziert anzusehen ist. ${ }^{142}$ Dies ändert aber nichts daran, dass der Verstoß gegen Unionsrecht in der Verletzung der zugrundeliegenden Norm des Unionsrechts liegt; das Fortbestehen des Verstoßes trotz einschlägiger Rechtsprechung führt lediglich zu dessen Qualifizierung.

Auch Art. 99 EuGH-VerfO kann nicht als Anerkennung des Präjudizcharakters der Rechtsprechung des Gerichtshofs gesehen werden. ${ }^{143}$ Zwar kann danach bei bereits entschiedenen Rechtsfragen durch mit Gründen versehenen Beschluss entschieden werden. Die Figur des acte éclairé könnte daher auf den ersten Blick als Zeichen der konstitutiven Wirkung der Auslegung und damit des Präjudizwertes des zugrundeliegenden Urteils gesehen werden. Eine Antwort durch mit Gründen versehenen Beschluss ist nach Art. 99 EuGH-VerfO aber auch in dem Falle möglich, in dem die Beantwortung der Vorlagefrage keinen Raum für vernünftige Zweifel

Rechtserzeugung, 2017, S. 476, Fn.140, wonach die Vorstellung, dass es eine sich aus dem Gesetz ergebende objektiv richtige rechtliche Entscheidung gibt, die Anerkennung einer normativen Wirkung von Präjudizien erschwert.

141 Zutreffend Koopmans, in: O'Keeffe/Schermers (Hrsg.), Essays, 1982, S. 11 (18 f.).

142 Vgl. Tridimas, in: Dickson/Eleftheriadis (Hrsg.), Philosophical Foundations of European Union Law, 2012, S. 307 (327). Siehe etwa EuGH, Urteil vom 5.3.1996, verb. Rs. C-46/93 und C-48/93 (Brasserie du pêcheur und Factortame), Rn. 57; EuGH, Urteil vom 12.12.2006, Rs. C-446/04 (Test Claimants in the FII Group Litigation), Rn. 214; EuGH, Urteil vom 25.11.2010, Rs. C-429/09 (Fuß), Rn. 52; EuGH, Urteil vom 28.7.2016, Rs. C-168/15 (Tomášová), Rn. 26; EuGH, Urteil vom 29.7.2019, Rs. C-620/17 (Hochtief Solutions Magyarországi Fióktelepe), Rn.43. Gleiches gilt im Rahmen der außervertraglichen Haftung der Union, vgl. EuGH, Urteil vom 30.5.2017, Rs. C-45/15 P (Safa Nicu Sepahan), Rn. 31.

143 Hierfür Tridimas, in: Dickson/Eleftheriadis (Hrsg.), Philosophical Foundations of European Union Law, 2012, S. 307 (328). 
lässt. In diesem Fall des acte clair gibt es bislang keine Rechtsprechung. Daher muss die ausgelegte Norm des Unionsrechts entscheidend sein. ${ }^{144}$

Hinzu kommt noch Folgendes: Präjudizien oberster Gerichte binden auch diese selbst bei einer stare decisis-Doktrin. ${ }^{145}$ Das Bestehen eines Präjudiziensystems im Unionsrecht hängt also auch vom Umgang des Gerichtshofs mit seiner eigenen Rechtsprechung ab. Der „precedential value" eines Auslegungsurteils zeigt sich daher daran, ob der EuGH dieses in seiner nachfolgenden Rechtsprechung „applies, distinguishes, reinterprets or extrapolates“. ${ }^{146}$ Damit ist es zwar denkbar, dass ein Auslegungsergebnis abstrakt Präjudizcharakter hat, es also die hierfür erforderlichen Eigenschaften aufweist. Noch nichts gesagt ist damit aber über seine tatsächliche Rolle. Seine Wirkung ist also noch offen, die Frage, ob es auch Präjudizfunktion hat, noch nicht beantwortet. ${ }^{147}$ Letztere ist wie erwähnt abhängig vom Umgang des EuGH mit seinen früheren Entscheidungen in nachfolgenden Entscheidungen. ${ }^{148}$ Der Grundsatz der Rechtssicherheit hindert den Gerichtshof aber nicht daran, von früherer Rechtsprechung abzuweichen, wenn dies erforderlich erscheint. ${ }^{149}$

EuGH-Urteile stellen daher lediglich „Auslegungspräjudizien“150 dar, denen keine Rechtsquelleneigenschaft zukommt, die vielmehr lediglich Ausdruck der richtigen/vernünftigen/besten Auslegung einer bereits bestehenden Norm sind. Dies gilt ebenfalls im Hinblick auf ungeschriebene Rechtsgrundsätze, auch wenn ein Urteil des Gerichtshofs insoweit weniger als deren bloße Anerkennung, sondern mehr als ihre Verkörperung und damit konstitutiver Natur erscheint. ${ }^{151}$ Entscheidend ist aber, dass der

144 So auch Düsterhaus, YEL 36 (2017), 237 (243).

145 von Ungern-Sternberg, AöR 138 (2013), 1 (7); Cross/Harris, Precedent, 4. Aufl. 1991, S. 5 f., $102 \mathrm{ff}$.

146 Düsterhaus, in: Kochenov (Hrsg.), EU Citizenship and Federalism, 2017, S. 642 (661 f.).

147 So geht etwa die Anerkennung einer normativen Wirkung von Präjudizien nicht zwingend mit einer Bindung an Präjudizien einher, siehe Payandeh, Judikative Rechtserzeugung, 2017, S. 256 ff.

148 Düsterhaus, EuR 2017, 30 (34) spricht insoweit von der Möglichkeit, dass die Auslegung „tatbestandlich abgeschichtet, normativ verengt, extrapoliert oder reinterpretiert" werden könne.

149 Düsterhaus, YEL 36 (2017), 237 (242). Siehe dazu näher unten bei Fn. 223 ff.

150 Siehe zu diesem Begriff Düsterhaus, EuR 2017, 30 (34), der ihn im Unterschied zum stare decisis verwendet und insoweit von einer "gelockerte[n] Bindungswirkung" spricht.

151 Tridimas, in: Dickson/Eleftheriadis (Hrsg.), Philosophical Foundations of European Union Law, 2012, S. 307 (309f.). GA Bobek, Schlussanträge vom 7.9.2017 in der Rs. C-251/16 (Cussens u.a.), Rn. 36 spricht daher davon, dass, wenn ein 
Gerichtshof diese nicht selbst schaffen kann. Er erfindet diese also nicht, sondern legt sie frei ${ }^{152}$, sodass er sie letztlich nur vorfindet, auch wenn ihre Anerkennung wie z.B. beim Grundsatz des Verbots der Altersdiskriminierung zum Teil kritisiert wird. ${ }^{153}$

\section{c) Ergebnis}

Eine Bindung der mitgliedstaatlichen Gerichte an die Auslegungsentscheidungen des EuGH ergibt sich also nicht aus einem Präjudiziensystem, das im Unionsrecht nicht nachweisbar ist. Sie folgt auch nicht aus der Rechtskraft, deren Wirkung, wenn man ihr denn überhaupt Bedeutung beimessen möchte, auf das vorlegende Gericht und das Ausgangsverfahren beschränkt ist. Das Auslegungsurteil teilt vielmehr die Verbindlichkeit der ausgelegten Norm. ${ }^{154}$

Damit hat sich erwiesen, dass es sich bei der hier diskutierten Bindungswirkung in Wirklichkeit nicht um die Wirkung des Auslegungsurteils, sondern um eine solche der ausgelegten Unionsnorm selbst handelt. ${ }^{155}$ Die Verpflichtung der mitgliedstaatlichen Gerichte zur Befolgung der Auslegung des EuGH folgt also aus der autoritativ ${ }^{156}$ ausgelegten Norm.

allgemeiner Grundsatz des Unionsrechts durch die Rechtsprechung des EuGH bestätigt werde, dieser die Eigenschaften der Rechtsprechung in zeitlicher Hinsicht teile; zwischen Grundsatz und Auslegung könne nicht getrennt werden; diese würden miteinander „verwachsen“"(Anführungszeichen im Original); siehe auch Rn. 40.

152 Begriff bei Buckler, EuR 2018, 371 (372).

153 Kritisch etwa Hailbronner, NZA 2006, 811 (814).

154 Lenaerts, CMLRev. 44 (2007), 1625 (1642); Masclet, RTDEur. 1986, 161 (169); Ludewig, Zeitliche Beschränkung, 2012, S.90; Düsterhaus, EuR 2017, 30 (33); Düsterhaus, YEL 36 (2017), 237 (240).

155 Im Ergebnis ebenso Düsterhaus, YEL 36 (2017), 237 (243); Rosenkranz, Beschränkung der Rückwirkung, 2015, S. 27. Von Ungern-Sternberg, AöR 138 (2013), 1 $(37,39$ ff.) bejaht eine Präjudizienbindung über die Vorlagepflicht zum EuGH und Art. 101 I 2 GG. Verwiesen sei an dieser Stelle noch darauf, dass selbst Payandeh, der für die deutsche Rechtsordnung von einer rechtserzeugenden Funktion der Judikative ausgeht, die demnach abstrakt-generell wirkendes ungeschriebenes Recht schafft, als Bezugspunkt der Verbindlichkeit weiterhin die Rechtsnorm ansieht. Er spricht daher von der „Normakzessorietät von Präjudizien“, Payandeh, Judikative Rechtserzeugung, 2017, S. 49 ff., 134 ff.

156 Bei einer autoritativen Auslegung besitzt der mit Bindungskraft Interpretierende nicht auch die Rechtsmacht, die interpretierte Norm selbst zu ändern; andernfalls ist von einer authentischen Interpretation zu sprechen, vgl. Jestaedt, 
An dieser normativen Bindungswirkung erga omnes ändert die fehlende Vorlagepflicht nicht-letztinstanzlicher Gerichte nichts. ${ }^{157}$ Die Bindung der mitgliedstaatlichen Gerichte an die Vorschrift des Unionsrechts in der Auslegung durch den Gerichtshof erscheint vor dem Hintergrund der jederzeit bestehenden Möglichkeit einer erneuten Vorlage an den Gerichtshof gerechtfertigt.

Aus den voranstehenden Erkenntnissen ergibt sich ein Weiteres. Da der EuGH nicht über den konkreten Rechtsstreit entscheidet, sondern die für dessen Entscheidung relevanten unionsrechtlichen Rechtsfragen beantwortet, ist das tatsächliche Umfeld der sich ihm stellenden Rechtsfragen weniger bedeutsam. ${ }^{158}$ Dies erschwert es, obiter dicta in seinen Urteilen zu identifizieren, die dann vorliegen, wenn Ausführungen des Gerichtshofs über die Beantwortung der Vorlagefrage hinausgehen. ${ }^{159}$ Die Feststellung des Vorliegens eines obiter dictum mag zwar dennoch möglich sein. ${ }^{160}$ Zum Teil verwenden Generalanwälte den Begriff des obiter dictum auch, um anzudeuten, dass nicht alle Teile eines Urteils gleich bedeutsam seien. ${ }^{161}$

in: Isensee/Kirchhof (Hrsg.), HStR XII, 3. Aufl. 2014, $\$ 264$, Rn. 29 und 50. Zur Kompetenz der Judikative zur autoritativen Interpretation nach der deutschen Rechts- und Verfassungsordnung näher Payandeh, Judikative Rechtserzeugung, 2017, S. 278 f.

157 Ebenso Lohse, Rechtsangleichungsprozesse, 2017, S. 267. Dass die Entscheidungen des Gerichtshofs nur zur strengen Vorlagepflicht nationaler Gerichte führen, kann damit entgegen Röhl/Röhl, Allgemeine Rechtslehre, 3. Aufl. 2008, S. 568 f. nicht behauptet werden.

158 Auch Lepsius, JZ 2019, 793 (797) weist darauf hin, dass der EuGH bei der Auslegungsvorabentscheidung keinen Einzelfall entscheidet, sondern „Auslegungsfragen vor dem Hintergrund der einheitlichen Anwendung des Europarechts“. Indem es die Entscheidungserheblichkeit der Vorlagefrage verlangt, ist das Vorabentscheidungsverfahren aber zumindest „nicht vollständig von einem konkreten streitigen Fall abgekoppelt“, Payandeh, Judikative Rechtserzeugung, 2017, S. 212, Fn. 271.

159 Vgl. Wollenschläger, NJW 2018, 2532 (2533 f.).

160 Komárek, CYELS 11 (2009), 399 (431 f., siehe auch Fn. 182). Er erblickt hinsichtlich der Bedeutung, die der EuGH den tatsächlichen Gegebenheiten beimisst, ein eher willkürliches Vorgehen („in a rather arbitrary fashion“). Genaue Trennlinien zur Unterscheidung von ratio decidendi und obiter dicta sind ihm zufolge noch nicht gezogen worden.

161 Zu diesem Befund gelangt Komárek, CYELS 11 (2009), 399 (401). Siehe etwa GA Alber, Schlussanträge vom 29.9.1999 in der Rs. C-165/98 (Mazzoleni und ISA), Rn. 19. Siehe in diesem Zusammenhang auch GA La Pergola, Schlussanträge vom 12.2.1998 in der Rs. C-262/96 (Sürül), Rn.36. 
Da es aber wie gesehen keine stare decisis-Doktrin im Unionsrecht gibt, ist die Unterscheidung zwischen ratio decidendi und obiter dictum für die Frage der Bindungswirkung nicht entscheidend. Alle Aussagen in einem Urteil können daher die gleiche Bindungswirkung haben. ${ }^{162}$ Auch die in einem obiter dictum geäußerte Rechtsansicht ist vom Willen des Gerichtshofs getragen. ${ }^{163}$

Hiergegen kann auch nicht vorgebracht werden, dass die Bindungswirkung nicht über die sachliche Reichweite der Rechtskraft hinaus erstreckt werden könne. ${ }^{164}$ Für das Ausgangsverfahren, für das die Rechtskraft Bedeutung erlangen könnte, sind obiter dicta nämlich ohne Belang, da sie ihrer Natur entsprechend für dessen Entscheidung nicht relevant werden können. Das Problem einer über die Rechtskraft hinausgehenden Bindungswirkung stellt sich insoweit also von vornherein nicht.

\section{Auslegung im Rahmen anderer Verfahren}

Im Fall eines sogenannten acte éclairé, d.h. beim Vorliegen einer gesicherten Rechtsprechung, die die entscheidungserhebliche Rechtsfrage löst, sind auch die sonst nach Art. 267 III AEUV zur Vorlage verpflichteten letztinstanzlichen Gerichte von der Vorlagepflicht befreit. Unerheblich ist dabei nach Auffassung des Gerichtshofs, in welcher Verfahrensart sich diese Rechtsprechung gebildet hat. ${ }^{165}$ Dann muss aber die Bindungswirkung der Auslegung verfahrensunabhängig sein. Die im Rahmen der Auslegungsvorabentscheidung gefundenen Ergebnisse können daher auch auf andere Verfahrensarten übertragen werden, in denen der Gerichtshof eine Vorschrift des Unionsrechts auslegt. ${ }^{166}$

162 Tridimas, in: Dickson/Eleftheriadis (Hrsg.), Philosophical Foundations of European Union Law, 2012, S. 307 (313); Arnull, in: Andenas/Jacobs (Hrsg.), European Community Law, 1998, S. 115 (126). A.A. Payandeh, Judikative Rechtserzeugung, 2017, S. 452 ff., der der Auffassung ist, Gerichte seien „für obiter getroffene Rechtsausführungen nicht legitimiert".

163 Dies hebt auch GA Roemer, Schlussanträge vom 7.6.1962 in der Rs.9/61 (Niederlande/Hohe Behörde), Slg. 1962, S. 493 hervor.

164 So aber Wollenschläger, NJW 2018, 2532 (2534, 2536).

165 EuGH, Urteil vom 6.10.1982, Rs. 283/81 (CILFIT u.a.), Rn. 14.

166 Ebenso Rosenkranz, Beschränkung der Rückwirkung, 2015, S. 27 f. Schröder, Gesetzesbindung, 2010, S. $150 \mathrm{f}$. vertritt dagegen die Ansicht, dass die Bindungswirkung der Urteile in anderen Verfahrensarten anders zu beurteilen sei, wenn dort Aussagen zur Auslegung getroffen werden. Diese Aussagen erfolgten lediglich als obiter dicta, sodass sie nur den Stellenwert einer Auslegungshilfe hätten. 
Durch einen solchen Ansatz werden nicht die Unterschiede der einzelnen Verfahrensarten unzulässigerweise nivelliert, die in der Tat bestehen. So prüft der Gerichtshof in einem Vertragsverletzungsverfahren etwa, ob die von der Kommission gerügte nationale Maßnahme allgemein geeignet ist, die Wirtschaftsteilnehmer anderer Mitgliedstaaten davon abzuhalten, von der betreffenden Freiheit Gebrauch zu machen. Im Rahmen eines Vorabentscheidungsverfahrens besteht die Aufgabe des Gerichtshofs hingegen darin, das vorlegende Gericht bei der Entscheidung des konkret bei ihm anhängigen Rechtsstreits zu unterstützen, was voraussetzt, dass feststeht, dass die entsprechende Freiheit auf diesen Rechtsstreit anwendbar ist. $^{167}$

Trotz dieser Unterschiede besteht ein gemeinsamer Kern von Vertragsverletzungsverfahren und Auslegungsvorabentscheidung - die Auslegung von Unionsrecht -, der durch die Betonung der verfahrensunabhängigen Bindungswirkung der Auslegung herausgearbeitet und sichtbar wird. Auch wenn Art. 260 I AEUV nur von der Feststellung des Verstoßes eines Mitgliedstaates gegen eine Verpflichtung aus den Verträgen durch den Gerichtshof spricht, so ist doch die Kompetenz des EuGH zur Auslegung des Unionsrechts eine notwendige Vorbedingung der Feststellung des Vertragsverstoßes. Einer Auslegung im Vertragsverletzungsverfahren Bindungswirkung über den Ausgangsfall hinaus zuzusprechen, begegnet daher keinen Bedenken.

Vor diesem Hintergrund vermag die Aussage des EuGH in der Rechtssache Minister for Fisheries nicht zu verwundern. In diesem Verfahren hatte ein irisches Gericht dem Gerichtshof Fragen zur Auslegung des damaligen Gemeinschaftsrechts vorgelegt. In seiner Antwort konnte sich der EuGH auf einen Verweis auf seine im zeitgleich gegen Irland geführten Vertragsverletzungsverfahren gemachten Ausführungen beschränken, da die in beiden Verfahren geprüften Rechtsfragen im Wesentlichen gleich waren. ${ }^{168}$

Vor dem Hintergrund der zur Bindungswirkung einer Auslegung getroffenen Aussagen vermag ebenfalls nicht zu verwundern ${ }^{169}$, dass Einzelne sich angesichts der Verpflichtung etwa der mitgliedstaatlichen Gerich-

167 So EuGH, Urteil vom 15.11.2016, Rs. C-268/15 (Ullens de Schooten), Rn. 49.

168 EuGH, Urteil vom 16.2.1978, Rs. 88/77 (Minister for Fisheries), Rn. 10/13.

169 Seer/Müller, IWB 2008, 255 (256 f.) sprechen dagegen davon, dass „der Feststellung der [Unionsrechts]widrigkeit selbstverständlich rein faktisch eine Präjudizwirkung zu[kommt]“. Siehe auch Rosenkranz, Beschränkung der Rückwirkung, 2015, S. 39. 
te aus Art. 260 I AEUV auf das unmittelbar anwendbare Unionsrecht berufen können, um in einem gerichtlichen Verfahren die aus dessen Anwendungsvorrang folgende Unanwendbarkeit des unionsrechtswidrigen nationalen Rechts geltend zu machen, auch wenn sie aus einem Urteil im Vertragsverletzungsverfahren keine Rechte herleiten können. ${ }^{170}$ Auch beim Vertragsverletzungsverfahren ergibt sich die normative Bindung nämlich aus der ausgelegten Norm, sodass eine Bindung an die in den Entscheidungen im Vertragsverletzungsverfahren vorgenommene Konkretisierung/ Auslegung des Unionsrechts besteht. ${ }^{171}$

\section{B. Der Grundsatz der ex tunc-Wirkung der Auslegung}

Nachdem die Bindungswirkung der Auslegung nach dem vorstehend Gesagten als Normwirkung eingeordnet werden konnte, ist im Folgenden der Frage nach der zeitlichen Wirkung der Auslegung nachzugehen. Zunächst ist wieder das Vorabentscheidungsverfahren in den Blick zu nehmen, um im Anschluss zu überprüfen, ob die erzielten Ergebnisse auch insoweit auf Auslegungen in anderen Verfahrensarten übertragbar sind.

\section{Auslegung im Rahmen der Auslegungsvorabentscheidung}

Nach Art. 267 I lit. a und lit. b Alt. 2 AEUV entscheidet der Gerichtshof über die Auslegung sowohl des Primär- als auch des Sekundärrechts. Eine Unterscheidung zwischen beiden Kategorien von Unionsrecht ist hier nicht angelegt, sodass auch keine Gründe für eine unterschiedliche Behandlung im Hinblick auf die zeitliche Wirkung der Auslegung von Primär- und Sekundärrecht ersichtlich sind. ${ }^{172}$ Auch der EuGH differenziert insoweit nicht. ${ }^{173}$

170 EuGH, Urteil vom 14.12.1982, verb. Rs. 314/81 bis 316/81 und 83/82 (Waterkeyn u.a.), Rn. 16. Ebenso Wunderlich, in: von der Groeben/Schwarze/Hatje (Hrsg.), Unionsrecht, 7. Aufl. 2015, Art. 260 AEUV, Rn. 4.

171 Lohse, Rechtsangleichungsprozesse, 2017, S. 268.

172 Für Gleichbehandlung auch Kovács, Temporale Wirkung, 2014, S. 123.

173 Für Primärrecht: EuGH, Urteil vom 27.3.1980, Rs.61/79 (Denkavit italiana), Rn. 16; EuGH, Urteil vom 2.2.1988, Rs. 309/85 (Barra), Rn. 11. Für Sekundärrecht: EuGH, Urteil vom 12.6.1980, Rs. 130/79 (Express Dairy Foods), Rn. 14. 


\section{Deklaratorisches Auslegungsverständnis und ex tunc-Wirkung}

Legt der Gerichtshof im Vorabentscheidungsverfahren eine Vorschrift des Unionsrechts aus, so erläutert und verdeutlicht er nach eigener Aussage, „in welchem Sinn und mit welcher Tragweite diese Vorschrift seit ihrem Inkrafttreten $\mathrm{zu}$ verstehen und anzuwenden ist oder gewesen wäre“..174 Dieses Verständnis entspricht - ebenfalls nach eigener Aussage - ständiger Rechtsprechung. ${ }^{175}$

Ablesen lässt sich an dieser Formulierung, dass die ex tunc-Wirkung der Auslegung für den EuGH zwanglos aus der Einordnung der Normauslegung als deklaratorische Rechtserkenntnis folgt. ${ }^{176}$

Unterstrichen wird die Vorstellung von der deklaratorischen Rechtserkenntnis und der mit ihr verbundenen zeitlichen Wirkung durch eine erstmals im Jahr 2008 im Anschluss an den soeben zitierten Textbaustein erfolgte Stellungnahme des Gerichtshofs: „Eine Vorabentscheidung [a preliminary ruling/un arrêt préjudiciel] ist, mit anderen Worten, nicht konstitutiver, sondern rein deklaratorischer Natur und wirkt daher grundsätzlich auf den Zeitpunkt des Inkrafttretens der ausgelegten Vorschrift zurück [...]."177 Zwar verwendet er diese Aussage nur selten in seinen Urtei-

174 Aus der Rechtsprechung des Gerichtshofs seien beispielhaft genannt EuGH, Urteil vom 27.3.1980, Rs.61/79 (Denkavit italiana), Rn.16; EuGH, Urteil vom 27.3.1980, verb. Rs.66/79, $127 / 79$ und 128/79 (Salumi u.a.), Rn.9f.; EuGH, Urteil vom 2.2.1988, Rs. 24/86 (Blaizot u.a.), Rn. 27; EuGH, Urteil vom 15.9.1998, Rs. C-231/96 (Edis), Rn. 15; EuGH, Urteil vom 4.5.1999, Rs. C-262/96 (Sürül), Rn. 107; EuGH, Urteil vom 10.2.2000, Rs. C-50/96 (Deutsche Telekom/Schröder), Rn. 43; EuGH, Urteil vom 10.2.2000, verb. Rs. C-270/97 und C-271/97 (Deutsche Post/Sievers und Schrage), Rn. 45; EuGH, Urteil vom 10.1.2006, Rs. C-402/03 (Skov und Bilka), Rn. 50; EuGH, Urteil vom 18.1.2007, Rs. C-313/05 (Brzeziński), Rn. 55; EuGH, Urteil vom 19.11.2009, Rs. C-540/07 (Kommission/Italien), Rn. 63; EuGH, Urteil vom 21.3.2013, Rs. C-92/11 (RWE Vertrieb), Rn.58; EuGH, Urteil vom 19.12.2013, Rs. C-262/12 (Association Vent De Colère! u.a.), Rn. 39; EuGH, Urteil vom 19.6.2014, verb. Rs. C-501/12 bis C-506/12, C-540/12 und C-541/12 (Specht u.a.), Rn. 105; EuGH, Urteil vom 14.4.2015, Rs.C-76/14 (Manea), Rn.53; EuGH, Urteil vom 9.6.2016, Rs. C-586/14 (Budişan), Rn. 45; EuGH, Urteil vom 22.11.2017, Rs. C-251/16 (Cussens u.a.), Rn. 41; EuGH, Urteil vom 20.12.2017, Rs. C-492/16 (Incyte), Rn. 41 f.; EuGH, Urteil vom 20.12.2017, Rs. C-500/16 (Caterpillar Financial Services), Rn. 31; EuGH, Urteil vom 28.2.2018, Rs. C-387/16 (Nidera), Rn. 30.

175 Siehe nur EuGH, Urteil vom 9.6.2016, Rs. C-586/14 (Budișan), Rn. 45.

176 In diesem Sinne versteht auch Osterloh, in: FS Hassemer, 2010, S. 173 (175) die Aussage des EuGH. Dieser schließt also von der deklaratorischen Rechtserkenntnis auf zwingende zeitliche Rechtswirkungen, vgl. Osterloh, a.a.O., S. 181.

177 EuGH, Urteil vom 12.2.2008, Rs. C-2/06 (Kempter), Rn. 35. 
len ${ }^{178}$, macht von ihr aber auch in neueren Urteilen Gebrauch und bringt dadurch zum Ausdruck, dass er ihr weiterhin Bedeutung beimisst. ${ }^{179}$

Vor dem Hintergrund, dass der EuGH in ihr davon spricht, dass die Vorabentscheidung auf den Zeitpunkt des Inkrafttretens der ausgelegten Vorschrift zurückwirke, wird dieser Äußerung zum Teil eine Aussage zum methodischen Vorgang der Auslegung abgesprochen. Geltend gemacht wird insoweit, sie beziehe sich nur auf die Wirkungen des Vorabentscheidungsverfahrens. ${ }^{180}$

Dieser Einwand schenkt allerdings der in der zitierten Passage ebenfalls enthaltenen Formulierung „mit anderen Worten“ zu wenig Beachtung. Der EuGH bringt hier also denselben bereits zuvor geäußerten Gedanken nochmals zum Ausdruck, nur eben „mit anderen Worten“, d.h. in abweichender Formulierung. Nur aufgrund des deklaratorischen Charakters der Auslegung ist auch die Vorabentscheidung deklaratorischer Natur; nur aufgrund der ex tunc-Wirkung der Auslegung wirkt auch die Vorabentscheidung auf den Zeitpunkt des Inkrafttretens der ausgelegten Norm zurück. Damit trifft der Gerichtshof aber auch eine Aussage zum Vorgang der Auslegung selbst. Es erschiene daher künstlich, zwischen dem Vorgang der Auslegung und den Wirkungen des Vorabentscheidungsverfahrens zu trennen.

Gegen den vom EuGH vollzogenen Schluss von der deklaratorischen Rechtserkenntnis auf deren zeitliche Wirkung wird noch eingewandt, dass der Gerichtshof seiner Aussage zum Wesen der Auslegung einer Vorschrift im Vorabentscheidungsverfahren ${ }^{181}$ noch einen zweiten Satz angefügt habe, der nicht als bloßes obiter dictum gewertet werden könne und daher für die Begründung der ex tunc-Wirkung entscheidend sei. ${ }^{182}$ Der EuGH führt in diesem zweiten Satz aus, Folge seiner Auslegung sei, dass die Vorschrift in dieser Auslegung auch auf Rechtsverhältnisse, die vor Erlass des auf das Ersuchen um Auslegung hin ergangenen Urteils entstanden sind, angewandt werden könne und müsse, wenn alle sonstigen Voraussetzungen für die Anrufung der zuständigen Gerichte in einem die Anwendung

178 Darauf verweist Rosenkranz, Beschränkung der Rückwirkung, 2015, S. 44, der ihr daher nur eingeschränkte Bedeutung beimessen möchte.

179 Zuletzt EuGH, Urteil vom 28.1.2015, Rs. C-417/13 (Starjakob), Rn. 63. Zuvor bereits EuGH, Urteil vom 16.1.2014, Rs. C-429/12 (Pohl), Rn. 30; EuGH, Urteil vom 8.9.2011, verb. Rs. C-89/10 und C-96/10 (Q-Beef und Bosschaert), Rn. 48.

180 So Rosenkranz, Beschränkung der Rückwirkung, 2015, S. 44.

181 Siehe oben Text zu Fn. 174.

182 Kovács, Temporale Wirkung, 2014, S. 120. 
dieser Vorschrift betreffenden Streit vorlägen. ${ }^{183}$ Dieser Satz enthält allerdings lediglich eine Beschreibung der aus dem ersten Satz zu ziehenden Folgen (vgl. den Wortlaut „Daraus folgt [...]“). Die ex tunc-Wirkung der Auslegung ist damit bereits im ersten Satz begründet. ${ }^{184}$ Bestätigt wird dies auch dadurch, dass der EuGH auf einen entsprechenden zweiten Satz bei der Begründung der ex tunc-Wirkung der Vorabentscheidung verzichtet. Auch wenn dies kritisiert wird ${ }^{185}$, lässt sich der Zusammenhang zwischen deklaratorischem Charakter der Auslegung und ihrer ex tunc-Wirkung auf Grundlage der EuGH-Rechtsprechung also sehr wohl begründen. ${ }^{86} \mathrm{Er}$

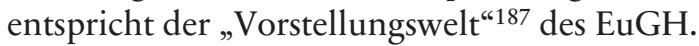

Durch die Erstreckung der Auslegung auf den gesamten Geltungszeitraum der Norm einschließlich der Vergangenheit ${ }^{188}$ wird sichergestellt, dass die Vorschrift von ihrem Inkrafttreten an grundsätzlich einheitlich in allen Mitgliedstaaten angewandt wird. Auf diese Weise wird einem mit dem Vorabentscheidungsverfahren verfolgten Ziel entsprochen, die einheitliche Anwendung des Unionsrechts durch alle Mitgliedstaaten zu gewährleisten. ${ }^{189}$ Letztlich wird so erreicht, dass das Unionsrecht in seiner zeitlichen Anwendung nicht verzerrt wird. ${ }^{190}$

Mit diesen Überlegungen ist ein weiterer wesentlicher Gesichtspunkt angesprochen. Damit die zeitliche Geltung des Unionsrechts nicht verzerrt wird, muss es von seinem Inkrafttreten an wirken. Dies verlangt sein Befehl, angewandt zu werden. ${ }^{191}$ Dieser Anwendungsbefehl gilt ab dem Inkrafttreten der Norm. Die zeitliche Wirkung der Auslegung ist damit an das Inkrafttreten der unionsrechtlichen Vorschrift zu knüpfen und nicht etwa erst an den Beginn der unmittelbaren Anwendbarkeit einer Vorschrift oder den Ablauf der Umsetzungsfrist einer Richtlinie. ${ }^{192}$ Bei

183 Vgl. nur EuGH, Urteil vom 9.6.2016, Rs. C-586/14 (Budișan), Rn. 45. Darauf ist später zurückzukommen, siehe unten bei Fn. $1308 \mathrm{ff}$.

184 Dies gesteht auch Kovács, Temporale Wirkung, 2014, S. 121 selbst ein.

185 Osterloh, in: FS Hassemer, 2010, S. 173 (181).

186 Siehe auch Kokott/Henze, NJW 2006, 177 (180): „[...] (deklaratorische) Erkenntnis $[\ldots]$ unterstützt $[\ldots]$ eine ex-tunc-Wirkung."

187 Begriff bei Osterloh, in: FS Hassemer, 2010, S. 173 (181).

188 Kokott/Henze, NJW 2006, 177 (178); siehe auch GA Szpunar, Schlussanträge vom 13.5.2015 in der Rs. C-8/14 (BBVA), Rn. 34.

189 Vgl. EuGH, Urteil vom 16.1.1974, Rs. 166/73 (Rheinmühlen-Düsseldorf), Rn. 2; EuGH, Urteil vom 6.10.1982, Rs. 283/81 (CILFIT u.a.), Rn. 7.

190 GA Léger, Schlussanträge vom 17.6.2003 in der Rs. C-453/00 (Kühne \& Heitz), Rn. 39.

191 Ebenso Rosenkranz, Beschränkung der Rückwirkung, 2015, S. 48 f.

192 In letzterem Sinne aber Eicker/Ketteler, BB 2005, 131 (132). 
Richtlinien führt „die allgemeine Regel der Ex-tunc-Wirkung“ daher bei einem horizontalen Rechtsverhältnis nicht etwa zu einer Wirkung ab dem Zeitpunkt des Inkrafttretens des nationalen Umsetzungsgesetzes, wenn ein solches bei Ablauf der Umsetzungsfrist noch nicht vorliegt. ${ }^{193}$ Die Auslegung gilt vielmehr seit Inkrafttreten der Richtlinie. In welcher zeitlichen Dimension die Richtlinie in ihrer Auslegung durch den EuGH im Horizontalverhältnis Bedeutung erlangt, ist eine Frage der Anwendung des Unionsrechts im Einzelfall, mit der sich der zweite Teil dieser Arbeit befasst.

Die Auslegung hat also an der gesamten zeitlichen Geltungsdauer der unionsrechtlichen Vorschrift teil. ${ }^{194}$ Damit wird deutlich, dass die Norm selbst in zeitlicher Hinsicht Wirkung entfaltet und nicht das Urteil, in dem die Auslegung erfolgt. Wird geltend gemacht, die Urteilswirkung sei von der Auslegung streng zu trennen, da es sich bei beiden um zwei voneinander zu trennende Schritte handle ${ }^{195}$, vermag dies daher insoweit nicht zu überzeugen, als die Auslegung von der Norm nicht getrennt werden kann. Die Normwirkung macht sozusagen die „Urteilswirkung“ aus; sie tritt gewissermaßen an deren Stelle.

Für eine zeitliche Begrenzung im Sinne der Defrenne-Rechtsprechung kann daher bereits an dieser Stelle der Schluss gezogen werden, dass sich auch im Falle einer solchen zeitlichen Begrenzung die "richtige“ Auslegung der Norm auf den gesamten Geltungszeitraum der Vorschrift erstreckt. Beschränkt wird durch eine zeitliche Begrenzung nicht die Berufung auf das Urteil, sondern auf die ausgelegte Norm. ${ }^{196}$

Nach dem vorstehend Gesagten entfaltet die ausgelegte Norm keine Rückwirkung im klassischen Sinn. Ihren seit Inkrafttreten bestehenden Inhalt hat der EuGH anlässlich des Vorabentscheidungsverfahrens lediglich

193 So aber GA Campos Sánchez-Bordona, Schlussanträge vom 13.7.2016 in den verb. Rs. C-313/15 und C-530/15 (Eco-Emballages und Melitta France u.a.), Rn. 58 (Hervorhebung im Original).

194 In diesem Sinne auch Weiß, EuR 1995, 377 (378); Schlachter, ZfA 2007, 249 (265).

195 Ludewig, Zeitliche Beschränkung, 2012, S. 179 f.; Huep, Beschränkung einer Rückwirkung, 2001, S. 207 f.

196 Näher unten bei Fn. 429 ff. Anders Ludewig, Zeitliche Beschränkung, 2012, S. 180. Siehe in diesem Zusammenhang auch Vogel, StuW 2005, 373 (375), der davon spricht, dass die Bindung an die gerichtlich festgestellte Auslegung in ihrer Wirkung auf vergangene Sachverhalte beschränkt sein könne. 
mit zeitlicher Verzögerung erkennen können und dann auch erkannt. ${ }^{197}$ Da die unionsrechtliche Bestimmung daher schon immer die Bedeutung hatte, die der Gerichtshof ihr in seiner Auslegung gegeben hat, sind die sich im nationalen Verfahren stellenden Rückwirkungsprobleme unmittelbare Folge der durch das mitgliedstaatliche Gericht vorgenommenen Anwendung des Unionsrechts. ${ }^{198}$ Der Sache nach sind sie aber natürlich in der ex tunc-Wirkung der Normauslegung durch den Gerichtshof bereits angelegt.

2. Ex tunc-Wirkung der Erstauslegung und Auslegungsbefugnis mitgliedstaatlicher Gerichte

Die Auslegung einer Norm des Unionsrechts durch den Gerichtshof kann erst dann erfolgen, wenn sich die Frage danach in einem Verfahren vor diesem stellt. Bis zu diesem Zeitpunkt haben mitgliedstaatliche Gerichte die Norm in aller Regel bereits in den von ihnen zu entscheidenden Rechtsstreitigkeiten zur Anwendung bringen müssen. Eine Auslegung der unionsrechtlichen Norm ist demnach bereits erfolgt, sodass zu klären ist, wie sich dies auf die zeitliche Wirkung einer später erfolgenden Erstauslegung durch den Gerichtshof auswirkt.

Für letztinstanzliche nationale Gerichte ergibt sich die Berechtigung zur Auslegung des Unionsrechts bereits aus den von der Vorlagepflicht nach Art. 267 III AEUV bestehenden Ausnahmen. Wenn diese letztinstanzlichen nationalen Gerichte nach der Rechtsprechung des Gerichtshofs das Vorliegen eines acte clair in eigener Verantwortung und unabhängig beurteilen ${ }^{199}$, bedeutet dies zugleich, dass ihre Auslegungszuständigkeit für Unionsrecht anerkannt ist. Dadurch dass ihnen im Grundsatz die Beurteilung des Vorliegens eines acte clair als Ausnahme von der Vorlagepflicht überlassen ist, dürfen sie von der Vorlage einer Frage nach der Auslegung von Unionsrecht absehen, wenn die richtige Anwendung des Unionsrechts aus ibrer Sicht offenkundig ist. ${ }^{200}$

197 Kokott/Henze, NJW 2006, 177 (178); Frenz, Handbuch Europarecht, Band 5, 2010, Rn.3413; Rosenkranz, Beschränkung der Rückwirkung, 2015, S. 46; Kovács, Temporale Wirkung, 2014, S. 110.

198 So Düsterhaus, YEL 36 (2017), 237 (244); Düsterhaus, EuR 2017, 30 (35).

199 EuGH, Urteil vom 9.9.2015, verb. Rs. C-72/14 und C-197/14 (X und van Dijk), Rn. 59.

200 EuGH, Urteil vom 9.9.2015, Rs. C-160/14 (Ferreira da Silva e Brito u.a.), Rn. 40. 
Unionsrechtlich verbindlich ist eine derartige Auslegung damit allerdings nicht. Als dementsprechend fragil erweist sich denn auch die vom Gerichtshof betonte Eigenständigkeit bei der Entscheidung über das Vorliegen einer Ausnahme von der Vorlagepflicht. Dies zeigt etwa die Bejahung einer Vertragsverletzung durch Frankreich als Folge eines Verstoßes gegen die Vorlagepflicht durch den Conseil d'État in der Rechtssache Kommission/Frankreich. Zur Begründung führt der Gerichtshof an, dass sich der Conseil d'État nicht habe sicher sein können, dass seine Entscheidung, angesichts von Unterschieden zwischen einer französischen und britischen Regelung von der Auslegung des Unionsrechts, die der Gerichtshof im Hinblick auf die britische Regelung vorgenommen hatte ${ }^{201}$, abzuweichen, beim Gerichtshof auf Zustimmung stoße. ${ }^{202} \mathrm{Da}$ das Ergebnis, zu dem der Conseil d'État durch Auslegung der Art. 49 und 63 AEUV gelangt ist, im Widerspruch zu der vom Gerichtshof nun ${ }^{203}$ vorgenommenen Auslegung steht, geht der EuGH davon aus, dass „zum Zeitpunkt der Entscheidung des Conseil d'État ein vernünftiger Zweifel hinsichtlich der Auslegung dieser Vorschriften nicht ausgeschlossen werden [konnte]“. 204 $\mathrm{Da}$ aber nie völlig ausgeschlossen werden kann, dass der EuGH zu einem anderen Ergebnis gelangt, wird das Bestehen einer Vorlagepflicht beträchtlich ausgeweitet. 205

Die Festlegung und Überprüfung der Grenzen für die Annahme eines acte clair ermöglichen es dem Gerichtshof, eine willkürliche Handhabung durch nationale Gerichte zu verhindern. ${ }^{206}$ In Rechnung zu stellen ist etwa, ob lediglich innerhalb eines Mitgliedstaats Unsicherheiten oder un-

201 EuGH, Urteil vom 13.11.2012, Rs. C-35/11 (Test Claimants in the FII Group Litigation).

$202 \mathrm{Zu}$ der in Rede stehenden Frage hatte sich der Gerichtshof in EuGH, Urteil vom 15.9.2011, Rs. C-310/09 (Accor) noch nicht geäußert.

203 In EuGH, Urteil vom 4.10.2018, Rs. C-416/17 (Kommission/Frankreich).

204 EuGH, Urteil vom 4.10.2018, Rs. C-416/17 (Kommission/Frankreich), Rn. $100 \mathrm{ff}$, insb. Rn. $111 \mathrm{f}$.

205 Delhomme/Larripa, European Law Blog, Blog vom 22.11.2018. Die Ausführungen des Gerichtshofs laufen darauf hinaus, das Bestehen eines vernünftigen Zweifels daraus abzuleiten, dass EuGH und Conseil d'État zu unterschiedlichen Ergebnissen gekommen sind. Dies begegnet allerdings, worauf Delhomme/Larri$p a$, a.a.O., zutreffend hinweisen, Bedenken: Zweifel können zu Beginn nämlich auch dann bestanden haben, wenn die Ergebnisse, zu denen die Gerichte letztlich gelangen, dieselben sind.

206 Silveira/Perez Fernandes, Revista de Derecho Comunitario Europeo 2016, 631 (643 ff.); siehe auch GA Stix-Hackl, Schlussanträge vom 12.4.2005 in der Rs. C-495/03 (Intermodal Transports), Rn. 102. 
terschiedliche Einschätzungen im Hinblick auf das Verständnis des Unionsrechts bestehen, die auch von einem letztinstanzlichen Gericht im Mitgliedstaat gelöst werden können, oder ob in verschiedenen Mitgliedstaaten auftretende Auslegungsschwierigkeiten auszumachen sind, die die Gefahr von Divergenzen in der Rechtsprechung innerhalb der EU begründen. ${ }^{207}$ Dürfte das letztinstanzliche nationale Gericht auch im letztgenannten Fall von einer Vorlage absehen, wäre dem Gerichtshof letztlich die Möglichkeit zur Auslegung genommen. ${ }^{208}$ Seine ihm in Art. 19 I UAbs. 1 S. 2 EUV übertragene Aufgabe, die Wahrung des Rechts bei der Auslegung und Anwendung der Verträge zu sichern, könnte er dann nicht mehr wahrnehmen. ${ }^{209}$

Mit Blick auf die nicht-letztinstanzlichen Gerichte, die angesichts der für sie fehlenden Vorlagepflicht zur Auslegung des Unionsrechts berechtigt sind, ist festzustellen, dass sie dabei nur frei sind, solange der EuGH nicht tätig geworden ist. Dies zeigt das dem EuGH in den Verträgen (Art. 19 I UAbs. 1 S. 2 EUV und Art. 267 AEUV) zugesprochene Letztentscheidungsrecht in Auslegungsfragen. ${ }^{210}$

Deutlich geworden ist damit, dass die erstmalige Auslegung einer unionsrechtlichen Vorschrift durch den EuGH die einzige unionsrechtlich verbindliche Auslegung ist. ${ }^{211} \mathrm{Da}$ den bis zu diesem Zeitpunkt von den mitgliedstaatlichen Gerichten vorgenommenen Auslegungen eine derartige unionsrechtliche Verbindlichkeit nicht zugesprochen werden kann, kann der Auslegung des EuGH nicht erst ab dem Zeitpunkt des Auslegungsurteils Wirkung beigemessen werden. Andernfalls fehlte es bis zu

207 EuGH, Urteil vom 9.9.2015, verb. Rs. C-72/14 und C-197/14 (X und van Dijk), Rn. 60 f.; EuGH, Urteil vom 9.9.2015, Rs. C-160/14 (Ferreira da Silva e Brito u.a.), Rn. 41 f. einerseits sowie EuGH, Urteil vom 9.9.2015, Rs. C-160/14 (Ferreira da Silva e Brito u.a.), Rn. 43 ff. andererseits. Siehe auch Silveira/Perez Fernandes, Revista de Derecho Comunitario Europeo 2016, 631 (646f.).

208 Über die bei Nichtvorliegen eines acte clair greifende Pflicht zur Vorlage kann der EuGH also der Gefahr einer fehlerhaften Auslegung des Unionsrechts vorbeugen, vgl. EuGH, Urteil vom 9.9.2015, Rs. C-160/14 (Ferreira da Silva e Brito u.a.), Rn. 44; EuGH, Urteil vom 4.10.2018, Rs. C-416/17 (Kommission/Frankreich), Rn. 113.

209 So zu Recht GA Bot, Schlussanträge vom 11.6.2015 in der Rs. C-160/14 (Ferreira da Silva e Brito u.a.), Rn. 102; zustimmend Wendenburg, EuZW 2016, 115 (116).

210 Schröder, Gesetzesbindung, 2010, S. 143 f. Trotz fehlender Vorlagepflicht müssen sie der Auslegung des EuGH also Folge leisten, siehe dazu bereits oben bei Fn. 85 ff., insb. bei Fn. 91 und Düsterhaus, YEL 36 (2017), 237 (241).

211 Middeke, in: Rengeling/Middeke/Gellermann (Hrsg.), Handbuch des Rechtsschutzes, 3. Aufl. 2014, $\mathbb{1 0}$, Rn. 31 spricht insoweit von der autoritativen Auslegungskompetenz des EuGH. 
diesem Zeitpunkt an einem aus unionsrechtlicher Sicht eindeutigen verbindlichen Inhalt der Norm, an dessen Stelle gegebenenfalls divergierende mitgliedstaatliche Auslegungen träten. Eine derartige unionsrechtlich unverbindliche Normsetzung würde den jeder unionsrechtlichen Vorschrift inhärenten Anwendungsbefehl untergraben und ist daher nicht hinnehmbar. $^{212}$

\section{Ex tunc-Wirkung und Rechtsfortbildung}

Ist die ex tunc-Wirkung der Auslegung damit gesichert, ist zu klären, ob Entsprechendes auch für die Rechtsfortbildung gilt. Auch diese gehört zu den Aufgaben des EuGH. ${ }^{213}$ Sprachlich unterscheidet der Gerichtshof allerdings nicht zwischen Auslegung und Rechtsfortbildung. Das zeigt etwa die Antwort des Gerichtshofs auf die Vorlagefrage des LG Köln in der Rechtssache Germanwings.

Dieses wollte in Erfahrung bringen, ob die vom Gerichtshof in der Rechtssache Sturgeon ${ }^{214}$ vorgenommene Auslegung der Verordnung (EG) Nr. 261/2004215 mit dem Gewaltenteilungsgrundsatz vereinbar sei, den der EuGH in Art. 13 II EUV verankert sieht und der die „Funktionsweise der Union als Rechtsunion“ kennzeichnet. In der Rechtssache Sturgeon hatte der Gerichtshof entschieden, dass Fluggäste verspäteter Flüge im Hinblick auf den in der Verordnung vorgesehenen Ausgleichsanspruch mit Fluggästen annullierter Flüge gleichgestellt werden können, obwohl die Verordnung den Ausgleichanspruch bei einer bloßen Verspätung des Fluges nicht ausdrücklich vorsieht. In der Sache hatte er also eine analoge Anwendung der Bestimmung vorgenommen. Nach Auffassung des Gerichtshofs hat er hierbei aber lediglich von seiner Befugnis zur Auslegung des Unionsrechts nach Art. 19 I und III lit.b EUV und Art. 267 AEUV Gebrauch gemacht, die den Grundsatz der Gewaltenteilung in der Union daher nicht

212 Ähnlich Rosenkranz, Beschränkung der Rückwirkung, 2015, S. 48 f.

213 Dass der Gerichtshof befugt ist, das Unionsrecht fortzubilden, erkennt selbst das Bundesverfassungsgericht an, vgl. BVerfG, Beschluss vom 8.4.1987, 2 BvR 687/85 - BVerfGE 75, 223 (240 ff., insb. 243 f.).

214 EuGH, Urteil vom 19.11.2009, verb. Rs. C-402/07 und C-432/07 (Sturgeon u.a.).

215 Verordnung (EG) Nr. 261/2004 des Europäischen Parlaments und des Rates vom 11. Februar 2004 über eine gemeinsame Regelung für Ausgleichs- und Unterstützungsleistungen für Fluggäste im Fall der Nichtbeförderung und bei Annullierung oder großer Verspätung von Flügen und zur Aufhebung der Verordnung (EWG) Nr. 295/91, ABl. L 46 vom 17.2.2004, S. 1. 
berührt. ${ }^{216}$ Was methodisch möglich ist, ist nach dem Verständnis des Gerichtshofs demnach Auslegung.

Dem ist insoweit zuzustimmen, als es sich bei Auslegung und Rechtsfortbildung in der Tat letztlich um „verschiedene Stufen desselben Vorgangs" handelt, sodass sie sich nicht qualitativ voneinander unterscheiden. ${ }^{217}$ Auch für die Rechtsfortbildung ist daher vor dem Hintergrund des Art. 19 I UAbs. 1 S. 2 EUV von ex tunc-Wirkung auszugehen. ${ }^{218}$ Bei einer Analogie bedeutet dies eine Wirkung ab dem Zeitpunkt des Inkrafttretens der analog angewendeten Norm. Bei der Heranziehung eines allgemeinen Rechtsgrundsatzes ist entscheidend, seit wann dieser Bestandteil der Unionsrechtsordnung ist. ${ }^{219}$

\section{Zeitliche Wirkung der Rechtsprechungsänderung}

$\mathrm{Zu}$ beantworten bleibt damit noch die Frage, ob sich die Überlegungen zur Auslegung (und Rechtsfortbildung) auch im Falle einer Rechtsprechungsänderung fruchtbar machen lassen. Kennzeichen einer Rechtsprechungsänderung ist, dass der EuGH bei der erneuten Bewertung der gleichen Rechtsfrage von der zunächst vorgenommenen Bewertung abweicht. ${ }^{220}$ Damit wird deutlich, dass es sich auch bei der Rechtsprechungsänderung um Auslegung handelt. ${ }^{221}$ Die zeitliche Wirkung ist daher auch insoweit als Norm- und nicht als Urteilswirkung einzuordnen. ${ }^{222}$

Bevor auf die zeitlichen Wirkungen einer Rechtsprechungsänderung eingegangen werden kann, ist zunächst die Frage nach ihrer Zulässigkeit zu stellen.

216 EuGH, Beschluss vom 18.4.2013, Rs. C-413/11 (Germanwings), Rn. 16, 22. Die Beantwortung der Vorlagefrage ließ nach Auffassung des EuGH keinen Raum für vernünftige Zweifel, weswegen er gemäß Art. 99 EuGH-VerfO durch mit Gründen versehenen Beschluss entschied, vgl. EuGH, a.a.O., Rn. $14 \mathrm{f}$.

217 Schroeder, in: FS Roth, 2011, S. 735 (739). Everling, JZ 2000, 217 (218 mit Fn. 12 und 13) meint, die Abgrenzung der Auslegung von der Rechtsfortbildung sei „weitgehend eine Frage der Terminologie“.

218 Vgl. Dänzer-Vanotti, RIW 1992, 733 (736). Wusterhausen, Wirkungen, 2016, S. $311 \mathrm{f}$. führt dagegen lediglich die Streitschlichtungsfunktion der Gerichte als Argument für die Rückwirkung an und hat ansonsten Bedenken.

219 Rosenkranz, Beschränkung der Rückwirkung, 2015, S. 77 ff.

220 In diesem Sinne Lunk, in: FS Reuter, 2010, S. 689 (694).

221 Rosenkranz, Beschränkung der Rückwirkung, 2015, S. 45 bezeichnet dies als „ändernde Zweitauslegung" (Anführungszeichen im Original).

222 Ebenso Rosenkranz, Beschränkung der Rückwirkung, 2015, S. 63. 
a) Zulässigkeit von Rechtsprechungsänderungen

An seine Urteile ist der EuGH wie bereits erwähnt nicht selbst gebunden. ${ }^{223}$ Beständigkeit der Rechtsprechung fördert zwar die Einheitlichkeit der Auslegung und damit die Rechtssicherheit in der Unionsrechtsordnung. ${ }^{224}$ Vor diesem Hintergrund folgt der Gerichtshof auch in aller Regel seinen Entscheidungen, wie sich bereits an der acte éclairé-Ausnahme ${ }^{225}$ von der Vorlagepflicht nach Art. 267 III AEUV zeigt: Dass die vorzulegende Frage bereits Gegenstand einer Auslegung durch den Gerichtshof war bzw. dass gesicherte Rechtsprechung zu einer bestimmten Rechtsfrage vorliegt, kann aus unionsrechtlicher Sicht nämlich nur dann sinnvollerweise von der Vorlagepflicht entbinden, wenn der Gerichtshof seiner Rechtsprechung in der Regel auch in Zukunft folgt. ${ }^{226}$ Die Anerkennung dieser Ausnahme ändert aber nichts an der grundsätzlichen Zulässigkeit einer Abänderung der Rechtsprechung, da beispielsweise veränderte rechtliche oder gesellschaftliche Rahmenbedingungen oder aber eine bessere Rechtserkenntnis eine Änderung der Rechtsprechung als erforderlich erscheinen lassen können. ${ }^{227}$

Mit der Frage, ob seine Rechtsprechung aufrechtzuerhalten oder $\mathrm{zu}$ ändern ist, setzt sich der Gerichtshof immer dann auseinander, wenn ihm neue Gesichtspunkte unterbreitet werden, die ihn dazu veranlassen könnten, eine bereits gestellte Frage abweichend zu beantworten. ${ }^{228}$ Dabei

223 Siehe dazu auch die Ausführungen von GA Trstenjak, Schlussanträge vom 28.3.2007 in der Rs. C-331/05 P (Internationaler Hilfsfonds/Kommission), Rn. 84f. Zustimmend GA Kokott, Schlussanträge vom 15.7.2010 in der Rs. C-163/09 (Repertoire Culinaire), Rn. 61. Siehe hierzu auch bereits oben bei Fn. $145 \mathrm{ff}$.

224 GA Poiares Maduro, Schlussanträge vom 1.2.2006 in den verb. Rs. C-94/04 und C-202/04 (Cipolla u.a.), Rn. 28; GA Trstenjak, Schlussanträge vom 28.3.2007 in der Rs. C-331/05 P (Internationaler Hilfsfonds/Kommission), Rn. 85.

225 EuGH, Urteil vom 6.10.1982, Rs. 283/81 (CILFIT u.a.), Rn. 14, 21.

226 Diesen Zusammenhang sieht auch GA Poiares Maduro, Schlussanträge vom 1.2.2006 in den verb. Rs. C-94/04 und C-202/04 (Cipolla u.a.), Rn. 28.

227 GA Poiares Maduro, Schlussanträge vom 1.2.2006 in den verb. Rs. C-94/04 und C-202/04 (Cipolla u.a.), Rn. 29: „[...] Stetigkeit [ist] kein absoluter Wert und darf es nicht sein." Siehe auch Steinberg/Bark, EuZW 2007, 245 (246).

228 EuGH, Urteil vom 6.3.2003, Rs. C-466/00 (Kaba), Rn. 39 unter Bezugnahme auf die Möglichkeit einer erneuten Vorlage durch das Gericht des ursprünglichen Ausgangsverfahrens. Gegen die Berechtigung auch jedes anderen nationalen Gerichts, sich mit einem erneuten Vorabentscheidungsersuchen an den Gerichtshof zu wenden, sind keine Gründe ersichtlich, siehe GA Jacobs, verb. Schlussanträge vom 11.7.1991 in den Rs. C-24/90, C-25/90 und C-26/90 
entscheidet er sich dann für eine Rechtsprechungsänderung, wenn er dies aus sachlichen Gründen für gerechtfertigt erachtet. Ein Verbot der Änderung der Rechtsprechung stellt er also nicht auf. ${ }^{229}$ Insbesondere ließe sich ein solches für die Zukunft auch nicht überzeugend begründen. ${ }^{230}$ Wird nämlich eine von einer früheren Entscheidung abweichende Entscheidung gefällt, entfällt „Vertrauen“ in die bisherige Rechtsprechungslinie. Einer Rechtsprechungsänderung für die Zukunft kann dieses Vertrauen dann nicht mehr entgegenstehen. ${ }^{231}$ Die in die Fortführung der bisherigen Rechtsprechung gesetzte Erwartung kann dadurch geschützt werden, dass die zeitliche Wirkung der neuen Rechtserkenntnis für die Vergangenheit beschränkt wird. ${ }^{232}$ Die „Fesseln der Vergangenheit“ ${ }^{233}$ können so für die Zukunft abgestreift werden.

Die Konsequenzen einer von der hier vertretenen Ansicht abweichenden Beurteilung der Zulässigkeit einer Rechtsprechungsänderung lassen sich an einer Erwägung des EuGH in der Rechtssache Bosman ablesen, auch wenn es dort nicht um eine Rechtsprechungsänderung ging. In ihr stand die Anwendbarkeit der Regeln der Arbeitnehmerfreizügigkeit auf durch Sportverbände aufgestellte Regeln in Rede. Angesichts der von diesem Urteil zu erwartenden Auswirkungen auf die Organisation des Fußballs wurde im Verfahren eine Ablehnung der Anwendung der Regeln der Arbeitnehmerfreizügigkeit gefordert. Die zu erwartenden Auswirkungen haben den Gerichtshof aber nicht davon abgehalten, die Anwendbarkeit der Arbeitnehmerfreizügigkeit auf sportliche Tätigkeiten wie die der Berufsfußballspieler zu bejahen. Hätte er den Forderungen entsprochen, wäre aus seiner Sicht die "Objektivität des Rechts gebeugt" worden. ${ }^{234}$ Um diese Konsequenz zu vermeiden, ist die „richtige“ Auslegung des Unionsrechts also vorzunehmen. Aus demselben Grund ist auch eine Recht-

(Werner Faust u.a.), Rn.34 und GA La Pergola, Schlussanträge vom 12.2.1998 in der Rs. C-262/96 (Sürül), Rn.31, Fn. 21 unter Verweis auf EuGH, Urteil vom 13.5.1981, Rs. 66/80 (International Chemical Corporation), Rn.9-17 und EuGH, Urteil vom 11.6.1987, Rs. 14/86 (Pretore di Salò/X), Rn. 12.

229 Letztlich würde ein solches zu einer Versteinerung der Rechtslage führen, Höpfner, RdA 2006, 156 (160).

230 GA Jääskinen, Schlussanträge vom 19.7.2012 in der Rs. C-35/11 (Test Claimants in the FII Group Litigation), Rn. 35 hat dagegen aus Gründen der Rechtssicherheit vorgeschlagen, von einer Rechtsprechungsänderung abzusehen, da sich die Rechtsunterworfenen auf die bisherige Rechtsprechung eingestellt hätten.

231 Höpfner, RdA 2006, 156 (160); Hyland, IJEL 2 (1995), 208 (231).

232 Louven, Rückwirkende Rechtsprechung, 1996, S. 12.

233 Piekenbrock, ZZP 119 (2006), 3 (15).

234 EuGH, Urteil vom 15.12.1995, Rs. C-415/93 (Bosman), Rn. 77. 
sprechungsänderung vorzunehmen, wenn die „richtige“ Auslegung des Unionsrechts sie erfordert. ${ }^{235}$

Düsterhaus möchte von der Befugnis zur Rechtsprechungsänderung bei "genuinem Richterrecht" eine Ausnahme machen. Dann sei dieses nämlich die Verkörperung des Rechts und nicht nur dessen Auslegung. Deswegen sei der Gerichtshof an seine "constitutional findings“ gebunden, sodass im Grundsatz auch eine Bindung an seine Rechtsprechung zur Begrenzung der zeitlichen Wirkung der Auslegung bestehe. ${ }^{236}$ Vor dem Hintergrund, dass der Gerichtshof aber auch insoweit Auslegung betreibt, überzeugt diese Überlegung nicht. ${ }^{237}$

\section{b) Zeitliche Wirkung der geänderten Rechtsprechung}

Ist die Zulässigkeit einer Änderung unionsgerichtlicher Rechtsprechung demnach zu bejahen, ist in einem zweiten Schritt zu fragen, wie diese in zeitlicher Hinsicht wirkt. Dafür sind die hinter einer Rechtsprechungsänderung stehenden Gründe näher in den Blick zu nehmen. So können sowohl eine bessere Rechtserkenntnis als auch ein Wandel des rechtlichen Bezugsrahmens zu einer veränderten Auslegung führen. ${ }^{238}$

Den Fall der besseren Rechtserkenntnis diskutiert Generalanwältin Kokott in ihren Schlussanträgen in der Rechtssache Repertoire Culinaire, da sie die vom Gerichtshof in der Rechtssache Gourmet Classic vorgenommene Einordnung des Alkohols in Kochwein als Ethylalkohol im Sinne einer Richtlinienbestimmung 239 für falsch hielt und daher eine Rechtsprechungsänderung empfahl. ${ }^{240}$ Eine Einschränkung der zeitlichen Wirkung der Rechtsprechung auf die Zukunft hielt sie in diesem Fall für nicht erforderlich, sodass in der Vergangenheit gezahlte Verbrauchsteuer auf

235 Vgl. Ludewig, Zeitliche Beschränkung, 2012, S. 103.

236 Düsterhaus, YEL 36 (2017), 237 (243).

237 Ausgelegt wird letztlich der Anwendungsbefehl der ausgelegten Norm unter Beachtung des unionsrechtlichen Grundsatzes der Rechtssicherheit, siehe dazu näher bei Fn. $392 \mathrm{ff}$.

238 Näher Käbler, Rechtsprechungsänderung, 2. Aufl. 2011, S. 80 ff., der eine Unterscheidung nach „anderer“ und „besserer“ Erkenntnis des Rechts trifft (S. 82). Siehe zu den Gründen für eine Rechtsprechungsänderung auch Payandeh, Judikative Rechtserzeugung, 2017, S. 319, 485 ff.

239 EuGH, Urteil vom 12.6.2008, Rs. C-458/06 (Gourmet Classic), Rn. 39.

240 GA Kokott, Schlussanträge vom 15.7.2010 in der Rs. C-163/09 (Repertoire Culinaire), Rn. 59, 61. 
Kochwein hätte zurückgefordert werden können. ${ }^{241}$ An diesen Ausführungen wird deutlich, dass Generalanwältin Kokott zufolge eine aufgrund besserer Rechtserkenntnis vorgenommene Auslegungsänderung ebenso wie die Erstauslegung seit Inkrafttreten der Vorschrift wirkt.

Dies überzeugt. Als Grundlage der Wirkung der Erstauslegung auf den Zeitpunkt des Inkrafttretens der Vorschrift war das ansonsten anzutreffende Fehlen einer unionsrechtlich verbindlichen Auslegung erkannt worden. Wenn eine solche wie im geschilderten Fall nun aber bereits existiert, könnte es daher auf den ersten Blick zwar an einer Begründung für die ex tunc-Wirkung der neuen Auslegung fehlen. ${ }^{242}$ Allerdings ist zu bedenken, dass die neu gefundene Auslegung, die nun als "richtige“ erkannt worden ist, zwangsläufig seit Inkrafttreten der Vorschrift als „richtig“ anzusehen ist. Einen Zeitpunkt, zu dem die neue Auslegung erst richtig geworden wäre, gibt es nicht, da sich die ursprünglich vorgenommene Auslegung als von Anfang an „falsch“ erwiesen hat. Die Vorschrift muss daher seit ihrem Inkrafttreten im Sinne der neuen Auslegung verstanden werden. ${ }^{243}$

Diese Einschätzung wird durch die Rechtsprechung des EuGH gestützt, der auch in Fällen der Rechtsprechungsänderung seine in ständiger Rechtsprechung wiederholte Formulierung anführt, wonach die von ihm vorgenommene Auslegung erläutert und verdeutlicht, wie die ausgelegte Vorschrift seit ihrem Inkrafttreten zu verstehen und anzuwenden ist oder gewesen wäre. ${ }^{244}$ Damit gibt er zu erkennen, dass auch die geänderte Auslegung bestehendes Recht lediglich erkennt, wenn auch erst im zweiten Anlauf richtig. ${ }^{245}$ Dass eine Rechtsprechungsänderung aufgrund besserer Rechtserkenntnis ex tunc wirkt, zeigt sich ebenso daran, dass der EuGH auch im Fall der Rechtsprechungsänderung eine Beschränkung der zeitlichen Wirkungen in Betracht zieht. Einer solchen bedarf es nämlich nur dann, wenn die ex tunc-Wirkung der Grundsatz ist. ${ }^{246}$ Der Gerichtshof behandelt die Erstauslegung und die Rechtsprechungsänderung damit gleich. ${ }^{247}$

241 GA Kokott, Schlussanträge vom 15.7.2010 in der Rs. C-163/09 (Repertoire Culinaire), Rn. 62.

242 In diesem Sinne Hyland, IJEL 2 (1995), 208 (230 f.).

243 Ebenso Rosenkranz, Beschränkung der Rückwirkung, 2015, S. 72 f.

244 EuGH, Urteil vom 20.9.2001, Rs. C-184/99 (Grzelczyk), Rn. 50; EuGH, Urteil vom 15.3.2005, Rs. C-209/03 (Bidar), Rn. 66.

245 Vgl. Louven, Rückwirkende Rechtsprechung, 1996, S. 110.

246 Vgl. Rosenkranz, Beschränkung der Rückwirkung, 2015, S. 70.

247 Louven, Rückwirkende Rechtsprechung, 1996, S. 109 f.; Rosenkranz, Beschränkung der Rückwirkung, 2015, S. 69. 
Damit bleibt noch der Fall der Rechtsprechungsänderung aufgrund eines Wandels der Umstände, der den EuGH zu einer Änderung seiner Rechtsprechung bewogen hat, zu untersuchen. In Bezug zu nehmen ist insoweit die Rechtssache Grzelczyk, in der die Gewährung des Existenzminimums an Studenten, die in einem anderen Mitgliedstaat studieren als demjenigen, dessen Staatsangehörigkeit sie besitzen - und damit das Diskriminierungsverbot aus Gründen der Staatsangehörigkeit -, in Rede stand. Der Gerichtshof hatte 1988 entschieden, dass „beim gegenwärtigen Entwicklungsstand des Gemeinschaftsrechts eine Förderung, die Studenten für den Lebensunterhalt und die Ausbildung gewährt wird, grundsätzlich außerhalb des Anwendungsbereichs des EWG-Vertrags im Sinne von dessen Artikel 7 [heute Art. 18 AEUV, Anmerkung des Verfassers] liegt“. ${ }^{248}$ Durch die Aufnahme u.a. der Unionsbürgerschaft in den EG-Vertrag hatte sich aber der rechtliche Rahmen zwischenzeitlich geändert. ${ }^{249}$ Die in Rede stehende belgische Regelung erwies sich daher als gemeinschaftsrechtswidrig.

Eine Begrenzung der zeitlichen Wirkung lehnte der Gerichtshof ab. Dabei bezieht er zwar den guten Glauben auf den Zeitpunkt des Wandels der Umstände ${ }^{250}$; eine zeitliche Begrenzung auf diesen Zeitpunkt verbindet er damit aber nicht. Ob der Gerichtshof auch einer Rechtsprechungsänderung infolge des Wandels des rechtlichen Bezugsrahmens ex tunc-Wirkung zuweist, ist damit noch nicht endgültig geklärt. Eine unterschiedliche Behandlung nach dem Grund der Rechtsprechungsänderung ist der EuGHRechtsprechung bislang jedenfalls nicht zu entnehmen. ${ }^{251}$

Wandelt sich der rechtliche Bezugsrahmen der Vorschrift, ohne dass die Vorschrift selbst geändert wird, ist die Frage, ob die neue Auslegung lediglich ab dem Zeitpunkt des Abschlusses des Wandels der Umstände gilt ${ }^{252}$ oder tatsächlich wiederum bereits seit Inkrafttreten der Vorschrift, nicht ganz einfach zu beantworten.

Für eine Geltung ab dem Wandel der Umstände spricht, dass die Rechtsprechung bis zu diesem Wandel auch aus der Sicht nach Abschluss des

248 EuGH, Urteil vom 21.6.1988, Rs. 197/86 (Brown), Rn. 18.

249 EuGH, Urteil vom 20.9.2001, Rs. C-184/99 (Grzelczyk), Rn. 35.

250 EuGH, Urteil vom 20.9.2001, Rs. C-184/99 (Grzelczyk), Rn. 54: „[...] nichts vorgetragen, was beweisen könnte, dass eine objektive und bedeutende Unsicherheit hinsichtlich der Tragweite der am 1. November 1993 in Kraft getretenen Vertragsbestimmungen über die Unionsbürgerschaft die nationalen Behörden zu einem mit diesen Bestimmungen unvereinbaren Verhalten veranlasst hätte.“

251 Dies räumt auch Rosenkranz, Beschränkung der Rückwirkung, 2015, S. 74 ein.

252 So Rosenkranz, Beschränkung der Rückwirkung, 2015, S. 73 f. 
Wandels als zutreffend einzustufen ist. ${ }^{253}$ Der Anwendungsbefehl der Vorschrift scheint vor dem Wandel die Geltung der neuen Rechtsprechung also nicht zu verlangen. ${ }^{254}$ Für eine Geltung ab dem Wandel der Umstände lässt sich zudem anführen, dass die Vorschrift in der neuen Auslegung sonst auch auf Zeiten anzuwenden wäre, in denen diese Auslegung den Inhalt der Vorschrift wegen des erst später einsetzenden rechtserheblichen Wandels nicht zutreffend widerspiegelt.

Um eine Geltung seit Inkrafttreten der Vorschrift zu begründen, könnte dagegen versucht werden, zu argumentieren, dass die Norm selbst sich mit dem Zeitpunkt des Wandels der Umstände und der damit verbundenen neuen Auslegung verändert, sie die alte Auslegung also gewissermaßen abstreift und dann nur noch in der neuen Auslegung existiert. Ist keine alte Auslegung mehr vorhanden, müsste die neue Auslegung dann in der Tat seit dem Inkrafttreten der Vorschrift wirken; der Anwendungsbefehl der Vorschrift verlangte dann eine ex tunc-Wirkung der neuen Auslegung. Ausgeschlossen ist eine solche Argumentation aber jedenfalls dann, wenn die Umstände vor dem Wandel einem Verständnis im Sinne der neuen Rechtsprechung entgegenstanden. In diesem Fall ist eine Wirkung seit dem Inkrafttreten der Vorschrift ausgeschlossen und auf den Zeitpunkt des Wandels der Umstände zu beziehen.

Hinzuweisen ist abschließend noch darauf, dass sich eine unionsgerichtliche Rechtsprechung nur bis zu einer Änderung der EU-Verträge auswirken kann, wenn es durch diese Vertragsänderung zu einer Verschiebung der Zuständigkeiten von den Mitgliedstaaten hin zur EU gekommen ist. ${ }^{255}$ Allgemeiner gesprochen gilt daher, dass im Falle der Änderung einer Vorschrift selbst durch den Unionsgesetzgeber von einer zeitlichen Wirkung der Auslegung lediglich auf den Zeitpunkt des Inkrafttretens der geänderten Vorschrift und nicht etwa auf den Zeitpunkt des Inkrafttretens der Vorschrift in ihrer ursprünglichen Fassung auszugehen ist. ${ }^{256}$

253 Vgl. Kähler, Rechtsprechungsänderung, 2. Aufl. 2011, S. 82, der zutreffend darauf hinweist, dass die aufgegebene Entscheidung unter den damaligen Umständen korrekt war.

254 In diesem Sinne Rosenkranz, Beschränkung der Rückwirkung, 2015, S. 74.

255 Vgl. GA Cruz Villalón, Schlussanträge vom 31.1.2013 in der Rs. C-414/11 (Daiichi Sankyo und Sanofi-Aventis Deutschland), Rn. 115 ff. im Hinblick auf das TRIPS-Übereinkommen unter Verweis auf Art. 3 und 207 AEUV in der Fassung des Vertrags von Lissabon, die der EU erst die entsprechende Zuständigkeit zugewiesen hätten.

256 Rosenkranz, Beschränkung der Rückwirkung, 2015, S. 73 f. 


\section{Auslegung im Rahmen anderer Verfahren}

Nach Klärung der zeitlichen Wirkung der in einem Vorabentscheidungsverfahren vorgenommenen Auslegung gilt es der Frage nachzuspüren, ob entsprechende Überlegungen auch für Auslegungen in anderen Verfahrensarten Geltung beanspruchen. Von Interesse ist dabei insbesondere das Vertragsverletzungsverfahren, Art. $258 \mathrm{ff}$. AEUV. Das in diesem Verfahren ergehende Urteil ist ein Feststellungsurteil, wie sich bereits aus dem Wortlaut des Art. 260 I AEUV ergibt, wonach der Gerichtshof feststellt, dass ein Mitgliedstaat gegen eine Verpflichtung aus den Verträgen verstoßen hat. ${ }^{257}$

In der Literatur wird daher vorgetragen, bei Vertragsverletzungsverfahren könne sich wegen des rein feststellenden Charakters des Urteils letztlich kein Rückwirkungsproblem stellen. ${ }^{258}$ Die Urteile im Vertragsverletzungsverfahren hätten nur feststellenden Charakter und wirkten daher nicht ex tunc, sodass es nicht zu rückwirkenden Auswirkungen auf die Haushalte der Mitgliedstaaten kommen könne. 259

Diese Aussagen erscheinen allerdings jedenfalls missverständlich. Wenn der EuGH den Verstoß lediglich feststellt, muss die Vertragsverletzung ja zwangsläufig bereits vor dieser Feststellung bestanden haben. ${ }^{260}$ Angesichts der deklaratorischen Natur des Urteils wird die Vertragsverletzung also ex tunc festgestellt. ${ }^{261}$

Eine davon zu unterscheidende Frage ist, ob der EuGH in einem klagestattgebenden Urteil dem verurteilten Mitgliedstaat auch die Pflicht zur ex tunc-Beseitigung aller Folgen des Vertragsverstoßes auferlegen kann. Aus Effektivitätsgründen wird eine derartige Verpflichtung des Mitgliedstaats teilweise bejaht, überwiegend aber abgelehnt. ${ }^{262}$ Zur Beantwortung dieser

257 Vgl. nur Pechstein, EU-Prozessrecht, 4. Aufl. 2011, Rn. 309.

258 Waldhoff, EuR 2006, 615 (625).

259 Hufen/Nörr Stiefenhofer Lutz, Beschränkung von Urteilswirkungen, Rechtsgutachten, Teil 1, 2008, S. $37 \mathrm{f}$.

260 Lenaerts/Arts/Maselis, Procedural Law, 2. Aufl. 2006, Rn. 5-063.

261 Prete/Smulders, CMLRev. 47 (2010), 9 (49).

262 Bejahend etwa Dörr/Lenz, Europäischer Verwaltungsrechtsschutz, 2006, Rn. 76. Schwarze/Wunderlich, in: Schwarze/Becker/Hatje/Schoo (Hrsg.), EU-Kommentar, 4. Aufl. 2019, Art. 260 AEUV, Rn. 7 führen Gründe für eine Pflicht zur ex tuncBeseitigung der Folgen des Vertragsverstoßes aus Art. 260 I AEUV an, verneinen aber auf der Grundlage der bisherigen Rechtsprechung eine über die Beseitigung des Verstoßes ex nunc hinausgehende Verpflichtung der Mitgliedstaaten. Auch Ebricke, in: Streinz (Hrsg.), EUV/AEUV, 3. Aufl. 2018, Art. 260 AEUV, Rn. 8 lehnt im Ergebnis eine Pflicht zur Folgenbeseitigung ex tunc ab, obwohl er sie als „naheliegend“ bezeichnet. Ablehnend auch Cremer, in: Calliess/Ruf- 
Frage sind die beiden Halbsätze des Art. 260 I AEUV getrennt zu beleuchten. Halbsatz 1 regelt dabei, wozu der Gerichtshof bei der Tenorierung befugt ist. Das ist lediglich die Feststellung des Vertragsverstoßes. ${ }^{263}$ Halbsatz 2 äußert sich dagegen nicht mehr zur Tenorierungskompetenz des EuGH, sondern nur zu den sich für den Mitgliedstaat aus dem Urteil ergebenden Folgen. ${ }^{264}$ Die demnach vom Mitgliedstaat zu ergreifenden Maßnahmen knüpfen aber an den Urteilstenor an. Bezieht dieser nicht auch die Folgen der Vertragsverletzung mit ein, ist aus unionsrechtlicher Sicht die Beendigung des Vertragsverstoßes ex nunc zur Urteilsbefolgung ausreichend. 265

Hinzu kommt Folgendes: In der Rechtssache Francovich hat der EuGH der mitgliedstaatlichen Schadensersatzpflicht für Unionsrechtsverstöße den effet utile-Gedanken sowie Art. 4 III EUV zugrunde gelegt, obwohl Italien zuvor wegen Nichtumsetzung der der Rechtssache Francovich zugrundeliegenden Richtlinie in einem Vertragsverletzungsverfahren verurteilt worden war. ${ }^{266}$ Auf diesen Umstand nimmt der Gerichtshof im Francovich-Urteil aber keinen Bezug, was zumindest darauf hindeutet, dass er mit der Verurteilung im Vertragsverletzungsverfahren keine Pflicht zur ex tunc-Beseitigung aller Folgen des Vertragsverstoßes verknüpft.

Aus den vorstehenden Erwägungen ergibt sich zugleich, dass der Mitgliedstaat auf der Grundlage von Art. 260 I AEUV auch die Folgen einer Vertragsverletzung beseitigen muss, wenn diese, wie etwa im Beihil-

fert (Hrsg.), EUV/AEUV, 5. Aufl. 2016, Art. 260 AEUV, Rn. 7; Wunderlich, in: von der Groeben/Schwarze/Hatje (Hrsg.), Unionsrecht, 7. Aufl. 2015, Art. 260 AEUV, Rn. 8.

263 Ehricke, in: Streinz (Hrsg.), EUV/AEUV, 3. Aufl. 2018, Art. 260 AEUV, Rn. 2. Pechstein, EU-Prozessrecht, 4. Aufl. 2011, Rn. 311 sieht dementsprechend die Tenorierung eines Folgenbeseitigungsanspruchs als dem Gerichtshof verwehrt an.

264 Karpenstein, in: Grabitz/Hilf/Nettesheim (Hrsg.), Recht der EU, Art. 260 AEUV, Rn. 5 (Stand: August 2018).

265 Karpenstein, in: Grabitz/Hilf/Nettesheim (Hrsg.), Recht der EU, Art. 260 AEUV, Rn. 15 (Stand: August 2018).

$266 \mathrm{EuGH}$, Urteil vom 19.11.1991, verb. Rs. C-6/90 und C-9/90 (Francovich u.a.), Rn. 33 ff. Vgl. auch Wunderlich, in: von der Groeben/Schwarze/Hatje (Hrsg.), Unionsrecht, 7. Aufl. 2015, Art. 260 AEUV, Rn. 8; Cremer, in: Calliess/Ruffert (Hrsg.), EUV/AEUV, 5. Aufl. 2016, Art. 260 AEUV, Rn. 7. 
fenrecht ${ }^{267}$, mit in den Tenor aufgenommen worden sind. ${ }^{268}$ Die nach Art. 260 I AEUV zu ergreifende Maßnahme ist in diesem Fall ja die Rückforderung der unionsrechtswidrigen Beihilfe. Eine darauf abzielende Klage der Kommission ist zulässig. ${ }^{269}$

Wiederum anders liegt der Fall, wenn der Vertragsverstoß in der fehlenden rückwirkenden Anpassung des nationalen Rechts an unionsrechtliche Vorgaben besteht. Hier geht es nämlich nicht um die Folgen des Vertragsverstoßes, sondern die Vertragsverletzung selbst. Angesichts der Verbindlichkeit des Tenors ist der Mitgliedstaat dann zur rückwirkenden Änderung seines Rechts verpflichtet. ${ }^{270}$

Die Überlegungen zur Reichweite der Pflicht zur Beseitigung der Folgen eines Vertragsverstoßes in zeitlicher Hinsicht ändern nichts daran, dass, wie oben bereits festgestellt wurde, das als vertragswidrig festgestellte mitgliedstaatliche Verhalten von Anfang an rechtswidrig war. Das Vertragsverletzungsverfahren insoweit anders als die Auslegungsvorabentscheidung zu behandeln, hieße, die zeitliche Wirkung der Auslegung von der Zufälligkeit abhängig zu machen, in welcher Verfahrensart der EuGH über die Auslegung von Unionsrecht entschieden hat. Die Auslegung von Unionsrecht liegt letztlich auch dem Vertragsverletzungsverfahren zugrunde. ${ }^{271}$

267 Z.B. EuGH, Urteil vom 20.9.1990, Rs. C-5/89 (Kommission/Deutschland), Tenor Nr. 1: „Die Bundesrepublik Deutschland hat dadurch gegen ihre Verpflichtungen aus dem EWG-Vertrag verstoßen, daß sie der Entscheidung 88/174/EWG der Kommission vom 17. November 1987 [...] nicht nachgekommen ist." Nach Artikel 2 der Entscheidung war die Beihilfe zurückzufordern.

268 Wunderlich, in: von der Groeben/Schwarze/Hatje (Hrsg.), Unionsrecht, 7. Aufl. 2015, Art. 260 AEUV, Rn. 9. Ebenso Karpenstein, in: Grabitz/Hilf/Nettesheim (Hrsg.), Recht der EU, Art. 260 AEUV, Rn. 15 f. (Stand: August 2018).

269 So ausdrücklich EuGH, Urteil vom 12.7.1973, Rs. 70/72 (Kommission/Deutschland), 1. Leitsatz und Rn. 13: Die Kommission darf demnach das Ausmaß der Konkretisierung der Verpflichtung des Mitgliedstaates bestimmen, da der Vertrag darauf abziele, Verstöße und deren Folgen in Vergangenheit und Zukunft zu beseitigen.

$270 \mathrm{Zu}$ einem solchen Fall siehe etwa EuGH, Urteil vom 21.1.2016, Rs. C-515/14 (Kommission/Zypern), Tenor Nr. 1: „Die Republik Zypern hat dadurch gegen ihre Verpflichtungen aus den Art. 45 AEUV und 48 AEUV sowie Art. 4 Abs. 3 EUV verstoßen, dass sie nicht rückwirkend zum 1. Mai 2004 die auf das Lebensalter abstellende Voraussetzung in Art. 27 des Gesetzes 97 (I)/1997 über die Altersruhegelder aufgehoben hat [...].“

271 Dass dies wertungsmäßig keinen Unterschied machen kann, erkennt auch $\mathrm{Lu}$ dewig, Zeitliche Beschränkung, 2012, S. 61 an. Siehe auch Rosenkranz, Beschränkung der Rückwirkung, 2015, S. 127. 
Die Ähnlichkeit zwischen den beiden Verfahrensarten fällt bereits bei der Betrachtung des Tenors der Urteile in der jeweiligen Verfahrensart auf. Während der EuGH im Vertragsverletzungsverfahren den Verstoß eines Mitgliedstaates gegen eine Verpflichtung aus den Verträgen selbst feststellt ${ }^{272}$, beschränkt er sich bei der Auslegungsvorabentscheidung zwar auf die Auslegung der unionsrechtlichen Vorschrift ${ }^{273}$, tut dies allerdings in einer Weise, die den Vertragsverstoß des Mitgliedstaates offenlegt. ${ }^{274}$

Mit dieser Überlegung soll die auf die Auslegung des Unionsrechts beschränkte Kompetenz des Gerichtshofs bei der Auslegungsvorabentscheidung nicht überspielt werden. Sie macht aber deutlich, dass hinsichtlich der Wirkung der Auslegung und damit der ausgelegten Norm Übereinstimmung besteht, unabhängig davon, in welcher Verfahrensart sie vorgenommen worden ist. ${ }^{275}$ Auch wenn der Tenor des Vertragsverletzungsurteils in seinen Rechtsfolgen beschränkt ist, ergeben sich durch die diesem zugrundeliegende Auslegung des Unionsrechts weitergehende Wirkungen. ${ }^{276}$ Hier zeigt sich der Unterschied von Norm- und Urteilswirkung. Entscheidend ist nicht das Urteil, sondern die ausgelegte Norm.

\section{Modifikationen der zeitlichen Wirkungen}

Die im vorhergehenden Kapitel herausgearbeitete grundsätzliche ex tuncWirkung der vom Gerichtshof vorgenommenen Auslegung des Unionsrechts führt dazu, dass sie auch auf in der Vergangenheit begründete

272 Z.B. EuGH, Urteil vom 15.10.2015, Rs. C-137/14 (Kommission/Deutschland), Tenor Nr. 1: „Die Bundesrepublik Deutschland hat gegen ihre Verpflichtungen aus Art. 11 der Richtlinie 2011/92/EU [...] verstoßen, indem sie - gemäß $\$ 46$ VwVfG die Aufhebung von Entscheidungen [...] beschränkt [...].“

273 Bereits der Tenor ist also so formuliert, dass das Urteil in allen Mitgliedstaaten Bedeutung erlangt, vgl. Schneider, EuR 2017, 433 (447).

274 Z.B. EuGH, Urteil vom 12.5.2011, Rs. C-115/09 (Bund für Umwelt und Naturschutz Deutschland, Landesverband Nordrhein-Westfalen, „Trianel“), Tenor Nr. 1: „Art. 10a der Richtlinie 85/337/EWG [...] steht Rechtsvorschriften entgegen, die einer Nichtregierungsorganisation [...] nicht die Möglichkeit zuerkennen $[\ldots] .$.

275 Rosenkranz, Beschränkung der Rückwirkung, 2015, S. 93 spricht von einer funktionalen Ähnlichkeit von Vertragsverletzungs- und Auslegungsverfahren.

276 Den Zusammenhang von Auslegung und Vertragsverletzungsverfahren stellt auch GA Ruiz-Jarabo Colomer in seinen Schlussanträgen vom 18.4.2002 in der Rs. C-299/01 (Kommission/Luxemburg), Rn. 23 her. Siehe auch Rosenkranz, Beschränkung der Rückwirkung, 2015, S. 128. 
Sachverhalte anzuwenden ist. Der Gerichtshof sieht sich im Hinblick auf diese Folgen seiner Rechtsprechung als berechtigt an, ihre Wirkungen in zeitlicher Hinsicht zu modifizieren. Woraus sich diese Berechtigung ergibt, welchen Voraussetzungen eine Begrenzung unterliegt und welche Rechtsfolgen sie nach sich zieht, ist Gegenstand der nachfolgenden Untersuchung.

\section{Zuständigkeit des Gerichtshofs}

Bei der Auslegung des Unionsrechts war neben der Vorstellung von der deklaratorischen Rechtserkenntnis der Anwendungsbefehl der ausgelegten Norm selbst als entscheidend für die ex tunc-Wirkung herausgearbeitet worden. ${ }^{277}$ Die ex tunc-Wirkung ergibt sich damit bereits aus allgemeinen der Unionsrechtsordnung zu entnehmenden Erwägungen. Möchte der Gerichtshof nun von dieser ex tunc-Wirkung abweichen, müssen sich daher ebenso gute (geschriebene oder ungeschriebene) Gründe finden lassen, die ihm eine derartige Modifikation der zeitlichen Wirkungen gestatten. ${ }^{278}$

Bevor der Frage nachgegangen werden kann, welche Bestimmung der Verträge bzw. welcher allgemeine Rechtsgrundsatz dem Gerichtshof eine Zuständigkeit zur Modifikation der zeitlichen Wirkungen vermittelt, stellt sich die noch grundsätzlichere Frage, ob der Gerichtshof angesichts der Aufgabenverteilung zwischen Gerichtshof und nationalen Gerichten überhaupt dazu berufen ist, sich zu den zeitlichen Folgen seiner Urteile zu äußern. Unmittelbar damit zusammen hängt bei Bejahung einer derartigen Kompetenz die Frage danach, ob es sich bei ihr um eine ausschließliche des Gerichtshofs oder eine solche handelt, die zwischen EuGH und nationalen Gerichten geteilt ist. Daran anschließend ist noch zu überlegen, ob der Gerichtshof zu entsprechenden Äußerungen von Amts wegen befugt ist. ${ }^{279}$

277 Siehe dazu oben bei Fn. 191 und Fn. 212.

278 Ebenso Rosenkranz, Beschränkung der Rückwirkung, 2015, S. 112; ähnlich Simon, in: Liber Amicorum Pescatore, 1987, S. 651 (659).

279 Diese Differenzierung nimmt auch Kovács, Temporale Wirkung, 2014, S. 97 vor. 


\section{Bestehen einer Zuständigkeit}

Ausdrücklich sehen die Verträge die Möglichkeit einer Modifikation der zeitlichen Wirkungen der Rechtsprechungstätigkeit nur in Art. 264 II AEUV für die Nichtigkeitsklage vor. Eine entsprechende Kompetenz nimmt der Gerichtshof aber auch im Rahmen der Vorabentscheidungsverfahren für sich in Anspruch.

Nicht zu überzeugen vermag es, diese Zuständigkeit als Folge einer verfassungsgerichtlichen Funktion des EuGH zu begreifen. ${ }^{280}$ Für die Ungültigkeitsvorabentscheidung ließe sich zwar noch überlegen, die Normverwerfung und die Bestimmung ihrer Folgen in zeitlicher Hinsicht als typisch verfassungsgerichtliche Aufgabe anzusehen. Bei der Auslegungsvorabentscheidung verfängt dieses Argument aber von vornherein nicht. Die Begründung mit einer verfassungsgerichtlichen Funktion des Gerichtshofs bedeutete zudem im Umkehrschluss, dass dieser in nicht-verfassungsgerichtlichen Angelegenheiten dem Problem der zeitlichen Dimension seiner Rechtsprechung keine Beachtung schenken dürfte. Auch hier kann sie aber virulent werden. ${ }^{281}$

Entscheidend ist, dass es sich bei der Bestimmung der Tragweite einer unionsrechtlichen Bestimmung in zeitlicher Hinsicht nicht um die Anwendung einer Norm auf einen Einzelfall handelt, für die die mitgliedstaatlichen Gerichte zuständig sind und für die dem Gerichtshof daher keine Zuständigkeit zusteht. ${ }^{282}$ Indem er die zeitlichen Wirkungen der Auslegung bestimmt, legt der EuGH vielmehr lediglich die in zeitlicher Hinsicht geltenden und vom nationalen Gericht zu beachtenden Vorgaben des Unionsrechts fest. ${ }^{283}$ Die Kompetenzen des Vorlagegerichts im Rahmen des Vorabentscheidungsverfahrens werden dadurch nicht geschmälert. Ist dem Gerichtshof nämlich die Entscheidung über die Auslegung zugewiesen, erscheint die Bestimmung der mit ihr verbundenen Folgen als die weniger weit reichende Zuständigkeit. Diese Kompetenz muss dem EuGH dann erst recht zustehen. ${ }^{284}$ Zur Entscheidung über die Auslegung gehört

280 In diesem Sinne aber Gundel, in: Ehlers (Hrsg.), Europäische Grundrechte und Grundfreiheiten, 4. Aufl. 2015, $\$ 27$, Rn. 57.

281 Kritisch äußert sich insoweit auch Rosenkranz, Beschränkung der Rückwirkung, 2015, S. 119.

282 Siehe hierzu auch Masclet, RTDEur. 1986, 161 (167 ff.).

283 Vgl. Everling, in: FS Börner, 1992, S. 57 (63).

284 Pietrek, Vorabentscheidungen, 1989, S. 48 f. Bebr, Michigan Law Review 82 (1984), 1229 (1245) spricht im Zusammenhang mit der Bestimmung der zeitlichen Wirkung einer Ungültigkeitsentscheidung im Rahmen des Vorabentschei- 
damit auch die Entscheidung über die damit verbundenen Wirkungen. ${ }^{285}$ Sie fällt in die Zuständigkeit der für die Auslegung zuständigen Instanz. ${ }^{286}$ Das ist der EuGH.

\section{Ausschließlichkeit dieser Zuständigkeit}

Diese Zuständigkeit nimmt der Gerichtshof für sich als ausschließliche in Anspruch. Im Vordergrund steht dabei die Sorge um die einheitliche Anwendung des Unionsrechts in allen Mitgliedstaaten. ${ }^{287}$

Deutlich wird dies zunächst mit Blick auf die Ungültigkeitsvorabentscheidung, in deren Rahmen der Gerichtshof ausführt, ihm sei die Befugnis, die Wirkungen der Ungültigkeit eines Unionsrechtsakts zeitlich zu begrenzen, im Interesse der einheitlichen Anwendung des Unionsrechts in der ganzen Union eingeräumt worden. 288 Überprüft man diese Aussage auf ihre Stichhaltigkeit, so wäre es in der Tat bei uneingeschränkter ex tunc-Wirkung der Ungültigerklärung nach dem Verfahrensrecht einzelner Mitgliedstaaten vielleicht unmöglich, alle bereits eingetretenen Wirkungen rückgängig zu machen. Der einheitlichen Nichtanwendung des Unionsrechtsaktes in Bezug auf die Vergangenheit wäre dies abträglich. ${ }^{289}$ Um Einheitlichkeit zu erreichen, bedarf es deshalb einer unionsweiten Regelung. Bei der Zuständigkeit zur Begrenzung der Wirkungen der Ungültigkeit kann es sich daher nur um eine ausschließliche Zuständigkeit des EuGH handeln.

Deutlich tritt der Gedanke der einheitlichen Anwendung des Unionsrechts aber auch im Hinblick auf Auslegungsentscheidungen hervor. So folgt für den Gerichtshof aus dem grundlegenden Erfordernis, dass das Unionsrecht in allen Fällen einheitlich anzuwenden ist, dass es allein

dungsverfahrens von der „lesser power“ im Vergleich zur Ungültigerklärung selbst.

285 Vgl. Everling, in: FS Börner, 1992, S. 57 (63).

286 Siehe auch Simon, in: Liber Amicorum Pescatore, 1987, S. 651 (669).

287 Siehe auch Simon, in: Liber Amicorum Pescatore, 1987, S. 651 (673).

288 In diesem Sinne EuGH, Urteil vom 26.4.1994, Rs. C-228/92 (Roquette Frères), Rn. 20; EuGH, Urteil vom 27.2.1985, Rs. 112/83 (Société des produits de maïs), Rn. 17.

289 Darauf weisen Lenaerts/Arts/Maselis, Procedural Law, 2. Aufl. 2006, Rn. 10-018 in Bezug auf EuGH, Urteil vom 27.2.1985, Rs. 112/83 (Société des produits de mais), Rn. 17 zutreffend hin. Siehe hierzu auch Masclet, RTDEur. 1986, 161 (174 ff.). 
seine Sache ist, darüber zu entscheiden, ob die Geltung der von ihm vorgenommenen Auslegung in zeitlicher Hinsicht einzuschränken ist. ${ }^{290}$ Den mitgliedstaatlichen Gerichten einen allgemeinen Rahmen für eine Begrenzung der zeitlichen Wirkung vorzugeben, innerhalb dessen diese eigenständig entscheiden könnten, würde dagegen aufgrund der dann möglichen divergierenden Entscheidungen die einheitliche Anwendung des Unionsrechts nicht sicherstellen. Dies spricht für eine ausschließliche Zuweisung an den EuGH.

Dennoch meint etwa Huep, aus Verhältnismäßigkeits- und Subsidiaritätsgründen sei eine zwischen EuGH und mitgliedstaatlichen Gerichten geteilte Zuständigkeit zur Bestimmung der zeitlichen Wirkung der Auslegung anzunehmen. Er zeigt sich damit bereit, eine je nach Gericht und Mitgliedstaat unterschiedliche zeitliche Wirkung hinzunehmen. ${ }^{291}$ Insoweit ist allerdings einzuwenden, dass es an dieser Stelle zunächst lediglich um die allein auf die Unionsebene bezogene Modifikation der zeitlichen Wirkungen der ausgelegten Norm des Unionsrechts geht. Dem Gerichtshof hierfür eine ausschließliche Zuständigkeit zuzusprechen, trifft noch keine endgültige Aussage darüber, ob damit Möglichkeiten nationaler Gerichte zur Reaktion auf diese zeitliche Dimension ausgeschlossen sind. Dies ist eine davon zu trennende Frage. ${ }^{292}$

Die Richtigkeit dieses Ergebnisses einer ausschließlichen Zuständigkeit des Gerichtshofs für die Bestimmung der Folgen seiner im Vorabentscheidungsverfahren vorgenommenen Auslegung in zeitlicher Hinsicht lässt sich weiter abstützen.

Im Rahmen der Nichtig- bzw. Ungültigerklärung einer Norm leuchtet unmittelbar ein, dass sinnvollerweise nur dasjenige Gericht eine Ausnahme von der ex tunc-Wirkung der Nichtig- bzw. Ungültigerklärung bestimmen kann, das in ausschließlicher Zuständigkeit zur Entscheidung über die Wirksamkeit der Norm berufen ist, wobei zwischen Nichtig- und Ungültigerklärung insoweit keine Unterschiede bestehen. Die ausschließliche Zuständigkeit des EuGH für die Nichtig- bzw. Ungültigerklärung zieht damit seine ausschließliche Zuständigkeit für eine Begrenzung der Wirkungen nach sich; eine „Aufteilung“ der Ausübung der ausschließlichen

290 EuGH, Urteil vom 27.3.1980, Rs. 61/79 (Denkavit italiana), Rn. 18; EuGH, Urteil vom 27.3.1980, verb. Rs. 66/79, 127/79 und 128/79 (Salumi u.a.), Rn. 11.

291 Hиер, Beschränkung einer Rückwirkung, 2001, S. 219 f.

292 Ob eine entsprechende Möglichkeit besteht, wird im zweiten Teil der Arbeit untersucht. Siehe auch Rosenkranz, Beschränkung der Rückwirkung, 2015, S. 431. 
Zuständigkeit des Gerichtshofs zur Entscheidung über die Rechtmäßigkeit kommt nicht in Betracht. ${ }^{293}$

Aber auch bei der Auslegung von Unionsrecht besteht ein ähnlicher Zusammenhang. Hier ist die Ausgangslage zwar insofern eine andere, als auch die nationalen Gerichte das Unionsrecht auslegen dürfen. Frei sind diese dabei allerdings wie gesehen nur solange, wie der EuGH noch keine Auslegung vorgenommen hat, da diesem das Letztentscheidungsrecht in Auslegungsfragen zugewiesen ist. ${ }^{294}$ Dies legt bereits eine ausschließliche Zuständigkeit des Gerichtshofs für eine Modulation der zeitlichen Wirkungen nahe. Hinzu kommt, dass bei einer Begrenzung der zeitlichen Wirkung der Auslegung der Anwendungsbefehl der ausgelegten Norm letztlich für einen bestimmten Zeitraum außer Kraft gesetzt wird. Zur Außerkraftsetzung des Anwendungsbefehls einer Norm des Unionsrechts kann aber allein der EuGH befugt sein. ${ }^{295}$ Sähe man dies anders, wäre die einheitliche Anwendung des Unionsrechts wiederum gefährdet. ${ }^{296}$

\section{Folgen für eine fehlende Begrenzung der ex tunc-Wirkung}

Die ausschließliche Zuständigkeit des EuGH zur Bestimmung der zeitlichen Wirkungen einer von ihm vorgenommenen Auslegung hat auch Folgen für den Fall, dass der Gerichtshof zu dieser Frage schweigt.

Angesichts des oben herausgearbeiteten Grundsatzes der ex tunc-Wirkung muss es im Falle des Schweigens des Gerichtshofs bei dieser Wirkung verbleiben. Unerheblich ist also, ob der Gerichtshof eine zeitliche Begrenzung ausdrücklich oder lediglich stillschweigend abgelehnt hat. ${ }^{297}$ Zurückzuweisen ist daher eine Ansicht, die nur dann von der Ablehnung einer Beschränkung der zeitlichen Wirkungen ausgeht, wenn das Schweigen des

293 GA Darmon, Schlussanträge vom 14.11.1984 in der Rs. 112/83 (Société des produits de maiis), Slg. 1985, S. 726, 728; zustimmend Rosenkranz, Beschränkung der Rückwirkung, 2015, S. 429. Ludewig, Zeitliche Beschränkung, 2012, S. 258 spricht von einer „Art ,Annex-Kompetenz' des EuGH“ im Hinblick auf die Frage der zeitlichen Wirkung der Ungültigkeit. Siehe auch GA Cruz Villalón, Schlussanträge vom 8.12.2011 in der Rs. C-533/10 (CIVAD), Rn. 43.

294 Siehe dazu bereits oben bei Fn. 210.

295 Siehe auch Rosenkranz, Beschränkung der Rückwirkung, 2015, S. 429 f.

296 Alexander, YEL 8 (1988), 11 (25); Kovács, Temporale Wirkung, 2014, S. 102; Ludewig, Zeitliche Beschränkung, 2012, S. 162.

297 Beides ist möglich, so ausdrücklich EuGH, Urteil vom 9.6.2016, Rs. C-586/14 (Budişan), Rn. 50. 
Gerichtshofs „beredt" ist, wenn eine solche also im Verfahren beantragt oder zumindest diskutiert wurde. ${ }^{298} \mathrm{Um}$ den Grundsatz der ex tunc-Wirkung nicht in Frage zu stellen, muss es bei diesem verbleiben, wenn der EuGH keine Ausnahme angeordnet hat. Dies hat zur Folge, dass selbst dann, wenn dem EuGH vom vorlegenden Gericht ausdrücklich eine Frage zur zeitlichen Begrenzung vorgelegt worden ist, aus einem Schweigen des Gerichtshofs nicht darauf geschlossen werden kann, dass er eine solche Begrenzung als zulässig erachtet. ${ }^{299}$ Auch eine solche Annahme ließe sich mit der ausschließlichen Zuständigkeit des EuGH zur Begrenzung der zeitlichen Wirkungen, die nur ausdrücklich erfolgen kann, nicht vereinbaren. Schweigt der Gerichtshof also zur Frage der zeitlichen Wirkungen, ist sie im Sinne der ex tunc-Wirkung beantwortet. ${ }^{300}$

Vor diesem Hintergrund erweist sich ein Vorgehen, wie es der französische Conseil d'État zu praktizieren scheint, als unionsrechtswidrig. Beispielhaft sind hier die Verfahren Association Vent De Colère! u.a. ${ }^{301}$ und Octapharma France ${ }^{302}$, in denen der Conseil d'État den Gerichtshof jeweils um Vorabentscheidung ersucht hatte. Während der Gerichtshof in der Rechtssache Association Vent De Colère! u.a. eine Begrenzung der zeitlichen Wirkungen der Auslegung ausdrücklich ablehnte, äußerte er sich in der Rechtssache Octapharma France anders als Generalanwalt Jäskinen in seinen Schlussanträgen ${ }^{303}$ nicht ausdrücklich dazu.

In Reaktion auf dieses Schweigen des Gerichtshofs sah sich der Conseil d'État bei der Entscheidung des Ausgangsrechtsstreits im Verfahren Octapharma France zu einer Begrenzung der von ihm vorzunehmenden Nichtigerklärung der in Rede stehenden nationalen Entscheidung in der Lage - mit dieser war nach einem industriellen Verfahren hergestelltes Plasma als labiles Blutprodukt eingestuft worden, was zur Folge hatte, dass Octapharma France dieses nicht in Frankreich vertreiben durfte, da das

298 In diesem Sinne Nirk/Hülsmann, in: FS Piper, 1996, S. 725 (741 f.).

299 Anders wohl BAG, Urteil vom 23.3.2010, 9 AZR 128/09, Rn. 77 - BAGE 134, 1: „Anderes gilt [...]“ unter Berufung auf Riesenhuber, AP KSchG 1969 \$17 Nr. 21 und Wißmann, in: FS Bauer, 2010, S. 1161 (1164).

300 So Everling, in: FS Börner, 1992, S. 57 (63) für die Ungültigkeitsvorabentscheidung.

301 EuGH, Urteil vom 19.12.2013, Rs. C-262/12 (Association Vent De Colère! u.a.), Rn. 38 ff.; Conseil d'État, Urteil vom 28.5.2014, No. 324852.

$302 \mathrm{EuGH}$, Urteil vom 13.3.2014, Rs. C-512/12 (Octapharma France); Conseil d'État, Entscheidung vom 23.7.2014, No. 349717.

303 GA Jääskinen, Schlussanträge vom 7.11.2013 in der Rs. C-512/12 (Octapharma France), Rn. $34 \mathrm{ff}$. 
Établissement français du sang hierfür ein Monopol besaß. Der Conseil d'État erklärte daher zwar die angefochtene Entscheidung für nichtig; dem bisherigen Monopolträger gestattete er aber, mit der Produktion und Verteilung des Plasmas nach den Regeln für labile Blutprodukte fortzufahren, da es sonst zu Engpässen bei der Plasmaversorgung komme. Zur Begründung machte er geltend, dass sich sonst ein Widerspruch zum Ziel der Union ergebe, ein hohes Gesundheitsschutzniveau zu garantieren. ${ }^{304}$

Einen solchen Weg sah er für sich im Verfahren Association Vent De Colère! u.a. dagegen als versperrt an, da sich der EuGH dort wie gesehen ausdrücklich gegen eine Begrenzung der zeitlichen Wirkungen im Sinne der Defrenne-Rechtsprechung ausgesprochen hatte. ${ }^{305}$ Die vor dem Conseil d'État beantragte zeitliche Begrenzung der Wirkungen der Nichtigerklärung des angegriffenen Rechtsakts lehnte dieser dementsprechend $\mathrm{ab}$ und stellte fest, dass der EuGH eine Abweichung von der ex tunc-Wirkung der Auslegung nicht für möglich erachtet hatte. Es sei daher ausgeschlossen, gleichartige Erwägungen anzustellen, die auf die zeitliche Begrenzung der Wirkungen der Nichtigerklärung des nationalen Rechtsakts abzielten. ${ }^{306}$

Die ausdrückliche Ablehnung des EuGH, die zeitlichen Wirkungen zu begrenzen, erkannte der Conseil d'État demnach im Nachgang der Entscheidung des Gerichtshofs als ihn von entsprechenden Erwägungen ausschließend an. Im Schweigen des EuGH sah er dagegen eine implizite Ermächtigung, eigenständig über die Frage der zeitlichen Wirkungen im nationalen Verfahren zu entscheiden. ${ }^{307}$

304 Conseil d'État, Entscheidung vom 23.7.2014, No. 349717, Punkt 8. Die Übergangsfrist zur Anpassung des nationalen Rechts bemaß er dabei wegen des Erfordernisses, unionsrechtliche Vorgaben vordringlich zu erfüllen, kurz. In Rede stand daher insbesondere eine Übertragung der in der Rechtssache Inter-Environnement Wallonie und Terre wallonne vorgesehenen Möglichkeit nationaler Gerichte, eine nationale Rechtsvorschrift anzuwenden, die es ihnen gestattet, bestimmte Wirkungen eines für nichtig erklärten nationalen Rechtsakts aufrechtzuerhalten, siehe zu dieser Rechtsprechung des Gerichtshofs ausführlich unten bei Fn. 1439 ff. Auch wenn diese Möglichkeit den Vorrang des Unionsrechts als „Durchsetzungsdimension“ betrifft und damit einen anderen Aspekt als die Defrenne-Rechtsprechung, so zeigt die Entscheidung des Conseil d'État doch sein Verständnis vom Wesen einer ausschließlichen Befugnis.

305 EuGH, Urteil vom 19.12.2013, Rs. C-262/12 (Association Vent De Colère! u.a.), Rn. 38-44.

306 Conseil d'État, Urteil vom 28.5.2014, No. 324852 unter Verweis auf EuGH, Urteil vom 19.12.2013, Rs. C-262/12 (Association Vent De Colère! u.a.), Rn. 3844.

307 Vgl. Coutron, RTDEur. 2017, 400 (406f.). 
Dieses Vorgehen offenbart eine Fehlvorstellung von der Bedeutung der Ausschließlichkeit einer Kompetenz. Für die Frage der Befugnisse mitgliedstaatlicher Gerichte kann es nämlich keinen Unterschied machen, ob der Gerichtshof sich zu der seiner ausschließlichen Zuständigkeit unterliegenden Frage äußert oder nicht. Die ausschließliche Zuständigkeit des Gerichtshofs für die Bestimmung der zeitlichen Wirkungen seiner Auslegung hat zur Folge, dass ein mitgliedstaatliches Gericht diese nicht selbst bestimmen darf, auch wenn der Gerichtshof zur zeitlichen Dimension seiner Auslegung schweigt. ${ }^{308}$ Die jeden anderen von der Zuständigkeit ausschließende Wirkung ist gerade Kennzeichen einer ausschließlichen Kompetenz.

Aus diesen Überlegungen folgt auch, dass es für die Befugnisse der das Unionsrecht auf den konkreten Fall anwendenden nationalen Gerichte nicht entscheidend ist, ob sich der Gerichtshof zur Frage der Modifikation der zeitlichen Wirkungen der Auslegung ausdrücklich ablehnend geäußert oder ob er dazu geschwiegen hat. Entscheidend ist vielmehr, inwieweit einer unterbliebenen zeitlichen Begrenzung eine „Sperrwirkung“ für mitgliedstaatliche Gerichte zu entnehmen ist, die Folgen der unionsrechtlichen Vorgaben im nationalen Verfahren in zeitlicher Hinsicht zu modifizieren. Dieser Frage wird im zweiten Teil der Arbeit nachgegangen. ${ }^{309}$

\section{Befugnis zur Prüfung von Amts wegen}

Nachdem geklärt werden konnte, dass der Gerichtshof für eine Modifikation der zeitlichen Wirkungen einer von ihm vorgenommenen Auslegung ausschließlich zuständig ist, gilt es noch herauszuarbeiten, ob eine Beschränkung der zeitlichen Wirkungen einen Antrag eines Verfahrensbeteiligten voraussetzt oder nicht.

In seinen Schlussanträgen in der eine Auslegungsfrage betreffenden Rechtssache Hedley Lomas führt Generalanwalt Léger aus, dass der Gerichtshof nie von Amts wegen eine Beschränkung der zeitlichen Wirkung vornehme und zog diese Behauptung als Argument neben anderen für seinen Vorschlag einer Ablehnung der Begrenzung der zeitlichen Wirkungen in dem von ihm zu beurteilenden Fall heran. ${ }^{310}$ In der Tat hat der

308 Siehe auch Bebr, CMLRev. 22 (1985), 771 (784).

309 Siehe hierzu bei Fn. 1301 ff. Dort wird auch das Vorgehen des Conseil d'État erneut anzusprechen sein.

310 GA Léger, Schlussanträge vom 20.6.1995 in der Rs. C-5/94 (Hedley Lomas), Rn. 208. 
Gerichtshof die zeitlichen Wirkungen bislang nur auf einen von außen kommenden Impuls hin begrenzt.

a) Bestehen eines Antragserfordernisses in der Rechtsprechung des Gerichtshofs?

Befasst man sich mit der Frage, ob der Gerichtshof rechtlich an einer zeitlichen Begrenzung gehindert ist, wenn eine solche von keinem Verfahrensbeteiligten „beantragt“ wurde oder ob er dazu im Gegenteil auch von Amts wegen befugt ist, fällt zunächst auf, dass manche Aussagen in seiner Rechtsprechung den Eindruck des Bestehens eines Antragserfordernisses erwecken. So wies er in seiner Antwort auf die Frage des vorlegenden Gerichts nach einer Begrenzung der zeitlichen Wirkungen in der Rechtssache Richards ${ }^{311}$ darauf hin, dass die Regierung des Vereinigten Königreichs im Ausgangsverfahren vor dem nationalen Gericht zwar einen entsprechenden Antrag gestellt, diesen aber vor dem Gerichtshof nicht wiederholt und damit nicht „aufrechterhalten“ habe. ${ }^{312}$ Auch wenn dies für die Ablehnung der Begrenzung der zeitlichen Wirkungen nicht allein ausschlaggebend war, legt der Gerichtshof damit doch die Vermutung nahe, dass er diesen Umstand als entscheidungserheblich erachtete. Ebenfalls auf ein (allerdings großzügig gehandhabtes) Antragserfordernis deutet es hin, wenn der Gerichtshof in den verbundenen Rechtssachen Santander Asset Management SGIIC u.a. zwar auch noch einen in der mündlichen Verhandlung erfolgten Anstoß berücksichtigt, sich aber über die späte Antragstellung überrascht zeigt. ${ }^{313}$

Dennoch besteht in der Rechtsprechung des Gerichtshofs letztlich kein Antragserfordernis. Es fällt zwar in der Tat auf, dass er häufig von einem „Antrag“ der Verfahrensbeteiligten spricht. ${ }^{314}$ Dass er dies aber nicht in

311 EuGH, Urteil vom 27.4.2006, Rs. C-423/04 (Richards), Rn. 19, 39.

312 EuGH, Urteil vom 27.4.2006, Rs. C-423/04 (Richards), Rn. 43. In abgeschwächter Form GA Jacobs, Schlussanträge vom 15.12.2005 in der Rs. C-423/04 (Richards), der in Rn. 61 ebenfalls erwähnt, dass die Regierung des Vereinigten Königreichs keine Beschränkung anstrebe, in Rn. 62 ff. aber ausführt, dass ,jedenfalls" die Voraussetzungen einer Beschränkung nicht vorlägen.

313 Vgl. EuGH, Urteil vom 10.5.2012, verb. Rs. C-338/11 bis C-347/11 (Santander Asset Management SGIIC u.a.), Rn. 62: „erst in der mündlichen Verhandlung“.

314 Z.B. EuGH, Urteil vom 9.4.2014, Rs. C-616/11 (T-Mobile Austria), Rn. 49; EuGH, Urteil vom 29.9.2015, Rs. C-276/14 (Gmina Wrocław), Rn. 43; EuGH, Urteil vom 17.9.2014, Rs. C-562/12 (Liivimaa Lihaveis), Rn. 77 f.; EuGH, Ur- 
einem rechtstechnischen Sinne versteht, zeigt schon die Gleichsetzung eines derartigen „Antrags“ mit einem „Ersuchen“315 oder mit dem Hinweis auf die Möglichkeit einer Beschränkung ${ }^{316}$. Dementsprechend finden sich auch Entscheidungen, in denen überhaupt nicht von einem Antrag, sondern lediglich von einem Ersuchen ${ }^{317}$ oder von einem Hinweis auf die Möglichkeit einer Beschränkung ${ }^{318}$ die Rede ist.

\section{b) Begründung der Befugnis zur Prüfung von Amts wegen}

Ein echtes Antragserfordernis ließe sich nach hier vertretener Ansicht auch nicht begründen. $\mathrm{Zu}$ befürworten ist vielmehr eine Kompetenz des Gerichtshofs zur Begrenzung der zeitlichen Wirkungen von Amts wegen.

Zum Teil wird eine solche Kompetenz in der Literatur mit dem Argument bejaht, der Gerichtshof dürfe die ihm gestellten Fragen umformulieren und auch Bestimmungen berücksichtigen, die das nationale Gericht nicht angeführt habe. ${ }^{319}$ Diese Argumentation erscheint an dieser Stelle allerdings insofern unpassend, als sich der EuGH im vorliegenden Zusammenhang gerade zur Reichweite des Anwendungsbefehls der ausgelegten Norm des Unionsrechts in zeitlicher Hinsicht äußert. Er berücksichtigt dabei zwar die Grundsätze der Rechtssicherheit und des effektiven Rechtsschutzes. Da dies aber mit Blick auf die in Rede stehende Bestimmung des Unionsrechts erfolgt, berücksichtigt er keine andere als die vom vorlegen-

teil vom 22.9.2016, Rs. C-110/15 (Microsoft Mobile Sales International u.a.), Rn. 57 f.; EuGH, Urteil vom 9.6.2016, Rs. C-586/14 (Budişan), Rn. 44.

315 EuGH, Urteil vom 21.3.2013, Rs. C-92/11 (RWE Vertrieb), Rn. 56 spricht davon, dass die deutsche Regierung den EuGH „ersucht“ habe und einen Atemzug später davon, dass RWE ebenfalls einen „Antrag“ in diesem Sinne gestellt habe.

316 EuGH, Urteil vom 21.10.2010, Rs. C-242/09 (Albron Catering), Rn. 33 f.: Rn. 33 spricht davon, dass Albron in ihren Erklärungen die Möglichkeit einer zeitlichen Beschränkung angesprochen habe; Rn. 34 führt dann aus, was Albron zur "Stützung ihres Antrags" geltend macht.

317 Z.B. EuGH, Urteil vom 18.10.2012, Rs. C-525/11 (Mednis), Rn. 39 f.; EuGH, Urteil vom 10.11.2016, Rs. C-452/16 PPU (Poltorak), Rn. 54; EuGH, Urteil vom 10.11.2016, Rs. C-477/16 PPU (Kovalkovas), Rn. 50.

318 Z.B. EuGH, Urteil vom 15.12.1995, Rs. C-415/93 (Bosman), Rn. 140.

319 Hyland, IJEL 2 (1995), 208 (232) unter Bezugnahme auf EuGH, Urteil vom 27.3.1990, Rs. C-315/88 (Bagli Pennacchiotti), Rn. 10. Masclet, RTDEur. 1986, 161 (167) sieht in einer Äußerung des Gerichtshofs zu den Folgen seiner Rechtsprechung einen Hinweis auf eine vom Vorlagegericht nicht beachtete Regel des Unionsrechts. 
den Gericht angeführte Bestimmung. Eine Antwort auf eine umformulierte Frage stellt die Begrenzung der zeitlichen Wirkungen daher ebenfalls nicht dar. Sie ist vielmehr untrennbar mit dem Verfahrensgegenstand der Hauptsache verbunden. ${ }^{320}$

Der häufig erfolgende Hinweis des Gerichtshofs darauf, dass er dem nationalen Gericht unabhängig von der Vorlagefrage alle nötigen Auslegungshinweise gebe, die diesem nützlich sein könnten und die Elemente des Unionsrechts herausarbeite, die unter Berücksichtigung des Gegenstands des Rechtsstreits einer Auslegung bedürften ${ }^{321}$, kann aber durchaus fruchtbar gemacht werden. Auch wenn es dem Gerichtshof insoweit um einen Hinweis auf die tatsächlich einschlägige Vorschrift des Unionsrechts geht, lässt sich der hier zum Ausdruck kommende Rechtsgedanke auf die Frage der zeitlichen Beschränkung übertragen: Äußert sich der Gerichtshof zur Reichweite des Anwendungsbefehls der ausgelegten Vorschrift in zeitlicher Hinsicht, gibt er einen Hinweis zur Auslegung der in Rede stehenden Norm und damit zum Verfahrensgegenstand selbst, zu dem er sich von Amts wegen äußern kann. ${ }^{322}$

Entscheidend kommt noch hinzu, dass die ausschließliche Befugnis des EuGH zur Modulation der zeitlichen Wirkungen eine leere Hülle bliebe, wollte man sie von einer entsprechenden Vorlagefrage oder zumindest von einer Anregung durch die Verfahrensbeteiligten abhängig machen. Da sich angesichts der Ausschließlichkeit der Befugnis nur der Gerichtshof hierzu äußern darf, muss ihm diese Befugnis von Amts wegen zustehen. Nur auf diese Weise ist sichergestellt, dass sie in den Fällen wahrgenommen werden kann, in denen dies erforderlich erscheint und nicht nur dort, wo diese Frage mehr oder weniger zufällig im Verfahren zur Sprache gekommen ist.

320 Ludewig, Zeitliche Beschränkung, 2012, S. 161 spricht von einem „inneren Zusammenhang" von Vorlagebeschluss und zeitlicher Beschränkung; Rosenkranz, Beschränkung der Rückwirkung, 2015, S. 409 ordnet die Entscheidung über eine Modifikation der zeitlichen Folgen als „Annex“ und „Anhängsel“ zur Hauptsache ein; Kovács, Temporale Wirkung, 2014, S. 107 spricht davon, dass jede Vorabentscheidung mit einer „latenten Prüfung“ ihrer zeitlichen Wirkung einhergehe.

321 EuGH, Urteil vom 7.6.2018, Rs. C-160/17 (Thybaut u.a.), Rn. 35; EuGH, Urteil vom 22.6.2017, Rs. C-549/15 (E.ON Biofor Sverige), Rn. 72; EuGH, Urteil vom 22.10.2015, Rs. C-425/14 (Impresa Edilux und SICEF), Rn. 20; EuGH, Urteil vom 27.10.2009, Rs. C-115/08 (ČEZ), Rn. 81.

322 Zudem sind Anträge betreffend den Verfahrensgegenstand dem Vorabentscheidungsverfahren fremd. Düsterhaus, EuR 2017, 30 (43) spricht daher im Hinblick auf ein förmliches Antragserfordernis von einem „Fremdkörper“. 
Nicht zu überzeugen vermag es daher, die Frage nach den zeitlichen Wirkungen als Bestandteil der Vorlagefrage aufzufassen ${ }^{323}$, da diese Auffassung vom gedanklichen Ausgangspunkt her eine Befugnis zur Prüfung von Amts wegen zu Unrecht ablehnt. Durch das Hineinlesen der Frage nach den zeitlichen Wirkungen in die Vorlagefrage wird der Auslöser für die Äußerung des Gerichtshofs zu den zeitlichen Wirkungen letztlich in einer Aufforderung des vorlegenden Gerichts gesehen, was mit einer von Amts wegen bestehenden Befugnis nicht zu vereinbaren ist. Immerhin gelangt aber auch diese Auffassung durch die Konstruktion einer impliziten Frage im Ergebnis dazu, dass der Gerichtshof ohne ausdrückliche Vorlagefrage zur zeitlichen Dimension seiner Rechtsprechung Stellung nehmen darf. 324

\section{c) Folgen}

Ein Antrag im rechtstechnischen Sinne ist für eine Begrenzung der zeitlichen Wirkungen also nicht erforderlich. Ist daher von einem „Antrag“ die Rede, ist dies als Anregung zu verstehen. ${ }^{325}$

Hinsichtlich der zu einer solchen Anregung Befugten kann es dann keine Einschränkungen etwa im Sinne einer Antragsbefugnis geben. Im Vorabentscheidungsverfahren als nicht-streitigem Verfahren kommt für eine „Antrag"stellung somit jeder in Betracht, der nach Art. 23 II der Satzung des Gerichtshofs Schriftsätze einreichen oder schriftliche Erklärungen abgeben kann. Dies sind die Parteien [des Ausgangsverfahrens], die Mitgliedstaaten, die Kommission und gegebenenfalls die Organe, Einrichtungen oder sonstigen Stellen der Union, von denen die Handlung ausgegangen ist, deren Gültigkeit oder Auslegung streitig ist. Dass etwa das Interesse einer Partei des Ausgangsverfahrens an einer zeitlichen Begrenzung nur schwach ausgeprägt ist, wenn sie selbst weniger stark von der Auslegung des Gerichtshofs als ihre Konkurrenten im Wirtschaftsleben betroffen ist, ist daher für Letztere zwar misslich, aber hinzunehmen, da ihnen ein Äußerungsrecht vor dem Gerichtshof nicht zusteht. ${ }^{326}$

323 So Simon, in: Liber Amicorum Pescatore, 1987, S. 651 (667 f.) zur Ungültigkeitsvorabentscheidung.

324 Vgl. Kovács, Temporale Wirkung, 2014, S. 108.

325 Rosenkranz, Beschränkung der Rückwirkung, 2015, S. 409.

326 Wusterhausen, Wirkungen, 2016, S. 396. 
Generalanwalt Jääskinen zieht zwar in Zweifel, dass eine Vorlagefrage nach den zeitlichen Wirkungen zu beantworten ist, wenn der Mitgliedstaat bzw. der Beklagte des Ausgangsverfahrens keinen entsprechenden Antrag gestellt hat. ${ }^{327}$ Diese Überlegung ist allerdings zurückzuweisen; das Gericht des Ausgangsverfahrens kann aus eigenem Antrieb Fragen nach den zeitlichen Wirkungen vorlegen. ${ }^{328}$ Die Erwägung des Generalanwalts überzeugt noch aus einem anderen Grund nicht. Er legt ein Verständnis nahe, wonach nur der Mitgliedstaat, aus dem die Vorlage stammt, und die Beteiligten des Ausgangsverfahrens dazu berechtigt sein sollen, einen entsprechenden „Antrag“ zu stellen. ${ }^{329}$ Dadurch wäre die Präklusion, wonach eine Begrenzung nur im erstauslegenden Urteil erfolgen kann ${ }^{330}$, noch sehr viel prekärer, als sie es ohnehin bereits ist. Einen Mitgliedstaat in einem nachfolgenden Auslegungsverfahren mit seinem Ersuchen um Begrenzung abzuweisen, könnte nicht gerechtfertigt werden, wenn er von einer „Antragstellung“ im ersten Verfahren abgehalten wird, weil der Vorlagesachverhalt aus einem anderen Mitgliedstaat stammt. ${ }^{331}$ Zutreffend ist es daher, sowohl das Vorbringen eines Mitgliedstaats im Hinblick auf

327 GA Jääskinen, Schlussanträge vom 15.7.2010 in der Rs. C-147/08 (Römer), Rn. 159: „Für den Fall, dass der Gerichtshof [...] eine Antwort geben will, obwohl weder die Bundesrepublik Deutschland noch die Freie und Hansestadt Hamburg ihn darum ersucht haben, [...]“ und Rn. 162: „Für den Fall, dass die sechste Vorlagefrage zu beantworten ist, [...]“. Der Gerichtshof führt die unterbliebene Beantragung zwar auch an, allerdings nur als ein Argument unter mehreren für die Ablehnung der Beschränkung der zeitlichen Wirkungen, vgl. EuGH, Urteil vom 10.5.2011, Rs. C-147/08 (Römer), Rn. 66.

328 So geschehen z.B. in EuGH, Urteil vom 25.10.2012, Rs. C-553/11 (Rintisch), Rn. 13, 34; EuGH, Urteil vom 23.10.2012, verb. Rs. C-581/10 und C-629/10 (Nelson u.a.), Rn. 26; EuGH, Urteil vom 1.4.2008, Rs. C-267/06 (Maruko), Rn. 33; EuGH, Urteil vom 27.4.2006, Rs. C-423/04 (Richards), Rn. 19.

329 In diesem Sinne aber GA Sharpston, Schlussanträge vom 13.7.2006 in der Rs. C-290/05 (Nádasdi), Rn. 81, die es "grundsätzlich nicht für wünschenswert“ hielte (in der englischen Originalfassung "[...] I think it would be undesirable in principle”), eine Begrenzung der zeitlichen Wirkungen vorzunehmen, wenn dies lediglich ein anderer Mitgliedstaat beantragt hat. Dieser Aussage liegt allerdings ein Verständnis von der Begrenzung der zeitlichen Wirkungen zugrunde, wonach deren Voraussetzungen gerade in dem betroffenen Mitgliedstaat vorliegen müssen. Die Bedenken der Generalanwältin teilt Domahidi, EuZW 2007, 127 (128).

330 Dazu ausführlich unten bei Fn. $881 \mathrm{ff}$.

331 Siehe auch Rosenkranz, Beschränkung der Rückwirkung, 2015, S. 414. 
den vom Verfahren „unmittelbar“ betroffenen Mitgliedstaat zuzulassen als auch auf ihn selbst bezogenes Vorbringen zu berücksichtigen. ${ }^{332}$

Stellt ein Verfahrensbeteiligter einen „Antrag“ auf Begrenzung der zeitlichen Wirkungen, tut er dies in aller Regel für den Fall, dass der Gerichtshof die Vorlagefrage nicht in seinem Sinne beantwortet, also etwa für den Fall, dass der Gerichtshof einer Richtlinie eine „unmittelbare und uneingeschränkte Haftung“ entnehmen sollte. Gelangt der Gerichtshof zu dem Ergebnis, dass die Richtlinie keine solche Haftung vorsieht, ist der „Antrag“ hinfällig. Dass in diesem Fall „kein Anlass“ für eine zeitliche Begrenzung besteht, wird die Regel sein. ${ }^{333}$ Ein Automatismus in diesem Sinne besteht nach hier vertretener Auffassung allerdings nicht. Der Gerichtshof ist daher dazu aufgerufen, auch von den Verfahrensbeteiligten nicht in den Blick genommene Konsequenzen seiner Auslegung zu bedenken.

\section{Anwendung des Art. 264 II AEUV?}

Zu klären bleibt noch, ob sich der Gerichtshof für die Begrenzung der zeitlichen Wirkungen der Auslegung, die er nach dem vorstehend Gesagten von Amts wegen vornehmen kann und für die er ausschließlich zuständig ist, auf Art. 264 II AEUV stützen kann oder ob vielmehr eine andere Rechtsgrundlage heranzuziehen ist.

\section{a) Art. 264 II AEUV als Ausgangspunkt der Überlegungen}

Zumindest auf den ersten Blick nahe liegen könnte eine analoge Anwendung des Art. 264 II AEUV als im AEU-Vertrag vorgesehener Kompetenz-

332 Von GA Kokott, Schlussanträge vom 15.2.2007 in der Rs. C-178/05 (Kommission/Griechenland), Rn. 86 lediglich im Ergebnis wegen unzureichender Substantiierung abgelehnt.

$333 \mathrm{Zu}$ einem solchen Fall siehe etwa EuGH, Urteil vom 16.2.2017, Rs. C-219/15 (Schmitt/TÜV Rheinland), Rn. 61 ff. Siehe auch EuGH, Urteil vom 12.3.2019 (Tjebbes u.a.), Rn. 49, wo der Gerichtshof ausführt, angesichts der Antwort auf die Vorlagefrage brauche nicht über den „Antrag“ der niederländischen Regierung entschieden zu werden. Dass der „Antrag“ nur für den Fall gestellt worden ist, dass der Gerichtshof das Unionsrecht in einem bestimmten Sinne auslegt, führt dieser auch in EuGH, Urteil vom 11.11.2020, Rs. C-287/19 (DenizBank), Rn. 109 an. 
zuweisung an den Gerichtshof zur Modifikation der Wirkungen seiner Rechtsprechung in zeitlicher Hinsicht. ${ }^{334}$

Bei der Nichtigkeitsklage eröffnet Art. 264 II AEUV dem Gerichtshof die Möglichkeit, diejenigen Wirkungen der für nichtig erklärten Handlung $\mathrm{zu}$ bezeichnen, die als fortgeltend zu betrachten sind. Damit besteht hier eine ausdrückliche Befugnis des EuGH zur Bestimmung der Folgen der Nichtigerklärung.

Bei oberflächlicher Betrachtung erschiene zunächst auch ein Verständnis des Art. 264 II AEUV denkbar, wonach dieser lediglich die Aufrechterhaltung der Wirkungen der rechtmäßigen (und von einer rechtswidrigen Bestimmung abtrennbaren) Bestimmungen der für nichtig erklärten Handlung ermögliche. Die Fortgeltung der Wirkungen einer rechtmäßigen Bestimmung bedarf aber bereits keiner gesonderten Anordnung. Ist eine Bestimmung rechtmäßig und auch ohne den rechtswidrigen Teil sinnvoll, ist vielmehr von einer Nichtigerklärung abzusehen. ${ }^{335}$ Art. 264 II AEUV gestattet daher die Aufrechterhaltung der Wirkungen rechtswidriger Bestimmungen. Der Gerichtshof erkennt in Art. 264 II AEUV deshalb zu Recht nicht nur eine Regelung der Teilnichtigkeit; vielmehr misst er ihr zutreffend Bedeutung auch für die Frage der zeitlichen Dimension der Nichtigkeit bei. ${ }^{336}$

Im Gegensatz zum früheren Art. 231 II EGV verwendet Art. 264 II AEUV den Begriff „Handlung“ und nicht mehr „Verordnung“. Gemeint ist damit jeder statthafte Klagegegenstand der Nichtigkeitsklage; für einen Ausschluss der in Art. 263 I AEUV neben den Handlungen gesondert aufgeführten Gesetzgebungsakte sind keine Gründe ersichtlich. ${ }^{337}$ Eine nach Normen und sonstigen Rechtsakten differenzierende Systematik lässt sich daher für das Unionsrecht nicht nachweisen. Art. 264 II AEUV gestattet dem Gerichtshof für sämtliche unionale Handlungen eine Modifikation der zeitlichen Wirkungen des Nichtigkeitsurteils.

334 Für eine Analogie sprechen sich Schmitz/Stammler, AöR 136 (2011), 479 (496) ebenso aus wie Sellmann/Augsberg, DÖV 2006, 533 (537) und Bydlinski, JBl. 2001, 2 (24f.).

335 Ebenso Gleiss/Kleinmann, NJW 1966, 1591 (1591f.).

336 EuGH, Urteil vom 5.6.1973, Rs. 81/72 (Kommission/Rat), Rn. 15: „[...] ist Artikel 174 Absatz 2 des Vertrages [heute Art. 264 II AEUV, Anm. des Verfassers] dahin anzuwenden, daß die für nichtig erklärten Artikel weiterhin ihre Wirkungen erzeugen, bis [...].“ Zustimmend auch Rosenkranz, Beschränkung der Rückwirkung, 2015, S. 113.

337 Dörr, in: Grabitz/Hilf/Nettesheim (Hrsg.), Recht der EU, Art. 264 AEUV, Rn. 12 (Stand: November 2012). 
Durch die Ausweitung wird die Rechtsprechung des EuGH nachvollzogen, der Art. 231 II EGV bereits vor der Änderung durch den Vertrag von Lissabon analog auf andere Rechtsakte als Verordnungen angewandt hatte. ${ }^{338}$ Das Bedürfnis nach einer analogen Anwendung des Art. 264 II AEUV besteht demnach insoweit nicht mehr. ${ }^{339}$

Einer analogen Anwendung bedürfte es dagegen bei einer Übertragung auf das Vorabentscheidungsverfahren. Bevor eine Heranziehung des Art. 264 II AEUV im Rahmen der Auslegungsvorabentscheidung in den Blick genommen wird, ist zunächst zu klären, ob dies für die mit der Nichtigkeitsklage in engem Zusammenhang stehende Ungültigkeitsvorabentscheidung in Betracht kommt. Auf diesem Weg können die für eine Fruchtbarmachung von Art. 264 II AEUV relevanten Gesichtspunkte herausgearbeitet werden.

b) Analoge Anwendung auf die Ungültigkeitsvorabentscheidung

Im Ausgangspunkt ist festzustellen, dass sich Art. 267 I AEUV nicht zu den Folgen einer im Vorabentscheidungsverfahren ergangenen Ungültigkeitserklärung äußert. ${ }^{340}$

aa) Rechtsprechung des Gerichtshofs

Zur Füllung dieser Lücke kommt bei vergleichbarer Interessenlage eine Analogie zu Art.264 II AEUV in Frage, die der EuGH zunächst auch ausdrücklich annahm. ${ }^{341}$ Auch wenn dies zum Teil anders gesehen wird, kann einer Analogie zu Art. 264 II AEUV nicht mit dem Argument entgegengetreten werden, dass sich Art. 264 II AEUV seinem Wortlaut und seiner systematischen Stellung entsprechend nur auf die Nichtigkeitsklage

338 Näher Müller, Begrenzung, 2009, S. 28 ff.

339 In diesem Sinne auch Ehricke, in: Streinz (Hrsg.), EUV/AEUV, 3. Aufl. 2018, Art. 264 AEUV, Rn. 10; Schwarze/Voet van Vormizeele, in: Schwarze/Becker/Hatje/Schoo (Hrsg.), EU-Kommentar, 4. Aufl. 2019, Art. 264 AEUV, Rn. 10.

340 Dies konstatiert auch der EuGH, Urteil vom 15.10.1980, Rs. 4/79 (Providence agricole de la Champagne), Rn. 44; EuGH, Urteil vom 15.10.1980, Rs. 109/79 (Maïseries de Beauce), Rn. 44; EuGH, Urteil vom 15.10.1980, Rs. 145/79 (Roquette Frères), Rn. 51.

341 Siehe die in Fn. 340 zitierten Urteile des Gerichtshofs Rs.4/79, Rn.45; Rs. 109/79, Rn. 45; Rs. 145/79, Rn. 52. 
beziehe und es sich dabei um eine Bestimmung handele, die eine Abweichung vom Grundsatz der ex tunc-Wirkung ermögliche und daher eng auszulegen (und nicht analogiefähig) sei. ${ }^{342}$ Eine solche Argumentation verkennt, dass die entsprechende Anwendung einer Ausnahmevorschrift nicht bereits aufgrund ihres Ausnahmecharakters ausgeschlossen ist, sondern dass es entscheidend darauf ankommt, ob die von ihr bereitgehaltene Lösung auch für das Parallelproblem als geeignet erscheint. ${ }^{343}$

Dennoch erklärte der Gerichtshof die Befugnis zur zeitlichen Begrenzung der Ungültigerklärung vor dem Hintergrund dieser an ihm insbesondere in Frankreich geübten Kritik eine Zeit lang nicht mehr ausdrücklich mit einer Analogie, sondern mit einer „Auslegung“ des damaligen Art. 174 EWG-Vertrag, „die die notwendige Kohärenz zwischen der Vorlage zur Vorabentscheidung und der in den Artikeln 173, 174 und 176 EWG-Vertrag geregelten Nichtigkeitsklage - zwei vom Vertrag vorgesehenen Arten der Rechtmäßigkeitskontrolle - berücksichtigt" ${ }^{344}$ Der einer Analogie zugrundeliegende Rechtsgedanke - die vergleichbare Interessenlage - blieb hierbei aber unverkennbar. Sie besteht insbesondere darin, dass bei beiden Verfahren Vorschriften des Unionsrechts auf ihre Vereinbarkeit mit höherrangigem Unionsrecht überprüft werden. ${ }^{345}$

In seiner neueren Rechtsprechung bezeichnet der Gerichtshof die entsprechende Anwendung des Art.264 II AEUV folgerichtig auch wieder ausdrücklich als solche. ${ }^{346}$ Damit wendet er zwar eine Bestimmung analog an, die seine eigenen Befugnisse betrifft, sodass er sich gewissermaßen selbst eine Kompetenz zuspricht, die die Verträge ihm nicht ausdrücklich gewähren. Zur Gewährleistung der Kohärenz zwischen beiden Verfahren bestehen hiergegen aber keine Bedenken. ${ }^{347}$

342 Vgl. Simon, in: Liber Amicorum Pescatore, 1987, S. 651 (660 f.).

343 Kritisch insoweit auch Ludewig, Zeitliche Beschränkung, 2012, S. 99.

344 EuGH, Urteil vom 27.2.1985, Rs. 112/83 (Société des produits de maïs), Rn. 17; siehe auch EuGH, Urteil vom 22.5.1985, Rs. 33/84 (Fragd), Rn. 17; EuGH, Urteil vom 26.4.1994, Rs. C-228/92 (Roquette Frères), Rn. 19; EuGH, Urteil vom 8.2.1996, Rs. C-212/94 (FMC u.a.), Rn. 56.

345 Darauf weist auch Weiß, EuR 1995, 377 (379ff.) hin.

346 Siehe nur EuGH, Urteil vom 6.11.2014, Rs. C-335/13 (Feakins), Rn. 65; EuGH, Urteil vom 28.4.2016, verb. Rs. C-191/14, C-192/14, C-295/14, C-389/14 und C-391/14 bis C-393/14 (Borealis Polyolefine u.a.), Rn. 103; EuGH, Urteil vom 9.11.2010, verb. Rs. C-92/09 und C-93/09 (Volker und Markus Schecke und Eifert), Rn.93; EuGH, Urteil vom 22.12.2008, Rs. C-333/07 (Régie Networks), Rn. 121; EuGH, Urteil vom 9.2.2017, Rs. C-585/15 (Raffinerie Tirlemontoise), Rn. 37.

347 Masclet, RTDEur. 1986, 161 (171 ff.). 
Dass hinter Art. 264 II AEUV der Gedanke der Rechtssicherheit steht ${ }^{348}$, hindert die analoge Anwendung von Art. 264 II AEUV nicht. Ein allgemeiner Rechtsgrundsatz wie derjenige der Rechtssicherheit ist weniger greifbar und verbleibt zunächst im Abstrakten. Existiert wie mit Art. 264 II AEUV eine Vorschrift, in der sich dieser allgemeine Rechtsgrundsatz niedergeschlagen hat, erscheint es vorzugswürdig, diese Regelung zur Anwendung zu bringen und nicht lediglich den dahinter stehenden Rechtsgrundsatz heranzuziehen. ${ }^{349}$ Wenn der Gerichtshof allerdings auf der Grundlage von Art. 264 II AEUV das Vorliegen zwingender Erwägungen der Rechtssicherheit verlangt, die mit allen betroffenen öffentlichen wie privaten Interessen zusammenhängen ${ }^{350}$ oder auch das Vorliegen gewichtiger/wichtiger Gründe der Rechtssicherheit ${ }^{351}$, zeigt sich, dass Art.264 II AEUV keine weitreichende Konkretisierung des Grundsatzes vornimmt, sondern selbst im Abstrakten verbleibt und dem Gerichtshof auf diese Weise großen Spielraum belässt.

bb) Kein Entgegenstehen der Unterschiede

Eine Übertragbarkeit des Art. 264 II AEUV auf die Ungültigkeitsvorabentscheidung scheitert zuletzt auch nicht an den zwischen Nichtigkeit und Ungültigkeit bestehenden Unterschieden.

348 Siehe etwa EuGH, Urteil vom 5.9.2012, Rs. C-355/10 (Parlament/Rat), Rn.90, wo es heißt, es bestünden wichtige Gründe der Rechtssicherheit, die es rechtfertigten, dass der Gerichtshof die ihm in Art. 264 II AEUV verliehene Befugnis ausübe. Siehe auch EuGH, Urteil vom 17.3.2016, Rs. C-286/14 (Parlament/Kommission), Rn. 70, wonach gewichtige Gründe der Rechtssicherheit die Aufrechterhaltung der Wirkungen rechtfertigten. Allgemeiner formuliert etwa EuGH, Urteil vom 28.7.2016, Rs. C-660/13 (Rat/Kommission), Rn. 51, dass Wirkungen aus Gründen der Rechtssicherheit aufrechterhalten werden können. Siehe auch Waldhoff, EuR 2006, 615 (630).

349 Bydlinski, JBl. 2001, 2 (24); Kovács, Temporale Wirkung, 2014, S. 227; Rosenkranz, Beschränkung der Rückwirkung, 2015, S. 117. Seer/Müller, IWB 2008, 255 (260) meinen, bei der Prüfung unionsrechtlicher Normen möge Art. 264 II AEUV seinen Platz haben.

350 EuGH, Urteil vom 15.1.1986, Rs. 41/84 (Pinna), Rn. 28 für die Ungültigkeitsvorlage.

351 EuGH, Urteil vom 17.3.2016, Rs. C-286/14 (Parlament/Kommission), Rn. 70 und EuGH, Urteil vom 5.9.2012, Rs. C-355/10 (Parlament/Rat), Rn. 90 für die Nichtigkeitsklage. 
Die Nichtigerklärung wirkt grundsätzlich für und gegen alle und damit erga omnes. ${ }^{352}$ Das ist gemeint, wenn der EuGH von absoluter Rechtskraft $^{353}$ bzw. absoluter Bindungswirkung ${ }^{354}$ des Nichtigkeitsurteils spricht. Folge der Nichtigerklärung ist, dass die Bestimmungen des aufgehobenen Rechtsakts nicht mehr angewandt werden dürfen. ${ }^{355}$ Anerkannt ist dies jedenfalls für Unionsrechtsakte mit allgemeiner Geltung. 356

Unmittelbarer Adressat eines Urteils des Gerichtshofs im Vorabentscheidungsverfahren zur Überprüfung der Gültigkeit eines Unionsrechtsakts ist dagegen das vorlegende Gericht. ${ }^{357}$ Dieses ist bei der Entscheidung des Ausgangsrechtsstreits an das Urteil des Gerichtshofs ebenso gebunden 358 wie die mit dem Ausgangsrechtsstreit gegebenenfalls befassten weiteren ${ }^{359}$

352 Dies entspricht ständiger Rechtsprechung, vgl. nur EuGH, Urteil vom 1.6.2006, verb. Rs. C-442/03 P und C-471/03 P (P \& O European Ferries [Vizcaya] und Diputación Foral de Vizcaya/Kommission), Rn. 43 und EuGH, Urteil vom 12.2.2008, Rs. C-199/06 (CELF und Ministre de la Culture et de la Communication), Rn. 61.

353 EuGH, Urteil vom 1.6.2006, verb. Rs. C-442/03 P und C-471/03 P (P \& O European Ferries [Vizcaya] und Diputación Foral de Vizcaya/Kommission), Rn. 43.

354 EuGH, Urteil vom 14.9.1999, Rs. C-310/97 P (Kommission/AssiDomän Kraft Products u.a.), Rn. 54.

355 Cremer, in: Calliess/Ruffert (Hrsg.), EUV/AEUV, 5. Aufl. 2016, Art. 264 AEUV, Rn. 2.

356 Siehe nur Dörr, in: Grabitz/Hilf/Nettesheim (Hrsg.), Recht der EU, Art. 264 AEUV, Rn. 7 (Stand: November 2012); Gaitanides, in: von der Groeben/Schwarze/Hatje (Hrsg.), Unionsrecht, 7. Aufl. 2015, Art. 264 AEUV, Rn. 3. Dementsprechend wird auch für allgemeine Beschlüsse nach Art. 288 IV 1 AEUV eine erga omnes-Wirkung der Nichtigerklärung befürwortet, Frenz, Handbuch Europarecht, Band 5, 2010, Rn. 2864. Zur umstrittenen Frage der Wirkungen des Nichtigkeitsurteils bei adressatenbezogenen Beschlüssen siehe sowohl Cremer, in: Calliess/Ruffert (Hrsg.), EUV/AEUV, 5. Aufl. 2016, Art. 264 AEUV, Rn. 2 als auch Ehricke, in: Streinz (Hrsg.), EUV/AEUV, 3. Aufl. 2018, Art. 264 AEUV, Rn. 3; Gaitanides, in: von der Groeben/Schwarze/Hatje (Hrsg.), Unionsrecht, 7. Aufl. 2015, Art. 264 AEUV, Rn. 3; Frenz, Handbuch Europarecht, Band 5, 2010, Rn. $2863 \mathrm{f}$.

357 Siehe nur EuGH, Urteil vom 13.5.1981, Rs. 66/80 (International Chemical Corporation), Rn. 13.

358 EuGH, Beschluss vom 5.3.1986, Rs. 69/85 (Wünsche), Rn. 13.

$359 \mathrm{Zu}$ denken ist hier neben den Rechtsmittelgerichten auch an Instanzgerichte, an die der Rechtsstreit nach der Vorlage eines Rechtsmittelgerichts zurückverwiesen wurde oder an Hauptsachegerichte bei einer Vorlage im Verfahren des einstweiligen Rechtsschutzes, vgl. Weth/Kerwer, in: Oetker/Preis/Rieble (Hrsg.), 50 Jahre Bundesarbeitsgericht, 2004, S. 1383 (1386). 
Gerichte. ${ }^{360}$ Während diese Bindungswirkung innerhalb des Ausgangsverfahrens allgemeiner Auffassung entspricht, ist auch eine über dieses Verfahren hinausgehende Bindungswirkung weitgehend anerkannt; in ihrer Herleitung bestehen aber entscheidende Unterschiede. ${ }^{361}$

Im Hinblick auf Ungültigkeitsvorlagen spricht der Gerichtshof davon, dass die Feststellung der Ungültigkeit einer unionalen Handlung für jedes andere Gericht „einen ausreichenden Grund dafür dar[stellt], diese Handlung bei den von ihm zu erlassenden Entscheidungen als ungültig anzusehen“. ${ }^{62}$ Zur Nichtanwendung der vom EuGH für ungültig erklärten Vorschrift sind die nationalen Gerichte allerdings nicht nur berechtigt, son-

360 Ehricke, in: Streinz (Hrsg.), EUV/AEUV, 3. Aufl. 2018, Art. 267 AEUV, Rn. 68; Wegener, in: Calliess/Ruffert (Hrsg.), EUV/AEUV, 5. Aufl. 2016, Art. 267 AEUV, Rn. 49; Gaitanides, in: von der Groeben/Schwarze/Hatje (Hrsg.), Unionsrecht, 7. Aufl. 2015, Art. 267 AEUV, Rn. 89; Karpenstein, in: Grabitz/Hilf/Nettesheim (Hrsg.), Recht der EU, Art. 267 AEUV, Rn. 102 (Stand: Mai 2013); Althammer, in: Gsell/Hau (Hrsg.), Zivilgerichtsbarkeit, 2012, S. 37 (40); Weth/Kerwer, in: Oetker/Preis/Rieble (Hrsg.), 50 Jahre Bundesarbeitsgericht, 2004, S. 1383 (1385). Die zur Bestätigung dieser Aussage herangezogene Passage des Urteils des EuGH vom 24.6.1969, Rs. 29/68 (Milch-, Fett- und Eierkontor), Rn. 2 f. bezieht sich zwar nur auf die Auslegungsvorabentscheidung. Gründe für eine abweichende Beurteilung dieser Frage bei der Ungültigkeitsvorabentscheidung sind aber nicht ersichtlich. Dies entspricht auch der Rechtsprechung des Bundesverfassungsgerichts, das in BVerfG, Beschluss vom 8.4.1987, 2 BvR 687/85 - BVerfGE 75, 223 (234) auf die abschließende Entscheidungsbefugnis des Gerichtshofs in allen Fällen des Art. 267 AEUV verweist und daher eine Bindung aller mit dem Ausgangsverfahren befassten mitgliedstaatlichen Gerichte annimmt.

361 Zur Frage der Bindungswirkung außerhalb des Ausgangsverfahrens bei einer Auslegungsvorabentscheidung siehe näher oben bei Fn. $80 \mathrm{ff}$. und bei einer Auslegung im Rahmen anderer Verfahren bei Fn. $165 \mathrm{ff}$.

362 EuGH, Urteil vom 13.5.1981, Rs. 66/80 (International Chemical Corporation), Rn. 13; in Bezug genommen von EuGH, Beschluss vom 8.11.2007, Rs. C-421/06 (Fratelli Martini und Cargill), Rn. 54. 
dern verpflichtet. ${ }^{363}$ Die zurückhaltende Formulierung des Gerichtshofs ${ }^{364}$ ist der Tatsache geschuldet, dass er bei der Ungültigkeitsvorlage anders als bei der Nichtigkeitsklage nicht zur Nichtigerklärung eines Rechtsakts befugt ist. ${ }^{365}$

Indem er anerkennt, dass der Rechtsakt trotz Feststellung seiner Ungültigkeit weiterhin existiert - nur wenn es ihn rechtlich noch gibt, kann ein Rechtsakt als ungültig angesehen werden - achtet der Gerichtshof einerseits die im AEU-Vertrag angelegte Unterscheidung zwischen Nichtigkeitsklage und Ungültigkeitsvorabentscheidung. Andererseits erreicht der Gerichtshof durch seine Formulierung eine weitgehende Annäherung der Urteilswirkungen der Ungültigkeitsvorabentscheidung an diejenigen des Nichtigkeitsurteils.

Diese Ausweitung der Reichweite des Ungültigkeitsurteils wird teilweise mit der Ähnlichkeit zum Nichtigkeitsurteil begründet. ${ }^{366}$ Ebenfalls an eine Parallele zum Nichtigkeitsurteil erinnert die Rede von einer uneingeschränkten erga omnes-Wirkung. ${ }^{367}$ Etwas zurückhaltender wird auch geltend gemacht, die Bindungswirkung der Ungültigerklärung komme einer erga omnes-Wirkung im Ergebnis gleich. ${ }^{368}$

Richtigerweise sind die Bindungswirkung von Nichtigkeits- und Ungültigkeitsurteil voneinander zu unterscheiden. Diese Unterscheidung findet auch in der Rechtsprechung des Gerichtshofs eine Stütze, wenngleich zuzugeben ist, dass dieser geneigt scheint, die Wirkung der Ungültigerklärung derjenigen der Nichtigerklärung noch weiter als bisher anzunähern. In Richtung einer weitgehenden Gleichsetzung mit den Wirkungen eines

363 Rosenkranz, Beschränkung der Rückwirkung, 2015, S. 23 f. mit Fn. 64 unter Bezugnahme auf EuG, Beschluss vom 5.2.2007, Rs. T-91/05 (Sinara Handel/Rat und Kommission), Rn.65. Das EuG spricht darin ausdrücklich von der Verpflichtung der mitgliedstaatlichen Gerichte, nach der Feststellung der Unwirksamkeit durch den Gerichtshof den Rechtsakt als ungültig anzusehen und zitiert EuGH, Urteil vom 13.5.1981, Rs. 66/80 (International Chemical Corporation), Rn. 12 f. Ebenso Karpenstein, in: Grabitz/Hilf/Nettesheim (Hrsg.), Recht der EU, Art. 267 AEUV, Rn. 107 (Stand: Mai 2013); Frenz, Handbuch Europarecht, Band 5, 2010, Rn. 3403. Siehe auch Germelmann, EuR 2009, 254 (263).

364 Althammer, in: Gsell/Hau (Hrsg.), Zivilgerichtsbarkeit, 2012, S. 37 (43) spricht von einer salomonischen Wendung.

365 Diese Beschränkung für sich ausdrücklich anerkennend EuGH, Urteil vom 1.12.1965, Rs. 16/65 (Schwarze), Slg. 1965, S. 1165.

366 In diese Richtung $H e \beta$, ZZP 108 (1995), 59 (69).

367 Karpenstein, in: Grabitz/Hilf/Nettesheim (Hrsg.), Recht der EU, Art. 267 AEUV, Rn. 107 (Stand: Mai 2013).

368 Kovács, Temporale Wirkung, 2014, S. 87. 
Nichtigkeitsurteils lässt sich etwa die Aussage des Gerichtshofs deuten, wonach eine Anpassung der Rechtslage durch die Unionsorgane im Anschluss an die Vorabentscheidung den Urteilsinhalt lediglich formell in die Unionsrechtsordnung umsetze. ${ }^{369}$

Dieser Überlegung ist zwar insofern zuzustimmen, als der Unionsgesetzgeber nicht dazu befugt sein kann, etwa die zeitlichen Wirkungen der Ungültigerklärung nach seinem Belieben hinauszuschieben. Angesichts der zwischen Nichtigkeitsklage und Ungültigkeitsvorabentscheidung bestehenden Unterschiede sollte aber keine Gleichsetzung erfolgen. Dass auch der Gerichtshof eine solche letztlich nicht vornimmt, zeigt sich daran, dass er in der Rechtssache Fratelli Martini und Cargill neben der im vorangehenden Absatz wiedergegebenen Aussage auch seine bereits oben $^{370}$ erwähnte zurückhaltende Formulierung anführt, in der er den Unterschied zur Nichtigkeitsklage anerkennt. ${ }^{371}$

Die über das Ausgangsverfahren hinausgehende Bindung folgt also bei der Ungültigkeitsvorabentscheidung anders als bei der Nichtigkeitsklage nicht aus dem Urteil selbst, da dieses den Rechtsakt gerade nicht aus der Unionsrechtsordnung entfernt. ${ }^{372}$ Eine rechtliche Bindung bewirkt vielmehr der Anwendungsbefehl der höherrangigen Norm des Unionsrechts, an dem der für ungültig erklärte Rechtsakt gemessen wurde. Er verlangt, dass dieser Rechtsakt nicht weiter zur Anwendung kommt. ${ }^{373}$ Eines Rückgriffs auf die Erfordernisse der Rechtssicherheit und einer einheitlichen Anwendung des Unionsrechts, wie sie das Vorabentscheidungsverfahren in der Tat prägen, bedarf es daher nicht. ${ }^{374}$

Obwohl eine Ungültigerklärung den Rechtsakt nicht aus der Unionsrechtsordnung entfernt, darf er also nicht mehr zur Anwendung kommen. Trotz Unterschieden in der Herleitung führt die Ungültigkeitsvorabentscheidung damit insoweit zum selben Ergebnis wie die Nichtigkeitsklage.

369 EuGH, Beschluss vom 8.11.2007, Rs. C-421/06 (Fratelli Martini und Cargill), Rn. 57.

370 Vgl. oben bei Fn. 362.

371 EuGH, Beschluss vom 8.11.2007, Rs. C-421/06 (Fratelli Martini und Cargill), Rn. 54.

372 Germelmann, EuR 2009, 254 (264).

373 Ähnlich Germelmann, EuR 2009, 254 (264, 265 f.), der die Bindungswirkung allerdings zudem mit der „Präjudizienwirkung“ der Entscheidung begründet. Dieser zusätzlichen Abstützung bedarf es nach hier vertretener Ansicht nicht.

374 So Ehricke, in: Streinz (Hrsg.), EUV/AEUV, 3. Aufl. 2018, Art. 267 AEUV, Rn. 70. 
Vor diesem Hintergrund liegt trotz der erwähnten Unterschiede auch eine analoge Anwendung des Art. 264 II AEUV auf die Ungültigkeitsvorabentscheidung nahe. Die Rechtsfolge des Art. 264 II AEUV besteht in der Fortgeltung der Wirkungen des überprüften Rechtsakts. Diese setzt begrifflich keine Nichtigerklärung voraus und passt auch zu einer Ungültigerklärung. ${ }^{375} \mathrm{Da}$ bei einer Ungültigerklärung der in Rede stehende Rechtsakt nicht aus der Unionsrechtsordnung entfernt wird, sondern diese lediglich einen ausreichenden Grund darstellt, den Rechtsakt nicht anzuwenden, bietet sich zwar eine von den Nichtigkeitsurteilen abweichende Tenorierung an; eine analoge Anwendung des Art. 264 II AEUV auf die Ungültigkeitsvorabentscheidung hindert dies aber nicht. ${ }^{376}$

Wie die analoge Anwendung des Art. 264 II AEUV bereits vermuten lässt, erfolgt auch für die Frage der zeitlichen Wirkung einer Ungültigerklärung eine Gleichbehandlung mit der Nichtigerklärung. In ständiger Rechtsprechung vertritt der Gerichtshof eine ex tunc-Wirkung sowohl des Nichtigkeitsurteils ${ }^{377}$ „ebenso wie“ der Ungültigkeitsfeststellung im Rahmen des Vorabentscheidungsverfahrens. ${ }^{378}$ Dies ist konsequent, da die höherrangige Norm nach Durchsetzung unabhängig von der Verfahrensart verlangt. Obwohl der EuGH die Ungültigkeitsvorabentscheidung dem-

375 Germelmann, EuR 2009, 254 (261 mit Fn. 31).

376 Auf die unterschiedliche, sich auf das praktische Ergebnis aber nicht auswirkende Tenorierungspraxis verweist auch Müller, Begrenzung, 2009, S. 44. Siehe auch Rosenkranz, Beschränkung der Rückwirkung, 2015, S. 308.

377 EuGH, Urteil vom 26.4.1988, verb. Rs. 97/86, 99/86, 193/86 und 215/86 (Asteris u.a./Kommission), Rn. 30; EuGH, Urteil vom 1.6.2006, verb. Rs. C-442/03 P und C-471/03 P (P \& O European Ferries [Vizcaya] und Diputación Foral de Vizcaya/Kommission), Rn. 43; EuGH, Urteil vom 12.2.2008, Rs. C-199/06 (CELF und Ministre de la Culture et de la Communication), Rn. $61 \mathrm{ff}$. Siehe auch EuG, Urteil vom 23.10.2008, Rs. T-256/07 (People's Mojahedin Organization of Iran/Rat), Rn. 64; EuG, Urteil vom 21.5.2010, verb. Rs. T-425/04, T-444/04, T-450/04 und T-456/04 (Frankreich u.a./Kommission), Rn. 329. Ebenso die einhellige Auffassung in der Literatur, siehe nur Dörr, in: Grabitz/Hilf/Nettesheim (Hrsg.), Recht der EU, Art. 264 AEUV, Rn. 10 (Stand: November 2012); Cremer, in: Calliess/Ruffert (Hrsg.), EUV/AEUV, 5. Aufl. 2016, Art. 264 AEUV, Rn. 3 mit Fn. 11 unter Bezugnahme auf den Wortlaut der französischen Fassung des Art. 264 I AEUV („nul et non avenu“); Gaitanides, in: von der Groeben/Schwarze/Hatje (Hrsg.), Unionsrecht, 7. Aufl. 2015, Art. 264 AEUV, Rn. 5; Ehricke, in: Streinz (Hrsg.), EUV/AEUV, 3. Aufl. 2018, Art. 264 AEUV, Rn. 5.

378 EuGH, Urteil vom 26.4.1994, Rs. C-228/92 (Roquette Frères), Rn. 17: „Ein Urteil des Gerichtshofes, mit dem im Vorabentscheidungsverfahren eine Gemeinschaftshandlung für ungültig erklärt wird, besitzt grundsätzlich ebenso wie ein Nichtigkeitsurteil Rückwirkung." Ebenso EuGH, Urteil vom 8.2.1996, Rs. C-212/94 (FMC u.a.), Rn. 55. 
nach „ebenso wie“ die Nichtigkeitsklage behandelt, stützt er sich dabei nicht auf eine Analogie zu Art. 264 I AEUV, wonach der Gerichtshof der Europäischen Union die angefochtene Handlung für nichtig erklärt, wenn die Klage begründet ist. Angesichts der Unterschiede der beiden Verfahren - Nichtigkeit als Folge der erfolgreichen Nichtigkeitsklage und Ungültigkeit als Folge der Ungültigkeitsvorabentscheidung - muss eine solche Analogie auch ausscheiden; Art. 264 I AEUV ist insoweit nicht analogiefähig. ${ }^{379}$ An einer Gleichbehandlung im Ergebnis - ex tunc-Wirkung sowohl des Nichtigkeitsurteils als auch der Ungültigkeitsfeststellung - hindert Art. 264 I AEUV den EuGH aber nicht.

Die vorstehenden Überlegungen haben zweierlei gezeigt: Zum einen scheidet eine analoge Anwendung des Art. 264 II AEUV nicht aufgrund seines Ausnahmecharakters aus. Zum anderen scheitert eine analoge Anwendung des Art.264 II AEUV auch nicht an den zwischen beiden Verfahrensarten bestehenden Unterschieden. Begründet ist dies in der vergleichbaren Interessenlage bei Nichtigkeitsklage und Ungültigkeitsvorabentscheidung. Für die Annahme einer vergleichbaren Interessenlage hat sich das unionsinterne Kollidieren zweier Normen des Unionsrechts als ausschlaggebend herausgestellt.

\section{c) Keine analoge Anwendung auf die Auslegungsvorabentscheidung}

Bei der Auslegungsvorabentscheidung ist eine solche Vergleichbarkeit mit der Nichtigkeitsklage nicht gegeben. Der Gerichtshof bestimmt hier lediglich den Inhalt einer Vorschrift des Unionsrechts und befasst sich nicht mit der unionsinternen Kollision zweier Normen. Dass sich die Auslegung des Unionsrechts durch den EuGH auf mitgliedstaatliche Bestimmungen auswirkt, denen diese Auslegung entgegensteht, kann zwar nicht bezweifelt werden; über den Anwendungsvorrang kann dies sogar zur Nichtanwendbarkeit des mitgliedstaatlichen Rechts in unionsrechtlichen Fallgestaltungen führen. ${ }^{380}$ Für nichtig oder ungültig wird dieses allerdings nicht

379 Darauf weist Germelmann, EuR 2009, 254 (261, Fn. 31) zutreffend hin. Auch Kovács, Temporale Wirkung, 2014, S. 200 f. versteht die Aussage des EuGH nicht im Sinne einer Analogiebildung.

380 Insoweit ist in der Literatur von einem „Unanwendbarkeitsausspruch“ des EuGH die Rede, vgl. Tillmanns, in: FS Buchner, 2009, S. 885 (895 und 887). Siehe auch Tavakoli/Westhauser, DB 2008, 702 (704). Sagan, Jahrbuch Junger Zivilrechtswissenschaftler 2010, 67 (93) sieht zwischen einer förmlichen Nichtigerklärung und einem Ausspruch der Unanwendbarkeit de facto keinen er- 
erklärt. Dafür fehlt dem Gerichtshof die Kompetenz; eine solche setzt aber Art. 264 II AEUV gerade voraus. ${ }^{381}$

Eine Analogie zu Art. 264 II AEUV vermögen entgegen des ersten Eindrucks auch die in der Rechtssache Skoma-Lux gemachten Ausführungen nicht zu begründen. In diesem Verfahren stand die unterbliebene Veröffentlichung eines vor dem Beitritt der Tschechischen Republik zur EU erlassenen Unionsrechtsakts in tschechischer Sprache als Amtssprache eines 2004 neu beigetretenen Mitgliedstaats im Mittelpunkt. Die unterbliebene Veröffentlichung in einer Amtssprache führt nach Ansicht des EuGH aber weder in dem betroffenen Mitgliedstaat noch in den anderen Mitgliedstaaten zur Ungültigkeit des Unionsrechtsakts; die in ihm vorgesehenen Verpflichtungen sind lediglich gegenüber dem Einzelnen im betroffenen Mitgliedstaat nicht anwendbar. ${ }^{382}$ Bei der Feststellung der Unanwendbarkeit dem Einzelnen gegenüber handelt es sich nach der Auffassung des EuGH dementsprechend um eine Auslegung des Unionsrechts und nicht um eine Entscheidung über dessen Gültigkeit. ${ }^{383}$

Dennoch wendet der EuGH hinsichtlich der Begrenzung der zeitlichen Wirkungen Art. 264 II AEUV an. Art. 264 II AEUV gestatte, so der Gerichtshof, die Aufrechterhaltung von Wirkungen im Falle der Nichtigerklärung. Dies müsse dann erst recht für die Unanwendbarkeit gelten. ${ }^{384}$

Auffällig ist zunächst, dass der Gerichtshof im Rahmen der Anwendung des Art. 264 II AEUV in Skoma-Lux auf die nationalen Entscheidungen Bezug nimmt, die auf dem dem Einzelnen gegenüber unanwendbaren Unionsrechtsakt beruhen. Insoweit erscheint es naheliegend, in der Entscheidung des EuGH eine Erläuterung zur Bestands- und Rechtskraft nationaler behördlicher und gerichtlicher Entscheidungen und ihrer Grenzen zu erblicken. ${ }^{385}$ Nicht übersehen werden darf aber die Heranziehung des Art. 264 II AEUV. Die vom EuGH gewählte Formulierung ist daher

kennbaren Unterschied. Auch Osterloh, in: FS Hassemer, 2010, S. 173 (180) und Bydlinski, JBl. 2001, 2 (24) nehmen eine Vergleichbarkeit der Problemstellung an.

381 Kovács, Temporale Wirkung, 2014, S. 142.

382 EuGH, Urteil vom 11.12.2007, Rs. C-161/06 (Skoma-Lux), Rn. 51, 58 f.

383 EuGH, Urteil vom 11.12.2007, Rs. C-161/06 (Skoma-Lux), Tenor Nr. 2 und Rn.61, Rn. 60 i.V.m. Rn. 57: Der EuGH bezieht sich auf eine gemeinsame Auslegung der Art. 254 II 1 EG-Vertrag, Art. 2 und 58 der Beitrittsakte und Art. 4 und 5 der Verordnung Nr. 1 des Rates zur Regelung der Sprachenfrage vom 15.4.1958 in der durch die Beitrittsakte geänderten Fassung.

384 EuGH, Urteil vom 11.12.2007, Rs. C-161/06 (Skoma-Lux), Rn. 70 f. Von einem Erst-recht-Schluss geht auch Küpper, JOR 2008, 147 (156) aus.

385 In diesem Sinne Rosenkranz, Beschränkung der Rückwirkung, 2015, S. 123. 
trotz der Bezugnahme auf die nationalen Entscheidungen dahin zu verstehen, dass Anknüpfungspunkt für die Aufrechterhaltung der Wirkungen der unanwendbare unionsrechtliche Rechtsakt bleibt, der insoweit weiterhin Wirkungen entfaltet, als er als Grundlage für die auf ihm beruhenden nationalen Entscheidungen dient. Eine solche Perspektive entspricht der Konzeption des Art. 264 II AEUV. ${ }^{386}$ Dies führt dazu, dass die unionsrechtliche Vorschrift trotz der mit ihrer unterbliebenen Veröffentlichung in der Sprache des betreffenden Mitgliedstaats einhergehenden Unanwendbarkeit als verbindlich angesehen werden muss. Darin liegt eine Beschränkung der zeitlichen Wirkungen der Unanwendbarkeit. ${ }^{387}$ Hinter der Entscheidung des EuGH mag die Erwägung stehen, dass auf diese Weise eine Ungleichbehandlung zwischen Wirtschaftsteilnehmern in den alten und dem neu beigetretenen Mitgliedstaat vermieden wird. ${ }^{388}$

Wie bereits erwähnt, nimmt der Gerichtshof mit der Feststellung der Unanwendbarkeit eine Auslegung des Unionsrechts vor. Den Überlegungen, die zur Feststellung der Unanwendbarkeit führen, liegt diese Auslegung des Unionsrechts allerdings lediglich zugrunde. Die Unanwendbarkeit selbst ist dann aber, gedanklich quasi in einem zweiten Schritt, der Nichtigkeit vergleichbar. Ebenso wie eine für nichtig erklärte Norm ist die Vorschrift ja unanwendbar. Dies rechtfertigt die entsprechende Anwendung von Art. 264 II AEUV. ${ }^{389}$ Damit hat der EuGH Recht, wenn er die hier beschriebene Fallkonstellation nicht als Fall einer Beschränkung der zeitlichen Wirkung der Auslegung einordnet, sondern als Begrenzung der Unanwendbarkeit eines Unionsrechtsakts dem Einzelnen gegenüber. ${ }^{390}$

Eine analoge Anwendung des Art.264 II AEUV auf die Auslegungsvorabentscheidung scheidet nach alledem aus. ${ }^{391}$ Auch der Gerichtshof nimmt eine solche nicht vor.

386 In diesem Sinne etwa EuGH, Urteil vom 13.12.2001, Rs. C-93/00 (Parlament/Rat), Tenor Nr. 2 und Rn. 48.

387 Siehe auch Lasiński-Sulecki, Intertax 37 (2009), 414 (416); a.A. Rosenkranz, Beschränkung der Rückwirkung, 2015, S. 123.

388 Vgl. Lasinsski-Sulecki, Intertax 37 (2009), 414 (418f.). Auf die Ungleichbehandlung der Unionsbürger, die aus der auf einen Mitgliedstaat beschränkten Unanwendbarkeit folgt, weist auch Küpper, JOR 2008, 147 (157) hin.

389 Diese Vergleichbarkeit gesteht auch Rosenkranz, Beschränkung der Rückwirkung, 2015, S. 124 ein.

390 EuGH, Urteil vom 11.12.2007, Rs. C-161/06 (Skoma-Lux), Rn. 68.

391 Dennoch wird nicht immer hinreichend differenziert, siehe etwa Ehricke, in: Streinz (Hrsg.), EUV/AEUV, 3. Aufl. 2018, Art. 267 AEUV, Rn. 75; Gaitanides, in: von der Groeben/Schwarze/Hatje (Hrsg.), Unionsrecht, 7. Aufl. 2015, Art. 267 AEUV, Rn. 94. 
d) Grundsatz der Rechtssicherheit

Gleichwohl stellt das Unionsrecht dem Gerichtshof eine Grundlage für seine Befugnis zur Begrenzung der zeitlichen Wirkungen der Auslegung zur Verfügung.

Sie liegt in der Auslegung des Anwendungsbefehls der vom Gerichtshof ausgelegten Bestimmung des Unionsrechts begründet, die von der Aufgabenzuweisung an den EuGH nach Art. 19 I UAbs. 1 S. 2 EUV und Art. 267 AEUV umfasst ist. ${ }^{392}$ Da der Gerichtshof damit die Reichweite des Anwendungsbefehls in zeitlicher Hinsicht bestimmen darf, kann die Vorstellung, dass der Gerichtshof bei einer zeitlichen Begrenzung eine über die Auslegung hinausgehende Regelung treffe und damit neues Recht setze, nicht überzeugen. ${ }^{393}$

Durch die Auslegung der Reichweite des Normbefehls betreibt der Gerichtshof Auslegung. Tut er dies, muss er den allgemeinen Rechtsgrundsätzen des Unionsrechts Rechnung tragen, zu denen neben dem Grundsatz des effektiven Rechtsschutzes auch der allgemeine unionsrechtliche Rechtsgrundsatz der Rechtssicherheit gehört. ${ }^{394}$ Dieser kann demnach zu einer Verpflichtung des Gerichtshofs führen, eine zeitliche Begrenzung vorzunehmen. Zudem liefert er die Grundlage für die Begrenzung der zeitlichen Wirkungen der Auslegung und die mit ihr einhergehenden Folgen. Es ist daher hinzunehmen, dass das Unionsrecht bei einer zeitlichen Begrenzung in dem vom Gerichtshof näher bestimmten Umfang nicht

392 Ebenso Düsterhaus, EuR 2017, 30 (37). Zur Abgrenzung der Zuständigkeit des Gerichtshofs von der Zuständigkeit der mitgliedstaatlichen Gerichte siehe bereits oben bei Fn. $282 \mathrm{ff}$.

393 Die hier zurückgewiesene Vorstellung findet sich bei Levits, SR 2015, 121 (124). Zwar ist eine zeitliche Begrenzung insofern rechtsgestaltend, als sie den Rechtsanwendungsbefehl der ausgelegten Norm für einen bestimmten Zeitraum aufhebt. Dies geschieht aber im Wege der Auslegung; auch wird dadurch der Inhalt der Norm als solcher nicht verändert, siehe hierzu bereits oben bei Fn. 237 und Fn. 295 sowie noch unten bei Fn. 1291. Siehe in diesem Zusammenhang auch die Darstellung bei Sharpston, in: Poiares Maduro/Azoulai (Hrsg.), The Past and Future of EU Law, 2010, S. 251 (258 ff.), die aufzeigt, dass manche in der Defrenne-Rechtsprechung die Anmaßung legislativer Befugnisse durch den EuGH erblicken, während andere in ihr die Bereitschaft des EuGH sehen, Verantwortung für die praktischen Konsequenzen seiner Entscheidungen zu übernehmen.

394 Vgl. Rosenkranz, Beschränkung der Rückwirkung, 2015, S. 119 f. 
mehr zu beachten ist ${ }^{395}$, obwohl dies der Effektivität des Unionsrechts abträglich ist. ${ }^{396}$ Auch die Beschneidung des Rechtsschutzes der Einzelnen ${ }^{397}$, die Zweck der Beschränkung der zeitlichen Wirkung und nicht bloße Nebenfolge ist ${ }^{398}$, ist daher hinzunehmen. Der Einzelne kann deswegen nicht mehr erfolgreich gegen Verstöße gegen das Unionsrecht vorgehen ${ }^{399}$, was in dem Bild, dass der Preis der Rechtssicherheit dem Einzelnen aufgebürdet wird, anschaulich zum Ausdruck gebracht wird. ${ }^{400}$

In eben diesem unionsrechtlichen Grundsatz der Rechtssicherheit sieht auch der Gerichtshof seine auf das Defrenne II-Urteil zurückgehende Rechtsprechung begründet. ${ }^{401}$ Dementsprechend verlangt er im Ausgangspunkt das Vorliegen zwingender Erwägungen der Rechtssicherheit ${ }^{402}$, die sich aus der Gesamtheit der beteiligten öffentlichen und privaten Interessen ergeben. ${ }^{403}$

395 Dieser Konsequenz ist sich der EuGH bewusst, vgl. EuGH, Urteil vom 17.12.2015, verb. Rs. C-25/14 und C-26/14 (UNIS und Beaudout Père et Fils), Rn. 51.

396 Hyland, IJEL 2 (1995), 208 (233).

397 Wenn davon in der Regel diejenigen ausgenommen werden, die bereits Klage erhoben oder einen anderen Rechtsbehelf eingelegt hatten, wird ihr Anspruch auf effektiven Rechtsschutz geschützt, vgl. GA Darmon, Schlussanträge vom 27.10.1993 in der Rs. C-228/92 (Roquette Frères), Rn. $61 \mathrm{f}$.

398 Ludewig, Zeitliche Beschränkung, 2012, S. 105. Anders Ellis, ELRev. 2000, 564 (567), die in Bezug auf das Defrenne II-Urteil meint, die zeitliche Begrenzung habe die Wahrung der Rechtssicherheit bezweckt und nicht den Entzug des Rechts der Arbeitnehmer(innen), den Gleichheitsgrundsatz durchzusetzen.

399 Wiedmann, EuZW 2007, 692 spricht von einer Enttäuschung des Rechtsgewährleistungsanspruchs des Bürgers; siehe auch Drüen/Kabler, StuW 2005, 171 (181).

400 Vgl. Simon, in: Liber Amicorum Pescatore, 1987, S. 651 (664).

401 Siehe aus jüngerer Zeit nur EuGH, Urteil vom 22.9.2016, Rs. C-110/15 (Microsoft Mobile Sales International u.a.), Rn.60; EuGH, Urteil vom 9.6.2016, Rs. C-586/14 (Budişan), Rn. 46; EuGH, Urteil vom 29.9.2015, Rs. C-276/14 (Gmina Wrocław), Rn. 45; EuGH, Urteil vom 14.4.2015, Rs. C-76/14 (Manea), Rn. 54; EuGH, Urteil vom 22.1.2015, verb. Rs. C-401/13 und C-432/13 (Balazs), Rn. 50; EuGH, Urteil vom 21.10.2010, Rs. C-242/09 (Albron Catering), Rn.36; EuGH, Urteil vom 18.1.2007, Rs. C-313/05 (Brzeziński), Rn. 56. Die Verankerung im Grundsatz der Rechtssicherheit geht zurück auf EuGH, Urteil vom 27.3.1980, Rs.61/79 (Denkavit italiana), Rn. 17. EuGH, Urteil vom 8.4.1976, Rs. 43/75 (Defrenne), Rn. 74/75 spricht bereits von zwingenden Erwägungen der Rechtssicherheit, ohne sie aber als Ausfluss eines allgemeinen Rechtsgrundsatzes des Unionsrechts zu bezeichnen.

402 Solche verlangt er auch bei den Unwirksamkeitsverfahren, siehe z.B. EuGH, Urteil vom 9.2.2017, Rs. C-585/15 (Raffinerie Tirlemontoise), Rn. 38 und ausführlich unten bei Fn. $950 \mathrm{ff}$.

403 EuGH, Urteil vom 8.4.1976, Rs. 43/75 (Defrenne), Rn. 74/75. 
Dass die Begründung mit einem Verweis auf Erwägungen der Rechtssicherheit tragfähig ist, bedarf allerdings noch näherer Untersuchung. ${ }^{404} \mathrm{Be}-$ mängelt wird in diesem Zusammenhang etwa, die Anwendung des Grundsatzes der Rechtssicherheit führe in letzter Konsequenz dazu, dass die objektive Kontinuität des Unionsrechts zu Gunsten einer objektiven Kontinuität des nationalen Rechts preisgegeben werde. Hinter letzterer trete der Vertrauensschutz als subjektive Komponente der unionsrechtlichen Rechtssicherheit zurück. Grundsätzlich werde auf diese Weise Vertrauen in nationales Recht geschützt. ${ }^{405}$ Gegen eine derartige Argumentation ist allerdings mehreres einzuwenden.

Zunächst ist festzuhalten, dass der Gerichtshof den unionsrechtlichen Grundsatz des Vertrauensschutzes im Rahmen seiner Defrenne-Rechtsprechung nicht fruchtbar macht. Auch der Vertrauensschutz kann zwar als Teilaspekt der Rechtssicherheit ${ }^{406}$, als deren subjektive Seite ${ }^{407}$, eingeordnet werden. Die Modifikation der zeitlichen Wirkung stützt der EuGH aber nicht auf den Grundsatz des Vertrauensschutzes als individuelle Rechtsposition ${ }^{408}$; vielmehr spricht er wie gesehen vom Grundsatz der Rechtssicherheit. Eine Begründung mit dem Grundsatz des Vertrauensschutzes wäre auch verfehlt, auch wenn die Berücksichtigung individuellen Vertrauensschutzes nicht zwingend zur Folge hat, dass eine Abwägung mit dem Einzelfall erfolgen muss, sondern „typisierende“ Abwägungen an-

404 Kritik an der fehlenden dogmatischen Begründungstiefe äußern etwa Ludewig, Zeitliche Beschränkung, 2012, S. 94 ff. und Huep, Beschränkung einer Rückwirkung, 2001, S. 231 f. Simon, in: Liber Amicorum Pescatore, 1987, S. 651 (663) zieht die Überzeugungskraft einer Ableitung aus Rechtssicherheitserwägungen in Zweifel.

405 Ludewig, Zeitliche Beschränkung, 2012, S. $95 \mathrm{ff}$.

406 EuGH, Urteil vom 19.9.2000, verb. Rs. C-177/99 und C-181/99 (Ampafrance und Sanofi), Rn. 67 bezeichnet den Vertrauensschutz als zwingend aus dem Grundsatz der Rechtssicherheit folgend. EuGH, Urteil vom 10.9.2009, Rs. C-201/08 (Plantanol), Rn. 46 spricht davon, dass sich der Grundsatz des Vertrauensschutzes aus dem Grundsatz der Rechtssicherheit ableitet; ebenso u.a. EuGH, Urteil vom 12.12.2013, Rs. C-362/12 (Test Claimants in the Franked Investment Income Group Litigation), Rn.44; EuGH, Urteil vom 11.6.2015, Rs. C-98/14 (Berlington Hungary u.a.), Rn. 77.

407 von Arnauld, Rechtssicherheit, 2006, S. 534: „subjektiv-rechtlich gefärbte Spielart des ,rechtssichernden' Kontinuitätsgedankens"; Schaer, Grenzen rückwirkender Rechtsprechung, 2010, S. 37: „subjektive Erwartungssicherheit“ unter Bezugnahme auf GA Cosmas, Schlussanträge vom 8.6.1995 in der Rs. C-63/93 (Duff u.a.), Rn. 25 .

408 Vgl. Rosenkranz, Beschränkung der Rückwirkung, 2015, S. 215. 
gesprochen sind. ${ }^{409}$ Erhellend ist in diesem Zusammenhang ein Vergleich mit dem Konzept des guten Glaubens als eine der Voraussetzungen einer Begrenzung im Sinne der Defrenne-Rechtsprechung.

Dass ein Unterschied zwischen Vertrauensschutz und gutem Glauben besteht, zeigt sich nicht nur in der deutschen Sprachfassung von Urteilen des Gerichtshofs, sondern auch in anderen Sprachfassungen, die etwa zwischen "protection of legitimate expectations" und "good faith" bzw. „confiance légitime“ und „bonne foi“ unterscheiden. ${ }^{410}$ Guter Glaube im Sinne der Defrenne-Rechtsprechung ist anzunehmen bei aus objektivierter Sicht bestehender Unsicherheit hinsichtlich des Unionsrechts. ${ }^{411}$ Bestand Unsicherheit in diesem Sinne etwa hinsichtlich der unmittelbaren Wirkung des heutigen Art.157 I AEUV (Grundsatz des gleichen Entgelts für Männer und Frauen bei gleicher oder gleichwertiger Arbeit), sodass jene für die Betroffenen nicht vorhersehbar war und die Möglichkeit der Berufung auf diese vom Gerichtshof festgestellte unmittelbare Wirkung deshalb beschränkt wurde, kann sich kein Vertrauen auf die unmittelbare Wirkung gebildet haben. Belohnt werden aus Gründen des effektiven Rechtsschutzes - und nicht etwa aus Vertrauensschutzgründen - lediglich diejenigen, die vor Erlass des Urteils bereits Klage erhoben oder einen entsprechenden Rechtsbehelf eingelegt haben. Diesen Arbeitnehmer(inne)n wird gestattet, sich trotz der für die übrigen Rechtsunterworfenen bestehenden zeitlichen Begrenzung auch für vor der Urteilsverkündung liegende Zeiträume auf die unmittelbare Wirkung zu berufen. ${ }^{412}$

Legt man sodann die Aspekte offen, die bei einer Begrenzung der zeitlichen Wirkung Bedeutung erlangen, zeigt sich, dass die „objektive Kontinuität" des nationalen Rechts keine Rolle spielt. In der Waagschale liegen lediglich Aspekte der unionsrechtlichen Rechtssicherheit.

Unionsrechtliche Rechtssicherheit bedeutet zum einen Erkennbarkeit, Verlässlichkeit und Berechenbarkeit des Rechts. ${ }^{413}$ Stellt man diesen Aspekt in den Vordergrund, spricht dies für eine Orientierung an einer

409 Siehe Osterloh, StuW 2015, 201 (206) zu diesem Inhalt des Vertrauensschutzgrundsatzes mit Blick auf die Problematik der Rückwirkung von Gesetzen im deutschen Recht.

410 Vgl. GA Cosmas, Schlussanträge vom 23.3.2000 in den verb. Rs. C-177/99 und C-181/99 (Ampafrance und Sanofi), Rn. 83; siehe auch Ludewig, Zeitliche Beschränkung, 2012, S. 255 mit Fn. 39.

411 Näher sogleich bei Fn. $488 \mathrm{ff}$.

412 Dargestellt am Beispiel von EuGH, Urteil vom 8.4.1976, Rs. $43 / 75$ (Defrenne).

413 von Arnauld, Rechtssicherheit, 2006, S. 498 bezeichnet diese Trias als Strukturelemente der Rechtssicherheit. 
Bedeutung unionsrechtlicher Normen, die für die von ihnen Betroffenen als vorhersehbar einzustufen ist. ${ }^{414}$ Rechtssicherheit bedeutet zum anderen aber auch Gesetzmäßigkeit. So führt etwa Generalanwalt Darmon aus, die größte Sicherheit ergebe sich aus der strikten Anwendung des Gesetzes. ${ }^{415}$ Orientiert man sich vorrangig hieran, bedeutete dies, die vom Gerichtshof als „richtig“ erkannte Auslegung des Unionsrechts in jedem Fall zur Geltung zu bringen, ohne Rücksicht auf die für die Rechtsunterworfenen damit verbundenen Auswirkungen zu nehmen.

Beide Teilaspekte der Rechtssicherheit - Vorhersehbarkeit und Gesetzmäßigkeit - sind bei der Entscheidung über eine Begrenzung der zeitlichen Wirkungen in Ausgleich zu bringen ${ }^{416}$, wobei zu bedenken ist, dass keiner von ihnen grundsätzlich den Vorzug vor dem anderen verdient. ${ }^{417}$ Erforderlich ist vielmehr eine Einzelfallentscheidung, bei der die Umstände des jeweiligen Falles zu berücksichtigen sind. ${ }^{418}$ Dementsprechend kann sich die Waage in beide Richtungen neigen: Werden die zeitlichen Wirkungen beschränkt, neigt sich die Waage in die genau entgegengesetzte Richtung als im Falle der Ablehnung einer Beschränkung.

Da bei der Entscheidung über eine Begrenzung der zeitlichen Wirkungen nur die unionsrechtliche Ebene in den Blick genommen wird, tritt die „objektive Kontinuität des Unionsrechts“ alleine aus unionsrechtlichen Gründen zurück. Geschützt wird damit nicht etwaiges Vertrauen in nationales Recht, das an dieser Stelle vielmehr irrelevant ist. ${ }^{419}$ In aller Regel führt eine zeitliche Begrenzung zwar dazu, dass auf die von ihr erfassten Sachverhalte im Ergebnis unionsrechtswidriges nationales Recht Anwendung findet, da sich der Normadressat in diesem Fall nicht mehr

414 Ähnlich wohl Frenz, Handbuch Europarecht, Band 5, 2010, Rn. 3415.

415 GA Darmon, Schlussanträge vom 14.11.1984 in der Rs. 112/83 (Société des produits de maïs), Slg. 1985, S. 728. Auf ihn nimmt auch Simon, in: Liber Amicorum Pescatore, 1987, S. 651 (663, Fn. 41) Bezug.

416 Von zwei Seiten der Rechtssicherheit spricht GA Darmon, Schlussanträge vom 27.10.1993 in der Rs. C-228/92 (Roquette Frères), Rn. 26.

417 Vgl. Simon, in: Liber Amicorum Pescatore, 1987, S. 651 (663).

418 GA Stix-Hackl, Schlussanträge vom 14.3.2006 in der Rs. C-475/03 (Banca Popolare di Cremona), Rn. 150; Rosenkranz, Beschränkung der Rückwirkung, 2015, S. 130 f.; Lenaerts/Maselis/Gutman, EU Procedural Law, 2014, Rn. 6.34 sprechen von einer Entscheidung auf „case-by-case basis“.

419 Offenbar anders Ludewig, Zeitliche Beschränkung, 2012, S. 96 f.; wie hier Rosenkranz, Beschränkung der Rückwirkung, 2015, S. 146. 
auf die unionsrechtliche Norm berufen kann. ${ }^{420}$ Dies ist allerdings nicht zwingend; zudem erfolgt dies wie gesehen aus im Unionsrecht wurzelnden Gründen. Auch wenn sich die Situation auf den ersten Blick im Ergebnis so darstellen mag, als sei Vertrauen in nationales Recht geschützt worden, ist dies tatsächlich nicht der Fall.

Von einem Zurücktreten des unionsrechtlichen Vertrauensschutzes hinter der objektiven Kontinuität des nationalen Rechts kann nach alledem aus mehreren Gründen nicht gesprochen werden. Vielmehr hat sich die Abstützung einer Begrenzung der zeitlichen Wirkungen auf den unionsrechtlichen Grundsatz der Rechtssicherheit im Ergebnis als tragfähig erwiesen.

\section{e) Vertragsverletzungsverfahren}

Im Unterschied zur Auslegungsvorabentscheidung fehlen klare Aussagen des Gerichtshofs zu der Frage einer Begrenzung der zeitlichen Wirkungen im Rahmen des Vertragsverletzungsverfahrens. Ein Zwang zur Festlegung hat sich aus den von ihm zu entscheidenden Verfahren noch nicht ergeben. So konnte der EuGH in den betreffenden Fällen - die Möglichkeit der Beschränkung der zeitlichen Wirkungen ausdrücklich offenlassend die von ihm im Rahmen der Auslegungsvorabentscheidung aufgestellten Voraussetzungen prüfen und deren Vorliegen verneinen. ${ }^{421}$

Klar ist daher lediglich, dass der Gerichtshof sich noch alle Möglichkeiten offenhalten möchte ${ }^{422}$, wie die zurückhaltend-vorsichtige Verwendung des Konjunktivs (,annähme“, „erforderlich machen könnten“, „vor-

420 Seer/Müller, IWB 2008, 255 (263) sehen hierin die „Konservierung“ eines unionsrechtswidrigen Zustands und Wiedmann, EuZW 2007, 692 die „Perpetuierung" eines rechtswidrigen Zustands.

421 U.a. EuGH, Urteil vom 8.4.2014, Rs. C-288/12 (Kommission/Ungarn), Rn. 64.

422 Vgl. EuGH, Urteil vom 6.10.2005, Rs. C-204/03 (Kommission/Spanien), Rn. 29 f.; EuGH, Urteil vom 7.6.2007, Rs. C-178/05 (Kommission/Griechenland), Rn. 65 ff.; EuGH, Urteil vom 12.2.2009, Rs. C-475/07 (Kommission/Polen), Rn. 60 ff.; EuGH, Urteil vom 26.3.2009, Rs. C-559/07 (Kommission/Griechenland), Rn. 75 ff.; EuGH, Urteil vom 15.12.2009, Rs. C-239/06 (Kommission/Italien), Rn. 56 ff.; EuGH, Urteil vom 15.12.2009, Rs. C-387/05 (Kommission/Italien), Rn. 56 ff.; EuGH, Urteil vom 15.12.2009, Rs. C-284/05 (Kommission/Finnland), Rn. 55 ff.; EuGH, Urteil vom 29.9.2011, Rs. C-82/10 (Kommission/Irland), Rn. 60 ff.; EuGH, Urteil vom 25.10.2012, Rs. C-387/11 (Kommission/Belgien), Rn. 89 ff.; EuGH, Urteil vom 8.4.2014, Rs. C-288/12 (Kommission/Ungarn), Rn. 63 ff. 
lägen") ${ }^{423}$ deutlich macht. Daher kann auch nicht eine Anwendung der Maßstäbe der Auslegungsvorabentscheidung unter Verweis auf Rn. 42 des Urteils in der Rechtssache C-426/98 (Kommission/Griechenland) angenommen werden. ${ }^{424}$ Zwar hat der Gerichtshof in dieser Entscheidung offenkundig eine Begrenzung der zeitlichen Wirkungen nach den Grundsätzen der Auslegungsvorabentscheidung erwogen, ohne in irgendeiner Weise auf die Problematik der Übertragbarkeit auf das Vertragsverletzungsverfahren hinzuweisen, was sich daran zeigt, dass er dort den Rechtssicherheitsgrundsatz ausdrücklich auf die Feststellung der Verletzung des Unionsrechts durch Griechenland angewendet und lediglich das Vorliegen der für eine Beschränkung erforderlichen Voraussetzungen verneint hat. ${ }^{425}$ Durch die nachfolgend ergangenen, diese Frage ausdrücklich offenlassenden Entscheidungen hat der Gerichtshof aber hinreichend deutlich gemacht, dass dieses Urteil nicht im Sinne einer Festlegung des Gerichtshofs auf eine Anwendbarkeit der Grundsätze der Begrenzung der zeitlichen Wirkungen der Auslegung im Vertragsverletzungsverfahren verstanden werden kann.

Wenngleich also ein eindeutiges Bekenntnis des Gerichtshofs fehlt, ist eine Übertragung dieser Grundsätze zu befürworten. Die ausschlaggebenden Argumente hat der Gerichtshof bereits selbst in der Rechtssache C-35/97 (Kommission/Frankreich) zur Sprache gebracht. In diesem ebenfalls in einem Vertragsverletzungsverfahren ergangenen Urteil spricht er ausdrücklich von der Beschränkung der Berufung ,auf die von ihm einer Bestimmung gegebene[n] Auslegung" und vom „Grundsatz der Rückwirkung der Auslegungsurteile“. ${ }^{426}$ Durch die Herausstellung der Bedeutung der Auslegung der dem Vertragsverletzungsverfahren zugrundeliegenden Norm des Unionsrechts legt er die entscheidenden Wertungen offen. Die Feststellung der Vertragsverletzung des Mitgliedstaats im Urteil ist das eine; die in ihm vorgenommene Auslegung des Unionsrechts das andere.

423 Zitiert nach EuGH, Urteil vom 25.10.2012, Rs. C-387/11 (Kommission/Belgien), Rn. 90.

424 So aber Karpenstein, in: Grabitz/Hilf/Nettesheim (Hrsg.), Recht der EU, Art. 260 AEUV, Rn. 21 mit Fn. 5 (Stand: August 2018).

425 EuGH, Urteil vom 19.3.2002, Rs. C-426/98 (Kommission/Griechenland), Rn. 42: „Nach der Rechtsprechung kann sich der Gerichtshof jedoch nur ausnahmsweise aufgrund des der Gemeinschaftsrechtsordnung innewohnenden allgemeinen Grundsatzes der Rechtssicherheit veranlasst sehen, die Wirkungen eines Urteils zeitlich zu beschränken, mit dem die Verletzung der gemeinschaftlichen Pflichten eines Mitgliedstaats festgestellt wird; [...].“

426 EuGH, Urteil vom 24.9.1998, Rs. C-35/97 (Kommission/Frankreich), Rn. 49 f. 
Ihr kommt über das Verfahren hinaus Wirkung zu, was die Begrenzung der zeitlichen Wirkungen der Auslegung erforderlich machen kann. ${ }^{427}$ Erneut bestätigt sich damit, dass die Verfahrensart, in der die Auslegung vorgenommen wird, nicht entscheidend ist. ${ }^{428}$ Durch eine Anwendung derselben Maßstäbe der Begrenzung der Wirkung der Auslegung in zeitlicher Hinsicht im Rahmen der Auslegungsvorabentscheidung und des Vertragsverletzungsverfahrens ist diesem Zusammenhang Rechnung zu tragen.

\section{6. „Art“ der Befugnis}

Zu klären bleibt, welcher „Art“ die dem Gerichtshof eingeräumte Befugnis zur Begrenzung der zeitlichen Wirkungen der Auslegung ist, auf welche Art und Weise eine zeitliche Begrenzung also erfolgt.

Zieht der EuGH eine Beschränkung der zeitlichen Wirkungen im Rahmen seiner Auslegungsentscheidungen in Betracht oder nimmt er eine solche vor, variieren die von ihm gewählten Formulierungen. Nicht zuletzt ist dies darin begründet, dass er sich anders als bei der Nichtigkeitsklage (und eingeschränkt auch bei der Ungültigkeitsvorabentscheidung) nicht an einer Vertragsbestimmung orientieren kann.

Häufig bezieht sich der Gerichtshof wie auch in der Rechtssache Budișan auf „die Möglichkeit, sich auf die Auslegung zu berufen, die er einer Bestimmung gegeben hat“. ${ }^{429}$ In der französischen Sprachfassung des Budişan-Urteils ist dagegen von „limiter la possibilité d'invoquer une disposition qu'elle a interprétée“ und in der englischen von „restrict the opportu-

427 GA Kokott, Schlussanträge vom 15.2.2007 in der Rs. C-178/05 (Kommission/Griechenland), Rn. 84.

428 Siehe dazu bereits oben bei Fn. 165 ff. zur Bindungswirkung und bei Fn. 275 f. zur zeitlichen Wirkung. Siehe auch Rosenkranz, Beschränkung der Rückwirkung, 2015, S. $127 \mathrm{f}$.

429 EuGH, Urteil vom 9.6.2016, Rs. C-586/14 (Budişan), Rn. 46. Von der (Beschränkung der) Berufung auf die Auslegung sprechen auch u.a. EuGH, Urteil vom 29.9.2015, Rs. C-276/14 (Gmina Wrocław), Rn.45; EuGH, Urteil vom 22.9.2016, Rs. C-110/15 (Microsoft Mobile Sales International u.a.), Rn.60; EuGH, Urteil vom 14.4.2015, Rs. C-76/14 (Manea), Rn. 54; EuGH, Urteil vom 22.1.2015, verb. Rs. C-401/13 und C-432/13 (Balazs), Rn. 50. Siehe bereits EuGH, Urteil vom 27.3.1980, Rs. 61/79 (Denkavit italiana), Rn. 17 unter Verweis auf EuGH, Urteil vom 8.4.1976, Rs. 43/75 (Defrenne). 
nity to rely on a provision which it has interpreted" die Rede. ${ }^{430}$ Sowohl von einer Beschränkung der Möglichkeit der Berufung auf die Auslegung mit Wirkung für alle Betroffenen als auch von einem Ausschluss der Berufung auf die in Rede stehenden Bestimmungen spricht der Gerichtshof in der Rechtssache Legros u.a. ${ }^{431}$ Teilweise spricht er auch nur von einem Ausschluss der Berufung auf die ausgelegte Bestimmung. ${ }^{432}$ In anderen Fällen schließt er mit wechselnden Formulierungen die Berufung auf die unmittelbare Geltung/Wirkung der ausgelegten Norm aus. ${ }^{433}$

In der Rechtssache Cabanis-Issarte heißt es dagegen, dass bestimmte Forderungen nicht auf das Urteil in dieser Rechtssache gestützt werden könnten. ${ }^{434}$ Anklänge, dass das Urteil als Bezugspunkt der zeitlichen Beschränkung angesehen wird, finden sich auch in der Aussage, die Wirkungen eines auslegenden Urteils des Gerichtshofes erfassten die ausgelegte Vorschrift regelmäßig ab ihrem Inkrafttreten. ${ }^{435}$ Lehnt der Gerichtshof eine Beschränkung der zeitlichen Wirkungen ab, beendet er seine Prüfung zudem in der Regel mit der Feststellung, dass die Wirkungen des Urteils

430 EuGH, Urteil vom 9.6.2016, Rs. C-586/14 (Budișan), Rn. 46. Siehe auch EuGH, Beschluss vom 3.2.2014, verb. Rs. C-97/13 und C-214/13 (Câmpean und Ciocoiu), Rn. 36.

431 EuGH, Urteil vom 16.7.1992, Rs. C-163/90 (Legros u.a.), Rn. 30 (Berufung auf die Auslegung) einerseits, Rn. 35 und Tenor Nr. 3 (Berufung auf die Bestimmungen) andererseits.

432 EuGH, Urteil vom 9.3.2000, Rs. C-437/97 (EKW und Wein \& Co.), Tenor Nr. 3 und Rn. 60; EuGH, Urteil vom 9.9.2004, Rs. C-72/03 (Carbonati Apuani), Tenor Nr. 2 und Rn. 42.

433 EuGH, Urteil vom 8.4.1976, Rs. 43/75 (Defrenne), Tenor Nr. 5 und Rn. 74/75: „[...] können auf die unmittelbare Geltung [...] keine Ansprüche gestützt werden [...]“; EuGH, Urteil vom 2.2.1988, Rs. 24/86 (Blaizot u.a.), Tenor Nr. 2 und Rn. 35: „Die unmittelbare Wirkung [...] kann [...] nicht [...] geltend gemacht werden [...]“; EuGH, Urteil vom 17.5.1990, Rs. C-262/88 (Barber), Tenor Nr. 5 und Rn. 45: „Niemand kann sich auf die unmittelbare Wirkung [...] berufen [...]“; EuGH, Urteil vom 15.12.1995, Rs. C-415/93 (Bosman), Tenor Nr. 3 und Rn. 145: „Die unmittelbare Wirkung [...] kann nicht [...] herangezogen werden [...]“; EuGH, Urteil vom 4.5.1999, Rs. C-262/96 (Sürül), Tenor Nr. 2 und Rn.113: „Die unmittelbare Wirkung [...] kann nicht [...] geltend gemacht werden $[\ldots]^{\text {“. }}$.

434 EuGH, Urteil vom 30.4.1996, Rs. C-308/93 (Cabanis-Issarte), Tenor Nr. 2 und Rn. 48.

435 EuGH, Urteil vom 15.9.1998, Rs. C-231/96 (Edis), Rn. 17. 
zeitlich nicht zu begrenzen/beschränken seien bzw. dass dazu kein Anlass bestehe. ${ }^{436}$

In einer neueren Entscheidung stellt der Gerichtshof ebenfalls ausdrücklich auf die Wirkungen seines Urteils ab, die nicht für vor Urteilsverkündung für allgemeinverbindlich erklärte Tarifverträge gelten sollen. ${ }^{437}$ In dieser Entscheidung sind allerdings im Zusammenhang mit der Begrenzung der zeitlichen Wirkungen gewisse Ungenauigkeiten zu erkennen, die jedoch die Sinne für den Bezugspunkt der Begrenzung schärfen. So vermischt der Gerichtshof unionale und mitgliedstaatliche Ebene, wenn er ausführt, die Aufrechterhaltung der Wirkungen der Allgemeinverbindlichkeitserklärungen des französischen Arbeitsministers sei gerechtfertigt. ${ }^{438}$ Die Nichtigerklärung der Allgemeinverbindlichkeitserklärungen wurde zwar im Verfahren vor dem nationalen Gericht beantragt, das diese Konsequenz auch aller Voraussicht nach ziehen würde, wenn sie sich als unionsrechtswidrig herausstellen sollten. ${ }^{439}$ Über die Allgemeinverbindlichkeitserklärungen selbst kann der Gerichtshof jedoch nicht befinden und deren Wirkungen damit auch nicht aufrechterhalten. Dementsprechend kann auch nur das Unionsrecht Bezugspunkt der Begrenzung sein.

Der Gerichtshof hat also eine Sprachverwirrung herbeigeführt, die es zu ordnen gilt. Letztlich kommen drei Anknüpfungspunkte für eine zeitliche Begrenzung in Betracht: die Auslegung selbst, die ausgelegte Norm und das (Auslegungs-)Urteil. Da die Auslegung Bestandteil der Norm ist, kann auf sie nicht abgestellt werden, ohne gleichzeitig auf die ausgelegte Norm abzustellen; Auslegung und Norm fallen zusammen. ${ }^{440}$ Auch das Urteil ist kein tauglicher Anknüpfungspunkt, da nicht diesem ex tunc-Wirkung zukommt, sondern der ausgelegten Norm. ${ }^{441}$ Damit kann nur die Norm selbst als Anknüpfungspunkt einer Beschränkung der ex tunc-Wirkung dienen. ${ }^{442}$

436 Siehe nur EuGH, Urteil vom 9.6.2016, Rs. C-586/14 (Budișan), Rn. 53; EuGH, Urteil vom 14.4.2015, Rs. C-76/14 (Manea), Rn. 59; EuGH, Urteil vom 22.9.2016, Rs. C-110/15 (Microsoft Mobile Sales International u.a.), Rn. 64.

$437 \mathrm{EuGH}$, Urteil vom 17.12.2015, verb. Rs. C-25/14 und C-26/14 (UNIS und Beaudout Père et Fils), Tenor Nr. 2 und Rn. 53.

438 EuGH, Urteil vom 17.12.2015, verb. Rs. C-25/14 und C-26/14 (UNIS und Beaudout Père et Fils), Rn. 52.

439 Vgl. GA Jääskinen, Schlussanträge vom 19.3.2015 in den verb. Rs. C-25/14 und C-26/14 (UNIS und Beaudout Père et Fils), Rn. 82 mit Fn. 47.

440 van der Stok/Thomson, Intertax 34 (2006), 552: „co-extensive“.

441 Ebenso Schaer, Grenzen rückwirkender Rechtsprechung, 2010, S. 43. Siehe dazu bereits oben bei Fn. 195.

442 Ebenso Rosenkranz, Beschränkung der Rückwirkung, 2015, S. 300. 
Durch den EuGH wird bei einer Beschränkung in zeitlicher Hinsicht also die Berufung auf die Norm ausgeschlossen, so wie dies in der oben wiedergegebenen französischen und englischen Sprachfassung des Budişan-Urteils treffender als in der deutschen zum Ausdruck gebracht wird. Dadurch dass der Gerichtshof lediglich die Berufung auf die Norm ausschließt, wird die Norm selbst nicht verändert. Selbst im Falle einer Begrenzung der zeitlichen Wirkungen ändert sich der Inhalt der Norm seit ihrem Inkrafttreten also nicht. Sie nimmt dem Einzelnen lediglich die Möglichkeit, die ihm angesichts der vom EuGH vorgenommenen Auslegung eigentlich zustehenden Rechte aus der Norm geltend zu machen. ${ }^{443}$ Es handelt sich damit letztlich um eine verfahrensrechtliche Erscheinung. ${ }^{444}$

\section{Ergebnis}

In den vorangegangenen Abschnitten konnte geklärt werden, dass der Gerichtshof von Amts wegen in ausschließlicher Zuständigkeit aufgrund einer Auslegung des Anwendungsbefehls der ausgelegten Norm im Hinblick auf den Grundsatz der Rechtssicherheit die Möglichkeit der Berufung auf diese Norm in zeitlicher Hinsicht beschränken kann. Im Folgenden wird zu untersuchen sein, welche Voraussetzungen hierfür erfüllt sein müssen.

II. Voraussetzungen einer zeitlichen Beschränkung bei Auslegungsentscheidungen

Wie erwähnt sind bei den Auslegungsentscheidungen für eine Beschränkung der zeitlichen Wirkungen „zwingende Erwägungen der Rechtssicherheit, die sich aus der Gesamtheit der beteiligten öffentlichen und privaten Interessen ergeben“, entscheidend. ${ }^{445}$ Diesen im Defrenne II-Urteil gewähl-

443 GA Cosmas, verb. Schlussanträge vom 8.10.1998 in den Rs. C-50/96, C-234/96 und C-235/96, C-270/97 und C-271/97 (Schröder u.a.), Rn. 62; a.A. Wißmann, in: FS Bauer, 2010, S. 1161 (1164); wohl auch Simon, in: Liber Amicorum Pescatore, 1987, S. 651 (663).

444 Kruis, Anwendungsvorrang, 2013, S. 206 f.; Rosenkranz, Beschränkung der Rückwirkung, 2015, S. $300 \mathrm{ff}$.

445 EuGH, Urteil vom 8.4.1976, Rs. 43/75 (Defrenne), Rn. 74/75. Siehe bereits oben bei Fn. $401 \mathrm{ff}$. 
ten noch sehr abstrakten Ausgangspunkt hat der Gerichtshof dadurch handhabbarer - aber auch unflexibler - gemacht, dass er ihn in zwei, nach anderer Lesart in drei Prüfungspunkte aufgegliedert hat, die nachfolgend näher zu beleuchten sind.

Voraussetzung einer zeitlichen Begrenzung ist das Bestehen von gutem Glauben und einer Gefahr schwerwiegender Störungen/wirtschaftlicher Auswirkungen. Zudem darf die Begrenzung nicht präkludiert sein, was bedeutet, dass sie nur im ersten zu einer Rechtsfrage ergehenden Urteil erfolgen kann. Da insoweit nicht frei von Zweifeln ist, ob es sich hierbei um einen neben dem Erfordernis guten Glaubens eigenständigen Aspekt handelt, bestehen unterschiedliche Auffassungen, ob von zwei oder drei Prüfungspunkten auszugehen ist. 446

Dass eine zeitliche Begrenzung nach Auffassung des Gerichtshofs „nur ganz ausnahmsweise“447 erfolgen kann, es sich bei ihr also um eine „außergewöhnliche Maßnahme“"448 handelt, die die „absolute Ausnahme“449 bleiben muss, folgt aus der grundsätzlichen ex tunc-Wirkung der Auslegung. ${ }^{450}$ Angesichts des deklaratorischen Auslegungsverständnisses des Gerichtshofs geht dieser davon aus, dass es auch den Rechtsunterworfenen möglich gewesen wäre, die Bedeutung des Unionsrechts zu finden und sich dementsprechend zu verhalten. ${ }^{451}$

446 Siehe zum Verhältnis von Präklusion und gutem Glauben näher unten bei Fn. $908 \mathrm{ff}$.

447 Z.B. EuGH, Urteil vom 20.12.2017, Rs. C-500/16 (Caterpillar Financial Services), Rn. 32; EuGH, Urteil vom 17.12.2015, verb. Rs. C-25/14 und C-26/14 (UNIS und Beaudout Père et Fils), Rn.50; EuGH, Urteil vom 22.9.2016, Rs. C-110/15 (Microsoft Mobile Sales International u.a.), Rn. 60; EuGH, Urteil vom 22.1.2015, verb. Rs. C-401/13 und C-432/13 (Balazs), Rn. 50; EuGH, Urteil vom 17.9.2014, Rs. C-562/12 (Liivimaa Lihaveis), Rn. 81. Auf den Ausnahmecharakter weist auch Osterloh, in: FS Hassemer, 2010, S. 173 (174) hin.

448 EuGH, Urteil vom 28.2.2018, Rs. C-672/16 (Imofloresmira - Investimentos Imobiliários), Rn. 59; EuGH, Urteil vom 19.12.2013, Rs. C-209/12 (Endress), Rn. 36.

$449 \mathrm{EuGH}$, Urteil vom 15.9.1998, Rs. C-231/96 (Edis), Rn. 16; EuGH, Urteil vom 13.2.1996, verb. Rs. C-197/94 und C-252/94 (Bautiaa und Société française maritime), Rn. 48; EuGH, Urteil vom 4.10.2001, Rs. C-294/99 (Athinaiki Zythopoiia), Rn. 36.

450 So auch GA Wahl, Schlussanträge vom 17.5.2017 in der Rs. C-501/15 P (EUIPO/ Cactus), Rn. 54: "The exceptionality of limiting the temporal effects of judgments is the logical corollary of how the effects of the Court's judgments are deployed. The Court's judgments produce effects, as a matter of principle, $e x$ tunc." (Kursivschrift im Original).

451 Levits, SR 2015, 121 (124). 
Der Ausnahmecharakter der zeitlichen Begrenzung ergibt sich auch aus dem Geltungsanspruch des objektiven Rechts. ${ }^{452}$ Hinzu kommt, dass der im Rahmen der Unwirksamkeitsverfahren (direkt oder analog) anwendbare Art. 264 II AEUV dem Gerichtshof bereits in seinem Wortlaut („falls er dies für notwendig hält“") Spielraum gewährt, auf den sich der Gerichtshof bei seinen Auslegungsentscheidungen aber wie gesehen nicht stützen kann. Die größere Strenge im Vergleich zu den Unwirksamkeitsverfahren überrascht daher nicht. Dass häufig unionsrechtswidriges nationales Recht im Raum steht, das bei einer zeitlichen Begrenzung gegebenenfalls weiterhin Anwendung finden könnte, spielt dagegen keine entscheidende Rolle. ${ }^{453}$

1. Kumulatives Vorliegen der Tatbestandsvoraussetzungen und die Rechtssache UNIS

Indem der EuGH ausführt, die Beschränkung der Möglichkeit, sich auf die von ihm vorgenommene Auslegung zu berufen, sei nur zulässig, „wenn zwei grundlegende Kriterien erfüllt sind“454, macht er deutlich, dass sowohl guter Glaube als auch eine Gefahr schwerwiegender Störungen/wirtschaftlicher Auswirkungen bestehen müssen. Es handelt sich bei ihnen also um kumulative Voraussetzungen. ${ }^{455}$ Dementsprechend muss eine Begrenzung der zeitlichen Wirkungen ausscheiden, wenn eines dieser Kriterien nicht erfüllt ist. Der Gerichtshof verzichtet in diesem Fall in der

452 In diesem Sinne Osterloh, in: FS Hassemer, 2010, S. 173 (175).

453 Dies hervorhebend aber Verstraelen, GLJ 14 (2013), 1687 (1716).

454 U.a. EuGH, Urteil vom 5.10.2006, verb. Rs. C-290/05 und C-333/05 (Nádasdi und Németh), Rn.63; EuGH, Urteil vom 18.1.2007, Rs. C-313/05 (Brzeziński), Rn. 56; EuGH, Urteil vom 12.2.2009, Rs. C-138/07 (Cobelfret), Rn. 68; EuGH, Urteil vom 13.4.2010, Rs. C-73/08 (Bressol u.a.), Rn.91; EuGH, Urteil vom 3.6.2010, Rs. C-2/09 (Kalinchev), Rn. 50; EuGH, Urteil vom 21.3.2013, Rs. C-92/11 (RWE Vertrieb), Rn. 59; EuGH, Urteil vom 14.4.2015, Rs. C-76/14 (Manea), Rn. 54; EuGH, Urteil vom 9.6.2016, Rs. C-586/14 (Budișan), Rn. 46.

455 So auch ausdrücklich GA Sharpston, Schlussanträge vom 22.5.2008 in der Rs. C-427/06 (Bartsch), Rn.127; GA Poiares Maduro, Schlussanträge vom 18.5.2006 in der Rs. C-17/05 (Cadman), Rn. 69. 
Rege $^{456}$ auf die Prüfung des anderen Kriteriums ${ }^{457}$ oder äußert sich zu diesem nur noch zur Bestätigung und Abstützung des bereits gefundenen Ergebnisses. ${ }^{458}$

In besonderen Fällen zeigt sich der Gerichtshof allerdings auch bereit, von seiner gewohnten Prüfung abzuweichen. So verweist er in seinem Urteil in den verbundenen Rechtssachen UNIS und Beaudout Père et Fils zwar auf seine ständige Rechtsprechung, wonach er die Möglichkeit der Berufung auf die Auslegung, die er einer Bestimmung gegeben hat, nur ganz ausnahmsweise beschränken könne. Im Anschluss an diese Feststellung verzichtet er dann aber auf die damit üblicherweise in Verbindung gebrachte Formulierung, wonach die beiden oben genannten grundlegenden Kriterien erfüllt sein müssen. Vielmehr verweist er insbesondere auf die „sehr speziellen Umstände“ der Sachverhalte der Ausgangsverfahren. 459

In der Sache ging es um die von einem Mitgliedstaat vorgenommene Allgemeinverbindlichkeitserklärung eines Tarifvertrags für sämtliche Arbeitgeber und Arbeitnehmer einer Branche, mit dem die Verwaltung eines obligatorischen Zusatzvorsorgesystems für die Arbeitnehmer einem einzigen Wirtschaftsteilnehmer übertragen wird. Als unionsrechtlich problematisch hatte sich im Hinblick auf die Anforderungen der sich aus Art. 56 AEUV (Dienstleistungsfreiheit) ergebenden Transparenzpflicht die Verleihung des Rechts zur Verwaltung des Zusatzvorsorgesystems ohne angemessene Öffentlichkeit erwiesen.

Für die Begründung der von ihm in seinem Urteil vorgenommenen zeitlichen Beschränkung stützt sich der EuGH auf die für die Mitgliedstaaten im Bereich der Vergabe öffentlicher Aufträge bestehende Möglichkeit zur Beschränkung der Anfechtung unionsrechtswidrig vergebener Aufträge.

456 Trotz Verneinung des Nachweises einer Gefahr schwerwiegender Störungen prüft und verneint der Gerichtshof auch das Bestehen von gutem Glauben z.B. in EuGH, Urteil vom 3.10.2019, Rs. C-274/18 (Schuch-Ghannadan), Rn. 63 ff.

457 Z.B. EuGH, Urteil vom 18.1.2007, Rs. C-313/05 (Brzeziński), Rn.61; EuGH, Urteil vom 21.3.2013, Rs.C-92/11 (RWE Vertrieb), Rn.63; EuGH, Urteil vom 14.4.2015, Rs. C-76/14 (Manea), Rn. 58; EuGH, Urteil vom 29.7.2010, Rs. C-577/08 (Brouwer), Rn. 40; EuGH, Urteil vom 27.2.2014, Rs. C-82/12 (Transportes Jordi Besora), Rn. 47; EuGH, Urteil vom 9.6.2016, Rs. C-586/14 (Budişan), Rn. 52; EuGH, Urteil vom 22.1.2015, verb. Rs. C-401/13 und C-432/13 (Balazs), Rn. 53; EuGH, Urteil vom 17.9.2014, Rs. C-562/12 (Liivimaa Lihaveis), Rn. 85.

458 EuGH, Urteil vom 22.9.2016, Rs. C-110/15 (Microsoft Mobile Sales International u.a.), Rn. 63.

$459 \mathrm{EuGH}$, Urteil vom 17.12.2015, verb. Rs. C-25/14 und C-26/14 (UNIS und Beaudout Père et Fils), Rn. 50. 
Zudem verweist er auf die Situation der betroffenen Arbeitgeber und Arbeitnehmer, die auf der Grundlage der vom französischen Arbeitsminister für allgemeinverbindlich erklärten Tarifverträge in einem besonders sensiblen sozialen Kontext einen Vertrag über eine Zusatzvorsorge geschlossen hätten. Die Arbeitgeber und Arbeitnehmer hätten sich bei der Eingehung vertraglicher Verpflichtungen auf eine Rechtslage gestützt, die der Gerichtshof hinsichtlich der konkreten Tragweite der sich aus Art. 56 AEUV ergebenden Transparenzpflicht erst jetzt im Urteil UNIS und Beaudout Père et Fils präzisiert habe. ${ }^{460}$

Generalanwalt Jääskinen hatte unter Zugrundelegung der „üblichen“ Kriterien eine Beschränkung der zeitlichen Wirkung noch abgelehnt. Für ihn war die Gefahr schwerwiegender Störungen nicht nachgewiesen. Auf nationaler Ebene ist die wahrscheinliche Folge einer Feststellung ihres Verstoßes gegen das Transparenzgebot zwar die Nichtigerklärung der in den Ausgangsverfahren in Rede stehenden Allgemeinverbindlichkeitserklärungen. Die Nichtigerklärung der Ministerialerlasse führt aber nicht zwangsläufig zur Beendigung der bestehenden versicherungsvertraglichen Beziehungen. Um die Auswirkungen der Nichtigerklärung auf die Arbeitgeber und die Versicherten zu bestimmen, sind daher auch die zivilrechtlichen Vorschriften im französischen Recht zu beachten. Generalanwalt Jääskinen verweist daher zur Bestimmung der mit dem Urteil des Gerichtshofs verbundenen Auswirkungen zu Recht auf das nationale Recht. ${ }^{461}$

Vor dem Hintergrund der Ausführungen des Generalanwalts wird deutlich, dass der Gerichtshof in UNIS und Beaudout Père et Fils die Frage des Bestehens einer Gefahr schwerwiegender Störungen durch materielle Erwägungen der Rechtssicherheit überlagert hat; gestützt hat er sich auf den materiellen Rechtfertigungsgrund der Stabilität bereits durchgeführter Vertragsverhältnisse. Zudem fällt auf, dass der Gerichtshof von einer „Präzisierung“ der konkreten Tragweite der Transparenzpflicht spricht. Eine solche „Präzisierung“ kann aber nur erfolgen, wenn bereits eine der Präzisierung fähige Grundlage vorhanden ist. In einem solchen Fall sind Anzeichen einer geklärten Rechtslage zu erkennen, was das vom Gerichtshof erzielte Ergebnis vorhersehbar machen würde. ${ }^{462}$ Guter Glaube

460 EuGH, Urteil vom 17.12.2015, verb. Rs. C-25/14 und C-26/14 (UNIS und Beaudout Père et Fils), Rn. 51 ff.

461 GA Jääskinen, Schlussanträge vom 19.3.2015 in den verb. Rs. C-25/14 und C-26/14 (UNIS und Beaudout Père et Fils), Rn. 82 mit Fn. 47 und Rn. 84.

462 Guten Glauben verneint der Gerichtshof etwa bei einer bloßen Klarstellung der Rechtsprechung auf einem Gebiet, vgl. EuGH, Urteil vom 3.10.2006, Rs. C-17/05 (Cadman), Rn. 43. 
als Voraussetzung einer Begrenzung der zeitlichen Wirkungen wäre dann ausgeschlossen.

Die Ausführungen des EuGH sind umso bemerkenswerter, als er hier nach einer mehrjährigen Pause wieder eine Begrenzung der zeitlichen Wirkungen vorgenommen hat. Er zeigt damit, dass eine zeitliche Begrenzung auch jenseits der tradierten Formeln möglich ist. Indem er eine materiellrechtliche Wertung auf die Frage der zeitlichen Wirkungen der richtigen Rechtsauslegung überträgt, nimmt der Gerichtshof einen Interessenausgleich auf Ebene des Unionsrechts vor, der dazu führen kann, dass die Vermeidung von Rechtsunsicherheit die Beachtung des Unionsrechts zurücktreten lässt. Sichtbar wird auch der Kern des hinter der DefrenneRechtsprechung stehenden Bedürfnisses, zu verhindern, dass mögliche negative Auswirkungen einer Auslegung die zutreffende Auslegung des Unionsrechts gefährden: Die „richtige“ Auslegung des Unionsrechts ist also vorzunehmen, in ihren Wirkungen aber gegebenenfalls zeitlich zu begrenzen. Angesichts der sehr zurückhaltenden, stark auf die Besonderheiten des Einzelfalles abstellenden Formulierungen hat der EuGH im UNIS und Beaudout Père et Fils-Urteil aber wohl keine Abkehr von seiner Defrenne-Rechtsprechung vorgenommen. ${ }^{463}$

Seine Ausführungen geben jedoch Anlass, auf die Gemeinsamkeiten und Unterschiede der möglichen Modifikationen des zeitlichen Geltungsanspruchs des Unionsrechts zu blicken. Diese kommen in vier Konstellationen in Betracht. Hierbei handelt es sich um (1) die direkte bzw. analoge Anwendung des Art. 264 II AEUV in den Unwirksamkeitsverfahren, (2) die Skoma Lux-Konstellation, die sich durch die unterbliebene Veröffentlichung eines Rechtsakts in einer Amtssprache auszeichnet und in der Art. 264 II AEUV entsprechend Anwendung findet, (3) die auf den unionsrechtlichen Grundsatz der Rechtssicherheit gestützte DefrenneRechtsprechung bei Auslegungsentscheidungen sowie (4) die Frage einer vorübergehenden Aussetzung der Verdrängungswirkung unmittelbar anwendbaren Unionsrechts in der Winner Wetten-Konstellation, in der der Gerichtshof eine entsprechende Anwendung des Art. 264 II AEUV in Erwägung zieht. ${ }^{464}$

463 Siehe zur Einordnung auch Düsterhaus, YEL 36 (2017), 237 (266f.); Düsterhaus, EuR 2017, 30 (52). Er sieht zudem eine Parallele zu EuGH, Urteil vom 28.2.2012, Rs. C-41/11 (Inter-Environnement Wallonie und Terre wallonne). $\mathrm{Zu}$ dieser Rechtssache ausführlich unten bei Fn. $1439 \mathrm{ff}$.

464 So auch die Einteilung bei Düsterhaus, YEL 36 (2017), 237 (269 f.). 
In allen Konstellationen geht es letztlich um die Aufrechterhaltung einer mit Unionsrecht unvereinbaren Situation, sodass jedenfalls im Ausgangspunkt zwischen ihnen kein wesensmäßiger Unterschied festzustellen ist. In allen Fällen ist jeweils eine Abwägung der betroffenen Interessen auf Unionsebene vorzunehmen. Eine Annäherung zwischen der DefrenneRechtsprechung und den Fällen der (direkten oder analogen) Anwendung von Art. 264 II AEUV erscheint daher jedenfalls nicht ausgeschlossen. Denkt man die sich in UNIS und Beaudout Père et Fils andeutende Entwicklung der Rechtsprechung daher einmal weiter, so zeigt sich, dass es durchaus möglich wäre, die Voraussetzungen des guten Glaubens und der Gefahr schwerwiegender Störungen durch materiellrechtliche Erwägungen abzulösen. ${ }^{465}$ Diesen Schritt einer Vereinheitlichung der Prüfungsmaßstäbe ist der Gerichtshof allerdings noch nicht gegangen. Zu bedenken ist auch, dass der Gerichtshof durch eine Ablösung der Kriterien der Defrenne-Rechtsprechung zwar mehr Flexibilität gewänne, er durch diese Kriterien seiner Rechtsprechung aber auch einen Rahmen gegeben hat, der sie vorhersehbarer macht. Diesen Gewinn muss er nicht ohne Not opfern.

Über die jeweiligen Besonderheiten der erwähnten Konstellationen können die angestellten Überlegungen auch nicht hinwegtäuschen. So ist etwa zu bedenken, dass in der Winner Wetten-Konstellation eine auf den jeweils betroffenen Mitgliedstaat bezogene Aussetzung der Verdrängungswirkung in Rede steht, während die Defrenne-Rechtsprechung eine unionsweit einheitliche Begrenzung der Möglichkeit, sich auf eine ausgelegte Norm zu berufen, im Blick hat. ${ }^{466}$

Angesichts dieses Unionsbezugs einer Begrenzung der zeitlichen Wirkungen im Sinne der Defrenne-Rechtsprechung ist besonderes Augenmerk darauf zu richten, inwieweit der Gerichtshof den von ihm herangezogenen Kriterien einen unionsweiten Maßstab zugrunde legt. Während sich beim Kriterium des guten Glaubens ein solcher aufdrängt, ist dies beim Kriterium der Gefahr schwerwiegender Störungen schon problematischer. Auch wenn hier ein unionsweiter Maßstab gewählt wird, tritt doch der

465 So die Überlegungen von Düsterhaus, EuR 2017, 30 (51 f., 55); Düsterhaus, YEL 36 (2017), 237 (266 f., 269 f.).

466 Dieser Befund soll hier bereits einmal Erwähnung finden, ist aber im weiteren Verlauf der Arbeit noch näher zu entfalten. Verwiesen sei an dieser Stelle daher auf die Ausführungen bei Fn. 1387 ff. und Fn. 1396 ff. zur Aussetzung der Verdrängungswirkung im Sinne der Winner Wetten-Rechtsprechung und bei Fn. 1023 ff. zur räumlichen Erstreckung einer zeitlichen Begrenzung im Sinne der Defrenne-Rechtsprechung. 
Mitgliedstaat des Ausgangsverfahrens stärker als bei der Voraussetzung des guten Glaubens in den Vordergrund. Die Untersuchung der Kriterien der Defrenne-Rechtsprechung beginnt daher mit einem Blick auf das Kriterium des guten Glaubens, um sich im Anschluss daran dem Kriterium der Gefahr schwerwiegender Störungen zuzuwenden.

\section{Guter Glaube}

Guten Glauben nimmt der Gerichtshof an, wenn eine „objektive, bedeutende Unsicherheit hinsichtlich der Tragweite der Unionsbestimmungen “ 467 bestand. ${ }^{468}$ Eine Auseinandersetzung mit der Voraussetzung guten Glaubens macht es erforderlich, herauszuarbeiten, welcher Personenkreis guten Glaubens sein muss, in Bezug worauf dieser gute Glaube bestehen muss und welches Verständnis sich hinter dem Begriff der „Unsicherheit“ verbirgt.

467 Siehe z.B. EuGH, Urteil vom 13.12.2018, Rs. C-385/17 (Hein), Rn. 58; EuGH, Urteil vom 22.9.2016, Rs. C-110/15 (Microsoft Mobile Sales International u.a.), Rn. 61; EuGH, Urteil vom 22.1.2015, verb. Rs. C-401/13 und C-432/13 (Balazs), Rn. 51; EuGH, Urteil vom 10.4.2014, Rs. C-190/12 (Emerging Markets Series of DFA Investment Trust Company), Rn.110; EuGH, Urteil vom 27.2.2014, Rs. C-82/12 (Transportes Jordi Besora), Rn. 42; EuGH, Urteil vom 10.5.2012, verb. Rs. C-338/11 bis C-347/11 (Santander Asset Management SGIIC u.a.), Rn.60. Zum Teil formuliert der Gerichtshof geringfügig abweichend, ohne dass damit ein Unterschied in der Sache verbunden wäre, siehe z.B. EuGH, Urteil vom 19.7.2012, Rs. C-263/11 (Rēdlihs), Rn. 60: „objektive, bedeutende Unsicherheit hinsichtlich der Tragweite der unionsrechtlichen Bestimmungen oder Grundsätze" und EuGH, Urteil vom 19.12.2013, Rs. C-209/12 (Endress), Rn. 36: „erhebliche objektive Unsicherheit hinsichtlich der Tragweite der Bestimmungen des Unionsrechts“.

468 Vgl. Karpenstein, in: Grabitz/Hilf/Nettesheim (Hrsg.), Recht der EU, Art. 267 AEUV, Rn. 115 (Stand: Mai 2013). Kovács, Temporale Wirkung, 2014, S. 146 spricht unter Verweis u.a. auf GA Kokott, Schlussanträge vom 18.9.2007 in der Rs. C-161/06 (Skoma-Lux), Rn. 89 f. von einer „synonymialen“ Verwendung der beiden Formulierungen; Rosenkranz, Beschränkung der Rückwirkung, 2015, S. 145 mit Fn. 188 spricht von einer „Gleichsetzung“. Siehe auch Forsthoff, DStR 2005, 1840 (1841). 


\section{a) Betroffene}

Beschreibt der Gerichtshof den Personenkreis, bei dem guter Glaube vorhanden sein muss, bezieht er sich häufig auf „die Einzelnen und die nationalen Behörden“. ${ }^{469}$ Damit sind die möglichen Adressaten unionsrechtlicher Bestimmungen angesprochen, zu denen neben privaten Rechtssubjekten auch die Mitgliedstaaten gehören. Es stehen also unionsrechtliche Rechtspositionen $^{470}$ der „Betroffenen“471 in Rede. Zum Teil spricht der Gerichtshof auch vom guten Glauben der „betroffenen Verkehrskreise“. 472

$\mathrm{Zu}$ betrachten hat der Gerichtshof die Frage des Vorliegens von gutem Glauben demnach aus einem sämtliche Betroffene umspannenden Blickwinkel. Wählt er diesen Ausgangspunkt, ist es unschädlich, wenn er im Anschluss an die Verneinung des Bestehens einer objektiven, bedeutenden Unsicherheit etwa mit Blick auf die im Anlassfall um die zeitliche Begrenzung ersuchende rumänische Regierung bilanzierend feststellt, dass bei den „Betroffenen bei den rumänischen Behörden“473 kein guter Glaube bestehe. Insoweit verengt der Gerichtshof nicht den Blickwinkel auf einen Ausschnitt des Adressatenkreises der unionsrechtlichen Norm, sondern hält lediglich fest, was auch für etwaige sonstige Betroffene gelten würde.

469 Z.B. EuGH, Urteil vom 18.1.2007, Rs. C-313/05 (Brzeziński), Rn. 57; EuGH, Urteil vom 13.4.2010, Rs. C-73/08 (Bressol u.a.), Rn.93; EuGH, Urteil vom 20.9.2001, Rs. C-184/99 (Grzelczyk), Rn. 53; EuGH, Urteil vom 22.9.2016, Rs. C-110/15 (Microsoft Mobile Sales International u.a.), Rn. 61; EuGH, Urteil vom 22.1.2015, verb. Rs. C-401/13 und C-432/13 (Balazs), Rn. 51; EuGH, Urteil vom 19.12.2013, Rs. C-209/12 (Endress), Rn. 36; EuGH, Urteil vom 10.4.2014, Rs. C-190/12 (Emerging Markets Series of DFA Investment Trust Company), Rn. 110; EuGH, Urteil vom 9.4.2014, Rs. C-616/11 (T-Mobile Austria), Rn. 51 f.; EuGH, Urteil vom 18.10.2012, Rs. C-525/11 (Mednis), Rn.43; EuGH, Urteil vom 13.12.2012, Rs. C-465/11 (Forposta und ABC Direct Contact), Rn. 45; EuGH, Urteil vom 28.2.2018, Rs. C-672/16 (Imofloresmira - Investimentos Imobiliários), Rn. 59; EuGH, Urteil vom 20.12.2017, Rs. C-516/16 (Erzeugerorganisation Tiefkühlgemüse), Rn. 90; EuGH, Urteil vom 19.10.2017, Rs. C-101/16 (Paper Consult), Rn. 66.

470 Entscheidend ist also die rechtliche Betroffenheit, vgl. Rosenkranz, Beschränkung der Rückwirkung, 2015, S. 213.

471 EuGH, Urteil vom 22.9.2016, Rs. C-110/15 (Microsoft Mobile Sales International u.a.), Rn. 60; EuGH, Urteil vom 18.10.2012, Rs. C-525/11 (Mednis), Rn. 42; EuGH, Urteil vom 29.9.2015, Rs. C-276/14 (Gmina Wrocław), Rn. 45.

472 EuGH, Urteil vom 28.9.1994, Rs. C-57/93 (Vroege), Rn. 28; EuGH, Urteil vom 28.9.1994, Rs. C-128/93 (Fisscher), Rn. 25. EuGH, Urteil vom 11.12.1997, Rs. C-246/96 (Magorrian und Cunningham), Rn. 28 spricht von „die betroffenen beruflichen Kreise“.

473 EuGH, Urteil vom 19.10.2017, Rs. C-101/16 (Paper Consult), Rn. 69. 
Die erste Voraussetzung für eine Begrenzung der zeitlichen Wirkungen lässt sich damit als „Kriterium der Gutgläubigkeit der Betroffenen“ ${ }^{474}$ beschreiben.

\section{b) Bezugspunkt des guten Glaubens}

Wendet man sich der Frage nach dem Bezugspunkt des guten Glaubens dieser Betroffenen zu, mag für diese zwar in vielen Fällen der Wunsch bestehen, sich bei ihrem Verhalten an nationalen Rechtsvorschriften zu orientieren. Es scheint daher zunächst naheliegend, das „Vertrauen“ auf den rechtlichen Bestand nationaler Normen als Anknüpfungspunkt zu wählen. ${ }^{475}$ In eine ähnliche Richtung weist auch die in der Literatur geäußerte Überlegung, wonach innerhalb des Mitgliedstaats des Ausgangsverfahrens ein sachlicher Grund für eine Unsicherheit über die Gültigkeit und Auslegung des Unionsrechts bestehen müsse. ${ }^{476}$ Beide Male werden die mitgliedstaatlichen Rechtsordnungen und ihre Besonderheiten in den Mittelpunkt der Betrachtung gerückt. Aus der Sicht des Unionsrechts sind diese für die Frage des guten Glaubens allerdings irrelevant; wie sich die innerstaatliche Vertrauenslage darstellt, wird vom EuGH nicht berücksichtigt. 477

Wenn die Betroffenen geltend machen, sie hätten „in gutem Glauben und in der vollen Überzeugung gehandelt, dass die in den Ausgangsverfahren fragliche nationale Regelung vollständig mit dem Unionsrecht vereinbar sei“478, erscheint dieser Vortrag zwar auf den ersten Blick im selben Licht wie die soeben zurückgewiesenen Ansichten. Letztlich wird aber doch ein entscheidend anderer Akzent gesetzt. In der wiedergegebenen Passage beziehen sich die Betroffenen nicht auf ihr Vertrauen in nationales Recht, sondern auf dessen Vereinbarkeit mit Unionsrecht. Von der Unionsrechtskonformität des nationalen Rechts können die Betroffenen aber

474 EuGH, Urteil vom 21.3.2013, Rs. C-92/11 (RWE Vertrieb), Rn. 63.

475 So Langohr-Plato, MDR 1992, 838 (840), der daraus den Schluss zieht, dass neue Rechtsentwicklungen nur mit Wirkung für die Zukunft Anwendung finden sollten.

476 Hufen/Nörr Stiefenhofer Lutz, Beschränkung von Urteilswirkungen, Rechtsgutachten, Teil 1, 2008, S. 47.

477 Ebenso Нuеp, Beschränkung einer Rückwirkung, 2001, S. 90 f. Näher sogleich bei Fn. $558 \mathrm{ff}$.

478 Vgl. EuGH, Urteil vom 22.9.2016, Rs. C-110/15 (Microsoft Mobile Sales International u.a.), Rn. 58. 
nur ausgehen, wenn sie die unionsrechtlichen Bestimmungen in einer Weise verstehen, die das nationale Recht als mit den unionsrechtlichen Vorgaben vereinbar erscheinen lässt. Im Ergebnis beziehen sie sich damit auf die Unionsrechtslage. Dieser Ansatz entspricht auch dem Verständnis des EuGH. Wenngleich er in der Rechtssache Emerging Markets Series of DFA Investment Trust Company mangels Nachweises des Bestehens einer Gefahr schwerwiegender Störungen das Kriterium des guten Glaubens nicht untersucht hat, so macht er doch deutlich, dass diese Untersuchung der Frage nachgegangen wäre, „ob die Republik Polen die Bestimmungen des Körperschaftsteuergesetzes in gutem Glauben für unionsrechtskonform gehalten hat" ${ }^{\text {479. }}$.

Als Bezugspunkt des guten Glaubens kommt demnach lediglich die unionsrechtliche Rechtslage in Betracht. ${ }^{480}$ Er findet sich auch bereits in der vom EuGH verwendeten Wortwahl wieder, wonach eine „objektive, bedeutende Unsicherheit hinsichtlich der Tragweite der Unionsbestimmungen" bestanden haben muss. ${ }^{481}$ Durch die Wahl dieses Bezugspunktes wird insbesondere die Eigenständigkeit der Unionsrechtsordnung gegenüber den mitgliedstaatlichen Rechtsordnungen betont. ${ }^{482}$

Vor dem Hintergrund dieser Erkenntnis sind die Ausführungen des EuGH in der Rechtssache Bosman zu beurteilen, die dem ersten Anschein nach Zweifel an der Richtigkeit des dem Gerichtshof hier zugeschriebenen Verständnisses aufkommen lassen könnten. Der EuGH bezieht sich dort nämlich auf eine Vielzahl unterschiedlicher, von den Sportverbänden aufgestellter Regeln und damit auf das Verhalten nichtstaatlicher Akteure, um den Zustand der Unsicherheit im Hinblick auf die Vereinbarkeit dieser Regeln mit dem Unionsrecht zu begründen. ${ }^{483}$ Der Gerichtshof erweckt damit den Eindruck, dass die Besonderheiten der Regeln der Sportverbän-

479 EuGH, Urteil vom 10.4.2014, Rs. C-190/12 (Emerging Markets Series of DFA Investment Trust Company), Rn. 113. Zu dem mit dieser Formulierung in anderer Hinsicht erweckten falschen Eindruck siehe sogleich bei Fn. $488 \mathrm{ff}$.

480 Ebenso Müller, Begrenzung, 2009, S. 121; Ludewig, Zeitliche Beschränkung, 2012, S. 130. Auch GA Wathelet, Schlussanträge vom 4.9.2014 in den verb. Rs. C-401/13 und C-432/13 (Balazs), Rn. 93 führt aus, der gute Glaube beziehe sich auf das Vertrauen auf die Auslegung des Unionsrechts und nicht des nationalen Rechts. Franzen, RIW 2010, 577 (578) sieht nur Fallgestaltungen erfasst, in denen die unionsrechtliche Rechtslage unsicher war; Schlachter, ZfA 2007, 249 (267) hält die abweichende Beurteilung der unionsrechtlichen Rechtslage durch mitgliedstaatliche Akteure für unzureichend.

481 Siehe die Nachweise oben in Fn. 467.

482 Vgl. Müller, Begrenzung, 2009, S. 122.

483 EuGH, Urteil vom 15.12.1995, Rs. C-415/93 (Bosman), Rn. 143. 
de ausschlaggebend für den Zustand der Unsicherheit seien. Dabei mag die Mächtigkeit dieser intermediären Gewalten für ihn eine Rolle gespielt haben. ${ }^{484}$ Das bedeutet aber noch nicht zwingend, dass er hier auf das Bestehen einer „Unsicherheit“ auf Unionsebene verzichtet hat. ${ }^{485}$

Zur Stützung dieser Einschätzung muss der Blick, ausgehend von der Komplexität der Verbandsregeln, auf das Unionsrecht gerichtet werden. Die Komplexität dieser Regeln führt dazu, dass die Beurteilung ihrer Unionsrechtskonformität Schwierigkeiten bereitet. Die unionsrechtlichen Vorgaben sind in diesem Fall also schwierig zu ermitteln, weswegen (auch) die Unvereinbarkeit der Verbandsregeln mit Unionsrecht schwierig zu beurteilen ist. Damit stellt der Gerichtshof aber trotz der anders anmutenden Formulierung nicht auf die Verbandsregeln als Bezugspunkt des guten Glaubens ab. 486

Wenn er allerdings von einem Zustand der Unsicherheit hinsichtlich der Vereinbarkeit der Verbandsregeln mit dem Unionsrecht spricht, scheint er einen weniger strengen Maßstab anzulegen, wenn man bedenkt, dass er sonst die scheinbare Eindeutigkeit der unionsrechtlichen Rechtslage fordert. ${ }^{487}$ Dass die Vereinbarkeit mit Unionsrecht unsicher ist, die streitige Regelung also nicht offensichtlich mit Unionsrecht unvereinbar ist, ist ja nicht gleichbedeutend mit einer Überzeugung von ihrer Vereinbarkeit mit Unionsrecht.

Gründe, den Maßstab bei einer unübersichtlichen nationalen Rechtslage gegenüber sonstigen Fällen abzusenken, sind jedoch nicht ersichtlich. So ist eine derartige Absenkung bei unübersichtlichen nationalen Regelungen insbesondere nicht zwingend, wie die folgende Überlegung zeigt: Gerade die Komplexität der Fragestellung kann den zutreffenden Blick auf die dafür geltenden unionsrechtlichen Anforderungen verstellen. Bei den Beteiligten kann in diesem Fall der (irrtümliche) Eindruck erweckt werden, die mitgliedstaatliche Regelung sei unionsrechtlich unbedenklich, da die unionsrechtliche Rechtslage als scheinbar eindeutig erscheint. Insoweit besteht dann auch die im Übrigen verlangte „Unsicherheit“ hinsichtlich

484 Vgl. Ludewig, Zeitliche Beschränkung, 2012, S. 140. Dass das Verhalten Privater ausschlaggebend für die Bejahung der Unsicherheit war, meinen auch Kovács, Temporale Wirkung, 2014, S. 159 und Lindemann/Hackemann, IStR 2005, 786 (788).

485 In diesem Sinne aber Müller, Begrenzung, 2009, S. 121.

486 Siehe dazu auch Rosenkranz, Beschränkung der Rückwirkung, 2015, S. 146 mit Fn. 192 und S. 201.

487 Siehe dazu näher sogleich bei Fn. 505 ff. 
der Tragweite der Unionsbestimmungen, die demnach auch bei einer unübersichtlichen nationalen Rechtslage zu fordern ist.

\section{c) Objektivierter Maßstab}

Einzelne Formulierungen des Gerichtshofs legen zwar ein Verständnis des Kriteriums des guten Glaubens nahe, wonach die Betroffenen tatsächlich in gutem Glauben gewesen sein bzw. gehandelt haben müssen. So hat der Gerichtshof etwa die Frage aufgeworfen, „ob die Republik Polen die Bestimmungen des Körperschaftsteuergesetzes in gutem Glauben für unionsrechtskonform gehalten hat" („whether the Republic of Poland held in good faith the belief that $\left.[\ldots]^{6}\right){ }^{488}$ Der hier erweckte Eindruck spiegelt den anzulegenden Maßstab aber nicht zutreffend wider.

Bei der Voraussetzung des guten Glaubens ist vielmehr entscheidend, ob das Verständnis des Unionsrechts nach einem objektivierten Maßstab als vernünftig erscheint ${ }^{489}$, wie die entsprechenden Passagen zahlreicher Urteile des Gerichtshofs zeigen. Dort heißt es etwa, der Mitgliedstaat „durfte [...] aufgrund des Verhaltens der Kommission annehmen, daß"490; ein vorhergehendes Urteil konnte „bei vernünftiger Betrachtung Ungewißheit darüber entstehen lassen“491; die Umstände konnten „bei vernünftiger Betrachtung zu der Annahme veranlassen “492; die Haltung der Kommission „konnte die betroffenen Kreise in Belgien zu Recht insbesondere zu der Annahme verleiten "493; angesichts unionsrechtlicher Bestimmungen „durften die Mitgliedstaaten und die Betroffenen vernünftigerweise annehmen" 494 .

Lässt die unionsrechtliche Rechtslage „keinen Zweifel“ zu und verstößt das nationale Recht „eindeutig“ gegen unionsrechtliche Vorgaben, besteht demnach keine „erhebliche objektive Unsicherheit““ ${ }^{495}$ In diesem Fall kön-

488 EuGH, Urteil vom 10.4.2014, Rs. C-190/12 (Emerging Markets Series of DFA Investment Trust Company), Rn. 113.

489 So auch Ludewig, Zeitliche Beschränkung, 2012, S. 142; Kovács, Temporale Wirkung, 2014, S. 145 f.; Broberg/Fenger, Vorabentscheidungsverfahren, 2014, S. 397.

490 EuGH, Urteil vom 9.3.2000, Rs. C-437/97 (EKW und Wein \& Co.), Rn. 58.

491 EuGH, Urteil vom 4.5.1999, Rs. C-262/96 (Sürül), Rn. 110.

492 EuGH, Urteil vom 16.7.1992, Rs. C-163/90 (Legros u.a.), Rn. 33.

493 EuGH, Urteil vom 2.2.1988, Rs. 24/86 (Blaizot u.a.), Rn. 33.

494 EuGH, Urteil vom 17.5.1990, Rs. C-262/88 (Barber), Rn. 43.

495 EuGH, Urteil vom 19.12.2013, Rs. C-209/12 (Endress), Rn. 38 f. 
nen die Betroffenen nicht zu der von ihnen geltend gemachten Annahme berechtigt gewesen sein. ${ }^{496}$

Konsequenz des objektivierten Prüfungsmaßstabs ${ }^{497}$ ist es, dass auf eine individuelle Vertrauensschutzprüfung verzichtet wird. Da das subjektive Verständnis der Betroffenen nicht entscheidend ist, kommt der gute Glaube auch demjenigen zugute, der nicht individuell „vertraut" hat. ${ }^{498}$

Auch wenn der Gerichtshof eine „objektive, bedeutende Unsicherheit“ fordert, musste er vor dem Hintergrund des vorstehend Gesagten das Merkmal der „bedeutenden“ Rechtsunsicherheit nicht eigenständig mit Leben füllen. ${ }^{499} \mathrm{Er}$ verzichtet ja hinsichtlich des Kriteriums des guten Glaubens auf eine Prüfung, in wie vielen Fällen tatsächlich eine vermeintliche Sicherheit bestand. Dass er hierauf verzichtet, ist folgerichtig, da lediglich entscheidend ist, ob die Betroffenen vernünftigerweise von einer bestimmten Rechtslage ausgehen durften. ${ }^{500}$ Auf die tatsächliche Verbreitung dieses Verständnisses kann es für die Frage des guten Glaubens daher nicht ankommen. Sie erlangt erst im Rahmen der zweiten Begrenzungsvoraussetzung - dem Bestehen einer Gefahr schwerwiegender Störungen Bedeutung, die insoweit als Korrektiv wirkt.

Die bisherigen Ausführungen erlauben eine Abgrenzung des Begriffs des guten Glaubens etwa vom subjektiven Element rechtsmissbräuchlichen Verhaltens. Vom Vorliegen eines Rechtsmissbrauchs in objektiver und subjektiver Hinsicht kann daher jedenfalls nicht ohne Weiteres auf fehlenden guten Glauben im Sinne der Beschränkungsrechtsprechung geschlossen werden. ${ }^{501} \mathrm{Da}$ der an den guten Glauben angelegte Maßstab kein subjektiver, sondern ein verobjektivierter ist, bei dem es letztlich darum geht, welche Auslegung einer Unionsrechtsnorm der EuGH vornehmen wird, wird eine im Ausgangspunkt andere Frage als die nach dem Vorliegen des subjektiven Elements eines Rechtsmissbrauchs gestellt.

Die Frage des guten Glaubens ist unionsweit einheitlich zu beantworten. Anders als Generalanwalt Campos Sánchez-Bordona in seinen Schluss-

496 EuGH, Urteil vom 12.10.2000, Rs. C-372/98 (Cooke), Rn. 46.

497 Siehe auch EuGH, Urteil vom 15.12.1995, Rs. C-415/93 (Bosman), Rn. 146; EuGH, Urteil vom 31.3.1992, Rs. C-200/90 (Dansk Denkavit und Poulsen Trading), Rn. 21.

498 Vgl. auch Ludewig, Zeitliche Beschränkung, 2012, S. 163; siehe auch Düsterhaus, YEL 36 (2017), 237 (252).

499 Kovács, Temporale Wirkung, 2014, S. 162.

500 Vgl. Ludewig, Zeitliche Beschränkung, 2012, S. 163.

501 So aber GA Bobek, Schlussanträge vom 7.9.2017 in der Rs. C-251/16 (Cussens u.a.), Rn. 53. 
anträgen in den verbundenen Rechtssachen Eco-Emballages und Melitta France u.a. meint, kann angesichts ihrer unionsweiten Bedeutung die Frage des guten Glaubens der im Vorlageverfahren betroffenen Unternehmen daher nicht dem für die Entscheidung des Ausgangsverfahrens zuständigen Gericht überlassen werden. ${ }^{502}$ Durch die vom Gerichtshof unionsweit einheitlich vorzunehmende Beantwortung der Frage nach dem Bestehen von gutem Glauben wird die Frage nach dem guten Glauben der im Vorlageverfahren betroffenen Unternehmen mitbeantwortet. Ist guter Glaube zu bejahen, können diese sich darauf auch dann berufen, wenn sie selbst keine entsprechende Überzeugung vom Inhalt des Unionsrechts gebildet haben. ${ }^{503}$

In Rede stand in diesen verbundenen Rechtssachen die Frage, ob Rollenkerne Verpackungen im Sinne einer Richtlinie über Verpackungen und Verpackungsabfälle darstellen, was Auswirkungen auf die Pflicht zur Tragung der Recyclingkosten durch die betroffenen Unternehmen hat. Für die Frage des guten Glaubens kommt es entscheidend darauf an, ob es als vermeintlich sicher angesehen werden konnte, dass es sich bei den Rollenkernen nicht um Verpackungen im Sinne der Richtlinie handelt. Dass es sich bei der Frage, ob die im Ausgangsverfahren betroffenen Unternehmen früher bereits entsprechende Beiträge für das Recycling von Rollenkernen entrichtet haben, um eine tatsächliche Frage handelt, die besser vor dem vorlegenden nationalen Gericht erörtert werden könnte, ist dagegen nicht entscheidend. Zwar mag man daraus, ob ein Unternehmen Beiträge für das Recycling von Rollenkernen entrichtet hat, Rückschlüsse darauf ziehen, wie es selbst zur Einordnung der Rollenkerne als Verpackung steht. Wie die einzelnen Unternehmen die Rollenkerne einordnen, lässt aber noch keinen endgültigen Rückschluss auf das Verständnis des Unionsrechts zu. Allenfalls handelt es sich um ein Indiz, da es auf die tatsächliche Verbreitung des Verständnisses vom Inhalt des Unionsrechts wie gesehen nicht ankommt. ${ }^{504}$

502 GA Campos Sánchez-Bordona, Schlussanträge vom 13.7.2016 in den verb. Rs. C-313/15 und C-530/15 (Eco-Emballages und Melitta France u.a.), Rn. 59 mit Fn. 32.

503 Nur in dem Fall, in dem für den Prozessgegner eine Ausnahme von einer möglichen zeitlichen Begrenzung gemacht wird, würde ihnen der gute Glaube nicht weiterhelfen.

$504 \mathrm{Zu}$ dieser Rechtssache ausführlich noch unten bei Fn. 693 ff. Der EuGH äußert sich in seinem Urteil nicht zur Frage einer zeitlichen Begrenzung, vgl. EuGH, Urteil vom 10.11.2016, verb. Rs. C-313/15 und C-530/15 (Eco-Emballages und Melitta France u.a.). 
d) Scheinbare Eindeutigkeit

Nachdem mit der unionsrechtlichen Rechtslage der Bezugspunkt des guten Glaubens herausgearbeitet worden ist und feststeht, dass ein objektivierter Prüfungsmaßstab zugrunde zu legen ist, stellt sich die Frage, welches Verständnis der EuGH mit dem Begriff der „Unsicherheit“ verbindet.

Dieser ist, anders als es ein unbefangenes Verständnis vielleicht nahelegen würde, nicht in dem Sinne zu verstehen, dass die unionsrechtliche Rechtslage derart unklar sein muss, dass die Vereinbarkeit des nationalen Rechts mit den unionsrechtlichen Vorgaben nicht eindeutig beurteilt werden kann. In einem solchen Fall sollten die Beteiligten Achtsamkeit walten lassen und eindeutig unionsrechtskonforme Wege beschreiten. ${ }^{505}$ Auch bloße Zweifel hinsichtlich des Inhalts des Unionsrechts genügen nicht für die Bejahung von „Unsicherheit“. Dahinter steht die Erwägung, dass sonst insbesondere die Mitgliedstaaten dazu verführt würden, die Grenzen des unionsrechtlich Erlaubten auszutesten ${ }^{506}$, was aber nicht bedeutet, dass sich die Voraussetzung des guten Glaubens stets gegen die Mitgliedstaaten richten würde. Ihnen kommt das Erfordernis des guten Glaubens etwa dann zugute, wenn der Gerichtshof eine nicht vorhersehbare, zu Lasten der Mitgliedstaaten gehende extensive Auslegung des Unionsrechts vornimmt, gegenüber der sie sich auf guten Glauben berufen können. ${ }^{507}$

„Unsicherheit“ im Sinne der Defrenne-Rechtsprechung ist gegeben, wenn die unionsrechtlichen Vorgaben scheinbar eindeutig sind. ${ }^{508}$ In diesem Fall liegt gewissermaßen eine in die Irre führende Lage vor. ${ }^{509}$ Die unionsrechtliche Norm muss also vermeintlich sicher in einem bestimm-

505 GA Sharpston, Schlussanträge vom 22.6.2006 in der Rs. C-228/05 (Stradasfalti), Rn. $87 \mathrm{f}$.

506 Seer, European Taxation 2006, 470 (475 f.). Er verweist zutreffend darauf, dass beim Bestehen einer „Unsicherheit“ diese vorrangig beseitigt und nur hilfsweise auf eine Begrenzung der Urteilsfolgen zurückgegriffen werden sollte, Verlässlichkeit und Vorhersehbarkeit der Rechtsprechung des Gerichtshofs also im Vordergrund stehen sollten. Siehe auch Seer/Müller, IWB 2008, 255 (263), die von einem ansonsten „nahezu unwiderstehlichen“ Anreiz für die Mitgliedstaaten zu unionsrechtswidrigem Verhalten sprechen.

507 Seer, European Taxation 2006, 470 (475) spricht insoweit von einer Stärkung der Position der Mitgliedstaaten.

508 Ludewig, Zeitliche Beschränkung, 2012, S. 130 nennt dies eine „objektive und bedeutende vermeintliche Sicherheit" (Hervorhebung im Original). Rosenkranz, ZfPW 2016, 351 (358, Fn. 29) sieht die Verwendung des Begriffs „Unsicherheit“ in einer Gegenüberstellung und Abgrenzung zur Rechtssicherheit begründet.

509 Lang, Intertax 35 (2007), 230 (231). 
ten Sinn zu verstehen gewesen sein, der sich im Nachhinein als unzutreffend erweist. Die Betroffenen können in diesem Fall behaupten, von der Vereinbarkeit mit Unionsrecht „überzeugt“510 gewesen zu sein. Dass diese Überzeugung nicht mit einem subjektiven Empfinden gleichzusetzen ist ${ }^{511}$, liegt im objektivierten Maßstab begründet.

Mit dem Fehlen von Bösgläubigkeit kann guter Glaube daher nicht gleichgesetzt werden. Ein solches Verständnis scheint allerdings Generalanwalt Wahl in seinen Schlussanträgen in der Rechtssache Carrefour Hypermarchés u.a. zugrunde zu legen. In Rede stand in dieser Rechtssache die Frage, ob eine starke Erhöhung der Einnahmen aus einer Abgabe, die eine genehmigte Beihilfenregelung finanziert, als „neue Beihilfe“ einzustufen ist, die der Kommission hätte gemeldet werden müssen. Wenn Generalanwalt Wahl ausführt, es habe erhebliche Rechtsunsicherheit in Bezug auf die richtige Auslegung des Begriffs „Änderungen bestehender Beihilfen" bestanden, sodass die französischen Behörden und die Begünstigten der Beihilfenregelung nicht bösgläubig gewesen seien ("nothing suggests that the French authorities or the beneficiaries under the aid scheme acted in bad faith"), da die Kommission die Erhöhung bislang nicht in Frage gestellt habe ${ }^{512}$, so ist dies zumindest missverständlich. Handeln die Betroffenen nicht bösgläubig, ist damit noch nicht gesagt, dass guter Glaube im Sinne der Defrenne-Rechtsprechung besteht. Nicht bösgläubig sind die Betroffenen auch, wenn sie keine Zweifel an der Unionsrechtskonformität ihres Verhaltens hegen. Damit ist aber noch nicht gesagt, dass sie deshalb keine Zweifel haben, weil sie vernünftigerweise von einem bestimmten Inhalt des Unionsrechts ausgehen durften.

e) Bildung einer Überzeugung vom Inhalt des Unionsrechts

Zur näheren Bestimmung, wann eine „objektive“ Unsicherheit anzunehmen ist, ist auch die Formulierung des EuGH anzusprechen, wonach für die Frage des Bestehens von gutem Glauben entscheidende Bedeutung erlangt, ob sich herausstellt, dass die Betroffenen zu einem mit der Unions-

510 Vgl. EuGH, Urteil vom 22.9.2016, Rs. C-110/15 (Microsoft Mobile Sales International u.a.), Rn. 62.

511 Dies betont auch Wusterhausen, Wirkungen, 2016, S. 188 f.; ebenso GA StixHackl, Schlussanträge vom 5.10.2006 in der Rs. C-292/04 (Meilicke u.a.), Rn. 41.

512 GA Wahl, Schlussanträge vom 30.11.2017 in der Rs. C-510/16 (Carrefour Hypermarchés u.a.), Rn. 101. 
regelung unvereinbaren Verhalten „veranlasst“ worden waren, „weil eine objektive, bedeutende Unsicherheit hinsichtlich der Tragweite der Unionsbestimmungen bestand, zu der eventuell auch das Verhalten anderer Mitgliedstaaten oder der Europäischen Kommission beigetragen hatte“ ${ }^{5} .13$

\section{aa) Veranlassung}

Aus dieser Äußerung des Gerichtshofs ergibt sich zunächst, dass „objektive" Unsicherheit nicht schon dann angenommen werden kann, wenn die Möglichkeit unterschiedlicher Auslegungen einer Vorschrift besteht. Normen, auch solche des Unionsrechts, offenbaren ihren genauen Inhalt in der Regel erst im Laufe der Zeit. Das Bestehen einer Vielzahl konkretisierungsbedürftiger unbestimmter Rechtsbegriffe zeigt, dass ihnen von vornherein „Unsicherheit" innewohnt. Diese Art der Unsicherheit kann im vorliegenden Zusammenhang aber nicht angesprochen sein, wenn nach der oben wiedergegebenen Formulierung des Gerichtshofs die Möglichkeit besteht, dass Kommission und Mitgliedstaaten zur „Unsicherheit“ beitragen. $\mathrm{Zu}$ einer durch die Unbestimmtheit einer Norm hervorgerufenen „Unsicherheit“ können die Kommission und die Mitgliedstaaten nämlich nicht im Anschluss an den Erlass der Norm beitragen. ${ }^{514}$

Die Formulierung, dass die Kommission und die Mitgliedstaaten zur Unsicherheit hinsichtlich der Tragweite der Unionsbestimmungen beitragen können ${ }^{515}$, weist noch eine weitere Dimension auf: Trägt ein Akteur zur Unsicherheit lediglich bei, muss sich die Unsicherheit bereits anderweitig und damit ohne Zutun der Kommission oder der Mitgliedstaaten ergeben können.

$\mathrm{Zu}$ etwas beitragen bedeutet, einen Anteil zur Verwirklichung dazuzutun, was das Erfordernis eines ursächlichen Zusammenhangs nahelegt. ${ }^{516}$

513 Siehe etwa EuGH, Urteil vom 19.10.2017, Rs. C-101/16 (Paper Consult), Rn. 66.

514 Zutreffend Rosenkranz, Beschränkung der Rückwirkung, 2015, S. 148.

515 Hervorgehoben etwa auch von Lang, in: Popelier/Verstraelen/Vanheule/Vanlerberghe (Hrsg.), The Effects of Judicial Decisions in Time, 2014, S. 245 (251).

516 Von vornherein nicht zur objektiven, bedeutenden Unsicherheit beigetragen haben können Stellungnahmen der Kommission, wenn sie erst nach dem Zeitraum abgegeben wurden, für den sie von den Betroffenen ins Feld geführt werden, vgl. EuGH, Urteil vom 28.10.2020, Rs. C-321/19 (Bundesrepublik Deutschland (Festlegung der Sätze der Mautgebühren für die Benutzung von Autobahnen)), Rn. $58 \mathrm{f}$. In Rede stand dort die Festsetzung von Mautsätzen, in die die Bundesrepublik Deutschland unzulässigerweise bestimmte Kosten einbezogen 
Ein Beitrag kann dann nicht hinweggedacht werden, ohne dass sich das Gesamtergebnis verändert. Auf die Frage des Bestehens einer Unsicherheit hinsichtlich der Tragweite der Unionsbestimmungen übertragen, hieße dies, dass das Verhalten beispielsweise der Kommission mitursächlich für die vermeintliche Sicherheit auf Unionsebene gewesen sein muss. Da der Gerichtshof aber wie gesehen ausführt, dass das Verhalten der Kommission „eventuell“ zur Unsicherheit beigetragen hat, muss dieses hinweggedacht werden können.

Damit kommt nach hier vertretener Ansicht auch eine der Norm inhärente „Unsicherheit“ für die Begründung guten Glaubens in Betracht, was voraussetzt, dass sie vermeintlich eindeutig in einem bestimmten Sinne zu verstehen ist. Hierfür müssen die Betroffenen unter Zugrundelegung der im Unionsrecht anerkannten Methoden der Rechtsfindung die der unionsrechtlichen Bestimmung zu entnehmende Aussage ermitteln. Gelangt der Gerichtshof nach Anwendung derselben Methoden zu einem anderen Ergebnis, ist Raum für die Annahme einer guten Glauben begründenden „Unsicherheit" des Unionsrechts. ${ }^{517}$

Die Rechtsunterworfenen müssen daher beispielsweise bedenken, dass sie eine Protokollerklärung zur Auslegung einer Ausnahmebestimmung nicht heranziehen können, wenn sich diese nicht im Wortlaut der Bestimmung niedergeschlagen hat. ${ }^{518}$ Auch Verhalten der Kommission im Anschluss an ein Urteil des Gerichtshofs in einer anderen Rechtssache kann nicht ohne Weiteres zur Begründung eines bestimmten Verständnisses des Unionsrechts herangezogen werden. So lehnte der EuGH etwa ein entsprechendes Ansinnen der deutschen Regierung mit der Erwägung ab, in dem früheren Urteil sei es um eine andere Fragestellung als im nun zu entscheidenden Fall gegangen. ${ }^{519}$ Bei der Bildung der Rechtsansicht müssen die Betroffenen also darauf achten, unterschiedliche Rechtsfragen nicht pauschal über einen Kamm zu scheren, sondern vielmehr mögliche Differenzierungen im Blick zu behalten, was die Vornahme einer Wertung erfordert.

hatte. Um das Bestehen von gutem Glauben zu begründen, hatte die Bundesrepublik Stellungnahmen der Kommission angeführt, die die Einbeziehung dieser Kosten gebilligt hatten; sie waren allerdings erst nach dem betroffenen Kalkulationszeitraum abgegeben worden.

517 Rosenkranz, Beschränkung der Rückwirkung, 2015, S. 162.

518 EuGH, Urteil vom 13.2.1996, verb. Rs. C-197/94 und C-252/94 (Bautiaa und Société française maritime), Rn. $50 \mathrm{ff}$.

519 EuGH, Urteil vom 17.2.2005, verb. Rs. C-453/02 und C-462/02 (Linneweber und Akritidis), Rn. 43; zustimmend Leonard/Szczekalla, UR 2005, 420 (423). 
Ebenfalls zu berücksichtigen sind die Besonderheiten der unionsrechtlichen Normauslegung. Eine isolierte Betrachtung einer Norm des Unionsrechts in einer ihrer Sprachfassungen ist danach nicht möglich; vielmehr ist die Vorschrift im Lichte ihrer Fassungen in den anderen Amtssprachen auszulegen. ${ }^{520}$ Angesichts der gleichen Verbindlichkeit aller Sprachfassungen kann es bei Unterschieden zwischen ihnen durch wertenden Vergleich zu einem neuen unionsautonomen Textverständnis kommen. ${ }^{521}$ Dies führt dazu, dass der durch eine einzelne Sprachfassung vermittelte Eindruck vom Verständnis einer Norm letztlich „schutzlos bleibt, wenn sich im Vergleich mit anderen Sprachfassungen ein anderer Normgehalt ergibt" ${ }^{.522}$ Ist der Wortlaut einer Bestimmung - gegebenenfalls unter Berücksichtigung seiner einzelnen Sprachfassungen - eindeutig, ist für abweichenden guten Glauben kein Raum. ${ }^{523}$

bb) Berücksichtigungsfähiges Verhalten

Die Beantwortung der Frage nach dem Bestehen von gutem Glauben beinhaltet letztlich eine vom Gerichtshof vorzunehmende Wertung. Eine Analyse der Rechtsprechung des EuGH kann daher lediglich Umstände veranschaulichen, die nach Ansicht des Gerichtshofs Anlass für guten Glauben geben, sie aber nicht abschließend aufführen. ${ }^{524}$ Zudem können der Rechtsprechung Aussagen entnommen werden, welche Gesichtspunkte zur Verneinung von gutem Glauben führen. Dabei zeigt sich, dass es

520 EuGH, Urteil vom 16.7.2009, Rs. C-428/07 (Horvath), Rn.35; EuGH, Urteil vom 15.10.2009, Rs. C-263/08 (Djurgården-Lilla Värtans Miljöskyddsförening), Rn. 25.

521 Levits, SR 2015, 121 (124).

522 Weiler, ZEuP 2010, 861 (879f.). Er äußert sich zu dieser Auslegungsmethode daher sehr kritisch und meint, sie verlange vom Rechtsanwender Unmögliches, a.a.O., S. 869.

523 EuGH, Urteil vom 30.3.2006, Rs. C-184/04 (Uudenkaupungin kaupunki), Rn. 58; GA Campos Sánchez-Bordona, Schlussanträge vom 28.3.2019 in der Rs. C-210/18 (WESTbahn Management), Rn.75; GA Saugmandsgaard Øe, Schlussanträge vom 28.2.2019 in der Rs. C-682/17 (ExxonMobil Production Deutschland), Rn. 104.

524 Düsterhaus, YEL 36 (2017), 237 (254f.) spricht von einem „comprehensive test executed with judicial discretion“, sodass guter Glaube auch unabhängig von den in der Rechtsprechung bislang thematisierten Konstellationen begründet werden kann. 
größere Schwierigkeiten bereitet, das Bestehen von gutem Glauben positiv festzustellen, als zu begründen, wann es zu verneinen ist. ${ }^{525}$

Allgemein gesprochen geht es um die Frage, welche Aspekte die Betroffenen neben den im Unionsrecht anerkannten Methoden der Rechtsauslegung in ihre Überzeugungsbildung einbeziehen dürfen. Der vom Gerichtshof in der oben wiedergegebenen Passage verwendete Begriff des "Veranlassens" zu einem mit der Unionsregelung unvereinbaren Verhalten beinhaltet einen Hinweis auf einen von außen kommenden Impuls. Werden die Betroffenen zu etwas veranlasst, werden sie dazu gebracht, etwas zu tun. Nach den bisherigen Erkenntnissen kann dieser Impuls auch von der Norm selbst ausgehen und muss nicht in der Äußerung einer Rechtsansicht durch einen tauglichen Akteur bestehen. ${ }^{526}$

Tätigt ein Akteur allerdings Aussagen zum Unionsrecht, stellt sich die Frage, ob seine Aussagen bei der Prüfung des guten Glaubens Berücksichtigung finden können. $\mathrm{Zu}$ untersuchen ist dies zunächst für die Akteure, die der Gerichtshof selbst ins Spiel bringt, die Kommission und die Mitgliedstaaten.

\section{(1) Kommission}

(a) Begründung der Beachtlichkeit von Verhalten der Kommission

Gegen die Berücksichtigung von Äußerungen der Kommission als Auslöser von gutem Glauben wird zum Teil ganz grundsätzlich eingewandt, diese seien rechtlich unverbindlich. Dies treffe erst recht auf ohne $\mathrm{Zu}-$ sammenhang zum Vertragsverletzungsverfahren getätigte Äußerungen zu, gelte aber auch für Äußerungen im Rahmen von Vertragsverletzungsverfahren. ${ }^{527}$ Eine solche Argumentation vermag jedoch nicht zu überzeugen.

Zuzugeben ist zwar, dass eine Pflicht zur Einleitung eines Vertragsverletzungsverfahrens seitens der Kommission ebenso wenig besteht wie eine Pflicht zur Klageerhebung nach Durchführung des Vorverfahrens. ${ }^{528} \mathrm{Zu}$ -

525 Nach Düsterhaus, YEL 36 (2017), 237 (252) lässt die bisherige Rechtsprechung des EuGH lediglich eine negative Definition zu.

526 In diesem Sinne aber wohl Rosenkranz, Beschränkung der Rückwirkung, 2015, S. 174 .

527 Dazu näher Müller, Begrenzung, 2009, S. $128 \mathrm{ff}$.

528 Siehe z.B. EuGH, Urteil vom 19.10.1995, Rs. C-137/94 (Richardson), Rn. 35, wo das Ermessen der Kommission im Hinblick auf die Einleitung eines Vertragsverletzungsverfahrens betont wird. 
treffend ist auch, dass Äußerungen der Kommission vor der Verfassung des das Vertragsverletzungsverfahren förmlich einleitenden Mahnschreibens wie auch im Mahnschreiben selbst noch ohne umfassende rechtliche Würdigung des mitgliedstaatlichen Verhaltens erfolgen; eine solche nimmt die Kommission also erst recht spät in der mit Gründen versehenen Stellungnahme vor. Zudem sind die Mitgliedstaaten nicht rechtlich verpflichtet, der rechtlichen Einschätzung der Kommission im Mahnschreiben und der mit Gründen versehenen Stellungnahme zu folgen.

Dass die Kommission im Vertragsverletzungsverfahren keine verbindliche Auslegung des Unionsrechts vornehmen kann, ist im hier diskutierten Zusammenhang aber ohne Bedeutung. Es geht lediglich darum, zu begründen, weshalb auch Äußerungen der Kommission für die Frage des Bestehens von gutem Glauben Bedeutung erlangen können.

Insoweit ist festzustellen, dass die Einschätzung der Unionsrechtswidrigkeit des mitgliedstaatlichen Verhaltens im Vertragsverletzungsverfahren zunächst der Kommission übertragen wird, bevor im Anschluss daran der Gerichtshof verbindlich entscheidet. Lässt man Äußerungen der Kommission als Auslöser von gutem Glauben zu, werden die Befugnisse der Kommission daher nicht überbewertet.

Zurückzuweisen ist auch der Einwand, die Beachtung von Kommissionsäußerungen im Zusammenhang mit Vertragsverletzungsverfahren als Auslöser von gutem Glauben würde präjudizähnliche Wirkung für das Vorabentscheidungsverfahren entfalten und wirke sich auf die materiellrechtliche Entscheidung des Gerichtshofs bei einer Auslegungsvorabentscheidung aus, was der Unabhängigkeit beider Verfahren widerspreche. ${ }^{529}$ Dem ist zunächst entgegenzuhalten, dass die Auslegung unabhängig von der Verfahrensart wirkt. ${ }^{530}$ Zudem entfalten die Äußerungen der Kommission keine präjudizähnliche Wirkung für das Vorabentscheidungsverfahren, wenn sie im Rahmen der Prüfung des guten Glaubens berücksichtigt werden. Die Begrenzung der zeitlichen Wirkungen wirkt ja nur als prozessuale Berufensschranke und führt nicht zu einer abweichenden Auslegung des Unionsrechts. ${ }^{531}$

Auch dass ein Mitgliedstaat für ihn positive wie negative Stellungnahmen der Kommission hinterfragen muss ${ }^{532}$, ändert nichts an ihrer Beacht-

529 So Müller, Begrenzung, 2009, S. 138.

530 Siehe dazu oben bei Fn. 165 und Fn. 275.

531 Näher zur „Art“ der Begrenzung oben bei Fn. 429 ff. und zusammenfassend bei Fn. $443 \mathrm{f}$.

532 Müller, Begrenzung, 2009, S. 137. 
lichkeit. Weshalb die Mitgliedstaaten nämlich „schlauer“533 als die Kommission sein sollen, ist nicht ersichtlich.

Die gegen die Berücksichtigung von Äußerungen der Kommission vorgebrachten Argumente sind daher zurückzuweisen. Mit der herausgehobenen Stellung der Kommission, die sich einerseits in ihrem Initiativrecht bei Rechtsetzungsvorhaben (Art. 294 II AEUV) und andererseits in ihrer Funktion als Hüterin der Verträge (Art.258 II, 218 XI, 263 II AEUV) widerspiegelt, lässt sich vielmehr begründen, weshalb ihrem Verhalten allgemein und damit auch außerhalb des durch ein Vertragsverletzungsverfahren abgesteckten Rahmens Bedeutung für das Vorliegen von gutem Glauben zukommt. Dementsprechend kann ihren Äußerungen beispielsweise Bedeutung für die Frage beigemessen werden, wie ein Rechtsakt zu verstehen ist, den sie initiiert hat, wobei allerdings zu berücksichtigen ist, dass er im Rechtsetzungsprozess Änderungen unterzogen worden sein kann. Da ihr als Hüterin der Verträge die Wahrung sowohl des Primärals auch des Sekundärrechts anvertraut ist und ihr daher eine Befugnis zur Äußerung über sämtliches Unionsrecht zusteht, kommt ihren Äußerungen darüber hinaus Bedeutung für das Verständnis sämtlichen Unionsrechts zu. 534

\section{(b) Beispiele aus der Rechtsprechung des Gerichtshofs}

In der Rechtsprechung des Gerichtshofs finden sich sowohl Beispiele für eine Begründung guten Glaubens durch Verhalten der Kommission als auch Fälle, in denen die Berufung der Betroffenen auf Verhalten der Kommission nicht erfolgreich war sowie Beispiele, in denen Verhalten der Kommission gutem Glauben entgegenstand.

An erster Stelle genannt sei hier eine Entscheidung, in der der Gerichtshof die Billigung einer mitgliedstaatlichen Steuerregelung durch die Kommission in den Beitrittsverhandlungen als Auslöser von gutem Glauben ansah. ${ }^{535}$ Auch der Nichtweiterverfolgung eines eingeleiteten Vertragsverletzungsverfahrens und dem Vorschlag eines Rechtsakts zur zeitweiligen Beibehaltung der in Rede stehenden Steuer hat der Gerichtshof bereits entscheidende Bedeutung für die Begründung von gutem Glauben beigemes-

533 Ludewig, Zeitliche Beschränkung, 2012, S. 134.

534 Siehe hierzu auch Rosenkranz, Beschränkung der Rückwirkung, 2015, S. 187.

535 EuGH, Urteil vom 9.3.2000, Rs. C-437/97 (EKW und Wein \& Co.), Rn. 56. 
sen. ${ }^{536}$ Dass der Gerichtshof ein wechselhaftes Verhalten der Kommission genügen ließ ${ }^{537}$, überrascht zunächst, da ein solches Verhalten der Begründung von gutem Glauben eigentlich zuwiderläuft. Ist die Kommission unschlüssig über die Vereinbarkeit mit Unionsrecht, kann von einer vermeintlichen Sicherheit hinsichtlich des Inhalts des Unionsrechts ja nicht mehr gesprochen werden. In dem vom Gerichtshof zu beurteilenden Fall entwickelte sich das Unionsrecht allerdings lediglich schrittweise. Dementsprechend nur langsam ändern kann sich dann auch der gute Glaube. ${ }^{538}$ Dass sich die Kommission wechselvoll verhielt, spielte daher im Ergebnis keine entscheidende Rolle.

Eine seit Jahren andauernde Diskussion zwischen Kommission und Mitgliedstaaten über bestimmte Sachfragen steht gutem Glauben jedenfalls entgegen. ${ }^{539}$ Guter Glaube besteht auch dann nicht mehr, wenn die Kommission ein Vertragsverletzungsverfahren eingeleitet hat oder zum Ausdruck gebracht hat, dass sie eine mitgliedstaatliche Regelung für mit dem Unionsrecht unvereinbar hält. ${ }^{540}$ Schweigen der Kommission kann kein Erklärungsgehalt im Sinne einer Billigung der Ansicht des Mitgliedstaats beigemessen werden, wenn sie keine Pflicht zur Antwort auf eine mitgliedstaatliche Äußerung trifft, und taugt daher nicht zur Begründung von gutem Glauben. ${ }^{541}$

Ebenso wenig kommt die Einstellung eines informellen Verfahrens als Auslöser von gutem Glauben in Betracht. So berief sich die rumänische Regierung in der Rechtssache Paper Consult zwar auf die Einstellung eines „EU-Pilot"-Verfahrens ${ }^{542}$ durch die Kommission, was der Gerichtshof aller-

536 EuGH, Urteil vom 16.7.1992, Rs. C-163/90 (Legros u.a.), Rn. 32.

537 EuGH, Urteil vom 2.2.1988, Rs. 24/86 (Blaizot u.a.), Rn. 32.

538 Vgl. Kovács, Temporale Wirkung, 2014, S. 152.

539 Cloer, EWS 2005, 213 (215).

540 EuGH, Urteil vom 27.2.2014, Rs. C-82/12 (Transportes Jordi Besora), Rn.44; EuGH, Urteil vom 11.8.1995, verb. Rs. C-367/93 bis C-377/93 (Roders u.a.), Rn. 45; EuGH, Urteil vom 31.3.1992, Rs. C-200/90 (Dansk Denkavit und Poulsen Trading), Rn. 22. Die Haltung der Kommission kann sich auch aus einem Arbeitsdokument ergeben, vgl. GA Mengozzi, Schlussanträge vom 12.9.2012 in der Rs. C-395/11 (BLV Wohn- und Gewerbebau), Rn. 107.

541 EuGH, Urteil vom 19.10.1995, Rs. C-137/94 (Richardson), Rn.35; siehe auch EuGH, Urteil vom 12.10.2000, Rs. C-372/98 (Cooke), Rn. 44.

542 Siehe zu diesem Verfahren die Mitteilung der Kommission vom 5. September 2007 „Ein Europa der Ergebnisse - Anwendung des Gemeinschaftsrechts“, $\operatorname{KOM}(2007) 502$ endg. Zu den Hintergründen dieses Vorschlags eines Pilotversuchs zur besseren Anwendung des Unionsrechts siehe auch GA Sharpston, Schlussanträge vom 17.11.2016 in der Rs. C-562/14 P (Schweden/Kommission), Rn. 9, 45 ff. 
dings zu Recht mit der Erwägung zurückwies, dass die Einstellung eines informellen Verfahrens, das durch eine freiwillige Zusammenarbeit von Kommission und Mitgliedstaaten gekennzeichnet sei, das Recht der Kommission zur Einleitung eines Vertragsverletzungsverfahrens nach Art. 258 AEUV unberührt lasse. 543

Dass sich die Mitgliedstaaten auf die Unionsrechtskonformität bejahende Aussagen der Kommission zu vergleichbaren Regelungen anderer Mitgliedstaaten nicht verlassen können ${ }^{544}$, leuchtet dagegen nicht recht ein. Denn wenn es auf der Hand liegt, dass die unionsrechtliche Bewertung auf die eigene Regelung übertragbar ist, wird in der Regel guter Glaube anzunehmen sein. Vor dem Hintergrund, dass sich die Kommission in dem hier in Bezug genommenen Fall allerdings auch bereits ablehnend zur Regelung des betroffenen Mitgliedstaats geäußert hatte, ist die Verneinung guten Glaubens durch den EuGH aber zumindest im Ergebnis zu Recht erfolgt. ${ }^{545}$

Hat die Kommission zwar eine mitgliedstaatliche Ansicht gebilligt, hat aber eine andere Unionsstelle wie der Mehrwertsteuerausschuss seine ablehnende Haltung deutlich gemacht, fehlt es angesichts der in unterschiedliche Richtungen weisenden Ansichten an gutem Glauben. ${ }^{546}$ Sich widersprechende Äußerungen gleichwertiger Unionsstellen schließen guten Glauben also aus. Es gibt insoweit kein Günstigkeitsprinzip. ${ }^{547}$

$\mathrm{Ob}$ auch die unterlassene Einleitung oder Fortführung eines Vertragsverletzungsverfahrens guten Glauben begründen kann, hat der Gerichtshof noch nicht abschließend geklärt. ${ }^{548}$ Zurückhaltung des Gerichtshofs deutet sich insoweit in seiner jüngeren Rechtsprechung an. Nach seinen Ausführungen in der Rechtssache Brouwer kann die unterbliebene Einlei-

543 EuGH, Urteil vom 19.10.2017, Rs. C-101/16 (Paper Consult), Rn. 67 ff.; siehe auch GA Mengozzi, Schlussanträge vom 31.5.2017 in der Rs. C-101/16 (Paper Consult), Rn. 80, 83, 85. Zu einem weiteren in dieser Rechtssache relevanten Aspekt siehe unten bei Fn. 684.

544 Vgl. EuGH, Urteil vom 27.2.2014, Rs. C-82/12 (Transportes Jordi Besora), Rn. 46.

545 EuGH, Urteil vom 27.2.2014, Rs. C-82/12 (Transportes Jordi Besora), Rn. 44.

546 EuGH, Urteil vom 14.9.2006, Rs. C-228/05 (Stradasfalti), Rn. 73.

547 Ebenso Rosenkranz, Beschränkung der Rückwirkung, 2015, S. 203.

548 Siehe einerseits EuGH, Urteil vom 8.4.1976, Rs. 43/75 (Defrenne), Rn. 71/73: guter Glaube wegen unterlassener Einleitung eines Vertragsverletzungsverfahrens trotz entsprechender Warnungen und andererseits EuGH, Urteil vom 27.5.1981, verb. Rs. 142/80 und 143/80 (Essevi und Salengo), Rn. 34: trotz unterlassener Fortführung des Vertragsverletzungsverfahrens kein guter Glaube wegen sonstiger Unsicherheit hinsichtlich der Vereinbarkeit mit Unionsrecht. 
tung eines Vertragsverletzungsverfahrens nicht als stillschweigendes Gutheißen der mitgliedstaatlichen Regelung angesehen werden. ${ }^{549}$ Auch aus der Nichtweiterführung eines Vertragsverletzungsverfahrens über längere Zeit kann kein guter Glaube abgeleitet werden, wenn die Kommission nicht zum Ausdruck gebracht hat, dass sie das Vertragsverletzungsverfahren nicht weiter betreiben möchte oder wenn sie in keinem Stadium des Verfahrens von ihrer grundsätzlichen Auffassung abgerückt ist. ${ }^{550}$

Bleibt die Kommission also lediglich untätig, genügt dies nicht für die Begründung von gutem Glauben. ${ }^{551}$ Entscheidend kommt es daher darauf an, ob zumindest eine gewisse Aktivität auf Seiten der Kommission zu erkennen ist. ${ }^{552}$ Nach diesen Leitlinien ist Verhalten der Kommission im Zusammenhang mit der Einleitung eines Vertragsverletzungsverfahrens zu beurteilen.

Hat die Kommission etwa die Unionsrechtswidrigkeit einer nationalen Regelung angemahnt und reagiert der Mitgliedstaat hierauf im Sinne der Kommission, so ist ein daraufhin erfolgender Verzicht auf die Einleitung eines Vertragsverletzungsverfahrens damit zu begründen, dass ein solches mit Blick auf die Zukunft nicht mehr erforderlich scheint. Eine Billigung des mitgliedstaatlichen Verhaltens für die Vergangenheit ist darin dagegen nicht zu erblicken. ${ }^{553}$ In diesem Fall ist die Kommission im Hinblick auf die ursprüngliche nationale Regelung also untätig geblieben. Zur Begründung von gutem Glauben für die Zeit bis zu einem Urteil des Gerichtshofs in einem Vorabentscheidungsverfahren, das diese ursprüngliche nationale Regelung betrifft, kann das Verhalten der Kommission demnach nicht herangezogen werden.

549 EuGH, Urteil vom 29.7.2010, Rs. C-577/08 (Brouwer), Rn. 25, 39.

550 EuGH, Urteil vom 12.9.2000, Rs. C-359/97 (Kommission/Vereinigtes Königreich), Rn. 94; EuGH, Urteil vom 15.12.2009, Rs. C-239/06 (Kommission/Italien), Rn. 59; EuGH, Urteil vom 15.12.2009, Rs. C-387/05 (Kommission/Italien), Rn. 59. Wird ein Vertragsverletzungsverfahren „aus politischen Gründen“ beendet, begründet dies ebenfalls keinen guten Glauben, GA Campos Sánchez-Bordona, Schlussanträge vom 10.9.2020 in den verb. Rs. C-407/19 und C-471/19 (Katoen Natie Bulk Terminals und General Services Antwerp), Rn. 103.

551 GA Sharpston, Schlussanträge vom 22.6.2006 in der Rs. C-228/05 (Stradasfalti), Rn.93; Rosenkranz, Beschränkung der Rückwirkung, 2015, S. 190. Skeptisch hinsichtlich "Gutglaubensschutz" bei Untätigkeit der Kommission auch Thömmes, IWB 2006, 375 (379).

552 Lang, in: Popelier/Verstraelen/Vanheule/Vanlerberghe (Hrsg.), The Effects of Judicial Decisions in Time, 2014, S. 245 (249).

553 Balmes/Ribbrock, BB 2006, 17 (19). 
In „beredtem Schweigen“ ist dagegen eine gewisse Aktivität auf Seiten der Kommission zu erblicken. Ein solches bereits dann anzunehmen, wenn die Kommission trotz entsprechender Warnungen kein Vertragsverletzungsverfahren einleitet, obwohl der Mitgliedstaat untätig geblieben ist, erscheint jedoch fragwürdig. 554 Die Annahme eines „beredten Schweigens" darf nämlich nicht so weit gehen, einer Mahnung der Kommission gutglaubensbegründende Wirkung beizumessen. ${ }^{555}$ Sonst wäre der Mitgliedstaat gut beraten, die Einleitung des Verfahrens zu ignorieren und auf anschließende Untätigkeit der Kommission zu hoffen, um diese dann als Auslöser von gutem Glauben anzuführen. Dies käme einer Umkehrung der Verantwortlichkeiten gleich. ${ }^{556}$ Die Mitgliedstaaten müssen sich bei der Kommission vielmehr nach dem Stand der Dinge erkundigen, um ihrer Verpflichtung aus Art. 4 III EUV gerecht zu werden, wenn diese längere Zeit untätig geblieben ist. ${ }^{557}$

\section{(2) Mitgliedstaaten}

Angesichts der oben bereits wiedergegebenen und in ständiger Rechtsprechung wiederkehrenden Formulierung des EuGH, wonach zur Unsicherheit hinsichtlich der Tragweite der Unionsbestimmungen „eventuell auch das Verhalten anderer Mitgliedstaaten" beigetragen hatte ${ }^{558}$, scheint neben Verhalten der Kommission auch mitgliedstaatliches Verhalten als Auslöser von gutem Glauben zu taugen. Hierfür kann sicherlich angeführt werden, dass Kommission und Mitgliedstaaten vom Gerichtshof in einem Atemzug genannt werden. Dementsprechend nennt ein Großteil der Literatur die Mitgliedstaaten ganz selbstverständlich zusammen mit auf Unionsebene

554 So aber Ludewig, Zeitliche Beschränkung, 2012, S. 132 ff., der das Vorgehen des EuGH im Defrenne II-Urteil wohl mit einem beredten Schweigen der Kommission begründet, vgl. zur Aussage des EuGH den Hinweis oben in Fn. 548.

555 Schaer, Grenzen rückwirkender Rechtsprechung, 2010, S. 55.

556 Klein, IStR 2006, 209 (210); Frenz, Handbuch Europarecht, Band 5, 2010, Rn. 3420.

557 Kokott/Henze, NJW 2006, 177 (180); Seer/Müller, IWB 2008, 255 (261); a.A. Rosenkranz, Beschränkung der Rückwirkung, 2015, S. 192.

558 Siehe etwa EuGH, Urteil vom 21.10.2010, Rs. C-242/09 (Albron Catering), Rn.37; EuGH, Urteil vom 19.7.2012, Rs. C-263/11 (Rēdlihs), Rn.60; EuGH, Urteil vom 19.12.2013, Rs. C-209/12 (Endress), Rn. 36; EuGH, Urteil vom 19.10.2017, Rs. C-101/16 (Paper Consult), Rn.66; EuGH, Urteil vom 13.12.2018, Rs. C-385/17 (Hein), Rn. 58. 
angesiedelten Auslösern von gutem Glauben. ${ }^{559}$ Ganz so einfach liegen die Dinge aber nicht.

(a) Fehlender Anknüpfungspunkt auf Unionsebene

Zuzugeben ist zunächst, dass sich der Gerichtshof in seinem Defrenne IIUrteil auf Praktiken bezogen hat, die nach nationalem Recht nicht verboten waren. ${ }^{560}$ Daraus wird zum Teil abgeleitet, der EuGH habe hier einen nationalen Vertrauenstatbestand zum Anlass für die Begrenzung der zeitlichen Wirkung genommen. ${ }^{561}$ Die Bezugnahme auf das nationale Recht ist aber ein Einzelfall geblieben und daher missverständlich. ${ }^{562}$ Der Zulässigkeit der Praktiken nach nationalem Recht kann keine Aussage über den Inhalt des Unionsrechts entnommen werden. Auf dessen Verständnis kommt es aber an. Skepsis ruft der EuGH daher auch hervor, wenn er den Eindruck erweckt, ein einheitliches Verständnis der Mitgliedstaaten könne guten Glauben begründen. ${ }^{563}$

Ausgeschlossen ist, dass ein mitgliedstaatliches Fehlverständnis vom Inhalt des Unionsrechts dessen guten Glauben zu begründen vermag. 564 Aber auch ein gemeinsames Fehlverständnis der Mitgliedstaaten kann für die Begründung guten Glaubens nicht ausreichen, da sich die Mitgliedstaaten sonst durch kollusives Verhalten den Vorgaben des Unionsrechts entziehen könnten. ${ }^{565}$ Nicht weiter führt in diesem Zusammenhang die Überlegung, dass ausgeschlossen sei, dass der im konkreten Fall betroffene Mitgliedstaat von eigenem Fehlverhalten profitiere, wenn man auf das Verhalten der anderen Mitgliedstaaten abstelle. ${ }^{566}$ In diesem Fall besteht das Problem, dass diese keine besondere Kompetenz für die Auslegung des

559 Lenaerts/Arts/Maselis, Procedural Law, 2. Aufl. 2006, Rn. 6-034; Sagan, Jahrbuch Junger Zivilrechtswissenschaftler 2010, 67 (71 ff.); Wiedmann, EuZW 2007, 692 (695).

560 EuGH, Urteil vom 8.4.1976, Rs. 43/75 (Defrenne), Rn. 71/73.

561 In diesem Sinne Sagan, Jahrbuch Junger Zivilrechtswissenschaftler 2010, 67 (80).

562 So auch Rosenkranz, Beschränkung der Rückwirkung, 2015, S. 199; a.A. Sagan, Jahrbuch Junger Zivilrechtswissenschaftler 2010, 67 (80).

563 EuGH, Urteil vom 12.9.2000, Rs. C-359/97 (Kommission/Vereinigtes Königreich), Rn. 93.

564 Schlachter, ZfA 2007, 249 (267).

565 Vgl. Koopmans, C.L.J. 39 (1980), 287 (293).

566 So aber Kovács, Temporale Wirkung, 2014, S. 159. 
Unionsrechts haben, nämlich fort. ${ }^{567}$ Das Verhalten der anderen Mitgliedstaaten erlangt nur insoweit Bedeutung, als es zumindest ein Indiz gegen das Vorliegen von gutem Glauben darstellt, wenn sich zeigt, dass in diesen keine Schwierigkeiten beim Verständnis des Unionsrechts aufgetreten sind. ${ }^{568}$

Auch ein Abstellen auf einen Teil der anderen Mitgliedstaaten hilft nicht weiter. Der Gerichtshof formuliert zwar wie gesehen, dass zu der Unsicherheit hinsichtlich der Tragweite der Unionsbestimmungen auch das Verhalten anderer Mitgliedstaaten beigetragen haben kann und verlangt damit nicht ein Verhalten der anderen Mitgliedstaaten, d.h. aller übrigen Mitgliedstaaten. Allerdings erschiene es nicht plausibel, einer in wenigen Mitgliedstaaten vertretenen Ansicht die Eignung zur Begründung guten Glaubens zuzusprechen, da in diesem Fall dieser Ansicht größere Bedeutung beigemessen würde als den Auffassungen der diese Ansicht nicht teilenden übrigen Mitgliedstaaten, obwohl eine Rechtfertigung für eine Ungleichbehandlung der Mitgliedstaaten nicht ersichtlich ist. ${ }^{569}$ Hiervon abgesehen fehlt aber auch einer in der überwiegenden Mehrzahl der Mitgliedstaaten vertretenen Ansicht jedenfalls der Anknüpfungspunkt auf Unionsebene.

Privaten Betroffenen eher eine Berufung auf das Verhalten anderer Mitgliedstaaten zu gestatten als den Mitgliedstaaten selbst, erscheint angesichts der fehlenden unionsrechtlichen Ermächtigung zur Äußerung dieser Ansichten ebenfalls nicht möglich. ${ }^{570}$ Insofern wird zwar vorgebracht, die Unionsbürger dürften nicht für unionsrechtswidriges mitgliedstaatliches Fehlverhalten in die Pflicht genommen werden, weswegen Unklarheiten auf mitgliedstaatlicher Ebene zu berücksichtigen seien. ${ }^{571}$ Was für staatliche Akteure keinen guten Glauben begründen kann, kann dies aber auch für private Akteure nicht. ${ }^{572}$ Als Rechtssubjekte der Unionsrechtsordnung stehen die Mitgliedstaaten und Einzelnen ${ }^{573}$ insoweit auf einer Ebene.

567 Ludewig, Zeitliche Beschränkung, 2012, S. 139.

568 Vgl. GA Campos Sánchez-Bordona, Schlussanträge vom 28.3.2019 in der Rs. C-210/18 (WESTbahn Management), Rn. 75.

569 Müller, Begrenzung, 2009, S. 141 f.; Ludewig, Zeitliche Beschränkung, 2012, S. 139.

570 So aber Ludewig, Zeitliche Beschränkung, 2012, S. 139.

571 Kovács, Temporale Wirkung, 2014, S. 158.

572 Anders Düsterhaus, EuR 2017, 30 (42 f.) und Düsterhaus, YEL 36 (2017), 237 (255), der die Rechtsprechung des Gerichtshofs in der zur hier vertretenen Auffassung entgegengesetzten Richtung versteht.

573 EuGH, Urteil vom 5.2.1963, Rs. 26/62 (Van Gend \& Loos), Slg. 1963, S. 25. 
Auch wenn nur private Akteure von der Auslegung der Norm betroffen sind, können demnach weder übereinstimmendes Verhalten der Mitgliedstaaten noch Regeln etwa von Sportverbänden zur Begründung von gutem Glauben herangezogen werden. Auf eine nur von den Stellen eines Mitgliedstaats vertretene Auslegung des Unionsrechts können die Privaten erst recht keinen guten Glauben stützen. ${ }^{574}$

Erweist sich eine nationale Regelung trotz bestehender Zweifel letztlich als unionsrechtskonform, sind auch private Parteien in ihrem Irrtum über den Inhalt des Unionsrechts jedenfalls nicht schutzwürdig, wie sich etwa an der Rechtssache T-Mobile Austria zeigt. So scheiterte T-Mobile Austria mit ihrem Antrag auf Begrenzung der zeitlichen Wirkungen der Auslegung von Bestimmungen einer Richtlinie auch deshalb, weil aufgrund ordnungsgemäßer Richtlinienumsetzung im österreichischen Recht keine Veranlassung zu einem mit dem Unionsrecht unvereinbaren Verhalten bestand und guter Glaube daher zu verneinen war. ${ }^{575}$

(b) Rechtsschein der Unionsrechtskonformität nationalen Rechts?

Neben mitgliedstaatlichem Verhalten ist insbesondere an nationales Recht zu denken, das eine Vorstellung vom Inhalt des Unionsrechts begründen könnte. Bestünde ein Rechtsschein der Unionsrechtskonformität nationalen Rechts, wäre dies in der Tat zu bejahen. Für einen solchen Rechtsschein wird angeführt, dass jedes positive Recht, wozu auch das nationale Recht im Anwendungsbereich des Unionsrechts gehöre, nach unionsrechtlichen Grundsätzen eine Richtigkeitsvermutung in sich trage. ${ }^{576} \mathrm{Zu}$ denken sein könnte also an einen Rechtsschein der Unionsrechtskonformität nationalen Rechts angesichts der Bindung der mitgliedstaatlichen Organe an Unionsrecht. ${ }^{577}$

574 Vgl. GA Saugmandsgaard Øe, Schlussanträge vom 28.2.2019 in der Rs. C-682/17 (ExxonMobil Production Deutschland), Rn. 104.

575 EuGH, Urteil vom 9.4.2014, Rs. C-616/11 (T-Mobile Austria), Rn. 49 ff. Das muss auch Düsterhaus, YEL 36 (2017), 237 (255) feststellen.

576 Latzel, EuR 2015, 415 (427) unter Verweis in Fn. 99 auf EuGH, Urteil vom 15.7.2004, Rs. C-459/02 (Gerekens und Procola), Rn. 21 ff. Rn. 21 des Urteils lautet: „Die in der Gemeinschaftsrechtsordnung anerkannten allgemeinen Grundsätze binden auch die Mitgliedstaaten, wenn sie Gemeinschaftsregelungen durchführen."

577 So Sagan, Jahrbuch Junger Zivilrechtswissenschaftler 2010, 67 (71). 
Diese Überlegung erinnert an die vom Gerichtshof anerkannte Gültigkeitsvermutung für Unionsrechtsakte, die daher zunächst in den Blick zu nehmen ist, um sodann die Frage ihrer Übertragbarkeit auf nationale Rechtsakte aufzuwerfen.

\section{(aa) Gültigkeitsvermutung für Unionsrechtsakte}

Die Verträge bilden nach einer Formulierung des EuGH „Grundlage, Rahmen und Grenzen" für die von den Unionsorganen erlassenen Rechtsakte. ${ }^{578}$ Aufgrund des Prinzips der begrenzten Einzelermächtigung (Art. 5 I 1, II EUV) müssen die Unionsorgane die in den Verträgen zwischen Union und Mitgliedstaaten vorgesehene Zuständigkeitsverteilung beachten und dürfen nur innerhalb der der Union gezogenen Zuständigkeitsgrenzen tätig werden. ${ }^{579}$ Die damit angesprochene beschränkte Verbandskompetenz der Union wird flankiert durch die in Art. 13 II 1 EUV normierte beschränkte Organkompetenz, wonach die Unionsorgane nur nach Maßgabe der ihnen in den Verträgen zugewiesenen Befugnisse handeln dürfen.

Aus diesen der unionalen Rechtsetzung durch die Verträge gezogenen Grenzen lässt sich der gegenüber Primärrecht niedrigere Rang des Sekundärrechts ersehen. ${ }^{580}$ Dafür spricht auch die Existenz der Nichtigkeitsklage, Art. 263 AEUV, und der Ungültigkeitsvorabentscheidung, Art. 267 I lit.b Alt. 1 AEUV. ${ }^{581}$ Es ist also vom Grundsatz der Normenhierarchie auszugehen, wonach das abgeleitete Recht ohne entsprechende Ermächtigung nicht vom Primärrecht abweichen darf. ${ }^{582}$ Bündig zusammengefasst bedeutet dies: Primärrecht hat Vorrang vor Sekundärrecht. ${ }^{583}$

578 EuGH, Urteil vom 5.10.1978, Rs. 26/78 (Viola), Rn.9/14 zu Verordnungen über die soziale Sicherheit der Wanderarbeitnehmer aus dem Jahr 1958 im Hinblick auf Art. 48-51 EWG-Vertrag.

579 Geismann, in: von der Groeben/Schwarze/Hatje (Hrsg.), Unionsrecht, 7. Aufl. 2015, Art. 288 AEUV, Rn. 17.

580 Auf den Zusammenhang mit der begrenzten Organkompetenz verweist auch Nettesheim, EuR 2006, 737 (746).

581 Vgl. Schroeder, in: Streinz (Hrsg.), EUV/AEUV, 3. Aufl. 2018, Art. 288 AEUV, Rn. 24.

582 EuG, Urteil vom 10.7.1990, Rs. T-51/89 (Tetra Pak/Kommission), Rn. 25. Auch EuG, Urteil vom 14.12.1995, Rs. T-285/94 (Pfloeschner/Kommission), Rn. 51 spricht von der „Rangordnung der Rechtsnormen“.

583 Vgl. nur Ruffert, in: Calliess/Ruffert (Hrsg.), EUV/AEUV, 5. Aufl. 2016, Art. 288 AEUV, Rn. 8. Geismann, in: von der Groeben/Schwarze/Hatje (Hrsg.), Unions- 
Aus den der organschaftlichen Rechtsetzung durch das Primärrecht gezogenen Grenzen folgt, dass dieses auch bei der Auslegung des Sekundärrechts Beachtung finden muss. ${ }^{584}$ Die damit angesprochene primärrechtskonforme Auslegung des Sekundärrechts praktiziert der EuGH in ständiger Rechtsprechung. ${ }^{585}$ Sie ist als mildestes Mittel Ausdruck richterlicher Zurückhaltung. ${ }^{586}$ Scheidet sie aus, stellt sich die Frage, welche Konsequenzen aus der Kollision der betroffenen sekundärrechtlichen Handlung mit dem Primärrecht zu ziehen sind.

Denkbar erscheint zunächst sowohl eine ipso iure, also von selbst eintretende Nichtigkeit des organgesetzten Rechts als auch dessen bloße Vernichtbarkeit. Dabei ist in Rechnung zu stellen, dass eine Normkollision rechtlich nicht zwingend die Nichtigkeit der rangniedrigeren Norm zur Folge hat. ${ }^{587}$ Die Auflösung der Normkollision kann vielmehr von Rechtsordnung zu Rechtsordnung verschieden erfolgen; sie ist daher rechtsordnungsspezifisch zu betrachten. Antworten auf die Frage der Konsequenzen der Normkollision sind dementsprechend in der Unionsrechtsordnung selbst zu suchen.

Als Ausgangspunkt bietet sich daher ein Blick auf Art.264 AEUV an, der sich mit den Rechtsfolgen einer erfolgreichen Nichtigkeitsklage nach Art. 263 AEUV befasst. Zur begrifflichen Klärung ist vorwegzuschicken, dass unter Nichtigkeit die von vornherein wirkende Ungültigkeit zu verstehen ist und damit die Tatsache, dass der in Rede stehende Rechtsakt aus rechtlicher Sicht nicht existiert. ${ }^{588}$

recht, 7. Aufl. 2015, Art. 288 AEUV, Rn. 26 spricht von der Nachrangigkeit des Sekundärrechts.

584 Ruffert, in: Calliess/Ruffert (Hrsg.), EUV/AEUV, 5. Aufl. 2016, Art. 288 AEUV, Rn. 9 spricht insoweit von einem Ausfluss des Vorrangs des Primärrechts.

585 Vgl. EuGH, Urteil vom 13.12.1983, Rs. 218/82 (Kommission/Rat), Rn. 15; EuGH, Urteil vom 25.11.1986, verb. Rs. 201/85 und 202/85 (Klensch u.a.), Rn. 21; EuGH, Urteil vom 21.3.1991, Rs. C-314/89 (Rauh), Rn. 17; EuGH, Urteil vom 27.1.1994, Rs. C-98/91 (Herbrink), Rn. 9; EuGH, Urteil vom 1.4.2004, Rs. C-1/02 (Borgmann), Rn. 30; EuGH, Urteil vom 29.4.2010, Rs. C-340/08 (M u.a.), Rn. 64; EuGH, Urteil vom 19.7.2012, Rs. C-250/11 (Lietuvos geležinkeliai), Rn. 40.

586 Vgl. Nettesheim, EuR 2006, 737 (746 f.).

587 Bettermann, in: FS Eichenberger, 1982, S. 593 (597): „Die Nichtigkeitsfolge [...] ist kein Gebot der Logik."

588 Breuer, DVBl. 2008, 555 (563); Ipsen, Rechtsfolgen, 1980, S. 150. Bei dem Begriff der ipso iure-Nichtigkeit handelt es sich bei näherer Betrachtung also um eine Tautologie, Breuer, a.a.O., Fn. 89; Ipsen, a.a.O. 
Die Einordnung eines mit höherrangigem Recht kollidierenden Unionsrechtsakts als Nichts scheint etwa die französische Sprachfassung des Art. 264 I AEUV nahezulegen, die davon spricht, dass die angefochtene Handlung für "nul et non avenu“ erklärt wird. ${ }^{589}$ Der Bezeichnung „nul et non avenu" (in der italienischen Fassung "nullo e non avvenuto") entspricht nämlich gerade die Einordnung als rechtliches Nichts. ${ }^{590}$ In entsprechender Weise lässt sich die Verwendung des Begriffs „nichtig“ in der deutschen Fassung des Art. 264 I AEUV eher für einen von selbst erfolgenden Eintritt der Rechtsfolgen anführen.

Die in Art. 264 I AEUV verwendete Formulierung des für Nichtig-Erklärens weist dagegen eher in Richtung Vernichtbarkeit, da sie als Gegensatz zur bloßen Nichtigkeitsfeststellung gedeutet werden könnte. ${ }^{591}$ Zuzugeben ist insoweit allerdings, dass diese Erwägung allein die Ablehnung eines Nichtigkeitsdogmas im Unionsrecht noch nicht zu beweisen imstande ist. ${ }^{592}$

So ist für die Frage nach der Existenz eines unionsrechtlichen Nichtigkeitsdogmas Art. 264 II AEUV in die Überlegungen mit einzubeziehen. Dieser spricht deutlicher als Absatz 1 gegen eine ipso iure-Nichtigkeit. ${ }^{593}$ In Art. 264 II AEUV heißt es, der Gerichtshof könne diejenigen der Wirkungen der für nichtig erklärten Handlung bezeichnen, die als fortgeltend zu betrachten seien. Fortgelten kann aber nur eine Wirkung, die von Anfang an bestand und bis zum Urteil nicht untergegangen ist. ${ }^{594}$ Weitere Sprachfassungen bekräftigen diese Deutung. Als "definitivi“/,definitive“/ "définitifs" und damit als endgültig können nur bereits bestehende Wirkungen bezeichnet werden.

Anhänger eines Nichtigkeitsdogmas müssten dagegen argumentieren, Art. 264 II AEUV ermächtige den Gerichtshof, den nach ihrer Auffassung

589 Vgl. Hein, Inzidentkontrolle, 2001, S. 181.

590 Vgl. Breuer, DVBl. 2008, 555 (563).

591 In diesem Sinne für $₫ 78$ BVerfGG Breuer, DVBl. 2008, 555 (557, 563).

592 So meint etwa Bethge, in: Maunz/Schmidt-Bleibtreu/Klein/Bethge, BVerfGG, $\$ 31$ BVerfGG, Rn. 146 (Stand: Februar 2019), dass der Ausdruck des für Nichtig-Erklärens von Puristen zwar als systemwidriges kassatorisches Spurenelement gedeutet werde, es sich dabei letztlich aber um semantische Manierismen handle.

593 Nettesheim, EuR 2006, 737 (748) spricht insoweit von einer in Art. 231 II EGV (jetzt Art. 264 II AEUV) zum Ausdruck kommenden gestaltenden Rolle des EuGH.

594 Ähnlich Rosenkranz, Beschränkung der Rückwirkung, 2015, S. 82; Cremer, in: Calliess/Ruffert (Hrsg.), EUV/AEUV, 5. Aufl. 2016, Art. 263 AEUV, Rn. 1 weist darauf hin, dass auch ein rechtswidriger Akt bis zu seiner Aufhebung gilt. 
von vornherein ungültigen Rechtsakt nun erstmals ganz oder zum Teil zur rechtlichen Existenz gelangen zu lassen. Woraus sich eine derartige Kompetenz herleiten lassen sollte, ist aber nicht ersichtlich. Eine entsprechende Ansicht ist fernliegend und daher abzulehnen. ${ }^{595}$ Mit den Wirkungen der Nichtigkeitsklage ist ein Nichtigkeitsdogma demnach nicht vereinbar. ${ }^{596}$ Ein solches ist dem Unionsrecht daher fremd.

Gegen ein Nichtigkeitsdogma sprechen zudem die fehlende erga omnes-Wirkung und die bloße Unanwendbarkeit im konkreten Verfahren als Rechtsfolge einer erfolgreichen Inzidentrüge nach Art. 277 AEUV. ${ }^{597}$ Trotz seiner Rechtswidrigkeit bleibt der Rechtsakt also gültig; er ist ja nur unanwendbar. Da keine erga omnes wirkende Entscheidung ergeht, müssen weitere Rügeberechtigte erneut eine Unanwendbarkeitserklärung erreichen. In ihrem Verfahren wird der Rechtsakt daher zunächst als anwendbar und damit zwangsläufig als gültig angesehen. ${ }^{598}$

Das Ergebnis des Nichtbestehens eines unionsrechtlichen Nichtigkeitsdogmas lässt sich mit der Erwägung weiter abstützen, dass es bei Zugrundelegung eines Nichtigkeitsdogmas zur Geltendmachung der Nichtigkeit keines bestimmten Verfahrens bedürfte. ${ }^{599}$ Sie könnte vielmehr von jedermann jederzeit geltend gemacht werden. Dies kann aber angesichts des Verwerfungsmonopols des EuGH für abgeleitetes Unionsrecht ${ }^{600}$ nicht behauptet werden.

Damit bleibt Raum für eine Gültigkeitsvermutung für Unionsrechtsakte, die der Gerichtshof nicht ganz zutreffend als „Vermutung der RechtmäBigkeit" bezeichnet. Sie besagt, dass die Rechtsakte der Organe, Institutionen und Einrichtungen der Union „Rechtswirkungen entfalten, solange sie nicht zurückgenommen, im Rahmen einer Nichtigkeitsklage für nichtig erklärt oder auf ein Vorabentscheidungsersuchen oder eine Rechtswid-

595 Ebenso Nettesheim, EuR 2006, 737 (749): „Plausibel ist diese Konstruktion aber nicht.“ Seine Formulierung „einen ungültigen Rechtsakt wieder zum Leben zu erwecken" erscheint allerdings als dogmatisch unsauber, da dieser Rechtsakt bei Zugrundelegung eines Nichtigkeitsdogmas ja nie am Leben gewesen wäre.

596 Ebenso Willers, Übergangsfristen, 2011, S. 36; etwas zurückhaltender Rosenkranz, Beschränkung der Rückwirkung, 2015, S. 83: „Die Wirkungen [...] sprechen $[\ldots .$.$] gegen ein Nichtigkeitsdogma."$

$597 \mathrm{Zu}$ diesen Wirkungen Pechstein, EU-Prozessrecht, 4. Aufl. 2011, Rn. 945.

598 Vgl. dazu auch Hein, Inzidentkontrolle, 2001, S. 182, 190.

599 Vgl. Breuer, DVBl. 2008, 555 (562).

600 EuGH, Urteil vom 22.10.1987, Rs. 314/85 (Foto-Frost), Rn. 15 ff.; EuGH, Urteil vom 6.12.2005, Rs. C-461/03 (Gaston Schul Douane-expediteur), Rn. $21 \mathrm{f}$. 
rigkeitseinrede hin für ungültig erklärt worden sind“. ${ }^{601}$ Dementsprechend sind sie solange von den mitgliedstaatlichen und den Unionsorganen weiter anzuwenden. ${ }^{602}$ Begründen lässt sich die Gültigkeitsvermutung mit der ausschließlichen Zuständigkeit des Gerichtshofs für die Nichtigkeitsklage, die Inzidentrüge und die Ungültigkeitsvorabentscheidung nach Art. $263 \mathrm{f}$. AEUV, Art. 277 AEUV sowie Art. 267 AEUV. ${ }^{603}$

Die Gültigkeitsvermutung trägt dem institutionellen Gleichgewicht auf Unionsebene Rechnung. ${ }^{604}$ Der ex tunc-Wirkung des Nichtigkeitsurteils steht sie nicht entgegen. Beide Grundsätze können vielmehr „nacheinander“ zur Anwendung kommen: Die Nichtigerklärung überwindet die Gültigkeitsvermutung dann rückwirkend. ${ }^{605}$

Zunächst wurde die Gültigkeitsvermutung für eine rechtswidrige Entscheidung aufgestellt ${ }^{606}$; ausgedehnt wurde sie in der Folge auf Verordnungen $^{607}$ und Richtlinien ${ }^{608}$. Bei der in den Urteilen vom EuGH verwendeten Formulierung fällt auf, dass zwischen normativen und Einzelakten nicht differenziert wird, sodass sich die Vermutung auf sämtliche Rechtsakte der Unionsorgane erstreckt. Sie gilt also unabhängig von der Handlungsform und kann daher als handlungsformneutral bezeichnet werden. ${ }^{609}$ Dadurch

601 EuGH, Urteil vom 14.6.2012, Rs. C-533/10 (CIVAD), Rn. 39; EuGH, Urteil vom 12.2.2008, Rs. C-199/06 (CELF und Ministre de la Culture et de la Communication), Rn. 60; in der Sache ebenso, mit leicht abweichenden Formulierungen EuGH, Urteil vom 6.10.2015, Rs. C-362/14 (Schrems), Rn. 52; EuGH, Urteil vom 4.2.2016, verb. Rs. C-659/13 und C-34/14 (C \& J Clark International und Puma), Rn. 184; EuGH, Urteil vom 5.10.2004, Rs. C-475/01 (Kommission/Griechenland), Rn. 18; EuGH, Urteil vom 15.6.1994, Rs. C-137/92 P (Kommission/BASF u.a.), Rn. 48; EuGH, Urteil vom 8.7.1999, Rs. C-245/92 P (Chemie Linz/Kommission), Rn. 93.

602 Rosenkranz, Beschränkung der Rückwirkung, 2015, S. 23, Fn. 61 verweist zutreffend darauf, dass angesichts dieser Rechtsfolge die Bezeichnung „Gültigkeitsvermutung" bzw. "Wirksamkeitsvermutung" treffender ist als die vom Gerichtshof verwendete Bezeichnung „Vermutung der Rechtmäßigkeit“.

603 EuGH, Urteil vom 13.2.1979, Rs. 101/78 (Granaria), Rn. 4.

604 Vgl. Kokott, in: FS Hirsch, 2008, S. 117 (118, 127).

605 In diesem Sinne EuGH, Urteil vom 12.2.2008, Rs. C-199/06 (CELF und Ministre de la Culture et de la Communication), Rn. 62, 64.

606 EuGH, Urteil vom 12.7.1957, verb. Rs. 7/56 und 3/57 bis 7/57 (Algera u.a./Gemeinsame Versammlung der EGKS), Slg. 1957, S. 126.

607 EuGH, Urteil vom 13.2.1979, Rs. 101/78 (Granaria), Rn. 4.

608 EuGH, Urteil vom 5.10.2004, Rs. C-475/01 (Kommission/Griechenland), Rn. 18.

609 So Gärditz, in: Rengeling/Middeke/Gellermann (Hrsg.), Handbuch des Rechtsschutzes, 3. Aufl. 2014, $\$ 34$, Rn. 22, wonach die „Dogmatik der Fehlerfolgen“ handlungsformneutral sei; siehe auch von Danwitz, Europäisches Verwaltungsrecht, 2008, S. 264. 
dass die Gültigkeitsvermutung auch Normativakte umfasst, wird Gefahr von der Einheit der Unionsrechtsordnung abgewendet. Sie dient damit auch der Sicherstellung der einheitlichen Anwendung des Unionsrechts. ${ }^{610}$ Eben dieses Ziel verfolgt das Verwerfungsmonopol des Gerichtshofs für Unionsrechtsakte. 611

Für sogenannte Nichtakte, denen besonders schwerwiegende, offensichtliche Fehler anhaften, gilt die Gültigkeitsvermutung dagegen nicht. ${ }^{612}$ Die Annahme eines Nichtakts ist allerdings auf Ausnahmefälle begrenzt und daher "ganz außergewöhnlichen Fällen vorbehalten“.613 Nichtakte sind rechtlich inexistent und entfalten keine Rechtswirkung; sie sind ipso iure nichtig. ${ }^{614}$ Sie sind daher unbeachtlich, ohne dass es einer Nichtigerklärung in einem Verfahren vor den Unionsgerichten bedürfte. ${ }^{615}$ Damit kann sich jeder jederzeit, d.h. auch nach Ablauf etwaiger Klagefristen, auf die Inexistenz des Aktes berufen. ${ }^{616}$

Durch die Beschränkung der Annahme eines Nichtaktes auf Ausnahmefälle bestätigt sich erneut, dass das Nichtigkeitsdogma der Unionsrechtsordnung nicht als Grundsatz zugrunde liegen kann. ${ }^{617}$ Dagegen spricht zu-

610 von Danwitz, Europäisches Verwaltungsrecht, 2008, S. 267 f.; Gärditz, in: Rengeling/Middeke/Gellermann (Hrsg.), Handbuch des Rechtsschutzes, 3. Aufl. 2014, \34, Rn. 19.

611 Z.B. EuGH, Urteil vom 6.10.2015, Rs. C-362/14 (Schrems), Rn. 61; EuGH, Urteil vom 22.6.2010, verb. Rs. C-188/10 und C-189/10 (Melki und Abdeli), Rn. 54; EuGH, Urteil vom 14.6.2012, Rs. C-533/10 (CIVAD), Rn. 40.

612 EuGH, Urteil vom 26.2.1987, Rs. 15/85 (Consorzio Cooperative d'Abruzzo/Kommission), Rn. 10; EuGH, Urteil vom 5.10.2004, Rs. C-475/01 (Kommission/Griechenland), Rn. 19; EuGH, Urteil vom 8.7.1999, Rs. C-245/92 P (Chemie Linz/Kommission), Rn. 94; EuGH, Urteil vom 15.6.1994, Rs. C-137/92 P (Kommission/BASF u.a.), Rn. 49; EuGH, Urteil vom 20.9.2007, Rs. C-177/06 (Kommission/Spanien), Rn.31; EuG, Urteil vom 23.10.2008, Rs. T-256/07 (People's Mojahedin Organization of Iran/Rat), Rn. 56.

613 EuGH, Urteil vom 18.10.2012, Rs. C-37/11 (Kommission/Tschechische Republik), Rn. 49; EuGH, Urteil vom 5.10.2004, Rs. C-475/01 (Kommission/Griechenland), Rn. 20; ebenso mit leicht abweichender Formulierung EuGH, Urteil vom 8.7.1999, Rs. C-245/92 P (Chemie Linz/Kommission), Rn. 95; EuGH, Urteil vom 15.6.1994, Rs. C-137/92 P (Kommission/BASF u.a.), Rn. 50.

614 In diesem Sinne ausdrücklich EuG, Urteil vom 23.10.2008, Rs. T-256/07 (People's Mojahedin Organization of Iran/Rat), Rn. 59.

615 Annacker, EuZW 1995, 755 (755 f., 760).

616 Gärditz, in: Rengeling/Middeke/Gellermann (Hrsg.), Handbuch des Rechtsschutzes, 3. Aufl. 2014, $\$ 34$, Rn. 23; Annacker, EuZW 1995, 755 (759); EuGH, Urteil vom 26.2.1987, Rs. 15/85 (Consorzio Cooperative d'Abruzzo/Kommission), Rn. 10.

617 Ebenso Rosenkranz, Beschränkung der Rückwirkung, 2015, S. 91. 
letzt auch nicht, dass die Funktion der Ungültigkeitsvorlage nach Art. 267 I lit. b Alt. 1 AEUV teilweise in der Feststellung gesehen wird, ob die im Rahmen des Vorabentscheidungsverfahrens überprüfte Norm rechtswidrig und daher nichtig ist. ${ }^{618}$ Dieser Aussage scheint die Annahme eines Nichtigkeitsdogmas zugrunde zu liegen. Dann müsste aber der in Art. 267 I lit.b Alt. 1 AEUV verwendete Begriff der Ungültigkeit Gegenbegriff zur Nichtigkeit sein. Ein solches Verständnis ist jedoch nicht zwingend. ${ }^{619}$

Entscheidend ist im vorliegenden Zusammenhang vielmehr, dass die Gültigkeitsvermutung auch im Hinblick auf die Ungültigkeitsvorlage trägt. Es ist in Erinnerung zu rufen, dass die unionalen Rechtsakte „Rechtswirkungen entfalten, solange sie nicht zurückgenommen, im Rahmen einer Nichtigkeitsklage für nichtig erklärt oder auf ein Vorabentscheidungsersuchen oder eine Rechtswidrigkeitseinrede hin für ungültig erklärt worden sind“. ${ }^{620}$ Insoweit behandelt der EuGH Nichtigkeitsklage und Ungültigkeitsvorlage also gleich. Dies ist auch insofern zwingend, als eine Ausgestaltung eines Rechtssystems, das in einem Verfahren eine ipso iure-Nichtigkeit vorsieht, in einem anderen aber nicht, nicht denkbar ist. ${ }^{621}$

Damit bleibt festzuhalten: Rechtswidrige Unionsrechtsakte sind nicht nichtig, sondern lediglich vernichtbar. Bis dahin kommt ihnen eine Gültigkeitsvermutung zu.

(bb) Keine Übertragbarkeit auf mitgliedstaatliches Recht

Ausgangspunkt der vorangegangenen Überlegungen zur Gültigkeitsvermutung für Unionsrechtsakte war die Frage nach dem Bestehen eines Rechtsscheins der Unionsrechtskonformität nationalen Rechts und damit danach, ob auch dieses eine für den guten Glauben relevante Vorstellung vom Inhalt des Unionsrechts begründen kann. Vor dem Hintergrund des im vorhergehenden Abschnitt Gesagten kann dies letztlich nur verneint werden.

So überzeugt der Verweis auf die mitgliedstaatliche Bindung an allgemeine Grundsätze des Unionsrechts, mit der der Rechtsschein begründet

618 In diesem Sinne Schwarze/Wunderlich, in: Schwarze/Becker/Hatje/Schoo (Hrsg.), EU-Kommentar, 4. Aufl. 2019, Art. 267 AEUV, Rn. 21.

619 Vgl. Hein, Inzidentkontrolle, 2001, S. 182.

620 Vgl. nur EuGH, Urteil vom 14.6.2012, Rs. C-533/10 (CIVAD), Rn. 39 (Hervorhebung nur hier).

621 Vgl. Toth, YEL 4 (1984), 1 (13f.): Ein Akt kann nicht zur selben Zeit in einem Fall ungültig sein und in einem anderen Fall gültig. 
werden soll, im Ergebnis nicht. Diese allgemeinen Grundsätze des Unionsrechts müssen von den Mitgliedstaaten zwar in der Tat beachtet werden. Einerseits kann aber unsicher sein, ob sie ihnen in zutreffender Weise Rechnung getragen haben. Andererseits, und das erscheint im vorliegenden Zusammenhang entscheidend, wurde die Gültigkeitsvermutung für Unionsrechtsakte mit dem Verwerfungsmonopol des EuGH und dem institutionellen Gleichgewicht auf Unionsebene begründet. Auch wenn nationalen Rechtsakten aus nationaler Perspektive eine Gültigkeits- bzw. Rechtmäßigkeitsvermutung zukommen sollte, ist dies daher aus der hier entscheidenden unionsrechtlichen Perspektive nicht maßgebend. Insoweit muss es bei der Feststellung bleiben, dass es nationalen Rechtsakten im Hinblick auf die Begründung der Gültigkeitsvermutung für Unionsrechtsakte an Vergleichbarkeit fehlt.

Begründet werden kann ein Rechtsschein der Unionsrechtskonformität in Bezug auf nationale Rechtsakte auch nicht damit, dass der EuGH bereit ist, aus Gründen der Rechtssicherheit die ex tunc-Wirkung der Auslegung zu begrenzen. ${ }^{622}$ An dieser Stelle soll ja gerade erst die Frage beantwortet werden, ob dem nationalen Recht hierfür Bedeutung zukommt. Dies vorauszusetzen, liefe auf einen unzulässigen Zirkelschluss hinaus.

Ein Rechtsschein der Unionsrechtskonformität nationalen Rechts ließe sich allenfalls bei in Durchführung eines Unionsrechtsaktes getroffenen mitgliedstaatlichen Maßnahmen annehmen. In diesem Fall erschiene der Rechtsschein dann aber als Rechtswirkung des Unionsrechtsakts, dem die Gültigkeitsvermutung zukommt. ${ }^{623}$ Insoweit ginge es lediglich darum, einen Verstoß gegen die Gültigkeitsvermutung für Unionsrechtsakte zu vermeiden, da bei einer Infragestellung der Gültigkeit einer na-

622 So aber Eder, EuR 2015, 746 (761 mit Fn. 43). GA Szpunar, Schlussanträge vom 22.10.2015 in der Rs. C-336/14 (Ince), Rn. 42 spricht davon, dass aus Sicht des Einzelnen eine Rechtmäßigkeitsvermutung für Gesetze gelte.

623 Vgl. EuG, Urteil vom 21.3.2012, verb. Rs. T-50/06 RENV, T-56/06 RENV, T-60/06 RENV, T-62/06 RENV und T-69/06 RENV (Irland u.a./Kommission), Rn. 109. Das Urteil des Gerichts wurde zwar vom EuGH aufgehoben, EuGH, Urteil vom 10.12.2013, Rs. C-272/12 P (Kommission/Irland u.a.). Begründet hat der Gerichtshof dies mit einer Missachtung der Kompetenzen der Kommission im Beihilfenrecht durch das EuG, vgl. Urteil, Rn. 45 ff., sodass im Ergebnis, anders als vom EuG angenommen, kein Verstoß gegen die Gültigkeitsvermutung bejaht werden konnte, vgl. Urteil, Rn. 54. An der grundsätzlichen, d.h. von den Besonderheiten des Falles losgelösten, Berechtigung der Aussagen des Gerichts ändert dies aber nichts. 
tionalen Durchführungsmaßnahme mittelbar auch die Gültigkeit ihrer unionsrechtlichen Rechtsgrundlage angezweifelt würde. ${ }^{624}$

Für die vorliegenden Zwecke bleibt festzuhalten, dass nationales Recht keine Vorstellung vom Inhalt des Unionsrechts begründen kann.

(c) Beachtlichkeit von Äußerungen nationaler Gerichte zum Inhalt des Unionsrechts?

Etwas anders gelagert ist die Frage, ob Äußerungen mitgliedstaatlicher Gerichte zum Inhalt des Unionsrechts bei der Bestimmung des Bestehens von gutem Glauben Berücksichtigung finden können. ${ }^{625}$ Für ihre Beachtlichkeit wird angeführt, dass sonst angesichts der lediglich punktuellen Rechtsprechung des EuGH und der lediglich punktuellen Rechtsetzung auf Unionsebene nur geringe Anknüpfungspunkte für guten Glauben vorhanden seien. ${ }^{626}$ Damit wird zwar durchaus ein Problem zutreffend erkannt. Dessen Lösung vermag aber nicht zu überzeugen.

Nationale Gerichte sind funktional zwar Unionsgerichte, wenn sie Unionsrecht auslegen und anwenden; insoweit zeigt sich die funktionale Verschränkung nationaler Gerichte mit der Unionsgerichtsbarkeit. ${ }^{627} \mathrm{Ihr}$ Verhalten kann der Union aber nicht zugerechnet werden, was für eine Begründung guten Glaubens hinsichtlich des Verständnisses des Unionsrechts jedoch zu fordern ist. ${ }^{628}$ In aller Regel fehlt es auch an der Möglichkeit, von den durch die nationalen Gerichte getroffenen Aussagen unionsweit Kenntnis zu nehmen. Dass der BGH in seinem Urteil zum unionsrechtlichen Staatshaftungsanspruch wegen der Verletzung des Unionsrechts im Bereich der Veranstaltung von Sportwetten der Betonung der Parallelität der verfassungs- und unionsrechtlichen Anforderungen durch das Bundesverfassungsgericht Bedeutung für die Frage des Vorliegens eines

624 EuG, Urteil vom 21.3.2012, verb. Rs. T-50/06 RENV, T-56/06 RENV, T-60/06 RENV, T-62/06 RENV und T-69/06 RENV (Irland u.a./Kommission), Rn. $104 \mathrm{f}$.

625 Siehe hierzu auch die zweite Vorlagefrage des Arbeitsgerichts Verden in der Rs. C-385/17 (Hein).

626 Herresthal, Rechtsfortbildung, 2006, S. 294.

627 Herresthal, Rechtsfortbildung, 2006, S. 293 f.; Sagan, Jahrbuch Junger Zivilrechtswissenschaftler 2010, 67 (71 ff.).

628 Vgl. Schlachter, ZfA 2007, 249 (267). 
hinreichend qualifizierten Unionsrechtsverstoßes zugebilligt hat, begegnet daher Bedenken. ${ }^{629}$

Damit verblieben lediglich die Fälle eines acte clair, in denen das Verhalten mitgliedstaatlicher Gerichte guten Glauben begründen könnte, da jene in diesem Fall, obwohl es an Rechtsprechung des Gerichtshofs fehlt, von einer Vorlage an den EuGH absehen können. ${ }^{630} \mathrm{Da}$ die mitgliedstaatlichen Gerichte bei der Annahme eines acte clair aber wie gesehen keine unbegrenzte Freiheit genießen ${ }^{631}$, ist letztlich nicht deren Verhalten und deren Verständnis des Unionsrechts ausschlaggebend, sondern weiterhin dasjenige auf Unionsebene. Voraussetzung eines acte clair ist gerade die Offensichtlichkeit des zutreffenden Verständnisses einer unionsrechtlichen Vorschrift, die nur dann anzunehmen ist, wenn das Ergebnis auch für den Gerichtshof selbst offensichtlich ist. Dann muss es aber auf Unionsebene Anhaltspunkte für ein derartiges Verständnis geben. Hinzu kommt, dass in einem Fall, in dem das unionsrechtlich zutreffende Verständnis offensichtlich ist, die vereinzelte Äußerung eines nationalen Gerichts, die von diesem Verständnis abweicht, nicht gutglaubensbegründend wirken kann.

\section{(d) Erforderlichkeit eines Bezugs zur Unionsebene}

Die Berücksichtigung mitgliedstaatlichen Verhaltens ließe sich auch nicht mit der Irrelevanz mitgliedstaatlicher Rechtsanwendungsschwierigkeiten vereinbaren und verstieße letztlich gegen den Vorrang des Unionsrechts. ${ }^{632}$ Die Mitgliedstaaten sind deshalb auf ihre Einflussmöglichkeiten auf Unionsebene verwiesen, wenn sie Einfluss auf die Bildung von gutem Glauben nehmen möchten. Treten sie als „Herren der Verträge“ auf, kann ihr Verhalten Bedeutung für den guten Glauben erlangen. Aus unions-

629 BGH, Urteil vom 18.10.2012, III ZR 196/11, Rn. 28 ff. - EuZW 2013, 194 mit Blick auf BVerfG, Urteil vom 28.3.2006, 1 BvR 1054/01 - BVerfGE 115, 276. Das Urteil des BGH betrifft zwar insofern einen anderen Zusammenhang, als dieser dort an eine verfassungsrechtliche Beurteilung des Bundesverfassungsgerichts angeknüpft hat; bedenklich ist aber gerade die Wirkung, die er der Äußerung eines nationalen Gerichts zuerkannt hat. Zum Urteil des Bundesverfassungsgerichts näher unten bei Fn. 1397 ff.

630 Vgl. Sagan, Jahrbuch Junger Zivilrechtswissenschaftler 2010, 67 (73 f.).

631 Siehe oben bei Fn. $201 \mathrm{ff}$.

632 Müller, Begrenzung, 2009, S. 142; Schaer, Grenzen rückwirkender Rechtsprechung, 2010, S. 59; Schlachter, ZfA 2007, 249 (267). 
rechtlicher Sicht bestehen hiergegen keine Einwände, da in diesem Fall ein Bezug zur unionsrechtlichen Ebene hergestellt ist. ${ }^{633}$

Mitgliedstaatliche Rechtsansichten können daher höchstens dann Berücksichtigung finden, wenn ein Rechtsstreit auf nationaler Ebene zu entscheiden ist. Dieser Problematik wird im zweiten Teil der Arbeit nachgegangen.

\section{(3) Zwischenergebnis und Schlussfolgerungen}

Die Frage nach tauglichem Verhalten für die Bildung von gutem Glauben bewegt sich in einem Spannungsfeld. Einerseits besteht ein Bedürfnis, hier nicht zu großzügig zu verfahren. Denn je mehr Äußerungen als geeignet angesehen werden, guten Glauben zu begründen, desto wahrscheinlicher wird eine Begrenzung der zeitlichen Wirkungen und umso größer sind die Einbußen für den Geltungsanspruch des Unionsrechts. Andererseits wäre die Bildung von gutem Glauben nur noch sehr eingeschränkt möglich, wenn ihr die Anknüpfung an eine rechtlich verbindliche Auslegung des Unionsrechts zugrunde liegen müsste, da die Äußerung einer Rechtsansicht etwa durch die Kommission dann angesichts ihrer rechtlichen Unverbindlichkeit als bloße Meinungsäußerung abgetan werden müsste. Lediglich die verbindliche Auslegung von Unionsrecht in einem Urteil des Gerichtshofs käme dann noch als Auslöser von gutem Glauben in Betracht. Da dies die Möglichkeit der Bildung von gutem Glauben zu sehr einschränken würde, kommt als berücksichtigungsfähige Rechtsansicht im Ergebnis auch rechtlich nicht bindendes Verhalten in Betracht. ${ }^{634}$ Angesichts des Unionsrechtsbezugs des guten Glaubens ist entscheidend, ob dieses Verhalten der Union zugerechnet werden kann.

Ist für die Betroffenen erkennbar, dass eine geäußerte Rechtsansicht mit Unionsrecht unvereinbar ist, kann mit ihr kein guter Glaube begründet werden. ${ }^{635}$ Von diesem Fall erkennbarer Unionsrechtswidrigkeit der Rechtsansicht abgesehen, ist es für die Begründung von gutem Glauben aber gerade kennzeichnend, dass bei den Betroffenen eine Fehlvorstellung

633 Rosenkranz, Beschränkung der Rückwirkung, 2015, S. 198 f. Er verweist etwa auf die Möglichkeit gemeinsamer Protokollerklärungen zum Primär- oder Sekundärrecht.

634 Zutreffend Sagan, Jahrbuch Junger Zivilrechtswissenschaftler 2010, 67 (72).

635 Vgl. EuGH, Urteil vom 19.9.2000, verb. Rs. C-177/99 und C-181/99 (Ampafrance und Sanofi), Rn. 68 f. 
vom Inhalt des Unionsrechts hervorgerufen wird. Die dem guten Glauben zugrundeliegende Rechtsansicht erweist sich daher nach einer Entscheidung des Gerichtshofs zwangsläufig als rechtswidrig. Dies ist aber unerheblich.

Greift eine Unionsstelle durch eine Äußerung in den Zuständigkeitsbereich einer anderen Unionsstelle über, ist die geäußerte Ansicht zwar eine solche der unzuständigen Stelle, der Union als solcher aber grundsätzlich weiterhin zurechenbar. Ist die fehlende Zurechnung zum zuständigen Organ für die Rechtsunterworfenen nicht erkennbar, besteht kein Grund, der Rechtsansicht guten Glauben begründende Kraft abzusprechen. Die Rechtsunterworfenen durften sich also eine Vorstellung vom Unionsrecht unter Einbeziehung dieser Äußerung bilden, da die Union in diesem Fall immerhin den Anschein der Zurechnung begründet hat. ${ }^{636}$

Angesichts des unionsweit einheitlichen Maßstabs des guten Glaubens muss die unionsweite Verbreitung der Rechtsansicht gewährleistet sein, was bei nicht veröffentlichten Äußerungen im Rahmen von Beitrittsverhandlungen nicht der Fall ist. Dass der Gerichtshof in der Rechtssache EKW und Wein \& Co. eben solchen Äußerungen guten Glauben begründende Kraft beigemessen hat, muss deswegen Kritik hervorrufen. ${ }^{637}$ Generalanwalt Saggio war in seinen Schlussanträgen in dieser Rechtssache daher zu Recht zu der Auffassung gelangt, dass guter Glaube auf diese Weise nicht begründet werden könne, da die angeführte Äußerung der Kommission aus den eingereichten Dokumenten nicht ersichtlich wurde. 638

Allgemeiner gesprochen gilt daher, dass solche Äußerungen der Kommission in ihrer Kommunikation mit den Mitgliedstaaten, die nicht für alle anderen Betroffenen ohne Weiteres zugänglich sind ${ }^{639}$, nur noch als Beleg und nicht als Begründung einer Unsicherheit hinsichtlich der Tragweite der Unionsbestimmungen herangezogen werden können sollten. ${ }^{640}$ Sie können die anderen Betroffenen, die von ihnen keine Kenntnis haben, von vornherein nicht zu einem bestimmten Verhalten „veranlassen“. Guter Glaube im Sinne einer vermeintlichen Sicherheit hinsichtlich des In-

636 Dies lässt Rosenkranz, Beschränkung der Rückwirkung, 2015, S. 177 nicht genügen und ist den Betroffenen gegenüber daher strenger.

637 Ebenso Lang, IStR 2007, 235 (238); Kovács, Temporale Wirkung, 2014, S. 163 f.

638 GA Saggio, Schlussanträge vom 1.7.1999 in der Rs. C-437/97 (EKW und Wein \& Co.), Rn. 64.

639 Vgl. Lang, IStR 2007, 235 (238).

640 In diesem Sinne auch Kovács, Temporale Wirkung, 2014, S. 162 ff., der derartiges Verhalten nur als Indikator für eine bestehende Rechtsunsicherheit und nicht als deren Auslöser verstanden wissen will. 
halts des Unionsrechts muss sich aber bei allen Betroffenen gleichermaßen bilden können. Entscheidend ist demnach nicht, welche Informationen dem die zeitliche Begrenzung Begehrenden zugänglich sind. Zur Abgrenzung zwischen für den guten Glauben relevanten und dafür unerheblichen Äußerungen ist vielmehr darauf abzustellen, was für den Gerichtshof ermittelbar und nachvollziehbar ist. ${ }^{641}$

Damit bleibt festzuhalten, dass Rechtsansichten von Unionsorganen mit unionsweiter Verbreitung in die Bildung des guten Glaubens einbezogen werden können. Mit dieser Erkenntnis vor Augen ist nach weiteren „Auslösern" guten Glaubens zu fragen, da es auf der Hand liegt, dass es Fälle gibt, in denen das Verhalten der Kommission (und anderer Mitgliedstaaten) keine Rolle gespielt hat. ${ }^{642}$ Dies ergibt sich bereits aus der Verwendung des Wortes „eventuell“ in der bereits mehrfach angesprochenen Aussage des Gerichtshofs: Wenn zum Bestehen einer objektiven, bedeutenden Unsicherheit hinsichtlich der Tragweite der Unionsbestimmungen eventuell auch das Verhalten anderer Mitgliedstaaten oder der Europäischen Kommission beigetragen hat ${ }^{643}$, muss es notwendigerweise Konstellationen geben, in denen sich diese Unsicherheit anderweitig ergibt. Neben einer sich aus der Norm selbst ergebenden Unsicherheit, die vermeintlich sicher in Richtung eines bestimmten Verständnisses weist, ist insbesondere denkbar, dass Verhalten anderer Akteure als der Kommission zum Bestehen von gutem Glauben beigetragen hat.

\section{(4) Gerichtshof}

Damit fällt der Blick insbesondere auf den Gerichtshof selbst. Können sogar rechtlich unverbindliche Ansichten anderer Unionsstellen guten Glauben begründen, dann muss dies erst recht für den nach Art. 19 I UAbs. 1 S. 2 EUV und Art. 267 AEUV zur verbindlichen Auslegung des Unionsrechts zuständigen Gerichtshof gelten. ${ }^{644}$ Die Rechtsprechung des

641 Vgl. GA Stix-Hackl, Schlussanträge vom 15.9.2005 in der Rs. C-184/04 (Uudenkaupungin kaupunki), Rn. 89, die von einem ansonsten erheblichen Unsicherheitsfaktor hinsichtlich der zeitlichen Wirkung der Urteile spricht.

642 Vgl. Wusterhausen, Wirkungen, 2016, S. 195.

643 Siehe z.B. EuGH, Urteil vom 22.9.2016, Rs. C-110/15 (Microsoft Mobile Sales International u.a.), Rn. 61.

644 Davon geht auch der Gerichtshof selbst aus, vgl. EuGH, Urteil vom 30.4.1996, Rs. C-308/93 (Cabanis-Issarte), Rn. 47; EuGH, Urteil vom 4.5.1999, Rs. C-262/96 (Sürül), Rn. 110. 
Gerichtshofs ist geradezu dazu angetan, das Verständnis des Unionsrechts in der EU zu prägen und eine Vorstellung von dessen Inhalt zu begründen. Stellt sie sich im Nachhinein als unzutreffend heraus, kommt sie den Betroffenen als guten Glauben begründende Fehlvorstellung zugute.

Verglichen mit der Rechtsetzung durch die Unionsorgane ist die Rechtsprechung des Gerichtshofs zwar leichter änderbar. Mit einer geringeren Bedeutung für den guten Glauben im Vergleich zur Rechtsetzung geht dies aber nicht einher. ${ }^{645}$ Davon wäre nur auszugehen, wenn der Unionsgesetzgeber durch authentische Auslegung das Unionsrecht verbindlich konkretisieren könnte. Diese Befugnis steht ihm nach hier vertretener Ansicht aber letztlich nicht zu. ${ }^{646}$

\section{(a) Erstauslegung}

Zur Bejahung von „Unsicherheit“ soll nach Auffassung von Lang bereits ausreichend sein, dass eine Vorschrift vom EuGH zum ersten Mal ausgelegt wird. ${ }^{647}$ Dies kann aber nicht zutreffend sein, da die ex tunc-Wirkung bei einer Erstauslegung ansonsten regelmäßig zu begrenzen wäre ${ }^{648}$, was aber angesichts des Ausnahmecharakters einer zeitlichen Begrenzung ersichtlich nicht der Fall ist.

Ebenfalls nicht überzeugend ist es, das Urteil des Gerichtshofs, das eine Bestimmung zum ersten Mal auslegt, als die Unsicherheit erst begründend anzusehen. ${ }^{649}$ Entstünde Unsicherheit erst durch das EuGH-Urteil selbst, fehlte es bis zu seinem Erlass ja daran. Für guten Glauben wäre dann kein Raum, sodass eine Begrenzung der zeitlichen Wirkungen bei der erstmaligen Auslegung einer Vorschrift von vornherein ausscheiden müsste. Auch dies ist aber nicht der Fall.

Die zur Bestätigung der soeben abgelehnten Auffassung zitierten Urteile ${ }^{650}$ erweisen sich bei näherer Betrachtung dann auch als ungeeignet zur Stützung dieser Auffassung. So wird etwa in Rn. 108 des Urteils in der

645 Anders Rosenkranz, Beschränkung der Rückwirkung, 2015, S. 179.

646 Siehe dazu oben bei Fn. 124.

647 Lang, in: Popelier/Verstraelen/Vanheule/Vanlerberghe (Hrsg.), The Effects of Judicial Decisions in Time, 2014, S. 245 (251).

648 Vgl. Peers, ELRev. 1999, 627 (633).

649 So aber Kovács, Temporale Wirkung, 2014, S. 153 f.

$650 \mathrm{EuGH}$, Urteil vom 2.2.1988, Rs. 24/86 (Blaizot u.a.), Rn.29; EuGH, Urteil vom 4.5.1999, Rs. C-262/96 (Sürül), Rn. 109; EuGH, Urteil vom 9.3.2000, Rs. C-437/97 (EKW und Wein \& Co.), Rn. 58. 
Rechtssache Sürül das Konnexitätsmerkmal angesprochen, wonach eine zeitliche Begrenzung im ersten zu einer Auslegungsfrage ergehenden Urteil erfolgen muss. ${ }^{651}$ In Rn. 109 wird sodann darauf hingewiesen, dass die betroffene Vorschrift nun zum ersten Mal ausgelegt worden sei. Erst Rn. 110 bezieht sich dann auf die „bei vernünftiger Betrachtung“ entstandene Ungewissheit hinsichtlich der unmittelbaren Anwendbarkeit der Vorschrift. Auch durch die Verwendung des Wortes „zudem“ in Rn. 110 wird deutlich, dass es in Rn. 109 noch um eine andere Fragestellung ging. Die Zuordnung dieser Randnummer zum Problem der Unsicherheit und damit zum guten Glauben ist daher abzulehnen. ${ }^{652}$ Entsprechendes gilt für die Rechtssache Blaizot. ${ }^{653}$ Auch in der Rechtssache EKW und Wein \& Co. wird zwischen der erstmaligen Behandlung einer Rechtsfrage und dem Bestehen von Unsicherheit unterschieden, wenn es sowohl heißt, die Vorschrift sei bislang nicht Gegenstand eines Auslegungsurteils gewesen als auch, dass die Regierung „auch“ annehmen durfte, dass die nationale Regelung unionsrechtskonform sei. ${ }^{654}$

Dass eine Vorschrift durch den Gerichtshof erstmalig ausgelegt wird, bedeutet also weder, dass die zeitlichen Wirkungen zwingend zu begrenzen sind noch dass dies zwingend ausscheidet.

\section{(b) Rechtsprechungsänderung}

Wird die gleiche Rechtsfrage vom Gerichtshof im Vergleich zum ersten Mal abweichend entschieden, liegt eine Rechtsprechungsänderung vor. In diesem Fall kommt eine Beschränkung der zeitlichen Wirkungen in Betracht und ist nicht wegen Präklusion gesperrt ${ }^{655}$, da die Rechtsfrage ja abweichend entschieden wird.

Ist wie soeben gesehen die Bejahung guten Glaubens möglich, wenn sich der Gerichtshof mit einer Frage noch nicht befasst hat, muss dies erst recht für den Fall gelten, in dem bereits einschlägige Rechtsprechung vorliegt. Die Argumente für eine Beschränkung der zeitlichen Wirkungen sind hier „stärker“, da Rechtsverhältnisse auf Grundlage einer Auslegung

651 Siehe dazu ausführlich unten bei Fn. $881 \mathrm{ff}$.

652 EuGH, Urteil vom 4.5.1999, Rs. C-262/96 (Sürül), Rn. 108-110.

653 EuGH, Urteil vom 2.2.1988, Rs. 24/86 (Blaizot u.a.), Rn. 28 und 29.

654 EuGH, Urteil vom 9.3.2000, Rs. C-437/97 (EKW und Wein \& Co.), Rn. 58.

655 Siehe hierzu näher unten bei Fn. $881 \mathrm{ff}$. 
des Unionsrechts durch die dafür zuständige Instanz begründet worden sind. 656

Um ein zutreffendes Bild von den anzulegenden Maßstäben zeichnen zu können, sind zum Teil feinsinnige Differenzierungen vorzunehmen. So scheidet eine zeitliche Begrenzung aus, wenn die bisherige Rechtsprechung vom Gerichtshof lediglich klargestellt wird. ${ }^{657}$ In der Begrenzung der Tragweite einer früheren ständigen Rechtsprechung liegt dagegen - anders als bei einer Klarstellung - eine Änderung dieser Rechtsprechung ${ }^{658}$, was den Gerichtshof dazu veranlasste, die zeitlichen Wirkungen der geänderten Auslegung zu begrenzen. Klarstellungen sind daher von Tragweitebeschränkungen abzugrenzen. ${ }^{659}$ Von einer Klarstellung ist etwa dann zu sprechen, wenn eine Aussage in einem Urteil scheinbar ohne Ausnahmen zu verstehen ist, sich dann aber herausstellt, dass trotz der Allgemeinheit der Aussage Ausnahmen möglich sind. ${ }^{600}$ Eine Tragweitebeschränkung ist anzunehmen, wenn die Tragweite der Rechtsprechung im Anschluss an ein vorangegangenes Urteil auf bestimmte Sachverhaltskonstellationen beschränkt wird.

Trotz einer Änderung einschlägiger Rechtsprechung kann guter Glaube zu verneinen sein. ${ }^{661}$ Eindeutige anderslautende Hinweise finden sich in der Rechtsprechung des Gerichtshofs nicht. So werden in der als Fall der Rechtsprechungsänderung einzuordnenden Rechtssache Bidar wie auch sonst üblich sowohl der gute Glaube als auch die Gefahr schwerwiegender wirtschaftlicher Auswirkungen angesprochen. Wenn der Gerichtshof ausführt, dass es im vorliegenden Fall genüge, die Gefahr schwerwiegender wirtschaftlicher Auswirkungen zu verneinen ${ }^{662}$, so wird deutlich, dass dies in anderen Fällen nicht genügen mag. In diesen Fällen müsste dann auch das Bestehen von gutem Glauben geprüft werden, an dessen Fehlen eine Begrenzung der zeitlichen Wirkungen scheitern könnte. Die Verneinung guten Glaubens dürfte insoweit aber nur ausnahmsweise in Betracht kom-

656 Vgl. GA Fennelly, Schlussanträge vom 6.6.1996 in den verb. Rs. C-267/95 und C-268/95 (Merck und Beecham), Fn. 182 und Rn. 169.

657 EuGH, Urteil vom 3.10.2006, Rs. C-17/05 (Cadman), Rn. 42 f. GA Poiares Maduro, Schlussanträge vom 18.5.2006 in der Rs. C-17/05 (Cadman), Rn. 70 bejahte dagegen in diesem Verfahren guten Glauben.

658 EuGH, Urteil vom 30.4.1996, Rs. C-308/93 (Cabanis-Issarte), Rn. 34, 46 f.

659 Darauf weist Müller, Begrenzung, 2009, S. 140 zu Recht hin.

660 EuGH, Urteil vom 3.10.2006, Rs. C-17/05 (Cadman), Rn. 37.

661 Hyland, IJEL 2 (1995), 208 (230); Rosenkranz, Beschränkung der Rückwirkung, 2015, S. 181.

662 EuGH, Urteil vom 15.3.2005, Rs. C-209/03 (Bidar), Rn. 70. 
men. Sie setzt voraus, dass die Rechtsprechungsänderung vorhersehbar war oder sich die rechtlichen bzw. tatsächlichen Umstände derart geändert haben, dass ein Festhalten an der Rechtsprechung nicht angenommen werden konnte. ${ }^{663}$

\section{(c) Anschein einer Rechtsprechungsänderung}

Von einer Rechtsprechungsänderung ist der Fall des Anscheins einer Rechtsprechungsänderung zu unterscheiden. In diesem Fall erweckt ein früheres Urteil des Gerichtshofs den Anschein, ihm könne eine Aussage für den nun zu entscheidenden Fall entnommen werden, was sich dann aber als unzutreffend herausstellt. Das Urteil ist also nicht einschlägig, konnte aber als einschlägig verstanden werden. Diese Konstellation ist zum Teil nur schwer von einer „echten“ Rechtsprechungsänderung zu unterscheiden. Illustrativ ist insoweit die Rechtssache Sürül, die an das Urteil in der Rechtssache Taflan-Met anknüpft.

Das Urteil in der Rechtssache Taflan-Met erweckte in seinen Entscheidungsgründen den Anschein, als sei keine Bestimmung des Assoziationsratsbeschlusses 3/80 664 ohne Durchführungsmaßnahmen unmittelbar anwendbar. ${ }^{665} \mathrm{Im}$ Tenor beschränkte sich der Gerichtshof dann allerdings auf die streitgegenständlichen Art. 12 und 13 des Beschlusses. Art. 3 des Assoziationsratsbeschlusses, um den es in der Rechtssache Sürül ging, fand im Tenor des Taflan-Met-Urteils also keine Erwähnung. Nicht eindeutig ist daher, ob der EuGH in Taflan-Met bereits eine Aussage zu Art. 3 des Assoziationsratsbeschlusses getroffen hat. Beschränkt man den Blick auf den Tenor, ist dies zu verneinen; bezieht man dagegen die Entscheidungsgründe mit ein, ist dies zu bejahen. Dann ließe sich sogar vertreten, es handele sich beim Sürül-Urteil, das die unmittelbare Wirkung von Art. 3 des Assoziationsratsbeschlusses bejaht, um den Fall einer Rechtsprechungsänderung. ${ }^{666}$

Im Hinblick auf die für eine zeitliche Begrenzung entscheidende Frage nach gutem Glauben hinsichtlich der fehlenden unmittelbaren Wir-

663 Vgl. Lunk, in: FS Reuter, 2010, S. 689 (694).

664 Beschluss Nr. 3/80 des Assoziationsrats vom 19. September 1980 über die Anwendung der Systeme der sozialen Sicherheit der Mitgliedstaaten der Europäischen Gemeinschaften auf die türkischen Arbeitnehmer und auf deren Familienangehörige, ABl. C 110 vom 25.4.1983, S. 60.

665 EuGH, Urteil vom 10.9.1996, Rs. C-277/94 (Taflan-Met u.a.), Rn. 37.

666 Vgl. Peers, ELRev. 1999, 627 (629, 631). 
kung von Art. 3 des Assoziationsratsbeschlusses spricht der Gerichtshof im Sürül-Urteil missverständlich davon, dass das Urteil in der Rechtssache Taflan-Met „bei vernünftiger Betrachtung Ungewißheit [...] entstehen lassen [konnte]“. ${ }^{667}$ Sollte damit Ungewissheit im Sinne von Unklarheit gemeint sein, bedeutete dies eine Absenkung des Gutglaubensmaßstabs. Wenn ein Urteil des EuGH lediglich geeignet ist, Missverständnisse zu begründen, könnte von gutem Glauben im Sinne der sonst verlangten vermeintlichen Sicherheit nämlich nicht gesprochen werden. Zugespitzt formuliert hieße das, dass guter Glaube dann bereits deshalb möglich wäre, weil das Taflan-Met-Urteil schlecht verfasst worden war. ${ }^{668}$

Die Anlegung eines derart veränderten Maßstabs wäre allerdings nicht überzeugend. Sie ist im Ergebnis auch nicht erfolgt: Dem Urteil in der Rechtssache Taflan-Met konnte „bei vernünftiger Betrachtung“ eine Aussage entnommen werden, die es nicht enthielt. Damit war die fehlende unmittelbare Wirkung von Art. 3 des Assoziationsratsbeschlusses vermeintlich sicher. Wenn der Gerichtshof hier also von „Ungewissheit" spricht, ist dies auch weiterhin im Sinne von ,vermeintlicher Sicherheit“ zu verstehen. Eine Begrenzung der zeitlichen Wirkungen kommt in diesem Fall also ebenfalls nur nach dem auch sonst anzulegenden Maßstab in Betracht.

\section{(d) Obiter dicta}

Rechtsprechung des Gerichtshofs kann wie gesehen taugliche Grundlage für guten Glauben sein. Fraglich ist, ob dies auch auf obiter dicta zutrifft.

Hinsichtlich der Bindungswirkung von obiter dicta bestehen verschiedene Auffassungen in der Literatur. So wird vertreten, dass sowohl ratio decidendi als auch obiter dictum allgemeine Bindungswirkung zukommen könne. ${ }^{669}$ Eine andere Ansicht lehnt eine rechtliche Bindungswirkung von obiter dicta dagegen ab. ${ }^{670}$ Die Bindungswirkung sei beschränkt auf den Tenor, der im Lichte der Entscheidungsgründe auszulegen sei. ${ }^{671}$ Als Mit-

667 EuGH, Urteil vom 4.5.1999, Rs. C-262/96 (Sürül), Rn. 110.

668 Vgl. Peers, ELRev. 1999, 627 (633): „badly drafted“.

669 Piekenbrock, ZZP 119 (2006), 3 (19f.); Arnull, in: Andenas/Jacobs (Hrsg.), European Community Law, 1998, S. 115 (126).

670 Germelmann, Rechtskraft, 2009, S. 430 f.; Wollenschläger, NJW 2018, 2532 (2534, 2536).

671 Wegener, in: Calliess/Ruffert (Hrsg.), EUV/AEUV, 5. Aufl. 2016, Art. 267 AEUV, Rn. 48. Eine Bindung auch an die tragenden Entscheidungsgründe nimmt wohl Wollenschläger, NJW 2018, 2532 (2535) an. 
telweg wird vorgeschlagen, die Möglichkeit einer Bindung an obiter dicta zu bejahen, aber eine Einzelfallprüfung zu verlangen. ${ }^{672}$

Nach dem bisher zu berücksichtigungsfähigem Verhalten Gesagten können diese Einordnungen für die hier interessierende Frage der Tauglichkeit eines obiter dictum als relevanter Umstand bei der Begründung von gutem Glauben nicht entscheidend sein. So hatte sich gezeigt, dass auch die Ansichten anderer Organe als des Gerichtshofs guten Glauben begründen können und zwar unabhängig von ihrer rechtlichen Verbindlichkeit. Dann kann es auch nicht darauf ankommen, ob es sich bei der Äußerung des Gerichtshofs um ein obiter dictum handelt. ${ }^{673}$ Auch dieses ist vom Willen des Gerichtshofs getragen und ihm daher zuzurechnen, sodass es für die Entstehung von gutem Glauben Bedeutung erlangen kann.

\section{(e) Untätigkeit des Gerichtshofs / Schlussanträge}

Wird der EuGH nicht tätig, kann dies dagegen keinen guten Glauben begründen. Da er nur Recht sprechen kann, wenn er angerufen wird, kann seinem Schweigen kein Aussagegehalt entnommen werden. ${ }^{674}$

Was die Bedeutung der Schlussanträge der Generalanwälte für den guten Glauben anbelangt, ist zunächst festzuhalten, dass der Gerichtshof an die Ausführungen seiner Generalanwälte nicht gebunden ist: „Weder die Schlussanträge des Generalanwalts noch ihre Begründung binden den Gerichtshof."675 „Vermeintlich sicher" kann es daher jedenfalls nicht sein, dass der Gerichtshof den Ausführungen der Generalanwälte folgt. Erachtet der Gerichtshof eine in den Schlussanträgen behandelte Rechtsfrage allerdings als nicht entscheidungserheblich und äußert sich zu dieser Frage daher in seinem Urteil selbst nicht, können die in den Schlussanträgen getroffenen Aussagen durchaus eine Rolle für den guten Glauben spielen. Sie sind ja unwidersprochen geblieben, sodass es an einer Äußerung des

672 Martens, Methodenlehre, 2013, S. 232. Kritisch Klöpfer, Missbrauch, 2016, S. 182 : Warnung vor einer Verallgemeinerung einer bloßen Randbemerkung (angesichts der damit verbundenen Folgen im konkreten Rechtsgebiet). Siehe zur Frage der Bindungswirkung von obiter dicta auch bereits oben bei Fn. $158 \mathrm{ff}$.

673 Siehe auch Rosenkranz, Beschränkung der Rückwirkung, 2015, S. 182.

674 Schaer, Grenzen rückwirkender Rechtsprechung, 2010, S. 50; Rosenkranz, Beschränkung der Rückwirkung, 2015, S. 185.

675 EuGH, Urteil vom 28.2.2018, Rs. C-577/16 (Trinseo Deutschland), Rn. 32 unter Verweis auf EuGH, Urteil vom 17.9.2015, Rs. C-33/14 P (Mory u.a./Kommission), Rn. 25. 
Gerichtshofs fehlt, die deren guten Glauben begründende Kraft zerstören könnte.

Der EuGH hat in einer früheren Rechtssache vorgelegte Schlussanträge bislang lediglich herangezogen, um guten Glauben in eine Rechtsansicht zu verneinen. Der Generalanwalt, so der Gerichtshof in seinem Urteil in den verbundenen Rechtssachen Lancry u.a., habe in seinen Schlussanträgen in der (früheren) Rechtssache Legros u.a. seine Auffassung von der Ungültigkeit der „octroi de mer"-Entscheidung des Rates sehr klar zum Ausdruck gebracht. ${ }^{676} \mathrm{Da}$ der Gerichtshof in der Rechtssache Legros u.a. nicht über deren Gültigkeit zu befinden hatte, hat er dem Generalanwalt dort weder widersprochen noch zugestimmt, sodass dessen Aussage unwidersprochen im Raum stand. Auch wenn dies im konkreten Fall zur Verneinung von gutem Glauben beitrug, lässt sich diese Argumentation auf den in die andere Richtung weisenden Fall übertragen, für den daher Gleiches gelten muss. Unter Verweis auf unwidersprochen gebliebene Schlussanträge der Generalanwälte kann nach hier vertretener Ansicht daher guter Glaube begründet werden.

\section{(f) Ausschluss guten Glaubens durch Rechtsprechung}

Ebenso wie Rechtsprechung des Gerichtshofs guten Glauben begründen kann, kann sie ihn auch ausschließen.

Ist eine Rechtsfrage in der Rechtsprechung geklärt, ist dieser Rechtsprechung entgegenstehender guter Glaube nicht möglich. Insbesondere kann dann keine Unsicherheit hinsichtlich der Tragweite der Unionsbestimmungen bestehen, wenn eine ständige Rechtsprechung nur auf die Umstände des Ausgangsverfahrens angewendet wird. ${ }^{677}$ Für einen Ausschluss des guten Glaubens muss die Rechtsfrage aber nicht zwingend „Gegenstand einer weit zurückreichenden, umfangreichen und mannigfaltigen

676 EuGH, Urteil vom 9.8.1994, verb. Rs. C-363/93 und C-407/93 bis C-411/93 (Lancry u.a.), Rn. 44 unter Verweis auf die Schlussanträge von GA Jacobs vom 21.11.1991 und 20.5.1992 in der Rs. C-163/90 (Legros u.a.).

677 GA Pitruzzella, Schlussanträge vom 27.6.2019 in der Rs. C-274/18 (SchuchGhannadan), Rn. 66. 
Rechtsprechung “678 sein. Ausreichend sein kann auch ein einzelnes Urteil. ${ }^{679}$

Die zur Frage der Konnexität bestehende Ähnlichkeit der Figur der geklärten Rechtslage ist dabei augenscheinlich: Wenn in einem früheren Urteil bereits über die erbetene Auslegung entschieden worden ist und dort keine Begrenzung in zeitlicher Hinsicht vorgenommen wurde, kann diese im späteren Urteil angesichts des Konnexitätsmerkmals nicht mehr erfolgen. Wenn über die erbetene Auslegung bereits in einem früheren Urteil entschieden worden ist, ist die Rechtslage aber auch geklärt und für guten Glauben kein Raum mehr. ${ }^{680}$

Wie sich Rechtsprechung des Gerichtshofs auf den guten Glauben auswirkt, zeigt sich etwa in der Rechtssache Imofloresmira - Investimentos Imobiliários, in der es um die Berichtigung von Vorsteuerabzügen ging. Nach Auffassung des EuGH steht die Mehrwertsteuerrichtlinie ${ }^{681}$ einer Regelung wie der portugiesischen entgegen, die beim Leerstand einer Immobilie für mehr als zwei Jahre davon ausgeht, dass diese vom Steuerpflichtigen nicht mehr für die Zwecke seiner besteuerten Umsätze verwendet wird und die daher eine Berichtigung der ursprünglich abgezogenen Vorsteuer vorsieht, woran sich auch dadurch nichts ändert, dass der Steuerpflichtige erwiesenermaßen versucht hat, sie während dieses Zeitraums zu verpachten. Die portugiesische Regierung beantragte daher

678 EuGH, Urteil vom 27.5.1981, verb. Rs. 142/80 und 143/80 (Essevi und Salengo), Rn. 33. Siehe z.B. auch EuGH, Urteil vom 27.3.1980, Rs. 61/79 (Denkavit italiana), Rn. 21 und EuGH, Urteil vom 10.5.2012, verb. Rs. C-338/11 bis C-347/11 (Santander Asset Management SGIIC u.a.), Rn.61, wo von einer „ständigen Rechtsprechung" die Rede ist.

679 Siehe u.a. EuGH, Urteil vom 22.9.2016, Rs. C-110/15 (Microsoft Mobile Sales International u.a.), Rn. 62; EuGH, Urteil vom 9.9.2004, Rs. C-72/03 (Carbonati Apuani), Rn. 41. Siehe auch EuGH, Urteil vom 8.4.2014, Rs. C-288/12 (Kommission/Ungarn), Rn. 64, wo der Gerichtshof anlässlich eines Vertragsverletzungsverfahrens, unter Verweis auf die im Rahmen der Auslegungsvorabentscheidung aufgestellten Voraussetzungen, auf die Auslegung der in Rede stehenden Vorschrift in einem anderen Verfahren verweist und das Bestehen von gutem Glauben daher ablehnt.

680 Beide Aspekte finden in EuGH, Urteil vom 6.3.2007, Rs. C-292/04 (Meilicke u.a.), Rn. 38 f. (Präklusion) bzw. Rn. 40 (guter Glaube) Erwähnung. Auf den engen Zusammenhang weist auch Rosenkranz, Beschränkung der Rückwirkung, 2015, S. 204 f. hin.

681 Richtlinie 2006/112/EG des Rates vom 28. November 2006 über das gemeinsame Mehrwertsteuersystem, ABl. L 347 vom 11.12.2006, S. 1. 
eine Begrenzung der zeitlichen Wirkungen und führte zur Begründung u.a. guten Glauben an. ${ }^{682}$

Der Gerichtshof lehnte eine Begrenzung ab und führte zur Begründung aus, dass eine Beschränkung des Rechts auf Vorsteuerabzug gegenüber Steuerpflichtigen eine „Ausnahme vom Grundprinzip des gemeinsamen Mehrwertsteuersystems" darstelle und "nach ständiger Rechtsprechung“ nur unter außergewöhnlichen Umständen rechtmäßig sei. Aus der Rechtsprechung des Gerichtshofs gehe daher hervor, „dass keine objektive, bedeutende Unsicherheit bezüglich der Tragweite des Unionsrechts, insbesondere der Bestimmungen der Mehrwertsteuerrichtlinie, besteht, was den Umfang des Vorsteuerabzugsrechts und dessen Rolle innerhalb des durch diese Richtlinie geschaffenen Systems angeht“".683 Rechtsprechung des Gerichtshofs ist von den Betroffenen also auch in ihrer Gesamtheit zu würdigen, sodass aus in ihr aufgestellten allgemeinen Grundsätzen Rückschlüsse auf einzelne Sachprobleme zu ziehen sind. Unterbleibt eine solche Würdigung, fehlt es an der Voraussetzung des guten Glaubens.

Nicht zuletzt in der Rechtssache Paper Consult zeigt sich, dass guter Glaube gegen die Rechtsprechung des Gerichtshofs auch dann nicht möglich ist, wenn sich andere Unionsorgane in einer grundsätzlich guten Glauben begründenden Weise geäußert haben sollten. Diese Rechtssache legt damit auch das Verständnis des Gerichtshofs vom Verhältnis seiner Rechtsprechung zu sonstigen Auslösern guten Glaubens offen. In ihr betroffen waren diejenigen Bestimmungen der Mehrwertsteuerrichtlinie, die nationalen Rechtsvorschriften entgegenstehen, die das Recht auf Vorsteuerabzug endgültig verweigern, ohne dass der Nachweis zugelassen wird, dass keine Steuerhinterziehung oder kein Steuerausfall vorliegt. Da es nach der in Rede stehenden rumänischen Regelung unmöglich war, einen entsprechenden Nachweis zu erbringen, erwies sich diese als unverhältnismäßig. Wie im vorhergehenden Absatz gesehen, ist der Rechtsprechung des Gerichtshofs zu entnehmen, dass die Versagung des Rechts auf Vorsteuerabzug eine Ausnahme vom Grundprinzip des gemeinsamen Mehrwertsteuersystems darstellt und nur unter außergewöhnlichen Umständen denkbar ist, was auch in diesem Fall zum Ausschluss des guten Glaubens führte. Ist guter Glaube ausgeschlossen, ändert sich daran ,jedenfalls“ nichts durch die Haltung der Kommission „als solche“, aus der ohne

682 EuGH, Urteil vom 28.2.2018, Rs. C-672/16 (Imofloresmira - Investimentos Imobiliários), Rn. 2, $19 \mathrm{ff} ., 53,56 \mathrm{ff}$.

683 EuGH, Urteil vom 28.2.2018, Rs. C-672/16 (Imofloresmira - Investimentos Imobiliários), Rn. $60 \mathrm{ff}$. 
entgegenstehende Rechtsprechung des Gerichtshofs gegebenenfalls guter Glaube hätte hergeleitet werden können. ${ }^{684}$

Gegen Rechtsprechung des Gerichtshofs können andere Akteure also keinen guten Glauben begründen.

\section{(g) Unvorhergesehene Einschlägigkeit der Rechtsprechung}

Vor dem Hintergrund dieser Erkenntnis ist auch die Frage zu beantworten, welche Rolle Rechtsprechung für den guten Glauben spielt, die aus der Sicht der Rechtsunterworfenen „unvorhergesehen“ einschlägig ist. ${ }^{685}$ Ist Rechtsprechung des Gerichtshofs „unvorhergesehen“ einschlägig, kann das Urteil des EuGH selbst nicht als Veranlasser des guten Glaubens wirken. Das frühere EuGH-Urteil entspricht ja tatsächlich dem auch im späteren Verfahren gefundenen Ergebnis. Die Rechtsunterworfenen hatten das frühere Urteil allerdings so verstanden, dass es für den später zu entscheidenden Fall nicht einschlägig sei.

Ist dieses Verständnis darauf zurückzuführen, dass sie das Urteil einfach falsch aufgefasst haben, ist von vornherein kein guter Glaube möglich. Nicht zweifelsfrei ist dagegen, ob andere Unionsorgane durch ihre Fehlinterpretation des Urteils als Veranlasser von gutem Glauben in Betracht kommen. Insoweit stellt sich die Frage nach dem Verhältnis zwischen der Begründung guten Glaubens durch andere Unionsstellen und dem Ausschluss des guten Glaubens bzw. der Präklusion einer zeitlichen Begrenzung durch das einschlägige Urteil des Gerichtshofs. Sie ist dahingehend zu beantworten, dass abweichender guter Glaube ausgeschlossen ist. Die Rechtsfrage ist geklärt. Nicht anders zu beurteilen ist der Fall, dass das Urteil des Gerichtshofs selbst „mehrdeutig“ ist, von ihm aber dennoch als einschlägig erachtet wird. Da es sich aus der Sicht des Gerichtshofs hier nur um eine „scheinbare“ Mehrdeutigkeit handelt, muss guter Glaube ausscheiden.

684 EuGH, Urteil vom 19.10.2017, Rs. C-101/16 (Paper Consult), Rn. 67 ff. Siehe auch GA Mengozzi, Schlussanträge vom 31.5.2017 in der Rs. C-101/16 (Paper Consult), Rn. 80, 83, 85.

685 Diese Frage ist eng mit dem Problemkreis der Präklusion verbunden. Siehe daher dazu noch näher unten bei Fn. 908 ff. 


\section{(5) Unionsgesetzgeber}

Nach der Kommission und dem Gerichtshof ist mit dem Unionsgesetzgeber ein weiterer Akteur auf Unionsebene als möglicher Auslöser guten Glaubens in den Blick zu nehmen. Auch dieser kann zur Entstehung von gutem Glauben beitragen.

Vom Unionsgesetzgeber erlassenes abgeleitetes Recht muss zwar die allgemeinen Grundsätze des Unionsrechts beachten. ${ }^{686}$ Dadurch ist aber nicht etwa die grundsätzliche Möglichkeit einer Begründung von gutem Glauben durch abgeleitetes Recht ausgeschlossen; deutlich wird nur, dass ein erkennbar fehlerhafter Rechtsakt keinen guten Glauben begründen kann. ${ }^{687}$

Der Rat und das Parlament als rechtsetzende Organe können daher zur „vermeintlichen Sicherheit“ beitragen. So können dem Primärrecht widersprechende Vorschriften in abgeleitetem Unionsrecht einen sich später als falsch herausstellenden Eindruck vom Primärrecht entstehen lassen. ${ }^{688}$ Insbesondere ist in diesem Zusammenhang auf die Gültigkeitsvermutung zu verweisen, nach der ein Unionsrechtsakt so lange als gültig anzusehen ist, bis er vom Gerichtshof für nichtig bzw. ungültig erklärt wird. ${ }^{689}$ Wenn er aber trotz Verstoßes gegen höherrangiges Recht als gültig anzusehen ist, muss er bis zu seiner Aufhebung als zutreffender Ausdruck des Inhalts des Unionsrechts gelten können. Bis zu dem Urteil des Gerichtshofs, in dem sich seine Ungültigkeit herausstellt, taugt er also als Grundlage des guten Glaubens. Etwas anderes gilt nur bei erkennbarer Primärrechts-

686 EuGH, Urteil vom 19.9.2000, verb. Rs. C-177/99 und C-181/99 (Ampafrance und Sanofi), Rn. 68.

687 Anders Müller, Begrenzung, 2009, S. 139; wie hier Rosenkranz, Beschränkung der Rückwirkung, 2015, S. 176. In den verbundenen Rechtssachen Ampafrance und Sanofi hatte die französische Regierung geltend gemacht, eine in Frankreich in Abweichung von einer Richtlinie getroffene Sondermaßnahme sei durch eine Äußerung der Kommission und eine Ratsentscheidung gebilligt worden, weshalb von Unionsrechtskonformität habe ausgegangen werden können. Die französischen Stellen hatten die Entscheidung des Rates aber maßgeblich beeinflusst, weshalb sie Kenntnis von deren Primärrechtswidrigkeit haben mussten, vgl. EuGH, Urteil vom 19.9.2000, verb. Rs. C-177/99 und C-181/99 (Ampafrance und Sanofi), Rn. 69.

688 EuGH, Urteil vom 17.5.1990, Rs. C-262/88 (Barber), Rn. 42 f.; EuGH, Urteil vom 28.9.1994, Rs. C-200/91 (Coloroll Pension Trustees), Rn. 53.

689 Siehe hierzu näher oben bei Fn. $601 \mathrm{ff}$. 
widrigkeit. ${ }^{690}$ Der hier angelegte Maßstab der „Erkennbarkeit“ darf nicht mit dem bei Nichtakten anzulegenden verwechselt werden. Während ein Nichtakt nur bei offensichtlichen Mängeln vorliegt, kann sich bereits beim Bestehen begründeter Zweifel an der Vereinbarkeit des Unionsrechtsakts mit höherrangigem Unionsrecht kein hierauf gestützter guter Glaube bilden.

Scheitert ein Rechtsetzungsvorhaben auf europäischer Ebene am Rat und damit letztlich an den Vertretern der Mitgliedstaaten, können diese keinen guten Glauben aus diesem Scheitern ableiten. Auch wenn der Rat als Unionsorgan von den Mitgliedstaaten zu unterscheiden ist, so haben diese durch ihr Abstimmungsverhalten im Rat doch entscheidenden Einfluss auf das Zustandekommen eines Rechtsakts. Hätte also etwa ein gescheiterter Rechtsakt Rechte vorgesehen, die private Betroffene aus dem Unionsrecht herzuleiten versuchen, können die Mitgliedstaaten aus dem Scheitern des Rechtsakts nicht ableiten, das Unionsrecht erwecke den Anschein, es gewähre diese Rechte nicht und begründe daher ihren dahingehenden guten Glauben. ${ }^{691}$

In den vom Gerichtshof bislang entschiedenen Fällen ging es um Verhalten des Unionsgesetzgebers, das sich in Sekundärrecht niedergeschlagen hat und seine Bedeutung für das Primärrecht. ${ }^{692}$ Noch nicht beantwortet ist damit die Frage, ob der Unionsgesetzgeber darüber hinaus auch im Hinblick auf den Inhalt des Sekundärrechts selbst guten Glauben begründen kann.

Mit dieser Frage befasste sich Generalanwalt Campos Sánchez-Bordona in seinen Schlussanträgen in den verbundenen Rechtssachen Eco-Emballages und Melitta France u.a. Dort war zu klären, ob „Rollenkerne“ Verpackungen im Sinne der Richtlinie 94/62/EG ${ }^{693}$ darstellen. Ein Beispiel hierfür bildet der Pappkern, um den Toilettenpapier gewickelt ist, sodass die Frage im Raum stand, ob dieser zur Verpackung des Toilettenpapiers

690 Vgl. etwa EuGH, Urteil vom 9.8.1994, verb. Rs. C-363/93 und C-407/93 bis C-411/93 (Lancry u.a.), Rn. 44, wo die Schlussanträge des Generalanwalts in der Rechtssache Legros u.a. der Begründung von gutem Glauben durch eine Entscheidung des Rates entgegenstanden - siehe dazu bereits oben bei Fn. 676. Siehe auch Rosenkranz, Beschränkung der Rückwirkung, 2015, S. 194.

691 Siehe hierzu auch Lindemann/Hackemann, IStR 2005, 786 (789).

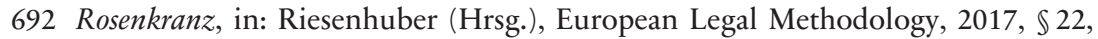
Rn. 31.

693 Richtlinie 94/62/EG des Europäischen Parlaments und des Rates vom 20. Dezember 1994 über Verpackungen und Verpackungsabfälle, ABl. L 365 vom 31.12.1994, S. 10. 
gehört. ${ }^{694}$ Die Antwort auf diese Frage hat Auswirkungen auf die Pflicht zur Tragung der Recyclingkosten. Ist sie zu bejahen, wären die Kosten von den Vertriebsunternehmen bzw. den Verbrauchern der Produkte, in denen Rollenkerne enthalten sind, zu tragen.

Die Definition von Verpackung im Sinne der Richtlinie ist jedenfalls nicht eindeutig. Mit der Richtlinie 2004/12/EG ${ }^{695}$ sollte daher mehr Klarheit geschaffen werden. Zu diesem Zweck wurden drei Kriterien zur Begriffsbestimmung und ein Anhang mit „Beispielen“ eingeführt, zu denen die Rollenkerne allerdings nicht gehörten. Zugleich wurde der Kommission aufgetragen, diese Beispiele zu prüfen und erforderlichenfalls zu ändern, wobei sie sich vorrangig u.a. mit Rollenkernen befassen sollte. Klarheit hinsichtlich der Einordnung von Rollenkernen bestand also weiterhin nicht. Die Richtlinie 2013/2/EU ${ }^{696}$ der Kommission nahm Rollenkerne dann als Beispiel für Verpackungen in die Liste im Anhang auf. Im zweiten Erwägungsgrund dieser Richtlinie wird ausgeführt, dass Fälle geklärt werden sollen, „bei denen noch nicht klar abgegrenzt ist, was eine Verpackung ist und was nicht".${ }^{697}$

Nach Auffassung von Generalanwalt Campos Sánchez-Bordona hat der Unionsgesetzgeber "über Jahre dauernder legislativer Unklarheit" mit seinem Verhalten dazu beigetragen, Zweifel an der Einstufung der Rollenkerne als Verpackung zu säen. In diesem Verhalten sieht er ein „bewusstes Schweigen“ zur Einstufung der Rollenkerne. Erst mit der Richtlinie 2013/2/EU der Kommission seien die Zweifel hinsichtlich der Einstufung der Rollenkerne ausgeräumt worden. ${ }^{698}$ Der Generalanwalt spricht sich daher für eine Begrenzung der zeitlichen Wirkungen aus. Der Gerichtshof geht auf diese Frage in seinem Urteil dagegen nicht ein und stellt lediglich fest, dass die Auslegung, nach der Rollenkerne Verpackungen im Sinne von Art. 3 Nr. 1 der Richtlinie 94/62/EG darstellen, durch den Erlass der

694 GA Campos Sánchez-Bordona, Schlussanträge vom 13.7.2016 in den verb. Rs. C-313/15 und C-530/15 (Eco-Emballages und Melitta France u.a.), Rn. 1 f.

695 Richtlinie 2004/12/EG des Europäischen Parlaments und des Rates vom 11. Februar 2004 zur Änderung der Richtlinie 94/62/EG über Verpackungen und Verpackungsabfälle, ABl. L 47 vom 18.2.2004, S. 26.

696 Richtlinie 2013/2/EU der Kommission vom 7. Februar 2013 zur Änderung von Anhang I der Richtlinie 94/62/EG des Europäischen Parlaments und des Rates über Verpackungen und Verpackungsabfälle, ABl. L 37 vom 8.2.2013, S. 10.

697 GA Campos Sánchez-Bordona, Schlussanträge vom 13.7.2016 in den verb. Rs. C-313/15 und C-530/15 (Eco-Emballages und Melitta France u.a.), Rn. 35 ff.

698 GA Campos Sánchez-Bordona, Schlussanträge vom 13.7.2016 in den verb. Rs. C-313/15 und C-530/15 (Eco-Emballages und Melitta France u.a.), Rn. 60 ff. 
Richtlinie 2013/2/EU bestätigt werde. ${ }^{699}$ Die Einordnung der Rollenkerne als Verpackung ergibt sich nach Auffassung des Gerichtshofs also bereits aus einer Auslegung des Art. 3 Nr. 1 der Richtlinie 94/62/EG, die ohne Heranziehung der Richtlinie der Kommission auskommt.

Wendet man sich aber noch einmal dem Gedankengang des Generalanwalts zu, so ist anzumerken, dass es für die Bejahung von gutem Glauben nicht genügen kann, Zweifel an der Einstufung der Rollenkerne zu säen. Allein deswegen können die Betroffenen also nicht davon ausgehen, bei Rollenkernen handele es sich nicht um Verpackungen im Sinne der Richtlinie. Dass der Unionsgesetzgeber die Einordnung offengelassen hat, genügt also nicht. Könnte seinem Verhalten dagegen der Sinn beigelegt werden, dass die Aufnahme der Rollenkerne in die Liste im Anhang unterblieben sei, weil der Verpackungsbegriff dies verbiete, wäre hierin ein Verhalten zu erblicken, das geeignet ist, guten Glauben zu begründen. Demnach ist auch guten Glauben begründendes Verhalten des Unionsgesetzgebers im Hinblick auf die von ihm erlassenen Rechtsakte nicht ausgeschlossen.

Treffen Rat und Parlament Äußerungen zum Unionsrecht, die sich nicht in Rechtsakten niedergeschlagen haben, wird zum Teil die Bedeutung des Parlaments als Auslöser von gutem Glauben im Vergleich zum Rat als abgeschwächt angesehen. Begründet wird dies damit, dass sich das Parlament nicht aus Vertretern der „Herren der Verträge“ zusammensetze. ${ }^{700}$ Dem ist allerdings entgegenzuhalten, dass es für die Frage der Begründung von gutem Glauben nicht auf die Zusammensetzung ankommen kann. Sowohl beim Rat als auch beim Parlament handelt es sich wie bei der Kommission und dem Gerichtshof um Unionsorgane. Eine Abstufung zwischen diesen vorzunehmen wäre nicht überzeugend.

Auch Verhalten etwa des Rates kann gutem Glauben entgegenstehen. So hatte in den Rechtssachen Kovalkovas und Poltorak ein Bericht des Rates über Litauen bzw. Schweden zur nationalen Praxis in Bezug auf den Europäischen Haftbefehl die Unvereinbarkeit der Ausstellung Europäischer Haftbefehle durch das litauische Justizministerium bzw. das schwedische Reichspolizeiamt mit dem Rahmenbeschluss über den Europäischen

699 EuGH, Urteil vom 10.11.2016, verb. Rs. C-313/15 und C-530/15 (Eco-Emballages und Melitta France u.a.), Rn. 36.

700 Rosenkranz, Beschränkung der Rückwirkung, 2015, S. 194 (Anführungszeichen im Original). 
Haftbefehl gerügt, sodass hinsichtlich dieser Frage guter Glaube ausgeschlossen war. ${ }^{701}$

(6) Sonstige Rechtsansichten

Zumindest unterstützende Bedeutung für das Vorliegen von gutem Glauben messen Teile der Literatur Stimmen im Schrifttum bei. ${ }^{702}$ Auch diese Teile der Literatur räumen aber jedenfalls indirekt ein, dass bereits ein Maßstab für das erforderliche Maß an Klarheit des Streitstandes in der Literatur nur sehr schwer zu bestimmen ist, wenn etwa darauf verwiesen wird, dass Zweifel an der Unionsrechtskonformität im Schrifttum „immer stärker" zum Vorschein gekommen seien.

Rechtsansichten von Privaten, seien es Wissenschaftler, Verbände oder sonstige Akteure, fehlt es zudem an der Zurechenbarkeit zur Union. Sie vermögen daher keine Überzeugung vom Inhalt des Unionsrechts zu begründen und können guten Glauben daher weder auslösen noch ausschließen. 703

cc) Ergebnis

Zur Bildung einer Überzeugung vom Inhalt des Unionsrechts muss das Unionsrecht von den Betroffenen nach den für dieses relevanten Methoden ausgelegt werden. Bei dieser Auslegung können Ansichten von Unionsorganen Berücksichtigung finden, deren unionsweite Verbreitung feststeht. Insbesondere der Gerichtshof ist zur Begründung von gutem Glauben in der Lage, aber auch die Kommission und der Unionsgesetzgeber. Äußerungen mitgliedstaatlicher Stellen kommt eine solche Wirkung ebenso wenig zu wie nationalen Rechtsakten.

701 EuGH, Urteil vom 10.11.2016, Rs. C-477/16 PPU (Kovalkovas), Rn. 53 i.V.m. Rn.12; EuGH, Urteil vom 10.11.2016, Rs. C-452/16 PPU (Poltorak), Rn. 57 i.V.m. Rn. 13.

702 Cloer, EWS 2006, 36 (37): „zumal“.

703 Nicht nachvollziehbar erscheint daher der Verweis in den verbundenen Rechtssachen Essevi und Salengo auf Unsicherheiten im innerstaatlichen Bereich, die gutem Glauben entgegenstehen sollen, EuGH, Urteil vom 27.5.1981, verb. Rs. 142/80 und 143/80 (Essevi und Salengo), Rn. 34; kritisch auch Rosenkranz, Beschränkung der Rückwirkung, 2015, S. 201. 
Guten Glauben schließt insbesondere einschlägige Rechtsprechung des Gerichtshofs aus, aber auch etwa die Einleitung eines Vertragsverletzungsverfahrens durch die Kommission. Insoweit genügt bereits, dass Zweifel an der unionsrechtlichen Rechtslage gesät werden, da in diesem Fall nicht mehr von einer vermeintlichen Sicherheit hinsichtlich des Inhalts des Unionsrechts gesprochen werden kann.

\section{f) Zeitpunkt/Zeitraum des guten Glaubens}

Abschließend bleibt zu klären, in welchem Zeitpunkt bzw. Zeitraum guter Glaube bestanden haben muss. Ludewig etwa meint, der EuGH erachte im Hinblick auf das Vorliegen von gutem Glauben den Zeitpunkt für maßgeblich, zu dem die vom Urteil des Gerichtshofs betroffenen Rechtsverhältnisse begründet worden seien. ${ }^{704}$ Diese Annahme geht fehl.

Das einzige dem Gerichtshof vorliegende und damit bekannte Rechtsverhältnis ist dasjenige des Ausgangsverfahrens der Auslegungsvorabentscheidung. Weshalb gerade dessen Begründung entscheidend sein soll für die Frage des guten Glaubens, könnte allerdings nicht erklärt werden. Wäre ein anderes Rechtsverhältnis Ausgangspunkt des Vorabentscheidungsverfahrens, müsste auf dessen Begründung abgestellt werden. Im Ergebnis würde dies dazu führen, es vom Zufall abhängen zu lassen, welcher Zeitpunkt als maßgeblich anzusehen ist.

Damit ist der Zeitpunkt der Urteilsverkündung für das Vorliegen des guten Glaubens entscheidend. ${ }^{705} \mathrm{Da}$ der Gerichtshof den Zeitraum bis zum Urteil einheitlich beurteilt, ändert der Zeitraum des Verfahrens vor dem EuGH nichts an der Beurteilung der Gutgläubigkeit. Weder die Schlussanträge, an die der Gerichtshof rechtlich nicht gebunden ist, noch Nachfragen des Gerichtshofs im Rahmen einer möglichen mündlichen Verhandlung vermögen den guten Glauben zu zerstören. Diese Wirkung kommt erst einem der Überzeugung widersprechenden Urteil zu. ${ }^{706}$ Eine abweichende Beurteilung verbietet sich, da die Annahme von gutem Glauben bis zum Erlass des Urteils dann nicht möglich wäre und eine Begrenzung auf den Zeitpunkt des Urteils, wie sie der EuGH vornimmt, ausscheiden müsste.

704 Ludewig, Zeitliche Beschränkung, 2012, S. 143; siehe in diesem Zusammenhang auch Forsthoff, DStR 2005, 1840 (1842).

705 Ebenso Rosenkranz, Beschränkung der Rückwirkung, 2015, S. 216.

706 Anders Ludewig, Zeitliche Beschränkung, 2012, S. 144. 
Ausnahmen von der Maßgeblichkeit des Zeitpunkts der Urteilsverkündung sind aber nicht denknotwendig ausgeschlossen. So erschiene es möglich, den guten Glauben in mehrere Phasen zu unterteilen, da bei erst später eintretender „Veranlassung“ für den Anfangszeitraum kaum von gutem Glauben gesprochen werden kann. Das Ende des guten Glaubens könnte man ebenfalls früher einsetzen lassen als zum Zeitpunkt der Urteilsverkündung und eine Begrenzung dann auf diesen Zeitpunkt vornehmen. ${ }^{707}$ Entsprechende Ausnahmen hat der Gerichtshof bislang allerdings nicht vorgesehen. ${ }^{708}$

\section{g) Ergebnis}

Bezugspunkt des guten Glaubens ist die unionsrechtliche Rechtslage. Gefragt wird danach, ob das von den Betroffenen ins Feld geführte Verständnis des Unionsrechts nach einem objektivierten Maßstab als vernünftig erscheint. Entscheidend ist, ob die Norm vermeintlich eindeutig in einem bestimmten Sinn zu verstehen ist, der sich dann nach der Auslegung der Norm durch den EuGH als unzutreffend herausstellt. Bei der Bildung ihrer Überzeugung vom Inhalt des Unionsrechts können die Betroffenen Rechtsansichten von Unionsorganen mit unionsweiter Verbreitung berücksichtigen. Nationales Recht kann dagegen mangels Rechtsscheins seiner Unionsrechtskonformität keine für den guten Glauben relevante Vorstellung vom Inhalt des Unionsrechts begründen. Da ihr Verhalten der Union nicht zugerechnet werden kann, können letztlich auch Äußerungen nationaler Gerichte zum Inhalt des Unionsrechts an dieser Stelle keine Berücksichtigung finden.

707 Siehe zu diesen Überlegungen bereits Rosenkranz, in: Riesenhuber (Hrsg.), European Legal Methodology, 2017, $\$ 22$, Rn. $37 \mathrm{f}$.

708 Sollte der Gerichtshof einmal in einem Vertragsverletzungsverfahren eine zeitliche Begrenzung vorsehen, müsste als Zeitpunkt der Begrenzung die Einleitung des Verfahrens durch die Kommission und nicht das Urteil des Gerichtshofs gewählt werden, da der Einleitung eines Vertragsverletzungsverfahrens für die Frage des guten Glaubens wie oben bei Fn. 540 gesehen Bedeutung zukommt. 


\section{Gefahr schwerwiegender Störungen}

Neben gutem Glauben muss für eine Begrenzung der zeitlichen Wirkungen auch eine „Gefahr schwerwiegender Störungen“709 bzw. eine „Gefahr schwerwiegender wirtschaftlicher Auswirkungen" 710 bestehen.

\section{a) „Störungen“ als Oberbegriff}

Häufig beginnt der Gerichtshof seine Ausführungen mit der allgemeinen Nennung des „grundlegenden Kriteriums“, das neben dem guten Glauben der Betroffenen für eine zeitliche Begrenzung erfüllt sein müsse, und bezeichnet dieses als „Gefahr schwerwiegender Störungen“711. In der nachfolgenden Randnummer des jeweiligen Urteils ist dann davon die Rede, dass der Gerichtshof eine solche Begrenzung nur unter ganz bestimmten Umständen ausgesprochen bzw. auf eine solche Lösung nur unter ganz bestimmten Umständen zurückgegriffen habe, wenn neben der objektiven und bedeutenden Unsicherheit eine „Gefahr schwerwiegender wirtschaftlicher Auswirkungen" bestand. ${ }^{712}$ Die in dieser Randnummer gemachten Ausführungen werden zum Teil mit den in den jeweiligen Sprachen entsprechenden Begrifflichkeiten „more specifically“, „plus spécifiquement“, „più specificamente“, „más concretamente/precisamente“ eingeleitet; in der deutschen Fassung fehlt dagegen ein entsprechender Begriff. Weiter heißt es, die zeitliche Begrenzung sei „namentlich“, „notably“, „notamment", „in particolare“ erfolgt, wenn eine Gefahr schwerwiegender wirtschaftlicher Auswirkungen bestand (und die zweite Begrenzungsvoraussetzung vorlag). Schwerwiegende wirtschaftliche Auswirkungen erscheinen hier also als Beispiel für schwerwiegende Störungen. Eine Gefahr muss

709 Siehe nur EuGH, Urteil vom 29.9.2015, Rs. C-276/14 (Gmina Wrocław), Rn. 45.

710 Siehe nur EuGH, Urteil vom 28.2.2018, Rs. C-672/16 (Imofloresmira - Investimentos Imobiliários), Rn. 59.

711 Z.B. EuGH, Urteil vom 10.7.2019, Rs. C-210/18 (WESTbahn Management), Rn. 45; EuGH, Urteil vom 20.12.2017, Rs. C-516/16 (Erzeugerorganisation Tiefkühlgemüse), Rn. 89; EuGH, Urteil vom 19.10.2017, Rs. C-101/16 (Paper Consult), Rn. 65; EuGH, Urteil vom 22.9.2016, Rs. C-110/15 (Microsoft Mobile Sales International u.a.), Rn. 60.

712 EuGH, Urteil vom 10.7.2019, Rs. C-210/18 (WESTbahn Management), Rn. 46; EuGH, Urteil vom 20.12.2017, Rs. C-516/16 (Erzeugerorganisation Tiefkühlgemüse), Rn.90; EuGH, Urteil vom 19.10.2017, Rs. C-101/16 (Paper Consult), Rn. 66; EuGH, Urteil vom 22.9.2016, Rs. C-110/15 (Microsoft Mobile Sales International u.a.), Rn. 61. 
daher nicht kumulativ im Hinblick auf schwerwiegende Störungen und schwerwiegende wirtschaftliche Auswirkungen bestehen. ${ }^{713}$ Der Begriff "Störungen“" ist vielmehr als Oberbegriff zu verstehen. Es handelt sich bei ihm demnach um einen unbestimmten Rechtsbegriff, mit dem Konsequenzen unterschiedlicher Art erfasst werden. ${ }^{714}$ Praktische Schwierigkeiten bei fehlender zeitlicher Beschränkung gehören allerdings nicht $\mathrm{zu}$ diesen Konsequenzen. ${ }^{715}$ Das Gleiche gilt für administrative Schwierigkeiten, die kaum von nur praktischen Schwierigkeiten abzugrenzen sind. ${ }^{716}$ Dass nationale Gerichte im Angesicht einer Auslegung des Unionsrechts durch den Gerichtshof unionsrechtswidriges nationales Recht unangewendet lassen und so "die innerstaatliche Rechtsordnung" in Frage gestellt wird, begründet ebenfalls keine Gefahr schwerwiegender Störungen. ${ }^{717}$ Eindeutig im Vordergrund stehen wirtschaftliche Auswirkungen. ${ }^{718}$

Auch wenn das Kriterium der Gefahr schwerwiegender Störungen/wirtschaftlicher Auswirkungen Assoziationen zum Bestehen der Gefahr eines "Nachteils“ wecken mag, sollte dieser Begriff im vorliegenden Zusammenhang vermieden werden, da Nachteile eines Beteiligten mit Vorteilen eines anderen Beteiligten korrespondieren können. ${ }^{719}$ Vorzugswürdig erscheint

713 Ein solches Verständnis legt allerdings wohl GA Mengozzi, Schlussanträge vom 12.7.2018 in der Rs. C-221/17 (Tjebbes u.a.), Rn. 155 nahe, wenn er von fehlenden Beweisen der niederländischen Regierung „für etwaige schwerwiegende Störungen und schwerwiegende wirtschaftliche Auswirkungen" spricht (Hervorhebung nur hier). In diesem Sinne formuliert ist auch die französische Originalfassung der Schlussanträge; in der englischen Übersetzung sind die Begriffe dagegen durch „or" verbunden.

714 Düsterhaus, YEL 36 (2017), 237 (255); Düsterhaus, EuR 2017, 30 (39).

$715 \mathrm{EuGH}$, Urteil vom 30.3.2006, Rs. C-184/04 (Uudenkaupungin kaupunki), Rn. 56.

716 So bereits EuGH, Urteil vom 12.10.2000, Rs. C-372/98 (Cooke), Rn. 43; siehe auch Lang, IStR 2007, 235 (238).

717 EuGH, Urteil vom 16.9.2020, Rs. C-339/19 (Romenergo und Aris Capital), Rn. 51. Darauf, dass auch die Unzufriedenheit Betroffener, die sich mit einer für sie nachteiligen Anpassung der nationalen Rechtslage an unionsrechtliche Vorgaben konfrontiert sehen, keine Gefahr schwerwiegender Störungen begründet, weist GA Campos Sánchez-Bordona, Schlussanträge vom 10.9.2020 in den verb. Rs. C-407/19 und C-471/19 (Katoen Natie Bulk Terminals und General Services Antwerp), Rn. 104 zu Recht hin.

718 So führt der Gerichtshof in EuGH, Urteil vom 3.10.2019, Rs. C-274/18 (SchuchGhannadan), Rn. 66 etwa aus, es sei nicht dargetan worden, „auf welche Weise und in welchem Umfang sich das vorliegende Urteil wirtschaftlich auswirkt" (Hervorhebung nur hier).

719 Ludewig, Zeitliche Beschränkung, 2012, S. 115. 
es daher, der Terminologie des Gerichtshofs zu folgen und von „Auswirkungen" ${ }^{\text {" }} 20$ oder "Störungen"721 zu sprechen.

\section{b) Intention des Kriteriums}

Zwischen dem Bestehen einer Gefahr schwerwiegender Störungen und der Anzahl der gutgläubig begründeten und durch die Auslegung betroffenen Rechtsverhältnisse besteht ein enger Zusammenhang und Abhängigkeitsverhältnis. ${ }^{722}$ Das Kriterium liefert daher Anhaltspunkte dafür, wie weit verbreitet der gute Glaube tatsächlich war.

Nur wenn eine Vielzahl von Betroffenen von dem sich durch die vom EuGH vorgenommene Auslegung als falsch herausstellenden Verständnis des Unionsrechts ausgegangen ist, erscheint eine Begrenzung in zeitlicher Hinsicht angezeigt, da sie dann mehr nutzt als schadet. ${ }^{723}$ Sind nur wenige von einem unzutreffenden Verständnis des Unionsrechts ausgegangen, während viele ein zutreffendes Verständnis zugrunde gelegt haben, erschiene es nicht gerechtfertigt, letzteren die unionsrechtlich zutreffende Grundlage durch eine zeitliche Begrenzung zu entziehen. ${ }^{724}$ Bei Vorliegen einer Gefahr schwerwiegender Störungen erscheint es dagegen interessengerecht - unter der Voraussetzung, dass die Betroffenen angesichts ihres guten Glaubens schutzwürdig sind -, der Tatsache Rechnung zu tragen, dass die Auslegung des Unionsrechts ohne zeitliche Begrenzung zu Aus-

720 EuGH, Urteil vom 18.1.2007, Rs. C-313/05 (Brzeziński), Rn. 57; EuGH, Urteil vom 15.3.2005, Rs. C-209/03 (Bidar), Rn. 69.

721 EuGH, Urteil vom 30.3.2006, Rs. C-184/04 (Uudenkaupungin kaupunki), Rn. 55; EuGH, Urteil vom 10.1.2006, Rs. C-402/03 (Skov und Bilka), Rn. 51.

722 GA Wathelet, Schlussanträge vom 4.9.2014 in den verb. Rs. C-401/13 und C-432/13 (Balazs), Rn. 100; Lang, in: Popelier/Verstraelen/Vanheule/Vanlerberghe (Hrsg.), The Effects of Judicial Decisions in Time, 2014, S. 245 (262). Siehe aus der Rechtsprechung etwa EuGH, Urteil vom 22.9.2016, Rs. C-110/15 (Microsoft Mobile Sales International u.a.), Rn.61; EuGH, Urteil vom 22.1.2015, verb. Rs. C-401/13 und C-432/13 (Balazs), Rn. 51; EuGH, Urteil vom 19.12.2013, Rs. C-209/12 (Endress), Rn. 36; EuGH, Urteil vom 10.4.2014, Rs. C-190/12 (Emerging Markets Series of DFA Investment Trust Company), Rn. 110; EuGH, Urteil vom 11.8.1995, verb. Rs. C-367/93 bis C-377/93 (Roders u.a.), Rn. 43; siehe auch EuGH, Urteil vom 8.4.1976, Rs.43/75 (Defrenne), Rn. 69/70.

723 Rosenkranz, ZfPW 2016, 351 (359).

724 In diesem Sinne auch Rosenkranz, Beschränkung der Rückwirkung, 2015, S. 225. 
wirkungen führen würde, deren Ausmaß als nicht mehr hinnehmbar erscheint. ${ }^{725}$ Daher ist auch der Einwand zurückzuweisen, der Maßstab an sich sei kritikwürdig, da durch ihn die schwersten Verstöße gegen Unionsrecht begünstigt würden. ${ }^{726}$ Aufgrund des zusätzlichen Erfordernisses des guten Glaubens ist auch bei einem „schweren“ Verstoß stets erforderlich, dass die gegen das Unionsrecht Verstoßenden schutzwürdig sind.

Der Berührungspunkt zwischen gutem Glauben und Gefahr schwerwiegender Störungen lässt sich etwa an einem von Generalanwalt Campos Sánchez-Bordona in seinen Schlussanträgen in den verbundenen Rechtssachen Eco-Emballages und Melitta France u.a. angesprochenen Umstand verdeutlichen, in denen es um die (letztlich zu bejahende) Einordnung von Rollenkernen als Verpackung ging. ${ }^{727}$ Dass manche Unternehmen Beiträge für das Recycling der Rollenkerne entrichtet haben, lässt darauf schließen, dass diese die Rollenkerne als Verpackungen angesehen haben. Dies spricht dafür, dass es nicht vermeintlich sicher war, dass es sich bei Rollenkernen nicht um Verpackungen handelt, und spricht damit gegen das Bestehen von gutem Glauben. Hierbei handelt es sich allerdings lediglich um ein Indiz zur Beurteilung des guten Glaubens, dessen tatsächliche Verbreitung nicht entscheidend ist. ${ }^{728}$ Bei der Beurteilung der Gefahr schwerwiegender Störungen würde seine tatsächliche Verbreitung dagegen Bedeutung erlangen.

Zum Teil wird geltend gemacht, einer unionsweiten Beschränkung der zeitlichen Wirkungen angemessener sei das Abstellen auf eine Beeinträchtigung des störungsfreien Funktionierens des Gemeinsamen Marktes. ${ }^{729}$ Angesprochen ist damit nach heutiger Begrifflichkeit der Binnenmarkt, den die EU nach Art. 3 III UAbs. 1 S. 1 EUV errichtet. ${ }^{730}$

725 Ebenso Ludewig, Zeitliche Beschränkung, 2012, S. 129.

726 So Balmes/Ribbrock, BB 2006, 17 (19).

727 GA Campos Sánchez-Bordona, Schlussanträge vom 13.7.2016 in den verb. Rs. C-313/15 und C-530/15 (Eco-Emballages und Melitta France u.a.), Fn. 32. Siehe zu diesen verbundenen Rechtssachen näher bereits oben bei Fn. $502 \mathrm{ff}$. und Fn. $693 \mathrm{ff}$.

728 Siehe insoweit auch Ludewig, Zeitliche Beschränkung, 2012, S. 163 und Rosenkranz, Beschränkung der Rückwirkung, 2015, S. 157.

729 So Dauses, Vorabentscheidungsverfahren, 2. Aufl. 1995, S.151, der diesen Gedanken aber zu Unrecht bereits der derzeitigen Rechtsprechung zuschreibt.

730 Dieser umfasst nach Art. 26 II AEUV einen Raum ohne Binnengrenzen, in dem der freie Verkehr von Waren, Personen, Dienstleistungen und Kapital gemäß den Bestimmungen der Verträge gewährleistet ist. Nach Art. 38 I UAbs. 2 S. 1 AEUV umfasst er auch die Landwirtschaft, die Fischerei und den Handel mit landwirtschaftlichen Erzeugnissen. 
In stark integrierten Bereichen wie etwa der Gemeinsamen Agrarpolitik mag es möglich sein, die mit einer Entscheidung des Gerichtshofs einhergehenden Auswirkungen auf den Binnenmarkt zu bestimmen, während dies in Bereichen, die in der Zuständigkeit der Mitgliedstaaten verblieben sind, Schwierigkeiten bereitet. Zwar ist auch in nicht harmonisierten Bereichen das Unionsrecht zu beachten, sodass die Mitgliedstaaten ihre Befugnisse etwa im Bereich der in ihrer Zuständigkeit verbliebenen direkten Steuern unter Wahrung des Unionsrechts ausüben müssen. ${ }^{731} \mathrm{Da}$ die Mitgliedstaaten ganz allgemein bei der Ausübung der ihnen vorbehaltenen Befugnisse ${ }^{732}$ die Grundregeln der Verträge zu beachten haben ${ }^{733}$, besteht auch in diesen Bereichen die Möglichkeit, Verletzungen des Unionsrechts entgegenzutreten. Allerdings ist nicht jeder Verstoß gegen Unionsrecht gleichbedeutend mit einer Beeinträchtigung des störungsfreien Funktionierens des Binnenmarkts. Eine solche Wirkung sämtlichen Verstößen gegen Unionsrecht zuzusprechen, könnte nicht überzeugen, da die Begrenzung der zeitlichen Wirkungen sonst drohte, zur Regel zu werden und nicht eine Ausnahme zu bleiben.

Letztlich besteht also auch bei einer Heranziehung des Binnenmarkts als Bezugspunkt das Problem einer näheren Beschreibung, wann genau dessen nicht mehr störungsfreies Funktionieren droht. Zur besseren Handhabbarkeit führte ein derartiges Kriterium daher nicht. Ausgeblendet würden auf diese Weise zudem auch Fälle, in denen es zu Verwerfungen kommt, denen zwar der Binnenmarktbezug fehlt, die aber aus Sicht des Unionsrechts dennoch als nicht hinnehmbar erscheinen.

Im Ergebnis nicht überzeugend ist auch der Vorschlag, auf das Kriterium der Gefahr schwerwiegender Störungen ganz zu verzichten und nur auf den guten Glauben abzustellen. ${ }^{734}$ Ebenso wenig verfängt eine Argumentation, die daraus, dass mit der europäischen Einigung angesichts des Ziels der Errichtung eines Binnenmarktes zwangsläufig wirtschaftliche Folgen verbunden und von den Mitgliedstaaten in Kauf zu nehmen sind, ableiten möchte, dass, wenn aus wirtschaftlichen Erwägungen eine Beschränkung der Grundfreiheiten nicht gerechtfertigt werden könne,

731 Siehe etwa EuGH, Urteil vom 7.9.2004, Rs. C-319/02 (Manninen), Rn. 19; EuGH, Urteil vom 25.10.2012, Rs. C-387/11 (Kommission/Belgien), Rn. 36; EuGH, Urteil vom 23.1.2014, Rs. C-296/12 (Kommission/Belgien), Rn. 27; EuGH, Urteil vom 19.12.2018, Rs. C-667/17 (Cadeddu), Rn. 15.

732 EuGH, Urteil vom 4.7.2019, Rs. C-393/17 (Kirschstein), Rn. 21.

733 EuGH, Urteil vom 24.1.2013, verb. Rs. C-186/11 und C-209/11 (Stanleybet International u.a.), Rn. 47; EuGH, Urteil vom 4.2.2016, Rs. C-336/14 (Ince), Rn. 55.

734 In diesem Sinne aber Lang, IStR 2007, 235 (244). 
dies auch für die vorliegende Problematik der sich aus der Auslegung des Unionsrechts durch den Gerichtshof ergebenden Folgen gelte. ${ }^{735}$

So plausibel diese Einwände auf den ersten Blick erscheinen mögen, so sehr drängt sich doch eine Betrachtung aus einem anderen Blickwinkel auf. Der Verzicht auf das Kriterium der Gefahr schwerwiegender Störungen bedeutete nämlich nicht nur eine strengere Herangehensweise als bisher - wirtschaftliche Folgen wären bei einem Verzicht auf das Kriterium ja kein Argument für eine zeitliche Begrenzung mehr -, sondern auch eine den Mitgliedstaaten deutlich entgegenkommende, wie folgende Überlegung zeigt: Scheitert eine Beschränkung der zeitlichen Wirkungen bei Zugrundelegung der derzeitigen Kriterien aus Gründen des fehlenden Nachweises der Gefahr schwerwiegender Störungen, wäre dies bei einem Verzicht auf das Merkmal nicht mehr der Fall. Eine Begrenzung in zeitlicher Hinsicht könnten die Mitgliedstaaten dann bereits beim Nachweis ihres guten Glaubens erreichen. Der Einwand, das Kriterium der Gefahr schwerwiegender Störungen wirke sich integrationshemmend aus, ist daher zurückzuweisen. ${ }^{736}$ Es ermöglicht lediglich die Berücksichtigung derjenigen Auswirkungen, die auf den guten Glauben zurückzuführen sind. Sonstige, mit dem guten Glauben nicht zusammenhängende wirtschaftliche Belastungen der Mitgliedstaaten können dagegen keine Gefahr schwerwiegender Störungen begründen. ${ }^{737}$ Das Kriterium trägt daher dazu bei, dass eine Begrenzung die Ausnahme bleibt.

\section{c) Bestehen einer Gefahr}

Aus der Rechtsprechung des Gerichtshofs ergibt sich, dass eine Gefahr schwerwiegender Störungen „bestehen“ muss, sollte der Gerichtshof die zeitlichen Wirkungen nicht begrenzen. ${ }^{738}$ Die schwerwiegenden Störun-

735 So aber Kovács, Temporale Wirkung, 2014, S. $178 \mathrm{ff}$.

736 Diesen Einwand erhebt aber Kovács, Temporale Wirkung, 2014, S. 179; wie hier Rosenkranz, Beschränkung der Rückwirkung, 2015, S. 225 f.

737 Hиер, Beschränkung einer Rückwirkung, 2001, S. 238 f.; Rosenkranz, Beschränkung der Rückwirkung, 2015, S. 226.

738 Vgl. EuGH, Urteil vom 22.9.2016, Rs. C-110/15 (Microsoft Mobile Sales International u.a.), Rn. 61; EuGH, Urteil vom 22.1.2015, verb. Rs. C-401/13 und C-432/13 (Balazs), Rn. 51; EuGH, Urteil vom 10.4.2014, Rs. C-190/12 (Emerging Markets Series of DFA Investment Trust Company), Rn. 110. 
gen müssen also nicht tatsächlich eintreten, sodass der Nachweis einer entsprechenden Gefährdungslage genügt. ${ }^{739}$

d) Wirtschaftliche und finanzielle Auswirkungen

Darauf, dass schwerwiegende wirtschaftliche Auswirkungen ein Beispiel für schwerwiegende Störungen bilden, wurde bereits hingewiesen. ${ }^{740}$ Soll näher bestimmt werden, was unter „wirtschaftlichen“ Auswirkungen zu verstehen ist, fällt auf, dass angesichts zum Teil bestehender Unterschiede in den einzelnen Sprachfassungen mancher Urteile eine weitgehende Gleichsetzung der Begrifflichkeiten der „finanziellen“ und „wirtschaftlichen" Auswirkungen erfolgt. So sprechen etwa in der Rechtssache Emerging Markets Series of DFA Investment Trust Company die deutsche und die französische Sprachfassung von „schwerwiegende[n] finanzielle[n] Störungen" bzw. "troubles financiers graves“, die englische dagegen von „serious economic difficulties“. ${ }^{741}$ In der Rechtssache Heininger wird in der deutschen und französischen Sprachfassung von der Prüfung des Vorliegens eines „erheblichen finanziellen Risikos“ bzw. „risque financier significatif“ gesprochen, während in der englischen vom „risk of serious difficulties“ die Rede ist. Damit geben die einzelnen Sprachfassungen die in Bezug genommene Randnummer des Urteils in der Rechtssache Fisscher, die von der „Gefahr schwerwiegender Störungen“/,risque de troubles graves“/,risk of serious difficulties" spricht, nicht einheitlich wieder. ${ }^{742}$

Vor diesem Hintergrund fragt sich, wie die vom Gerichtshof in ständiger Rechtsprechung wiederholte Formulierung einzuordnen ist, wonach finanzielle Konsequenzen für sich allein die Begrenzung der zeitlichen Wirkungen der Auslegung nicht rechtfertigen können, was er zum einen damit begründet, dass sonst die schwersten Verstöße gegen Unionsrecht günstiger behandelt würden, weil diese in der Regel die bedeutendsten finanziellen Auswirkungen haben können, und zum anderen damit, dass

739 Lindemann/Hackemann, IStR 2005, 786 (788).

740 Siehe Text vor Fn. 713.

741 EuGH, Urteil vom 10.4.2014, Rs. C-190/12 (Emerging Markets Series of DFA Investment Trust Company), Rn. 113.

742 Vgl. die Inbezugnahme von EuGH, Urteil vom 28.9.1994, Rs. C-128/93 (Fisscher), Rn. 18 in EuGH, Urteil vom 13.12.2001, Rs. C-481/99 (Heininger), Rn.52. Auf diese sprachlichen Divergenzen weist auch Düsterhaus, YEL 36 (2017), 237 (255) hin. 
der Rechtsschutz gegen Verletzungen des Unionsrechts dann zu sehr eingeschränkt wäre. ${ }^{743}$

Die Formulierung, die der Gerichtshof zunächst im Urteil in den verbundenen Rechtssachen Roders u.a. verwendete, das seinerseits auf das Urteil in der Rechtssache Dansk Denkavit verweist, wirft die Frage auf, ob der EuGH dadurch, dass er finanzielle Auswirkungen „für sich allein“ für eine Begrenzung nicht genügen lässt, nur anerkennt, dass auch das Gutglaubenserfordernis erfüllt sein muss oder ob er damit eine Erläuterung der schwerwiegenden wirtschaftlichen Auswirkungen vornimmt. ${ }^{744}$ Handelt es sich um eine Erläuterung, müssen die finanziellen Auswirkungen „systemrelevant ${ }^{\text {“745 }}$ sein, da sie „allein“ ja nicht genügen.

In Dansk Denkavit hatte die dänische Regierung den Gerichtshof um eine zeitliche Begrenzung ersucht und auf die „äußerst schwerwiegenden Auswirkungen" auf die Staatsfinanzen und die dänische Gerichtsbarkeit verwiesen. Nach Ansicht des EuGH fehlte es allerdings bereits am guten Glauben der dänischen Regierung, weswegen er die zeitliche Begrenzung ablehnte. ${ }^{76}$ In den verbundenen Rechtssachen Roders u.a. führt der Gerichtshof dann aus, dass die „möglichen finanziellen Konsequenzen der Rechtswidrigkeit einer Steuer für eine Regierung für sich allein niemals die Beschränkung der Wirkungen eines Urteils des Gerichtshofes gerechtfertigt [haben]" und verweist hierfür auf das Dansk Denkavit-Urteil. ${ }^{747}$ Jedenfalls im Ausgangspunkt betont der Gerichtshof damit, dass finanzielle Konsequenzen alleine nicht für eine zeitliche Begrenzung genügen, sondern guter Glaube hinzutreten muss. ${ }^{748}$

743 EuGH, Urteil vom 27.2.2014, Rs. C-82/12 (Transportes Jordi Besora), Rn. 48 f.; EuGH, Urteil vom 11.8.1995, verb. Rs. C-367/93 bis C-377/93 (Roders u.a.), Rn. 48; EuGH, Urteil vom 4.10.2001, Rs. C-294/99 (Athinaiki Zythopoiia), Rn. 39. Karpenstein, in: Grabitz/Hilf/Nettesheim (Hrsg.), Recht der EU, Art. 267 AEUV, Rn. 114 (Stand: Mai 2013) bezeichnet die Rechtsprechung des Gerichtshofs insoweit als „zu starr“, da dieser auch „erhebliche Haushaltsrisiken für den betroffenen Mitgliedstaat“ nicht genügen lasse.

744 Vgl. van der Stok/Thomson, Intertax 34 (2006), 552 (558).

745 Zur näheren Erläuterung des Merkmals „schwerwiegend“ siehe bei Fn. $781 \mathrm{ff}$.

746 EuGH, Urteil vom 31.3.1992, Rs. C-200/90 (Dansk Denkavit und Poulsen Trading), Rn. 20 ff.

747 EuGH, Urteil vom 11.8.1995, verb. Rs. C-367/93 bis C-377/93 (Roders u.a.), Rn. 48.

748 Siehe etwa GA Wabl, Schlussanträge vom 24.10.2013 in der Rs. C-82/12 (Transportes Jordi Besora), Rn. 54. In diesem Sinne auch Düsterhaus, YEL 36 (2017), 237 (256); Düsterhaus, EuR 2017, 30 (39). 
In der Rechtssache Transportes Jordi Besora stellt der EuGH dann allerdings zunächst fest, dass mangels guten Glaubens das Bestehen der Gefahr schwerwiegender Störungen nicht untersucht werden müsse. „Dennoch“, so betont der Gerichtshof, sei daran zu erinnern, dass finanzielle Konsequenzen für sich allein für eine zeitliche Begrenzung nicht ausreichten. ${ }^{749}$ Finanzielle Konsequenzen erscheinen hier damit als Voraussetzung für das Bestehen der Gefahr schwerwiegender Störungen. ${ }^{750}$

In diese Richtung deutet es auch, wenn der Gerichtshof „hinsichtlich der Gefahr schwerwiegender Störungen" auf diese Formulierung hinweist und verlangt, dass ihm Zahlen vorgelegt werden, die die Gefahr schwerwiegender wirtschaftlicher Auswirkungen nachweisen. ${ }^{751}$ Anführen lassen sich auch die Aussagen des EuGH in den verbundenen Rechtssachen Santander Asset Management SGIIC u.a. Die französische Regierung hatte sich dort auf erhebliche haushaltsrechtliche Folgen des Urteils berufen. Im Anschluss an die Wiederholung seiner ständigen Rechtsprechung, wonach die finanziellen Konsequenzen für sich allein keine zeitliche Begrenzung rechtfertigen können, stellt der EuGH fest, dass die französische Regierung nichts für das tatsächliche Bestehen einer Gefahr schwerwiegender wirtschaftlicher Auswirkungen vorgetragen habe. ${ }^{752}$ Den finanziellen Folgen fehlte es also an der systemischen Dimension.

Konsequent verfährt der Gerichtshof hier allerdings nicht. So begrenzte er im Defrenne II-Urteil die zeitlichen Wirkungen ,angesichts der Unbekanntheit des Gesamtbetrags der in Betracht kommenden Entgelte“ ${ }^{753}$ In der Rechtssache Bosman spricht er von einem Zustand der Unsicherheit und meint dann, „unter diesen Umständen“ sei eine zeitliche Begrenzung vorzunehmen. Die wirtschaftlichen Auswirkungen erwähnt er in diesem Zusammenhang also nicht. ${ }^{754}$ In den verbundenen Rechtssachen UNIS

749 EuGH, Urteil vom 27.2.2014, Rs. C-82/12 (Transportes Jordi Besora), Rn. 47 f.

750 Düsterhaus, EuR 2017, 30 (39f.) spricht von einem „Eigenleben“ dieser Aussage und der allmählichen „Mutation“ zu einem Tatbestandsmerkmal der schwerwiegenden Störungen.

751 EuGH, Urteil vom 14.4.2015, Rs. C-76/14 (Manea), Rn. 55. Siehe auch EuGH, Urteil vom 19.12.2013, Rs. C-262/12 (Association Vent De Colère! u.a.), Rn. 42: „in Bezug auf die Gefahr schwerwiegender Störungen“; EuGH, Urteil vom 7.7.2011, Rs. C-263/10 (Nisipeanu), Rn.34: „Quant au risque de troubles graves".

752 EuGH, Urteil vom 10.5.2012, verb. Rs. C-338/11 bis C-347/11 (Santander Asset Management SGIIC u.a.), Rn. 62.

753 EuGH, Urteil vom 8.4.1976, Rs. 43/75 (Defrenne), Rn. 74/75.

754 EuGH, Urteil vom 15.12.1995, Rs. C-415/93 (Bosman), Rn. 143 f. Geltend gemacht worden waren schwerwiegende Folgen für die Organisation des Fuß- 
und Beaudout Père et Fils prüfte der EuGH ohnehin abweichend vom üblichen Schema und setzte materielle Erwägungen an dessen Stelle. ${ }^{755}$ Im Urteil in der Rechtssache Cabanis-Issarte erfolgte die Begrenzung, obwohl die Regierungen der Mitgliedstaaten nicht in der Lage waren, die finanziellen Folgen für die Finanzierung der Systeme der sozialen Sicherheit auch nur annähernd abzuschätzen. ${ }^{756}$ Dass finanzielle Folgen immer systemrelevanten Ausmaßes sein müssen, scheint sich hier also nicht $\mathrm{zu}$ bestätigen. Erklären lässt sich dieser Befund aber wohl damit, dass sich der Gerichtshof auf diese Weise Flexibilität bewahrt und eine Begrenzung dann vornehmen kann, wenn ihm dies erforderlich erscheint. Letztlich zeigt sich hier das Ermessen des Gerichtshofs bei der Anwendung des Kriteriums. Um eine Besonderheit der Prüfung bei horizontalen Rechtsstreitigkeiten handelt es sich daher nach hier vertretener Auffassung nicht. ${ }^{757}$

Damit bleibt zunächst festzuhalten, dass die herausgehobene Bedeutung finanzieller Auswirkungen nicht bestritten werden kann. ${ }^{758}$ Deutlich wird dies nicht zuletzt an der Rechtssache EKW und Wein \& Co. Hier geht der Gerichtshof zwar unter anderem auf den in Rede stehenden Gesamtbetrag und die bedeutende Anzahl geringfügiger Umsätze, bei denen es also jeweils um kleine Beträge ging, nicht ein und gibt damit vor, die Anzahl und den Gesamtbetrag der in Rede stehenden Rückzahlungsansprüche bei der Bestimmung der Gefahr schwerwiegender Störungen zu ignorieren. ${ }^{759}$ Dennoch sieht er die Gefahr einer rückwirkenden Erschütterung des Finanzierungssystems der österreichischen Gemeinden in seinen Grundlagen. Da viele von der Verwaltung vorzunehmende Rückzahlungen kleiner Beträge diese zwar belasten, aber noch nicht das Finanzierungssystem der österreichischen Gemeinden erschüttern, kann die Anzahl der Fälle, in denen eine Rückzahlung zu leisten ist, für den Gerichtshof in der Tat letztlich nicht entscheidend gewesen sein. Ausschlaggebende Bedeutung muss aber vielmehr der Gesamtsumme der zu leistenden Rückzahlungen zugekommen sein. Dies führt zu der Erkenntnis, dass schwerwiegende finan-

balls, vgl. Urteil, Rn. 139. Dass der Gerichtshof hierauf nicht eingeht, überrascht daher, weil diese in der Tat nahelagen, vgl. Hyland, IJEL 2 (1995), 208 (227).

$755 \mathrm{EuGH}$, Urteil vom 17.12.2015, verb. Rs. C-25/14 und C-26/14 (UNIS und Beaudout Père et Fils), Rn. 50 ff.

756 EuGH, Urteil vom 30.4.1996, Rs. C-308/93 (Cabanis-Issarte), Rn. 47.

757 Düsterhaus, YEL 36 (2017), 237 (256) dagegen meint, das Kriterium der finanziellen Konsequenzen systemischen Ausmaßes scheine bei horizontalen Rechtsstreitigkeiten nicht zu gelten.

758 Darauf weist auch Lang, IStR 2007, 235 (235 f.) hin.

759 EuGH, Urteil vom 9.3.2000, Rs. C-437/97 (EKW und Wein \& Co.), Rn. 59. 
zielle Auswirkungen im Gewand schwerwiegender Störungen anerkannt werden. ${ }^{760}$ Finanzielle Schwierigkeiten können also, wenn sie schwerwiegend sind, zu einer Begrenzung führen, allerdings nur, wenn zugleich guter Glaube besteht. ${ }^{761}$

Damit bleibt ebenso festzuhalten, dass eine Beschränkung der zeitlichen Wirkungen selbst dann, wenn die finanziellen Schwierigkeiten gravierend sind, nicht begründet werden kann, wenn es keinen aus unionsrechtlicher Sicht tauglichen Anhaltspunkt für die von den Betroffenen wie etwa den Mitgliedstaaten gebildete Vorstellung vom Inhalt des Unionsrechts gibt. ${ }^{762}$ Sonst würde „,selbst verschuldeter“ guter Glaube der Mitgliedstaaten berücksichtigt. Zurückzuweisen ist deshalb die Erwägung, eine Ausnahme von der ex tunc-Wirkung allein aufgrund finanzieller Folgen bei einer drohenden Funktionsunfähigkeit des Mitgliedstaats bzw. bei einer Aushöhlung des Budgetrechts des nationalen Parlaments zuzulassen und in diesem Fall auf das Kriterium des guten Glaubens zu verzichten. ${ }^{763}$ Möglich sein kann dies auch nicht in "ganz außergewöhnlichen“ Fällen. ${ }^{764}$

e) Maßgeblichkeit der Auswirkungen auf alle Rechtsunterworfenen

Die Frage, im Hinblick auf welchen Bezugspunkt die Gefahr schwerwiegender Störungen zu ermitteln ist, könnte auf den ersten Blick dahingehend zu beantworten sein, dass die entsprechende Gefahr mitgliedstaatsbezogen zu beurteilen ist. Ganz in diesem Sinne wird geltend gemacht, dass das Kriterium der Gefahr schwerwiegender Störungen in der Regel auf einen Mitgliedstaat bezogen sei. ${ }^{765}$ Dafür scheint auch zu sprechen,

760 Hierzu ausführlich Vording/Lubbers, B.T.R. 2006, 91 (104f.); siehe auch van der Stok/Thomson, Intertax 34 (2006), 552 (554).

761 Siehe in diesem Zusammenhang auch Vording/Lubbers, B.T.R. 2006, 91 (107 f.), die zwar eine Anerkennung finanzieller Schwierigkeiten als „eigenständigen“ Beschränkungsgrund fordern, aber zugleich einräumen, dass dies die Gefahr einer Übertreibung auf Seiten der Mitgliedstaaten begründet, weswegen sie auf das Kriterium des guten Glaubens nicht verzichten möchten. Auf dessen Nachweis komme es dann vielmehr, um Missbrauch zu verhindern, noch entscheidender an.

762 Berkemann, DVBl. 2017, 950 (952) meint, diese Frage bleibe „kritisch“.

763 So aber Wusterhausen, Wirkungen, 2016, S. $330 \mathrm{ff}$.

764 Dies in Erwägung ziehend aber GA Wahl, Schlussanträge vom 24.10.2013 in der Rs. C-82/12 (Transportes Jordi Besora), Rn. 58.

765 Müller, Begrenzung, 2009, S. 83. Siehe auch die Kritik von Arnull, The European Union and its Court of Justice, 2. Aufl. 2006, S. 539 daran, dass der EuGH in 
wenn der Gerichtshof etwa die Auswirkungen auf die gesamte Branche der Strom- und Gasversorgung in Deutschland in den Blick nimmt. ${ }^{766}$

Dennoch ist ein anderer Zugang zu wählen. So sind „schon aus Gründen der Gleichbehandlung“ etwa alle Sozialleistungen, die unionsweit von dem in der Rechtssache Sürül in Rede stehenden Beschluss des Assoziationsrates betroffen sind, bei der Beurteilung der Gefahr schwerwiegender Störungen zu berücksichtigen. ${ }^{767} \mathrm{Zu}$ Recht nahm Generalanwalt Jacobs daher in einem die Diskriminierung Mann-zu-Frau-Transsexueller betreffenden Fall die „in der gesamten Europäischen Union“ denkbaren Auswirkungen des Urteils des Gerichtshofs in den Blick. Zuvor hatte er festgestellt, dass die Zahl der Betroffenen „wohl kaum“ eine Situation begründe, die zu einer Gefahr schwerwiegender Störungen im Vereinigten Königreich führen könnte. Da viele andere Mitgliedstaaten bereits eine rechtliche Anerkennung von Transsexuellen vorsehen und diese nicht diskriminieren, sind die Auswirkungen im Hinblick auf die gesamte EU noch weniger bedeutend. ${ }^{768}$

Abzustellen ist bei der Beurteilung der schwerwiegenden Auswirkungen daher auf alle von der Auslegung Betroffenen und dementsprechend keinesfalls allein auf die Beteiligten des Ausgangsverfahrens. ${ }^{769}$ Nur dann, wenn sich Auswirkungen in nur einem oder wenigen Mitgliedstaaten ergeben, ist es zulässig, lediglich diese in Rechnung zu stellen. ${ }^{770}$

Alle von der Auslegung Betroffenen können etwa die Kreditinstitute sein, die Realkreditverträge unter den Voraussetzungen der Haustürwiderrufrichtlinie ohne Belehrung über das Widerrufsrecht geschlossen haben $^{771}$, ebenso wie die Unternehmen des Telekommunikationssektors in-

der Rechtssache 43/75 (Defrenne) dem Umstand zu wenig Beachtung geschenkt habe, dass die Auswirkungen der vom EuGH in seinem Urteil in dieser Rechtssache vorgenommenen Auslegung in den Mitgliedstaaten, die die Begrenzung in zeitlicher Hinsicht angeregt hatten (Irland und das Vereinigte Königreich), angesichts ihres erst 1973 erfolgten Beitritts, geringer gewesen wären als in den Gründungsstaaten.

766 EuGH, Urteil vom 23.10.2014, verb. Rs. C-359/11 und C-400/11 (Schulz und Egbringhoff), Rn. 60.

767 BSG, Urteil vom 18.2.2004, B 10 EG 10/03 R, Rn. 15 - BSGE 92, 182 (186) im Hinblick auf EuGH, Urteil vom 4.5.1999, Rs. C-262/96 (Sürül).

768 GA Jacobs, Schlussanträge vom 15.12.2005 in der Rs. C-423/04 (Richards), Rn. 63.

769 Allein diese in den Blick nehmend allerdings GA Trstenjak, Schlussanträge vom 13.9.2012 in der Rs. C-92/11 (RWE Vertrieb), Rn. 100.

770 Rosenkranz, Beschränkung der Rückwirkung, 2015, S. $226 \mathrm{f}$.

771 EuGH, Urteil vom 13.12.2001, Rs. C-481/99 (Heininger), Rn. 53. 
nerhalb der Union ${ }^{772}$, sämtliche Unternehmen, die eine Übertragung von Unternehmen vorgenommen haben ${ }^{773}$, „namentlich “ Universitäten ${ }^{774}$, die „Banken als solche“ und das „Bankensystem als Ganzes"775 oder eben auch die gesamte Branche der Strom- und Gasversorgung in Deutschland ${ }^{776}$.

Entgegen dem hier befürworteten Erfordernis, die Auswirkungen auf alle Betroffenen in Rechnung zu stellen, scheint der Gerichtshof in der Rechtssache Endress nur auf die betroffene Partei des Ausgangsverfahrens abgestellt zu haben. Dort ließ er die Beschränkung der zeitlichen Wirkungen am fehlenden Nachweis des Risikos für die Allianz-Versicherung scheitern, da diese nur auf eine hohe Anzahl an geschlossenen Versicherungsverträgen und nicht auf die im vorliegenden Fall entscheidende Zahl an ohne Belehrung über ein bestehendes Widerrufsrecht geschlossenen Versicherungsverträgen verwiesen hatte. ${ }^{777}$ Eine Abkehr von einer unionsweiten Betrachtung kann hierin letztlich aber nicht erblickt werden. Das Vorgehen des Gerichtshofs lässt sich vielmehr damit begründen, dass er sich hier deshalb auf den Blick auf die Allianz-Versicherung beschränkt hat, da dieser schon nicht der Nachweis ihrer eigenen Gefährdung gelungen ist, ihr also erst recht nicht der Nachweis einer Gefährdung der gesamten Versicherungsbranche gelungen wäre. ${ }^{778}$ Gleiches gilt in der Rechtssache WESTbahn Management für die wenig substantiierten und daher für den Nachweis einer Gefahr schwerwiegender Störungen ungenügenden Ausführungen der ÖBB-Infrastruktur AG als Infrastrukturbetreiber, die Auswirkungen auf Rechtsverhältnisse geltend gemacht hatte, die sie gutgläubig mit Eisenbahnunternehmen eingegangen sei und deren Rückabwicklung eine übermäßige wirtschaftliche Last für sie darstelle. ${ }^{779}$

Im Grundsatz liegt also auch dem Merkmal der Gefahr schwerwiegender Störungen ein unionsweiter Maßstab zugrunde. ${ }^{780}$ In der Praxis stehen allerdings häufig lediglich der Mitgliedstaat oder Akteure in diesem Mit-

772 EuGH, Urteil vom 9.4.2014, Rs. C-616/11 (T-Mobile Austria), Rn. 53.

773 EuGH, Urteil vom 21.10.2010, Rs. C-242/09 (Albron Catering), Rn. 38.

774 EuGH, Urteil vom 3.10.2019, Rs. C-274/18 (Schuch-Ghannadan), Rn. 64.

775 EuGH, Urteil vom 3.3.2020, Rs. C-125/18 (Gómez del Moral Guasch), Rn. 71.

776 EuGH, Urteil vom 23.10.2014, verb. Rs. C-359/11 und C-400/11 (Schulz und Egbringhoff), Rn. 60.

777 EuGH, Urteil vom 19.12.2013, Rs. C-209/12 (Endress), Rn. 37.

778 In diesem Fall könnten den Gerichtshof Pflichten zur Amtsermittlung treffen, siehe dazu bei Fn. $876 \mathrm{ff}$.

779 EuGH, Urteil vom 10.7.2019, Rs. C-210/18 (WESTbahn Management), Rn. 47.

780 Er zeigt sich etwa auch, wenn der Gerichtshof verlangt, dass die von ihm „herangezogenen Auslegungsgesichtspunkte“ eine Gefahr schwerwiegender Störungen „für die Verfahren zur Vollstreckung Europäischer Haftbefehle“ begrün- 
gliedstaat im Mittelpunkt der Betrachtung, auf den/die sich die in Rede stehende EuGH-Entscheidung am stärksten auswirkt.

\section{f) Schwerwiegende Auswirkungen}

Was genau bestimmte Auswirkungen zu schwerwiegenden macht, lässt sich der Rechtsprechung des Gerichtshofs nur sehr eingeschränkt entnehmen. Aus ihr lässt sich aber ablesen, dass zwischen Auswirkungen mit und ohne strukturelle Bedeutung unterschieden werden muss. ${ }^{781}$

\section{aa) Betroffenheit von „Subsystemen“}

Einen betragsmäßigen Schwellenwert festzulegen, um die schwerwiegenden Störungen/wirtschaftlichen Auswirkungen zu bestimmen, wäre nicht überzeugend. ${ }^{782}$ Absolute Schwellenwerte können schon angesichts der Vielfalt an möglicherweise durch eine Auslegung des EuGH betroffenen Konstellationen nicht weiterhelfen, da die Beurteilung der Schwere der Auswirkungen für diese nicht nach einem einheitlichen Maßstab erfolgen kann. An konkreten Zahlen lässt sich die Schwere der Auswirkungen also nicht festmachen. ${ }^{783}$ Dennoch hat sich der Gerichtshof in Ausnahmefällen in der Lage gesehen, das Vorbringen einer Regierung mit der Erwägung zurückzuweisen, die konkret genannte Zahl lasse für sich genommen nicht auf eine Gefahr schwerwiegender Störungen schließen. ${ }^{784}$

Angesichts der unterschiedlichen Wirtschaftskraft der Mitgliedstaaten schlägt Wiedmann einen bestimmten Prozentsatz des Haushaltsvolumens des Mitgliedstaats als Bezugsgröße vor und stellt damit auf den Mitgliedstaat als solchen ab. Für einen derartigen Ansatz spricht auf den ersten Blick, dass es aus unionsrechtlicher Perspektive für die Beurteilung der Vereinbarkeit etwa einer Steuer mit Unionsrecht nicht auf die Ebene innerhalb des Mitgliedstaats ankommt, die den Unionsrechtsverstoß begeht,

den, EuGH, Urteil vom 24.11.2020, Rs. C-510/19 (Openbaar Ministerie (Urkundenfälschung)), Rn. 75 .

781 Vgl. Düsterhaus, YEL 36 (2017), 237 (255 f.).

782 So auch Thömmes, IWB 2006, 997 (1000).

783 Siehe auch Ludewig, Zeitliche Beschränkung, 2012, S.121; Kovács, Temporale Wirkung, 2014, S. 172.

784 EuGH, Urteil vom 14.4.2015, Rs. C-76/14 (Manea), Rn. 56 f.; EuGH, Urteil vom 5.10.2006, verb. Rs. C-290/05 und C-333/05 (Nádasdi und Németh), Rn. 68. 
sodass auch nicht zwischen dem Fall einer Verursachung durch den Gesamtstaat oder eine seiner Untereinheiten unterschieden werden kann. ${ }^{785}$ Dieser Ansatz entspricht aber nicht dem Vorgehen des EuGH.

Dieser sieht etwa eine Erschütterung des Finanzierungssystems der örtlichen Körperschaften der französischen überseeischen Departemente (DOM) als „schwerwiegend“ an. ${ }^{786}$ Ebenso bejaht er eine Gefahr schwerwiegender wirtschaftlicher Auswirkungen, wenn ohne zeitliche Begrenzung das Finanzierungssystem der österreichischen Gemeinden in seinen Grundlagen erschüttert ${ }^{787}$, das System der Finanzierung des Hochschulunterrichts erschüttert ${ }^{788}$, das finanzielle Gleichgewicht zahlreicher an die Stelle des gesetzlichen Systems getretener betrieblicher Versorgungssysteme gestört ${ }^{789}$ oder die Finanzierung des Systems der sozialen Sicherheit der Mitgliedstaaten erschüttert ${ }^{790}$ würden. Er stellt damit auf die konkret betroffene „Einheit“, das konkret betroffene wirtschaftliche „Subsystem“ ab und verlangt, dass dieses nicht lediglich belastet, sondern in seiner Existenz bedroht ist. ${ }^{791}$

Auch wenn daran festzuhalten ist, dass die Auswirkungen auf alle Betroffenen in Rechnung zu stellen sind, so ist doch festzustellen, dass dem Gerichtshof in aller Regel nur Zahlen aus einem Mitgliedstaat vorliegen. Für die Beurteilung der Schwere der Auswirkungen sieht er sich daher mit einem nationalen Kontext konfrontiert, dem er sich nicht verschließen kann und der auf diese Weise entscheidende Bedeutung erlangt. Ein gewisses Korrektiv stellt es dar, dass nicht nur Einzelfälle in den Blick genommen werden können. Dies hindert allerdings nicht daran, auch auf kleinere Einheiten abzustellen. So betrachtet der Gerichtshof in der Rechtssache Maruko etwa das finanzielle Gleichgewicht des Systems der Versorgungsanstalt der deutschen Bühnen und verneint dessen rückwirkende Erschütterung bei einer unterbleibenden zeitlichen Begrenzung. ${ }^{792}$ Die in den Blick genommene Einheit sollte aber jedenfalls groß genug sein, um die sich zum grundsätzlich unionsweiten Maßstab ergebenden

785 Wiedmann, EuLF 2006, I-197 (I-198 f.).

786 EuGH, Urteil vom 16.7.1992, Rs. C-163/90 (Legros u.a.), Rn. 34.

787 EuGH, Urteil vom 9.3.2000, Rs. C-437/97 (EKW und Wein \& Co.), Rn. 59.

788 EuGH, Urteil vom 2.2.1988, Rs. 24/86 (Blaizot u.a.), Rn. 34.

789 EuGH, Urteil vom 17.5.1990, Rs. C-262/88 (Barber), Rn. 44.

790 EuGH, Urteil vom 4.5.1999, Rs. C-262/96 (Sürül), Rn. 111.

791 Rosenkranz, Beschränkung der Rückwirkung, 2015, S. 239 f.; Balmes/Ribbrock, BB 2006, 17 (19); Seer/Müller, IWB 2008, 255 (261); Schaer, Grenzen rückwirkender Rechtsprechung, 2010, S. 68.

792 EuGH, Urteil vom 1.4.2008, Rs. C-267/06 (Maruko), Rn. 78. 
Verwerfungen nicht zu tief werden zu lassen. In gewissem Maße erscheinen diese mangels unionsweiter Kennzahlen, die als Referenzwert herangezogen werden könnten, allerdings unvermeidbar.

\section{bb) Relativität der Auswirkungen}

Wenn es nach dem vorstehend Gesagten entscheidend auf das betroffene Subsystem ankommt, ist zur Beurteilung der Schwere der Auswirkungen auf einen „relativen Schwellenwert" abzustellen, der die einem Subsystem zur Verfügung stehenden Mittel zu den auf dieses System zu erwartenden Auswirkungen ins Verhältnis setzt. Damit erweist sich die Leistungsfähigkeit des betroffenen Systems als ausschlaggebend dafür, ob die Folgen schwerwiegend sind. ${ }^{793}$

Bedeutung erlangt damit etwa, welche Gebietskörperschaft eine nun zu erstattende Abgabe erhebt. Was für ein System als nicht schwerwiegend anzusehen ist, kann für ein anderes System existenzbedrohend wirken. ${ }^{794}$ Ist nicht das Finanzaufkommen einer Untereinheit des Staates betroffen, sondern das Steueraufkommen des Gesamtstaates, sind die Auswirkungen der ex tunc-Wirkung dementsprechend unterschiedliche. ${ }^{795}$ Auch können etwa Finanzierungssysteme derart miteinander verwoben sein, dass bei schwerwiegenden wirtschaftlichen Auswirkungen auf die Gemeinden oder Universitäten der Gesamtstaat „einspringt“, in Bezug auf den dann aber keine schwerwiegenden wirtschaftlichen Auswirkungen im Sinne der Rechtsprechung mehr begründet werden könnten. ${ }^{796}$ Durch die Beachtung dieser Umstände hängt es zwar von der Gestaltung des Steuersystems im jeweiligen Mitgliedstaat ab, ob die zeitlichen Wirkungen zu begrenzen sind. Sie ermöglicht es allerdings zugleich, das im betroffenen Mitgliedstaat geltende Steuersystem unangetastet zu lassen. ${ }^{797}$

Sind Mitgliedstaaten als solche betroffen, bieten sich zur Beurteilung der Schwere der Auswirkungen Bezugsgrößen wie das Bruttoinlandspro-

793 Vgl. Forsthoff, DStR 2005, 1840 (1842), der auf die entscheidende Bedeutung der „Relation des Erstattungsbetrages zu dem Mittelaufkommen für das jeweilige Subsystem und die Konsequenzen hierauf" hinweist. Siehe auch Rosenkranz, Beschränkung der Rückwirkung, 2015, S. 236.

794 Vgl. Lang, IStR 2007, 235 (238).

795 Vgl. Balmes/Ribbrock, BB 2006, 17 (19).

796 Lang, IStR 2007, 235 (239).

797 Rosenkranz, Beschränkung der Rückwirkung, 2015, S. 243. 
dukt $^{798}$, staatliche Einnahmen ${ }^{799}$ oder das mitgliedstaatliche Haushaltsdefi$\mathrm{zit}^{800}$ an. Auch Art. 126 AEUV und Protokoll (Nr. 12) über das Verfahren bei einem übermäßigen Defizit mit ihrem Kriterium des $3 \%$-Defizits können eine erste Orientierung bieten. Zudem weisen die in der Finanzkrise gezahlten „Rettungsmilliarden“ darauf hin, dass die Mitgliedstaaten selbst davon ausgehen, dass sie finanziell große Lasten schultern können. ${ }^{801}$

Da nach den Auswirkungen auf die jeweils betroffene Einheit zu fragen ist, sind deren Besonderheiten zu berücksichtigen. Ist etwa die Finanzierung der betroffenen Versorgungssysteme darauf ausgerichtet, dass die Arbeitnehmer heiraten würden, so kann es im Hinblick auf eine Hinterbliebenenrente keinen Unterschied machen, ob eine Ehe zwischen Mann und Frau oder aber eine gleichgeschlechtliche Ehe geschlossen wird. Die Finanzierung der Hinterbliebenenrente wäre bei einer Ehe zwischen Mann und Frau in der Kalkulation des Versorgungssystems ja enthalten gewesen. In Rechnung zu stellen ist bei der Betrachtung der drohenden Auswirkungen ebenfalls, dass bei einer unionsrechtswidrigen Benachteiligung Homosexueller - anders als in einem Fall der Diskriminierung nach dem Geschlecht - weniger Arbeitnehmer bzw. Hinterbliebene betroffen sind, was sich dämpfend auf die Mehrbelastung für die betroffenen Versorgungssysteme auswirkt. ${ }^{802}$

Angesichts der jeweils im Hinblick auf das betroffene Subsystem zu beurteilenden Schwere der Auswirkungen ist bei einem Erst-recht-Schluss Vorsicht geboten, wie ihn Generalanwalt Wahl in seinen Schlussanträgen in der Rechtssache Carrefour Hypermarchés u.a. vornimmt. Die französi-

798 GA Sharpston, Schlussanträge vom 22.6.2006 in der Rs. C-228/05 (Stradasfalti), Rn. $94 \mathrm{f}$.

799 Vgl. EuGH, Urteil vom 31.3.1992, Rs. C-200/90 (Dansk Denkavit und Poulsen Trading), Rn. 20.

800 GA Stix-Hackl, Schlussanträge vom 5.10.2006 in der Rs. C-292/04 (Meilicke u.a.), Rn. 62; GA Wathelet, Schlussanträge vom 15.5.2014 in der Rs. C-331/13 (Nicula), Rn. 69 f. In der Rechtssache Budișan machte die rumänische Regierung geltend, das Haushaltsdefizit würde ohne zeitliche Begrenzung um 0,9\% für 2015 erhöht und stiege von 1,83\% auf 2,7\% des Bruttoinlandsprodukts, siehe EuGH, Urteil vom 9.6.2016, Rs. C-586/14 (Budișan), Rn. 48.

801 Vgl. zu diesen Anknüpfungspunkten Rosenkranz, Beschränkung der Rückwirkung, 2015, S. $240 \mathrm{f}$.

802 Siehe hierzu GA Kokott, Schlussanträge vom 30.6.2016 in der Rs. C-443/15 (Parris), Rn. 161, die daher eine Gefahr schwerwiegender Störungen verneint. Der Gerichtshof verneinte das Vorliegen einer Diskriminierung, sodass sich ihm die Frage einer zeitlichen Begrenzung nicht stellte, EuGH, Urteil vom 24.11.2016, Rs. C-443/15 (Parris). 
sche Regierung verweist dort zur Begründung der Gefahr schwerwiegender Störungen auf das Bestehen von Rechtsverhältnissen zwischen den französischen Behörden und einerseits den Abgabenpflichtigen und andererseits den Begünstigten der streitigen Beihilfenregelung, an die die Beihilfe zwischen 2006 und 2011 in einem Umfang von rund 2,1 Milliarden Euro ausgezahlt worden war. Dass die französische Regierung nicht nachgewiesen hat, dass bei Rückzahlung der Beihilfe verheerende Folgen drohen, begründet Generalanwalt Wahl auch mit einem Erst-rechtSchluss zu den Erwägungen des Gerichtshofs in den verbundenen Rechtssachen Schulz und Egbringhoff. Dort hatte der Gerichtshof ausgeführt, dass die Infragestellung von Rechtsverhältnissen, deren Wirkungen sich in der Vergangenheit erschöpft hatten, nicht rückwirkend die Branche der Strom- und Gasversorgung in Deutschland erschüttert. ${ }^{803}$ Daher, so Generalanwalt Wahl, sei im vorliegenden Fall erst recht keine entsprechende Gefahr ersichtlich. ${ }^{804}$ Ein solcher Erst-recht-Schluss ist aber jedenfalls nicht zwingend. Er nimmt zwar in nicht zu beanstandender Weise die zur Begründung einer Gefahr schwerwiegender Störungen erforderlichen Ausmaße in Bezug. In den jeweiligen Rechtssachen betroffen sind jedoch unterschiedliche Subsysteme, sodass eine Vergleichbarkeit - insbesondere auch vor dem Hintergrund, dass sich ein einheitlicher Schwellenwert wie gesehen nicht festlegen lässt - nicht ohne Weiteres auf der Hand liegt.

Auf die Beurteilung der Gefahr schwerwiegender Störungen übertragen lässt sich eine Überlegung des Gerichtshofs, die bei der Auslegung des Unionsrechts eine gravierende Störung der Volkswirtschaft und des Finanzsystems eines Mitgliedstaats berücksichtigt, um die finanzielle Stabilität der Union zu bewahren. ${ }^{805}$ Für die Frage der Beurteilung der Gefahr schwerwiegender Störungen bedeutet dies, zu berücksichtigen, ob durch die Belastung eines Mitgliedstaats auch Auswirkungen auf die Union als Ganzes drohen. Aber auch ohne derartige Auswirkungen sollten wirtschaftliche Schwierigkeiten eines Landes nicht von vornherein als irrelevant abgetan werden und daher zumindest als ein Faktor in die Bestimmung der Schwere der Auswirkungen Eingang finden. ${ }^{806}$ Entsprechendem Vorbringen der Regierungen hat der Gerichtshof allerdings bislang kein Gehör geschenkt.

803 EuGH, Urteil vom 23.10.2014, verb. Rs. C-359/11 und C-400/11 (Schulz und Egbringhoff), Rn. 60-62.

804 GA Wahl, Schlussanträge vom 30.11.2017 in der Rs. C-510/16 (Carrefour Hypermarchés u.a.), Rn. $102 \mathrm{f}$.

805 EuGH, Urteil vom 8.11.2016, Rs. C-41/15 (Dowling u.a.), Rn. 53.

806 Vgl. GA Wahl, Schlussanträge vom 24.10.2013 in der Rs. C-82/12 (Transportes Jordi Besora), Rn. 52. 
So hatte die rumänische Regierung in den Rechtssachen Nisipeanu und Manea die das Land treffende Wirtschaftskrise ins Feld geführt, war mit ihrem Vorbringen aber nicht gehört worden, sei es unter Hinweis auf das Fehlen hinreichender Angaben oder aufgrund der Einstufung des genannten Betrages als für sich genommen nicht ausreichend. ${ }^{807}$

cc) Fazit

So wünschenswert klare Abgrenzungskriterien sind, um zu bestimmen, was bestimmte Auswirkungen zu schwerwiegenden macht, so schwierig ist der entscheidende Bezugspunkt zu bestimmen. Letztlich geht es hier um eine Wertungsfrage ${ }^{808}$, die jeweils nur im Verhältnis zu einem Subsystem beantwortet und nicht in absoluten Zahlen ausgedrückt werden kann. Das Subsystem muss in seinem Bestand gefährdet und groß genug sein, um eine unionsweite Begrenzung der zeitlichen Wirkungen rechtfertigen zu können. Indem der Gerichtshof weder einen absoluten Betrag noch einen bestimmten Prozentsatz festlegt, hält er sich für die Zukunft alle Optionen offen.

\section{g) Ermittlung der Auswirkungen}

Um das Bestehen einer Gefahr schwerwiegender Störungen beurteilen zu können, ist der Gerichtshof in aller Regel darauf angewiesen, dass die Betroffenen ihm entsprechende Informationen vorlegen. Hinsichtlich der Ermittlung der drohenden Auswirkungen sind von den Betroffenen einige Maßgaben zu beachten.

aa) Schwierigkeiten und Besonderheiten der Ermittlung

Stehen Auswirkungen auf einen Mitgliedstaat in Rede, hat dieser bei seinem Vorbringen auch seine nationalen Besonderheiten einzubeziehen,

807 EuGH, Urteil vom 7.7.2011, Rs. C-263/10 (Nisipeanu), Rn. 35 f.; EuGH, Urteil vom 14.4.2015, Rs. C-76/14 (Manea), Rn. $56 \mathrm{f}$.

808 GA Stix-Hackl, Schlussanträge vom 5.10.2006 in der Rs. C-292/04 (Meilicke u.a.), Rn. 60; Schaer, Grenzen rückwirkender Rechtsprechung, 2010, S. 67; Ludewig, Zeitliche Beschränkung, 2012, S. $121 \mathrm{f}$. 
wenn sie Einfluss auf die Beurteilung des Bestehens der Gefahr haben. Vor dem Hintergrund, dass das Ausmaß der Auswirkungen der Auslegung ohne Blick auf die nationale Rechtslage häufig nicht bestimmt werden kann, da diese Auslegung im Mitgliedstaat im Rahmen des nationalen Rechts noch zur Anwendung gebracht werden muss, ist auch diesem Umstand bei der Beurteilung der Gefahr schwerwiegender Störungen Beachtung zu schenken. ${ }^{809}$ Dies bedeutet zugleich, dass sich der Gerichtshof auch mit den Folgen seiner Auslegung in den nationalen Rechtsordnungen befassen muss, obwohl er dies ansonsten als nicht zu seinen Aufgaben gehörend ablehnt. $^{810}$

Eine zeitliche Beschränkung scheidet dementsprechend aus, wenn sich die Folgen nicht allein auf der Grundlage der Auslegung des Unionsrechts durch den Gerichtshof bestimmen lassen. ${ }^{811}$ Dies ist etwa dann der Fall, wenn nationale Gerichte auf Grundlage der Auslegung des Unionsrechts durch den Gerichtshof noch eine Entscheidung nach Maßgabe der Umstände des Einzelfalles treffen müssen. Ebenso verhält es sich, wenn dem nationalen Gericht noch die Entscheidung über das Vorliegen einer Diskriminierung und deren eventuelle Rechtfertigung anhand der vom Gerichtshof formulierten Maßstäbe überlassen ist. ${ }^{812}$ Können die Auswirkungen einer vom vorlegenden Gericht noch zu treffenden Entscheidung dagegen bereits abgeschätzt werden, da sie angesichts der Auslegung durch den Gerichtshof vorgezeichnet ist, ist eine Beurteilung auf Grundlage dieser Auslegung möglich. ${ }^{813}$

Muss ein Mitgliedstaat von Unionsrechts wegen eine gegenüber Einzelnen verhängte Geldbuße nur zum Teil zurückzahlen, kann auch nur dieser Teil bei der Beurteilung der schwerwiegenden Auswirkungen berücksichtigt werden. ${ }^{814}$ Ist nur eine bestimmte Art von Verträgen betroffen, etwa Versicherungsverträge ohne Belehrung über ein bestehendes Wider-

809 Huеp, Beschränkung einer Rückwirkung, 2001, S. 106; Schaer, Grenzen rückwirkender Rechtsprechung, 2010, S. 74.

810 Lang, IStR 2007, 235 (237, 243): Rechtsfolgen nach nationalem Recht zumindest nachprüfen.

811 Z.B. EuGH, Urteil vom 17.9.2014, Rs. C-562/12 (Liivimaa Lihaveis), Rn. 82 f.; EuGH, Urteil vom 21.3.2013, Rs. C-92/11 (RWE Vertrieb), Rn. 60 f.; EuGH, Urteil vom 3.3.2020, Rs. C-125/18 (Gómez del Moral Guasch), Rn. 70 f.

812 EuGH, Urteil vom 3.10.2019, Rs. C-274/18 (Schuch-Ghannadan), Rn. 63 f.

813 Vgl. EuGH, Urteil vom 20.9.2018, Rs. C-510/16 (Carrefour Hypermarchés u.a.), Rn. 63 f. im Hinblick auf einen Verstoß gegen Art. 108 III AEUV.

814 EuGH, Urteil vom 19.7.2012, Rs. C-263/11 (Rēdlihs), Rn. 62; EuGH, Urteil vom 3.6.2010, Rs. C-2/09 (Kalinchev), Rn. 54 f.; EuGH, Urteil vom 18.1.2007, Rs. C-313/05 (Brzeziński), Rn. 59. 
rufsrecht, ist maßgeblich, ob deren Rückabwicklung eine entsprechende Gefahr begründet. ${ }^{815}$ Berücksichtigung können daher nur diese finden.

Die Anforderungen, die der Gerichtshof hinsichtlich der Ermittlung der Auswirkungen an die Betroffenen stellt, sind zum Teil übermäßig streng. So hatte die britische Regierung in der Rechtssache Test Claimants in the FII Group Litigation unterstellt, der Gerichtshof würde sämtliche Vorlagefragen im Sinne der Kläger des Ausgangsverfahrens beantworten. Diese Hypothese, aufgrund derer sie die finanziellen Auswirkungen berechnet hatte, bewahrheitete sich allerdings nicht. Die britische Regierung hatte die Summe daher zu hoch angesetzt, sodass der EuGH eine Beschränkung der zeitlichen Wirkungen ablehnte. ${ }^{816}$ Erforderlich wäre also gewesen, sämtliche denkbaren Antwortmöglichkeiten des EuGH im Voraus zu erahnen und eine darauf abgestimmte Berechnung vorzunehmen. Derartige Anforderungen können die Mitgliedstaaten letztlich nicht erfüllen. ${ }^{817}$ Nachsichtiger zu verfahren ist allerdings kaum möglich. Vom Gerichtshof kann kaum verlangt werden, den Mitgliedstaaten vor Urteilsverkündung das Auslegungsergebnis, zu dem er gelangt, mitzuteilen, damit diese ihren Vortrag darauf einstellen können. Vor diesem Hintergrund ist daher zu erwägen, wie auch Ludewig es vorschlägt, in besonders schwierig gelagerten Fällen an das Verfahren, in dem der Gerichtshof die Auslegung vornimmt, ein sich ausschließlich mit der Frage der Begrenzung der zeitlichen Wirkungen befassendes Verfahren anzuschließen, das dann eine auf die Auslegung des Gerichtshofs abgestimmte Bestimmung der Auswirkungen ermöglichen würde. ${ }^{818}$

\section{bb) Abwälzung der Lasten}

Bedeutung für die Ermittlung der Auswirkungen einer vom EuGH vorgenommenen Auslegung kann auch einer Abwälzung der Lasten zukommen.

Im Rahmen der Frage, ob eine unionsrechtswidrig erhobene Abgabe von den Mitgliedstaaten zu erstatten ist, kann berücksichtigt werden, ob

815 EuGH, Urteil vom 19.12.2013, Rs. C-209/12 (Endress), Rn. 37.

816 EuGH, Urteil vom 12.12.2006, Rs. C-446/04 (Test Claimants in the FII Group Litigation), Rn. 224.

817 Kritisch daher Lang, IStR 2007, 235 (237).

818 Dafür Ludewig, Zeitliche Beschränkung, 2012, S. 282 ff.; ablehnend Wusterhausen, Wirkungen, 2016, S. 387 ff. 
die von ihr Betroffenen ihre Belastung auf andere Wirtschaftsteilnehmer oder den Verbraucher abwälzen konnten. ${ }^{819}$ Ein Mitgliedstaat kann einem Abgabepflichtigen die Erstattung daher versagen, wenn er feststellt, dass die Abgabenlast in vollem Umfang von einem anderen als dem Abgabepflichtigen getragen wurde und wenn die Erstattung an den Abgabepflichtigen zu dessen ungerechtfertigter Bereicherung führen würde. ${ }^{820}$ Diese Ausnahme von der Erstattungspflicht ist allerdings eng auszulegen; die Prüfung der in jedem Einzelfall unter Umständen abweichend zu beurteilenden Sachverhaltsfrage fällt in den Zuständigkeitsbereich der nationalen Gerichte. ${ }^{821}$

$\mathrm{Da}$ es sich um eine Frage des Einzelfalls handelt, ist eine pauschale Antwort auf die Frage, welchen Einfluss die Abwälzung der Lasten auf das Bestehen einer Gefahr schwerwiegender wirtschaftlicher Auswirkungen hat, nicht möglich. Klar ist aber jedenfalls, dass ein Mitgliedstaat durch eine Abwälzung der Lasten vom Abgabepflichtigen auf andere Wirtschaftsteilnehmer oder Verbraucher nicht belastet wird, da er diese abgewälzten Abgaben ja nicht erstatten muss und insoweit entlastet wird. Die Gefahr einer schwerwiegenden Störung kann der Mitgliedstaat mit dem Argument, Lasten seien abgewälzt worden, daher nicht begründen. ${ }^{822}$ Können die Betroffenen im Falle einer für sie nachteiligen Auslegung des Unionsrechts durch den EuGH vom Mitgliedstaat eine Entschädigung erlangen und stellt dieser keinen Antrag auf Begrenzung, spricht dies gegen das Bestehen einer Gefahr schwerwiegender Störungen. ${ }^{823}$

Etwas überraschen muss nach dem vorstehend Gesagten, dass die österreichische Regierung in der Rechtssache EKW und Wein \& Co. die Abwälzung der Lasten (von den der unionsrechtswidrigen Getränkesteuer unterliegenden Lieferanten auf die Verbraucher) als Argument für die von ihr erstrebte Begrenzung der zeitlichen Wirkungen angeführt hat. ${ }^{824} \mathrm{Da}-$

819 EuGH, Urteil vom 11.8.1995, verb. Rs. C-367/93 bis C-377/93 (Roders u.a.), Rn. 49. Siehe hierzu näher Vording/Lubbers, B.T.R. 2006, 91 (108 ff.).

820 EuGH, Urteil vom 2.10.2003, Rs. C-147/01 (Weber's Wine World u.a.), Rn.94; EuGH, Urteil vom 14.1.1997, verb. Rs. C-192/95 bis C-218/95 (Comateb u.a.), Rn. 27.

821 EuGH, Urteil vom 2.10.2003, Rs. C-147/01 (Weber's Wine World u.a.), Rn.95, 96.

822 Ludewig, Zeitliche Beschränkung, 2012, S. 175 f.; Rosenkranz, Beschränkung der Rückwirkung, 2015, S. 231.

823 Vgl. GA Campos Sánchez-Bordona, Schlussanträge vom 28.3.2019 in der Rs. C-210/18 (WESTbahn Management), Rn. 75.

824 EuGH, Urteil vom 9.3.2000, Rs. C-437/97 (EKW und Wein \& Co.), Rn. 56. 
hinter stand wohl die Überlegung, bei infolge einer zeitlichen Begrenzung unterbleibender Rückzahlung der Steuer an die Steuerpflichtigen ändere sich für diese nichts, da diese ihre Belastung ja weitergegeben haben. Das mag zwar richtig sein, führt aber eher dazu, dass bereits keine Rückzahlungsansprüche gegenüber dem Mitgliedstaat mehr bestehen, sodass diese auch nicht mehr in die dem Mitgliedstaat drohenden wirtschaftlichen Auswirkungen einberechnet werden können. ${ }^{825}$

Bei Rechtsstreitigkeiten zwischen Privaten ist die Ausgangslage bei einer Abwälzung der Lasten eine etwas andere. Wenn hier das Bestehen einer Gefahr schwerwiegender Störungen zu beurteilen ist, ist zwar grundsätzlich die wirtschaftliche Gesamtbilanz entscheidend. Der Verlust eines Anspruchs kann daher theoretisch - wobei allerdings etwaige Folgekosten in Rechnung zu stellen sind - durch die Existenz eines anderen Anspruchs aufgewogen werden. ${ }^{826}$ Nicht vergessen werden darf dabei aber, dass die schwerwiegenden wirtschaftlichen Auswirkungen für alle betroffenen Privaten zu untersuchen sind. In der Rechtssache Skov und Bilka hat der Gerichtshof dies übersehen.

Dort ging es um den Schaden nach dem Verzehr von Eiern (fehlerhaftes Produkt), die von Bilka (Lieferant) verkauft und von Skov (Hersteller) erzeugt worden waren. Nach dänischem Recht trat der Lieferant unbeschränkt in die verschuldensunabhängige Haftung des Herstellers ein, was nach Auffassung des Gerichtshofs allerdings der Produkthaftungsrichtlinie widersprach. Die Geschädigten, die Ansprüche gegen den Lieferanten durchgesetzt hatten, sorgten sich daher davor, erneut Prozesse, nun gegen den Hersteller, führen zu müssen und beantragten eine zeitliche Begrenzung. Dass der Gerichtshof im Rahmen der Prüfung der Gefahr schwerwiegender Störungen nur die Situation der Lieferanten in den Blick nimmt, die die Geschädigten entschädigt haben und die dann nach dänischem Recht in die Rechte des Geschädigten gegen den Hersteller eintreten, überzeugt nicht. ${ }^{827} \mathrm{Da}$ sie beim Hersteller Regress nehmen können, sind für sie keine schwerwiegenden Störungen zu befürchten. Anders, und das prüft der Gerichtshof nicht, mag dies aber für die Geschädigten sein, die bei einer ex tunc-Wirkung ihre zwar bereits gerichtlich, aber noch nicht rechtskräftig festgestellten Ansprüche gegen die Lieferanten verlieren könnten und diese dann gegenüber dem Hersteller in einem

825 Siehe auch Ludewig, Zeitliche Beschränkung, 2012, S. 175 f.

826 Ludewig, Zeitliche Beschränkung, 2012, S. 176 f.

827 EuGH, Urteil vom 10.1.2006, Rs. C-402/03 (Skov und Bilka), Rn. 52. 
zweiten Prozess geltend machen müssten. ${ }^{828} \mathrm{Ob}$ dies eine Gefahr schwerwiegender wirtschaftlicher Auswirkungen begründet, bleibt zu Unrecht unberücksichtigt. Für wen eine solche Gefahr besteht, ist nämlich nicht entscheidend; entscheidend ist nur ihr Bestehen. ${ }^{829}$

\section{cc) Mitgliedstaatliche Verfahrensautonomie}

Auch der Grundsatz der mitgliedstaatlichen Verfahrensautonomie findet im Rahmen der Bestimmung der Auswirkungen einer vom Gerichtshof vorgenommenen Auslegung Berücksichtigung, sodass das nationale Verfahrensrecht Bedeutung erlangt.

Dies kann sich zunächst zu Lasten der Mitgliedstaaten auswirken, wenn man bedenkt, dass bei der Beurteilung des Bestehens einer Gefahr schwerwiegender Störungen die Rechtsverhältnisse außer Betracht bleiben müssen, die angesichts der nationalen Verfahrensvorschriften von der Auslegung des Unionsrechts durch den Gerichtshof nicht mehr betroffen sein können. ${ }^{830}$

Auch für den Mitgliedstaat positive Folgen sind aber denkbar. So galt in dem der Rechtssache Legros u.a. zugrundeliegenden Sachverhalt für die Erstattungsanträge hinsichtlich der unionsrechtswidrig erhobenen Abgabe die dreißigjährige Verjährungsfrist des französischen Rechts. Mangels anderweitiger Ausführungen zu den schwerwiegenden wirtschaftlichen Auswirkungen ist davon auszugehen, dass der Gerichtshof dem Vorbringen der französischen Regierung, dass die Geltung der langen Verjährungsfrist zu einer Verschärfung der finanziellen Folgen führe ${ }^{831}$, Gehör geschenkt hat. ${ }^{832}$ Dem unmittelbar betroffenen Mitgliedstaat wird also zugestanden, Aussagen über die wirtschaftlichen Auswirkungen unter Berücksichtigung seines Verfahrensrechts zu treffen. Da diese Auswirkungen in einem anderen Mitgliedstaat mit kürzerer Verjährungsfrist weniger schwerwiegend ausfallen würden, zeigt sich auch an dieser Stelle die häufig auf einen Mitgliedstaat begrenzte Beurteilung des Kriteriums.

828 Näher Ludewig, Zeitliche Beschränkung, 2012, S. $176 \mathrm{f}$.

829 Zutreffend Rosenkranz, Beschränkung der Rückwirkung, 2015, S. 231.

$830 \mathrm{He}$, ZZP 108 (1995), 59 (70 f.); ihm zustimmend auch Rosenkranz, Beschränkung der Rückwirkung, 2015, S. 229.

831 EuGH, Urteil vom 16.7.1992, Rs. C-163/90 (Legros u.a.), Rn. 29.

832 EuGH, Urteil vom 16.7.1992, Rs. C-163/90 (Legros u.a.), Rn. 34. 
Dass der EuGH zum Teil zu pauschal auf die Verfahrensautonomie verweist, zeigt das Urteil in den verbundenen Rechtssachen Brasserie du pêcheur und Factortame. Hier nutzte der Gerichtshof die Tatsache, dass die Mitgliedstaaten beim unionsrechtlichen Staatshaftungsanspruch die Folgen des entstandenen Schadens im Rahmen des nationalen Haftungsrechts zu beheben haben, als Anknüpfungspunkt, um die von der deutschen Regierung angesichts der Höhe der zu erwartenden Schadensersatzansprüche erstrebte Begrenzung der zeitlichen Wirkungen auszuschließen. Er führte aus, dass die im Schadensersatzrecht der einzelnen Mitgliedstaaten festgelegten materiellen und formellen Voraussetzungen (unter Wahrung des Äquivalenz- und Effektivitätsgrundsatzes) den Erfordernissen des Grundsatzes der Rechtssicherheit Rechnung tragen könnten. ${ }^{833}$ Mit diesem Hinweis wälzt der Gerichtshof seine Urteilsfolgenverantwortung auf die Mitgliedstaaten ab; den Schutz des unionsrechtlichen Grundsatzes der Rechtssicherheit gibt er auf diese Weise ohne Not auf. ${ }^{834}$

h) Kohärenz mit den übrigen Aspekten der Begrenzungsrechtsprechung

Dass bei der Bestimmung der Gefahr schwerwiegender Störungen nur die auf den guten Glauben zurückführbaren Auswirkungen berücksichtigt werden können, wurde bereits erwähnt. Sie hat aber auch die übrigen Aspekte der Begrenzungsrechtsprechung in Rechnung zu stellen.

aa) Rückausnahme und Gefahr schwerwiegender Störungen

So dürfen die von einer zeitlichen Begrenzung ausgenommenen Fälle („Rückausnahme für Rechtsbehelfsführer“835) nicht berücksichtigt werden. ${ }^{836}$ Der von einer Regierung geltend gemachte Betrag, der bei einer

833 EuGH, Urteil vom 5.3.1996, verb. Rs. C-46/93 und C-48/93 (Brasserie du pêcheur und Factortame), Rn. $98 \mathrm{f}$.

834 Kritisch auch Rosenkranz, Beschränkung der Rückwirkung, 2015, S. 230 f.

835 Zur Rückausnahme für Rechtsbehelfsführer näher unten bei Fn. 1102 ff.

836 EuGH, Urteil vom 22.1.2015, verb. Rs. C-401/13 und C-432/13 (Balazs), Rn. 52 unter Verweis auf EuGH, Urteil vom 15.12.1995, Rs. C-415/93 (Bosman), Rn. 144 und GA Wathelet, Schlussanträge vom 4.9.2014 in den verb. Rs. C-401/13 und C-432/13 (Balazs), Rn. $98 \mathrm{f}$. Zudem genügte der bloße Verweis der rumänischen Regierung auf ähnliche Klagen nicht; anzugeben gewesen wäre vielmehr die Gesamtzahl der Personen, die sich in einer ähnlichen Lage 
ex tunc-Wirkung vom Mitgliedstaat zu zahlen wäre, darf also die Kosten nicht einbeziehen, die mit denjenigen Rechtsbehelfen verbunden sind, die von Rechtsbehelfsführern eingelegt worden sind, die auch bei einer zeitlichen Begrenzung von der ex tunc-Wirkung profitieren, da sie vom Gerichtshof von der zeitlichen Begrenzung ausgenommen werden.

Diese Kosten sind zwar insoweit Folge der Auslegung des EuGH, als den entsprechenden Rechtsbehelfen erst durch die Auslegung des Gerichtshofs zum Erfolg verholfen wird. Allerdings machen diejenigen, die bereits einen Rechtsbehelf eingelegt haben, vor dem Hintergrund, dass ihre Rechtsbehelfe dem Urteil zeitlich vorausgehen, Unionsrecht nicht nachträglich geltend und profitieren daher von der Rückausnahme. ${ }^{837}$ Die zeitliche Begrenzung soll also eine durch die nachträgliche Geltendmachung des Unionsrechts entstehende Gefahr abwenden, weswegen die Gefahr schwerwiegender Störungen durch die nachträgliche Geltendmachung verursacht werden muss. Zur Folge hat dies, dass die mit den unter die Rückausnahme fallenden Rechtsbehelfen verbundenen Kosten nicht berücksichtigt werden können.

Die demnach erforderliche getrennte Betrachtung von einerseits unter die Rückausnahme fallenden anhängigen und damit für die Ermittlung der Auswirkungen außer Betracht bleibenden und andererseits noch nicht anhängigen und daher berücksichtigungsfähigen Verfahren kann zu einer Verneinung der Gefahr schwerwiegender Störungen führen, während eine Zusammenschau eventuell zu einer Bejahung geführt hätte: Begründen die mit den noch nicht anhängigen Verfahren verbundenen Kosten in Höhe des Betrages X noch keine Gefahr schwerwiegender Störungen, ist nicht ausgeschlossen, dass bei einer Zusammenrechnung mit den mit der Rückausnahme verbundenen Kosten in Höhe des Betrages Y eine entsprechende Gefahr bestünde. Da der Gerichtshof diese Zusammenrechnung nicht zulässt, muss der Mitgliedstaat durch die getrennte Betrachtung im Ergebnis den gesamten Betrag aufbringen.

wie die Kläger der Ausgangsverfahren befanden. Siehe auch EuGH, Urteil vom 10.5.2001, Rs. C-463/98 (Cabletron), Rn. 26 i.V.m. GA Jacobs, Schlussanträge vom 1.2.2001 in der Rs. C-463/98 (Cabletron), Rn. 114.

Vgl. Düsterhaus, YEL 36 (2017), 237 (248). 
bb) Präklusion und Gefahr schwerwiegender Störungen

Die Berührungspunkte des Kriteriums der Gefahr schwerwiegender Störungen mit dem Konnexitätskriterium zeigen sich in der Rechtssache Budișan. Der Gerichtshof bettet dort Ausführungen zum Problemkreis der Konnexität in die Prüfung des Vorliegens einer Gefahr schwerwiegender Störungen ein. Die Rechtssache Budișan reiht sich in eine Vielzahl von Verfahren ein, die verschiedene bei Zulassungen von Kraftfahrzeugen in Rumänien erhobene Abgaben betreffen. Die ihr vorangegangenen Entscheidungen des Gerichtshofs betreffen einerseits die Unvereinbarkeit der erhobenen Abgaben mit Art. 110 AEUV ${ }^{838}$ und andererseits die Pflicht zu deren Erstattung zuzüglich Zinsen ${ }^{839}$. Die vom rumänischen Staat jeweils in bestimmten, aufeinander folgenden Zeiträumen erhobenen Abgaben litten zum Teil an demselben Mangel, den der EuGH bereits in vorangegangenen Entscheidungen festgestellt hatte; zum Teil zog der Gerichtshof weitere Erwägungen zur Begründung der Unionsrechtswidrigkeit der jeweils in Rede stehenden rumänischen Regelungen heran.

Die rumänische Regierung machte in Budișan geltend, die Erstattung der bei der Zulassung von Fahrzeugen unionsrechtswidrig vereinnahmten Abgaben zuzüglich Zinsen belaufe sich auf mehr als 1,4 Milliarden Euro und führe daher zu einer Erhöhung des Haushaltsdefizits des rumänischen Staates um $0,9 \%$. Von Interesse ist im vorliegenden Zusammenhang, mit welcher Begründung der EuGH das Vorliegen einer Gefahr schwerwiegender Störungen als nicht nachgewiesen ansieht.

So weist er in seinem Budișan-Urteil darauf hin, dass er eine Begrenzung der zeitlichen Wirkungen in den früheren Entscheidungen stillschweigend oder ausdrücklich abgelehnt hatte. ${ }^{840}$ In der Rechtssache Nisipeanu etwa sah es der EuGH mangels hinreichender Angaben als nicht erwiesen an, dass die rumänische Wirtschaft durch die Auswirkungen des Urteils einer Gefahr schwerwiegender Störungen ausgesetzt wäre. In der Rechtssache Manea hielt er den von der rumänischen Regierung geltend gemachten Betrag für nicht ausreichend. In der Rechtssache Nicula betraf der Vortrag der rumänischen Regierung andere Fälle als die im Ausgangsverfahren be-

838 EuGH, Urteil vom 7.4.2011, Rs. C-402/09 (Tatu), Rn. 48 ff.; EuGH, Urteil vom 7.7.2011, Rs. C-263/10 (Nisipeanu), Rn. 34 ff.; EuGH, Beschluss vom 3.2.2014, verb. Rs. C-97/13 und C-214/13 (Câmpean und Ciocoiu), Rn. 37 ff.; EuGH, Urteil vom 14.4.2015, Rs. C-76/14 (Manea), Rn. 56 ff.

839 EuGH, Urteil vom 18.4.2013, Rs. C-565/11 (Irimie), Rn. 16 ff.; EuGH, Urteil vom 15.10.2014, Rs. C-331/13 (Nicula), Rn. $40 \mathrm{ff}$.

840 EuGH, Urteil vom 9.6.2016, Rs. C-586/14 (Budișan), Rn. 50. 
troffenen. In den verbundenen Rechtssachen Câmpean und Ciocoiu lehnte der EuGH die Begrenzung wegen Präklusion ab und wies darauf hin, dass die rumänische Regierung nicht geltend machen könne, in gutem Glauben gehandelt zu haben, da sie lediglich eine bereits als unionsrechtswidrig eingestufte Regelung aufrechterhalten habe. ${ }^{841}$

Dieser Hinweis des Gerichtshofs im Budișan-Urteil auf die in den vorangegangenen Entscheidungen unterbliebene zeitliche Begrenzung erinnert an seine Präklusionsrechtsprechung. Dazu passt auch der wenige Randnummern zuvor erfolgte Hinweis darauf, dass eine Beschränkung der zeitlichen Wirkungen nur im erstauslegenden Urteil erfolgen könne. ${ }^{842}$ Eine zeitliche Begrenzung lässt der Gerichtshof in der Rechtssache Budișan dennoch nicht an Präklusion scheitern. Deutlich wird dies daran, dass er auf Ausführungen zur hinter der Präklusion stehenden Zielsetzung verzichtet, die er regelmäßig dann anführt, wenn die Begrenzung in entscheidungserheblicher Weise an Präklusion scheitert. ${ }^{843}$

Fruchtbar macht er aber im Rahmen der Prüfung des Bestehens der Gefahr schwerwiegender Störungen Erwägungen, die im Zusammenhang mit der Präklusion stehen. So weist er darauf hin, dass die Beträge, mit deren Rückzahlung der rumänische Staat in Verzug ist, den Staat im Zeitpunkt des Urteils in der Rechtssache Budişan nicht mehr belasten würden, wenn sich Rumänien unionsrechtskonform verhalten hätte. Sie können daher nicht in die Berechnung einbezogen werden, da sie nicht auf das Budişan-Urteil zurückzuführen sind. ${ }^{844}$ Eine kumulierte Geltendmachung der aus unionsrechtswidrigem Verhalten folgenden Kosten ist daher ausgeschlossen. Damit kann auch keine Globalbetrachtung der sich aus den verschiedenen gescheiterten Versuchen einer unionsrechtskonformen Ausgestaltung der nationalen Rechtslage ergebenden wirtschaftlichen Auswirkungen erfolgen. Dies führt dazu, dass die mehrdeutigen Erklärungen der rumänischen Regierung zu der Frage, ob sich ihre Schätzung der

841 EuGH, Urteil vom 7.7.2011, Rs. C-263/10 (Nisipeanu), Rn. 36; EuGH, Urteil vom 14.4.2015, Rs. C-76/14 (Manea), Rn.57; EuGH, Urteil vom 15.10.2014, Rs. C-331/13 (Nicula), Rn. $41 \mathrm{f} . ;$ EuGH, Beschluss vom 3.2.2014, verb. Rs. C-97/13 und C-214/13 (Câmpean und Ciocoiu), Rn. 37 ff.

842 EuGH, Urteil vom 9.6.2016, Rs. C-586/14 (Budișan), Rn. 47. Siehe zur Präklusionsrechtsprechung des Gerichtshofs näher sogleich bei Fn. $881 \mathrm{ff}$.

843 So etwa in EuGH, Beschluss vom 3.2.2014, verb. Rs. C-97/13 und C-214/13 (Câmpean und Ciocoiu), Rn. 40 und EuGH, Urteil vom 6.3.2007, Rs. C-292/04 (Meilicke u.a.), Rn. 37.

844 EuGH, Urteil vom 9.6.2016, Rs. C-586/14 (Budișan), Rn. 51. 
wirtschaftlichen Auswirkungen auch auf die aufgrund der vorhergehenden Entscheidungen zu erstattenden Beträge bezieht, zu ihren Lasten gehen. ${ }^{845}$

Die unionsrechtswidrigen Steuern, hinsichtlich deren Erstattung eine zeitliche Begrenzung präkludiert ist, können also nicht in die Berechnung der schwerwiegenden wirtschaftlichen Auswirkungen einbezogen werden. Der Nachweis des Bestehens einer Gefahr schwerwiegender Störungen kann daher auch daran scheitern, dass eine Einbeziehung bestimmter Folgen präkludiert ist. ${ }^{846}$

\section{i) Ergebnis}

Ebenso wie der gute Glaube ist das Bestehen einer Gefahr schwerwiegender Störungen nicht mitgliedstaatsbezogen zu bestimmen. Auch diesem Merkmal liegt damit ein unionsweiter Maßstab zugrunde, wohingegen der Blick in der Praxis angesichts der Unterschiedlichkeit der Auswirkungen einer EuGH-Entscheidung häufig auf einen Mitgliedstaat oder eine Einheit in diesem Mitgliedstaat begrenzt ist. Der unionsweite Maßstab verlangt, dass die von der Auslegung des Gerichtshofs nachteilig betroffene Einheit groß genug ist, um eine unionsweite Begrenzung zu rechtfertigen. Sie muss in ihrem Bestand gefährdet sein, wenn keine zeitliche Begrenzung erfolgen sollte. Die Beurteilung des Bestehens einer Gefahr schwerwiegender Störungen muss den übrigen Aspekten der Begrenzungsrechtsprechung Rechnung tragen, kann also nur die auf den guten Glauben zurückzuführenden Auswirkungen berücksichtigen, nicht aber die Kosten, die mit den unter die Rückausnahme fallenden Rechtsbehelfen verbunden sind und ebenso wenig diejenigen Auswirkungen, deren Geltendmachung präkludiert ist.

\section{Fragen der „Beweislast“}

Der Gerichtshof nimmt eine Begrenzung der zeitlichen Wirkungen nur vor, wenn er davon überzeugt ist, dass guter Glaube und eine Gefahr schwerwiegender Störungen bestehen. In aller Regel sind ihm nicht sämtliche Umstände bekannt, die für die Beurteilung des Vorliegens der beiden Kriterien erforderlich sind, wobei ihm die für die Frage des Bestehens

845 EuGH, Urteil vom 9.6.2016, Rs. C-586/14 (Budişan), Rn. 49.

846 Vgl. EuGH, Urteil vom 9.6.2016, Rs. C-586/14 (Budişan), Rn. 50. 
von gutem Glauben relevanten Gesichtspunkte eher zugänglich sind als die für die Frage des Bestehens einer Gefahr schwerwiegender Störungen maßgebenden. Ist er auf Tatsachenvortrag der Betroffenen angewiesen, kommt der Frage entscheidende Bedeutung zu, welche Grundsätze bei nicht nachweisbaren Tatsachenbehauptungen bzw. unzureichendem Vortrag zu den Begrenzungsvoraussetzungen gelten. Daneben gibt es Fälle, in denen der Vortrag der Betroffenen an sich ausreichend ist, der Gerichtshof das Vorliegen der Voraussetzungen aber dennoch verneint. Um diese geht es an dieser Stelle nicht.

\section{a) Feststellungslast}

Nach weit verbreiteter Ansicht ist die Beweislast für das Vorliegen der Voraussetzungen einer Begrenzung der zeitlichen Wirkungen dem „Antragsteller" auferlegt. ${ }^{847}$ Dieser Ansicht ist nicht zu folgen. Zunächst können die Ausführungen des EuGH in der Rechtssache Richardson für eine Stützung dieser These nicht fruchtbar gemacht werden. Der Gerichtshof führte hier zwar aus, dass Tatsachen oft kaum oder gar nicht nachprüfbar seien und dass die Beweislast dem, der sich auf die behaupteten Tatsachen beruft, obliege, sodass insoweit eventuell auftretende Schwierigkeiten in jedem Fall den Antragsteller benachteiligen würden. ${ }^{848}$ Allerdings war mit „Antragsteller" dort derjenige gemeint, der vom Mitgliedstaat Schadensersatz wegen der Verletzung von Unionsrecht begehrte. Aufgrund seiner Beweisbelastung, was die Voraussetzungen seines Begehrens betrifft, konnten seine Schwierigkeiten, das Vorliegen der Voraussetzungen des Schadensersatzanspruchs zu beweisen, vom Mitgliedstaat nicht zu Gunsten einer Begrenzung der zeitlichen Wirkungen ins Feld geführt werden. Scheitert ein Schadensersatzanspruch des „Antragstellers“ an seiner Beweisbelastung, entlastet dies ja vielmehr den Mitgliedstaat, da dieser dann keinen Schadensersatz leisten muss. Dementsprechend reduziert ist damit auch die Gefahr schwerwiegender Störungen für den Mitgliedstaat. Die Aussagen des Gerichtshofs zur Beweisbelastung des Antragstellers betreffen damit

847 GA Stix-Hackl, Schlussanträge vom 5.10.2006 in der Rs. C-292/04 (Meilicke u.a.), Rn. 29 ff.; Schaer, Grenzen rückwirkender Rechtsprechung, 2010, S. 75 ff.; Müller, Begrenzung, 2009, S. 99; Karpenstein, in: Grabitz/Hilf/Nettesheim (Hrsg.), Recht der EU, Art. 267 AEUV, Rn. 114 (Stand: Mai 2013); Lenaerts/Maselis/Gutman, EU Procedural Law, 2014, Rn. 6.34.

848 EuGH, Urteil vom 19.10.1995, Rs. C-137/94 (Richardson), Rn. 36 f. Darauf Bezug nehmend Broberg/Fenger, Vorabentscheidungsverfahren, 2014, S. 402. 
nicht den hier angesprochenen Fall, in dem es um den Nachweis des Vorliegens der Voraussetzungen einer zeitlichen Begrenzung geht.

Da es sich beim Vorabentscheidungsverfahren um ein parteiloses Verfahren handelt ${ }^{849}$, ist diesem eine Darlegungs- und Beweislast im engeren Sinne fremd. Von einer subjektiven Beweislast kann zudem angesichts der auch von Amts wegen ${ }^{850}$ möglichen Prüfung der Tatbestandsvoraussetzungen nicht gesprochen werden. In Rede stehen kann vorliegend also lediglich eine einfache materielle Feststellungslast und damit ein objektives Erfordernis. ${ }^{851}$ Letztlich ist damit derjenige belastet, zu dessen Gunsten sich die Wirkungsbeschränkung primär auswirken würde. ${ }^{852}$ In der Regel ist das der „Antragsteller“. Zwingend ist dies aber nicht.

b) Anforderungen in der Rechtsprechung

Auch wenn keine Beweislast besteht, verlangt der Gerichtshof - mit in den einzelnen Sprachfassungen leicht variierenden Begrifflichkeiten - zum Teil den „Beweis“853 bzw. „Nachweis“ 854 der Tatbestandsvoraussetzungen.

849 EuGH, Urteil vom 27.3.1963, verb. Rs. 28 bis 30/62 (Da Costa en Schaake N.V. u.a.), Slg. 1963, S. 81.

850 Siehe dazu näher oben bei Fn. $310 \mathrm{ff}$.

851 Düsterhaus, EuR 2017, 30 (44 f.); Düsterhaus, YEL 36 (2017), 237 (259).

852 Wusterhausen, Wirkungen, 2016, S. 390 f., Fn. 1262; ähnlich Rosenkranz, Beschränkung der Rückwirkung, 2015, S. 420: reflexhafte Beweisbelastung derjenigen, die ein Interesse an der Beschränkung der zeitlichen Wirkung haben.

853 EuGH, Urteil vom 20.9.2001, Rs. C-184/99 (Grzelczyk), Rn. 54: „nichts vorgetragen, was beweisen könnte“. In der englischen Sprachfassung ist von „has produced no evidence“ die Rede, in der französischen von „n'a [...] invoqué aucun élément de nature à établir“.

854 Vgl. z.B. EuGH, Urteil vom 16.9.2020, Rs. C-339/19 (Romenergo und Aris Capital), Rn. 50, wo der Gerichtshof verlangt, „Nachweise vorzulegen“, was in der englischen Sprachfassung mit „adduce evidence“ und in der französischen mit "produire des éléments tendant à démontrer" wiedergegeben ist. Siehe auch EuGH, Urteil vom 18.1.2007, Rs. C-313/05 (Brzeziński), Rn. 60: „nicht nachgewiesen“/,has not been established“/,ne saurait être considérée comme établie“; EuGH, Urteil vom 22.9.2016, Rs. C-110/15 (Microsoft Mobile Sales International u.a.), Rn.63: „nicht nachgewiesen hat“/,has not demonstrated“/,n'a pas démontré"; EuGH, Urteil vom 29.9.2015, Rs. C-276/14 (Gmina Wrocław), Rn. 46: „nicht nachgewiesen hat“/,has not established“/,n'a pas démontré"; EuGH, Urteil vom 17.9.2014, Rs. C-562/12 (Liivimaa Lihaveis), Rn. 84: „nicht als erwiesen angesehen werden kann“/,has not been established“/,ne saurait être considérée comme établie“. 
Wird „nichts“ oder „nichts Konkretes“ vorgetragen, was den Antrag auf Begrenzung der zeitlichen Wirkungen untermauern könnte, muss er daher erfolglos bleiben. ${ }^{855}$ Auf einen "lakonischen Hinweis“, aus dem sich nicht ein Anhaltspunkt für die Anzahl der betroffenen Personen ergibt und der nicht darlegt, „welchen Störungen und eventuellen wirtschaftlichen Auswirkungen" der betreffende Mitgliedstaat ausgesetzt wäre, kann sich eine Regierung bei ihrem Vortrag daher nicht beschränken. ${ }^{856}$ Das Vorbringen ist vielmehr zu untermauern. ${ }^{857}$ Sieht der Gerichtshof die gemachten Angaben als unzureichend an, bringt er dies häufig bereits zu Beginn seiner Ausführungen zu dieser Frage zum Ausdruck. ${ }^{858}$

Der Gerichtshof hat sich insbesondere in Bezug auf den für den Nachweis des Bestehens einer Gefahr schwerwiegender Störungen erforderlichen Vortrag geäußert. Zurückzuführen ist dies darauf, dass er wie bereits angedeutet hinsichtlich des Ausmaßes der Auswirkungen auf einen Mitgliedstaat oder ein Subsystem nur über deutlich beschränkte Erkenntnismöglichkeiten verfügt. Vor diesem Hintergrund obliegt es, so der EuGH, dem eine zeitliche Begrenzung „beantragenden“ Mitgliedstaat, Zahlen vorzulegen, die die Gefahr schwerwiegender wirtschaftlicher Auswirkungen belegen/nachweisen. ${ }^{859} \mathrm{Um}$ diesen Nachweis zu erbringen, muss die Regierung Angaben machen, die dem Gerichtshof eine Beurteilung des Bestehens einer Gefahr erlauben. ${ }^{860}$ Müssen nationale Gerichte im Anschluss an das Urteil des EuGH noch eine Entscheidung „nach Maßgabe der Umstände des Einzelfalls" treffen, kann ein Hinweis auf eine drohende große Zahl von Klagen von vornherein nicht genügen. ${ }^{861}$ Kann eine Regierung

855 EuGH, Urteil vom 28.2.2018, Rs. C-577/16 (Trinseo Deutschland), Rn. 76 ff.; EuGH, Urteil vom 20.6.2019, Rs. C-682/17 (ExxonMobil Production Deutschland), Rn. 130 f. Siehe auch EuGH, Urteil vom 3.10.2019, Rs. C-274/18 (SchuchGhannadan), Rn. 66. EuGH, Urteil vom 11.11.2020, Rs. C-287/19 (DenizBank), Rn. 109 bemängelt, es seien nur „Argumente allgemeiner Art“ vorgebracht worden.

856 GA Mengozzi, Schlussanträge vom 12.7.2018 in der Rs. C-221/17 (Tjebbes u.a.), Rn. 155.

857 EuGH, Urteil vom 14.3.2019, Rs. C-724/17 (Skanska Industrial Solutions u.a.), Rn. 58.

858 EuGH, Urteil vom 22.9.2016, Rs. C-110/15 (Microsoft Mobile Sales International u.a.), Rn. 63: „nur“; EuGH, Urteil vom 9.4.2014, Rs. C-616/11 (T-Mobile Austria), Rn. 53: „lediglich“.

859 Siehe z.B. EuGH, Urteil vom 20.12.2017, Rs. C-516/16 (Erzeugerorganisation Tiefkühlgemüse), Rn.91; EuGH, Urteil vom 14.4.2015, Rs. C-76/14 (Manea), Rn. 55.

860 EuGH, Urteil vom 18.10.2012, Rs. C-525/11 (Mednis), Rn. 45.

861 EuGH, Urteil vom 17.9.2014, Rs. C-562/12 (Liivimaa Lihaveis), Rn. 79, 82 ff. 
die sich aus der Auslegung ergebenden Auswirkungen nicht beurteilen, geht dies daher zu ihren Lasten. ${ }^{862}$ Ebenso verhält es sich mit Lücken in der Berechnung. ${ }^{863}$ Die Verlässlichkeit der Berechnung im Hinblick auf beträchtliche finanzielle Konsequenzen muss also nachgewiesen werden. ${ }^{864}$ Als Sachferner ohne Kenntnis der Lage im jeweiligen Mitgliedstaat bzw. im jeweiligen Subsystem tritt der Gerichtshof demnach nicht in eine eigene Prüfung ein.

Ist die Nennung der Zahlen zu pauschal und insbesondere eine Aufschlüsselung der Zahlen unterblieben, die zeigt, welcher Teil sich als Folge der im Urteil vorgenommenen Auslegung ergibt, lehnt der Gerichtshof eine Beschränkung ab. ${ }^{865}$ Ebenso verfährt er, wenn die Argumentation der Regierung an der Problematik gewissermaßen vorbeigeht, ihre Argumente also andere Fälle als den im Ausgangsverfahren fraglichen betreffen, so etwa, wenn sie beantragt, die Wirkungen im Falle der Bejahung der Unionsrechtswidrigkeit der nationalen Vorschrift zu beschränken, es im Verfahren aber um die Rückerstattung von Steuern aufgrund einer Vorgängervorschrift geht. ${ }^{866}$

Zum Teil wird geltend gemacht, die hier nachgezeichneten Anforderungen an den Nachweis des Bestehens einer Gefahr schwerwiegender Störungen differierten, je nachdem, wer von ihr betroffen sei. Sei der Gerichtshof bei privaten Betroffenen und beim Aufwerfen der Frage durch ein nationales Gericht nachsichtiger, verhalte er sich gegenüber Mitgliedstaaten strenger. ${ }^{867}$

Zutreffend ist zwar, dass beispielsweise im Defrenne II-Urteil die Unbekanntheit des Gesamtbetrags den Gerichtshof nicht von einer Begrenzung abhielt und dort insbesondere die Interessen von Arbeitgebern betroffen waren. Allerdings muss dann bei Zugrundelegung obiger Einschätzung etwa das EKW und Wein \& Co.-Urteil angesichts seiner Großzügigkeit gegenüber der österreichischen Regierung überraschen. ${ }^{868}$ Auch als ein na-

862 EuGH, Urteil vom 29.9.2015, Rs. C-276/14 (Gmina Wrocław), Rn. 46.

863 EuGH, Urteil vom 13.3.2007, Rs. C-524/04 (Test Claimants in the Thin Cap Group Litigation), Rn. 132: „Dem Gerichtshof liegen daher keine ausreichenden Angaben für eine Prüfung des Antrags des Vereinigten Königreichs vor.“

864 EuGH, Urteil vom 14.9.2006, Rs. C-228/05 (Stradasfalti), Rn. 76.

865 EuGH, Urteil vom 3.6.2010, Rs. C-2/09 (Kalinchev), Rn. 54.

866 EuGH, Urteil vom 15.10.2014, Rs. C-331/13 (Nicula), Rn. 42.

$867 \mathrm{Zu}$ diesem Befund gelangt Kovács, Temporale Wirkung, 2014, S. 168 ff.; siehe auch Lang, IStR 2007, 235 (242).

868 EuGH, Urteil vom 8.4.1976, Rs. 43/75 (Defrenne), Rn. 74/75; EuGH, Urteil vom 9.3.2000, Rs. C-437/97 (EKW und Wein \& Co.), Rn. 59. 
tionales Gericht in der Rechtssache Bidar eine Frage nach der Begrenzung der zeitlichen Wirkungen vorgelegt und die finanziellen Auswirkungen dargestellt hatte, stufte der Gerichtshof das Vorbringen der Regierungen, die sich lediglich auf die Ausführungen des vorlegenden Gerichts bezogen hatten, als ungeeignet ein, da es auch mit dem Ausgangsverfahren nicht vergleichbare Fälle betraf. ${ }^{869}$ Ein unterschiedlicher Maßstab der Anforderungen an den Nachweis des Bestehens einer Gefahr schwerwiegender Störungen lässt sich der Rechtsprechung also letztlich nicht entnehmen. Zwischen Privaten und Mitgliedstaaten zu differenzieren, ließe sich auch nicht rechtfertigen, da Private und Mitgliedstaaten aus der Sicht des Unionsrechts insoweit auf einer Stufe stehen. ${ }^{870}$

Hinsichtlich der Gefahr schwerwiegender Störungen ${ }^{871}$ verlangt der EuGH also substantiierten Vortrag zu ihrem Vorliegen, was auch hinsichtlich des guten Glaubens ${ }^{872}$ gilt. Auch die Voraussetzung des guten Glaubens muss daher "dargetan“ werden. ${ }^{873}$ Lediglich zu behaupten, auf der Grundlage einer nationalen Rechtsnorm seien zahlreiche Rechtsverhältnisse begründet worden, ist für den Nachweis des Bestehens einer bedeutenden objektiven Unsicherheit hinsichtlich der Tragweite der Bestimmungen des Unionsrechts daher nicht ausreichend. ${ }^{874}$

Die in der Rechtsprechung gestellten Anforderungen an den Vortrag der Verfahrensbeteiligten führen dazu, dass auch dann, wenn die Voraussetzungen einer zeitlichen Begrenzung objektiv vorliegen, der Gerichtshof darüber aber nicht hinreichend informiert worden ist, eine Begrenzung ausscheiden muss. ${ }^{875}$

869 EuGH, Urteil vom 15.3.2005, Rs. C-209/03 (Bidar), Rn. 65, 70.

870 Schaer, Grenzen rückwirkender Rechtsprechung, 2010, S. 80 hält einen anderen Maßstab für „in rechtsstaatlicher Hinsicht“ bedenklich; für Gleichbehandlung plädiert auch Rosenkranz, Beschränkung der Rückwirkung, 2015, S. 426.

871 Siehe nur EuGH, Urteil vom 13.12.2001, Rs. C-481/99 (Heininger), Rn. 53.

872 Siehe EuGH, Urteil vom 20.9.2001, Rs. C-184/99 (Grzelczyk), Rn. 54; EuGH, Urteil vom 13.4.2010, Rs. C-73/08 (Bressol u.a.), Rn. 94.

873 Vgl. EuGH, Urteil vom 28.10.2020, Rs. C-321/19 (Bundesrepublik Deutschland (Festlegung der Sätze der Mautgebühren für die Benutzung von Autobahnen)), Rn. 57.

874 EuGH, Urteil vom 3.10.2019, Rs. C-274/18 (Schuch-Ghannadan), Rn. 67.

875 Schaer, Grenzen rückwirkender Rechtsprechung, 2010, S. 78, Fn. 291 unter Verweis auf EuGH, Urteil vom 10.1.2006, Rs. C-402/03 (Skov und Bilka), Rn. 53. 
c) Urteilsfolgenverantwortung des EuGH

Dadurch gerät der Gerichtshof in Konflikt mit seiner Urteilsfolgenverantwortung, die daher stärker betont werden sollte. Er erkennt sie für sich zwar selbst bereits im Grundsatz an ${ }^{876}$, müsste ihr in der Praxis aber noch stärker zur Geltung verhelfen. ${ }^{877}$ Wusterhausen etwa fordert daher insbesondere bei privaten Betroffenen erhöhte Amtsermittlungspflichten und ein verstärktes Gebrauchmachen von den in Art. $24 \mathrm{ff}$. der Satzung des Gerichtshofs vorgesehenen Möglichkeiten. ${ }^{878}$ Das dieser Forderung zugrundeliegende Anliegen ist insoweit zu unterstützen, als der Gerichtshof jedenfalls in einen stärkeren Dialog mit den um eine Begrenzung Ersuchenden treten sollte.

Zur Begründung der Forderung nach einer ausgeprägteren Urteilsfolgenverantwortung wird in der Literatur zum Teil ein umfassendes Verständnis des Art. 19 I UAbs. 1 S. 2 EUV ins Feld geführt. Zur Wahrung des Unionsrechts gehört nach dieser Ansicht „als notwendige Vorbedingung für den Bestand der Unionsrechtsordnung" auch die finanzielle Stabilität der Mitgliedstaaten, wodurch auch die finanzielle Stabilität der EU geschützt werde. ${ }^{879}$ Eines weiten Verständnisses des Art. 19 I UAbs. 1 S. 2 EUV bedarf es für die Begründung einer ausgeprägteren Urteilsfolgenverantwortung allerdings nicht; sie folgt zwanglos aus dem Begriff „Recht“ im Sinne der Vorschrift. Gemeint sind damit sowohl das Primär- als auch das Sekundärrecht, die allgemeinen Rechtsgrundsätze und Unionsgewohnheitsrecht sowie die für die Union bindenden völkerrechtlichen Verträge. ${ }^{880}$ Vor diesem Hintergrund ist vom Gerichtshof auch der Grundsatz der Rechtssicherheit zu „wahren“, in dem die Begrenzung der ex

876 EuGH, Urteil vom 8.4.1976, Rs. 43/75 (Defrenne), Rn. 71/73.

877 Dass die Möglichkeiten des Gerichtshofs hierbei nicht unbegrenzt sind, soll nicht bestritten werden; siehe in diesem Zusammenhang Payandeh, Judikative Rechtserzeugung, 2017, S. 218 f. zu den Grenzen der Möglichkeiten von Gerichten bei der Informationsbeschaffung.

878 Wusterhausen, Wirkungen, 2016, S. $392 \mathrm{ff}$.

879 Wusterhausen, Wirkungen, 2016, S. 325 f., 386.

880 Gaitanides, in: von der Groeben/Schwarze/Hatje (Hrsg.), Unionsrecht, 7. Aufl. 2015, Art. 19 EUV, Rn.12; Wegener, in: Calliess/Ruffert (Hrsg.), EUV/AEUV, 5. Aufl. 2016, Art. 19 EUV, Rn. 10: „alle verbindlichen Normen einer weitverstandenen Unionsrechtsordnung"; Schwarze/Wunderlich, in: Schwarze/Becker/ Hatje/Schoo (Hrsg.), EU-Kommentar, 4. Aufl. 2019, Art. 19 EUV, Rn. 22: „alle Normen der Unionsrechtsordnung, die verbindliche Rechtswirkungen entfalten"; weitergehend Mayer, in: Grabitz/Hilf/Nettesheim (Hrsg.), Recht der EU, Art. 19 EUV, Rn. 23 (Stand: Februar 2019): keine Begrenzung auf das Unions- 
tunc-Wirkung im Sinne der Defrenne-Rechtsprechung letztlich begründet liegt. Über ihn als Anknüpfungspunkt ist der Gerichtshof dazu berufen und verpflichtet, die Folgen seiner Urteile zu bedenken und bei der Beurteilung des Vorliegens der Begrenzungsvoraussetzungen entsprechend $\mathrm{zu}$ handeln.

\section{Präklusion / Konnexität}

Nach der ständigen ${ }^{881}$ Rechtsprechung des Gerichtshofs kann eine Begrenzung der zeitlichen Wirkungen nur in dem Urteil vorgenommen werden, in dem über die erbetene Auslegung entschieden wird. ${ }^{882}$ In einem späteren Urteil muss eine solche Begrenzung also ausscheiden, wenn dieselbe Rechtsfrage bereits Gegenstand einer früheren Auslegungsentscheidung war, ohne dass die zeitlichen Wirkungen dort beschränkt worden wären. ${ }^{883}$ Es bietet sich an, insoweit von einer „Präklusion“ der Begrenzung zu sprechen. Angesichts ihres inneren Zusammenhangs zu der im ersten Verfahren beantworteten Rechtsfrage kann hinsichtlich der sich im nachfolgenden Verfahren stellenden Rechtsfrage von einer „konnexen“ Frage gesprochen werden. ${ }^{884}$

Das Konnexitätskriterium ist nicht unumstritten. Während es manche als konsequente Umsetzung der Bindung an bereits ergangene EuGH-Ent-

recht, „Inbegriff der Gerechtigkeitsidee der abendländischen Verfassungskultur".

881 EuGH, Urteil vom 19.4.2018, Rs. C-65/17 (Oftalma Hospital), Rn. 57.

882 EuGH, Urteil vom 6.3.2007, Rs. C-292/04 (Meilicke u.a.), Rn. 36; EuGH, Urteil vom 17.7.2008, Rs. C-426/07 (Krawczyński), Rn.43; EuGH, Urteil vom 9.6.2016, Rs. C-586/14 (Budișan), Rn. 47; EuGH, Beschluss vom 3.2.2014, verb. Rs. C-97/13 und C-214/13 (Câmpean und Ciocoiu), Rn. 39; EuGH, Urteil vom 27.3.1980, Rs. 61/79 (Denkavit italiana), Rn. 18; EuGH, Urteil vom 23.10.2012, verb. Rs. C-581/10 und C-629/10 (Nelson u.a.), Rn.91; EuGH, Urteil vom 23.4.2020, Rs. C-401/18 (Herst), Rn. 57.

883 Vgl. etwa die aus diesem Grund abgelehnte Begrenzung der zeitlichen Wirkungen in EuGH, Urteil vom 23.4.2020, Rs. C-401/18 (Herst), Rn. 57 f.; EuGH, Urteil vom 19.4.2018, Rs. C-65/17 (Oftalma Hospital), Rn. 57 f.; EuGH, Beschluss vom 3.2.2014, verb. Rs. C-97/13 und C-214/13 (Câmpean und Ciocoiu), Rn. 41 f.; EuGH, Urteil vom 23.10.2012, verb. Rs. C-581/10 und C-629/10 (Nelson u.a.), Rn.92 f.; EuGH, Urteil vom 17.7.2008, Rs. C-426/07 (Krawczyński), Rn. 42 f.; EuGH, Urteil vom 6.3.2007, Rs. C-292/04 (Meilicke u.a.), Rn. 38 ff.

884 Siehe zu den Begrifflichkeiten z.B. Wiedmann, EuZW 2007, 692 (693). 
scheidungen befürworten ${ }^{885}$, finden sich auch Stimmen in der Literatur, die sich für einen Verzicht darauf aussprechen. ${ }^{886}$

\section{a) Begründung und Folgen der Konnexität}

Der Gerichtshof begründet die Präklusion mit dem Erfordernis der Gleichbehandlung der Mitgliedstaaten und der Einzelnen in Ansehung des Unionsrechts, die die Festlegung eines einheitlichen Zeitpunkts erfordere, von dem an die Auslegung wirksam werden solle. ${ }^{887}$ Dahinter steht die Überlegung, dass sich ansonsten aufgrund des Unterbleibens einer Beschränkung im erstauslegenden Urteil das Unionsrecht in einem Mitgliedstaat auch mit Wirkung für die Vergangenheit durchsetzen würde, während dies in einem anderen Mitgliedstaat wegen einer zeitlichen Beschränkung in einem späteren Urteil nicht der Fall wäre. Für denselben Zeitraum in der Vergangenheit fände dann eine Ungleichbehandlung der dem Unionsrecht Unterworfenen statt. ${ }^{88}$

Ist Präklusion eingetreten, kann eine Prüfung der Kriterien des guten Glaubens und der Gefahr schwerwiegender Störungen unterbleiben. Beispielhaft genannt sei hier die Rechtssache Oftalma Hospital. Dort hatte ein Erbringer spezialisierter Dienstleistungen der Augenheilkunde vor dem Gerichtshof geltend gemacht, dass durch die Anwendung des Grundsatzes der Transparenz auf die Vergabe öffentlicher Dienstleistungsaufträge nach Art. 9 der Richtlinie 92/50/EWG ${ }^{889}$ das gesamte italienische Gesundheitssystem destabilisiert würde, da dann die Gültigkeit sämtlicher Vereinba-

885 So Seer/Müller, IWB 2008, 255 (262).

886 Siehe etwa Wiedmann, EuZW 2007, 692 (696); Schaer, Grenzen rückwirkender Rechtsprechung, 2010, S. 97.

887 EuGH, Beschluss vom 3.2.2014, verb. Rs. C-97/13 und C-214/13 (Câmpean und Ciocoiu), Rn. 40; EuGH, Urteil vom 23.10.2012, verb. Rs. C-581/10 und C-629/10 (Nelson u.a.), Rn.90f.; EuGH, Urteil vom 6.3.2007, Rs. C-292/04 (Meilicke u.a.), Rn. 37.

888 Thömmes, IWB 2006, 375 (380) spricht von „Verzerrungen der Rechtslage“ und „Ungerechtigkeit“, sowohl aus Sicht der privaten Betroffenen als auch aus Sicht der Mitgliedstaaten, wenn die Möglichkeit einer nachträglichen Einschränkung des zeitlichen Geltungsanspruchs des ausgelegten Unionsrechts bestünde.

889 Richtlinie 92/50/EWG des Rates vom 18. Juni 1992 über die Koordinierung der Verfahren zur Vergabe öffentlicher Dienstleistungsaufträge, ABl. L 209 vom 24.7.1992, S. 1 in der durch die Richtlinie 97/52/EG des Europäischen Parlaments und des Rates vom 13. Oktober 1997, ABl. L 328 vom 28.11.1997, S. 1 geänderten Fassung. 
rungen zur Gesundheitsversorgung zwischen privaten Einrichtungen mit öffentlichen Stellen in Frage gestellt würde. Auf diese Argumentation zur Gefahr schwerwiegender Störungen geht der Gerichtshof aber gar nicht ein, sondern stellt lediglich fest, dass eine Begrenzung der zeitlichen Wirkungen nur im erstauslegenden Urteil erfolgen könne, der Gerichtshof aber bereits entschieden habe, dass für Aufträge über Dienstleistungen des Anhangs IB der Richtlinie 92/50/EWG, wenn an ihnen ein eindeutiges grenzüberschreitendes Interesse besteht, die Grundregeln und die allgemeinen Grundsätze des AEU-Vertrags, aus denen sich die Transparenzpflicht ergibt, gelten. ${ }^{890}$

\section{b) „Bestimmtes Rechtsproblem“}

Für den Eintritt der Präklusion ist damit entscheidend, ob ein „bestimmtes Rechtsproblem“891 zum ersten Mal vom Gerichtshof entschieden wird oder bereits Gegenstand eines vorangegangenen Verfahrens war. Bei dieser nach einem objektiven Maßstab zu beantwortenden Frage handelt es sich um eine Wertungsfrage. ${ }^{892}$ Entscheidende Bedeutung kommt insoweit dem Abstraktionsniveau der Rechtsfrage zu. ${ }^{893}$ Dabei gilt: Je niedriger das Abstraktionsniveau bestimmt wird, desto seltener tritt Präklusion ein; je höher es festgelegt wird, je mehr Fragen also unter das „bestimmte Rechtsproblem" fallend gefasst werden, desto prekärer ist die Präklusionsfolge. ${ }^{894}$

890 EuGH, Urteil vom 19.4.2018, Rs. C-65/17 (Oftalma Hospital), Rn. 56 ff.: Rn. 58 verweist auf Rn. 36, die ihrerseits auf EuGH, Urteil vom 17.3.2011, Rs. C-95/10 (Strong Segurança), Rn. 35 und die dort angeführte Rechtsprechung verweist.

891 GA Kokott, Schlussanträge vom 30.6.2016 in der Rs. C-443/15 (Parris), Rn. 162.

892 Ebenso Rosenkranz, Beschränkung der Rückwirkung, 2015, S. 140; Düsterhaus, EuR 2017, 30 (45); Düsterhaus, YEL 36 (2017), 237 (260 f.).

893 Lang, IStR 2007, 235 (239 f.); Kokott/Henze, NJW 2006, 177 (181 f.).

894 Im Hinblick auf die Rechtssachen Parris und Maruko sieht Generalanwältin Kokott beispielsweise die eine zeitliche Begrenzung in Parris präkludierende Rechtsfrage in der in Maruko beantworteten Frage der Anwendbarkeit der Richtlinie 2000/78/EG auf Hinterbliebenenrenten aus Systemen der betrieblichen Altersversorgung, vgl. GA Kokott, Schlussanträge vom 30.6.2016 in der Rs. C-443/15 (Parris), Rn. 162 im Hinblick auf EuGH, Urteil vom 1.4.2008, Rs. C-267/06 (Maruko), Rn.77ff. Der Gerichtshof musste angesichts seiner Antwort auf die in der Rechtssache Parris gestellte Vorlagefrage gar nicht auf das Problem der zeitlichen Begrenzung eingehen, vgl. EuGH, Urteil vom 24.11.2016, Rs. C-443/15 (Parris). 
Von Belang ist im vorliegenden Zusammenhang auch die Frage, ob eine einheitliche rechtliche Behandlung zweier Fälle gerechtfertigt erscheint, was zu verneinen sein kann, sollten die den Verfahren zugrundeliegenden Sachverhalte zu unterschiedlich sein. ${ }^{895}$ Ist keine einheitliche rechtliche Behandlung gerechtfertigt, bedeutet dies, dass über ein Rechtsproblem zwar bereits entschieden worden ist, sich dieses auf den nun zu entscheidenden Fall aber nicht übertragen lässt, für den vielmehr ein anderes Rechtsproblem entscheidend ist, über das der EuGH noch nicht entschieden hat. Ganz losgelöst von dem zugrundeliegenden Sachverhalt lässt sich das Problem der Identität der Rechtsfragen also nicht lösen.

Wiederholt der Gerichtshof seine Auslegung lediglich, liegt die Annahme der Identität der Rechtsfragen auf der Hand. ${ }^{896}$ Für das Vorliegen einer identischen Rechtsfrage genügt aber weder, dass dieselbe unionsrechtliche Norm erneut ausgelegt wird noch dass dieselbe mitgliedstaatliche Norm betroffen ist. ${ }^{897}$ Verdeutlichen lässt sich dies an den Rechtssachen Gravier, Barra und Blaizot und dem Begriff der „Berufsausbildung“ in Art. 128 I EWGV (heute Art. 166 I AEUV). Insoweit differenzierte der EuGH zwischen dem Zugang zu einem Fachhochschulstudium und dem Zugang zu einem Universitätsstudium. Da es in der Rechtssache Gravier um den Zugang zu einem Fachhochschulstudium (Kunsthochschule) ging, war eine Beschränkung der zeitlichen Wirkungen in der Rechtssache Barra nicht mehr möglich, da auch dort ein Fachhochschulstudium (Berufsschule) in Rede stand. In der Rechtssache Blaizot konnte eine Beschränkung dagegen noch vorgenommen werden, da es hier um den Zugang zu einem Universitätsstudium ging. ${ }^{898}$ Diesbezüglich macht der EuGH geltend, die Frage, ob Universitätsunterricht als Berufsausbildung angesehen werden könne, werde nun zum ersten Mal gerichtlich entschieden. ${ }^{899}$ Ausgangspunkt der Verfahren war dieselbe nationale Rechtsvorschrift.

895 Hufen/Nörr Stiefenhofer Lutz, Beschränkung von Urteilswirkungen, Rechtsgutachten, Teil 1, 2008, S. 52.

896 EuGH, Beschluss vom 3.2.2014, verb. Rs. C-97/13 und C-214/13 (Câmpean und Ciocoiu), Rn. 41.

897 Siehe auch den Hinweis von GA Stix-Hackl, Schlussanträge vom 5.10.2006 in der Rs. C-292/04 (Meilicke u.a.), Rn. 21.

898 EuGH, Urteil vom 13.2.1985, Rs. 293/83 (Gravier); EuGH, Urteil vom 2.2.1988, Rs. 309/85 (Barra), Rn. 14; EuGH, Urteil vom 2.2.1988, Rs. 24/86 (Blaizot u.a.), Rn. 29.

899 EuGH, Urteil vom 2.2.1988, Rs. 24/86 (Blaizot u.a.), Rn. 29. 
Ob der Gerichtshof in der Rechtssache Meilicke u.a. ${ }^{900}$ dadurch eine Verschärfung der Anforderungen für eine Beschränkung der zeitlichen Wirkungen vorgenommen hat, dass er dort bereits die Ähnlichkeit der Rechtsfragen als ausreichend für das Vorliegen von Konnexität ansah, lässt sich nicht mit letzter Sicherheit sagen. ${ }^{901}$ Als Argument dafür führen Kokott/Henze an, dass das vom EuGH zur Begründung der Präklusion ins Feld geführte Urteil in der Rechtssache Verkooijen ${ }^{902}$ lediglich eine ähnliche Rechtsfrage betroffen habe, während es im Urteil in der Rechtssache Manninen ${ }^{903}$, das vom Gerichtshof in seinem Meilicke-Urteil aber nicht in Bezug genommen wurde, um eine identische Rechtsfrage gegangen sei. ${ }^{904}$

\section{c) Präklusion nur bei Auslegungsvorabentscheidungen?}

Wenn der EuGH ausführt, die in Rede stehende unionsrechtliche Bestimmung sei noch nicht "Gegenstand eines Auslegungsurteils aufgrund eines Vorabentscheidungsersuchen" gewesen, erweckt er den Eindruck, nur die Beantwortung einer Rechtsfrage im Rahmen einer Auslegungsvorabentscheidung sei in der Lage, präkludierend zu wirken. ${ }^{905}$ Dies wäre allerdings nicht überzeugend. So hat der Gerichtshof bereits seine Ausführungen in Vertragsverletzungsverfahren genügen lassen, um guten Glauben auszuschließen. ${ }^{906}$ Für die Frage der präkludierenden Wirkung der Beantwortung einer Rechtsfrage in einem Vertragsverletzungsverfahren kann dann nichts anderes gelten. Der Unterschied zwischen objektiver (Präklusion) und objektivierter Sichtweise (guter Glaube) ist insoweit ohne Belang. Auch spricht für einen Gleichlauf der Wertungen die unabhängig von der Verfahrensart identische Bindungswirkung der vom EuGH vorgenommenen Normauslegung. ${ }^{907}$

900 EuGH, Urteil vom 6.3.2007, Rs. C-292/04 (Meilicke u.a.), Rn. 38.

901 Dafür Kokott/Henze, BB 2007, 913 (917); Hufen/Nörr Stiefenhofer Lutz, Beschränkung von Urteilswirkungen, Rechtsgutachten, Teil 1, 2008, S. 53 f.; ablehnend Rosenkranz, Beschränkung der Rückwirkung, 2015, S. 139.

902 EuGH, Urteil vom 6.6.2000, Rs. C-35/98 (Verkooijen), Rn. 62.

903 EuGH, Urteil vom 7.9.2004, Rs. C-319/02 (Manninen).

904 In diesem Sinne Kokott/Henze, BB 2007, 913 (917).

905 EuGH, Urteil vom 9.3.2000, Rs. C-437/97 (EKW und Wein \& Co.), Rn. 58 (Hervorhebung nur hier).

906 EuGH, Urteil vom 27.5.1981, verb. Rs. 142/80 und 143/80 (Essevi und Salengo), Rn. 33 unter Verweis auf EuGH, Urteil vom 14.12.1962, verb. Rs. 2 und 3/62 (Kommission/Luxemburg und Belgien), Slg. 1962, S. 867.

907 Siehe dazu oben bei Fn. 165 ff. 
d) Verwerfungen?

Die Anwendung des Konnexitätskriteriums wirft schwierige Fragen der Abgrenzung vom Kriterium des guten Glaubens auf. Durch den objektiven Prüfungsmaßstab unterscheidet sich die Prüfung des Konnexitätskriteriums von der Prüfung des guten Glaubens, der wie gesehen ein verobjektivierter Maßstab zugrunde liegt. Dem Verhältnis der beiden Kriterien ist im Folgenden zunächst nachzugehen. Anzusprechen ist im Anschluss daran auch das Problem der Vornahme einer Begrenzung in einem nachfolgenden Urteil zu einer identischen Rechtsfrage. Im Vordergrund stehen wird dabei die Frage der Nachholbarkeit der Begrenzung, wenn diese im ersten Urteil unterblieben ist. Sie stellt sich unabhängig von einer eventuellen Mehrdeutigkeit des Inhalts des ersten Urteils und möchte eine Begrenzung auf den Zeitpunkt dieses ersten Urteils erreichen, was der EuGH aufgrund seiner Präklusionsrechtsprechung allerdings ablehnt.

\section{aa) Verhältnis zum guten Glauben}

In aller Regel weisen Konnexität und guter Glaube in dieselbe Richtung: Ist eine Rechtsfrage im erstauslegenden Urteil entschieden worden, ist die Begrenzung der zeitlichen Wirkungen hinsichtlich der damit konnexen Frage präkludiert. In diesem Fall ist dann aber auch von einer geklärten Rechtslage ${ }^{908}$ auszugehen, die gutem Glauben entgegensteht. ${ }^{909}$

Als zunächst problematisch erscheinen aber Situationen, in denen trotz einer bereits entschiedenen Rechtsfrage nach den allgemeinen Regeln guter Glaube in Betracht käme ${ }^{910}$, sodass grundsätzlich eine Begrenzung auf den Zeitpunkt des zweiten Urteils, wie sie der EuGH in seinem Urteil in der Rechtssache Sürül vorgenommen hat ${ }^{911}$, denkbar wäre. Hier scheinen sich Verwerfungen im Verhältnis von Konnexität und gutem Glauben zu ergeben.

Zur Annäherung an die Problematik sind zwei Konstellationen auseinanderzuhalten. Zunächst ist der Fall in den Blick zu nehmen, in dem die

908 Siehe dazu bereits oben bei Fn. 677 ff.

909 Schaer, Grenzen rückwirkender Rechtsprechung, 2010, S. 81.

910 Schaer, Grenzen rückwirkender Rechtsprechung, 2010, S. 82.

911 EuGH, Urteil vom 4.5.1999, Rs. C-262/96 (Sürül), Tenor Nr. 2 und Rn. 113. Diese Rechtssache wurde oben der Fallgruppe des Anscheins einer Rechtsprechungsänderung zugeordnet, siehe bei Fn. $664 \mathrm{ff}$. 
im erstauslegenden Urteil getroffene Aussage an sich eindeutig für das nachfolgende Auslegungsurteil ist. Tritt nun das Verhalten etwa der Kommission hinzu, das nach allgemeinen Maßstäben guten Glauben „gegen“ das Urteil begründen würde, so ist eine Begrenzung der zeitlichen Wirkungen im nachfolgenden Auslegungsurteil dennoch nicht mehr möglich, da wegen des Vorliegens konnexer Rechtsfragen Präklusion eingetreten ist. $^{912}$ Ist das erstauslegende Urteil in seiner Aussage eindeutig, können die Rechtsunterworfenen Verhalten der Kommission also nicht in ihre Überzeugungsbildung im Hinblick auf die in diesem Urteil getroffene Aussage einbeziehen. Dass guter Glaube wegen Verhaltens der Kommission nicht gegen eine vom Gerichtshof vorgenommene Auslegung ins Feld geführt werden kann ${ }^{913}$, lässt sich mit dem Letztentscheidungsrecht des Gerichtshofs für Auslegungsfragen aber begründen.

Problematischer erscheint der zweite Fall, in dem das erstauslegende Urteil des Gerichtshofs selbst in seiner Aussage aus Sicht der Betroffenen nicht eindeutig ist, wobei unerheblich ist, ob Verhalten eines anderen Unionsorgans hinzutritt, das das Verständnis der im Urteil getroffenen Aussagen in eine bestimmte Richtung lenkt. Gehen die Betroffenen in diesem Fall davon aus, die sich im nachfolgenden Verfahren und die im ersten Urteil stellenden Rechtsfragen seien nicht konnex, was der Gerichtshof aber abweichend beurteilt, muss wegen Präklusion eine Begrenzung der zeitlichen Wirkungen im nachfolgenden Auslegungsurteil ausscheiden. ${ }^{914}$

Diese Konstellation wird daher im Vergleich zur Situation der Mehrdeutigkeit einer unionsrechtlichen Norm ungleich behandelt. Ist eine unionsrechtliche Bestimmung in ihrer Aussage nicht eindeutig, erkennt der EuGH guten Glauben "gegen“ die Norm bei der Erstauslegung ja an. Bei einem „vermeintlich sicher" in einem bestimmten Sinn zu verstehenden Urteil des Gerichtshofs scheidet guter Glaube "gegen das Urteil“ dagegen aus, obwohl Urteile des Gerichtshofs grundsätzlich geeignet sind, guten Glauben zu begründen. Rechtsprechung und Rechtsetzung werden damit ebenso ungleich behandelt wie einschlägige und nicht einschlägige Rechtsprechung.

Ließe man daher, um diese Ungleichbehandlungen zu verhindern, eine Begrenzung der zeitlichen Wirkungen im nachfolgenden Urteil zu, behan-

912 So der bei Wiedmann, EuZW 2007, 692 (695) geschilderte Fall.

913 Dies kritisieren etwa Rosenkranz, Beschränkung der Rückwirkung, 2015, S. 144 f., 202 und Wiedmann, EuLF 2006, I-197 (I-202).

914 Auf diese Konstellation weist auch Rosenkranz, Beschränkung der Rückwirkung, 2015, S. 144 hin. 
delte man Gerichtshof und Kommission im Hinblick auf ihre Funktion als Auslöser von gutem Glauben unterschiedlich. Während wie im Rahmen der ersten Konstellation gesehen guter Glaube wegen Verhaltens der Kommission gegen das Urteil nicht in Betracht kommt, wäre guter Glaube gegen das Urteil aufgrund seiner Mehrdeutigkeit möglich.

Da gegen diese Ungleichbehandlung allerdings keine Bedenken bestehen und den ansonsten mit der Präklusion verbundenen Ungleichbehandlungen begegnet werden könnte, scheint viel für eine Begrenzung der zeitlichen Wirkungen im nachfolgenden Urteil zu sprechen. Ein solches Vorgehen ist dennoch nicht zwingend, sodass es möglich scheint, es auch bei einem mehrdeutigen Urteil bei der Rechtsfolge der Präklusion zu belassen. Zurückzuführen ist dies auf die Stellung des EuGH im institutionellen Gefüge. ${ }^{915}$ Vor dem Hintergrund der Konkretisierungskompetenz des Gerichtshofs hinsichtlich des Inhalts des Unionsrechts ist gegen die Ungleichbehandlung von Rechtsprechung und Rechtsetzung nichts einzuwenden. Danach ist bei einer mehrdeutigen Unionsrechtsnorm abweichender guter Glaube möglich, während dies bei mehrdeutiger Rechtsprechung ausscheidet, da es sich aus der Sicht des Gerichtshofs hierbei nur um scheinbare Mehrdeutigkeit handelt. Es obliegt dem Gerichtshof, selbst zu entscheiden, ob seine Rechtsprechung tatsächlich als mehrdeutig anzusehen ist oder nicht.

Ebenso obliegt ihm, zu entscheiden, ob seine Rechtsprechung einschlägig ist oder nicht. Während in der Rechtssache Sürül im Hinblick auf das vorangegangene Urteil in der Rechtssache Taflan-Met der Anschein einer Rechtsprechungsänderung im Raum stand, der eine zeitliche Begrenzung rechtfertigte, wird bei unvorhergesehen einschlägiger Rechtsprechung kein Eindruck einer Änderung erweckt. Deshalb begegnet auch die unterschiedliche Vorgehensweise bei einschlägiger und nicht einschlägiger Rechtsprechung keinen Bedenken.

Letztlich erscheint das Konnexitätskriterium damit als gerechtfertigte Ausnahme von der sonst üblichen Vorgehensweise bei der Prüfung von gutem Glauben. Dem Konnexitätskriterium kann daher nicht angesichts des objektivierten Gutglaubensmaßstabs eigenständige Bedeutung abgesprochen werden. ${ }^{916} \mathrm{Zu}$ betonen ist vielmehr, dass bei einschlägiger Rechtsprechung kein Unterschied zwischen objektivierter Gutglaubensprüfung und objektiver Konnexitätsprüfung besteht.

915 Zum Verhältnis von Rechtsetzung und Rechtsprechung im Unionsrecht näher bei Fn. $108 \mathrm{ff}$.

916 Dies tut etwa Düsterhaus, YEL 36 (2017), 237 (260). 
bb) Begrenzung der zeitlichen Wirkungen im nachfolgenden Urteil

Soll die der Auslegung im ersten Urteil zugewiesene zeitliche Wirkung in einem späteren Urteil verändert werden, sind zwei Fallgestaltungen in den Blick zu nehmen. In Erwägung gezogen werden könnte zunächst, eine Begrenzung auf den Zeitpunkt des späteren Urteils vorzunehmen. Denkbar erscheint auch, die Begrenzung auf den Zeitpunkt des ersten Urteils nachzuholen.

\section{(1) Keine Begrenzung auf den Zeitpunkt des späteren Urteils}

Zieht man in Betracht, in einem späteren Urteil zu einer identischen Rechtsfrage eine im ersten Urteil unterbliebene Begrenzung vorzunehmen und diese auf den Zeitpunkt des späteren Urteils zu beziehen, setzt dies zunächst voraus, auf das Konnexitätskriterium zu verzichten. Ein solches Vorgehen bedeutete zudem, die zeitliche Geltung des Unionsrechts territorial aufzuspalten, wenn die Auslegung anlässlich aus unterschiedlichen Mitgliedstaaten stammender Vorabentscheidungsersuchen erfolgt. Ist eine zeitliche Begrenzung beispielsweise in einem "finnischen" Verfahren unterblieben und erfolgte sie nun in einem nachfolgenden "deutschen" Verfahren auf den Zeitpunkt des „deutschen“ Urteils, bliebe es in Finnland angesichts der im "finnischen" Verfahren unterbliebenen zeitlichen Begrenzung bei der ex tunc-Wirkung, während es in Deutschland zu deren Beschränkung vom Inkrafttreten der Norm bis zum „deutschen“ Urteil käme. Ein solches Szenario ist zu vermeiden. Zeitliche Wirkungen einer identischen Rechtsfrage sollten nicht aufgespalten werden.

Dem kann auch nicht entgegengehalten werden, dass jede Auslegung einen Bezug zu einem konkreten Sachverhalt aufweist. Jener ist zwar in der Tat in aller Regel in den Verfahren ,unterschiedlich, auch wenn der Problemkreis [...] vergleichbar ist". Für die Frage des Vorliegens einer identischen Rechtsfrage kommt dem zugrundeliegenden Sachverhalt daher wie gesehen gewisse Bedeutung zu. Die vom Gerichtshof vorgenommene Auslegung ist aber nicht derart mitgliedstaatsbezogen, dass sie nur für einen Mitgliedstaat Bedeutung hätte. ${ }^{917}$ Unions- und mitgliedstaatliche

917 So allerdings Steinberg/Bark, EuZW 2007, 245 (246), die aber auch von einer bloBen inter partes-Wirkung der Vorabentscheidungsurteile ausgehen. Zur räumlichen Erstreckung einer Begrenzung der zeitlichen Wirkungen näher unten bei Fn. $1023 \mathrm{ff}$. 
Ebene lassen sich so weit voneinander trennen, dass eine „unionsbezogene" Auslegung möglich ist. ${ }^{918}$ Vor diesem Hintergrund wird vom Gerichtshof auch ein unionsweiter Gutglaubensmaßstab angelegt. Demnach kann eine zeitliche Begrenzung nur unionsweit einheitlich erfolgen oder muss unterbleiben. Eine Begrenzung auf den Zeitpunkt des späteren Urteils ist damit nicht möglich.

\section{(2) Begrenzung auf den Zeitpunkt des ersten Urteils?}

$\mathrm{Zu}$ diskutieren bleibt damit noch die Frage, ob in einem späteren Urteil eine Begrenzung auf den Zeitpunkt des ersten Urteils vorgenommen werden kann. Soll dies erfolgen, sind zwei Konstellationen zu unterscheiden. Angesprochen ist damit der Unterschied zwischen „akzessorischen“ und „konstitutiven“ Beschränkungen. ${ }^{919}$

\section{(a) Akzessorische Beschränkungen}

In der ersten Konstellation hat der Gerichtshof im ersten Urteil eine Beschränkung der zeitlichen Wirkungen vorgenommen. Geht es in einem zweiten Verfahren um eine konnexe Frage, ist eine Beschränkung nicht präkludiert; eine Begrenzung bezogen auf den Tag des ersten Urteils ist vielmehr möglich. ${ }^{920}$ Mit einer solchen akzessorischen Begrenzung soll letztlich verhindert werden, dass die im früheren Urteil angeordnete Begrenzung durch die Wirkungen der in der späteren Entscheidung erfolgten Auslegung ausgehebelt wird. ${ }^{921}$ Die Wirkungen der in der späteren Entscheidung erfolgten Auslegung erstrecken sich daher nicht auf den Zeitraum vor der früheren Entscheidung, sondern nur auf den Zeitraum seit der früheren Entscheidung. Im Grunde genommen handelt es sich hierbei lediglich um eine deklaratorische Übertragung der im ersten Urteil

918 Siehe in diesem Zusammenhang bereits oben Fn. 158.

919 Dieses Begriffspaar verwendet etwa auch Düsterhaus, EuR 2017, 30 (37), Düsterhaus, YEL 36 (2017), 237 (249).

920 So z.B. EuGH, Urteil vom 6.10.1993, Rs. C-109/91 (Ten Oever), Rn. 19f. und EuGH, Urteil vom 14.12.1993, Rs. C-110/91 (Moroni), Rn. 27 ff. in Folge von EuGH, Urteil vom 17.5.1990, Rs. C-262/88 (Barber). Siehe auch Kokott/Henze, NJW 2006, 177 (181); Schaer, Grenzen rückwirkender Rechtsprechung, 2010, S. $82 \mathrm{ff}$.

921 Düsterhaus, EuR 2017, 30 (37). 
vorgenommenen Begrenzung. Da hierin nur deren Bestätigung zu sehen ist, erfolgt im späteren Urteil keine erneute Prüfung der Begrenzungsvoraussetzungen. Eine Begrenzung auf den Tag des nachfolgenden Urteils ist dagegen auch hier ausgeschlossen, da der Gerichtshof die Rechtsfrage in seinem ersten Urteil beantwortet hat. ${ }^{922}$

\section{(b) Konstitutive Beschränkungen}

In der zweiten Konstellation ist im ersten Urteil eine Begrenzung der zeitlichen Wirkungen unterblieben. $\mathrm{Zu}$ überlegen ist dann, ob eine solche im zweiten Urteil auf den Tag des ersten Urteils erfolgen kann, eine Begrenzung der zeitlichen Wirkungen der im ersten Urteil erfolgten Auslegung also sozusagen nachgeholt werden kann. ${ }^{923}$ Da diesem Ansinnen nach derzeitiger Rechtsprechung das Präklusionskriterium entgegensteht, geht es im Folgenden um die Frage, ob eine Nachholung der Beschränkung entgegen der Auffassung des Gerichtshofs möglich sein sollte. Insoweit wird zum Teil vertreten, es gebe keinen Grund prinzipieller Natur, weshalb die Frage der zeitlichen Wirkungen später nicht neu bewertet werden könne. 924

(aa) Ausgangslage

Zuzugeben ist, dass es bei einer Begrenzung auf den Tag des ersten Urteils zu keiner territorialen Aufsplitterung käme. Wurden die zeitlichen Wirkungen in einem „finnischen“ Verfahren nämlich nicht beschränkt und würde die Beschränkung nun im „deutschen“ Verfahren auf den Zeitpunkt des Urteils des „finnischen“ Verfahrens nachgeholt, wirkte sich die Beschränkung auch auf Finnland aus. Es kann also nicht zu einer Situation kommen, in der dem Unionsrecht in Deutschland Unterworfenen etwas versagt wird, was dem Unionsrecht in Finnland Unterworfenen weiterhin möglich wäre. ${ }^{925}$

922 Vgl. auch Ludewig, Zeitliche Beschränkung, 2012, S. 194.

923 Ablehnend Frenz, Handbuch Europarecht, Band 5, 2010, Rn. 3427; Kokott/Henze, NJW 2006, 177 (182); Ludewig, Zeitliche Beschränkung, 2012, S. 195.

924 Hyland, IJEL 2 (1995), 208 (217).

925 Anders wohl Kokott/Henze, NJW 2006, 177 (182); Wiedmann, EuZW 2007, 692 (693). 
Dessen ungeachtet kommt die Begründung für das Merkmal der Konnexität hier zum Tragen, wonach eine Ungleichbehandlung der Unionsbürger vermieden werden soll. Problematisch erscheint insoweit insbesondere, dass es um denselben Zeitraum geht, hinsichtlich dessen eine Ungleichbehandlung bei einer Nachholung der Begrenzung erfolgen würde ${ }^{926}$, den Zeitraum vor dem ersten Urteil.927

Deutlich macht dies folgende Überlegung: Wird über einen vor dem ersten Urteil gelegenen Sachverhalt vor dem zweiten Urteil entschieden, ist die unionsrechtliche Vorschrift angesichts der im ersten Urteil unterbliebenen Begrenzung mit Wirkung ex tunc im Sinne der Auslegung des EuGH anzuwenden. Wird über einen vor dem ersten Urteil gelegenen Sachverhalt dagegen nach dem zweiten Urteil entschieden, könnte sich der Betroffene, wenn er nicht unter eine Rückausnahme für Rechtsbehelfsführer fällt, nicht mehr auf die der Unionsbestimmung gegebene Auslegung berufen, da die Begrenzung im zweiten Urteil ja nun nachgeholt wurde. Ist hinsichtlich der vor dem zweiten Urteil entschiedenen Fälle bereits Rechtskraft eingetreten, können diese nicht mehr an die geänderte zeitliche Wirkung angepasst werden. ${ }^{928}$

Die Beschränkung der zeitlichen Wirkungen nachzuholen bedeutete also, der Auslegung nachträglich die Wirkung für die Vergangenheit zu nehmen. So entfiele etwa eine sich aufgrund des ersten EuGH-Urteils ergebende Steuererstattungspflicht nach dem zweiten Urteil wieder. Einige Steuerpflichtige hätten dann bereits eine Erstattung erhalten; andere Erstattungsanträge, die erst nach dem zweiten Urteil beschieden werden, würden dagegen abgelehnt. ${ }^{929}$

(bb) Vergleichbarkeit mit einer Rechtsprechungsänderung?

Ob eine Nachholung der Begrenzung trotz der soeben geschilderten Einwände möglich ist bzw. sein sollte, müssen weitere Überlegungen zeigen.

Geltend gemacht wird, dass bei einer Nachholbarkeit der zeitlichen Begrenzung das Erfordernis guten Glaubens nicht aufgegeben werde, sondern sich lediglich dessen Bezugspunkt verändere, der in der im Ersturteil

926 Siehe Kokott/Henze, NJW 2006, 177 (182).

927 Vgl. Rosenkranz, Beschränkung der Rückwirkung, 2015, S. 332.

928 Ludewig, Zeitliche Beschränkung, 2012, S. 165 spricht insoweit von einem zeitlichen Flickenteppich.

929 Kokott/Henze, BB 2007, 913 (917). 
fehlerhaft getroffenen Feststellung zu sehen sei, dass die Begrenzungsvoraussetzungen nicht vorlägen. Im Nachhinein würde sich das erste Urteil also als falsche Einschätzung der Kriterien erweisen. ${ }^{930}$

Während nach dieser Vorstellung zunächst also die betroffene Unionsbestimmung Bezugspunkt des guten Glaubens ist, ist es nunmehr die im ersten Urteil getroffene Aussage des EuGH, der Auslegung der Unionsbestimmung komme ex tunc-Wirkung zu. Dem guten Glauben wird damit ein anderer Inhalt zugewiesen. Auf diese Weise wird erreicht, dass auch im Zeitpunkt des zweiten Urteils noch von gutem Glauben als Voraussetzung einer Beschränkung ausgegangen werden kann, sodass sich sogar eine Begrenzung auf den Zeitpunkt des zweiten Urteils begründen ließe.

Bezugspunkt des guten Glaubens muss aber die Norm als solche bleiben, womit von vornherein nur eine Begrenzung auf den Zeitpunkt des ersten Urteils in Betracht kommt. Damit verbleibt lediglich eine Argumentation dahingehend, dass das erstauslegende EuGH-Urteil zwar gutem Glauben ab dem Urteilszeitpunkt entgegenstehe, nicht aber gutem Glauben bis zu seinem Erlass. Trotz der Auslegung des Unionsrechts durch den EuGH muss also geltend gemacht werden, bis zu diesem Urteil sei das Unionsrecht in einem bestimmten Sinn zu verstehen gewesen, sodass bei einer zutreffenden Prüfung des Kriteriums des guten Glaubens eine zeitliche Begrenzung erfolgt wäre, die nun vom Gerichtshof korrigiert werden müsse.

Wenn die Präklusionswirkung, wie von den Befürwortern einer Nachholbarkeit der zeitlichen Begrenzung gefordert, aufgegeben wird, kann die Beurteilung der zeitlichen Wirkungen in der Tat später anders ausfallen, wenn sich die Bewertung der Begrenzungskriterien ändert.

Voraussetzung der damit ermöglichten Nachholbarkeit der Begrenzung ist zunächst, dass der EuGH die Begrenzung im ersten Urteil auch ohne Antrag und damit von Amts wegen hätte vornehmen können. Ansonsten hätte er über diese gar nicht entscheiden dürfen, sodass bereits nicht von einer unzutreffenden Beurteilung der Begrenzungskriterien im ersten Urteil gesprochen werden könnte. Eine Befugnis zur Begrenzung von Amts wegen steht dem Gerichtshof nach hier vertretener Auffassung $\mathrm{zu}^{931}$, weshalb eine Nachholung jedenfalls nicht aus diesem Grund scheitert.

Um die oben aufgezeigte Ungleichbehandlung hinsichtlich des Zeitraums vor dem ersten Urteil zu rechtfertigen, wird ein Vergleich mit rechtskräftig entschiedenen Fällen herangezogen. Bei einer ex tunc wirken-

930 Düsterhaus, EuR 2017, 30 (45 f.); Düsterhaus, YEL 36 (2017), 237 (261).

931 Siehe hierzu näher bei Fn. $310 \mathrm{ff}$. 
den Rechtsprechungsänderung sind in der Tat alle Sachverhalte, die sich bis zu dem die Rechtsprechung ändernden Urteil abspielen und über die noch nicht bestands- oder rechtskräftig entschieden worden ist, nach der neuen Rechtslage zu beurteilen, während die bereits rechtskräftig entschiedenen Fälle unberührt bleiben und der Rechtsprechungsänderung nicht entgegenstehen. Dies sei, so wird vorgebracht, vergleichbar mit der Situation bei einer Nachholung der Begrenzung der ex tunc-Wirkung, von der nur Sachverhalte bis zum ersten Urteil betroffen seien; die bereits rechtskräftig entschiedenen Fälle blieben unberührt und stünden der Nachholung nicht entgegen. ${ }^{932}$

Ob die Nachholung einer Begrenzung und eine Rechtsprechungsänderung tatsächlich vergleichbar sind, liegt allerdings nicht auf der Hand. Hier ist zu unterscheiden.

Eine Rechtsprechungsänderung kommt wie gesehen bei besserer Rechtserkenntnis und einer Änderung der Umstände in Betracht. ${ }^{933}$ Hat der Gerichtshof das Vorliegen von gutem Glauben und der Gefahr schwerwiegender Störungen geprüft und verneint und soll er die Begrenzung nun nachholen, so ist festzustellen, dass sich die Umstände nicht geändert haben. Eine Nachholung der Begrenzung wegen Änderung der Umstände kommt daher nicht in Betracht. Ändert sich die Beurteilung des Vorliegens von gutem Glauben bzw. der Gefahr schwerwiegender Störungen, ist es jedoch nicht ausgeschlossen, von einer besseren Erkenntnis zu sprechen, die der besseren Rechtserkenntnis bei der Auslegung einer Norm jedenfalls nicht unvergleichbar ist.

In dem Fall allerdings, in dem der EuGH eine Begrenzung stillschweigend abgelehnt hat, da das Problem der zeitlichen Wirkungen gar nicht ausdrücklich aufgeworfen wurde, hat er sich über dieses keine Gedanken gemacht. Es könnte also nur unterstellt werden, dass der Gerichtshof die für eine Beschränkung erforderlichen Kriterien geprüft hat. Jedenfalls hinsichtlich der Gefahr schwerwiegender Störungen erscheint dies aber als reine Fiktion, da er deren Bestehen ohne ihm vorgelegte Informationen letztlich nicht beurteilen kann. Auch werden ihm trotz des Erfordernisses ihrer unionsweiten Verbreitung nicht sämtliche für den guten Glauben re-

932 Rosenkranz, Beschränkung der Rückwirkung, 2015, S.333. Die Befugnis zur Änderung der Rechtsprechung trotz der mit ihr verbundenen unterschiedlichen Behandlung abgeschlossener und offener Sachverhalte führt auch Düsterhaus, EuR 2017, 30 (45), Düsterhaus, YEL 36 (2017), 237 (261) zur Begründung dafür an, dass eine Begrenzung mit konstitutiver Wirkung auch bei nachfolgenden Urteilen zugelassen werden sollte.

933 Siehe hierzu bereits bei Fn. 238. 
levanten Aspekte unmittelbar geläufig sein. Von einer besseren Erkenntnis im nachfolgenden Verfahren kann in diesem Fall also nicht gesprochen werden.

Die Verantwortung dafür, dass die Frage der zeitlichen Wirkungen erstmalig im späteren Verfahren aufgeworfen wird, grundsätzlich dem EuGH zuzuweisen, würde seine Urteilsfolgenverantwortung überspannen. Demnach sind insbesondere die Mitgliedstaaten aufgefordert, tätig zu werden. Nicht zuletzt durch ihr Beteiligungsrecht in Verfahren vor dem Gerichtshof etwa nach Art.23 II der Satzung des Gerichtshofs ist ihnen diese Aufgabe zugewiesen.

Einher geht damit eine nicht unerhebliche Belastung der Mitgliedstaaten. Da das Ergebnis, zu dem der Gerichtshof bei seiner Auslegung gelangt, zum Teil nur schwer vorhersehbar ist, ist eine Vorabeinschätzung der Folgen durch die Mitgliedstaaten kaum möglich, wenn eine neue Rechtsfrage in der Rechtsprechung des EuGH geklärt wird. ${ }^{934}$ Aus Gründen der Verfahrensökonomie erscheint es zwar nicht erstrebenswert, die Mitgliedstaaten zu zwingen, rein vorsorglich eine zeitliche Beschränkung zu beantragen, um dem „Damoklesschwert der Präklusion“ ${ }^{435}$ zu entgehen, da ihre Überlegungen zu diesem Zeitpunkt nicht auf das erst noch zu fällende Urteil des EuGH abgestimmt sein können und daher im Hypothetisch-Abstrakten verbleiben müssen. ${ }^{936} \mathrm{Im}$ Grundsatz ist aber darauf hinzuweisen, dass die Belastung der Mitgliedstaaten angesichts des Rechts auf Beteiligung im ersten Verfahren hinnehmbar erscheint. ${ }^{937}$

Möchte der Gerichtshof dem hier geschilderten Problem begegnen, ist in Ausnahmefällen an ein sich an das Hauptsacheverfahren anschließendes Verfahren zu denken, das sich allein mit der Frage der zeitlichen Wirkungen befasst. ${ }^{938}$ Der Vorschlag von Wusterhausen, der Konnexität ein weiteres Kriterium hinzuzufügen und zu untersuchen, ob der Mitgliedstaat es bösgläubig unterlassen hatte, auf die Urteilsfolgen hinzuweisen ${ }^{939}$, ermöglicht dagegen keine rechtssicheren Abgrenzungen.

934 GA Stix-Hackl, Schlussanträge vom 5.10.2006 in der Rs. C-292/04 (Meilicke u.a.), Rn. $25 \mathrm{f}$.

935 Begriff bei Wiedmann, EuZW 2007, 692 (696).

936 Billig, FR 2007, 785 (786); Wiedmann, EuLF 2006, I-197 (I-203). Siehe auch Wiedmann, EuZW 2007, 692 (696), die geltend macht, auf diese Weise werde das Vorabentscheidungsverfahren nicht „entschlackt“.

937 So auch Düsterhaus, YEL 36 (2017), 237 (260).

938 Siehe hierzu bereits bei Fn. 818.

939 Wusterhausen, Wirkungen, 2016, S. $346 \mathrm{ff}$. 
Anders als die Mitgliedstaaten haben Private, von den Parteien des Ausgangsverfahrens einmal abgesehen, kein Beteiligungsrecht an Vorabentscheidungsverfahren. Eine Rechtfertigung des Präklusionskriteriums ihnen gegenüber bereitet daher Schwierigkeiten. Sie setzt die Wahrnehmung größerer Urteilsfolgenverantwortung durch den EuGH voraus, was nicht zuletzt eine gewissenhafte Auseinandersetzung mit ihm auch nur ansatzweise bekannten Anhaltspunkten bedingt, über die er sich gegebenenfalls näher erkundigen muss. Daneben erforderlich ist eine gewissenhafte Wahrnehmung des Beteiligungsrechts der Mitgliedstaaten aus Art. 23 II der Satzung des Gerichtshofs, die zu Gunsten der betroffenen Privaten durch einen unionsrechtlichen Staatshaftungsanspruch wegen drittschützender Wirkung des Beteiligungsrechts abgesichert werden kann.

\section{(cc) Schlussfolgerung}

Die vorstehenden Überlegungen legen für die hier interessierende Frage einer Nachholung der Begrenzung eine Unterscheidung zwischen der erstmaligen Geltendmachung einer Begrenzung der zeitlichen Wirkungen im späteren Verfahren und einer irrigen Einschätzung der Kriterien durch den Gerichtshof im ersten Verfahren nahe.

Danach scheidet eine Nachholung aus, wenn die Begrenzung erstmalig im späteren Verfahren geltend gemacht wird. Hat der Gerichtshof die Schwere der Urteilsfolgen oder die Bedeutung einer Äußerung etwa der Kommission für die Frage des guten Glaubens dagegen im ersten Verfahren falsch eingeschätzt und eine Begrenzung der zeitlichen Wirkungen daher abgelehnt ${ }^{940}$, ist eine Nachholung der Beschränkung nicht grundsätzlich ausgeschlossen. Entscheidend kommt es dann darauf an, ob dem Gerichtshof inhaltlich zutreffende und vollständige Tatsachen vorgetragen wurden, die dieser aber „falsch“ bewertet hat. In diesem Fall liegt die Verantwortung nicht bei den Verfahrensbeteiligten, die ihre Möglichkeiten zur Beteiligung wahrgenommen haben. Eine Nachholung der Beschränkung ist dann möglich.

Gleichzeitig bedeutet dies aber auch, dass eine Korrektur hin zur ex tunc-Wirkung möglich sein muss, wenn das Vorliegen der Begrenzungsvoraussetzungen irrig bejaht wurde. ${ }^{941}$ Dagegen kann dann nicht eingewendet werden, dass jeder Auslegung eine zeitliche Dimension immanent

940 Siehe auch Wusterhausen, Wirkungen, 2016, S. 345, Fn. 1122.

941 Vgl. Müller, Begrenzung, 2009, S. $119 \mathrm{f}$. 
ist, sodass die Entscheidung über die zeitlichen Wirkungen grundsätzlich immer zusammen mit der Entscheidung über die Auslegung getroffen werden müsse. ${ }^{942}$ Dies verlangt der Gerichtshof zwar mit seinem Konnexitätskriterium für die Begrenzung der zeitlichen Wirkungen, was sich sinngemäß auch auf die Aufhebung der Begrenzung übertragen lässt, sodass ein nachträgliches Einschwenken auf die zeitlich unbegrenzte Wirkung grundsätzlich ausgeschlossen ist. Im Falle eines Irrtums des Gerichtshofs ist hiervon aber ausnahmsweise abzuweichen.

Eine Nachholung der Begrenzung kommt nach alledem nur bei einer Fehleinschätzung durch den EuGH in Betracht, wenn ihm vollständige und zutreffende Tatsachen vorgetragen wurden.

e) Zurückweisung weiterer Einwände gegen das Konnexitätskriterium

Abschließend sind bislang noch nicht zur Sprache gekommene Einwände gegen das Konnexitätskriterium in den Blick zu nehmen.

So wird gegen dieses vorgebracht, dass es nicht gestatte, zwei voneinander zu trennende Fragen auseinanderzuhalten: Einerseits müsse geklärt werden, ob es sich bei den im ersten und zweiten Verfahren behandelten Fragen um konnexe Rechtsfragen im Sinne der EuGH-Rechtsprechung handele. Davon abzugrenzen sei die für die Mitgliedstaaten zur Vermeidung der Präklusion entscheidende Frage danach, ob sie die Erforderlichkeit eines Antrags auf Beschränkung der zeitlichen Wirkungen bereits im ersten Verfahren erkennen konnten. Während ersteres aus der Perspektive des nachfolgenden Verfahrens beurteilt werden könne, bedürfe letzteres einer Einschätzung bereits zum Zeitpunkt des ersten Verfahrens. Dahinter steht die Überlegung, dass, wenn beispielsweise die finnische Regierung in einem Verfahren, in dem Unionsrecht vor dem Hintergrund einer finnischen Vorschrift ausgelegt wird, keinen Antrag auf zeitliche Begrenzung stellt, auch die deutsche Regierung im Zeitpunkt des „finnischen“ Verfahrens keine schweren Auswirkungen auf Deutschland erwarten müsse. Die Präklusion des Ersuchens der deutschen Regierung um Begrenzung der zeitlichen Wirkungen in einem späteren „deutschen" Verfahren vor dem Gerichtshof zu einer konnexen Rechtsfrage sei dann nicht gerechtfertigt, da die Erforderlichkeit, ein solches zu stellen, für Deutschland zum Zeitpunkt des „finnischen“ Verfahrens nicht zu erkennen gewesen sei. ${ }^{943}$

942 In diesem Sinne aber Seer/Müller, IWB 2008, 255 (268).

943 Wiedmann, EuZW 2007, 692 (695). 
Eine solche Erwartung Deutschlands wäre aber weder plausibel noch gerechtfertigt. Erwartet die finnische Regierung für Finnland keine schwerwiegenden Auswirkungen, kann die deutsche Regierung daraus für die Situation in Deutschland keine Schlüsse ziehen. Problematisch erscheint vielmehr bereits, im Rahmen des „finnischen“ Verfahrens nur nach Auswirkungen auf Finnland zu fragen, die zu erwartenden Auswirkungen also nach Mitgliedstaaten getrennt zu beurteilen. Ausgelegt wird ja, wenn auch vor dem Hintergrund der finnischen Regelung, eine Vorschrift des Unionsrechts, sodass bereits im ersten Verfahren die Auswirkungen auf sämtliche Mitgliedstaaten in Rechnung zu stellen sind. ${ }^{944}$

Nicht zu überzeugen vermag letztlich auch der Hinweis auf Art. 4 III EUV als gegen das Konnexitätskriterium vorgebrachtes Argument. Dieses nimmt seinen Ausgangspunkt in der Feststellung, dass ein Mitgliedstaat seiner Verpflichtung aus Art. 4 III EUV nachkommt, wenn er nach einer Auslegungsentscheidung des EuGH, der ein Verfahren aus einem anderen Mitgliedstaat zugrunde lag, seine Rechtsordnung im Hinblick auf diese Entscheidung anpasst. ${ }^{945}$ Daher, so wird vorgetragen, sei es unbillig, diesem Mitgliedstaat eine zeitliche Beschränkung in einem seine frühere Regelung betreffenden Verfahren wegen Präklusion zu verwehren, wenn die Begrenzungsvoraussetzungen im Übrigen vorlägen; Art. 267 AEUV diene nicht der Bestrafung der Mitgliedstaaten. ${ }^{946}$ Negative Auswirkungen für die Mitgliedstaaten seien zu vermeiden, wo sie nicht unbedingt erforderlich sind. ${ }^{947}$

Gegen eine Heranziehung von Art. 4 III EUV spricht allerdings, dass der darin aufgestellte Grundsatz der loyalen Zusammenarbeit die Beziehungen der Union zu den Mitgliedstaaten prägt und, von einer Ermessensreduzierung auf Null einmal abgesehen, keine unmittelbaren Rechte für den Ein-

944 Siehe dazu bereits oben bei Fn. 765 ff.

945 Die Bedeutung der Anpassung der nationalen Rechtslage betonen etwa Steinberg/Bark, EuZW 2007, 245 (246).

946 Wiedmann, EuZW 2007, 692 (695); Wiedmann, EuLF 2006, I-197 (I-203). Siehe auch Forsthoff, DStR 2005, 1840 (1842), der die Bedeutung der Aufhebung einer unionsrechtlich bedenklichen Vorschrift vor Urteilsverkündung betont und in diesem Zusammenhang auf die Ausführungen der Kommission in der mündlichen Verhandlung der Rechtssache Meilicke u.a. verweist, in der sie die Reaktion Deutschlands auf das Urteil in der "niederländischen“ Rechtssache Verkooijen (EuGH, Urteil vom 6.6.2000, Rs. C-35/98 (Verkooijen)) hervorhebt.

947 GA Tizzano, Schlussanträge vom 10.11.2005 in der Rs. C-292/04 (Meilicke u.a.), Rn. 42. 
zelnen begründet. ${ }^{948}$ Anderen vom Unionsrecht Betroffenen wäre es daher nicht möglich, unter Berufung auf Art. 4 III EUV Rücksichtnahme ihnen gegenüber einzufordern. Um eine Ungleichbehandlung von Mitgliedstaaten und sonstigen Rechtsunterworfenen zu vermeiden, kann Art. 4 III EUV daher nicht gegen das Konnexitätskriterium in Stellung gebracht werden. ${ }^{949}$

\section{f) Ergebnis}

Das Präklusionskriterium ist nicht aufgrund der mit ihm einhergehenden Ungleichbehandlung zwischen Rechtsetzung und Rechtsprechung und zwischen einschlägiger und nicht einschlägiger Rechtsprechung problematisch. Probleme ergeben sich allerdings im Hinblick auf private Betroffene, denen kein Beteiligungsrecht in Verfahren vor dem Gerichtshof zusteht. Insoweit sind Gerichtshof und Mitgliedstaaten aufgerufen, gemeinsam dafür Sorge zu tragen, dass negative Auswirkungen auf diese vermieden werden.

III. Voraussetzungen einer Fortwirkungsanordnung in den Unwirksamkeitsverfahren

Die vorangehenden Überlegungen haben sich mit den Voraussetzungen einer zeitlichen Begrenzung bei Auslegungsentscheidungen befasst. Im Folgenden sind dagegen die Voraussetzungen einer Fortwirkungsanordnung in den Unwirksamkeitsverfahren in den Blick zu nehmen. Weshalb dies im Rahmen dieser Arbeit erforderlich ist, zeigt das Urteil des Gerichtshofs in der Rechtssache Winner Wetten. Bei dieser handelt es sich selbst zwar um eine Auslegungsvorabentscheidung; hinsichtlich der im zweiten Teil dieser Arbeit zu beleuchtenden Frage einer vorübergehenden Aussetzung der Verdrängungswirkung des unmittelbar anwendbaren Unionsrechts zieht der Gerichtshof aber eine mögliche Analogie zu seiner Rechtsprechung zu Art. 264 II AEUV in Erwägung. Über diese Überlegung des Gerichtshofs kann nur geurteilt werden, wenn klar ist, welche Ge-

948 Siehe nur Calliess/Kahl/Puttler, in: Calliess/Ruffert (Hrsg.), EUV/AEUV, 5. Aufl. 2016, Art. 4 EUV, Rn. 45.

949 Kritisch auch Rosenkranz, Beschränkung der Rückwirkung, 2015, S. 156. 
sichtspunkte er im Rahmen des Art. 264 II AEUV für berücksichtigungsfähig hält.

Auch wenn der EuGH in Verfahren der Nichtigkeitsklage nach Art. 263 AEUV die Art.264 II AEUV zugrundeliegenden Rechtssicherheitserwägungen nicht näher spezifiziert hat, ist seiner Rechtsprechung dennoch zu entnehmen, dass er einen Gleichlauf der Anforderungen bei Nichtigkeitsklage und Ungültigkeitsvorlage (Art. 267 I lit. b Alt. 1 AEUV), auf die er Art. 264 II AEUV entsprechend anwendet, annimmt. Danach kann sowohl bei einer für nichtig erklärten als auch bei einer für ungültig erklärten Handlung der Union die Aufrechterhaltung ihrer Wirkungen durch zwingende Erwägungen der Rechtssicherheit gerechtfertigt sein, die mit allen betroffenen öffentlichen wie privaten Interessen zusammenhängen. ${ }^{950}$ Vor dem Hintergrund, dass der Gerichtshof beide Verfahren als Verfahren zur Überprüfung der Rechtmäßigkeit ansieht, verwundert diese Gleichsetzung nicht, sondern erscheint als Gebot der Kohärenz.

Dadurch, dass der Gerichtshof als einzige Tatbestandsvoraussetzung zwingende Erwägungen der Rechtssicherheit nennt, verbleibt er im sehr Abstrakten. Zurückzuführen ist dies auf Art. 264 II AEUV, der dem Gerichtshof bereits in seinem Wortlaut („falls er dies für notwendig hält") hinsichtlich des „Ob“ einer Fortwirkungsanordnung einen Beurteilungsspielraum zuweist ${ }^{951}$, den dieser auch für sich in Anspruch nimmt. ${ }^{952}$ Auf diese Weise gewährt Art. 264 II AEUV Raum für eine Berücksichtigung der im jeweiligen Fall betroffenen Interessen. ${ }^{953}$ Von einem Tätigwerden lediglich „auf Antrag“ ist in Art. 264 II AEUV nicht die Rede. Selbst wenn also die Verfahrensbeteiligten keinen entsprechenden „Antrag“ gestellt haben, ist der Gerichtshof berechtigt, von der Befugnis des Art. 264 II

950 Vgl. zusammenfassend EuGH, Urteil vom 8.9.2010, Rs. C-409/06 (Winner Wetten), Rn.66; siehe auch EuGH, Urteil vom 9.2.2017, Rs. C-585/15 (Raffinerie Tirlemontoise), Rn. 38 unter Verweis auf EuGH, Urteil vom 8.11.2001, Rs. C-228/99 (Silos), Rn. 36.

951 Auch Dörr, in: Grabitz/Hilf/Nettesheim (Hrsg.), Recht der EU, Art. 264 AEUV, Rn. 13 (Stand: November 2012) verweist auf den Normwortlaut.

952 Vgl. EuGH, Urteil vom 27.2.1985, Rs. 112/83 (Société des produits de maïs), Rn. 18. Seine Ausführungen in dieser Randnummer 18 zitiert der Gerichtshof wörtlich in EuGH, Urteil vom 22.5.1985, Rs. 33/84 (Fragd), Rn. 18.

953 Gleiss/Kleinmann, NJW 1966, 1591 (1592) sprechen von „Maßarbeit“ (Anführungszeichen im Original). 
AEUV Gebrauch zu machen; er entscheidet von Amts wegen. ${ }^{954}$ An die „Vorschläge“ 955 der Verfahrensbeteiligten ist er nicht gebunden.956

Die abstrakte Nennung von Rechtssicherheitserwägungen als Voraussetzung einer Fortwirkungsanordnung zu konkretisieren, würde den Beurteilungsspielraum des Gerichtshofs nur verengen. Hier zeigt sich ein Unterschied zu den Auslegungsvorabentscheidungen, für die der Gerichtshof mit dem guten Glauben und der Gefahr schwerwiegender Störungen die Anforderungen der Rechtssicherheit näher bezeichnet hat, die hinter der Defrenne-Rechtsprechung stehen. ${ }^{957}$ Daher vermag es nicht zu verwundern, dass der Gerichtshof eine Beschränkung der zeitlichen Wirkungen im Rahmen der Unwirksamkeitsverfahren anders als bei den Auslegungsentscheidungen nicht als Ausnahme begreift. ${ }^{958}$ Der Weg von einem Verständnis des „falls“ in Art.264 II AEUV zu einem „wann immer“ ist nämlich nicht weit. ${ }^{959}$ Bei den Unwirksamkeitsentscheidungen verfährt der EuGH also flexibler als bei der Anwendung seiner Defrenne-Rechtsprechung und ist eher willens, eine Beschränkung vorzunehmen. ${ }^{960}$ In seiner neueren Rechtsprechung im Urteil UNIS und Beaudout Père et Fils hat der Gerichtshof nunmehr aber wie gesehen auch hinsichtlich der Begrenzung der zeitlichen Wirkungen der Auslegung größere Flexibilität angedeutet, wenngleich mit ihr noch keine generelle Abkehr von den Kriterien der Defrenne-Rechtsprechung verbunden ist. ${ }^{961}$

Unter den hinter Art. 264 II AEUV stehenden Grundsatz der Rechtssicherheit fasst der Gerichtshof sehr unterschiedliche Aspekte, die zum Teil auch nur noch eine sehr lose Verbindung zu ihm aufzuweisen scheinen.

954 EuGH, Urteil vom 1.4.2008, verb. Rs. C-14/06 und C-295/06 (Parlament und Dänemark/Kommission), Rn. 85 nimmt ebenfalls auf den Wortlaut des Art. 264 II AEUV Bezug. Zur Befugnis des Gerichtshofs zur Prüfung von Amts wegen bei Auslegungsentscheidungen näher oben bei Fn. $310 \mathrm{ff}$.

955 EuGH, Urteil vom 31.3.1992, Rs. C-284/90 (Rat/Parlament), Rn. 36.

956 EuGH, Urteil vom 23.12.2015, Rs. C-595/14 (Parlament/Rat), Rn. 29; EuGH, Urteil vom 30.9.2003, Rs. C-239/01 (Deutschland/Kommission), Rn. 78. In diesem Sinne auch Daig, Nichtigkeits- und Untätigkeitsklagen, 1985, S. 198.

957 Vgl. auch Ludewig, Zeitliche Beschränkung, 2012, S. 250; Düsterhaus, YEL 36 (2017), 237 (247): „overt flexibility“.

958 In diesem Sinne auch Isaac, C.D.E. 1987, 444 (464); Ludewig, Zeitliche Beschränkung, 2012, S. 256. EuGH, Urteil vom 15.1.1986, Rs. 41/84 (Pinna), Rn. 27 („ist ausnahmsweise zu berücksichtigen") ist insoweit als Sonderfall zu werten, als die Ausgangssituation einer Auslegungsvorabentscheidung ähnelte.

959 Vgl. Ludewig, Zeitliche Beschränkung, 2012, S. 256.

960 Vgl. Costa/Peers, Steiner \& Woods EU Law, 14. Aufl. 2020, S. 247.

961 EuGH, Urteil vom 17.12.2015, verb. Rs. C-25/14 und C-26/14 (UNIS und Beaudout Père et Fils). Siehe dazu bereits oben bei Fn. $459 \mathrm{ff}$. 
Der Grundsatz der Rechtssicherheit wird hier also für eine Vielzahl von Fallgestaltungen fruchtbar gemacht, was ein weites Begriffsverständnis erfordert. ${ }^{962}$ Häufig ist auch nicht nur ein einzelner Gesichtspunkt für eine Anwendung des Art. 264 II AEUV ausschlaggebend, sondern ein Bündel an Erwägungen. Eine genaue Zuordnung der bei den Unwirksamkeitsverfahren vom Gerichtshof herangezogenen Aspekte zu bestimmten Fallgruppen ist daher nicht immer möglich; sie wird vom Gerichtshof selbst auch nur in sehr rudimentärer Weise vorgenommen. Die nachfolgende Zuweisung zu einzelnen Kategorien ist daher nicht zwingend; sie hilft aber, die für den Gerichtshof relevanten Gesichtspunkte herauszuarbeiten.

\section{Rechtssicherheitserwägungen im öffentlichen Interesse}

Im Vordergrund der Rechtsprechung stehen Rechtssicherheitserwägungen im öffentlichen Interesse, die eine Aufrechterhaltung von Wirkungen des für unwirksam erklärten Rechtsakts begründen können.

\section{a) Vermeidung einer Regelungslücke}

Häufig soll durch eine derartige Aufrechterhaltung ein Rechtsvakuum vermieden werden, das durch die Nichtig- bzw. Ungültigerklärung des betroffenen Unionsrechtsakts entstünde. Die Aufrechterhaltung erscheint insbesondere dann gerechtfertigt, wenn „lediglich“ formelle Mängel des Rechtsakts geltend gemacht werden und keine inhaltlichen. ${ }^{963}$ In diesem Sinne formuliert der Gerichtshof zusammenfassend, dass die Wirkungen eines Unionsrechtsakts aus Gründen der Rechtssicherheit aufrechterhalten werden können, insbesondere wenn unmittelbare Auswirkungen der Nichtigerklärung schwerwiegende negative Folgen für die Betroffenen hätten und die Rechtmäßigkeit nicht wegen ihres Ziels oder ihres Inhalts in Abrede gestellt werde, sondern wegen Unzuständigkeit des Urhebers oder der Verletzung wesentlicher Formvorschriften. ${ }^{964}$

962 Vgl. Rosenkranz, Beschränkung der Rückwirkung, 2015, S. 259.

963 Siehe z.B. EuGH, Urteil vom 20.9.2017, Rs. C-183/16 P (Tilly-Sabco/Kommission), Rn. $122 \mathrm{ff}$.

964 Siehe z.B. EuGH, Urteil vom 17.3.2016, Rs. C-286/14 (Parlament/Kommission), Rn. 67; EuGH, Urteil vom 26.11.2014, verb. Rs. C-103/12 und C-165/12 (Parlament und Kommission/Rat), Rn. 90. 
Dass mit einer Nichtigkeitsklage nicht zwingend die Beseitigung der Wirkungen des angefochtenen Rechtsakts angestrebt wird, sondern auch die verbindliche Klärung einer Rechtsfrage für die Zukunft im Vordergrund stehen kann, wird deutlich, wenn etwa das Parlament sowohl die Nichtigerklärung als auch die Aufrechterhaltung der Wirkungen der angefochtenen Beschlüsse bis zu ihrer Ersetzung durch neue Rechtsakte beantragt. ${ }^{965}$ Wenn der Rechtsakt ohne den gerügten Formverstoß rechtmäßig erlassen werden kann, da Zielsetzung und Inhalt rechtmäßig sind, erscheint es in der Tat angezeigt, die Wirkungen des Rechtsakts zu Gunsten des mit ihm verfolgten Zwecks aufrechtzuerhalten. ${ }^{966}$ Aber auch bei einem materiell rechtswidrigen Rechtsakt ist eine solche Aufrechterhaltung der Wirkungen zur Vermeidung einer Regelungslücke denkbar, wenn die Herstellung materieller Rechtmäßigkeit nicht ausgeschlossen ist. ${ }^{967}$

Die in Betracht kommenden schützenswerten Ziele sind vielfältig und können hier nicht erschöpfend aufgezählt werden. Zur Veranschaulichung mag daher ein kurzer Überblick genügen. Aufrechterhalten hat der Gerichtshof die Wirkungen eines für unwirksam erklärten Unionsrechtsakts etwa dann, wenn er der Bekämpfung von Terrorismus und schwerer Kriminalität diente, da ansonsten die Aufrechterhaltung der öffentlichen Ordnung erschwert wäre ${ }^{968}$, aber auch dann, wenn ansonsten die Wirksamkeit der Kontrolle psychoaktiver Substanzen und damit der Schutz der öffentlichen Gesundheit gefährdet wäre ${ }^{969}$ oder wenn ansonsten der Ablauf der auf der Grundlage des EU-Tansania-Abkommens durchgeführten Operationen behindert und die Wirksamkeit der strafrechtlichen Verfolgung und Aburteilung von mutmaßlichen Seeräubern beeinträchtigt wäre ${ }^{970}$. In diesem Sinne schützenswert erscheinen auch die Erhaltung und nachhaltige Nutzung der Fischereiressourcen im Rahmen der Gemeinsamen Fischereipolitik, die der angefochtene Rechtsakt gewährleisten sollte, sodass mit einer Nichtigerklärung ohne Fortwirkungsanordnung schwerwiegende negative Folgen für diese Politik und die betroffenen

965 EuGH, Urteil vom 16.4.2015, verb. Rs. C-317/13 und C-679/13 (Parlament/Rat), Rn. 10.

966 Vgl. EuGH, Urteil vom 16.4.2015, verb. Rs. C-317/13 und C-679/13 (Parlament/Rat), Rn. $72 \mathrm{ff}$.

967 Zutreffend Rosenkranz, Beschränkung der Rückwirkung, 2015, S. 268.

968 EuGH, Urteil vom 16.4.2015, Rs. C-540/13 (Parlament/Rat), Rn. 63.

969 EuGH, Urteil vom 16.4.2015, verb. Rs. C-317/13 und C-679/13 (Parlament/Rat), Rn. 73; EuGH, Urteil vom 23.12.2015, Rs. C-595/14 (Parlament/Rat), Rn. 48.

970 EuGH, Urteil vom 14.6.2016, Rs. C-263/14 (Parlament/Rat), Rn. 88. 
Wirtschaftsteilnehmer einhergehen würden. ${ }^{971}$ Vermieden werden sollen durch eine Fortwirkungsanordnung etwa auch schwerwiegende Folgen für die Betroffenen, wenn die für unwirksam erklärten Vorschriften die Preise festgesetzt haben, zu denen eine öffentliche Intervention vorzunehmen ist, und diese Intervention die Stabilität der Märkte gewährleisten und der landwirtschaftlichen Bevölkerung einen angemessenen Lebensstandard sichern sollte. ${ }^{972}$ Anerkannt hat der Gerichtshof ebenfalls, dass ein „vorübergehendes Rechtsvakuum“ zu vermeiden ist, um die Durchführung des mit einer Richtlinie eingerichteten Systems für den Handel mit Treibhausgasemissionszertifikaten nicht zu gefährden. Der Gerichtshof stellt hier in Rechnung, dass jede Unterbrechung des Handels mit Zertifikaten dem Hauptziel der Richtlinie - dem Schutz der Umwelt durch eine Verringerung von Treibhausgasen - zuwiderliefe. ${ }^{973}$

b) Wahrung des institutionellen Gleichgewichts / Verstöße gegen den Gleichheitsgrundsatz

Erklärt er einen Unionsrechtsakt für unwirksam, nimmt der Gerichtshof auch Rücksicht auf die Kompetenzen anderer Unionsorgane. Von Interesse sind in diesem Zusammenhang insbesondere die einige Eigenheiten aufweisenden Entscheidungen des Gerichtshofs in den Rechtssachen Ruckdeschel, Moulins et Huileries de Pont-à-Mousson sowie van Landschoot.

In Ruckdeschel und Moulins et Huileries de Pont-à-Mousson stellte der EuGH bei seiner Überprüfung von Bestimmungen aus dem Agrarsektor fest, dass die Abschaffung der Produktionserstattungen für Quellmehl bzw. für Grobgrieß und Feingrieß aus Mais unter Beibehaltung der Erstattungen für Quellstärke bzw. Maisstärke gegen den Gleichheitsgrundsatz verstößt. Da sich die Rechtswidrigkeit aus dem ergebe, was die Vorschrift nicht vorsehe und nicht aus dem, was sie vorsehe, d.h. aus der Nichterwähnung von Quellmehl bzw. Grobgrieß und Feingrieß aus Mais, könne der Verstoß durch eine Ungültigerklärung nicht beseitigt werden; die Beseitigung der Unvereinbarkeit obliege den zuständigen Organen, denen dafür

971 EuGH, Urteil vom 1.12.2015, verb. Rs. C-124/13 und C-125/13 (Parlament und Kommission/Rat), Rn. 88.

972 EuGH, Urteil vom 7.9.2016, Rs. C-113/14 (Deutschland/Parlament und Rat), Rn. 83.

973 EuGH, Urteil vom 28.4.2016, verb. Rs. C-191/14, C-192/14, C-295/14, C-389/14 und C-391/14 bis C-393/14 (Borealis Polyolefine u.a.), Rn. 106. 
mehrere Möglichkeiten zur Verfügung stünden. Trotz ihrer Rechtswidrigkeit erklärte der Gerichtshof die gleichheitswidrigen Vorschriften daher nicht für ungültig. ${ }^{974}$

Der Verzicht des EuGH auf eine Ungültigerklärung wird in der Literatur zum Teil damit begründet, dass die mit ihr verbundene ex tuncWirkung auch den Begünstigten ihren Vorteil genommen hätte. ${ }^{975}$ Das erscheint allerdings insoweit unzutreffend, als die diskriminierende Regelung eine nichtdiskriminierende Vorgängerregelung ersetzt hatte, sodass eine ex tunc-Wirkung die Vorgängerregelung wieder zur Anwendung hätte bringen können. ${ }^{976}$ In diesem Fall wäre aber der Gestaltungsspielraum des Unionsgesetzgebers beschnitten worden, der sich mit einer Regelung konfrontiert gesehen hätte, die er zuvor geändert hatte. ${ }^{977}$ Der Verzicht auf die Ungültigerklärung erscheint daher im Ergebnis verständlich.

Das Fehlen einer Ungültigerklärung bringt es mit sich, dass hier nicht von einer Beschränkung ihrer zeitlichen Wirkungen gesprochen werden kann. Dennoch wird in der Literatur geltend gemacht, die vom EuGH ausgesprochene Unvereinbarkeit mit dem Gleichheitsgrundsatz verschiebe faktisch die Urteilswirkung in die Zukunft ${ }^{978}$, was im Ergebnis dann doch einer Beschränkung der zeitlichen Wirkungen entspreche. Allerdings zeigt sich bereits an den Ausführungen des EuGH, dass er seiner Unvereinbarkeitserklärung nicht bloß eine in die Zukunft gerichtete Wirkung angedeihen lassen wollte. So führt er aus, dass es mehrere Möglichkeiten der Wiederherstellung der Gleichbehandlung und der Wiedergutmachung des den Betroffenen möglicherweise entstandenen Schadens gebe und der Unionsgesetzgeber insoweit zwischen diesen auswählen müsse. ${ }^{979}$ Indem er auch von der Wiedergutmachung des Schadens spricht, gibt der Gerichtshof zu erkennen, dass er nur das „Wie“ der Abhilfe für die Vergangenheit

974 EuGH, Urteil vom 19.10.1977, verb. Rs. 117/76 und 16/77 (Ruckdeschel u.a.), Rn. 10 ff.; EuGH, Urteil vom 19.10.1977, verb. Rs. 124/76 und 20/77 (Moulins et Huileries de Pont-à-Mousson), Rn. 22 ff.

975 Dauses, Vorabentscheidungsverfahren, 2. Aufl. 1995, S. 150.

976 Darauf weist auch Schima, Vorabentscheidungsverfahren, 2. Aufl. 2004, S. 106, Fn. 566 hin.

977 A.A. Müller, Begrenzung, 2009, S. 59, der meint, die Ungültigerklärung hätte den Handlungsspielraum des Unionsgesetzgebers nicht verengt, da dann insoweit keine Norm mehr in Geltung gewesen wäre.

978 Ludewig, Zeitliche Beschränkung, 2012, S. 260; Isaac, C.D.E. 1987, 444 (453).

979 EuGH, Urteil vom 19.10.1977, verb. Rs. 117/76 und 16/77 (Ruckdeschel u.a.), Rn. 13; EuGH, Urteil vom 19.10.1977, verb. Rs. 124/76 und 20/77 (Moulins et Huileries de Pont-à-Mousson), Rn. 27/29. 
dem Gesetzgeber überlässt. ${ }^{980}$ Über das „Ob“ hat er bereits entschieden; insoweit kommt der Feststellung der Unvereinbarkeit mit dem Gleichheitsgrundsatz also eine ex tunc-Wirkung zu. ${ }^{981}$

Ansonsten wäre auch nicht zu erklären, weshalb dem Verlangen nach Schadensersatz für die Zeit vom 1.8.1974, dem Zeitpunkt der erstmaligen Anwendung der diskriminierenden Verordnung, bis zum 19.10.1977, dem Tag des Urteils in der Rechtssache Ruckdeschel, Erfolg beschieden war. ${ }^{982}$ Der hier geltend gemachte Schaden bezieht sich auf einen vor der Feststellung der Rechtswidrigkeit gelegenen Zeitraum. Würde diese Feststellung nur ex nunc wirken, hätten die zuvor eingetretenen Schäden nicht mit Erfolg geltend gemacht werden können. Im Wege der Schadensersatzgewährung wird damit die Diskriminierung auch mit Wirkung für die Vergangenheit ausgeglichen, noch bevor der Unionsgesetzgeber eine neue diskriminierungsfreie Regelung erlassen hat. ${ }^{983}$

Ein Verstoß gegen den Gleichheitsgrundsatz stand auch in der Rechtssache van Landschoot in Rede. Die diesem Verfahren zugrundeliegende Verordnung sah eine Befreiung von einer Abgabe in diskriminierender Weise nur für bestimmte Wirtschaftsteilnehmer vor, weswegen der EuGH die Verordnung insoweit für ungültig erklärte. In ausdrücklicher entsprechender Anwendung des damaligen Art. 174 II EWGV (heute Art. 264 II AEUV) verfügte der Gerichtshof die weitere Anwendung der für ungültig erklärten Vorschrift und ordnete die Erstreckung der Befreiung von der Abgabe auf die bislang Diskriminierten an. ${ }^{984}$

Eine solche Anordnung mag zwar einem rechtspolitischen Bedürfnis entsprechen. Mit dem Wortlaut des Art. 264 II AEUV ist sie allerdings kaum zu vereinbaren, da von einem „Fortgelten“ im Sinne des Art. 264 II AEUV nur dann gesprochen werden kann, wenn die betreffende Wirkung dem Rechtsakt bereits zuvor zu eigen war. Im Hinblick auf die vom EuGH getroffene Anordnung ist aber festzustellen, dass hier nicht mehr der für ungültig erklärte Rechtsakt fortgelten, sondern ein Rechtsakt mit

980 Seer/Müller, IWB 2008, 255 (259); Kovács, Temporale Wirkung, 2014, S. 207.

981 Schima, Vorabentscheidungsverfahren, 2. Aufl. 2004, S. 106 f.; GA Capotorti, Schlussanträge vom 12.9.1979 in der Rs. 238/78 (Ireks-Arkady/Rat und Kommission), Slg. 1979, S. 2991.

982 EuGH, Urteil vom 4.10.1979, Rs. 238/78 (Ireks-Arkady/Rat und Kommission), Rn. 12.

983 Ebenso Kovács, Temporale Wirkung, 2014, S. 195, 207 f.

984 EuGH, Urteil vom 29.6.1988, Rs. 300/86 (van Landschoot), Rn. 23 f. 
veränderter Bedeutung zur Anwendung kommen soll. ${ }^{985}$ Einer Heranziehung von Art. 264 II AEUV steht auch entgegen, dass die Einbeziehung der diskriminierten Gruppe nicht erst ab Urteilsverkündung, sondern bereits seit Inkrafttreten der diskriminierenden Regelung zu erfolgen hat. Von einer Beschränkung der zeitlichen Wirkungen der Ungültigerklärung kann daher nicht gesprochen werden, da dies ja eine Aufrechterhaltung der diskriminierenden Wirkungen des für ungültig erklärten Rechtsakts bis zur Urteilsverkündung voraussetzen würde. Diese wurden aber gerade nicht aufrechterhalten..$^{986}$

Bedenken, der vom EuGH getroffenen Übergangsregelung ex tunc-Wirkung beizumessen ${ }^{987}$, sodass der EuGH eine Beseitigung der Diskriminierung auch für die Vergangenheit erreicht, bestehen aber insoweit nicht, als die weitere Anwendung der für ungültig erklärten Vorschrift unter Einbeziehung der diskriminierten Gruppe bis zu einer Neuregelung durch den Unionsgesetzgeber nicht gegen das Diskriminierungsverbot verstößt.

An diesem Beispiel zeigt sich, dass der Gerichtshof auch jenseits der von Art. 264 II AEUV vorgesehenen Möglichkeiten Lösungen entwickelt, die aus seiner Sicht zu sachgerechten Ergebnissen führen, wobei er sich nicht daran gehindert sieht, diese auf Art. 264 II AEUV zu stützen. Nicht zuletzt diese Flexibilität könnte als Anknüpfungspunkt für ein weites Verständnis des Art. 264 II AEUV dienen, wenn im zweiten Teil der Arbeit die Bedingungen einer vorübergehenden Aussetzung der Verdrängungswirkung des unmittelbar anwendbaren Unionsrechts diskutiert werden.

\section{c) Vermeidung von Wettbewerbsverzerrungen}

Drohen durch eine Rückabwicklung der Handlungen (z.B. Erhebung oder Zahlung von Währungsausgleichsbeträgen), die auf Grundlage eines für unwirksam erklärten Rechtsakts vorgenommen worden sind, Wettbewerbsverzerrungen, begrenzt der Gerichtshof die Wirkungen der Unwirksamkeitserklärung. ${ }^{988} \mathrm{Ob}$ diese tatsächlich drohen, muss allerdings sorgfäl-

985 Kritisch auch Müller, Begrenzung, 2009, S. 60 f. und Dörr, in: Grabitz/Hilf/Nettesheim (Hrsg.), Recht der EU, Art. 264 AEUV, Rn. 16 (Stand: November 2012).

986 Siehe auch Rosenkranz, Beschränkung der Rückwirkung, 2015, S. 263.

987 Dafür etwa Kovács, Temporale Wirkung, 2014, S. 207 f.

988 EuGH, Urteil vom 15.10.1980, Rs. 4/79 (Providence agricole de la Champagne), Rn. 45; EuGH, Urteil vom 15.10.1980, Rs. 109/79 (Maïseries de Beauce), Rn. 45; EuGH, Urteil vom 15.10.1980, Rs. 145/79 (Roquette Frères), Rn.52; EuGH, Urteil vom 26.4.1994, Rs. C-228/92 (Roquette Frères), Rn. 21 f. 
tig geprüft werden. Dies zeigt nicht zuletzt das Urteil des Gerichtshofs in der Rechtssache Raffinerie Tirlemontoise. Dort stand die Rückforderung zu viel gezahlter Produktionsabgaben für Zucker für die Wirtschaftsjahre 1999/2000 und 2000/2001 zwischen einer Zucker herstellenden Gesellschaft und dem belgischen Staat vor dem Hintergrund in Rede, dass der Gerichtshof die diesen Zahlungen zugrundeliegenden Verordnungen ${ }^{989}$ für ungültig erklärt hatte.

Die von der Kommission für eine Begrenzung der Wirkungen der Ungültigerklärung vorgebrachten Argumente lässt der EuGH sämtlich nicht gelten. Recht lapidar stellt er zunächst fest, dass weder die Schwierigkeit, die Daten für die Wirtschaftsjahre 1999/2000 und 2000/2001 aufzufinden, noch der Umstand, dass es bestimmte in der im Ausgangsverfahren maßgeblichen Zeit existierende Wirtschaftsteilnehmer nicht mehr gibt, als zwingende Erwägungen der Rechtssicherheit angesehen werden können, die eine zeitliche Begrenzung rechtfertigen würden. Zudem werde der Wettbewerb zwischen Unternehmen in den „alten“ und den der EU seit 2004 beigetretenen „neuen“ Mitgliedstaaten nicht verfälscht, da die Erstattung der zu viel gezahlten Abgaben nur das Ziel habe, eine für die Unternehmen in den „alten“ Mitgliedstaaten nachteilige Situation zu beseitigen. ${ }^{990}$

\section{d) Haushaltsplan der EU}

Wird die Handlung, mit der der Präsident des Europäischen Parlaments festgestellt hat, dass der Gesamthaushaltsplan der Union für ein Haushaltsjahr endgültig erlassen sei, für nichtig erklärt, verliert der Haushaltsplan für das betroffene Jahr seine Rechtswirksamkeit. Ist ein erheblicher Teil des Haushaltsjahres bereits abgelaufen, sind aus Gründen der Kontinuität des europäischen öffentlichen Dienstes und der Rechtssicherheit die Wirkungen des Haushaltsplans zu bezeichnen, die als fortgeltend zu betrach-

989 Verordnung (EG) Nr. 2267/2000 der Kommission vom 12. Oktober 2000 zur Festsetzung der Produktionsabgaben sowie des Berechnungskoeffizienten für die Ergänzungsabgabe im Zuckersektor für das Wirtschaftsjahr 1999/2000, ABl. L 259 vom 13.10.2000, S. 29 und Verordnung (EG) Nr. 1993/2001 der Kommission vom 11. Oktober 2001 zur Festsetzung der Produktionsabgaben im Zuckersektor für das Wirtschaftsjahr 2000/01, ABl. L 271 vom 12.10.2001, S. 15 .

990 EuGH, Urteil vom 9.2.2017, Rs. C-585/15 (Raffinerie Tirlemontoise), Rn. 39 f. 
ten sind. ${ }^{991}$ Dies gilt dann erst recht, wenn das gesamte Haushaltsjahr bereits abgelaufen ist. ${ }^{992}$

\section{e) Vermeidung jeglicher Unsicherheit im völkerrechtlichen Verkehr}

Auch die Stellung der EU im Verhältnis zu ihren Partnern auf internationaler Ebene spielt für den Gerichtshof im Rahmen des Art. 264 II AEUV eine Rolle. Art. 264 II AEUV zieht der Gerichtshof etwa dann heran, „wenn die Nichtigerklärung eines Beschlusses, der vom Rat im Rahmen des in Art. 218 AEUV vorgesehenen Verfahrens der Aushandlung und des Abschlusses internationaler Übereinkünfte erlassen wurde, die Teilnahme der Union an der betreffenden internationalen Übereinkunft oder ihre Durchführung in Frage stellen kann, obwohl die Zuständigkeit der Union hierfür nicht in Zweifel steht".993

Mit der Aufrechterhaltung der Wirkungen entsprechender Beschlüsse möchte der Gerichtshof Unsicherheit über die Anwendbarkeit völkerrechtlicher Pflichten in der Unionsrechtsordnung vermeiden.994 Art. 264 II

991 EuGH, Urteil vom 3.7.1986, Rs. 34/86 (Rat/Parlament), Rn. 46, 48.

992 GA Wathelet, Schlussanträge vom 5.6.2018 in der Rs. C-73/17 (Frankreich/Parlament), Rn. $51 \mathrm{ff}$. Der Gerichtshof lehnte dagegen bereits die Nichtigerklärung ab, vgl. EuGH, Urteil vom 2.10.2018, Rs. C-73/17 (Frankreich/Parlament), Rn. 65.

993 Z.B. EuGH, Urteil vom 25.10.2017, Rs. C-389/15 (Kommission/Rat), Rn. 81 zu einem Beschluss über die Ermächtigung zur Aufnahme von Verhandlungen unter Verweis auf EuGH, Urteil vom 22.10.2013, Rs. C-137/12 (Kommission/Rat), Rn. 80 und 81, EuGH, Urteil vom 24.6.2014, Rs. C-658/11 (Parlament/Rat), Rn. 90 und EuGH, Urteil vom 28.4.2015, Rs. C-28/12 (Kommission/Rat), Rn. 61 und 62, die Beschlüsse über die Unterzeichnung internationaler Übereinkünfte betreffen.

994 EuGH, Urteil vom 11.9.2003, Rs. C-211/01 (Kommission/Rat), Rn. 57 betreffend Beschlüsse über den Abschluss von Abkommen: „um jede Rechtsunsicherheit über die Anwendbarkeit der von der Gemeinschaft eingegangenen internationalen Verpflichtungen in der Gemeinschaftsrechtsordnung zu verhindern“. Siehe auch EuGH, Urteil vom 22.10.2013, Rs. C-137/12 (Kommission/Rat), Rn. 80 f. betreffend einen Beschluss über die Unterzeichnung eines Abkommens nach Art. 218 V AEUV: „die Unterzeichnung des Übereinkommens durch die Union vom 21. Dezember 2011 [würde] in Frage gestellt" und die in dieser Rechtssache vorgelegten Schlussanträge, GA Kokott, Schlussanträge vom 27.6.2013 in der Rs. C-137/12 (Kommission/Rat), Rn. 125, wonach durch die Anwendung von Art. 264 II AEUV ,auf internationaler Ebene jeder Zweifel am Mandat der im Namen der Union vertretungsberechtigten Personen zur Unterzeichnung des Übereinkommens vermieden [wird], die Rechtswirkungen einer etwa bereits 
AEUV macht der Gerichtshof daher fruchtbar, um insbesondere die Vertragspartner der Union über die Folgen einer Nichtigerklärung nicht im Unklaren zu lassen. Bei Unklarheiten auf Unionsebene kann mit Hilfe von Art. 264 II AEUV also Rücksicht auf andere Akteure genommen werden.

Wird der Beschluss nach Art. 218 VI AEUV über den Abschluss, d.h. zur Genehmigung einer völkerrechtlichen Übereinkunft vom Gerichtshof für nichtig erklärt, weil etwa für den Beschluss die falsche Rechtsgrundlage gewählt wurde, ist der Beschluss ungültig und damit auch die Zustimmung der Union, an das Abkommen gebunden zu sein. Die völkerrechtliche Bindung bleibt davon aber unberührt. ${ }^{995}$ Es hängt nun vom Verständnis des Verhältnisses von Unions- und Völkerrecht $a b$, ob das Nichtigkeitsurteil die innerunionale Geltung des Völkerrechts unberührt lässt oder nicht. Gilt dieses als Völkerrecht in der Unionsrechtsordnung, bedarf es der Aufrechterhaltung der Wirkungen des Beschlusses für die innerunionale Geltung des Abkommens nicht. Die Anwendung von Art. 264 II AEUV würde die Rechtslage insoweit also nur klarstellen. ${ }^{996}$

Vor dem Hintergrund der Problematik der Unterscheidung von unionsund völkerrechtlicher Bindung der Union an ein Abkommen empfiehlt Generalanwältin Kokott in von ihr vorgelegten Schlussanträgen, ,zur Vermeidung jeglicher Rechtsunsicherheit“, die Aufrechterhaltung der Wirkungen der Teile der angefochtenen Beschlüsse, deren Nichtigerklärung sie vorschlägt, da sonst „im internationalen Verkehr Zweifel an der Tragweite der von der Union und von ihren Mitgliedstaaten jeweils eingegangenen völkerrechtlichen Verpflichtungen aufkommen [könnten]“.997 In eben diese Richtung weisen von ihr vorgelegte Schlussanträge, in denen sie zwar festhält, dass die völkerrechtliche Gültigkeit der Entscheidungen völkerrechtlicher Gremien „sorgsam von der Gültigkeit eines vom Rat im Vorfeld festgelegten Standpunkts der Union zu unterscheiden ist“.

erfolgten Unterzeichnung nicht in Frage gestellt werden [können], und es zu keinen Verzögerungen im Ratifizierungsverfahren [kommt]“. Siehe zudem Schmalenbach, in: Calliess/Ruffert (Hrsg.), EUV/AEUV, 5. Aufl. 2016, Art. 216 AEUV, Rn. 27.

995 Siehe nur Schmalenbach, in: Calliess/Ruffert (Hrsg.), EUV/AEUV, 5. Aufl. 2016, Art. 216 AEUV, Rn. 24.

996 Rosenkranz, Beschränkung der Rückwirkung, 2015, S. 267 sieht eine Anwendung des Art. 264 II AEUV zur bloßen Klarstellung der Rechtslage kritisch.

997 GA Kokott, Schlussanträge vom 31.5.2018 in den verb. Rs. C-626/15 und C-659/16 (Kommission/Rat), Rn. 136f. Der Gerichtshof hat die von der Kommission erhobenen Nichtigkeitsklagen dagegen abgewiesen, EuGH, Urteil vom 20.11.2018, verb. Rs. C-626/15 und C-659/16 (Kommission/Rat), Tenor Nr. 1. 
Dennoch „sollten jegliche Zweifel im Hinblick auf Art und Ausmaß der Bindung der Union an die vom Kooperationsrat erlassenen Rechtsakte von vornherein ausgeräumt werden", was die Generalanwältin zur Anwendung des Art. 264 II AEUV führt. ${ }^{998}$ In seinem zu dieser Rechtssache ergangenen Urteil hält der Gerichtshof die Wirkungen des für nichtig erklärten Beschlusses vor dem Hintergrund aufrecht, dass der im Beschluss vorgesehene Standpunkt bereits vertreten wurde und der Kooperationsrat bereits Rechtsakte erlassen hat. Andernfalls, so der Gerichtshof, entstünde eine Situation, die geeignet wäre, die Arbeit der durch das Partnerschaftsabkommen eingesetzten Gremien zu beeinträchtigen, die Bindung der Union an die im Gremium erlassenen Rechtsakte in Frage zu stellen und damit die ordnungsgemäße Durchführung dieses Abkommens zu behindern. 999

Zur Aufrechterhaltung der Wirkungen einer Handlung sah sich der Gerichtshof auch veranlasst, um schwerwiegende negative Folgen für die Beziehungen der Union zur Schweiz zu vermeiden. Durch den für nichtig erklärten Beschluss der Kommission über die Unterzeichnung des Nachtrags zur Vereinbarung über einen finanziellen Beitrag der Schweizerischen Eidgenossenschaft war die Unterzeichnung des Nachtrags ermöglicht worden, mit der die Kommission im Namen der Union politische Zusagen der Schweiz sowie den Abschluss von Verhandlungen zwischen der Union und der Schweiz billigte. ${ }^{1000}$

Darüber hinaus erfolgt eine Aufrechterhaltung der Wirkungen im Sinne des Art. 264 II AEUV auch zur Vermeidung einer Verletzung völkerrechtlicher Verpflichtungen der Union. So wurden die Wirkungen einer Angemessenheitsentscheidung der Kommission aufrechterhalten, die in engem Zusammenhang mit dem Abkommen über die Verarbeitung von Fluggastdaten mit den USA stand, da die Nichtdurchführung eines Abkommens nicht unter Berufung auf Unionsrecht gerechtfertigt werden kann. ${ }^{1001}$

998 GA Kokott, Schlussanträge vom 31.5.2018 in der Rs. C-244/17 (Kommission/Rat), Rn. $79 \mathrm{ff}$.

$999 \mathrm{EuGH}$, Urteil vom 4.9.2018, Rs. C-244/17 (Kommission/Rat), Rn. 51 f. zu einem Beschluss über einen im Namen der Europäischen Union zu vertretenden Standpunkt nach Art. 218 IX AEUV.

1000 EuGH, Urteil vom 28.7.2016, Rs. C-660/13 (Rat/Kommission), Rn. 52 f.

1001 EuGH, Urteil vom 30.5.2006, verb. Rs. C-317/04 und C-318/04 (Parlament/Rat und Kommission), Rn. 73. 


\section{Rechtssicherheitserwägungen im Interesse Privater}

Neben öffentlichen Interessen schenkt der Gerichtshof im Rahmen der Anwendung des Art. 264 II AEUV auch den Interessen betroffener Wirtschaftsteilnehmer Beachtung, wie sich bereits im Rahmen der Fallgruppe der Vermeidung einer Regelungslücke gezeigt hat. ${ }^{1002}$ Rücksicht nimmt er damit auf diejenigen, die Rechte aus dem Unionsrecht abgeleitet haben. ${ }^{1003}$

Bedeutung erlangt in diesem Zusammenhang die jedem Unionsrechtsakt zukommende Gültigkeitsvermutung. ${ }^{1004}$ Da eine Bestimmung des Unionsrechts so lange gilt, bis sie von der Unionsgerichtsbarkeit aufgehoben wird, wird die Gültigkeitsvermutung erst durch diese gerichtliche Entscheidung zerstört. Bis dahin müssen sich die Betroffenen also keine Gedanken über die Vereinbarkeit der nun für ungültig erklärten Vorschrift mit höherrangigem Unionsrecht gemacht haben. ${ }^{1005}$ Angesichts der allen Wirtschaftsteilnehmern zugutekommenden Gültigkeitsvermutung ist individuelles Vertrauen der Betroffenen nicht erforderlich. Ausnahmsweise kann die Gültigkeitsvermutung durch im Unionsrecht wurzelnde Gründe erschüttert worden sein: Liegt etwa die Rechtswidrigkeit eines Unionsrechtsakts durch ein vorangegangenes Urteil des Gerichtshofs oder durch in einer früheren Rechtssache vorgelegte Schlussanträge auf der Hand,

1002 Siehe oben bei Fn. $971 \mathrm{f}$.

1003 GA Kokott, Schlussanträge vom 30.9.2010 in der Rs. C-236/09 (Association belge des Consommateurs Test-Achats u.a.), Rn.76. Siehe als Beispiele aus der Rechtsprechung EuGH, Urteil vom 30.9.2003, Rs. C-239/01 (Deutschland/Kommission), Rn. 78 und EuGH, Urteil vom 1.4.2008, verb. Rs. C-14/06 und C-295/06 (Parlament und Dänemark/Kommission), Rn. 86. Zu weiteren Beispielen ausführlich Rosenkranz, Beschränkung der Rückwirkung, 2015, S. 253 f. Weiß, EuR 1995, 377 (391f.) dagegen meint, öffentliche Interessen stünden bei der Anwendung des Art. 264 II AEUV eindeutig im Vordergrund.

1004 Darauf weisen Costa/Peers, Steiner \& Woods EU Law, 14. Aufl. 2020, S. 247 f. zu Recht hin. Siehe zu dieser Vermutung bereits oben bei Fn. $601 \mathrm{ff}$.

1005 Ebenso Rosenkranz, Beschränkung der Rückwirkung, 2015, S. 248 f. Höpfner, Systemkonforme Auslegung, 2008, S. 222 f. ist dagegen der Auffassung, dass es eine Vermutung der Rechtmäßigkeit von Sekundärrecht nicht geben könne. Zur Begründung führt er die Vielzahl von gegen Unionsrechtsakte gerichteten Verfahren vor dem EuGH sowie die Existenz von Nichtigkeitsklage und Ungültigkeitsvorabentscheidung an, in denen der EuGH unionsrechtliche Normen verwerfen könne und die das Misstrauen der Mitgliedstaaten gegenüber dem Unionsgesetzgeber zeigten. Da hier aber weniger eine Vermutung der Rechtmäßigkeit als eine Vermutung der Gültigkeit eines Unionsrechtsakts in Rede steht, geht die Kritik letztlich fehl. 
kann dieser Rechtsakt von den Betroffenen letztlich nicht mehr als gültig angesehen werden. ${ }^{1006}$

Vor dem Hintergrund der Bedeutung der eingeräumten Rechtspositionen kommt ein Gebrauchmachen von Art. 264 II AEUV grundsätzlich auch bei einer geringen Anzahl betroffener Rechtsverhältnisse in Betracht. ${ }^{1007}$ Die Ausführungen des Gerichtshofs in den verbundenen Rechtssachen Borealis Polyolefine u.a. scheinen insoweit allerdings in eine andere Richtung zu weisen. Er spricht dort davon, dass die Aufhebung des sektorübergreifenden Korrekturfaktors im Emissionshandelsrecht alle vor Urteilsverkündung erfolgten endgültigen Zertifikatszuteilungen in Frage stellen könne, was die Gefahr schwerwiegender Auswirkungen auf eine Vielzahl gutgläubig begründeter Rechtsverhältnisse hervorrufe. Diese zwingenden Erwägungen der Rechtssicherheit könnten eine zeitliche Begrenzung der Wirkungen der Ungültigkeitsfeststellung rechtfertigen. ${ }^{1008}$ Hier klingen unverkennbar die bei den Auslegungsentscheidungen zugrunde gelegten Kriterien an. Dies geht wohl allerdings auf die entsprechenden Ausführungen von Generalanwältin Kokott in ihren Schlussanträgen zurück, die zudem - anders als sodann der EuGH - zur Begrenzung der zeitlichen Wirkungen im Rahmen von Auslegungsentscheidungen ergangene Urteile zitiert. ${ }^{1009}$ Dass der Gerichtshof die dort entwickelten Kriterien auf die Unwirksamkeitsentscheidungen übertragen möchte, liegt daher nicht nahe. Sind die strengeren Kriterien der Defrenne-Rechtsprechung als Ausprägung des Rechtssicherheitsgrundsatzes auch im Rahmen einer Ungültigkeitsvorabentscheidung erfüllt, spricht allerdings nichts dagegen, wenn der EuGH sie auch dort anspricht.

1006 Näher Rosenkranz, Beschränkung der Rückwirkung, 2015, S. $251 \mathrm{f}$. Siehe in diesem Zusammenhang EuGH, Urteil vom 9.8.1994, verb. Rs. C-363/93 und C-407/93 bis C-411/93 (Lancry u.a.), Rn. 42 ff.; siehe auch EuGH, Urteil vom 9.11.2010, verb. Rs. C-92/09 und C-93/09 (Volker und Markus Schecke und Eifert), Rn. 94, wo der Gerichtshof auf eine große Zahl von Veröffentlichungen verweist, „die in den Mitgliedstaaten auf der Grundlage von Rechtsvorschriften erfolgt sind, die als gültig angesehen wurden".

1007 Siehe z.B. EuGH, Urteil vom 12.5.1998, Rs. C-106/96 (Vereinigtes Königreich/Kommission), Rn. 40 i.V.m. Rn. 14: 86 Vorhaben zur Bekämpfung der sozialen Ausgrenzung.

1008 EuGH, Urteil vom 28.4.2016, verb. Rs. C-191/14, C-192/14, C-295/14, C-389/14 und C-391/14 bis C-393/14 (Borealis Polyolefine u.a.), Rn. 105.

1009 GA Kokott, Schlussanträge vom 12.11.2015 in den verb. Rs. C-191/14 und C-192/14, C-295/14 sowie C-389/14, C-391/14, C-392/14 und C-393/14 (Borealis Polyolefine u.a.), Rn. 216 mit Fn. 73. 


\section{Präklusion / Nachholbarkeit}

Während nach der Rechtsprechung des Gerichtshofs zur Auslegungsvorabentscheidung eine Begrenzung der zeitlichen Wirkungen der ausgelegten Norm nur im erstauslegenden Urteil vorgenommen werden kann ${ }^{1010}$, hat er dies für die Unwirksamkeitsverfahren bislang nicht statuiert. ${ }^{1011}$

Geht man der Frage nach dem Bestehen einer Präklusionswirkung im Rahmen der Unwirksamkeitsverfahren nach, ist danach zu differenzieren, ob es um eine Nachholung der Aufrechterhaltung der Wirkungen hinsichtlich des für unwirksam erklärten Rechtsaktes in einem späteren Verfahren geht oder ob die (erstmalige) Befassung mit einem anderen Unionsrechtsakt in Rede steht, der aber an denselben Mängeln leidet wie ein bereits für unwirksam erklärter Rechtsakt.

Hinsichtlich der erstgenannten Fallgestaltung ist festzustellen, dass die Möglichkeit zur Nachholung der Aufrechterhaltung der Wirkungen in einem späteren Verfahren nicht besteht. ${ }^{1012}$ Die gegenteilige Ansicht wurde zwar im Verfahren in der Rechtssache International Chemical Corporation von einigen Verfahrensbeteiligten tatsächlich vorgetragen. ${ }^{1013}$ Folgte man ihr, wäre dies allerdings sowohl der einheitlichen Anwendung des Unionsrechts als auch der Rechtssicherheit abträglich. ${ }^{1014}$ Gegen eine Nachholbarkeit spricht zudem, dass der Gerichtshof die Möglichkeit der mitgliedstaatlichen Gerichte zu einer erneuten Vorlage im Anschluss an eine Ungültigkeitsfeststellung auf Nachfragen begrenzt hat, die sich nicht mit der Ungültigerklärung an sich, sondern mit deren Gründen, Umfang und Folgen befassen. ${ }^{1015}$ Hinzu kommt, dass es im Fall der Nichtigerklärung eines Rechtsakts angesichts seiner Entfernung aus der Unionsrechts-

1010 Dazu oben bei Fn. $881 \mathrm{ff}$.

1011 Costa/Peers, Steiner \& Woods EU Law, 14. Aufl. 2020, S. 248.

1012 Für diese Möglichkeit scheinen sich Costa/Peers, Steiner \& Woods EU Law, 14. Aufl. 2020, S. 248 hinsichtlich der Ungültigerklärung auszusprechen. Sie betonen, dass der Gerichtshof insoweit bislang nicht darauf bestanden habe, dass die zeitliche Begrenzung in dem Verfahren, „in which the ruling itself is given“, erfolgen müsse. Wie hier dagegen Rosenkranz, Beschränkung der Rückwirkung, 2015, S. 348 f.

1013 Vgl. die Auffassung der Kommission, des Rates und der italienischen Regierung, wiedergegeben bei GA Reischl, Schlussanträge vom 21.1.1981 in der Rs. 66/80 (International Chemical Corporation), Slg. 1981, S. 1236.

1014 Vgl. Ludewig, Zeitliche Beschränkung, 2012, S. 257 f.

1015 EuGH, Urteil vom 13.5.1981, Rs. 66/80 (International Chemical Corporation), Rn. 14. Zu dieser Einschätzung gelangt auch Pietrek, Vorabentscheidungen, 1989, S. 232. 
ordnung bereits an einem tauglichen Verfahrensgegenstand fehlen würde. ${ }^{1016} \mathrm{Im}$ Fall der Ungültigerklärung ist der Rechtsakt dagegen zwar noch rechtlich existent; er durfte aber nicht mehr angewandt werden. Von der insoweit geklärten Rechtslage nachträglich abzuweichen, ließe sich nicht überzeugend begründen; an ihr ist daher festzuhalten. ${ }^{1017}$

Sodann ist die in einem späteren Verfahren erfolgende Unwirksamkeitserklärung eines anderen als des im ersten Verfahren verfahrensgegenständlichen, aber an denselben Mängeln leidenden Rechtsakts zu beurteilen. Dabei ist zu bedenken, dass die Unwirksamkeitserklärung rechtsaktsbezogen erfolgt. Auch wenn der Gerichtshof die zur Unwirksamkeit des „ersten" Rechtsakts führende Auslegung der höherrangigen Norm des Unionsrechts in einem nachfolgenden Verfahren erneut anwendet, wäre die Aufrechterhaltung der Wirkungen des im zweiten Verfahren für unwirksam erklärten Rechtsakts also grundsätzlich weiterhin möglich. Es handelt sich bei ihm ja um einen eigenständigen Verfahrensgegenstand.

Die Ausführungen des Gerichtshofs in der Rechtssache Zhejiang Aokang Shoes/Rat erinnern allerdings an das bei Auslegungsentscheidungen zu prüfende Konnexitätsmerkmal, weshalb die Frage im Raum steht, ob dieses auch bei den Unwirksamkeitsverfahren Geltung beansprucht. Rosenkranz wirft vor diesem Hintergrund zu Recht die Frage nach einer Neuausrichtung der Rechtsprechung im Rahmen der Unwirksamkeitsverfahren auf. ${ }^{1018}$

Ins Auge fällt zunächst die vom Gerichtshof in dem erwähnten Urteil getroffene Unterscheidung zwischen der Nichtigerklärung der verfahrensgegenständlichen Verordnung, soweit sie die Rechtsmittelführerin betrifft, und der Auslegung der Grundverordnung, die der Gerichtshof bereits in einer früheren Entscheidung ${ }^{1019}$ vorgenommen hatte. ${ }^{1020}$ Die Wirkungen der Auslegung der Grundverordnung hatte der Gerichtshof nicht beschränkt. Auf diese Auslegung waren aber die wirtschaftlichen Auswirkungen zurückzuführen, auf die sich die Kommission im Rahmen ihrer

1016 Siehe auch Rosenkranz, Beschränkung der Rückwirkung, 2015, S. 22, der auf die Gestaltungswirkung des Nichtigkeitsurteils verweist.

1017 Vgl. auch Rosenkranz, Beschränkung der Rückwirkung, 2015, S. 24 und S. $348 \mathrm{f}$., der ein überwiegendes Interesse an der Endgültigkeit der geklärten Rechtslage annimmt.

1018 Rosenkranz, Beschränkung der Rückwirkung, 2015, S. 250 f. und S. 290.

1019 EuGH, Urteil vom 2.2.2012, Rs. C-249/10 P (Brosmann Footwear (HK) u.a./ Rat).

1020 EuGH, Urteil vom 15.11.2012, Rs. C-247/10 P (Zhejiang Aokang Shoes/Rat), Rn. 39. 
Geltendmachung von Art. 264 II AEUV in Zhejiang Aokang Shoes/Rat stützte. Angesichts der Begrenzung der Nichtigerklärung der in Rede stehenden Verordnung auf die Rechtsmittelführerin ergaben sie sich dagegen nicht aus der Nichtigerklärung. Da er die Wirkungen der Auslegung der Grundverordnung nicht beschränkt hatte, schloss der Gerichtshof eine Anwendung des Art. 264 II AEUV auf die für nichtig erklärte Verordnung aus. ${ }^{1021}$

Auf diese Passage nimmt der Gerichtshof selbst in einem späteren Urteil mit den Worten Bezug, er habe entschieden, dass die Auswirkungen der Auslegung der Grundverordnung zeitlich nicht zu beschränken seien (,not appropriate to limit the temporal effects of the interpretation of Regulation [...]“/„qu'il n'y avait pas lieu de limiter dans le temps les effets

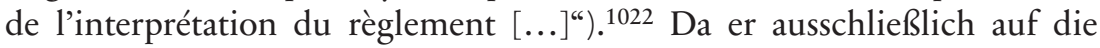
Auslegung Bezug nimmt und seine Aussage nicht in den Zusammenhang der Unwirksamkeitsprüfung stellt, kann von einer Ausdehnung des Konnexitätsmerkmals auf die Unwirksamkeitsverfahren daher bislang nicht ausgegangen werden.

\section{Zusammenfassung}

Eine direkte oder analoge Anwendung des Art. 264 II AEUV kommt aus einer Vielzahl unterschiedlicher Erwägungen in Betracht, wobei sowohl öffentliche als auch private Interessen in der Rechtsprechung des Gerichtshofs eine Rolle spielen. Die von ihm berücksichtigten Interessen zeichnen sich durch ihren Unionsrechtsbezug aus. Rein mitgliedstaatliche Interessen sind insoweit nicht von Belang.

IV. Rechtsfolgen einer Begrenzung der zeitlichen Wirkungen

Nimmt der Gerichtshof eine Begrenzung der zeitlichen Wirkungen vor, stellt sich die Frage nach ihren Folgen in räumlicher, sachlicher, zeitlicher und persönlicher Hinsicht. Zunächst ist die Frage der territorialen Reich-

1021 EuGH, Urteil vom 15.11.2012, Rs. C-247/10 P (Zhejiang Aokang Shoes/Rat), Rn. $40 \mathrm{f}$.

1022 EuGH, Urteil vom 4.2.2016, verb. Rs. C-659/13 und C-34/14 (C \& J Clark International und Puma), Rn. 40 unter Verweis auf EuGH, Urteil vom 15.11.2012, Rs. C-247/10 P (Zhejiang Aokang Shoes/Rat), Rn. 39-41. 
weite der zeitlichen Beschränkung anzusprechen. Daneben ist zu klären, welche sachliche Reichweite der Gerichtshof der zeitlichen Begrenzung beimisst, welche Sachverhalte sie also erfasst. Daraus kann im Umkehrschluss abgeleitet werden, welche Sachverhalte auf alle Fälle von der ex tunc-Wirkung erfasst werden. Zudem ist der Frage nachzugehen, welche Zeitpunkte als Stichtag für eine Begrenzung in Betracht kommen. Von Interesse ist dabei insbesondere, ob dies auch ein in der Zukunft liegender Zeitpunkt sein kann, wie dies zum Teil gefordert wird, um eine Anpassung des mitgliedstaatlichen Rechts an unionsrechtliche Vorgaben zu ermöglichen. Schließlich ist darauf einzugehen, ob und wenn ja welche Ausnahmen von einer zeitlichen Begrenzung in persönlicher Hinsicht bestehen.

$\mathrm{Zu}$ untersuchen sind diese Rechtsfolgen sowohl im Hinblick auf die Begrenzung der zeitlichen Wirkungen im Rahmen von Auslegungsentscheidungen als auch durch einen vergleichenden Blick im Hinblick auf die Unwirksamkeitsverfahren.

\section{Auslegungsentscheidungen}

a) Räumliche Erstreckung

Vor dem Hintergrund, dass oben ${ }^{1023}$ bereits kurz erwähnt wurde, dass einer vom Gerichtshof angeordneten Begrenzung der ex tunc-Wirkung nach derzeitiger Rechtsprechung keine auf einzelne Mitgliedstaaten beschränkte Wirkung zukommt, ist mit der territorialen Reichweite der zeitlichen Beschränkung insbesondere die Frage angesprochen, ob der Gerichtshof in Zukunft von der Anordnung einer unionsweiten Beschränkung abrücken sollte. Näher zu entfalten ist an dieser Stelle daher, welche Argumente für und gegen ein solches Ansinnen vorgebracht werden können.

1023 Siehe bei Fn. 917 f. 
aa) Eingehen auf mitgliedstaatliche Bedürfnisse

Generalanwältin Stix-Hackl spricht sich für eine territoriale Differenzierung der Beschränkung der zeitlichen Wirkungen aus. ${ }^{1024}$ Die Reichweite der Auslegung - insoweit bliebe es bei einer unionsweit einheitlichen ex tunc-Wirkung - und der Beschränkung - diese soll je nach Mitgliedstaat unterschiedlich ausgestaltet sein - fielen dann auseinander. ${ }^{1025}$ Für eine nach Mitgliedstaaten differenzierende Begrenzung kann daher angeführt werden, dass dem EuGH ermöglicht würde, flexibler auf mitgliedstaatliche Bedürfnisse zu reagieren. ${ }^{1026}$

bb) Einwand: unionsweit einheitliche Maßstäbe

Allerdings ist zu bedenken, dass zwar der Kontext der anlässlich eines Vorabentscheidungsersuchens erfolgenden Auslegung einer unionsrechtlichen Vorschrift national gefärbt ist ${ }^{1027}$, die vom Gerichtshof vorgenommene Auslegung durch ihre Bedeutung für den gesamten Rechtsraum der EU dennoch „allgemeine Wirkung“ hat. ${ }^{1028}$ Deutlich wird dies nicht zuletzt daran, dass der Gerichtshof eine Vorschrift des nationalen Rechts lediglich beispielhaft nennt, auch wenn er die unionsrechtliche Bestimmung im Hinblick auf diese auslegt. Dementsprechend führt er etwa aus, dass das von ihm ausgelegte Unionsrecht „der Beibehaltung einer auf alkoholische Getränke erhobenen Steuer wie derjenigen entgegen[steht], um die es im Ausgangsverfahren geht“. ${ }^{1029}$ Gleiches gilt für die Wirkung der zeitlichen Begrenzung, wenn der Gerichtshof ausführt, dass sich (von den unter die Rückausnahme fallenden Rechtsbehelfsführern abgesehen) niemand auf die ausgelegte unionsrechtliche Bestimmung berufen könne, „um Ansprü-

1024 GA Stix-Hackl, Schlussanträge vom 14.3.2006 in der Rs. C-475/03 (Banca Popolare di Cremona), Rn. 178 ff.; GA Stix-Hackl, Schlussanträge vom 5.10.2006 in der Rs. C-292/04 (Meilicke u.a.), Rn. 14.

1025 Vgl. Billig, FR 2007, 785 (786).

1026 Vgl. Verstraelen, GLJ 14 (2013), 1687 (1718).

1027 GA Stix-Hackl, Schlussanträge vom 14.3.2006 in der Rs. C-475/03 (Banca Popolare di Cremona), Rn. 183 meint, die Entscheidung erfolge fallbezogen im tatsächlichen Kontext des Vorabentscheidungsersuchens.

1028 Das räumt auch GA Stix-Hackl, Schlussanträge vom 14.3.2006 in der Rs. C-475/03 (Banca Popolare di Cremona), Rn. 180 ein.

1029 EuGH, Urteil vom 9.3.2000, Rs. C-437/97 (EKW und Wein \& Co.), Tenor Nr. 2. 
che betreffend Abgaben wie die Steuer auf alkoholische Getränke, die vor Erlaß dieses Urteils entrichtet wurden oder fällig geworden sind, geltend zu machen“. ${ }^{1030}$ Damit macht er zugleich deutlich, dass sowohl von der Auslegung als auch der zeitlichen Begrenzung Regelungen anderer Mitgliedstaaten ebenfalls betroffen sein können. Ausgelegt und in seiner zeitlichen Wirkung begrenzt wird eben das Unionsrecht und nicht das mitgliedstaatliche Recht.

Ganz in diesem Sinne ist das Vorliegen von gutem Glauben nach einem unionsweit einheitlichen Maßstab zu beurteilen. Entscheidend ist also auch bei einem italienischen Ausgangsverfahren nicht allein der gute Glaube der betroffenen Verkehrskreise in Italien, sondern vielmehr die Frage, ob alle Betroffenen (einschließlich der „italienischen“"Verkehrskreise) wegen einer objektiven bedeutenden Unsicherheit von einer bestimmten Auslegung des Unionsrechts ausgehen durften. ${ }^{1031}$ Dagegen wird zwar eingewendet, die Auslegung einer Bestimmung des Unionsrechts könne, wenn auch nicht allgemein, so doch im Hinblick auf die besondere Rechtslage in einem Mitgliedstaat unsicher gewesen sein. ${ }^{1032}$ Eine derartige Sichtweise verkennt aber, dass sich unionsrechtliche und mitgliedstaatliche Ebene so weit voneinander trennen lassen, dass zwischen der losgelöst von nationalen Besonderheiten erfolgenden Rechtserkenntnis des EuGH zum Unionsrecht und Problemen seiner Anwendung in den Mitgliedstaaten unterschieden werden kann. Alles andere hieße, einen unionsweit einheitlichen Maßstab des guten Glaubens aufzugeben.

Auch die Rechtssachen Poltorak und Kovalkovas bieten keinen in eine andere Richtung weisenden Anhaltspunkt. Ihnen zugrunde lagen Vorabentscheidungsersuchen eines niederländischen Gerichts, das mit Fällen der Vollstreckung eines vom litauischen Justizministerium bzw. schwedischen Reichspolizeiamt ausgestellten Europäischen Haftbefehls in den Niederlanden zur Vollstreckung einer Freiheitsstrafe in Litauen bzw. Schweden befasst war. Um Beschränkung der zeitlichen Wirkungen ersucht wurde

1030 EuGH, Urteil vom 9.3.2000, Rs. C-437/97 (EKW und Wein \& Co.), Tenor Nr. 3. Auf diese Praxis des Gerichtshofs weist auch Rosenkranz, Beschränkung der Rückwirkung, 2015, S. 377 f. hin, Bezug nehmend auf EuGH, Urteil vom 16.7.1992, Rs. C-163/90 (Legros u.a.), Tenor Nr. 3 und Rn. 35, worin von „Abgaben wie dem ,octroi de mer“" die Rede ist.

1031 Anders GA Stix-Hackl, Schlussanträge vom 14.3.2006 in der Rs. C-475/03 (Banca Popolare di Cremona), Rn. 181, die nur auf die „Gutgläubigkeit“ des italienischen Staates abstellt.

1032 Lang, in: Popelier/Verstraelen/Vanheule/Vanlerberghe (Hrsg.), The Effects of Judicial Decisions in Time, 2014, S. 245 (259). 
der Gerichtshof in dem einen Fall von der niederländischen Regierung und der Kommission, im anderen zusätzlich von der litauischen Regierung. ${ }^{1033} \mathrm{Im}$ Hinblick auf die Prüfung des guten Glaubens führte der Gerichtshof aus, das Königreich Schweden bzw. die Republik Litauen seien nicht zu einem mit dem Unionsrecht unvereinbaren Verhalten veranlasst worden: Ein Gutachten/Bericht des Rates vom 21.10.2008 (Poltorak) bzw. vom 14.12.2007 (Kovalkovas) hatte gerügt, dass die Ausstellung Europäischer Haftbefehle durch das litauische Justizministerium/das schwedische Reichspolizeiamt mit dem im Rahmenbeschluss zum Europäischen Haftbefehl enthaltenen Erfordernis der Bestimmung einer "Justizbehörde“ unvereinbar sei. ${ }^{1034}$ Hier tritt also ein einzelner Mitgliedstaat in den Mittelpunkt der Betrachtungen. Die Ausführungen des Gerichtshofs sind aber insoweit nicht schädlich, als jeder andere Betroffene in der Situation Litauens/Schwedens keinen guten Glauben hätte bilden können, sodass im Ergebnis der unionsweite Maßstab nicht aufgeweicht worden ist. Dass auch bei einer spezifisch in einem Mitgliedstaat wurzelnden bzw. auf diesen bezogenen Auslegungsfrage die Wirkung der Auslegung nicht auf diesen Mitgliedstaat begrenzt ist, zeigt der jeweilige Tenor, in dem der Gerichtshof wieder offener formuliert, wenn er ausführt, dass ein Exekutivorgan "wie“ das litauische Justizministerium bzw. eine Polizeibehörde „wie“ das Rikspolisstyrelsen (Reichspolizeiamt, Schweden) nicht unter den im Rahmenbeschluss verwendeten Begriff „ausstellende Justizbehörde“ falle. Gleiches hätte dann für die Begrenzung der zeitlichen Wirkungen gegolten, die der Gerichtshof aber eben wegen fehlenden guten Glaubens abgelehnt hat.

Vor diesem Hintergrund zu sehen sind auch die Ausführungen des Gerichtshofs in den verbundenen Rechtssachen UNIS und Beaudout Père et Fils. Der Gerichtshof stellt hier einen sehr starken Bezug zu den Sachverhalten der Ausgangsverfahren her, wenn er die "sehr speziellen Umstände“ („the very particular nature of the situation“; „le caractère très particulier de la situation") anspricht, die die in den Ausgangsverfahren fraglichen Sachverhalte kennzeichneten. Auch führt er aus, dass die Entscheidung

1033 EuGH, Urteil vom 10.11.2016, Rs. C-477/16 PPU (Kovalkovas), Rn. 50; EuGH, Urteil vom 10.11.2016, Rs. C-452/16 PPU (Poltorak), Rn. 54.

1034 EuGH, Urteil vom 10.11.2016, Rs. C-477/16 PPU (Kovalkovas), Rn. 53 i.V.m. Rn. 12; EuGH, Urteil vom 10.11.2016, Rs. C-452/16 PPU (Poltorak), Rn. 57 i.V.m. Rn. 13. Siehe in diesem Zusammenhang auch EuGH, Urteil vom 19.12.2013, Rs. C-262/12 (Association Vent De Colère! u.a.), Rn. 41, wo der Gerichtshof, verkürzt gesagt, ausführt, der französischen Regierung habe das Verbot des Art. 108 III AEUV nicht verborgen bleiben können. 
über die zeitliche Wirkung daher ,unter den konkreten Umständen der beiden Ausgangsverfahren“ („In the specific circumstances of the cases in the main proceedings“; „Dans les conditions propres aux affaires au principal“) erfolge. ${ }^{1035}$ In den Tenor hat er diese Bezüge aber nicht aufgenommen. Zwar verzichtet er dort auf das „wie“1036, sodass es nur schwer vorstellbar erscheint, dass die zeitliche Begrenzung auch für Sachverhalte in anderen Mitgliedstaaten Bedeutung erlangt. Ausgeschlossen erscheint dies aber nicht. Dass der Gerichtshof die besonderen Umstände der Ausgangsverfahren betont, erklärt sich wie gesehen aus dem Verzicht auf sein übliches Prüfprogramm, der es ihm gestattete, jenseits der tradierten Kriterien eine Begrenzung der zeitlichen Wirkungen vorzunehmen. Dass er hiermit auch den Weg hin zu einer territorial begrenzten Beschränkung beschreiten wollte, ist nicht erkennbar. Demnach hat der Gerichtshof in UNIS und Beaudout Père et Fils keine auf Frankreich beschränkte Begrenzung vorgenommen.

Auch die Rechtssache Skoma-Lux weist nicht in die Richtung einer territorial differenzierten zeitlichen Geltung des Unionsrechts. Die dortige Fallgestaltung betraf einen anderen Aspekt. Angesichts der fehlenden Veröffentlichung eines Unionsrechtsakts in der Sprache des betroffenen Mitgliedstaats kam es dort zwar zu einer territorial gespaltenen Anwendbarkeit des Unionsrechts. Die hier in Rede stehende zeitliche Wirkung der Auslegung des Unionsrechts war aber nicht betroffen; vielmehr ging es im Rahmen der entsprechenden Anwendung des Art. 264 II AEUV um die (auf den betroffenen Mitgliedstaat beschränkte) Begrenzung der Unanwendbarkeit eines Unionsrechtsakts dem Einzelnen gegenüber. ${ }^{1037}$ Für die vorliegend interessierende Frage lässt sich aus den Ausführungen des EuGH in der Rechtssache Skoma-Lux also keine Abkehr von der unionsweit einheitlichen zeitlichen Wirkung ableiten. ${ }^{1038}$

1035 EuGH, Urteil vom 17.12.2015, verb. Rs. C-25/14 und C-26/14 (UNIS und Beaudout Père et Fils), Rn. 53 und Rn. 50.

1036 Tenor Nr. 2 lautet: „Die Wirkungen des vorliegenden Urteils gelten nicht für die eine einzige Einrichtung mit der Verwaltung eines Zusatzvorsorgesystems beauftragenden Tarifverträge, die vor der Verkündung des vorliegenden Urteils von einer Behörde für sämtliche Arbeitgeber und Arbeitnehmer einer Branche für verbindlich erklärt wurden, wobei vor diesem Zeitpunkt erhobene Klagen unberührt bleiben.“

1037 EuGH, Urteil vom 11.12.2007, Rs. C-161/06 (Skoma-Lux), Rn. 68 und näher oben bei Fn. $382 \mathrm{ff}$.

1038 Ebenso Lang, in: Popelier/Verstraelen/Vanheule/Vanlerberghe (Hrsg.), The Effects of Judicial Decisions in Time, 2014, S. 245 (247 f.). 
Das Urteil in der Rechtssache Carbonati Apuani scheint dagegen auf den ersten Blick von der Erforderlichkeit einer für jeden Mitgliedstaat gesonderten Anordnung der zeitlichen Beschränkung auszugehen. Der Gerichtshof führt dort aus, dass die gleichen Rechtssicherheitserwägungen wie in der Rechtssache Legros u.a. ${ }^{1039}$ zu berücksichtigen seien, sodass „die im Urteil Legros u.a. ausgesprochene zeitliche Begrenzung auch für Anträge auf Erstattung der Beträge gilt, die mit der im Ausgangsverfahren in Rede stehenden Abgabe erhoben wurden“. ${ }^{1040}$ Entsprechende Ausführungen finden sich im Urteil in der Rechtssache Simitzi. ${ }^{1041}$ Läse man die jeweilige Passage als Anordnung der zeitlichen Beschränkung für Italien (Carbonati Apuani) bzw. Griechenland (Simitzi), bedeutete dies in der Tat zugleich, dass die Beschränkung der zeitlichen Wirkungen in Legros u.a. auf Frankreich (bzw. die französischen überseeischen Departements) beschränkt gewesen wäre.

Zuzugeben ist, dass die erwähnten Aussagen auf die Anordnung einer (konstitutiven) zeitlichen Begrenzung hindeuten. Letztlich stellt der Gerichtshof in beiden Fällen aber lediglich (deklaratorisch) fest, dass die in Legros u.a. vorgenommene Begrenzung auch für die entsprechende italienische bzw. griechische Abgabe gilt. ${ }^{1042}$ Deutlich wird dies an seinem Gedankengang. So führt er aus, dass die jeweils in Rede stehende italienische bzw. griechische Abgabe dem in der Rechtssache Legros u.a. streitigen französischen „octroi de mer“ entspreche. Bis zum 16.7.1992, dem Tag des Urteils in der Rechtssache Legros u.a. konnten, so der Gerichtshof, die Gemeinde Carrara bzw. Griechenland daher von der Unionsrechtskonformität der jeweils erhobenen Abgaben ausgehen. Ab dem 16.7.1992 hätten sie allerdings wissen müssen, dass diese nicht mit dem Unionsrecht vereinbar sind. ${ }^{1043}$

1039 EuGH, Urteil vom 16.7.1992, Rs. C-163/90 (Legros u.a.).

1040 EuGH, Urteil vom 9.9.2004, Rs. C-72/03 (Carbonati Apuani), Rn. 40. Auf dieses Urteil verweist etwa Lang, Intertax 35 (2007), 230 (237).

1041 EuGH, Urteil vom 14.9.1995, verb. Rs. C-485/93 und C-486/93 (Simitzi), Rn. 32.

1042 Ebenso Ludewig, Zeitliche Beschränkung, 2012, S. 201. Siehe auch Verstraelen, GLJ 14 (2013), 1687 (1718), die zwar meint, der Anwendungsbereich der in Legros u.a. vorgenommenen zeitlichen Begrenzung sei in Carbonati Apuani „ausgedehnt" worden, zugleich aber einräumt, der Gerichtshof habe hier keinen neuen Ansatz verfolgt.

1043 EuGH, Urteil vom 9.9.2004, Rs. C-72/03 (Carbonati Apuani), Rn. 38 ff.; EuGH, Urteil vom 14.9.1995, verb. Rs. C-485/93 und C-486/93 (Simitzi), Rn. 30 ff. 
Der Gerichtshof prüft also nicht das Vorliegen der Voraussetzungen einer Begrenzung der zeitlichen Wirkungen im Hinblick auf Italien bzw. Griechenland. Er bestätigt lediglich seine in Legros u.a. getroffenen Aussagen. Da dort eine Begrenzung vorgenommen wurde, steht fest, dass auch die betreffenden Akteure in Italien bzw. Griechenland bis zu diesem Zeitpunkt guten Glaubens waren. Ebenso profitieren sie von der Gefahr der Erschütterung des Finanzierungssystems der örtlichen Körperschaften der französischen überseeischen Departements, die in Legros u.a. für die zeitliche Begrenzung mit ausschlaggebend war. ${ }^{1044} \mathrm{Ob}$ eine solche auch im Hinblick auf Italien bzw. Griechenland drohte, untersucht der Gerichtshof nicht. Eine zeitliche Beschränkung muss also nicht im Hinblick auf jeden Mitgliedstaat gesondert angeordnet werden.

Abzusichern ist das bislang gefundene Ergebnis einer unionsweit einheitlichen zeitlichen Geltung des Unionsrechts noch gegen den Eindruck, dass die für die Bejahung einer Gefahr schwerwiegender Störungen erforderlichen Feststellungen auf den ersten Blick für eine territorial differenzierte zeitliche Wirkung des Unionsrechts sprechen. So wird ein betroffenes Subsystem, dessen finanzielle Grundlagen durch eine Auslegung mit ex tunc-Wirkung gefährdet sind, in der Regel in einem anderen Mitgliedstaat keine Entsprechung finden. ${ }^{1045}$ Dennoch sind auch im Hinblick auf die Gefahr schwerwiegender Störungen die Auswirkungen in sämtlichen Mitgliedstaaten zu berücksichtigen. Grundlage bleibt ja der gute Glaube in allen Mitgliedstaaten.

Der Mitgliedstaat, in dem keine schwerwiegenden Störungen drohen, wird durch eine unionsweite Begrenzung nicht beeinträchtigt, da die Beteiligten auch hier angesichts des unionsweiten guten Glaubens von einem bestimmten Inhalt des Unionsrechts ausgehen durften. ${ }^{1046}$ Die objektiv richtige Rechtslage gilt dann zwar auch in diesem Mitgliedstaat nicht; durch die zeitlich einheitliche Geltung des Unionsrechts werden aber die einheitliche Anwendung des Unionsrechts und die Gleichbehandlung der Mitgliedstaaten sichergestellt.

Zwar trifft es zu, dass sich für die Mitgliedstaaten bei einer territorial differenzierten Begrenzung ein „Ausweg aus dem Präklusionsdilemma“ eröffnete, da sie sich dann nicht mehr um Verfahren aus anderen Mitgliedstaaten kümmern müssten, um die Rechtsfolge der Präklusion zu vermei-

1044 EuGH, Urteil vom 16.7.1992, Rs. C-163/90 (Legros u.a.), Rn. 34.

1045 Vgl. dazu Lang, Intertax 35 (2007), 230 (238).

1046 Rosenkranz, Beschränkung der Rückwirkung, 2015, S. 379. 
den. ${ }^{1047}$ Dann käme es aber zu der bereits im Rahmen der Frage nach der Nachholbarkeit der Beschränkung der zeitlichen Wirkung beschriebenen und nach hier vertretener Auffassung zu vermeidenden Situation, dass die Wirkung in den vom ersten Verfahren nicht betroffenen Mitgliedstaaten zunächst eine solche ex tunc ist und dann nachträglich noch zu einer ex nunc-Wirkung wird. ${ }^{1048}$ Auch darf kein Verstoß gegen den Gleichheitssatz begangen werden, was aber der Fall wäre, wenn etwa nur Unternehmen in einzelnen Mitgliedstaaten ihren weiblichen Beschäftigten rückwirkend höheren Lohn zahlen müssten. ${ }^{1049}$ Sowohl zwischen den Unternehmen als auch zwischen den Mitgliedstaaten muss „Wettbewerbsgleichheit" ${ }^{\text {"1050 }}$ herrschen.

$\mathrm{Zu}$ bedenken ist schließlich noch, dass durch eine zeitliche Begrenzung zwar eine Gefahr schwerwiegender Störungen von einem betroffenen Mitgliedstaat abgewendet wird. Andere Mitgliedstaaten haben sich in diesem Zeitraum allerdings unter Umständen bereits unter Inkaufnahme schwerwiegender Störungen unionsrechtskonform verhalten. Damit die zeitliche Begrenzung den sich bislang nicht unionsrechtskonform verhaltenden Mitgliedstaat nicht begünstigt, ist daher eine sehr sorgfältige Prüfung des guten Glaubens angezeigt, ohne den es ja zu keiner Begrenzung kommen kann. Verhalten sich manche Mitgliedstaaten bereits unionsrechtskonform, ist dies ein ernst zu nehmendes Indiz gegen das Bestehen von gutem Glauben. Es erscheint dann nämlich jedenfalls zweifelhaft, eine objektive bedeutende Unsicherheit hinsichtlich der Tragweite der Unionsbestimmungen bejahen zu können. ${ }^{1051}$

\section{cc) Entgegenstehen des Konnexitätskriteriums}

Schließlich passt das Kriterium der Konnexität, an dem der EuGH bis heute festhält, nicht zu einer räumlich begrenzten Beschränkung. ${ }^{1052}$ Ist

1047 Ludewig, Zeitliche Beschränkung, 2012, S. 203.

1048 Siehe dazu oben bei Fn. $923 \mathrm{ff}$.

1049 Darauf weist Ludewig, Zeitliche Beschränkung, 2012, S. 204 zu Recht hin.

1050 Begriff bei Leonard/Szczekalla, UR 2005, 420 (423) mit Blick auf (unionsrechtswidrige) mitgliedstaatliche Steuergesetze.

1051 Siehe in diesem Zusammenhang auch Rosenkranz, Beschränkung der Rückwirkung, 2015, S. 228 und Leonard/Szczekalla, UR 2005, 420 (423).

1052 Verstraelen, GLJ 14 (2013), 1687 (1717, 1729f.); Ludewig, Zeitliche Beschränkung, 2012, S. 201 f.; Schaer, Grenzen rückwirkender Rechtsprechung, 2010, S. 106 mit Fn. 417. 
im erstauslegenden Urteil eine zeitliche Begrenzung unterblieben, kommt ihre Anordnung im nachfolgenden Urteil wegen Präklusion nicht mehr in Betracht, sodass sie von vornherein auch nicht mehr im Hinblick auf einen anderen Mitgliedstaat vorgenommen werden könnte. Wenn die Anordnung der Beschränkung der zeitlichen Wirkungen nur im erstauslegenden Urteil erfolgen kann, kann darüber auch dann nicht mehr im nachfolgenden Urteil entschieden werden, wenn dort „nur“ die Wirkungen bis zum erstauslegenden Urteil beschränkt werden sollen. Wenn wegen Präklusion überhaupt keine Entscheidung mehr getroffen werden kann, muss auch die Festlegung eines Zeitpunkts ausscheiden.

dd) Vergleich mit den Unwirksamkeitsverfahren

Die Kriterien einer Begrenzung der zeitlichen Wirkung in den Unwirksamkeitsverfahren sind in der Regel auf den unionalen Bereich bezogen und daher von mitgliedstaatlichen Besonderheiten unabhängig. Der sich allein auf Unionsebene abspielende Normenkonflikt eröffnet daher grundsätzlich keinen Raum für eine nach Mitgliedstaaten differenzierende zeitliche Begrenzung. ${ }^{1053}$ Eine Besonderheit besteht etwa in einem Fall, in dem die Aussaat von Baumwollpflanzen betroffen ist. Dann sind die Auswirkungen auf die Mitgliedstaaten (und auf die Landwirte in diesen Mitgliedstaaten) beschränkt, in denen der Anbau von Baumwolle möglich ist. ${ }^{1054}$ Eine unionsweite Aufrechterhaltung der Wirkungen des betreffenden Rechtsakts schadet aber auch in diesem Fall nicht, sodass kein Grund besteht, vom Grundsatz der unionsweiten Aufrechterhaltung abzuweichen.

ee) Ergebnis

Damit ist noch einmal zu betonen, dass nach der derzeitigen Rechtsprechung die Begrenzung der ex tunc-Wirkung nicht territorial begrenzt ist. Sie tritt also nicht nur in dem Mitgliedstaat ein, der sie "beantragt" hat oder aus dem der Sachverhalt des Vorlageverfahrens stammt. ${ }^{1055}$ Eine ter-

1053 Ebenso Rosenkranz, Beschränkung der Rückwirkung, 2015, S. 380.

1054 EuGH, Urteil vom 7.9.2006, Rs. C-310/04 (Spanien/Rat), Rn. 139 f.

1055 So aber Wiedmann, EuLF 2006, I-197 (I-199) unter Verweis auf GA Stix-Hackl, Schlussanträge vom 5.10.2006 in der Rs. C-292/04 (Meilicke u.a.), Rn.14; 
ritorial differenzierte Begrenzung ist auch angesichts des mit ihr einhergehenden Verzichts auf die einheitliche Anwendung des Unionsrechts und des damit einhergehenden Verlusts an Rechtssicherheit nicht erstrebenswert.

\section{b) Sachliche Erstreckung}

Hat der Gerichtshof eine Begrenzung der zeitlichen Wirkungen angeordnet, ist der Betroffene wie gesehen daran gehindert, sich (für einen sogleich noch näher zu bestimmenden Zeitraum) auf die ausgelegte unionsrechtliche Norm zu berufen ${ }^{1056}$ und damit auch an der Geltendmachung eines Verstoßes gegen diese Norm. Ohne zeitliche Begrenzung ist die unionsrechtliche Vorschrift in der Auslegung durch den EuGH dagegen auf sämtliche betroffenen Rechtsverhältnisse anzuwenden, unabhängig davon, ob sie vor Erlass des Urteils entstanden sind oder nicht, vorausgesetzt, alle sonstigen Voraussetzungen für die Anrufung der zuständigen Gerichte in einem die Anwendung dieser Vorschrift betreffenden Streit liegen vor. ${ }^{1057}$ Das damit angesprochene nationale Verfahrensrecht kann demnach ebenfalls dazu führen, dass ein Verstoß gegen Unionsrecht bestehen bleibt. ${ }^{1058}$ Die beiden „Beschränkungsregime“ 1059 weisen insoweit in dieselbe Richtung: Die vom Gerichtshof vorgenommene Begrenzung der zeitlichen Wirkungen schließt Sachverhalte von der Beeinflussung durch die ausgelegte Norm aus; das nationale Verfahrensrecht tut dies ebenfalls. ${ }^{1060}$

Wiedmann, EuZW 2007, 692 (693); Frenz, Handbuch Europarecht, Band 5, 2010, Rn. 3425; Karpenstein, in: Grabitz/Hilf/Nettesheim (Hrsg.), Recht der EU, Art. 267 AEUV, Rn. 115 (Stand: Mai 2013); Weiß, EuR 1995, 377 (388); Billig, FR 2007, 785 (786f.).

1056 Siehe hierzu bereits bei Fn. 443.

1057 EuGH, Urteil vom 2.2.1988, Rs. 24/86 (Blaizot u.a.), Rn.27; EuGH, Urteil vom 4.5.1999, Rs. C-262/96 (Sürül), Rn. 107; EuGH, Urteil vom 17.2.2005, verb. Rs. C-453/02 und C-462/02 (Linneweber und Akritidis), Rn. 41; EuGH, Urteil vom 10.11.2016, Rs. C-477/16 PPU (Kovalkovas), Rn. 51; EuGH, Urteil vom 17.9.2014, Rs. C-562/12 (Liivimaa Lihaveis), Rn. 80; EuGH, Urteil vom 22.9.2016, Rs. C-110/15 (Microsoft Mobile Sales International u.a.), Rn.59; EuGH, Urteil vom 9.6.2016, Rs. C-586/14 (Budişan), Rn. 45.

1058 Siehe dazu näher unten bei Fn. 1223 ff.

1059 Ludewig, Zeitliche Beschränkung, 2012, S. 228 (Anführungszeichen im Original).

1060 Weiß, DÖV 2008, 477 (478, Fn. 35); Finke, IStR 2006, 212 (215); siehe auch Ludewig, Zeitliche Beschränkung, 2012, S. $227 \mathrm{f}$. 
Die Begrenzung der zeitlichen Wirkungen ist nur für diejenigen Rechtsverhältnisse relevant, „deren Wirkungen sich in der Vergangenheit erschöpft haben “. ${ }^{1061}$ Dauert das Rechtsverhältnis dagegen in der Gegenwart noch an, erlangt die Auslegung auf jeden Fall Bedeutung. ${ }^{1062}$ Was unter Rechtsverhältnissen zu verstehen ist, deren Wirkungen sich in der Vergangenheit erschöpft haben, ist unionsautonom zu bestimmen, damit die Mitgliedstaaten die sachliche Reichweite der Beschränkung nicht selbst bestimmen können. ${ }^{1063}$

Insofern erscheinen die zur Rückwirkung von Rechtsakten entwickelten Maßstäbe übertragbar. Auch wenn die Ausgangslagen bei Rechtsetzung und Rechtsprechung wie gesehen unterschiedliche sind, steht hier die für beide Fälle vergleichbare Frage im Raum, vor welchen Anpassungen die Betroffenen geschützt werden sollen. Das sind diejenigen, auf die sie durch eigenes Verhalten nicht mehr reagieren können. ${ }^{1064}$

Ein Blick auf die Rechtsprechung des Gerichtshofs zeigt, dass die Beschränkung jedenfalls Abgaben erfasst, die vor Erlass des entsprechenden Urteils entrichtet wurden. ${ }^{1065}$ Erfolgte die Einfuhr einer Ware vor dem auslegenden Urteil des Gerichtshofs, die Entrichtung der auf die Einfuhr erhobenen Abgabe aber danach, so entschied der Gerichtshof zunächst, dass die Begrenzung der zeitlichen Wirkungen nicht gelte, sodass Erstattung verlangt werden konnte. ${ }^{1066}$ In der Folge hat der Gerichtshof seine Rechtsprechung dahingehend ausgeweitet, dass Abgaben, die vor Erlass des Urteils entrichtet wurden oder fällig geworden sind, nicht zurückverlangt werden können. ${ }^{1067}$ Durch diese Erweiterung genügt die bloße Zahlungsverweigerung trotz Fälligkeit nicht, um von der zeitlichen Begrenzung

1061 Siehe beispielhaft EuGH, Urteil vom 17.5.1990, Rs. C-262/88 (Barber), Rn. 44; EuGH, Urteil vom 15.12.1995, Rs. C-415/93 (Bosman), Rn.144; ebenso mit leicht abweichender Formulierung EuGH, Urteil vom 2.2.1988, Rs. 24/86 (Blaizot u.a.), Rn.34; EuGH, Urteil vom 16.7.1992, Rs. C-163/90 (Legros u.a.), Rn.34; EuGH, Urteil vom 9.3.2000, Rs. C-437/97 (EKW und Wein \& Co.), Rn. 59.

1062 Ludewig, Zeitliche Beschränkung, 2012, S. 147 f.

1063 Unerheblich ist, ob die betroffenen rechtlichen Beziehungen freiwillig oder "zwangsweise" (wie dies etwa bei der Steuerzahlung der Fall ist) begründet worden sind, vgl. van der Stok/Thomson, Intertax 34 (2006), 552 (553).

1064 Vgl. EuGH, Urteil vom 16.2.1982, Rs. 258/80 (Rumi/Kommission), Rn. 10 mit Blick auf eine Entscheidung der Kommission; ebenso Rosenkranz, Beschränkung der Rückwirkung, 2015, S. 317.

1065 EuGH, Urteil vom 16.7.1992, Rs. C-163/90 (Legros u.a.), Rn. 35.

1066 EuGH, Urteil vom 16.7.1992, Rs. C-163/90 (Legros u.a.), Rn. 36.

1067 EuGH, Urteil vom 9.3.2000, Rs. C-437/97 (EKW und Wein \& Co.), Rn. 60. 
zu profitieren. ${ }^{1068} \mathrm{Um}$ die Abgaben trotz zeitlicher Begrenzung zurückverlangen zu können, muss vor der Urteilsverkündung ein Rechtsbehelf eingelegt worden sein. Anderenfalls würde die bevorzugte Behandlung der Rechtsbehelfsführer konterkariert. ${ }^{1069}$

Einschreibegebühren, die für Zeiten vor Erlass des Urteils rechtsgrundlos gezahlt worden sind, können bei einer zeitlichen Begrenzung nicht zurückgefordert werden. ${ }^{1070}$ Auch eine Transfer-, Ausbildungs- oder Förderungsentschädigung, die zum Zeitpunkt des betreffenden Urteils bereits gezahlt worden ist oder die zur Erfüllung einer vor diesem Zeitpunkt entstandenen Verpflichtung noch geschuldet wird, kann nicht zurückgefordert werden. ${ }^{1071}$ „Erschöpft“ im Sinne der Rechtsprechung ist ein Rechtsverhältnis also bereits dann, wenn es wirksam begründet wurde; eine Zahlung muss noch nicht erfolgt sein. ${ }^{1072}$ So bleiben auch etwa Tarifverträge unberührt, die vor Verkündung des Urteils für allgemeinverbindlich erklärt wurden. ${ }^{1073}$

Geht es um Ansprüche auf Leistungen, kann etwa im Falle einer zeitlichen Begrenzung die unmittelbare Wirkung einer Vorschrift nicht zur Begründung von Ansprüchen für Zeiten vor Erlass des Urteils geltend gemacht werden. ${ }^{1074}$ Denn sonst würde ein Rechtsverhältnis in Frage gestellt, das vor Urteilserlass bereits abschließend geregelt war. ${ }^{1075}$ Die Fälligkeit der Ansprüche bis zum Urteilstag spielt insoweit keine Rolle; entscheidend ist allein der Bezug zu der Zeit vor Urteilserlass. ${ }^{1076}$

Da Ansprüche, die vor dem Tag der Verkündung des Urteils liegende Lohn- oder Gehaltsperioden betreffen, bei einer zeitlichen Begrenzung nicht geltend gemacht werden können ${ }^{1077}$, kommt es auf ihre Entstehung an. Vor dem Urteil liegende Beschäftigungszeiten bleiben also aufgrund der Beschränkung der zeitlichen Wirkungen unangetastet. Das gilt auch

1068 Rosenkranz, Beschränkung der Rückwirkung, 2015, S. 318.

1069 Zur „Rückausnahme für Rechtsbehelfsführer“ siehe sogleich bei Fn. $1102 \mathrm{ff}$.

1070 EuGH, Urteil vom 2.2.1988, Rs. 24/86 (Blaizot u.a.), Rn. 35.

1071 EuGH, Urteil vom 15.12.1995, Rs. C-415/93 (Bosman), Rn. 145.

1072 Siehe auch Rosenkranz, Beschränkung der Rückwirkung, 2015, S. 319.

1073 EuGH, Urteil vom 17.12.2015, verb. Rs. C-25/14 und C-26/14 (UNIS und Beaudout Père et Fils), Rn. 53.

1074 EuGH, Urteil vom 4.5.1999, Rs. C-262/96 (Sürül), Rn. 113.

1075 EuGH, Urteil vom 4.5.1999, Rs. C-262/96 (Sürül), Rn. 111.

1076 Wie hier Rosenkranz, Beschränkung der Rückwirkung, 2015, S.320. Peers, ELRev. 1999, 627 (632) meint, das Urteil in der Rechtssache Sürül sei insoweit nicht klar.

1077 EuGH, Urteil vom 8.4.1976, Rs. 43/75 (Defrenne), Rn. 74/75 und Tenor Nr. 5. 
für Renten. ${ }^{1078}$ So stellte der Gerichtshof klar, dass die Gleichbehandlung auf dem Gebiet der betrieblichen Renten nur für Leistungen geltend gemacht werden kann, die für Beschäftigungszeiten nach dem 17.5.1990, dem Tag des Erlasses des Urteils in der Rechtssache Barber, geschuldet werden. ${ }^{1079}$

Im Steuerrecht sind Besonderheiten zu beachten. So erschöpft sich bei Veranlagungssteuern das Rechtsverhältnis in der Regel erst mit Abgabe der Steuererklärung. ${ }^{1080}$ Damit es als erschöpft angesehen werden kann, müsste die Abgabe der Steuererklärung also noch vor Urteilserlass erfolgt sein. Ist ein Steuerbescheid erforderlich, könnte darauf abgestellt werden, ob dieser vor Urteilserlass ergangen ist oder nicht. ${ }^{1081}$ Bejaht man die Erschöpfung des Rechtsverhältnisses erst dann, wenn der Steuerbescheid bereits ergangen ist, sind alle Rechtsverhältnisse, in denen dies noch nicht der Fall ist, aus unionsrechtlicher Sicht der Rückabwicklung zugänglich.

Es gilt also: Je später der Zeitpunkt für die Erschöpfung des Rechtsverhältnisses angesetzt wird, desto weniger Rechtsverhältnisse werden von der zeitlichen Begrenzung erfasst, d.h. desto mehr Rechtsverhältnisse sind grundsätzlich rückabzuwickeln, also an die im Urteil vom EuGH vorgenommene Auslegung des Unionsrechts anzupassen.

Bedeutung erlangt die Erschöpfung der Rechtsverhältnisse auch für die Gefahr schwerwiegender Störungen: So ist darzulegen, dass die Infragestellung der Rechtsverhältnisse, deren Wirkungen sich in der Vergangenheit erschöpft haben, zu der Gefahr schwerwiegender Störungen führen würde, die Voraussetzung für eine Begrenzung der zeitlichen Wirkungen ist. ${ }^{1082}$ Gelingt dies, werden sie von der ex tunc-Wirkung ausgenommen und sind nicht rückabzuwickeln.

1078 Lang, Intertax 35 (2007), 230 (234 f.).

1079 EuGH, Urteil vom 6.10.1993, Rs. C-109/91 (Ten Oever), Rn. 19, EuGH, Urteil vom 14.12.1993, Rs. C-110/91 (Moroni), Rn.31 und EuGH, Urteil vom 22.12.1993, Rs. C-152/91 (Neath), Rn. 16 zur Verdeutlichung der Tragweite von EuGH, Urteil vom 17.5.1990, Rs. C-262/88 (Barber), Rn. 44.

1080 Auf diese Problematik weisen Lindemann/Hackemann, IStR 2005, 786 (788) hin.

1081 Dautzenberg, RIW 2005, 959 (960).

1082 EuGH, Urteil vom 23.10.2014, verb. Rs. C-359/11 und C-400/11 (Schulz und Egbringhoff), Rn. 60. 
c) Zeitliche Erstreckung

Soll geklärt werden, ab welchem Zeitpunkt und bis zu welchem Zeitpunkt die Berufung auf die ausgelegte Norm ausgeschlossen ist, sodass in diesen Zeitraum die vom EuGH vorgenommene Auslegung keine Anwendung findet, fällt auf, dass der Gerichtshof bislang stets eine Begrenzung vom Inkrafttreten der von ihm ausgelegten Norm des Unionsrechts bis zum Tag der Urteilsverkündung ausgesprochen hat.

\section{a) Tag der Urteilsverkündung}

Das Abstellen auf den Tag der Urteilsverkündung liegt in der Tatsache begründet, dass der Gerichtshof nicht zwischen einzelnen Phasen des guten Glaubens unterscheidet. Er beurteilt das Bestehen von gutem Glauben vielmehr einheitlich und verlangt, dass er vom Inkrafttreten der Vorschrift bis zu ihrer Auslegung durch den Gerichtshof vorliegt. ${ }^{1083}$

Auf den Tag der Urteilsverkündung abzustellen, ist einerseits dadurch gerechtfertigt, dass nach Art. 37 S. 2 der Satzung des Gerichtshofs die Urteile des Gerichtshofs in öffentlicher Sitzung verlesen werden. Zum anderen steht das Urteil auf der Website CURIA am Tag der Urteilsverkündung zur Verfügung, nachdem diese dort bereits mehrere Wochen im Voraus angekündigt worden war. Eine Verfügbarkeit in allen Amtssprachen (außer dem Irischen) ist hierbei die Regel; dass das Urteil lediglich in französischer und der Verfahrenssprache, bei Vorabentscheidungsersuchen also der Sprache des vorlegenden Gerichts (Art. 37 III 1 EuGH-VerfO), verfügbar ist, ist die Ausnahme. ${ }^{1084}$

Um klare Abgrenzungen zu ermöglichen, erfolgt die Grenzziehung zwischen den von der Begrenzung erfassten und von ihr nicht erfassten Sachverhalten nicht anhand des genauen Zeitpunkts der Urteilsverkündung am jeweiligen Tag, sondern bereits zu Beginn, also um 0 Uhr des Urteilstages. Dann muss der Sachverhalt abgeschlossen sein, um von der Begrenzung erfasst zu werden.

Dass für die Frage, bis zu welchem Zeitpunkt eine Begrenzung erfolgt, nicht auf die Gefahr schwerwiegender Störungen abgestellt wird, erklärt sich aus den Schwierigkeiten, einen genauen Zeitraum zu bestimmen, in dem die drohenden Störungen schwerwiegend sind. Auch wenn eine

1083 Siehe hierzu bereits oben bei Fn. $704 \mathrm{ff}$.

1084 Siehe zur Sprachenfrage auch Art. 40 und 41 EuGH-VerfO. 
Begrenzung nur beim gleichzeitigen Bestehen von gutem Glauben und einer Gefahr schwerwiegender Störungen vorgenommen werden kann, muss daher für die Frage, bis zu welchem Zeitpunkt eine Begrenzung erfolgt, auf den guten Glauben Bezug genommen werden. ${ }^{1085}$

\section{bb) Zukünftiger Zeitpunkt?}

Wie bei den Fällen der Unwirksamkeit einer unionsrechtlichen Vorschrift noch zu sehen sein wird, ist dort die Wahl eines in der Zukunft liegenden Zeitpunkts, bis zu dem die Wirkungen des für unwirksam erklärten Rechtsakts aufrechterhalten werden, nicht selten. ${ }^{1086} \mathrm{Ob}$ dies auf die Fälle der Auslegung des Unionsrechts übertragbar ist, ist noch nicht abschlieBend geklärt. ${ }^{1087}$ Zwar wurde vor dem EuGH bereits ein „Aufschub der Urteilswirkungen" gefordert, um den von der Auslegung betroffenen Unternehmen und dem nationalen Gesetzgeber eine Anpassung an die Folgen des Urteils zu ermöglichen. ${ }^{1088}$ Da die Beurteilung des Bestehens einer Gefahr schwerwiegender Störungen im betreffenden Fall aber nicht allein aufgrund des Urteils des Gerichtshofs vorgenommen werden konnte und sie daher nicht nachgewiesen war, sah der Gerichtshof von einer Beschränkung der zeitlichen Wirkungen ab. ${ }^{1089}$ Einer Stellungnahme zu der hier in Rede stehenden Frage konnte er sich damit enthalten.

Entscheidend für die Beantwortung der Frage nach der Zulässigkeit der Bestimmung eines zukünftigen Zeitpunkts, zu dem die Berufung auf die ausgelegte Norm erst möglich sein soll, ist, welche Aussage dem Unionsrecht insoweit entnommen werden kann.

Gegen die Zulässigkeit der Wahl eines zukünftigen Zeitpunkts wird geltend gemacht, dass der EuGH die Mitgliedstaaten dann von ihrer Loyalitätspflicht nach Art. 4 III EUV entbinde, wozu aber nicht er, sondern nur die Mitgliedstaaten als „Herren der Verträge“ befugt seien. ${ }^{1090}$ Die

1085 Siehe zum Ganzen bereits Rosenkranz, Beschränkung der Rückwirkung, 2015, S. $329 \mathrm{f}$.

1086 Zur zeitlichen Erstreckung bei Unwirksamkeitsverfahren siehe näher unten bei Fn. $1201 \mathrm{ff}$.

1087 Broberg/Fenger, Vorabentscheidungsverfahren, 2014, S. 399 f. bezeichnen die Antwort auf diese Frage als „nicht klar“.

1088 EuGH, Urteil vom 21.3.2013, Rs. C-92/11 (RWE Vertrieb), Rn. 56.

1089 EuGH, Urteil vom 21.3.2013, Rs. C-92/11 (RWE Vertrieb), Rn. 60 ff.

1090 Müller, Begrenzung, 2009, S. 97 f. Kovács, Temporale Wirkung, 2014, S. 271 spricht von einer „Befreiung“ von Art. 4 III EUV. 
Stichhaltigkeit einer derartigen Argumentation setzt allerdings voraus, dass Art. 4 III EUV in einem solchen Fall überhaupt Geltung beansprucht. Die Loyalitätspflicht bezieht sich auf die Erfüllung einer unionsrechtlichen Verpflichtung der Mitgliedstaaten; besteht eine solche Verpflichtung nicht, kann Art. 4 III EUV auch keine Anforderungen an die Mitgliedstaaten stellen. Sollte der Gerichtshof die Möglichkeit, sich auf eine unionsrechtliche Norm zu berufen, auch für einen Zeitraum in der Zukunft ausschließen, wären die unionsrechtlichen Vorgaben für diesen Zeitraum aufgehoben; Art. 4 III EUV käme nicht zum Tragen und könnte dementsprechend kein Hindernis darstellen. ${ }^{1091}$

Zur Beantwortung der hier diskutierten Frage bedarf es daher eines anderen Anknüpfungspunktes. Der Rechtsprechung des Gerichtshofs sind zu dieser Frage zwar keine eindeutigen Aussagen zu entnehmen; es finden sich aber immerhin entsprechende Hinweise. Seine Ausführungen in der Rechtssache Winner Wetten sind für die vorliegende Problematik allerdings unergiebig, da der Gerichtshof dort einen anderen Blickwinkel eingenommen hat. Während in Winner Wetten die ausnahmsweise Zulässigkeit einer vorübergehenden Aussetzung der Verdrängungswirkung einer unmittelbar anwendbaren Vorschrift des Unionsrechts gegenüber nationalem Recht in Rede stand ${ }^{1092}$, geht es vorliegend um die Zulässigkeit eines Ausschlusses der Berufung auf die Norm in der Auslegung durch den EuGH für die Zukunft, d.h. für einen Zeitraum nach Verkündung des entsprechenden Auslegungsurteils. Diese Frage betrifft den Anwendungsbefehl der unionsrechtlichen Norm und nicht den Vorrang als „Durchsetzungsdimension" hinsichtlich nationalen Rechts. ${ }^{1093}$ Sie ist damit nicht auf unmittelbar anwendbare Vorschriften beschränkt.

Der Gerichtshof betont, dass die Objektivität des Rechts nicht gebeugt und seine zukünftige Anwendung nicht unterbunden werden dürfe, nur weil eine Gerichtsentscheidung für die Vergangenheit gewisse Auswirkungen haben könne. ${ }^{1094}$ Dies müsse „bei der Entscheidung darüber, $o b$ die Tragweite eines Urteils zeitlich zu begrenzen ist", berücksichtigt werden. ${ }^{1095}$ Denkbar ist zwar, dieser Formulierung lediglich den Aussagege-

1091 Ebenso Rosenkranz, Beschränkung der Rückwirkung, 2015, S. 345.

1092 EuGH, Urteil vom 8.9.2010, Rs. C-409/06 (Winner Wetten), Rn. 67.

1093 Auf diese Unterscheidung wird unten bei Fn. 1317 ff. näher eingegangen.

1094 EuGH, Urteil vom 8.4.1976, Rs. 43/75 (Defrenne), Rn.71/73; EuGH, Urteil vom 11.3.1981, Rs. 69/80 (Worringham und Humphreys), Rn. 31.

1095 EuGH, Urteil vom 16.7.1992, Rs. C-163/90 (Legros u.a.), Rn. 30 (Hervorhebung nur hier); ebenso EuGH, Urteil vom 9.3.2000, Rs. C-437/97 (EKW und Wein \& Co.), Rn. 57; EuGH, Urteil vom 19.9.2000, verb. Rs. C-177/99 und 
halt beizumessen, dass eine dogmatisch unzutreffende Auslegung des Unionsrechts aus falscher Rücksichtnahme auf die praktischen Auswirkungen in der Vergangenheit vermieden werden soll. ${ }^{1096}$ Nicht übersehen werden darf aber die Bezugnahme auf das „Ob“ der zeitlichen Begrenzung. Die Beschränkung der zeitlichen Wirkungen darf also nicht zu einer Beugung der Objektivität des Rechts führen. ${ }^{1097}$ Dann liegt aber ein Verständnis nahe, wonach eine Beschränkung für die Zukunft ausgeschlossen ist.

Hinzu kommt, dass sich der Ausschluss der Berufung auf die ausgelegte Norm für einen Zeitraum nach Urteilserlass und damit die Wahl eines zukünftigen Zeitpunkts als Bezugspunkt der Begrenzung mit den vom EuGH einer zeitlichen Begrenzung zugrunde gelegten Maßstäben nicht erklären ließe. Eine Begrenzung setzt guten Glauben und als dessen Voraussetzung eine „objektive und bedeutende Unsicherheit“ voraus. Eine solche besteht aber nach einer Klärung herbeiführenden unionsgerichtlichen Entscheidung nicht mehr. ${ }^{1098}$ Allenfalls könnte noch von einer Fernwirkung des bis zum Urteil vorliegenden guten Glaubens gesprochen werden. Das erscheint aber als nicht ausreichend. Guter Glaube darf nicht in Gefahr geraten, von rein finanziellen Überlegungen verdrängt zu werden, die häufig für die Wahl eines zukünftigen Zeitpunkts ins Feld geführt werden.

Letztlich sprechen auch erhebliche Abgrenzungsschwierigkeiten gegen die Wahl eines solchen Zeitpunkts. Wenn ein Übergangszeitraum mit der Erwägung gefordert wird, den Betroffenen Zeit zu geben, sich an unionsrechtliche Vorgaben anzupassen, so ist zu bedenken, dass eine vom EuGH vorgenommene Auslegung in aller Regel und nicht nur in besonders gelagerten Ausnahmefällen für die Betroffenen die Notwendigkeit einer Anpassung an unionsrechtliche Vorgaben begründet. Dementsprechend schwer fällt es, brauchbare Abgrenzungskriterien dafür zu finden, wann die Anpassungsschwierigkeiten derart groß sind, dass ein Übergangszeitraum gerechtfertigt erscheint. ${ }^{1099}$ Dies gilt umso mehr vor dem Hintergrund, dass die Mitgliedstaaten versucht sein werden, ihre Probleme als

C-181/99 (Ampafrance und Sanofi), Rn.66; EuGH, Urteil vom 14.9.2006, Rs. C-228/05 (Stradasfalti), Rn. 72.

1096 In diesem Sinne Ludewig, Zeitliche Beschränkung, 2012, S. 103.

1097 Rainer, IStR 1996, 328 (328f.).

1098 Vgl. Kovács, Temporale Wirkung, 2014, S. 271.

1099 Das räumt auch Rosenkranz, Beschränkung der Rückwirkung, 2015, S. 345 ein. 
überaus groß darzustellen, um den unionsrechtlichen Vorgaben möglichst lange nicht Folge leisten zu müssen. ${ }^{1100}$

Demnach ist es abzulehnen, die Auslegung durch den Gerichtshof erst in der Zukunft nach Ablauf einer bestimmten Zeitspanne Wirkung entfalten zu lassen. ${ }^{1101}$

\section{d) Persönliche Erstreckung - Rückausnahme für Rechtsbehelfsführer?}

Bei einer Begrenzung der ex tunc-Wirkung durch den EuGH findet das Unionsrecht in seiner vom Gerichtshof für richtig erkannten Gestalt in der Zeit vom Inkrafttreten der Norm bis zum Tag der Urteilsverkündung keine Anwendung. Wird für sie keine Ausnahme gemacht, gilt dies auch für den Kläger des Ausgangsverfahrens und andere Rechtsbehelfsführer. Ihre besondere Schutzwürdigkeit liegt aber zumindest nahe, sodass zu überlegen ist, ob für sie eine Ausnahme von der Begrenzung - eine „Rückausnahme für Rechtsbehelfsführer" - vorzusehen ist. ${ }^{1102}$ In der Tat nimmt der Gerichtshof diejenigen, die rechtzeitig Schritte zur Wahrung ihrer Rechte unternommen haben, von der Begrenzung der zeitlichen Wirkungen aus, was von Generalanwältin Kokott als „ständige Rechtsprechung“ bezeichnet wird. ${ }^{1103}$ Schlagwortartig kann die Frage der Reichweite der

1100 Vgl. Müller, Begrenzung, 2009, S. 98. Kokott/Henze, NJW 2006, 177 (180) weisen auf die Gefahr einer abnehmenden Bereitschaft der Mitgliedstaaten zur Befolgung des Unionsrechts hin.

1101 Ablehnend auch Wiedmann, EuLF 2006, I-197 (I-201). Befürwortend dagegen GA Jacobs, Schlussanträge vom 17.3.2005 in der Rs. C-475/03 (Banca Popolare di Cremona), Rn. 86 mit dem Vorschlag einer Orientierung an der aus der Rechtsprechung des Bundesverfassungsgerichts bekannten Unvereinbarkeitserklärung; Forsthoff, DStR 2005, 1840 (1843); Schwarze, NJW 2005, 3459 (3465).

1102 Seer/Müller, IWB 2008, 255 (264) sprechen davon, dass eine fehlende Rückausnahme für einen Rechtsbehelfsführer letztlich ein „Pyrrhus-Sieg“ sei. „Er erhielte ,Steine statt Brot'.“

1103 GA Kokott, Schlussanträge vom 30.6.2016 in der Rs. C-443/15 (Parris), Rn. 163. In Fn. 89 verweist sie zutreffend darauf, dass der Gerichtshof in EuGH, Urteil vom 17.12.2015, verb. Rs. C-25/14 und C-26/14 (UNIS und Beaudout Père et Fils), Rn. 53 „ähnlich“ vorging. Dort spricht er zwar nur davon, dass „erhobene Klagen" unberührt bleiben und erwähnt die entsprechenden Rechtsbehelfe nicht. Eine Abkehr von der bisherigen Rechtsprechung ist darin aber nicht zu erblicken. Hätte er eine solche im Sinn gehabt, hätte sich der Gerichtshof deutlicher geäußert. 
Ausnahme von der zeitlichen Begrenzung mit dem Begriff der „Anlassfallwirkung" 1104 bezeichnet werden.

\section{aa) Begriff des Rechtsbehelfsführers}

Rechtsbehelfsführer ist, wer zum Zeitpunkt des eine unionsrechtliche Norm auslegenden Urteils des Gerichtshofs bereits Klage eingereicht oder einen entsprechenden Rechtsbehelf eingelegt hatte. Indem der EuGH auch Rechtsbehelfsführer in anderen als dem Ausgangsverfahren von der Beschränkung der zeitlichen Wirkungen ausnimmt, unterstreicht er die über das Ausgangsverfahren hinausgehende Wirkung seiner Rechtsprechung.

Mit dem Begriff der „Klage“ ist die Geltendmachung der Rechte vor einem mitgliedstaatlichen Gericht gemeint; mit einem „entsprechenden Rechtsbehelf" 1105 werden die Rechte außergerichtlich geltend gemacht. ${ }^{1106}$ Beide Begriffe sind unionsautonom auszulegen. Ob eine Klage erhoben oder ein Rechtsbehelf eingelegt worden ist, bestimmt sich dagegen nach nationalem Recht. ${ }^{1107}$ Ob ein Rechtsbehelf einer Klage „gleichwertig“1108 ist, richtet sich nach Unionsrecht, für das entscheidend ist, ob er "gleich“ einer Klage zur Durchsetzung des Unionsrechts geeignet ist. ${ }^{1109}$

\section{bb) Begründungsansätze}

Bevor auf Einzelfragen eingegangen werden kann, ist die grundsätzliche Frage nach der Begründung der „Rückausnahme für Rechtsbehelfsführer“ zu beantworten. Nahe liegt zunächst, sie auf das Gebot effektiven

1104 Begriff bei Sperlich, in: FS Ruppe, 2007, S. 551 (563 mit Fn. 42).

1105 EuGH, Urteil vom 9.3.2000, Rs. C-437/97 (EKW und Wein \& Co.), Rn. 60.

1106 EuGH, Urteil vom 26.4.1994, Rs. C-228/92 (Roquette Frères), Rn. 28 f. stellt die „Klage“ und den „außergerichtlichen Rechtsbehelf“ gegenüber; EuGH, Urteil vom 4.5.1999, Rs. C-262/96 (Sürül), Rn. 113 spricht von der gerichtlichen Klageerhebung und der Einlegung eines gleichwertigen Rechtsbehelfs.

1107 EuGH, Urteil vom 17.5.1990, Rs. C-262/88 (Barber), Rn. 45; EuGH, Urteil vom 15.12.1995, Rs. C-415/93 (Bosman), Rn. 145.

1108 Dieser Begriff wird etwa in EuGH, Urteil vom 10.3.1992, verb. Rs. C-38/90 und C-151/90 (Lomas u.a.), Rn. 30 verwendet, ebenso in EuGH, Urteil vom 15.12.1995, Rs. C-415/93 (Bosman), Rn. 145 und EuGH, Urteil vom 22.12.2008, Rs. C-333/07 (Régie Networks), Rn. 128 sowie EuGH, Urteil vom 4.5.1999, Rs. C-262/96 (Sürül), Rn. 113.

1109 Rosenkranz, Beschränkung der Rückwirkung, 2015, S. 374. 
Rechtsschutzes zu stützen, wie dies in Rechtsprechung und Literatur geschieht. ${ }^{1110}$

\section{(1) Effektiver Rechtsschutz}

Die Begründung mit dem Gebot effektiven Rechtsschutzes erweist sich im Ergebnis als tragfähig, wie die folgenden Überlegungen zeigen.

Mit der Rückausnahme ist eine Ungleichbehandlung der Rechtsbehelfsführer mit anderen dem Unionsrecht unterworfenen Rechtssubjekten verbunden. ${ }^{1111}$ Sie besteht darin, dass die Rechtsbehelfsführer die ex tunc-Wirkung in Anspruch nehmen können, während dies allen anderen Rechtsunterworfenen verwehrt ist. ${ }^{112}$ Im Falle des Erlasses eines Urteils mit zeitlicher Beschränkung haben die Letztgenannten keine Aussicht mehr darauf, ihre ihnen nach Unionsrecht eigentlich zustehenden Rechtspositionen durchzusetzen. Die für sie mit der Begrenzung der zeitlichen Wirkungen einhergehende und gerade bezweckte Einschränkung der Rechtsschutzmöglichkeiten ${ }^{1113}$ ist auf ihre Inaktivität zurückzuführen. Zwar mögen die Betroffenen mit der Einlegung eines Rechtsbehelfs aus scheinbar nachvollziehbaren Gründen noch gezögert haben, etwa um ihre Ansprüche zunächst noch genauer zu prüfen oder um ein Urteil eines nationalen Gerichts abzuwarten. ${ }^{1114}$ Dies ändert aber nichts daran, dass sie sich gescheut haben, sich einem Prozessrisiko auszusetzen. Die Rechtsbehelfsführer haben sich dagegen trotz unionsweit in die entgegengesetzte Richtung weisenden guten Glaubens nicht von der Einlegung ihrer Rechtsbehelfe abbringen lassen.

Bei der Bestimmung der Tatbestandsvoraussetzungen einer Begrenzung in zeitlicher Hinsicht ist das Gebot effektiven Rechtsschutzes nicht von

1110 EuGH, Urteil vom 4.5.1999, Rs. C-262/96 (Sürül), Rn. 112 (Auslegungsvorlage); EuGH, Urteil vom 26.4.1994, Rs. C-228/92 (Roquette Frères), Rn. 27 (Ungültigkeitsvorlage). Aus der Literatur Kovács, Temporale Wirkung, 2014, S. 243 f.; Schaer, Grenzen rückwirkender Rechtsprechung, 2010, S. 101; Osterloh, in: FS Hassemer, 2010, S. 173 (178); Schlachter, ZfA 2007, 249 (266); Düsterhaus, EuR 2017, 30 (54). Düsterhaus, YEL 36 (2017), 237 (272 f.) bezeichnet die Anordnung einer Rückausnahme daher als zwingend.

1111 Vgl. Düsterhaus, EuZW 2006, 393 (397); Forsthoff, DStR 2005, 1840 (1843); Koopmans, C.L.J. 39 (1980), 287 (299 f.).

1112 Siehe hierzu etwa die Übersicht bei van der Stok/Thomson, Intertax 34 (2006), $552(556)$.

1113 Zutreffend Rosenkranz, Beschränkung der Rückwirkung, 2015, S. 360.

1114 Darauf weist Bydlinski, JBl. 2001, 2 (9) hin. 
durchschlagender Bedeutung, da insoweit angesichts der unionsweiten Bedeutung der zeitlichen Wirkung unionsrechtlicher Normen ein generalisierender Maßstab zu Grunde zu legen ist. ${ }^{1115}$ Insbesondere werden hier der Grundsatz der einheitlichen Anwendung des Unionsrechts und der Grundsatz der Rechtssicherheit in Ausgleich gebracht. Mehr Raum für die Beachtung individueller Rechtspositionen bietet sich dagegen im Rahmen der Bestimmung der Reichweite einer Begrenzung in persönlicher Hinsicht. An dieser Stelle kann daher der Rechtsschutzfunktion des Vorabentscheidungsverfahrens Rechnung getragen werden. ${ }^{1116}$

$\mathrm{Ob}$ ein Betroffener mit seinem Rechtsbehelf im Ergebnis erfolgreich ist, ihm seine unionsrechtlichen Rechtspositionen also gewährt werden, stellt im Hinblick auf den effektiven Rechtsschutz einen nicht nur graduellen, sondern qualitativen Unterschied dar. Ein eingelegter Rechtsbehelf erscheint aus Rechtsschutzgründen also entscheidend schutzwürdiger als ein nicht eingelegter Rechtsbehelf. Es ist daher gerechtfertigt, die Grenze des schutzwürdigen Rechtsschutzinteresses danach zu bestimmen, ob ein Rechtsbehelf eingelegt worden ist oder nicht. ${ }^{1117}$ Hinzu kommt Folgendes: Diejenigen, die schon vor dem Urteil des Gerichtshofs einen Rechtsbehelf eingelegt hatten, machen anders als diejenigen, die ihn danach einlegen, keine rückwirkende Anwendung des Unionsrechts geltend, da ihr Rechtsbehelf dem Urteil vorausgeht. Auch deshalb kommen erstere in den Genuss der Rückausnahme. ${ }^{1118}$

Zuzugeben ist, dass der EuGH dadurch, dass er das Ende des Tages vor der Urteilsverkündung als spätesten Zeitpunkt für die Einlegung eines Rechtsbehelfs ansieht, etwa diejenigen Betroffenen von der Begünstigung durch die Rückausnahme ausschließt, deren Rechtsbehelfsfrist eben erst zu laufen begann. Insoweit spielt es nämlich keine Rolle, wann diese jeweils zu laufen begann bzw. wann sie endet. Das Gebot effektiven Rechtsschutzes wird daher vom EuGH nicht mit allerletzter Konsequenz durchgesetzt.

1115 Anders Rosenkranz, Beschränkung der Rückwirkung, 2015, S.360, der das Rechtsschutzinteresse des Klägers als Ausprägung der „Objektivität des Unionsrechts" (Anführungszeichen im Original) ansieht.

1116 Eine solche frühzeitig anerkennend GA Roemer, Schlussanträge vom 16.12.1963 in den verb. Rs. 73/63 und 74/63 (Internationale Crediet- en Handelsvereniging Rotterdam), Slg. 1964, S.47. Er sieht darin einen teilweisen Ausgleich für die von ihm als unbefriedigend bezeichnete Einschränkung des Rechtsschutzes im Rahmen der Nichtigkeitsklage.

1117 Abweichend Rosenkranz, Beschränkung der Rückwirkung, 2015, S. 361.

1118 Düsterhaus, YEL 36 (2017), 237 (247 f.). 
Dies ist aber vor dem Hintergrund, dass die Rückausnahme auf diese Weise handhabbar gemacht werden kann, hinzunehmen.

\section{(2) Praktische Wirksamkeit des Vorabentscheidungsverfahrens}

Bei der Begründung der Rückausnahme für Rechtsbehelfsführer in Rechtsprechung und Literatur spielt zudem die praktische Wirksamkeit des Art. 267 AEUV und damit die Bedeutung privater Rechtsdurchsetzung für das Unionsrecht eine Rolle. ${ }^{119}$ Dagegen einzuwenden, das Unionsrecht werde auch ohne ex tunc-Wirkung zwar eingeschränkt, aber immerhin für die Zukunft durchgesetzt, überzeugt nicht. ${ }^{1120}$ Wenn mangels Rückausnahme niemand die ex tunc-Wirkung geltend machen könnte, bestünde kein echter Anreiz zur Einleitung von Verfahren, die den Anstoß zur Durchsetzung des Unionsrechts geben. Ein solcher Anreiz wird nur durch eine Rückausnahme geschaffen, von der die Rechtsbehelfsführer profitieren.

Die Argumentation, dass Rechtsbehelfsführer zur allgemeinen Durchsetzung des Unionsrechts beigetragen haben, passt allerdings nicht recht für die Fälle, in denen das vorlegende Gericht von sich aus, ohne Anregung durch den Rechtsbehelfsführer, die Frage der Auslegung des Unionsrechts aufgeworfen hat. ${ }^{1121}$ Die Bedeutung der Rechtsbehelfsführer ist dort auf die Einleitung des jeweiligen Ausgangsverfahrens beschränkt. Diese führten aber immerhin jeweils erst zu der Vorlage an den EuGH, sodass dem Argument der Bedeutung für die Durchsetzung des Unionsrechts auch dort zumindest untergeordnete Bedeutung zukommt.

\section{(3) Rückausnahme und Entscheidungserheblichkeit}

Nicht zielführend ist dagegen eine dahingehende Argumentation, dass die Rückausnahme auch im Ausgangsverfahren zur Anwendung kommen müsse, da einerseits die vom Gerichtshof im Vorabentscheidungsverfahren

1119 EuGH, Urteil vom 8.2.1996, Rs. C-212/94 (FMC u.a.), Rn. 58 (Ungültigkeitsvorlage); Kokott/Henze, NJW 2006, 177 (182); Osterloh, in: FS Hassemer, 2010, S. 173 (178); Hyland, IJEL 2 (1995), 208 (229).

1120 So aber Rosenkranz, Beschränkung der Rückwirkung, 2015, S. 361.

1121 Sperlich, in: FS Ruppe, 2007, S. 551 (561 f.); zustimmend Seer/Müller, IWB 2008, 255 (266). 
vorgenommene Auslegung sonst nicht entscheidungserheblich sei und die nationalen Gerichte dann an der Vorlage gehindert wären ${ }^{1122}$ und andererseits dem Rechtsbehelfsführer das Abwarten des EuGH-Urteils unzumutbar sei, wenn die Vorabentscheidung für die Entscheidung des Ausgangsverfahrens ohne Relevanz sei ${ }^{1123}$.

Geht man nämlich davon aus, dass eine Auslegung nicht entscheidungserheblich ist, wenn die zeitlichen Wirkungen beschränkt werden und erst dadurch entscheidungserheblich wird, dass trotz einer solchen Beschränkung eine Rückausnahme vorgesehen wird, dürfte eigentlich schon die ex tunc-Wirkung nicht beschränkt werden. Eine Begrenzung der ex tuncWirkung wäre ja nur dann für das Ausgangsverfahren entscheidungserheblich, wenn sie nicht mit einer Rückausnahme versehen ist. Sieht sie dagegen eine Rückausnahme vor, wäre sie für das Ausgangsverfahren unerheblich. ${ }^{1124}$ Wenn aber die ex tunc-Wirkung mangels Entscheidungserheblichkeit nicht begrenzt werden dürfte, müsste es in allen Fällen bei der „normalen“ ex tunc-Wirkung verbleiben. Damit würde der gesamten Defrenne-Rechtsprechung die Grundlage entzogen. Diese Konsequenz wird von den Befürwortern des Arguments aber nicht gezogen. ${ }^{1125}$

Festzuhalten bleibt, dass das nationale Gericht der Entscheidung des EuGH auch dann Folge leisten müsste, wenn der Gerichtshof keine Rückausnahme vorgesehen haben sollte. Der Antwort des Gerichtshofs auf das Vorabentscheidungsersuchen wäre in diesem Fall die Aussage zu entnehmen, dass sich für Zeiten vor Urteilserlass niemand auf die Auslegung des Unionsrechts berufen kann und damit auch der Kläger des Ausgangsverfahrens nicht. Auch dies ist für das nationale Vorlagegericht eine für den Erlass seines Urteils erhebliche Entscheidung.

1122 Schima, Vorabentscheidungsverfahren, 2. Aufl. 2004, S. 107; Seer/Müller, IWB 2008, 255 (266).

1123 Sperlich, in: FS Ruppe, 2007, S. 551 (568 f. und 555 mit einem Hinweis auf Art. 6 EMRK); siehe auch Seer/Müller, IWB 2008, 255 (266).

1124 Rosenkranz, Beschränkung der Rückwirkung, 2015, S. $57 \mathrm{f}$.

1125 Rosenkranz, Beschränkung der Rückwirkung, 2015, S. $58 \mathrm{f}$. erachtet daher einen anderen Zugang zum Begriff der Entscheidungserheblichkeit als vorzugswürdig, wonach nicht nur das entscheidungserheblich ist, was den Ausgangsfall entscheidet, sondern auch das, was „zur Klärung des Inhalts des Unionsrechts beiträgt und so seine einheitliche Anwendung sicherstellt". Auf diese Weise wird die Bedeutung des Vorabentscheidungsverfahrens für die Entwicklung des Unionsrechts sichtbarer. 
cc) Andere Rechtsbehelfsführer

Dass neben dem Kläger des Ausgangsverfahrens noch weitere Rechtsbehelfsführer unter die Rückausnahme fallen, erscheint auf den ersten Blick nur dann gerechtfertigt, wenn Argumente gefunden werden können, die für eine Gleichbehandlung von "Quasianlassfall“ und „Anlassfall“ sprechen. Voraussetzung wäre dann, dass es sich bei den „Quasianlassfällen“ um Fälle handelt, die ebenso gut den „Anlassfall“ hätten darstellen können, sodass sie bei einer vorlageberechtigten Instanz anhängig sein müssten. ${ }^{1126}$ Dies ist allerdings für den Gerichtshof nicht entscheidend; nach seiner Auffassung muss lediglich der Rechtsweg beschritten sein. Hinsichtlich der außerhalb des Ausgangsverfahrens auftretenden Rechtsbehelfsführer ist daher festzustellen, dass für ihre Privilegierung nicht entscheidend ist, ob sie den Rechtsbehelf derart frühzeitig eingelegt haben, dass es als zufällig erscheint, dass nicht „ihr“, sondern ein anderer Fall zum EuGH gelangt ist. Unerheblich ist für den Gerichtshof auch, ob sie ihn mit dem Ziel der Durchsetzung des Unionsrechts eingelegt haben.

dd) Ausnahmen von der Rückausnahme?

Ist geklärt, wer unter die Rückausnahme fällt und wie sie begründet werden kann, ist der Blick auf mögliche Ausnahmen von der Rückausnahme zu richten. Eine Ausnahme von der Rückausnahme ist dann zu erwägen, wenn die Rückausnahme die Begrenzung der ex tunc-Wirkung „konterkarieren" würde. Die Ausnahme von der Rückausnahme würde dazu führen, dass sich auch ein Rechtsbehelfsführer nicht auf die ex tunc-Wirkung berufen könnte. Hinter den Überlegungen zur Ausnahme von der Rückausnahme steht die Erwägung, dass die Begrenzung der zeitlichen Wirkungen effektiv sein muss, um dem Gebot der Rechtssicherheit tatsächlich Rechnung zu tragen. ${ }^{1127}$ Der Gerichtshof hat sich zu der hier untersuchten Frage noch nicht geäußert.

1126 So Sperlich, in: FS Ruppe, 2007, S. 551 (568f.), auf die auch die Verwendung dieses Begriffspaars zurückgeht; siehe auch Düsterhaus, EuZW 2006, 393 (395).

1127 Forsthoff, DStR 2005, 1840 (1843). 
(1) Rein wirtschaftliche Überlegungen

Erforderlich erscheint eine Ausnahme von der Rückausnahme für Rechtsbehelfsführer dann, wenn die wirtschaftlichen Auswirkungen aufgrund der Rückausnahme derart schwerwiegend wären, dass der vor ihnen mit der Begrenzung der ex tunc-Wirkung bezweckte Schutz nicht mehr gewährleistet wäre. Unerheblich ist dabei, aus welcher Motivationslage heraus die Betroffenen Rechtsbehelfe eingelegt haben. ${ }^{1128}$

Die Ausnahme von der Rückausnahme erfolgt in dem hier in den Blick genommenen Fall daher aus allein wirtschaftlichen Gründen. Ist absehbar, dass bereits wenige Rechtsbehelfe schwerwiegende wirtschaftliche Auswirkungen zeitigen, bleibt letztlich nur eine Alles-oder-Nichts-Lösung übrig. Würde durch eine Rückausnahme die Begrenzung der ex tunc-Wirkung konterkariert, muss sie konsequenterweise für alle Rechtsbehelfsführer entfallen. Dann kann auch der Kläger des Ausgangsverfahrens nicht bevorzugt werden. ${ }^{1129}$

\section{(2) Trittbrettfahrerproblematik}

Etwas anders gelagert ist die Situation bei der sogenannten „Trittbrettfahrerproblematik“. Dort werden angesichts der besonderen Publizität eines Vorabentscheidungsverfahrens in Erwartung eines günstigen Urteils des Gerichtshofs Rechtsbehelfe eingelegt, um in den Genuss der Rückausnahme für Rechtsbehelfsführer zu gelangen. Aufgrund der Fülle an eingelegten Rechtsbehelfen kommt es dann auch hier zu einer Situation, in der die Rückausnahme zu einer Gefahr schwerwiegender Störungen führt, vor der die Begrenzung der zeitlichen Wirkungen gerade bewahren sollte.

Die Bezeichnung als „Trittbrettfahrer“ legt bereits nahe, dass dieser Art von Rechtsbehelfsführern die Schutzwürdigkeit abgesprochen wird, die bei Rechtsbehelfsführern ansonsten bejaht wird. Daher steht die Überlegung im Raum, eine Rückausnahme lediglich für „sorgfältige Anspruchsteller"1130 vorzusehen. Dabei von der Vorstellung auszugehen, dass ein

1128 Vgl. Müller, Begrenzung, 2009, S. 93.

1129 A.A. Rosenkranz, Beschränkung der Rückwirkung, 2015, S. 367.

1130 GA Stix-Hackl, Schlussanträge vom 14.3.2006 in der Rs. C-475/03 (Banca Popolare di Cremona), Rn.181. Siehe auch Sperlich, in: FS Ruppe, 2007, S. 551 (567 f.): Abgrenzung „,engagierte[r] $]^{\varsigma}$ Forderungen von solchen von ,Trittbrettfahrern“"; Wiedmann, EuLF 2006, I-197 (I-201 f., I-203): Unterscheidung beson- 
Rechtsbehelfsführer desto schutzwürdiger erscheint, je weiter zeitlich entfernt vom Urteil des Gerichtshofs er den Rechtsbehelf eingelegt hat, überzeugt allerdings von vornherein nicht. ${ }^{1131}$ Wie eine Entscheidung des Gerichtshofs ausfallen wird, ist bis zur Urteilsverkündung nicht sicher, weshalb bis dahin auf jeden Fall ein Risiko besteht. Die Trittbrettfahrerproblematik dadurch zu bewältigen, im Einzelfall zu ermitteln, wann das Prozessrisiko nur noch als sehr niedrig einzuschätzen ist, wofür eine wertende Entscheidung hinsichtlich der Rechtzeitigkeit der Rechtsverfolgung entscheidend sein soll, kann daher nicht überzeugen. ${ }^{1132}$ Deutlich wird, dass nicht geleugnet werden kann, dass die Festlegung eines in allen Fällen überzeugenden Zeitpunkts im Umgang mit „Trittbrettfahrern“ mit einem gewissen Willkürelement verbunden ist. ${ }^{1133}$ Begründet liegt dies in dem Umstand, dass subjektive Wertungen ins Spiel kommen, was aufgrund der Schwierigkeiten, persönliche Motivationen zu erforschen, jedoch von vornherein Bedenken begegnet. ${ }^{1134}$

Hinsichtlich der Bestimmung des Zeitpunkts, bis zu dem der Rechtsbehelf eingelegt sein muss, um noch als schutzwürdig zu erscheinen, bestehen unterschiedliche Vorschläge. Den meisten von ihnen ist gemein, dass sie das Leerlaufen der zeitlichen Beschränkung nicht als Problem des Stichtags der Begrenzung, sondern der Rückausnahme ansehen. ${ }^{1135}$ Ihnen geht es damit um eine „rechtsfolgenorientierte Lösung“. ${ }^{1136}$

Der Zeitpunkt eines früheren Urteils erscheint als Bezugspunkt nicht geeignet. Hat der EuGH im erstauslegenden Urteil keine Begrenzung vorgenommen, scheidet sie im nachfolgenden Urteil bei einer identischen Rechtsfrage angesichts der eingetretenen Präklusion in aller Regel ${ }^{1137}$ aus. Dann kann es auch keine Rückausnahme geben, von der Ausnahmen in

ders aufmerksamer Rechtsunterworfener von Trittbrettfahrern; Forsthoff, DStR 2005, 1840 (1843).

1131 So aber Ludewig, Zeitliche Beschränkung, 2012, S. $214 \mathrm{f}$.

1132 So aber Wusterhausen, Wirkungen, 2016, S. 412. Siehe auch Seer/Müller, IWB 2008, 255 (267) und ihre Überlegungen zur „Wahrscheinlichkeitsschwelle des Unterliegens“ und zum „Risikoerwartungswert in Geldeinheiten“.

1133 Seer/Müller, IWB 2008, 255 (267).

1134 Sperlich, in: FS Ruppe, 2007, S. 551 (571), die daher ein Abstellen auf objektive Gesichtspunkte vorschlägt.

1135 Ludewig, Zeitliche Beschränkung, 2012, S. 191 f.; Kokott, The jurisprudence, Vortrag Florenz 2006, S. 8.

1136 Düsterhaus, EuZW 2006, 393 (395).

1137 Eine Nachholung der Begrenzung ist nach hier vertretener Auffassung nur bei einer Fehleinschätzung des Gerichtshofs im Hinblick auf das Vorliegen der Begrenzungsvoraussetzungen möglich, wenn ihm vollständige und zutreffen- 
Erwägung zu ziehen sind. Geht es im späteren Verfahren dagegen lediglich um eine „entfernt ähnliche“ Rechtsfrage, ist die Begrenzung nicht präkludiert. Es ist aber eben auch unsicher, wie der EuGH entscheiden wird. Wer aufgrund des ersten Urteils einen Rechtsbehelf einlegt, ist daher kein „Trittbrettfahrer“. ${ }^{1138}$

Vorgeschlagen wird daher zum Teil das Datum der Verlesung der Schlussanträge, da sich damit das Prozessrisiko verringert, die Wahrscheinlichkeit also erhöht habe, in einem nach ihrer Verlesung angestrengten Verfahren zu obsiegen. ${ }^{1139} \mathrm{Da}$ der Gerichtshof an die Schlussanträge nicht gebunden ist, kann ein solcher Zusammenhang aber letztlich nicht begründet werden. Gegen den Vorschlag, auf das Verkündungsdatum des Vorlagebeschlusses oder dessen Eingang beim Gerichtshof abzustellen, da der Veröffentlichung des Vorlagebeschlusses im Amtsblatt anderweitige Veröffentlichungen etwa in Fachzeitschriften vorausgehen können ${ }^{1140}$, ist einzuwenden, dass jedenfalls die amtliche Veröffentlichung aus Rechtsschutzgründen zwingend erscheint, um eine Kenntnisnahmemöglichkeit für alle Betroffenen zu gewährleisten. ${ }^{1141}$ Am ehesten zu überzeugen vermag daher der Vorschlag, den Zeitpunkt der Veröffentlichung des Vorlagebeschlusses im Amtsblatt als entscheidend anzusehen. ${ }^{1142}$

Angesichts der Schwierigkeiten bei der Bestimmung eines geeigneten Zeitpunkts ist der Vorschlag von Rosenkranz, die Trittbrettfahrerproblematik beim Gutglaubenserfordernis zu verorten, da es dieser Gruppe

de Tatsachen vorgetragen wurden, siehe dazu ausführlich oben bei Fn. 923 ff., insb. bei Fn. $940 \mathrm{ff}$.

1138 Wie hier Ludewig, Zeitliche Beschränkung, 2012, S. 217 f.

1139 GA Stix-Hackl, Schlussanträge vom 14.3.2006 in der Rs. C-475/03 (Banca Popolare di Cremona), Rn. 172. Sie räumt ein, dass die Festlegung eines konkreten Zeitpunkts zur Bewältigung der Trittbrettfahrerproblematik nicht frei von Willkür sei; mit dem Zeitpunkt der Verlesung der Schlussanträge habe aber eine „echte Wahrscheinlichkeit“ für eine entsprechende Entscheidung des Gerichtshofs bestanden. Die Rechtssache Banca Popolare di Cremona, in der sie diese Ausführungen macht, ist allerdings insofern ein Sonderfall, als GA Jacobs in dieser bereits zuvor ebenfalls Schlussanträge vorgelegt hatte.

1140 So der Vorschlag von Forsthoff, DStR 2005, 1840 (1844, Fn. 37).

1141 Düsterhaus, EuR 2017, 30 (54 f. mit Fn. 175), Düsterhaus, YEL 36 (2017), 237 (273 mit Fn. 255), der damit sein in EuZW 2006, 393 (397) befürwortetes Abstellen auf den Erlass des Vorlagebeschlusses im Ausgangsfall „präzisiert“.

1142 GA Tizzano, Schlussanträge vom 10.11.2005 in der Rs. C-292/04 (Meilicke u.a.), Rn. 62. Als einen möglichen Zeitpunkt in Betracht ziehend auch Schaer, Grenzen rückwirkender Rechtsprechung, 2010, S. 105; ablehnend dagegen Müller, Begrenzung, 2009, S. 95; siehe auch Ludewig, Zeitliche Beschränkung, 2012, S. 219. 
an Rechtsbehelfsführern an gutem Glauben fehle, jedenfalls erwägenswert. ${ }^{1143}$ Eine Verortung beim guten Glauben legt etwa auch Generalanwältin Stix-Hackl nahe, wenn sie von einer Vorhersehbarkeit des Urteilsinhalts mit „echter Wahrscheinlichkeit" spricht. ${ }^{1144}$ Eine Fruchtbarmachung des Kriteriums des guten Glaubens führt allerdings dazu, keinen wie sonst üblich objektivierten Gutglaubensmaßstab, sondern - durch die Bewertung ihrer Motivation - einen auf die Rechtsbehelfsführer abstellenden Maßstab an diese anzulegen. Ein solcher Maßstab führt auch zur Benachteiligung des Rechtsbehelfsführers gegenüber seinem Prozessgegner. Obwohl die Unionsrechtswidrigkeit für diesen „erkennbar“ war, schadet ihm sein fehlender guter Glaube anders als dem „Trittbrettfahrer" nicht. Gegen eine Benachteiligung des Rechtsbehelfsführers spricht auch, dass die Ursache für die Trittbrettfahrerproblematik letztlich im mitgliedstaatlichen Verfahrensrecht zu suchen ist, für das nicht die Union, sondern die Mitgliedstaaten verantwortlich sind. ${ }^{1145}$ Um diesen Einwänden Rechnung zu tragen, sieht Rosenkranz daher nur die Möglichkeit, den Endzeitpunkt des guten Glaubens insgesamt nach vorne zu verlagern, um so eine Trennung der Zeitpunkte, auf die die zeitliche Begrenzung und die Rückausnahme bezogen sind, zu vermeiden.

Klare Trennlinien können auf diese Weise letztlich nicht gezogen werden, da eine vom Einzelfall abhängige Wertung mit großen Unsicherheiten verbunden ist. Wann das Bestehen von gutem Glauben endet, ist kaum treffsicher zu bestimmen. ${ }^{1146}$ Betont werden sollte daher die Zulässigkeit der Ausnutzung von Rechtsschutzmöglichkeiten unabhängig von der persönlichen Motivation. ${ }^{1147}$ Konsequent ist es dann, wie auch in den „normalen“ Fällen eine Rückausnahme für alle Rechtsbehelfsführer bis zur Urteilsverkündung zuzulassen. ${ }^{1148}$ Lediglich in besonders gelagerten Ausnahmefällen ist wie in der Fallgruppe der rein wirtschaftlichen Überlegungen eine Alles-oder-Nichts-Lösung zu erwägen.

1143 Rosenkranz, Beschränkung der Rückwirkung, 2015, S. 218 ff.

1144 Siehe oben in Fn. 1139.

1145 Kokott/Henze, NJW 2006, 177 (179).

1146 Siehe auch Maurer, in: Isensee/Kirchhof (Hrsg.), HStR IV, 3. Aufl. 2006, $\mathbb{} 79$, Rn. 148 f. zum Problem der Erkennbarkeit von Rechtsprechungsänderungen. Als praktische Schwierigkeiten in diesem Zusammenhang identifiziert er, dass zum Teil unklar sei, ob und wann eine Rechtsprechungsänderung vorliege und es schwierig sei, diese sachlich und zeitlich klar abzugrenzen. Ähnliches gilt für die Frage der Beendigung des Bestehens von gutem Glauben.

1147 Müller, Begrenzung, 2009, S. 93.

1148 Seer/Müller, IWB 2008, 255 (267). 
ee) Vergleich mit den Unwirksamkeitsentscheidungen

Die Frage des Umgangs mit Rechtsbehelfsführern stellt sich auch bei Unwirksamkeitsentscheidungen. Bei diesen führt eine Rückausnahme dazu, dass die Norm für die von ihr erfassten Rechtsbehelfsführer unwirksam ist. Die Aufrechterhaltung der Wirkungen des für unwirksam erklärten Unionsrechtsakts hat für sie daher keine Bedeutung.

\section{(1) Ungültigkeitsvorabentscheidung}

Die Fortwirkungsanordnung bei der Ungültigkeitsvorabentscheidung ist nicht immer mit einer personellen Rückausnahme verbunden. ${ }^{1149}$

Sie ist lediglich die Regel. ${ }^{1150}$ Der Gerichtshof entscheidet hier von Fall zu Fall. So sieht er etwa in seinem Urteil zur Gültigkeit des sektorübergreifenden Korrekturfaktors im Emissionshandelssystem keine Ausnahme für Rechtsbehelfsführer vor. ${ }^{1151} \mathrm{Er}$ verweist zur Begründung auf seine Rechtsprechung aus dem Jahr 1994 in der Rechtssache Roquette Frères, wonach es ihm obliege, über die Ausnahme für Rechtsbehelfsführer zu entscheiden. Der Gerichtshof hält es demnach für möglich, dass auch für die Partei des Ausgangsverfahrens eine „nur in die Zukunft wirkende Feststellung der Ungültigkeit der Unionshandlung in angemessener Weise Abhilfe schafft". ${ }^{1152}$ Dass in dem in Bezug genommenen Verfahren zum

1149 Rosenkranz, Beschränkung der Rückwirkung, 2015, S.370; anders Müller, Begrenzung, 2009, S. 47 f.; Kovács, Temporale Wirkung, 2014, S. 237 f.; Lenaerts/Arts/Maselis, Procedural Law, 2. Aufl. 2006, Rn. 10-019; zurückhaltender Schwarze/Wunderlich, in: Schwarze/Becker/Hatje/Schoo (Hrsg.), EU-Kommentar, 4. Aufl. 2019, Art. 267 AEUV, Rn. 73: EuGH kann Rückausnahme vorsehen „und tut dies regelmäßig auch"; siehe auch Borchardt, in: Lenz/Borchardt (Hrsg.), EU-Verträge, 6. Aufl. 2012, Art. 264 AEUV, Rn. 8, 10 mit Blick auf Nichtigkeitsklage und Ungültigkeitsvorabentscheidung: EuGH und EuG behalten sich Rückausnahme vor.

1150 Ebenso Ludewig, Zeitliche Beschränkung, 2012, S. 263: „regelmäßige Rückausnahme“. Gundel, in: Ehlers (Hrsg.), Europäische Grundrechte und Grundfrei-

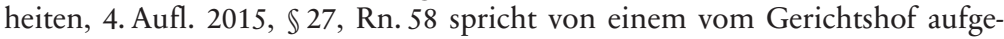
stellten „Grundsatz“.

1151 EuGH, Urteil vom 28.4.2016, verb. Rs. C-191/14, C-192/14, C-295/14, C-389/14 und C-391/14 bis C-393/14 (Borealis Polyolefine u.a.), Rn. 110.

1152 EuGH, Urteil vom 28.4.2016, verb. Rs. C-191/14, C-192/14, C-295/14, C-389/14 und C-391/14 bis C-393/14 (Borealis Polyolefine u.a.), Rn. 108 unter Verweis auf EuGH, Urteil vom 26.4.1994, Rs. C-228/92 (Roquette Frères), Rn. 25; zurückgehend auf EuGH, Urteil vom 27.2.1985, Rs. 112/83 (Société des produits 
sektorübergreifenden Korrekturfaktor im Emissionshandelssystem auch die Klägerinnen der Ausgangsverfahren - Treibhausgase ausstoßende Unternehmen - von der Begrenzung der zeitlichen Wirkungen erfasst werden, geschieht in der Tat in ihrem Interesse, da bei einem Korrekturfaktor, der nach seiner Überarbeitung im Anschluss an die Feststellung seiner Ungültigkeit höher ausfällt, die Anzahl an Emissionszertifikaten sinkt, was zu Lasten dieser Unternehmen ginge. ${ }^{1153}$

\section{(2) Nichtigkeitsklage}

Bei der Anordnung der Aufrechterhaltung der Wirkungen eines für nichtig erklärten Rechtsakts sucht man eine Rückausnahme für Rechtsbehelfsführer vergeblich. ${ }^{1154}$

In der Literatur wird insoweit ausgeführt, die Rückausnahme finde auf Nichtigerklärungen nach Art. 264 AEUV keine Anwendung, da es hier - im Gegensatz zum Vorabentscheidungsverfahren - lediglich um die Wirkungen auf Unionsebene und nicht um ihre Verknüpfung mit der mitgliedstaatlichen Rechtsordnung gehe. ${ }^{1155}$ Diese Unterscheidung zur Ungültigkeitsvorabentscheidung mag jedoch nicht recht einleuchten. $\mathrm{Ob}$ ein Unionsrechtsakt im Rahmen der Nichtigkeitsklage oder der Ungültigkeitsvorabentscheidung für unwirksam erklärt wird, macht insoweit keinen Unterschied, wie bereits die analoge Anwendung des Art. 264 II AEUV auf letztere zeigt.

ff) Fazit

Auffällig ist, dass der Gerichtshof eine Rückausnahme für Rechtsbehelfsführer durchgängig lediglich im Rahmen der Auslegungsvorabentscheidung vorsieht. Bei der Ungültigkeitsvorabentscheidung entscheidet der

de maïs), Rn. 18. Siehe auch EuGH, Urteil vom 15.1.1986, Rs. 41/84 (Pinna), Rn. 29.

1153 EuGH, Urteil vom 28.4.2016, verb. Rs. C-191/14, C-192/14, C-295/14, C-389/14 und C-391/14 bis C-393/14 (Borealis Polyolefine u.a.), Rn. 109; Positionspapier der DEHSt, Juni/Juli 2016, S. 5, 6.

1154 Costa/Peers, Steiner \& Woods EU Law, 14. Aufl. 2020, S. 293 weisen dennoch zu Recht auf die Bedeutung der Rechtsposition der Rechtsbehelfsführer hin.

1155 Dörr, in: Grabitz/Hilf/Nettesheim (Hrsg.), Recht der EU, Art. 264 AEUV, Rn. 14 (Stand: November 2012). 
EuGH jeweils im Einzelfall, während er bei der Nichtigkeitsklage von der Anordnung einer Rückausnahme absieht. Trotz vergleichbarer Probleme in allen Verfahrensarten wird die Frage der Rückausnahme also unterschiedlich behandelt. Fragen des individuellen Rechtsschutzes und der einheitlichen Durchsetzung von Unionsrecht stellen sich aber in allen Verfahrensarten, sodass eine Gleichbehandlung von Rechtsbehelfsführern unabhängig von der Verfahrensart angezeigt erschiene. ${ }^{1156}$ Insoweit ist eine Entscheidung von Fall zu Fall vorzugswürdig, um maßgeschneiderte Lösungen finden zu können.

\section{Unwirksamkeitsverfahren}

Im Rahmen der Besprechung der Rechtsfolgen einer zeitlichen Begrenzung bei Auslegungsentscheidungen wurde bereits auf die räumliche und persönliche Erstreckung einer Fortwirkungsanordnung in den Unwirksamkeitsverfahren hingewiesen. An dieser Stelle ist noch ihrer sachlichen und zeitlichen Erstreckung nachzugehen, nachdem ein Blick darauf geworfen wurde, welcher „Art“ die Befugnis des Gerichtshofs ist, von der er in (direkter oder analoger) Anwendung des Art. 264 II AEUV Gebrauch macht.

a) „Art“ der Befugnis

aa) Nichtigkeitsklage

Wörtlich übernimmt der Gerichtshof die Formulierung des Art.264 II AEUV („als fortgeltend zu betrachten“) in den Tenor nur in wenigen Fällen. ${ }^{1157}$ In der weit überwiegenden Zahl der Urteile hält er die Wirkungen der für nichtig erklärten Handlung aufrecht. ${ }^{1158}$ Vereinzelt geblieben ist

1156 Rosenkranz, Beschränkung der Rückwirkung, 2015, S. $371 \mathrm{f}$.

1157 EuGH, Urteil vom 26.3.1987, Rs. 45/86 (Kommission/Rat), Tenor Nr. 2; EuGH, Urteil vom 27.9.1988, Rs.51/87 (Kommission/Rat), Tenor Nr. 2; EuGH, Urteil vom 13.12.2001, Rs. C-93/00 (Parlament/Rat), Tenor Nr. 2; EuGH, Urteil vom 11.9.2003, Rs. C-445/00 (Österreich/Rat), Tenor Nr. 2.

1158 Siehe aus jüngerer Zeit etwa EuGH, Urteil vom 28.7.2016, Rs. C-660/13 (Rat/ Kommission), Tenor Nr. 2; EuGH, Urteil vom 14.6.2016, Rs. C-263/14 (Parlament/Rat), Tenor Nr. 2; EuGH, Urteil vom 17.3.2016, Rs. C-286/14 (Parlament/Kommission), Tenor Nr. 2; EuGH, Urteil vom 23.12.2015, Rs. C-595/14 
ein Abstellen auf die Wirkungen der Nichtigerklärung, die der Gerichtshof ausgesetzt hat. ${ }^{1159}$ Ein Abgehen von der üblichen Dogmatik war damit aber nicht verbunden.

Dem Wortlaut des Art. 264 II AEUV entsprechend ist das Vorgehen des Gerichtshofs zutreffend, die Wirkungen der für nichtig erklärten Handlung und nicht die Handlung selbst aufrechtzuerhalten. Die Aufrechterhaltung der Wirkungen ändert also nichts daran, dass der angefochtene Rechtsakt selbst ex tunc für nichtig erklärt wird. ${ }^{1160}$ Die Nichtigerklärung kann der EuGH also nicht zeitlich verzögern, weshalb Rechtsgrundlage der nach dem Urteil eingetretenen Wirkungen das Urteil und nicht der für nichtig erklärte Rechtsakt ist. ${ }^{1161}$

Ohne Gebrauchmachen von Art.264 II AEUV würden sämtliche Wirkungen des Rechtsakts beseitigt. ${ }^{1162}$ Mit Hilfe von Art. 264 II AEUV können diese Wirkungen dagegen ganz oder zum Teil bestehen bleiben. ${ }^{1163}$ Dass auch sämtliche Wirkungen eines für nichtig erklärten Rechtsakts aufrechterhalten werden können, folgt aus der Beobachtung, dass dem Wortlaut des Art.264 II AEUV keine Einschränkung hinsichtlich der

(Parlament/Rat), Tenor Nr. 2; EuGH, Urteil vom 16.4.2015, Rs. C-540/13 (Parlament/Rat), Tenor Nr. 2; EuGH, Urteil vom 16.4.2015, verb. Rs. C-317/13 und C-679/13 (Parlament/Rat), Tenor Nr. 2.

1159 EuGH, Urteil vom 7.9.2006, Rs. C-310/04 (Spanien/Rat), Tenor Nr. 2.

1160 Nicolaysen, Europarecht I, 2. Aufl. 2002, S.381; Dervisopoulos, in: Rengeling/Middeke/Gellermann (Hrsg.), Handbuch des Rechtsschutzes, 3. Aufl. 2014, \$7, Rn. 123; Ehricke, in: Streinz (Hrsg.), EUV/AEUV, 3. Aufl. 2018, Art. 264 AEUV, Rn.9; Rosenkranz, Beschränkung der Rückwirkung, 2015, S. 296. Siehe auch EuGH, Urteil vom 11.12.2007, Rs. C-161/06 (Skoma-Lux), Rn. 70, der davon spricht, dass der Rechtsakt als „nicht existierend“ anzusehen sei.

1161 Verstraelen, GLJ 14 (2013), 1687 (1697).

1162 EuGH, Urteil vom 23.12.2015, Rs. C-595/14 (Parlament/Rat), Rn. 28.

1163 Nach EuGH, Urteil vom 11.12.2007, Rs. C-161/06 (Skoma-Lux), Rn. 70 kann auch davon gesprochen werden, dass trotz der Nichtigerklärung „einige Rechtsfolgen dieses Aktes gleichwohl Bestand haben“. 
Reichweite der von ihm verliehenen Befugnis zu entnehmen ist. ${ }^{1164}$ Die aufrechterhaltenen Wirkungen wirken für und gegen jedermann. ${ }^{1165}$

bb) Ungültigkeitsvorabentscheidung

Vor dem Hintergrund der analogen Anwendung des Art. 264 II AEUV auf die Ungültigkeitsvorabentscheidung liegt zunächst eine Anlehnung an die im Rahmen der Nichtigkeitsklage verwendeten Formulierungen nahe.

Im Rahmen einer (aus Anlass einer Auslegungsvorabentscheidung erfolgten) zusammenfassenden Wiedergabe seiner Rechtsprechung greift der Gerichtshof tatsächlich die in Art. 264 II AEUV gewählte Formulierung auch für die Ungültigkeitsvorabentscheidung auf und führt aus, sowohl bei einer für nichtig als auch bei einer für ungültig erklärten Handlung halte er die Wirkungen der betroffenen Handlung aufrecht. ${ }^{1166}$

Bei genauerem Hinsehen tenoriert der Gerichtshof bei der Ungültigkeitsvorabentscheidung allerdings deutlich variabler, als er selbst vorgibt. Wenn er etwa denjenigen Marktteilnehmern, die Klage oder einen außergerichtlichen Rechtsbehelf eingelegt haben, die Berechtigung, sich auf die Ungültigkeit zu berufen, zuspricht, bedeutet dies im Umkehrschluss, dass für alle anderen Normadressaten die Berufung auf die Ungültigkeit ausgeschlossen ist. ${ }^{1167}$ An anderer Stelle heißt es, die Feststellung der Ungültigkeit könne nicht geltend gemacht werden. ${ }^{1168}$ Daneben finden sich auch Formulierungen wie: „Die festgestellte Ungültigkeit [...] berechtigt

1164 EuGH, Urteil vom 7.7.1992, Rs. C-295/90 (Parlament/Rat), Rn. 27 etwa hält ausdrücklich alle Wirkungen der für nichtig erklärten Richtlinie aufrecht. Auch EuGH, Urteil vom 27.9.1988, Rs. 51/87 (Kommission/Rat), Rn. 22 spricht allgemein davon, dass „die Wirkungen der beiden für nichtig erklärten Verordnungen [...] als fortgeltend zu betrachten [sind]". Siehe auch EuGH, Urteil vom 23.12.2015, Rs. C-595/14 (Parlament/Rat), Rn. 29: „wenn die Wirkungen [...] vollständig aufrechterhalten werden sollten" (Hervorhebung nur hier).

1165 Rosenkranz, Beschränkung der Rückwirkung, 2015, S. 297.

1166 EuGH, Urteil vom 8.9.2010, Rs. C-409/06 (Winner Wetten), Rn. 66.

1167 EuGH, Urteil vom 26.4.1994, Rs. C-228/92 (Roquette Frères), Tenor Nr.2 und 3.

1168 EuGH, Urteil vom 10.3.1992, verb. Rs. C-38/90 und C-151/90 (Lomas u.a.), Tenor Nr. 2. 
nicht dazu [...] in Frage zu stellen“1169 oder „Die Ungültigkeit [...] lässt es nicht zu, die Wirkungen [...] in Frage zu stellen [...]"1170.

Die hier mitunter zu beobachtende Ähnlichkeit zur Tenorierung bei der Auslegungsvorabentscheidung ${ }^{1171}$ ist nicht auf eine angebliche Vergleichbarkeit von Auslegungs- und Ungültigkeitsvorabentscheidung zurückzuführen. Vielmehr ist sie dem Umstand geschuldet, dass ein für ungültig erklärter Unionsrechtsakt nicht aus der Unionsrechtsordnung entfernt wird, sondern lediglich nicht mehr angewandt werden darf. Der Ausschluss der Berufung auf die Ungültigkeit bzw. der Ausschluss ihrer Geltendmachung trägt dieser Besonderheit eher Rechnung als die Aufrechterhaltung der Wirkungen des für ungültig erklärten Rechtsakts. ${ }^{1172}$ Auch im Rahmen der Ungültigkeitsvorabentscheidung entfaltet die Entscheidung des Gerichtshofs über die Begrenzung der zeitlichen Wirkungen erga omnesWirkung. ${ }^{1173}$

Einen interessanten Sonderfall bildet eine Tenorierung, wonach die Wirkungen der Feststellung der Ungültigkeit auszusetzen sind. ${ }^{1174}$ Werden die Wirkungen der Ungültigkeit lediglich ausgesetzt ${ }^{1175}$, werden die Wirkungen des rechtswidrigen Rechtsakts nicht endgültig bis zu einem zukünftigen Zeitpunkt aufrechterhalten. Die nur aufgeschobene Ungültig-

$1169 \mathrm{EuGH}$, Urteil vom 15.10.1980, Rs. 4/79 (Providence agricole de la Champagne), Tenor Nr. 2; EuGH, Urteil vom 15.10.1980, Rs.109/79 (Maïseries de Beauce), Tenor Nr.2; EuGH, Urteil vom 15.10.1980, Rs. 145/79 (Roquette Frères) spricht im Tenor Nr.3 nur von „Die Ungültigkeit $[\ldots]$ “. Siehe auch EuGH, Urteil vom 15.1.1986, Rs. 41/84 (Pinna), Tenor Nr. 2: „Die festgestellte Ungültigkeit [...] kann nicht [...] herangezogen werden [...]"; EuGH, Urteil vom 22.5.1985, Rs. 33/84 (Fragd), Tenor: „Die Ungültigerklärung der betreffenden Bestimmungen [...] berechtigt nicht dazu, [...] in Frage zu stellen“.

1170 EuGH, Urteil vom 9.11.2010, verb. Rs. C-92/09 und C-93/09 (Volker und Markus Schecke und Eifert), Tenor Nr. 2.

1171 Dazu oben bei Fn. 429 ff.

1172 Vgl. Pietrek, Vorabentscheidungen, 1989, S. 45; a.A. Rosenkranz, Beschränkung der Rückwirkung, 2015, S. 309.

1173 Vgl. Pietrek, Vorabentscheidungen, 1989, S. 57, siehe auch S. 225.

1174 EuGH, Urteil vom 22.12.2008, Rs. C-333/07 (Régie Networks), Tenor Nr. 2: „Die Wirkungen der Feststellung der Ungültigkeit der besagten Entscheidung der Kommission der Europäischen Gemeinschaften vom 10. November 1997 sind bis zum Erlass einer neuen Entscheidung durch die Kommission gemäß Art. 88 EG auszusetzen." Siehe in ebendiesem Sinne auch Rn. 126 und 128 des Urteils.

1175 Streitig ist insoweit, ob der Gerichtshof dies im Régie Networks-Urteil vorgesehen hat, siehe hierzu Gundel, EWS 2009, 350 (357; siehe auch Fn. 89) und den Ansatz bei GA Kokott, Schlussanträge vom 26.6.2008 in der Rs. C-333/07 (Régie Networks), Rn. $132 \mathrm{ff}$. 
keit wirkt dann nach Ablauf der für die Aussetzung vorgesehenen Frist zurück; die Wirkung der Ungültigkeit tritt dann unbeschränkt ex tunc ein und nicht wie sonst ex nunc. ${ }^{1176}$

\section{cc) Abgrenzungen}

Nicht mit den bisher angesprochenen Fällen zu verwechseln ist der Fall, dass der EuGH eine Vorschrift für einen Übergangszeitraum als rechtmäBig ansieht und danach für ungültig erklärt. Als Beispiel sei hier das Urteil in der Rechtssache Association belge des Consommateurs Test-Achats u.a. angeführt.

Dort hatte er ausgeführt, dass die Gestattung gegenüber Mitgliedstaaten in Art. 5 II RL 2004/113/EG 1177 , eine Ausnahme von der Regel geschlechtsneutraler Prämien und Leistungen im Versicherungssektor unbefristet aufrechtzuerhalten, gegen Art. 21 und 23 GRCh verstößt. ${ }^{1178}$ Von Interesse ist im vorliegenden Zusammenhang die zeitliche Dimension dieser Feststellung des Gerichtshofs.

Betrachtet man zunächst eine vom Gerichtshof in einem späteren Urteil mit Blick auf das Test-Achats-Urteil getroffene Aussage, so fällt auf, dass er dort den diskriminierenden Charakter des Art. 5 II RL 2004/113/EG betont und meint, er habe im Test-Achats-Urteil klargestellt, dass jene Bestimmung als ungültig anzusehen sei. Damit erweckt der Gerichtshof den Eindruck, dass Art. 5 II RL 2004/113/EG zu jedem Zeitpunkt gegen höherrangiges Recht verstoßen habe. ${ }^{1179}$ Allerdings bezieht sich der Gerichtshof bei dieser Aussage verkürzend nur auf Rn. 32 seines Test-Achats-Urteils. ${ }^{1180}$ In die Betrachtung miteinzubeziehen sind daher auch die in den folgenden Randnummern des Test-Achats-Urteils gemachten Ausführungen, wonach Art. 5 II RL 2004/113/EG aufgrund seiner Unvereinbarkeit mit Art. 21 und 23 GRCh nach Ablauf einer angemessenen Übergangszeit als ungültig

1176 Rosenkranz, Beschränkung der Rückwirkung, 2015, S. 324, 357.

1177 Richtlinie 2004/113/EG des Rates vom 13. Dezember 2004 zur Verwirklichung des Grundsatzes der Gleichbehandlung von Männern und Frauen beim Zugang zu und bei der Versorgung mit Gütern und Dienstleistungen, ABl. L 373 vom 21.12.2004, S. 37.

1178 EuGH, Urteil vom 1.3.2011, Rs. C-236/09 (Association belge des Consommateurs Test-Achats u.a.), Rn. 32.

1179 Vgl. Hoffmann, ZIP 2011, 1445 (1451).

1180 EuGH, Urteil vom 3.9.2014, Rs. C-318/13 (X), Rn. 49. 
anzusehen und mit Wirkung vom 21.12.2012 ungültig sei. ${ }^{1181}$ Wenn die Bestimmung aber erst nach einer Übergangszeit als ungültig anzusehen ist ${ }^{1182}$, ist sie bis dahin als rechtmäßig und daher gültig anzusehen. Art. 5 II RL 2004/113/EG ist demnach vom EuGH nicht mit ex tunc-Wirkung für ungültig erklärt worden.

In diesem Fall ist für eine Beschränkung der zeitlichen Wirkungen im Sinne von Art. 264 II AEUV kein Raum. ${ }^{1183}$ Die Einschätzung, dass Art. 264 II AEUV keine Anwendung fand, wird durch einen Vergleich mit den Schlussanträgen in dieser Rechtssache bestätigt, in denen sich Generalanwältin Kokott für eine entsprechende Anwendung des Art. 264 II AEUV ausgesprochen hatte ${ }^{1184}$ und auf die der Gerichtshof keinen Bezug nimmt. Am 21.12.2012 ist Art. 5 II RL 2004/113/EG ex nunc unwirksam geworden. ${ }^{1185}$

Einen ebenfalls eigentümlichen Fall bildet die Entscheidung in der Rechtssache Heinrich. In diesem Urteil entschied der Gerichtshof, dass der Anhang einer Verordnung über die Sicherheit der Zivilluftfahrt, der nicht im Amtsblatt veröffentlicht worden war, keine Bindungswirkung entfaltet, soweit mit ihm dem Einzelnen Verpflichtungen auferlegt werden sollen. ${ }^{1186}$ Darin läge nämlich ein Verstoß gegen den Grundsatz der Rechtssicherheit, wonach die Einzelnen den Umfang der ihnen auferlegten Verpflichtungen eindeutig erkennen können müssen. ${ }^{1187}$ Eine Anwendung des Art. 264 II AEUV lehnte der EuGH ab. Zur Begründung führte er u.a. an, dass es den Erfordernissen der Rechtssicherheit widerspräche, die Wirkungen des Anhangs der Verordnung aufrechtzuerhalten, soweit er

1181 EuGH, Urteil vom 1.3.2011, Rs. C-236/09 (Association belge des Consommateurs Test-Achats u.a.), Rn. 33 und 34 sowie Tenor.

1182 Das Vorlagegericht in der Rs. C-318/13 (X) spricht in seiner zweiten Vorlagefrage von einer Übergangszeit bis zum Eintritt der Ungültigkeit, vgl. EuGH, Urteil vom 3.9.2014, Rs. C-318/13 (X), Rn. 20.

1183 Ebenso Hoffmann, ZIP 2011, 1445 (1452).

1184 GA Kokott, Schlussanträge vom 30.9.2010 in der Rs. C-236/09 (Association belge des Consommateurs Test-Achats u.a.), Rn. $73 \mathrm{ff}$.

1185 Vgl. Kommission, Leitlinien zur Anwendung der Richtlinie 2004/113/EG des Rates auf das Versicherungswesen im Anschluss an das Urteil des Gerichtshofs der Europäischen Union in der Rechtssache C-236/09 (Test-Achats), ABl. C 11 vom 13.1.2012, S. 1 (2); Hoffmann, ZIP 2011, 1445 (1452).

1186 EuGH, Urteil vom 10.3.2009, Rs. C-345/06 (Heinrich), Tenor und Rn. 63. Ausgangspunkt des Verfahrens war eine Beschwerde von Herrn Heinrich, dem das Besteigen eines Flugzeugs untersagt worden war, weil er in seinem Handgepäck Tennisschläger mit sich führte, die verbotene Gegenstände im Sinne des nicht veröffentlichten Anhangs darstellten.

1187 EuGH, Urteil vom 10.3.2009, Rs. C-345/06 (Heinrich), Rn. 43 ff. 
den Einzelnen Pflichten auferlegen soll. ${ }^{1188}$ Von näherem Interesse ist hier die Bedeutung dieser Erwägung.

Wie etwa der Fall der Aufrechterhaltung der Wirkungen einer für nichtig erklärten Verordnung zeigt, mit der Gelder von Terrorverdächtigen eingefroren werden, kann Art. 264 II AEUV auch zulasten des Einzelnen angewendet werden. ${ }^{1189}$ Mit dem Verweis auf die Rechtssicherheit kann also nicht gemeint sein, dass Art. 264 II AEUV den Einzelnen nicht zum Nachteil gereichen kann. ${ }^{1190}$ Überlegt werden könnte, dass es dem Gerichtshof um die Rechtsklarheit als Ausprägung der Rechtssicherheit ging und diese einer Anwendung von Art. 264 II AEUV grundsätzlich entgegensteht. ${ }^{1191}$ Insoweit bestehen aber durchaus berechtigte Zweifel, da es sich beim Verweis auf die Rechtssicherheit nur um eine unter mehreren Erwägungen des Gerichtshofs („schließlich“) handelt, mit denen er eine Anwendung des Art. 264 II AEUV ablehnt. ${ }^{1192}$ Letztlich bestand kein Bedürfnis nach Aufrechterhaltung der Wirkungen des Anhangs, um eine Gefährdung der öffentlichen Sicherheit auf Flughäfen zu verhindern. Die Sicherheit der Zivilluftfahrt, die mit dem Anhang bezweckt wurde, konnte anderweitig sichergestellt werden. ${ }^{193}$

\section{b) Sachliche Erstreckung}

Wird die Frage gestellt, welche Wirkungen im Sinne des Art. 264 II AEUV als fortgeltend zu betrachten sind, ist die sachliche Erstreckung der Fortwirkungsanordnung angesprochen. ${ }^{1194}$ Denkbar ist sowohl eine Aufrechterhaltung einzelner als auch sämtlicher Wirkungen des für unwirksam

1188 EuGH, Urteil vom 10.3.2009, Rs. C-345/06 (Heinrich), Rn. 64 ff.

1189 EuGH, Urteil vom 3.9.2008, verb. Rs. C-402/05 P und C-415/05 P (Kadi und Al Barakaat International Foundation/Rat und Kommission), Rn. $373 \mathrm{ff}$.

1190 So aber Frenz, DVBl. 2009, 590 (591).

1191 GA Sharpston, Schlussanträge vom 10.4.2008 in der Rs. C-345/06 (Heinrich), Rn. 99 meint, bei einer Aufrechterhaltung würde die Rechtssicherheit noch weiter leiden, was der sonst üblichen Anwendung der Aufrechterhaltungsbefugnis durch den EuGH zuwiderliefe.

1192 EuGH, Urteil vom 10.3.2009, Rs. C-345/06 (Heinrich), Rn. 68.

1193 GA Sharpston, Schlussanträge vom 10.4.2008 in der Rs. C-345/06 (Heinrich), Rn. 100. Zu dieser Rechtssache näher auch Rosenkranz, Beschränkung der Rückwirkung, 2015, S. $281 \mathrm{f}$.

1194 Vgl. Dörr, in: Grabitz/Hilf/Nettesheim (Hrsg.), Recht der EU, Art. 264 AEUV, Rn. 15 (Stand: November 2012); Rosenkranz, Beschränkung der Rückwirkung, 2015, S. 293. 
erklärten Rechtsakts. Daneben hält der EuGH zum Teil lediglich die auf der Grundlage des Rechtsakts erlassenen Durchführungsmaßnahmen aufrecht. ${ }^{1195}$ Da sonstige Wirkungen des Rechtsakts nicht aufrechterhalten werden, reicht diese Anordnung weniger weit als die Aufrechterhaltung aller Wirkungen des Rechtsakts. ${ }^{1196}$

Mit der Aufrechterhaltung der Durchführungsmaßnahmen ist allerdings der Anknüpfungspunkt falsch gewählt, da sich Art. 264 II AEUV auf die Möglichkeit, die Wirkungen der für nichtig erklärten Handlung aufrechtzuerhalten, beschränkt. Angesprochen ist damit aber der Basisrechtsakt, dessen Wirkung als Grundlage der Durchführungsmaßnahmen aufrechtzuerhalten ist. ${ }^{197}$ Ist dies geschehen, besteht die Bindung an die Durchführungsmaßnahmen weiterhin. ${ }^{1198}$

Genau zu untersuchen ist, welche Wirkungen der Gerichtshof aufrechterhält. So hat er in den verbundenen Rechtssachen Borealis Polyolefine u.a. angeordnet, dass die bis zu dem im Urteil festgelegten Stichtag (zehn Monate ab der am 28.4.2016 erfolgten Urteilsverkündung) „auf der Grundlage der für ungültig erklärten Bestimmungen erlassenen Maßnahmen nicht in Frage gestellt werden können ". ${ }^{1199}$ Eine solche Anordnung ruft Abgrenzungsschwierigkeiten hervor, wenn die Reichweite des Begriffs der „Maßnahme“ unsicher ist. ${ }^{1200}$

1195 Z.B. EuGH, Urteil vom 26.3.1996, Rs. C-271/94 (Parlament/Rat), Tenor Nr. 2 und Rn. 40.

1196 Rosenkranz, Beschränkung der Rückwirkung, 2015, S. 323 spricht insoweit von einem „Minus zur vollständigen Aufrechterhaltung“.

1197 Ebenso Rosenkranz, Beschränkung der Rückwirkung, 2015, S. 323.

1198 Vgl. Karpenstein, in: FS Sellner, 2010, S. 125 (127).

1199 EuGH, Urteil vom 28.4.2016, verb. Rs. C-191/14, C-192/14, C-295/14, C-389/14 und C-391/14 bis C-393/14 (Borealis Polyolefine u.a.), Tenor Nr.3 und Rn. 111.

1200 Siehe hierzu etwa Ehrmann, NVwZ 2016, 1311 (1312); Mitteilung der Kommission vom 23.6.2016 auf ihrer Homepage, abrufbar unter https://ec.europa .eu/clima/news/articles/news_2016062302_en; Beschluss (EU) 2017/126 der Kommission vom 24. Januar 2017 zur Änderung des Beschlusses 2013/448/EU in Bezug auf die Festlegung eines einheitlichen sektorübergreifenden Korrekturfaktors gemäß Art. 10a der Richtlinie 2003/87/EG des Europäischen Parlaments und des Rates, ABl. L 19 vom 25.1.2017, S. 93. 


\section{c) Zeitliche Erstreckung}

Gegenstand der nachfolgenden Überlegungen zur zeitlichen Erstreckung einer Fortwirkungsanordnung ist die Frage, wie lange die Wirkungen des für unwirksam erklärten Rechtsakts aufrechterhalten werden. Sie entscheidet darüber, welche Sachverhalte noch von den aufrechterhaltenen Wirkungen des Rechtsakts erfasst werden sollen. ${ }^{1201}$

Durch die Formulierung „diejenigen ihrer Wirkungen, die als fortgeltend zu betrachten sind" legt die Vorschrift des Art.264 II AEUV ein Verständnis nahe, dass von ihr nur bereits vor dem Erlass des Urteils eingetretene Wirkungen erfasst sein sollen. ${ }^{1202}$ Denn fortgelten kann eine Wirkung im strengen Wortsinne nur dann, wenn sie bereits zuvor existierte. Angesprochen sind von Art. 264 II AEUV damit eigentlich nur die Wirkungen des Rechtsakts zwischen seinem Inkrafttreten und dem Unwirksamkeitsurteil, sodass nur deren Aufrechterhaltung in Betracht käme; Art. 264 II AEUV gestattet dem EuGH seinem Wortlaut nach also eigentlich lediglich den Ausspruch einer ex nunc-Wirkung. ${ }^{203}$ Auch für die Zeit nach dem Urteil hält der Gerichtshof aber Wirkungen aufrecht. ${ }^{1204}$ Seine Rechtsprechung erfasst insoweit nicht nur bereits eingetretene Wirkungen, die über den Zeitpunkt des Urteilserlasses hinaus aufrechterhalten werden, sondern auch solche, die erst danach zum Tragen kommen, um in dieser Zeit etwa Durchführungsmaßnahmen auf den für unwirksam erklärten Rechtsakt stützen zu können oder weiterhin eine taugliche Grundlage beispielsweise für restriktive Maßnahmen zu haben. Der Einbeziehung künftiger Wirkungen in den Anwendungsbereich des Art. 264 II AEUV ist mit der Erwägung zuzustimmen, dass auf diese Weise die sich ansonsten

1201 Vgl. Dörr, in: Grabitz/Hilf/Nettesheim (Hrsg.), Recht der EU, Art. 264 AEUV, Rn. 15 (Stand: November 2012); Rosenkranz, Beschränkung der Rückwirkung, 2015, S. 346.

1202 Vgl. Daig, Nichtigkeits- und Untätigkeitsklagen, 1985, S. 199.

1203 Verstraelen, GLJ 14 (2013), 1687 (1698); siehe auch Dörr, in: Grabitz/Hilf/Nettesheim (Hrsg.), Recht der EU, Art. 264 AEUV, Rn.15 (Stand: November 2012), der darauf hinweist, dass der Gerichtshof „ohne nähere Begründung“ von der Möglichkeit einer Aufrechterhaltung für die Zeit nach dem Urteil ausgehe.

1204 Schwarze/Voet van Vormizeele, in: Schwarze/Becker/Hatje/Schoo (Hrsg.), EUKommentar, 4. Aufl. 2019, Art. 264 AEUV, Rn. 9; Dörr, in: Grabitz/Hilf/Nettesheim (Hrsg.), Recht der EU, Art. 264 AEUV, Rn. 15 (Stand: November 2012). 
ergebende Konsequenz eines, wenn auch nur vorübergehenden, Rechtsvakuums vermieden werden kann. ${ }^{1205}$

Werden Wirkungen des für unwirksam erklärten Rechtsaktes aufrechterhalten, erfolgt dies für die Zeit von dessen Inkrafttreten bis zu einem vom Gerichtshof in seinem Urteil festgelegten Zeitpunkt. Dies kann der Tag der Urteilsverkündung, ein zukünftiger Zeitpunkt oder in seltenen Fällen auch einmal ein Zeitpunkt vor dem Urteil ${ }^{1206}$ sein.

aa) Aufrechterhaltung bis zum Urteil

Ist der Sachverhalt vor dem Tag der Urteilsverkündung abgeschlossen und werden die Wirkungen des Rechtsakts bis zum Urteil aufrechterhalten, bestimmen jene Wirkungen die rechtliche Beurteilung dieses Sachverhalts. Eine derartige Konstellation ist etwa in der Anordnung des Gerichtshofs zu sehen, wonach „die Nichtigerklärung die Gültigkeit der aufgrund der streitigen Verträge vorgenommenen Zahlungen und eingegangenen Verpflichtungen nicht berührt“ ${ }^{1207}$ In diesem Fall sind von der Aufrechterhaltung der Wirkungen nur die bis zum Urteil abgeschlossenen Sachverhalte erfasst.

bb) Aufrechterhaltung bis zu einem zukünftigen Zeitpunkt

Sollen die Wirkungen des für unwirksam erklärten Rechtsakts bis zu einem zukünftigen Zeitpunkt aufrechterhalten werden, kann dies in der Weise geschehen, dass sie bis zu einem im Urteil ausdrücklich genannten Datum aufrechterhalten werden. ${ }^{1208}$ Damit vergleichbar und ebenfalls

1205 Daig, Nichtigkeits- und Untätigkeitsklagen, 1985, S. 199 f. spricht insoweit von einer Beifall verdienenden pragmatischen Haltung des EuGH.

1206 Siehe zu dieser Fallgruppe näher Rosenkranz, Beschränkung der Rückwirkung, 2015, S. $348 \mathrm{ff}$.

1207 EuGH, Urteil vom 12.5.1998, Rs. C-106/96 (Vereinigtes Königreich/Kommission), Rn. 42, wiederholt in Tenor Nr. 2. Siehe auch Rosenkranz, Beschränkung der Rückwirkung, 2015, S. 347 f.

1208 Z.B. EuGH, Urteil vom 1.4.2008, verb. Rs. C-14/06 und C-295/06 (Parlament und Dänemark/Kommission), Tenor Nr. 2 und Rn. 86. 
denkbar ist die Aufrechterhaltung für einen im Urteil genannten Zeitraum. ${ }^{1209}$

Die Wirkungen können auch aufrechterhalten werden, bis ein neuer, den Rechtsakt ersetzender Rechtsakt in Kraft getreten ist. ${ }^{1210}$ Dass der Zeitpunkt des Inkrafttretens des neuen Rechtsakts und nicht seines Erlasses als Bezugspunkt gewählt wird, ist überzeugend, da dieser ja erst mit seinem Inkrafttreten Wirkungen entfaltet, wodurch eine Kontinuität der Wirkungen erreicht wird. ${ }^{1211}$ Selbst wenn sprachlich ungenau im Urteil des Gerichtshofs einmal vom Erlass die Rede sein sollte ${ }^{1212}$, ist dies daher als „Inkrafttreten“ auszulegen. Dies folgt aus der Erwägung, dass der Gerichtshof durch die Aufrechterhaltung der Wirkungen ein Rechtsvakuum $^{1213}$ verhindern möchte.

Eine Aufrechterhaltung der Wirkungen auf unbestimmte Zeit nimmt der Gerichtshof, wenn überhaupt, nur sehr zurückhaltend an. ${ }^{1214} \mathrm{Da}$ es im Ergebnis keinen Unterschied macht, ob ein Rechtsakt für unwirksam erklärt wird und seine Wirkungen unbegrenzt für zukünftige Sachverhalte aufrechterhalten werden oder ob er schon gar nicht für unwirksam erklärt wird, ist diese Zurückhaltung angebracht. Sonst könnte auf die Unwirksamkeitserklärung auch von vornherein verzichtet werden. ${ }^{1215}$

Für eine dauerhafte Aufrechterhaltung der Wirkungen eines für nichtig erklärten Rechtsaktes, d.h. für eine solche ohne Endzeitpunkt in der $\mathrm{Zu}$ kunft, entschied sich der Gerichtshof in den völkerrechtliche Abkommen zwischen der EU und Mauritius bzw. Tansania betreffenden Rechtssachen

1209 Z.B. EuGH, Urteil vom 3.9.2008, verb. Rs. C-402/05 P und C-415/05 P (Kadi und Al Barakaat International Foundation/Rat und Kommission), Tenor Nr. 3 und Rn. 375.

1210 Siehe etwa EuGH, Urteil vom 17.3.2016, Rs. C-286/14 (Parlament/Kommission), Rn. 71.

1211 EuGH, Urteil vom 5.2.2004, Rs. C-157/02 (Rieser Internationale Transporte), Rn. 60; siehe auch Rosenkranz, Beschränkung der Rückwirkung, 2015, S. 353.

1212 So geschehen in EuGH, Urteil vom 5.7.1995, Rs. C-21/94 (Parlament/Rat), Rn. 32 und Tenor Nr. 2.

1213 EuGH, Urteil vom 5.2.2004, Rs. C-157/02 (Rieser Internationale Transporte), Rn. 60 spricht von einem „regelungsfreien Zustand“.

1214 Vgl. GA Kokott, Schlussanträge vom 28.10.2015 in der Rs. C-263/14 (Parlament/Rat), Rn. 108 unter Verweis in Fn. 56 auf Urteile des Gerichtshofs, in denen dieser Wirkungen nur aufrechterhält, „bis innerhalb einer angemessenen Frist" ein neuer Rechtsakt in Kraft tritt.

1215 Rosenkranz, Beschränkung der Rückwirkung, 2015, S. 356 spricht von einem vollständigen Aushebeln der Nichtigerklärung. 
C-658/11 ${ }^{1216}$ und C-263/14 ${ }^{1217}$. Durch einen Verstoß gegen die Pflicht zur Unterrichtung des Parlaments nach Art. 218 X AEUV hatte der Rat nach Auffassung des Gerichtshofs zwar eine wesentliche Formvorschrift verletzt, sodass der jeweilige Beschluss über die Unterzeichnung und den Abschluss der Abkommen für nichtig zu erklären war. ${ }^{1218} \mathrm{Da}$ aber selbst bei korrekter Unterrichtung des Parlaments für dieses nicht einmal ein Anhörungsrecht, geschweige denn ein weitergehendes Mitspracherecht bestünde, wäre die Wiederholung der Beschlussfassung übertriebener Formalismus. ${ }^{1219}$

Bevor eine Aufrechterhaltung der Wirkungen eines für unwirksam erklärten Unionsrechtsakts auf unbestimmte Zeit in Betracht gezogen wird, erscheint es allerdings vorzugswürdig, vorrangig zu klären, ob tatsächlich die Verletzung einer wesentlichen Formvorschrift in Rede steht, die zur Nichtigerklärung führen muss. Bei rein formalen Fehlern unterbleibt eine solche nämlich. ${ }^{1220}$ Handelt es sich dagegen nicht um einen bloß formalen Fehler, sondern um die Missachtung eines wesentlichen Formerfordernisses wie etwa bei der fehlenden Angabe der Rechtsgrundlage ${ }^{1221}$ oder einer fehlenden Anhörung des Parlaments ${ }^{1222}$, führt der Verstoß zur Nichtigerklärung. In solchen Fällen sollte aber eine Aufrechterhaltung nur bis zum Erlass eines korrigierenden Rechtsakts in Frage kommen. Hiermit bricht der Gerichtshof in den erwähnten beiden Rechtssachen, indem er trotz der von ihm angenommenen Verletzung einer wesentlichen Formvorschrift eine dauerhafte Aufrechterhaltung der Wirkungen angeordnet hat.

1216 EuGH, Urteil vom 24.6.2014, Rs. C-658/11 (Parlament/Rat), Rn. 91.

1217 EuGH, Urteil vom 14.6.2016, Rs. C-263/14 (Parlament/Rat), Rn. 89.

1218 EuGH, Urteil vom 24.6.2014, Rs. C-658/11 (Parlament/Rat), Rn. 80, 86, 87; EuGH, Urteil vom 14.6.2016, Rs. C-263/14 (Parlament/Rat), Rn. 84, 85.

1219 GA Kokott, Schlussanträge vom 28.10.2015 in der Rs. C-263/14 (Parlament/Rat), Rn. 107.

1220 EuGH, Urteil vom 27.9.1988, Rs. 165/87 (Kommission/Rat), Rn. 18 ff.; EuGH, Urteil vom 9.9.2004, verb. Rs. C-184/02 und C-223/02 (Spanien und Finnland/Parlament und Rat), Rn. 42 ff.; EuGH, Urteil vom 14.12.2004, Rs. C-210/03 (Swedish Match), Rn. 44; EuGH, Urteil vom 18.12.2014, Rs. C-81/13 (Vereinigtes Königreich/Rat), Rn. 67.

1221 EuGH, Urteil vom 1.10.2009, Rs. C-370/07 (Kommission/Rat), Rn. $61 \mathrm{f}$.

1222 EuGH, Urteil vom 30.3.1995, Rs. C-65/93 (Parlament/Rat), Rn. 21; EuGH, Urteil vom 10.5.1995, Rs. C-417/93 (Parlament/Rat), Rn.9; EuGH, Urteil vom 16.4.2015, verb. Rs. C-317/13 und C-679/13 (Parlament/Rat), Rn. 63. 


\section{V. Überleitung}

Im ersten Teil dieser Arbeit war nach der zeitlichen Dimension einer vom Gerichtshof vorgenommenen Auslegung des Unionsrechts gefragt worden. Es hat sich gezeigt, dass der im Anwendungsbefehl der ausgelegten Norm und im deklaratorischen Auslegungsverständnis des Gerichtshofs begründete Grundsatz der ex tunc-Wirkung der gesamten Auslegungstätigkeit des Gerichtshofs zugrunde liegt, und damit unabhängig von der Verfahrensart, in der die Auslegung erfolgt.

Für eine Modifikation der Wirkungen der Auslegung in zeitlicher Hinsicht ist der Gerichtshof ausschließlich zuständig. Zur Begründung seiner Zuständigkeit kann er sich auf den unionsrechtlichen Grundsatz der Rechtssicherheit stützen, der es ihm gestattet, im Rahmen der Auslegung der Reichweite des Anwendungsbefehls der ausgelegten Norm diesen für einen bestimmten Zeitraum aufzuheben. Auf diese Weise schließt der EuGH mit unionsweiter Wirkung, also nicht begrenzt auf einzelne Mitgliedstaaten, die Berufung auf die Norm aus.

Von dieser Möglichkeit macht der Gerichtshof nur ganz ausnahmsweise Gebrauch, wenn nämlich die Voraussetzungen seiner auf das Defrenne II-Urteil zurückgehenden Defrenne-Rechtsprechung vorliegen, von der er letztlich auch im Urteil in den verbundenen Rechtssachen UNIS und Beaudout Père et Fils keine Abkehr vollzogen hat. Sie erfordert sowohl das Bestehen von gutem Glauben als auch einer Gefahr schwerwiegender Störungen. Darüber hinaus kann eine Begrenzung in zeitlicher Hinsicht nur im ersten zu einer Rechtsfrage ergehenden Urteil erfolgen; die Begrenzung darf mit anderen Worten nicht präkludiert sein. Kennzeichen der Defrenne-Rechtsprechung ist ihr Unionsbezug. Nicht nur das Bestehen von gutem Glauben, sondern auch das Bestehen einer Gefahr schwerwiegender Störungen ist daher nach einem unionsweiten Maßstab zu bestimmen.

Bei der direkten oder entsprechenden Anwendung des Art. 264 II AEUV im Rahmen der Unwirksamkeitsverfahren verfährt der Gerichtshof flexibler und sieht eine Begrenzung der zeitlichen Wirkungen nicht als Ausnahme an. Der Gerichtshof lässt hier sehr unterschiedliche Aspekte für eine Begrenzung genügen, die zum Teil nur lose in dem Art. 264 II AEUV zugrundeliegenden Grundsatz der Rechtssicherheit verankert sind. Während der Gerichtshof hier nicht selten einen in der Zukunft liegenden Zeitpunkt wählt, bis zu dem die Wirkungen eines für unwirksam erklärten Rechtsakts aufrechterhalten werden, hat er es bislang zu Recht abgelehnt, seine Auslegung des Unionsrechts erst in der Zukunft nach Ablauf einer 
bestimmten Zeitspanne Wirkung entfalten zu lassen. Die Defrenne-Rechtsprechung ermöglicht also nur eine Begrenzung der Berufung auf eine vom Gerichtshof ausgelegte Norm für vor dem Urteilszeitpunkt liegende Zeiträume.

Diese im ersten Teil der Arbeit gewonnenen Erkenntnisse bilden den Hintergrund für die nun im zweiten Teil in den Blick zu nehmenden Reaktionsmöglichkeiten mitgliedstaatlicher Gerichte im Hinblick auf die zeitliche Dimension der Rechtsprechung des Gerichtshofs. 


\section{Zweiter Teil: Reaktionsmöglichkeiten mitgliedstaatlicher Gerichte}

Wird nach Reaktionsmöglichkeiten mitgliedstaatlicher Gerichte auf die zeitliche Dimension der Rechtsprechung des Gerichtshofs gefragt, ist dessen Defrenne-Rechtsprechung zunächst in den Kontext des nationalen Verfahrens einzuordnen. Sodann ist die „Durchsetzungsdimension“ des Unionsrechts in den Blick zu nehmen und zu fragen, ob eine Begrenzung des Anwendungsvorrangs des Unionsrechts und der Pflicht zu richtlinienkonformer Auslegung in zeitlicher Hinsicht auch dann in Betracht kommt, wenn eine zeitliche Beschränkung der Auslegung des Unionsrechts durch den EuGH im Sinne der Defrenne-Rechtsprechung unterblieben ist. Im Anschluss an diese Betrachtung aus dem Blickwinkel des Unionsrechts ist die zeitliche Dimension der EuGH-Rechtsprechung noch vom Standpunkt des nationalen Verfassungsrechts aus zu beurteilen.

\section{A. Einordnung der Defrenne-Rechtsprechung in den Kontext des nationalen Verfahrens}

Eine Einordnung der Defrenne-Rechtsprechung in den Kontext des nationalen Verfahrens macht ihre Einordnung in den Gesamtzusammenhang der Grundsätze erforderlich, die das Verhältnis von Unionsrecht und nationalem Recht prägen. Zu ihnen zu zählen ist der Grundsatz der Verfahrensautonomie der Mitgliedstaaten. ${ }^{1223}$

Daneben ist Klarheit darüber zu erlangen, ob die durch den EuGH nach den Grundsätzen der Defrenne-Rechtsprechung erfolgende Vornahme oder Ablehnung einer zeitlichen Begrenzung eine eigenständige Bindungswirkung entfaltet, um die Frage beantworten zu können, welche Aussage damit für das nationale Verfahren getroffen ist.

$1223 \mathrm{Zu}$ diesem monographisch etwa Krönke, Die Verfahrensautonomie der Mitgliedstaaten der Europäischen Union, 2013. 
I. Grundsatz der Verfahrensautonomie der Mitgliedstaaten

Der Grundsatz nationaler Verfahrensautonomie bleibt anerkanntermaßen auch bei zeitlich unbegrenzt wirkender Rechtsprechung des Gerichtshofs unberührt. ${ }^{1224}$ Eine Bestimmung seiner Reichweite erlaubt eine Einschätzung darüber, wie sich eine Anwendung von Verfahrensmodalitäten zu einer Begrenzung der zeitlichen Reichweite mitgliedstaatlicher Rechtsprechung im Anwendungsbereich des Unionsrechts verhält.

\section{Bedeutung nationaler Verfahrensmodalitäten}

Nationale Verfahrensmodalitäten sind wiederholt im Zusammenhang mit dem Erstattungsanspruch, den das Unionsrecht bei unter Verstoß gegen Unionsrecht geleisteten Abgaben begründet, relevant geworden. Ihre Bedeutung lässt sich daher an seinem Beispiel veranschaulichen. Angesichts der ex tunc-Wirkung der vom EuGH vorgenommenen Auslegung erfasst der Erstattungsanspruch den gesamten Zeitraum seit Inkrafttreten der betreffenden Vorschrift des Unionsrechts. Während das Unionsrecht über das Bestehen des Erstattungsanspruchs entscheidet, haben die Mitgliedstaaten die Möglichkeit, dessen Geltendmachung zu beschränken. ${ }^{1225}$ Die Modalitäten der Geltendmachung des unionsrechtlichen Erstattungsanspruchs richten sich beim Fehlen einer einschlägigen Unionsregelung zu seiner Durchsetzung nämlich nach dem Grundsatz der Verfahrensautonomie der Mitgliedstaaten.

Auch wenn die Verfahrensmodalitäten Sache der Rechtsordnung der Mitgliedstaaten sind, dürfen sie nicht ungünstiger sein als diejenigen, die gleichartige Sachverhalte innerstaatlicher Art regeln. Die Verfahrensmodalitäten der Klagen zur Durchsetzung unionsrechtlicher Rechte dürfen nicht weniger günstig ausgestaltet sein als die entsprechender innerstaatlicher Klagen (Äquivalenzgrundsatz). Zudem darf die Ausübung der durch das Unionsrecht verliehenen Rechte nicht praktisch unmöglich gemacht oder übermäßig erschwert werden (Effektivitätsgrundsatz). ${ }^{1226}$

1224 Siehe z.B. EuGH, Urteil vom 15.9.1998, Rs. C-231/96 (Edis), Rn.26; EuGH, Urteil vom 15.4.2010, Rs. C-542/08 (Barth), Rn. 30.

1225 Rosenkranz, Beschränkung der Rückwirkung, 2015, S. $433 \mathrm{f}$.

1226 Vgl. in diesem Sinne etwa EuGH, Urteil vom 8.3.2017, Rs. C-14/16 (Euro Park Service), Rn.36; EuGH, Urteil vom 21.1.2010, Rs. C-472/08 (Alstom Power Hydro), Rn. 17; EuGH, Urteil vom 13.3.2007, Rs. C-524/04 (Test Claimants in the Thin Cap Group Litigation), Rn.111; EuGH, Urteil vom 
Dass der Gerichtshof keine zeitliche Begrenzung im Sinne der DefrenneRechtsprechung vorgenommen hat, ändert am Recht eines Mitgliedstaats, sich gegenüber dem Erstattungsanspruch auf eine nationale Ausschlussfrist zu berufen, nichts. ${ }^{1227}$ Veranschaulichen lässt sich dies nicht zuletzt an einem Beispiel aus der jüngeren Rechtsprechung des Gerichtshofs: In der Rechtssache Caterpillar Financial Services hatte eine Gesellschaft polnischen Rechts aufgrund der (sich später als unionsrechtswidrig herausstellenden) Rechtsprechung eines nationalen Gerichts und einer bevorstehenden Steuerprüfung mehr Mehrwertsteuer gezahlt als von ihr geschuldet. Nach dem der Mehrwertsteuerüberzahlung die Grundlage entziehenden Urteil des EuGH vom 17.1.2013 in der Rechtssache BGZ̈ Leasing ${ }^{1228}$ verlangte die Gesellschaft am 11.3.2013 die zu viel gezahlte Steuer für den Zeitraum von Dezember 2005 bis Dezember 2011 zurück, was für den Zeitraum von Dezember 2005 bis November 2007 wegen Ablaufs der im nationalen Recht vorgesehenen Verjährungsfrist abgelehnt wurde. ${ }^{1229} \mathrm{Da}$ der Gerichtshof die Berufung auf die im Urteil BGŻ Leasing ausgelegten Bestimmungen der Mehrwertsteuerrichtlinie nicht in zeitlicher Hinsicht begrenzt hatte, waren diese vom Zeitpunkt ihres Inkrafttretens an im Sinne der Auslegung des Gerichtshofs zu verstehen und anzuwenden. ${ }^{1230}$

Das nach Ablauf der Verjährungsfrist ergangene und die Unionsrechtswidrigkeit aufzeigende EuGH-Urteil ändert aber nichts an der Vereinbarkeit der Verjährungsfrist mit Unionsrecht. Dass es erst nach Ablauf der Verjährungsfrist erging, bedeutet nämlich nicht, dass Caterpillar Financial Services vor Ablauf der Verjährungsfrist ihre Rechte nicht hätte geltend machen können. Die Gesellschaft hatte lediglich keinen Rechtsbehelf ergriffen, um ihren Standpunkt gerichtlich durchzusetzen, sondern vielmehr die Auslegung der Bestimmungen der Mehrwertsteuerrichtlinie durch den EuGH abgewartet. Auch wenn damit die ex tunc-Wirkung der Auslegung

12.12.2006, Rs. C-446/04 (Test Claimants in the FII Group Litigation), Rn. 203; EuGH, Urteil vom 9.2.1999, Rs. C-343/96 (Dilexport), Rn. 25; EuGH, Urteil vom 15.9.1998, Rs. C-231/96 (Edis), Rn. 19, 34; EuGH, Urteil vom 2.2.1988, Rs. 309/85 (Barra), Rn. 18; EuGH, Urteil vom 16.12.1976, Rs.33/76 (ReweZentralfinanz und Rewe-Zentral), Rn. 5; EuGH, Urteil vom 16.12.1976, Rs. 45/76 (Comet), Rn. 13, 16.

1227 EuGH, Urteil vom 28.11.2000, Rs. C-88/99 (Roquette Frères), Rn. 36; EuGH, Urteil vom 15.9.1998, Rs. C-231/96 (Edis), Rn. 26.

1228 EuGH, Urteil vom 17.1.2013, Rs. C-224/11 (BGŻ Leasing).

$1229 \mathrm{EuGH}$, Urteil vom 20.12.2017, Rs. C-500/16 (Caterpillar Financial Services), Rn. $16 \mathrm{ff}$.

1230 EuGH, Urteil vom 20.12.2017, Rs. C-500/16 (Caterpillar Financial Services), Rn. $33 \mathrm{f}$. 
der Bestimmungen der Mehrwertsteuerrichtlinie für den von der Verjährung erfassten Zeitraum im Ergebnis nicht zum Tragen kommt, begegnet dies keinen unionsrechtlichen Bedenken.

Anders ist dagegen der Fall zu beurteilen, in dem das Verhalten der nationalen Behörden in Verbindung mit einer Ausschlussfrist den Betroffenen jede Möglichkeit zur Geltendmachung ihrer Rechte vor den nationalen Gerichten genommen hat. Angesprochen ist also ein Fall, in dem die Betroffenen an der Geltendmachung ihrer Rechte gehindert waren. Eine solche Situation setzt allerdings die objektive Unmöglichkeit für den Betroffenen voraus, anders zu handeln, und ist daher nicht bereits bei der bloßen subjektiven Überzeugung, nicht anders handeln zu können, anzunehmen. ${ }^{1231}$

Dass es unter Effektivitätsgesichtspunkten unbedenklich ist, dass der Ablauf angemessener Ausschlussfristen für die Rechtsverfolgung zur (vollständigen oder teilweisen) Abweisung einer Klage auf Rückzahlung führt ${ }^{1232}$, bedeutet nicht, dass der nationale Gesetzgeber nach Verkündung eines für den Mitgliedstaat „nachteiligen“ Urteils des Gerichtshofs eine Regelung treffen könnte, die speziell die Möglichkeiten einschränkt, auf Erstattung zu klagen. Die Erstattung der Abgabe darf nämlich nicht Voraussetzungen unterworfen werden, die „speziell“ diese Abgabe betreffen und die ungünstiger sind als diejenigen, die ohne die Neuregelung anwendbar gewesen wären. ${ }^{1233}$ Dass ein Mitgliedstaat ein solches „Maßnahmegesetz“ unter dem Deckmantel scheinbar neutraler Formulierungen erlässt, kann damit aber wohl nicht verhindert werden. ${ }^{1234}$ Dies wird ihm

1231 EuGH, Urteil vom 20.12.2017, Rs. C-500/16 (Caterpillar Financial Services), Rn. 45 ff., 51 f.; EuGH, Urteil vom 8.9.2011, verb. Rs. C-89/10 und C-96/10 (QBeef und Bosschaert), Rn. 50 f., 52; EuGH, Urteil vom 21.12.2016, Rs. C-327/15 (TDC), Rn. $103 \mathrm{f}$.

1232 EuGH, Urteil vom 8.9.2011, verb. Rs. C-89/10 und C-96/10 (Q-Beef und Bosschaert), Rn.36; EuGH, Urteil vom 20.12.2017, Rs. C-500/16 (Caterpillar Financial Services), Rn. 41 ff. Ein Verstoß gegen Art. 4 III EUV muss bei einer den Grundsätzen der Äquivalenz und Effektivität genügenden Bestimmung des nationalen Rechts konsequenterweise ebenfalls ausscheiden, wie der Gerichtshof in Caterpillar Financial Services klarstellt, vgl. EuGH, a.a.O., Rn. 44.

1233 EuGH, Urteil vom 29.6.1988, Rs.240/87 (Deville), Rn.13; EuGH, Urteil vom 15.9.1998, Rs. C-231/96 (Edis), Rn. 23 f.; EuGH, Urteil vom 9.2.1999, Rs. C-343/96 (Dilexport), Rn. 38 f.; EuGH, Urteil vom 11.7.2002, Rs. C-62/00 (Marks \& Spencer), Rn.36; EuGH, Urteil vom 2.10.2003, Rs. C-147/01 (Weber's Wine World u.a.), Rn. $86 \mathrm{f} . ;$ EuGH, Urteil vom 30.6.2016, Rs. C-200/14 (Câmpean), Rn. 40.

1234 Siehe Seer/Müller, IWB 2008, 311 (323). 
nicht zuletzt dadurch erleichtert, dass Gesetze „aus Anlass der europarechtlichen Streitigkeit" von vornherein nicht ausgeschlossen sind. ${ }^{1235}$ Dann kann auch eine rückwirkende Regelung des Mitgliedstaats zulässig sein. Bei einer rückwirkenden Änderung der Erstattungsmodalitäten durch den Gesetzgeber sind allerdings Übergangsregelungen erforderlich, wenn sonst die Erstattungsansprüche nicht mehr geltend gemacht werden könnten, um einen Verstoß gegen den Effektivitätsgrundsatz zu vermeiden. ${ }^{1236}$

Aus unionsrechtlicher Sicht unterschiedlich zu behandeln sind Fälle, in denen nur der vor Klageerhebung liegende Zeitraum begrenzt wird, für den rückständige Leistungen bezogen werden können, und Fälle, in denen eine Vorschrift etwa die Berücksichtigung von Dienstzeiten für die Berechnung von Zusatzleistungen hindert, die nach Klageerhebung geschuldet wären. Im erstgenannten Fall wird im Interesse der Rechtssicherheit die Rückwirkung einer Klage auf Gewährung bestimmter Leistungen begrenzt, was das Wesen der unionsrechtlichen Rechte nicht berührt und somit unionsrechtlich zulässig erscheint. Im letztgenannten Fall macht die Vorschrift die Klage eines sich auf Unionsrecht Berufenden dagegen praktisch unmöglich, was nach Ansicht des Gerichtshofs in der Rechtssache Magorrian und Cunningham im Übrigen darauf hinaus läuft, die unmittelbare Wirkung des in dieser Rechtssache in Rede stehenden Art.119 EWGV (heute Art. 157 AEUV) zeitlich zu begrenzen („the effect of that national rule is to limit in time the direct effect of Article 119 of the Treaty“), obwohl eine derartige Begrenzung im Unionsrecht nicht vorgesehen und daher unzulässig ist. ${ }^{1237}$ Ebenfalls nicht zulässig ist eine Regelung, die „einfach“ das Recht auf Erstattung der ohne Rechtsgrund gezahlten Beträge nimmt, da dies die Ausübung der durch das Unionsrecht eingeräumten Rechte verhindert. ${ }^{1238}$

Im Zusammenspiel von ex tunc wirkender Auslegung durch den EuGH und der Anwendung nationaler Verfahrensregeln zeigt sich damit deren eigenständige Bedeutung: Trotz unterbliebener Begrenzung der zeitlichen Wirkungen im Sinne der Defrenne-Rechtsprechung kommen diese weiterhin zur Anwendung. ${ }^{1239}$ Die vom EuGH vorgenommene Auslegung ist da-

1235 Rosenkranz, Beschränkung der Rückwirkung, 2015, S. 435.

1236 EuGH, Urteil vom 30.6.2011, Rs. C-262/09 (Meilicke u.a.), Rn. 57; Schlücke, Umsetzung, 2014, S. $324 \mathrm{f}$.

1237 EuGH, Urteil vom 11.12.1997, Rs. C-246/96 (Magorrian und Cunningham), Rn. $43 \mathrm{ff}$.

1238 EuGH, Urteil vom 2.2.1988, Rs. 309/85 (Barra), Rn. 19.

1239 Ist eine zeitliche Begrenzung unter Anordnung einer Rückausnahme für Rechtsbehelfsführer erfolgt, führt die eigenständige Bedeutung nationaler Ver- 
her seit dem Inkrafttreten der betreffenden Bestimmung anwendbar. Ihre Durchsetzung auf nationaler Ebene kann allerdings nur im Rahmen im nationalen Recht vorgesehener angemessener Ausschlussfristen und weiteren mitgliedstaatlichen Verfahrensrechts erfolgen, das das Äquivalenz- und Effektivitätsprinzip wahrt. ${ }^{1240}$

\section{Schranke der Bestands- und Rechtskraft}

Als Ausfluss der nationalen Verfahrensautonomie kommt den Grundsätzen der Bestands- und Rechtskraft besondere Bedeutung zu. Ist Bestandsoder Rechtskraft eingetreten, zwingt die ex tunc-Wirkung grundsätzlich zu keiner Anpassung der zugrundeliegenden Rechtsverhältnisse an die unionsrechtlichen Vorgaben. ${ }^{1241}$ Grund hierfür ist die Rechtssicherheit. So trägt die Bestandskraft einer Verwaltungsentscheidung auch nach Ansicht des EuGH zur Rechtssicherheit bei ${ }^{1242}$; die Rechtskraft dient sowohl in den nationalen Rechtsordnungen als auch der Unionsrechtsordnung der Gewährleistung des Rechtsfriedens und der Beständigkeit rechtlicher Beziehungen sowie einer geordneten Rechtspflege ${ }^{1243}$. Der Stellenwert von Bestands- und Rechtskraft soll an Beispielen aus der Rechtsprechung kurz veranschaulicht werden.

In der Rechtssache Kühne \& Heitz stellte sich die Frage, ob die grundsätzlich gebotene Anwendung des Unionsrechts in der Auslegung

fahrensmodalitäten dazu, dass diese auch gegenüber den von der Begrenzung der zeitlichen Wirkung ausgenommenen Rechtsbehelfsführern zur Anwendung kommen können. Darauf weist Gundel, in: Liber Amicorum Berg, 2011, S. 54 (67, Fn. 63) zu Recht hin.

1240 Vgl. GA Tanchev, Schlussanträge vom 3.5.2018 in der Rs. C-51/17 (OTP Bank und OTP Faktoring), Rn. 48.

1241 Ludewig, Zeitliche Beschränkung, 2012, S. 228 f.; Weiß, DÖV 2008, 477 (483 f.); Rennert, DVBl. 2007, 400 (407 f.); Schlücke, Umsetzung, 2014, S. 84 f.; Gärditz, in: Rengeling/Middeke/Gellermann (Hrsg.), Handbuch des Rechtsschutzes, 3. Aufl. 2014, $\$ 35$, Rn. 42, 62; Ehricke, in: Streinz (Hrsg.), EUV/AEUV, 3. Aufl. 2018, Art. 267 AEUV, Rn. 77; Finke, IStR 2006, 212 (215); de Weerth, DStR 2008, 1669 (1671).

1242 Siehe nur EuGH, Urteil vom 4.10.2012, Rs. C-249/11 (Byankov), Rn. 76.

1243 Siehe nur EuGH, Urteil vom 11.11.2015, Rs. C-505/14 (Klausner Holz Niedersachsen), Rn. 38; EuGH, Urteil vom 6.10.2015, Rs. C-69/14 (Târşia), Rn. 28; EuGH, Urteil vom 10.7.2014, Rs. C-213/13 (Impresa Pizzarotti), Rn. 58; EuGH, Urteil vom 16.3.2006, Rs. C-234/04 (Kapferer), Rn. 20; EuGH, Urteil vom 30.9.2003, Rs. C-224/01 (Köbler), Rn. 38. 
durch den Gerichtshof auf vor Erlass der Vorabentscheidung entstandene Rechtsbeziehungen auch im Hinblick auf bestandskräftig gewordene Verwaltungsentscheidungen erforderlich ist. ${ }^{1244}$ Der EuGH entschied, dass sich dem Unionsrecht keine grundsätzliche Verpflichtung zur Rücknahme einer bestandskräftigen Verwaltungsentscheidung entnehmen lässt. Nur unter bestimmten Voraussetzungen kommt eine Verpflichtung der Verwaltungsbehörde zur Überprüfung der Entscheidung nach Art. 4 III EUV in Betracht, um einer später vorgenommenen Auslegung des EuGH Rechnung zu tragen. ${ }^{1245}$ Die Überprüfungspflicht der Behörde steht damit unter einschränkenden Voraussetzungen. Ihre Verdichtung zu einer Rücknahmeverpflichtung ist nur in Ausnahmefällen anzunehmen. ${ }^{1246}$

Hinter diesen Überlegungen steht letztlich das Bedürfnis, Rechtssicherheit und Unionsrechtmäßigkeit in Ausgleich zu bringen. Dies erfordert es auch, die Besonderheiten und die Interessenlage des Einzelfalls zu berücksichtigen. ${ }^{1247}$ Bedeutung kommt daher dem Umstand $\mathrm{zu}$, wenn es nicht darum geht, ob eine Behörde ihre Entscheidung überprüfen muss, sondern lediglich die Berichtigung der Laufzeit eines Zertifikats in Rede steht. In diesem Fall sind die im Kühne \& Heitz-Urteil für die Überprüfungspflicht der Behörde aufgestellten einschränkenden Voraussetzungen nicht anwendbar, wie der Gerichtshof in seiner Entscheidung in der Rechtssache Incyte deutlich gemacht hat. In dem ihr zugrundeliegenden Sachverhalt war ein ergänzendes Schutzzertifikat für ein Medikament vor der Verkündung des Urteils in der Rechtssache Seattle Genetics erteilt worden. Aus jenem Urteil ${ }^{1248}$ ergab sich für den der Rechtssache Incyte zugrundeliegen-

1244 EuGH, Urteil vom 13.1.2004, Rs. C-453/00 (Kühne \& Heitz), Rn. 22 f.

1245 EuGH, Urteil vom 13.1.2004, Rs. C-453/00 (Kühne \& Heitz), Rn. 24, 28. Die Rechtssache Kühne \& Heitz zeichnet sich nicht zuletzt dadurch aus, dass das betroffene Unternehmen sämtliche ihm zur Verfügung stehenden Rechtsbehelfe ausgeschöpft hatte, vgl. EuGH, Urteil vom 19.9.2006, verb. Rs. C-392/04 und C-422/04 (i-21 Germany und Arcor), Rn. 53 f. Siehe auch EuGH, Urteil vom 12.2.2008, Rs. C-2/06 (Kempter), Rn. 37 f.; EuGH, Urteil vom 4.10.2012, Rs. C-249/11 (Byankov), Rn. $76 \mathrm{f}$.

1246 Schmahl/Köber, EuZW 2010, 927 (928) gehen von einer Ermessensreduzierung auf Null aus, wenn dadurch Rechte Dritter nicht verletzt werden und andere Möglichkeiten eines unionsrechtskonformen Ausgleichs nicht bestehen.

1247 EuGH, Urteil vom 4.10.2012, Rs. C-249/11 (Byankov), Rn. 77 unter Verweis auf EuGH, Urteil vom 13.1.2004, Rs. C-453/00 (Kühne \& Heitz), Rn. 25 f., EuGH, Urteil vom 19.9.2006, verb. Rs. C-392/04 und C-422/04 (i-21 Germany und Arcor), Rn. 53, 63 f., EuGH, Urteil vom 12.2.2008, Rs. C-2/06 (Kempter), Rn. 46, 55, 60 und EuGH, Urteil vom 3.9.2009, Rs. C-2/08 (Fallimento Olimpiclub), Rn. 22, 26, 31 .

1248 EuGH, Urteil vom 6.10.2015, Rs. C-471/14 (Seattle Genetics), Tenor Nr. 2. 
den Fall, dass in der von Incyte eingereichten Zertifikatsanmeldung ein anderes Datum hätte angegeben und von der nationalen Behörde zugrunde gelegt werden müssen. ${ }^{1249}$ Dies warf die Frage nach dem Bestehen einer unionsrechtlichen Pflicht zur Berichtigung des Ablaufdatums des Zertifikats auf, um dieses in Einklang mit der im Urteil Seattle Genetics vorgenommenen Rechtsauslegung zu bringen. ${ }^{1250}$ Der EuGH bejahte sie.

Dass die in den nationalen Rechtsvorschriften vorgesehene Frist für die Einlegung eines Rechtsbehelfs gegen die Entscheidung, mit der das Zertifikat erteilt worden war, mit der Folge der Bestandskraft der Verwaltungsentscheidung bereits abgelaufen war, lässt das Bestehen der Berichtigungspflicht unberührt. ${ }^{1251}$ Die Berichtigung der Laufzeit eines Zertifikats ist nach Auffassung des Gerichtshofs ,aufgrund ihrer Art weniger geeignet, die Rechtssicherheit zu beeinträchtigen, als die wesentlichen Änderungen, die eine erneute Sachprüfung voraussetzen“. Neben der Auslegung der einschlägigen unionsrechtlichen Bestimmungen im Bereich der Schutzzertifikate ist für die Begründung der Berichtigungspflicht also von Bedeutung, dass die Berichtigung nicht geeignet ist, die Rechtssicherheit zu beeinträchtigen. ${ }^{1252}$

Auch hinsichtlich der Rechtskraft gerichtlicher Entscheidungen ist zunächst davon auszugehen, dass es der Grundsatz der Verfahrensautonomie den Mitgliedstaaten gestattet, die Modalitäten der Wirkung der Rechtskraft für ihre innerstaatlichen Rechtsordnungen selbst festzulegen. ${ }^{1253}$ Grundsätzlich hinzunehmen ist es daher, dass sich diese durchsetzt, sodass eine mit dem Unionsrecht unvereinbare nationale Situation weiterbe-

1249 Entscheidend ist der Zeitpunkt, zu dem die Entscheidung über die Zulassung ihrem Adressaten bekannt gegeben worden ist. Damit ist jedes andere in der Zertifikatsanmeldung angegebene Datum unrichtig, vgl. EuGH, Urteil vom 20.12.2017, Rs. C-492/16 (Incyte), Rn. 43.

1250 Im konkreten Fall ging es um eine Ersetzung des als Ablaufdatum genannten Datums des 24.8.2027 durch das Datum des 28.8.2027.

1251 EuGH, Urteil vom 20.12.2017, Rs. C-492/16 (Incyte), Rn. 45 ff.

1252 EuGH, Urteil vom 20.12.2017, Rs. C-492/16 (Incyte), Rn. 49, 58.

1253 Siehe etwa EuGH, Urteil vom 10.7.2014, Rs. C-213/13 (Impresa Pizzarotti), Rn. 54; EuGH, Urteil vom 3.9.2009, Rs. C-2/08 (Fallimento Olimpiclub), Rn. 24; EuGH, Urteil vom 6.10.2009, Rs. C-40/08 (Asturcom Telecomunicaciones), Rn. 38. Nach Schmabl/Köber, EuZW 2010, 927 (927 mit Fn. 7) wird die Wirkung der Rechtskraft durch den unionsrechtlichen Staatshaftungsanspruch, der auch rechtskräftige Entscheidungen nicht ausnimmt, „im Ergebnis relativiert“. 
steht. ${ }^{1254}$ Auf die Frage der Pflicht zur Wiederaufnahme eines rechtskräftig abgeschlossenen Verfahrens lassen sich die Erwägungen des Gerichtshofs in der Rechtssache Kühne \& Heitz nicht übertragen; sie betreffen nach seiner Ansicht „unstreitig nur die etwaige Überprüfung einer bestandskräftigen Entscheidung einer Verwaltungsbehörde und nicht [...] eines Gerichts". 1255

Dem Unionsrecht ist also keine grundsätzliche Pflicht der Gerichte zu entnehmen, eine in Rechtskraft erwachsene Entscheidung rückgängig zu machen, um einer späteren Auslegung der betroffenen unionsrechtlichen Bestimmungen durch den Gerichtshof Rechnung zu tragen. Eine abweichende Beurteilung ist allerdings in einem Fall angezeigt, in dem die grundsätzliche Verteilung der Zuständigkeiten zwischen den Mitgliedstaaten und der EU in Rede steht. So steht das Unionsrecht etwa im besonders bedeutsamen Bereich des Beihilfenrechts der Anwendung einer Vorschrift über die Rechtskraft entgegen, die die Rückforderung einer unionsrechtswidrigen Beihilfe behindern würde, obwohl die Kommission deren Unvereinbarkeit mit dem Gemeinsamen Markt/Binnenmarkt durch eine bestandskräftig gewordene Entscheidung festgestellt hatte. ${ }^{1256}$ Letztlich geht also mit der ausschließlichen Entscheidungskompetenz der Unionsorgane eine Einschränkung der Rechtskraft nationaler Urteile einher, die zur Nichtanwendung einer nationalen Rechtskraftregelung verpflich-

1254 EuGH, Urteil vom 10.7.2014, Rs. C-213/13 (Impresa Pizzarotti), Rn. 59 unter Verweis auf EuGH, Urteil vom 1.6.1999, Rs. C-126/97 (Eco Swiss), Rn. 46 f., EuGH, Urteil vom 16.3.2006, Rs. C-234/04 (Kapferer), Rn. 20 f., EuGH, Urteil vom 3.9.2009, Rs. C-2/08 (Fallimento Olimpiclub), Rn. 22 f., EuGH, Urteil vom 6.10.2009, Rs. C-40/08 (Asturcom Telecomunicaciones), Rn. 35 ff. und EuGH, Urteil vom 22.12.2010, Rs. C-507/08 (Kommission/Slowakei), Rn. 59 f. Ebenso EuGH, Urteil vom 6.10.2015, Rs. C-69/14 (Târşia), Rn. 29; EuGH, Urteil vom 11.11.2015, Rs. C-505/14 (Klausner Holz Niedersachsen), Rn. 39.

1255 EuGH, Urteil vom 29.7.2019, Rs. C-620/17 (Hochtief Solutions Magyarországi Fióktelepe), Rn. $58 \mathrm{f}$.

1256 EuGH, Urteil vom 18.7.2007, Rs. C-119/05 (Lucchini), Rn. 63 und Tenor. Übertragbar sind diese Überlegungen etwa auch auf Fälle, in denen die ausschließliche Zuständigkeit der Europäischen Zentralbank und die damit zusammenhängende ausschließliche Zuständigkeit der Unionsgerichte betroffen sind, vgl. EuGH, Urteil vom 19.12.2018, Rs. C-219/17 (Berlusconi und Fininvest), Rn. 58. 
tet. ${ }^{1257}$ Dabei handelt es sich nach Aussage des EuGH aber um einen „ganz besonders gelagerten Fall“. ${ }^{1258}$

Zusammenfassend lässt sich damit festhalten, dass sowohl eine Durchbrechung der Bestandskraft als auch eine Durchbrechung der Rechtskraft trotz der ex tunc-Wirkung der Auslegung des Gerichtshofs nur ausnahmsweise in Betracht kommen.

3. Reaktionen mitgliedstaatlicher Gerichte als Ausfluss nationaler Verfahrensautonomie?

Nach diesen Klarstellungen zur Bedeutung des Grundsatzes der Verfahrensautonomie der Mitgliedstaaten kann gefragt werden, ob sich Reaktionen mitgliedstaatlicher Gerichte auf die zeitliche Dimension der Rechtsprechung des Gerichtshofs als Ausfluss dieses Grundsatzes beschreiben lassen.

Ebenso wie der Gerichtshof dem Unionsrecht - Art. 264 II AEUV und dem allgemeinen unionsrechtlichen Grundsatz der Rechtssicherheit - Regeln zu den zeitlichen Wirkungen seiner Rechtsprechung entnehmen konnte, finden sich auch auf nationaler Ebene Regeln zu den zeitlichen Wirkungen der Rechtsprechung nationaler Gerichte. ${ }^{1259}$ Vor dem Hintergrund des Grundsatzes der nationalen Verfahrensautonomie legt dies auf den ersten Blick die Einstufung einer den Anforderungen des Äquivalenz- und Effektivitätsgrundsatzes entsprechenden Anwendung dieser Regeln als unionsrechtlich unbedenklich nahe. Zugleich bedeutete dies, dass eine Anwendung dieser Regeln durch ein nationales Gericht bei der Entscheidung konkreter Rechtsstreitigkeiten die zeitliche Wirkung der

1257 Schmabl/Köber, EuZW 2010, 927 (929); siehe auch Rennert, DVBl. 2007, 400 (406 mit Fn. 65). Zur Bedeutung der Rechtskraft in Fallgestaltungen mit Bezug zum Unionsrecht näher Sowery, CMLRev. 53 (2016), 1705 ff. Zur Frage, ob ein rechtskräftig abgeschlossenes Verfahren nach Ergehen einer EuGH-Entscheidung, aus der sich eine Verletzung des Unionsrechts durch das rechtskräftige Urteil ergibt, wiederaufzunehmen ist, siehe Schneider, EuR 2017, $433 \mathrm{ff}$.

1258 EuGH, Urteil vom 10.7.2014, Rs. C-213/13 (Impresa Pizzarotti), Rn. 60 f.; siehe auch EuGH, Urteil vom 3.9.2009, Rs. C-2/08 (Fallimento Olimpiclub), Rn. 25; EuGH, Urteil vom 11.11.2015, Rs. C-505/14 (Klausner Holz Niedersachsen), Rn. 44.

1259 GA Mengozzi, Schlussanträge vom 13.7.2016 in den verb. Rs. C-154/15, C-307/15 und C-308/15 (Gutiérrez Naranjo u.a.), Rn. 80 spricht von den „Modalitäten, die die Bedingungen regeln, unter denen ein oberstes Gericht eines Mitgliedstaats die Wirkungen seiner eigenen Urteile beschränken kann“. 
Auslegung des Unionsrechts durch den EuGH in den mitgliedstaatlichen Rechtsordnungen bestimmen würde. ${ }^{1260}$ Allgemeiner gesprochen würde bei Zugrundelegung eines derartigen Verständnisses das Verhältnis zwischen der Defrenne-Rechtsprechung und der Berücksichtigung nationaler Vertrauensumstände über den Grundsatz der mitgliedstaatlichen Verfahrensautonomie bestimmt, als deren Grenzen lediglich Äquivalenz- und Effektivitätsgrundsatz zu beachten wären.

Einen ähnlichen Ansatz macht auch Generalanwalt Mengozzi in seinen Schlussanträgen in den verbundenen Rechtssachen Gutiérrez Naranjo u.a. fruchtbar. Ausgangspunkt des Verfahrens war eine Entscheidung des spanischen Obersten Gerichtshofs (Tribunal Supremo), der die Wirkungen der Nichtigerklärung einer missbräuchlichen AGB-Klausel unter Heranziehung der vom EuGH im Rahmen seiner Defrenne-Rechtsprechung entwickelten Kriterien des guten Glaubens und der Gefahr schwerwiegender Störungen zeitlich begrenzt hatte. Dieses Vorgehen des Tribunal Supremo ordnet Generalanwalt Mengozzi als Frage der nationalen Verfahrensautonomie und ihrer im Äquivalenz- und Effektivitätsgrundsatz bestehenden Grenzen ein, die er im konkreten Fall als gewahrt ansieht. Er fordert, dass eine solche Beschränkung eine Ausnahme bleiben müsse, und erklärt sie mit den besonderen Umständen der Ausgangsverfahren. ${ }^{1261}$

Den Ansatz des Generalanwalts macht sich der EuGH in seinem Urteil in dieser Rechtssache allerdings zu Recht nicht zu eigen und bevorzugt vielmehr eine Beurteilung aus einer anderen Perspektive. ${ }^{1262}$ Für sämtliches Unionsrecht gilt demnach, dass wie gesehen nur der EuGH die Berufung auf die von ihm ausgelegte Norm in zeitlicher Hinsicht beschränken kann. ${ }^{1263}$ Den nationalen Gerichten die Befugnis zuzusprechen, die vom Gerichtshof entwickelten Kriterien heranzuziehen, um auf dieser Grundlage die zeitlichen Wirkungen ihrer eigenen Rechtsprechung zu

1260 In diesem Sinne Vanistendael, in: Dourado/da Palma Borges (Hrsg.), The Acte Clair, 2008, S. 157 (169) in einem Abschnitt, der mit "The relationship of the retroactive interpretation of EC law and the national rules on the retroactive effect of national judicial decisions" überschrieben ist.

1261 GA Mengozzi, Schlussanträge vom 13.7.2016 in den verb. Rs. C-154/15, C-307/15 und C-308/15 (Gutiérrez Naranjo u.a.), Rn. 68, 79.

1262 Die Schlussanträge des Generalanwalts und das Urteil des Gerichtshofs beurteilen die Frage, ob ein Gericht die Wirkungen seines Urteils begrenzen kann, wenn es über die Folgen einer missbräuchlichen Klausel nach Art. 6 I der Richtlinie 93/13/EWG („Klauselrichtlinie“) entscheidet, also unterschiedlich.

1263 Zur ausschließlichen Zuständigkeit des EuGH siehe oben bei Fn. 287 ff. Siehe auch Winter, jurisPR-ArbR 8/2011 Anm. 6, Orientierungssatz und unter C. 
begrenzen, liefe im Ergebnis darauf hinaus, sie an die Stelle des EuGH treten zu lassen. Eine Rolle als „Ersatz-EuGH“ ist ihnen aber verwehrt. Prüft ein nationales Gericht daher die Kriterien des guten Glaubens und der Gefahr schwerwiegender Störungen, um über die Begrenzung der zeitlichen Wirkungen der von ihm zu treffenden Entscheidung zu befinden, offenbart sich ein unzutreffendes Verständnis von der Aufgabenverteilung zwischen EuGH und mitgliedstaatlichen Gerichten: Hat der Gerichtshof eine Begrenzung der zeitlichen Wirkungen nicht vorgenommen, ist es den Gerichten der Mitgliedstaaten verwehrt, dies zu tun. ${ }^{1264}$

Nationale Gerichte sind zwar für alle Fragen zuständig, die nach den Verträgen nicht dem EuGH anvertraut sind ${ }^{1265}$, sodass auf den ersten Blick die Erwägung naheliegt, einem nationalen Gericht sei gestattet, die Wirkungen einer unionsrechtswidrigen nationalen Norm aus denselben Rechtssicherheitsgründen aufrechtzuerhalten, die für den EuGH bei der Aufrechterhaltung der Wirkungen rechtswidriger Unionsrechtsakte entscheidend sind. Ließe der EuGH eine solche Aufrechterhaltung zu etwa um ein rechtliches Vakuum, das für das Unionsrecht nachteilig ist, zu verhindern und dem Urheber des Rechtsakts Zeit zur Nachbesserung zu geben -, würde er den nationalen Gerichten daher auf den ersten Blick lediglich das gestatten, was er selbst für sich im Hinblick auf Unionsrechtsakte in Anspruch nimmt.

Ein solcher Ansatz gibt allerdings die einheitliche Anwendung des Unionsrechts auf, weswegen er nicht überzeugen kann. Da es nicht darum geht, dem EuGH ein Monopol zur Aufrechterhaltung der Wirkungen nationalen Rechts zuzuweisen, kann dem Gerichtshof nicht zum Vorwurf gemacht werden, dass er sich ein solches zum Preis einer fragwürdigen Auslegung des Vertrages sichern wolle, während dieser ihm im Hinblick auf nationales Recht keine derartige Befugnis verleihe. ${ }^{1266}$ Es geht vielmehr nur darum, ihm eine ausschließliche Zuständigkeit dafür zu sichern, über

1264 GA Tanchev, Schlussanträge vom 3.5.2018 in der Rs. C-51/17 (OTP Bank und OTP Faktoring), Rn. 47 unter Verweis auf EuGH, Urteil vom 21.12.2016, verb. Rs. C-154/15, C-307/15 und C-308/15 (Gutiérrez Naranjo u.a.), Rn. 70-73.

1265 Cassagnabère, Les nouveaux cahiers du Conseil Constitutionnel 2017, 47 (56).

1266 So aber Cassagnabère, Les nouveaux cahiers du Conseil Constitutionnel 2017, 47 (58 f.), der meint, im Winner Wetten-Urteil (Rs. C-409/06) scheine der EuGH die Möglichkeit nationaler Gerichte zur Aufrechterhaltung bestimmter Wirkungen des nationalen Rechts implizit ausgeschlossen zu haben. Zur Winner Wetten-Rechtsprechung und zur Kompetenz nationaler Gerichte zur Aufrechterhaltung von Wirkungen unionsrechtswidrigen nationalen Rechts ausführlich unten bei Fn. 1396 ff. und Fn. 1504 ff. 
die Zulässigkeit eines entsprechenden mitgliedstaatlichen Vorgehens zu entscheiden und damit über die Befugnis der mitgliedstaatlichen Gerichte, von ihrem nationalen Verfahrensrecht, das eine entsprechende Möglichkeit vorsieht, Gebrauch zu machen.

Demnach bleibt festzuhalten, dass eine Anwendung der im nationalen Recht bestehenden Regeln zu den zeitlichen Wirkungen der Rechtsprechung nationaler Gerichte nur möglich ist, wenn sie sich mit Unionsrecht vereinbaren lässt. Während der Gerichtshof für die Beurteilung der zeitlichen Wirkungen der Rechtsprechung der mitgliedstaatlichen (Verfassungs)gerichte dann nicht zuständig ist, wenn diese sich außerhalb des Anwendungsbereichs des Unionsrechts bewegt ${ }^{1267}$, sind ihm Möglichkeiten eröffnet, über die Vereinbarkeit der Begrenzung ihrer zeitlichen Wirkungen mit Unionsrecht zu entscheiden, wenn sie im Anwendungsbereich des Unionsrechts ergeht. ${ }^{1268}$

Hinsichtlich der Frage, wie diese Einwirkungsmöglichkeiten des Gerichtshofs beschaffen sind, ist zunächst die unionsrechtliche Zulässigkeit angemessener Ausschlussfristen für die Rechtsverfolgung in Erinnerung zu rufen. An dieser Stelle geht es nun darum, derartige Verfahrensmodalitäten von einer dem Gerichtshof vorbehaltenen Beschränkung der Berufung auf eine Vorschrift des Unionsrechts in zeitlicher Hinsicht abzugrenzen. ${ }^{1269}$

Dabei ist der Rechtsprechung des Gerichtshofs entsprechend davon auszugehen, dass die Vorschrift des Unionsrechts mit Wirkung ex tunc im Sinne der Auslegung durch den Gerichtshof zu verstehen ist, wenn er keine Begrenzung der zeitlichen Wirkungen vorgenommen hat. Scheitert eine Geltendmachung der unionsrechtlichen Rechte im Hinblick auf vor dem EuGH-Urteil liegende Sachverhalte am Fehlen einer nationalen Verfahrensvoraussetzung, so kommt die Norm in der Auslegung durch den Gerichtshof in diesem Fall zwar nicht zum Tragen. Festzustellen ist aber

1267 EuGH, Beschluss vom 18.2.2016, Rs. C-407/15 (Rîpanu), Rn. 21 ff.

1268 Vgl. GA Mengozzi, Schlussanträge vom 13.7.2016 in den verb. Rs. C-154/15, C-307/15 und C-308/15 (Gutiérrez Naranjo u.a.), Rn. 80.

$1269 \mathrm{EuGH}$, Urteil vom 21.12.2016, verb. Rs. C-154/15, C-307/15 und C-308/15 (Gutiérrez Naranjo u.a.), Rn. 69 f. unter Verweis hinsichtlich der Zulässigkeit angemessener Ausschlussfristen auf EuGH, Urteil vom 6.10.2009, Rs. C-40/08 (Asturcom Telecomunicaciones), Rn.41, hinsichtlich der Abgrenzung von Verfahrensmodalitäten und einer zeitlichen Begrenzung auf EuGH, Urteil vom 15.4.2010, Rs. C-542/08 (Barth), Rn. 30 und hinsichtlich seiner ausschließlichen Zuständigkeit für eine zeitliche Begrenzung auf EuGH, Urteil vom 2.2.1988, Rs. 309/85 (Barra), Rn.13. 
dennoch, dass der vom Unionsrecht Begünstigte bei Wahrung der im nationalen Recht vorgesehenen Verfahrensmodalitäten in der Lage gewesen wäre, seine unionsrechtlichen Rechte geltend zu machen, während bei einer zeitlichen Begrenzung die Möglichkeit einer Berufung auf die durch das Unionsrecht eingeräumten Rechte von vornherein nicht bestanden hätte. ${ }^{1270}$

Die Anwendung einer Verfahrensmodalität ändert also nichts an der ex tunc-Wirkung der Auslegung der Norm und beeinträchtigt lediglich deren Durchsetzung. Damit unterscheiden sich die allein vom Gerichtshof vorzunehmende zeitliche Begrenzung des unionsrechtlichen Normbefehls und die im nationalen Recht zulässigerweise vorgesehenen verfahrensrechtlichen Schranken in ihrer Wirkungsweise und sind unabhängig voneinander. ${ }^{1271}$ Darüber, ob es sich tatsächlich um eine Verfahrensmodalität oder doch um eine verdeckte Begrenzung der zeitlichen Wirkungen handelt, wacht der EuGH.

Während also die Durchsetzung des Unionsrechts aufgrund jeweils unterschiedlicher Verfahrensmodalitäten von Mitgliedstaat zu Mitgliedstaat variieren kann, ist die Frage, ob sich die Betroffenen vor den nationalen Gerichten auf eine Bestimmung des Unionsrechts berufen können, unionsweit einheitlich zu beantworten. Auf diese Weise ist sichergestellt, dass sich die Berufung auf Unionsrecht - in dem vom Mitgliedstaat bestimmten verfahrensrechtlichen Rahmen - nach unionsweit einheitlichen Kriterien richtet. ${ }^{1272}$

In der Regel begründet Unionsrecht also lediglich Rechte, während die Mitgliedstaaten die verfahrensrechtlichen Bedingungen und Rechtsbehelfe zur Durchsetzung dieser Rechte (Bestimmung der zuständigen Gerichte und Ausgestaltung der Verfahren) unter Wahrung der Grundsätze der Äquivalenz und Effektivität festlegen. ${ }^{1273}$ Die verbundenen Rechtssachen Gutiérrez Naranjo u.a. unterscheiden sich hiervon insofern, als das Unionsrecht selbst einen Rechtsbehelf vorsieht, dessen Umfang und Inhalt es dementsprechend auch selbst festlegt. Der dort in Rede stehende Art. 6 I

1270 EuGH, Urteil vom 15.4.2010, Rs. C-542/08 (Barth), Rn. 30; EuGH, Urteil vom 15.9.1998, Rs. C-231/96 (Edis), Rn. 17 und 18.

1271 Gundel, in: Liber Amicorum Berg, 2011, S. 54 (67 mit Fn. 63).

1272 Lenaerts/Corthaut, ELRev. 2006, 287 (309).

1273 Siehe hierzu auch Lenaerts, 46 Irish Jurist (2011), 13 (13 f.); Leskinen/de Elizalde, CMLRev. 55 (2018), 1595 (1610). Aus der Rechtsprechung etwa EuGH, Urteil vom 16.12.1976, Rs. 33/76 (Rewe-Zentralfinanz und Rewe-Zentral), Rn. 5. EuGH, Urteil vom 8.9.2011, verb. Rs. C-89/10 und C-96/10 (Q-Beef und Bosschaert), Rn. 32 spricht insoweit von „ständiger Rechtsprechung“. 
der Klauselrichtlinie 93/13/EWG legt nämlich fest, dass missbräuchliche Klauseln für den Verbraucher unverbindlich sind. Dies versteht der EuGH dahingehend, dass eine solche Klausel grundsätzlich als von Anfang an nicht existent anzusehen ist, sodass der Verbraucher in eine Lage zu versetzen ist, in der er sich ohne die Klausel befunden hätte. ${ }^{1274}$ Die vom Tribunal Supremo vorgesehene zeitliche Begrenzung der Wirkungen der Nichtigerklärung einer missbräuchlichen AGB-Klausel begrenzt nun aber die Unverbindlichkeit im Sinne des Art. 6 I der Klauselrichtlinie und legt nicht die verfahrensrechtlichen Bedingungen der Geltendmachung eines unionsrechtlichen Rechts fest. Das ist keine Frage mitgliedstaatlicher Verfahrensautonomie, sondern eine unter das Unionsrecht fallende Angelegenheit. Das Vorgehen des Tribunal Supremo führt dazu, dass die Unverbindlichkeit der missbräuchlichen Klauseln und die einheitliche Auslegung des Art. 6 I der Klauselrichtlinie erst ab dem Zeitpunkt des spanischen Urteils sichergestellt wären. Es hat damit das in der Klauselrichtlinie vorgesehene Recht des Verbrauchers begrenzt, was aus unionsrechtlicher Sicht unzulässig ist. ${ }^{1275}$

In der Begrenzung der zeitlichen Wirkungen der Nichtigerklärung der missbräuchlichen AGB-Klausel liegt also eine Überschreitung der Befugnisse des Tribunal Supremo. ${ }^{1276}$ Da nur der EuGH das Unverbindlichkeitsgebot des Art. 6 I der Klauselrichtlinie beschränken kann, sind „Rechtssicherheits- und Vertrauensschutzprüfungen" durch nationale Gerichte nicht möglich. ${ }^{1277}$ Im Hinblick auf die Begrenzung der Wirkungen dieser Bestimmung des Unionsrechts besitzt der EuGH also ein „Monopol auf die Herstellung von Rechtssicherheit" ${ }^{\text {"1278 }}$, das die Befugnisse nationaler Gerichte eingrenzt. ${ }^{1279}$ Dass hier die Auslegung einer Richtlinie betroffen ist, ändert nichts an dieser Feststellung.

Die Begrenzung der aus der Nichtigerklärung der missbräuchlichen Klausel zu ziehenden Konsequenzen erfolgte zudem unter Missachtung

1274 EuGH, Urteil vom 21.12.2016, verb. Rs. C-154/15, C-307/15 und C-308/15 (Gutiérrez Naranjo u.a.), Rn. $61 \mathrm{f}$.

1275 Überzeugend Leskinen/de Elizalde, CMLRev. 55 (2018), 1595 (1610ff.).

1276 Siehe auch de Elizalde, EuCML 2015, 184 (187).

1277 Düsterhaus, EuR 2017, 30 (49).

1278 Micklitz, VbR 2017, 80 (82).

1279 Mak, ELRev. 2018, 447 (449f.) sieht hierin die Inanspruchnahme einer „Kompetenz-Kompetenz" durch den EuGH und meint, in ihr die Vorstellung von einer einheitlichen Rechtsordnung aus Unionsrechtsordnung und mitgliedstaatlichen Rechtsordnungen mit der EU an der Spitze zu erkennen. 
der mit Unionsrecht vereinbaren nationalen Rechtslage. ${ }^{1280}$ Das Tribunal Supremo hat sich durch sein Vorgehen gewissermaßen der Rechtsprechung des EuGH bedient, um den auf den Fall eigentlich anwendbaren Art. 1303 Codigo Civil ${ }^{1281}$ nicht anzuwenden. Damit stützt es sich auf Unionsrecht, um das nationale Recht contra legem auszulegen, obwohl Unionsrecht nicht als Grundlage für eine Auslegung contra legem des nationalen Rechts dienen kann. ${ }^{1282}$ Entscheidend ist aber bereits die aus Sicht des EuGH erfolgte Kompetenzüberschreitung des Tribunal Supremo.

Da die mitgliedstaatliche Verfahrensautonomie durch die Verpflichtung zur Wiederherstellung der ohne die Klausel bestehenden rechtlichen und tatsächlichen Lage begrenzt wird ${ }^{1283}$, lässt sich auf diese im vorliegenden Fall keine zeitliche Begrenzung stützen. Dies bedeutet allerdings nicht, dass eine zeitliche Begrenzung grundsätzlich ausgeschlossen ist. Über sie müsste aber der Gerichtshof entscheiden. ${ }^{1284}$

Die zeitliche Begrenzung der Wirkungen mitgliedstaatlicher Rechtsprechung kann daher nicht als bloßer Aspekt mitgliedstaatlicher Verfahrensautonomie angesehen werden, der es mitgliedstaatlichen Gerichten gestat-

1280 Siehe hierzu GA Mengozzi, Schlussanträge vom 13.7.2016 in den verb. Rs. C-154/15, C-307/15 und C-308/15 (Gutiérrez Naranjo u.a.), Rn. 65 mit Fn. 71 und Fn. 76, der darauf hinweist, dass die Rechtsfolge der Nichtigkeit mit Anspruch auf vollständige Rückerstattung bei missbräuchlichen Klauseln bereits nach spanischem Recht besteht. Vgl. auch Leskinen/de Elizalde, CMLRev. 55 (2018), 1595 (1597 mit Fn. 9, 1616).

1281 Dieser lautet übersetzt: „Ist eine Verpflichtung für nichtig erklärt worden, müssen die Vertragsparteien unbeschadet der folgenden Artikel einander die Sachen, die Gegenstand des Vertrags gewesen sind, mit ihren Früchten sowie den Preis mit den Zinsen rückerstatten."

1282 Siehe dazu näher unten bei Fn. $2041 \mathrm{ff}$. Dass das Tribunal Supremo sich für die contra legem-Auslegung nicht auf die Richtlinie, sondern auf die DefrenneRechtsprechung des EuGH stützt, macht insoweit keinen Unterschied, worauf auch de Elizalde, EuCML 2015, 184 (187 mit Fn. 36) hinweist.

1283 Vgl. Gazin, Europe 2017, 39 (40), die den keinen Widerspruch duldenden Tonfall des EuGH hervorhebt.

1284 Siehe dazu auch Micklitz, VbR 2017, 80 (81), der dies wohl mit der Formulierung zum Ausdruck bringen möchte, diese Differenzierung reiche nicht aus, um dem Einwand zu begegnen, dass es besondere Umstände geben könne, in denen eine zeitliche Befristung gerechtfertigt sei. Ob der Gerichtshof "nationalem Vertrauensschutz" bei der Betroffenheit von Richtlinien dadurch eine generelle Absage erteilt hat, dass er im Gutiérrez Naranjo-Urteil auf seine Defrenne-Rechtsprechung Bezug genommen hat, ist an späterer Stelle noch näher zu beleuchten, siehe dazu unten bei Fn. $2264 \mathrm{ff}$. 
tete, die Wirkungen der Auslegung einer unionsrechtlichen Vorschrift in zeitlicher Hinsicht zu begrenzen. ${ }^{1285}$

II. Eigenständige Bindungswirkung der Vornahme bzw. Ablehnung einer zeitlichen Begrenzung?

Um sich dem Verhältnis von Defrenne-Rechtsprechung und Reaktionsmöglichkeiten mitgliedstaatlicher Gerichte zu nähern, ist zudem Klarheit über die diesen bei der Vornahme oder Ablehnung einer Begrenzung der zeitlichen Wirkungen im Sinne der Defrenne-Rechtsprechung auferlegten Verpflichtungen zu erlangen. Nur dann lässt sich überhaupt die Frage beantworten, in welcher zeitlichen Dimension sie die vom Gerichtshof vorgenommene Auslegung bei der Entscheidung konkreter Rechtsstreitigkeiten zur Anwendung bringen müssen.

Genauer zu untersuchen ist daher, welche Aussage mit der Vornahme einer Begrenzung der zeitlichen Wirkungen im Sinne der Defrenne-Rechtsprechung für das nationale Verfahren getroffen ist. Zudem ist herauszuarbeiten, ob Unterschiede zwischen der ausdrücklichen bzw. impliziten Ablehnung einer Begrenzung bestehen. Daneben ist kurz die Bedeutung der Rechtskraft im hier interessierenden Zusammenhang anzusprechen.

\section{Vornahme einer zeitlichen Begrenzung}

Hat der Gerichtshof eine zeitliche Begrenzung vorgenommen, ist den Betroffenen durch die vorübergehende Aufhebung des Normbefehls die Möglichkeit genommen, sich auf das Unionsrecht zu berufen. Die zugrundeliegende unionsrechtliche Norm kann für den betreffenden Zeitraum daher nicht zur Grundlage einer Entscheidung gemacht werden. Lediglich für die Begründung der Entscheidung kann sie noch Bedeutung er-

1285 In diesem Sinne wohl auch Verstraelen, GLJ 14 (2013), 1687 (1728, 1729). Ihre Überlegung, dass sich eine Einordnung der Reaktionen mitgliedstaatlicher Gerichte als Ausfluss der mitgliedstaatlichen Verfahrensautonomie nicht zuletzt in Widerspruch zum Effektivitätsgrundsatz setzen würde, kann allerdings insoweit nicht überzeugen, als es an dieser Stelle gerade um die Frage ging, ob der Effektivitätsgrundsatz der zutreffende Maßstab für die Möglichkeit einer Berücksichtigung nationaler Vertrauensumstände ist. 
langen. ${ }^{1286}$ Ihrer Berücksichtigung als Rechtsgewinnungsquelle steht die zeitliche Begrenzung daher nicht entgegen. ${ }^{1287}$

Im Falle der Vornahme einer zeitlichen Begrenzung kann sich auch die Frage nach der unionsrechtlichen Zulässigkeit einer die unionsrechtlichen Vorgaben in zeitlicher Hinsicht „übererfüllenden“ Norm des nationalen Rechts stellen. Sie war in vom EuGH entschiedenen Fällen aufgeworfen, in denen Art. 119 EWGV (jetzt Art. 157 AEUV) und im Wesentlichen (neben weiteren nationalen Vorschriften) Art. 3 GG in Rede standen.

Die zeitliche Dimension der unmittelbaren Wirkung des in Art. 119 EWGV niedergelegten Gleichbehandlungsgrundsatzes (gleiches Entgelt für Männer und Frauen) war vom EuGH im Defrenne II-Urteil begrenzt worden; bei Art. 3 GG bestand hingegen keine entsprechende Begrenzung in zeitlicher Hinsicht. Da die nationalen Vorschriften nach Ansicht des EuGH zur Durchführung der Deutschland seit 1.1.1962 obliegenden Verpflichtungen beitrugen, untersagte der unionsrechtliche Grundsatz der Rechtssicherheit ungeachtet der Begrenzung der zeitlichen Wirkungen im Defrenne II-Urteil die Anwendung von Art. 3 GG nicht. ${ }^{1288}$ Diese stand somit nicht im Widerspruch zum Unionsrecht, da diesem keine Vorschriften zu entnehmen waren, die in der Zeit vor Erlass des Defrenne II-Urteils eine Verwirklichung des Grundsatzes des gleichen Entgelts für Männer und Frauen untersagten. Die damit einhergehende Belastung deutscher Versorgungsschuldner - in den Ausgangsverfahren ging es um die Voraussetzungen für den Anschluss an ein betriebliches Zusatzversorgungssystem

1286 Vgl. Canaris, in: Basedow (Hrsg.), Europäische Vertragsrechtsvereinheitlichung, 2000, S. 5 (9), der als Rechtsgewinnungsquelle Faktoren bezeichnet, die im Rahmen der Rechtsgewinnung eine Rolle spielen, aber als solche keine normative Verbindlichkeit aufweisen.

1287 Herresthal, Rechtsfortbildung, 2006, S. $304 \mathrm{f}$.

1288 EuGH, Urteil vom 10.2.2000, Rs. C-50/96 (Deutsche Telekom/Schröder), Rn. 46 ff.; EuGH, Urteil vom 10.2.2000, verb. Rs. C-234/96 und C-235/96 (Deutsche Telekom/Vick und Conze), Rn. 46 ff.; EuGH, Urteil vom 10.2.2000, verb. Rs. C-270/97 und C-271/97 (Deutsche Post/Sievers und Schrage), Rn. 48 ff. Die zeitliche Beschränkung der Möglichkeit, sich auf die unmittelbare Wirkung des Art. 119 EWG-Vertrag zu berufen, ist vom Gerichtshof in EuGH, Urteil vom 8.4.1976, Rs. 43/75 (Defrenne), Tenor Nr. 5 (und Rn. 74/75) vorgenommen worden. 
und die Gewährung einer entsprechenden Rente ${ }^{1289}$ - ist aus unionsrechtlicher Sicht daher hinzunehmen. ${ }^{1290}$

Erklären lässt sich dieses vom Gerichtshof gefundene Ergebnis auch mit der Wirkung der Vornahme einer Begrenzung der zeitlichen Wirkungen durch den EuGH im Sinne der Defrenne-Rechtsprechung. Eine solche bewirkt lediglich, dass sich die Betroffenen nicht auf den vom EuGH bestimmten Inhalt der ausgelegten unionsrechtlichen Norm berufen können, während der Norminhalt als solcher unverändert bleibt. Der Gerichtshof setzt hierdurch also kein neues Recht für die Zeit vom Inkrafttreten der Norm bis zum Urteil und legt ihr keinen anderen Inhalt bei als ab dem Tag des Urteils. ${ }^{1291}$

Die vom Gerichtshof gewählte Formulierung, eine Begrenzung der zeitlichen Wirkungen erfolge aus „zwingende[n] Erwägungen der Rechtssicherheit “ ${ }^{1292}$ mag bei unbefangener Betrachtung zwar ein Verständnis nahelegen, wonach die Begrenzung insofern „zwingend“ ist, als sie über die Zulässigkeit weitergehenden nationalen Rechts entscheidet. ${ }^{1293}$ Das ist aber gerade nicht der Fall, da sie lediglich den Normbefehl vorübergehend aufhebt und sich in dieser Wirkung erschöpft. ${ }^{1294}$ Aus diesem Grund „erlaubt" sie den Mitgliedstaaten aber auch nicht eine Abweichung von der in zeitlicher Hinsicht beschränkten Norm.

Dass aus der hier in Bezug genommenen Entscheidung in der Literatur zum Teil abgeleitet wurde, dass die zeitliche Beschränkung durch den Gerichtshof nicht an der Vorrangwirkung teilnehme ${ }^{1295}$, kann daher nicht

1289 EuGH, Urteil vom 10.2.2000, Rs. C-50/96 (Deutsche Telekom/Schröder), Rn. 2; EuGH, Urteil vom 10.2.2000, verb. Rs. C-234/96 und C-235/96 (Deutsche Telekom/Vick und Conze), Rn.2; EuGH, Urteil vom 10.2.2000, verb. Rs. C-270/97 und C-271/97 (Deutsche Post/Sievers und Schrage), Rn. 2.

1290 Aus diesem Grunde kritisch Huep, RdA 2001, 325 (332).

1291 In diesem Sinne aber Levits, SR 2015, 121 (124). Wißmann, in: FS Bauer, 2010, S. 1161 (1164) spricht davon, dass die Begrenzung durch den EuGH zu einer Einschränkung des festgestellten Norminhalts führe. Siehe auch Rosenkranz, ZfPW 2016, 351 (360), wonach die Norm des Unionsrechts für die Zeit zwischen Inkrafttreten und dem Tag der Urteilsverkündung einen anderen Inhalt habe als ab dem Tag des Urteils, während er in Rosenkranz, Beschränkung der Rückwirkung, 2015, S. 301 ausführt, der materielle Inhalt der Norm werde nicht verändert, sondern sei für die Zeit vor und nach dem Urteil identisch.

1292 EuGH, Urteil vom 8.4.1976, Rs. 43/75 (Defrenne), Rn. 74/75.

1293 Besselink, CMLRev. 38 (2001), 437 (451 ff.).

1294 Rosenkranz, Beschränkung der Rückwirkung, 2015, S. 304 f. Eine Aussage über die Zulässigkeit weitergehenden nationalen Rechts ist damit nicht getroffen, Rosenkranz, a.a.O., S. 430.

1295 So Wölker, EuR 2007, 32 (51). 
überzeugen, da bereits der gedankliche Ausgangspunkt falsch gewählt ist: Eine Teilhabe an der Vorrangwirkung ist dadurch ausgeschlossen, dass sie sich nur auf den unionsrechtlichen Normbefehl bezieht, den sie begrenzt, nicht aber den unionsrechtlichen Normbefehl umkehrt. ${ }^{1296}$

Ebenfalls nicht überzeugend ist es demnach, in den Entscheidungen des Gerichtshofs den Ausdruck eines Günstigkeitsprinzips zu erblicken, auf das dieser in entscheidungserheblicher Weise abgestellt habe. Ein solches ist nicht der Grund für die Zulässigkeit der Anwendung weitergehenden nationalen Rechts; dafür, dass ein mit dem Unionsgrundrecht vergleichbares Grundrecht, das in seinem zeitlichen Anwendungsbereich weiter zurückreicht als das Unionsgrundrecht, zur Anwendung gelangen kann, ist kein „Mehr“ an Gerechtigkeit die Ursache. ${ }^{1297}$ Dem in seiner zeitlichen Wirkung begrenzten unionsrechtlichen Grundsatz des gleichen Entgelts für Männer und Frauen wird mit der Zulassung der Anwendung des Art. 3 GG lediglich „als Nebenfolge“ so weit wie möglich zur Geltung verholfen.

Eine die unionsrechtlichen Vorgaben in zeitlicher Hinsicht „übererfüllende" Norm des nationalen Rechts ist daher nicht aufgrund einer zeitlichen Beschränkung der Wirkungen der unionsrechtlichen Norm unionsrechtlich unzulässig. ${ }^{1298}$ Hierüber entscheidet das sonstige Unionsrecht unter Ausblendung der in zeitlicher Hinsicht beschränkten Norm.

Für die Frage der Zulässigkeit "nationalen Vertrauensschutzes“ lässt sich aus den vorangegangenen Überlegungen ableiten, dass es entscheidend auf den inhaltlichen Widerspruch zwischen Unionsrecht und nationalem Recht in einem bestimmten Zeitpunkt ankommt, zu dem die Gewährung „nationalen Vertrauensschutzes“ im Vergleich zur DefrenneRechtsprechung führt. ${ }^{1299}$ Dass Defrenne-Rechtsprechung und „nationaler Vertrauensschutz" ihre jeweilige zeitliche Anwendbarkeit unterschiedlich beurteilen, ist also nicht ausschlaggebend. ${ }^{1300}$

1296 Eine eigenständige Vorrangwirkung ebenfalls ablehnend Rosenkranz, Beschränkung der Rückwirkung, 2015, S. 437.

1297 Entscheidend hierauf abstellend Wusterhausen, Wirkungen, 2016, S. 350 ff., der auch Art. 53 GRCh fruchtbar machen möchte, S. 353, Fn. 1146.

1298 Im Ergebnis ebenso GA Cosmas, verb. Schlussanträge vom 8.10.1998 in den Rs. C-50/96, C-234/96 und C-235/96, C-270/97 und C-271/97 (Schröder u.a.), Rn. $62 \mathrm{ff}$.

1299 Rosenkranz, Beschränkung der Rückwirkung, 2015, S. 437; Wißmann, in: FS Bauer, 2010, S. 1161 (1167).

1300 So aber Schaer, Grenzen rückwirkender Rechtsprechung, 2010, S.157; Нuер, RdA 2001, 325 (331). 


\section{Unterbleiben einer Begrenzung}

Schweigt der EuGH zu einer zeitlichen Begrenzung, ist dies wie gesehen gleichbedeutend mit deren Ablehnung. ${ }^{1301}$ Dass in diesem Schweigen keine implizite Ermächtigung der mitgliedstaatlichen Gerichte zur Begrenzung der zeitlichen Wirkungen gesehen werden kann, kann daher nicht bestritten werden: Der unionsrechtliche Normbefehl ist nicht suspendiert; eine Möglichkeit für nationale Gerichte, dies aus eigenem Antrieb zu tun, besteht nicht.

Umgekehrt gilt aber auch, dass die Tatsache, dass der Gerichtshof eine zeitliche Begrenzung ausdrücklich abgelehnt hat, nicht gleichbedeutend mit einem Verbot der zeitlichen Modulation der Wirkungen der Entscheidungen mitgliedstaatlicher Gerichte ist. Einer gesteigerten Bindung sind die Wirkungen, die der EuGH seiner Auslegung in zeitlicher Hinsicht gegeben hat, nicht unterworfen. ${ }^{1302}$ Selbstverständlich ist wie gesehen $\mathrm{zu}$ beachten, dass mitgliedstaatliche Gerichte die vom Gerichtshof geprüften Kriterien nicht einer eigenständigen Beurteilung unterziehen können, da ihnen insoweit bereits die Prüfungsbefugnis entzogen ist. Unabhängig davon, ob der EuGH eine zeitliche Begrenzung im Sinne der DefrenneRechtsprechung ausdrücklich oder stillschweigend abgelehnt hat, ist dieser Ablehnung aber lediglich die Aussage zu entnehmen, dass das Unionsrecht nicht bereits aus Gründen der unionsrechtlichen Rechtssicherheit zurücktritt. ${ }^{1303}$ Eine weitergehende Aussage ist hiermit nicht verbunden, sodass Reaktionsmöglichkeiten nationaler Gerichte auch bei der ausdrücklichen Ablehnung einer Begrenzung nicht von vornherein ausgeschlossen sind.

Die Erwägung des Conseil d'État in der Rechtssache Association Vent De Colère! u.a., der Begrenzung der Wirkungen der von ihm vorzunehmenden Nichtigerklärung der unionsrechtswidrigen nationalen Regelung stehe die Zurückweisung der von der französischen Regierung beantragten Begrenzung im Sinne der Defrenne-Rechtsprechung durch den EuGH entgegen, gibt also die unionsrechtlichen Maßstäbe nicht zutreffend wieder. Die „Erwägungen derselben Natur“, an denen sich der Conseil d'État gehindert sieht, sind nicht zwingend mit einer Prüfung der vom EuGH seiner Defrenne-Rechtsprechung zugrunde gelegten Kriterien gleichzuset-

1301 Siehe oben bei Fn. 297 ff.

1302 In diese Richtung aber Cassagnabère, Les nouveaux cahiers du Conseil Constitutionnel 2017, 47 (58).

1303 Dies betont Rosenkranz, Beschränkung der Rückwirkung, 2015, S. 437 zutreffend. 
zen. ${ }^{1304} \mathrm{Ob}$ der Conseil d'État dennoch zum richtigen Ergebnis gelangt ist, hängt von der Befragung der „Durchsetzungsdimension“ des Unionsrechts ab, der sich die Arbeit sogleich zuwenden wird.

\section{Rechtskraft und Begrenzung der zeitlichen Wirkungen}

Die Begrenzung der zeitlichen Wirkungen erwächst mit Begrenzung auf das Ausgangsverfahren in Rechtskraft. Eine Rechtskraftwirkung erga omnes ist damit allerdings nicht verbunden. Dies bewirkt auch die Präklusion nicht. ${ }^{1305}$ Die Ablehnung der Begrenzung der zeitlichen Wirkungen wird dagegen nicht in den Tenor aufgenommen. Dass sich die Rechtskraft für das vorlegende Gericht auch auf die ausdrückliche Ablehnung einer zeitlichen Begrenzung bezieht, ist daher jedenfalls nicht eindeutig. ${ }^{1306}$ Insoweit erscheint es vorzugswürdig, darauf abzustellen, dass die Ausschließlichkeit der Befugnis des EuGH zur Begrenzung der zeitlichen Wirkungen ein nationales Gericht an einer abweichenden Beurteilung der vom Gerichtshof geprüften Kriterien hindert.

Sollte der Gerichtshof eine zeitliche Begrenzung ohne Rückausnahme für Rechtsbehelfsführer vornehmen, bedeutet dies, dass sich für den im Urteil bezeichneten Zeitraum auch der Kläger des Ausgangsverfahrens nicht auf die Norm in ihrer Auslegung durch den EuGH berufen kann. Die Rechtskraftwirkung hinsichtlich der Auslegung ist in einem solchen Fall demnach insoweit modifiziert, als sie für das Ausgangsverfahren keine Bedeutung erlangt. ${ }^{1307}$

\section{B. Die „Durchsetzungsdimension"}

Wie der Gerichtshof in ständiger Rechtsprechung wiederholt, äußert er sich im Rahmen der Auslegung des Unionsrechts dazu, in welchem Sinne eine Bestimmung des Unionsrechts „seit ihrem Inkrafttreten zu verstehen

1304 Conseil d'État, Urteil vom 28.5.2014, No. 324852 unter Verweis auf EuGH, Urteil vom 19.12.2013, Rs. C-262/12 (Association Vent De Colère! u.a.), Rn. 38-44.

1305 Rosenkranz, Beschränkung der Rückwirkung, 2015, S. 404 f., der auf die unterschiedliche Zielsetzung von Präklusion und Rechtskraft hinweist.

1306 Hierfür Cassagnabère, Les nouveaux cahiers du Conseil Constitutionnel 2017, $47(58)$.

1307 Siehe in diesem Zusammenhang auch Germelmann, Rechtskraft, 2009, S. 422 f. 
und anzuwenden ist oder gewesen wäre“, und zieht daraus den Schluss, dass die nationalen Gerichte die Vorschrift in der vom EuGH vorgenommenen Auslegung bei Vorliegen der nationalen Verfahrensvoraussetzungen ,auch auf Rechtsverhältnisse, die vor Erlass des auf das Ersuchen um Auslegung ergangenen Urteils entstanden sind, anwenden können und müssen“. ${ }^{1308}$ Durch diese Verknüpfung weist der Gerichtshof der Auslegung einer unionsrechtlichen Norm auch Auswirkungen auf die Ebene der Anwendung in laufenden und ausnahmsweise auch abgeschlossenen Verfahren vor mitgliedstaatlichen Gerichten zu. ${ }^{1309}$ Dieser Zusammenhang zwischen Auslegung und Anwendung des Unionsrechts sowie die Möglichkeiten einer Differenzierung zwischen beiden Ebenen sollen im Folgenden näher in den Blick genommen werden.

\section{Zusammenhang zwischen Auslegung und Anwendung des Unionsrechts}

In der Rechtssache Cussens hat der Gerichtshof eine Anwendung des Grundsatzes des Verbots missbräuchlicher Praktiken „wie er aus dem Urteil Halifax hervorgeht" auf Umsätze, die vor dem Erlass des Halifax-Urteils ${ }^{1310}$ durchgeführt wurden, als mit den Grundsätzen der Rechtssicherheit und des Vertrauensschutzes vereinbar eingeordnet. Die zeitlichen Wirkungen der im Halifax-Urteil vorgenommenen Auslegung des Grundsatzes des Verbots missbräuchlicher Praktiken im Bereich der Mehrwertsteuer

1308 Siehe nur EuGH, Urteil vom 13.12.2018, Rs. C-385/17 (Hein), Rn. 56; EuGH, Urteil vom 22.9.2016, Rs. C-110/15 (Microsoft Mobile Sales International u.a.), Rn. 59; EuGH, Urteil vom 22.1.2015, verb. Rs. C-401/13 und C-432/13 (Balazs), Rn. 49. Entsprechend auch EuGH, Urteil vom 20.9.2018, Rs. C-510/16 (Carrefour Hypermarchés u.a.), Rn. 61; EuGH, Urteil vom 19.10.2017, Rs. C-101/16 (Paper Consult), Rn. 64; EuGH, Urteil vom 22.11.2017, Rs. C-251/16 (Cussens u.a.), Rn. 41; EuGH, Urteil vom 10.11.2016, Rs. C-477/16 PPU (Kovalkovas), Rn. 51; EuGH, Urteil vom 10.11.2016, Rs. C-452/16 PPU (Poltorak), Rn. 55.

1309 GA Bobek, Schlussanträge vom 7.9.2017 in der Rs. C-251/16 (Cussens u.a.), Rn. 35 spricht hinsichtlich der zeitlichen Anwendung der Rechtsprechung des EuGH von einer „allgemeine[n] Regel der inzidenten Rückwirkung“ (Hervorhebung im Original); so auch bereits GA Bobek, Schlussanträge vom 13.7.2017 in der Rs. C-574/15 (Scialdone), Rn. 179. Für die abgeschlossenen Verfahren verweist er jeweils auf EuGH, Urteil vom 13.1.2004, Rs. C-453/00 (Kühne \& Heitz), Rn. 28 und EuGH, Urteil vom 18.7.2007, Rs. C-119/05 (Lucchini), Rn. 63.

1310 EuGH, Urteil vom 21.2.2006, Rs. C-255/02 (Halifax u.a.). 
hatte er nicht begrenzt, sodass eine Nachholung der Begrenzung nach der Präklusionsrechtsprechung des Gerichtshofs nicht in Betracht kam. Auch wenn in der hier vorgestellten Rechtssache die Besonderheit hinzukam, dass den sich missbräuchlich Verhaltenden eine Berufung auf die Grundsätze der Rechtssicherheit und des Vertrauensschutzes verwehrt ist ${ }^{1311}$, so bleibt für die vorliegenden Zwecke von Interesse, dass der Gerichtshof einerseits auf seine Rechtsprechung zur Begrenzung der Berufung auf eine ausgelegte Norm in zeitlicher Hinsicht verweist, die er wie gesehen am Grundsatz der Rechtssicherheit ausrichtet (und Vertrauensschutz dementsprechend nicht prüft) und andererseits auf die Passage in seinem Urteil in der Rechtssache DI, in der er eine Heranziehung des nationalen Vertrauensschutzgrundsatzes, die darauf abzielt, eine Anwendung des Verbots der Altersdiskriminierung zu verhindern, ablehnt. ${ }^{1312}$ Damit nimmt er sowohl auf die erste Stufe der Auslegung als auch auf das Problem der Anwendung bzw. Durchsetzung des Unionsrechts im konkreten Fall auf nationaler Ebene Bezug.

Der in der Rechtssache Cussens im Mittelpunkt stehende Grundsatz des Verbots missbräuchlicher Praktiken „wie er im Bereich der Mehrwertsteuer durch die aus dem Urteil Halifax hervorgegangene Rechtsprechung angewandt wird", ist nach Auffassung des EuGH keine durch eine Richtlinie aufgestellte Regel. ${ }^{1313} \mathrm{Er}$ ordnet ihn dort vielmehr als allgemeinen Rechtsgrundsatz des Unionsrechts ein ${ }^{1314}$, sodass seine Anwendung auch zu Lasten Privater möglich ist und es hierfür einer Umsetzung im nationalen Recht nicht bedarf. Das ansonsten aufgeworfene Problem einer zu Lasten des Einzelnen ausgeschlossenen unmittelbaren Wirkung der Richtlinie besteht daher nicht, auch wenn es im nationalen Recht zum maßgeblichen Zeitpunkt an einem Anknüpfungspunkt für die Unbeachtlichkeit missbräuchlicher Praktiken fehlte. ${ }^{1315}$

1311 EuGH, Urteil vom 22.11.2017, Rs. C-251/16 (Cussens u.a.), Rn. 42 f.; zustimmend Buckler, EuR 2018, 371 (378).

1312 EuGH, Urteil vom 22.11.2017, Rs. C-251/16 (Cussens u.a.), Rn. 39 f. unter Verweis auf EuGH, Urteil vom 22.1.2015, verb. Rs. C-401/13 und C-432/13 (Balazs), Rn. 49, 50 und EuGH, Urteil vom 19.4.2016, Rs. C-441/14 (DI), Rn. 3840.

1313 EuGH, Urteil vom 22.11.2017, Rs. C-251/16 (Cussens u.a.), Rn. 27 f.

1314 EuGH, Urteil vom 22.11.2017, Rs. C-251/16 (Cussens u.a.), Rn. 31; bestätigt in EuGH, Urteil vom 6.2.2018, Rs. C-359/16 (Altun u.a.), Rn. 49.

1315 Buckler, EuR 2018, 371 (373 f., 376 f.). GA Kokott, Schlussanträge vom 1.3.2018 in der Rs. C-116/16 (T Danmark), Rn. $101 \mathrm{ff}$. ordnet diese Rechtsprechung des Gerichtshofs als Besonderheit des Mehrwertsteuerrechts ein. 
Ist ein unmittelbare Wirkung entfaltender unionsrechtlicher Rechtsgrundsatz betroffen, stellt der Gerichtshof also selbst einen Zusammenhang zwischen der Auslegung des Unionsrechts durch ihn selbst und dessen Anwendung durch die nationalen Gerichte her - unter Einbeziehung insbesondere auch seiner Begrenzungsrechtsprechung. Im Hinblick auf mittelbar wirkendes Unionsrecht fehlt es an einer entsprechend eindeutigen Aussage des Gerichtshofs. Dennoch darf nicht übersehen werden, dass auch bei diesem ein Zusammenhang zwischen Auslegung und Anwendung besteht. Dieser Zusammenhang ist zwar insofern „mittelbarer“, als hier nationales Recht zur Anwendung gelangt, in das die Auslegung durch den Gerichtshof eingepasst werden muss. Auch könnte die in der zu Beginn des Kapitels wiedergegebenen Aussage des EuGH aufgestellte Verpflichtung, wonach die nationalen Gerichte bei Vorliegen der nationalen Verfahrensvoraussetzungen die Vorschrift in der vom EuGH vorgenommenen Auslegung auch auf Rechtsverhältnisse anwenden können und müssen, die vor Erlass des auf das Ersuchen um Auslegung ergangenen Urteils entstanden sind ${ }^{1316}$, für den Fall der richtlinienkonformen Auslegung keine Bedeutung erlangen, wenn sie begrifflich eng zu verstehen wäre - es wird ja nicht die Vorschrift des Unionsrechts selbst unmittelbar auf den Sachverhalt angewandt, sondern das nationale Recht. Allerdings ist kein Grund ersichtlich, weshalb dem Begriff der „Anwendung“ in diesem Zusammenhang nicht ein weites Verständnis beigemessen werden könnte. Es spricht nichts dagegen, von einer Anwendung der ausgelegten Vorschrift des Unionsrechts bereits dann zu sprechen, wenn die Richtlinie in ihrer Auslegung durch den Gerichtshof herangezogen wird, um eine Bestimmung des nationalen Rechts in ihrem Sinne auszulegen. Der $\mathrm{Zu}-$ sammenhang zwischen der Auslegung des Unionsrechts durch den EuGH und seiner Anwendung durch nationale Gerichte besteht daher auch bei mittelbar wirkendem Unionsrecht.

\section{Trennung von Auslegung und Durchsetzungsdimension?}

Gegen die sich hier abzeichnende Pflicht zur in zeitlicher Hinsicht unbegrenzten Anwendung des vom EuGH ausgelegten und nicht mit einer Begrenzung im Sinne der Defrenne-Rechtsprechung versehenen Unionsrechts kommen sowohl auf das nationale (Verfassungs)recht gestützte Einwände als auch vom Unionsrecht selbst zugelassene Schranken in Betracht.

1316 Nachweise in Fn. 1308. 
Vor dem Hintergrund, dass sich aus mitgliedstaatlicher Sicht insbesondere in den Fällen, in denen sich das Unionsrecht der Berücksichtigung nationaler Besonderheiten verschließt, ein Bedürfnis nach einem Rückgriff auf im nationalen Recht wurzelnde Erwägungen ergibt, erscheint es angezeigt, zunächst die vom Unionsrecht selbst anerkannten Schranken in den Blick zu nehmen.

Angesprochen sind damit insbesondere die unionsrechtlichen Grenzen des Anwendungsvorrangs sowie der Pflicht zu richtlinien- (und gegebenenfalls rahmenbeschluss)konformer Auslegung. Sie sind in Bezug zur Begrenzung der ex tunc-Wirkung im Sinne der Defrenne-Rechtsprechung zu setzen und daher vor dem Hintergrund der „Beschränkungsprärogative“ des Gerichtshofs hinsichtlich der Begrenzung der Berufung auf eine ausgelegte Norm in zeitlicher Hinsicht zu betrachten. ${ }^{1317}$ Damit ist das Verhältnis der jeweiligen „Durchsetzungsdimension“ - Anwendungsvorrang bzw. richtlinienkonforme Auslegung - zur Defrenne-Rechtsprechung zu untersuchen und zu fragen, ob neben dem Instrument der Begrenzung des Rechtsanwendungsbefehls der ausgelegten Norm in zeitlicher Hinsicht im Sinne der Defrenne-Rechtsprechung auch eine Begrenzung des dieser Norm zukommenden Vorrangs oder der Verpflichtung, das nationale Recht im Sinne dieser Norm auszulegen, denkbar ist.

Dabei kann nach hier vertretener Auffassung nicht davon ausgegangen werden, dass sich der Anwendungsbereich der Defrenne-Rechtsprechung mit den Grenzen unmittelbar anwendbaren Unionsrechts deckt. ${ }^{1318}$ Auch wenn sich der Gerichtshof in Verfahren, die die Auslegung von Richtlinienbestimmungen betreffen, die horizontale Rechtsstreitigkeiten prägen und daher nach der Rechtsprechung des Gerichtshofs keine unmittelbare Wirkung entfalten, bislang zu keiner zeitlichen Begrenzung im Sinne der Defrenne-Rechtsprechung veranlasst gesehen hat, so legt er seiner Prüfung doch dieselben Kriterien zugrunde wie in Fällen, in denen unmittelbar anwendbare Unionsrechtsbestimmungen betroffen sind. ${ }^{1319}$ Unterschiede zwischen beiden Kategorien von Unionsrecht bestehen im hier interessierenden Zusammenhang daher nicht bereits aus diesem Grund.

1317 Siehe in diesem Zusammenhang auch Düsterhaus, EuR 2017, 30 (47).

1318 So aber Düsterhaus, YEL 36 (2017), 237 (273 f.).

1319 EuGH, Urteil vom 13.12.2001, Rs. C-481/99 (Heininger), Rn.52, die auf EuGH, Urteil vom 28.9.1994, Rs. C-128/93 (Fisscher), Rn. 18 verweist, wo der EuGH auf das Defrenne II-Urteil und seine dort begründete Rechtsprechung zur Beschränkung der zeitlichen Wirkungen Bezug nimmt. 
Zwischen der Begrenzung der Auslegung und der Begrenzung der Durchsetzungsdimension trennen nicht sämtliche Autoren. So führt etwa Generalanwältin Kokott in ihren Schlussanträgen in der Rechtssache Association France Nature Environnement ${ }^{1320}$ unter der Überschrift „Zur Aufrechterhaltung der Wirkung unionsrechtswidriger Bestimmungen“ aus, dass dem Gebot der Richtlinie 2001/42/EG, wonach eine ausreichende Autonomie der im Rahmen einer Umweltprüfung zu konsultierenden Stelle zu gewährleisten sei, Vorrang zukomme und sich nun die Frage stelle, ob dessen Wirkung vorübergehend zugunsten der diese Autonomie nicht vorsehenden französischen Regelungen ausgesetzt werden könne. Im Anschluss daran führt sie die ständige Rechtsprechung des Gerichtshofs zur Begrenzung der Berufung auf die von ihm vorgenommene Auslegung an und verweist in Fn. 17 u.a. auf das Defrenne II-Urteil. ${ }^{1321} \mathrm{Im}$ selben Atemzug zitiert sie, wie Fn. 16 deutlich macht, zum Nachweis der Ausschließlichkeit der Befugnis des Gerichtshofs im Rahmen der DefrenneRechtsprechung Rn. 67 des Urteils in der Rechtssache Winner Wetten. ${ }^{1322}$ Dort hatte der Gerichtshof ausgeführt, dass nur er über die Voraussetzungen einer Aussetzung der Verdrängungswirkung unmittelbar anwendbaren Unionsrechts entscheiden könnte. Das Problem der vorübergehenden Aussetzung der Verdrängungswirkung und die mit dem Defrenne II-Urteil begründete Beschränkungsrechtsprechung setzt Generalanwältin Kokott damit gleich. ${ }^{1323}$ Dass eine solche Gleichsetzung stattfindet, zeigt sich auch in ihrer Aussage, das Urteil in der Rechtssache Inter-Environnement Wallonie und Terre wallonne begründe neben der Defrenne-Rechtsprechung „keine zusätzliche Ausnahme“ vom Vorrang. ${ }^{1324}$ Die Defrenne-Rechtspre-

$1320 \mathrm{Zu}$ dieser Rechtssache ausführlich unten bei Fn. $1454 \mathrm{ff}$.

1321 EuGH, Urteil vom 8.4.1976, Rs. 43/75 (Defrenne), Rn. 71-75. Daneben zitiert sie EuGH, Urteil vom 6.3.2007, Rs. C-292/04 (Meilicke u.a.), Rn. 35 und EuGH, Urteil vom 23.10.2012, verb. Rs. C-581/10 und C-629/10 (Nelson u.a.), Rn. 89.

1322 EuGH, Urteil vom 8.9.2010, Rs. C-409/06 (Winner Wetten), Rn. 67.

1323 GA Kokott, Schlussanträge vom 28.4.2016 in der Rs. C-379/15 (Association France Nature Environnement), Rn. 31 ff., insb. Rn. 34 mit Fn. 16 und 17. Beide Fälle gleich setzt auch GA Bobek, Schlussanträge vom 13.7.2017 in der Rs. C-574/15 (Scialdone), Rn. 180. Auf die Voraussetzungen und die Zuständigkeitsverteilung bei einer Suspendierung des Anwendungsvorrangs wird noch zurückzukommen sein, siehe unten bei Fn. $1375 \mathrm{ff}$.

1324 GA Kokott, Schlussanträge vom 28.4.2016 in der Rs. C-379/15 (Association France Nature Environnement), Rn. 37 (Hervorhebung nur hier). Zum InterEnvironnement Wallonie und Terre wallonne-Urteil siehe ausführlich unten bei Fn. 1439 ff. 
chung stellt ihrer Auffassung zufolge also eine Ausnahme vom Vorrang dar.

Ganz fern liegt eine solche Einordnung auf den ersten Blick in der Tat nicht: Durch die Begrenzung des Rechtsanwendungsbefehls in zeitlicher Hinsicht erlangt die vom Gerichtshof vorgenommene Auslegung des Unionsrechts erst mit zeitlicher Verzögerung Bedeutung. Zu einer Verdrängung nationalen Rechts kann es damit erst zu dem Zeitpunkt kommen, in dem die Begrenzung des Rechtsanwendungsbefehls endet. Von einer zeitlichen Einschränkung des Vorranganspruchs bzw. einer vorübergehenden Aussetzung der Verdrängungswirkung ${ }^{1325}$ oder einer Verzögerung der Befolgung des Vorrangs unter Verweis auf primärrechtliche Grundsätze ${ }^{1326}$ kann dennoch nicht gesprochen werden.

Gegen eine Gleichsetzung sprechen bei genauerer Betrachtung nämlich die Ausführungen des Gerichtshofs in der Rechtssache Winner Wetten. Dieser ordnet die sich dort stellende Problematik als Frage der Aussetzung der Verdrängungswirkung des unmittelbar geltenden Unionsrechts ein. Mit der Verdrängungswirkung spricht er in der Tat einen Aspekt des Vorrangs an. Im Rahmen der Defrenne-Rechtsprechung geht es dagegen um eine Begrenzung des Rechtsanwendungsbefehls in zeitlicher Hinsicht, auf die der Gerichtshof im Winner Wetten-Urteil deswegen konsequenterweise keinen Bezug nimmt. Die Begrenzung der ex tunc-Wirkung im Sinne der Defrenne-Rechtsprechung stellt daher dogmatisch keine Begrenzung des Anwendungsvorrangs dar. ${ }^{1327}$ Sie hat „mit einer Durchbrechung des

1325 So Gundel, in: Liber Amicorum Berg, 2011, S. 54 (63), der ebenfalls auf EuGH, Urteil vom 8.9.2010, Rs. C-409/06 (Winner Wetten), Rn. 67 verweist.

1326 In diesem Sinne Sowery, CMLRev. 54 (2017), 1157 (1164 mit Fn. 24). Dass sie EuGH, Urteil vom 17.12.2015, verb. Rs. C-25/14 und C-26/14 (UNIS und Beaudout Père et Fils) als Beispiel dafür anführt, dass das Interesse an der Vermeidung von Rechtsunsicherheit die Stabilität vertraglicher Beziehungen über die Beachtung des Unionsrechts stellen kann, liegt insofern nahe, als in diesem Urteil materielle Kriterien an die Stelle der „üblichen“ Kriterien des guten Glaubens und der Gefahr schwerwiegender Störungen getreten sind. Dies bringt gewisse Annäherungen an die Winner Wetten-Rechtsprechung mit sich, siehe insoweit bereits oben bei Fn. 465. Die Konstellationen sind auf der Grundlage der derzeitigen Rechtsprechung des Gerichtshofs dennoch auseinanderzuhalten.

1327 Kruis, Anwendungsvorrang, 2013, S. 206. 
Anwendungsvorrangs [...] freilich nichts zu tun“. ${ }^{1328}$ Zwischen beiden Instrumenten ist folglich zu unterscheiden. ${ }^{1329}$

Dafür, dass die Möglichkeit einer Trennung zwischen Auslegung und Durchsetzung des Unionsrechts besteht, sprechen auch die in der Rechtsprechung des Gerichtshofs anzutreffenden Besonderheiten bei der Geltendmachung von Richtlinien. Während ein Bürger die Bestimmung einer nicht oder nicht richtig umgesetzten Richtlinie jedenfalls bei Vorliegen der Voraussetzungen der unmittelbaren Wirkung in einem vertikalen Rechtsverhältnis geltend machen kann, ist ihm dies im horizontalen Rechtsverhältnis nach der ständigen Rechtsprechung des Gerichtshofs verwehrt. In diesem Fall ist er auf eine richtlinienkonforme Auslegung des nationalen Rechts verwiesen und im Falle ihres Scheiterns auf einen unionsrechtlichen Staatshaftungsanspruch gegen den Mitgliedstaat. ${ }^{1330}$ Die in einem vertikalen bzw. horizontalen Rechtsverhältnis unterschiedliche Art der Durchsetzung einer Richtlinienbestimmung lässt die zugrundeliegende Auslegung dieser Richtlinienbestimmung unberührt. Im richtliniengeprägten Horizontalverhältnis kommt die Möglichkeit einer Trennung zwischen Auslegung und Durchsetzung daher noch deutlicher als bei unmittelbar anwendbarem Unionsrecht zum Ausdruck.

Der hier verwendete Begriff der „Durchsetzungsdimension“ meint keinen Mechanismus im Sinne eines eigenständigen Verfahrens. Zum Ausdruck gebracht werden soll vielmehr, dass die „Durchsetzungsdimension“ der unionsrechtlichen Norm zwar anhaftet, es sich bei ihr allerdings um einen von der Auslegung selbst unterscheidbaren Aspekt handelt. Dass der zeitliche Aspekt der Auslegung und der Durchsetzungsdimension getrennt voneinander betrachtet werden können, sagt natürlich noch nichts über das Ergebnis dieser Betrachtung aus. Eine Gleichbehandlung im Ergebnis von Auslegung und Durchsetzung ist daher nicht ausgeschlossen: Eine zeitlich unbegrenzt wirkende Auslegung kann zu einer zeitlich unbegrenzt wirkenden Durchsetzung führen; lediglich logisch zwingend ist dies nicht.

Vor dem Hintergrund dieser Differenzierung kann die Erwägung, dass die „Gewährung nationalen Vertrauensschutzes gegenüber der Wirkung

1328 Karpenstein/Kubnert, DVB1. 2006, 1466 (1467).

1329 Die in EuGH, Urteil vom 6.10.2020, verb. Rs. C-511/18, C-512/18 und C-520/18 (La Quadrature du Net u.a.), Rn. 216 erfolgte Gleichsetzung ist daher zurückzuweisen.

1330 EuGH, Urteil vom 7.7.2016, Rs. C-46/15 (Ambisig), Rn. 23 ff.; EuGH, Urteil vom 24.1.2012, Rs. C-282/10 (Dominguez), Rn. 40 ff.; EuGH, Urteil vom 7.8.2018, Rs. C-122/17 (Smith), Rn. 55 f. Zur Ablehnung der Horizontalwirkung von Richtlinien durch den EuGH noch unten bei Fn. 1916 ff. 
von Richtlinien" nicht zulässig sei, da nur der EuGH selbst eine Begrenzung der zeitlichen Wirkungen vornehmen könne, nicht allein ausschlaggebend sein. ${ }^{1331}$ Sie unterscheidet nicht hinreichend zwischen den Ebenen von Auslegung und Durchsetzung des Unionsrechts. Äußert sich der Gerichtshof nicht zu der Frage einer zeitlichen Beschränkung der Berufung auf seine Auslegung, ist dies nicht gleichzusetzen mit einer Ablehnung nationalen Vertrauensschutzes. ${ }^{1332}$ Zwischen der Defrenne-Rechtsprechung und „Vertrauensschutz" bei der richtlinienkonformen Auslegung und Anwendung des nationalen Rechts ist vielmehr zu trennen. ${ }^{1333}$ Gleiches gilt dann auch für das Verhältnis von Defrenne-Rechtsprechung und Anwendungsvorrang.

Zu einseitig ist aber auch die Überlegung, dass der EuGH (nur) über die zeitlichen Wirkungen der Auslegung des Unionsrechts entscheide und das nationale Gericht ihre Folgen für das nationale Recht zu bestimmen habe, sodass die Gewährung von Vertrauensschutz auf europäischer und nationaler Ebene auseinanderzuhalten sei. Ist die Auslegung des Unionsrechts für alle Mitgliedstaaten ex tunc verbindlich, ist das zwar nicht zwangsläufig gleichbedeutend mit der unbegrenzt rückwirkenden Unanwendbarkeit des nationalen Rechts in einem Mitgliedstaat. ${ }^{1334}$ Insoweit besteht wie soeben herausgearbeitet die Möglichkeit der Unterscheidung zwischen der Auslegung und der Durchsetzung des Unionsrechts. Dass unionsrechtliche und nationale Ebene aber derart strikt voneinander zu trennen wären, dass die Mitgliedstaaten bei der Anwendung des Unionsrechts auf den konkreten Fall im Hinblick auf die Berücksichtigung nationaler Vertrauensumstände gänzlich frei wären, ist nicht zutreffend.

Auch dem Anwendungsvorrang und der Pflicht zu richtlinienkonformer Auslegung sind Vorgaben in zeitlicher Hinsicht zu entnehmen. Sie sind von den mitgliedstaatlichen Gerichten neben den Vorgaben zur Wirkung der Auslegung in zeitlicher Hinsicht zu beachten. ${ }^{1335}$ Auch wenn es bei der Anwendung des Unionsrechts in einem Rechtsstreit vor einem nationalen Gericht um eine nachgelagerte Stufe der Reaktion auf die Auslegung des Unionsrechts geht, erlangen daher unionsrechtliche Maßstäbe Bedeutung. ${ }^{1336} \mathrm{Zu}$ beachten ist hierbei, dass sich der EuGH in aller Regel

1331 So aber Winter, jurisPR-ArbR 8/2011 Anm. 6, unter C. und D.

1332 Zutreffend Picker, ZTR 2009, 230 (235).

1333 Vgl. Herdegen, WM 2005, 1921 (1927).

1334 Vgl. Krois, DB 2010, 1704 (1707).

1335 Zwischen Auslegung und Durchsetzung des Unionsrechts trennt auch Rosenkranz, ZfPW 2016, 351 (367).

1336 Siehe in diesem Zusammenhang auch Berkemann, DVBl. 2017, 950 (951 f.). 
nicht zu den Grenzen der jeweiligen Durchsetzungsdimension äußert. Seinen Urteilen ist daher in aller Regel lediglich eine ausdrückliche oder implizite Aussage zur zeitlichen Wirkung des ausgelegten Unionsrechts zu entnehmen. ${ }^{1337}$

Die Frage, inwieweit für mitgliedstaatliche Gerichte eine Möglichkeit zur Berücksichtigung nationaler Vertrauensumstände besteht, wird in den Abschnitten zum Anwendungsvorrang und der Pflicht zu richtlinienkonformer Auslegung noch näher beleuchtet. ${ }^{1338}$

\section{Folgerungen für die Frage „nationalen Vertrauensschutzes“}

Auch das BAG hat die Frage der Gewährung von „nationalem Vertrauensschutz" bei der Betroffenheit von Unionsrecht bereits beschäftigt. Dabei hat es die Trennung zwischen Auslegung und Durchsetzung des Unionsrechts fruchtbar gemacht, wie sich anhand zweier von ihm entschiedener Fallgestaltungen verdeutlichen lässt. Es hat sie zum Anlass genommen, die Möglichkeiten für nationale Gerichte, Vertrauensschutz zu gewähren, unterschiedlich zu beurteilen, je nachdem, ob „unmittelbar“ oder „mittelbar“ wirkendes Unionsrecht betroffen ist. ${ }^{1339}$

In der ersten Konstellation stand die Auslegung von $\$ 17$ I 1 KSchG in Rede, wonach ein Arbeitgeber verpflichtet ist, der Agentur für Arbeit Anzeige zu erstatten, bevor er mehr als die in $\$ 17$ I 1 KSchG genannte Zahl an Arbeitnehmern innerhalb von 30 Kalendertagen entlässt. In dem Verfahren, das letztlich zu einer Verfassungsbeschwerde geführt hat, wurde dem Arbeitnehmer mit Schreiben vom 18.11.2004 zum 31.3.2005 betriebsbedingt gekündigt; mit Schreiben vom 25.1.2005 wurde die Entlassung bei der Agentur für Arbeit angezeigt. Die (in diesem Fall angesichts zahlreicher weiterer Entlassungen erforderliche) Massenentlassungsanzeige erfolgte damit zwar vor dem Ablauf der Kündigungsfrist, aber nach der Kündigungserklärung. Den unionsrechtlichen Anforderungen genügte dies nicht.

1337 Rosenkranz, ZfPW 2016, 351 (368 f. mit Fn. 97).

1338 Siehe hierzu bei Fn. 1564 ff. und Fn. 2034 ff.

1339 Da die Fallkonstellationen auch das Bundesverfassungsgericht beschäftigt haben (siehe BVerfG, Beschluss vom 10.12.2014, 2 BvR 1549/07 - NZA 2015, 375 sowie BVerfG, Beschluss vom 6.7.2010, 2 BvR 2661/06 - BVerfGE 126, 286), zeigt sich an ihnen auch das Zusammenspiel von Unions- und Verfassungsrecht. 
In seinem Urteil vom 27.1.2005 in der Rechtssache Junk hatte der EuGH nämlich festgestellt, dass die Art. 2-4 der Richtlinie 98/59/EG ${ }^{1340}$ dahin auszulegen sind, dass die Kündigungserklärung des Arbeitgebers das Ereignis ist, das als Entlassung gilt. ${ }^{1341}$ Die Entlassung hätte aus unionsrechtlicher Sicht damit bereits vor der Kündigungserklärung bei der Agentur für Arbeit angezeigt werden müssen. In ständiger Rechtsprechung hatte das BAG darunter bislang allerdings die tatsächliche Beendigung des Arbeitsverhältnisses mit Ablauf der Kündigungsfrist verstanden. Die Kündigung durch den Arbeitgeber war im zu entscheidenden Fall daher zwar im Einklang mit der Rechtsprechung des BAG - d.h. mit der unionsrechtswidrigen Auslegung der $\$ \mathbb{S} 17 \mathrm{f}$. KSchG durch das BAG - erfolgt, stand aber im Widerspruch zur im Junk-Urteil vorgenommenen Auslegung durch den EuGH.

Auch wenn die Entscheidung des EuGH eine Rechtsprechungsänderung aufseiten des BAG auslöste, die dazu führte, dass es die Kündigung als rechtswidrig ansah, entschied das BAG, dass sich seine Rechtsprechungsänderung aus Vertrauensschutzgründen nicht auf vor dem 27.1.2005 - dem Tag der Verkündung des Junk-Urteils - erklärte Kündigungen auswirke. Es hielt also die Kündigung des Arbeitgebers aus Vertrauensschutzgründen für wirksam, um eine für diesen nach seiner Auffassung ansonsten unzumutbare Härte zu vermeiden.

Zur Frage der Vereinbarkeit der Gewährung von Vertrauensschutz mit Unionsrecht führte der 2. Senat des BAG aus, die Entscheidung über den Vertrauensschutz sei ihm „nicht 'entzogen'“. Er sei nicht zur Vorlage an den EuGH verpflichtet gewesen, da er lediglich seine eigene Rechtsprechung und die Auslegung der nationalen Regelung des $\$ 17$ I 1 KSchG an das Unionsrecht angepasst habe. Es handele sich um eine Frage der nationalen Rechtsanwendung, wenn er den Begriff der Entlassung in $\$ 17$ I $1 \mathrm{KSchG}$ zukünftig im Einklang mit den vom EuGH im Junk-Urteil dargelegten Richtlinienvorgaben verstanden wissen wolle. Unionsrecht habe er nicht ausgelegt, sondern das nationale Kündigungsschutzrecht richtlinienkonform angewendet. ${ }^{1342}$

1340 Richtlinie 98/59/EG des Rates vom 20. Juli 1998 zur Angleichung der Rechtsvorschriften der Mitgliedstaaten über Massenentlassungen, ABl. L 225 vom 12.8.1998, S. 16.

1341 EuGH, Urteil vom 27.1.2005, Rs. C-188/03 (Junk), Tenor Nr. 1.

1342 BAG, Urteil vom 1.2.2007, 2 AZR 15/06, Rn. 22 f. - juris. Der Senat verweist zur Stützung seiner Aussage auf Canaris, in: FS Bydlinski, 2002, S. 47 (64) sowie Piekenbrock, ZZP 119 (2006), 3 (30) und stellt sich gegen Schiek, AuR 2006, 41 (43 f.), die eine Pflicht zur Vorlage an den EuGH angenommen hatte. 
Kurz zusammengefasst bedeutet dies, dass das BAG hier davon ausgeht, durch die Gewährung von Vertrauensschutz zwar die richtlinienkonforme Auslegung des Kündigungsschutzgesetzes, nicht aber die Auslegung des Entlassungsbegriffs der Massenentlassungsrichtlinie beschränkt zu haben, was es als unionsrechtlich unbedenklich einstuft. ${ }^{1343}$

Die zweite Konstellation betraf das primärrechtliche Verbot der Altersdiskriminierung. In dem zu einer Verfassungsbeschwerde führenden Verfahren hatte ein Unternehmen mit einem Arbeitnehmer, der das 52. Lebensjahr bereits vollendet hatte, am 18.2.2003 für den Zeitraum vom 19.2.2003 bis zum 31.3.2004 einen sachgrundlos befristeten Arbeitsvertrag geschlossen. In seinem Urteil vom 22.11.2005 in der Rechtssache Mangold hatte der EuGH festgestellt, dass das Unionsrecht und insbesondere Art. 6 I der Richtlinie 2000/78/EG ${ }^{1344}$ einer Regelung wie $\$ 14$ III 4 TzBfG entgegenstehe, der als Grundlage für die Befristung des Arbeitsvertrages gedient hatte. Dem Verbot der Diskriminierung wegen des Alters als allgemeinem Grundsatz des Unionsrechts müsse durch Nichtanwendung der entgegenstehenden Vorschriften des nationalen Rechts zur Wirksamkeit verholfen werden. ${ }^{1345}$

Das BAG entschied daraufhin, dass Vertrauensschutzgründe es nicht erforderten, $\mathbb{} 14$ III 4 TzBfG auf eine vor dem 22.11.2005 - dem Tag des Mangold-Urteils - getroffene Befristungsabrede anzuwenden. Allein der EuGH sei dafür zuständig, die Unanwendbarkeit einer primärrechtswidrigen Norm des nationalen Rechts zeitlich zu begrenzen; die zeitlichen Wirkungen seines Unanwendbarkeitsausspruchs habe dieser in seinem Mangold-Urteil aber nicht begrenzt. $\mathbb{} 14$ III 4 TzBfG blieb daher unangewendet. Die abweichende Beurteilung der Vertrauensschutzproblematik durch das BAG im Nachgang der Junk-Entscheidung des EuGH stehe dazu nicht im Widerspruch, da das BAG dort nicht über Vertrauensschutz wegen der Unvereinbarkeit mit Primärrecht zu entscheiden gehabt habe. ${ }^{1346}$

Sie verweist darauf, dass einem nationalen Gericht die Entscheidung über die Frage, ob der Gerichtshof „aus Gründen des Vertrauensschutzes verpflichtet gewesen wäre, die Rückwirkung der Entscheidung Junk zu beschränken“, entzogen ist.

1343 Siehe auch Wißmann, in: FS Bauer, 2010, S. 1161 (1165).

1344 Richtlinie 2000/78/EG des Rates vom 27. November 2000 zur Festlegung eines allgemeinen Rahmens für die Verwirklichung der Gleichbehandlung in Beschäftigung und Beruf, ABl. L 303 vom 2.12.2000, S. 16.

1345 EuGH, Urteil vom 22.11.2005, Rs. C-144/04 (Mangold).

1346 BAG, Urteil vom 26.4.2006, 7 AZR 500/04, Rn. 45 - BAGE 118, 76. Zustimmend Koch, JbArbR 44 (2007), 91 (105): unterschiedliche Rechtsquellen des 
Im weiteren Verlauf dieser Arbeit gilt es, der Frage nachzugehen, ob die vom BAG zwischen „unmittelbar“ und „mittelbar" wirkendem Unionsrecht vorgenommene Differenzierung überzeugend ist.

\section{Anwendungsvorrang}

Mit dem Vorrang als das Wesen des Unionsrechts selbst betreffendes besonderes Merkmal ist zunächst einer der Grundpfeiler des Unionsrechts in den Blick zu nehmen. ${ }^{1347}$

I. Stellenwert des Vorrangs im Unionsrecht und Einführung in die Problematik

Nach der Erklärung Nr. 17 zum Vertrag von Lissabon wird der Vorrang des Unionsrechts vor dem Recht der Mitgliedstaaten im Einklang mit der Rechtsprechung des Gerichtshofs unter den dort festgelegten Bedingungen anerkannt. ${ }^{1348} \mathrm{Im}$ Vertrag von Lissabon selbst wurde er also nicht verankert, was an seiner Existenz und der Rechtsprechung des EuGH aber nichts ändert.

Der Vorrang führt dazu, dass durch das Inkrafttreten einer unionsrechtlichen Bestimmung jede entgegenstehende Vorschrift des nationalen Rechts ohne Weiteres unanwendbar wird. ${ }^{1349}$ Jedenfalls bei Vorliegen der Voraussetzungen unmittelbarer Anwendbarkeit/Wirkung wird das nationale Recht in dem Umfang verdrängt, der aus Sicht des Unionsrechts zu

Unionsrechts. Busch, FA 2006, 235 (236) dagegen meint, es sei „merkwürdig“ und „ein verblüffendes Ergebnis“, dass das Vertrauen auf die Verabschiedung eines rechtmäßigen Gesetzes durch den Gesetzgeber nicht schutzwürdig sei, während bei Vertrauen auf die Rechtsprechung des BAG und die Verwaltungspraxis Vertrauensschutz gewährt werde. Die von ihm bei seiner Argumentation ausgeblendeten und möglicherweise zwischen unmittelbar und mittelbar wirkendem Unionsrecht bestehenden Unterschiede sind im Folgenden näher in den Blick zu nehmen.

1347 EuGH, Gutachten 2/13 vom 18.12.2014 (Beitritt der Union zur EMRK), Rn. 166.

1348 Erklärungen zur Schlussakte der Regierungskonferenz, die den am 13. Dezember 2007 unterzeichneten Vertrag von Lissabon angenommen hat, Erklärung Nr. 17 (Erklärung zum Vorrang), ABl. C 83 vom 30.3.2010, S. 344.

1349 Siehe nur EuGH, Urteil vom 8.9.2015, Rs. C-105/14 (Taricco u.a.), Rn. 52; EuGH, Urteil vom 14.6.2012, Rs. C-606/10 (ANAFE), Rn. 73. 
seiner Verwirklichung erforderlich ist. Indem der EuGH verlangt, dass das nationale Recht „ohne Weiteres“ unanwendbar wird, bringt er zum Ausdruck, dass dessen Nichtanwendung weder von einem nationalen Zwischenverfahren abhängig ist noch einen zeitlichen Aufschub duldet. Damit verfügt der Anwendungsvorrang auch selbst über eine zeitliche Dimension. ${ }^{1350}$

Da der Vorrang des Unionsrechts das Fundament des Rechtssystems der Union bildet, lässt er nach Auffassung etwa von Generalanwalt Wahl keine Ausnahme zu. ${ }^{1351}$ Ganz in diesem Sinne wird der unionsrechtlichen Position in der Literatur zum Teil ein absolutes und unbedingtes Verständnis vom Vorrang zugeschrieben. ${ }^{1352} \mathrm{Ob}$ dies die Sicht des EuGH zutreffend widerspiegelt, wird im Folgenden zu hinterfragen sein.

Wird wie in dieser Arbeit nach Ausnahmen vom Vorrang gefragt, ist ein Vergleich mit der nationalen Ebene nicht zielführend. Erkennt das Bundesverfassungsgericht Ausnahmen von der grundsätzlichen Rechtsfolge der Nichtigkeit bei einem Verstoß gegen das Grundgesetz an, bedeutet dies nämlich nicht, dass Vergleichbares auch für den Fall eines Verstoßes des nationalen Rechts gegen Unionsrecht und damit für den Anwendungsvorrang gelten muss. ${ }^{1353}$

Da der Vorrang den unionsrechtlichen Bestimmungen als „Durchsetzungsdimension“ anhaftet, kann er nicht isoliert, sondern nur im Zusammenhang mit den Vorschriften des Unionsrechts betrachtet werden, denen er innewohnt. Eine Einschränkung des Vorrangs hat dementsprechend

1350 Ebenso Rosenkranz, ZfPW 2016, 351 (377 f.).

1351 GA Wahl, Schlussanträge vom 11.9.2018 in der Rs. C-378/17 (Minister for Justice and Equality und Commissioner of An Garda Síochána), Rn. 60: „Es ist sehr wichtig, an dieser Stelle zu betonen, dass die verfassungsrechtliche Bedeutung des Vorrangs des Unionsrechts als fundamentaler Grundsatz des Sui-generis-Rechtssystems der Union nicht überschätzt werden kann. Wegen seiner fundamentalen Bedeutung erlaubt der Vorrang des Unionsrechts keine Ausnahme. Tatsächlich wäre die Zulassung von Ausnahmen schädlich für ebendieses Fundament, auf das das Rechtssystem der Union gebaut ist." (Kursivschrift im Original). In der Literatur wird der Anwendungsvorrang daher auch als „Heiligtum' der europäischen Rechtsentwicklung“ bezeichnet, Neuschl/Schumm, ZEuS 2008, 527 (532). Nettesheim, EuR 2006, 737 bezeichnet Kollisionsregeln als „Metaregeln eines Rechtssystems“.

1352 In diesem Sinne etwa Claes, in: Chalmers/Arnull (Hrsg.), Oxford Handbook, 2015, S. 178 (179); ebenso Mayer, Kompetenzüberschreitung, 2000, S. 74 f. Nationale Auffassungen akzeptieren dagegen in aller Regel lediglich den Vorrang vor nationalem Gesetzesrecht, nicht aber für die bzw. Teile der nationalen Verfassung, vgl. den Befund bei Claes, a.a.O.

1353 So aber Mertens, DVBl. 2006, 1564 (1567). 
unmittelbaren Einfluss auf das materielle Unionsrecht. Bei einer im Folgenden näher in den Blick zu nehmenden temporären Suspendierung der Verdrängungswirkung des Vorrangs werden daher auch alle materiellen Normen, auf die sich der Vorrang bezieht, vorübergehend suspendiert. ${ }^{1354}$ Diese Feststellung ändert nichts an der Richtigkeit einer Trennung von Auslegung und Durchsetzung des Unionsrechts; eine solche Unterscheidung ebnet den Weg für eine Begrenzung der Durchsetzungsdimension in zeitlicher Hinsicht, die daher neben einer Begrenzung des Rechtsanwendungsbefehls der unionsrechtlichen Norm in zeitlicher Hinsicht in Betracht zu ziehen ist. Die aufgezeigte Wirkung des Anwendungsvorrangs lässt aber bereits erkennen, dass gewisse Parallelen im erzielten Ergebnis bei einer Suspendierung des Anwendungsvorrangs und einer zeitlichen Begrenzung im Sinne der Defrenne-Rechtsprechung zu beobachten sind, die in Rechnung zu stellen sein werden.

Den Kern der Diskussion um die Möglichkeit einer temporären Suspendierung des Anwendungsvorrangs bilden die Forderung nach einer Berücksichtigung mitgliedstaatlicher Interessen und die Sorge um das Entstehen von Regelungslücken. Erreicht werden soll insbesondere, dass den Mitgliedstaaten hinreichend Zeit zur Anpassung ihres Rechts an unionsrechtliche Vorgaben zur Verfügung steht. Wer Rücksichtnahme auf die nationale Gewaltenteilung einfordert, muss sich allerdings mit dem Einwand auseinandersetzen, dass er die Durchführung des Unionsrechts auf nationaler Ebene dann jedenfalls zum Teil vom Tätigwerden des nationalen Gesetzgebers abhängig macht, was mit dem Anwendungsvorrang gerade vermieden werden soll. ${ }^{1355} \mathrm{Im}$ Grundsatz etwas unverdächtiger erscheint daher das Ziel der Vermeidung eines Rechtsvakuums, das auch aus Sicht des Unionsrechts problematisch sein kann. Angesprochen sind jedenfalls in erster Linie Fälle, in denen einem nationalen Gericht ermöglicht werden soll, die Nichtanwendung des nationalen Rechts nicht sofort vorzunehmen, sondern auf die Zukunft zu verschieben. ${ }^{1356}$

Neben der Problematik der Übergangsfrist für die Zukunft ist auch die Frage des Vertrauensschutzes für die Vergangenheit an dieser Stelle einzuordnen. Eine Kollision zwischen nationalem Recht und Unionsrecht wird auch durch „nationalen Vertrauensschutz" hervorgerufen, da er darauf ge-

1354 Terhechte, EuR 2006, 828 (835 f.).

1355 Vgl. Streinz, EuZ 2006, 126 (130); siehe auch Kruis, Anwendungsvorrang, 2013, S. 207.

$1356 \mathrm{Zu}$ den hierfür vorgebrachten Argumenten siehe insbesondere Paulus, NJW 2011, 3686 (3688f.). 
richtet ist, die Durchsetzung einer unionsrechtlich gebotenen Rechtsfolge abzuwenden. ${ }^{1357} \mathrm{Zu}$ fragen ist also danach, ob sich ein nationales Gericht einer Nichtanwendung des nationalen Rechts mit Wirkung auch für in der Vergangenheit liegende Zeiträume verweigern kann.

\section{Einschränkbarkeit des Vorrangs}

Aufgeworfen ist in den hier betrachteten Fällen damit die Frage, ob der Vorrang den mitgliedstaatlichen Gerichten Spielräume in zeitlicher Hinsicht bietet. Zu ihrer Beantwortung bedarf es zunächst einer Bestimmung der Rechtsnatur des Vorrangs und damit seiner Einordnung in die Kategorien von Regel und Prinzip. ${ }^{1358}$ Während eine Regel einen unmittelbaren Grund für eine gerichtliche Entscheidung darstellt, rechtfertigt ein Prinzip nur die Gründe einer Entscheidung. ${ }^{1359}$

Auf den ersten Blick scheint die Einordnung auf der Hand zu liegen: Damit Klarheit darüber besteht, welche zweier kollidierender Normen unangewendet bleiben muss - dies kann nur entweder die eine oder die andere Norm sein -, muss der Anwendungsvorrang eine Kollisionsregel sein, die hierüber Auskunft gibt. ${ }^{1360}$ Für die Einordnung des Vorrangs als Kollisionsregel spricht auch, dass der Vorrang selbst nicht am Normenkonflikt beteiligt ist. Er wohnt zwar der unionsrechtlichen Norm inne, lässt sich von dieser aber jedenfalls soweit abstrahieren, dass man ihn gewissermaßen als unbeteiligten Dritten ansehen kann, der die Normkolli-

1357 Ebenso Rosenkranz, Beschränkung der Rückwirkung, 2015, S. 453.

1358 Alexy, Theorie der Grundrechte, 1. Aufl., Nachdruck, 2006, S. 72 weist darauf hin, dass über die Unterscheidung dieser Kategorien „Unklarheit und Streit“ herrscht. Nach seiner Auffassung unterscheiden sich Regeln und Prinzipien qualitativ voneinander; eine Norm könne nur entweder Regel oder Prinzip sein, siehe $\mathrm{S} .75 \mathrm{ff}$.

1359 von Danwitz, Verwaltungsrechtliches System, 1996, S. 114. Alexy, Theorie der Grundrechte, 1. Aufl., Nachdruck, 2006, S. 75 f. zufolge sind Prinzipien „Normen $[\ldots]$, die gebieten, daß etwas in einem relativ auf die rechtlichen und tatsächlichen Möglichkeiten möglichst hohen Maße realisiert wird“. Prinzipien als Optimierungsgebote können danach „in unterschiedlichen Graden“ erfüllt werden, wohingegen Regeln „nur entweder erfüllt oder nicht erfüllt werden können“.

1360 Näher zur Diskussion um die Einordnung des Anwendungsvorrangs als Kollisions- oder Rangregel Schlücke, Umsetzung, 2014, S. 66 ff. m.w.N. aus der Literatur. 
sion „als Schiedsrichter“ entscheidet. ${ }^{1361}$ Eine solche Sichtweise entspricht der Vorstellung eines als absolut und unbedingt verstandenen Vorrangs des Unionsrechts, wie sie auch in der Rechtsprechung des EuGH jedenfalls im Grundsatz zu Tage tritt. ${ }^{1362}$ Für eine zeitliche Verzögerung der Anwendung der Vorrangregel ist dann kein Raum.

Im Gegensatz zu einer Regel ist ein Prinzip einer Abwägung zugänglich. ${ }^{1363}$ Bei einer Einordnung des Vorrangs selbst als Prinzip würde daher die Möglichkeit einer Abwägung etwa mit dem (unionsrechtlichen) Grundsatz der Rechtssicherheit eröffnet, die in der Lage ist, praktische Konkordanz zwischen den Prinzipien herzustellen. ${ }^{1364}$ Einher ginge damit die Anerkennung von Grenzen des Vorranggrundsatzes.

In seiner Rechtsprechung zeigt sich der Gerichtshof einer solchen Möglichkeit gegenüber in Ansätzen offen. So führt er in seinem Urteil in der Rechtssache Association France Nature Environnement aus, dass er durch die Verleihung der Befugnis an nationale Gerichte, die Wirkungen der Nichtigerklärung einer unionsrechtswidrigen Bestimmung des nationalen Rechts (im Wege der Aufrechterhaltung bestimmter Wirkungen dieses Rechtsakts) anzupassen, Rechtmäßigkeit und Vorrang des Unionsrechts auf der einen Seite und das aus Art. 3 III EUV und Art. 191 I, II AEUV folgende primärrechtliche Umweltschutzgebot auf der anderen Seite miteinander in Einklang bringen wollte. ${ }^{1365}$ Nach eigener Aussage des Gerichtshofs kann die Ausübung dieser Ausnahmebefugnis durch ein nationales Gericht die Wahrung des Grundsatzes des Vorrangs des Unionsrechts beeinträchtigen. ${ }^{1366}$

1361 Siehe zu den Argumenten für eine Einordnung als Regel insbesondere Kruis, Anwendungsvorrang, 2013, S. 96 ff., 201, wonach nur der Grundsatz „alles oder nichts" (Anführungszeichen im Original) gelten könne; siehe auch Becker, CMLRev. 44 (2007), 1035 (1047 mit Fn.33). Funke, DÖV 2007, 733 (735) sieht im Anwendungsvorrang „die Folge der Anwendung einer Kollisionsregel".

$1362 \mathrm{Zu}$ verweisen ist dabei insbesondere auf EuGH, Urteil vom 9.3.1978, Rs. 106/77 (Simmenthal), Rn. 24.

1363 Bei einer Prinzipienkollision ist nach Alexy, Theorie der Grundrechte, 1. Aufl., Nachdruck, 2006, S. 79 das Prinzip „mit dem jeweils größeren Gewicht“ im konkreten Fall vorrangig.

1364 Vgl. Dashwood/Dougan/Rodger/Spaventa/Wyatt, Wyatt and Dashwood's European Union Law, 6. Aufl. 2011, S. 272. Siehe auch Wölker, EuR 2007, 32 (52); Lenaerts/Corthaut, ELRev. 2006, 287 (303).

1365 EuGH, Urteil vom 28.7.2016, Rs. C-379/15 (Association France Nature Environnement), Rn. $34 \mathrm{ff}$.

1366 EuGH, Urteil vom 28.7.2016, Rs. C-379/15 (Association France Nature Environnement), Rn. 52. 
In besonders gelagerten Fällen deutet der EuGH also seine Bereitschaft an, den Vorrang des Unionsrechts unter strengen Voraussetzungen hinter andere Belange zurücktreten zu lassen. ${ }^{1367}$ Daraus wird zum Teil geschlossen, dass der EuGH den Vorrang hier nicht als absolute Regel handhabe, sondern ausnahmsweise bereit sei, den Vorrang nur als, wenn auch gewichtigen, Grundsatz anzusehen. ${ }^{1368}$ Seine Rechtsprechung deute auf eine je nach Fallgestaltung variierende Handhabung des Vorrangs als Regel oder als Prinzip hin. ${ }^{1369}$

Gegen eine solche Doppelnatur des Vorrangs wird angeführt, dass es angesichts der Unterschiede in der Wirkungsweise einer Regel bzw. eines Prinzips nicht denkbar sei, den Vorrang im Hinblick auf dieselbe Fragestellung sowohl als Regel als auch als Prinzip einzuordnen. Da bei einer Normkollision feststehen müsse, welche Norm anzuwenden ist, müsse eine Einordnung als Regel erfolgen. ${ }^{1370}$ Dass der Vorrang aber sowohl Elemente einer Regel als auch eines Prinzips in sich vereinen kann, zeigt ein Wechsel des Blickwinkels.

Dem Gerichtshof ist darin zuzustimmen, dass der Anwendungsvorrang und ein allgemeiner Grundsatz des Unionsrechts auf Unionsebene miteinander in Konflikt geraten können. In diesem Fall ist eine unionsinterne Begrenzung des Anwendungsvorrangs denkbar; eine unionsinterne Abwägung kann dazu führen, dass der Vorrang im Ergebnis nicht zum Tragen kommt. ${ }^{1371}$ Für das mit dem Normenkonflikt zwischen Unionsrecht und nationalem Recht konfrontierte nationale Gericht ergibt sich daraus, dass es davon auszugehen hat, dass das Unionsrecht die Nichtanwendung des

1367 Worin die Befugnis des EuGH zur vorübergehenden Aussetzung der Verdrängungswirkung unionsrechtlicher Normen ihre Grundlage findet, wird an späterer Stelle noch untersucht, siehe unten bei Fn. $1384 \mathrm{ff}$.

1368 So van der Hulle, NtEr 2016, $284(284,288)$.

1369 Siehe Sowery, CMLRev. 53 (2016), 1705 (1716ff.), die im Rahmen ihrer Analyse des Umgangs des EuGH mit dem Grundsatz der Rechtssicherheit bei rechtskräftigen nationalen Gerichtsentscheidungen von einer "dual nature“ des Vorrangs spricht, mit vom Kontext, in dem er zur Anwendung kommt, abhängigen unterschiedlichen Wirkungen. Sie erkennt hierin ein bedingteres Verständnis des Vorrangs auf Unionsebene als es dieser in der Regel zugeschrieben wird. Zur Stützung ihrer Überlegungen führt sie allerdings etwa mit der Defrenne-Rechtsprechung auch ein Beispiel an, das sich wie gesehen dogmatisch nicht als Begrenzung des Anwendungsvorrangs darstellt.

1370 In diesem Sinne Kruis, Anwendungsvorrang, 2013, S. 97 f.

1371 Der Abwägungsfähigkeit des Vorrangs ablehnend gegenüberstehend dagegen Funke, DÖV 2007, 733 (740); gegen dessen Ansicht bereits Rosenkranz, Beschränkung der Rückwirkung, 2015, S. 461. 
nationalen Rechts in diesem Fall gerade nicht verlangt. ${ }^{1372}$ Führt die unionsinterne Abwägung dagegen zu einem Überwiegen des Anwendungsvorrangs, ist die Normkollision vom nationalen Gericht zugunsten des Unionsrechts aufzulösen. Die Ansiedelung des Abwägungsvorgangs auf Unionsebene verhindert, dass das nationale Gericht den Vorrang im Anschluss daran aus eigenem Antrieb und gestützt auf nationale Erwägungen begrenzen kann. Etwas anderes ergibt sich letztlich auch nicht aus dem Taricco II-Urteil des Gerichtshofs. Dieses legt zwar in der Tat ein Verständnis nahe, wonach der Gerichtshof den Vorrang gegenüber nationalem Verfassungsrecht relativiert hat. Letztlich kann aber nicht davon ausgegangen werden, dass der EuGH eine derartige Aussage treffen wollte, da er den Vorrang des Unionsrechts sonst beträchtlich geschwächt hätte. ${ }^{1373}$

Fasst man die vorstehenden Überlegungen zusammen, ergibt sich daher folgendes Bild: Auf Ebene des Unionsrechts ist der Vorrang einer Abwägung zugänglich, sodass ihm andere unionsrechtliche Prinzipien entgegenstehen können. Für diese Zwecke ist der Vorrang demnach Prinzip. Eine solche Abwägung findet immer statt, sie wird aber nur in eng begrenzten Ausnahmefällen nicht zu einem Überwiegen des Vorrangs führen. Solange der EuGH davon ausgeht, dass nur er das Ergebnis dieser Abwägung vorgeben kann, ändert sich im Verhältnis der Vermittlung zwischen unionsrechtlicher und nationaler Norm nichts an der Einordnung als Regel. Insoweit bleibt es bei der klaren Aussage, ob die nationale Norm unangewendet zu lassen ist oder nicht. Für diese Zwecke ist der Vorrang daher Regel. Einer Trennung zwischen Kern und Randbereichen, wonach der Vorrang zwar im Kern eine Regel sein soll, sein „weitergehender Normgehalt" aber ein Rechtsprinzip, bedarf es damit nicht. ${ }^{1374}$

Vielmehr ist für die Ebene des Unionsrechts davon auszugehen, dass der EuGH den Vorrang mit anderen unionsrechtlichen Grundsätzen abwägen

1372 An der Verpflichtung zur unionsrechtskonformen Auslegung des nationalen Rechts ändert dies nichts; insoweit besteht der Vorrang weiter. Siehe auch Düsterhaus, EuR 2017, 30 (50), dem zufolge die Verdrängungswirkung „nur ein Aspekt des unionsrechtlichen Vorrangs“ ist.

1373 EuGH, Urteil vom 5.12.2017, Rs. C-42/17 (M.A.S. und M.B.). Zu diesem Urteil ausführlich unten bei Fn. $1685 \mathrm{ff}$.

1374 So aber von Danwitz, Verwaltungsrechtliches System, 1996, S. 114, nach dessen Vorstellung es sich beim Vorrang demnach um ein Prinzip mit Regelkern handelt, sodass er im Bereich außerhalb des Regelkerns einer Abwägung zugänglich ist: Ist der Regelkern betroffen, liegt demnach eine echte Normkollision mit Vorrang des Unionsrechts vor. Ist dies nicht der Fall, liegt eine Prinzipienkollision vor, die eine Abwägung der betroffenen Rechtsgüter erfordert und an der Herstellung praktischer Konkordanz zu orientieren ist. 
kann, was den Vorrang aus Sicht des EuGH als Prinzip erscheinen lässt. Auf mitgliedstaatlicher Ebene besteht eine solche Möglichkeit der Abwägung dagegen nicht, sodass der Vorrang aus Sicht der mitgliedstaatlichen Gerichte als Regel einzustufen ist. Hieran müssen sich die Aussagen des EuGH zur Suspendierung des Anwendungsvorrangs messen lassen.

III. Konturierung der Voraussetzungen und der Zuständigkeitsverteilung bei einer Suspendierung des Anwendungsvorrangs

Ausnahmen vom Anwendungsvorrang sind nach dem vorstehend Gesagten nur in Betracht zu ziehen, wenn sie auf unionsrechtsinterne Kriterien und Maßstäbe gestützt werden, damit der Anwendungsvorrang nicht unter dem „Vorbehalt mitgliedstaatlicher Gesetzgebung und Rechtsprechung "1375 steht.

Zurückzuweisen ist daher zunächst das Ansinnen, die Gewährung einer Übergangsfrist durch ein mitgliedstaatliches Gericht als indirekte Kollision zu beschreiben, um dann den unionsrechtlichen Maßstab für eine Suspendierung des Anwendungsvorrangs zu entwickeln. Näher zu untersuchen ist, welche Gesichtspunkte für eine Suspendierung des Anwendungsvorrangs in Betracht kommen und wie die Zuständigkeiten zwischen EuGH und mitgliedstaatlichen Gerichten in diesem Bereich aufgeteilt sind.

\section{Kein Anknüpfen an den Kollisionsbegriff}

Zum Teil wird versucht, sich dem Problem der vorübergehenden Suspendierung des Anwendungsvorrangs, die für eine Übergangsfrist das Fortbestehen von Wirkungen unionsrechtswidrigen nationalen Rechts ermöglicht, auf der Grundlage der Unterscheidung zwischen direkten und indirekten Kollisionen zu nähern.

Eine direkte/echte/unmittelbare Normkollision zeichnet sich durch die Anordnung unterschiedlicher Rechtsfolgen aus, wenn unionsrechtliche und nationale Norm auf denselben Sachverhalt angewandt werden - ein Problem, das durch die Verdrängung der nationalen Norm aufgrund des Anwendungsvorrangs der unionsrechtlichen Norm gelöst wird. Bei einer indirekten/unechten/mittelbaren Kollision wird dagegen eine unionsrechtliche Sachnorm durch eine nationale Verwaltungs-, Verfahrens-

1375 Rosenkranz, Beschränkung der Rückwirkung, 2015, S. 466. 
oder Prozessnorm beeinträchtigt, zu deren Anwendung es aufgrund der nationalen Verfahrensautonomie kommt. Damit kommen sowohl die unionsrechtliche Norm als auch die nationale Norm zur Anwendung, wobei die unionsrechtlichen Grundsätze der Äquivalenz und Effektivität über die unionsrechtliche Zulässigkeit der Anwendung der nationalen Norm entscheiden. ${ }^{1376}$ An einer indirekten Kollision sind daher grundsätzlich eine Norm des nationalen Rechts und zwei unionsrechtliche Normen beteiligt. ${ }^{1377}$

Zur indirekten Kollision wird zum Teil vertreten, dass es sich bei ihr nicht um eine Frage des Anwendungsvorrangs handele, da dieser nur bei direkten Kollisionen zum Tragen komme. ${ }^{1378}$ Ein derartiges Verständnis übersieht aber, dass auf seiner Grundlage nicht erklärt werden kann, weshalb es Fälle gibt, in denen nationale Verfahrensregelungen unangewendet bleiben müssen. ${ }^{1379}$ Auch der Äquivalenz- und Effektivitätsgrundsatz entfalten unmittelbare Wirkung und verdrängen bei einem Verstoß die verfahrensrechtliche Vorschrift des nationalen Rechts. Eine indirekte Kollision kann damit auch als direkte beschrieben werden, bei der die nationale Verfahrensnorm mit den unmittelbar wirkenden Grundsätzen der Äquivalenz und Effektivität kollidiert. Die Bedeutung dieser Grundsätze ergibt sich zwar erst im Einzelfall unter Beachtung der allgemeinen Rechtsgrundsätze des Unionsrechts. Ist diese aber geklärt, muss die nationale Verfahrensvorschrift unangewendet bleiben.

Eine indirekte Kollision unterscheidet sich daher insoweit von einer direkten, als sie sich erst und nur im konkreten Anwendungsfall ergibt und nicht von vornherein feststeht. ${ }^{1380}$ Zur Beantwortung der Frage nach den Folgen der Kollisionsauflösung ist die Unterscheidung zwischen direkten und indirekten Kollisionen aber nicht aussagekräftig: Sie dient nur der Feststellung von Kollisionslagen, trifft aber keine Aussage über die Folgen

1376 Näher Kruis, Anwendungsvorrang, 2013, S. 98 f.; von Danwitz, Verwaltungsrechtliches System, 1996, S. 115. Jarass/Beljin, NVwZ 2004, 1 (3 f.) bezeichnen jede Beeinträchtigung der Wirksamkeit des Unionsrechts durch nationale Rechtsakte, die keine direkte Kollision darstellt, als indirekte Kollision; ebenso Beljin, NVwZ 2008, 156 (157).

1377 Kadelbach, Verwaltungsrecht, 1999, S. 49 f.

1378 Vgl. die Nachweise aus der Literatur bei Jarass/Beljin, NVwZ 2004, 1 (5 mit Fn. 62).

1379 Siehe etwa EuGH, Urteil vom 20.3.1997, Rs. C-24/95 (Alcan Deutschland), Rn. $37 \mathrm{f}$.

1380 Überzeugend Kruis, Anwendungsvorrang, 2013, S. 102. 
der Kollisionsauflösung. ${ }^{1381}$ Ein Anknüpfen an den Kollisionsbegriff hilft daher im vorliegenden Zusammenhang nicht weiter. Unabhängig von der Frage, unter welchen Voraussetzungen ein nationales Gericht überhaupt einmal selbst eine Übergangsfrist gewähren kann, ist dementsprechend eine Auffassung zurückzuweisen, die in der Gewährung von Übergangsfristen durch nationale Gerichte eine indirekte Kollision erblickt und daher lediglich die Grundsätze der Äquivalenz und Effektivität als Grenze beachten möchte. ${ }^{1382}$ Ebenso wenig überzeugt eine Ansicht, die bei einer indirekten Kollision (anders als bei einer direkten) dem Anwendungsvorrang eine Wirkung als Prinzip (und nicht als Regel) zuweist. ${ }^{1383}$

\section{Rechtsgrundlage einer vorübergehenden Aussetzung der Verdrängungswirkung}

Da sich der Gerichtshof wie gesehen im Grundsatz zu Recht offen dafür gezeigt hat, den Vorrang hinter andere Belange zurücktreten zu lassen, bedarf der näheren Untersuchung, worin eine Befugnis des Gerichtshofs zur vorübergehenden Aussetzung der Verdrängungswirkung einer Bestimmung des Unionsrechts ihre Grundlage findet. Dass mit einem derart vagen Phänomen wie dem "Zeitgeist“ jedenfalls keine Diskussionen über grundlegende unionsrechtliche Strukturmerkmale verbunden werden sollten, auch wenn der EuGH diesen in seine Entscheidungen mit einbeziehen mag, um politischen und wirtschaftlichen Gegebenheiten Rechnung zu tragen, kann dabei nicht ernsthaft bezweifelt werden. ${ }^{1384}$

Nach Ansicht des VG Köln läuft eine Fortgeltung nationalen Rechts entgegen den Vorgaben des Unionsrechts auf eine Unwirksamkeitserklärung der betroffenen Normen des Unionsrechts hinaus. ${ }^{1385}$ Danach wäre in der

1381 Ehlers/Eggert, JZ 2008, 585 (589); diesen zustimmend Kruis, Anwendungsvorrang, 2013, S. 207 f., Fn. 910.

1382 So aber Beljin, NVwZ 2008, 156 (157 ff.).

1383 In diesem Sinne aber Kadelbach, Verwaltungsrecht, 1999, S. 51, 54, wonach eine direkte Kollision durch eine Regel entschieden werde, eine indirekte dagegen unter Berücksichtigung der objektiven Gehalte unionsrechtlicher Normen. Die direkte Kollision wird nach seiner Auffassung also durch regelgeleitete Rechtsanwendung, die indirekte durch prinzipiengeleitete Rechtsanwendung aufgelöst.

1384 So aber Neuschl/Schumm, ZEuS 2008, 527 (536 f.).

1385 VG Köln, Urteil vom 6.7.2006, 1 K 9196/04, Rn. 52 - juris in Bezug auf die im Bereich der Sportwetten maßgebliche Niederlassungs- und Dienstleistungsfrei- 
hier untersuchten Problemstellung die Gültigkeit des Unionsrechts betroffen - Primärrecht verwerfen bzw. aussetzen dürfte aber nicht einmal der EuGH. ${ }^{1386}$ Einem derartigen Ansatz ist zwar zuzugeben, dass das Unionsrecht bei einer vorübergehenden Aussetzung des Anwendungsvorrangs im Ergebnis nicht zur Anwendung kommt, so als ob es für unwirksam erklärt worden wäre. Dennoch kann nicht argumentiert werden, dass der EuGH den Vorrang überhaupt nicht suspendieren darf, da der Ausgangspunkt bei einer solchen Betrachtung unzutreffend gewählt ist.

Vor dem Hintergrund, dass zwischen der Norm und ihrer Durchsetzung (auch wenn diese Dimension der Norm innewohnt) unterschieden werden kann, ist hier nicht die Gültigkeit der Norm betroffen, sondern lediglich ihre Durchsetzung. Erachtet man wie hier den Vorrang als einer Abwägung durch den EuGH zugänglich, kann er hinter anderen primärrechtlichen Grundsätzen zurücktreten. Durch eine vorübergehende Suspendierung des Anwendungsvorrangs wird die Gültigkeit bzw. Wirksamkeit der unionsrechtlichen Normen also nicht berührt. In diesem Sinne erscheint eine Fortgeltung nationalen Rechts entgegen der Auffassung des VG Köln nicht als Unwirksamkeitserklärung des Unionsrechts.

Als Grundlage einer vorübergehenden Aussetzung der Verdrängungswirkung führt der EuGH eine mögliche entsprechende Anwendung von Art. 264 II AEUV an. ${ }^{1387}$ Die Fruchtbarmachung von Art. 264 II AEUV sollte nicht vorschnell als „in die Irre“ führend abgelehnt werden. ${ }^{1388}$ Bei seiner direkten oder analogen Anwendung im Rahmen der Nichtigkeitsklage bzw. Ungültigkeitsvorabentscheidung geht es zwar in der Tat nicht um das Verhältnis von nationalem zu Unionsrecht, sondern um Konflikte innerhalb der Unionsrechtsordnung. ${ }^{1389}$ Ebenso kommt es dadurch zu einem Konflikt mit der einheitlichen Anwendung des Unionsrechts in den Mitgliedstaaten, dass die Durchbrechung des Anwendungsvorrangs

heit; siehe auch VG Köln, Beschluss vom 14.7.2006, 1 L 928/06, Rn. 42 - juris. Mertens, DVBl. 2006, 1564 (1567) kritisiert diesen Vergleich.

1386 So Terhechte, EuR 2006, 828 (841 f.).

1387 EuGH, Urteil vom 8.9.2010, Rs. C-409/06 (Winner Wetten), Rn. 67. Dass eine Heranziehung der Defrenne-Rechtsprechung ausscheidet, liegt auch darin begründet, dass nach ihr ein Ausschluss der Berufung auf die ausgelegte Norm für die Zukunft ausscheidet, siehe Koenig/Schreiber, DÖV 2008, 450 (454).

1388 So aber Terhechte, EuR 2006, 828 (836).

1389 Vor diesem Hintergrund bezeichnet etwa Kruis, EuZW 2006, 606 (607) das Bestehen einer aus Art. 264 II AEUV ableitbaren allgemeinen Regel als „zweifelhaft“. Beljin, NVwZ 2008, 156 (161) sieht einen „begrenzten Stellenwert“ des Art. 264 II AEUV im vorliegenden Zusammenhang. Siehe auch Willers, Übergangsfristen, 2011, S. 84. 
auf den betroffenen Mitgliedstaat begrenzt erfolgen soll, wohingegen die einheitliche Anwendung des Unionsrechts in den Mitgliedstaaten bei der sonst üblichen Anwendung des Art. 264 II AEUV unberührt bleibt. ${ }^{1390}$

Diese Argumente sprechen aber lediglich gegen eine entsprechende Anwendung des Art. 264 II AEUV, nicht aber dagegen, seinen Rechtsgedanken fruchtbar zu machen. ${ }^{1391}$ Andere sprechen deshalb von einer doppelten Analogie zu Art. 264 II AEUV. Angesprochen ist damit der in Art. 264 II AEUV angelegte Vorgang einer „im Anwendungsbereich des Vorrangs“ erfolgenden Abwägung der betroffenen Interessen im Hinblick auf die betroffene Norm des Unionsrechts. ${ }^{1392}$

Bedeutung erlangt damit der unionsrechtliche Grundsatz der Rechtssicherheit in seinen unterschiedlichen Ausprägungen, was eine Orientierung an den Fallgruppen des Art. 264 II AEUV ermöglicht. ${ }^{1393}$ Dass damit ein sehr weitreichender Rechtssicherheitsbegriff zum Tragen kommt, zeigt sich etwa daran, dass der Gerichtshof in den verbundenen Rechtssachen Kadi und Al Barakaat International Foundation mit der Terrorismusbekämpfung auch einen eher dem Gemeinwohl zuzuordnenden Grund als Auslöser für eine Anwendung des Art. 264 II AEUV anerkannt hat. ${ }^{1394}$

Wird der Vorrang auf unionsrechtlicher Ebene durch eine unionsinterne Abwägung begrenzt, fehlt es im Verhältnis zum nationalen Recht an einer zu dessen Verdrängung führenden Kollision. Die Heranziehung des Rechtsgedankens des Art. 264 II AEUV bzw. seine doppelt analoge Anwen-

1390 Eine Übertragung bzw. Heranziehung daher ablehnend Koenig/Schreiber, DÖV 2008, 450 (453); Talos/Arzt, ELRep. 2010, 172 (173); Kovács, Temporale Wirkung, 2014, S. $314 \mathrm{f}$.

1391 Neuschl/Schumm, ZEuS 2008, 527 (540); Ehlers/Eggert, JZ 2008, 585 (588); Rosenkranz, Beschränkung der Rückwirkung, 2015, S. 464 mit Fn. 175; Hüsken, ZfWG 2009, 13 (16) spricht von der Heranziehung der Leitgedanken der Rechtsprechung. Das Problem der nicht mehr gegebenen einheitlichen Anwendung des Unionsrechts besteht dabei natürlich weiterhin.

1392 So auch Düsterhaus, EuR 2017, 30 (50 f.); Düsterhaus, YEL 36 (2017), 237 (268f.). Zumindest erwägenswert erscheint es daher, die Erwähnung einer möglichen Analogie zu Art. 264 II AEUV im Winner Wetten-Urteil als Anknüpfungspunkt für eine Gleichbehandlung der Fälle der Defrenne-Rechtsprechung mit Art. 264 II AEUV zu sehen. Der EuGH hat sich hierzu noch nicht geäußert. Siehe zu dieser Frage bereits oben bei Fn. $465 \mathrm{f}$.

1393 Rosenkranz, Beschränkung der Rückwirkung, 2015, S. $466 \mathrm{f}$. Zu diesen Fallgruppen ausführlich oben bei Fn. $962 \mathrm{ff}$.

1394 EuGH, Urteil vom 3.9.2008, verb. Rs. C-402/05 P und C-415/05 P (Kadi und Al Barakaat International Foundation/Rat und Kommission), Rn. $373 \mathrm{ff}$. Hierauf weisen auch van der Hulle/van der Hulle, SEW 2012, 490 (497, 501) zu Recht hin. 
dung führen daher im hier vorliegenden Zusammenhang zu einer Begrenzung des Vorrangs selbst. ${ }^{1395}$ Diese Begrenzung hat zur Folge, dass die Kollision zwischen Unions- und nationalem Recht erst zu dem Zeitpunkt eintritt, zu dem die Suspendierung endet.

\section{Die Winner Wetten-Rechtsprechung}

Die Diskussion um die Möglichkeit einer temporären Suspendierung des Anwendungsvorrangs nahm ihren Ursprung in der Problematik der Sportwettenmonopole und ihrer umstrittenen Vereinbarkeit mit Unionsrecht, genauer gesagt der unmittelbar anwendbaren Dienstleistungs- und Niederlassungsfreiheit. Die darüber in Literatur und Rechtsprechung geführte Auseinandersetzung liegt in ihrem Kern zwar bereits einige Jahre zurück; im Jahr 2016 hat der EuGH allerdings auf seine im Rahmen dieser Auseinandersetzung ergangene Entscheidung in der Rechtssache Winner Wetten Bezug genommen und die darin angesprochene Möglichkeit einer vorübergehenden Aussetzung der Verdrängungswirkung aufgegriffen. ${ }^{1396}$ Die Hintergründe dieser Diskussion sind daher kurz zu beleuchten.

Den Ausgangspunkt bildete eine Entscheidung des Bundesverfassungsgerichts aus dem Jahr 2006, die das in Bayern geltende Sportwettenmonopol für mit dem Grundgesetz unvereinbar erklärte und dem bayerischen Gesetzgeber eine Übergangsfrist zur Herstellung eines grundgesetzkonformen Zustands gewährte. Die Nichtigkeit der in Rede stehenden Regelung hatte das Bundesverfassungsgericht also nicht festgestellt. Indem es die verschiedenen gesetzgeberischen Möglichkeiten zur Reaktion auf sein Urteil aufzeigte ${ }^{1397}$, gab es zu erkennen, dass es ihm dabei um die Achtung vor dem Gesetzgeber ging. Die Gewährung der Übergangsfrist erfolgte

1395 Anders Kruis, Anwendungsvorrang, 2013, S. 203; auf S. 207 f. spricht er von einer „Begrenzung der zeitlichen Wirkung einer Kollision“; siehe auch $E$ blers/Eggert, JZ 2008, 585 (588), die bei der direkten Anwendung des Art. 264 II AEUV von einer variierenden Bestimmung der Folgen der Kollision sprechen.

1396 EuGH, Urteil vom 28.7.2016, Rs. C-379/15 (Association France Nature Environnement), Rn.33; EuGH, Urteil vom 8.9.2010, Rs. C-409/06 (Winner Wetten), Rn. 66 und 67.

1397 BVerfG, Urteil vom 28.3.2006, 1 BvR 1054/01 - BVerfGE 115, 276 (317f.) erwähnt sowohl eine konsequente Ausgestaltung des Monopols, die sicherstellt, dass es wirklich der Suchtbekämpfung dient, als auch eine gesetzlich normierte und kontrollierte Zulassung gewerblicher Veranstaltung durch private Wettanbieter. 
also mit Blick auf den Grundsatz der Gewaltenteilung, der von der Rechtsprechung Zurückhaltung verlangt, wenn vom Gesetzgeber politische Entscheidungen zu treffen sind, um die festgestellte Unvereinbarkeit mit dem Grundgesetz zu beseitigen. ${ }^{1398}$ Die Frage der Vermeidung eines Rechtsvakuums spielte in den Überlegungen des Bundesverfassungsgerichts dagegen keine erkennbare Rolle. Da auch bei einer Nichtigerklärung der Regelung ordnungsbehördliche Eingriffsmöglichkeiten gegenüber privaten Wettanbietern bestanden hätten, verwundert die verfassungsgerichtliche Akzentsetzung nicht.

Das Bundesverfassungsgericht führte aus, dass die bisherige Rechtslage für die Übergangszeit "mit der Maßgabe anwendbar“ sei, dass ein „Mindestmaß an Konsistenz" zwischen dem Ziel der Begrenzung der Wettsucht und der tatsächlichen Ausübung des Monopols herzustellen sei und dass in der Übergangszeit mit der Ausrichtung des Wettmonopols an der Bekämpfung der Wettsucht begonnen werden müsse. ${ }^{1399}$ Nicht auf den ersten Blick klar ist, ob die Erfüllung der vom Bundesverfassungsgericht aufgestellten Maßgaben Bedingung für die weitere Anwendbarkeit der gesetzlichen Regelung ist. ${ }^{1400}$ Lediglich als Appell können die Ausführungen des Bundesverfassungsgerichts jedenfalls nicht verstanden werden, da die Herstellung von Konsistenz in diesem Fall in das Belieben der Verwaltung gestellt und eine Durchsetzung der Maßgaben letztlich nicht möglich wäre. Angesichts der vom Bundesverfassungsgericht ins Feld geführten Parallelität der verfassungs- und unionsrechtlichen Anforderungen ${ }^{1401}$ wäre bei einem Verständnis als bloßer Appell zudem recht offensichtlich, dass weiterhin eine unionsrechtswidrige Regelung zur Anwendung käme. Dass das Bundesverfassungsgericht eine derartige Aussage treffen wollte, kann ihm ohne konkrete Anhaltspunkte allerdings nicht unterstellt werden. Bedingung für die Wirksamkeit des Übergangsrechts sind die Maßgaben letztlich dennoch nicht: Das Monopol ist weiterhin anwendbar; die Maßgaben sind Teil der Übergangsregelung, deren Einhaltung ist eine selbständig durchsetzbare Anordnung. ${ }^{1402}$

1398 van der Hulle/van der Hulle, SEW 2012, 490 (492) umschreiben dies plastisch damit, dass ein Gericht dem Gesetzgeber in einem solchen Fall keine Knüppel zwischen die Beine werfen solle.

1399 BVerfG, Urteil vom 28.3.2006, 1 BvR 1054/01 - BVerfGE 115, 276 (319).

1400 Dafür Mertens, DVBl. 2006, 1564 (1566).

1401 BVerfG, Urteil vom 28.3.2006, 1 BvR 1054/01 - BVerfGE 115, 276 (316f.).

1402 In diesem Sinne auch Hüsken, ZfWG 2009, 13 (18 f. mit Fn. 69) und Schmid, GewArch 2006, 177 (178). Siehe auch VG Köln, Urteil vom 6.7.2006, 1 K 9196/04, Rn. 71 - juris: „Aus der Entscheidung lässt sich nämlich kein Junktim 
Hinsichtlich der Frage des Verhältnisses der gewährten Übergangsfrist zum Unionsrecht ist zu unterscheiden. Zunächst ist festzustellen, dass das Bundesverfassungsgericht selbst anerkannt hat, dass es für die Beurteilung der Vereinbarkeit der nationalen Rechtslage mit Unionsrecht nicht zuständig ist. ${ }^{1403}$ Es konnte und wollte das Unionsrecht in seinem Sportwettenurteil nicht verbindlich auslegen. ${ }^{1404}$ Angesichts des Hinweises des Bundesverfassungsgerichts auf die parallele unionsrechtliche Beurteilung ${ }^{1405}$ sowie des Wortlauts der Übergangsregelung, die nicht auf rein innerstaatliche Sachverhalte beschränkt worden, sondern „ohne jeden Vorbehalt“ ergangen ist ${ }^{1406}$, ist sodann festzuhalten, dass das Bundesverfassungsgericht eine einheitliche Übergangsfrist für sämtliche Sachverhalte angeordnet hat. Für die Beurteilung der Übergangsregelung aus unionsrechtlicher Sicht ist daher entscheidend, ob die Kollision mit Unionsrecht durch die vom Bundesverfassungsgericht angeordneten Modifikationen entfallen ist. Die hier interessierende Frage der Suspendierung des Anwendungsvorrangs stellt sich demnach nur, wenn die Übergangsregelung an der Unionsrechtswidrigkeit nichts geändert hat. ${ }^{1407}$

Insoweit wird in der Literatur zum Teil geltend gemacht, dass die Maßgaben der Weitergeltensanordnung den unionsrechtlichen Anforderungen für eine Übergangszeit genügten. ${ }^{1408} \mathrm{Da}$ sie zur Verfassungskonformität des Monopols führten, führten sie angesichts der Parallelität der beiden Maßstäbe auch zur Unionsrechtskonformität. ${ }^{1409}$ Allerdings gehen die vom Bundesverfassungsgericht verlangten Änderungen weniger weit, als eine Neuregelung gehen müsste. ${ }^{1410}$ Auch kann eine tatsächliche Änderung der Rechtspraxis der Unionsrechtswidrigkeit der zugrundeliegenden rechtlichen Regelung nicht abhelfen. ${ }^{1411} \mathrm{Da}$ das Bundesverfassungsgericht auch ein Regelungsdefizit festgestellt hat ${ }^{1412}$, können lediglich tatsächliche

zwischen der Erfüllung dieser Vorgaben und der ordnungsrechtlichen Befugnis zum Einschreiten gegen private Wettveranstalter herleiten.“

1403 BVerfG, Urteil vom 28.3.2006, 1 BvR 1054/01 - BVerfGE 115, 276 (299 f.).

1404 Siehe auch Unterreitmeier, NJW 2013, 127 (129).

1405 Beljin, NVwZ 2008, 156 weist darauf hin, dass kein Hinweis auf eine Beschränkung auf rein innerstaatliche Sachverhalte zu finden ist.

1406 Schmid, GewArch 2006, 177 (178f.).

1407 Hüsken, ZfWG 2009, 13 (14): „denknotwendig“.

1408 Bethge, ZfWG 2007, 245 (248); tendenziell ebenso Kruis, EuZW 2006, 606.

1409 So Hüsken, ZfWG 2009, 13 (18 f.).

1410 Beljin, NVwZ 2008, 156 (158).

1411 Deutlich auch VG Köln, Beschluss vom 21.9.2006, 1 K 5910/05 - GewArch 2006, 467 (468).

1412 BVerfG, Urteil vom 28.3.2006, 1 BvR 1054/01 - BVerfGE 115, 276 (309). 
Maßnahmen dieses nicht beheben. ${ }^{1413}$ Der Verstoß gegen Unionsrecht besteht damit fort; die Kollision ist durch die vom Bundesverfassungsgericht angeordneten Modifikationen nicht entfallen.

Vor diesem Hintergrund setzt das OVG Münster eine Stufe früher an und möchte über die von ihm ins Spiel gebrachte Durchbrechung des Vorrangs bereits das Bestehen einer Kollision zwischen Unionsrecht und nationalem Recht vermeiden. ${ }^{1414}$ So begründete es (in einem gegen die Anordnung der sofortigen Vollziehung einer Untersagung der Vermittlung von Sportwetten gerichteten einstweiligen Rechtsschutzverfahren) seine Ansicht von der fehlenden Unionsrechtswidrigkeit der Untersagungsverfügung damit, dass dem Anwendungsvorrang des Unionsrechts und der damit korrespondierenden Nichtanwendungspflicht hinsichtlich des nationalen Rechts gewisse Grenzen gesetzt seien. Bei Entstehung einer inakzeptablen Gesetzeslücke durch die Nichtanwendung des nationalen Rechts könne der Anwendungsvorrang vorerst nicht greifen, sodass es zu dessen temporärer Durchbrechung komme. Dafür müsse die Nichtanwendung des nationalen Rechts absehbar zu einer Gefährdung wichtiger Allgemeininteressen führen, die ersichtlich schwerer wiege als die Beeinträchtigung der durch die jeweils verletzte europarechtliche Vorschrift geschützten Rechtsgüter und nicht anders abgewendet werden könne als durch eine zeitlich begrenzte weitere Anwendung der betroffenen nationalen Rechtsvorschriften. Der Anwendungsvorrang bleibe so lange suspendiert, bis der nationale Gesetzgeber hinreichend Gelegenheit gehabt habe, eine unionsrechtskonforme Regelung zu treffen. ${ }^{1415}$

Das OVG Münster entwickelt die Voraussetzungen für eine Aussetzung des Vorrangs also selbst und lehnt eine Verpflichtung zur Vorlage an den EuGH mit der Erwägung ab, die Angelegenheit sei eilbedürftig und es gehe nicht um die Gültigkeit, sondern nur um die Auslegung von Unionsrecht. ${ }^{1416}$ Insoweit befindet es sich im Einklang mit dem Bundesverfassungsgericht, demzufolge im Eilverfahren keine Pflicht zur Vorlage an den

1413 VG Arnsberg, Beschluss vom 23.5.2006, 1 L 379/06, Rn. 16 - juris: Werbung zwar eingeschränkt, rechtliche Ausgestaltung aber unverändert; insoweit zustimmend OVG Münster, Beschluss vom 28.6.2006, 4 B 961/06 - EuR 2006, 821 (825): Defizit der gesetzlichen Regelung selbst nicht beseitigt; VG Köln, Urteil vom 6.7.2006, 1 K 9196/04, Rn. 44 - juris; zustimmend Mertens, DVBl. 2006, 1564 (1567).

1414 Vgl. Terhechte, EuR 2006, 828 (832).

1415 OVG Münster, Beschluss vom 28.6.2006, 4 B 961/06 - EuR 2006, 821 (825 f.).

1416 OVG Münster, Beschluss vom 28.6.2006, 4 B 961/06 - EuR 2006, 821 (827). 
EuGH „wegen der ,Suspendierung primären [Unions]rechts “ “ besteht. ${ }^{1417}$ Zwar stellte sich die Frage nach der Vorlagepflicht im Rahmen einer Verfassungsbeschwerde gegen einen Beschluss des Bayerischen Verwaltungsgerichtshofs letztlich nicht, da dieser von der Vereinbarkeit der bayerischen Rechtslage und Praxis mit Unionsrecht ausgegangen war und es für ihn auf das Problem der Aussetzung des Vorrangs daher gar nicht ankam. Das Bundesverfassungsgericht führte aber aus, dass auch bei der Bejahung einer temporären Aussetzung der Anwendbarkeit von primärem Unionsrecht eine Vorlagepflicht im Verfahren des einstweiligen Rechtsschutzes nicht zwangsläufig anzunehmen sei, da sich der EuGH zum Bestehen der Vorlagepflicht in einem solchen Falle noch nicht geäußert habe und der Beschwerdeführer eine entsprechende Auslegung des Art. 267 III AEUV vom EuGH lediglich erwarte. ${ }^{1418}$

Bei der Gegenüberstellung der Entscheidungen des Bundesverfassungsgerichts und des OVG Münster fällt auf, dass das Bundesverfassungsgericht sich in seinem Sportwettenurteil bei der Anordnung der Übergangsfrist auf die Gestaltungsmöglichkeiten des Gesetzgebers berufen hat, während sich das OVG Münster für die Begründung einer temporären Durchbrechung des Anwendungsvorrangs auf die drohende Entstehung eines Rechtsvakuums stützte. Zu beiden Entscheidungen äußerte sich der EuGH in seinem auf ein Vorabentscheidungsersuchen des VG Köln ergangenen Winner Wetten-Urteil.

Im Hinblick auf das Argument der innerstaatlichen Gewaltenteilung ${ }^{1419}$ ist festzustellen, dass der EuGH diesem keine Beachtung schenkt, da er sich mit der Motivationslage des Bundesverfassungsgerichts nicht näher auseinandersetzt. ${ }^{1420}$ Er stellt lediglich fest, dass nationale Verfassungsgerichte die Verpflichtung nationaler Gerichte zur Nichtanwendung unionsrechtswidrigen nationalen Rechts nicht einschränken können, sodass eine verfassungsgerichtliche Entscheidung, die Wirkungen innerstaatlicher Rechtsvorschriften im Anschluss an die Feststellung ihrer Verfassungswidrigkeit vorübergehend aufrechterhält, keine Abweichung vom Vorrang rechtfertigt. ${ }^{1421}$ Obwohl er der verfassungsgerichtlichen Übergangsrege-

1417 BVerfG, Beschluss vom 19.10.2006, 2 BvR 2023/06 - BVerfGK 9, 330 (335).

1418 BVerfG, Beschluss vom 19.10.2006, 2 BvR 2023/06 - BVerfGK 9, 330 (336). Zur Frage des Bestehens einer Vorlagepflicht bei der Suspendierung des Vorrangs näher sogleich bei Fn. $1504 \mathrm{ff}$.

1419 Dies ist Paulus, NJW 2011, 3686 (3689) ein besonderes Anliegen.

1420 Siehe auch Beukers, CMLRev. 48 (2011), 1985 (1996, 1997 f., 1999).

1421 Das kann nicht weiter überraschen, vgl. etwa EuGH, Urteil vom 9.3.1978, Rs. 106/77 (Simmenthal), Rn. 24. Der EuGH, Urteil vom 8.9.2010, 
lung damit die Anwendbarkeit auf das Unionsrecht versagt ${ }^{1422}$, bedeutet dies nicht, dass er auf die Gewaltenteilung gestützten Argumenten grundsätzlich ablehnend gegenüberstünde. So hat er einerseits etwa in seinen im ersten Teil dieser Arbeit behandelten Urteilen in den verbundenen Rechtssachen Moulins et Huileries de Pont-à-Mousson sowie Ruckdeschel u.a. ${ }^{1423}$ entsprechende, die Ebene des Unionsrechts betreffende Überlegungen ernst genommen. Andererseits hat er sich in seinem im weiteren Verlauf der Arbeit noch näher zu besprechenden Taricco II-Urteil auch durchaus offen für die nationale Gewaltenteilung betreffende Einwände gezeigt und akzeptiert, dass die Rechtsprechung nach italienischem Verständnis bestehende Lücken nicht anstelle des Gesetzgebers füllen kann. ${ }^{1424}$ Die Schlussfolgerung, dass der Gerichtshof dem Argument der Rücksichtnahme auf die Gewaltenteilung nach seinem Winner Wetten-Urteil keine Bedeutung mehr beimisst, ist also nicht gerechtfertigt. ${ }^{1425}$

Im Übrigen kann auch daraus, dass der Gerichtshof bei Verstößen gegen den Gleichheitssatz zum Teil selbst der benachteiligten Gruppe den ihr vorenthaltenen Vorteil der bevorzugten Gruppe zuspricht, bis der Gesetzgeber der Unvereinbarkeit abgeholfen hat, nicht zwingend geschlossen werden, dass der Gerichtshof dem „demokratischen Argument" abneigend gegenübersteht. Daran, dass er in seinem Urteil in den verbundenen Rechtssachen Sturgeon u.a. ${ }^{1426}$ auf eine Auslegung des in Rede stehenden Unionsrechtsakts im Einklang mit dem primärrechtlichen Gleichbehandlungsgrundsatz zurückgreift, um eine Gleichbehandlung der Fluggäste ver-

Rs. C-409/06 (Winner Wetten), Rn. 60 zitiert EuGH, Urteil vom 19.11.2009, Rs. C-314/08 (Filipiak), Rn. 84. Die Rechtssache Filipiak betraf eine ganz ähnliche Frage, da das polnische Verfassungsgericht entschieden hatte, dass ein verfassungswidriges Gesetz bis zum 30.11.2008 anwendbar sei. Auch diese Entscheidung des Verfassungsgerichts änderte nichts an der Pflicht der nationalen Gerichte zur Nichtanwendung des nationalen Gesetzes. Siehe auch EuGH, Urteil vom 5.10.2010, Rs. C-173/09 (Elchinov), Rn. 32 sowie Beukers, CMLRev. 48 (2011), 1985 (1998 f.) und Verstraelen, GLJ 14 (2013), 1687 (1720).

1422 Kritisch Paulus, NJW 2011, 3686 (3689).

1423 EuGH, Urteil vom 19.10.1977, verb. Rs. 124/76 und 20/77 (Moulins et Huileries de Pont-à-Mousson), Rn. 27/29; EuGH, Urteil vom 19.10.1977, verb. Rs. 117/76 und 16/77 (Ruckdeschel u.a.), Rn. 13. Siehe oben bei Fn. 974 ff.

1424 EuGH, Urteil vom 5.12.2017, Rs. C-42/17 (M.A.S. und M.B.), Rn. 41, 59. Zum Taricco II-Urteil näher unten bei Fn. 1685 ff.

1425 A.A. van der Hulle/van der Hulle, SEW 2012, 490 (498 f.).

1426 EuGH, Urteil vom 19.11.2009, verb. Rs. C-402/07 und C-432/07 (Sturgeon u.a.), insb. Rn. 48. Dieses Urteil nehmen auch van der Hulle/van der Hulle, SEW 2012, 490 (499 mit Fn. 84) in Bezug. Siehe auch das Nachfolgeurteil EuGH, Urteil vom 23.10.2012, verb. Rs. C-581/10 und C-629/10 (Nelson u.a.). 
späteter und annullierter Flüge zu erreichen, zeigt sich lediglich, dass dem Unionsrecht selbst die Vorgaben bis zu einer Neuregelung zu entnehmen sind. ${ }^{1427}$

$\mathrm{Da}$ es den unionsrechtlichen Vorgaben wesenseigen ist, dass nationale Gerichte nationale Normen außer Anwendung lassen können und müssen, kann im Hinblick auf das Argument der Rücksichtnahme auf die innerstaatliche Gewaltenteilung letztlich kein nationales Verständnis des Verhältnisses zwischen Gesetzgebung und Rechtsprechung Geltung beanspruchen. Dass sich ein nationales Gericht über Entscheidungen des nationalen Gesetzgebers hinwegsetzen kann, ist anerkannte Rechtsfolge des Anwendungsvorrangs. Droht die Entstehung einer Regelungslücke, ist diese unmittelbar im Rahmen seiner Entscheidung auch durch ein mitgliedstaatliches Gericht unionsrechtskonform zu schließen; die Lückenschließung ist nicht dem nationalen Gesetzgeber vorbehalten. ${ }^{1428}$

Damit muss ein einheitliches unionsrechtliches Konzept des Verhältnisses von Gesetzgebung und Rechtsprechung über die Aussetzung der Verdrängungswirkung entscheiden. Im Hinblick auf das Gebot der Achtung der nationalen Identität nach Art. 4 II EUV werden zwar Zweifel geltend gemacht, ob ein europäisches Gewaltenteilungskonzept den nationalen Besonderheiten übergestülpt werden könne. ${ }^{1429}$ Entgegenzuhalten ist dem aber, dass danach, jedenfalls nach hier vertretener Auffassung, lediglich eine für Einflüsse aufgrund der europäischen Integration offene Identität eine Identität als Mitgliedstaat der Europäischen Union - geschützt ist. ${ }^{1430}$

Ein weiterer Blick auf das Winner Wetten-Urteil zeigt, dass der EuGH dort im Hinblick auf die Frage der vorübergehenden Aussetzung der Verdrängungswirkung, die sich natürlich auch unabhängig von der Existenz einer verfassungsgerichtlichen Entscheidung stellen kann, behutsam vorgeht. Indem er eine analoge Anwendung seiner Rechtsprechung zur Aufrechterhaltung der Wirkungen unwirksamer Unionsrechtsakte auf diesen Fall nicht ausschließt, deutet er eine vorsichtige Öffnung an, für die

1427 Kim/Dübbers, ZfWG 2006, 107 (112f.) machen dem OVG Münster daher zum Vorwurf, „deutsche“ Erwägungen auf Unionsrecht übertragen zu haben; Jarass/Beljin, NVwZ 2004, 1 (5) weisen darauf hin, dass der Gerichtshof Lücken zum Teil selbst schließt oder gar nicht erst entstehen lässt. Siehe auch Willers, Übergangsfristen, 2011, S. 85 f.; Prechal, CMLRev. 37 (2000), 1047 (1060 f.); Kruis, Anwendungsvorrang, 2013, S. $227 \mathrm{f}$.

1428 Koenig/Schreiber, DÖV 2008, 450 (451 f.).

1429 Siehe etwa Beukers, CMLRev. 48 (2011), 1985 (2000 mit Fn. 96).

1430 Auf den Schutz lediglich der mitgliedstaatlichen und nicht der rein staatlichen Identität weist etwa auch Haratsch, EuR 2016, 131 (144) hin. 
er aber im konkreten Fall keinen Raum sieht. Selbst wenn man eine vorübergehende Aussetzung der Verdrängungswirkung für möglich erachte, scheide, so der EuGH, eine solche in dem ihm vorliegenden Fall von vornherein aus, da mangels kohärenter und systematischer Begrenzung der Wetttätigkeiten keine zwingenden Erwägungen der Rechtssicherheit vorlägen, die sie rechtfertigen könnten. ${ }^{1431}$ Die vom OVG Münster ins Feld geführte Begründung mit der Gefahr der Entstehung eines Rechtsvakuums lehnt er also ab, was verständlich ist, da das Unionsrecht letztlich unter dem Vorbehalt nationalen Rechts stünde, wenn man das Vorliegen einer inakzeptablen Lücke aus dessen Perspektive bestimmte. ${ }^{1432}$

Die Ausführungen des Gerichtshofs geben zu erkennen, dass es sich bei dem hier diskutierten Problem richtigerweise um ein solches der Aussetzung der Verdrängungswirkung des Unionsrechts handelt und nicht um ein solches der Aufrechterhaltung der Wirkungen des nationalen Rechts, für die ihm die Befugnis fehlte. ${ }^{1433}$ Wenn er einem nationalen Gericht unter bestimmten Voraussetzungen die Anwendung einer nationalen Verfahrensvorschrift erlaubt, die eine Aufrechterhaltung bestimmter Wirkungen des nationalen Rechts gestattet ${ }^{1434}$, so denkt er demnach vom Unionsrecht her. Die Aufrechterhaltung von Wirkungen des nationalen Rechts ist dann lediglich eine Folge der Zurücknahme des Geltungsanspruchs des Unionsrechts.

Seine im Winner Wetten-Urteil getroffene Aussage hat der Gerichtshof in der Folgezeit bestätigt: Danach verhindert der Vorrang des unmittelbar geltenden Unionsrechts („primacy of directly-applicable European Union law“; „primauté du droit de l'Union directement applicable“), dass eine nationale Regelung für eine Übergangszeit weiter angewandt werden darf, die nicht in kohärenter und systematischer Weise dazu beiträgt, Wetttätigkeiten $\mathrm{zu}$ begrenzen, und daher unionsrechtswidrig ist. ${ }^{1435}$ Das ist aber,

1431 EuGH, Urteil vom 8.9.2010, Rs. C-409/06 (Winner Wetten), Rn. 67 f.; siehe auch van der Hulle/van der Hulle, SEW 2012, 490 (495 f.).

1432 Vgl. Kim/Dübbers, ZfWG 2006, 107 (114).

1433 Aubert/Broussy/Donnat, AJDA 2010, 2305 (2306).

1434 Vgl. z.B. EuGH, Urteil vom 28.2.2012, Rs. C-41/11 (Inter-Environnement Wallonie und Terre wallonne), Rn. 63; EuGH, Urteil vom 28.7.2016, Rs. C-379/15 (Association France Nature Environnement), Rn. 43; EuGH, Urteil vom 29.7.2019, Rs. C-411/17 (Inter-Environnement Wallonie und Bond Beter Leefmilieu Vlaanderen), Rn. 182.

1435 EuGH, Urteil vom 24.1.2013, verb. Rs. C-186/11 und C-209/11 (Stanleybet International u.a.), Rn.38 unter Verweis auf EuGH, Urteil vom 8.9.2010, Rs. C-409/06 (Winner Wetten), Rn.69; wiederholt in EuGH, Urteil vom 4.2.2016, Rs. C-336/14 (Ince), Rn. 53. 
um im Bereich der Glücksspiele zu bleiben, nicht gleichbedeutend mit einer Pflicht des Mitgliedstaats etwa zur Liberalisierung des Glücksspielmarkts. So kommt eine Reform eines bestehenden Monopols ebenso in Frage wie die Einführung eines Systems vorheriger behördlicher Genehmigung. Voraussetzung ist dann lediglich, dass sichergestellt ist, dass ein Ermessensmissbrauch der nationalen Behörden verhindert wird. ${ }^{1436}$

Damit hat der EuGH den Grundsatz, dass er keine Übergangsfrist gewährt, nicht abgeschwächt. ${ }^{1437}$ Vielmehr trägt er dem Umstand, dass die Ausgestaltung des Sportwettenmonopols Sache der Mitgliedstaaten ist, auf andere Weise Rechnung. Diese verfügen also über gewisse Gestaltungsmöglichkeiten, sodass Raum für die Berücksichtigung mitgliedstaatlicher Besonderheiten besteht. Durch die Gewährung einer Übergangsfrist können jene aber keine Anerkennung finden. ${ }^{1438}$

4. Nähere Konturierung der Voraussetzungen in der Rechtsprechung des $\mathrm{EuGH}$

Die vorangegangenen Überlegungen haben gezeigt, dass der Vorrang des Unionsrechts nach Auffassung des Gerichtshofs zu Recht einer Abwägung grundsätzlich zugänglich ist. In der Tat lässt sich hierfür der in Art. 264 II AEUV zum Ausdruck kommende Rechtsgedanke eines unionsinternen Interessenausgleichs fruchtbar machen. Dem Winner Wetten-Urteil lässt sich entnehmen, dass der EuGH einer von einem mitgliedstaatlichen Verfassungsgericht angeordneten Übergangsfrist eine Anwendbarkeit auf das Unionsrecht versagt und die bloße Behauptung eines mitgliedstaatlichen Gerichts, es drohe die Entstehung eines Rechtsvakuums, eine Rücknahme unionsrechtlicher Vorgaben nicht begründen kann. Auch wenn in der Winner Wetten-Konstellation kein Raum für eine vorübergehende Suspendierung des Vorrangs war, so zeigt das Urteil des EuGH doch, dass dieser einer solchen keine grundsätzliche Absage erteilt hat. Im Folgenden gilt es daher, näher zu untersuchen, in welchen Situationen sie in Betracht kommt, welche Aspekte also überhaupt geeignet sind, sich dem Vorrang

1436 EuGH, Urteil vom 4.2.2016, Rs. C-336/14 (Ince), Rn. 54 f.; EuGH, Urteil vom 24.1.2013, verb. Rs. C-186/11 und C-209/11 (Stanleybet International u.a.), Rn. 46 f. Der EuGH spricht von „objektiven und nicht diskriminierenden Kriterien [...], die im Voraus bekannt sind“.

1437 Vgl. GA Szpunar, Schlussanträge vom 22.10.2015 in der Rs. C-336/14 (Ince), Rn. 28, 32.

1438 Eine solche fordern etwa Neuschl/Schumm, ZEuS 2008, 527 (537 f.). 
in einer Abwägung gegenüberzustellen. Die Rechtsprechung des EuGH liefert hier erste Anhaltspunkte. Neben dem bereits vorgestellten Winner Wetten-Urteil sind hier insbesondere die Urteile in den Rechtssachen Inter-Environnement Wallonie und Terre wallonne sowie Association France Nature Environnement zu nennen. Um ein zutreffendes Bild zeichnen zu können, sind neben den Urteilen auch die in den jeweiligen Rechtssachen vorgelegten Schlussanträge zu skizzieren und den Urteilen gegenüberzustellen.

Insbesondere gilt es auch der Frage nachzugehen, wie die Befugnisse zwischen EuGH und mitgliedstaatlichen Gerichten in diesem Bereich verteilt sind, in welchen Fällen also eine Kompetenz mitgliedstaatlicher Gerichte denkbar ist, Wirkungen des nationalen Rechts trotz seiner Unionsrechtswidrigkeit aufrechtzuerhalten.

\section{a) Die Rechtssache Inter-Environnement Wallonie und Terre wallonne}

Gegenstand des vor der Großen Kammer des EuGH geführten Verfahrens in der Rechtssache Inter-Environnement Wallonie und Terre wallonne war die Frage der unionsrechtlichen Zulässigkeit der Weitergeltung bis zum Erlass einer Ersatzmaßnahme - eines eine Richtlinie - im konkreten Fall betroffen war die Nitratrichtlinie ${ }^{1439}$ - umsetzenden Aktionsprogramms im Umweltbereich, das unter Verstoß gegen verfahrensrechtliche Bestimmungen einer anderen Richtlinie - der Richtlinie über die Prüfung der Umweltauswirkungen bestimmter Pläne und Programme (SUP-Richtlinie) $)^{1440}$ - erlassen worden war. ${ }^{1441}$ Der in der Nitratrichtlinie vorgesehene Erlass des Aktionsprogramms bedurfte einer Umweltprüfung

1439 Richtlinie 91/676/EWG des Rates vom 12. Dezember 1991 zum Schutz der Gewässer vor Verunreinigung durch Nitrat aus landwirtschaftlichen Quellen (ABl. L 375 vom 31.12.1991, S. 1), in der Fassung durch die Verordnung (EG) Nr. 1882/2003 des Europäischen Parlaments und des Rates vom 29. September 2003 zur Anpassung der Bestimmungen über die Ausschüsse zur Unterstützung der Kommission bei der Ausübung von deren Durchführungsbefugnissen, die in Rechtsakten vorgesehen sind, für die das Verfahren des Artikels 251 des EG-Vertrags gilt, an den Beschluss 1999/468/EG des Rates, ABl. L 284 vom 31.10.2003, S. 1.

1440 Richtlinie 2001/42/EG des Europäischen Parlaments und des Rates vom 27. Juni 2001 über die Prüfung der Umweltauswirkungen bestimmter Pläne und Programme, ABl. L 197 vom 21.7.2001, S. 30.

1441 So pointiert GA Kokott, Schlussanträge vom 8.12.2011 in der Rs. C-41/11 (Inter-Environnement Wallonie und Terre wallonne), Rn. 1. 
nach der SUP-Richtlinie, die die Region Wallonien allerdings unterlassen hatte. Folge einer rückwirkenden Aufhebung des Aktionsprogramms wäre die unvollständige Umsetzung der Nitratrichtlinie durch Wallonien gewesen. Sie hätte zum Entfallen von Beschränkungen der Ausbringung von Dünger und eventuell auch von Düngerechten von Landwirten geführt. Angesichts des Inkrafttretens eines neuen, unter Beachtung der Vorgaben der SUP-Richtlinie erlassenen wallonischen Aktionsprogramms, das allerdings nicht rückwirkend galt, ging es vor dem Gerichtshof um die Frage der Fortgeltung des ursprünglichen Aktionsprogramms für die Zeit vom 15.2.2007 bis zum 6.5.2011.

In ihren Schlussanträgen verneint Generalanwältin Kokott die Betroffenheit des Vorrangs im geschilderten Fall. Sie macht insoweit geltend, dass der Verstoß gegen die SUP-Richtlinie durch die Anwendung des Aktionsprogramms nicht zwangsläufig vertieft werde, da die Durchführung der Umweltprüfung nicht zwingend zum Erlass einer anderen Maßnahme geführt hätte; der Verstoß dagegen sei vielmehr abgeschlossen. Anders sei dies bei einem Verstoß etwa gegen die Grundfreiheiten, wo jede Anwendung des nationalen Rechts das Unionsrecht erneut verletze. ${ }^{1442}$ Sie unterscheidet daher die sich hier stellende Problematik von derjenigen in der Rechtssache Winner Wetten, in der - anders als nun in der Rechtssache Inter-Environnement Wallonie und Terre wallonne - mit der Dienstleistungs- und Niederlassungsfreiheit wie gesehen unmittelbar anwendbares Unionsrecht und dessen Vorrang betroffen war.

Dementsprechend zieht sie Effektivitäts- und Äquivalenzgrundsatz zur Problemlösung heran. Zwar müsse der Verstoß gegen die verfahrensrechtlichen Regelungen der SUP-Richtlinie nach Art. 4 III EUV beseitigt werden; wie das geschehe sei in den Grenzen der genannten Grundsätze aber Sache der Mitgliedstaaten. ${ }^{1443}$ Bei einem Plan/Programm sei es denkbar, dass bei dessen Aufhebung eine ältere oder allgemeinere Regelung an dessen Stelle trete, die unter Umweltschutzgesichtspunkten weniger günstig sei, was die Situation von der Rücknahme oder Aussetzung der Genehmigung eines konkreten Projekts unterscheide, da deren Wirkungen dann endeten. Die Generalanwältin sieht in diesem Fall in der vorübergehenden Aufrechterhaltung des Programms keinen Verstoß gegen den Effektivitätsgrundsatz, mahnt aber an, dass dies nicht zu einem unangemessen

1442 GA Kokott, Schlussanträge vom 8.12.2011 in der Rs. C-41/11 (Inter-Environnement Wallonie und Terre wallonne), Rn. $23 \mathrm{f}$.

1443 GA Kokott, Schlussanträge vom 8.12.2011 in der Rs. C-41/11 (Inter-Environnement Wallonie und Terre wallonne), Rn. $27 \mathrm{ff}$. 
langen Zeitraum bis zum Erlass einer verfahrensrechtlich ordnungsgemäßen Nachfolgemaßnahme führen dürfe. ${ }^{1444}$ Vorliegend waren die vor dem Erlass des alten Aktionsprogramms geltenden Vorschriften in der Tat mit der Nitratrichtlinie unvereinbar. ${ }^{1445}$

Da die SUP-Richtlinie zu den Folgen eines Verstoßes gegen die in ihr festgelegten Verfahrensvorschriften schweigt, knüpft der EuGH in seinem Urteil ebenfalls an Art. 4 III EUV an und nimmt die nationalen Gerichte bei gegen die Pläne/Programme gerichteten Klagen (im Rahmen der Verfahrensautonomie und ihrer unionsrechtlichen Grenzen) in die Pflicht, dem Unterbleiben der Umweltverträglichkeitsprüfung abzuhelfen. Diese haben danach Maßnahmen zur Aussetzung oder Aufhebung der Pläne/Programme zu ergreifen, damit deren Durchführung ohne Umweltprüfung verhindert wird. ${ }^{1446}$

Angesichts der Besonderheiten des Ausgangssachverhalts erkennt der EuGH aber die Gefahr an, dass durch die Nichtigerklärung des angefochtenen Erlasses der wallonischen Regierung in einem Verfahren vor den belgischen Gerichten zwar der Verstoß gegen die Verfahrensanforderungen der SUP-Richtlinie beseitigt, zugleich aber ein rechtliches Vakuum hinsichtlich der Umsetzung der Nitratrichtlinie geschaffen würde. Mit dem Umweltschutz als wesentlichem Ziel der Union mit Querschnittscharakter und grundlegender Bedeutung sei ein zwingendes Erfordernis gegeben, das ausnahmsweise zur Anwendung einer nationalen Rechtsvorschrift berechtige, die dem nationalen Gericht gestattet, bestimmte Wirkungen eines für nichtig erklärten nationalen Rechtsakts aufrechtzuerhalten. ${ }^{1447}$

Dazu müssen aber vier vom EuGH näher bestimmte Voraussetzungen erfüllt sein ${ }^{1448}$ : (1) Der alte (angefochtene) Erlass muss die Nitratrichtlinie ordnungsgemäß umsetzen; (2) der neue Erlass darf nicht geeignet sein, die schädlichen Wirkungen der Nichtigerklärung des alten Erlasses „abzu-

1444 GA Kokott, Schlussanträge vom 8.12.2011 in der Rs. C-41/11 (Inter-Environnement Wallonie und Terre wallonne), Rn. $36 \mathrm{ff} ., 42 \mathrm{f}$., 45 .

1445 Dies hatte der Gerichtshof bereits festgestellt, siehe EuGH, Urteil vom 22.9.2005, Rs. C-221/03 (Kommission/Belgien), Tenor Nr. 1.

$1446 \mathrm{EuGH}$, Urteil vom 28.2.2012, Rs. C-41/11 (Inter-Environnement Wallonie und Terre wallonne), Rn. $42 \mathrm{ff} ., 46 \mathrm{f}$.

$1447 \mathrm{EuGH}$, Urteil vom 28.2.2012, Rs. C-41/11 (Inter-Environnement Wallonie und Terre wallonne), Rn. $56 \mathrm{ff}$.

1448 EuGH, Urteil vom 28.2.2012, Rs. C-41/11 (Inter-Environnement Wallonie und Terre wallonne), Rn. $59 \mathrm{ff}$. und Tenor. 
federn"1449; (3) die Nichtigerklärung des alten Erlasses muss hinsichtlich der Umsetzung der Nitratrichtlinie zu einem rechtlichem Vakuum mit größerem Schaden für die Umwelt führen (in diesem Fall also zu einem geringeren Schutz der Gewässer vor Verunreinigung durch Nitrat aus landwirtschaftlichen Quellen); (4) die Aufrechterhaltung der Wirkungen des alten Erlasses darf nur für den zum ordnungsgemäßen Neuerlass zwingend erforderlichen Zeitraum ${ }^{1450}$ erfolgen. ${ }^{1451}$ Damit ist eine Aufrechterhaltung der Wirkungen nicht schon dann gestattet, wenn nach der Nichtigerklärung der betreffenden Vorschriften wieder eine ihnen vorausgehende mit der Richtlinie unvereinbare Regelung gelten würde. Eine Suspendierung von der Pflicht zur ordnungsgemäßen Umsetzung des Unionsrechts kommt nämlich nicht infrage. ${ }^{1452}$

Auch wenn es sowohl in der Rechtssache Winner Wetten als auch in der Rechtssache Inter-Environnement Wallonie und Terre wallonne um eine Verletzung des Unionsrechts geht, unterscheidet sich die Art des in den jeweiligen Verfahren in Rede stehenden Verstoßes in einem wesentlichen Punkt. Geht es im ersten Fall um einen inhaltlichen Verstoß gegen Unionsrecht, behandelt der letztgenannte eine auf unionsrechtswidrige Weise zustande gekommene Vorschrift. Insoweit besteht also kein inhaltlicher Konflikt zwischen nationalem und Unionsrecht. Da der Gerichtshof aber auch hier strenge Voraussetzungen aufstellt, um einem nationalen Gericht eine vorübergehende Aufrechterhaltung bestimmter Wirkungen eines für nichtig erklärten Rechtsakts zu gestatten, ist eine noch restriktivere Vorgehensweise bei inhaltlichen Konflikten zu vermuten. ${ }^{1453}$

1449 Überprüft werden muss also, inwieweit es möglich ist, eine neue Regelung mit Rückwirkung zu erlassen, vgl. van der Hulle, NtEr 2016, 284 (289).

1450 EuGH, Urteil vom 29.7.2019, Rs. C-411/17 (Inter-Environnement Wallonie und Bond Beter Leefmilieu Vlaanderen), Rn. 181 spricht von einem „Zeitraum [...], der absolut notwendig ist, um die Rechtswidrigkeit zu beseitigen“.

1451 Der EuGH hat sich nicht dazu geäußert, wie bei Verstreichen des für den ordnungsgemäßen Neuerlass zwingend erforderlichen Zeitraums zu verfahren ist. Bei einer „unbegrenzten“ Nichtigerklärung des Rechtsakts, der das Aktionsprogramm enthält, bestünde das Problem des Rechtsvakuums jedenfalls noch immer, worauf auch Lock, CMLRev. 50 (2013), 217 (229) hinweist.

1452 Vgl. EuGH, Urteil vom 27.6.2019, Rs. C-597/17 (Belgisch Syndicaat van Chiropraxie u.a.), Rn. $61 \mathrm{f}$.

1453 van der Hulle/van der Hulle, SEW 2012, 490 (499f.). 
b) Die Rechtssache Association France Nature Environnement

In der von der Ersten Kammer des Gerichtshofs entschiedenen Rechtssache Association France Nature Environnement knüpft diese an die vorangegangenen Urteile in den Rechtssachen Winner Wetten und Inter-Environnement Wallonie und Terre wallonne an und versucht, sie zueinander in Beziehung zu setzen. In der Sache ging es letztlich um die Frage, ob ein mitgliedstaatliches Gericht - in diesem Fall der französische Conseil d'État - in einem Normenkontrollverfahren, das gegen ein eine Richtlinie fehlerhaft umsetzendes Ministerialdekret gerichtet ist, dieses mit Wirkung ex tunc aufheben muss oder ob es dessen vorübergehende Fortgeltung bis zu einer Korrektur durch den Gesetzgeber anordnen darf. Im Unterschied zur Rechtssache Inter-Environnement Wallonie und Terre wallonne stand hier angesichts der unzureichenden Autonomie der nach dem französischen Ministerialdekret zu konsultierenden Stellen die fehlerhafte Umsetzung der SUP-Richtlinie selbst in Rede. ${ }^{1454}$

Problematisch war der Verstoß gegen Art. 6 III dieser Richtlinie, da das Dekret entgegen den Vorgaben der Richtlinie nicht sicherstellte, dass die Beratung im Rahmen der Umweltprüfung durch eine autonome Einheit durchgeführt wurde. Angesichts der nach französischem Recht unbefristeten Möglichkeit, die Einrede der Rechtswidrigkeit geltend zu machen, würde eine rückwirkende Nichtigerklärung der die Richtlinie falsch umsetzenden Bestimmungen des Dekrets die Rechtmäßigkeit der Pläne und Programme und der auf diese gestützten Maßnahmen in Frage stellen, da die auf Grundlage des Dekrets erfolgten Konsultationen dann als rechtswidrig gelten würden. Folge könnte ein rechtliches Vakuum zulasten des Umweltschutzes sein. ${ }^{1455}$

Damit galt es herauszuarbeiten, ob ein mitgliedstaatliches Gericht die Wirkung des vorrangig anwendbaren Gebots, eine ausreichende Autonomie der zu konsultierenden Stellen zu gewährleisten, vorübergehend zugunsten einer mitgliedstaatlichen Regelung aussetzen kann, die diese Autonomie nicht vorsieht, obwohl mit dem Vorrang im Grundsatz die Pflicht des nationalen Gerichts verbunden ist, jede Bestimmung des natio-

1454 GA Kokott, Schlussanträge vom 28.4.2016 in der Rs. C-379/15 (Association France Nature Environnement), Rn. 1 f., 4.

1455 Vgl. EuGH, Urteil vom 28.7.2016, Rs. C-379/15 (Association France Nature Environnement), Rn. 28. 
nalen Rechts unangewendet zu lassen, die es zu einer im Widerspruch zum Unionsrecht stehenden Entscheidung veranlassen würde. ${ }^{1456}$

Generalanwältin Kokott unterscheidet in ihren Überlegungen zwischen der Aufrechterhaltung der Wirkungen des Dekrets, die sie ablehnt und der Aufrechterhaltung der Pläne/Programme und der auf diese gestützten Maßnahmen, für die sie die in der Rechtssache Inter-Environnement Wallonie und Terre wallonne entwickelten Kriterien heranzieht.

In der Sache geht es insbesondere um die Aufrechterhaltung der Wirkungen unionsrechtswidriger Bestimmungen für bereits angenommene Pläne und nicht um die Aufrechterhaltung der Bestimmungen für die Zukunft hinsichtlich neuer Pläne. ${ }^{1457}$ Da Art. 6 III der SUP-Richtlinie vom Gerichtshof bereits im Urteil Seaport (NI) u.a. ${ }^{1458}$ ausgelegt worden, eine Begrenzung im Sinne der Defrenne-Rechtsprechung dort aber unterblieben war, schied eine solche Begrenzung nunmehr aus. Ein Ausschluss der Berufung auf Art. 6 III der SUP-Richtlinie gegenüber unter Verstoß gegen diese Bestimmung erlassenen Plänen/Programmen kam also nicht in Betracht, sodass diese Möglichkeit der Aufrechterhaltung der Wirkungen des nationalen Umsetzungsrechts („dergestalt ${ }^{\text {“1459) }}$ zu verneinen war. ${ }^{1460}$

Unter der Überschrift „Zur Aufrechterhaltung der in Anwendung von unionsrechtswidrigen Bestimmungen erlassenen Pläne und Programme“ geht Generalanwältin Kokott dann der Frage nach, ob der Conseil d'État in dem bei ihm anhängigen Verfahren, in dem es um das gegen Art. 6 III der Richtlinie verstoßende Dekret geht, über die Aufrechterhaltung der unter Verstoß gegen die SUP-Richtlinie erlassenen Pläne/Programme entscheiden kann. Angesichts der nur ausnahmsweisen Zulässigkeit eines derartigen Vorgehens nach den im Inter-Environnement Wallonie und Terre wallonne-Urteil niedergelegten Kriterien könne dies, so die Generalanwältin, nicht pauschal beantwortet werden, sondern erfordere eine Würdigung jedes einzelnen Rechtsakts und der Folgen seiner Aufhebung

1456 GA Kokott, Schlussanträge vom 28.4.2016 in der Rs. C-379/15 (Association France Nature Environnement), Rn. $32 \mathrm{f}$.

1457 GA Kokott, Schlussanträge vom 28.4.2016 in der Rs. C-379/15 (Association France Nature Environnement), Rn. 15, $20 \mathrm{f}$.

1458 EuGH, Urteil vom 20.10.2011, Rs. C-474/10 (Seaport (NI) u.a.).

1459 GA Kokott, Schlussanträge vom 28.4.2016 in der Rs. C-379/15 (Association France Nature Environnement), Rn. 38.

1460 GA Kokott, Schlussanträge vom 28.4.2016 in der Rs. C-379/15 (Association France Nature Environnement), Rn. $31 \mathrm{ff}$. 
und damit eine Einzelfallentscheidung. ${ }^{1461}$ Sie erkennt zwar an, dass es über die Umsetzung der Nitratrichtlinie hinaus aus Gründen des Umweltschutzes erforderlich sein könne, unter Verstoß gegen die SUP-Richtlinie erlassene Pläne/Programme aufrechtzuerhalten. Da insoweit aber noch Unsicherheit herrsche, bestehe für Gerichte nach Art. 267 III AEUV eine Vorlagepflicht. ${ }^{1462}$

Der Gerichtshof nimmt in seiner Entscheidung auf sein Urteil in der Rechtssache Winner Wetten Bezug und führt aus, dass nur er ,in Ausnahmefällen und aus zwingenden Erwägungen der Rechtssicherheit eine vorübergehende Aussetzung der Verdrängungswirkung herbeiführen kann“. Nichtsdestotrotz (,jedoch“) habe er in der Rechtssache Inter-Environnement Wallonie und Terre wallonne den nationalen Gerichten im Einzelfall und ausnahmsweise die Befugnis verliehen, die Wirkungen der Nichtigerklärung einer unionsrechtswidrigen nationalen Bestimmung anzupassen. ${ }^{1463}$ Ungeachtet der dort erfolgten Begrenzung dieser Befugnis auf eine ordnungsgemäße Umsetzung der Nitratrichtlinie versteht der Gerichtshof diese Voraussetzung nunmehr aus Gründen des Umweltschutzes erweiternd dahingehend, dass sie jede Maßnahme erfasst, die trotz Verstoßes gegen die SUP-Richtlinie das Umweltschutzrecht der Union ordnungsgemäß umsetzt. ${ }^{1464}$ Damit kann ein nationales Gericht von der ihm zugestandenen Ausnahmebefugnis bei Vorliegen der (modifizierten) vier Kriterien Gebrauch machen, wenn als Grundvoraussetzung für ihre Anwendung ein zwingendes Erfordernis im Zusammenhang mit dem Umweltschutz unter Berücksichtigung der besonderen Umstände der Rechtssache gegeben ist. ${ }^{1465}$

Die Anwendung dieser Voraussetzungen auf das Ausgangsverfahren kann allerdings nicht ganz reibungslos erfolgen. Trotz der erweiterten,

1461 GA Kokott, Schlussanträge vom 28.4.2016 in der Rs. C-379/15 (Association France Nature Environnement), Rn. 39, 45 ff.

1462 GA Kokott, Schlussanträge vom 28.4.2016 in der Rs. C-379/15 (Association France Nature Environnement), Rn. $52 \mathrm{ff}$.

1463 EuGH, Urteil vom 28.7.2016, Rs. C-379/15 (Association France Nature Environnement), Rn. 33 und 34. In Rn. 37 und 44 spricht der Gerichtshof dann von der Befugnis, ausnahmsweise „bestimmte Wirkungen eines mit dem Unionsrecht unvereinbaren nationalen Rechtsakts aufrechtzuerhalten“. In Rn. 43 ist davon die Rede, „bestimmte Wirkungen einer Feststellung der Rechtswidrigkeit einer Bestimmung des nationalen Rechts zeitlich [zu] begrenzen“.

1464 EuGH, Urteil vom 28.7.2016, Rs. C-379/15 (Association France Nature Environnement), Rn. 39.

1465 EuGH, Urteil vom 28.7.2016, Rs. C-379/15 (Association France Nature Environnement), Rn. 43. 
wenngleich auf das Umweltschutzrecht beschränkten Fassung der Voraussetzung ordnungsgemäßer Umsetzung ${ }^{1466}$ bleibt etwa die Frage, wie eine unter Verstoß gegen die umweltrechtliche SUP-Richtlinie getroffene Maßnahme das Unionsrecht im Bereich des Umweltschutzes korrekt umsetzen kann. ${ }^{1467}$ Dass der EuGH an dieser Stelle von einer ordnungsgemäßen Umsetzung spricht, mag damit zusammenhängen, dass er von einem leicht korrigierbaren Verfahrensfehler ausgeht. Dass hier ein solcher in Rede steht, muss allerdings bezweifelt werden, da die von einer unabhängigen Stelle durchgeführte Prüfung wohl anders ausgefallen wäre. ${ }^{1468}$

Das Erfordernis „ordnungsgemäßer“ Umsetzung des Umweltschutzrechts der Union hat seinen Ursprung in der Rechtssache Inter-Environnement Wallonie und Terre wallonne, wo die Nitratrichtlinie inhaltlich ordnungsgemäß umgesetzt worden war. Daraus erklärt sich zwar, weshalb der Gerichtshof auch im vorliegenden Zusammenhang eine ordnungsgemäße Umsetzung des Umweltschutzrechts der Union fordert. Dies ändert aber nichts daran, dass es in der Rechtssache Association France Nature Environnement daran fehlte. ${ }^{1469}$ Nahe gelegt wird dadurch ein Verständnis, wonach es dem Gerichtshof bei der Aufrechterhaltung der Wirkungen von unter Verstoß gegen die SUP-Richtlinie erlassenen Maßnahmen ganz allgemein um die Vermeidung nachteiliger Umweltauswirkungen unabhängig von der Umsetzung des Umweltrechts der Union geht. ${ }^{1470}$

In seiner jüngsten Rechtsprechung hat der Gerichtshof dann allerdings wieder gezeigt, dass es ihm mit der Wahrung der Voraussetzung ordnungsgemäßer Umsetzung durchaus ernst ist. Ist ein nationaler Rechtsakt unter

1466 Vgl. Cassagnabère, Les nouveaux cahiers du Conseil Constitutionnel 2017, 47 (60 f.).

1467 Clément-Wilz, European Papers 2017, 259 (265).

1468 Siehe Coutron, RTDEur. 2017, 400 (405), der Bezüge zur „légalité externe au sens du droit administratif français" erkennt.

1469 Ein Übersetzungsproblem vom Französischen ins Englische ist jedenfalls nicht erkennbar. Dieses vermutet dagegen Sowery, CMLRev. 54 (2017), 1157 (1162, Fn. 18). In der französischen Sprachfassung des Urteils heißt es „toute mesure qui [...] procède à la transposition correcte du droit de l'Union dans le domaine de la protection de l'environnement“, in der englischen "any measure which [...] correctly transposes EU law in the field of environmental protection“, vgl. EuGH, Urteil vom 28.7.2016, Rs. C-379/15 (Association France Nature Environnement), Rn. 39.

1470 GA Kokott, Schlussanträge vom 29.11.2018 in der Rs. C-411/17 (Inter-Environnement Wallonie und Bond Beter Leefmilieu Vlaanderen), Rn. 204 unter Verweis auf EuGH, Urteil vom 28.2.2012, Rs. C-41/11 (Inter-Environnement Wallonie und Terre wallonne), Rn. 57, 58 und EuGH, Urteil vom 28.7.2016, Rs. C-379/15 (Association France Nature Environnement), Rn. 34-36. 
Verstoß gegen die SUP-Richtlinie verfahrensfehlerhaft zustande gekommen, können bestimmte Wirkungen dieses Rechtsakts nur aufrechterhalten werden, wenn der Mitgliedstaat durch die Aufhebung des Rechtsakts gegen seine Pflicht zur Umsetzung eines anderen Unionsrechtsakts zum Schutz der Umwelt verstieße. ${ }^{1471}$ Findet sich solch ein anderer Unionsrechtsakt, ist aber genau zu untersuchen, ob die Aufhebung des nationalen Rechtsakts die Umsetzung des anderen Unionsrechtsakts im betroffenen Mitgliedstaat tatsächlich allgemein gefährdet. Nicht der Fall ist dies etwa, wenn mit dem nationalen Rechtsakt zwar ein Beitrag beispielsweise zur Umsetzung einer Richtlinie betreffend die Stromerzeugung aus erneuerbaren Energiequellen geleistet wird, die Aufhebung der Genehmigung für die Errichtung einer begrenzten Anzahl von Windkraftanlagen aber nur ein geringfügiges Hindernis für die Stromerzeugung aus erneuerbaren Energiequellen darstellt. ${ }^{1472}$

Was die Erfüllung der dritten im Inter-Environnement Wallonie und Terre wallonne-Urteil aufgestellten Voraussetzung anbelangt, so ist in Erinnerung zu rufen, dass sie verlangt, dass die Nichtigerklärung der in Rede stehenden Maßnahmen zu einem größeren Schaden für die Umwelt führt. Da das Hauptziel der SUP-Richtlinie ausweislich ihres Art. 1 darin besteht, bestimmte Pläne und Programme mit voraussichtlich erheblichen Umweltauswirkungen einer Umweltprüfung zu unterziehen, um ein hohes Umweltschutzniveau sicherzustellen, ist genau zu prüfen, ob die Nichtigerklärung dieser Pläne und Programme tatsächlich zu einer für die Umwelt nachteiligeren Situation führt. Der Wegfall der Pläne und Programme ist aufgrund ihrer Auswirkungen für die Umwelt ja eher von Vorteil, falls sie nicht auch Maßnahmen zum Schutz der Umwelt enthalten. Erforderlich ist jedenfalls eine Einzelfallprüfung. ${ }^{1473}$ Ist etwa ein Plan betroffen, der auf bestimmten Flächen Baumaßnahmen untersagt, entstünde bei dessen Nichtigerklärung eine für die Umwelt nachteiligere Situation. Ist ein Plan betroffen, dem ein Vorhaben genügt, dem bei Unabhängigkeit der beratenden Stelle aber strengere Schutzbestimmungen

1471 EuGH, Urteil vom 25.6.2020, Rs. C-24/19 (A u.a. (Windkraftanlagen in Aalter und Nevele)), Rn. 90.

1472 EuGH, Urteil vom 25.6.2020, Rs. C-24/19 (A u.a. (Windkraftanlagen in Aalter und Nevele)), Rn. 91.

1473 van der Hulle, NtEr 2016, 284 (289); siehe auch Sowery, CMLRev. 54 (2017), 1157 (1173 f.). 
beigefügt worden wären, führte die Nichtigerklärung dagegen wohl zu keinem geringeren Schutz für die Umwelt. ${ }^{1474}$

\section{c) Einordnung}

Nicht zuletzt angesichts des Bezugs der beiden hier vorgestellten Entscheidungen zur Richtlinie über die strategische Umweltprüfung ist bei ihrer weiteren Analyse zu bedenken, dass hier noch eine in ihren Anfängen steckende und damit noch nicht voll entfaltete Rechtsprechungslinie in Rede steht. ${ }^{1475}$ Wenngleich in beiden Entscheidungen von der Nichtigerklärung des nationalen Rechts die Rede ist, gelten die dort gemachten Ausführungen auch für den Fall seiner „bloßen“ Nichtanwendung. ${ }^{1476}$ Ebenso gelten sie sowohl bei direkt gegen die unionsrechtswidrigen nationalen Maßnahmen gerichteten Klagen als auch bei indirekten Klagen, in deren Rahmen die Einrede der Rechtswidrigkeit erhoben wird. ${ }^{1477}$

Vor diesem Hintergrund ist im Folgenden der Versuch zu unternehmen, herauszuarbeiten, welche Ziele neben dem Umweltschutz für ein Gebrauchmachen von einer im nationalen Recht vorgesehenen Ausnahmebefugnis zur Aufrechterhaltung bestimmter Wirkungen unionsrechtswidrigen nationalen Rechts in Betracht kommen, wie die Befugnisse zwischen EuGH und mitgliedstaatlichen Gerichten im Hinblick auf eine Suspendierung des Vorrangs verteilt sind und ob sich überhaupt Auswirkungen auf den Vorrang ergeben.

1474 Siehe zu diesen Beispielen GA Kokott, Schlussanträge vom 28.4.2016 in der Rs. C-379/15 (Association France Nature Environnement), Rn. 23 und 24. $\mathrm{Zu}$ einem eine andere Rechtssache betreffenden Beispiel siehe GA Campos Sánchez-Bordona, Schlussanträge vom 3.3.2020 in der Rs.C-24/19 (A u.a. (Windkraftanlagen in Aalter und Nevele)), Rn. 134.

1475 Mamoudy, AJDA 2016, 2229 (2232) spricht von einem „régime encore embryonnaire".

1476 Dougan, CMLRev. 56 (2019), 1459 (1497, Fn. 140); ebenso GA Campos SánchezBordona, Schlussanträge vom 15.1.2020 in der Rs. C-520/18 (Ordre des barreaux francophones und germanophone u.a.), Rn. 152.

1477 GA Campos Sánchez-Bordona, Schlussanträge vom 3.3.2020 in der Rs. C-24/19 (A u.a. (Windkraftanlagen in Aalter und Nevele)), Rn. $123 \mathrm{ff} . ;$ ihm folgend EuGH, Urteil vom 25.6.2020, Rs. C-24/19 (A u.a. (Windkraftanlagen in Aalter und Nevele)), Rn. 85. 
aa) Taugliche Ziele

Schwierig zu bestimmen ist bereits, was ein Ziel zu „eine[m] der wesentlichen Ziele der Union"1478 macht, mit dessen Betroffenheit der Gerichtshof die Anwendung der nationalen Verfahrensvorschriften über die Aufrechterhaltung bestimmter Wirkungen eines für nichtig erklärten nationalen Rechtsakts gestattete. ${ }^{1479}$

Nicht überzeugend wäre es jedenfalls, von einer - in den Verträgen auch nicht eindeutig angelegten - herausgehobenen Stellung des Umweltschutzes auszugehen. Der EuGH argumentiert in den beiden dargestellten Verfahren zwar mit dem Umweltschutz, nicht aber mit Art. 11 AEUV, wonach die Erfordernisse des Umweltschutzes bei der Festlegung und Durchführung der Unionspolitiken und -maßnahmen insbesondere zur Förderung einer nachhaltigen Entwicklung einbezogen werden müssen. ${ }^{1480}$

In Betracht zu ziehen ist zunächst, unter das „wesentliche Ziel der Union" alle primärrechtlichen Rechtsgrundlagen $\mathrm{zu}$ fassen, in denen sich Ziele der EU widerspiegeln, die mit dem Vorrang in Einklang zu bringen sind. ${ }^{1481} \mathrm{Zu}$ denken ist dann - insbesondere auch angesichts der Erwähnung von Art. 3 III EUV durch den Gerichtshof im Association France Nature Environnement-Urteil ${ }^{1482}$ - in erster Linie an Art. 3 EUV. Diesen macht in der Tat Generalanwalt Campos Sánchez-Bordona fruchtbar, wenn er zwingende Gründe im Zusammenhang mit dem Schutz der nationalen Sicherheit als geeignet ansieht, eine Aufrechterhaltung der Wirkungen eines unionsrechtswidrigen nationalen Rechtsakts zu rechtfertigen, da das Ziel der Schaffung eines Raums der Sicherheit im Sinne von Art. 3 EUV auch die Achtung der in Art. 4 II EUV aufgeführten Aspekte bedeute. ${ }^{1483}$ Unter einem „wesentlichen Ziel der Union“ tatsächlich alle in

1478 EuGH, Urteil vom 28.2.2012, Rs. C-41/11 (Inter-Environnement Wallonie und Terre wallonne), Rn. 57.

1479 Siehe auch Sowery, CMLRev. 54 (2017), 1157 (1174 ff.) zu verschiedenen Deutungsmöglichkeiten, welche Interessen zu einem vorübergehenden Zurücktreten unionsrechtlicher Verpflichtungen führen können. Rein finanzielle Sorgen der Mitgliedstaaten sind unzureichend, vgl. Lock, CMLRev. 50 (2013), 217 (226 ff.).

1480 Art. 11 AEUV findet Erwähnung bei Lock, CMLRev. 50 (2013), 217 (227).

1481 Cassagnabère, Les nouveaux cahiers du Conseil Constitutionnel 2017, 47 (62).

1482 EuGH, Urteil vom 28.7.2016, Rs. C-379/15 (Association France Nature Environnement), Rn. 35.

1483 GA Campos Sánchez-Bordona, Schlussanträge vom 15.1.2020 in der Rs. C-520/18 (Ordre des barreaux francophones und germanophone u.a.), Rn. $148 \mathrm{ff}$. 
Art. 3 EUV genannten Ziele zu verstehen, ließe allerdings eine inflationäre Handhabung befürchten.

$\mathrm{Zu}$ erwägen ist daher, eine Vergleichbarkeit mit dem vom Gerichtshof ebenfalls angesprochenen Art. 191 AEUV zu fordern und damit auf das Bestehen einer Unionskompetenz abzustellen. ${ }^{1484}$ Auf diese Weise könnte etwa angesichts von Art. 169 AEUV der Verbraucherschutz Eingang in den Kreis der wesentlichen Ziele finden. Ein solcher Ansatz bedeutete allerdings, andere in Art. 3 EUV genannte Ziele zwar als wichtig, aber eben nicht als wesentlich im Sinne der Inter-Environnement Wallonie und Terre wallonne-Rechtsprechung einzustufen.

Nahe liegt es daher, die in den beiden vorgestellten Verfahren vom Gerichtshof angestellten Überlegungen dahingehend zusammenzufassen, dass es entscheidend darauf ankommt, einen noch unionsrechtsferneren Zustand $^{1485}$ und damit ein rechtliches Vakuum im Hinblick auf die Umsetzung von Unionsrecht zu vermeiden. ${ }^{1486}$ Eine Aktivierung dieser Rechtsprechungslinie müsste demnach immer dann erfolgen, wenn innerstaatlicher Rechtsschutz gegen eine unzureichende Umsetzung des Unionsrechts dazu führen würde, die Umsetzung zusätzlich zu verschlechtern. ${ }^{1487}$

In seiner jüngsten Rechtsprechung hat der Gerichtshof eine vorsichtige Weitung vorgenommen. $\mathrm{Zu}$ erwähnen ist in diesem Zusammenhang zunächst die Rechtssache Inter-Environnement Wallonie und Bond Beter Leefmilieu Vlaanderen, in der die Aufrechterhaltung der Wirkungen von Maßnahmen für die Zeit der Beseitigung ihrer Rechtswidrigkeit

1484 Siehe dazu die Erwähnung von Art.191 I und II AEUV in EuGH, Urteil vom 28.7.2016, Rs. C-379/15 (Association France Nature Environnement), Rn. 35.

1485 Ehlers/Eggert, JZ 2008, 585 (589); Rosenkranz, Beschränkung der Rückwirkung, 2015, S. 472 f.; siehe auch Koenig/Schreiber, DÖV 2008, 450 (452).

1486 Sowery, CMLRev. 54 (2017), 1157 (1176). Siehe auch GA Kokott, Schlussanträge vom 29.11.2018 in der Rs. C-411/17 (Inter-Environnement Wallonie und Bond Beter Leefmilieu Vlaanderen), Rn. 207 ff. zu verfahrensfehlerhaften Einzelfallentscheidungen, bei deren Aufhebung oder Aussetzung grundsätzlich kein rechtliches Vakuum entsteht.

1487 GA Kokott, Schlussanträge vom 12.4.2018 in der Rs. C-561/16 (Saras Energía), Rn. 21 unter Verweis auf EuGH, Urteil vom 28.2.2012, Rs. C-41/11 (Inter-Environnement Wallonie und Terre wallonne), Rn. 56-58 und EuGH, Urteil vom 28.7.2016, Rs. C-379/15 (Association France Nature Environnement), Rn. 3436. 
im Hinblick auf die UVP-Richtlinie ${ }^{1488}$ und die Habitatrichtlinie ${ }^{1489}$ in Rede stand. Ausgangspunkt war die Annahme eines Gesetzes zur Verlängerung des Zeitraums der industriellen Stromerzeugung von belgischen Kernkraftwerken. Beide Richtlinien äußern sich nicht zu den Folgen eines Verstoßes gegen die in ihnen aufgestellten Pflichten, weswegen der Gerichtshof die aus der Rechtssache Inter-Environnement Wallonie und Terre wallonne bekannte Anknüpfung an Art. 4 III EUV, die auch die nationalen Gerichte trifft, wieder aufgreift. ${ }^{1490}$

Neben dem Hinweis darauf, dass das Unionsrecht in bestimmten Fällen die in nationalen Vorschriften zugelassene Legalisierung unionsrechtswidriger Vorgänge oder Handlungen gestattet, wobei allerdings bestimmte Anforderungen zu wahren sind ${ }^{1491}$, bezieht er sich auf seine Winner Wetten-Rechtsprechung. Danach kommt die Aufrechterhaltung der Wirkungen der in Rede stehenden Maßnahmen im vorliegenden Fall grundsätzlich aus zwingenden Erwägungen, die mit der Stromversorgungssicherheit des betreffenden Mitgliedstaats zusammenhängen, in Betracht. Dies setzt aber voraus, dass bei einer Aufhebung oder Aussetzung der Wirkungen der nationalen Maßnahmen die „tatsächliche und schwerwiegende Gefahr einer Unterbrechung der Stromversorgung“ des Mitgliedstaats bestünde. Zudem dürfen keine anderen Mittel und Alternativen, insbesondere im Rahmen des Binnenmarkts, zur Verfügung stehen, die dieser Gefahr entge-

1488 Richtlinie 2011/92/EU des Europäischen Parlaments und des Rates vom 13. Dezember 2011 über die Umweltverträglichkeitsprüfung bei bestimmten öffentlichen und privaten Projekten, ABl. L 26 vom 28.1.2012, S. 1 (UVPRichtlinie).

1489 Richtlinie 92/43/EWG des Rates vom 21. Mai 1992 zur Erhaltung der natürlichen Lebensräume sowie der wildlebenden Tiere und Pflanzen, ABl. L 206 vom 22.7.1992, S. 7 in der durch die Richtlinie 2013/17/EU des Rates vom 13. Mai 2013 zur Anpassung bestimmter Richtlinien im Bereich Umwelt aufgrund des Beitritts der Republik Kroatien (ABl. L 158 vom 10.6.2013, S. 193) geänderten Fassung (Habitatrichtlinie).

$1490 \mathrm{EuGH}$, Urteil vom 29.7.2019, Rs. C-411/17 (Inter-Environnement Wallonie und Bond Beter Leefmilieu Vlaanderen), Rn. $167 \mathrm{ff}$. Die mitgliedstaatlichen Gerichte müssen demnach Maßnahmen zur Aussetzung oder Aufhebung einer unter Verstoß gegen die Pflicht zur Durchführung einer Umweltprüfung erteilten Genehmigung ergreifen.

$1491 \mathrm{EuGH}$, Urteil vom 29.7.2019, Rs. C-411/17 (Inter-Environnement Wallonie und Bond Beter Leefmilieu Vlaanderen), Rn. $173 \mathrm{ff}$. unter Verweis auf EuGH, Urteil vom 26.7.2017, verb. Rs. C-196/16 und C-197/16 (Comune di Corridonia u.a.), Rn. 37 f., 43 und EuGH, Urteil vom 28.2.2018, Rs. C-117/17 (Comune di Castelbellino), Rn. 30. 
genwirken können. ${ }^{1492}$ Erforderlich sind also signifikante Auswirkungen auf die Stromversorgung des gesamten Mitgliedstaats, an denen es etwa bei der Einstellung des Betriebs einer begrenzten Anzahl an Windkraftanlagen in aller Regel fehlen wird. ${ }^{1493}$

Dass auf einen Mitgliedstaat bezogene Erwägungen für eine Suspendierung des Anwendungsvorrangs nicht ausreichen, kann in dieser Pauschalität also nicht behauptet werden. ${ }^{1494}$ Ein betroffenes Unionsinteresse kann vielmehr auch mit Blick auf einen Mitgliedstaat bestimmt werden. So hat etwa die Union auch ein Interesse an der Stromversorgungssicherheit ihrer Mitgliedstaaten. Ausweislich Art. 194 I lit. b AEUV ist die Gewährleistung der Energieversorgungssicherheit in der Europäischen Union nämlich eines der grundlegenden Ziele der Unionspolitik im Energiebereich. ${ }^{1495}$

In seiner Rechtsprechung hat der Gerichtshof demnach mit der Stromversorgungssicherheit eines Mitgliedstaats neben dem Umweltschutz einen weiteren zwingenden Grund des Allgemeininteresses anerkannt, der ein Gebrauchmachen von der im nationalen Recht vorgesehenen Ausnahmebefugnis zur Aufrechterhaltung bestimmter Wirkungen des nationalen Rechts rechtfertigt. ${ }^{1496}$

In der Rechtssache Belgisch Syndicaat van Chiropraxie u.a. schließlich deutet der Gerichtshof das seiner hier in Rede stehenden Rechtsprechungslinie zugrundeliegende Potential an, indem er die im Inter-Environnement Wallonie und Terre wallonne- bzw. Association France Nature Environnement-Urteil vorgesehene Begrenzung auf die ordnungsgemäße Umsetzung der Nitratrichtlinie bzw. des Umweltschutzrechts der Union nicht wiederholt, sondern das Erfordernis der ordnungsgemäßen Umsetzung - im Zusammenhang mit einem Verstoß gegen die Mehrwertsteuerrichtlinie - auf die Umsetzung einer unionsrechtlichen Pflicht bezieht. ${ }^{1497}$

1492 EuGH, Urteil vom 29.7.2019, Rs. C-411/17 (Inter-Environnement Wallonie und Bond Beter Leefmilieu Vlaanderen), Rn. $177 \mathrm{ff}$.

1493 EuGH, Urteil vom 25.6.2020, Rs. C-24/19 (A u.a. (Windkraftanlagen in Aalter und Nevele)), Rn. 93 und 95.

1494 So aber Sowery, CMLRev. 54 (2017), 1157 (1175, Fn. 60).

$1495 \mathrm{EuGH}$, Urteil vom 29.7.2019, Rs. C-411/17 (Inter-Environnement Wallonie und Bond Beter Leefmilieu Vlaanderen), Rn. 156.

1496 Vgl. EuGH, Urteil vom 19.12.2019, Rs. C-236/18 (GRDF), Rn. 43; GA Campos Sánchez-Bordona, Schlussanträge vom 3.3.2020 in der Rs. C-24/19 (A u.a. (Windkraftanlagen in Aalter und Nevele)), Rn. 131.

1497 EuGH, Urteil vom 27.6.2019, Rs. C-597/17 (Belgisch Syndicaat van Chiropraxie u.a.), Rn. 61 unter Verweis auf EuGH, Urteil vom 28.2.2012, Rs. C-41/11 (Inter-Environnement Wallonie und Terre wallonne), Rn. 63 und EuGH, Ur- 
Im konkreten Fall scheiterte die Befugnis zur Anwendung der nationalen Vorschrift zur Aufrechterhaltung bestimmter Wirkungen des nationalen Rechts zwar daran, dass die angefochtenen Vorschriften keine Maßnahme zur ordnungsgemäßen Umsetzung darstellten. ${ }^{1498}$ Dennoch hat der Gerichtshof damit den Grundstein gelegt für eine Ausdehnung auf eine Vielzahl von Vorschriften des Unionsrechts und auf andere öffentliche Interessen jenseits des Umweltschutzes und der Stromversorgungssicherheit eines Mitgliedstaates. Vor dem Hintergrund, dass der EuGH seine Überlegungen im Winner Wetten-Urteil im Rechtsgedanken des Art.264 II AEUV verankert und ganz allgemein auf den Grundsatz der Rechtssicherheit Bezug genommen hat, vermag dies nicht zu überraschen. Generalanwalt Jääskinen etwa war bereits im Anschluss an das Inter-Environnement Wallonie und Terre wallonne-Urteil dem Vorbringen der französischen Regierung in der Rechtssache Octapharma France, die eine Gefährdung der öffentlichen Gesundheit, insbesondere der Patientensicherheit, geltend gemacht hatte, nicht mit grundsätzlichen Bedenken begegnet. Vielmehr begründete er seine Ablehnung einer Übertragung der im Inter-Environnement Wallonie und Terre wallonne-Urteil vorgesehenen Möglichkeit insbesondere mit einem nur entfernten Bezug des Ansinnens der französischen Regierung zu der dem EuGH vorgelegten Frage, für dessen Beurteilung der Gerichtshof nicht über hinreichende Angaben verfüge. ${ }^{1499}$

Denkbar ist eine Suspendierung des Vorrangs demnach beim Vorliegen von „spezifische[n] Risiken der Rechtsunsicherheit" 1500 , worüber das unionsrechtliche Konzept der Rechtssicherheit in seiner Auslegung durch den EuGH entscheidet. ${ }^{1501}$ Da der Grundsatz der Rechtssicherheit in der Lage ist, sehr unterschiedliche Interessen in sich aufzunehmen, ist im Rahmen der Bewertung der betroffenen Interessen darauf $\mathrm{zu}$ achten, eine Abstu-

teil vom 28.7.2016, Rs. C-379/15 (Association France Nature Environnement), Rn. 43.

1498 EuGH, Urteil vom 27.6.2019, Rs. C-597/17 (Belgisch Syndicaat van Chiropraxie u.a.), Rn. 62.

1499 Vgl. GA Jääskinen, Schlussanträge vom 7.11.2013 in der Rs. C-512/12 (Octapharma France), Rn. $34 \mathrm{ff}$. Der Gerichtshof ging in seinem Urteil auf diese Erwägung dann auch nicht ein, EuGH, Urteil vom 13.3.2014, Rs. C-512/12 (Octapharma France).

1500 EuGH, Urteil vom 27.6.2019, Rs. C-597/17 (Belgisch Syndicaat van Chiropraxie u.a.), Rn. 59; EuGH, Urteil vom 19.12.2019, Rs. C-236/18 (GRDF), Rn. 44.

1501 Beukers, CMLRev. 48 (2011), 1985 (1998, 2000); ihm zustimmend Verstraelen, GLJ 14 (2013), 1687 (1722). 
fung nach ihrem jeweiligen Gewicht vorzunehmen. ${ }^{1502}$ Über das Gewicht und den Inhalt der kollidierenden Unionsinteressen kann nur der EuGH bestimmen. ${ }^{1503}$

\section{bb) Bestehen einer Vorlagepflicht}

Möchte ein nationales Gericht den Anwendungsvorrang vorübergehend suspendieren, stellt sich die Frage, ob dies nur nach Gestattung durch den Gerichtshof oder auch ohne vorheriges Vorabentscheidungsersuchen möglich ist. Die vom Gerichtshof in seiner Rechtsprechung getroffenen Aussagen ergeben kein ganz klares Bild. Erkennen lässt sich aber jedenfalls, dass der Gerichtshof eine Kombination aus einer Zuständigkeit des Gerichtshofs selbst und einer den mitgliedstaatlichen Gerichten zustehenden Kompetenz im Sinn hat. ${ }^{1504}$

Zunächst ist festzuhalten, dass der EuGH in seinem Winner Wetten-Urteil erläutert hat, dass die Voraussetzungen einer vorübergehenden Aussetzung der Verdrängungswirkung nur von ihm selbst bestimmt werden können. ${ }^{1505}$ Demnach behält sich der EuGH dieses „Privileg“ ausschließlich vor. ${ }^{1506}$

Die im Winner Wetten-Urteil getroffene Aussage legt zunächst die Überlegung nahe, dass der EuGH den nationalen Gerichten die Befugnis zur selbständigen Entscheidung über die Aussetzung der Verdrängungswirkung gerade nicht übertragen möchte, sodass diese ihn stets im Wege des Vorabentscheidungsverfahrens anrufen müssten, so wie dies von der Foto-Frost-Rechtsprechung 1507 her bekannt ist, wenn die Gültigkeit von Sekundärrecht in Rede steht. Nicht von vornherein ausgeschlossen er-

1502 Vgl. GA Kokott, Schlussanträge vom 29.11.2018 in der Rs. C-411/17 (Inter-Environnement Wallonie und Bond Beter Leefmilieu Vlaanderen), Rn. 196 und Rn. 219. Sie stellt dort öffentliche Sicherheit und wirtschaftliche Interessen gegenüber. $\mathrm{Zu}$ letztgenanntem Aspekt siehe EuGH, Urteil vom 28.2.2012, Rs. C-41/11 (Inter-Environnement Wallonie und Terre wallonne), Rn. 57.

1503 Sowery, CMLRev. 54 (2017), 1157 (1170).

1504 So zu Recht Dougan, CMLRev. 56 (2019), 1459 (1491).

1505 EuGH, Urteil vom 8.9.2010, Rs. C-409/06 (Winner Wetten), Rn. 67. In diesem Sinne auch EuGH, Urteil vom 29.7.2019, Rs. C-411/17 (Inter-Environnement Wallonie und Bond Beter Leefmilieu Vlaanderen), Rn. 179.

1506 GA Campos Sánchez-Bordona, Schlussanträge vom 3.3.2020 in der Rs. C-24/19 (A u.a. (Windkraftanlagen in Aalter und Nevele)), Rn. 119.

1507 EuGH, Urteil vom 22.10.1987, Rs. 314/85 (Foto-Frost), Rn. $11 \mathrm{ff}$, insb. Rn. $15 \mathrm{ff}$. 
scheint aber auch die Erwägung, dass es einer solchen Anrufung des EuGH nicht in jedem Fall bedarf, wenn die Befugnis der nationalen Gerichte durch die Aufstellung bestimmter Kriterien durch den EuGH begrenzt ist. ${ }^{1508}$ Während demnach eine vorläufige Weiteranwendung des nationalen Rechts jedenfalls nur bei einem Einverständnis des EuGH möglich ist, ist es denkbar, dass dieser einen allgemeinen Rahmen vorgibt, der den nationalen Gerichten eine eigenständige Beurteilung erlaubt. ${ }^{1509}$ Für den Gerichtshof hätte dies den Vorteil, dass er nicht über jeden Einzelfall entscheiden müsste. Zugleich stünde aber die unterschiedliche Ausfüllung des vorgegebenen Rahmens zu befürchten. ${ }^{1510}$

Vor diesem Hintergrund ist der Versuch einer Einordnung der Ausführungen des Gerichtshofs in der Rechtssache Association France Nature Environnement zu unternehmen. Dort hatte der Gerichtshof aus seinen Ausführungen im Winner Wetten-Urteil zunächst die Folgerung gezogen, dass nur er in Ausnahmefällen und aus zwingenden Erwägungen der Rechtssicherheit eine vorübergehende Aussetzung der Verdrängungswirkung herbeiführen kann, was er damit begründet, dass eine Befugnis nationaler Gerichte, nationalen Bestimmungen auch nur vorübergehend Vorrang vor Unionsrecht einzuräumen, die einheitliche Anwendung des Unionsrechts beeinträchtigen würde. ${ }^{1511}$ Wenig überraschend bestätigt der EuGH damit seine eigene Befugnis zur Suspendierung des Vorrangs. ${ }^{1512}$

Abzugrenzen und in Beziehung zu setzen ist sie von der den mitgliedstaatlichen Gerichten zugewiesenen Zuständigkeit, zu der sich der Gerichtshof im Association France Nature Environnement-Urteil ebenfalls äußert. Erforderlich war dies, da aus dem Urteil in der Rechtssache InterEnvironnement Wallonie und Terre wallonne nicht klar hervorgegangen

1508 Siehe zu diesen Möglichkeiten auch Aubert/Broussy/Donnat, AJDA 2010, 2305 (2306f.), die im Falle der letztgenannten Möglichkeit ein Eilverfahren vor dem Gerichtshof anmahnen. Für eine Vorlagepflicht nicht-letztinstanzlicher Gerichte sprechen sich etwa Ehlers/Eggert, JZ 2008, 585 (591) aus.

1509 van der Hullelvan der Hulle, SEW 2012, 490 (501); siehe auch Rosenkranz, Beschränkung der Rückwirkung, 2015, S. 477 f.

1510 Verstraelen, GLJ 14 (2013), 1687 (1724). Sie verweist zu Recht darauf, dass es den mitgliedstaatlichen Gerichten dann nach ihrem nationalen Recht gestattet sein muss, bestimmte Wirkungen des nationalen Rechts aufrechtzuerhalten.

1511 EuGH, Urteil vom 28.7.2016, Rs. C-379/15 (Association France Nature Environnement), Rn. 33. Ebenso EuGH, Urteil vom 29.7.2019, Rs. C-411/17 (InterEnvironnement Wallonie und Bond Beter Leefmilieu Vlaanderen), Rn. 177; EuGH, Urteil vom 25.6.2020, Rs. C-24/19 (A u.a. (Windkraftanlagen in Aalter und Nevele)), Rn. 84.

1512 Dougan, CMLRev. 56 (2019), 1459 (1492). 
war, ob die dort erteilte Ermächtigung zum Gebrauchmachen von der nationalen Verfahrensvorschrift über die Aufrechterhaltung von Wirkungen eines für nichtig erklärten Rechtsakts jeweils im Einzelfall erteilt werden musste.

Im Association France Nature Environnement-Urteil geht der EuGH davon aus, dass ein nationales Gericht von seiner ihm vom EuGH zugesprochenen Befugnis zur Aufrechterhaltung von Wirkungen eines unionsrechtswidrigen nationalen Rechtsakts nur im Einzelfall und nicht abstrakt oder allgemein Gebrauch machen darf, wobei die im Inter-Environnement Wallonie und Terre wallonne-Urteil aufgestellten Voraussetzungen erfüllt sein müssen. ${ }^{1513}$ Während nicht-letztinstanzliche Gerichte den EuGH nach Art. 267 II AEUV anrufen können, statuiert der Gerichtshof für letztinstanzliche Gerichte im Sinne des Art. 267 III AEUV beim geringsten Zweifel hinsichtlich der richtigen Auslegung oder Anwendung des Unionsrechts eine Vorlagepflicht. Er überträgt damit seine CILFIT-Rechtsprechung ${ }^{1514}$ auf diese Fallgestaltung. ${ }^{1515}$ Hinsichtlich der Ausübung der Ausnahmebefugnis darf demnach kein vernünftiger Zweifel bestehen, was substantiiert nachzuweisen ist, damit das letztinstanzliche Gericht von einer Vorlage absehen kann. ${ }^{1516}$ Damit entscheidet „beim gegenwärtigen Stand des Unionsrechts“ grundsätzlich der EuGH über die Zulässigkeit der Aufrechterhaltung unionsrechtswidrigen nationalen Rechts aus Umweltschutzgründen, das letztinstanzliche nationale Gericht dagegen nur, wenn „kein vernünftiger Zweifel“ hinsichtlich der im Inter-Environnement Wallonie und Terre wallonne-Urteil aufgestellten Voraussetzungen besteht. ${ }^{1517}$

Die vom EuGH betonte Vorlageverpflichtung hält sich damit im Rahmen der in Art. 267 AEUV aufgestellten Anforderungen, wonach nur letztinstanzliche Gerichte im Sinne des Art. 267 III AEUV vorlageverpflichtet sind. Haben diese keine Zweifel hinsichtlich der unionsrechtlichen Vorgaben, was angesichts der vom EuGH aufgestellten Voraussetzungen

1513 EuGH, Urteil vom 28.7.2016, Rs. C-379/15 (Association France Nature Environnement), Rn. $40 \mathrm{f}$.

1514 EuGH, Urteil vom 6.10.1982, Rs. 283/81 (CILFIT u.a.), Rn. 21.

1515 EuGH, Urteil vom 28.7.2016, Rs. C-379/15 (Association France Nature Environnement), Rn. 45 f., 47 ff., 51.

1516 EuGH, Urteil vom 28.7.2016, Rs. C-379/15 (Association France Nature Environnement), Rn. 52.

1517 EuGH, Urteil vom 28.7.2016, Rs. C-379/15 (Association France Nature Environnement), Rn. 53. 
aber nicht sehr wahrscheinlich scheint ${ }^{1518}$, können sie ohne Einholung der Zustimmung des EuGH von ihrer Ausnahmebefugnis Gebrauch machen.

Hinsichtlich der nicht-letztinstanzlichen Gerichte drängt sich durch die Bezugnahme des EuGH in seinem Association France Nature Environnement-Urteil auf die CILFIT-Rechtsprechung, in der festgelegt ist, in welchen Situationen letztinstanzliche Gerichte den EuGH nicht anrufen müssen, der Umkehrschluss auf, dass nicht-letztinstanzliche Gerichte den EuGH nicht vorher anrufen müssen, um von der im Inter-Environnement Wallonie und Terre wallonne-Urteil vorgesehenen Befugnis Gebrauch zu machen. ${ }^{1519}$

Festzuhalten bleibt damit, dass der EuGH keine Übertragung seiner Foto-Frost-Rechtsprechung vorgenommen hat. Mit der Dichte seiner Vorgaben erreicht er allerdings ein ähnliches Ergebnis. Durch die Aufstellung von Bedingungen, die an gesetzliche Vorgaben erinnern, möchte er miteinander unvereinbaren mitgliedstaatlichen Gerichtsentscheidungen vorbeugen $^{1520}$ und so der Gefahr für die einheitliche Anwendung des Unionsrechts begegnen. ${ }^{1521}$

Dass das nationale Gericht, sollte es die vier im Inter-Environnement Wallonie und Terre wallonne-Urteil aufgestellten Bedingungen beachten, den Gerichtshof nicht anrufen muss, um die Wirkungen des unionsrechtswidrigen nationalen Rechts vorübergehend aufrechtzuerhalten, zeigt sich auch an der Gegenüberstellung des Winner Wetten- und Inter-Environnement Wallonie und Terre wallonne-Urteils im Association France Nature Environnement-Urteil. In Rn. 33 jenes Urteils ist nämlich von Rn. 66 und 67 des Winner Wetten-Urteils die Rede, in denen der Gerichtshof seine ausschließliche Zuständigkeit für eine Herbeiführung der Aussetzung der Verdrängungswirkung betont, um dann in Rn. 34 mit Blick auf Rn. 58 des Inter-Environnement Wallonie und Terre wallonne-Urteils einen Gegensatz aufzubauen („,cela étant“/,nevertheless“/,jedoch“), wonach ein nationales Gericht bei Vorliegen bestimmter Voraussetzungen zur Anwendung einer nationalen Verfahrensvorschrift berechtigt sei, um bestimmte Wirkungen nationalen Rechts aufrechtzuerhalten. ${ }^{1522}$

1518 Mamoudy, AJDA 2016, 2229 (2231 f.).

1519 Cassagnabère, Les nouveaux cahiers du Conseil Constitutionnel 2017, 47 (61 f.).

1520 Sowery, CMLRev. 54 (2017), 1157 (1168ff.; siehe auch Fn. 43).

1521 Die Bedrohung der einheitlichen Anwendung des Unionsrechts betont Gentile, European Papers 2017, 321 (327).

1522 EuGH, Urteil vom 28.7.2016, Rs. C-379/15 (Association France Nature Environnement), Rn. 33 und 34. Ebenso EuGH, Urteil vom 29.7.2019, Rs. C-411/17 
In seinem Association France Nature Environnement-Urteil erkennt der EuGH also auch eine eigene Zuständigkeit mitgliedstaatlicher Gerichte im Hinblick auf die Suspendierung des Vorrangs an. ${ }^{1523}$ Gleichsam als Ausgleich für die Nichtübertragung der Foto-Frost-Rechtsprechung erscheinen die vom Gerichtshof getroffenen Vorkehrungen, um die Reichweite der mitgliedstaatlichen Zuständigkeit zu begrenzen. So ist den nationalen Gerichten lediglich eine „Anpassung“1524 der Wirkungen der Nichtigerklärung gestattet und nicht etwa eine Missachtung des Vorrangs. Zudem legt der EuGH die Bedingungen der Ausübung der Kompetenz der mitgliedstaatlichen Gerichte fest, deren Befugnis zur Aufrechterhaltung bestimmter Wirkungen des nationalen Rechts im Übrigen aus diesem nationalen Recht erwachsen muss, also nicht im Unionsrecht wurzelt. ${ }^{1525}$

Hinzu kommt, dass der EuGH die vom Conseil d'État gewählte Reihenfolge der Vorlagefragen bei der Beantwortung umgekehrt hat. Zunächst war er nach dem Bestehen einer Vorlagepflicht in allen Fällen für nationale Gerichte und erst dann nach der Befugnis zur Aufrechterhaltung der Wirkungen des in Rede stehenden unionsrechtswidrigen nationalen Rechts gefragt worden. Aus der Sicht des Conseil d'État stand dahinter die Überlegung, dass der EuGH den nationalen Gerichten nur beim Bestehen einer Vorlagepflicht Hinweise im Einzelfall erteilen kann. ${ }^{1526}$

Durch die Umkehrung der Vorlagefragen lässt der EuGH Vorbehalte gegenüber einer Zuweisung der Beurteilung an nationale Gerichte erkennen. Er macht auf diese Weise deutlich, dass die zentrale Frage für ihn diejenige nach den Befugnissen der mitgliedstaatlichen Gerichte ist. ${ }^{1527}$ Während sich der Conseil d'État auf alle nationalen Gerichte bezogen hatte, beschränkt sich der EuGH auf die für letztinstanzliche Gerichte bestehende Verpflichtung nach Art. 267 III AEUV. Dies entspricht der Natur des Vorabentscheidungsverfahrens, das dem vorlegenden Gericht Hilfestel-

(Inter-Environnement Wallonie und Bond Beter Leefmilieu Vlaanderen), Rn. 177 und 178.

1523 GA Hogan, Schlussanträge vom 11.9.2019 in den verb. Rs. C-13/18 und C-126/18 (Sole-Mizo u.a.), Rn. 41 meint, unter ganz außergewöhnlichen Umständen sei es denkbar, dass es nicht dem EuGH vorbehalten sei, die Wirkung des Unionsrechts zu begrenzen oder aufzuschieben.

1524 Vgl. EuGH, Urteil vom 28.7.2016, Rs. C-379/15 (Association France Nature Environnement), Rn. 34 .

1525 Siehe zu diesen Beobachtungen auch Dougan, CMLRev. 56 (2019), 1459 (1496f.).

1526 Vgl. Clément-Wilz, European Papers 2017, 259 (260).

1527 Clément-Wilz, European Papers 2017, 259 (260 f.). 
lung bei der Beurteilung der sich in dem ihm vorliegenden Rechtsstreit stellenden Fragen leisten soll. ${ }^{1528}$

Den mitgliedstaatlichen Gerichten steht also eine Befugnis zu, die weniger weit als diejenige des EuGH reicht. In welchem Verhältnis diese Zuständigkeiten zueinander stehen, legt der Gerichtshof im Association France Nature Environnement-Urteil aber nicht klar offen. Nach seinen Aussagen erscheint jedenfalls sowohl eine Zuständigkeit nationaler Gerichte, die parallel zu derjenigen des EuGH besteht, als auch eine solche, die vom EuGH auf diese delegiert ist, denkbar. ${ }^{1529}$

Seine im Association France Nature Environnement-Urteil getroffene Aussage hat der Gerichtshof in der Folgezeit im Urteil in der Rechtssache Inter-Environnement Wallonie und Bond Beter Leefmilieu Vlaanderen dahingehend präzisiert, dass die Befugnis des nationalen Gerichts zur Anpassung der Wirkungen der Nichtigerklärung nur „unter Berücksichtigung der von der Rechtsprechung des Gerichtshofs aufgestellten Voraussetzungen“ ausgeübt werden kann und dass nur er allein nach der Winner Wetten-Rechtsprechung befugt ist, die Voraussetzungen einer Aufrechterhaltung der Wirkungen nationaler Maßnahmen festzulegen. ${ }^{1530}$ Die Ausübung der Zuständigkeit eines nationalen Gerichts hängt damit im Ergebnis von der vorherigen Genehmigung durch den EuGH ab; in der Rechtssache Inter-Environnement Wallonie und Bond Beter Leefmilieu Vlaanderen hat der Gerichtshof sie im Hinblick auf die Stromversorgungssicherheit eines Mitgliedstaats erteilt. Die Zuständigkeit mitgliedstaatlicher Gerichte erscheint danach als vom EuGH auf sie delegierte Kompetenz. Nicht ganz passend ist dann allerdings der Hinweis des Gerichtshofs auf die nach nationalem Recht bestehende Befugnis, die gegeben sein muss, damit das nationale Gericht eine Aufrechterhaltung von Wirkungen des unionsrechtswidrigen nationalen Rechts herbeiführen kann. ${ }^{1531}$

1528 Coutron, RTDEur. 2017, 400 (406). Nach seinen Worten ist der EuGH hin- und hergerissen zwischen dem Verständnis für die Forderung des Conseil d'État nach einer Befugnis zur Begrenzung der Wirkungen der Nichtigerklärung des nationalen Rechts und seiner Überzeugung, dass die Zeit noch nicht reif ist für ein Überschreiten des Rubikon.

1529 Siehe zu diesen Möglichkeiten Dougan, CMLRev. 56 (2019), 1459 (1500 ff.).

$1530 \mathrm{EuGH}$, Urteil vom 29.7.2019, Rs. C-411/17 (Inter-Environnement Wallonie und Bond Beter Leefmilieu Vlaanderen), Rn. 178 und 179.

$1531 \mathrm{EuGH}$, Urteil vom 29.7.2019, Rs. C-411/17 (Inter-Environnement Wallonie und Bond Beter Leefmilieu Vlaanderen), Rn.182. In diesem Sinne jüngst erneut EuGH, Urteil vom 25.6.2020, Rs. C-24/19 (A u.a. (Windkraftanlagen in Aalter und Nevele)), Rn. 95. 
Durch die Einordnung der Zuständigkeit der nationalen Gerichte in den durch das Winner Wetten-Urteil gesteckten Rahmen erscheint das Association France Nature Environnement-Urteil als Beispiel für die im Einzelfall an die mitgliedstaatlichen Gerichte zu erteilende Gestattung zur Anpassung der Wirkungen der Nichtigerklärung. ${ }^{1532}$ Im Hinblick auf das Association France Nature Environnement-Urteil bleibt damit festzuhalten, dass sich der EuGH zu seiner dort getroffenen Aussage nur hat durchringen können, weil er den nationalen Gerichten für den besonderen Bereich des unionsrechtlichen Umweltschutzes das Gebrauchmachen von der ihnen nach nationalem Recht zustehenden Befugnis bereits gestattet hat.

Für andere Regelungsbereiche bleibt es nach dem hier zugrunde gelegten Verständnis schlussendlich also doch bei der Pflicht zur vorherigen Anrufung des EuGH. ${ }^{1533}$ Die in Rn.34 des Association France Nature Environnement-Urteils erfolgte Aussage erweist sich damit in der Tat als „missverständlich, soweit sie der ständigen Rechtsprechung widersprechen könnte, dass allein der Gerichtshof vorübergehend die zeitliche Anwendung des vorrangig anwendbaren Unionsrechts aufschieben kann". 1534

Zusammenfassend führt der EuGH daher mit Blick auf sich selbst aus, dass er „in Ausnahmefällen und aus zwingenden Erwägungen der Rechtssicherheit eine vorübergehende Aussetzung der Verdrängungswirkung herbeiführen kann" und mit Blick auf mitgliedstaatliche Gerichte, dass „ein nationales Gericht unter Voraussetzungen, die allein der Gerichtshof festlegen kann, aus zwingenden Erwägungen, die mit dem Umweltschutz und der Stromversorgungssicherheit des betreffenden Mitgliedstaats zusammenhängen, ausnahmsweise zur Anwendung einer nationalen Rechtsvorschrift berechtigt sein kann, die es ihm gestattet, bestimmte Wirkungen eines für nichtig erklärten nationalen Rechtakts aufrechtzuerhalten ". ${ }^{1535}$

Letztlich würde es der Einheit der Unionsrechtsordnung den „Todesstoß" versetzen, wenn man die Befugnis zur Begrenzung der zeitlichen Wirkungen der Nichtigerklärung unionsrechtswidrigen nationalen Rechts generell den nationalen Gerichten übertrüge. ${ }^{1536}$ Die Erteilung einer

1532 Siehe hierzu Dougan, CMLRev. 56 (2019), 1459 (1506f.).

1533 Darauf weist auch Clément-Wilz, European Papers 2017, 259 (266) hin.

1534 GA Kokott, Schlussanträge vom 29.11.2018 in der Rs. C-411/17 (Inter-Environnement Wallonie und Bond Beter Leefmilieu Vlaanderen), Rn. 202 (Hervorhebung im Original).

1535 EuGH, Urteil vom 19.12.2019, Rs. C-236/18 (GRDF), Rn. 43.

1536 So plastisch Coutron, RTDEur. 2017, 400 (404). Der Verweis Coutrons auf EuGH, Urteil vom 9.3.2006, Rs. C-499/04 (Werhof), Rn. 32 erscheint in diesem 
entsprechenden Gestattung muss daher beim Gerichtshof monopolisiert sein. Lediglich über die Aufrechterhaltung der Wirkungen der angefochtenen Maßnahmen an sich entscheidet dann das nationale Gericht. Dies erscheint auch vor dem Hintergrund gerechtfertigt, dass es dabei gegebenenfalls dem Mitgliedstaat zur Verfügung stehende Mittel zu berücksichtigen hat, die diesem beispielsweise eine Gewährleistung seiner Stromversorgung ermöglichen ${ }^{1537}$ und für deren Beurteilung es besser als der EuGH geeignet ist.

$\mathrm{Zu}$ unterscheiden ist nach dem vorstehend Gesagten also zwischen zwei Arten der Durchführung der Aussetzung der Verdrängungswirkung, einem „zentralisierte[n] Verfahren unter der Kontrolle des Gerichtshofs“ und einem dezentralisierten, „das unter sehr engen Voraussetzungen den nationalen Gerichten zugewiesen wird“. 1538

\section{cc) Auswirkungen auf den Vorrang}

Abschließend soll ein Blick auf die Auswirkungen der vorgestellten Entscheidungen auf den Vorrang als Wesensmerkmal des Unionsrechts geworfen werden. Zu diesem Zweck ist noch einmal genau danach zu fragen, worauf sich der Gerichtshof bei ihnen gestützt hat.

In der Rechtssache Inter-Environnement Wallonie und Terre wallonne standen sich wie gesehen zwei unionsrechtliche Verpflichtungen - diejenige zur Durchführung einer Umweltprüfung und diejenige zum Erlass eines Aktionsprogramms zur Durchführung der Nitratrichtlinie - gegenüber, die in Ausgleich zu bringen waren. Den Vorrang hat der Gerichtshof dort nicht erwähnt. ${ }^{1539}$

Auch wenn daher auf den ersten Blick die Vermutung nahe liegt, dass der EuGH die oben beschriebene Ausnahmebefugnis der nationalen Ge-

Zusammenhang aber irreführend, da es dort nicht um das Verhältnis des Unionsrechts zum nationalen Recht geht, sondern um die Auslegung des Sekundärrechts im Lichte der allgemeinen Grundsätze des Unionsrechts zur Wahrung der Einheit der Unionsrechtsordnung.

$1537 \mathrm{EuGH}$, Urteil vom 29.7.2019, Rs. C-411/17 (Inter-Environnement Wallonie und Bond Beter Leefmilieu Vlaanderen), Rn. 180; EuGH, Urteil vom 25.6.2020, Rs. C-24/19 (A u.a. (Windkraftanlagen in Aalter und Nevele)), Rn. 95.

1538 So pointiert GA Campos Sánchez-Bordona, Schlussanträge vom 3.3.2020 in der Rs. C-24/19 (A u.a. (Windkraftanlagen in Aalter und Nevele)), Fn. 64.

1539 Siehe auch Lock, CMLRev. 50 (2013), 217 (225 f.). 
richte zum Gebrauchmachen von einer im nationalen Recht vorgesehenen Befugnis zur Aufrechterhaltung bestimmter Wirkungen unionsrechtswidrigen nationalen Rechts aus Gründen der nationalen Verfahrensautonomie anerkannt hat, so wird doch sehr bald deutlich, dass dies nicht der Fall ist. Zwar deutet auf einen solchen Anknüpfungspunkt hin, dass der EuGH die nationale Verfahrensautonomie dort zur Sprache gebracht hat und sie den Rahmen bildet, innerhalb dessen die nationalen Gerichte dem Unterbleiben der Umweltverträglichkeitsprüfung abhelfen müssen. ${ }^{1540}$

Die Anknüpfung einer Verzögerung der Wirkung des Vorrangs an die nationale Verfahrensautonomie mit den Grenzen von Äquivalenz- und Effektivitätsgrundsatz wäre allerdings nicht überzeugend. Hierfür ist weniger von Bedeutung, dass es in den vom Gerichtshof entschiedenen Fällen nicht um die Anwendung einer zwingenden nationalen Verfahrensvorschrift, sondern um eine dem nationalen Gericht nach nationalem Recht ausnahmsweise eingeräumte Befugnis geht, da die Betroffenheit von unionsrechtlichen Gründen die Anwendung der nationalen Verfahrensregel ja erst recht nahelegen könnte. Ein Anknüpfen an die nationale Verfahrensautonomie würde aber den unionsrechtlichen Rahmen verschleiern, in den sich diese Befugnis einfügen muss. ${ }^{1541} \mathrm{Wie}$ gesehen richten sich die Bedingungen der Ausübung der Zuständigkeit mitgliedstaatlicher Gerichte daher gerade nicht nach Äquivalenz- und Effektivitätsgrundsatz. Dadurch dass der EuGH die Bedingungen der Ausübung dieser Zuständigkeit detailgenau festlegt, haben die mitgliedstaatlichen Gerichte letztlich keinen Spielraum, der ihnen bei einer Verankerung in der Verfahrensautonomie in größerem Umfang zustünde. ${ }^{1542} \mathrm{Da}$ die zugrunde liegende Abwägung unionsintern erfolgt, können die nationalen Gerichte nicht autonom über den Ausgleich der widerstreitenden Interessen entscheiden.

Dass der EuGH den mitgliedstaatlichen Gerichten die erwähnte Befugnis zugesprochen hat, erklärt sich daraus, dass in der Rechtssache Inter-Environnement Wallonie und Terre wallonne kein inhaltlicher Widerspruch der innerstaatlichen Maßnahmen zum Unionsrecht bestand und dieses zu den Folgen des Verfahrensfehlers, der ihnen anhaftet, schweigt. Der Verfahrensfehler führt nicht zur Unanwendbarkeit der innerstaatlichen

1540 EuGH, Urteil vom 28.2.2012, Rs. C-41/11 (Inter-Environnement Wallonie und Terre wallonne), Rn. $42 \mathrm{ff}$.

1541 Lock, CMLRev. 50 (2013), 217 (222 f.). Verstraelen, GLJ 14 (2013), 1687 (1726f.) verneint die Aufstellung eines neuen allgemeinen Grundsatzes durch den EuGH.

1542 Dougan, CMLRev. 56 (2019), 1459 (1497, 1499). 
Maßnahmen wegen Verstoßes gegen vorrangig anzuwendendes Unionsrecht. ${ }^{1543}$ Aus der Sicht des Vorrangs ergeben sich insoweit keine Probleme. ${ }^{1544}$

Das Urteil in der Rechtssache Association France Nature Environnement knüpft dagegen an das Winner Wetten-Urteil an, auch wenn es jenes nur einmal in Rn. 33 erwähnt. Die vom Gerichtshof gewählten Formulierungen offenbaren dabei ein Verständnis, wonach es ihm um eine Begrenzung des Vorrangs geht. Auch die „Begrenzung der Wirkungen“ der Feststellung der Rechtswidrigkeit/der Nichtigerklärung, von der der EuGH spricht und die er dem nationalen Gericht gestattet, weckt Assoziationen zu der im Winner Wetten-Urteil erwähnten möglichen Analogie zu Art. 264 II AEUV. ${ }^{1545}$

Aufgrund der jeweils unterschiedlichen Ausgangssituation in den beiden Verfahren liegt es nicht auf der Hand, die Inter-Environnement Wallonie und Terre wallonne-Rechtsprechung auf die Association France Nature Environnement-Konstellation zu erstrecken. Dadurch dass der Gerichtshof die von Generalanwältin Kokott in ihren Schlussanträgen noch auseinandergehaltenen Fragen der Aufrechterhaltung der Wirkungen des Umsetzungsrechts und der in seiner Anwendung erlassenen Pläne/Programme vermengt, erweckt er den Anschein einer Abschwächung des Vorrangs. ${ }^{1546}$ Da er aber, abgesehen von der Ausweitung des Kriteriums der ordnungsgemäßen Umsetzung der Nitratrichtlinie auf die ordnungsgemäße Umsetzung des Umweltrechts der Union, auch in seinem Association France Nature Environnement-Urteil dem im Inter-Environnement Wallonie und Terre wallonne-Urteil gesteckten Rahmen verhaftet bleibt ${ }^{1547}$, kann nicht behauptet werden, dass durch dieses die Rechtsprechung zum Vorrang außer Kraft gesetzt werde. ${ }^{1548}$

Auch die in Art. 6 III der SUP-Richtlinie niedergelegte Verpflichtung, um die es in Association France Nature Environnement ging, hat verfah-

1543 GA Kokott, Schlussanträge vom 29.11.2018 in der Rs. C-411/17 (Inter-Environnement Wallonie und Bond Beter Leefmilieu Vlaanderen), Rn. 203.

1544 Cassagnabère, Les nouveaux cahiers du Conseil Constitutionnel 2017, 47 (60). Er spricht plastisch vom Versuch einer "conciliation inter-temporelle“ mit dem Vorrang.

1545 So auch Sowery, CMLRev. 54 (2017), 1157 (1166 mit Fn. 31; 1167 mit Fn. 37).

1546 Gentile, European Papers 2017, 321 (325).

1547 Coutron, RTDEur. 2017, 400 (403 ff.); so auch GA Kokott, Schlussanträge vom 29.11.2018 in der Rs. C-411/17 (Inter-Environnement Wallonie und Bond Beter Leefmilieu Vlaanderen), Rn. 203.

1548 Gentile, European Papers 2017, 321 (322). 
rensrechtlichen Charakter. Der Verstoß gegen das dort vorgesehene Autonomieerfordernis führt nicht zwingend zu einem inhaltlichen Konflikt mit dem Unionsrecht. Dazu, wie bei einem solchen zu verfahren ist, hat sich der Gerichtshof also auch dort nicht klar geäußert. ${ }^{1549}$ Die Befugnis zur Aufrechterhaltung der Wirkungen unionsrechtswidrigen nationalen Rechts ist danach auf die Umstände des Einzelfalles begrenzt. Gestattet ist den nationalen Gerichten, „unter bestimmten Bedingungen vorübergehend die Wirkungen von Maßnahmen aufrechtzuerhalten, die unter Verletzung der SUP-Richtlinie erlassen wurden". 1550

Die im Winner Wetten-Urteil angedeutete Möglichkeit einer vorübergehenden Aussetzung der Verdrängungswirkung hat der Gerichtshof hier also noch nicht voll entfaltet. ${ }^{1551}$ Die im Winner Wetten-Urteil erkennbare Zurückhaltung im Hinblick auf materielles Unionsrecht hat der Gerichtshof daher in der Rechtssache Association France Nature Environnement nicht aufgegeben. ${ }^{1552}$ Sie ist auch in seiner nachfolgenden Rechtsprechung zu beobachten. ${ }^{1553}$

Dass die Antwort des Gerichtshofs in der Rechtssache Association France Nature Environnement nicht zu einer Aufrechterhaltung des unionsrechtswidrigen Ministerialdekrets führen konnte und daher von begrenzter Reichweite ist, zeigt auch das im Anschluss an das EuGH-Urteil

1549 van der Hulle, NtEr 2016, 284 (289).

1550 GA Kokott, Schlussanträge vom 25.1.2018 in der Rs. C-671/16 (Inter-Environnement Bruxelles u.a.), Rn.39. Jedenfalls „teilweise“ mildert diese Befugnis nationaler Gerichte die Rechtsunsicherheit ab, die sich nach Ansicht mancher Mitgliedstaaten aus der Rechtsprechung des EuGH ergibt, die zahlreiche Maßnahmen in den Anwendungsbereich der SUP-Richtlinie einbezieht und damit auch viele allgemeine Regelungen erfasst, die seit dem Ablauf der Umsetzungsfrist der SUP-Richtlinie ohne Umweltprüfung unter Verstoß gegen die SUPRichtlinie erlassen worden sind, GA Kokott, a.a.O., Rn. $38 \mathrm{f}$.

1551 Mamoudy, AJDA 2016, 2229 (2229 f.).

1552 So aber Sowery, CMLRev. 54 (2017), 1157 (1173f.).

1553 Siehe EuGH, Urteil vom 6.10.2020, verb. Rs. C-511/18, C-512/18 und C-520/18 (La Quadrature du Net u.a.), Rn. 219 mit Blick auf einen Verstoß gegen Art. 15 I der Richtlinie 2002/58/EG im Licht der Art. 7, 8 und 11 sowie von Art. 52 I GRCh. In Rede stand eine nationale Rechtsvorschrift, die Betreibern elektronischer Kommunikationsdienste eine Pflicht zur Vorratsspeicherung von Verkehrs- und Standortdaten auferlegte. Eine Aufrechterhaltung der Wirkungen dieser Vorschrift hätte nach Ansicht des EuGH zur Folge, dass „den Betreibern elektronischer Kommunikationsdienste weiterhin Verpflichtungen auferlegt würden, die gegen das Unionsrecht verstoßen und mit schwerwiegenden Eingriffen in die Grundrechte der Personen verbunden sind, deren Daten gespeichert wurden“. 
ergangene Urteil des Conseil d'État, in dem die oben bereits angesprochene Frage, wer im konkreten Fall über die Aussetzung des Anwendungsvorrangs entscheidet, wieder auftaucht.

Im Anschluss an die Wiederholung der wichtigsten Aussagen des EuGH stellt der Conseil d'État fest, dass die Bestimmungen des angegriffenen Dekrets allgemeine Verfahrensregeln aufstellen, die für sich genommen keine Auswirkungen auf den Umweltschutz haben. In Ermangelung einer Möglichkeit des Conseil d'État, die auf der Grundlage des Dekrets getroffenen Entscheidungen im Voraus eingehend im Hinblick auf die vom EuGH für eine Aufrechterhaltung gestellten Bedingungen zu beurteilen, bedarf es einer Prüfung dieser Frage durch die Verwaltungsgerichte, vor denen die Pläne und Programme und darauf gestützte Akte angegriffen werden. Jene haben daher darüber zu entscheiden, ob diese aufrechterhalten werden können. Folgerichtig erklärt der Conseil d'État die Bestimmungen des Dekrets, soweit sie unionsrechtswidrig sind, für nichtig. ${ }^{1554}$ Dieses hat Unionsrecht nicht ordnungsgemäß umgesetzt, sodass seine Aufrechterhaltung ausscheiden muss. ${ }^{1555}$

Diese Entscheidung des Conseil d'État war durch das EuGH-Urteil bereits vorgezeichnet, da der Gerichtshof eine abstrakte Betrachtung abgelehnt und damit implizit dem die Rechtmäßigkeit der Pläne und Programme überprüfenden Gericht die Modulation der Wirkungen der Nichtigerklärung vorbehalten hatte. ${ }^{1556}$ Die Ausführungen des Gerichtshofs erweisen sich damit letztlich als weniger weitreichend, als sie es dem ersten Eindruck nach vermuten ließen.

Die Rechtssache Inter-Environnement Wallonie und Bond Beter Leefmilieu Vlaanderen, die der Stromversorgungssicherheit eines Mitgliedstaats Beachtung schenkt, verlässt den Rahmen der im Umweltrecht der Union vorgesehenen Umweltprüfungen ebenfalls nicht. Auch hier hat sich der Gerichtshof eng an seine bisherige Rechtsprechung angelehnt und eine Entscheidung in Ansehung der Umstände des Einzelfalls getroffen. ${ }^{1557}$ In der Rechtssache Belgisch Syndicaat van Chiropraxie u.a. verneint er wie bereits im Winner Wetten-Urteil das Vorliegen zwingender Erwägungen der Rechtssicherheit und zeigt durch die Betonung des Erfordernisses einer ordnungsgemäßen Umsetzung einer unionsrechtlichen Pflicht - im

1554 Conseil d'État, Urteil vom 3.11.2016, No. 360212, Punkt 3 und Tenor.

1555 Mamoudy, AJDA 2016, 2229 (2231).

1556 Clément-Wilz, European Papers 2017, 259 (262).

1557 EuGH, Urteil vom 29.7.2019, Rs. C-411/17 (Inter-Environnement Wallonie und Bond Beter Leefmilieu Vlaanderen), Rn. $177 \mathrm{ff}$. 
konkreten Fall betroffen war die Mehrwertsteuerrichtlinie - seine Vorbehalte gegenüber einem Zurücktreten des vorrangigen Unionsrechts im Falle seiner Verletzung. ${ }^{1558}$ Durch diese Bezugnahme auf die Umsetzung einer unionsrechtlichen Pflicht hat der Gerichtshof insbesondere die Situation bei Richtlinien im Blick und möchte ein Vakuum hinsichtlich ihrer Umsetzung vermeiden. Bei unmittelbar anwendbarem Unionsrecht fällt diese Überlegung weg, sodass insoweit noch größere Zurückhaltung geboten ist. ${ }^{1559}$

Einen allgemeinen Rahmen zur Aufrechterhaltung unionsrechtswidrigen nationalen Rechts durch ein nationales Gericht hat der EuGH nach alledem noch nicht geschaffen. ${ }^{1560}$ Nur im Einzelfall und unter den vom Gerichtshof festgelegten Bedingungen ist mitgliedstaatlichen Gerichten gestattet, Wirkungen unionsrechtswidrigen nationalen Rechts aufrechtzuerhalten. ${ }^{1561}$ Bislang hat der Gerichtshof ihnen lediglich eine Befugnis für den Bereich des Umweltschutzes und der Stromversorgungssicherheit eines Mitgliedstaates zuerkannt ${ }^{1562}$ - unter der Voraussetzung, dass ihr nationales Recht eine Vorschrift bereithält, die die Aufrechterhaltung bestimmter Wirkungen eines für nichtig erklärten Rechtsakts gestattet. Mit Blick auf den EuGH selbst ist festzustellen, dass dessen Befugnis weiter als diejenige der mitgliedstaatlichen Gerichte reicht. Entscheidend kommt es für das Eingreifen seiner Zuständigkeit für die Suspendierung des Anwendungsvorrangs auf das Bestehen einer Gefahr für die unionsrechtliche Rechtssicherheit an. ${ }^{1563}$

1558 EuGH, Urteil vom 27.6.2019, Rs. C-597/17 (Belgisch Syndicaat van Chiropraxie u.a.), Rn. $57 \mathrm{ff}$.

1559 Siehe hierzu auch Sowery, CMLRev. 54 (2017), 1157 (1167). Dougan, CMLRev. 56 (2019), 1459 (1494) ist ebenfalls der Auffassung, dass die Art des in Rede stehenden Unionsrechts Auswirkungen darauf hat, ob eine Aussetzung der Verdrängungswirkung gerechtfertigt ist.

1560 Mamoudy, AJDA 2016, 2229 (2229f.) unter Verweis auf EuGH, Urteil vom 8.9.2010, Rs. C-409/06 (Winner Wetten), Rn. 66, 67 und EuGH, Urteil vom 28.2.2012, Rs. C-41/11 (Inter-Environnement Wallonie und Terre wallonne), Rn. 58.

1561 Vgl. GA Campos Sánchez-Bordona, Schlussanträge vom 10.9.2020 in den verb. Rs. C-407/19 und C-471/19 (Katoen Natie Bulk Terminals und General Services Antwerp), Rn. 97.

1562 Vgl. jetzt auch EuGH, Urteil vom 6.10.2020, verb. Rs. C-511/18, C-512/18 und C-520/18 (La Quadrature du Net u.a.), Rn.218f., wo der Gerichtshof die Bedeutung des Vorliegens eines Verstoßes gegen eine verfahrensrechtliche Verpflichtung zur „vorherigen Prüfung der Auswirkungen eines Projekts im speziellen Bereich des Umweltschutzes" besonders betont.

1563 Ebenso Ehlers/Eggert, JZ 2008, 585 (589). 
IV. Suspendierung des Vorrangs im Hinblick auf Vertrauen in nationales Recht?

Ging es im vorhergehenden Abschnitt um die aus unionsrechtlicher Sicht bestehenden Möglichkeiten zur Vermeidung eines Rechtsvakuums, das durch die Nichtanwendung unionsrechtswidrigen nationalen Rechts drohte, ist im Folgenden der Frage nachzugehen, ob eine Suspendierung des Vorrangs auch im Hinblick auf Vertrauen in nationales Recht denkbar ist. Aufgeworfen ist damit das Problem, ob der Anwendungsvorrang auch im Hinblick auf die grundsätzlich bestehende Pflicht zur rückwirkenden Nichtanwendung unionsrechtswidrigen nationalen Rechts Grenzen unterliegt. In Rede steht also die Frage nach der Möglichkeit nationaler Gerichte zur Begrenzung der Nichtanwendung des nationalen Rechts durch auf das nationale Recht gestützte Vertrauensschutzerwägungen. Ihre Beantwortung bedarf zunächst einer Betrachtung der Unterschiede und Gemeinsamkeiten mit der im ersten Teil dieser Arbeit untersuchten Begrenzung der Berufung auf eine ausgelegte Norm in zeitlicher Hinsicht durch den EuGH im Sinne der Defrenne-Rechtsprechung.

1. Unterschiede und Gemeinsamkeiten mit der Begrenzung der ex tuncWirkung

Unterbleibt eine Begrenzung im Sinne der Defrenne-Rechtsprechung, wirkt eine unmittelbar anwendbare unionsrechtliche Vorschrift seit ihrem Inkrafttreten über den Anwendungsvorrang auf sämtliche Mitgliedstaaten ein. ${ }^{1564} \mathrm{Da}$ auch dieser selbst über einen zeitlichen Aspekt verfügt, steht fest, dass die Normkollision mit Wirkung auf den Zeitpunkt zu beseitigen ist, in dem die Normen zum ersten Mal kollidiert sind, da der Konflikt zwischen nationalem und Unionsrecht bereits seit diesem Zeitpunkt besteht. ${ }^{1565}$ Anders ist dies nur, wenn der Anwendungsvorrang durch eine unionsinterne Abwägung eingeschränkt wurde.

1564 Rosenkranz, ZfPW 2016, 351 (367).

1565 So auch Rosenkranz, ZfPW 2016, 351 (377). A.A. Beljin, NVwZ 2008, 156 (159), der zwar das Bestehen einer Prüfungs- und Verwerfungspflicht der innerstaatlichen Rechtsanwender bejaht, darin aber keine Pflicht zur sofortigen Nichtanwendung erkennt und auch keine zeitlich unbegrenzte Pflicht zur Beachtung des Anwendungsvorrangs daraus ableitet. 
Die Begrenzung der ex tunc-Wirkung ist also eine der Suspendierung des Anwendungsvorrangs vorgelagerte Option. Im Gegensatz zur erstgenannten Möglichkeit, von der nur unionsweit einheitlich Gebrauch gemacht werden kann, ist die zweite territorial begrenzt. Zudem unterscheiden sich beide Instrumente insoweit in ihren Rechtsfolgen, als durch die Begrenzung der ex tunc-Wirkung der Anwendungsbefehl der Norm des Unionsrechts in der Regel für den Zeitraum vom Inkrafttreten bis zum entsprechenden EuGH-Urteil aufgehoben wird, während bei der Aussetzung des Anwendungsvorrangs lediglich die der Bestimmung aufgrund ihres Vorrangs zukommende Verdrängungswirkung vorübergehend suspendiert wird und so anders als im ersten Fall etwa eine unionsrechtskonforme Auslegung und Staatshaftung noch möglich sind. Eine temporäre Suspendierung des Anwendungsvorrangs zielt also nicht lediglich auf die Erreichung eines im Vergleich zur Defrenne-Rechtsprechung identischen Ergebnisses ab.

Unter Anwendung der Maßstäbe der Defrenne-Rechtsprechung ließe sich dieses auch gar nicht erreichen, wie sich einerseits an der fehlenden Möglichkeit einer territorialen Differenzierung, aber auch, jedenfalls nach hier vertretener Auffassung, an der nicht bestehenden Möglichkeit einer Begrenzung der ex tunc-Wirkung bis zu einem in der Zukunft gelegenen Zeitpunkt zeigt. ${ }^{1566}$

Angesichts der Unterschiede in der Wirkungsweise der Defrenne-Rechtsprechung und einer temporären Suspendierung des Anwendungsvorrangs bedeutet die Erwähnung einer möglichen Analogie zu Art. 264 II AEUV für die Frage der Suspendierung des Anwendungsvorrangs nicht, dass der Gerichtshof von den im Rahmen der Defrenne-Rechtsprechungslinie angeführten Voraussetzungen des guten Glaubens und der Gefahr schwerwiegender Störungen Abstand genommen und sich stärker an allgemeine Rechtssicherheitserwägungen angelehnt hat. Auch wenn eine vorübergehende Suspendierung des Anwendungsvorrangs nur den jeweiligen Mitgliedstaat betrifft, muss der Gerichtshof daher seine aus dem ersten Teil dieser Arbeit bekannte Präklusionsrechtsprechung nicht aufgeben. ${ }^{1567}$

Dennoch kann nicht geleugnet werden, dass ein Spannungsverhältnis zu seiner Begrenzungsrechtsprechung besteht, das der EuGH in seinem

1566 So auch Koenig/Schreiber, DÖV 2008, 450 (453 f.). Zur Frage, ob die Berufung auf die ausgelegte Norm bis zu einem in der Zukunft gelegenen Zeitpunkt ausgeschlossen werden kann, siehe näher oben bei Fn. $1086 \mathrm{ff}$.

1567 So aber Verstraelen, GLJ 14 (2013), 1687 (1723 f., 1729). Zur Präklusionsrechtsprechung näher oben bei Fn. $881 \mathrm{ff}$. 
Winner Wetten-Urteil allerdings anders als Generalanwalt Bot in seinen in dieser Rechtssache vorgelegten Schlussanträgen nicht anspricht, obwohl es sich auch dort abzeichnete. Generalanwalt Bot hatte einerseits auf die Beeinträchtigung des Anspruchs auf effektiven Rechtsschutz hingewiesen und andererseits geltend gemacht, dass die zur Unionsrechtswidrigkeit des nationalen Rechts führenden Gründe bereits im Gambelli-Urteil ersichtlich geworden waren und damit bereits einige Zeit vor dem Sachverhalt des Ausgangsverfahrens in der Rechtssache Winner Wetten. Damit nimmt er einerseits die bei der Defrenne-Rechtsprechung bislang stets vorgenommene Rückausnahme für Rechtsbehelfsführer und zum anderen die im Gambelli-Urteil unterbliebene und zur Präklusion führende Beschränkung der zeitlichen Wirkungen in Bezug. ${ }^{1568}$

Deutlich wird hierdurch, dass sich bei beiden Möglichkeiten insoweit keine Unterschiede ergeben, als die eigentlich einschlägige unionsrechtliche Vorschrift auf den Ausgangsfall keine Anwendung findet. Nicht die Augen verschließen sollte man daher davor, dass über das Instrument einer temporären Suspendierung des Anwendungsvorrangs im betroffenen Mitgliedstaat eine Umgehung der Kriterien der Defrenne-Rechtsprechung droht. ${ }^{1569}$ Hier wie dort kann daher „bloße“ Rechtsunsicherheit nicht genügen, um vom jeweiligen Instrument Gebrauch machen zu können, sondern nur eine sich als unzutreffend herausstellende Vorstellung vom Inhalt des Unionsrechts. ${ }^{1570} \mathrm{Um}$ die Einschnitte für den Anspruch auf effektiven Rechtsschutz zu begrenzen, erscheint es zudem angezeigt, die im Rahmen der Defrenne-Rechtsprechung zur Rückausnahme für Rechtsbehelfsführer angestellten Erwägungen auf den Fall der Suspendierung des Anwendungsvorrangs zu übertragen. ${ }^{1571}$

Dadurch dass die Befugnis zur Begrenzung der ex tunc-Wirkung nur in Ausnahmefällen besteht, steht die Defrenne-Rechtsprechung ebenso wie der Anwendungsvorrang selbst im Dienste der einheitlichen Anwendung des Unionsrechts. Im Ergebnis in der rechtlichen Behandlung zwischen

1568 GA Bot, Schlussanträge vom 26.1.2010 in der Rs. C-409/06 (Winner Wetten), Rn. 84, 103 ff., $114 \mathrm{ff}$. Siehe hierzu auch Verstraelen, GLJ 14 (2013), 1687 (1723f.). Zur Rückausnahme für Rechtsbehelfsführer näher oben bei Fn. $1102 \mathrm{ff}$.

1569 Siehe in diesem Zusammenhang auch Dougan, CMLRev. 56 (2019), 1459 (1501f.).

1570 Vgl. Rosenkranz, Beschränkung der Rückwirkung, 2015, S. 468 ff.

1571 Dougan, CMLRev. 56 (2019), 1459 (1489) weist zu Recht darauf hin, dass es aber auch Fälle geben kann, in denen der Anspruch auf effektiven Rechtsschutz hinter den betroffenen Allgemeininteressen zurückzutreten hat. 
der Begrenzung der Durchsetzungsdimension und der Begrenzung des unionsrechtlichen Normbefehls zu differenzieren, würde daher nicht überzeugen. ${ }^{1572}$ In dieses Bild fügt sich der Vorschlag ein, für die Frage der Suspendierung des Vorrangs die Art. 264 II AEUV zugrundeliegenden Rechtssicherheitserwägungen unter Bezugnahme auf die Kriterien der Defrenne-Rechtsprechung mit Leben zu füllen und auf diese Weise die Defrenne- und Winner Wetten-Rechtsprechung weitgehend zu vereinen. ${ }^{1573}$

Die enge Verbindung zwischen beiden Begrenzungsmöglichkeiten zeigt sich auch in der Rechtssache Belgisch Syndicaat van Chiropraxie u.a., in der angesichts der in einem belgischen Gesetz vorgesehenen Befreiung von der Mehrwertsteuer nur für Angehörige eines reglementierten ärztlichen oder arztähnlichen Berufs, nicht aber etwa für Chiropraktiker und Osteopathen die Frage eines Verstoßes gegen eine Bestimmung der Richtlinie über das gemeinsame Mehrwertsteuersystem in Rede stand. Die Frage der Befugnis des nationalen Gerichts zur Aufrechterhaltung der Wirkungen des unionsrechtswidrigen nationalen Rechts bis zu dessen Ersetzung durch richtlinienkonformes Recht verneint der Gerichtshof mit der Begründung, dass das vorlegende Gericht bereits keine konkreten Gesichtspunkte genannt habe, die bei einer Rückwirkung der Nichtigerklärung der nationalen Vorschriften "spezifische Risiken der Rechtsunsicherheit“ begründen könnten. Als Beleg hierfür führt er die entsprechende Passage im Winner Wetten-Urteil an. ${ }^{574}$ „Insbesondere“, so der Gerichtshof, stellten haushalts- und verwaltungstechnische Schwierigkeiten keine solchen zwingenden Erwägungen der Rechtssicherheit dar. Zur Stützung dieser Aussage zieht er zwei Urteile der Defrenne-Rechtsprechungslinie heran, in denen er ausführt, dass finanzielle Konsequenzen, die sich aus einem Urteil im Vorabentscheidungsverfahren für einen Mitgliedstaat ergeben könnten, für sich allein keine zeitliche Begrenzung rechtfertigen. ${ }^{1575}$ Ein Argument, dem im Rahmen der Defrenne-Rechtsprechung kein Gehör geschenkt wird, kann also nicht über den Umweg der Winner Wetten-Rechtsprechung Beachtung finden.

1572 Siehe auch Rosenkranz, ZfPW 2016, 351 (380).

1573 In diesem Sinne van der Hulle/van der Hulle, SEW 2012, 490 (499, 501).

1574 EuGH, Urteil vom 27.6.2019, Rs. C-597/17 (Belgisch Syndicaat van Chiropraxie u.a.), Rn. 59 unter Verweis auf EuGH, Urteil vom 8.9.2010, Rs. C-409/06 (Winner Wetten), Rn. 67.

1575 EuGH, Urteil vom 27.6.2019, Rs. C-597/17 (Belgisch Syndicaat van Chiropraxie u.a.), Rn. 60 unter Verweis auf EuGH, Urteil vom 18.10.2012, Rs. C-525/11 (Mednis), Rn. 44 und EuGH, Urteil vom 10.4.2014, Rs. C-190/12 (Emerging Markets Series of DFA Investment Trust Company), Rn. 111. 


\section{Irrelevanz nationaler Vertrauensumstände}

Nach dem bisher Gesagten muss hinsichtlich unmittelbar anwendbaren Unionsrechts die Berücksichtigung nationaler Vertrauensumstände durch ein nationales Gericht ausscheiden.

a) Verletzung der zeitlichen Wirkungen eines EuGH-Urteils durch „nationalen Vertrauensschutz"?

Dies kann allerdings nicht damit begründet werden, dass in „nationalem Vertrauensschutz" die Verletzung der zeitlichen Wirkung eines EuGH-Urteils zu erblicken sei. ${ }^{1576}$ Zum Anknüpfungspunkt für die Beurteilung der Zulässigkeit nationalen Vertrauensschutzes würde damit nämlich das Urteil des EuGH selbst gemacht. Nach den im ersten Teil dieser Arbeit getroffenen Feststellungen handelt es sich bei der Bindungswirkung einer EuGH-Entscheidung aber in Wirklichkeit um eine solche der unionsrechtlichen Norm, die vom EuGH ausgelegt wurde und in dieser Auslegung verbindlich ist. Eine darüber hinausgehende Bindungswirkung des Urteils selbst besteht nicht. ${ }^{1577}$ Die Erwägung des BAG, dass die Gesetzeswirkung einer Entscheidung des Bundesverfassungsgerichts die Gewährung von Vertrauensschutz sperren könnte ${ }^{1578}$, ist damit im Hinblick auf die Rechtsprechung des EuGH nicht entsprechend heranzuziehen.

Eine Privilegierung der Wirkung unionsgerichtlicher Rechtsprechung gegenüber der Wirkung unionsrechtlicher Normen findet insoweit nicht statt. ${ }^{1579}$ Daran ändert auch die Präklusionsrechtsprechung des Gerichtshofs nichts. Dass danach die Bildung abweichenden guten Glaubens gegen ein Urteil des Gerichtshofs anders als gegenüber unionsrechtlichen Normen nicht möglich ist, hatte sich als der Stellung des EuGH im institutionellen Gefüge entsprechend erwiesen. ${ }^{1580} \mathrm{Da}$ sich die herausgehobene

1576 Seifert, JbArbR 48 (2011), 119 (129f.) etwa macht geltend, dass eine Entscheidung des Gerichtshofs unterschiedliche Rechtswirkungen in den Mitgliedstaaten hervorbringe (und die einheitliche Wirkung des Unionsrechts gefährdet sei), wenn die nationalen Gerichte dem Vertrauensschutz autonom Rechnung trügen.

1577 So auch Düsterhaus, YEL 36 (2017), 237 (243). Siehe dazu zusammenfassend oben bei Fn. $154 \mathrm{ff}$.

1578 BAG, Urteil vom 23.1.2019, 7 AZR 161/15, Rn. 29 - juris.

1579 Diese befürchtet ansonsten Rosenkranz, ZfPW 2016, 351 (368).

1580 Siehe dazu näher oben bei Fn. $914 \mathrm{f}$. 
Stellung der Rechtsprechung im Verhältnis zum nationalen Recht aber nur vermittelt über die unionsrechtliche Norm auswirken kann, ist deren Verhältnis zum nationalen Recht entscheidend für die Frage, ob ein mitgliedstaatliches Gericht bei der Entscheidung eines konkreten Rechtsstreits nationale Vertrauensumstände berücksichtigen kann.

Durch eine Anknüpfung an das Urteil selbst würde einer Differenzierung nach der unterschiedlichen Wirkungsweise des Unionsrechts auch von vornherein die Grundlage entzogen. Deutlich wird dies etwa an einer Aussage in der Literatur, die im Honeywell-Beschluss des Bundesverfassungsgerichts die Bestätigung dafür sieht, dass die Entscheidung des BAG im Anschluss an das Junk-Urteil des EuGH abzulehnen sei. ${ }^{1581}$ Sie entnimmt damit der Ablehnung der Gewährung „nationalen Vertrauensschutzes" bei der Betroffenheit des primärrechtlichen Grundsatzes des Verbots der Altersdiskriminierung eine Aussage hinsichtlich der Situation bei der richtlinienkonformen Auslegung, da die Junk-Konstellation die richtlinienkonforme Auslegung und die Honeywell-Konstellation den Anwendungsvorrang betraf. Ein solcher Zusammenhang kann allerdings nicht begründet werden.

Dass ein Beschluss des Bundesverfassungsgerichts, der mehrere Jahre nach einem die Junk-Konstellation betreffenden Urteil des BAG ergangen ist, in eine andere Richtung weist, führt zu keiner abweichenden Beurteilung. Nicht zuletzt hält das Bundesverfassungsgericht dem BAG darin zwar vor, dass es sich mit der unionsrechtlichen Bindungswirkung von Vorabentscheidungen hätte auseinandersetzen müssen, als es im Anschluss an die Junk-Entscheidung des EuGH Vertrauensschutz gewährte. ${ }^{1582}$ Auch diese verfassungsgerichtliche Stellungnahme kann aber die Feststellung, dass die Bindungswirkung nicht dem EuGH-Urteil, sondern der ausgelegten Norm zukommt, nicht in Frage stellen. „Nationaler Vertrauensschutz“ kann sich damit nicht in Widerspruch zu den zeitlichen Wirkungen eines Urteils des Gerichtshofs setzen. Zweifel daran, dass diese Erkenntnis auch der Vorstellung des EuGH entspricht, sät letztlich auch das Urteil des Gerichtshofs in der Rechtssache DI ${ }^{1583}$ nicht, das nur auf den ersten Blick

1581 So Seifert, JbArbR 48 (2011), 119 (130). Siehe zur Entscheidung des BAG in der Junk-Konstellation bereits oben bei Fn. 1340 ff.; zur Honeywell-Konstellation näher oben bei Fn. $1344 \mathrm{ff}$. und unten bei Fn. $1621 \mathrm{ff}$.

1582 BVerfG, Beschluss vom 10.12.2014, 2 BvR 1549/07, Rn. 42 - NZA 2015, 375.

1583 EuGH, Urteil vom 19.4.2016, Rs. C-441/14 (DI). 
in die Richtung eines an die Rechtsprechung des EuGH anzulegenden, ganz eigenen Maßstabs zu weisen scheint. ${ }^{1584}$

\section{b) „Sperrwirkung“ der Defrenne-Rechtsprechung}

Für die Beachtlichkeit nationaler Vertrauensumstände wird auf grundsätzlicher Ebene vorgebracht, dass der EuGH die Unanwendbarkeit des nationalen Rechts nicht selbst feststellen könne, weshalb er auch die zeitlichen Wirkungen des Unanwendbarkeitsausspruchs nicht begrenzen könne. ${ }^{1585}$ Da vielmehr das nationale Gericht die Entscheidung über die Anwendung bzw. Nichtanwendung treffe und die Folgen der Nichtanwendung eines Gesetzes in das nationale Rechtssystem eingepasst werden müssten, seien landesspezifische Kenntnisse erforderlich, an denen es dem EuGH fehle. Vor dem Hintergrund, dass die Gewährung von je nach nationalem Verfassungsrecht unterschiedlichem Vertrauensschutz nur Ungleichheit auf Zeit bewirke, halte sich der Schaden für die einheitliche Anwendung des Unionsrechts in Grenzen. ${ }^{1586}$

Dagegen, dass die mitgliedstaatlichen Gerichte hierdurch verstärkt in den Blickpunkt der Betrachtung gestellt werden, ist zwar nichts einzuwenden. Diese treffen in der Tat die Entscheidung über die Nichtanwendung des nationalen Rechts im konkreten Verfahren. Auch entspricht die Trennung der Ebenen der Auslegung durch den EuGH und der nachfolgen-

1584 In diesem Sinne Rosenkranz, ZfPW 2016, 351 (369): „Hiermit wird die Judikative daher entweder privilegiert oder einer ganz eigenen rechtsquellentheoretischen Wirkungsweise unterworfen, die dem Anwendungsvorrang von Unionslegislativakten nicht gleichartig ist.“ Zur Rechtssache DI näher sogleich bei Fn. $1588 \mathrm{ff}$.

1585 Höpfner, ZfA 2010, 449 (483 f.). Er wendet sich damit gegen BAG, Urteil vom 26.4.2006, 7 AZR 500/04, Rn. 40 - BAGE 118, 76. Ähnlich wie das BAG spricht auch das Bundesverfassungsgericht in seinem Honeywell-Beschluss in Bezug auf das in Rede stehende nationale Gesetz von der „rückwirkende[n] Feststellung seiner Nichtanwendbarkeit durch den Gerichtshof", siehe BVerfG, Beschluss vom 6.7.2010, 2 BvR 2661/06 - BVerfGE 126, 286 (313).

1586 Krois, DB 2010, 1704 (1707); Steiner, EuZA 2009, 140 (153). Wenn Steiner allerdings davon spricht, unionsrechtliche Handlungsspielräume seien grundrechtsschonend auszufüllen, und dafür auf BVerfG, Urteil vom 18.7.2005, 2 BvR 2236/04 - BVerfGE 113, 273 (300) verweist, wählt er bereits einen falschen Ansatz. Ging es in der zitierten Entscheidung des Bundesverfassungsgerichts um den Mitgliedstaaten in einem Rahmenbeschluss eingeräumte Umsetzungsspielräume, ist im vorliegenden Zusammenhang gerade fraglich, ob derartige mitgliedstaatliche Freiräume bestehen. 
den Nichtanwendung des nationalen Rechts durch die mitgliedstaatlichen Gerichte im Grundsatz der oben herausgearbeiteten Unterscheidbarkeit von Auslegung und Durchsetzungsdimension. ${ }^{1587}$ Dennoch kommt eine Trennung der Ebenen bei unmittelbar anwendbarem Unionsrecht nicht in der von den wiedergegebenen Literaturstimmen angedachten Weise in Betracht.

Zur Begründung dieser Feststellung ist ein Blick auf das Urteil des Gerichtshofs in der Rechtssache DI erhellend. Dieses beantwortete ein Vorabentscheidungsersuchen des Obersten Gerichtshofs Dänemarks (Højesteret) zur Wirkung des primärrechtlichen Verbots der Altersdiskriminierung zwischen Privaten.

\section{aa) Das Urteil in der Rechtssache DI}

In dem vom Højesteret zu beurteilenden Sachverhalt wurde Herr Rasmussen Ende Juni 2009 entlassen. Aufgrund seiner ununterbrochenen Beschäftigung bei demselben Unternehmen seit 1984 hatte er grundsätzlich Anspruch auf eine Entlassungsabfindung in Höhe von drei Monatsgehältern nach $\$ 2$ a I des dänischen Angestelltengesetzes. Bei seinem Ausscheiden aus dem Unternehmen hatte er allerdings das 60. Lebensjahr bereits vollendet und damit das Mindestalter für den Bezug einer Altersrente erreicht ${ }^{1588}$, weswegen er Anspruch hatte auf eine vom Arbeitgeber geschuldete Altersrente nach einem Rentensystem, dem er vor Vollendung des 50. Lebensjahrs beigetreten war. Nach der auf den Ausgangsfall anwendbaren Fassung des $₫ 2$ a III des Angestelltengesetzes entfiel die Entlassungsabfindung für Angestellte, wenn diese bei ihrem Ausscheiden eine Altersrente vom Arbeitgeber erhielten und dem entsprechenden Rentensystem vor Vollendung des 50. Lebensjahrs beigetreten waren. Das Højesteret legte $\$ 2$ a III des Angestelltengesetzes in ständiger Rechtsprechung dahin gehend aus, dass schon die Möglichkeit des Bezugs einer Altersrente den Anspruch auf Entlassungsabfindung ausschließt, unabhängig davon, ob der entlassene Angestellte tatsächlich eine Altersrente bezog oder nicht. Demnach genügte es nach dieser Rechtsprechung für das Entfallen des An-

1587 Siehe hierzu näher bei Fn. 1308 ff.

1588 In den meisten dänischen Rentensystemen (und auch in dem Herrn Rasmussen betreffenden) ist das Mindestalter für den Bezug einer Altersrente auf 60 Jahre festgelegt, vgl. GA Kokott, Schlussanträge vom 6.5.2010 in der Rs. C-499/08 (Ingeniørforeningen i Danmark), Rn. 37. 
spruchs auf Entlassungsabfindung, dass die Angestellten eine Altersrente erhalten konnten.

Herr Rasmussen war auf dem Arbeitsmarkt geblieben und wurde bei einem anderen Unternehmen weiterbeschäftigt; er bezog daher keine Altersrente. Aufgrund des Eingreifens des $\$ 2$ a III des Angestelltengesetzes in der Auslegung durch den Obersten Gerichtshof verweigerte sein bisheriger Arbeitgeber die Zahlung der Entlassungsabfindung. Die dänische Rechtsprechung setzte also diejenigen Personen, die tatsächlich eine Altersrente erhielten, denjenigen Personen gleich, die eine solche Rente erhalten konnten, zum Bezug einer Altersrente also (lediglich) berechtigt waren, auf sie aber vorübergehend verzichten, um auf dem Arbeitsmarkt zu bleiben.

Der relevante Sachverhalt in dem zum DI-Urteil des EuGH führenden Verfahren spielte sich über ein Jahr vor dem Urteil des Gerichtshofs in der Rechtssache Ingeniørforeningen i Danmark ${ }^{1589} \mathrm{ab}$, in der der EuGH einen Verstoß der dänischen Rechtslage gegen Art. 2 und 6 I der Richtlinie 2000/78/EG ${ }^{1590}$ angenommen und dies mit der auf dem Kriterium des Alters beruhenden Ungleichbehandlung begründet hatte, die nicht zu rechtfertigen sei, da sie über das zur Verwirklichung ihrer Ziele erforderliche Maß hinausgehe. Betroffen war dort mit der Region Syddanmark ein öffentlicher Arbeitgeber.

Das Højesteret führte in seinem ein privatrechtliches Arbeitsverhältnis betreffenden Vorabentscheidungsersuchen in der Rechtssache DI aus, eine richtlinienkonforme Auslegung des $\$ 2$ a III des Angestelltengesetzes scheide aus, da sie contra legem erfolgen würde; zu klären sei dann, ob der allgemeine unionsrechtliche Grundsatz des Verbots der Altersdiskriminierung anzuwenden sei und ob eine Abwägung zwischen dem Verbot der Altersdiskriminierung einerseits und der Rechtssicherheit und dem Vertrauensschutz andererseits möglich sei, sodass das unionsrechtliche Verbot der Altersdiskriminierung bei entsprechendem Abwägungsergebnis nicht zur Anwendung gelangen würde. Bedenken äußerte der Oberste Gerichtshof insbesondere dahingehend, dass es bei einer Anwendung des Verbots der Altersdiskriminierung dazu komme, dass ein ungeschriebener allgemeiner Rechtsgrundsatz des Unionsrechts (in seiner Konkretisierung in einer Richtlinie) Privaten verwehrt, sich auf eine nationale gesetzliche

1589 EuGH, Urteil vom 12.10.2010, Rs. C-499/08 (Ingeniørforeningen i Danmark).

1590 Richtlinie 2000/78/EG des Rates vom 27. November 2000 zur Festlegung eines allgemeinen Rahmens für die Verwirklichung der Gleichbehandlung in Beschäftigung und Beruf, ABl. L 303 vom 2.12.2000, S. 16. 
Bestimmung zu stützen. ${ }^{1591}$ Diesen Bedenken im Hinblick auf den Grundsatz der Rechtssicherheit misst der Gerichtshof in seiner Antwort auf das Vorabentscheidungsersuchen allerdings keine entscheidende Bedeutung zu. ${ }^{1592}$ Letztlich veranlasste dies das Højesteret in seinem auf das EuGHUrteil hin ergangenen Urteil dazu, dem allgemeinen Rechtsgrundsatz des Verbots der Altersdiskriminierung in Dänemark unmittelbare Wirkung abzusprechen. ${ }^{1593}$

Zur Einordnung der Entscheidung des EuGH ist zunächst festzuhalten, dass sich an der in der Rechtssache Ingeniørforeningen i Danmark vor dem Hintergrund eines öffentlich-rechtlichen Arbeitsverhältnisses bejahten Unverhältnismäßigkeit der dänischen Rechtslage bei der Betroffenheit eines privatrechtlichen Arbeitsverhältnisses nichts ändert, da es nicht von der Rechtsnatur des Arbeitsverhältnisses abhängt, ob eine nicht zu rechtfertigende Ungleichbehandlung vorliegt. Aus unionsrechtlicher Sicht

1591 Siehe hierzu auch die Wiedergabe der Passage aus dem Vorabentscheidungsersuchen in dem auf das Vorabentscheidungsurteil des EuGH hin ergangenen Urteil des Obersten Gerichtshofs Dänemarks, Højesteret, Urteil vom 6.12.2016, 15/2014, englische Übersetzung, S. 3 ff. (Fundstellenangabe oben in Fn. 16).

1592 Zur Begründung seiner Bedenken nimmt das Højesteret auf GA Trstenjak, Schlussanträge vom 8.9.2011 in der Rs. C-282/10 (Dominguez), Rn. 164 Bezug, vgl. die Wiedergabe des Vorabentscheidungsersuchens in Højesteret, Urteil vom 6.12.2016, 15/2014, englische Übersetzung, S. 4.

1593 Nach Ansicht der Richtermehrheit ist es eine Frage des Gesetzes über den Beitritt Dänemarks zur EU, ob eine Regel des Unionsrechts tatsächlich entsprechend den unionsrechtlichen Vorgaben im dänischen Recht unmittelbare Wirkung entfalten kann. Da der allgemeine Grundsatz des Verbots der Altersdiskriminierung seine Grundlage nicht in einer bestimmten Vertragsbestimmung habe, bestehe eine im Beitrittsgesetz nicht vorgesehene Situation, sodass er in Dänemark keine unmittelbare Wirkung entfalte. Auf der Grundlage dieser Auffassung kann das Verbot der Altersdiskriminierung $\mathbb{\$} 2 \mathrm{a}$ III des Angestelltengesetzes also nicht vorgehen. Der Oberste Gerichtshof würde daher aus Sicht der Richtermehrheit seine Befugnisse als Gericht überschreiten, wenn er die Bestimmung unangewendet ließe, Højesteret, Urteil vom 6.12.2016, 15/2014, englische Übersetzung, S. 44 ff. Das Højesteret sah sich zu diesen Ausführungen veranlasst, da es daran festhielt, dass eine richtlinienkonforme Auslegung nicht möglich sei, sodass eine contra legem-Situation bestehe, Urteil, S. 43 f. Die Reaktion des Højesteret begegnet Bedenken, da sie aus der Frage der Wirkung des Unionsrechts letztlich eine Frage dänischen Rechts macht, indem sie diese als Frage der Grenzen des Beitrittsgesetzes auffasst, Madsen/Olsen/Šadl, ELJ 23 (2017), 140 (149). Der „selektive Ansatz“ im Hinblick auf den Vorrang des Unionsrechts wirft Fragen hinsichtlich des Grundsatzes loyaler Zusammenarbeit und der Pflicht zur Befolgung des Vorrangs auf, vgl. Gualco, European Papers 2017, 223 (228). 
musste der EuGH zur Beantwortung des Vorabentscheidungsersuchens des Højesteret daher lediglich das aus seinem Mangold-Urteil bekannte allgemeine Verbot der Diskriminierung wegen des Alters (in seiner Konkretisierung durch die Richtlinie 2000/78/EG) fruchtbar machen. Aus diesem Blickwinkel betrachtet lagen die zutreffende Lösung des Rechtsstreits und damit auch die Antwort des Gerichtshofs also auf der Hand. ${ }^{1594}$ Daher verwundert es nicht, wenn in der Literatur vorgebracht wird, die vom Højesteret angeführten Grundsätze der Rechtssicherheit und des Vertrauensschutzes dienten lediglich als „Feigenblatt“, um die Reformunwilligkeit Dänemarks zu verdecken, da die Unionsrechtswidrigkeit des dänischen Rechts seit 2010 feststehe. ${ }^{1595}$

In seiner Antwort auf das Vorabentscheidungsersuchen führt der Gerichtshof aus, dass sich das Højesteret nicht auf den Grundsatz des Vertrauensschutzes berufen könne, um weiterhin eine nationale altersdiskriminierende Regelung anzuwenden, da dies - vor dem Hintergrund, dass die Auslegung dann im Ausgangsverfahren keine Anwendung fände - auf eine Begrenzung der zeitlichen Wirkungen der vom Gerichtshof vorgenommenen Auslegung hinauslaufe. Dem EuGH geht es dabei nach eigenen Worten um die Anwendung des Vertrauensschutzes „in der vom vorlegenden Gericht in Betracht gezogenen Weise“. 1596

Bei der Beurteilung der Antwort des Gerichtshofs ist daher die Stoßrichtung der Vorlagefrage des Højesteret in Rechnung zu stellen. Sie zielte nämlich darauf $a b$, in Erfahrung zu bringen, ob, und wenn ja unter welchen Voraussetzungen es möglich sei, der Rechtssicherheit und dem Vertrauensschutz Vorrang vor dem Verbot der Altersdiskriminierung einzuräumen. ${ }^{1597}$ In der Vorstellung des Højesteret standen sich also allgemeine Rechtsgrundsätze gegenüber, die angesichts ihrer Bedeutung als Strukturmerkmal der EU in der Literatur anschaulich auch als „Titanen“1598 bezeichnet werden. Dem Højesteret schwebte damit letztlich vor, den nationalen Gerichten eine Abwägung zwischen dem unionsrechtlichen Verbot der Altersdiskriminierung und dem Rechtssicherheitsgrundsatz zu gestatten, damit diese in konkreten Fällen bei Bedarf zu aus ihrer Sicht angemessenen Ergebnissen gelangen können. Wäre der Gerichtshof diesem

1594 Vgl. Dubout, R.A.E. 2016, 287. Zur Mangold-Rechtsprechung siehe EuGH, Urteil vom 22.11.2005, Rs. C-144/04 (Mangold).

1595 Forst, EWiR 2016, 381 (382).

1596 EuGH, Urteil vom 19.4.2016, Rs. C-441/14 (DI), Rn. 38 f.

1597 Vgl. Gualco/Lourenço, European Papers 2016, 643 (645).

1598 Gualco, European Papers 2017, 223 (223 f.); siehe bereits Gualco/Lourenço, European Papers 2016, 643. 
Ansinnen gefolgt, hätte jedes nationale Gericht selbst entscheiden können, ob die Befolgung des Unionsrechts Rechtssicherheit und Vertrauensschutz zuwiderläuft, sodass diese letztlich vom nationalen Recht abhinge.

Die Antwort des Gerichtshofs ist vor diesem Hintergrund dahingehend zu verstehen, dass die vom Højesteret ins Auge gefasste Abwägung darauf hinausliefe, die zeitlichen Wirkungen der Auslegung zu begrenzen. ${ }^{1599}$ Aus ihr kann dagegen nicht auf eine zwischen diesen allgemeinen Rechtsgrundsätzen bestehende Hierarchie geschlossen werden, wonach sich das Verbot der Altersdiskriminierung gegenüber anderen konfligierenden allgemeinen Rechtsgrundsätzen durchsetze. ${ }^{1600}$ Aus Sicht des Gerichtshofs bestand bereits kein Konflikt mit der unionsrechtlichen Rechtssicherheit, da er einen anderen Blickwinkel als das Højesteret einnimmt, sodass sich das Problem einer Abwägung allgemeiner Rechtsgrundsätze für ihn gar nicht stellte. Daran, dass die Berücksichtigung nationaler Vertrauensumstände ausgeschlossen ist, ändert dies natürlich nichts. Die weitreichende Bedeutung der Antwort des EuGH wird deutlich, wenn man bedenkt, dass gerichtlicher Vertrauensschutz jedenfalls im Ergebnis regelmäßig auf eine Begrenzung der zeitlichen Wirkungen der Auslegung hinausläuft. ${ }^{1601}$

Hinter dem vom Højesteret vorgetragenen Anliegen stand wohl die Überlegung, die Folgen der Mangold-Rechtsprechung des Gerichtshofs für das dänische Recht abzumildern, worauf sich der Gerichtshof aber nicht eingelassen hat. Nach seiner Auffassung kann das Vertrauen des privaten Arbeitgebers Herrn Rasmussen nicht das Recht nehmen, eine unmittelbar anwendbare Bestimmung des Unionsrechts geltend zu machen. ${ }^{1602}$

In seinen Schlussanträgen in der Rechtssache DI hatte Generalanwalt Bot betont, dass der Gerichtshof in seinem Urteil in der Rechtssache Ingeniørforeningen i Danmark die zeitlichen Wirkungen der Auslegung der Richtlinie nicht beschränkt hatte, sodass eine Nachholung dieser Beschränkung ausscheiden musste. ${ }^{1603}$ Dieser Verweis des Generalanwalts auf

1599 Vgl. Gualco/Lourenço, European Papers 2016, 643 (648).

1600 So aber Gualco, European Papers 2017, 223 (223 f.); Gualco/Lourenço, European Papers 2016, 643 (651 f.).

1601 Deshalb kritisch Benecke, EuZW 2016, 469 (470).

1602 Holdgaard/Elkan/Krohn Schaldemose, CMLRev. 55 (2018), 17 (38f. mit Fn. 84).

1603 GA Bot, Schlussanträge vom 25.11.2015 in der Rs. C-441/14 (DI), Rn. $81 \mathrm{f}$. unter Verweis auf EuGH, Urteil vom 2.2.1988, Rs. 309/85 (Barra), Rn. 13. Er sieht in der Berufung des Højesteret auf den Grundsatz der Rechtssicherheit den Versuch, die Verpflichtung zur unionsrechtskonformen Auslegung zu begrenzen und meint, dass dies auf eine Beschränkung der zeitlichen Wirkung des Urteils Ingeniørforeningen i Danmark hinauslaufe. Es sei aber allein Sache 
die Präklusionsrechtsprechung, wonach eine im erstauslegenden Urteil unterbliebene zeitliche Begrenzung nicht nachgeholt werden kann ${ }^{1604}$, wird in der Literatur mit der Erwägung kritisiert, dass die Richtlinie gegenüber einer öffentlichen Arbeitgeberin wie der Region Syddanmark in der Rechtssache Ingeniørforeningen i Danmark - anders als gegenüber einem privaten Arbeitgeber - „in jeder Auslegung des EuGH unmittelbar anwendbar" gewesen sei. ${ }^{1605}$

Aufgeworfen ist damit die Frage der Bedeutung des in der Rechtsprechung des EuGH entwickelten Präklusionskriteriums im vorliegenden Fall. Auf den ersten Blick scheint für seine Fruchtbarmachung zu sprechen, dass die Auslegung des Unionsrechts nicht von der dem ersten Urteil zugrundeliegenden Rechtsbeziehung abhängen kann, sodass sich an der Auslegung des Unionsrechts nichts ändert, je nachdem, ob dem Ausgangsverfahren ein Bürger-Staat- oder ein Horizontalverhältnis zugrunde liegt und lediglich die Durchsetzung des Unionsrechts auf unterschiedlichen Wegen erfolgt.

In der Tat führt der Gerichtshof im DI-Urteil seine Defrenne-Rechtsprechung an, wie in seinem Verweis auf die entsprechende Passage im Urteil in der Rechtssache Gmina Wrocław ${ }^{1606}$ deutlich wird. Auffällig ist zunächst, dass er im DI-Urteil eine andere Formulierung als in dem Urteil verwendet, auf das er verweist. Heißt es im Gmina Wrocław-Urteil, dass die nationalen Gerichte bei Vorliegen der nationalen Verfahrensvoraussetzungen die Vorschrift in der Auslegung durch den EuGH auch auf vor Erlass des Urteils entstandene Rechtsverhältnisse anwenden müssten und dass der Gerichtshof nur ganz ausnahmsweise aufgrund des allgemeinen unionsrechtlichen Grundsatzes der Rechtssicherheit die Möglichkeit beschränken könne, sich auf seine Auslegung des Unionsrechts zu berufen, so erweckt er im DI-Urteil einen etwas anderen Eindruck. Dort führt er nämlich aus, dass ein Richter das Unionsrecht in der Auslegung des Gerichtshofs „abgesehen von ganz außergewöhnlichen Umständen, deren Vorliegen hier jedoch nicht geltend gemacht worden ist“ („unless there are truly exceptional circumstances“), auch auf vor Erlass des Urteils entstan-

des Gerichtshofs, über eine Einschränkung der Geltung der Auslegung in zeitlicher Hinsicht zu entscheiden.

1604 Siehe dazu näher oben bei Fn. 881 ff.

1605 Sprenger, EuZA 2016, 460 (468).

1606 Der Gerichtshof verweist auf EuGH, Urteil vom 29.9.2015, Rs. C-276/14 (Gmina Wrocław), Rn. 44 und 45. 
dene Rechtsverhältnisse anwenden muss. ${ }^{1607}$ Hier entsteht demnach der Anschein, als könne unter ganz außergewöhnlichen Umständen von der Anwendung der Auslegung aus eigenem Antrieb der mitgliedstaatlichen Gerichte abgesehen werden. ${ }^{1608}$

Dass der Gerichtshof hier eine Akzentverschiebung vornehmen möchte, erscheint aber angesichts des Verweises auf das Urteil in der Rechtssache Gmina Wrocław ausgeschlossen. Bestätigung findet diese Einschätzung in den Ausführungen in der Rechtssache Hein, in der der Gerichtshof die Frage des Vorliegens außergewöhnlicher Umstände aufwirft, um sodann auf den fehlenden Nachweis der Gefahr schwerwiegender wirtschaftlicher Auswirkungen und damit die Defrenne-Rechtsprechung zu verweisen. ${ }^{1609}$

Deutlich wird der Bezug zu seiner bekannten Rechtsprechungslinie auch im Verweis des DI-Urteils auf Aussagen im Defrenne II- bzw. BarberUrteil. ${ }^{1610}$ Mit Blick auf diese führt der Gerichtshof aus, Vertrauensschutz könne jedenfalls nicht gegen den Kläger des Ausgangsverfahrens (d.h. gegenüber „demjenigen, der das Verfahren eingeleitet hat, das den Gerichtshof veranlasst, das Unionsrecht dahin auszulegen, dass es der fraglichen nationalen Rechtsvorschrift entgegensteht") geltend gemacht werden; ihm dürfe der Vorteil aus der Auslegung nicht versagt werden. ${ }^{1611}$

So unverdächtig diese Aussage dem ersten Anschein nach klingt, so lässt sie doch aufhorchen, da die Unverhältnismäßigkeit der dänischen Regelung ja wie gesehen bereits nach dem Urteil in der Rechtssache Ingeniørforeningen i Danmark feststand, sodass das Urteil in der Rechtssache DI nicht als dasjenige erscheint, in dem das Unionsrecht dahin ausgelegt wurde, dass es der fraglichen nationalen Rechtsvorschrift entgegensteht. Das Argument des Schutzes der Rechtsbehelfsführer ${ }^{1612}$ erscheint bei einer Be-

1607 EuGH, Urteil vom 19.4.2016, Rs. C-441/14 (DI), Rn. 40. Ebenso EuGH, Urteil vom 22.11.2017, Rs. C-251/16 (Cussens u.a.), Rn. 41.

1608 Frantzen, Staatshaftung, 2018, S. 115 spricht unter Verweis auf EuGH, Urteil vom 19.4.2016, Rs. C-441/14 (DI), Rn. 40 in der Tat von einem Letztvorbehalt für absolut unbillige Ausnahmefälle, der allerdings weitestgehend bedeutungslos sei.

1609 EuGH, Urteil vom 13.12.2018, Rs. C-385/17 (Hein), Rn. 62.

1610 EuGH, Urteil vom 8.4.1976, Rs. 43/75 (Defrenne), Rn. 75; EuGH, Urteil vom 17.5.1990, Rs. C-262/88 (Barber), Rn. 44 und 45.

1611 EuGH, Urteil vom 19.4.2016, Rs. C-441/14 (DI), Rn. 41.

1612 Kritisch etwa Benecke, EuZW 2016, 469 (470), die ausführt, es überzeuge nicht, dass der Schutz des Klägers in der Regel vorgehe, da oft Zufälle darüber entschieden, wer klage. $\mathrm{Zu}$ den Argumenten für eine Rückausnahme von einer zeitlichen Begrenzung zugunsten von Rechtsbehelfsführern siehe bereits oben bei Fn. $1110 \mathrm{ff}$. 
trachtung aus diesem Blickwinkel daher zunächst fragwürdig. Bei genauerem Hinsehen lässt sich daraus aber ein Argument gegen ein Verständnis herleiten, wonach der EuGH „nationalen Vertrauensschutz“ in Bezug zur zeitlichen Wirkung seiner früheren Urteile setzt. Dementsprechend ordnet er diesen letztlich auch nicht als Verletzung der zeitlichen Wirkung einer solchen früheren Entscheidung ein. ${ }^{1613}$

Deutlich wird dies an der Feststellung des Gerichtshofs, dass hinsichtlich der im Ingeniørforeningen i Danmark-Urteil im Hinblick auf die Richtlinie 2000/78/EG festgestellten Unionsrechtswidrigkeit des nationalen Rechts „das Gleiche für den tragenden Grundsatz der Gleichbehandlung [gilt], der im allgemeinen Verbot der Diskriminierung wegen des Alters lediglich eine besondere Ausprägung findet". ${ }^{1614}$ Demnach ist in der Übertragung auf das Verbot der Altersdiskriminierung die Auslegung zu sehen, deren Schutz der EuGH im Sinn hat. Da sich die Rechtssache Ingeniørforeningen i Danmark mit der Gleichbehandlungsrichtlinie und nicht mit dem allgemeinen Rechtsgrundsatz des Verbots der Altersdiskriminierung befasst hatte, wäre eine Begrenzung der Wirkungen der Auslegung im DI-Urteil jedenfalls bei einem sehr engen Verständnis des Begriffs der identischen Rechtsfrage wohl noch in Betracht gekommen, auf die das Højesteret aber nicht abzielte. Dieses hatte den Gerichtshof vielmehr nur vor die Wahl gestellt, seine Mangold-Rechtsprechung aufzugeben oder diese aufrechtzuerhalten, den nationalen Gerichten im Gegenzug aber eine eigenständige Abwägung zu ermöglichen. ${ }^{1615}$ Dadurch dass der Gerichtshof die Bedenken des Højesteret im Hinblick auf den Grundsatz der Rechtssicherheit nicht auf die besondere Art der im Mangold-Urteil vorgesehenen Durchsetzung bezieht, sondern sie in den Rahmen der DefrenneRechtsprechung einordnet, umgeht er das Problem einer Ausnahme von der Durchsetzung des Unionsrechts in der Mangold-Konstellation, die der Wirksamkeit des Unionsrechts abträglich wäre. ${ }^{1616}$

Entscheidend für die gegenüber dem Højesteret ablehnende Haltung des EuGH ist also nicht, dass zum Zeitpunkt der Entscheidung in der Rechtssache DI bereits bekannt war, dass das Unionsrecht dem dänischen Recht entgegensteht, sodass Vertrauensschutz erst recht nicht in Betracht

1613 Rosenkranz, ZfPW 2016, 351 (369) etwa stellt auf die früheren Entscheidungen $\mathrm{ab}$.

1614 EuGH, Urteil vom 19.4.2016, Rs. C-441/14 (DI), Rn. 26.

1615 Siehe hierzu auch Holdgaard/Elkan/Krohn Schaldemose, CMLRev. 55 (2018), 17 (40 f.).

1616 Haket, NtEr 2016, 237 (241f.). 
kommt. ${ }^{1617}$ Entscheidend ist vielmehr, dass sich die Gewährung von „Vertrauensschutz" nach den Kriterien der Defrenne-Rechtsprechung richtet. Hätte der EuGH das vom Højesteret in Erwägung gezogene Vorgehen gebilligt, wäre es diesem erlaubt gewesen, selbst die zeitlichen Wirkungen der unionsgerichtlichen Auslegung zu begrenzen. Dies fällt aber in die ausschließliche Zuständigkeit des EuGH. ${ }^{1618}$

Aus diesem Grund setzt der EuGH den Vertrauensschutz in seinen Konsequenzen mit einer Begrenzung der zeitlichen Wirkungen der Auslegung gleich. ${ }^{1619}$ Dass eine Gleichsetzung in den Konsequenzen erfolgt, ändert nichts an der grundsätzlichen Richtigkeit einer Trennung zwischen Auslegung und Durchsetzungsdimension. Deren Begrenzung für die Vergangenheit aus Vertrauensschutzgründen ist den mitgliedstaatlichen Gerichten angesichts der vorstehenden Ausführungen zwar untersagt; eine temporäre Suspendierung des Anwendungsvorrangs zur Vermeidung des Entstehens von Regelungslücken ist dadurch aber nicht ausgeschlossen.

Dass sowohl der EuGH als auch das Højesteret Rechtssicherheit und Vertrauensschutz Bedeutung beimessen, kann nicht bestritten werden. Bei ihrer Gewichtung nehmen sie ihren Ausgangspunkt allerdings in ihrer jeweiligen Rechtsordnung: Da für den EuGH die Unionsrechtsordnung entscheidend ist, verwundert es nicht, dass er dem nationalen Verständnis der Rechtssicherheit und des Vertrauensschutzes weniger Bedeutung beimisst als seinem eigenen unionsweiten Verständnis derselben Grundsätze. Da nach dem Vorschlag des Højesteret unklar gewesen wäre, anhand welcher Kriterien die Abwägung hätte erfolgen sollen, wäre mit ihr eine Gefährdung der unionsweiten Rechtssicherheit einhergegangen. Der Verweis des Gerichtshofs auf seine Defrenne-Rechtsprechung ist damit vor allem Ausdruck der Sorge um unionsweite Rechtssicherheit. ${ }^{1620}$ Er schließt eine nach Mitgliedstaaten variierende zeitliche Wirkung aus und damit auch Vertrauensschutz für die im jeweiligen Mitgliedstaat betroffenen Rechtsunterworfenen.

1617 Vgl. Kainer, GPR 2016, 262 (267).

1618 Coutron, RTDEur. 2017, 389 (392). Auch hätte der EuGH dem Rechtsbehelfsführer des Ausgangsverfahrens die Möglichkeit einer Geltendmachung seiner unionsrechtlichen Rechte verwehrt.

1619 So auch Dubout, R.A.E. 2016, 287 (292 f. und Fn. 31).

1620 Siehe hierzu ausführlich auch Holdgaard/Elkan/Krohn Schaldemose, CMLRev. 55 (2018), 17 (40 ff.). 
bb) Abbildung im deutschen Recht

Damit ist noch ein Blick auf die oben ${ }^{1621}$ bereits erwähnte und ebenfalls die Wirkungen des primärrechtlichen Verbots der Altersdiskriminierung im Horizontalverhältnis betreffende Honeywell-Konstellation zu richten, um zu überprüfen, ob das vorstehend gefundene Ergebnis in der deutschen Rechtsordnung zutreffend abgebildet wird. Überlegt wird in der Literatur, diese Fallgestaltung nach den Grundsätzen der Solange II-Rechtsprechung zu behandeln. Insofern wird geltend gemacht, dass es letztlich um Grundrechtsschutz für die Marktteilnehmer gehe, die auf die Gültigkeit und damit Anwendbarkeit des nationalen Rechts vertraut hätten. Da die Rechtsprechung des Gerichtshofs zu diesem Problemkreis das noch akzeptable Maß nicht unterschreite, könne aber auf die verfassungsrechtlichen Maßstäbe des Vertrauensschutzes zugunsten des beklagten Arbeitgebers nicht zurückgegriffen werden. ${ }^{1622}$ Unabhängig von der Frage der Fortgeltung der Solange II-Rechtsprechung ${ }^{1623}$ wird bei einem derartigen Ansatz der Blick letztlich auf die verfassungsrechtlichen Integrationsgrenzen gerichtet. Da es an dieser Stelle aber um die Frage geht, ob unabhängig davon nationale Vertrauensumstände Berücksichtigung finden können, führt ein Verweis auf eine Rücknahme verfassungsgerichtlicher Prüfungskompetenzen in diesem Zusammenhang nicht weiter.

Weiterführend und zutreffend ist nach der Analyse der Rechtsprechung des EuGH dagegen der Blickwinkel des Bundesverfassungsgerichts, das es zu Recht für mit Unionsrecht unvereinbar hält, Vertrauensschutz dadurch zu gewähren, dass die unionsrechtswidrige nationale Regelung für die Zeit vor der Entscheidung des Gerichtshofs weiter angewandt wird. ${ }^{1624}$ Es macht damit zu Recht deutlich, dass die Mitgliedstaaten auch aus seiner Sicht keine Befugnis besitzen, „nationalen Vertrauensschutz“ gegen den Anwendungsvorrang ins Feld zu führen. Damit ist das nationale Recht auch für in der Vergangenheit liegende Rechtsverhältnisse unangewendet zu lassen. ${ }^{1625}$

Gegen das in der Honeywell-Konstellation erzielte Ergebnis wird zwar vorgebracht, dass eine richtlinienkonforme Auslegung des betroffenen

1621 Siehe bei Fn. $1344 \mathrm{ff}$.

1622 Franzen, AP TzBfG $\$ 14$ Nr. 23.

1623 Siehe dazu unten bei Fn. 2349 ff.

1624 BVerfG, Beschluss vom 6.7.2010, 2 BvR 2661/06 - BVerfGE 126, 286 (314).

1625 Koch, JbArbR 44 (2007), 91 (107); Kokott, RdA 2006, Sonderbeilage zu Heft 6, 30 (37); Preis/Temming, NZA 2010, 185 (188); Franzen, AP TzBfG $\$ 14$ Nr. 23; Wusterhausen, Wirkungen, 2016, S. $359 \mathrm{f}$. 
$\$ 14$ III TzBfG a.F. ausgeschieden wäre, sodass $\$ 14$ III 4 TzBfG a.F. angesichts der fehlenden unmittelbaren Wirkung von Richtlinien im Privatrechtsverhältnis eigentlich trotz seiner Unionsrechtswidrigkeit weiterhin anzuwenden gewesen wäre und zur wirksamen Befristung des Arbeitsvertrags geführt hätte. Die Mangold-Entscheidung des EuGH hatte mit der „Entdeckung“ eines primärrechtlichen Grundsatzes des Verbots der Altersdiskriminierung aber die anzuwendenden Maßstäbe verschoben und die Unanwendbarkeit des nationalen Rechts zur Folge. Diese zu Lasten der privaten Arbeitgeber gehende „überraschende Kehrtwende“1626 lässt sich nur damit rechtfertigen, dass allgemeine Rechtsgrundsätze durch den EuGH lediglich „freigelegt" ${ }^{1627}$ und nicht von ihm "erfunden“ werden, mag diese Vorstellung zum Teil auch als Wunschdenken erscheinen. ${ }^{1628}$

Von Tillmanns wird erwogen, angesichts des Anwendungsvorrangs und des Grundsatzes der einheitlichen Auslegung und Anwendung des Unionsrechts die fehlende Befugnis mitgliedstaatlicher Gerichte zur Gewährung von Vertrauensschutz und die damit einhergehende Enttäuschung der negativ betroffenen Partei hinzunehmen, dann aber einen Ausgleich auf vertraglicher Ebene etwa nach den Grundsätzen der Störung der Geschäftsgrundlage durch Anpassung des Arbeitsvertrags zu suchen. Sie nimmt also hin, dass $\$ 14$ III TzBfG a.F. auch für die Vergangenheit unanwendbar und die darauf gestützte Befristung aufgrund des Alters damit unzulässig ist; eine Befristung aus einem sachlichen Grund hält sie dennoch unter bestimmten Voraussetzungen für möglich. Hierfür spricht zwar, dass die mit dem Verbot der Altersdiskriminierung bezweckte Abschreckung vor Verstößen gegen dieses nicht mehr erreicht werden kann, wenn der Arbeitgeber in gutem Glauben gehandelt hat, sodass die Umgestaltung des befristeten in einen unbefristeten Arbeitsvertrag nicht erforderlich erscheint. ${ }^{1629}$ Diesem Ansatz ist allerdings entgegenzuhalten, dass er es ermöglicht, die mit dem Anwendungsvorrang verbundenen Folgen zu umgehen. ${ }^{1630}$

1626 Aus diesem Grunde kritisch Bauer/Arnold, NJW 2006, 6 (11).

1627 Begriff bei Buckler, EuR 2018, 371 (372).

1628 GA Kokott, Schlussanträge vom 1.3.2018 in der Rs. C-116/16 (T Danmark), Rn. 100 mit Fn. 61 etwa kritisiert das Vorgehen des Gerichtshofs in seinem Mangold-Urteil und die dort erfolgte Anerkennung einer unmittelbaren Horizontalwirkung des Verbots der Altersdiskriminierung, vgl. EuGH, Urteil vom 22.11.2005, Rs. C-144/04 (Mangold), Rn. 74-77.

1629 Ausführlich Tillmanns, in: FS Buchner, 2009, S. 885 (895).

1630 Kritisch auch Sagan, Jahrbuch Junger Zivilrechtswissenschaftler 2010, 67 (95). 
cc) Ergebnis

Sowohl aus der Rechtsprechung des Gerichtshofs als auch der des Bundesverfassungsgerichts ergibt sich damit, dass Vertrauen in die nationale Rechtslage bei der Betroffenheit von unmittelbar anwendbarem Unionsrecht ausscheiden muss. Mangels „Rechtsschein[s] der Europarechtskonformität der einzelstaatlichen Rechtsordnung" fehlt es insoweit auch an einem Anknüpfungspunkt. ${ }^{1631}$ Nicht begründen lässt sich nämlich, woraus sich ein derartiger Rechtsschein ergeben sollte. So kann insbesondere aus der bloßen Existenz nationalen Rechts nicht auf dessen Vereinbarkeit mit Unionsrecht geschlossen werden. Auch wenn man davon ausgeht, dass sich die Mitgliedstaaten unionsrechtskonform verhalten wollten, besteht die Möglichkeit, dass sie ohne Veranlassung durch europäische Stellen die unionsrechtlichen Anforderungen falsch bewerten.

Bei der Betroffenheit des Anwendungsvorrangs kommt es entscheidend auf das Verständnis des Unionsrechts an, das bereits im Rahmen der Defrenne-Rechtsprechung Berücksichtigung findet. Das Vertrauen in die Unionsrechtskonformität nationalen Rechts ist daher gewissermaßen in die im dortigen Rahmen erfolgende Prüfung des Bestehens von gutem Glauben hinsichtlich des Inhalts des Unionsrechts aufgenommen. Die Berücksichtigung nationaler Vertrauensumstände muss daher ausscheiden. ${ }^{1632}$ Insoweit ist also die „Messe für den nationalen Vertrauensschutz gesungen“. 1633 Dies bedeutet zugleich, dass eine Rechtsprechungsänderung mit Wirkung nur für die Zukunft nicht in Betracht kommt. ${ }^{1634}$

Festzuhalten bleibt, dass für den EuGH entscheidend ist, dass eine zeitliche Begrenzung der Wirkungen der Auslegung im Sinne der Defrenne-Rechtsprechung und eine zeitliche Beschränkung des Anwendungsvorrangs im Hinblick auf seine vergangenheitsbezogenen Wirkungen letztlich auf dasselbe hinauslaufen, sodass bei unmittelbar anwendbarem Unionsrecht nationaler Vertrauensschutz neben der Defrenne-Rechtsprechung

1631 Einen solchen nimmt aber Sagan, Jahrbuch Junger Zivilrechtswissenschaftler 2010, 67 (71) im Anschluss an Steiner, EuZA 2009, 140 (151) an, der „Schutz des Vertrauens in die Europarechtskonformität eines nationalen Gesetzes" fordert; ebenso bereits Tavakoli/Westhauser, DB 2008, 702 (705).

1632 Giegerich, EuR 2012, 373 (379); Seifert, JbArbR 48 (2011), 119 (129); BAG, Urteil vom 30.9.2010, 2 AZR 456/09, Rn. 22 - juris; BVerfG, Beschluss vom 6.7.2010, 2 BvR 2661/06 - BVerfGE 126, 286 (314).

1633 So Spelge, FA 2011, 34.

1634 Siehe Koch, SR 2012, 159 (166). 
ausscheidet. ${ }^{1635}$ An diesem Ergebnis ändert sich auch dann nichts, wenn im Rahmen der unionsrechtskonformen Auslegung, die auch bei unmittelbar anwendbarem Unionsrecht zum Tragen kommt, eine Berücksichtigung nationaler Vertrauensumstände möglich sein sollte. Der Anwendungsvorrang kann sich auch dann durchsetzen, wenn eine unionsrechtskonforme Auslegung scheitern sollte. ${ }^{1636}$

\section{Vergleich zur Winner Wetten-Rechtsprechung}

Vergleicht man die mit der Defrenne- bzw. Winner Wetten-Rechtsprechung einhergehende Aufgabenverteilung zwischen EuGH und mitgliedstaatlichen Gerichten, so sind Unterschiede feststellbar.

Hintergrund hierfür ist insbesondere der Umstand, dass eine zeitliche Begrenzung der Wirkung der Auslegung im Sinne der Defrenne-Rechtsprechung zukünftige Rechtswirkungen des ausgelegten Unionsrechts nicht erfasst, da eine Begrenzung der ex tunc-Wirkung bis zu einem in der Zukunft liegenden Zeitpunkt ausscheidet. Das DI-Urteil des Gerichtshofs macht deutlich, dass für eine Begrenzung vergangenheitsbezogener Wirkungen des Unionsrechts aus Rechtssicherheitsgründen allein die Maßstäbe der Defrenne-Rechtsprechung heranzuziehen sind. Von einer in zeitlicher Hinsicht nicht begrenzten Auslegung des Gerichtshofs unberührt bleibt lediglich der Grundsatz der Verfahrensautonomie der Mitgliedstaaten. Wahrt mitgliedstaatliches Verfahrensrecht die unionsrechtlichen Grenzen des Äquivalenz- und Effektivitätsgrundsatzes, kommt dieses trotz unterbliebener Begrenzung im Sinne der Defrenne-Rechtsprechung weiterhin zur Anwendung; eine Durchbrechung der Bestands- und Rechtskraft kommt trotz der ex tunc-Wirkung der Auslegung des Unionsrechts nur ganz ausnahmsweise in Betracht.

Eine „allgemeine“ Begrenzung vergangenheitsbezogener Wirkungen des ausgelegten Unionsrechts etwa durch Heranziehung des nationalen Vertrauensschutzgrundsatzes ist den mitgliedstaatlichen Gerichten also verwehrt; sie kommt nur punktuell durch Anwendung nationaler Verfahrensregeln in Betracht. In diesem Bereich ist der Spielraum mitgliedstaatlicher

1635 Ebenso Rosenkranz, ZESAR 2018, 24 (25).

1636 In diesem Sinne auch Rosenkranz, ZfPW 2016, 351 (382). Angesichts der bei Zugrundelegung dieser Auffassung zwischen unmittelbar und mittelbar wirkendem Unionsrecht bestehenden Unterschiede kritisch Sagan, NZA 2015, 341 (342). 
Gerichte aber vergleichsweise groß, da er seine Grenzen „nur“ im Äquivalenz- und Effektivitätsgrundsatz findet. Wie das Urteil des Gerichtshofs in den verbundenen Rechtssachen Gutiérrez Naranjo u.a. zeigt, wacht der EuGH genau darüber, dass nicht unter Berufung auf verfahrensrechtliche Grundsätze eine Einmischung in seinen Kompetenzbereich erfolgt.

Was die temporäre Suspendierung des Anwendungsvorrangs des Unionsrechts im Sinne der Winner Wetten-Rechtsprechung anbelangt, hat der Gerichtshof einen etwas anderen Ansatz gewählt. Auch wenn das Verhältnis von EuGH und mitgliedstaatlichen Gerichten insoweit noch nicht vollständig geklärt ist, so haben die oben angestellten Untersuchungen doch deutliche Hinweise dafür hervorgebracht, dass der EuGH seine im Rechtsgedanken des Art. 264 II AEUV wurzelnde umfassende Zuständigkeit für die Suspendierung des Anwendungsvorrangs aus Rechtssicherheitserwägungen zum Teil - hinsichtlich des Umweltschutzes und der Stromversorgungssicherheit eines Mitgliedstaates - auf die mitgliedstaatlichen Gerichte übertragen hat, wenn diese über eine entsprechende Befugnis nach ihrem nationalen Recht verfügen, bestimmte Wirkungen unionsrechtswidrigen nationalen Rechts aufrechtzuerhalten. Bei der Winner Wetten-Rechtsprechung geht es daher insbesondere darum, die Entstehung eines auch aus Sicht des Unionsrechts nachteiligen Rechtsvakuums zu verhindern, das die zukunftsbezogenen Wirkungen des Unionsrechts sonst dadurch schaffen könnten, dass sie unionsrechtswidriges nationales Recht verdrängen. Sollen unter Berufung auf die Winner Wetten-Rechtsprechung vergangenheitsbezogene Wirkungen des Unionsrechts begrenzt werden, kommt das von vornherein nur in Betracht, wenn keine Erwägungen ins Feld geführt werden, denen im Rahmen der Defrenne-Rechtsprechung hätte Rechnung getragen werden können.

Sowohl der vergangenheits- als auch der zukunftsbezogenen Nichtanwendung unionsrechtswidrigen nationalen Rechts sind also Grenzen gesetzt. Die Aufgabenverteilung zwischen EuGH und mitgliedstaatlichen Gerichten hat der EuGH insoweit jeweils unterschiedlich ausgestaltet. ${ }^{1637}$

1637 Siehe zum Ganzen eingehend auch Dougan, CMLRev. 56 (2019), 1459 (1471, $1474 \mathrm{f} ., 1476,1479,1499)$ sowie bereits oben bei Fn. $1086 \mathrm{ff} .$, Fn. $1224 \mathrm{ff} .$, Fn. 1504 ff., Fn. 1588 ff. zu den vorstehend angesprochenen Einzelfragen. 
V. Besonderheiten bei individuellen Rechtspositionen gegenüber dem Mitgliedstaat

Im Hinblick auf die Gewährung "nationalen Vertrauensschutzes“ aufgrund von Vertrauen in die nationale Rechtslage hat sich die DefrenneRechtsprechung wie soeben gesehen als abschließend erwiesen. ${ }^{1638}$ Dennoch sind (neben den unter die nationale Verfahrensautonomie fallenden Konstellationen) Fallgestaltungen denkbar, in denen das Unionsrecht trotz der Ablehnung einer Aktivierung der Defrenne-Rechtsprechung durch den Gerichtshof Einschränkungen seiner Durchsetzung hinnimmt. Deutlich wird dies etwa an verwaltungsrechtlichen Fallgestaltungen, in denen der Grundsatz des Vertrauensschutzes, aber auch der Rechtssicherheit entscheidende Bedeutung erlangt hat. Einzugehen ist an dieser Stelle daher auf zwei Urteile des EuGH, die sich dadurch auszeichnen, dass im einen Fall die Defrenne-Rechtsprechung in einem verwaltungsrechtlichen Zusammenhang Bedeutung erlangte und im anderen Fall nationale Vorschriften einen Anknüpfungspunkt für Vertrauen bildeten. Im Anschluss an ihre Darstellung ist die Frage aufgeworfen, inwieweit die dort angestellten Überlegungen auf andere Fallgestaltungen übertragbar sind.

\section{Defrenne-Rechtsprechung und Verwaltungsrecht}

Im ersten Fall hatte eine Erzeugerorganisation für Tiefkühlgemüse die Förderung eines operationellen Programms für die Jahre 2010-2014 und damit eine Beihilfe der EU u.a. für die Anschaffung einer Spinatverarbeitungslinie zur Verarbeitung von frisch geerntetem Spinat zu Tiefkühlspinat beantragt. Die Verarbeitungslinie befand sich auf dem Gelände eines Vertragspartners der Erzeugerorganisation. Der Bundesminister für Landund Forstwirtschaft, Umwelt und Wasserwirtschaft als zuständige österreichische Behörde genehmigte das operationelle Programm im Januar 2010 und stufte die Investition - in Kenntnis des Standorts der Verarbeitungslinie - als beihilfefähig ein. Die Agrarmarkt Austria, die (in der Rechtsform einer juristischen Person des öffentlichen Rechts) in diesem Fall als Zahlstelle auftrat, ordnete die Investition in die Verarbeitungslinie im Oktober 2015 als nicht beihilfefähig ein, verweigerte die Zahlung des Restbetrags,

1638 Siehe hierzu näher oben bei Fn. 1585 ff. 
d.h. der Beihilfe für das Jahr 2014, und verlangte die Rückzahlung der für diese Investition bereits gewährten Beihilfe. ${ }^{1639}$

Nr. 23 des Anhangs IX der Durchführungsverordnung Nr. 543/2011 ${ }^{1640}$ schließt Investitionen, die nicht in den Liegenschaften und/oder Räumlichkeiten der Erzeugerorganisation stattfinden, von der Förderung aus. Entscheidend für die Beihilfefähigkeit war daher, ob dieser autonome unionsrechtliche Begriff dahingehend zu verstehen ist, dass die Liegenschaft/Räumlichkeit im Eigentum der Erzeugerorganisation stehen muss oder ob auch eine gewisse Ausübung von Kontrolle darüber genügt. Da ausgeschlossen werden soll, dass Dritte in den Genuss der Beihilfe kommen, sprach sich der Gerichtshof dafür aus, dass die Liegenschaft/Räumlichkeit „sowohl rechtlich als auch tatsächlich unter der alleinigen Kontrolle der Erzeugerorganisation“ stehen muss, „so dass jede Nutzung der Investitionen zugunsten eines Dritten ausgeschlossen ist“. Das war im Ausgangsverfahren allerdings nicht der Fall. Ausschlaggebend für den Ausschluss der Förderung war also nicht, dass die Investition auf einem fremden Grundstück erfolgte - danach hatte das vorlegende Gericht gefragt - sondern, dass die Räumlichkeit nicht unter der alleinigen Kontrolle der Erzeugerorganisation stand. Die zuständige österreichische Behörde hatte bei Genehmigung des operationellen Programms „volle Kenntnis von den Modalitäten" hinsichtlich der Verarbeitungslinie. ${ }^{1641}$

In seinem Vorlagebeschluss hatte das österreichische Bundesverwaltungsgericht zutreffend darauf hingewiesen, dass ein Beihilfeempfänger ein Interesse an einer für ihn günstigen Auslegung der die Grundlage der Beihilfe bildenden unionsrechtlichen Rechtsgrundlagen hat. Erfolgt die Auslegung durch den Gerichtshof dann nicht im Sinne des Beihilfeempfängers, wird er auf eine Begrenzung der ex tunc-Wirkung der Auslegung dringen. Sollte diese deshalb unterbleiben, weil der EuGH nur eine generalisierende und objektivierte Betrachtung anstellt und daher individuelle Fälle nicht in den Blick nimmt, wird er im nationalen Gerichtsverfahren die besonderen individuellen Umstände seines Falles ins Feld führen, um

1639 EuGH, Urteil vom 20.12.2017, Rs. C-516/16 (Erzeugerorganisation Tiefkühlgemüse), Rn. 28 ff., 66.

1640 Durchführungsverordnung (EU) Nr. 543/2011 der Kommission vom 7. Juni 2011 mit Durchführungsbestimmungen zur Verordnung (EG) Nr. 1234/2007 des Rates für die Sektoren Obst und Gemüse und Verarbeitungserzeugnisse aus Obst und Gemüse, ABl. L 157 vom 15.6.2011, S. 1.

1641 EuGH, Urteil vom 20.12.2017, Rs. C-516/16 (Erzeugerorganisation Tiefkühlgemüse), Rn. 42 ff., insb. Rn. 56 f., 59 und 67. 
die Rückforderung der Beihilfe zu vermeiden oder die Auszahlung zugesicherter Beträge zu erzwingen. ${ }^{1642}$

An diesen Ausführungen des österreichischen Bundesverwaltungsgerichts zeigt sich, dass die Untersuchung der Kriterien der Defrenne-Rechtsprechung durch den EuGH jedenfalls nicht als im Vergleich zu einer Prüfung auf nationaler Ebene speziellere Prüfung angesehen werden kann: Im Rahmen der Defrenne-Rechtsprechung legt der EuGH im Hinblick auf den guten Glauben einen objektivierten Maßstab zugrunde und lässt das Betroffensein Einzelner nicht genügen, da das Merkmal der Gefahr schwerwiegender Störungen eine systemische Verwerfung erfordert. Im Verfahren vor dem mitgliedstaatlichen Gericht steht dagegen eine Berücksichtigung individueller Umstände im Vordergrund. Eine ihm verwehrte Beurteilung der der Defrenne-Rechtsprechung zugrundeliegenden Kriterien würde das mitgliedstaatliche Gericht durch die Berücksichtigung individueller Umstände also nicht vornehmen.

Deutlich geworden ist damit auch, dass im hier vorgestellten Fall grundsätzlich verschiedene Möglichkeiten in Betracht kommen, um eine Rückzahlung der bereits gewährten Beihilfe zu verhindern und die Zahlung des Restbetrags zu erreichen.

$\mathrm{Zu}$ denken ist zunächst an den Grundsatz des Vertrauensschutzes als tragender Grundsatz der Union. ${ }^{1643}$ Dessen Inhalt wird durch eine Abwägung zwischen den der Beibehaltung bestehender Rechtsverhältnisse zugrundeliegenden privaten Interessen und dem durch den Grundsatz der Gesetzmäßigkeit zum Ausdruck kommenden öffentlichen Interesse an der wirksamen Anwendung des Unionsrechts bestimmt. Ob die Erwartung der betroffenen Einzelnen Vorrang hat, bestimmt sich „anhand einer spezifischen Untersuchung der jeder Rechtssache eigenen tatsächlichen Umstände“, weshalb die Situation des jeweiligen Falls entscheidend ist. ${ }^{1644}$ Vertrauen kann also „nur konkret im jeweiligen Fall bestimmt und geschützt werden“, was den Grundsatz des „individuellen“ Vertrauensschutzes von demjenigen der „allgemeinen“ Rechtssicherheit unterscheidet, die „ein abstrakter Wert“ ist. ${ }^{1645}$

1642 Siehe BVwG, Vorlagebeschluss vom 27.9.2016, W230.2122334 unter 8. (zur Vorlagefrage IV).

1643 Siehe nur EuGH, Urteil vom 14.3.2013, Rs.C-545/11 (Agrargenossenschaft Neuzelle), Rn. 23.

1644 GA Mengozzi, Schlussanträge vom 30.5.2018 in der Rs. C-120/17 (Ministru kabinets), Rn. 50 f., 55.

1645 Martens, JZ 2011, 348 (352f.). Eine Abwägung mit dem Einzelfall muss aber nicht zwingend erfolgen; „typisierende“ Abwägungen genügen den Anforde- 
Vertrauensschutz kann aber nach der Rechtsprechung des Gerichtshofs „nicht gegen eine klare unionsrechtliche Bestimmung“ ins Feld geführt werden; zudem wirkt „das unionsrechtswidrige Verhalten einer mit der Anwendung des Unionsrechts betrauten nationalen Behörde" nicht vertrauensbegründend. Da seit langem bekannt gewesen sei, dass aus Gründen der Wettbewerbsgleichheit eine „enge Auslegung“ zwingend sei, was die Voraussetzungen für die Gewährung einer EU-Beihilfe im Rahmen der Gemeinsamen Agrarpolitik betreffe, könne gegen Nr. 23 des Anhangs IX der Durchführungsverordnung kein Vertrauensschutz gewährt werden. Da die zuständige österreichische Behörde nicht zur Zusage einer unionsrechtswidrigen Behandlung befugt war, sei trotz der Genehmigung des operationellen Programms und der bereits erfolgten Zahlungen für die Investition unabhängig vom guten Glauben der Erzeugerorganisation kein berechtigtes Vertrauen begründet worden. Der Grundsatz des Vertrauensschutzes konnte der Ablehnung der Zahlung des Restbetrags der Beihilfe und der Rückforderung der bereits gewährten Beihilfe daher nicht entgegengehalten werden. ${ }^{1646}$

Dass der Gerichtshof davon ausgeht, dass es bei Nr. 23 des Anhangs IX der Durchführungsverordnung um eine klare unionsrechtliche Bestimmung geht, überzeugt allerdings vor dem Hintergrund nicht, dass er der Auslegung der Bestimmung zahlreiche Randnummern widmen musste. ${ }^{1647}$ So klar wie er vorgibt, kann die unionsrechtliche Bestimmung demnach nicht sein.

Der Versuch, der Rückzahlung der Beihilfe durch eine Aktivierung der Defrenne-Rechtsprechung entgegenzutreten, blieb ebenfalls erfolglos. Die österreichische Regierung hatte für den Fall der Verneinung der Beihilfefähigkeit der Investitionen zwar eine zeitliche Begrenzung im Sinne der Defrenne-Rechtsprechung beantragt. ${ }^{1648}$ Wegen ihres fehlenden Nachweises des Bestehens einer Gefahr schwerwiegender wirtschaftlicher Auswirkun-

rungen, siehe Osterloh, StuW 2015, 201 (206), allerdings mit Blick auf die Problematik der Rückwirkung von Gesetzen im deutschen Recht.

1646 EuGH, Urteil vom 20.12.2017, Rs. C-516/16 (Erzeugerorganisation Tiefkühlgemüse), Rn. 66 ff. Siehe auch EuGH, Urteil vom 20.6.2013, Rs. C-568/11 (Agroferm), Rn. 52.

1647 Vgl. van den Brink/den Ouden, AB Rechtspraak Bestuursrecht 2018, 1112 (1113).

1648 Zum Vorbringen der österreichischen Regierung siehe EuGH, Urteil vom 20.12.2017, Rs. C-516/16 (Erzeugerorganisation Tiefkühlgemüse), Rn. 86 f. 
gen lehnte der Gerichtshof eine zeitliche Begrenzung aber ab. Das Kriterium des guten Glaubens untersuchte er dementsprechend nicht mehr. ${ }^{1649}$

Im Rahmen der Frage, ob für die Erzeugerorganisation "gleichwohl“ eine Berufung auf den Grundsatz der Rechtssicherheit möglich sei, verwies der EuGH auf Art. 4 III EUV (und Vorschriften aus Verordnungen aus dem Bereich der Gemeinsamen Agrarpolitik) und führte aus, dass die Mitgliedstaaten für die Durchführung der Gemeinsamen Agrarpolitik zu sorgen hätten. In den Grenzen von Effektivitäts- und Äquivalenzgrundsatz sei dies aber eine Frage des nationalen Rechts, wobei das nationale Recht auch den Grundsatz der Rechtssicherheit berücksichtigen dürfe, der Bestandteil der Unionsrechtsordnung ist. Er verlangt, dass die Betroffenen den Umfang der ihnen mit einer Unionsregelung auferlegten Verpflichtungen genau erkennen können, sodass sie in der Lage sind, ihre Rechte und Pflichten eindeutig zu erkennen und sich darauf einzustellen. ${ }^{1650}$ Die systematische und teleologische Auslegung von Nr.23 des Anhangs IX der Durchführungsverordnung habe aber gezeigt, dass dies bei dieser Bestimmung der Fall sei. Auch sonst müsse dem Interesse der Union an der Rückforderung von unionsrechtswidrigen Beihilfen „in vollem Umfang Rechnung getragen werden“; der Begünstigte müsse hinsichtlich der Rechtmäßigkeit der Beihilfe guten Glaubens gewesen sein. ${ }^{1651}$ Der Gerichtshof endet mit der Feststellung, dass die unterbliebene zeitliche Begrenzung im Sinne der Defrenne-Rechtsprechung einer Heranziehung des Grundsatzes der Rechtssicherheit gegen die Rückzahlung einer zu Unrecht gezahlten Beihilfe nicht entgegensteht, sofern dem Äquivalenzgrundsatz Genüge getan ist, das Unionsinteresse vollumfänglich berücksichtigt wird und der gute Glaube des Begünstigten nachgewiesen ist. ${ }^{1652}$

Damit bleibt festzuhalten: Eine Begrenzung der Wirkungen der ausgelegten Norm im Sinne der Defrenne-Rechtsprechung hat der Gerichtshof abgelehnt. Unionsrechtlicher Vertrauensschutz kommt angesichts der Klarheit der betroffenen Norm des Unionsrechts nicht in Betracht. Eine

1649 EuGH, Urteil vom 20.12.2017, Rs. C-516/16 (Erzeugerorganisation Tiefkühlgemüse), Rn. $91 \mathrm{ff}$.

1650 EuGH, Urteil vom 20.12.2017, Rs. C-516/16 (Erzeugerorganisation Tiefkühlgemüse), Rn. $94 \mathrm{ff}$.

1651 EuGH, Urteil vom 20.12.2017, Rs. C-516/16 (Erzeugerorganisation Tiefkühlgemüse), Rn. $99 \mathrm{ff}$.

1652 EuGH, Urteil vom 20.12.2017, Rs. C-516/16 (Erzeugerorganisation Tiefkühlgemüse), Rn. 102. 
Berücksichtigung des Rechtssicherheitsgrundsatzes im nationalen Recht ist dennoch nicht ausgeschlossen. ${ }^{1653}$

Was die Berücksichtigung des nationalen Rechtssicherheits- und Vertrauensschutzgrundsatzes bei der Rückforderung von Beihilfen betrifft, sind nach der Rechtsprechung des Gerichtshofs unterschiedliche Konstellationen auseinanderzuhalten. In den verbundenen Rechtssachen Deutsche Milchkontor u.a. hatte der Gerichtshof ausgeführt, dass die Grundsätze des Vertrauensschutzes und der Rechtssicherheit Bestandteil der Unionsrechtsordnung seien, sodass es dieser Rechtsordnung nicht widerspreche, wenn das nationale Recht in einem Bereich wie der Rückforderung von zu Unrecht gezahlten Gemeinschaftsbeihilfen (in den Grenzen der Äquivalenz und Effektivität) berechtigtes Vertrauen und Rechtssicherheit schütze. ${ }^{1654}$ Nach seinen Erläuterungen in der Rechtssache Agroferm richtet sich die Anwendung des Vertrauensschutzgrundsatzes dagegen nach den Regeln des Unionsrechts, wenn die betroffene unionsrechtliche Bestimmung eine Verpflichtung der Mitgliedstaaten begründet, die infolge von Unregelmäßigkeiten oder Versäumnissen abgeflossenen Beträge wiedereinzuziehen, sie also eine Rückforderungsverpflichtung aufstellt. ${ }^{1655}$ Obwohl Letzteres auch in der vorliegenden Rechtssache der Fall war, ist es nach dem Erzeugerorganisation Tiefkühlgemüse-Urteil denkbar, dass der nationale Rechtssicherheitsgrundsatz einer Rückforderung der Beihilfe entgegensteht. Der Gerichtshof betont, dass (in Übereinstimmung mit den Ausführungen in den verbundenen Rechtssachen Deutsche Milchkontor u.a. und anders als in der Rechtssache Agroferm) bei der Anwendung des Rechtssicherheitsgrundsatzes Verfahrensautonomie besteht. ${ }^{1656}$

Was der nationale Rechtssicherheitsgrundsatz bewirken kann, bleibt aber undeutlich. Obwohl die Vorschrift des Unionsrechts klar ist, soll das nationale Gericht zu dem Ergebnis gelangen können, dass die Bei-

1653 Nach Einschätzung von van den Brink/den Ouden, AB Rechtspraak Bestuursrecht 2018, 1112 könnte der Fall daher ein „Klassiker“ werden.

1654 EuGH, Urteil vom 21.9.1983, verb. Rs. 205/82 bis 215/82 (Deutsche Milchkontor u.a.), Rn. 30.

1655 EuGH, Urteil vom 20.6.2013, Rs. C-568/11 (Agroferm), Rn. 50 f.

1656 EuGH, Urteil vom 20.12.2017, Rs. C-516/16 (Erzeugerorganisation Tiefkühlgemüse), Rn.96f. verweist einerseits auf EuGH, Urteil vom 19.9.2002, Rs. C-336/00 (Huber), Rn. 56 und die dort angeführte Rechtsprechung, nimmt also auch EuGH, Urteil vom 21.9.1983, verb. Rs. 205/82 bis 215/82 (Deutsche Milchkontor u.a.), Rn. 30 in Bezug, und verweist andererseits auf EuGH, Urteil vom 21.6.2007, Rs. C-158/06 (ROM-projecten), Rn. 24, wo auch EuGH, Urteil vom 21.9.1983, verb. Rs. 205/82 bis 215/82 (Deutsche Milchkontor u.a.), Rn. 30 zitiert wird. 
hilfe wegen Entgegenstehens des nationalen Rechtssicherheitsgrundsatzes nicht zurückgefordert werden kann, wenn bestimmte Bedingungen erfüllt sind. 1657

Die Urteile, auf die der EuGH zur Begründung dieser Aussage verweist ${ }^{1658}$, betreffen allerdings eine ganz andere Situation, da die unionsrechtliche Verpflichtung in diesen Fällen für den Beihilfeempfänger nicht oder nur sehr schwer feststellbar war, während es in Erzeugerorganisation Tiefkühlgemüse wie gesehen nach Aussage des Gerichtshofs um eine klare unionsrechtliche Bestimmung geht. ${ }^{1659}$ In der in Bezug genommenen Rechtssache ROM-projecten führte der Gerichtshof aus, dass es der Grundsatz der Rechtssicherheit verbiete, dem Endbegünstigten eines Gemeinschaftszuschusses in der Zuschussentscheidung genannte Bedingungen entgegenzuhalten, von denen dieser keine Kenntnis hat. Der Rückforderung des Zuschusses könne sich der Begünstigte dann widersetzen, wenn er hinsichtlich der Rechtmäßigkeit der Zuschussgewährung gutgläubig war. ${ }^{1660}$ In der ebenfalls in Bezug genommenen Rechtssache Huber hatte der Gerichtshof die Kriterien für den guten Glauben hinsichtlich der Rechtmäßigkeit der Beihilfe näher beschrieben. Zu prüfen ist demnach u.a., wie klar die Beihilfebedingungen gefasst sind und ob sie dem Betroffenen bekannt sind. Im Falle fehlender Kenntnis ist zu prüfen, ob der Betroffene eine Fahrlässigkeit begangen hat, die ein durchschnittlich sorgfältiger Landwirt nicht begangen hätte, indem er sich keine genaue Kenntnis von den Beihilfebedingungen durch Einsichtnahme beim zuständigen Ministerium verschafft hat oder ob dies eine übermäßige Belastung dargestellt hätte. ${ }^{1661}$

Damit geht es bei der Frage des guten Glaubens hinsichtlich der Rechtmäßigkeit der Beihilfe um einen anderen Maßstab als denjenigen im Rahmen der Defrenne-Rechtsprechung. In Rede steht damit nicht guter Glaube hinsichtlich des Verständnisses des Unionsrechts, sondern hinrei-

1657 Siehe insoweit EuGH, Urteil vom 20.12.2017, Rs. C-516/16 (Erzeugerorganisation Tiefkühlgemüse), Rn.100-102. Danach besteht in Fällen von Fehlern der nationalen Ausführungsbehörde die Möglichkeit einer „Untergrabung“ der Agroferm-Rechtsprechung des Gerichtshofs durch nationale Rechtssicherheitserwägungen, vgl. van den Brink/den Ouden, $\mathrm{AB}$ Rechtspraak Bestuursrecht 2018, 1112 (1115).

1658 EuGH, Urteil vom 21.6.2007, Rs. C-158/06 (ROM-projecten) und EuGH, Urteil vom 19.9.2002, Rs. C-336/00 (Huber).

1659 van den Brink/den Ouden, AB Rechtspraak Bestuursrecht 2018, 1112 (1114f.).

1660 EuGH, Urteil vom 21.6.2007, Rs. C-158/06 (ROM-projecten), Rn. 30 und 31.

1661 EuGH, Urteil vom 19.9.2002, Rs. C-336/00 (Huber), Rn. 58. 
chende Kenntnis bzw. fahrlässige Unkenntnis der Beihilfebedingungen. Diesen Unterschied verschleiert der Gerichtshof in seinem Erzeugerorganisation Tiefkühlgemüse-Urteil allerdings. Die Bedeutung der Ausführungen des Gerichtshofs für das diesem Urteil zugrundeliegende Ausgangsverfahren ist daher alles andere als klar. ${ }^{1662}$ Dass der nationale Rechtssicherheitsgrundsatz der Rückforderung der Beihilfe im konkreten Fall tatsächlich entgegensteht, erscheint jedenfalls nicht denkbar.

\section{Nationales Recht als Anknüpfungspunkt für Vertrauensschutz}

Im zweiten hier vorzustellenden Fall, der „lettischen“ Rechtssache Ministru kabinets, ging es um die Gültigkeit öffentlich-rechtlicher Verträge über die Gewährung einer Vorruhestandsbeihilfe in der Landwirtschaft sie wird einem älteren Landwirt als Gegenleistung für die Abgabe seines Betriebs gewährt - auf der Grundlage der Art. 10 bis 12 der Verordnung (EG) Nr. 1257/19991663. Der Rechtssache zugrunde lag die Frage, ob diese Vorschriften es den Mitgliedstaaten erlauben oder verbieten, „im Rahmen der Durchführung dieser Artikel Maßnahmen zu erlassen, nach denen die Vorruhestandsbeihilfe durch Vererbung übertragen werden kann“. Für die vorliegenden Zwecke von Interesse ist die Rechtssache deshalb, weil sich in ihr die Frage stellte, ob eine nationale Rechtsvorschrift, die die Übertragung der Vorruhestandsbeihilfe durch Vererbung vorsah und von der Kommission als mit der Verordnung vereinbar genehmigt wurde, bei den Erben der Landwirte ein berechtigtes Vertrauen in die Übertragbarkeit der Beihilfe durch Vererbung begründet hat. ${ }^{1664}$

Beim Erlass von Maßnahmen zur Durchführung des Unionsrechts und damit auch bei der Durchführung der Vorruhestandsbeihilfe ist der Grundsatz des Vertrauensschutzes zu beachten. Auf ihn kann sich jeder berufen, bei dem eine nationale Verwaltungsbehörde aufgrund bestimmter Zusicherungen, die sie ihm gegeben hat, begründete Erwartungen geweckt hat. Die Verwaltungsbehörde muss in der Vorstellung des Einzelnen also ein vernünftiges Vertrauen („reasonable expectation“/,une confiance rai-

1662 van den Brink/den Ouden, AB Rechtspraak Bestuursrecht 2018, 1112 (1115).

1663 Verordnung (EG) Nr. 1257/1999 des Rates vom 17. Mai 1999 über die Förderung der Entwicklung des ländlichen Raums durch den Europäischen Ausrichtungs- und Garantiefonds für die Landwirtschaft (EAGFL) und zur Änderung bzw. Aufhebung bestimmter Verordnungen, ABl. L 160 vom 26.6.1999, S. 80.

1664 EuGH, Urteil vom 7.8.2018, Rs. C-120/17 (Ministru kabinets), Rn. 30, 47. 
sonnable“) begründet haben; dieses muss zudem berechtigt („legitimate“/ "caractère légitime") sein. $\mathrm{Zu}$ beachten ist wiederum, dass Vertrauensschutz nicht gegen eine klare unionsrechtliche Bestimmung möglich ist und dass das unionsrechtswidrige Verhalten einer mit der Anwendung des Unionsrechts betrauten nationalen Behörde kein berechtigtes Vertrauen eines Einzelnen darauf begründen kann, in den Genuss einer unionsrechtswidrigen Behandlung zu kommen. ${ }^{1665}$

In den Art. 10 bis 12 der Verordnung (EG) Nr. 1257/1999 wird die Übertragung des Anspruchs auf Vorruhestandsbeihilfe durch Vererbung weder erlaubt noch verboten. Ausgelegt im Lichte ihrer Zielsetzungen ergibt sich jedoch, dass die entsprechenden Vorschriften der Verordnung die Vorruhestandsbeihilfe auf die Person des seinen Betrieb abgebenden Landwirts beziehen. Diese personenbezogene Natur der Beihilfe steht einer Übertragung auf die Erben entgegen, sodass die Art. 10 bis 12 der Verordnung es den Mitgliedstaaten im Ergebnis verbieten, Durchführungsvorschriften zu erlassen, die die Übertragung der Beihilfe durch Vererbung vorsehen. ${ }^{1666}$

Da die Art. 10 bis 12 der Verordnung nach Auffassung des Gerichtshofs keine klaren unionsrechtlichen Bestimmungen sind, konnten die Betroffenen dies aber nicht unzweifelhaft erkennen. In diesen Bestimmungen ist ja nicht angegeben, ob ein Mitgliedstaat für ihre Durchführung die Übertragung des Anspruchs auf Vorruhestandsbeihilfe durch Vererbung vorsehen kann. ${ }^{1667}$ Aus Sicht der Betroffenen kam hinzu, dass die Kommission den lettischen Entwicklungsplan, der die Übertragung der Vorruhestandsbeihilfe durch Vererbung vorsah, inhaltlich auf seine Vereinbarkeit mit der Verordnung geprüft und daraufhin genehmigt hatte. Außerdem bestätigte die Unterzeichnung der Verträge über die Gewährung der Vorruhestandsbeihilfe durch den lettischen Dienst zur Unterstützung des ländlichen Raums ${ }^{1668}$ das Vertrauen auf die Rechtmäßigkeit der Übertragung der Beihilfe durch Vererbung. ${ }^{1669}$ All diese Aspekte führten dazu, dass die

1665 EuGH, Urteil vom 7.8.2018, Rs. C-120/17 (Ministru kabinets), Rn. 50 ff.

1666 EuGH, Urteil vom 7.8.2018, Rs. C-120/17 (Ministru kabinets), Rn. 30 ff.

1667 EuGH, Urteil vom 7.8.2018, Rs. C-120/17 (Ministru kabinets), Rn. $54 \mathrm{f}$.

1668 Dass der lettische Dienst befugt ist, den Staat zur Gewährung der Beihilfe zu verpflichten, nährt bei den Betroffenen die Erwartung, dass dieser unionsrechtsgemäß handelt, so zu Recht van den Brink/den Ouden, AB Rechtspraak Bestuursrecht 2019, 242 (244).

1669 Als Vertrauen begründende Rechtsakte der lettischen Behörden waren hier also das Dekret des Ministerrats von 2004, das die Grundlage des Entwicklungsplans bildete, der Entwicklungsplan und die Verträge über die Gewährung 
Rechtsakte der lettischen Behörden vernünftiges Vertrauen der Erben ${ }^{1670}$ in die Übertragbarkeit der Beihilfe durch Vererbung begründeten. ${ }^{1671}$

Die vorstehenden Ausführungen zeigen, dass sich aus einer nicht mit dem Unionsrecht vereinbaren nationalen Praxis schützenswertes Vertrauen ergeben kann. Entscheidend kommt es insoweit auf die unionsrechtliche Bestimmung an, auf der die rechtswidrige Praxis der nationalen Behörden beruht. Ausschlaggebend ist, ob diese Bestimmung „klar“/,précise“/,precisa“ ist oder nicht. Wie die englische Sprachfassung zeigt, ist „klar“ im Sinne von „unambiguous“ zu verstehen. Da die Art. 10 bis 12 der Verordnung Raum für abweichende Auslegungen lassen, sind sie nicht „klar“, weswegen vernünftiges Vertrauen trotz Verstoßes der nationalen Praxis gegen diese Bestimmungen begründet werden kann. ${ }^{1672}$

Der EuGH verlangt wie gesehen zudem, dass das vernünftige Vertrauen auch berechtigt ist, um als schützenswert anerkannt zu werden. Das Vertrauen ist nach Auffassung des Gerichtshofs berechtigt, „wenn sich der Einzelne, der sich darauf beruft, in einer besonderen, als schutzwürdig zu qualifizierenden Situation wie der im Ausgangsverfahren fraglichen befindet“. Mit der Genehmigung der nationalen Regelung durch die Kommission, ihrer nicht erkennbaren Unvereinbarkeit mit der Verordnung und der in den Verträgen über die Gewährung der Vorruhestandsbeihilfe erfolgten Konkretisierung führt der Gerichtshof an dieser Stelle allerdings lediglich Gesichtspunkte an, die er bereits zuvor im Rahmen der Prüfung vernünftigen Vertrauens erwähnt hatte. ${ }^{1673}$

der Vorruhestandsbeihilfe durch den Dienst zur Unterstützung des ländlichen Raums anzusehen.

1670 van den Brink/den Ouden, AB Rechtspraak Bestuursrecht 2019, 242 (244f.) sind der Auffassung, dass die Erben auch deshalb beim Vertragsschluss nicht bösgläubig sein konnten, da sie keine Vertragsparteien waren.

1671 EuGH, Urteil vom 7.8.2018, Rs. C-120/17 (Ministru kabinets), Rn. 56 ff.

1672 GA Mengozzi, Schlussanträge vom 30.5.2018 in der Rs. C-120/17 (Ministru kabinets), Rn. $57 \mathrm{ff}$. Er teilt damit, wie er selbst ausführt, die von GA StixHackl, Schlussanträge vom 1.12.2005 in den verb. Rs. C-181/04 bis C-183/04 (Elmeka), Rn. 43-45 und von GA Kokott, Schlussanträge vom 24.1.2013 in der Rs. C-568/11 (Agroferm), Rn. 59 vertretene Auffassung, wonach es für die Frage des Vertrauensschutzes entscheidend auf das der nationalen Praxis zugrundeliegende Unionsrecht ankommt, siehe GA Mengozzi, a.a.O., Rn. 60 mit Fn. 23.

1673 EuGH, Urteil vom 7.8.2018, Rs. C-120/17 (Ministru kabinets), Rn. 63 unter Verweis auf GA Mengozzi, Schlussanträge vom 30.5.2018 in der Rs. C-120/17 (Ministru kabinets), Rn.52. Siehe zur Prüfung des Vorliegens berechtigten Vertrauens Rn. 62 ff. des Urteils. 
Auch wenn im Grundsatz gilt, dass unionsrechtswidriges Verhalten einer für die Anwendung des Unionsrechts zuständigen nationalen Stelle kein berechtigtes Vertrauen darauf begründen kann, in den Genuss einer unionsrechtswidrigen Behandlung zu kommen ${ }^{1674}$, ist es in Angelegenheiten des Unionsrechts also durchaus denkbar, dass sich Betroffene auf Entscheidungen nationaler Behörden und Gerichte verlassen dürfen. ${ }^{1675} \mathrm{Da}$ raus, dass in manchen Urteilen des Gerichtshofs nur von den „zuständigen Unionsbehörden“, einem „Unionsorgan“ oder der „Gemeinschaftsverwaltung" bzw. „Unionsverwaltung“ die Rede ist ${ }^{1676}$, kann nicht geschlossen werden, dass nationale Stellen nicht als Auslöser von Vertrauensschutz in Betracht kämen. Neben Organen der Union kommen für Vertrauen begründende Zusicherungen auch sonstige Stellen in Frage, die „als ,Beauftragte" der Union" handeln. ${ }^{1677}$ Besteht in einem Fall eine ausschließliche Zuständigkeit eines Unionsorgans wie etwa der Kommission, kann ein sorgfältiger Wirtschaftsteilnehmer aus einer nicht von diesem Organ stammenden Entscheidung allerdings kein berechtigtes Vertrauen herleiten. ${ }^{1678}$ Dies erklärt, weshalb beispielsweise eine nationale Behörde bei Unternehmen kein berechtigtes Vertrauen darauf begründen kann, dass das Verhalten der Unternehmen nicht gegen Art. 101 AEUV (Kartellverbot) verstößt: Die nationale Behörde ist nicht dazu befugt, eine Entscheidung zu erlassen, mit der das Fehlen eines Verstoßes gegen Art. 101 AEUV festgestellt wird. ${ }^{1679}$

$\mathrm{Zu}$ erwähnen ist schließlich noch ein weiterer Aspekt der Rechtssache Ministru kabinets. Er betrifft die Frage, ob Schlussfolgerungen, die im Ausschuss für die Entwicklung des ländlichen Raums der Kommission

1674 EuGH, Urteil vom 20.12.2017, Rs. C-516/16 (Erzeugerorganisation Tiefkühlgemüse), Rn. 69 unter Verweis auf EuGH, Urteil vom 1.4.1993, verb. Rs. C-31/91 bis C-44/91 (Lageder u.a.), Rn.35 und EuGH, Urteil vom 20.6.2013, Rs. C-568/11 (Agroferm), Rn. 52. Siehe auch EuGH, Urteil vom 7.4.2011, Rs. C-153/10 (Sony Supply Chain Solutions [Europe]), Rn. 47 unter Verweis u.a. auf EuGH, Urteil vom 26.4.1988, Rs. 316/86 (Krücken), Rn. 24 und EuGH, Urteil vom 16.3.2006, Rs. C-94/05 (Emsland-Stärke), Rn. 31.

1675 Näher hierzu GA Kokott, Schlussanträge vom 28.2.2013 in der Rs. C-681/11 (Schenker \& Co. u.a.), Rn. 85, 87, 92, 93 und 94 m.w.N.

1676 EuGH, Urteil vom 13.6.2013, verb. Rs. C-630/11 P bis C-633/11 P (HGA u.a./ Kommission), Rn. 132; EuGH, Urteil vom 17.3.2011, Rs. C-221/09 (AJD Tuna), Rn. 71; EuGH, Urteil vom 30.4.2019, Rs. C-611/17 (Italien/Rat), Rn. 112.

1677 GA Wabl, Schlussanträge vom 8.6.2017 in der Rs. C-322/16 (Global Starnet), Rn. 63.

1678 EuGH, Urteil vom 15.12.2005, Rs. C-148/04 (Unicredito Italiano), Rn. 107.

1679 EuGH, Urteil vom 18.6.2013, Rs. C-681/11 (Schenker \& Co. u.a.), Rn. 42. 
getroffen wurden, das berechtigte Vertrauen der Erben beendet haben. In den Schlussfolgerungen war sieben Jahre nach der Genehmigung des Entwicklungsplans durch die Kommission der Standpunkt vertreten worden, dass die Übertragung der Vorruhestandsbeihilfe durch Vererbung mit der Verordnung unvereinbar sei. Die Schlussfolgerungen waren allerdings allein an die Mitgliedstaaten gerichtet. Die Erben der Landwirte wussten weder von der Sitzung des Ausschusses noch von dessen Schlussfolgerungen. Da von ihnen auch nicht verlangt werden kann, so umsichtig zu sein, sich selbst über den Inhalt der Schlussfolgerungen zu informieren, haben diese keinen Einfluss auf das berechtigte Vertrauen der Erben. ${ }^{1680}$ Als Privatpersonen gelten für sie damit andere Anforderungen als für "Großunternehmen auf dem Gebiet des Wettbewerbsrechts“. ${ }^{1681}$ Insoweit unterscheidet sich der hier anzulegende Maßstab von dem sonst allgemein bei Vertrauen auf nationales Recht anzulegenden. Dort muss ein einheitlicher Maßstab gegenüber sämtlichen Adressaten gelten und darüber entscheiden, ob Vertrauen gerechtfertigt ist. ${ }^{1682}$

Die Rechtssache Ministru kabinets führt vor Augen, dass dem Verständnis des Unionsrechts in zweierlei Zusammenhängen Bedeutung zukommen kann. Hierbei handelt es sich um die (in Ministru kabinets nicht betroffene) Frage des guten Glaubens im Rahmen der Defrenne-Rechtsprechung einerseits und die (in Ministru kabinets) zentrale Frage des Vorliegens einer klaren unionsrechtlichen Bestimmung im Rahmen der Prüfung des Bestehens von Vertrauen andererseits.

Diese Konzepte unterscheiden sich voneinander, weshalb sich auch die Möglichkeiten für die Berücksichtigung nationalen Rechts voneinander unterscheiden. Hinsichtlich des guten Glaubens im Sinne der DefrenneRechtsprechung wird gefragt, ob eine unionsrechtliche Norm in einem bestimmten Sinne verstanden werden darf. Ist dies nicht der Fall, besteht dennoch die Möglichkeit, dass die Vorschrift „nicht klar“ ist: Sie kann ja noch andere Auslegungen zulassen und damit nicht „unambiguous“ sein. Gutem Glauben im Sinne der Defrenne-Rechtsprechung steht das Vorliegen einer „nicht klaren“ Norm zwar in aller Regel, aber nicht zwingend entgegen.

Die Unterschiedlichkeit der Maßstäbe rechtfertigt sich aus der Unterschiedlichkeit der zugrundeliegenden Situationen, für die sie entwickelt

1680 EuGH, Urteil vom 7.8.2018, Rs. C-120/17 (Ministru kabinets), Rn. 70 ff.

1681 GA Mengozzi, Schlussanträge vom 30.5.2018 in der Rs. C-120/17 (Ministru kabinets), Rn. 92.

1682 Siehe in diesem Zusammenhang auch Frantzen, Staatshaftung, 2018, S. 100. 
wurden. Bei der Prüfung von Vertrauensschutz etwa im Rahmen der Beihilfegewährung ist ein ,individuelles“1683 Element erkennbar. Bedeutung erlangen hier einzelfallbezogene Umstände wie eine Zusicherung durch mitgliedstaatliche Behörden. Auch wenn sie dem geltenden Recht widerspricht, ist sie geeignet, Vertrauen zu begründen, solange die betroffene unionsrechtliche Norm nicht „klar“ ist. Bei der Anwendung abstrakt-genereller Regelungen durch ein nationales Gericht fehlt es an solchen einzelfallbezogenen Umständen regelmäßig. Hier erhalten die Betroffenen in aller Regel keine Zusicherung. ${ }^{1684}$ Daher ist insoweit auch ein anderer Maßstab anzulegen.

Wenn sich in der Rechtssache Ministru kabinets nationale Rechtsnormen als Anknüpfungspunkt für Vertrauensschutz dargestellt haben, ist dies daher mit den Besonderheiten der verwaltungsrechtlichen Konstellation zu erklären, in der hinzukam, dass die zugrundeliegende Verordnung eine inhaltliche Prüfung der nationalen Maßnahmen durch die Kommission vorsah.

\section{Ergebnis}

In den hier vorgestellten Rechtssachen haben sich damit Ansatzpunkte für eine Beachtlichkeit „nationaler Vertrauensumstände“ gezeigt. Zu erklären ist dies aber mit den verwaltungsrechtlichen Besonderheiten der Verfahren. Angesichts ihrer Eigenart ergeben sich aus ihnen daher keine Folgen für den im vorangegangenen Abschnitt behandelten Fall des Vertrauens auf die nationale Rechtslage. Es bleibt damit bei der im DI-Urteil des EuGH getroffenen Aussage, dass die Defrenne-Rechtsprechung und Vertrauen auf die nationale Rechtslage letztlich zum gleichen Ergebnis führen, sodass letzteres bei Fehlen einer zeitlichen Begrenzung im Sinne der Defrenne-Rechtsprechung nicht zum Zurücktreten der unionsrechtlichen Anforderungen führen kann.

1683 Gemeint ist damit ein den Einzelfall betreffendes, nicht aber ein rein „subjektives" Element.

1684 Vgl. Rosenkranz, Beschränkung der Rückwirkung, 2015, S. 486 f. 
VI. Begrenzung des Vorrangs durch Zulassung der Anwendung nationaler Grundrechte?

Zum Abschluss der Betrachtung möglicher Begrenzungen des Anwendungsvorrangs ist im Folgenden besonderes Augenmerk auf die vom Gerichtshof in seinen Urteilen in den Rechtssachen Taricco ${ }^{1685}$ („Taricco I“) und M.A.S. und M.B. ${ }^{1686}$ („Taricco II“) begründete Rechtsprechung zu legen. Im Taricco II-Urteil erblickt etwa Burchardt eine „Relativierung [...] des Anwendungsvorrangs des Unionsrechts“. ${ }^{1687}$ Dubout veranlasst es sogar zur Befürchtung einer Gefährdung der Normativität des Unionsrechts und zu der Frage, ob die im Costa/ENEL-Urteil des Gerichtshofs entworfene Idee einer eigenen Rechtsordnung, der aufgrund ihrer Eigenständigkeit keine innerstaatlichen Rechtsvorschriften vorgehen können ${ }^{1688}$, tot sei. ${ }^{1689}$

Aufgeworfen ist in der Taricco-Konstellation die Frage der unionsrechtlich zugelassenen Berufung auf ein im jeweiligen Mitgliedstaat bestehendes Grundrechtsschutzniveau. Auch hinsichtlich dieser Frage zeigen sich die vielfachen Berührungspunkte zwischen der Unionsrechtsordnung und den nationalen Rechtsordnungen. Diese enge Verbindung hat der Gerichtshof an anderer Stelle durch die Betonung der wechselseitigen Bindung der Union und ihrer Mitgliedstaaten und der Mitgliedstaaten untereinander in einem „strukturierten Netz von miteinander verflochtenen Grundsätzen, Regeln und Rechtsbeziehungen“ zum Ausdruck gebracht. ${ }^{1690}$ Die Auffassungen zur Anwendbarkeit nationaler Grundrechte in unionsrechtlichen Fallgestaltungen sind vielfältig und können hier nur in ihren Grundzügen dargestellt werden; einen unionsrechtlichen Anhaltspunkt hält Art. 53 GRCh bereit, wonach keine Bestimmung der Charta als Einschränkung oder Verletzung der Menschenrechte auszulegen ist, die durch die Verfassungen der Mitgliedstaaten anerkannt werden.

1685 EuGH, Urteil vom 8.9.2015, Rs. C-105/14 (Taricco u.a.).

1686 EuGH, Urteil vom 5.12.2017, Rs. C-42/17 (M.A.S. und M.B.). Die Bezeichnung des M.A.S. und M.B.-Urteils als Taricco II-Urteil rechtfertigt sich dadurch, dass es auf ein Vorabentscheidungsersuchen des italienischen Verfassungsgerichtshofs (Corte costituzionale) im Nachgang zum Taricco-Urteil ergangen ist.

1687 Burchardt, EuR 2018, 248 (248f.).

1688 EuGH, Urteil vom 15.7.1964, Rs. 6/64 (Costa/ENEL), Slg. 1964, S. 1269 f.

1689 Dubout, RTDEur. 2018, 563 (564 ff., 580 ff.).

1690 In diesem Sinne EuGH, Gutachten 2/13 vom 18.12.2014 (Beitritt der Union zur EMRK), Rn. 167. Siehe auch Schmahl, in: Breuer (Hrsg.), Principled Resistance, 2019, S. 299 (322). 
Es gilt daher im Folgenden herauszuarbeiten, ob der Gerichtshof in seinem Taricco II-Urteil den Vorrang des Unionsrechts hinter einem nationalen Grundrechtsstandard hat zurücktreten lassen. In diesem Fall erschiene es nicht ausgeschlossen, diesen Ansatz ebenso für die Frage der Gewährung „nationalen Vertrauensschutzes“ fruchtbar zu machen, da dieser auch grundrechtlich verankert ist.

\section{Die Taricco-Problematik}

Zunächst sind der tatsächliche Hintergrund der Taricco-Problematik sowie die Aussagen des EuGH im Taricco I und II-Urteil darzustellen, um im Anschluss daran den Versuch einer Einordnung in die Systematik des europäischen Grundrechtsschutzes und insbesondere der Auswirkungen auf den Vorrang des Unionsrechts zu unternehmen.

Den Ausgangspunkt der zu besprechenden Verfahren bilden die italienischen Vorschriften über die Verfolgungsverjährung von Mehrwertsteuerstraftaten. Aus unionsrechtlicher Sicht problematisch erscheint dabei die Begrenzung der absoluten Verjährungsfrist nach Verjährungsunterbrechungen. Da Unterbrechungshandlungen im Rahmen der Strafverfolgung von schwerem Mehrwertsteuerbetrug lediglich zu einer Verlängerung der Verjährungsfrist um ein Viertel ihrer ursprünglichen Dauer führen können und eine darüberhinausgehende Verlängerung ausgeschlossen ist, tritt Verjährung angesichts der Komplexität und Länge der Strafverfahren häufig bereits vor Abschluss des Strafprozesses ein. Die betreffenden italienischen Verjährungsregeln sind also so ausgestaltet, dass sie eine systematische Straffreiheit von schwerem Mehrwertsteuerbetrug zur Folge haben können. ${ }^{1691}$

a) Verpflichtung zur Nichtanwendung der italienischen Verjährungsregeln

In seinem Taricco I-Urteil hatte der Gerichtshof entschieden, dass die Mitgliedstaaten schwere Betrugsfälle zum Nachteil der finanziellen Interessen der Union durch wirksame und abschreckende Strafen ahnden müssen und dass die insoweit ergriffenen Maßnahmen die gleichen sein

1691 Siehe dazu auch Burchardt, EuR 2018, 248 (249) und EuGH, Urteil vom 8.9.2015, Rs. C-105/14 (Taricco u.a.), Rn. 46 f. 
müssen, die die Mitgliedstaaten zur Bekämpfung von ebenso schweren Betrugsfällen vorsehen, die sich gegen ihre eigenen finanziellen Interessen richten. ${ }^{1692} \mathrm{Da}$ zur Begründung dieser Pflicht insbesondere Art. 325 I und II AEUV maßgeblich sind, die nach Auffassung des Gerichtshofs unmittelbare Wirkung entfalten und daher Vorrang genießen, führt sie zur Unanwendbarkeit der nationalen Bestimmungen im Falle ihrer Unionsrechtswidrigkeit. ${ }^{1693}$

Ein zur Unanwendbarkeit führender Verstoß der italienischen Regelungen (zu den verjährungsunterbrechenden Handlungen) gegen Unionsrecht ist nach Auffassung des Gerichtshofs dann zu bejahen, wenn sie „die Verhängung von wirksamen und abschreckenden Sanktionen in einer beträchtlichen Anzahl von gegen die finanziellen Interessen der Union gerichteten schweren Betrugsfällen verhindern“. ${ }^{1694}$ Zum Tragen kommt der Anwendungsvorrang demnach nur bei schweren Betrugsfällen und sofern es „in einer ,beträchtlichen Anzahl von Fällen` zu erheblichen Durchsetzungsdefiziten kommt“. ${ }^{1695}$ Die Fälle, in denen der Anwendungsvorrang eingreifen soll, hat der Gerichtshof damit lediglich recht vage umschrieben. Die Überprüfung der Kriterien der Taricco-Regel überlässt der Gerichtshof den Strafgerichten, indem er ihnen die Aufgabe der Einschätzung der Wirkung der italienischen Verjährungsregeln überträgt. ${ }^{1696}$

1692 EuGH, Urteil vom 8.9.2015, Rs. C-105/14 (Taricco u.a.), Rn. 43 i.V.m. 37, 3941. Das Strafrecht wird damit als Mittel zur effektiven Durchsetzung bestimmter Politiken wie etwa der finanziellen Interessen der Union eingesetzt, siehe nur Di Francesco Maesa, eucrim 2018, 50 (51).

1693 EuGH, Urteil vom 8.9.2015, Rs. C-105/14 (Taricco u.a.), Rn. 49, 50 ff. Dazu, welche Regelung anstelle der unanwendbaren zum Tragen kommen soll, äuBert sich der Gerichtshof nicht näher. Anwendung finden müsste in diesem Fall aber jedenfalls eine unionsrechtskonforme nationale Regelung, vgl. Kokott, NZWiSt 2017, 409 (411). Siehe GA Kokott, Schlussanträge vom 30.4.2015 in der Rs. C-105/14 (Taricco u.a.), Rn. 121 ff. sowohl zum Vorschlag der Anwendung der Verjährungsregeln ohne Anwendung der absoluten Verjährungsfrist als auch zu weiteren denkbaren Vorgehensweisen. Reiß, UR 2016, 342 (352) sieht in dem Hinweis des EuGH, a.a.O., Rn. 48, dass für die Straftat des Zusammenschlusses zur Begehung von Delikten auf dem Gebiet der Verbrauchsteuern auf Tabakerzeugnisse keine absolute Verjährungsfrist bestehe, einen Hinweis auf die statt der unanwendbaren Regelung anzuwendende Vorschrift.

1694 EuGH, Urteil vom 8.9.2015, Rs. C-105/14 (Taricco u.a.), Rn. 58 und 46 f.

1695 Meyer, JZ 2018, 304 (305, Fn. 8).

1696 Siehe EuGH, Urteil vom 8.9.2015, Rs. C-105/14 (Taricco u.a.), Rn. 44 ff. Staffler, EuGRZ 2018, 613 (619) spricht von einem „tatgerichtliche[n] Prüfungsauftrag kriminalpolitischer Natur“; siehe auch Rauchegger, CMLRev. 55 (2018), 
Die Nichtanwendung der italienischen Verjährungsregeln würde die Verhängung von Sanktionen ermöglichen, die bei ihrer Anwendung nicht verhängt worden wären. Der Gerichtshof betont deshalb, dass die Grundrechte der betreffenden Personen beachtet werden müssen. $\mathrm{Zu}$ einer Verletzung der Rechte der Angeschuldigten aus Art. 49 GRCh darf es daher nicht kommen. Obwohl die Ausführungen des Gerichtshofs zur Wirkung der Nichtanwendung der nationalen Bestimmungen lediglich „vorbehaltlich der Prüfung durch das nationale Gericht ${ }^{\text {"1697 }}$ ergehen, beurteilt der EuGH die Vereinbarkeit der Folgen der Nichtanwendung des nationalen Rechts mit den Unionsgrundrechten letztlich selbst ${ }^{1698}$ : Vor dem Hintergrund, dass die Nichtanwendung der fraglichen nationalen Bestimmungen nach Auffassung des Gerichtshofs weder zu einer rückwirkenden Strafbegründung noch zu einer rückwirkenden Strafverschärfung führt, erblickt dieser in der Nichtanwendung der italienischen Verjährungsregeln allerdings keinen Verstoß gegen Art. 49 GRCh. ${ }^{1699}$ Zurückzuführen ist dies auf die im Unionsrecht erfolgende Einordnung der Verjährung als verfahrensrechtliche Frage.

Aus italienischer Sicht ist die Taricco-Regel dagegen verfassungsrechtlich problematisch, weil das italienische Recht die Verjährung von Straftaten als Frage des materiellen Strafrechts ansieht, sodass auf sie der Grundsatz der Gesetzmäßigkeit im Zusammenhang mit Straftaten und Strafen anwendbar ist. Da der Legalitätsgrundsatz nach italienischem Verständnis also auch Verjährungsregeln erfasst, bedarf es insoweit einer vom Gesetzgeber in hinreichend bestimmten Gesetzen festgelegten Regelung, die nur auf nach ihrem Inkrafttreten begangene Taten anwendbar ist. Das Unionsrecht bewirkt aus der Sicht des nationalen Verfassungsrechts also eine Verschlechterung der Rechtsposition des Beschuldigten im Strafverfahren. ${ }^{1700}$

1521 (1522, 1526). Der italienische Verfassungsgerichtshof hat sich diese Prüfung allerdings selbst vorbehalten, siehe dazu noch kurz unten bei Fn. 1716.

1697 EuGH, Urteil vom 8.9.2015, Rs. C-105/14 (Taricco u.a.), Rn. 55.

1698 Darauf weist auch Di Francesco Maesa, eucrim 2018, 50 (51) hin.

1699 EuGH, Urteil vom 8.9.2015, Rs. C-105/14 (Taricco u.a.), Rn. 53, 55 ff. Zur Bestätigung verweist der Gerichtshof auf die Rechtsprechung des EGMR zu Art. 7 EMRK. Siehe auch Kokott, NZWiSt 2017, 409 (411f.), die auf die rückwirkende Änderbarkeit von Verjährungsvorschriften hinweist, da diese nach unionsrechtlichem Verständnis nicht zum rückwirkungsfesten materiellen Recht gehören.

1700 Vgl. Timmerman, CMLRev. 53 (2016), 779 (791f.), der beide Einordnungen als „reasonable“ ansieht. Siehe auch Kokott, NZWiSt 2017, 409 (411f.), wonach sich auch für eine materiellrechtliche Einordnung Argumente finden lassen. 
Damit die Betroffenen im Zeitpunkt der Tatbegehung die (nicht rückwirkend zu ihrem Nachteil änderbare) Verjährungsregelung kennen, wäre es nach italienischem Verständnis in der hier in Rede stehenden Konstellation erforderlich gewesen, dass der Einzelne im Zeitpunkt der Tatbegehung hätte vorhersehen können, dass das Unionsrecht die Nichtanwendung bestimmter italienischer Rechtsvorschriften verlangt. Dafür hätte er die Auslegung des EuGH vorhersehen können müssen, was der italienische Verfassungsgerichtshof (Corte costituzionale) verneint. Zugleich betont dieser, dass sich durch Auslegung nicht mit der erforderlichen Klarheit bestimmen lasse, was unter einer beträchtlichen Anzahl an Fällen zu verstehen sei, weshalb ein Verstoß gegen den Gewaltenteilungsgrundsatz nach italienischem Recht vorliege. ${ }^{1701}$

Die unterschiedliche Einordnung der Verjährungsregeln als Frage des Verfahrens- oder materiellen Rechts hat demnach zur Folge, dass eine mit der Grundrechtecharta vereinbare Regel des Unionsrechts mit einem nationalen Grundrecht in Konflikt gerät: Nach der im Taricco I-Urteil geäußerten Ansicht des EuGH ist die Pflicht zur Nichtanwendung der Verjährungsregeln des italienischen Rechts mit Art. 49 GRCh vereinbar, während sie aus italienischer Sicht gegen das in der italienischen Verfassung niedergelegte und auch auf die Verjährung anwendbare Legalitätsprinzip verstößt.

b) „Konkretisierung“ dieser Pflicht im „Dialog“ mit dem italienischen Verfassungsgerichtshof

Der von italienischen Gerichten im Nachgang des Taricco I-Urteils mit der Problematik befasste italienische Verfassungsgerichtshof richtete ein Vorabentscheidungsersuchen an den EuGH, von dessen Beantwortung er sich Klarheit hinsichtlich des Taricco I-Urteils erwartete ${ }^{1702}$, in dem er diesen aber auch darauf hinwies, dass er es verhindern würde, dass die An-

1701 Corte costituzionale, Vorlagebeschluss 24/2017 vom 26.1.2017, S. 4 f., englische Übersetzung abrufbar unter https:/www.cortecostituzionale.it/document i/download/doc/recent_judgments/O_24_2017.pdf.

1702 Corte costituzionale, Vorlagebeschluss 24/2017 vom 26.1.2017, S.3. Dieser versöhnlich im Ton klingende Ansatz kann den dahinter stehenden Konflikt allerdings kaum verbergen, siehe - auch mit Blick auf das im Anschluss an das Taricco II-Urteil des EuGH ergangene Urteil des italienischen Verfassungsgerichtshofs - Staffler, EuGRZ 2018, 613 (618). Dubout, RTDEur. 2018, 563 (569 ff.) sieht eine Entwicklung von einem „pluralisme «coopératif॰“ zu einem 
wendung von Art. 325 AEUV einer im Widerspruch zum „italienischen“ strafrechtlichen Legalitätsgrundsatz stehenden Regel Eingang in die italienische Rechtsordnung verschafft. ${ }^{1703}$

In seiner im Taricco II-Urteil gegebenen Antwort hebt der Gerichtshof die Bedeutung von Vorhersehbarkeit, Bestimmtheit und Nichtrückwirkung der anzuwendenden Strafvorschriften auch auf europäischer Ebene hervor, wobei er Art. 49 GRCh in Bezug nimmt. Er weist darauf hin, dass der Grundsatz der Gesetzmäßigkeit im Zusammenhang mit Straftaten und Strafen bei der Verhängung von Strafen wegen Straftaten im Bereich der Mehrwertsteuer von den Mitgliedstaaten angesichts der Regelung des Art. 51 I GRCh (Bindung der Mitgliedstaaten an die Charta bei der Durchführung des Rechts der Union) zu beachten sei. ${ }^{1704}$ Der Grundsatz sei Bestandteil der „gemeinsamen verfassungsrechtlichen Traditionen der Mitgliedstaaten" und u.a. in Art. 7 I EMRK festgehalten. ${ }^{1705}$

Nach der im Taricco II-Urteil geäußerten Auffassung des Gerichtshofs steht es den Mitgliedstaaten bei einer zwischen der EU und den Mitgliedstaaten nach Art. 4 II AEUV geteilten Zuständigkeit bis zur Ausübung der Kompetenz durch die EU frei, nationale Grundrechtsstandards anzuwenden. Da die Rechtsvorschriften über die Verjährung von Straftaten im Bereich der Mehrwertsteuer zu der im Ausgangsverfahren maßgebenden Zeit auf Unionsebene noch nicht harmonisiert waren ${ }^{1706}$, konnte Italien diese demnach materiellrechtlich einordnen und dem strafrechtlichen Ge-

„pluralisme «contestatif“, als deren Ausgangspunkt er die Vorlage des Bundesverfassungsgerichts in der Rechtssache Gauweiler u.a. (C-62/14) ausmacht.

1703 Corte costituzionale, Vorlagebeschluss 24/2017 vom 26.1.2017, S. 3. Kritisch zur Einordnung der Verjährungsregeln als wesentlicher Kern des Gesetzmäßigkeitsprinzips und damit als Bestandteil der nationalen Verfassungsidentität (siehe Vorlagebeschluss, S. 7) etwa Faraguna, Verfassungsblog vom 31.1.2017; ihm zustimmend Schmabl, in: Breuer (Hrsg.), Principled Resistance, 2019, S. 299 (305 mit Fn. 36). Zum im Vorlagebeschluss zum Ausdruck kommenden Vorrangverständnis des italienischen Verfassungsgerichtshofs Amoroso, IYIL 27 (2018), 452 (456f.).

1704 EuGH, Urteil vom 5.12.2017, Rs. C-42/17 (M.A.S. und M.B.), Rn. $51 \mathrm{f}$.

1705 EuGH, Urteil vom 5.12.2017, Rs. C-42/17 (M.A.S. und M.B.), Rn. 53 ff. Dies veranlasst den EuGH dazu, diesbezügliche Rechtsprechung des EGMR zu zitieren.

1706 Eine Harmonisierung ist mittlerweile teilweise erfolgt. Da sich die vom Gerichtshof in Bezug genommene Richtlinie (Richtlinie (EU) 2017/1371 des Europäischen Parlaments und des Rates vom 5. Juli 2017 über die strafrechtliche Bekämpfung von gegen die finanziellen Interessen der Union gerichtetem Betrug, ABl. L 198 vom 28.7.2017, S. 29) jedenfalls nicht ausdrücklich zur Rechtsnatur der Verjährung äußert, sind die Folgen ihres Inkrafttretens für die 
setzmäßigkeitsgrundsatz unterwerfen. ${ }^{1707}$ Die fehlende Harmonisierung der Verjährungsregeln auf Unionsebene ermöglicht es den italienischen Gerichten also, die italienischen Verjährungsregelungen anzuwenden und auf diese das Gesetzmäßigkeitsprinzip zur Anwendung zu bringen. ${ }^{1708}$

Das nationale Gericht, so der EuGH weiter, müsse prüfen, ob durch die Nichtanwendung der Verjährungsregeln in der italienischen Rechtsordnung Unsicherheit entstehe. Sollte dies der Fall sein, bestehe angesichts des dann zu bejahenden Verstoßes gegen den Bestimmtheitsgrundsatz keine Verpflichtung zur Nichtanwendung der Verjährungsregeln. ${ }^{1709}$

Hinsichtlich der vor Verkündung des Taricco I-Urteils (8.9.2015) begangenen Mehrwertsteuerstraftaten ${ }^{1710}$ bejaht der EuGH selbst einen Verstoß gegen das Rückwirkungsverbot, zu dem es durch die Nichtanwendung der nationalen Verjährungsregeln komme. ${ }^{1711}$ Für diese Straftaten darf das nationale Gericht die Verjährungsregeln also nicht unangewendet lassen. Die damit einhergehende Verpflichtung zur Anwendung der Verjährungsregeln unterscheidet sich von der in der Rechtsprechung des Gerichtshofs bislang anzutreffenden Konstellation, in der dieser die Anwendung eines nationalen Grundrechtsstandards zwar gestattet, aber keine Verpflichtung hierzu begründet. Da der EuGH die Verpflichtung zur Anwendung der Verjährungsregeln aufgestellt hat, kann sie nicht im nationalen Recht wurzeln. ${ }^{1712}$ Das Verbot der Anwendung der Taricco-Regel auf vor dem

zukünftige Anwendung des nationalen Grundrechtsschutzniveaus aber nicht ganz klar, vgl. Staffler, EuGRZ 2018, 613 (616).

1707 EuGH, Urteil vom 5.12.2017, Rs. C-42/17 (M.A.S. und M.B.), Rn. 43 ff. Der EuGH akzeptiert damit die parallele Anwendbarkeit nationalen Grundrechtsschutzes, vgl. Schmahl, in: Breuer (Hrsg.), Principled Resistance, 2019, S. 299 (306) unter Verweis in Fn. 48 auf EuGH, Urteil vom 5.12.2017, Rs. C-42/17 (M.A.S. und M.B.), Rn. 44, 45.

1708 Kritisch dazu aus strafrechtlicher Perspektive Peristeridou/Ouwerkerk, Verfassungsblog vom 12.12.2017.

1709 EuGH, Urteil vom 5.12.2017, Rs. C-42/17 (M.A.S. und M.B.), Rn. 59. Budinska/Vikarska, EU Law Analysis, Blog vom 7.12.2017, erkennen hierin die Aussage, dass die italienischen Gerichte nicht verpflichtet seien, der (eigentlich bestehenden) Verpflichtung nachzukommen und bezeichnen dies als „magical formulation“. Zur Kritik des im Taricco I-Urteil aufgestellten Erfordernisses der Verhinderung der Verhängung von Strafen in einer beträchtlichen Anzahl schwerer, gegen die finanziellen Interessen der Union gerichteter Betrugsfälle siehe etwa Peristeridou/Ouwerkerk, Verfassungsblog vom 12.12.2017.

1710 Die im Taricco I-Urteil aufgestellte Pflicht zur Nichtanwendung bezieht sich nur auf zum Zeitpunkt seiner Verkündung noch nicht verjährte Straftaten.

1711 EuGH, Urteil vom 5.12.2017, Rs. C-42/17 (M.A.S. und M.B.), Rn. 60.

1712 Krajewski, European Law Blog, Blog vom 18.12.2017. 
8.9.2015 begangene Taten ergibt sich demnach unmittelbar aus dem Unionsrecht. ${ }^{1713}$ Auf diese Weise begrenzt der Gerichtshof im Ergebnis die Wirkungen der im Taricco I-Urteil vorgenommenen Auslegung in zeitlicher Hinsicht auf nach dessen Verkündung begangene Straftaten. Auch wenn dieses Vorgehen an die Defrenne-Rechtsprechung erinnert, ist nicht anzunehmen, dass der EuGH damit ganz generell die zeitliche Wirkung seiner Rechtsprechung an den für den Unionsgesetzgeber geltenden Grundsatz der Nichtrückwirkung der Gesetzgebung angenähert hat. Auch nach dem Taricco II-Urteil verbleibt es daher beim Grundsatz der ex tunc-Wirkung der Auslegung. ${ }^{1714}$

Im Ergebnis bleibt festzuhalten: Der Verpflichtung zur Nichtanwendung nationalen Rechts kann ein nationales Gericht den Grundsatz der Gesetzmäßigkeit im Zusammenhang mit Straftaten und Strafen entgegenhalten. Gelangt es zu dem Ergebnis, dass die Nichtanwendung des nationalen Rechts zu einem Verstoß gegen den Legalitätsgrundsatz führt, muss es der Verpflichtung zur Nichtanwendung des nationalen Rechts nicht nachkommen, auch wenn dadurch die Unionsrechtswidrigkeit der nationalen Sachlage nicht beseitigt wird. In diesem Fall gerät der nationale Gesetzgeber in den Blick, der tätig werden muss, um den unionsrechtswidrigen Zustand zu beseitigen. ${ }^{1715}$

Abschließend ist noch auf die Reaktion des italienischen Verfassungsgerichtshofs auf das Taricco II-Urteil hinzuweisen. Obwohl die vor ihm in Rede stehenden Straftaten vor dem 8.9.2015 begangen worden waren, äußert er sich dazu, wie Taten nach diesem Zeitpunkt aus Sicht des italienischen Verfassungsrechts zu behandeln sind. Er macht deutlich, dass die Taricco-Regel auch auf diese nicht anwendbar ist und begründet dies mit einem Widerspruch zum Bestimmtheitsgrundsatz in Strafsachen nach Art. 25 II der italienischen Verfassung, dessen Beurteilung in seine eigene Zuständigkeit (und nicht die der italienischen Strafgerichte) falle. ${ }^{1716}$ Die

1713 So auch die Einschätzung der Corte costituzionale, Urteil vom 10.4.2018, Nr. 115, EuGRZ 2018, 685 (691) unter Verweis auf Rn. 60 des Taricco II-Urteils; ebenso Amalfitano/Pollicino, Verfassungsblog vom 5.6.2018.

1714 Siehe auch Peristeridou/Ouwerkerk, Verfassungsblog vom 12.12.2017.

1715 EuGH, Urteil vom 5.12.2017, Rs. C-42/17 (M.A.S. und M.B.), Rn. 61 (und Rn. 42 zum Umfang der Verpflichtung des Gesetzgebers). Kritisch Burchardt, EuR 2018, 248 (250 f., 255 ff.).

1716 Näher Corte costituzionale, Urteil vom 10.4.2018, Nr. 115, EuGRZ 2018, 685 (689, 691 f.). Siehe auch Staffler, EuGRZ 2018, 613 (617), der darauf hinweist, dass daher auch der Erlass der in Fn. 1706 erwähnten Richtlinie nichts daran ändert, dass die Taricco-Regel im italienischen Recht nicht anwendbar ist. 
Taricco-Regel kann daher im italienischen Rechtsraum unabhängig davon keine Anwendung finden, ob sich der Sachverhalt vor oder nach dem 8.9.2015 abgespielt hat. ${ }^{1717}$

2. Einordnung des Taricco II-Urteils in die (bisherige) Systematik des Grundrechtsschutzes

Die Einordnung des Taricco II-Urteils bereitet Schwierigkeiten und fält in der Literatur dementsprechend unterschiedlich aus. Positiv hervorgehoben wird dort das Bemühen des Gerichtshofs um Zusammenarbeit mit nationalen Akteuren durch die Betonung gemeinsamer Verfassungstraditionen und die gemeinsame Betrachtung von Grundrechten und grundlegenden Prinzipien, was das Taricco II-Urteil sowohl von den Schlussanträgen von Generalanwalt Bot als auch dem Taricco I-Urteil unterscheide. ${ }^{1718}$ Die Rede ist von einem „Friedensangebot“ bzw. „Kooperationsangebot“".1719 Als Zeichen der Schwäche wird dagegen gewertet, dass der EuGH dem Druck eines nationalen Gerichts mit der Folge nachgegeben habe, dass nun ein nationaler Grundrechtsstandard primärrechtlichen Anforderungen entgegengehalten werden könne, die daher trotz ihrer formalen Aufrechterhaltung von den nationalen Gerichten nicht beachtet werden müssten. ${ }^{1720}$

Auch wenn man das diplomatische Geschick des EuGH hervorhebt, dem es gelungen sei, die Taricco-Konstellation nicht als Ringen zwischen Vorrang und nationaler Identität um das letzte Wort darzustellen ${ }^{1721}$, so ist doch das Bild, das er stattdessen zeichnet, kein wirklich zufriedenstellendes, da die Folgen für den Vorrang des Unionsrechts alles andere als eindeutig sind.

Zum Problemkreis der mangelnden Bestimmtheit näher Meyer, JZ 2018, 304 (308); GA Bobek, Schlussanträge vom 25.7.2018 in der Rs. C-310/16 (Dzivev u.a.), Rn. 103 ff.; Rauchegger, CMLRev. 55 (2018), 1521 (1545); Staffler, EuGRZ 2018, 613 (619).

1717 Amalfitano/Pollicino, Verfassungsblog vom 5.6.2018, weisen zu Recht darauf hin, dass der italienische Verfassungsgerichtshof Art. 325 AEUV auf diese Weise letztlich unmittelbare Wirkung abspricht.

1718 Fichera, EU Law Analysis, Blog vom 7.12.2017, bezeichnet dies als „'primacy' mindframe“, im Gegensatz zum früheren „'supremacy' mindframe“.

1719 Klein, DÖV 2018, 605 (609).

1720 Dubout, RTDEur. 2018, 563 (564ff.): „davantage comme un renoncement qu'un simple revirement".

1721 Lobend Budinska/Vikarska, EU Law Analysis, Blog vom 7.12.2017. 
a) Bestimmung des Verhältnisses der Grundrechtsebenen

Um die Auswirkungen des Taricco II-Urteils auf den Vorrang des Unionsrechts bestimmen zu können, bedarf es seiner Einordnung in den Gesamtzusammenhang des auf Unionsebene und in den mitgliedstaatlichen Rechtsordnungen gewährten Grundrechtsschutzes. Dazu sind die vom Gerichtshof entwickelten Leitlinien zur Anwendbarkeit eines nationalen Grundrechtsschutzniveaus in den Blick zu nehmen, die allerdings kein ganz klares Bild des Verhältnisses der Grundrechtsebenen ergeben.

Dass Art. 51 I 1 GRCh keine Aussage zur Frage der Verdrängung der nationalen Grundrechte bei der Durchführung von Unionsrecht zu entnehmen ist, ergibt sich bereits aus seinem Regelungsgehalt, der sich mit der Frage der Anwendbarkeit der Grundrechtecharta und nicht mit ihrem Verhältnis zu nationalen Grundrechten befasst. ${ }^{1722}$ Insoweit gilt nach Auffassung des Gerichtshofs, dass die Anwendbarkeit des Unionsrechts die Anwendbarkeit der Chartagrundrechte nach sich zieht. ${ }^{1723}$ Da Unionsrecht auch dann durchgeführt wird, wenn mitgliedstaatliche Spielräume bestehen ${ }^{1724}$, ist die Determinierung der Rechtslage durch Unionsrecht für die Anwendbarkeit der Unionsgrundrechte (anders als im Rahmen der Frage nach dem den nationalen Grundrechten verbleibenden Anwendungsbereich) nicht entscheidend. ${ }^{1725}$

Führt eine nationale Vorschrift oder Maßnahme das Unionsrecht im Sinne von Art. 51 I GRCh durch, können nationale Grundrechtsstandards zur Anwendung kommen, wenn das Handeln des Mitgliedstaats nicht vollständig durch das Unionsrecht bestimmt wird und sofern durch deren Anwendung „weder das Schutzniveau der Charta, wie sie vom Gerichtshof ausgelegt wird, noch der Vorrang, die Einheit und die Wirksamkeit des Unionsrechts beeinträchtigt werden". ${ }^{1726}$ Die Anwendung eines nationalen Schutzstandards durch ein nationales Gericht steht also u.a. unter der Bedingung, dass dadurch der Vorrang, die Einheit und die Wirksamkeit

1722 Siehe nur Kirchbof, NVwZ 2014, 1537 (1538).

1723 EuGH, Urteil vom 26.2.2013, Rs. C-617/10 (Åkerberg Fransson), Rn. 20 f.

1724 In diesem Sinne GA Trstenjak, Schlussanträge vom 22.9.2011 in der Rs. C-411/10 (N.S.), Rn. 82 im Hinblick auf Entscheidungen, die Mitgliedstaaten auf der Grundlage des ihnen im Rahmen einer Unionsregelung zustehenden Ermessens treffen.

1725 Franzius, ZaöRV 75 (2015), 383 (386, 393 f.).

1726 EuGH, Urteil vom 26.2.2013, Rs. C-617/10 (Åkerberg Fransson), Rn. 29 unter Verweis auf EuGH, Urteil vom 26.2.2013, Rs. C-399/11 (Melloni), Rn. 60. 
des Unionsrechts nicht beeinträchtigt werden ${ }^{1727}$, wobei diese vom Gerichtshof formulierten Grenzen der Anwendung nationaler Grundrechtsgewährleistungen nicht wörtlich genommen werden können, da eine $\mathrm{Zu}$ lassung nationaler Grundrechtsstandards zwangsläufig zu einer uneinheitlichen Durchsetzung des Unionsrechts in den Mitgliedstaaten führt. ${ }^{1728}$

Festzuhalten bleibt, dass mit der Anwendbarkeit der Unionsgrundrechte keine generelle Verdrängung nationaler Grundrechte einhergeht, die Befugnis der Mitgliedstaaten zur parallelen Anwendung ihrer nationalen Grundrechte aber jedenfalls unionsrechtlich eingehegt ist. ${ }^{1729}$ Die Anwendung eines nationalen Schutzstandards kommt nur in Betracht, soweit etwa die Bestimmungen einer Richtlinie keine vollständige Harmonisierung bewirken. Die im nationalen Recht belassenen Umsetzungsspielräume, die eine Anwendung nationaler Grundrechtsstandards ermöglichen, müssen sich daher auf den durch die Richtlinienbestimmungen bewirkten Harmonisierungsgrad beziehen. ${ }^{1730}$ Eine durch Unionsrecht vollständig bestimmte Konstellation und eine solche mit mitgliedstaatlichen Spielräumen sind demnach unterschiedlich zu behandeln. ${ }^{1731}$

Von der Determinierung einer Fallgestaltung durch Unionsrecht hängt demnach ab, ob die Charta gemeinsamer Höchststandard ${ }^{1732}$ oder unionsrechtlicher Mindeststandard ist. Bei fehlender Harmonisierung gilt für den den Mitgliedstaaten belassenen Spielraum der (strengere) nationale

1727 Siehe aus jüngerer Zeit nur EuGH, Urteil vom 5.6.2018, Rs. C-612/15 (Kolev u.a.), Rn. 75 unter Verweis auf EuGH, Urteil vom 5.12.2017, Rs. C-42/17 (M.A.S. und M.B.), Rn. 47.

1728 GA Bobek, Schlussanträge vom 25.7.2018 in der Rs. C-310/16 (Dzivev u.a.), Rn. 90 f. Zu den mit der Wertungsoffenheit des Kriteriums der Gefährdung des Vorrangs bzw. der Eröffnung des Anwendungsbereichs der Grundrechtecharta verbundenen Problemen und möglichen Lösungen siehe etwa Riemer, Investitionspflichten, 2017, S. 443 f.; siehe auch Obler, NVwZ 2013, 1433 (1437 f.); Thym, NVwZ 2013, 889 (895 f.).

1729 EuGH, Urteil vom 11.9.2014, Rs. C-112/13 (A), Rn. 44.

1730 EuGH, Urteil vom 29.7.2019, Rs. C-476/17 (Pelham u.a.), Rn. 81.

1731 Vgl. GA Bobek, Schlussanträge vom 7.9.2017 in der Rs. C-298/16 (Ispas), Rn. 62, der allerdings einen „erheblichen“ Spielraum der Mitgliedstaaten fordert, während der EuGH lediglich verlangt, dass das Handeln der Mitgliedstaaten nicht vollständig durch Unionsrecht bestimmt wird, vgl. etwa EuGH, Urteil vom 26.2.2013, Rs. C-617/10 (Åkerberg Fransson), Rn. 29. Siehe auch Kingreen, in: Calliess/Ruffert (Hrsg.), EUV/AEUV, 5. Aufl. 2016, Art. 51 GRCh, Rn. 10.

1732 Unionsgrundrechte sind daher ,in ihrem Anwendungsbereich grundsätzlich Vollgrundrechtsordnung“, Britz, EuGRZ 2015, 275 (276). 
Schutzstandard. An ihm kann das nationale, nicht aber das unionale Handeln gemessen werden. ${ }^{1733}$

Eine unionsrechtliche Verpflichtung kann der Mitgliedstaat damit nicht unter Verweis auf den Grundrechtsschutz nach nationalem Recht abwehren. ${ }^{1734}$ Verpflichtet das Unionsrecht dagegen nicht zu einem bestimmten Ergebnis, steht dieses der Anwendung nationaler Grundrechte neben der Charta nicht grundsätzlich entgegen. ${ }^{1735}$

$\mathrm{Zu}$ einer Verdrängung der nationalen Grundrechte kommt es in dem Fall, in dem der Anwendungsvorrang des zwingenden Unionsrechts außerhalb der Grundrechte beeinträchtigt zu werden droht. ${ }^{1736}$ Hier sind Einheit und Wirksamkeit des Unionsrechts gefährdet, wenn die Grundrechte im Unions- und nationalen Recht einen unterschiedlichen Gehalt aufweisen. ${ }^{1737} \mathrm{Ob}$ nationale Grundrechte Sekundärrecht widersprechen ${ }^{1738}$ oder gegen eine primärrechtliche Bestimmung wie Art. 325 AEUV verstoßen, ist dabei nicht entscheidend.

Der unionale Schutzstandard kann sich daher auch gegenüber einem höheren nationalen Schutzstandard durchsetzen. ${ }^{1739}$ Beispielhaft ist insbesondere das Urteil in der Rechtssache Melloni, in dem der Gerichtshof die Anwendung eines nationalen Grundrechtsstandards ausgeschlossen hat, da Art. 4a I des Rahmenbeschlusses 2002/584/JI ${ }^{1740}$ die Ausnahmen von

1733 GA Bobek, Schlussanträge vom 25.7.2018 in der Rs. C-310/16 (Dzivev u.a.), Rn. $92 \mathrm{ff}$.

1734 Ist eine mitgliedstaatliche Maßnahme unionsrechtlich untersagt, wird die Wirksamkeit des Unionsrechts dagegen jedenfalls nicht abgeschwächt, wenn diese Maßnahme auch wegen Verstoßes gegen nationale Grundrechte beseitigt wird, so Stelkens, in: FS Wendt, 2015, S. 467 (471 ff.); siehe auch Britz, EuGRZ 2015, 275 (277).

1735 Thym, JZ 2015, 53 (55).

1736 Jarass, EuR 2013, 29 (37f.); siehe auch Honer, JuS-Extra 2017, 21 (25, 27) und Klein, DÖV 2018, 605 (606).

1737 Siehe Kokott, NZWiSt 2017, 409 (410) mit Blick auf die „einheitliche Durchsetzung und Sanktionierung des Mehrwertsteueranspruchs“.

1738 Starke, EU-Grundrechte und Vertragsrecht, 2016, S. 109.

1739 Um ein zu weites Ausgreifen der Grundrechtecharta zu vermeiden, ist deren Anwendbarkeit auf mitgliedstaatliches Handeln nicht zu großzügig zu bestimmen, siehe Riemer, Investitionspflichten, 2017, S. 430. Der EuGH scheint dem inzwischen Rechnung zu tragen, vgl. EuGH, Urteil vom 26.2.2013, Rs. C-617/10 (Åkerberg Fransson), Rn. 16 ff. und EuGH, Urteil vom 30.4.2014, Rs. C-390/12 (Pfleger u.a.), Rn. 31 ff. einerseits sowie EuGH, Urteil vom 10.7.2014, Rs. C-198/13 (Julián Hernández u.a.), Rn. 36 andererseits.

1740 Rahmenbeschluss 2002/584/JI des Rates vom 13. Juni 2002 über den Europäischen Haftbefehl und die Übergabeverfahren zwischen den Mitgliedstaa- 
der Verpflichtung zur Auslieferung bei Verurteilungen in Abwesenheit abschließend regelt. ${ }^{174}$ Hier ist eine Abwägung zwischen unionsrechtlichen Interessen und Grundrechtsschutz - zwischen den Rechten des in Abwesenheit Verurteilten und der gegenseitigen Anerkennung gerichtlicher Entscheidungen - auf europäischer Ebene bereits erfolgt, die nicht durch die Anwendung eines nationalen Grundrechtsstandards konterkariert werden darf. ${ }^{1742}$ Die Möglichkeit, auf der Grundlage einer nationalen Rechtsvorschrift einen zusätzlichen Grund für die Nichtvollstreckung eines Europäischen Haftbefehls zu schaffen und für dieses Ansinnen Art. 53 GRCh fruchtbar zu machen, besteht daher nicht, da dies dem Vorrang des Unionsrechts widerspräche. ${ }^{1743}$

Vor dem Hintergrund, dass nationale Grundrechte nur zur Anwendung kommen können, wenn der Vorrang des Unionsrechts sichergestellt ist, begründet Art. 53 GRCh keine Ausnahme vom Vorrang. ${ }^{1744}$ Art. 53 GRCh wird vom Gerichtshof vielmehr zugunsten des Vorrangs ausgelegt, was im Konfliktfall die Maßgeblichkeit der Unionsgrundrechte begründet. ${ }^{1745}$ Über die Lösung eines solchen Konfliktfalls entscheidet der Gerichtshof. ${ }^{1746}$

Die parallele Anwendung nationaler Grundrechte steht damit unter den beiden Vorbehalten, dass weder das Schutzniveau der Charta noch Vorrang, Einheit und Wirksamkeit des Unionsrechts beeinträchtigt werden. Während im unionsrechtlich harmonisierten Bereich selbst höhere nationale Grundrechtsstandards bereits überhaupt nicht anwendbar sind, müssen Vorrang, Einheit und Wirksamkeit des Unionsrechts auch in

ten (ABl. L 190 vom 18.7.2002, S. 1) in der durch den Rahmenbeschluss 2009/299/JI des Rates vom 26. Februar 2009 (ABl. L 81 vom 27.3.2009, S. 24) geänderten Fassung.

1741 EuGH, Urteil vom 26.2.2013, Rs. C-399/11 (Melloni), Rn. 60.

1742 Lenaerts, EuR 2015, 3 (24f.).

1743 EuGH, Urteil vom 26.2.2013, Rs. C-399/11 (Melloni), Rn.58f.; GA Bobek, Schlussanträge vom 25.7.2018 in der Rs. C-310/16 (Dzivev u.a.), Rn. 86 ff.; Lenaerts, in: European Court of Human Rights, Dialogue between judges, 2018, S. 57 (62).

1744 Franzius, ZaöRV 75 (2015), 383 (388, 395 f., 399); Jarass, GRCh-Kommentar, 3. Aufl. 2016, Art. 53 GRCh, Rn. 25, 27.

1745 Klein, DÖV 2018, 605 (609); Franzius, ZaöRV 75 (2015), 383 (394). In mehrpoligen Grundrechtsbeziehungen ist die Anwendbarkeit des Art. 53 GRCh strittig. Sie sollte aber dann zum Tragen kommen, wenn die Mitgliedstaaten selbst eine Balance zwischen den betroffenen Schutzgütern herstellen dürfen, Franzius, ZaöRV 75 (2015), 383 (396). Kritisch zur Unterscheidbarkeit von biund multipolaren Konstellationen Kingreen, JZ 2013, 801 (808).

1746 Thym, NVwZ 2013, 889 (895). 
nicht harmonisierten Bereichen, wo nationale Grundrechte zur Anwendung kommen können, beachtet werden. ${ }^{1747}$ Der Vorrang spielt also nicht nur beim zur Vollharmonisierung führenden Eingreifen des Unionsgesetzgebers eine Rolle. ${ }^{1748}$ Die Anwendung nationaler Grundrechtsstandards kann den Vorrang, die Einheit und die Wirksamkeit des Unionsrechts auch dann beeinträchtigen, wenn die nationale Maßnahme nicht vollständig durch Unionsrecht determiniert ist. ${ }^{1749}$

\section{b) Anwendung des Art. 53 GRCh?}

Der italienische Verfassungsgerichtshof meint, in der Taricco-Konstellation ein Eingreifen des Art. 53 GRCh mit der Überlegung begründen zu können, dass die materiellrechtliche Einordnung der Verjährungsregeln einen höheren Schutz als Art. 49 GRCh (und Art. 7 EMRK) gewähre. ${ }^{1750}$ Hierfür macht er geltend, dass der EuGH im Taricco I-Urteil zwar die Anwendbarkeit von Art. 49 GRCh verneint habe, nicht aber die Anwendbarkeit für den Angeklagten günstigerer nationaler Grundrechte. ${ }^{1751}$

Bei der Einordnung des Taricco II-Urteils fällt auf, dass der Gerichtshof keinen ausdrücklichen Bezug zu Art. 53 GRCh herstellt. Dabei hätte es ihm insbesondere durch Bezugnahme auf diese Bestimmung gelingen können, einen unionsrechtlichen Ansatzpunkt für eine grundrechtliche Vielfalt zu finden, indem er etwa den Vorrang des Unionsrechts selbst

1747 Burchardt, EuR 2018, 248 (253 f.; siehe insbesondere auch Fn. 16).

1748 Siehe GA Bot, Schlussanträge vom 18.7.2017 in der Rs. C-42/17 (M.A.S. und M.B.), Rn. 163 im Anschluss an die Feststellung, dass es auf Unionsebene an einer gemeinsamen Definition der Tragweite des Gesetzmäßigkeitsgrundsatzes und seines Schutzumfangs im Hinblick auf Verjährungsregeln fehlt: „Die Mitgliedstaaten verfügen deshalb grundsätzlich über einen größeren Spielraum für die Anwendung eines höheren Schutzstandards, jedoch unter der Voraussetzung, dass dieser den Vorrang und die Effektivität des Unionsrechts gewährleistet.“ Thym, NVwZ 2013, 889 (891f.) nimmt dagegen bei „nur begrenzt“ determinierten Konstellationen einen noch weitergehenden „Freiraum zur nationalen Gestaltung“ an.

1749 Eine andere Einordnung nimmt Rauchegger, CMLRev. 55 (2018), 1521 (1531f.) vor.

1750 Ablehnend GA Bot, Schlussanträge vom 18.7.2017 in der Rs. C-42/17 (M.A.S. und M.B.), Rn. $144 \mathrm{ff}$.

1751 Corte costituzionale, Vorlagebeschluss 24/2017 vom 26.1.2017, S. 8 f. 
im Lichte des Art. 53 GRCh restriktiv ausgelegt hätte. ${ }^{1752}$ Demgegenüber stützt sich der Gerichtshof auf die "gemeinsamen verfassungsrechtlichen Traditionen der Mitgliedstaaten" ${ }^{1753}$, deren Bedeutung sich im vorliegenden Zusammenhang allerdings nicht ganz erschließt, da sie hier gerade nicht, wie sonst üblich, auf Vereinheitlichung angelegt sind, sondern die unterschiedliche (verfahrens- bzw. materiellrechtliche) Einordnung der Verjährungsregeln im Unions- und nationalen Recht in Rede steht. ${ }^{1754}$

Erst im Nachgang des Urteils ordnet Lenaerts das Taricco II-Urteil in einen Zusammenhang mit Art. 53 GRCh ein. Demnach handelt es sich bei ihm um eine konsequente Fortschreibung der in der Rechtsprechung des Gerichtshofs vorgesehenen Abschichtung der Grundrechtssphären. ${ }^{1755}$ Vor dem Hintergrund, dass eine inhaltliche Auseinandersetzung mit Art. 53 GRCh unterblieben ist, überzeugt es allerdings nicht, dem Urteil eine Aussage zuzuschreiben, die dieses nicht ausdrücklich enthält. ${ }^{1756}$

Der Bezug zu Art. 53 GRCh ist lediglich ein impliziter: Der Verweis des Gerichtshofs in Rn. 47 des Taricco II-Urteils auf diejenige Passage des Åkerberg Fransson-Urteils (und damit auch die dort zitierte Randnummer des Melloni-Urteils), nach der die Möglichkeit der Anwendung nationaler Schutzstandards für die Grundrechte eröffnet ist, wenn dadurch weder das Schutzniveau der Charta noch der Vorrang, die Einheit und die Wirksamkeit des Unionsrechts beeinträchtigt werden, erfolgt unmittelbar im Anschluss an die Feststellung der Bedeutung der Grundrechte in Rn. 46, in der der Gerichtshof feststellt, dass bei der Nichtanwendung der Vorschriften des italienischen Strafgesetzbuchs die Grundrechte zu beachten seien. Da Rn. 47 mit dem Wort "dabei“ (,in that respect“) eingeleitet wird, sollen die darin erfolgenden Ausführungen Rn. 46 näher erläutern. In Rn. 48 heißt es dann, dass „insbesondere“ die Rechte aus dem strafrechtlichen Legalitätsgrundsatz zu wahren seien. Auch Rn. 48 setzt sich also mit der

1752 Klein, DÖV 2018, 605 (609 f.); siehe auch den Hinweis von Lenaerts, EuR 2012, 3 (15) auf Art. 53 GRCh als „Ausdruck eines Verfassungspluralismus“.

1753 EuGH, Urteil vom 5.12.2017, Rs. C-42/17 (M.A.S. und M.B.), Rn. 53.

1754 Siehe in diesem Zusammenhang auch GA Cruz Villalón, Schlussanträge vom 14.1.2015 in der Rs. C-62/14 (Gauweiler u.a.), Rn. 61, der betont, dass die „gemeinsamen Verfassungstraditionen" der Mitgliedstaaten auch die Identität der Union prägen, sodass die Verfassungsidentität der Union und der Mitgliedstaaten nicht ,astronomisch weit entfernt" voneinander sind, sondern sich mittelund langfristig im Grundsatz annähern.

1755 Lenaerts, in: European Court of Human Rights, Dialogue between judges, 2018, S. 57 (61 ff.).

1756 Insoweit kritisch auch Dubout, RTDEur. 2018, 563 (576ff.). 
zuvor getroffenen Aussage näher auseinander. Dieser vom Gerichtshof hergestellte Zusammenhang lässt zumindest darauf schließen, dass er jedenfalls keine Abkehr von seiner Melloni-Rechtsprechung beabsichtigte. Hierfür spricht auch der fehlende Verweis auf Art. 53 GRCh selbst. ${ }^{1757}$

Der EuGH nimmt die Åkerberg Fransson- (und Melloni-) Rechtsprechung in Bezug, nachdem er auf die fehlende unionsrechtliche Harmonisierung der Verjährungsregeln bei Strafverfahren wegen Mehrwertsteuerbetrugs, die die finanziellen Interessen der EU berühren, verwiesen hatte. Diese fehlende sekundärrechtliche Harmonisierung war für ihn mitentscheidend für die Befugnis der nationalen Gerichte zur Anwendung des nationalen Grundrechtsstandards. Auch wenn Art. 325 AEUV ${ }^{1758}$ nach den Feststellungen des EuGH im Taricco I-Urteil eine Verpflichtung zur Nichtanwendung der nationalen Verjährungsregeln enthält, die zur Straflosigkeit von schwerem Mehrwertsteuerbetrug in einer beträchtlichen Anzahl von Fällen führen, und unmittelbar anwendbar ist ${ }^{1759}$, geht der Gerichtshof also nicht von einer vollständigen Determinierung der italienischen Verjährungsregeln durch Unionsrecht aus. ${ }^{1760}$ Dass in der Taricco-Konstellation anders als in der Melloni-Konstellation eine Anwendung nationaler Grundrechtsstandards möglich ist, liegt daher in der jeweils unterschiedlichen Ausgangslage begründet. ${ }^{1761}$

Nach Auffassung des Gerichtshofs werden Vorrang, Einheit und Wirksamkeit des Unionsrechts in der Taricco-Konstellation demnach nicht beeinträchtigt. ${ }^{1762}$ Nach dieser Lesart lässt sich das Taricco II-Urteil als

1757 Siehe Di Francesco Maesa, eucrim 2018, 50 (53 mit Fn. 43 und 44), die auf diesen sprachlichen Zusammenhang verweist, dabei aber Rn. 47 und 48 des Urteils vermischt.

1758 Die unterbliebene Festlegung gemeinsamer Standards durch den Unionsgesetzgeber hatte zur Folge gehabt, dass der Gerichtshof mit Art. 325 AEUV eine Vorschrift des Primärrechts heranziehen musste.

1759 EuGH, Urteil vom 8.9.2015, Rs. C-105/14 (Taricco u.a.), Rn. 47-49.

1760 Rauchegger, CMLRev. 55 (2018), 1521 (1532 ff.).

1761 So Di Francesco Maesa, eucrim 2018, 50 (54) unter Verweis auf Peristeridou/Ouwerkerk, Verfassungsblog vom 12.12.2017. Neben der unionsrechtlichen Harmonisierung lag der Melloni-Konstellation auch ein grenzüberschreitendes Element zugrunde, das auf dem Grundsatz gegenseitigen Vertrauens zwischen den Mitgliedstaaten aufbaut, der für die Wirksamkeit des Europäischen Haftbefehls einen einheitlichen Schutzstandard erfordert, siehe Dubout, RTDEur. 2018, 563 (576 ff.); Rauchegger, CMLRev. 55 (2018), 1521 (1534, 1545).

1762 Jedenfalls stellen die einschränkenden Kriterien für den Gerichtshof kein Hindernis für die Anwendung des nationalen Grundrechtsverständnisses dar. Bassini/Pollicino, Verfassungsblog vom 5.12.2017, sprechen davon, dass dem 
Anwendungsfall bekannter Rechtsprechungslinien darstellen. ${ }^{1763}$ Die Achtung von Vorrang, Einheit und Wirksamkeit des Unionsrechts erlangt insoweit Bedeutung, als sie ein Tätigwerden des Gesetzgebers verlangt. ${ }^{1764}$

\section{Nationaler Grundrechtsstandard als Grenze des Vorrangs?}

Jedenfalls überraschen muss dann allerdings, dass in der Literatur auch im Taricco I-Urteil eine Fortschreibung der bisherigen Systematik des Grundrechtsschutzes erblickt wird. ${ }^{1765}$ Die dort getroffene Feststellung des Gerichtshofs, dass die vom italienischen Recht vorgesehenen Maßnahmen zur Bekämpfung von Betrug und sonstigen gegen die finanziellen Interessen der Union gerichteten rechtswidrigen Handlungen nicht wirksam und abschreckend sind, wenn sie in einer Vielzahl von Fällen zu Straffreiheit führen ${ }^{1766}$, hatte gezeigt, dass das italienische Recht Vorrang und Effektivität des Unionsrechts zu beeinträchtigen droht. Vor diesem Hintergrund hatte der Gerichtshof eine Verpflichtung zur Nichtanwendung des italienischen Rechts aufgestellt, sodass der italienische Grundrechtsschutz auf den unionsrechtlichen Mindeststandard hinsichtlich des Legalitätsprinzips abzusenken war. Diese Feststellung lässt dann doch Auswirkungen des Taricco II-Urteils auf den Vorrang des Unionsrechts vermuten. Sie sind an dieser Stelle noch näher zu betrachten.

Der EuGH legt letztlich nicht offen, was genau er im Taricco II-Urteil den aus Art. 325 AEUV folgenden Verpflichtungen entgegengestellt hat. Wäre dies ein unionsrechtliches Verständnis des Legalitätsgrundsatzes, hätte er eine Abschwächung des Vorrangs des Unionsrechts im Verhältnis zum nationalen Recht vermieden, da es der Unionsrechtsordnung selbst inhärent wäre. ${ }^{1767}$ Die verfassungsrechtlichen Erwägungen der Corte costituzionale wären in diesem Fall in unionsrechtsinterne Erwägungen

formalen Verweis auf die einschränkenden Kriterien durch die nachfolgenden Urteilsteile inhaltlich widersprochen werde.

1763 Rauchegger, CMLRev. 55 (2018), 1521 (1531f.). Sarmiento, Despite our Differences, Blog vom 5.12.2017, meint, der EuGH nehme eine vernünftige Anwendung der Melloni-Kriterien vor.

1764 Lenaerts, in: European Court of Human Rights, Dialogue between judges, 2018, S. 57 (63). Dem Vorrang, der Einheit und der Wirksamkeit des Unionsrechts kann damit auf unterschiedliche Weise Rechnung getragen werden.

1765 Timmerman, CMLRev. 53 (2016), 779 (780, 792, 794 f.).

1766 EuGH, Urteil vom 8.9.2015, Rs. C-105/14 (Taricco u.a.), Rn. 47.

1767 In diesem Sinne Bassini/Pollicino, Verfassungsblog vom 5.12.2017. 
transformiert worden und zu einer Frage der Interpretation der Grundrechtecharta geworden, also gewissermaßen von Art. 49 GRCh absorbiert worden. ${ }^{1768}$ Eine Grenze des Vorrangs von Art. 325 AEUV in der Achtung der Grundrechte innerhalb des Unionsrechts zu ziehen, entspräche seiner Abwägbarkeit mit unionsrechtlichen Grundrechten und Grundsätzen. ${ }^{1769}$

Eine solche Argumentation übersieht aber, dass der Gerichtshof keine Auslegung des Legalitätsgrundsatzes aus Art. 49 GRCh vorgenommen hat, die der Verpflichtung aus Art. 325 AEUV entgegensteht. Da kein Konflikt zwischen Art. 325 AEUV und Art. 49 GRCh besteht, kann der Gerichtshof auch keinen Ausgleich zwischen beiden Vorschriften hergestellt haben. ${ }^{1770}$ Da es nicht entscheidend auf die im Unionsrecht anerkannte Bedeutung des Legalitätsgrundsatzes ankommt und daher keine unionsinterne Abwägung erfolgt, zeigt sich im Übrigen, dass dem Vorgehen des Gerichtshofs eine andere Konstruktion als der Winner Wetten-Konstellation zugrunde liegt, sodass diese beiden Ansätze nicht miteinander vergleichbar sind. ${ }^{1771}$

Die Ausführungen des Gerichtshofs deuten daher darauf hin, dass er den Vorrang durch die Zulassung einer Anwendung nationaler Grundrechte gegenüber der Verpflichtung aus Art. 325 AEUV im Verhältnis zum nationalen Verfassungsrecht abgeschwächt hat. ${ }^{1772} \mathrm{Ob}$ dieser Eindruck täuscht oder nicht, muss näher untersucht werden.

Der Gerichtshof stellt in seinem Taricco II-Urteil entscheidend auf seine im Taricco I-Urteil getroffene Aussage ab, wonach die Grundrechte der betreffenden Personen bei der Nichtanwendung des nationalen Rechts zu beachten seien. ${ }^{1773}$ Was im Unklaren bleibt, ist allerdings der genaue Verlauf der Argumentationskette des EuGH.

Zunächst ist festzuhalten, dass er am Vorrang auch des Art. 325 AEUV festhält und die italienischen Verjährungsregeln mit Art. 325 AEUV für unvereinbar erklärt. ${ }^{1774}$ Insoweit vollzieht der Gerichtshof also keine Abkehr von der im Taricco I-Urteil aufgestellten Aussage, was es nahe legt, im Taricco II-Urteil lediglich eine Nuancierung seines ursprünglichen An-

1768 Meyer, JZ 2018, 304 (306) spricht von einer „Internalisierung des Konflikts“.

1769 Pilz, NJW 2018, 221.

1770 Überzeugend Di Francesco Maesa, eucrim 2018, 50 (53).

1771 Siehe auch Rauchegger, CMLRev. 55 (2018), 1521 (1535 ff.).

1772 Dubout, RTDEur. 2018, 563 (567 ff.) sieht im Taricco II-Urteil daher den „acte officiel de décès“ des Vorrangs.

1773 EuGH, Urteil vom 5.12.2017, Rs. C-42/17 (M.A.S. und M.B.), Rn. 46 unter Verweis auf EuGH, Urteil vom 8.9.2015, Rs. C-105/14 (Taricco u.a.), Rn. 53.

1774 EuGH, Urteil vom 5.12.2017, Rs. C-42/17 (M.A.S. und M.B.), Rn. 30 ff., 40. 
satzes zu sehen. ${ }^{1775}$ Die Aussage des Gerichtshofs, dass ihm die italienische Problematik bei der Entscheidung des Taricco I-Verfahrens nicht bekannt gewesen sei ${ }^{1776}$, untermauert die These, dass er seine Rechtsprechung lediglich präzisieren und so einen unvorhergesehenen Konflikt vermeiden wollte. ${ }^{1777}$

In seinem Taricco I-Urteil hat der Gerichtshof hervorgehoben, dass durch die Nichtanwendung der italienischen Verjährungsregeln hinsichtlich vor der Verkündung des Taricco I-Urteils begangener Straftaten rückwirkend strengere Strafbarkeitsbedingungen gelten könnten als zur Zeit der Begehung der Taten beachtet werden mussten. ${ }^{1778} \mathrm{Da}$ er dies als unbedenklich einstuft ${ }^{1779}$, bezieht er sich dort auf das unionsrechtliche Verständnis des Legalitätsprinzips. Wenn er dann aber im Taricco II-Urteil abermals darauf zu sprechen kommt ${ }^{1780}$, schwingt das italienische Verständnis des Legalitätsgrundsatzes unverkennbar mit. ${ }^{1781}$

Indem der EuGH die nationalen Gerichte auffordert, die Anforderungen der Vorhersehbarkeit, Bestimmtheit und Nichtrückwirkung, die dem Legalitätsprinzip innewohnen und sich aus der EuGH-Rechtsprechung ergeben, zu beachten, weist er sie gewissermaßen an, die Anforderungen der Charta auf Verjährungsregeln anzuwenden. ${ }^{1782}$ Hierin eine Ausdehnung des Anwendungsbereichs der Charta auf Verjährungsregeln zu erblicken, würde allerdings vor dem Hintergrund des Taricco I-Urteils, in dem der Gerichtshof eine Anwendung des Art. 49 GRCh auf Verjährungsregeln gerade verneint hat, nicht überzeugen. Lenaerts erklärt das Vorgehen des Gerichtshofs daher damit, dass Art. 49 GRCh in den Mitgliedstaaten, die die Verjährung materiellrechtlich einordnen, beachtet werden müsse. Nach dieser Vorstellung besteht keine Verpflichtung der mitgliedstaatlichen Gerichte zur Nichtanwendung der nationalen Verjährungsregeln, wenn

1775 So auch Rauchegger, CMLRev. 55 (2018), 1521 (1540). Sarmiento, Despite our Differences, Blog vom 5.12.2017, spricht davon, dass das Taricco I-Urteil um eine zusätzliche Schicht ergänzt werde.

1776 EuGH, Urteil vom 5.12.2017, Rs. C-42/17 (M.A.S. und M.B.), Rn. 28.

1777 Auf diese Aussage des Gerichtshofs weist auch Dubout, RTDEur. 2018, 563 (568) hin. Vor ihrem Hintergrund sieht auch Amoroso, IYIL 27 (2018), 452 (458 f.) das Taricco II-Urteil als „bloße Klarstellung“ an.

1778 EuGH, Urteil vom 8.9.2015, Rs. C-105/14 (Taricco u.a.), Rn. 53.

1779 EuGH, Urteil vom 8.9.2015, Rs. C-105/14 (Taricco u.a.), Rn. 55 ff.

1780 EuGH, Urteil vom 5.12.2017, Rs. C-42/17 (M.A.S. und M.B.), Rn. 60.

1781 Klein, DÖV 2018, 605 (609 und Fn. 43).

1782 Rauchegger, CMLRev. 55 (2018), 1521 (1537 ff.). 
die Verpflichtung hierzu mit Art. 49 GRCh unvereinbar ist. ${ }^{1783}$ Dessen Anwendung würde sich demnach akzessorisch nach mitgliedstaatlichem Recht richten. ${ }^{1784}$

Eine solche Einschätzung ist nur möglich, da der Gerichtshof eine klare Unterscheidung zwischen dem jeweils unterschiedlichen Verständnis des Gesetzmäßigkeitsgrundsatzes nach nationalem Recht bzw. Unionsrecht unterlässt, was wohl damit zusammenhängt, dass die Elemente der Bestimmtheit, Vorhersehbarkeit und Nichtrückwirkung abstrakt einheitlich $\mathrm{zu}$ verstehen sind. Nicht übersehen werden darf aber, dass damit noch nicht gesagt ist, worauf sich diese Elemente beziehen, was also bestimmt, vorhersehbar, nichtrückwirkend sein muss. Die Frage, ob Verjährungsregeln vom Legalitätsgrundsatz erfasst werden, wird ja gerade unterschiedlich beurteilt. $\mathrm{Zu}$ sagen, dass keine unterschiedliche Auslegung des Legalitätsgrundsatzes auf unionaler und nationaler Ebene bestehe, da nur seine Anwendbarkeit auf das Verjährungsrecht in Streit stehe ${ }^{1785}$, bedeutete daher, eine Trennung des Legalitätsgrundsatzes von seinem Inhalt vorzunehmen. Nicht in Abrede gestellt werden kann, dass das nationale Verständnis des Gesetzmäßigkeitsgrundsatzes zum Konflikt mit Art. 325 AEUV führt. ${ }^{1786}$

Die Rücknahme der in Art. 325 AEUV enthaltenen unionsrechtlichen Verpflichtungen erfolgt angesichts der nationalen Grundrechtsgewährleistung. ${ }^{1787}$ Auch wenn er dies nicht offenlegt, hat der Gerichtshof damit eine auf nationales Verfassungsrecht gründende Ausnahme vom Vorrang

1783 Lenaerts, in: European Court of Human Rights, Dialogue between judges, 2018, S. 57 (63).

1784 Im Falle der Harmonisierung einer Materie entscheidet dagegen etwa der unionsrechtliche Grundsatz der Gesetzmäßigkeit der Besteuerung (und nicht eine Auslegung dieses Grundsatzes im nationalen Recht) darüber, welche Aspekte einer Steuer wie etwa der Mehrwertsteuer gesetzlich geregelt sein müssen, siehe EuGH, Urteil vom 8.5.2019, Rs. C-566/17 (Związek Gmin Zagłębia Miedziowego), Rn. 41 f., siehe auch Rn. 44.

1785 So Di Francesco Maesa, eucrim 2018, 50 (54).

1786 Dazu näher Burchardt, Verfassungsblog vom 7.12.2017, die vom „Öffnen einer Büchse der Pandora“ spricht. In der Entscheidung zugunsten des nationalen Verfassungsrechts, ohne auf Art. 53 GRCh Bezug zu nehmen, erkennt sie die Grundlage für weitreichende Folgen für den Vorrang, sollte die vom EuGH eröffnete Möglichkeit auch für andere Verfassungsgrundsätze genutzt werden.

1787 Klein, DÖV 2018, 605 (607). Er weist darauf hin, dass es in der Taricco-Konstellation nicht um mehrpolige Rechtsverhältnisse geht. Zu deren Behandlung etwa Jarass, GRCh-Kommentar, 3. Aufl. 2016, Art. 53 GRCh, Rn. 31 ff., wonach der Vorrang als Kollisionsregel greift; anders Hwang, EuR 2014, 400 (416 ff.). 
des Unionsrechts - im konkreten Fall des Art. 325 AEUV - anerkannt. ${ }^{1788}$ Trotz Fehlens eines Umsetzungsspielraums ist es den nationalen Gerichten gestattet, den Konflikt zwischen dem unmittelbar anwendbaren Art. 325 AEUV und den italienischen Verjährungsvorschriften zugunsten der nationalen Grundrechtsgewährleistung aufzulösen. ${ }^{1789}$

Eine solche beachtliche Schwächung des Vorrangs gegenüber nationalem Verfassungsrecht hatte der Gerichtshof allerdings wohl kaum im Sinn. Das Ergebnis, zu dem er gelangt, ist daher eher Ausdruck und Ausfluss einer „kompromisshafte[n] Lösung“. ${ }^{1790}$ In der Tat gelingt es dem Gerichtshof geschickt, durch die Betonung der vorrangigen Verpflichtung des nationalen Gesetzgebers zur Änderung der Rechtslage eine direkte Konfrontation mit dem italienischen Verfassungsgerichtshof zu vermeiden. ${ }^{1791}$

Nicht zuletzt das vom Gerichtshof in Bezug genommene Urteil in der Rechtssache Impresa Pizzarotti ${ }^{1792}$ zeigt, dass der EuGH keine Begrenzung des Vorrangs im Sinn hatte. Dort wird nämlich die Bedeutung der Rechtskraft in der Unionsrechtsordnung und den nationalen Rechtsordnungen betont, was den EuGH zu der Aussage führt, dass nationale Verfahrensvorschriften, die zur Rechtskraft einer Gerichtsentscheidung führen, nicht unangewendet bleiben müssen, obwohl durch deren Nichtanwendung „einer mit dem Unionsrecht unvereinbaren nationalen Situation abgeholfen werden könnte"1793.

Dass der EuGH eine materiell unionsrechtswidrige nationale Sachlage im Angesicht nationaler Verfahrensregeln hinnimmt, kann nach den im Abschnitt zur Bedeutung der nationalen Verfahrensautonomie getroffenen Feststellungen nicht weiter überraschen. ${ }^{1794}$ Dafür, dass es auch beim Taricco II-Urteil in erster Linie um eine Frage der nationalen Verfahrensau-

1788 Burchardt, EuR 2018, 248 (251 ff.).

1789 Rauchegger, CMLRev. 55 (2018), 1521 (1535, 1546 f.).

1790 Siehe Meyer, JZ 2018, 304 (305).

1791 Schmahl, in: Breuer (Hrsg.), Principled Resistance, 2019, S. 299 (305 f.).

1792 EuGH, Urteil vom 5.12.2017, Rs. C-42/17 (M.A.S. und M.B.), Rn. 61 unter Verweis auf EuGH, Urteil vom 10.7.2014, Rs. C-213/13 (Impresa Pizzarotti), Rn. 58 und 59.

1793 EuGH, Urteil vom 10.7.2014, Rs. C-213/13 (Impresa Pizzarotti), Rn. 59.

1794 Siehe Thym, Kommentar zum Verfassungsblogbeitrag von Burchardt vom 7.12.2017. Zur Bedeutung nationaler Verfahrensmodalitäten im Zusammenhang mit der zeitlichen Dimension der Rechtsprechung des Gerichtshofs siehe näher oben bei Fn. $1223 \mathrm{ff}$. 
tonomie geht ${ }^{1795}$, spricht in der Tat auf den ersten Blick, dass es sich beim Verjährungsrecht aus unionsrechtlicher Perspektive ja um einen verfahrensrechtlichen Aspekt handelt. ${ }^{1796}$ Allerdings tritt dieses Verständnis in den Urteilsgründen kaum zutage. Zudem unterscheidet sich die hier in Rede stehende Konstellation dadurch von den „üblichen“ Fällen der Verfahrensautonomie, dass sich in ihr mit dem nationalen Verständnis des Legalitätsprinzips, das die Verjährung materiellrechtlich einordnet, materielles nationales Recht gegenüber materiellem Unionsrecht - Art. 325 AEUV - durchsetzt. ${ }^{1797}$

Insbesondere ein Blick auf das im Anschluss an das Taricco II-Urteil ergangene Urteil des Gerichtshofs in der Rechtssache Kolev zeigt, dass dessen Rechtsprechung zur Pflicht zur Nichtanwendung des nationalen Rechts bei Mehrwertsteuerstraftaten noch nicht endgültig gefestigt ist.

So betont der Gerichtshof in der Rechtssache Kolev einerseits erneut die vorrangige Verpflichtung des nationalen Gesetzgebers, die erforderlichen Maßnahmen zu ergreifen, um zu verhindern, dass aufgrund der anwendbaren Verfahrensvorschriften „aus ihnen selbst innewohnenden Gründen die systemische Gefahr besteht, dass solche Straftaten ungeahndet bleiben“" - bestimmte Vorschriften der bulgarischen Strafprozessordnung führen dazu, dass bei zollrechtlich relevanten Straftaten die Wirksamkeit der Strafverfolgung beeinträchtigt und die Ahndung der Taten zum Nachteil der finanziellen Interessen der Union verhindert wird, worin ein Verstoß gegen Art. 325 I AEUV liegt. ${ }^{1798}$ Andererseits fordert der Gerichtshof die nationalen Gerichte aber auch dazu auf, die Regelungen so weit wie mög-

1795 Mit dem Verweis auf Verfahrensmodalitäten zur Umsetzung unionsrechtlicher Verpflichtungen ist auch eine Vergleichbarkeit mit EuGH, Urteil vom 30.5.2013, Rs. C-168/13 PPU (F.) angesprochen, vgl. Dubout, RTDEur. 2018, 563 (577 f.); Peristeridou/Ouwerkerk, Verfassungsblog vom 12.12.2017. Siehe in diesem Zusammenhang auch Rauchegger, CMLRev. 55 (2018), 1521 (1535) und Lenaerts, in: European Court of Human Rights, Dialogue between judges, 2018, S. 57 (62). Verwiesen sei an dieser Stelle auch auf Corte costituzionale, Vorlagebeschluss 24/2017 vom 26.1.2017, S. 8 f. und ihren Vorschlag einer Abgrenzung von der Melloni-Fallgestaltung sowie den Hinweis auf die „außerhalb des Unionsrechts" liegende Einordnung der Verjährungsregeln.

1796 Ganz in diesem Sinne bejaht etwa auch Schmahl, in: Breuer (Hrsg.), Principled Resistance, 2019, S. 299 (306) eine Vergleichbarkeit mit Fällen der Rechtskraft und ihren im Äquivalenz- und Effektivitätsgrundsatz bestehenden Grenzen.

1797 Überzeugend Burchardt, EuR 2018, 248 (255 ff.).

1798 EuGH, Urteil vom 5.6.2018, Rs. C-612/15 (Kolev u.a.), Rn. 59 ff. Von unionsrechtlicher Relevanz ist der Fall, weil die Zölle des Gemeinsamen Zolltarifs zu den Eigenmitteln der Union zu rechnen sind. 
lich im Lichte von Art. 325 I AEUV in der Auslegung durch den Gerichtshof auszulegen oder sie gegebenenfalls unangewendet zu lassen. ${ }^{1799}$ Dass hierbei auch die Grundrechte der Betroffenen zu wahren sind, bedeute nicht, dass eine Einstellung des mit Verstößen gegen wesentliche Verfahrensregeln behafteten Strafverfahrens allein aus dem Grund in Betracht komme, dass das nationale Gericht hierin die für die Wahrung der Grundrechte „günstigste Lösung“ erblicke. Entscheidend stellt der Gerichtshof darauf ab, dass auch bei der in der Kolev-Konstellation möglichen Anwendung nationaler Grundrechtsstandards der Vorrang, die Einheit und die Wirksamkeit des Unionsrechts nicht beeinträchtigt werden dürften. ${ }^{1800}$ Diesen Vorbehalt nimmt der Gerichtshof also durchaus weiter bzw. wieder ernst, weswegen den Ausführungen des Gerichtshofs im Kolev-Urteil zum Teil eine Rückkehr zur im Taricco I-Urteil vertretenen Auffassung zugeschrieben wird. ${ }^{1801}$

Die Aussagen des Gerichtshofs zur Pflicht der nationalen Gerichte zur Nichtanwendung des nationalen Rechts bei Mehrwertsteuerstraftaten bewegen sich also, wie Generalanwalt Bobek pointiert zusammenfasst, „von ja, wenn es sich um eine beträchtliche Anzahl von Fällen handelt' (Taricco), zu ,nein, da es Sache des nationalen Gesetzgebers ist, solche Systemfehler zu beheben' (M.A.S. und Scialdone), bis zu ,nein, aber doch ja, wenn dies systemisch ist, sofern die Grundrechte des Angeklagten gewahrt werden' (Kolev) "1802, weswegen der Generalanwalt diese Rechtsprechung von „milde ausgedrückt, inneren Unstimmigkeiten“"1803 gekennzeichnet sieht. Auf eine solche Rechtsprechung sollte keine grundlegende Abkehr von bewährten Grundsätzen gestützt werden.

1799 EuGH, Urteil vom 5.6.2018, Rs. C-612/15 (Kolev u.a.), Rn. 65 zu den Pflichten des nationalen Gesetzgebers einerseits und Rn. 66 f. zu den Pflichten des vorlegenden Gerichts andererseits.

1800 EuGH, Urteil vom 5.6.2018, Rs. C-612/15 (Kolev u.a.), Rn. 68 ff. und Rn. 75 unter Verweis auf EuGH, Urteil vom 5.12.2017, Rs. C-42/17 (M.A.S. und M.B.), Rn. 47. In Rede standen hier u.a. das Recht auf Unterrichtung über den Tatvorwurf und das Recht auf Zugang zur Verfahrensakte (Art. 48 II GRCh) sowie das Recht der Beschuldigten darauf, dass ihre Sache innerhalb angemessener Frist verhandelt wird (allgemeiner Grundsatz des Unionsrechts, der in Art. 6 I EMRK und Art. 47 II GRCh niedergelegt ist).

1801 GA Bobek, Schlussanträge vom 25.7.2018 in der Rs. C-310/16 (Dzivev u.a.), Rn. 4.

1802 GA Bobek, Schlussanträge vom 25.7.2018 in der Rs. C-310/16 (Dzivev u.a.), Rn. 66.

1803 GA Bobek, Schlussanträge vom 25.7.2018 in der Rs. C-310/16 (Dzivev u.a.), Rn. 4. 


\section{Ergebnis}

Im Ergebnis bleibt demnach festzuhalten, dass der Gerichtshof im Taricco II-Urteil in der Sache den Vorrang des Art. 325 AEUV durch nationales Verfassungsrecht begrenzt hat. Die Urteilsgründe sind allerdings so formuliert, dass erkennbar wird, dass er dem Urteil ein solches Verständnis nicht beigelegt wissen möchte. Aus diesem Grund kann auf das Taricco II-Urteil auch kein allgemeiner Vorbehalt zugunsten nationalen Verfassungsrechts gestützt werden und damit auch nicht zugunsten in nationalen Grundrechten verankerter Vertrauensschutzerwägungen. An dieser Stelle ist also durch die Kontextualisierung des Taricco II-Urteils des EuGH einer Verallgemeinerung der von ihm getroffenen Aussagen vorzubeugen. ${ }^{1804}$

\section{Zusammenfassung}

Die vorangegangenen Überlegungen haben gezeigt, dass eine Suspendierung des Anwendungsvorrangs nur in Ausnahmefällen denkbar ist. Die Rechtsprechung des Gerichtshofs eröffnet in engen Grenzen unter Berufung auf unionsrechtliche Interessen die Möglichkeit eines zeitlichen Aufschubs der Pflicht zur Befolgung der „eigentlich“ zu beachtenden unionsrechtlichen Vorgaben. Den Weg für eine Abwägung mit Vertrauen auf eine unionsrechtswidrige nationale Rechtslage ebnet der Gerichtshof allerdings nicht. Obwohl Vertrauen auf die nationale Rechtslage bei der Nichtanwendung des nationalen Rechts als Folge des Vorrangs stets enttäuscht wird, kann kein „nationaler Vertrauensschutz“ gewährt werden, da die Defrenne-Rechtsprechung insoweit eine abschließende Regelung trifft.

Dass der Gerichtshof in seinem Taricco II-Urteil letztlich keine Begrenzung des Vorrangs durch Anwendung nationaler Grundrechtsstandards vorgenommen hat, ergibt sich erst aus einer Betrachtung, die dieses Urteil in den Zusammenhang des „Dialogs“ mit dem italienischen Verfassungsgerichtshof stellt. Dadurch wird deutlich, dass der Gerichtshof einen Kompromiss gesucht und gefunden hat, der eine direkte Konfrontation mit

1804 Die Kontextualisierung von Gerichtsentscheidungen ist Lepsius, JZ 2015, 435 (441 ff.), Lepsius, JZ 2019, 793 ff. ein besonderes Anliegen; ganz ähnlich wie dieser Payandeh, Judikative Rechtserzeugung, 2017, S. 461 f., 465 ff., der aber auch deutlich auf die Grenzen dieses Konzepts hinweist. Wie oben bei und in Fn. 158 bereits erwähnt, entscheidet der EuGH bei der Auslegungsvorabentscheidung keine Einzelfälle, weswegen eine Verallgemeinerung seiner Aussagen grundsätzlich nichts Ungewöhnliches ist. 
dem italienischen Verfassungsgerichtshof und eine Aktivierung der nach italienischem Recht bestehenden Integrationsgrenzen vermeiden sollte.

Die in der Rechtsprechung des Gerichtshofs zu findenden Ansätze zur Berücksichtigung nationaler Vertrauensumstände sind auf verwaltungsrechtliche Sonderkonstellationen beschränkt. Für die etwa im Bereich der Rückforderung von Beihilfen mögliche Berufung auf den nationalen Rechtssicherheitsgrundsatz mag aus Sicht der Betroffenen zwar auch bei der Verdrängung nationaler Rechtsnormen Bedarf bestehen. Dennoch ist für weitergehenden Vertrauensschutz neben der Defrenne-Rechtsprechung kein Raum, um eine Erosion der Substanz des Vorrangs zu verhindern. Die Einschätzung des BAG in der Mangold/Honeywell-Konstellation, dass ihm dort angesichts der unterbliebenen zeitlichen Begrenzung im Mangold-Urteil des EuGH die Gewährung von "nationalem Vertrauensschutz“ verwehrt sei, wird damit bestätigt.

\section{Mittelbar wirkendes Unionsrecht}

\section{Einführung}

Wie bereits erwähnt, wird in weiten Teilen der Literatur und Rechtsprechung im Hinblick auf die Möglichkeiten der Berücksichtigung nationaler Vertrauensumstände zwischen der Betroffenheit von unmittelbar und mittelbar wirkendem Unionsrecht unterschieden. ${ }^{1805}$ Mit dieser Differenzierung einher geht in aller Regel die Bejahung der Möglichkeit der Gewährung „nationalen Vertrauensschutzes“ im letztgenannten Fall, während dessen Ausschluss bei unmittelbare Wirkung entfaltendem Unionsrecht in aller Regel anerkannt wird. ${ }^{1806}$ Auch wenn in der Rechtsprechung zum Teil etwas ungenau von einer im Hinblick auf die Gewährung von Vertrauensschutz zu treffenden Unterscheidung zwischen Primär- und Sekundärrecht die Rede ist ${ }^{1807}$, ist damit in der Sache ebenfalls die noch

1805 Auch Herrmann, Richtlinienumsetzung, 2003, S. 39 bevorzugt den Begriff der „Wirkung“ im Vergleich zu dem der „Anwendbarkeit“. Grundsätzlich ablehnend gegenüber dem Begriff der „unmittelbaren Anwendbarkeit“ Funke, Umsetzungsrecht, 2010, S. 129, Fn. 47.

1806 Picker, ZTR 2009, 230 (235); Tillmanns, in: FS Buchner, 2009, S. 885 (894 f.); Wißmann, in: FS Bauer, 2010, S. 1161 (1165 ff.); Höpfner, ZfA 2010, 449 (482 ff.); siehe auch Benecke, RdA 2011, 241 (242); Bauer/Arnold, AP BUrlG $\$ 7$ Nr. 39; Schlachter, RdA 2009, Sonderbeilage zu Heft 5, 31 (35 f.).

1807 BAG, Urteil vom 23.3.2010, 9 AZR 128/09, Rn. 80 - BAGE 134, 1. 
näher zu untersuchende Unterscheidung von unmittelbar und mittelbar wirkendem Unionsrecht gemeint.

Vereinzelt wird in der Rechtsprechung auch eine Differenzierung in die genau entgegengesetzte Richtung vorgenommen, wonach die Gewährung „nationalen Vertrauensschutzes" bei unmittelbar wirkendem Unionsrecht möglich sein soll, nicht aber im Falle der richtlinienkonformen Auslegung des nationalen Rechts. Zutreffend ist an dieser Überlegung zwar, dass bei der richtlinienkonformen Auslegung an eine nationale Regelung anzuknüpfen ist, die im Hinblick auf eine Richtlinie und damit einen geschriebenen Unionsrechtsakt auszulegen ist, was Normunterworfenen grundsätzlich einen Anhaltspunkt für das zu erwartende Auslegungsergebnis liefert, während es im Gegensatz hierzu in der Mangold-Konstellation um die Unanwendbarkeit unionsrechtswidrigen nationalen Rechts im Hinblick auf ungeschriebenes bzw. in allgemeinen Grundsätzen bestehendes Primärrecht ${ }^{1808}$ geht. Dies erschwert es für den Einzelnen in der Tat, die Unanwendbarkeit vorherzusehen. ${ }^{1809}$ In einem solchen Fall besteht aber wie gesehen kein Raum für Vertrauen in die nationale Rechtslage, wenn der Gerichtshof eine Begrenzung im Sinne der Defrenne-Rechtsprechung unterlassen hat. Die Unterscheidung zwischen unmittelbar und mittelbar wirkendem Unionsrecht kann daher nicht herangezogen werden, um zu begründen, dass Vertrauensschutz im Falle der Unanwendbarkeit eines Gesetzes wegen Verstoßes gegen unmittelbar wirkendes und damit vorrangiges Primärrecht in Betracht komme und bei richtlinienkonformer Auslegbarkeit eines Gesetzes ausscheide. ${ }^{1810}$

Im Ausgangspunkt ist daran zu erinnern, dass der Gerichtshof bislang nur bei unmittelbar anwendbarem Unionsrecht eine Begrenzung der ex tunc-Wirkung vorgenommen hat. Bei dessen Betroffenheit ist in aller Regel ausschließlich die Auslegung des Unionsrechts durch den EuGH für die Entscheidung eines Rechtsstreits ausschlaggebend. Das durch den EuGH offengelegte Verständnis des Unionsrechts kann angesichts des Anwendungsvorrangs in allen Mitgliedstaaten einheitlich zur Anwendung kommen. Dann erscheint es auch folgerichtig, allein den Gerichtshof darüber befinden zu lassen, ob eine Begrenzung in zeitlicher Hinsicht in

1808 EuGH, Urteil vom 22.11.2005, Rs. C-144/04 (Mangold), Rn. 77.

1809 Siehe in diesem Sinne LAG Düsseldorf, Beschluss vom 21.11.2007, $12 \mathrm{Sa}$ 1311/07 - ZIP 2008, 1786 (1791).

1810 So aber LAG Düsseldorf, Urteil vom 2.2.2009, 12 Sa 486/06 - NZA-RR 2009, 242 (249). Höpfner, RdA 2013, 16 (27, Fn. 175) bezeichnet dies angesichts der "für den Mitgliedstaat weitaus einschneidenderen Unanwendbarkeit" als „wenig nachvollziehbar“. 
Frage kommt oder nicht. ${ }^{1811}$ Bei mittelbar wirkendem Unionsrecht steht zwar auch die Auslegung des Unionsrechts nach einer Entscheidung des Gerichtshofs mit bindender Wirkung für alle Mitgliedstaaten fest. Damit ist aber noch nicht gesagt, ob der Rechtsstreit auch in dem vom EuGH vorgegebenen Sinn entschieden werden kann. Denkbar ist etwa, dass eine den Vorgaben des EuGH entsprechende Auslegung des nationalen Rechts scheitert. In diesem Fall rücken die mitgliedstaatlichen Gerichte verstärkt in den Mittelpunkt, die dann mit dem Ausgleich der betroffenen Interessen konfrontiert sind. ${ }^{1812}$

Trotz dieser unterschiedlichen Ausgangslage erscheint nicht zuletzt angesichts der im Primärrecht verankerten Pflicht zur Richtlinienumsetzung eine Gleichbehandlung aller Kollisionslagen nicht ausgeschlossen. ${ }^{1813}$ Vor dem Hintergrund neuerer Entscheidungen von EuGH und Bundesverfassungsgericht ist daher zu klären, ob eine Differenzierung zwischen Verstößen gegen unmittelbar bzw. mittelbar wirkendes Unionsrecht tatsächlich angezeigt ist, ob die Trennlinien anderweitig verlaufen oder sämtliche Verstöße gegen Unionsrecht im Hinblick auf die Frage des Vertrauensschutzes einheitlich zu beurteilen sind. Eng damit verbunden ist die Frage, anhand welchen Maßstabs dieser zu beurteilen ist - eines unionsrechtlichen oder von Mitgliedstaat zu Mitgliedstaat variierenden - und wie dieser Maßstab konkret beschaffen ist. Auch dies ist in die Überlegungen mit einzubeziehen.

Als wenig hilfreich erweist sich in diesem Zusammenhang eine derart allgemein gehaltene Aussage, wonach gegebenenfalls Vertrauensschutz durch eine zeitliche oder bereichsmäßige Beschränkung der Rückwirkung einer Rechtsfortbildung möglich sei, die sowohl auf EU-Ebene als auch auf nationaler Ebene gewährt werden könne, wenn der gute Glaube der Bürger an die Fortdauer des bisherigen Rechtsverständnisses schutzwürdig

1811 Siehe auch Düsterhaus, EuR 2017, 30 (46).

1812 Düsterhaus, EuR 2017, 30 (46); Düsterhaus, YEL 36 (2017), 237 (262). Dass mitgliedstaatliche Gerichte zur Lösung der sich in richtliniengeprägten Fallgestaltungen stellenden Probleme aufgerufen sind, folgt daraus, dass auch sie zur Richtlinienumsetzung verpflichtet sind, siehe nur EuGH, Urteil vom 10.4.1984, Rs. 14/83 (von Colson und Kamann), Rn. 26. Reimer, JZ 2015, 910 (911 f., 919) möchte Art. 288 III AEUV dagegen nur eine Verpflichtung der Mitgliedstaaten als solchen zur Richtlinienumsetzung entnehmen, nicht aber ihrer Organe.

1813 Siehe etwa Temming, ZESAR 2015, 298 (300). Rosenkranz, ZfPW 2016, 351 (371 mit Fn. 117) wendet dagegen qualitativ andere Wirkungen von unmittelbar und mittelbar wirkendem Unionsrecht ein. 
sei. ${ }^{1814}$ Den entscheidenden Fragen wird damit ausgewichen. Ebenso unbefriedigend erscheint es, wenn zwar gesagt wird, eine Vertrauensschutz ablehnende Sichtweise sei zu engherzig, und der EuGH deshalb aufgefordert wird, das nationale Interesse in seine Abwägung mit aufzunehmen und vorzusehen, dass sich dieses gegenüber unionsrechtlichen Interessen durchsetzen könne, es aber zugleich heißt, es solle im Rahmen einer Einschätzungsprärogative des nationalen Richters berücksichtigt werden dürfen. ${ }^{1815}$ Dann wird ebenso wenig klar, wer anhand welchen Maßstabs entscheiden soll.

II. Unterscheidung von unmittelbar und mittelbar wirkendem Unionsrecht wegen ihrer unterschiedlichen Wirkungsweise?

Zu Beginn ist die Prämisse der in weiten Teilen der Literatur im Hinblick auf die Möglichkeit der Berücksichtigung nationaler Vertrauensumstände getroffenen Unterscheidung zu hinterfragen. In Frage steht also die von ihnen zugrunde gelegte unterschiedliche Wirkungsweise von „unmittelbar“ und "mittelbar" wirkendem Unionsrecht. Herauszuarbeiten ist, ob nicht doch gemeinsame Charakteristika gefunden werden können, die für eine Gleichbehandlung beider Kategorien von Unionsrecht auch in zeitlicher Hinsicht sprechen. Damit sind insbesondere das Verhältnis von Vorrang und unmittelbarer Wirkung sowie von unmittelbarer Wirkung und richtlinienkonformer Auslegung näher zu betrachten. Aus der Rechtsprechung des Gerichtshofs ergibt sich hier kein gänzlich geschlossenes Bild.

\section{Unmittelbare Geltung von Richtlinien}

Im Winner Wetten-Urteil spricht der EuGH vom Vorrang des unmittelbar geltenden Unionsrechts und von der von einer unmittelbar geltenden Rechtsvorschrift der Union („directly-applicable rule of Union law“; „règle de droit de l'Union directement applicable“) ausgeübten Verdrängungswirkung. ${ }^{1816}$ Mit der unmittelbaren Geltung verwendet er ein Merkmal, von dem unsicher ist, ob es auch Richtlinien zukommt oder ob es ihnen abzusprechen ist. Um beurteilen zu können, ob der Gerichtshof mit seiner

1814 So aber in der Tat Schlachter, EuZA 2015, 1 (14).

1815 Temming, ZESAR 2015, 298 (302).

1816 EuGH, Urteil vom 8.9.2010, Rs. C-409/06 (Winner Wetten), Rn. 67, 69. 
Aussage Richtlinien vom Vorrang des Unionsrechts ausnehmen wollte, ist der Versuch zu unternehmen, für terminologische Klarheit zu sorgen.

Die Geltung einer Norm in einer Rechtsordnung ist der „Anspruch, beachtliches Recht zu sein“. ${ }^{1817}$ Zum Teil wird die unmittelbare Geltung einer Richtlinie mit der Begründung verneint, dass sie keine Rechtsbeziehungen zwischen den Einzelnen, sondern nur Verpflichtungen für die Mitgliedstaaten begründen könne. ${ }^{1818}$ Hiergegen ist allerdings einzuwenden, dass unmittelbare Geltung lediglich bedeutet, dass eine Norm ohne Zutun der Mitgliedstaaten Rechtswirkungen in den mitgliedstaatlichen Rechtsordnungen erzeugt. ${ }^{1819}$ Hierfür kommt es nicht auf die Fähigkeit an, Rechtsbeziehungen zwischen den Einzelnen zu begründen. ${ }^{1820} \mathrm{Zum}$ Teil wird eine allgemeine unmittelbare Geltung von Richtlinien auch mit der Erwägung abgelehnt, dass an die unmittelbare Wirkung von Richtlinien weitergehende Anforderungen als die bloße Existenz eines vollziehbaren Inhalts gestellt würden, womit sich die Voraussetzungen, unter denen eine Richtlinie unmittelbare Wirkungen entfaltet, von den Voraussetzungen unterschieden, unter denen geltendes Recht Wirkungen entfaltet. ${ }^{1821}$ Erhöhte Anforderungen an die unmittelbare Wirkung von Richtlinien können der unmittelbaren Geltung aber nicht die Grundlage entziehen, da sich diese mit der Besonderheit der mehrstufigen Rechtsetzung bei Richtlinien im Mehrebenensystem erklären.

In der Rechtssache van Duyn führt der EuGH im Zusammenhang mit Verordnungen aus, dass diese unmittelbar gelten („are directly applicable“/,sont directement applicables“) und „infolgedessen schon wegen ihrer Rechtsnatur unmittelbare Wirkungen erzeugen [können]“. Letzteres wird in der englischen bzw. französischen Sprachfassung des Urteils mit „direct effects“ bzw. „effets directs“ wiedergegeben. ${ }^{1822}$ Der Gerichtshof macht damit deutlich, dass unmittelbare Geltung und unmittelbare Wirkung zu

1817 Klein, Unmittelbare Geltung, 1988, S. 8.

1818 GA Reischl, Schlussanträge vom 20.2.1979 in der Rs. 148/78 (Ratti), Slg. 1979, S. 1650.

1819 Berger, Anwendungsvorrang, 2016, S. 11, 52 f.

1820 Klein, Unmittelbare Geltung, 1988, S. 12.

1821 Herrmann, Richtlinienumsetzung, 2003, S. 40.

1822 EuGH, Urteil vom 4.12.1974, Rs. 41/74 (van Duyn), Rn. 12. Auf den Unterschied zwischen direct effect (unmittelbare Wirkung) und direct applicability (unmittelbare Geltung) weisen auch Lenaerts/Corthaut, ELRev. 2006, 287 (311, Fn. 149) hin. 
unterscheiden sind. ${ }^{1823}$ Für Verordnungen bedeutet dies, dass sie ohne mitgliedstaatlichen Umsetzungsakt Bestandteil der nationalen Rechtsordnung werden, ihre unmittelbare Wirkung aber davon abhängt, dass sie „klare und unbedingte Verpflichtungen begründen". ${ }^{1824}$

In dieser terminologischen Klarheit äußert sich der Gerichtshof allerdings nicht immer. So ist in der englischen Sprachfassung des Urteils in der Rechtssache Klohn im Hinblick auf Bestimmungen des Unionsrechts („provisions of EU law“) davon die Rede, dass diese "directly applicable“ sind, wenn sie den Einzelnen Rechte verleihen, die diese vor den nationalen Gerichten geltend machen können. Diese Bestimmungen legen den Mitgliedstaaten eine eindeutige Verpflichtung auf, die zu ihrer Wirksamkeit keine Durchführungsmaßnahme erfordert und den Mitgliedstaaten keinen Ermessensspielraum überlässt. In der deutschen Sprachfassung des Urteils ist an dieser Stelle von "unmittelbar gelten“ die Rede. ${ }^{1825}$ Zur Bestätigung verweist der Gerichtshof auf diejenige Passage im van DuynUrteil, in der es mit Art. 48 EWG-Vertrag (Arbeitnehmerfreizügigkeit) um eine Vorschrift des Primärrechts ging, von der geklärt werden sollte, ob sie Einzelpersonen Rechte verleiht, die diese vor mitgliedstaatlichen Gerichten geltend machen können. In der Sache geht es also um die weitläufig als unmittelbare Anwendbarkeit bezeichnete Eigenschaft. In Rn. 33 des Klohn-Urteils ist dann von der unmittelbaren Anwendbarkeit („directly applicable“) der Bestimmungen einer Richtlinie die Rede, die ebenso bestimmt werde wie bei Bestimmungen eines von der Union unterzeichneten Abkommens. Da die der Richtlinienbestimmung entsprechende Bestimmung der Aarhus-Konvention keine unmittelbare Wirkung habe (,is not directly applicable“), habe die Kostenregel in Art. 10a V der

1823 Dennoch hat dies nicht zu einem Ende der Diskussionen über das zutreffende Begriffsverständnis geführt. Zu unterschiedlichen begrifflichen Grenzziehungen näher Prechal, Directives, 2. Aufl. 2005, S. 227 ff. Herrmann, Richtlinienumsetzung, 2003, S. $36 \mathrm{f}$. etwa übersetzt „direct applicability“ trotz der sich in anderen Sprachfassungen ergebenden terminologischen Überschneidung mit unmittelbarer Anwendbarkeit und nicht mit unmittelbarer Geltung.

1824 Ebers, Unionsprivatrecht, 2016, S.380, Fn. 4 unter Verweis auf EuGH, Urteil vom 11.1.2001, Rs. C-403/98 (Monte Arcosu), Rn. 26-28 und Winter, CMLRev. 9 (1972), 425 (435).

1825 EuGH, Urteil vom 17.10.2018, Rs. C-167/17 (Klohn), Rn. 27 f. unter Verweis auf EuGH, Urteil vom 4.12.1974, Rs. 41/74 (van Duyn), Rn. 4 und 8 sowie 6. 
geänderten Richtlinie 85/337/EWG keine unmittelbare Wirkung („does not have direct effect"). ${ }^{1826}$

An diesem Sprachvergleich wird deutlich: Der Begriff „directly applicable“ wird einerseits mit „unmittelbarer Geltung“, andererseits mit „unmittelbarer Anwendbarkeit", aber auch mit "unmittelbarer Wirkung“" übersetzt, wobei zwischen Geltung, Anwendbarkeit und Wirkung nicht trennscharf unterschieden wird. ${ }^{1827}$

Zur Klärung erforderlich erscheint daher ein Blick in die sich mit den Rechtsakten der Union befassende Vertragsbestimmung. Nach Art. 288 II 2 AEUV gilt eine Verordnung unmittelbar in jedem Mitgliedstaat; in der englischen bzw. französischen Fassung dieser Bestimmung finden die Begriffe „directly applicable“ bzw. „directement applicable“ Verwendung. ${ }^{1828}$ Entgegen zum Teil vertretener Auffassung muss die in der deutschen Fassung des Art. 288 II 2 AEUV gebrauchte Wendung "gilt unmittelbar" nicht durch „ist unmittelbar anwendbar" ausgetauscht werden, da der in der englischen bzw. französischen Fassung verwendete Begriff „directly applicable“ bzw. „directement applicable“ die „unmittelbare Geltung“ meint. Die „unmittelbare Anwendbarkeit/Wirkung“ kann dagegen mit „direct effect" bzw. „effet direct“" wiedergegeben werden. ${ }^{1829}$

Art. 288 AEUV spricht also in der Tat bei Verordnungen von der unmittelbaren Geltung und nicht der unmittelbaren Anwendbarkeit, während er bei Richtlinien hierzu schweigt. Damit kann die unmittelbare Geltung

1826 EuGH, Urteil vom 17.10.2018, Rs. C-167/17 (Klohn), Rn. 33. In Rn. 32 ist davon die Rede, dass Art. 9 IV Aarhus-Konvention keine unmittelbare Wirkung habe (,is not directly applicable“).

1827 Im Hinblick auf Richtlinien verwendet der Gerichtshof damit sowohl den Begriff „unmittelbare Anwendbarkeit“ als auch „unmittelbare Wirkung“. Mit „unmittelbarer Wirkung“ bezeichnen ansonsten zahlreiche Autoren bei Richtlinien das Phänomen, das im Übrigen mit „unmittelbarer Anwendbarkeit“ bezeichnet wird, vgl. Gänswein, Unionsrechtskonforme Auslegung, 2009, S. 21.

1828 Der in Art. 288 II 2 AEUV verwendete Begriff "directly applicable“ meint etwas anderes als die unmittelbare Anwendbarkeit, siehe Winter, CMLRev. 9 (1972), 425 (435). Zum Unterschied zwischen „direct applicability“ und „direct effect" siehe auch Arnull, The European Union and its Court of Justice, 2. Aufl. 2006, S. 185 ff.

1829 Ebenso Brechmann, Richtlinienkonforme Auslegung, 1994, S. 185 f.; a.A. Grabitz, EuR 1971, 1 (8f.), wonach die Formulierung in der deutschen Sprachfassung "gilt unmittelbar" in den anderen Sprachfassungen der Formulierung „ist unmittelbar anwendbar" entspricht. Herrmann, Richtlinienumsetzung, 2003, S. 36 vertritt die Auffassung, die englische Fassung des Art. 288 II 2 AEUV verwende den Begriff der unmittelbaren Anwendbarkeit, die deutsche Fassung mit dem Begriff der unmittelbaren Geltung sei aber passender. 
der Richtlinie jedenfalls nicht mit einem Übersetzungsfehler des Art. 288 II 2 AEUV in der deutschen Fassung begründet werden, was in Betracht gekommen wäre, wenn es dort nicht um die unmittelbare Geltung ginge und einem Umkehrschluss auf die fehlende unmittelbare Geltung der Richtlinie damit die Grundlage entzogen wäre. Da sich für Verordnungen eine Aussage zu ihrer Geltung im AEUV findet, besteht also grundsätzlich eine Grundlage für den Umkehrschluss, dass Richtlinien nicht unmittelbar gelten. Er muss dennoch nicht zwingend gezogen werden.

Dass die Richtlinie als Bestandteil des Unionsrechts automatisch in die nationalen Rechtsordnungen inkorporiert wird, ergibt sich nämlich daraus, dass sich das Konzept der unmittelbaren Wirkung ${ }^{1830}$ sonst nicht erklären ließe. Dass sich Einzelne auf Richtlinien berufen können und die nationalen Gerichte diese berücksichtigen müssen, basiert auf einem Verständnis, wonach Richtlinien Teil der nationalen Rechtsordnung sind. ${ }^{1831}$ Da die Fähigkeit der Richtlinie zur Entfaltung unmittelbarer Wirkung ohne ihre innerstaatliche Geltung nicht zu erklären ist, hat sie im Mitgliedstaat Geltung wie eine Verordnung. ${ }^{1832}$

Zwar ordnet der EuGH in den Fällen, in denen er die unmittelbare Wirkung einer Richtlinienbestimmung ablehnt, auch keine unmittelbare Geltung an. ${ }^{1833}$ Im Bürger-Staat-Verhältnis erkennt er aber unter bestimmten Voraussetzungen eine unmittelbare Wirkung der Richtlinie an. Hält man daran fest, dass eine solche im Horizontalverhältnis abzulehnen ist, hieße das, dass eine unmittelbare Geltung der Richtlinie nur im Vertikalverhältnis in Betracht käme, während sie im Horizontalverhältnis ausscheiden müsste. Eine solche „gespaltene" Geltung kann es nach hier vertretener Auffassung aber nicht geben: entweder die Richtlinie gilt oder sie gilt

1830 Skeptisch gegenüber diesem Konzept Reimer, JZ 2015, 910 (917 f.), der meint, es sei „nicht ganz leicht“, Art. 288 III AEUV die unmittelbare Wirkung von Richtlinien zu entnehmen, und in ihr eine „auf den ersten Blick überraschende Auslegung der Handlungsformen des Art. 288 AEUV“ sieht. Schroeder, in: Streinz (Hrsg.), EUV/AEUV, 3. Aufl. 2018, Art. 288 AEUV, Rn. 87 ordnet die unmittelbare Wirkung dagegen als „vollständig vereinbar“ mit dem Wortlaut des Art. 288 III AEUV ein; sie ist inzwischen „nicht mehr in ihrer grundsätzlichen Zulässigkeit umstritten".

1831 Prechal, Directives, 2. Aufl. 2005, S. 92 f.

1832 Timmermans, CMLRev. 16 (1979), 533 (534); Funke, Umsetzungsrecht, 2010, S. 138 f.; Berger, Anwendungsvorrang, 2016, S. 53.

1833 Baldauf, Richtlinienverstoß, 2013, S. 17. Für Baldauf, a.a.O., S. 37 ist daher im Ergebnis nicht die Richtlinie selbst Teil der nationalen Rechtsordnung; vielmehr gilt nach ihrer Auffassung nur der primärrechtliche Umsetzungsbefehl in der nationalen Rechtsordnung. 
nicht. Damit muss die Richtlinie unmittelbar gelten; lediglich ihre unmittelbare Wirkung kann auf bestimmte Rechtsverhältnisse begrenzt sein. ${ }^{1834}$

Wenn der EuGH vom Anwendungsvorrang einer unmittelbar geltenden Rechtsvorschrift der Union spricht ${ }^{1835}$, schließt dies die Richtlinien also jedenfalls nicht vom Anwendungsvorrang aus. Im Urteil in der Rechtssache Inter-Environnement Wallonie und Bond Beter Leefmilieu Vlaanderen nimmt er dann auch offener auf die Verdrängungswirkung einer unionsrechtlichen Vorschrift („rule of EU law“/,règle du droit de l'Union“) Bezug. ${ }^{1836}$

\section{Vorrang von Richtlinien}

Noch nicht beantwortet ist damit die Frage nach dem Verhältnis von Vorrang und unmittelbarer Wirkung/Anwendbarkeit und der Stellung, die Richtlinien insoweit zukommt. Dass die zum Vorrang von Richtlinien vertretenen Ansichten variieren, überrascht nicht. ${ }^{1837}$

Klar ist zunächst, dass es ohne unmittelbare Geltung einer Norm keinen Vorrang geben kann, während es jedenfalls denkbar ist, dass der Vorrang auch bei fehlender unmittelbarer Wirkung/Anwendbarkeit eingreift. ${ }^{1838}$ Einen untrennbaren Zusammenhang zwischen unmittelbarer Anwendbar-

1834 Ebenso kommt Rahmenbeschlüssen innerstaatliche Geltung zu. Auch wenn bei ihnen die unmittelbare Wirkung ausgeschlossen ist, sind sie unionsrechtlich verbindlich und sollen daher innerhalb der Rechtsordnungen der Mitgliedstaaten rechtlich gelten, vgl. Schönberger, ZaöRV 67 (2007), 1107 (1125 f.).

1835 So auch EuGH, Urteil vom 27.6.2019, Rs. C-597/17 (Belgisch Syndicaat van Chiropraxie u.a.), Rn. 59.

$1836 \mathrm{EuGH}$, Urteil vom 29.7.2019, Rs. C-411/17 (Inter-Environnement Wallonie und Bond Beter Leefmilieu Vlaanderen), Rn. 177.

1837 Ablehnend etwa Höpfner, in: Franzen/Gallner/Oetker (Hrsg.), Arbeitsrecht, 3. Aufl. 2020, Art. 288 AEUV, Rn. 22; bejahend dagegen etwa Göbel-Zimmermann/Kern, NVwZ 2014, 1202 (1204); unklar Schlachter, EuZA 2015, 1 (1f.), die eine Vorrangwirkung bejaht, angesichts der ihrer Ansicht nach fehlenden unmittelbaren Geltung die Möglichkeit einer Normkollision verneint, um dann von einer nicht auf den Vorrang gestützten Verdrängungswirkung zu sprechen.

1838 Vgl. Berger, Anwendungsvorrang, 2016, S. 12, die meint, Letzteres sei „zu untersuchen". Es stellt sich dann die Frage, ob die unmittelbare Geltung nicht nur notwendige, sondern auch hinreichende Bedingung für das Eingreifen des Vorrangs ist, siehe Berger, a.a.O., S. 55. Siehe auch Mayer, Kompetenzüberschreitung, 2000, S. 74, wonach die unmittelbare Geltung eine Kollision zwischen Unions- und nationalem Recht überhaupt erst möglich macht. 
keit und Vorrang allein über den Begriff des „Anwendungs“vorrangs als solchen herzustellen, kann jedenfalls nicht gelingen, da die in anderen Sprachen für den Anwendungsvorrang gebräuchlichen Begriffe wie „primacy“ oder "primauté" eine derartige Verbindung nicht erkennen lassen. Zudem beschreibt auch der Begriff des Anwendungsvorrangs lediglich die Rechtsfolgen des Vorrangs und nicht dessen Voraussetzungen, um die es hier aber gerade geht. ${ }^{1839}$

Generalanwalt Wahl spricht im Zusammenhang mit der im Simmenthal-Urteil betonten Verpflichtung zur Nichtanwendung des nationalen Rechts von einer „unvermeidbaren logischen Folge der Verfassungsdoktrin der unmittelbaren Wirksamkeit im Urteil van Gend \& Loos". ${ }^{1840}$ Sind die Voraussetzungen unmittelbarer Wirkung gegeben, besteht demnach eine Verpflichtung zur Anwendung der entsprechenden Vorschrift des Unionsrechts und eine Pflicht zur Nichtanwendung der mit ihr nicht im Einklang stehenden Bestimmungen des nationalen Rechts. Dieser Zusammenhang zwischen der unmittelbaren Wirkung und der Pflicht zur Nichtanwendung wird in der Literatur zum Teil zum Anlass genommen, hervorzuheben, dass der Vorrang einer Norm des Unionsrechts erst bei einem Normenkonflikt zwischen dem Unionsrecht und dem nationalen Recht zum Tragen komme, was sich nicht nach dem Vorrangprinzip, sondern nach dem Konzept der unmittelbaren Wirkung bemesse, da dieses sonst obsolet sei. ${ }^{1841}$ Obsolet ist das Konzept der unmittelbaren Wirkung aber bereits deshalb nicht, weil es der nationalen Rechtsordnung etwas hinzufügt, was dieser bisher gefehlt hat. Der unmittelbaren Wirkung ist daher jedenfalls auch eine Ersetzungsfunktion zuzuschreiben, sodass sich ihre Wirkung nicht darin erschöpft, eine unionsrechtswidrige nationale Rechtsvorschrift zu verdrängen. Da ihr mit der Ersetzungsfunktion bereits eine Funktion zukommt, erscheint es nicht ausgeschlossen, die Unanwendbarkeit als Folge des Vorrangs des Unionsrechts zu beschreiben: Die unmittelbare Wirkung wird hierfür nicht zwingend benötigt. ${ }^{1842}$

Dass sowohl ein durch die unmittelbare Wirkung bedingtes Eingreifen des Vorrangs als auch eine allein auf den Vorrang gestützte („ent-

1839 Insoweit zutreffend Berger, Anwendungsvorrang, 2016, S. 57.

1840 GA Wahl, Schlussanträge vom 11.9.2018 in der Rs. C-378/17 (Minister for Justice and Equality und Commissioner of An Garda Síochána), Rn. 47 unter Verweis auf EuGH, Urteil vom 9.3.1978, Rs. 106/77 (Simmenthal), Rn. 21-24 und EuGH, Urteil vom 5.2.1963, Rs. 26/62 (Van Gend \& Loos).

1841 Ebers, Unionsprivatrecht, 2016, S. 398.

1842 GA Bobek, Schlussanträge vom 26.6.2018 in der Rs. C-384/17 (Link Logistik N\&N), Rn. 93 ff. 
koppelte“) Verdrängungswirkung grundsätzlich denkbar sind, erklärt sich nicht zuletzt mit den unterschiedlichen Auffassungen zum Verhältnis von Unionsrechtsordnung und nationalen Rechtsordnungen. Während ein Modell, das diese als unterschiedliche Rechtsordnungen begreift, der unmittelbaren Wirkung bedarf, damit das Unionsrecht in den nationalen Rechtsordnungen wirken kann, ist ein derartiger Zwischenschritt entbehrlich, wenn man bereits eine einheitliche Rechtsordnung erkennt. ${ }^{1843}$

In der das Verbot der Altersdiskriminierung betreffenden Rechtssache Kücükdeveci ${ }^{1844}$ hat der EuGH den Vorrang jedenfalls nicht als freischwebenden Grundsatz anerkannt ${ }^{1845}$, da das nunmehr in Art. 21 I GRCh verankerte Verbot der Altersdiskriminierung auch im Horizontalverhältnis unmittelbare Wirkung entfaltet, wie sich im Unterschied etwa zu der zu Art. 27 GRCh (Recht auf Unterrichtung und Anhörung der Arbeitnehmerinnen und Arbeitnehmer im Unternehmen) ergangenen Rechtsprechung zeigt. ${ }^{1846}$

\section{a) Keine Hierarchie}

Die zur Beschreibung des Verhältnisses von Unionsrechtsordnung und nationalen Rechtsordnungen entwickelten Modelle können in der gebotenen Kürze unterschieden werden in solche, die von einer einheitlichen Rechtsordnung ausgehen (mit Primat entweder des Unionsrechts oder des nationalen Rechts) und solche, die vom Nebeneinander zweier unabhängiger Rechtsordnungen ausgehen. Da das nationale Recht seine Geltung nicht aus dem Unionsrecht ableitet und auch in die umgekehrte Richtung kein solcher Ableitungszusammenhang besteht, kann im Ergebnis nicht von einer einheitlichen Rechtsordnung ausgegangen werden. Die demnach eigenständigen Rechtsordnungen können ihr Verhältnis zueinander jeweils selbständig bestimmen. ${ }^{1847}$ Als koordinierende Gesamtrechtsordnung, die die Vorrangfrage verbindlich regelt, kann nach derzeitigem

1843 Dougan, CMLRev. 44 (2007), 931 (942 ff.). Prechal, CMLRev. 37 (2000), 1047 (1064 ff.) etwa schlägt einen Verzicht auf das Erfordernis der unmittelbaren Wirkung vor.

1844 EuGH, Urteil vom 19.1.2010, Rs. C-555/07 (Kücükdeveci).

1845 So aber Avbelj, ELJ 17 (2011), 744 (757).

1846 EuGH, Urteil vom 15.1.2014, Rs. C-176/12 (Association de médiation sociale), Rn. $47 \mathrm{f}$.

1847 Siehe hierzu näher Kruis, Anwendungsvorrang, 2013, S. 7, 9 ff. 
Stand auch nicht das Primärrecht angesehen werden, da es insoweit an der Akzeptanz der Mitgliedstaaten fehlt. ${ }^{1848}$

Gegen ein hierarchisches Modell lassen sich weitere Indizien finden. So heißt es in der englischen Fassung der Erklärung zum Vorrang: "The Conference recalls that, in accordance with well settled case law of the Court of Justice of the European Union, the Treaties and the law adopted by the Union on the basis of the Treaties have primacy over the law of Member States, under the conditions laid down by the said case law."1849 In der slowenischen Fassung war dagegen zunächst eine Begrifflichkeit vorgesehen, der die Bedeutung „are above the law of the member states“ zukommt. Um den Eindruck einer hierarchischen Höherrangigkeit zu vermeiden, findet sich diese dort nun aber nicht wieder. ${ }^{1850}$

Auch bei der Analyse der Rechtsprechung fällt auf, dass der vom Gerichtshof üblicherweise in der englischen Sprachfassung der Urteile verwendete Begriff für den Vorrang „primacy“ ist. Den Begriff „supremacy“ bzw. „supreme“ trifft man dagegen nur ganz selten an. In anderen als der englischen Sprachfassung ist darüber hinaus auch in diesen Fällen von „caractère prééminent" und „primaute“" bzw. „Vorrang“ die Rede. ${ }^{1851}$ Dass eine Kollision zwischen Unionsrecht und nationalem Recht dessen Unanwendbarkeit und nicht die Nichtigkeit bzw. Inexistenz der betroffenen Bestimmung des nationalen Rechts zur Folge hat, spricht ebenso gegen ein hierarchisches Modell wie die Tatsache, dass der Gerichtshof die Erforderlichkeit einer Ersetzung unionsrechtswidrigen nationalen Rechts durch unionsrechtskonforme Bestimmungen damit begründet, dass sie dazu dient, für die Rechtsunterworfenen einen „Zustand der Ungewissheit“ hinsichtlich des Umfangs ihrer unionsrechtlichen Rechte zu vermeiden. Die Sorge um Rechtssicherheit und Effektivität steht damit im Vergleich zum Vorrang im Vordergrund. Damit alle Rechtsordnungen zur bestmöglichen Geltung kommen, darf es keine Hierarchie geben. ${ }^{1852}$

1848 Kruis, Anwendungsvorrang, 2013, S. $34 \mathrm{ff}$.

1849 Declarations annexed to the Final Act of the Intergovernmental Conference which adopted the Treaty of Lisbon, Declaration no. 17 (Declaration concerning primacy), ABl. C 83 vom 30.3.2010, S. 344.

1850 Wiedergegeben nach Avbelj, ELJ 17 (2011), 744 (755 f.).

1851 EuGH, Urteil vom 13.2.1969, Rs. 14/68 (Wilhelm u.a.), Rn. 5; EuGH, Urteil vom 10.10.1973, Rs.34/73 (Variola), Rn.15. Darauf weist Avbelj, ELJ 17 (2011), 744 (744f.) zu Recht hin.

1852 Avbelj, ELJ 17 (2011), 744 (760) unter Verweis einerseits auf EuGH, Urteil vom 22.10.1998, verb. Rs. C-10/97 bis C-22/97 (IN.CO.GE.'90 u.a.), Rn. 21 und andererseits auf EuGH, Urteil vom 4.6.2002, Rs. C-367/98 (Kommission/Portu- 
b) Bedeutung der unmittelbaren Wirkung

Auf eine hierarchische Höherrangigkeit des Unionsrechts kann eine etwaige Vorrangwirkung der Richtlinie also nicht gestützt werden. Als nicht existent kann eine Richtlinie angesichts ihrer unmittelbaren Geltung, die sie zum Bestandteil der Rechtsordnungen der Mitgliedstaaten macht, aber auch nicht behandelt werden, selbst wenn sie keine unmittelbare Wirkung entfaltet. ${ }^{1853}$ Zur Annäherung an die denkbaren Wirkungen einer Richtlinie ist ein dreistufiges Modell der Rechtsanwendung, wie es Prechal vorschlägt, hilfreich: Danach erfolgt auf der ersten Stufe ein Vergleich zwischen nationalem Recht und Unionsrecht, um deren Vereinbarkeit miteinander beurteilen zu können. Erweist sich das nationale Recht als mit Unionsrecht unvereinbar, bestehen mit der Nichtanwendung nationalen Rechts bzw. dessen konformer Auslegung zwei Möglichkeiten, um Abhilfe zu schaffen. Während in einigen Fällen bereits die Nichtanwendung des nationalen Rechts (Ausschlusswirkung) genügt, führt diese in anderen Fällen zu einer Lücke. In diesen letztgenannten Fällen ist eine Ersetzung des nationalen Rechts durch die unionsrechtliche Vorschrift in Betracht zu ziehen (Ersetzungswirkung) und alternativ an eine konforme Auslegung des nach Nichtanwendung verbliebenen nationalen Rechts zu denken. Führt keiner der beschriebenen Wege zum Ziel, verbleibt nur der unionsrechtliche Staatshaftungsanspruch. ${ }^{1854}$

Soll nun das Verhältnis von unmittelbarer Wirkung und Vorrang bestimmt werden, hängt vieles vom zugrunde gelegten Verständnis der unmittelbaren Wirkung ab. Versteht man diese sehr weit, ist bereits in dem auf der ersten Stufe erfolgenden Vergleich zwischen Unionsrecht und nationalem Recht eine unmittelbare Wirkung der Richtlinie (als Maßstabsnorm) zu erkennen mit der Folge, dass Vorschriften, denen keine unmittelbare Wirkung zukommt, gar nicht denkbar sind. Vorrang ohne

gal), Rn. 41. Avbelj, a.a.O., S. 761 ff. spricht sich daher für ein heterarchisches Modell aus. Auch dieses hat aber Schwächen, da es der entscheidenden Frage, wie im Konfliktfall zu entscheiden ist, ausweicht, vgl. Claes, in: Chalmers/Arnull (Hrsg.), Oxford Handbook, 2015, S. 178 (202 f.). Siehe auch Somek, in: Avbelj/Komárek (Hrsg.), Constitutional Pluralism, 2012, S. 343 (357): "Pluralists throw up their hands and exclaim 'legally irresolvable conflict'."

1853 Prechal, CMLRev. 37 (2000), 1047 (1047 f.).

1854 Die Schilderung ist Prechal, in: Barnard (Hrsg.), The Fundamentals of EU Law Revisited, 2007, S. 35 (41 ff.) entnommen. Prechal bezeichnet die erste Stufe als "obligation to apply I“, die Ersetzung des nationalen Rechts durch das Unionsrecht als „obligation to apply II“. 
unmittelbare Wirkung kann es in diesem Fall nicht geben. Bei einem engen Verständnis der unmittelbaren Wirkung, das diese auf die Ersetzungswirkung beschränkt, muss dagegen bereits der Vergleich auf erster Stufe auf den Vorrang gestützt werden. ${ }^{1855}$ Schon über das Konzept der unmittelbaren Wirkung herrscht damit Unklarheit. ${ }^{1856}$ Sie spiegelt sich auch in der Rechtsprechung des Gerichtshofs wider. ${ }^{1857}$

\section{c) Anklänge einer „entkoppelten“ Ausschlusswirkung}

Widmet man sich dieser Rechtsprechung des Gerichtshofs, lassen sich Anklänge einer von der unmittelbaren Wirkung entkoppelten Ausschlusswirkung nicht verleugnen. So ist das Recht, durch ein Gericht überprüfen zu lassen, ob sich eine nationale Regelung und deren Anwendung in den Grenzen des von der Richtlinie definierten Ermessensspielraums halten, nicht dadurch ausgeschlossen, dass es der Richtlinienvorschrift an hinreichender Bestimmtheit fehlt, weswegen sich die Einzelnen nicht unmittelbar auf diese Bestimmung berufen können. Der EuGH begründet dies mit der verbindlichen Wirkung der Richtlinien nach Art.288 III AEUV und ihrer praktischen Wirksamkeit. ${ }^{1858}$ Dass den Mitgliedstaaten ein Ermessensspielraum eingeräumt ist, ändert also grundsätzlich nichts an der gerichtlichen Überprüfbarkeit der Einhaltung dieses Spielraums. ${ }^{1859}$ Auch Richtlinienbestimmungen mit Gestaltungsspielraum können damit nationales Recht verdrängen, wenn dieses die Grenzen des Gestaltungs-

1855 Näher Prechal, in: Barnard (Hrsg.), The Fundamentals of EU Law Revisited, 2007, S. 35 (51, 44 ff.).

1856 Wohlfabrt, Vermutung, 2016, S. 46. Für GA Bobek, Schlussanträge vom 26.6.2018 in der Rs. C-384/17 (Link Logistik N\&N), Rn. 69 und Schlussanträge vom 5.6.2018 in der Rs. C-167/17 (Klohn), Rn. 46 ist letztlich entscheidend, ob die Regelung einer gerichtlichen Überprüfung zugänglich (,justiciable“) ist.

1857 Ausführlich Wohlfahrt, Vermutung, 2016, S. 11, 13 ff. mit Nachweisen aus der Rechtsprechung.

1858 EuGH, Urteil vom 24.10.1996, Rs. C-72/95 (Kraaijeveld u.a.), Rn. 56; EuGH, Urteil vom 7.9.2004, Rs. C-127/02 (Waddenvereniging und Vogelbeschermingsvereniging), Rn. 66; EuGH, Urteil vom 5.9.2012, Rs. C-83/11 (Rahman u.a.), Rn. 25; EuGH, Urteil vom 26.5.2011, verb. Rs. C-165/09 bis C-167/09 (Stichting Natuur en Milieu u.a.), Rn. 92 ff.

1859 So kann insbesondere überprüft werden, ob Mindestgarantien eingehalten werden, vgl. GA Bobek, Schlussanträge vom 5.6.2018 in der Rs. C-167/17 (Klohn), Rn. 44 f. mit Nachweisen aus der Rechtsprechung des Gerichtshofs. 
spielraums nicht einhält. ${ }^{1860}$ Die Verdrängungswirkung scheint hier also auf dem Vorrang des Unionsrechts zu beruhen. ${ }^{1861}$

Ganz sicher ist dies aber nicht, da sich dieses Ergebnis ebenso erklären lässt, wenn man den in einer Richtlinie enthaltenen konkreten Verpflichtungen unmittelbare Wirkung zuschreibt. ${ }^{1862}$ Dies legt eine Differenzierung zwischen Ausschluss- und Ersetzungswirkung nach dem erforderlichen Grad an Klarheit, Genauigkeit und Unbedingtheit nahe ${ }^{1863}$, der höher sein soll, wenn die Richtlinienbestimmung positiv zur Anwendung kommen soll und niedriger, soweit sie nur dazu herangezogen werden soll, eine Bestimmung des nationalen Rechts zu verdrängen. ${ }^{1864}$ Die Schwelle für eine unmittelbare Wirkung ist demnach eine unterschiedliche, je nachdem, ob in der Richtlinie ein Verbot enthalten ist oder durch sie ein Recht geschaffen wird. ${ }^{1865}$

\section{aa) Die Rechtssache Link Logistik N\&N}

Schwierigkeiten bereitet dann allerdings die Einordnung von Aussagen des Gerichtshofs in der Rechtssache Link Logistik N\&N. Die Regelung der Sanktion für die Benutzung einer mautpflichtigen Straße ohne vorherige Entrichtung der Mautgebühr im ungarischen Recht hatte sich als mit

1860 Kruis, Anwendungsvorrang, 2013, S. 116.

1861 Coutron, RTDEur. 2015, 39 (45) bezeichnet dies als „ligne jurisprudentielle ultra-minoritaire“. Er verweist zutreffend darauf, dass es nach EuGH, Urteil vom 1.2.1977, Rs.51/76 (Verbond van Nederlandse Ondernemingen), Rn. 25/29 möglich erscheint, den „harten Kern“ eines Rechts aus einer Richtlinie zu identifizieren, obwohl es an Genauigkeit und damit unmittelbarer Wirkung mangelt. Im Umweltrecht lässt sich diese Vorgehensweise häufiger nachweisen. Siehe auch EuGH, Urteil vom 18.10.2011, verb. Rs. C-128/09 bis C-131/09, C-134/09 und C-135/09 (Boxus u.a.), Rn. 52-57.

1862 Siehe hierzu auch Berger, Anwendungsvorrang, 2016, S. 55, insbesondere mit Fn. 265. Sie meint, diesen Verpflichtungen komme unmittelbare Geltung zu, da sich die Frage der unmittelbaren Anwendbarkeit bei Richtlinien nicht an die Frage der unmittelbaren Geltung anschließe. Die in dieser Arbeit erfolgte Anerkennung der unmittelbaren Geltung einer Richtlinie spricht allerdings dagegen, die unmittelbare Geltung wie Berger, a.a.O., als Folge der unmittelbaren Anwendbarkeit/Wirkung einzuordnen.

1863 Dougan, CMLRev. 44 (2007), 931 (941).

1864 In diesem Sinne Kruis, Anwendungsvorrang, 2013, S. 120.

1865 Ebers, Unionsprivatrecht, 2016, S. 380 ff.; GA Bobek, Schlussanträge vom 5.6.2018 in der Rs. C-167/17 (Klohn), Rn. 40 mit Fn. 22 unter Verweis auf GA Léger, Schlussanträge vom 11.1.2000 in der Rs. C-287/98 (Linster), Rn. 57. 
dem in Art. 9a der Richtlinie 1999/62/EG ${ }^{1866}$ aufgestellten Erfordernis der Verhältnismäßigkeit unvereinbar erwiesen, da die ungarische Regelung die Verhängung einer Geldbuße in pauschaler Höhe vorsah und damit unabhängig von der Art und Schwere des Verstoßes, sodass es den nationalen Behörden nicht möglich war, den Umständen des Einzelfalles Rechnung zu tragen. ${ }^{1867}$ Für den Zeitraum bis zum Erlass eines neuen Rechtsrahmens durch die zuständigen nationalen Stellen stehen nationale Gerichte damit vor der Frage, wie sie auf die Unionsrechtswidrigkeit im Einzelfall zu reagieren haben. ${ }^{1868}$ Nach Ansicht des Gerichtshofs scheitert die unmittelbare Wirkung des Art.9a der Richtlinie daran, dass die Mitgliedstaaten Rechtsakte zur Umsetzung des Verhältnismäßigkeitsgrundsatzes erlassen müssen und ihnen ein beträchtlicher Ermessensspielraum eingeräumt ist, der bei Bejahung der unmittelbaren Wirkung verloren ginge. ${ }^{1869}$

Eine Berufung auf Art.9a der Richtlinie vor den nationalen Behörden scheidet damit aus; das nationale Gericht ist nicht dazu verpflichtet, die Aufgaben des nationalen Gesetzgebers zu übernehmen. ${ }^{1870}$ Auch wenn der Gerichtshof dem vorlegenden Gericht die entsprechende Prüfung („Unter dem Vorbehalt der vom vorlegenden Gericht vorzunehmenden Prüfungen“) überlässt, erkennt er, dass eine Auslegung des nationalen Rechts im Einklang mit Art.9a der Richtlinie zu einer Auslegung contra legem führen könnte, da das Gericht die Geldbuße herabsetzen müsste, obwohl die ungarischen Rechtsvorschriften hierfür keinen Anknüpfungs-

1866 Richtlinie 1999/62/EG des Europäischen Parlaments und des Rates vom 17. Juni 1999 über die Erhebung von Gebühren für die Benutzung bestimmter Verkehrswege durch schwere Nutzfahrzeuge (ABl. L 187 vom 20.7.1999, S. 42) in der durch die Richtlinie 2011/76/EU des Europäischen Parlaments und des Rates vom 27. September 2011 (ABl. L 269 vom 14.10.2011, S. 1) geänderten Fassung.

1867 Diese Unvereinbarkeit war vom Gerichtshof bereits zuvor festgestellt worden, siehe EuGH, Urteil vom 22.3.2017, verb. Rs. C-497/15 und C-498/15 (EuroTeam und Spirál-Gép), Rn. 50, 60. Art. 9a der Richtlinie lautet: „Die Mitgliedstaaten sehen geeignete Kontrollen vor und legen Sanktionen zur Ahndung von Verstößen gegen die aufgrund dieser Richtlinie erlassenen innerstaatlichen Vorschriften fest. Sie treffen die zur Anwendung dieser Vorschriften erforderlichen Maßnahmen. Die Sanktionen müssen wirksam, angemessen und abschreckend sein."

1868 Vgl. GA Bobek, Schlussanträge vom 26.6.2018 in der Rs. C-384/17 (Link Logistik N\&N), Rn. 47.

1869 EuGH, Urteil vom 4.10.2018, Rs. C-384/17 (Link Logistik N\&N), Rn. 47 ff. Siehe auch GA Bobek, Schlussanträge vom 26.6.2018 in der Rs. C-384/17 (Link Logistik N\&N), Rn. $73 \mathrm{ff}$.

1870 EuGH, Urteil vom 4.10.2018, Rs. C-384/17 (Link Logistik N\&N), Rn. 55 f. 
punkt bieten. ${ }^{1871}$ Sollte diese Konformauslegung wie erwartet scheitern, ist das nationale Gericht nach Auffassung des EuGH allerdings dazu verpflichtet, „das Unionsrecht in vollem Umfang anzuwenden und die Rechte, die dieses dem Einzelnen einräumt, zu schützen, indem es notfalls jede Bestimmung unangewendet lässt, deren Anwendung im konkreten Fall zu einem unionsrechtswidrigen Ergebnis führen würde“. ${ }^{1872}$ Dabei geht es dem Gerichtshof ausdrücklich um eine Umsetzung des Art. 9a der Richtlinie. ${ }^{1873}$

Diese Vorgehensweise wirft Fragen auf. Nicht klar ist nämlich, auf welchem Weg das nationale Gericht nun zu einer unionsrechtskonformen Entscheidung gelangen kann. Lässt es das nationale Recht unangewendet, entfällt zuallererst die Rechtsgrundlage für die Sanktion der Benutzung einer mautpflichtigen Straße ohne vorherige Entrichtung der Mautgebühr. Wenn sich das nationale Gericht aber nun nicht an die Stelle des Gesetzgebers setzen muss, liefe dies darauf hinaus, solange keine Sanktion verhängen zu müssen, bis der Gesetzgeber eine Neuregelung getroffen hat. Das erscheint aber nicht plausibel, da die Richtlinie ja nicht die Verhängung einer Sanktion, sondern nur deren Unverhältnismäßigkeit verbietet. ${ }^{1874}$ Zur Verhängung einer verhältnismäßigen Sanktion könnte das nationale Gericht dadurch kommen, dass es der Richtlinienbestimmung Kriterien für die Herstellung von Verhältnismäßigkeit entnähme. Darin läge aber ebenfalls eine unmittelbare Wirkung von Art. 9a der Richtlinie, die ihr der Gerichtshof im Hinblick auf das Erfordernis der Angemessenheit jedoch gerade abgesprochen hat.

Wie Rn. 62 seines Urteils zeigt, unterscheidet der Gerichtshof deutlich zwischen der unmittelbaren Wirkung einerseits und der konformen Auslegung und der Verdrängungswirkung andererseits: Obwohl er die unmittel-

1871 EuGH, Urteil vom 4.10.2018, Rs. C-384/17 (Link Logistik N\&N), Rn. 60.

1872 EuGH, Urteil vom 4.10.2018, Rs. C-384/17 (Link Logistik N\&N), Rn. 61. Der Gerichtshof verweist dabei auf EuGH, Urteil vom 13.7.2016, Rs. C-187/15 (Pöpperl), Rn. 45. Dort wird EuGH, Urteil vom 18.12.2007, Rs. C-357/06 (Frigerio Luigi \& C.), Rn. 28 zitiert. In der Rechtssache Pöpperl ging es um einen Verstoß gegen den unmittelbar anwendbaren Art. 45 AEUV, in der Rechtssache Frigerio Luigi \& C. um einen Verstoß gegen Bestimmungen der Richtlinie 92/50/EWG über die Koordinierung der Verfahren zur Vergabe öffentlicher Dienstleistungsaufträge, die als hinreichend bestimmt und unbedingt erscheinen.

1873 EuGH, Urteil vom 4.10.2018, Rs. C-384/17 (Link Logistik N\&N), Rn. 62.

1874 Ebenso GA Bobek, Schlussanträge vom 26.6.2018 in der Rs. C-384/17 (Link Logistik N\&N), Rn. 83, 90, 93 ff. Indem er eine unmittelbare Wirkung des Art. 9a der Richtlinie bejahte, gelangte er zu schlüssigeren Ergebnissen. 
bare Wirkung von Art. 9a der Richtlinie verneint hat, erkennt er dieser Bestimmung Verdrängungswirkung zu. Die Verdrängungswirkung erscheint damit als Ausfluss des Vorrangs des Unionsrechts. ${ }^{1875}$

Dieser wird hier demnach von der Voraussetzung der unmittelbaren Wirkung „abgekoppelt" ${ }^{\text {“1876 }}$ und erscheint als „freischwebende“ Eigenschaft des Unionsrechts; schlagwortartig zusammengefasst ergibt sich an dieser Stelle damit das Bild einer auf der unmittelbaren Wirkung beruhenden Ersetzungswirkung und einer sich auf den Vorrang gründenden Ausschluss- bzw. Verdrängungswirkung. ${ }^{1877}$ Eine solche Differenzierung war in der Literatur bereits zuvor befürwortet worden. Für sie wird angeführt, dass es bei der Begründung des Vorrangs im Costa/ENEL-Urteil ${ }^{1878}$ letztlich um die Vereinbarkeit des nationalen Rechts mit Unionsrecht gehe. Lasse sich dem Unionsrecht ein identifizierbares Ergebnis entnehmen, müsse das mit Unionsrecht unvereinbare nationale Recht zurücktreten, um die Erzielung des unionsrechtlich vorgegebenen Ergebnisses nicht zu vereiteln. Damit soll der Vorrang Widersprüche beseitigen, während der unmittelbaren Wirkung die Aufgabe zugewiesen wird, die Geltendmachung von Rechten zu ermöglichen, die das Unionsrecht im Unterschied zum nationalen Recht gewährt. ${ }^{1879}$ Bei Zugrundelegung eines solchen Verständnisses stellt sich der Vorrang als ein allumfassender Grundsatz dar, dem sämtliche Beziehungen zwischen Unionsrecht und nationalem Recht unterliegen. ${ }^{1880}$

Eine Unterscheidung zwischen Ausschluss- und Ersetzungswirkung findet zum Teil auch bei den Generalanwälten Anklang. So führt etwa Generalanwalt Saggio aus, dass der Ablauf der Umsetzungsfrist einer Richtlinie unabhängig von der fehlenden unmittelbaren Wirkung der Richtlinienbestimmungen zur Aussonderung des richtlinienwidrigen nationalen Rechts führen müsse, und verweist dabei auf den Vorrang des Unionsrechts und das Erfordernis seiner einheitlichen Anwendung. Eine Ausschlusswirkung bejaht er also auch in dem Fall, in dem eine Richtlinienbestimmung nicht hinreichend genau ist, um unmittelbare Wirkung zu entfalten, und ebenso in Rechtsstreitigkeiten zwischen Privaten, in denen eine unmittelbare

1875 Dies konstatiert auch GA Campos Sánchez-Bordona, Schlussanträge vom 27.11.2018 in der Rs. C-573/17 (Popławski), Rn. 117 mit Fn. 53.

1876 Diesen Begriff verwendet auch GA Bot, Schlussanträge vom 7.7.2009 in der Rs. C-555/07 (Kücükdeveci), Rn. 63.

1877 Vgl. zu diesem Bild von Kielmansegg, EuR 2014, 30 (42 mit Fn. 63).

1878 EuGH, Urteil vom 15.7.1964, Rs. 6/64 (Costa/ENEL).

1879 Siehe näher Lenaerts/Corthaut, ELRev. 2006, 287 (289 ff.).

1880 Vgl. Dougan, CMLRev. 44 (2007), 931 (932 ff.). 
Wirkung nach der bisherigen Rechtsprechung des Gerichtshofs ausscheidet. ${ }^{1881}$

bb) Verdrängung des verfassungsrechtlichen Prüfungsmaßstabs

Anzeichen einer „entkoppelten“ Ausschlusswirkung lassen sich auch an anderer Stelle in der Rechtsprechung des Gerichtshofs nachweisen. Angesprochen ist in erster Linie das Urteil des Gerichtshofs in der Rechtssache Melloni. ${ }^{1882}$

Um den Vorrang von Rahmenbeschlüssen zu begründen, hat Generalanwalt Bot unter anderem auf eine Aussage des Melloni-Urteils verwiesen, der zufolge „nach dem Grundsatz des Vorrangs des Unionsrechts, der die Unionsrechtsordnung wesentlich prägt [...], die Geltung des Unionsrechts in einem Mitgliedstaat nicht dadurch beeinträchtigt werden [kann], dass dieser Staat Vorschriften des nationalen Rechts, und haben sie auch Verfassungsrang, geltend macht“. ${ }^{1883}$ Auch der Gerichtshof selbst stellt die hier wiedergegebene Passage in einen Zusammenhang mit seinen grundlegenden Urteilen zum Vorrang. ${ }^{1884}$

Bei einem näheren Blick auf das Melloni-Urteil fällt zunächst auf, dass das Problem der unmittelbaren Wirkung und seiner Bedeutung für den Anwendungsvorrang dort keine Erwähnung findet, obwohl es die Frage behandelt, ob Art. 53 GRCh es ermöglicht, der Anwendung unionsrechtlicher Vorschriften einen höheren nationalen Grundrechtsstandard entgegenzuhalten. ${ }^{1885}$ Einem derartigen Ansinnen tritt der EuGH mit der Erwägung entgegen, dass eine entsprechende Auslegung von Art. 53 GRCh

1881 GA Saggio, Schlussanträge vom 16.12.1999 in den verb. Rs. C-240/98 bis C-244/98 (Océano Grupo Editorial und Salvat Editores), Rn. 30.

1882 Siehe zu diesem Urteil bereits oben bei Fn. $1739 \mathrm{ff}$.

1883 GA Bot, Schlussanträge vom 6.2.2018 in der Rs. C-390/16 (Lada), Rn. 117 unter Verweis auf EuGH, Urteil vom 26.2.2013, Rs. C-399/11 (Melloni), Rn. 59.

1884 Siehe etwa die in EuGH, Urteil vom 24.10.2018, Rs. C-234/17 (XC u.a.), Rn. 36 und EuGH, Gutachten 2/13 vom 18.12.2014 (Beitritt der Union zur EMRK), Rn. 166 in einem Atemzug zitierten Urteile EuGH, Urteil vom 15.7.1964, Rs. 6/64 (Costa/ENEL), Slg. 1964, S. 1269 und 1270, EuGH, Urteil vom 17.12.1970, Rs. 11/70 (Internationale Handelsgesellschaft), Rn.3, EuGH, Gutachten 1/91 vom 14.12.1991 (EWR-Abkommen I), Rn. 21, EuGH, Gutachten 1/09 vom 8.3.2011 (Schaffung eines einheitlichen Patentgerichtssystems), Rn. 65 und EuGH, Urteil vom 26.2.2013, Rs. C-399/11 (Melloni), Rn. 59.

1885 Dies hat auch Claes, in: Chalmers/Arnull (Hrsg.), Oxford Handbook, 2015, S. 178 (183) beobachtet. 
gegen den Grundsatz des Vorrangs des Unionsrechts verstoßen würde: Ein Mitgliedstaat könnte sonst die Anwendung eines Unionsrechtsakts unterlassen, der zwar den in der Verfassung dieses Staats garantierten Grundrechten nicht entspricht, aber vollständig mit der Grundrechtecharta in Einklang steht, was dem Vorrang des Unionsrechts widerspräche, da die Geltung des Unionsrechts dann durch die Geltendmachung nationaler Vorschriften beeinträchtigt wäre. ${ }^{1886}$

Erfordert ein Unionsrechtsakt nationale Durchführungsmaßnahmen, besteht nach Art. 53 GRCh zwar die Möglichkeit zur Anwendung nationaler Grundrechtsstandards; ihre Anwendung darf aber, so der Gerichtshof, weder das Schutzniveau der Charta in ihrer Auslegung durch den EuGH noch den Vorrang, die Einheit und die Wirksamkeit des Unionsrechts beeinträchtigen. ${ }^{1887} \mathrm{Im}$ konkreten Fall bedeutete dies, dass eine Anwendung des nationalen Grundrechtsstandards angesichts dessen, dass Art. 4a I des Rahmenbeschlusses 2002/584/JI die von der Verpflichtung zur Auslieferung vorgesehenen Ausnahmen bei Verurteilungen in Abwesenheit abschließend regelt und damit einen einheitlichen Grundrechtsstandard festlegt, ausscheiden musste. ${ }^{1888}$

Zwar führt der EuGH lediglich aus, dass Art. 53 GRCh es einem Mitgliedstaat nicht gestatte, nationalverfassungsrechtliche Bedingungen gegen die Verpflichtung aus dem Rahmenbeschluss ins Feld zu führen. Hinter dem dem Melloni-Urteil zugrundeliegenden Auslegungsersuchen steht aber das Anliegen des spanischen Tribunal Constitucional, in Erfahrung zu bringen, ob der Rahmenbeschluss es den spanischen Gerichten im vorliegenden Fall verbietet, den nationalen Grundrechtsstandard anzuwenden. ${ }^{1889}$ Damit die Antwort des Gerichtshofs für das vorlegende Gericht von Nutzen ist und sich nicht auf allgemeine Aussagen über mitgliedstaatliche Verpflichtungen beschränkt, kann sie nur im Sinne einer Verdrängung der spanischen Verfassung als Prüfungsmaßstab verstanden werden. Daraus folgt dann, dass der Rahmenbeschluss Anwendungsvorrang ge-

1886 EuGH, Urteil vom 26.2.2013, Rs. C-399/11 (Melloni), Rn. 58 f.

1887 EuGH, Urteil vom 26.2.2013, Rs. C-399/11 (Melloni), Rn. 60.

1888 EuGH, Urteil vom 26.2.2013, Rs. C-399/11 (Melloni), Rn. $61 \mathrm{ff}$.

1889 EuGH, Urteil vom 26.2.2013, Rs. C-399/11 (Melloni), Rn. 26 (dritte Vorlagefrage) und Rn. 64 (Antwort) einerseits, Rn. 24 (Anliegen des Tribunal Constitucional) andererseits. Angesichts der Formulierung der dritten Vorlagefrage kann aber, entgegen Mörth, ZöR 70 (2015), 33 (46) nicht davon gesprochen werden, dass der EuGH „eine ausdrückliche Antwort schuldig [bleibt]“, da er den Wortlaut der Vorlagefrage aufgreift und auf diese antwortet. 
nießt. ${ }^{1890}$ Bei unionsrechtlicher Determinierung mitgliedstaatlichen Handelns wird entgegenstehendes Verfassungsrecht durch die Verpflichtung zur Umsetzung des Unionsrechts also verdrängt. Auf diese Weise erfolgt letztlich eine Verdrängung des nationalverfassungsrechtlichen Prüfungsmaßstabs durch Unionsrecht, hier also durch den Rahmenbeschluss.

Vor dem Hintergrund, dass die Eigenschaften eines Rahmenbeschlusses nach Art. 9 des Protokolls über die Übergangsbestimmungen so erhalten bleiben, wie sie vor dem Vertrag von Lissabon bestanden, wenn der Rahmenbeschluss seit dem Inkrafttreten des Vertrags von Lissabon nicht geändert wurde, womit seine unmittelbare Wirkung ausgeschlossen ist ${ }^{1891}$, muss die aus dem Melloni-Urteil zu ziehende Konsequenz aufhorchen lassen. ${ }^{1892}$ Erkennbar wird also auch hier ein Anzeichen für die Entkoppelung des Anwendungsvorrangs vom Erfordernis unmittelbarer Wirkung. Zwar zitiert der Gerichtshof die Simmenthal-Rechtsprechung ${ }^{1893}$ nicht, wohl aber sein Urteil in der Rechtssache Winner Wetten. ${ }^{1894}$ Auch wenn er den in Rn. 67 des Winner Wetten-Urteils verwendeten Begriff der „Verdrängungswirkung“ im Melloni-Urteil nicht ausdrücklich in Bezug nimmt, so spricht er durch den Verweis auf das Winner Wetten-Urteil, das mit den Grundfreiheiten unmittelbar anwendbares Unionsrecht betraf,

$1890 \mathrm{Zu}$ dieser Schlussfolgerung gelangt auch Lenaerts, EuR 2015, 3 (23), der ausdrücklich davon spricht, dass nationale Gerichte entgegenstehende nationale Vorschriften einschließlich solcher von Verfassungsrang unbeachtet lassen müssen, wenn der Unionsrechtsakt (hier also Art. 4a I des Rahmenbeschlusses 2002/584/JI) mit Primärrecht vereinbar ist.

1891 Art. 9 des den Verträgen beigefügten Protokolls (Nr. 36) über die Übergangsbestimmungen, ABl. C 83 vom 30.3.2010, S.325. Ein Rahmenbeschluss entfaltet damit seine Rechtswirkungen weiterhin gemäß Art. 34 II lit.b EUV a.F., wonach Rahmenbeschlüsse nicht unmittelbar wirksam sind. Darauf weist auch der Gerichtshof hin, siehe EuGH, Urteil vom 24.6.2019, Rs. C-573/17 (Popławski), Rn.70; siehe auch EuGH, Urteil vom 8.11.2016, Rs. C-554/14 (Ognyanov), Rn. 57; EuGH, Urteil vom 29.6.2017, Rs. C-579/15 (Popławski), Rn. 27.

1892 Darauf weist auch Mörth, ZöR 70 (2015), 33 (47) hin.

1893 EuGH, Urteil vom 9.3.1978, Rs. 106/77 (Simmenthal). Dort wird die Wirkung des Vorrangs beschrieben, wonach das entgegenstehende nationale Recht ohne weiteres unanwendbar wird, ohne dass der Gesetzgeber oder nationale Gerichte diese Bestimmung zuvor beseitigen müssten, siehe zusammenfassend Rn. 24 des Urteils.

1894 Angeführt wird in Rn.59 des Melloni-Urteils EuGH, Urteil vom 8.9.2010, Rs. C-409/06 (Winner Wetten), Rn. 61. Zitiert wird auch EuGH, Urteil vom 17.12.1970, Rs. 11/70 (Internationale Handelsgesellschaft), Rn. 3, womit der Vorrang vor nationalem Verfassungsrecht in Bezug genommen wird. 
doch implizit auch dem nicht unmittelbar wirkenden Unionsrecht eine derartige Verdrängungswirkung zu. Im Ergebnis führt dies dazu, dass die Vorschrift des spanischen Verfassungsrechts unangewendet bleiben muss. ${ }^{1895}$

Aus unionsrechtlicher Sicht darf also nicht nur der Rahmenbeschluss selbst nicht am nationalen Recht gemessen werden; darüber hinaus wird im Kollisionsfall aufgrund des Vorrangs des Rahmenbeschlusses auch das nationale Verfassungsrecht als Prüfungsmaßstab des nationalen Umsetzungsrechts verdrängt.

\section{d) Unzertrennlichkeit von Vorrang und unmittelbarer Wirkung}

Im Rahmen der sich mit der Wirkung von Rahmenbeschlüssen befassenden Rechtsprechung hat sich zudem bereits die Frage gestellt, ob es bei einer rahmenbeschlusswidrigen nationalen Vorschrift zu deren Nichtanwendung kommen kann bzw. muss, wenn ihre rahmenbeschlusskonforme Auslegung scheitert. Hierfür haben sich etwa die Generalanwälte Bot und Campos Sánchez-Bordona ausgesprochen.

Mitentscheidend ist für Generalanwalt Bot, dass die fehlende unmittelbare Wirkung des Rahmenbeschlusses durch die Aufspaltung in eine „Ersetzungswirkung" und eine dem Vorrang des Unionsrechts entnommene „Ausschlusswirkung" kein Hindernis für ein nationales Gericht ist, das rahmenbeschlusswidrige nationale Recht nicht anzuwenden. ${ }^{1896}$ In der Tat schließt Art. 34 II EUV a.F. nach überzeugender Auffassung nicht zwingend sämtliche Formen der Berufung auf Rahmenbeschlüsse aus. ${ }^{1897}$ Dass nach ständiger Rechtsprechung eine Verpflichtung zu rahmenbeschlusskonformer Auslegung des nationalen Rechts besteht, bedeutet, dass dieses auf seine Vereinbarkeit mit dem Rahmenbeschluss untersucht werden können muss. Dann erscheint eine Nichtanwendung des nationalen Rechts (im Gegensatz zu seiner Ersetzung durch den Rahmenbeschluss)

1895 Besselink, ELRev. 2014, 531 (544f.).

1896 GA Bot, Schlussanträge vom 15.2.2017 in der Rs. C-579/15 (Popławski), Rn. $87 \mathrm{ff}$.

1897 GA Campos Sánchez-Bordona, Schlussanträge vom 27.11.2018 in der Rs. C-573/17 (Popławski), Rn.112ff. sieht einen „wirkliche[n] Unterschied“ zwischen der unmittelbaren Wirkung und der Eignung zur Verdrängung einer nationalen Vorschrift. 
aber nicht grundsätzlich ausgeschlossen. ${ }^{1898}$ Einen „fundamentalen Widerspruch“ zum Grundsatz des Vorrangs sieht Generalanwalt Campos Sánchez-Bordona angesichts des zwingenden Charakters eines Rahmenbeschlusses, wenn das nationale Recht mit diesem unvereinbar ist und es auch nicht rahmenbeschlusskonform ausgelegt werden kann. Aufgelöst werden könne dieser Widerspruch nur durch die Nichtanwendung der nationalen Vorschrift, da die nationalen Gerichte zur Gewährleistung der vollen Wirksamkeit der Rahmenbeschlüsse verpflichtet seien. ${ }^{1899}$

Im Gegensatz dazu hat der Gerichtshof bereits in seinem ersten Urteil in der Rechtssache Popławski aus dem Jahr 2017 weder eine Ausschlusswirkung erwähnt noch vom Vorrang des Rahmenbeschlusses gesprochen. Damit stand bereits zu erwarten, dass er lediglich den Weg über die rahmenbeschlusskonforme Auslegung beschreiten wollte, um zu dem von ihm gewünschten Ziel zu gelangen. Unter Betonung seiner fehlenden Befugnis zur Auslegung des nationalen Rechts hatte er dem vorlegenden Gericht dementsprechend für dessen Entscheidung "geeignete Hinweise“ gegeben, die insofern sehr weitreichend waren, als er konkret vorgab, wozu die rahmenbeschlusskonforme Auslegung seiner Auffassung nach („das bedeutet im vorliegenden Fall“) führen musste. ${ }^{1900}$ Die in seinem ersten Popławski-Urteil angesichts der Betonung, dass die Gerichte „insbesondere" zur rahmenbeschlusskonformen Auslegung verpflichtet seien, noch offen gelassene Tür für eine Verpflichtung zur Nichtanwendung des rahmenbeschlusswidrigen nationalen Rechts ${ }^{1901}$ hat der Gerichtshof in seinem zweiten Popławski-Urteil nun geschlossen. ${ }^{1902}$

1898 Prechal, in: Barnard (Hrsg.), The Fundamentals of EU Law Revisited, 2007, S. 35 (62f.).

1899 GA Campos Sánchez-Bordona, Schlussanträge vom 27.11.2018 in der Rs. C-573/17 (Popławski), Rn. 104 ff. Er stimmt den Schlussanträgen von GA Bot vom 15.2.2017 in der Rs. C-579/15 (Popławski), Rn. 76-91 und vom 6.2.2018 in der Rs. C-390/16 (Lada), Rn. 106-118 zu, siehe GA Campos SánchezBordona, a.a.O., Rn. 107.

1900 EuGH, Urteil vom 29.6.2017, Rs. C-579/15 (Popławski), Rn. 37, 39 f., 43.

1901 EuGH, Urteil vom 29.6.2017, Rs. C-579/15 (Popławski), Rn. 31 m.w.N. aus der Rechtsprechung. Die Verwendung des Wortes „insbesondere“ ist auch GA Campos Sánchez-Bordona, Schlussanträge vom 27.11.2018 in der Rs. C-573/17 (Popławski), Rn. 111 ins Auge gefallen.

1902 EuGH, Urteil vom 24.6.2019, Rs. C-573/17 (Popławski), Rn. 60, 68. Das niederländische Vorlagegericht hatte beim Gerichtshof nachgefragt, ob es, wenn eine Konformauslegung scheitert, nicht doch das nationale Recht unangewendet zu lassen hat. 
Zur Begründung führt der Gerichtshof aus, dass neben dem Vorrang auch die anderen wesentlichen Merkmale des Unionsrechts zu berücksichtigen seien, was ihn zu der Feststellung führt, dass nur bei einem Teil der unionsrechtlichen Bestimmungen eine unmittelbare Wirkung anerkannt ist. Der Vorrang könne diesen „wesentliche[n] Unterschied“ („essential distinction“/,distinction essentielle“) zwischen Vorschriften mit und ohne unmittelbare Wirkung nicht in Frage stellen, sodass eine einheitliche Anwendung sämtlicher unionsrechtlicher Bestimmungen nicht möglich sei. 1903

Während das nationale Recht bei einem Verstoß gegen Bestimmungen mit unmittelbarer Wirkung unangewendet bleiben muss, kommt Bestimmungen ohne unmittelbare Wirkung keine Verdrängungswirkung zu. ${ }^{1904}$ Die Verpflichtung zur Nichtanwendung einer unionsrechtswidrigen nationalen Bestimmung ist damit durch die unmittelbare Wirkung der unionsrechtlichen Bestimmung im konkreten Rechtsstreit bedingt, „wenn sie sich aus dem der letztgenannten Bestimmung zuerkannten Vorrang ergibt“. ${ }^{1905}$ Für den Rahmenbeschluss bedeutet dies, dass er mangels unmittelbarer Wirkung keine Verpflichtung zur Nichtanwendung des gegen ihn verstoßenden nationalen Rechts begründet. Für die Richtlinie kann dann in den Fällen, in denen ihre unmittelbare Wirkung zu verneinen ist, nichts anderes gelten. Ohne unmittelbare Wirkung besteht demnach keine Pflicht zur Nichtanwendung nationalen Rechts. Vorrang und unmittelbare Wirkung erscheinen als „untrennbare Zwillinge“. 1906

Darauf hatten bereits diejenigen Urteile hingedeutet, in denen der Gerichtshof die Pflicht zur Nichtanwendung des unionsrechtswidrigen nationalen Rechts erst im Anschluss an eine Bejahung der unmittelbaren Anwendbarkeit der zugrundeliegenden Unionsrechtsbestimmung anspricht. ${ }^{1907}$ Damit hatte er zu erkennen gegeben, dass die Kriterien der unmittelbaren Wirkung nicht nur für den Fall der Ersetzungswirkung,

1903 EuGH, Urteil vom 24.6.2019, Rs. C-573/17 (Popławski), Rn. 59 f.

1904 EuGH, Urteil vom 24.6.2019, Rs. C-573/17 (Popławski), Rn. 61 f.

1905 EuGH, Urteil vom 24.6.2019, Rs. C-573/17 (Popławski), Rn. 68. Auch andere Sprachfassungen bringen diesen Zusammenhang deutlich zum Ausdruck: „dependent on the direct effect“/,conditionnée par l'effet direct“. Ebenso EuGH, Urteil vom 4.3.2020, Rs. C-183/18 (Bank BGZ̈ BNP Paribas), Rn. 63.

1906 Begriff bei Griller, ecolex 1996, 639 (Anführungszeichen im Original).

1907 Vgl. Kruis, Anwendungsvorrang, 2013, S. 49 f. mit Nachweisen aus der Rechtsprechung in Fn. 200. 
sondern auch den der Verdrängungswirkung gelten. ${ }^{1908}$ Der Vorrang tritt hier also ebenfalls als Begleiterscheinung der unmittelbaren Wirkung in Erscheinung. ${ }^{1909}$

Für die Unzertrennlichkeit von Vorrang und unmittelbarer Wirkung spricht auch, dass bei einer Unterscheidung von Ausschluss- und Ersetzungswirkung nicht einleuchtend erklärt werden kann, warum der Vorrang nur die Ausschluss- und nicht auch die Ersetzungswirkung zulassen soll. ${ }^{1910}$ Dies gilt umso mehr vor dem Hintergrund, dass sich beide Wirkungen nicht trennscharf voneinander unterscheiden lassen. Sie fließen beide aus der zugrundeliegenden Norm des Unionsrechts, sodass es sich bei beiden um eine Art der unmittelbaren Wirkung handelt. ${ }^{1911}$ Auch bei einer bloßen Verdrängung des nationalen Rechts, an dessen Stelle das verbleibende nationale Recht tritt, bestimmt das Unionsrecht dadurch über das anwendbare nationale Recht, dass es gewissermaßen zu einer „Ersetzung“ der einen durch die andere Bestimmung führt. ${ }^{1912}$

Zudem können durch eine entkoppelte Ausschlusswirkung Regelungslücken entstehen. Zwar wird zum Teil versucht, diese Gefahr herunterzuspielen und eine „möglichst schonende Nichtanwendung" des nationalen Rechts vorgeschlagen. ${ }^{1913}$ Die Möglichkeit unionsrechtskonformer Auslegung und die Anwendung des übrigen nationalen Rechts verhindern aber nicht in allen Fällen die Entstehung von Lücken. Angesprochen sind damit etwa Fälle, in denen anstelle des verdrängten nationalen Rechts nur die Anwendung der Richtlinie in Betracht käme, da das nationale Recht in einem Punkt insgesamt unionsrechtswidrig ist und die bloße Verdrängung des nationalen Rechts zur Herstellung unionsrechtskonformer Zustände nicht ausreicht. ${ }^{1914}$

1908 Siehe z.B. EuGH, Urteil vom 17.7.2008, Rs. C-226/07 (Flughafen Köln/Bonn), Rn. 22, 33, 39. Siehe auch Woblfahrt, Vermutung, 2016, S. 66 f. Dass im anwendbaren Maßstab keine Unterschiede erkennbar sind, betonen auch Arnull, The European Union and its Court of Justice, 2. Aufl. 2006, S. 241 f. und Woblfahrt, Vermutung, 2016, S. 62 ff. mit zahlreichen Nachweisen aus Literatur und Rechtsprechung.

1909 Arnull, The European Union and its Court of Justice, 2. Aufl. 2006, S. 179.

1910 Ebers, Unionsprivatrecht, 2016, S.398; Dougan, CMLRev. 44 (2007), 931 (941 f., 947 f.); von Danwitz, JZ 2007, 697 (702 f.).

1911 von Kielmansegg, EuR 2014, 30 (43); Schroeder, in: Streinz (Hrsg.), EUV/AEUV, 3. Aufl. 2018, Art. 288 AEUV, Rn. 104, 109.

1912 Dougan, CMLRev. 44 (2007), 931 (937 ff.).

1913 Kruis, Anwendungsvorrang, 2013, S. 118.

1914 Vgl. Prechal, CMLRev. 42 (2005), 1445 (1460). Ebers, Unionsprivatrecht, 2016, S. 398 f. verweist auf „erhebliche Rechtsunsicherheit“ als Folge der Ausschluss- 
Hinzu kommt, dass sich eine Unterscheidung zwischen Ausschluss- und Ersetzungswirkung von der Ausgestaltung des nationalen Rechts abhängig macht: Je nachdem, ob in diesem nur eine unionsrechtswidrige Ausnahme verdrängt werden muss oder etwa bei fehlender Richtlinienumsetzung eine Anwendung des Unionsrechts erforderlich ist, sind Ausschluss bzw. Ersetzung erforderlich. Wenn es aber gewissermaßen von Zufällen abhängt, welche der Wirkungen zum Tragen kommt, leuchtet es nicht ein, weshalb zwischen beiden Wirkungen kategorisch unterschieden werden sollte. Ganz in diesem Sinne hat der Gerichtshof festgestellt, dass das Unionsrecht keinen Mechanismus enthalte, dem zufolge richtlinienwidrige Bestimmungen des nationalen Rechts bei fehlender unmittelbarer Wirkung der Richtlinienvorschriften eliminiert werden könnten. ${ }^{1915}$ Eine Ausschlusswirkung ohne unmittelbare Wirkung ist damit ausgeschlossen.

\section{e) Ablehnung der Horizontalwirkung von Richtlinien durch den} Gerichtshof

Der Vorschlag einer Aufspaltung der Wirkung einer Richtlinie in eine positive Ersetzungs- und eine negative Ausschlusswirkung ${ }^{1916}$ hatte nicht zuletzt dazu gedient, einen Konflikt mit der Rechtsprechung des EuGH zu vermeiden, nach der eine Richtlinie keine Verpflichtungen zu Lasten des Einzelnen begründen kann. ${ }^{1917}$

Hinter den in der Literatur vorgenommenen Differenzierungen stand damit auch der Versuch, die Urteile des Gerichtshofs in Rechtssachen wie CIA Security International ${ }^{1918}$ und Unilever ${ }^{1919}$ zu erklären, ohne eine positive horizontale Richtlinienwirkung bejahen zu müssen. An der in diesen Fällen begründeten Rechtsprechung hält der Gerichtshof bis heute fest. Sie wird von ihm selbst als ständige Rechtsprechung bezeichnet und besagt, dass die Unanwendbarkeit einer nicht notifizierten innerstaatlichen

wirkung, da die von den nationalen Gerichten dann vorzunehmende Lückenschließung vielfach ohne unionsweite Maßstäbe erfolgen müsste.

1915 EuGH, Urteil vom 26.9.1996, Rs. C-168/95 (Arcaro), Rn. 39 f., 43.

1916 Siehe hierzu aus der Literatur nur Lenaerts/Corthaut, ELRev. 2006, 287 (289 ff., 302 ff.); Herrmann, Richtlinienumsetzung, 2003, S. 78 ff.; Herrmann, EuZW 2006, 69 (70); von Kielmansegg, EuR 2014, 30 (41).

1917 Wohlfahrt, Vermutung, 2016, S. 65.

1918 EuGH, Urteil vom 30.4.1996, Rs. C-194/94 (CIA Security International), Rn. 54.

1919 EuGH, Urteil vom 26.9.2000, Rs. C-443/98 (Unilever), Rn. 40-43, 48 und 49. 
technischen Vorschrift ${ }^{1920}$ auch in einem Rechtsstreit zwischen Privaten geltend gemacht werden kann. ${ }^{1921}$ Durch die Unanwendbarkeit der technischen Vorschrift kann ein Privater damit von einem anderen Privaten nicht verlangen, dass er die in der technischen Vorschrift enthaltenen (richtlinienwidrigen) Anforderungen beachtet. ${ }^{1922}$

Die fehlende Notifizierung wird vom EuGH als wesentlicher Verfahrensfehler eingeordnet. ${ }^{1923}$ Obwohl damit noch keine Aussage über die materielle Vereinbarkeit der technischen Vorschrift mit der Warenverkehrsfreiheit getroffen ist, wird dieser Verstoß mit der Folge der Unanwendbarkeit der technischen Vorschrift geahndet. ${ }^{1924}$ Nach Ansicht des Gerichtshofs ist seine Rechtsprechung zum Ausschluss der Horizontalwirkung auf die hier beschriebene Fallkonstellation deshalb nicht anwendbar, weil die betroffene Richtlinie weder Rechte noch Pflichten für Einzelne begründe und den materiellen Inhalt der Rechtsnorm, auf deren Grundlage das nationale Gericht entscheidet, nicht festlege. ${ }^{1925}$

1920 Begründet wurde die Rechtsprechung im Hinblick auf die entsprechenden Regelungen in der Richtlinie 83/189/EWG des Rates vom 28. März 1983 über ein Informationsverfahren auf dem Gebiet der Normen und technischen Vorschriften, ABl. L 109 vom 26.4.1983, S. 8. Heute sind die Regelungen in der Richtlinie (EU) 2015/1535 des Europäischen Parlaments und des Rates vom 9. September 2015 über ein Informationsverfahren auf dem Gebiet der technischen Vorschriften und der Vorschriften für die Dienste der Informationsgesellschaft, ABI. L 241 vom 17.9.2015, S. 1 enthalten.

1921 Siehe nur EuGH, Urteil vom 27.10.2016, Rs. C-613/14 (James Elliott Construction), Rn. 64; EuGH, Urteil vom 12.9.2019, Rs. C-299/17 (VG Media), Rn. 39. Siehe auch EuGH, Urteil vom 10.7.2014, Rs. C-307/13 (Ivansson u.a.), Rn. 48; EuGH, Urteil vom 4.2.2016, Rs. C-336/14 (Ince), Rn. 67 und EuGH, Urteil vom 1.2.2017, Rs. C-144/16 (Município de Palmela), Rn. 36.

1922 Ebers, Unionsprivatrecht, 2016, S. 399 f.

1923 Siehe zusammenfassend EuGH, Urteil vom 7.8.2018, Rs. C-122/17 (Smith), Rn. 53.

1924 Vgl. GA Szpunar, Schlussanträge vom 4.7.2017 in der Rs. C-320/16 (Uber France), Rn. 37 f. Geschützt werden soll durch die Richtlinie der freie Warenverkehr durch eine vorbeugende Kontrolle, deren Wirksamkeit umso größer ist, wenn die technische Vorschrift unanwendbar ist, vgl. EuGH, Urteil vom 30.4.1996, Rs. C-194/94 (CIA Security International), Rn. 48.

1925 Vgl. EuGH, Urteil vom 7.8.2018, Rs. C-122/17 (Smith), Rn. 53. Da die in der Rechtssache Smith in Rede stehende Vorschrift den materiellen Inhalt einer Rechtsnorm enthält, wird sie von der Rechtsprechung erfasst, nach der eine Horizontalwirkung von Richtlinien ausgeschlossen ist, siehe EuGH, a.a.O., Rn. 54 ff. Der Betroffene ist damit auf einen Staatshaftungsanspruch verwiesen. 
Damit ist letztlich, unter Betonung der Besonderheiten technischer Vorschriften ${ }^{1926}$, der horizontale Charakter des Rechtsstreits zu verneinen. ${ }^{1927}$ Nicht recht einleuchten mag allerdings die aus der Rechtsprechung des Gerichtshofs folgende Konsequenz, dass die in Rede stehende Richtlinie die Rechte Einzelner zwar eigentlich gar nicht berührt, im Ergebnis aber letztlich genau dies als Nebenfolge ${ }^{1928}$ tut, während einer Richtlinie, die Rechte Einzelner betrifft, die horizontale Wirkung versagt wird. ${ }^{1929}$

Von diesem „Sonderfall“1930 einmal abgesehen, geht der Gerichtshof in ständiger Rechtsprechung davon aus, dass eine unmittelbare Wirkung einer Richtlinie zwischen Privaten ausgeschlossen ist. ${ }^{1931}$

Die Ablehnung der Horizontalwirkung lässt sich zwar mit guten Gründen kritisch hinterfragen, da die hierfür angeführten Gründe im Ergebnis nicht überzeugen. So sprechen weder der vom Gerichtshof herangezogene Wortlaut des Art. 288 III AEUV ${ }^{1932}$ noch Rechtssicherheitserwägungen für einen Ausschluss der Horizontalwirkung. ${ }^{1933}$ Der Unterschied zwischen Verordnungen und Richtlinien ${ }^{1934}$ trägt ihn ebenso wenig ${ }^{1935}$, weswegen Stimmen zuzustimmen ist, die eine Abkehr von der Ablehnung der Horizontalwirkung fordern. ${ }^{1936}$ Angesichts der Ziel- bzw. - wie in den anderen

1926 Coutron, RTDEur. 2015, 39 (51).

1927 Kroll-Ludwigs/Ludwigs, ZJS 2009, 7 (11).

1928 Vgl. Eder, EuR 2015, 746 (761).

1929 Ausführlich zu unterschiedlichen Begründungsansätzen Dougan, CMLRev. 44 (2007), 931 (957 ff.).

1930 EuGH, Urteil vom 7.8.2018, Rs. C-122/17 (Smith), Rn. 52 und 53.

1931 Siehe nur EuGH, Urteil vom 7.8.2018, Rs. C-122/17 (Smith), Rn. 42 ff.

1932 EuGH, Urteil vom 26.2.1986, Rs. 152/84 (Marshall), Rn. 48.

1933 Craig, ELRev. 2009, 349 (351 f., 353 f.).

1934 Diesen nimmt der Gerichtshof in Bezug, vgl. EuGH, Urteil vom 14.7.1994, Rs. C-91/92 (Faccini Dori), Rn. 24 und EuGH, Urteil vom 7.3.1996, Rs. C-192/94 (El Corte Inglés), Rn. 17, wo die Sorge zum Ausdruck gebracht wird, dass die EU bei Anerkennung einer Horizontalwirkung dann mit unmittelbarer Wirkung Verpflichtungen zu Lasten Einzelner schaffe, obwohl sie dies nur dürfe, wenn sie Verordnungen (oder Beschlüsse) erlassen dürfe. Dies wird vom EuGH weiterhin als Begründung für einen Ausschluss der Horizontalwirkung angeführt, vgl. EuGH, Urteil vom 10.10.2017, Rs. C-413/15 (Farrell), Rn. 31; EuGH, Urteil vom 22.1.2019, Rs. C-193/17 (Cresco Investigation), Rn. 72; EuGH, Urteil vom 24.6.2019, Rs. C-573/17 (Popławski), Rn. 66.

1935 Craig, ELRev. 2009, 349 (354f.); siehe auch Coutron, RTDEur. 2015, 39 (48 mit Fn. 70), der auf die Regelung des Art. 296 AEUV verweist, in der zum Ausdruck kommt, dass die jeweiligen Anwendungsbereiche von Verordnung und Richtlinie nicht scharf voneinander abgegrenzt sind.

1936 Siehe nur GA Sharpston, Schlussanträge vom 22.6.2017 in der Rs. C-413/15 (Farrell), Rn. $148 \mathrm{ff}$. 
Sprachfassungen des Art. 288 III AEUV deutlicher zum Ausdruck kommt - Ergebnisverbindlichkeit der Richtlinie stünde Art. 288 III AEUV einer Horizontalwirkung von Richtlinien nicht entgegen. ${ }^{1937}$

Da der Gerichtshof diesen Schritt aber bislang nicht gegangen ist und auch nicht zu erwarten steht, dass er ihn demnächst gehen wird, ist weiterhin davon auszugehen, dass ausdrücklich zwischen der Möglichkeit, sich gegenüber dem Staat unmittelbar auf die Richtlinie zu berufen, unabhängig davon, in welcher Eigenschaft dieser handelt, und der gegenüber einem Privaten ausgeschlossenen unmittelbaren Wirkung der Richtlinie zu unterscheiden ist. Aufgrund des Ausschlusses der Horizontalwirkung ist in letzterem Fall zunächst eine richtlinienkonforme Auslegung des nationalen Rechts zu versuchen. Scheitert diese, kann die Richtlinienbestimmung zwischen Privaten weder geltend gemacht werden, um die Wirksamkeit eines in ihr vorgesehenen Anspruchs zu gewährleisten, noch um die Nichtanwendung entgegenstehender Bestimmungen des nationalen Rechts zu erreichen. Im Falle des Scheiterns der richtlinienkonformen Auslegung verbleibt damit nur die auf die Rechtsprechung des Gerichtshofs in den verbundenen Rechtssachen Francovich u.a. ${ }^{1938}$ zurückgehende Möglichkeit der Haftung des Mitgliedstaats für den Unionsrechtsverstoß. 1939

Auch der Ausschluss der Anwendung einer richtlinienwidrigen Regelung eines Mitgliedstaats ist im Horizontalverhältnis also nicht möglich. ${ }^{1940}$ Ein „effet d'exclusion“ im Horizontalverhältnis kommt einer Richtlinie damit nicht zu. ${ }^{1941}$ Zurückzuweisen ist daher der Vortrag, es handele sich nur um eine unionsrechtlich unbedenkliche negative Auswirkung, wenn infolge der Nichtanwendung einer nationalen Vorschrift im Horizontalverhältnis ein auf diese Vorschrift gestützter Anspruch entfal-

1937 Raff, Jahrbuch Junger Zivilrechtswissenschaftler 2016, 67 (87 mit Fn. 78) meint, dafür sei es „höchste Zeit“.

1938 EuGH, Urteil vom 19.11.1991, verb. Rs. C-6/90 und C-9/90 (Francovich u.a.).

1939 EuGH, Urteil vom 26.3.2015, Rs. C-316/13 (Fenoll), Rn. 48. GA Wathelet, Schlussanträge vom 3.3.2016 in der Rs. C-46/15 (Ambisig), Rn. 36 mit Fn. 14 spricht daher von einer „Rangordnung der in einem Rechtsstreit zwischen Privatpersonen einschlägigen Lösungen“. Siehe in diesem Zusammenhang auch EuGH, Urteil vom 7.7.2016, Rs. C-46/15 (Ambisig), Rn. 23 ff. und EuGH, Urteil vom 24.1.2012, Rs. C-282/10 (Dominguez), Rn. $40 \mathrm{ff}$.

1940 EuGH, Urteil vom 7.8.2018, Rs. C-122/17 (Smith), Rn. 44; EuGH, Urteil vom 27.2.2014, Rs. C-351/12 (OSA), Rn. 48.

1941 Deutlich GA Kokott, Schlussanträge vom 17.1.2019 in der Rs. C-637/17 (Cogeco Communications), Rn. 69. 
le. ${ }^{1942}$ Eine derartige Aussage ist mit den in der Rechtsprechung des EuGH anzutreffenden unionsrechtlichen Rahmenbedingungen nicht vereinbar.

Entscheidende Bedeutung für das nach Unionsrecht mögliche Vorgehen bei der Bewältigung eines Rechtsstreits zwischen Privaten kommt der Beantwortung der Frage zu, ob eine Richtlinienbestimmung einen allgemeinen Grundsatz des Unionsrechts konkretisiert. Ist dies der Fall, kann der Einzelne zwar kein Recht aus der Richtlinie, wohl aber aus dem allgemeinen Grundsatz des Unionsrechts ableiten und dieses im Horizontalverhältnis geltend machen. In diesem Sinne hat der Gerichtshof etwa entschieden, dass ein nationales Gericht den dem Einzelnen aus Art. 21 und 47 GRCh (Verbot der Diskriminierung wegen der Religion oder der Weltanschauung und Recht auf wirksamen gerichtlichen Rechtsschutz) erwachsenden Rechtsschutz dadurch zu gewährleisten hat, dass es eine unionsrechtswidrige Bestimmung unangewendet lässt, wenn eine mit Art. 4 II der RL 2000/78/EG vereinbare Auslegung des nationalen Rechts scheitert. ${ }^{1943}$

Konkretisiert die betroffene Richtlinie dagegen keinen allgemeinen Grundsatz des Unionsrechts, besteht im Horizontalverhältnis, wenn eine richtlinienkonforme Auslegung des nationalen Rechts nicht möglich ist, keine unionsrechtliche Pflicht („nicht allein auf der Grundlage des Unionsrechts verpflichtet“; "not obliged, solely on the basis of EU law“) zur Nichtanwendung des richtlinienwidrigen nationalen Rechts. ${ }^{1944}$ Es besteht also keine Verpflichtung, die Möglichkeit der Berufung auf Richtlinien auf den Bereich der Beziehungen zwischen Privaten auszudehnen.

Mit der Unterscheidung zwischen positiver Anwendung der Richtlinie und negativer Reflexwirkung kann der Ablehnung der Horizontalwirkung durch den EuGH nicht begegnet werden, da die Nichtanwendung des nationalen Rechts als bloße Kehrseite der unmittelbaren Anwendung der Richtlinie erscheint. ${ }^{1945}$ Gegen die Anerkennung einer negativen unmittelbaren Richtlinienwirkung spricht auch, dass deren Reichweite dann von der Zufälligkeit der Ausgestaltung des nationalen Rechts abhinge, worauf sich das Unionsrecht nicht einlassen sollte. ${ }^{1946}$

1942 In diesem Sinne aber Kruis, Anwendungsvorrang, 2013, S. 120.

1943 EuGH, Urteil vom 17.4.2018, Rs. C-414/16 (Egenberger), Rn. 79.

1944 EuGH, Urteil vom 7.8.2018, Rs. C-122/17 (Smith), Rn. 46 ff.

1945 Zöchling-Jud, in: FS Mayer, 2011, S. 871 (877 ff.) im Zusammenhang mit der Frage der unmittelbaren Wirkung des Verbots der Altersdiskriminierung.

1946 Kroll-Ludwigs/Ludwigs, ZJS 2009, 7 (11); Osterloh-Konrad, CR 2008, 545 (547 f.); Schürnbrand, JZ 2007, 910 (911). 
Vor dem Hintergrund, dass auch die Verdrängung des nationalen Rechts eine Anwendung der Richtlinie darstellt, wird das Horizontalverhältnis zum Teil in eine Dreiecksbeziehung zwischen den beiden Parteien und dem Gericht als Träger öffentlicher Gewalt umgedeutet. Auf diese Weise sollen Vertikalbeziehungen entstehen, in denen die vertikale Wirkung der Richtlinie und das Verbot der umgekehrt vertikalen Wirkung zum Tragen kommen können. Die Anwendung richtlinienwidrigen nationalen Rechts soll dann von der betroffenen Partei abgewehrt werden können. ${ }^{1947}$ Eine solche Sichtweise ist allerdings bereits aus dem Grund abzulehnen, dass es sich hier um die „bloße Umdefinition“ eines Horizontalverhältnisses in Vertikalverhältnisse handelt. Nicht plausibel ist, dass sich allein durch die Einleitung eines Gerichtsverfahrens etwas an der Natur des zugrundeliegenden Rechtsstreits ändern sollte. ${ }^{1948}$

\section{Fazit}

$\mathrm{Ob}$ man eine Ausschlusswirkung ohne unmittelbare Wirkung annimmt oder ob man sie unter dem Begriff der negativen unmittelbaren Wirkung als Anwendungsfall unmittelbarer Wirkung beschreibt, hängt von der Enge bzw. Weite des zugrunde gelegten Verständnisses der unmittelbaren Wirkung ab. Auch wenn man die Ausschlusswirkung vollständig von der unmittelbaren Wirkung abkoppelt, kann dies nicht darüber hinwegtäuschen, dass es sich bei ihr letztlich um den Ausfluss der Wirkung einer Richtlinienbestimmung handelt, die der Gerichtshof im Horizontalverhältnis ablehnt. Ebenso verweigert er sich einer positiven unmittelbaren Horizontalwirkung, obwohl diese nach hier vertretener Auffassung im Einklang mit Primärrecht stünde. Im Horizontalverhältnis steht daher „lediglich“ die richtlinienkonforme Auslegung zur Erzielung unionsrechtskonformer Ergebnisse zur Verfügung, wenn sich das nationale Recht als richtlinienwidrig erweist. Scheitert auch diese, verbleibt die unsichere Möglichkeit eines unionsrechtlichen Staatshaftungsanspruchs.

Die in der Rechtsprechung aufgezeigten Ansätze eines entkoppelten Anwendungsvorrangs würden dem Gerichtshof, wenn man sie konsequent zu Ende denkt, zwar eine Lösung aller Kollisionsfälle zwischen Unions-

1947 So Herrmann, Richtlinienumsetzung, 2003, S. 80 f.

1948 Ebenso bereits Baldauf, Richtlinienverstoß, 2013, S. 169. 
recht und nationalem Recht ermöglichen. ${ }^{1949}$ Dass der Gerichtshof einen solchen Schritt gehen wird, steht allerdings nicht zu erwarten.

Durch die Ablehnung einer eigenständigen Vorrangwirkung der Richtlinie kommt es zu keiner Verdrängung des nationalen Rechts. Dies unterscheidet die Situation vom Anwendungsbereich des Anwendungsvorrangs, was grundsätzlich Raum für eine abweichende Behandlung im Hinblick auf die Möglichkeit der Berücksichtigung nationaler Vertrauensumstände eröffnet. Ob dennoch eine Gleichbehandlung im Ergebnis zu erfolgen hat, hängt damit von der Reichweite des Art. 288 III AEUV ab. Dieser Frage wird im Rahmen der nun erfolgenden näheren Beleuchtung der Verpflichtung der mitgliedstaatlichen Gerichte zu richtlinienkonformer Auslegung nachgegangen.

\section{Richtlinienkonforme Auslegung}

Die Verpflichtung zu richtlinienkonformer Auslegung verlangt von den nationalen Gerichten, bei der Auslegung und Anwendung des nationalen Rechts den Inhalt der Richtlinie heranzuziehen, um das von der Richtlinie vorgegebene Ergebnis zu erreichen. ${ }^{1950}$ Das nationale Recht ist anhand des Wortlauts und des Zwecks der Richtlinie auszulegen. ${ }^{1951}$ Auch wenn die Verpflichtung zu unionsrechtskonformer Auslegung nicht nur bei Richtlinien besteht, sondern sämtliches Unionsrecht und damit auch das unmittelbar anwendbare umfasst, so steht im Folgenden die richtlinienkonforme Auslegung im Mittelpunkt, da sich bei ihrem Scheitern der Anwendungsvorrang nicht durchsetzen kann, wenn es der zugrundeliegenden Richtlinienbestimmung an unmittelbarer Wirkung fehlt. ${ }^{1952}$

1949 Vgl. Mörth, ZöR 70 (2015), 33 (49 ff.). Er nennt dies „holistisches Vorrangprinzip“.

1950 Siehe nur EuGH, Urteil vom 7.7.2016, Rs. C-46/15 (Ambisig), Rn. 25.

1951 Siehe nur EuGH, Urteil vom 26.10.2016, Rs. C-611/14 (Canal Digital Danmark), Rn. 32, 33; EuGH, Urteil vom 21.4.2016, Rs. C-377/14 (Radlinger und Radlingerová), Rn. 79.

1952 Für das unmittelbar anwendbare Unionsrecht hat die unionsrechtskonforme Auslegung insoweit eigenständige Bedeutung, als sich die Frage der Nichtanwendung des nationalen Rechts gar nicht stellt, wenn die nationale Norm unionsrechtskonform ausgelegt werden kann, vgl. EuGH, Urteil vom 24.1.2012, Rs. C-282/10 (Dominguez), Rn. 23; EuGH, Urteil vom 10.10.2013, Rs. C-306/12 (Spedition Welter), Rn. 28; EuGH, Urteil vom 6.11.2018, verb. Rs. C-569/16 und C-570/16 (Bauer und Willmeroth), Rn. 25. Scheitert diese, 
Einzelnen kann der Staat eine richtlinienkonforme Auslegung des nationalen Rechts grundsätzlich entgegenhalten ${ }^{1953}$, was die noch näher zu untersuchende Frage, ob allgemeine Rechtsgrundsätze Privaten Schutz vor nachteiligen Auswirkungen bieten, in das Zentrum der Aufmerksamkeit rückt. ${ }^{1954}$ Auch zwischen Privaten findet die richtlinienkonforme Auslegung Anwendung. ${ }^{1955}$

Anders als bei der unmittelbaren Wirkung sind inhaltliche Unbedingtheit und hinreichende Genauigkeit keine Voraussetzungen der richtlinienkonformen Auslegung. ${ }^{1956}$ Trotz fehlender unmittelbarer Wirkung ist es nach Auffassung des Gerichtshofs möglich, den Zweck der betroffenen Richtlinienbestimmungen zu identifizieren, dem durch Auslegung des nationalen Rechts Rechnung zu tragen ist, wenn es an einer Umsetzung in nationales Recht fehlt. ${ }^{1957}$ Dass damit bei unmittelbarer Wirkung und konformer Auslegung verschiedene Standards der Bestimmtheit und Genauigkeit im Raum stehen, leuchtet allerdings nicht unmittelbar ein. Deutlich wird dies etwa an der Überlegung, dass es zur Festlegung, ab wann Kosten „übermäßig teuer“ sind, eines identischen Maßstabs bedarf, unabhängig davon, ob dies im Wege richtlinienkonformer Auslegung oder unmittelbarer Wirkung ermittelt werden soll. ${ }^{1958}$ Gleiches gilt beispiels-

kann sich der Anwendungsvorrang aber immer noch durchsetzen, siehe dazu bereits oben bei Fn. 1636.

1953 EuGH, Urteil vom 5.7.2007, Rs. C-321/05 (Kofoed), Rn. 45 unter Verweis auf EuGH, Urteil vom 8.10.1987, Rs. 80/86 (Kolpinghuis Nijmegen), Rn. 12-14 und EuGH, Urteil vom 26.9.1996, Rs. C-168/95 (Arcaro), Rn. 41 f. Siehe auch EuGH, Urteil vom 15.9.2011, Rs. C-53/10 (Franz Mücksch), Rn. 34. GA Kokott, Schlussanträge vom 8.2.2007 in der Rs. C-321/05 (Kofoed), Rn. 65 führt aus, dass „eine durch Bestimmungen des nationalen Rechts vermittelte, d.h. eine mittelbare Anwendung des Gemeinschaftsrechts zulasten des Einzelnen, [...] zulässig [ist]“" (Hervorhebung im Original).

1954 Vgl. GA Bobek, Schlussanträge vom 5.6.2018 in der Rs. C-167/17 (Klohn), Rn. 74 mit Fn. 49 und Rn. 104 mit Fn. 63.

1955 Siehe nur EuGH, Urteil vom 15.1.2014, Rs. C-176/12 (Association de médiation sociale), Rn. 38; aus der Literatur etwa von Kielmansegg, EuR 2014, 30 (36); ebenso Michael/Payandeh, NJW 2015, 2392 (2395) unter Verweis allerdings auf zwei Urteile des EuGH, in denen sich Staat und Private gegenüberstanden.

1956 EuGH, Urteil vom 4.7.2006, Rs. C-212/04 (Adeneler u.a.), Rn. 113; Riesenhuber/Domröse, RIW 2005, 47 (50); Michael/Payandeh, NJW 2015, 2392 (2395); Kroll-Ludwigs/Ludwigs, ZJS 2009, 7 (9 f.); a.A. Rüffler, ÖJZ 1997, 121 (124 f.).

1957 EuGH, Urteil vom 17.10.2018, Rs. C-167/17 (Klohn), Rn. 34.

1958 GA Bobek, Schlussanträge vom 5.6.2018 in der Rs. C-167/17 (Klohn), Rn. 66 ff. Er hielte verschiedene Standards für „irreführend“. 
weise für die Frage, ab wann sich eine Sanktion als unverhältnismäßig darstellt.

1. Verpflichtung zu richtlinienkonformer Auslegung als Ausfluss des Vorrangs?

Die richtlinienkonforme Auslegung wird vom Gerichtshof als Unterfall der unionsrechtskonformen Auslegung eingeordnet, deren wichtigsten Anwendungsfall sie darstellt. ${ }^{1959}$ Die unionsrechtskonforme Auslegung ist daher als Oberbegriff dafür zu verstehen, dass das Unionsrecht bei der Auslegung des nationalen Rechts zu berücksichtigen ist, um ihm auf diese Weise zur Durchsetzung zu verhelfen. ${ }^{1960}$ Vor dem Hintergrund, dass in der Literatur geltend gemacht wird, dass sich in der richtlinienkonformen Auslegung der Anwendungsvorrang verwirkliche, was die Frage der Gewährung von Vertrauensschutz zu einer solchen des Unionsrechts mache ${ }^{1961}$, ist der Ursprung der Pflicht zu richtlinienkonformer Auslegung kurz näher zu betrachten.

Wenn der EuGH die Verpflichtung zu richtlinienkonformer Auslegung als dem AEU-Vertrag bzw. dem System des AEU-Vertrags immanenten Grundsatz einordnet, geht es ihm um die Gewährleistung der vollen Wirksamkeit des Unionsrechts. ${ }^{1962}$ Aus dem Vorrang geht sie damit aber noch nicht hervor. Die Aussage des Gerichtshofs ändert nämlich nichts an der vorrangigen Verankerung der Pflicht zu richtlinienkonformer Aus-

1959 EuGH, Urteil vom 5.10.2004, verb. Rs. C-397/01 bis C-403/01 (Pfeiffer u.a.), Rn. 114 f., 118; EuGH, Urteil vom 30.4.2014, Rs. C-26/13 (Kásler und Káslerné Rábai), Rn. 65 f.; ebenso zur rahmenbeschlusskonformen Auslegung EuGH, Urteil vom 5.9.2012, Rs. C-42/11 (Lopes Da Silva Jorge), Rn. 54 ff. Ruffert, in: Calliess/Ruffert (Hrsg.), EUV/AEUV, 5. Aufl. 2016, Art. 1 AEUV, Rn. 24 spricht hinsichtlich der richtlinienkonformen Auslegung von einem „besonders bedeutsamen Bereich" der unionsrechtskonformen Auslegung.

1960 Siehe auch Roth/Jopen, in: Riesenhuber (Hrsg.), Europäische Methodenlehre, 3. Aufl. 2015, $\mathbb{1} 13$, Rn. 9.

1961 Schiek, AuR 2006, 41 (43).

1962 EuGH, Urteil vom 26.10.2016, Rs. C-611/14 (Canal Digital Danmark), Rn. 33; EuGH, Urteil vom 5.10.2004, verb. Rs. C-397/01 bis C-403/01 (Pfeiffer u.a.), Rn. 114; EuGH, Urteil vom 21.4.2016, Rs. C-377/14 (Radlinger und Radlingerová), Rn. 79; EuGH, Urteil vom 17.10.2018, Rs. C-167/17 (Klohn), Rn. 60. Siehe auch Ebers, Unionsprivatrecht, 2016, S. $404 \mathrm{ff}$. 
legung in Art. 288 III AEUV (und Art. 4 III EUV). ${ }^{1963}$ Art. 288 III AEUV können die entscheidenden Gesichtspunkte (Umsetzungspflicht, Effektivitätsgrundsatz) bereits entnommen werden, sodass letztlich dahinstehen kann, ob es zu ihrer Begründung neben der Umsetzungsverpflichtung aus Art. 288 III AEUV zusätzlich eines Rückgriffs auf Art. 4 III EUV bedarf. ${ }^{1964}$ Damit vergleichbar begründet der Gerichtshof die Verpflichtung zur rahmenbeschlusskonformen Auslegung insbesondere mit dem verbindlichen Charakter des Rahmenbeschlusses. ${ }^{1965}$

Die an die mitgliedstaatlichen Gerichte gestellten Anforderungen hat Generalanwalt Bobek plastisch beschrieben. Danach ist im Rahmen der konformen Auslegung nicht nur der jeweils betroffene Ast des nationalen Rechts zu berücksichtigen, sondern der gesamte innerstaatliche Gesetzesbaum einschließlich seines verfassungs- und verwaltungsrechtlichen Stamms und Wurzelwerks. Verbirgt sich an irgendeiner Stelle dieses Baums eine Regelung, die eine andere Auslegung des konkreten Astes nahelegt, ist diese vorzunehmen. ${ }^{1966}$ In der Verpflichtung zur Konformauslegung des gesamten nationalen Rechts und nicht nur des Umsetzungsrechts ${ }^{1967}$ ist aber ebenfalls nicht zwingend eine Verbindung zum Vorrang des Unionsrechts (und nicht nur zur Richtlinienumsetzung) zu sehen. ${ }^{1968}$ Wenn die Richtlinie, wie hier angenommen, innerstaatlich gilt, wäre es

1963 EuGH, Urteil vom 5.10.2004, verb. Rs. C-397/01 bis C-403/01 (Pfeiffer u.a.), Rn. 110, 113; siehe auch Roth/Jopen, in: Riesenhuber (Hrsg.), Europäische Methodenlehre, 3. Aufl. 2015, $\mathbb{1} 13$, Rn. 10.

1964 Ebenso Baldauf, Richtlinienverstoß, 2013, S. 83.

1965 EuGH, Urteil vom 28.7.2016, Rs. C-294/16 PPU (JZ), Rn.32; EuGH, Urteil vom 5.9.2012, Rs. C-42/11 (Lopes Da Silva Jorge), Rn. 53 spricht vom „zwingende[n] Charakter" der Rahmenbeschlüsse. Auch zur Begründung der Pflicht zur rahmenbeschlusskonformen Auslegung rekurriert der EuGH auf das „System des AEU-Vertrags“, dem diese Verpflichtung immanent sei, vgl. EuGH, Urteil vom 29.6.2017, Rs. C-579/15 (Popławski), Rn.31; EuGH, Urteil vom 8.11.2016, Rs. C-554/14 (Ognyanov), Rn. 59. Diese Formulierung muss überraschen, unterliegen die Wirkungen der Rahmenbeschlüsse doch wie oben bei und in Fn. 1891 gesehen nach wie vor den Regeln der vor dem Vertrag von Lissabon geltenden Fassung des EU-Vertrags.

1966 GA Bobek, Schlussanträge vom 26.6.2018 in der Rs. C-384/17 (Link Logistik N\&N), Rn. 58 f.

1967 Siehe nur EuGH, Urteil vom 4.7.2006, Rs. C-212/04 (Adeneler u.a.), Rn. 108; EuGH, Urteil vom 23.4.2009, verb. Rs. C-378/07 bis C-380/07 (Angelidaki u.a.), Rn. 197; EuGH, Urteil vom 10.3.2011, Rs. C-109/09 (Deutsche Lufthansa), Rn. 52; EuGH, Urteil vom 13.11.1990, Rs. C-106/89 (Marleasing), Rn. 8.

1968 So aber Simon, in: Mélanges Mengozzi, 2013, S. 279 (282 f.). Für Simon, a.a.O., S. 300 ist die Konformauslegung Vorrang, fortgeführt mit anderen Mitteln. 
nicht verständlich, wenn sie als Teil der innerstaatlichen Rechtsordnung keine Bedeutung für das übrige nationale Recht hätte.

Dass die Pflicht zur richtlinienkonformen Auslegung nicht aus dem Vorrang des Unionsrechts entspringen kann, zeigen schließlich die ihr gezogenen Grenzen. Zwar ließe sich die Grenze der allgemeinen Rechtsgrundsätze mit einer Ableitung aus dem Vorrang vereinbaren. Erkennt man nämlich dessen Einschränkbarkeit an ${ }^{1969}$, können ihm die allgemeinen Rechtsgrundsätze entgegenstehen. Zugleich erkennt der Gerichtshof aber auch die (in ihrer Bedeutung allerdings sehr umstrittene) contra legem-Grenze an, die dazu führt, dass eine Konformauslegung aus im nationalen Recht wurzelnden Gründen scheitern kann. Wäre die Pflicht zur richtlinienkonformen Auslegung aus dem Vorrang abzuleiten, würde nicht recht einleuchten, weshalb dieser entgegenstehendes nationales Recht nicht einfach verdrängt.

Diese Möglichkeit besteht aber lediglich bei einer unmittelbare Wirkung entfaltenden Richtlinienbestimmung. ${ }^{1970}$ Kommt eine unmittelbare Wirkung dagegen nicht in Betracht, kann die contra legem-Grenze nicht durch Nichtanwendung des nationalen Rechts übergangen werden. Ihre Anerkennung steht einer Ableitung der Pflicht zu richtlinienkonformer Auslegung aus dem Vorrang daher diametral entgegen. ${ }^{1971}$ Verzichtete man mit den Befürwortern eines derartigen Vorgehens auf das Erfordernis unmittelbarer Wirkung und entkoppelte damit den Vorrang von ihr, wäre die contra legem-Grenze letztlich obsolet. Da der EuGH sie aber weiterhin anerkennt, zeigt sich auch hier, dass er einer Entkopplung letztlich doch ablehnend gegenübersteht.

$\mathrm{Zu}$ Recht hat der Gerichtshof nach alledem die Pflicht zu richtlinienkonformer Auslegung in Art. 288 III AEUV (und Art. 4 III EUV) verankert. An dieser Feststellung ändert sich auch nichts durch die Auffassung des Gerichtshofs, dass „der Grundsatz des Vorrangs des Unionsrechts“ den nationalen Gerichten „zur Gewährleistung der Wirksamkeit sämtlicher Bestimmungen des Unionsrechts" auferlegt, ihr nationales Recht so weit wie möglich unionsrechtskonform auszulegen. ${ }^{1972}$ Die der richtlinienkonformen Auslegung gesetzten Grenzen können damit nicht überspielt werden.

1969 Siehe dazu ausführlich oben bei Fn. $1358 \mathrm{ff}$.

1970 GA Trstenjak, Schlussanträge vom 21.10.2008 in den verb. Rs. C-261/07 und C-299/07 (VTB-VAB und Galatea), Fn. 22.

1971 Dougan, CMLRev. 44 (2007), 931 (946f.). Eine Ableitung aus dem Vorrang nehmen dagegen Lenaerts/Corthaut, ELRev. 2006, 287 (293) vor.

1972 EuGH, Urteil vom 24.6.2019, Rs. C-573/17 (Popławski), Rn. 57. In der englischen bzw. französischen Sprachfassung ist dies mit „the primacy principle 
2. Vertrauensschutz gegen Rechtsprechung im deutschen Recht

Da die Pflicht zu richtlinienkonformer Auslegung nach hier vertretener Ansicht nicht aus dem Vorrang des Unionsrechts entspringt, ist die Frage der Berücksichtigung nationaler Vertrauensumstände im Rahmen der richtlinienkonformen Auslegung nicht bereits aus diesem Grund eine allein nach unionsrechtlichen Maßstäben zu beurteilende. In der Literatur finden sich verschiedene Überlegungen, eine Berücksichtigung nationaler Vertrauensumstände in diesem Bereich zu ermöglichen. Insbesondere ist dort der Wunsch zu erkennen, die im nationalen Recht anerkannten Grundsätze des Vertrauensschutzes auf die richtlinienkonforme Auslegung $\mathrm{zu}$ übertragen. Bevor genauer zu untersuchen ist, ob dieses Ansinnen erfolgversprechend ist, ist zunächst darzulegen, welchen Wert Vertrauensschutz gegen Rechtsprechung nach rein nationalem Verständnis genießt. $\mathrm{Da}$ als nationaler Vertrauensumstand insbesondere eine langjährige, sich später als unionsrechtswidrig herausstellende nationale Rechtsprechung in Betracht kommt, erscheint dieser Blick auf den nach deutschem Recht gegen Rechtsprechung gewährten Vertrauensschutz angezeigt. Nur in dem Umfang, in dem dieses Vertrauensschutz anerkennt, kann er vor dem Hintergrund des Äquivalenzgrundsatzes im Anwendungsbereich des Unionsrechts überhaupt zum Tragen kommen.

Das Bundesverfassungsgericht sieht Vertrauensschutz in der Rechtssicherheit als Ausfluss des Rechtsstaatsprinzips und den Grundrechten verankert. ${ }^{1973}$ Rechtsstaatsprinzip und Grundrechte gewährleisten nach seinen Ausführungen die Verlässlichkeit der Rechtsordnung und schaffen damit eine Voraussetzung für die Selbstbestimmung des Einzelnen über den eigenen Lebensentwurf. Durch seine Betonung der ohne diese Verlässlichkeit bestehenden Gefährdung der Betroffenen in ihrer Freiheit wird der mit der Gewährung von Vertrauensschutz verfolgte Zweck deutlich: er ist auf Freiheitssicherung gerichtet und denkt vom Individuum her. ${ }^{1974}$

requires, inter alia, national courts“ bzw. „le principe de primauté impose, notamment, aux juridictions nationales" wiedergegeben. Auch die Pflicht, dem Einzelnen gegebenenfalls einen Entschädigungsanspruch zuzuerkennen, führt der Gerichtshof an der zitierten Stelle auf den Vorrang zurück. Die Aussage zur Pflicht zu unionsrechtskonformer Auslegung wiederholend EuGH, Urteil vom 4.3.2020, Rs. C-183/18 (Bank BGŻ BNP Paribas), Rn. 60.

1973 BVerfG, Beschluss vom 17.12.2013, 1 BvL 5/08, Rn. 59 - BVerfGE 135, 1.

1974 BVerfG, Beschluss vom 25.4.2015, 1 BvR 2314/12, Rn. 13 - NJW 2015, 1867; BVerfG, Beschluss vom 17.12.2013, 1 BvL 5/08, Rn. 60 - BVerfGE 135, 1; BVerfG, Beschluss vom 5.3.2013, 1 BvR 2457/08, Rn. 41 - BVerfGE 133, 143. 
Sind der öffentlichen Gewalt damit auch im Hinblick auf die zeitliche Dimension ihres Handelns Grenzen gesetzt, muss sich auch „rückwirkende“ Rechtsprechung an verfassungsrechtlichen Maßstäben messen lassen. Werden die unionsrechtlichen Rahmenbedingungen erst einmal ausgeblendet, sind dies die Vorgaben, an die die nationalen Gerichte bei der Entscheidung von Rechtsstreitigkeiten gebunden sind.

\section{a) Rechtsprechung als Anknüpfungspunkt für Vertrauensschutz}

Grenze jeglicher Rechtsprechung ist das Willkürverbot. Diese Grenze ist dann überschritten, wenn die Rechtsprechung unter keinem denkbaren Aspekt rechtlich vertretbar ist, sodass davon auszugehen ist, sie sei von sachfremden Erwägungen geleitet. ${ }^{1975}$ Dies ist etwa der Fall, wenn eine offensichtlich einschlägige Norm nicht berücksichtigt oder der Inhalt einer Vorschrift in krasser Weise missgedeutet wurde. ${ }^{1976}$ An dieser Grenze ist nicht nur die erstmalige Beantwortung einer Rechtsfrage zu messen, sondern auch eine Rechtsprechungsänderung. Im Hinblick auf diese lässt sich das Willkürverbot als Verbot der willkürlichen Abweichung von bisheriger Rechtsprechung formulieren. Ist Gerichten aber eine willkürliche Änderung ihrer Rechtsprechung nicht gestattet, hat diese einen Wert an sich und ist damit grundsätzlich als Vertrauenstatbestand geeignet. ${ }^{1977}$

Bei der Beurteilung der an die zeitliche Dimension von Rechtsprechung zu stellenden verfassungsrechtlichen Anforderungen darf die Besonderheit der Aufgabe der Rechtsprechung nicht außer Acht gelassen werden. Diese im Vergleich zur Gesetzgebung unterschiedliche Ausgangslage betont auch das Bundesverfassungsgericht. So darf angesichts der Bindung der Rechtsprechung an Recht und Gesetz nach Art. 20 III GG die richterliche Tätigkeit, soll sie verfassungsrechtlich unbedenklich sein, den durch das Gesetz gesteckten Rahmen nicht verlassen. Selbst für höchstrichterli-

1975 Dies wird vom Bundesverfassungsgericht selbst als ständige Rechtsprechung bezeichnet, siehe nur BVerfG, Beschluss vom 17.2.2017, 2 BvR 1558/16, Rn. 16 - NVwZ 2017, 1133; BVerfG, Beschluss vom 9.8.2016, 2 BvR 1287/16, Rn. 62 NVwZ 2017, 46.

1976 BVerfG, Beschluss vom 9.2.2001, 1 BvR 781/98 - DVB1. 2001, 892.

1977 Neuner, in: FS Canaris, 2017, S. 205 (214). Er verweist auch auf den Rechtsmittelzug, mit dem eine einheitliche Rechtsprechung gesichert werden soll. Dies verstärkt in der Tat die Kontinuitätserwartung der Betroffenen noch einmal, da ein Hinwirken auf Einheitlichkeit ohne Festhalten an der einmal erzielten Einheitlichkeit seinen Sinn verlöre. 
che Rechtsprechung ist danach eine dem Gesetzesrecht vergleichbare Bindungswirkung zu verneinen. Unterscheidet sich die Bindungswirkung von Rechtsprechung aber von derjenigen von Gesetzen, kann Rechtsprechung anders als eine Norm keine generelle Verbindlichkeit beanspruchen. Nimmt man die verfassungsrechtlich vorgeschriebene Unabhängigkeit der Richter, Art. 97 I GG, mit in den Blick, muss Rechtsprechung zwangsläufig uneinheitlich sein. ${ }^{1978}$ Gerichten grundsätzlich zuzugestehen, aufgrund besserer Rechtserkenntnis von einer Rechtsprechungslinie auch mit Wirkung für die Vergangenheit abzuweichen, ist daher nur konsequent. ${ }^{1979}$

Bei den bisherigen verfassungsrechtlichen Maßstäben verbleibt es auch im Hinblick auf eine Entscheidung des Bundesverfassungsgerichts zu gesetzgeberischen Klarstellungen, auf die im ersten Teil dieser Arbeit bereits hingewiesen wurde. ${ }^{1980}$ Indem das Bundesverfassungsgericht eine gesetzliche Regelung, die bei einem auslegungsbedürftigen Gesetz eine denkbare Auslegung als verbindlich festgeschrieben hatte, als konstitutiv einstufte, hat es diese dem Rückwirkungsverbot unterworfen. Die danach erforderliche Prüfung am Maßstab des grundsätzlichen Verbots echter Rückwirkung führte zur Einordnung der Regelung als verfassungswidrig, obwohl die Rechtsprechung, unabhängig von der gesetzlichen Klarstellung, durch Auslegung zu demselben Ergebnis wie der Gesetzgeber hätte gelangen können, ohne dass dies auf verfassungsrechtliche Bedenken gestoßen wäre. Auch wenn gegen die Entscheidung des Bundesverfassungsgerichts argumentiert wird, dass dem Gesetzgeber damit eine Regelung verboten werde, die Gerichte durch Auslegung herbeiführen dürften ${ }^{1981}$, ist sie im

1978 BVerfG, Beschluss vom 21.7.2010, 1 BvL 11/06, 1 BvL 12/06, 1 BvL 13/06, 1 BvR 2530/05 - BVerfGE 126, 369 (394f.). Kritisch zur Argumentation mit Art. 97 I GG Payandeh, Judikative Rechtserzeugung, 2017, S. 166 ff.

1979 Brocker, NJW 2012, 2996 (2998); Maultzsch, RabelsZ 79 (2015), 322 (344).

1980 BVerfG, Beschluss vom 17.12.2013, 1 BvL 5/08 - BVerfGE 135, 1. Siehe oben bei Fn. $108 \mathrm{f}$.

1981 Abweichende Meinung des Richters Masing zum Beschluss des Ersten Senats vom 17. Dezember 2013 - 1 BvL 5/08 -, Rn. 5 - BVerfGE 135, 1 (30). Kritisch auch Lepsius, JZ 2014, 488 (491), der „Zweierlei Maß“ für Gesetzgebung und Rechtsprechung beklagt, was zu einer „Besserstellung der Rechtsprechung gegenüber der Gesetzgebung" führe. Dem Bundesverfassungsgericht im Ergebnis zustimmend Michael, JZ 2015, 425 (431 ff.), der das „zweierlei Maß“ zu Recht als „Folge einer differenzierten Funktionalität der Gewalten“ einordnet und einen „Kernbereich judikativer Eigenverantwortung“ angesichts der Unabhängigkeit der Gerichte einfordert, denen die seinerzeit existierende Entscheidungsgrundlage nicht entzogen werden dürfe. Zustimmung äußert auch Payandeh, Judikative Rechtserzeugung, 2017, S. 284. 
Ergebnis überzeugend. Auch nach ihrem Erlass hat das Bundesverfassungsgericht an seiner Rechtsprechung zur Zulässigkeit von Rechtsprechungsänderungen festgehalten. ${ }^{1982}$ Mit der Anwendung des Rückwirkungsverbots auf gesetzgeberische Klarstellungen geht also keine Neubewertung der zeitlichen Wirkung von Rechtsprechungsänderungen einher; insbesondere ist mit ihr keine Übertragung der für den Gesetzgeber geltenden Rückwirkungsschranken verbunden. ${ }^{1983}$ Der an eine Rechtsprechungsänderung anzulegende Maßstab ist daher derselbe, unabhängig davon, ob die Rechtsprechungsänderung im Sinne der zur Rückwirkung von Gesetzen entwickelten Terminologie zu einer unechten oder echten Rückwirkung führt. ${ }^{1984}$

Das Bundesverfassungsgericht erkennt zwar eine über den Einzelfall hinausreichende Geltung fachgerichtlicher Gesetzesauslegung an, verweist aber gleichzeitig darauf, dass diese nur auf der Überzeugungskraft der Gründe der Auslegung sowie der Autorität und den Kompetenzen des Gerichts beruhe. ${ }^{1985}$ Demnach sind auch Entscheidungen oberster Gerichte zwar über den entschiedenen Fall hinaus richtungsweisend, aber eben kein Präjudiz im engeren Sinne. ${ }^{1986}$ Der Verweis auf die Überzeugungskraft der Gründe einer bestimmten Gesetzesauslegung macht deutlich, dass die Wirkung von Rechtsprechung auf einer wandelbaren Grundlage beruht: Gründe können immer wieder neu und dann eben auch abweichend beurteilt werden.

Durch das Abstellen auf die Überzeugungskraft der Gründe einer Gesetzesauslegung und damit die Überzeugungskraft der der Rechtsprechung

1982 Siehe z.B. BVerfG, Beschluss vom 5.11.2015, 1 BvR 1667/15, Rn. 12 - DB 2015, 2927.

1983 Siehe hierzu auch Maultzsch, RabelsZ 79 (2015), 322 (345 f.). Wenn BVerfG, Beschluss vom 21.12.2009, 1 BvR 2738/08 - BVerfGK 16, 449 (463) ausführt, die Frage der Anwendung der verfassungsrechtlichen Grundsätze zum Rückwirkungsverbot auf die richterliche Rechtsfortbildung bedürfe keiner grundsätzlichen Klärung, hält es sich damit allerdings die Option einer Übertragung des Maßstabs offen.

1984 Maultzsch, RabelsZ 79 (2015), 322 (342).

1985 BVerfG, Beschluss vom 25.4.2015, 1 BvR 2314/12, Rn. 13 - NJW 2015, 1867; BVerfG, Beschluss vom 5.11.2015, 1 BvR 1667/15, Rn. 12, 29 - DB 2015, 2927; BVerfG, Beschluss vom 2.5.2012, 2 BvL 5/10 - BVerfGE 131, 20 (42); BVerfG, Beschluss vom 15.1.2009, 2 BvR 2044/07 - BVerfGE 122, 248 (277). Hierzu näher Payandeh, Judikative Rechtserzeugung, 2017, S. 299 ff.

1986 BVerfG, Beschluss vom 2.5.2012, 2 BvL 5/10 - BVerfGE 131, 20 (42). Oberste Gerichte sind „vornehmlich zur grundsätzlichen Auslegung und Weiterentwicklung des Rechts berufen“. 
zugrundeliegenden Argumentation kann auch kritischen Literaturstimmen Einfluss auf die Beständigkeit der Rechtsprechung und damit die Schutzwürdigkeit des Vertrauens zugestanden werden. ${ }^{1987}$ So überrascht es nicht, dass die Existenz unterschiedlicher Meinungen hinsichtlich einer bestimmten Rechtsfrage zum Zeitpunkt des Abschlusses von Darlehensverträgen - zitiert werden hier Literaturstimmen - für das Bundesverfassungsgericht dafür entscheidend war, dass nicht auf eine bestimmte Auslegung vertraut werden durfte, mit der Folge, dass sich die Betroffenen nicht auf den Fortbestand einer entsprechenden Rechtsprechungslinie verlassen durften. ${ }^{1988}$ Das BAG hat dagegen in der Literatur im Hinblick auf Unionsrecht vorgebrachte Zweifel bereits einmal als nicht vertrauenserschütternd angesehen. ${ }^{1989}$

Dass Literaturstimmen für die Frage des Vertrauensschutzes gegenüber nationaler Rechtsprechung Bedeutung erlangen können, ist aus unionsrechtlicher Sicht dann unbedenklich, wenn im Hinblick auf die Unionsrechtskonformität der nationalen Rechtsprechung geäußerten Bedenken vertrauenserschütternde Wirkung beigemessen wird. Bedenken würde dies dagegen dann begegnen, wenn die Literatur eine sich als unionsrechtswidrig herausstellende Rechtsprechungslinie befürwortet, etwa weil die Betroffenheit von Unionsrecht „übersehen“ wird oder die unionsrechtlichen Maßstäbe verkannt werden und dies als vertrauensbegründend bzw. -verstärkend gewertet würde. Eine solche Wirkung ist aber bislang soweit ersichtlich in der deutschen Rechtsprechung nicht anerkannt worden.

1987 Auf diesen Zusammenhang weist Maultzsch, RabelsZ 79 (2015), 322 (344) zutreffend hin. Siehe auch Payandeh, Judikative Rechtserzeugung, 2017, S. 479, $486 \mathrm{f}$.

1988 BVerfG, Beschluss vom 26.9.2011, 2 BvR 2216/06, 2 BvR 469/07 - BVerfGK 19, 89 (105). Dass das Bundesverfassungsgericht Literaturstimmen vertrauenserschütternde Bedeutung beimisst, hat sich daneben auch im Rahmen der Prüfung von Vertrauen auf den Fortbestand einer gesetzlichen Regelung gezeigt, vgl. BVerfG, Beschluss vom 18.2.2009, 1 BvR 3076/08 - BVerfGE 122, 374 (395 f.). Siehe etwa auch Neuner, in: FS Canaris, 2017, S. 205 (215), nach dessen Auffassung die „Wirkkraft des Vertrauensschutzprinzips“ auch davon abhängt, ob die Rechtsprechung in der Literatur kritisiert oder befürwortet wurde.

1989 BAG, Urteil vom 23.3.2006, 2 AZR 343/05, Rn. 42 - BAGE 117, 281. Danach können vereinzelte Literaturstimmen (und die Entscheidung eines einzelnen Arbeitsgerichts) das Vertrauen in die bisherige Rechtsprechung nicht relevant erschüttern. Kritisch zur Berücksichtigung von Literaturmeinungen auch Herdegen, WM 2009, 2202 (2208); Höpfner, RdA 2006, 156 (160). Zur Unerheblichkeit von Literaturstimmen im Rahmen der Defrenne-Rechtsprechung siehe oben bei Fn. $702 \mathrm{f}$. 
Machen die Rechtsunterworfenen „Vertrauensschutz gegen Rechtsprechung" geltend, kommen hierfür nach dem vorstehend Gesagten zwei Anknüpfungspunkte in Betracht - nationale Rechtsprechung und nationale Normen. ${ }^{1990}$ Ins Feld geführt werden kann also einerseits die über den Einzelfall hinausgehende Geltung fachgerichtlicher Gesetzesauslegung, die die Erwartung weckt, dass ein Gericht bei seiner Entscheidung frühere Rechtsprechung berücksichtigt. Andererseits kann die Bindung der Rechtsprechung an Recht und Gesetz angeführt werden, die es den Gerichten untersagt, den durch das Gesetz gesteckten Rahmen zu verlassen. Sie weckt die Erwartung, dass sich die Rechtsprechung innerhalb des gesetzlichen Rahmens bewegt. Unterschiedliche Auffassungen zur Verfassungsmäßigkeit einer Norm können dabei ihre Tauglichkeit als Vertrauensgrundlage angesichts der ausschließlichen Befugnis des Bundesverfassungsgerichts zur Entscheidung über ihre Verfassungsmäßigkeit nicht in Frage stellen. ${ }^{1991}$ Vertrauensschutz gegen Rechtsprechung ist damit gegen Rechtsprechung gerichtet, die „legitime Erwartungen in die Rechtslage“ enttäuscht. ${ }^{1992}$

\section{b) Unterschiede zwischen Erstauslegung und Rechtsprechungsänderung}

Wird Vertrauensschutz gegen Rechtsprechung geltend gemacht, ist zwischen der erstmaligen Auslegung einer Norm („Erstauslegung“) und einer Rechtsprechungsänderung zu unterscheiden. Bei einer Rechtsprechungsänderung wird die gleiche Rechtsfrage bei einer erneuten Bewertung abweichend von der zunächst vorgenommenen Bewertung beurteilt. Die Änderung des in der bisherigen Rechtsprechung aufgestellten Rechtssatzes ist dabei entscheidend für den Ausgang des Verfahrens. ${ }^{1993}$

1990 Siehe zu diesen Anknüpfungspunkten auch Neuner, in: FS Canaris, 2017, S. 205.

1991 BVerfG, Urteil vom 6.12.2016, 1 BvR 2821/11, 1 BvR 321/12, 1 BvR 1456/12, Rn. 378 - BVerfGE 143, 246.

1992 Herdegen, WM 2009, 2202 (2204).

1993 Lunk, in: FS Reuter, 2010, S. 689 (694); Koch, SR 2012, 159 (162). Zur zeitlichen Wirkung einer Rechtsprechungsänderung des EuGH näher oben bei Fn. 220 ff., insb. Fn. 238 ff. 
aa) Erstauslegung

Zwar ist den Rechtsunterworfenen eine Berufung auf die Unkenntnis der Rechtslage nicht gestattet, sodass konsequenterweise umgekehrt auch der Schutz abstrakten Vertrauens in diese anzuerkennen ist, was konkretes, individuelles Vertrauen der Rechtsunterworfenen entbehrlich macht. ${ }^{1994}$ Bei einer Erstauslegung muss die Gewährung von Vertrauensschutz dennoch letztlich ausscheiden.

Da die Betroffenen mit der Anwendung sämtlicher Auslegungsmethoden durch die Gerichte rechnen müssen, können sie nämlich kein Vertrauen auf die Anwendung einer für sie günstigen Auslegungsmethode gründen. ${ }^{1995}$ Letztlich würde das Vertrauen bei einer Erstauslegung daher allein darauf beruhen, eine Rechtsfrage werde im Sinne der Betroffenen entschieden. ${ }^{1996}$ Eine derartige Erwartung steht aber nicht unter dem Schutz der Verfassung. ${ }^{1997}$ Demnach kann auch die „herrschende Meinung“ im Rahmen der erstmaligen Beantwortung einer Rechtsfrage durch die Rechtsprechung kein Anknüpfungspunkt für Vertrauen sein. ${ }^{1998}$ Auch bei in der Literatur zu findender Unterstützung für die eigene Rechtsansicht ändert sich ja nichts daran, dass lediglich auf eine bestimmte Auslegung vertraut wird, ohne dass erkennbar wäre, weshalb dieses Verständnis verfassungsrechtlichen Schutz genießen sollte. ${ }^{1999}$

1994 Neuner, in: FS Canaris, 2017, S. 205 (208) nennt dies „generelle Inpflichtnahme der Normadressaten durch die Rechtsordnung“ einerseits und „generelles Vertrauen-Dürfen auf die Rechtsordnung“ andererseits. Siehe auch Klappstein, Rechtsprechungsänderung, 2009, S. 380 ff. Höpfner, RdA 2006, 156 (157) lässt dagegen den Beweis der Unkenntnis der Rechtslage zu, um ein „Zufallsgeschenk" an den Prozessgegner zu vermeiden. Neuner, a.a.O., S. 216 führt Beispiele an, wann das abstrakte Vertrauen zerstört ist.

1995 BVerfG, Beschluss vom 23.5.2016, 1 BvR 2230/15, 1 BvR 2231/15, Rn. 58 f. NJW-RR 2016, 1366 zum Verhältnis der Auslegung nach dem Wortlaut und der teleologischen, an der Rechtsprechung des EuGH orientierten Reduktion.

1996 Koch, SR 2012, 159 (161).

1997 BVerfG, Beschluss vom 25.4.2015, 1 BvR 2314/12, Rn. 16 - NJW 2015, 1867 unter Verweis auf BAG, Urteil vom 13.3.2013, 5 AZR 954/11, Rn. 24 - BAGE 144, 306.

1998 A.A. Neuner, in: FS Canaris, 2017, S. 205 mit Fn. 3.

1999 Herdegen, WM 2009, 2202 (2205) meint dagegen, Vertrauensschutz sei auch dann zu gewähren, wenn das Vertrauen auf einem bislang unangefochtenen Verständnis der Rechtslage und einer entsprechenden Geschäftspraxis beruhe und nun erstmalig eine abweichende Rechtskonkretisierung durch die Rechtsprechung stattfinde. 
Nach den an die Erstauslegung anzulegenden verfassungsrechtlichen Maßstäben muss die gerichtliche Entscheidung also lediglich "vertretbar" und damit methodisch sauber begründet sein. ${ }^{2000}$ Anders als der EuGH, der grundsätzlich bereit ist, auch bei der Erstauslegung guten Glauben zu bejahen, verfährt das Bundesverfassungsgericht demnach restriktiver. Die verfassungsrechtlichen Maßstäbe des Vertrauensschutzes bei einer Erstauslegung hindern die nationalen Gerichte damit nicht an einer unionsrechtskonformen Rechtsfindung und stehen ihr deshalb nicht entgegen.

bb) Rechtsprechungsänderung

Wird der Blick auf die Rechtsprechungsänderung gerichtet, ist festzuhalten, dass es aus verfassungsrechtlicher Sicht im Ausgangspunkt keinen Unterschied macht, ob ein in der Rechtsprechung entwickelter Rechtssatz bereits lange Zeit Bestand hatte oder nicht. Auch ein bereits länger bestehender Rechtssatz ist einer Änderung ebenso zugänglich wie jeder andere Rechtssatz, damit die Rechtsprechung ihrer Aufgabe zur gegebenenfalls erforderlichen Weiterentwicklung dieser Rechtssätze nachkommen kann. Im Ausgangspunkt gilt daher, dass eine Änderung der Rechtsprechung auch auf Altfälle anzuwenden ist. ${ }^{2001}$ Dass sich die Verhältnisse oder allgemeinen Auffassungen wesentlich geändert haben, ist nicht erforderlich, um das Abgehen von der früheren Rechtsprechung als im Hinblick auf Art. 20 III GG unbedenklich anzusehen. ${ }^{2002}$

Nach Auffassung des Bundesverfassungsgerichts unterscheiden sich „die verfassungsrechtlichen Maßstäbe, an denen Rechtsprechungsänderungen zu messen sind, [...], abgesehen von dem Gesichtspunkt des Vertrauensschutzes, nicht von denjenigen, die gegenüber dem erstmaligen Aufstellen eines Rechtssatzes durch ein Gericht angezeigt sind“. ${ }^{2003}$ Gerade dieser Gesichtspunkt des Vertrauensschutzes erlangt im vorliegenden Zusammenhang allerdings Bedeutung.

2000 Rosenkranz, ZfPW 2016, 351 (362).

2001 Maurer, in: Isensee/Kirchhof (Hrsg.), HStR IV, 3. Aufl. 2006, \$ 79, Rn. 149.

2002 BVerfG, Beschluss vom 25.4.2015, 1 BvR 2314/12, Rn. 13 - NJW 2015, 1867; BVerfG, Beschluss vom 5.11.2015, 1 BvR 1667/15, Rn. 12 - DB 2015, 2927; BVerfG, Beschluss vom 26.6.1991, 1 BvR 779/85 - BVerfGE 84, 212 (227f.); BVerfG, Beschluss vom 15.1.2009, 2 BvR 2044/07 - BVerfGE 122, 248 (277).

2003 BVerfG, Beschluss vom 5.11.2015, 1 BvR 1667/15, Rn. 12 - DB 2015, 2927 (Hervorhebung nur hier); siehe auch BVerfG, Beschluss vom 15.1.2009, 2 BvR 2044/07 - BVerfGE 122, 248 (267). 
Von einer Rechtsprechungsänderung ist zunächst der Fall abzugrenzen, dass keine entgegenstehende höchstrichterliche Rechtsprechung bestand, sondern vielmehr eine bereits angelegte Rechtsprechungslinie lediglich fortgeführt wird. Unter dem Gesichtspunkt des Vertrauensschutzes ergeben sich dann keine Probleme. ${ }^{2004}$ Besteht lediglich Unsicherheit über den Inhalt der geltenden Rechtslage, ist dies für die Begründung von Vertrauen unzureichend. Geltend gemacht werden kann auch nicht, dass das Verhalten anderer Stellen als des zur Entscheidung berufenen Gerichts vertrauensbegründend gewirkt hätte. Ebenso wenig besteht etwa die Möglichkeit, eine gerichtliche Entscheidung „in einem gänzlich anders gelagerten Rechtsstreit" heranzuziehen. ${ }^{2005}$

Rechtsprechung muss vielmehr zwei Voraussetzungen erfüllen, um vom Bundesverfassungsgericht als vertrauensschutzrelevant anerkannt zu werden: Es muss sich erstens um eine Rechtsprechungsänderung handeln, die sich zweitens als Abweichung von einer ständigen höchstrichterlichen ${ }^{2006}$ Rechtsprechungslinie darstellt. Vertrauensschutz kommt also von vornherein nur ausnahmsweise in Betracht. ${ }^{2007} \mathrm{Ob}$ höchstrichterliche Rechtsprechung besteht, die derart gefestigt ist, dass sie als ständige Rechtsprechung

2004 BVerfG, Beschluss vom 8.12.2011, 1 BvR 2514/11 - BVerfGK 19, 254 (257). Dies gilt auch für die Rechtsprechung des EuGH, vgl. GA Wahl, Schlussanträge vom 22.6.2016 in der Rs. C-41/15 (Dowling u.a.), Rn. 76, wonach zwischen einer Klarstellung oder Nuancierung der Rechtsprechung und ihrer Änderung unterschieden werden muss.

2005 Siehe dazu BVerfG, Beschluss vom 25.4.2015, 1 BvR 2314/12, Rn. 18 - NJW 2015, 1867.

2006 Danach erlangt etwa Bedeutung, dass die Fachgerichte hinsichtlich der Auslegung und Anwendung „spezifischen Verfassungsrechts“ nicht höchste Instanz sind, wenn also z.B. die Bedeutung der Grundrechte im Privatrechtsverkehr in Rede steht. Ein Betroffener muss dann damit rechnen, dass beispielsweise eine vom BAG vorgenommene verfassungskonforme Auslegung vor dem Bundesverfassungsgericht keinen Bestand hat, vgl. BAG, Urteil vom 23.1.2019, 7 AZR 161/15, Rn. 34 f. - juris; BAG, Urteil vom 23.1.2019, 7 AZR 733/16, Rn. 46 f. NZA 2019, 700.

2007 Vgl. nur BVerfG, Beschluss vom 21.7.2010, 1 BvL 11/06, 1 BvL 12/06, 1 BvL 13/06, 1 BvR 2530/05 - BVerfGE 126, 369 (395): „Schutzwürdiges Vertrauen in eine bestimmte Rechtslage aufgrund höchstrichterlicher Rechtsprechung kann allenfalls bei gefestigter, langjähriger Rechtsprechung entstehen [...]." Siehe auch BVerfG, Beschluss vom 12.6.1986, 2 BvL 5/80, 2 BvL 17/82, 2 BvR 635/80 - BVerfGE 72, 302 (326); BVerfG, Beschluss vom 15.1.2009, 2 BvR 2044/07 - BVerfGE 122, 248 (277 f.); BVerfG, Beschluss vom 2.5.2012, 2 BvL 5/10 - BVerfGE 131, 20 (42); BVerfG, Beschluss vom 5.11.2015, 1 BvR 1667/15, Rn. 12 - DB 2015, 2927. Siehe zu dieser Fragestellung auch Koch, SR 2012, 159 (160 ff.). 
bezeichnet werden kann, wird dadurch beeinflusst, wie häufig oder selten eine Rechtsfrage bislang entschieden wurde und ob dagegen Widerstand bei den Instanzgerichten oder in der Literatur zu verzeichnen ist. ${ }^{2008}$

Das Bundesverfassungsgericht führt aus, dass die Änderung einer ständigen höchstrichterlichen Rechtsprechung unbedenklich sei, wenn sie hinreichend begründet sei und sich im Rahmen einer vorhersehbaren Entwicklung halte. ${ }^{2009}$ Vorhersehbarkeit und hinreichende Begründung sind nicht schon dann zu bejahen, wenn sich das Gericht nicht von sachfremden Erwägungen hat leiten lassen. Angesichts der Unterschiede im Maßstab ist daher die Auffassung unzutreffend, die Rechtsprechungsänderung werde generell nur einer Willkürkontrolle unterzogen. ${ }^{2010}$ So bedarf es zur Begründung der Vorhersehbarkeit einer Rechtsprechungsänderung etwa des Nachweises, dass bislang ein „nur schwer erträglicher Widerspruch“ zwischen verwaltungs- und arbeitsgerichtlicher Rechtsprechung bestand, sodass eine Rechtsprechungsänderung zur Beseitigung der unterschiedlichen Beurteilung der Rechtsfrage „früher oder später" zu erwarten war. ${ }^{2011}$

Auch wenn das Bundesverfassungsgericht einen anderen Eindruck erweckt, können die Kriterien der hinreichenden Begründung und der Vorhersehbarkeit nicht streng voneinander getrennt werden. So ist eine Rechtsprechungsänderung sowohl hinreichend begründet als auch vorhersehbar, wenn sie eine Gesetzesänderung erwidert oder auf eine Änderung der tatsächlichen Umstände reagiert. Erfolgt sie als Konsequenz besserer Rechtserkenntnis, kommt der Methodenlehre bei der Beurteilung der Wahrung der vom Bundesverfassungsgericht an Begründung und Vorhersehbarkeit gestellten Anforderungen entscheidende Bedeutung zu. ${ }^{2012}$

2008 Siehe Koch, SR 2012, 159 (161f.). Er spricht davon, ob die Rechtsprechung angesichts geäußerter Kritik als „krisenfest“ (Anführungszeichen im Original) bezeichnet werden kann.

2009 Siehe nur BVerfG, Beschluss vom 15.1.2009, 2 BvR 2044/07 - BVerfGE 122, 248 (277); BVerfG, Beschluss vom 25.4.2015, 1 BvR 2314/12, Rn. 13 - NJW 2015, 1867; BVerfG, Beschluss vom 26.6.1991, 1 BvR 779/85 - BVerfGE 84, 212 (227 f.).

2010 So aber Brocker, NJW 2012, 2996 (3000); siehe auch von Arnauld, Rechtssicherheit, 2006, S. 452, der auf Art. 3 I GG verweist.

2011 BVerfG, Beschluss vom 6.5.2008, 2 BvR 1926/07 - BVerfGK 13, 521 (527f.). In der Sache ging es um eine formularmäßig verwendete arbeitsvertragliche Nebenabrede, die vom einen Gerichtszweig für nichtig erklärt, vom anderen dagegen für wirksam erachtet wurde, sodass der Erfolg einer Klage davon abhing, vor welchem Gerichtszweig sie erhoben wurde.

2012 Siehe hierzu auch Rosenkranz, ZfPW 2016, 351 (363) unter Verweis auf Käbler, Rechtsprechungsänderung, 2. Aufl. 2011, S. 83 ff. 
Nicht auf den ersten Blick erschließt sich, ob das Bundesverfassungsgericht bei Vorliegen eines durch ständige höchstrichterliche Rechtsprechung begründeten Vertrauenstatbestandes von der Unzulässigkeit der Rechtsprechungsänderung selbst ausgeht oder die Änderung zwar vorgenommen werden kann, sie dann aber gegebenenfalls abzumildern ist.

Die Aussage des Bundesverfassungsgerichts, die Änderung einer ständigen höchstrichterlichen Rechtsprechung sei unbedenklich, wenn sie hinreichend begründet sei und sich im Rahmen einer vorhersehbaren Entwicklung halte, deutet bei erstem Hinsehen auf ein Verständnis, wonach eine Rechtsprechungsänderung aus Vertrauensschutzgründen unzulässig ist, wenn sie nicht hinreichend begründet ist oder sich nicht im Rahmen einer vorhersehbaren Entwicklung hält. Zudem spricht das Bundesverfassungsgericht von besonderen Voraussetzungen, unter denen eine Änderung der Rechtsprechung ausnahmsweise Vertrauensschutz nach Art. 20 III GG verletzen könne. ${ }^{2013}$ Auch dies lässt vermuten, dass die bisherige Rechtsprechung bei Vorliegen schutzwürdigen Vertrauens fortzuführen ist, die Frage nach der Zulässigkeit der Rechtsprechungsänderung, ihrem „Ob“, also zu verneinen ist. Eine solche Sichtweise hätte allerdings zur Folge, dass Rechtsprechung nur noch durch Gesetzgebung geändert werden könnte. ${ }^{2014}$

Nicht zuletzt angesichts dieser unerwünschten Konsequenz geht wohl auch das Bundesverfassungsgericht letztlich von der Änderbarkeit der Rechtsprechung aus, wie sich an der Aussage zeigt, dass bei Bestehen eines Vertrauenstatbestandes aufgrund gefestigter Rechtsprechung diesem erforderlichenfalls ${ }^{2015}$ durch Bestimmungen zur zeitlichen Anwendbarkeit ${ }^{2016}$

2013 BVerfG, Beschluss vom 25.4.2015, 1 BvR 2314/12, Rn. 15 - NJW 2015, 1867.

2014 Höpfner, RdA 2006, 156 (160); Piekenbrock, ZZP 119 (2006), 3 (15) erblickt in dieser Ansicht eine unzulässige Vermengung der zukunfts- und vergangenheitsbezogenen Funktion revisionsgerichtlicher Rechtsprechung.

2015 Spelge, FA 2011, 34 bezeichnet diese Formulierung als „durchaus wolkig“.

2016 Gemeint ist die zeitliche Anwendbarkeit der geänderten Rechtsprechung. In diesem Sinne auch BAG, Urteil vom 13.3.2013, 5 AZR 954/11, Rn. 24 - BAGE $144,306$. 
oder Billigkeitserwägungen im Einzelfall ${ }^{2017}$ Rechnung getragen werden könne. ${ }^{2018}$

Im Anschluss an dieses Postulat spricht das Bundesverfassungsgericht beispielsweise $\mathbb{} 17$ StGB und damit die Figur des unvermeidbaren Verbotsirrtums an, mit der das Vertrauen bei einer Rechtsprechungsänderung geschützt werden soll. ${ }^{2019}$ Demnach ist bei Vorliegen einer gefestigten Rechtsprechung im Tatzeitpunkt, die ein Verhalten als straflos einordnet, $\$ 17$ StGB anzuwenden, wenn zugleich eine Änderung dieser Rechtsprechung nicht absehbar war. Die Änderung der Rechtsprechung kann daher vorgenommen werden und ist durch Anwendung des $\$ 17$ StGB abzumildern. In dem in Bezug genommenen Fall prüfte das Bundesverfassungsgericht das Fehlen eines Vertrauenstatbestandes und das Vorliegen einer vorhersehbaren Entwicklung zusammen; es unterschied also nicht trennscharf zwischen beiden Kriterien. ${ }^{2020}$ Ihre Prüfung geht damit ineinander über.

Wenn das Bundesverfassungsgericht ausführt, dem Vertrauenstatbestand sei „erforderlichenfalls“ Rechnung zu tragen, ließe dies zwar auch die Möglichkeit offen, trotz Bestehens eines solchen die Rechtsprechungsänderung ohne zeitliche Begrenzung vorzunehmen. ${ }^{2021}$ Überzeugender erscheint es aber, bei Vorliegen eines Vertrauenstatbestandes die Gewährung von Vertrauensschutz als verfassungsrechtlich zwingend anzusehen. ${ }^{2022}$ Nur auf diese Weise werden unzumutbare Härten vermieden. ${ }^{2023}$

Zum Teil stellt das einfache Recht, wie etwa mit $\$ 17$ StGB oder $\$ 242$ BGB, Möglichkeiten zum Schutz des Vertrauens bei einer Rechtsprechungsänderung zur Verfügung. Finden sich dort dagegen in einem Fall

2017 Rieble, BB 2012, 2945 (2947) fasst darunter die nach einfachem Recht bestehenden Möglichkeiten der Berücksichtigung vertrauensschutzrelevanter Umstände und damit den einfachrechtlichen Vertrauensschutz. Gleichbedeutend ist eine Bezeichnung als sachrechtlicher Vertrauensschutz, vgl. Maultzsch, RabelsZ 79 (2015), 322 (348 f.).

2018 BVerfG, Beschluss vom 16.5.2011, 2 BvR 1230/10 - BVerfGK 18, 430 (434); BVerfG, Beschluss vom 5.11.2015, 1 BvR 1667/15, Rn. 12 - DB 2015, 2927; BVerfG, Beschluss vom 15.1.2009, 2 BvR 2044/07 - BVerfGE 122, 248 (277f.); BVerfG, Beschluss vom 26.6.1991, 1 BvR 779/85 - BVerfGE 84, 212 (227).

2019 BVerfG, Beschluss vom 16.5.2011, 2 BvR 1230/10 - BVerfGK 18, 430 (434).

2020 BVerfG, Beschluss vom 16.5.2011, 2 BvR 1230/10 - BVerfGK 18, 430 (434 f.).

2021 In diese Richtung wohl auch Koch, SR 2012, 159 (162): „kann oder sogar muss".

2022 Vgl. Spelge, FA 2011, 34. Siehe auch Payandeh, Judikative Rechtserzeugung, 2017, S. 179, 310, $330 \mathrm{ff}$.

2023 Spelge, FA 2011, 34. 
keine Anknüpfungspunkte für Vertrauensschutz, ist die Wirkung der geänderten Rechtsprechung für Altfälle gegebenenfalls auf andere Weise zu begrenzen. ${ }^{2024}$ Ansonsten hinge es von den im einfachen Recht vorhandenen Instrumenten $\mathrm{ab}$, ob Vertrauensschutz gewährt werden kann, obwohl es sich hierbei um eine Frage des Verfassungsrechts handelt. ${ }^{2025}$ Einfachrechtliche Instrumente können damit zwar vorrangig zum Tragen kommen; subsidiär muss ein Rückgriff auf verfassungsrechtlichen Vertrauensschutz aber immer möglich sein. ${ }^{2026}$

Demnach ist davon auszugehen, dass bei einer nicht hinreichend begründeten Rechtsprechungsänderung bzw. einer solchen, die sich nicht im Rahmen einer vorhersehbaren Entwicklung hält, diese zwar vorgenommen werden darf, allerdings nur mit zeitlicher Beschränkung. ${ }^{2027}$ Ist etwa durch bessere Rechtserkenntnis nach materiellem Recht klar, dass eine Rechtsfrage abweichend von der bisherigen Rechtsprechung zu beantworten ist, kann von einem Gericht kein Festhalten an ihr erwartet werden. Überzeugend ist es daher, die Rechtsprechungsänderung in dem Urteil bereits vorzunehmen, deren Wirkung für Altfälle aber einzuschränken. Die zeitliche Begrenzung ist zwingend, da bei einem Überwiegen des Vertrauensschutzes nur die Lösung „richtig“ ist, die auch Art. 20 III GG berücksichtigt. ${ }^{2028}$ Der erforderliche Interessenausgleich zwischen der Durchsetzung der nun als zutreffend erkannten Lösung und dem Vertrauensschutz

2024 Maultzsch, RabelsZ 79 (2015), 322 (350) spricht insoweit von einem eigenständigen intertemporalrechtlichen Rückwirkungsschutz. Gemeint ist damit das prospective overruling, bei dem, anders als bei einer Ankündigung der Rechtsprechungsänderung, selbige vollzogen wird, ihre Wirkung aber auf intertemporalrechtlicher Ebene für Altfälle eingeschränkt wird.

2025 In diesem Sinne auch Herdegen, WM 2009, 2202 (2204). Brocker, NJW 2012, 2996 (3000) versteht die wiedergegebene Aussage des Bundesverfassungsgerichts als Verweis auf die Möglichkeiten des einfachen Rechts, einer Rechtsprechungsänderung Rechnung zu tragen. Nur wenn dieses entsprechende Möglichkeiten eröffne, komme eine zeitliche Begrenzung der Rückwirkung in Betracht. Siehe auch Maurer, in: Isensee/Kirchhof (Hrsg.), HStR IV, 3. Aufl. 2006, $\mathbb{7} 79$, Rn. 153, der Vertrauensschutz gegen eine Rechtsprechungsänderung an sich ablehnt, sich aber für eine „vertrauensschutzorientierte Folgenbewältigung" durch einfachrechtliche Institute wie etwa $\$ 242$ BGB ausspricht.

2026 So auch Neuner, in: FS Canaris, 2017, S. 205 (215).

2027 Anders Rosenkranz, ZfPW 2016, 351 (363).

2028 Näher Langenbucher, JZ 2003, 1132 (1135). Siehe auch Pieroth/Hartmann, ZIP 2010, 753 (756), die zutreffend darauf hinweisen, dass einer Partei, die wegen schutzwürdigen Vertrauens des Gegners vor Gericht unterliegt, kein Unrecht geschieht, das Gericht vielmehr nach Recht und Gesetz entscheidet, wenn es verfassungsrechtlich schutzwürdiges Vertrauen schützt. 
der Gegenseite kann auch berücksichtigen, dass etwa im Falle nunmehr missbilligter AGB der Durchsetzung der materiellen Rechtslage großes Gewicht zukommt. 2029

\section{c) Zusammenfassung}

Bei einer Erstauslegung scheidet Vertrauensschutz nach Art. 20 III GG aus. Bei einer Rechtsprechungsänderung ist er auf Ausnahmefälle begrenzt, wobei dem Bestehen einer ständigen höchstrichterlichen Rechtsprechung entscheidende Bedeutung zukommt. ${ }^{2030}$ In einem solchen Fall kann die Rechtsprechungsänderung zwar vorgenommen werden; sie ist aber abzumildern. Diese Abmilderung durch Nichtanwendung auf Altfälle wirft aus unionsrechtlicher Perspektive Fragen auf, wenn das unionsrechtlich geforderte Ergebnis durch die Gewährung von Vertrauensschutz nicht erreicht wird. Einen solchen Vertrauensschutz hat etwa das BAG im Fall der die Massenentlassungsanzeige betreffenden Junk-Problematik gewährt. ${ }^{2031}$

Der Wunsch der Mitgliedstaaten nach Berücksichtigung nationaler Vertrauensumstände wie einer ständigen nationalen höchstrichterlichen Rechtsprechung liegt insbesondere darin begründet, dass eine Möglichkeit geschaffen werden soll, Faktoren zu berücksichtigen, für die sich der EuGH im Rahmen seiner Defrenne-Rechtsprechung nicht interessiert. ${ }^{2032}$ Sie besteht nur, wenn die nationalen Vertrauenstatbestände nicht „durch

2029 Langenbucher, JZ 2003, 1132 (1134 f., 1137). Einen anderen Akzent setzt Herdegen, WM 2009, 2202, der betont, dass die Inanspruchnahme von Privatautonomie bei nunmehr als unwirksam eingestuften AGB nicht mit einem Verzicht auf Vertrauensschutz gleichgesetzt werden dürfe. Zur Problematik der zeitlichen Begrenzung der Rückabwicklung aufgrund für unwirksam erklärter AGB vor dem Hintergrund der Klauselrichtlinie siehe unten bei Fn. $2264 \mathrm{ff}$.

2030 Payandeh, Judikative Rechtserzeugung, 2017, S. 334 f. spricht sich dagegen für eine noch stärkere Anerkennung von Vertrauen in den Bestand von Rechtsprechung aus, da sich die Rechtslage in aller Regel erst unter Einbeziehung der Rechtsprechung ergebe.

2031 Siehe etwa BAG, Urteil vom 23.3.2006, 2 AZR 343/05, Rn. 32 ff. - BAGE 117, 281. Das entsprechende Vorgehen des BAG im Urteil vom 1.2.2007, 2 AZR 15/06 - siehe dazu oben bei Fn. 1340 ff. - hat letztlich das Bundesverfassungsgericht beschäftigt, das dem BAG einen Entzug des gesetzlichen Richters zum Vorwurf macht. Auf diesen Beschluss des Bundesverfassungsgerichts ist zurückzukommen, siehe unten bei Fn. $2155 \mathrm{ff}$.

2032 Siehe auch Rosenkranz, ZfPW 2016, 351 (365). 
unionsrechtliche Vorgaben ,überlagert" werden“. ${ }^{2033}$ Diese sind im Folgenden daher näher zu entfalten.

3. Übertragung der Grundsätze des „nationalen Vertrauensschutzes“ auf die richtlinienkonforme Auslegung durch Fruchtbarmachung ihrer Grenzen?

In der Literatur bestehen zahlreiche Vorschläge für mögliche Anknüpfungspunkte, um die im nationalen Recht anerkannten und soeben herausgearbeiteten Grundsätze für den Schutz des Vertrauens gegen Rechtsprechung auch in Fällen der richtlinienkonformen Auslegung zur Anwendung zu bringen. In den Blick zu nehmen sind an dieser Stelle diejenigen Stimmen, denen die Grenzen richtlinienkonformer Auslegung als Anknüpfungspunkt dienen.

a) Keine Unterscheidung zwischen einfach- und verfassungsrechtlichem Vertrauensschutz

Zunächst ist klarzustellen, dass es aus unionsrechtlicher Sicht ohne Belang ist, auf welchem rechtstechnischen Weg nationale Vertrauensumstände Berücksichtigung finden sollen. Ob dies auf der Grundlage etwa des $\$ 313$ BGB, des Verschuldenserfordernisses eines Schadensersatzanspruchs, von Treu und Glauben oder durch direkte Berufung auf Art. 20 III GG geschehen soll, macht im Ergebnis keinen Unterschied. ${ }^{2034}$ Sämtliche Instrumente können sich der Erzielung eines unionsrechtlich „eigentlich“ gebotenen Ergebnisses entgegenstellen. Ihre unionsrechtliche Zulässigkeit kann damit einheitlich beurteilt werden. ${ }^{2035}$ Nicht entscheidend ist also, ob

2033 Ebers, Unionsprivatrecht, 2016, S. $414 \mathrm{f}$.

2034 Rosenkranz, ZESAR 2018, 24 (27) spricht insoweit unter Verweis auf Domröse, Jahrbuch Junger Zivilrechtswissenschaftler 2009, 109 (123ff.) von im Verhältnis zum verfassungsrechtlichen Vertrauensschutz „funktionsäquivalente[n] Instrumenten einer nationalen Rechtsordnung“. Er bezeichnet sie als „Institute eines materiell verstandenen Vertrauensschutzes“.

2035 So sieht Pfeiffer, NJW 2017, 913 (914) etwa auch die ergänzende Vertragsauslegung im Anschluss an EuGH, Urteil vom 21.12.2016, verb. Rs. C-154/15, C-307/15 und C-308/15 (Gutiérrez Naranjo u.a.) nur noch in gewissen Grenzen als zulässig an. 
Vertrauensschutz auf einfachrechtlicher oder verfassungsrechtlicher Ebene gewährt werden soll. ${ }^{2036}$

Für eine Gleichbehandlung spricht auch, dass die Grenzen richtlinienkonformer Auslegung, sollten sie eine Berücksichtigung nationaler Vertrauensumstände zulassen, ihr Einverständnis nicht zwangsläufig auf einfachrechtlichen Vertrauensschutz beschränken. ${ }^{2037}$ Auf nationaler Ebene wird zwar vorgebracht, dass die Ablehnung verfassungsrechtlichen Vertrauensschutzes hinnehmbar erscheint, wenn auf einfachrechtlicher Ebene mit den Mitteln des Zivilrechts - etwa mit Hilfe der ergänzenden Vertragsauslegung - noch ein angemessener Interessenausgleich hergestellt werden kann. ${ }^{2038}$ Eines solchen Ausweichens auf „sekundären Vertrauensschutz“ bedarf es aber nicht, wenn die Grenzen der richtlinienkonformen Auslegung auch verfassungsrechtlichen Einflüssen gegenüber offen sein sollten.

\section{b) Die Grenzen richtlinienkonformer Auslegung}

$\mathrm{Zu}$ untersuchen ist damit die Ausfüllung der in der Rechtsprechung des EuGH anerkannten Grenzen der richtlinienkonformen Auslegung durch Berücksichtigung nationaler Vertrauensumstände. Hierfür müssen sie sich als Bestandteil dieser Grenzen beschreiben lassen. Dieses Unterfangen wird dadurch erschwert, dass der Gerichtshof zwar festgestellt hat, dass „der Grundsatz der unionsrechtskonformen Auslegung des nationalen Rechts

2036 So aber Gundel, in: Liber Amicorum Berg, 2011, S. 54 (70, Fn. 80), der nur Letzteres für ausgeschlossen hält. Siehe auch Rieble, BB 2012, 2945 (2951), der angesichts der Solange II-Rechtsprechung des Bundesverfassungsgerichts meint, dass die nationale Grundrechtsgewährleistung verdrängt sei. Das gelte aber nur für die Gesetzesbindung (Art. 20 III GG) und nicht für den einfachrechtlichen Vertrauensschutz. Gegenüber auf nationales Verfassungsrecht gestütztem Vertrauensschutz skeptisch ebenfalls Kreft, RdA 2006, Sonderbeilage zu Heft 6, 38 (43 f.).

2037 Auch das BAG hat sich auf seine Bindung an Art. 20 III GG berufen und betont, die innerstaatlichen verfassungsrechtlichen Vorgaben entschieden über die Gewährung von Vertrauensschutz, siehe etwa BAG, Urteil vom 23.3.2010, 9 AZR 128/09, Rn. 98 f. - BAGE 134, 1. Zum Vorwurf des Bundesverfassungsgerichts, auf diesem Wege unzulässigerweise Verfassungsrecht gegen Unionsrecht ins Feld geführt zu haben, näher unten bei Fn. $2155 \mathrm{ff}$.

2038 Vgl. Uffmann, Verbot, 2010, S. 86, 88 zur ergänzenden Vertragsauslegung bei unwirksamen AGB. Mit ihr wird von der Rechtsprechung Vertrauensschutz gewährt bei bislang als wirksam angesehenen AGB, siehe z.B. BGH, Urteil vom 6.4.2016, VIII ZR 79/15, Rn. 18 ff. - BGHZ 209, 337. 
bestimmten Schranken [unterliegt]" und diese Feststellung insoweit konkretisiert hat, dass „die Verpflichtung des nationalen Richters, bei der Auslegung und Anwendung der einschlägigen Vorschriften des innerstaatlichen Rechts den Inhalt des Unionsrechts heranzuziehen, ihre Schranken in den allgemeinen Rechtsgrundsätzen [findet] und [...] nicht als Grundlage für eine Auslegung contra legem des nationalen Rechts dienen [darf] "2039, dies aber nicht darüber hinwegtäuschen kann, dass der EuGH die in dieser Passage erwähnten Schranken nur zum Teil mit Leben gefüllt hat. Immerhin können für die hier im Vordergrund stehende richtlinienkonforme Auslegung auch die Ausführungen des EuGH im Zusammenhang mit den Grenzen der rahmenbeschlusskonformen Auslegung herangezogen werden, da er diese Verbindung selbst herstellt. ${ }^{2040}$

Dass es sich auch bei der contra legem-Grenze um eine Begrenzung der Pflicht zur richtlinienkonformen Auslegung handelt, zeigt ein Vergleich der deutschen mit der englischen und französischen Sprachfassung der Urteile, in denen es heißt, dass die richtlinienkonforme Auslegung nicht als Grundlage für eine Auslegung contra legem dienen könne („cannot serve as the basis“ bzw. „ne peut pas servir de fondement“). Das Unionsrecht zwingt demnach nicht zur contra legem-Auslegung, verbietet sie aber auch nicht ${ }^{2041}$, auch wenn die deutsche Sprachfassung der zitierten Urteile

2039 EuGH, Urteil vom 4.10.2018, Rs. C-384/17 (Link Logistik N\&N), Rn. 59 (Kursivschrift im Original). Ebenso (mit zum Teil leicht abweichender Formulierung) EuGH, Urteil vom 13.7.2016, Rs. C-187/15 (Pöpperl), Rn. 44; EuGH, Urteil vom 7.8.2018, Rs. C-122/17 (Smith), Rn. 40; EuGH, Urteil vom 19.4.2016, Rs. C-441/14 (DI), Rn. 32; EuGH, Urteil vom 24.1.2012, Rs. C-282/10 (Dominguez), Rn. 25; EuGH, Urteil vom 15.1.2014, Rs. C-176/12 (Association de médiation sociale), Rn. 39; EuGH, Urteil vom 15.4.2008, Rs. C-268/06 (Impact), Rn. 100; EuGH, Urteil vom 28.7.2016, Rs. C-294/16 PPU (JZ), Rn. 33; siehe auch EuGH, Urteil vom 17.10.2018, Rs. C-167/17 (Klohn), Rn. 65; EuGH, Urteil vom 17.4.2018, Rs. C-414/16 (Egenberger), Rn. 71.

2040 So verweist er in EuGH, Urteil vom 4.7.2006, Rs. C-212/04 (Adeneler u.a.), Rn. 110 „im Wege der Analogie“ auf seine Ausführungen in EuGH, Urteil vom 16.6.2005, Rs. C-105/03 (Pupino), Rn. 44 und 47 zu den Grenzen der rahmenbeschlusskonformen Auslegung.

2041 Das BAG sieht in der contra legem-Grenze dagegen ein unionsrechtliches Verbot, das nationale Recht contra legem auszulegen. Damit konkretisiere der EuGH die verfassungsrechtlichen Prinzipien der richterlichen Gesetzesbindung und Gewaltenteilung, die es den nationalen Gerichten untersagten, an die Stelle des Gesetzgebers zu treten, BAG, Urteil vom 23.1.2019, 7 AZR 733/16, Rn. 34 - NZA 2019, 700. 
(„darf nicht“) in eine andere Richtung deutet. ${ }^{2042}$ Für das hier befürwortete Verständnis spricht auch, dass ebenfalls Urteile zu finden sind, die dieses Verständnis auch in der deutschen Sprachfassung zum Ausdruck bringen. ${ }^{2043}$ Noch deutlicher wird dies daran, dass der Gerichtshof seine Aussage dahingehend verstanden wissen will („mit anderen Worten“), dass die Verpflichtung zur konformen Auslegung dann nicht mehr besteht, wenn das nationale Recht nicht so angewandt werden kann, dass ein mit den unionsrechtlichen Vorgaben vereinbares Ergebnis erzielt wird. ${ }^{2044}$

Damit ist es dem nationalen Recht überlassen, darüber zu entscheiden, ob eine contra legem-Auslegung möglich sein soll oder nicht. ${ }^{2045}$ Nationale Gerichte dürfen damit gegebenenfalls "gegen das Gesetz“ auslegen; allerdings dürfen sie ihre nach nationalem Recht bestehenden Befugnisse nicht unter Berufung auf Unionsrecht erweitern. ${ }^{2046}$ Dahinter steht die Überlegung, dass es ausgeschlossen ist, dass der Grundsatz richtlinienkonformer Auslegung zu einer Auslegung contra legem des nationalen Rechts führt, wenn die Verpflichtung zu richtlinienkonformer Auslegung endet, da sich eine solche Auslegung dann jenseits dieses Grundsatzes bewegen würde. Dem Unionsrecht ist damit lediglich ein Verbot zu entnehmen, sich für eine contra legem-Auslegung auf Unionsrecht zu stützen. ${ }^{2047}$

Hinsichtlich der vom Gerichtshof formulierten Grenzen besteht weitgehend Einigkeit, dass es sich bei ihnen um zwei voneinander unabhängige

2042 Auf den Unterschied in den einzelnen Sprachfassungen weisen auch Roth/Jopen, in: Riesenhuber (Hrsg.), Europäische Methodenlehre, 3. Aufl. 2015, $\mathbb{1} 13$, Rn. 29 hin. Ebenso Kühling, JuS 2014, 481 (484 mit Fn. 37) und Ebers, Unionsprivatrecht, 2016, S. 411 mit Fn. 200. Siehe auch EuGH, Urteil vom 15.4.2008, Rs. C-268/06 (Impact), Rn. 103, wonach das nationale Gericht nicht zu einer contra legem-Auslegung gezwungen werden soll. Nach dem Äquivalenzgrundsatz besteht aber dann eine entsprechende Verpflichtung, wenn das nationale Recht diese erlaubt, vgl. Prechal, in: Barnard (Hrsg.), The Fundamentals of EU Law Revisited, 2007, S. 35 (50, Fn. 69).

2043 Siehe z.B. EuGH, Urteil vom 8.11.2016, Rs. C-554/14 (Ognyanov), Rn. 66 zur rahmenbeschlusskonformen Auslegung: „[...] kann der Grundsatz [...] nicht die Grundlage [...] bilden“.

2044 EuGH, Urteil vom 24.6.2019, Rs. C-573/17 (Popławski), Rn. 76 zur rahmenbeschlusskonformen Auslegung.

2045 In diesem Sinne Roth/Jopen, in: Riesenhuber (Hrsg.), Europäische Methodenlehre, 3. Aufl. 2015, $\mathbb{1} 13$, Rn. 29; siehe auch Gänswein, Unionsrechtskonforme Auslegung, 2009, S. 65.

2046 Rosenkranz, Beschränkung der Rückwirkung, 2015, S. 484.

2047 Siehe auch Manthey/Unseld, DÖV 2011, 921 (922 f.). 
Grenzen handelt ${ }^{2048}$, was aber nicht darüber hinwegtäuschen darf, dass zwischen ihnen eine enge Verbindung besteht. Für das Bestehen der Verpflichtung zu richtlinienkonformer Auslegung müssen beide Grenzen gewahrt sein. ${ }^{2049}$ Dieses Verständnis legt auch der Gerichtshof selbst zugrunde, wenn er im Anschluss an die Diskussion der einen Grenze fortfährt, dass die Verpflichtung „auch dann nicht mehr [besteht]“ („ceases, moreover“; „cesse également“), wenn die andere Grenze nicht gewahrt ist. ${ }^{2050}$

Die Einschätzung, dass bei der Grenze der allgemeinen Rechtsgrundsätze unionsrechtliche Maßstäbe anzulegen seien, während die contra legemGrenze auf nationale Zuständigkeitsgrenzen verweise ${ }^{2051}$, kann nur ein erster Anhaltspunkt sein. Eine scharfe Trennung zwischen unions- und nationalrechtlichen Grenzen wird nämlich dadurch erschwert, dass es sich bei der richtlinienkonformen Auslegung letztlich um ein „hybrid legal instrument" handelt, das Elemente des Unions- und nationalen Rechts miteinander verbindet. ${ }^{2052}$

c) Ausformung der Grenze der allgemeinen Rechtsgrundsätze in der Rechtsprechung des EuGH

Angesichts des stärkeren Bezugs zur Unionsebene stünde auf den ersten Blick zu erwarten, dass der Gerichtshof sich in seiner Rechtsprechung bereits deutlich zur Bedeutung der allgemeinen Rechtsgrundsätze als Grenze der Pflicht zu richtlinienkonformer Auslegung geäußert hätte. Die Grenze der allgemeinen Rechtsgrundsätze hat der Gerichtshof aber nur teilweise näher ausgeformt. Im Folgenden soll ein Überblick darüber gegeben werden, in welchen Konstellationen sie dort bislang Bedeutung erlangt hat.

2048 Rüffler, ÖJZ 1997, 121 (126); Weber, Grenzen, 2010, S. 141 ff., 180 ff.; Herrmann, Richtlinienumsetzung, 2003, S. 134 mit Fn. 300 m.w.N. aus der Literatur und dem Hinweis, eine entsprechende Unterscheidung werde allgemein durchgeführt.

2049 Düsterhaus, EuR 2017, 30 (47) spricht von kumulativen Voraussetzungen.

2050 EuGH, Urteil vom 8.11.2016, Rs. C-554/14 (Ognyanov), Rn. 66 zur rahmenbeschlusskonformen Auslegung.

2051 Michael/Payandeh, NJW 2015, 2392 (2395).

2052 Begriff bei Brenncke, Statute Law Review 39 (2018), 134 (152). 
aa) Strafrecht und umgekehrt vertikale Verhältnisse

Die Begrenzung der Pflicht zu richtlinienkonformer Auslegung durch allgemeine Rechtsgrundsätze wird regelmäßig als Besonderheit des Strafrechts eingeordnet. ${ }^{2053}$ Auch in diesem Bereich hat der Gerichtshof die Bedeutung des Grundsatzes der Rechtssicherheit aber dadurch begrenzt, dass er ihn nur auf das materielle Strafrecht bezieht - im Pupino-Urteil werden insoweit die Festlegung oder Verschärfung der strafrechtlichen Verantwortlichkeit der Betroffenen genannt - und nicht auf die Verfahrensregeln wie den Verfahrensablauf und die Modalitäten der Beweiserhebung. ${ }^{2054}$ Eine Auslegung, die sich nur auf die Richtlinie stützen kann und dazu führt, dass die strafrechtliche Verantwortlichkeit für den Einzelnen begründet oder verschärft wird, darf demnach nicht erfolgen. Einem nach ausschließlich nationaler Methodenlehre begründeten Auslegungsergebnis steht die Richtlinie dagegen nicht entgegen. ${ }^{2055}$

Auch in anderem Zusammenhang hat der Gerichtshof die allgemeinen Rechtsgrundsätze als Grenze der richtlinienkonformen Auslegung nunmehr fruchtbar gemacht, wie sich an Urteilen in zwei Rechtssachen zeigt, in denen es um die Frage der Befreiung von der Mehrwertsteuer, im Besonderen um die Auslegung von Art.132 I lit.f der Richtlinie über das gemeinsame Mehrwertsteuersystem, ging. ${ }^{2056}$ Der EuGH entschied dort, dass die in der Richtlinienbestimmung vorgesehene Befreiung von der Mehrwertsteuer auf bestimmte Dienstleistungen und damit auf $\mathrm{Zu}$ sammenschlüsse von Personen beschränkt ist, deren Mitglieder derartige

2053 GA Bot, Schlussanträge vom 25.11.2015 in der Rs. C-441/14 (DI), Rn.76f. unter Bezugnahme in Fn. 32 auf EuGH, Urteil vom 28.6.2012, Rs. C-7/11 (Caronna), Rn. 51 f.; GA Jacobs, Schlussanträge vom 16.3.2000 in der Rs. C-456/98 (Centrosteel), Rn. 34; Lenaerts/Corthaut, ELRev. 2006, 287 (295 f.); Prechal, CMLRev. 42 (2005), 1445 (1459f.).

2054 Das wird an EuGH, Urteil vom 16.6.2005, Rs. C-105/03 (Pupino), Rn. 45 f. zur rahmenbeschlusskonformen Auslegung deutlich. Siehe auch Simon, in: Mélanges Mengozzi, 2013, S. 279 (293).

2055 Ebenso Herrmann, Richtlinienumsetzung, 2003, S. 162. Gegen ein aus Unionsrecht abgeleitetes Ergebnisverbot angesichts eines aus ihrer Sicht sonst unzulässigen Eingriffs in die nationale Methodenlehre Weber, Grenzen, 2010, S. 141; Herresthal, Rechtsfortbildung, 2006, S. $304 \mathrm{f}$.

2056 Richtlinie 2006/112/EG des Rates vom 28. November 2006 über das gemeinsame Mehrwertsteuersystem, ABl. L 347 vom 11.12.2006, S. 1. 
Dienstleistungen erbringen. ${ }^{2057}$ In einem vorangegangenen Urteil ${ }^{2058}$ hatte der EuGH zwar noch nicht über die hier interessierende Beschränkung der Befreiung von der Mehrwertsteuer entschieden. Dennoch hatten mehrere Mitgliedstaaten die in jenem Urteil vorgenommene Auslegung zum Anlass einer Steuerbefreiung auch weiterer Zusammenschlüsse genommen, die, wie sich nun herausstellte, nicht unter die Befreiung fallen. Die Mitgliedstaaten hatten der Auslegung des Gerichtshofs damit irrtümlich einen Bedeutungsgehalt beigelegt, der ihr tatsächlich nicht zu entnehmen war.

Dass diese Mitgliedstaaten im Anschluss an die nun erfolgte Klärung durch den EuGH gewillt sein könnten, diesen weiteren Zusammenschlüssen und den von ihnen erbrachten Dienstleistungen die unionsrechtlich nicht geforderte Steuerbefreiung zu versagen und rückgängig zu machen, liegt auf der Hand. Endgültig abgeschlossene Besteuerungszeiträume kommen hierfür allerdings nicht in Frage; sie sind einer Wiedereröffnung entzogen. ${ }^{2059}$ Hinsichtlich der noch nicht abgeschlossenen Besteuerungszeiträume ist zu bedenken, dass eine unmittelbare Wirkung der Richtlinie gegenüber dem Einzelnen in dieser umgekehrt vertikalen Konstellation ausscheidet, sodass die nationalen Behörden sich nicht auf die Richtlinienbestimmung in der Auslegung durch den EuGH berufen können, um die Mehrwertsteuerbefreiung zu versagen. ${ }^{2060}$

Damit verbleibt nur die Möglichkeit, die richtlinienkonforme Auslegung der nationalen Umsetzungsbestimmungen in den Dienst des mitgliedstaatlichen Ansinnens zu stellen. Vor diesem Hintergrund erinnert

2057 EuGH, Urteil vom 21.9.2017, Rs. C-326/15 (DNB Banka), Rn. 37; EuGH, Urteil vom 21.9.2017, Rs. C-605/15 (Aviva), Rn. 32. Demnach betrifft die darin vorgesehene Befreiung nur die selbständigen Zusammenschlüsse von Personen, deren Mitglieder in diesem Artikel genannte dem Gemeinwohl dienende Tätigkeiten ausüben. Dienstleistungen von selbständigen Zusammenschlüssen von Personen, deren Mitglieder eine wirtschaftliche Tätigkeit im Versicherungswesen ausüben, die keine solche dem Gemeinwohl dienende Tätigkeit darstellt, fallen daher nicht unter diese Befreiung.

2058 EuGH, Urteil vom 20.11.2003, Rs. C-8/01 (Taksatorringen).

2059 In EuGH, Urteil vom 21.9.2017, Rs. C-605/15 (Aviva), Rn. 35 ist davon die Rede, dass diese nicht wiedereröffnet werden dürfen. In der englischen bzw. französischen Sprachfassung ist dagegen von „could not reopen [...] on the basis of" bzw. „ne sauraient rouvrir [...] sur le fondement“ die Rede. In der Parallelentscheidung EuGH, Urteil vom 21.9.2017, Rs. C-326/15 (DNB Banka), Rn. 40 ist auch in der deutschen Sprachfassung davon die Rede, dass diese nicht auf der Grundlage der Richtlinienbestimmung in der Auslegung durch den EuGH wiedereröffnet werden können.

2060 EuGH, Urteil vom 21.9.2017, Rs. C-326/15 (DNB Banka), Rn. 41; EuGH, Urteil vom 21.9.2017, Rs. C-605/15 (Aviva), Rn.36. 
der EuGH an die Grenzen der richtlinienkonformen Auslegung ${ }^{2061}$ und zieht daraus den Schluss, dass die Auslegung, die der nationale Richter dem nationalen Umsetzungsrecht zu geben hat, die allgemeinen Grundsätze des Unionsrechts und insbesondere den Grundsatz der Rechtssicherheit zu beachten habe. ${ }^{2062}$

Unabhängig von der genauen Einordnung in den Vorgang der richtlinienkonformen Rechtsfindung ${ }^{2063}$ läuft diese Aussage des EuGH darauf hinaus, eine Anwendung des richtlinienkonformen Verständnisses im Hinblick auf die in der Vergangenheit begonnenen, aber noch nicht abgeschlossenen Besteuerungszeiträume weitestgehend zu verhindern. Im Ergebnis kommen insoweit nämlich die im nationalen Recht vorgesehenen Steuerbefreiungen in ihrer aus Sicht des Unionsrechts zu weiten Auslegung zur Anwendung. ${ }^{2064}$

Auch außerhalb des Bereichs des Strafrechts hat der allgemeine Rechtsgrundsatz der Rechtssicherheit damit Bedeutung als Grenze der Verpflichtung zur Konformauslegung erlangt. Obwohl der Gerichtshof dazu keinen Anlass gegeben hatte, ermöglicht er den Betroffenen die Berufung auf eine durch nationale Stellen vorgenommene Auslegung des Unionsrechts und gestattet ihnen insoweit die Berufung auf nationale Vertrauensumstände. Die Betroffenen können sich also auf ein nationales Fehlverständnis der Richtlinienvorgaben stützen, um sich gegen das mitgliedstaatliche Rück-

2061 EuGH, Urteil vom 21.9.2017, Rs. C-326/15 (DNB Banka), Rn. 42; EuGH, Urteil vom 21.9.2017, Rs. C-605/15 (Aviva), Rn. 37.

2062 EuGH, Urteil vom 21.9.2017, Rs. C-326/15 (DNB Banka), Rn. 43. In diesem Sinne auch die englische und französische Sprachfassung der Urteile: „[...] the interpretation which the national court must give to the relevant rules of national law implementing Article 132(1)(f) of Directive 2006/112 must abide by the general principles of EU law [...]" / „[... l'interprétation que le juge national doit donner des règles pertinentes du droit national [...] doit respecter [...]“. EuGH, Urteil vom 21.9.2017, Rs. C-605/15 (Aviva), Rn. 38 spricht dagegen davon, dass „der nationale Richter bei der Auslegung der einschlägigen Vorschriften des innerstaatlichen Rechts [...] die allgemeinen Grundsätze des Unionsrechts, insbesondere den Grundsatz der Rechtssicherheit, zu beachten [hat]“" (Hervorhebung nur hier).

2063 Nimmt man die Aussage des EuGH wörtlich, kann der Grundsatz der Rechtssicherheit gegen die Auslegung an sich in Stellung gebracht werden. Nicht ausgeschlossen ist aber auch ein Verständnis, wonach das nationale Recht zwar (in den Grenzen des methodisch Möglichen) ex tunc im Sinne der Richtlinie auszulegen ist, dessen Anwendung im Sinne der unionsrechtlichen Vorgaben auf den Sachverhalt im konkreten Fall aber am Grundsatz der Rechtssicherheit scheitern kann. Siehe zu dieser Abgrenzung noch unten bei Fn. $2151 \mathrm{ff}$.

2064 Ebenso Ismer/Piotrowski, MwStR 2017, 834. 
abwicklungsbegehren zu wenden. Ihnen kommt damit letztlich „Vertrauensschutz aus der jeweiligen nationalen Gesetzgebung“2065 zugute. Fruchtbar zu machen ist diese Überlegung für sämtliche umgekehrt vertikale Verhältnisse, um dem Mitgliedstaat nicht die Möglichkeit zu eröffnen, sich trotz fehlender bzw. fehlerhafter Umsetzung auf die Richtlinie zu stützen. ${ }^{2066}$

bb) Vertrauensschutz und ,immediate applicability“

Im Rahmen der Untersuchung der Bedeutung der Grenze der allgemeinen Rechtsgrundsätze in der Rechtsprechung des Gerichtshofs ist auch die oben $^{2067}$ bereits erwähnte Rechtssache Klohn in den Blick zu nehmen, in der es der dem Rechtsstreit zugrundeliegenden Richtlinienvorschrift an unmittelbarer Wirkung fehlt. In der Sache ging es um einen Rechtsstreit zwischen Herrn Klohn und dem irischen Raumordnungsrat über die Auferlegung der Kosten des Gerichtsverfahrens, das Herr Klohn gegen die vom Raumordnungsrat erteilte Baugenehmigung für eine TierkörperUntersuchungseinrichtung angestrengt hatte. Seine Klage war abgewiesen worden; die dem Raumordnungsrat entstandenen Kosten waren ihm auferlegt worden. Den entsprechenden Gerichtsbeschluss hatte Herr Klohn nicht angefochten. In dem sich anschließenden Verfahren über die Höhe der zu erstattenden Kosten wandte Herr Klohn ein, dass die Richtlinie bestimmte, dass die Höhe der Kosten nicht „übermäßig teuer" sein dürfe. ${ }^{2068}$

Mit dem Instrument der richtlinienkonformen Auslegung haben die nationalen Gerichte durch Auslegung des nationalen Rechts das von den nicht umgesetzten Bestimmungen einer Richtlinie angestrebte Ergebnis „so weit wie möglich“ zu erreichen. Hierzu gehört auch die „immediate“/,immédiate“ (in der deutschen Fassung des Klohn-Urteils missverständlich mit „unmittelbare“ übersetzt) Anwendbarkeit einer neuen aus einer Richtlinie hervorgegangenen Vorschrift auf künftige Auswirkungen eines bestehenden Sachverhalts. Nationales Recht ist daher ab Ablauf der Umsetzungsfrist so auszulegen, dass die künftigen Auswirkungen eines

2065 Einen solchen erkennt Erdbrügger, UR 2018, 301 (304) als Folge der Ausführungen des Gerichtshofs.

2066 Herrmann, Richtlinienumsetzung, 2003, S. 163; Brechmann, Richtlinienkonforme Auslegung, 1994, S. 277 f.

2067 Siehe bei Fn. 1825 f.

2068 EuGH, Urteil vom 17.10.2018, Rs. C-167/17 (Klohn), Rn. 2, 16 ff. 
unter Geltung der alten Vorschrift entstandenen Sachverhalts sofort mit der Richtlinie vereinbar werden. Bei dem im vorliegenden Fall vor Ablauf der Umsetzungsfrist eingeleiteten Gerichtsverfahren handelt es sich um einen solchen Sachverhalt, der unter Geltung der alten Vorschrift entstanden ist, ebenso wie es sich bei der Kostenentscheidung bei Abschluss des Verfahrens um eine künftige ungewisse Auswirkung des laufenden Verfahrens handelt. Ein nationales Gericht muss daher bei seiner Kostenentscheidung im Hinblick auf ein Verfahren, das bei Ablauf der Umsetzungsfrist anhängig war, das nationale Recht im Einklang mit der in der Richtlinie enthaltenen Kostenregel auslegen. Ob die Kosten vor oder nach Ablauf der Umsetzungsfrist entstanden sind, ist insoweit unerheblich. Die Verpflichtung zu richtlinienkonformer Auslegung ist also auf die hier in Rede stehende Kostenentscheidung anwendbar. ${ }^{2069}$

Dieser Verpflichtung möchte der irische Raumordnungsrat den Grundsatz der Rechtssicherheit entgegenhalten. Die „immediate applicability“ der Richtlinie wirft damit die Frage der Aktivierung der der Pflicht zu richtlinienkonformer Auslegung gesetzten Grenze der Rechtssicherheit auf.

Der Gerichtshof verweist in Ausfüllung dieser Grenze auf das Erfordernis der Klarheit, Bestimmtheit und Vorhersehbarkeit der Auswirkungen einer Bestimmung. Zudem erwähnt er seine Rechtsprechung zum Vertrauensschutz und zum Wecken begründeter Erwartungen durch Zusicherungen der zuständigen Behörde. Im Hinblick auf den konkreten Fall verneint er aber, dass die Parteien des Ausgangsverfahrens eine Zusicherung erhalten haben, dass die ursprünglich geltende Kostenverteilungsregel bis zum Verfahrensende beibehalten werde. Diese hätten vielmehr von Beginn des Verfahrens an (24.6.2004) damit rechnen können, dass diese Vorschrift spätestens bis zum 25.6.2005 (dem Ablauf der Umsetzungsfrist) und damit wahrscheinlich vor Verfahrensende geändert werden müsse (,in Anbetracht der Verpflichtungen Irlands aus der am 25. Juni 2003 in Kraft getretenen Richtlinie 2003/35“). ${ }^{2070}$

Unter die Rechtssicherheit als Grenze der Pflicht zu richtlinienkonformer Auslegung fasst der Gerichtshof hier also unionsrechtliche Rechtsgrundsätze, deren Inhalt er nicht im Zusammenhang mit der richtlinienkonformen Auslegung entwickelt hat, der vielmehr aus seiner sonstigen Rechtsprechung bekannt ist. So finden wie gesehen der aus dem Verwaltungsrecht bekannte Vertrauensschutzgrundsatz und der objektiv-rechtlich

2069 EuGH, Urteil vom 17.10.2018, Rs. C-167/17 (Klohn), Rn. 44 ff.

2070 EuGH, Urteil vom 17.10.2018, Rs. C-167/17 (Klohn), Rn. 48 ff. 
geprägte Rechtssicherheitsgrundsatz Erwähnung. Dies ist insofern bemerkenswert, als Vertrauensschutz hier damit zum ersten Mal als Grenze der richtlinienkonformen Auslegung anerkannt wird. Auch wenn der Gerichtshof im Ergebnis Vertrauensschutz verneint hat, so zeigt das KlohnUrteil doch, dass der Vertrauensschutzgrundsatz als Grenze der richtlinienkonformen Auslegung grundsätzlich Bedeutung erlangen kann, da der Gerichtshof auf dessen Prüfung sonst von vornherein hätte verzichten können. ${ }^{2071}$

Dabei ist allerdings auf die Besonderheit der „immediate applicability“ hinzuweisen, d.h. der Anwendung der Richtlinie auf vor Ablauf der Umsetzungsfrist eingeleitete, aber noch nicht abgeschlossene Verfahren. Insoweit muss zu Beginn des Verfahrens nicht zwangsläufig mit einer Änderung des Rechtsrahmens gerechnet werden, wenn ein Abschluss des Verfahrens vor Ablauf der Umsetzungsfrist zu erwarten steht. Zudem ist es hier der betroffene Mitgliedstaat, der sich auf den Grundsatz der Rechtssicherheit berufen hat. Dieser muss aber damit rechnen, dass sich etwas ändert, wenn das nationale Recht nicht bereits als richtlinienkonform erachtet werden konnte und er untätig geblieben ist und die Richtlinie nicht umgesetzt hat.

„Insbesondere“ kann sich nämlich ein Mitgliedstaat einschließlich seiner Behörden nicht auf ein berechtigtes Vertrauen in die Beibehaltung einer Vorschrift berufen, die er angesichts seiner Pflicht zur Richtlinienumsetzung hätte ändern müssen. Dass der irische Raumordnungsrat als mitgliedstaatliche Behörde den Grundsatz der Rechtssicherheit der Verpflichtung zu richtlinienkonformer Auslegung nicht entgegenhalten kann, ist daher nur konsequent. ${ }^{2072}$ Vertrauensschutz zugunsten mitgliedstaatlicher Stellen kommt also bei einem Verstoß gegen die Umsetzungspflicht nicht in Betracht. $^{2073}$

2071 Haket, AB Rechtspraak Bestuursrecht 2019, 1517 (1519) spricht von einer impliziten Anerkennung.

2072 EuGH, Urteil vom 17.10.2018, Rs. C-167/17 (Klohn), Rn. 52. Den Verstoß des nationalen Rechts gegen die Richtlinie hatte der Gerichtshof bereits in einem Vertragsverletzungsverfahren im Jahr 2009 festgestellt.

2073 Höpfner, ZfA 2010, 449 (483). Zur Frage der Möglichkeit öffentlicher Arbeitgeber, unionsrechtlichen Vertrauensschutz geltend zu machen, siehe Picker, ZTR 2009, 230 (236); siehe auch GA Kokott, Schlussanträge vom 9.1.2008 in der Rs. C-268/06 (Impact), Rn. 141 f.; Bauer/Arnold, NJW 2009, 631 (634, Fn. 26); Sagan, Jahrbuch Junger Zivilrechtswissenschaftler 2010, 67 (72, Fn. 17). 
cc) Beachtung der Rechtskraft

Die Rechtssache Klohn ist im vorliegenden Zusammenhang noch aus einem anderen Grund anzusprechen, da sie sich als Folge der besonderen Ausgestaltung des irischen Verfahrensrechts durch einen weiteren Umstand auszeichnet. Nach irischem Verfahrensrecht erfolgt die Festsetzung der Höhe der Kosten eines Verfahrens in einem späteren Verfahren durch einen Kostenfestsetzungsbeamten, während die Auferlegung der Kosten an sich bereits im vorhergehenden Verfahren erfolgt. In dem der Rechtssache Klohn zugrundeliegenden Sachverhalt war der Beschluss, mit dem Herrn Klohn die Kosten der mitgliedstaatlichen Behörde auferlegt worden waren, mangels fristgemäßer Anfechtung rechtskräftig geworden. Ein Kostenfestsetzungsbeamter hatte zwei Jahre später dann in einer Entscheidung die Höhe der Kosten festgesetzt, die Herr Klohn wie gesehen in der Folge anfocht. Auch insoweit stellte sich die Frage der Begrenzung der Pflicht zu richtlinienkonformer Auslegung des nationalen Rechts, in diesem Fall vor dem Hintergrund des rechtskräftig gewordenen Beschlusses im vorangegangenen Verfahren.

Unter die allgemeinen Rechtsgrundsätze als Grenze der Pflicht zu richtlinienkonformer Auslegung fasst der Gerichtshof für die vorliegenden Zwecke den Grundsatz der Rechtskraft. Zudem betont er die contra legem-Grenze. Er weist darauf hin, dass der Gerichtshof im Vorabentscheidungsverfahren nicht dafür zuständig sei, zu beurteilen, „ob die oben genannten Beschränkungen einer mit einer unionsrechtlichen Norm vereinbaren Auslegung des innerstaatlichen Rechts entgegenstehen“. Das nationale Gericht müsse daher die Rechtskraft des Beschlusses beurteilen. Der Gerichtshof könne aber „Klarstellungen vornehmen“ und dem nationalen Gericht anzeigen, welche Auslegung des nationalen Rechts seiner Verpflichtung zur unionsrechtskonformen Auslegung genügen würde. ${ }^{2074}$ Diese Klarstellungen umfassen unter anderem den Hinweis darauf, dass es einen Verstoß gegen den Grundsatz der Rechtssicherheit und der Vorhersehbarkeit des Unionsrechts darstelle, wenn die irische Behörde sämtliche Kosten erstattet bekäme, da Herr Klohn bei seiner Entscheidung, ob er die Kostenentscheidung anficht, die Höhe der Kosten nicht absehen konnte. ${ }^{2075}$

2074 EuGH, Urteil vom 17.10.2018, Rs. C-167/17 (Klohn), Rn. 61 ff., insb. Rn. 66 und 68.

2075 Näher EuGH, Urteil vom 17.10.2018, Rs. C-167/17 (Klohn), Rn. 69 f.; GA Bobek, Schlussanträge vom 5.6.2018 in der Rs. C-167/17 (Klohn), Rn. 130. 
Der Gerichtshof überlässt also dem nationalen Gericht die Beurteilung des Eingreifens der Grenze der Rechtskraft, gibt ihm hierfür aber eine „Richtschnur“2076 an die Hand, an der sich dieses orientieren muss. Dies fügt sich in das Bild ein, wonach der Gerichtshof über die Anwendung des Grundsatzes der Rechtskraft nationaler Gerichtsentscheidungen als Ausfluss nationaler Verfahrensautonomie grundsätzlich nur eine eingeschränkte Kontrolle ausübt. ${ }^{2077} \mathrm{Da}$ es bei der Rechtskraft weniger um eine Grenze nur der Auslegbarkeit nationalen Rechts geht, sondern vielmehr um eine allgemeine Grenze der Durchsetzbarkeit des Unionsrechts ${ }^{2078}$, zeigt sich, dass insoweit keine Unterschiede in der „Durchsetzung“ des Unionsrechts bestehen.

\section{dd) Horizontalverhältnisse}

Im Hinblick auf Horizontalverhältnisse hat die Rechtsprechung des Gerichtshofs bislang kaum Klarheit geschaffen, was die Bedeutung der Grenzen der richtlinienkonformen Auslegung für die Berücksichtigung von „Vertrauensschutzerwägungen“ anbelangt. Da diese Frage im Folgenden im Vordergrund stehen wird, sei an dieser Stelle lediglich das Urteil des Gerichtshofs in der Rechtssache Pohotovost' erwähnt. Es lässt den engen Zusammenhang von allgemeinen Rechtsgrundsätzen und contra legem-Grenze erkennen, der im weiteren Verlauf der Arbeit noch näher zu untersuchende Abgrenzungsschwierigkeiten mit sich bringt.

In dem dieser Rechtssache zugrundeliegenden Ausgangsverfahren sah sich das vorlegende Gericht an einer richtlinienkonformen Auslegung des slowakischen Rechts im Hinblick auf einen Verbraucherkreditvertrag gehindert, der vor einer die Richtlinienwidrigkeit des nationalen Rechts beseitigenden Gesetzesänderung geschlossen worden war. Es begründete dies mit der contra legem-Grenze und dem Grundsatz der Rechtssicherheit. Dem im Verfahren vor dem Gerichtshof vorgebrachten Einwand, dass sich das vorlegende Gericht auf den nationalen Grundsatz der Rechtssicherheit berufen habe, für dessen Auslegung der Gerichtshof nicht zuständig sei,

2076 EuGH, Urteil vom 17.10.2018, Rs. C-167/17 (Klohn), Rn. 68. Den Begriff verwendet auch EuGH, Urteil vom 24.6.2019, Rs. C-573/17 (Popławski), Rn. 87.

2077 Siehe zur Behandlung der Rechtskraft nationaler Entscheidungen durch den Gerichtshof auch Sowery, CMLRev. 53 (2016), 1705 (1712 f.).

2078 Darauf weist Haket, AB Rechtspraak Bestuursrecht 2019, 1517 (1519) zu Recht hin. 
entgegnet dieser, dass die Vorlagefragen die Auslegung einer Richtlinie ${ }^{2079}$ und damit eines Unionsrechtsakts beträfen und es um Erläuterungen zum Urteil in der Rechtssache Home Credit Slovakia gehe. ${ }^{2080}$

Das zum Zeitpunkt des Vertragsschlusses am 1.10.2015 geltende nationale Recht muss das nationale Gericht, so der EuGH, „bestmöglich und ohne Rückgriff auf eine Auslegung contra legem im Einklang mit der Richtlinie 2008/48 in ihrer Auslegung im Urteil vom 9. November 2016, Home Credit Slovakia [...]" auslegen. ${ }^{2081}$ Unter Verweis auf seine Aussage im Urteil in der Rechtssache Mono Car Styling 2082 führt der Gerichtshof aus, dass die Pflicht zu unionsrechtskonformer Auslegung in den allgemeinen Rechtsgrundsätzen, insbesondere im Grundsatz der Rechtssicherheit, ihre Schranke finde, und zwar in dem Sinne, dass sie nicht als Grundlage für eine Auslegung contra legem des nationalen Rechts dienen dürfe. Dennoch müssten die nationalen Gerichte gegebenenfalls eine gefestigte nationale Rechtsprechung abändern, wenn sie auf einer nicht mit den Zielen der Richtlinie vereinbaren Auslegung beruhe. Die Ausführungen des Gerichtshofs zeigen, dass die Richtlinienvorschriften in ihrer Auslegung durch den Gerichtshof im Home Credit Slovakia-Urteil auf den vor Verkündung dieses Urteils und vor Änderung des nationalen Rechts geschlossenen Kreditvertrag anwendbar sind. ${ }^{2083}$

\section{d) Berücksichtigung nationaler Vertrauensumstände im Rahmen der contra legem-Grenze?}

In der Rechtsprechung des Gerichtshofs fehlt es im Hinblick auf die Bedeutung der Grenzen der richtlinienkonformen Auslegung für die Frage der Berücksichtigung nationaler Vertrauensumstände nach dem vorstehend Gesagten bislang weitgehend an einer Maßstabsbildung. Nachgewiesen werden konnten nur einzelne Aussagen zu ihrer Tragweite wie etwa

2079 Richtlinie 2008/48/EG des Europäischen Parlaments und des Rates vom 23. April 2008 über Verbraucherkreditverträge und zur Aufhebung der Richtlinie 87/102/EWG des Rates, ABl. L 133 vom 22.5.2008, S. 66 (und nachfolgende Berichtigungen).

2080 EuGH, Urteil vom 5.9.2019, Rs. C-331/18 (Pohotovost'), Rn. 30 f., 37 unter Verweis auf EuGH, Urteil vom 9.11.2016, Rs. C-42/15 (Home Credit Slovakia).

2081 EuGH, Urteil vom 5.9.2019, Rs. C-331/18 (Pohotovost'), Rn. 54 (Kursivschrift im Original).

2082 EuGH, Urteil vom 16.7.2009, Rs. C-12/08 (Mono Car Styling), Rn. 61.

2083 EuGH, Urteil vom 5.9.2019, Rs. C-331/18 (Pohotovost'), Rn. 56 f. 
im Strafrecht und umgekehrt vertikalen Konstellationen sowie hinsichtlich der Erscheinung der immediate applicability. Sollten sie sich darin erschöpfen, erschiene die Betonung dieser Grenzen in ständiger Rechtsprechung als kaum mehr als ein bloßes Lippenbekenntnis.

Angesichts der nur kargen Aussagen des Gerichtshofs insbesondere im Hinblick auf das Horizontalverhältnis ist im Folgenden der Frage nachzugehen, ob diese Grenzen in der Rechtsprechung zu Recht nur eine untergeordnete Rolle spielen. Zu diesem Zweck ist der Versuch zu unternehmen, nationale Vertrauensumstände als Ausfluss der contra legem-Grenze bzw. der allgemeinen Rechtsgrundsätze zu formulieren.

Unternimmt man einen solchen Versuch der Einordnung nationaler Vertrauensumstände, so scheint auf den ersten Blick die contra legemGrenze den Mitgliedstaaten größere Spielräume zu verschaffen. Wendet man sich ihr zu, fallen nämlich zunächst einmal die Ausführungen des Gerichtshofs in seinem Pupino-Urteil zur rahmenbeschlusskonformen Auslegung auf. Zunächst führte er dort aus, dass die Verpflichtung hierzu durch die allgemeinen Rechtsgrundsätze und insbesondere durch den Grundsatz der Rechtssicherheit und das Rückwirkungsverbot begrenzt werde, weshalb sie insbesondere nicht dazu führen dürfe, dass auf der Grundlage eines Rahmenbeschlusses unabhängig von einem zu seiner Durchführung erlassenen Gesetz die strafrechtliche Verantwortlichkeit derjenigen, die gegen die Vorschriften dieses Beschlusses verstoßen, festgelegt oder verschärft werde. ${ }^{2084} \mathrm{Da}$ die Grenze der allgemeinen Rechtsgrundsätze in diesem Fall aber nicht zum Tragen kam, forderte der EuGH das vorlegende Gericht auf, zu prüfen, ob das nationale Recht einer rahmenbeschlusskonformen Auslegung zugänglich ist. Die Verpflichtung ende, wenn dieses nicht so angewandt werden könne, dass ein rahmenbeschlusskonformes Ergebnis erzielt werde. „Mit anderen Worten“, so der EuGH, dürfe 2085 der Grundsatz konformer Auslegung nicht zu einer Auslegung contra legem des nationalen Rechts führen. ${ }^{2086}$ Die Bestimmung dessen, was als

2084 EuGH, Urteil vom 16.6.2005, Rs. C-105/03 (Pupino), Rn. 44 f. Der Gerichtshof verweist dabei auf seine im Rahmen der Verpflichtung zur richtlinienkonformen Auslegung gemachten Ausführungen in EuGH, Urteil vom 12.12.1996, verb. Rs. C-74/95 und C-129/95 (X), Rn. 24 und EuGH, Urteil vom 3.5.2005, verb. Rs. C-387/02, C-391/02 und C-403/02 (Berlusconi u.a.), Rn. 74.

2085 Nach dem oben bei Fn. 2041 ff. Gesagten wäre besser zu formulieren gewesen, dass der Grundsatz konformer Auslegung nicht als Grundlage für eine Auslegung contra legem des nationalen Rechts dienen kann, so auch Kühling, JuS 2014, 481 (484 mit Fn. 37).

2086 EuGH, Urteil vom 16.6.2005, Rs. C-105/03 (Pupino), Rn. 47 f. 
Auslegung contra legem anzusehen ist, richtet sich nach dieser Formulierung ausschließlich nach dem nationalen Recht, wie die Gleichsetzung („,mit anderen Worten“) der contra legem-Grenze mit der vom nationalen Gericht vorzunehmenden Prüfung, ob das nationale Recht in einem rahmenbeschlusskonformen Sinn angewandt werden kann, deutlich macht.

In der Rechtsprechung des EuGH lassen sich allerdings auch Aussagen nachweisen, in denen dieser ein Verständnis nahelegt, wonach auch die contra legem-Grenze keine national-autonom auszufüllende ist, da sie dem unionsrechtlichen Rechtssicherheitsgrundsatz zu entspringen scheint. ${ }^{2087}$ So hat er etwa im Urteil in der Rechtssache Mono Car Styling ausgeführt, dass die Pflicht zur unionsrechtskonformen Auslegung ihre Schranken in den allgemeinen Rechtsgrundsätzen, insbesondere im Grundsatz der Rechtssicherheit finde, „und zwar in dem Sinne“, dass eine contra legemAuslegung nicht gefordert sei. ${ }^{2088}$ In der Tat gewährleisten Gesetze Rechtssicherheit, sodass diese bei einer Auslegung "gegen das Gesetz" Einbußen erleidet. Die contra legem-Grenze stellt sich damit auch als Ausfluss des unionsrechtlichen Rechtssicherheitsgrundsatzes dar. ${ }^{2089}$ Sie „[entspricht] zweifellos dem Gebot der Rechtssicherheit sowie der Vorhersehbarkeit des Rechts". 2090

Würde die Grenze des contra legem-Judizierens allein der Ausfüllung durch die nationale Methodenlehre überlassen, würde einer letztlich auch unionsrechtlichen Grenze eine eigenständige Bedeutung versagt. Der Vorbehalt des nach nationalem Recht Möglichen, die Verpflichtung zur Auslegung des nationalen Rechts im Sinne der Richtlinie nur „so weit wie möglich“, bestand nämlich schon vor der ausdrücklichen Betonung der contra legem-Grenze. Würde dasselbe gemeint sein, hätte sie nur deklara-

2087 Siehe Prechal, Directives, 2. Aufl. 2005, S. 207.

2088 EuGH, Urteil vom 16.7.2009, Rs. C-12/08 (Mono Car Styling), Rn. 61. Die Urteilsfassung in französischer Sprache als Verfahrenssprache bedient sich ebenfalls der Formulierung „en ce sens“, während etwa die englische Sprachfassung die sonst übliche Formulierung wählt, so wie es auch der Verweis des Gerichtshofs auf seine eigene Rechtsprechung nahelegt. Eingeleitet mit einem „vgl. in diesem Sinne“ führt er EuGH, Urteil vom 8.10.1987, Rs. 80/86 (Kolpinghuis Nijmegen), Rn. 13, EuGH, Urteil vom 4.7.2006, Rs. C-212/04 (Adeneler u.a.), Rn. 110, EuGH, Urteil vom 15.4.2008, Rs. C-268/06 (Impact), Rn. 100 und EuGH, Urteil vom 23.4.2009, verb. Rs. C-378/07 bis C-380/07 (Angelidaki u.a.), Rn. 199 an.

2089 Siehe auch Prechal, in: Barnard (Hrsg.), The Fundamentals of EU Law Revisited, 2007, S. 35 (50 mit Fn. 69), wonach der Grundsatz der Rechtssicherheit erkläre, warum es keine Verpflichtung zur contra legem-Auslegung gebe.

2090 Vgl. EuGH, Urteil vom 1.10.2020, Rs. C-526/19 (Entoma), Rn. 43. 
torische Bedeutung. Als Ausprägung des unionsrechtlichen Grundsatzes der Rechtssicherheit muss sie damit eine eigenständige unionsrechtliche Bedeutung haben. ${ }^{2091}$

Dies bedeutet aber noch nicht, dass sich ihr Inhalt nach Unionsrecht richtet. So versteht etwa Höpfner die im Mono Car Styling-Urteil getroffene Aussage dahingehend, dass der Grundsatz der Rechtssicherheit Bestandteil des nach innerstaatlichem Recht methodisch Erlaubten sei und die (nationale) Rechtssicherheit damit letztlich der contra legem-Grenze zugeordnet werde. ${ }^{2092}$ Auch vom Bundesverfassungsgericht ist die Aussage des EuGH bereits in Bezug genommen worden, um im Anschluss an ihre Wiedergabe festzustellen, dass nur innerstaatliche Gerichte beurteilen könnten, ob und inwieweit das innerstaatliche Recht eine richtlinienkonforme Auslegung zulasse. ${ }^{2093}$ Trotz des vom EuGH hergestellten Ableitungszusammenhangs ist damit immer noch ein national geprägtes Verständnis der contra legem-Grenze möglich. ${ }^{2094}$

Aus der Anerkennung der contra legem-Grenze wird zum Teil gefolgert, dass ein nationales Gericht das Vertrauen in eine etablierte Rechtsprechung im Falle seiner Schutzwürdigkeit wahren müsse. ${ }^{2095} \mathrm{Da}$ sich nach dieser Auffassung eine verfassungskonforme Auslegung gegenüber der richtlinienkonformen durchsetzt ${ }^{2096}$, soll Vertrauensschutz nach Maßgabe des Grundgesetzes zu gewähren sein ${ }^{2097}$ und damit aus dem verfassungsrechtlichen Rechtsstaatsprinzip abzuleitender Vertrauensschutz gemäß Art. 20 III GG in Verbindung mit dem betroffenen Einzelgrundrecht. ${ }^{2098}$

2091 Grosche/Höft, NJOZ 2009, 2294 (2301 f.) sprechen von einer „,Doppelgesichtigkeit' der contra legem-Schranke“; die Reichweite sei aber kaum geklärt. Siehe auch Schürnbrand, JZ 2007, 910 (912).

2092 Höpfner, RdA 2013, 16 (27).

2093 BVerfG, Beschluss vom 26.9.2011, 2 BvR 2216/06, 2 BvR 469/07 - BVerfGK 19, 89 (100).

2094 So bezieht etwa Reimer, JZ 2015, 910 (915) den contra legem-Begriff auf „ein Überschreiten der nach mitgliedstaatlicher Methode bestehenden Konkretisierungsspielräume“.

2095 Schlachter, RdA 2009, Sonderbeilage zu Heft 5, 31 (36); siehe auch Kokott, RdA 2006, Sonderbeilage zu Heft 6, 30 (37).

2096 Wißmann, in: FS Bauer, 2010, S. 1161 (1166).

2097 Vgl. Bauer/Arnold, NJW 2009, 631 (633 f.).

2098 BAG, Urteil vom 22.3.2007, 6 AZR 499/05, Rn. 18 - NZA 2007, 1101; Koch, JbArbR 44 (2007), 91 (108); siehe auch Höpfner, in: Franzen/Gallner/Oetker (Hrsg.), Arbeitsrecht, 3. Aufl. 2020, Art. 288 AEUV, Rn. 52. 
Unter die contra legem-Grenze wird danach auch der materiell-rechtliche Inhalt der mitgliedstaatlichen Verfassungen gezählt. ${ }^{2099}$

Ins Feld geführt wird, dass nationale Vertrauensschutzgesichtspunkte zu den für die Anwendung von Gesetzen anerkannten und daher vom EuGH respektierten Auslegungsregeln zu rechnen seien ${ }^{2100}$, da Vertrauensschutz der richterlichen Rechtsanwendung Grenzen setze und die nationalen Methoden der Rechtsanwendung beeinflusse. ${ }^{2101}$ Durch die Begrenzung der im nationalen Recht bestehenden methodischen Möglichkeiten soll nationaler Vertrauensschutz also der richtlinienkonformen Rechtsgewinnung eine vom Unionsrecht anerkannte engere Grenze ziehen. ${ }^{2102}$ Auf eine rein nationale Betrachtung muss dies dennoch nicht hinauslaufen, da die Befürworter einer Verankerung nationaler Vertrauensumstände in der contra legem-Grenze in der Regel auch eine Einbeziehung des Unionsrechts in den Vertrauenstatbestand fordern, was zur Modifikation der nationalen Maßstäbe angesichts der Grundsätze von Äquivalenz und Effektivität führt. ${ }^{2103}$

Auch wenn seine Befürworter für die Gewährung von Vertrauensschutz das nationale Verfassungsrecht fruchtbar machen möchten, ist ihr Bemühen zu erkennen, sich mit der contra legem-Grenze auf eine vom Gerichtshof formulierte Grenze der richtlinienkonformen Auslegung zu stützen. Ein solchermaßen eingeforderter Vertrauensschutz ist daher insofern nicht „autonom“, als er sich auf eine unionsrechtliche Gestattung zu stützen sucht. Eine Einschränkung der Pflicht zur Konformauslegung aus ,autonomen" Erwägungen erschiene aus Sicht eines Mitgliedstaats in der Tat auch erst dann sinnvoll, wenn feststeht, dass die unionsrechtliche Pflicht die Grenzen des seiner Meinung nach Hinnehmbaren übersteigt. ${ }^{2104}$

Da die Berücksichtigung im Rahmen der Grenzen der richtlinienkonformen Auslegung erfolgen soll, erscheint es vorzugswürdig, nicht von

2099 Nach Auffassung etwa von Höpfner, Jahrbuch Junger Zivilrechtswissenschaftler 2009, 73 (89) gehört die verfassungskonforme Auslegung zum vom Unionsrecht respektierten nationalen Methodenkanon. Siehe in diesem Zusammenhang auch Canaris, in: FS Bydlinski, 2002, S. 47 (80, 96).

2100 Koch, JbArbR 44 (2007), 91 (106); siehe auch Koch, SR 2012, 159 (166); ihm folgend Wusterhausen, Wirkungen, 2016, S. $367 \mathrm{f}$.

2101 Höpfner, ZfA 2010, 449 (484).

2102 Herresthal, JuS 2014, 289 (294).

2103 Rosenkranz, ZfPW 2016, 351 (375); Riesenhuber, AP KSchG 1969 \$17 Nr.21; Schaer, Grenzen rückwirkender Rechtsprechung, 2010, S. 203; Herresthal, Rechtsfortbildung, 2006, S. $310 \mathrm{f}$.

2104 Ähnlich Sagan, Jahrbuch Junger Zivilrechtswissenschaftler 2010, 67 (83). 
„nationalem Vertrauensschutz“, sondern von der Berücksichtigung nationaler Vertrauensumstände zu sprechen. Ein solcher Ansatz kann sich von vornherein nicht zu der vom Gerichtshof im Melloni-Urteil getroffenen Aussage, wonach ein nationaler Prüfungsmaßstab unter bestimmten Voraussetzungen verdrängt wird, in Widerspruch setzen. Wenn „nationale Vertrauensumstände“ im Rahmen der vom Unionsrecht selbst vorgesehenen Schranken der richtlinienkonformen Auslegung Berücksichtigung finden können, ist dies unionsrechtlich unbedenklich, da eine Verdrängung dieser Schranken selbst nicht in Betracht kommt.

aa) Zuständigkeit für die Bestimmung der contra legem-Grenze

Soll die contra legem-Grenze den geeigneten Anknüpfungspunkt für die Berücksichtigung nationaler Vertrauensumstände bilden ${ }^{2105}$, ist auch der Begriff „contra legem“ („gegen das Gesetz“) näher in den Blick zu nehmen. Bereits im nationalen Recht bestehen unterschiedliche Vorstellungen, was hierunter zu verstehen ist.

Wenn gesagt wird, er bezeichne eine unzulässige Rechtsfortbildung ${ }^{2106}$, ist dagegen zwar nichts einzuwenden. Eine eindeutige Einordnung lässt dies aber nicht $\mathrm{zu}$, da es dann entscheidend darauf ankommt, welcher Theorie der Auslegung man folgt. So ist "lex“ bei einem subjektiven Verständnis die Regelungsentscheidung des Gesetzgebers, nach einem objektiven dagegen die geschriebene Norm. ${ }^{2107}$ Jedenfalls deutet der Begriff darauf hin, dass zwischen einer richtigen und falschen Auslegung der Vorschrift unterschieden werden kann. ${ }^{2108} \mathrm{Um}$ entscheiden zu können, was in diesem Sinne „richtig“ und was „falsch“ ist, muss letztlich klar sein, wer über dessen Verständnis bestimmen kann.

Insbesondere Generalanwalt Bot hat sich in seinen Schlussanträgen in der Rechtssache DI näher mit den den Mitgliedstaaten bei der Ausfüllung

2105 Hierfür Höpfner, RdA 2013, 16 (26f.); Rosenkranz, ZfPW 2016, 351 (374). A.A. Latzel, EuR 2015, 415 (428 f., 435 ff.); Sagan, NZA 2015, 341 (342).

2106 Kroll-Ludwigs/Ludwigs, ZJS 2009, 7 (13); Kroll-Ludwigs/Ludwigs, ZJS 2009, 123 (124).

2107 Baldauf, Richtlinienverstoß, 2013, S. 62 ff. Siehe auch Herresthal, Rechtsfortbildung, 2006, S. 290 zur Vielfalt an unterschiedlichen Begriffsverständnissen und Rüthers/Höpfner, JZ 2005, 21 zur unterschiedlich erfolgenden Abgrenzung zwischen Auslegung und Rechtsfortbildung, je nachdem, ob eine objektive oder subjektive Auslegungsmethode zugrunde gelegt wird.

2108 Ebenso Dubout, R.A.E. 2016, 287 (293 f.). 
der contra legem-Grenze gesetzten Grenzen beschäftigt. Er erkennt zwar an, dass die Auslegung des nationalen Rechts in die Zuständigkeit der nationalen Gerichte fällt und damit ebenfalls die Entscheidung darüber, ob eine richtlinienkonforme Auslegung des nationalen Rechts möglich ist. Zugleich möchte er aber einen unsachgemäßen Gebrauch der contra legem-Grenze durch die nationalen Gerichte verhindern und besteht daher darauf, dass es Aufgabe des Gerichtshofs sei, ihre Bedeutung klarzustellen, da er diese selbst gesetzt habe. ${ }^{2109}$ Auch in der Literatur wird eine solche Missbrauchskontrolle gefordert. ${ }^{2110}$

Im Hinblick auf die in der Rechtssache DI in Rede stehende Regelung des dänischen Rechts, die unter bestimmten Voraussetzungen ein Entfallen des Anspruchs auf Entlassungsabfindung vorsieht ${ }^{2111}$, lässt sich nach Ansicht des Generalanwalts aus den Ausführungen des Gerichtshofs im Ingeniørforeningen i Danmark-Urteil entnehmen, dass nicht der Wortlaut der Vorschrift, sondern vielmehr die Auslegung, die die ständige nationale Rechtsprechung ihr gegeben hat, die Unionsrechtswidrigkeit begründet. ${ }^{2112}$ Dies bringt ihn dazu, festzustellen, dass eine richtlinienkonforme Auslegung der dänischen Regelung im Einklang mit ihrem Wortlaut möglich sei. ${ }^{2113}$ Er meint, ein Rechtsprechungshindernis sei nicht vergleichbar mit einem sich aus dem Wortlaut einer nationalen Rechtsvorschrift ergebenden Hindernis, da Ersteres von einem nationalen Gericht im Rahmen seiner Zuständigkeiten beseitigt werden könne. ${ }^{2114}$

Dass das Højesteret die von ihm auszulegende Norm als eindeutig bezeichnet, deutet in der Tat darauf hin, dass sein Vorbringen, eine richtlinienkonforme Auslegung wäre nur contra legem möglich und sei daher abzulehnen, missbräuchlich erfolgt, da die Bedeutung der Norm gerade umstritten ist. ${ }^{2115}$

2109 GA Bot, Schlussanträge vom 25.11.2015 in der Rs. C-441/14 (DI), Rn. 52 f.

2110 Kainer, GPR 2016, 262 (266).

2111 Siehe dazu oben bei Fn. $1588 \mathrm{ff}$.

2112 GA Bot, Schlussanträge vom 25.11.2015 in der Rs. C-441/14 (DI), Rn. $31 \mathrm{f}$. unter Verweis auf EuGH, Urteil vom 12.10.2010, Rs. C-499/08 (Ingeniørforeningen i Danmark), Rn. 40 und $47 \mathrm{f}$.

2113 Vgl. GA Bot, Schlussanträge vom 25.11.2015 in der Rs. C-441/14 (DI), Rn. 66.

2114 GA Bot, Schlussanträge vom 25.11.2015 in der Rs. C-441/14 (DI), Rn. 72.

2115 So auch Baldus/Raff, GPR 2016, 71 (73). Dies erklärt im Übrigen auch, weshalb Generalanwalt Bot den vom Højesteret ins Spiel gebrachten Rechtssicherheitsund Vertrauensschutzerwägungen ablehnend gegenübersteht, so anschaulich Madsen/Olsen/Šadl, ELJ 23 (2017), 140 (144 mit Fn. 23). 
Die Einschätzung des Generalanwalts, die Unionsrechtswidrigkeit gehe nicht auf die Norm selbst, sondern auf die zu ihr ergangene Rechtsprechung zurück, ist dennoch problematisch. Wenn nationale Gerichte dazu berufen sind, das nationale Recht auszulegen, hat dieses die Bedeutung, die das nationale Gericht ihm beimisst. Dann ist aber eine Unterscheidung danach, ob die Unionsrechtswidrigkeit auf die Norm selbst oder die zu ihr ergangene Rechtsprechung zurückzuführen ist, nicht möglich. Kann zwischen Norm und auslegender Instanz nicht getrennt werden, sind Norm und Rechtsprechung gewissermaßen identisch. Beide führen damit zwangsläufig zum selben Ergebnis. ${ }^{2116}$ Das bedeutet dann aber auch, dass eine Auslegung des nationalen Rechts gegen die Auffassung der zur verbindlichen Auslegung berufenen Instanz contra legem wäre. Damit kann der EuGH über die Frage, was die nationale Norm und was die Rechtsprechung sagt, letztlich nicht entscheiden. ${ }^{2117}$

Das bedeutet aber nicht, dass eine Bestimmung der contra legem-Grenze ohne unionsrechtliche Einflüsse auskommt. So verlangt der Gerichtshof etwa, die Auslegung an Wortlaut und Zweck der Richtlinie ungeachtet entgegenstehender Auslegungshinweise, die sich aus den vorbereitenden Arbeiten zu der nationalen Regelung ergeben könnten, auszurichten. ${ }^{2118}$ Daneben haben die nationalen Gerichte bei der Auslegung eines Umsetzungsgesetzes davon auszugehen, dass sich der Mitgliedstaat bei der Umsetzung richtlinienkonform verhalten wollte. ${ }^{2119}$ Durch die Aufstellung dieser Vermutung ordnungsgemäßer Umsetzung ergeben sich im Rahmen der Auslegung Auswirkungen etwa auf die Bestimmung des klar erkennbaren gesetzgeberischen Willens. ${ }^{2120}$

Auch wenn er die Grenzen der nationalen Methodenlehre grundsätzlich anerkennt, verpflichtet der Gerichtshof die nationalen Gerichte damit zur Beachtung einer von ihm entwickelten eigenständigen unionsrechtlichen Auslegungsmethodik. ${ }^{2121}$ Demnach kann nicht behauptet werden, dass nur die nationale Rechtsprechung entscheiden kann, ob mit Hilfe der nationalen Methoden ein richtlinienkonformes Ergebnis erzielt werden

2116 Ebenso Dubout, R.A.E. 2016, 287 (293 f.).

2117 Baldus/Raff, GPR 2016, 71 (74).

$2118 \mathrm{EuGH}$, Urteil vom 29.4.2004, Rs. C-371/02 (Björnekulla Fruktindustrier), Rn. 13.

2119 EuGH, Urteil vom 5.10.2004, verb. Rs. C-397/01 bis C-403/01 (Pfeiffer u.a.), Rn. 112.

2120 Siehe dazu Brenncke, Statute Law Review 39 (2018), 134 (144 f.).

2121 Holdgaard/Elkan/Krohn Schaldemose, CMLRev. 55 (2018), 17 (32 ff.). 
kann. ${ }^{2122}$ Das ließe sich mit dem unionsrechtlichen Ursprung der Verpflichtung zu richtlinienkonformer Auslegung nicht vereinbaren.

Auszugehen ist danach davon, dass das Unionsrecht auch die Bestimmung der contra legem-Grenze beeinflusst. Was unter dieser zu verstehen ist, wird zwar grundsätzlich vom nationalen Recht bestimmt, allerdings nur innerhalb der durch die europäischen Methodenregeln gezogenen Grenzen, sodass die Mitgliedstaaten insoweit nicht völlig frei sind. ${ }^{2123}$

bb) Vertrauensschutz als Methodenregel?

Wie zu Beginn des Kapitels bereits gesehen, wird durch eine Zurechnung des Vertrauensschutzes zu den Auslegungsmethoden versucht, ein Einfallstor für die Berücksichtigung nationaler Vertrauensumstände zu begründen. ${ }^{2124} \mathrm{Da}$ die Ausgestaltung der Methoden Sache des nationalen Rechts ist, scheint sich ein solches Vorgehen in der Tat anzubieten. Dennoch bestehen hier unionsrechtliche Bedenken.

\section{(1) Keine Anerkennung im Impact-Urteil}

Zum Teil wird das Urteil des Gerichtshofs in der Rechtssache Impact herangezogen, um zu begründen, dass Vertrauensschutz schon bei der Prüfung, ob nach den nationalen Maßstäben noch eine richtlinienkonforme Auslegung möglich ist, zur Geltung gebracht werden könne ${ }^{2125}$, weswegen es unionsrechtlich nicht geboten sei, nationales Recht „,ontra legem und rückwirkend" auszulegen. ${ }^{2126}$ Der Gerichtshof habe hier gezeigt, dass er die contra legem-Grenze ernst nehme und Ausführungen zu den innerstaatlichen Grenzen und der Methodik grundsätzlich nicht hinterfrage. ${ }^{2127}$

2122 So aber Raff, Jahrbuch Junger Zivilrechtswissenschaftler 2016, 67 (86).

2123 Siehe auch Kainer, NZA 2018, 894 (895).

2124 Hierfür im Ergebnis etwa auch Riesenhuber, AP KSchG 1969 \$17 Nr. 21.

2125 Spelge, FA 2011, 34 (35 mit Fn. 11) unter Verweis auf EuGH, Urteil vom 15.4.2008, Rs. C-268/06 (Impact), Rn. $102 \mathrm{f}$.

2126 Michael, Der Staat 54 (2015), 349 (350, Fn. 7) unter Verweis auf EuGH, Urteil vom 15.4.2008, Rs. C-268/06 (Impact), Rn. 102-104.

2127 Michael/Payandeh, NJW 2015, 2392 (2396). Sie nehmen an, dass der Rechtssache Impact und BGH-Entscheidungen zum Versicherungsvertragsrecht eine „strukturell vergleichbare Rückwirkungsproblematik“ zugrunde liegt. 
Ausgangspunkt des Verfahrens war die Beschäftigung von Bediensteten bei irischen Ministerien auf der Grundlage von aufeinanderfolgenden befristeten Verträgen für Zeiträume, die vor dem 14.7.2003, dem Zeitpunkt des Inkrafttretens des die Richtlinie 1999/70/EG ${ }^{2128}$ umsetzenden Gesetzes, begonnen haben und über diesen Zeitpunkt hinaus fortdauern. Die in Rede stehenden Beschwerden der Bediensteten stützten sich für den Zeitraum vom 10.7.2001, dem Tag des Ablaufs der Umsetzungsfrist der Richtlinie, bis zum 14.7.2003 auf $\mathbb{S} 4$ und 5 der Rahmenvereinbarung, die im Anhang der Richtlinie enthalten ist, und für die Zeit nach dem 14.7.2003 auf das nationale Umsetzungsgesetz. Das nationale Umsetzungsgesetz hatte dem vorlegenden Gericht die Zuständigkeit für Klagen übertragen, die auf dieses Gesetz gestützt waren. Fraglich war dann, ob das Unionsrecht das Gericht dazu verpflichtet, seine Zuständigkeit auch für unmittelbar auf die Richtlinie gestützte Ansprüche zu bejahen, die sich auf den Zeitraum zwischen dem Ablauf der Umsetzungsfrist und dem Inkrafttreten des Umsetzungsgesetzes beziehen.

Der EuGH entschied im Hinblick auf diese erste Frage des vorlegenden Gerichts, dass es sich dann für die auf die Richtlinie gestützten Beschwerden für zuständig erklären muss, wenn bei einer Verpflichtung zur Erhebung einer Klage vor einem ordentlichen Gericht, die sich unmittelbar auf die Richtlinie stützt (und der damit einhergehenden Verpflichtung zur Aufteilung des Rechtsbehelfs in zwei unterschiedliche Klagen) Verfahrensnachteile für den Kläger entstünden, sodass ein Verstoß gegen den Effektivitätsgrundsatz vorläge. ${ }^{2129}$ Muss sich das Gericht nicht für zuständig erklären, bedeutet dies im Umkehrschluss, dass kein Verstoß gegen den Effektivitätsgrundsatz vorliegt, wenn der Kläger eine zweite Klage erheben muss; seine unionsrechtlichen Rechte für den gesamten Zeitraum wären gewahrt.

Von Interesse ist im vorliegenden Zusammenhang insbesondere die vierte Frage des vorlegenden Gerichts. Mit ihr wollte es in Erfahrung bringen, ob das nationale Umsetzungsgesetz dahin ausgelegt werden muss, dass es rückwirkend zum 10.7.2001 gilt. Der Gerichtshof beantwortete diese Frage für den Fall (,in Anbetracht der Antwort auf seine erste Fra-

Siehe zu diesen BGH-Entscheidungen unten bei Fn. 2202 ff., Fn. 2216 ff. und Fn. $2223 \mathrm{ff}$.

2128 Richtlinie 1999/70/EG des Rates vom 28. Juni 1993 zu der EGB-UNICECEEP-Rahmenvereinbarung über befristete Arbeitsverträge, ABl. L 175 vom 10.7.1999, S. 43.

2129 EuGH, Urteil vom 15.4.2008, Rs. C-268/06 (Impact), Rn. 55. 
ge $\left.^{(2130}\right)^{21}$, dass das vorlegende Gericht nicht verpflichtet sein sollte, sich für die Entscheidung über die unmittelbar auf die Richtlinie gestützten Ansprüche für zuständig zu erklären. Die Antwort des Gerichtshofs beruhte also auf der Annahme der Zuständigkeit des vorlegenden Gerichts nur für die auf den Verstoß gegen das nationale Gesetz gestützten Ansprüche, sodass die Zuständigkeit nicht für sämtliche im Ausgangsverfahren geltend gemachten Ansprüche bestand. Sie erging daher „nur für diesen Fall““. ${ }^{2131}$ Vorgelegt hatte das irische Gericht dem Gerichtshof diese vierte Frage, da eine im irischen Recht enthaltene Regel die rückwirkende Anwendung eines Gesetzes ausschließt, sofern keine klaren und eindeutigen gegenteiligen Anhaltspunkte vorliegen.

Da das Gericht, wie die Antwort des EuGH voraussetzt, nicht verpflichtet war, sich für die Entscheidung über die unmittelbar auf die Richtlinie gestützten Ansprüche für zuständig zu erklären, ist eine Bezugnahme auf die Richtlinie in der Zeit zwischen dem Ablauf der Umsetzungsfrist und dem Inkrafttreten des Umsetzungsgesetzes nur durch eine rückwirkende Anwendung des Umsetzungsgesetzes möglich, wenn eine Auslegung des sonstigen nationalen Rechts zur Erzielung richtlinienkonformer Ergebnisse ausscheidet.

Der Gerichtshof entschied, dass ein nationales Gericht, bei dem eine Klage wegen eines Verstoßes gegen eine Bestimmung des nationalen Gesetzes zur Umsetzung der Richtlinie 1999/70/EG anhängig ist, aufgrund des Unionsrechts nur dann verpflichtet ist, diese Bestimmung rückwirkend auf den Zeitpunkt des Ablaufs der Frist zur Umsetzung der Richtlinie anzuwenden, wenn es im betreffenden nationalen Recht Anhaltspunkte gibt, die es ermöglichen, dieser Bestimmung eine solche Rückwirkung zu verleihen. ${ }^{2132}$ Auch wenn die richtlinienkonforme Auslegung insbesondere auch für den Zeitraum zwischen dem Ablauf der Umsetzungsfrist und dem Inkrafttreten des Umsetzungsgesetzes gedacht ist ${ }^{2133}$, gelten auch insoweit die Grenzen richtlinienkonformer Auslegung. Demnach ist das nationale Gericht nicht zur rückwirkenden Anwendung des Umsetzungsgesetzes verpflichtet, wenn das nationale Recht dem entgegensteht. ${ }^{2134}$ Enthält dieses aber eine Regel, die dem nationalen Gericht die richtlini-

2130 EuGH, Urteil vom 15.4.2008, Rs. C-268/06 (Impact), Rn. 93; siehe auch Rn. 96.

2131 Dies stellte der Gerichtshof in einem späteren Urteil klar, EuGH, Urteil vom 22.12.2010, verb. Rs. C-444/09 und C-456/09 (Gavieiro Gavieiro und Iglesias Torres), Rn. $94 \mathrm{f}$.

2132 EuGH, Urteil vom 15.4.2008, Rs. C-268/06 (Impact), Tenor Nr. 4.

2133 EuGH, Urteil vom 4.7.2006, Rs. C-212/04 (Adeneler u.a.), Rn. 115 f.

2134 Hanau, EuZA 2009, 534 (543 f.). 
enkonforme Auslegung erlaubt, ist es hierzu verpflichtet. Nur wenn es im nationalen Recht überhaupt keine Regel gibt, die in der Lage ist, die Konformauslegung zu ermöglichen, greift die contra legem-Grenze. ${ }^{2135}$

Deutlich geworden ist damit, dass das Impact-Urteil keine Aussage zum Vertrauensschutz, sondern zur Beachtlichkeit einer Methodenregel trifft. Nur danach und nicht nach der Möglichkeit der Gewährung von Vertrauensschutz hatte das vorlegende irische Gericht gefragt. Dass sich der EuGH zur Möglichkeit der Gewährung von Vertrauensschutz nicht geäußert hat, verdeutlichen auch die in dieser Rechtssache vorgelegten Schlussanträge von Generalanwältin Kokott. Sie hatte nämlich ausgeführt, dass die allgemeinen Rechtsgrundsätze des Unionsrechts der rückwirkenden Auslegung des irischen Rechts nicht entgegenstünden, da es um ein vertikales Rechtsverhältnis zwischen einem Arbeitnehmer und einem Arbeitgeber des öffentlichen Sektors gehe. ${ }^{2136}$

(2) Verpflichtung zur Abänderung einer richtlinienwidrigen Rechtsprechung

Hat der EuGH nach dem vorstehend Gesagten eine Zurechnung des Vertrauensschutzes zu den Methodenregeln nicht vorgenommen, Vertrauensschutz also nicht als Methodenregel anerkannt, ist nach weiteren Hinweisen in der Rechtsprechung zu suchen, die eine Einordnung des Vertrauensschutzes ermöglichen.

Von besonderem Interesse ist im vorliegenden Zusammenhang die Feststellung des EuGH, dass das Erfordernis unionsrechtskonformer Auslegung die Verpflichtung der nationalen Gerichte umfasst, eine gefestigte Rechtsprechung gegebenenfalls abzuändern, wenn sie auf einer Auslegung des nationalen Rechts beruht, die mit den Zielen einer Richtlinie nicht vereinbar ist. Dadurch dass nach seiner Auffassung ständige unionsrechtswidrige Rechtsprechung der Möglichkeit unionsrechtskonformer Auslegung nicht entgegensteht ${ }^{2137}$, trifft der Gerichtshof eine Aussage über den rechtlichen Wert der bisherigen nationalen Rechtsprechung.

2135 Simon, in: Mélanges Mengozzi, 2013, S. 279 (295) unter Verweis auf EuGH, Urteil vom 15.4.2008, Rs. C-268/06 (Impact), Rn. 102 und 103.

2136 GA Kokott, Schlussanträge vom 9.1.2008 in der Rs. C-268/06 (Impact), Rn. 139.

2137 Siehe z.B. EuGH, Urteil vom 19.4.2016, Rs. C-441/14 (DI), Rn. 33 f. und EuGH, Urteil vom 17.4.2018, Rs. C-414/16 (Egenberger), Rn. 72 f. zur richtlinienkonformen Auslegung sowie EuGH, Urteil vom 24.6.2019, Rs. C-573/17 (Popławski), Rn. 78 f. zur rahmenbeschlusskonformen Auslegung. 
Zur Abstützung seiner Aussage verweist er im DI-Urteil auf sein Urteil in der Rechtssache Centrosteel, in dem er ausgeführt hatte, dass das mit dem Rechtsstreit befasste vorlegende Gericht „bei der Anwendung der Rechtsvorschriften oder - was im Ausgangsverfahren der Fall zu sein scheint - einer gefestigten nationalen Rechtsprechung diese so auszulegen [hat], daß sie im Einklang mit den Zielen der Richtlinie angewandt werden können“. ${ }^{2138}$ Die Corte suprema di Cassazione, auf die die gefestigte nationale Rechtsprechung zurückzuführen war, hatte diese aber aufgrund eines vorhergehenden EuGH-Urteils bereits geändert, sodass sie einem richtlinienkonformen Auslegungsergebnis nicht mehr im Wege stand. Der Verweis auf das Centrosteel-Urteil trägt die im DI-Urteil aufgestellte weitreichende Verpflichtung zur Abänderung einer richtlinienwidrigen Rechtsprechung daher eigentlich nicht. ${ }^{2139}$ Daran, dass der Gerichtshof sie aufgestellt hat, ändert dies aber natürlich nichts.

Auch wenn damit der Weg versperrt ist, eine Auslegung allein aus dem Grund als contra legem einzustufen, dass ihr eine ständige Rechtsprechung entgegensteht, ist damit keine Aussage zur Möglichkeit richtlinienkonformer Auslegung des nationalen Rechts getroffen. Die Behauptung, aus dem DI-Urteil des Gerichtshofs ergebe sich, dass die Vereinbarkeit bzw. Unvereinbarkeit der Auslegung mit dem Wortlaut des nationalen Rechts für die Frage des Bestehens der Verpflichtung zu richtlinienkonformer Auslegung entscheidend sei, findet im Urteil des EuGH daher keine Bestätigung, da sich dieser zur Auslegbarkeit des nationalen Rechts dort nicht äußert, sondern diese Frage vielmehr offenlässt. ${ }^{2140}$

Aus Sicht von Rechtssystemen mit Präjudizienbindung ist allerdings bereits die Aufforderung, eine ständige höchstrichterliche Rechtsprechung abzuändern, als contra legem zu bezeichnen. ${ }^{2141}$ Diese Überlegung hindert den EuGH jedoch auch nicht daran, eine Verpflichtung nationaler Gerichte aufzustellen, sich der Rechtsprechung eines übergeordneten Gerichts, an die sie sonst gebunden wären, zu entledigen. ${ }^{2142}$ Dass nationale Gerichte aufgefordert sind, ihre bisherige Rechtsprechung zu überdenken, ist zwangsläufige Folge der Verpflichtung zu richtlinienkonformer Ausle-

2138 EuGH, Urteil vom 13.7.2000, Rs. C-456/98 (Centrosteel), Rn. 17.

2139 Darauf weisen auch Holdgaard/Elkan/Krohn Schaldemose, CMLRev. 55 (2018), 17 (35 mit Fn. 74) hin.

2140 So aber Heuschmid, AuR 2016, 422 (424). Er zieht allerdings auch die Schlussanträge von GA Bot vom 25.11.2015 in der Rs. C-441/14 (DI) heran, denen der Gerichtshof insoweit nicht gefolgt ist.

2141 Darauf weist Kainer, GPR 2016, 262 (267) zu Recht hin.

2142 Siehe z.B. EuGH, Urteil vom 29.6.2017, Rs. C-579/15 (Popławski), Rn. 36. 
gung, weswegen für Rechtssysteme mit Präjudizienbindung keine Besonderheiten bestehen. ${ }^{2143}$ Die Verpflichtung zur Rechtsprechungsänderung und das Nichtbestehen einer Verpflichtung zu einer Auslegung contra legem sind zweierlei. ${ }^{2144}$

Dass eine höchstrichterliche Rechtsprechung der richtlinienkonformen Auslegung nicht entgegengehalten werden kann, lässt für die Frage der Berücksichtigung nationaler Vertrauensumstände aufhorchen, da insoweit ja gerade ein besonderes Interesse besteht, höchstrichterliche nationale Rechtsprechung ins Feld zu führen. Zwar sind damit im Zusammenhang mit ständiger Rechtsprechung stehende Rechtssicherheitserwägungen eine Berücksichtigung nationaler Rechtsprechung als nationaler Vertrauensumstand - nicht zwingend ausgeschlossen. ${ }^{2145}$ Denkbar ist es nämlich, in der Aussage des Gerichtshofs einen Verweis auf die Aufgabenverteilung zwischen Rechtsprechung und Gesetzgeber zu erblicken. ${ }^{2146}$ Eine entgegenstehende höchstrichterliche Rechtsprechung ist für die contra legemGrenze aber jedenfalls nicht relevant. ${ }^{2147}$

\section{(3) Zeitliche Dimension der Pflicht zu richtlinienkonformer Auslegung}

Gegen eine Formulierung des Vertrauensschutzes als Methodenregel spricht letztlich die zeitliche Dimension der Pflicht zu richtlinienkonformer Auslegung. Die Pflicht zu richtlinienkonformer Auslegung gilt mit Ablauf der Umsetzungsfrist ${ }^{2148}$, wohingegen für die Zeit vom Inkrafttreten der Richtlinie bis zum Ablauf der Umsetzungsfrist lediglich ein Frustrati-

2143 Holdgaard/Elkan/Krohn Schaldemose, CMLRev. 55 (2018), 17 (32 ff.).

2144 Vgl. Coutron, RTDEur. 2017, 389 (391).

2145 Haket, NtEr 2016, 237 (240).

2146 Rosenkranz, ZESAR 2018, 24 (26).

2147 Sagan, NZA 2015, 341 (342) sieht daher die Bindung der Gerichte an Recht und Gesetz als Grenze zum contra legem-Judizieren an.

2148 EuGH, Urteil vom 4.7.2006, Rs. C-212/04 (Adeneler u.a.), Rn. 115; EuGH, Urteil vom 27.6.2013, verb. Rs. C-457/11 bis C-460/11 (VG Wort u.a.), Rn. 26; GA Bobek, Schlussanträge vom 11.10.2016 in der Rs. C-439/16 PPU (Milev), Rn.40; siehe auch EuGH, Urteil vom 27.6.2000, verb. Rs. C-240/98 bis C-244/98 (Océano Grupo Editorial und Salvat Editores), Rn. 31. Zunächst hatte der EuGH zwar noch einen Beginn mit Inkrafttreten der Richtlinie im Sinn, vgl. EuGH, Urteil vom 8.10.1987, Rs. 80/86 (Kolpinghuis Nijmegen), Rn. 15, wo er betonte, dass die Grenzen der Konformauslegung bereits mit dem Inkrafttreten der Richtlinie greifen und damit nahelegte, dass dies dann auch für die Verpflichtung zur Konformauslegung selbst gelten muss. Hiervon 
onsverbot gilt ${ }^{2149}$, aus dem grundsätzlich keine Verpflichtung zur richtlinienkonformen Auslegung folgt, da die Zielerreichung nach Ablauf der Umsetzungsfrist durch eine richtlinienwidrige Einzelfallentscheidung nicht berührt wird. ${ }^{2150}$

Wie oben bereits ausgeführt, besteht auch hinsichtlich mittelbar wirkenden Unionsrechts ein Zusammenhang zwischen der Auslegung und Anwendung des Unionsrechts, der die nationalen Gerichte grundsätzlich dazu verpflichtet, das nationale Recht mit Wirkung auf den Ablauf der Umsetzungsfrist im Sinne der Richtlinie auszulegen. ${ }^{2151}$ Eine der Richtlinie widersprechende nationale Rechtsprechung ist dann ebenfalls grundsätzlich mit Wirkung auf diesen Zeitpunkt aufzugeben. ${ }^{2152}$ Ist also eine Begrenzung der zeitlichen Wirkungen durch den EuGH im Sinne der Defrenne-Rechtsprechung unterblieben, wirkt die Richtlinienbestimmung über die Pflicht zu richtlinienkonformer Auslegung seit Ablauf der Umsetzungsfrist auf das nationale Recht ein. ${ }^{2153}$

Hinsichtlich der ersten Stufe der reinen Auslegung besteht demnach ein Automatismus in dem Sinne, dass das nationale Recht (in den Grenzen des methodisch Möglichen) ex tunc in dem vom EuGH der Richtlinienbestimmung zuerkannten Sinn zu verstehen ist. Diese Überlegung würde durch eine Formulierung des Vertrauensschutzes als Methodenregel weitestgehend konterkariert. Eine Pflicht zur Anwendung des nationalen Rechts mit Wirkung ex tunc ist damit noch nicht begründet; insoweit besteht weiterhin die Möglichkeit, dass der Rechtsstreit nicht im Sinne der Richtlinie zu entscheiden ist. ${ }^{2154}$ Wenn aber das nationale Recht ex tunc im Sinne der Richtlinie zu verstehen ist, kann Vertrauensschutz nicht einfach als nationale Methodenregel formuliert werden, die bereits der Auslegung an sich entgegensteht.

Zutreffend ist daher der Hinweis des Bundesverfassungsgerichts darauf, dass die richtlinienkonforme Auslegung der $\$ \mathbb{S} 17 \mathrm{f}$. KSchG in dem

ist der EuGH in der Folgezeit aber abgerückt, worin Coutron, RTDEur. 2015, 39 (56) einen Rückschritt sieht.

2149 EuGH, Urteil vom 4.7.2006, Rs. C-212/04 (Adeneler u.a.), Rn. $121 \mathrm{ff}$.

2150 Maul-Sartori, in: Boecken/Düwell/Diller/Hanau (Hrsg.), Gesamtes Arbeitsrecht, 2016, Art. 153 AEUV, Rn. 61.

2151 Siehe bei Fn. 1316.

2152 Sagan, Jahrbuch Junger Zivilrechtswissenschaftler 2010, 67 (74).

2153 Vgl. Riesenhuber, AP KSchG 1969 \$ 17 Nr. 21.

2154 Ähnlich Latzel, EuR 2015, 415 (437ff.), allerdings unter weniger strenger Trennung der Ebenen. 
oben $^{2155}$ angesprochenen Fall des BAG nicht nur unionsrechtlich geboten, sondern auch methodisch möglich war. ${ }^{2156}$ Das BAG hatte im Rahmen der Junk-Problematik wie gesehen Vertrauen auf seine bisherige Rechtsprechung geschützt und deswegen die Erzielung eines richtlinienkonformen Ergebnisses unterlassen. Da ihm dies den Vorwurf eines Verstoßes gegen Art. 101 I 2 GG eingebracht hat ${ }^{2157}$, zögert es die richtlinienkonforme Auslegung nun zu Recht nicht mehr aus Vertrauensschutzerwägungen hinaus, wenn das nationale Recht im Sinne der Richtlinie auslegbar ist, auch wenn es bislang nicht im Einklang mit Unionsrecht ausgelegt worden war. ${ }^{2158}$

Von besonderem Interesse ist an dieser Stelle die Erwägung des Bundesverfassungsgerichts, dem BAG sei vorzuwerfen, dass es mit der Anwendung von Art. 20 III GG die praktische Wirksamkeit der Massenentlassungsrichtlinie in der Auslegung des Gerichtshofs beeinträchtigt und der unionsrechtlichen Verpflichtung, das nationale Recht richtlinienkonform auszulegen, nicht ausreichend Rechnung getragen habe. ${ }^{2159}$ Indem es deutlich gemacht hat, dass die verfassungsrechtlichen Grundsätze des Vertrauensschutzes bei Rechtsprechungsänderungen einer methodisch möglichen richtlinienkonformen Auslegung nicht entgegenstehen ${ }^{2160}$ und daher nicht als Bestandteil der nationalen Methodenlehre aufgefasst werden können $^{2161}$, hat das Bundesverfassungsgericht die zugrundeliegenden unionsrechtlichen Maßstäbe zutreffend erkannt.

Angesichts der engen Verbindung zwischen Unions- und nationalem Recht durch die Anforderungen der richtlinienkonformen Auslegung kann sich ihr eine ständige nationale höchstrichterliche Rechtsprechung

2155 Bei Fn. $1340 \mathrm{ff}$.

2156 BVerfG, Beschluss vom 10.12.2014, 2 BvR 1549/07, Rn. 34, 36 - NZA 2015, 375.

2157 BVerfG, Beschluss vom 10.12.2014, 2 BvR 1549/07, Rn. 14 - NZA 2015, 375. Einen Verfahrensverstoß des BAG ebenfalls bejahend Düsterhaus, EuR 2017, 30 (47); angesichts der Abstützung des Verstoßes gegen Art. 101 I 2 GG i.V.m. Art. 267 III AEUV auf die bislang nicht anerkannte Kategorie der „Verneinung einer Vorlagepflicht wegen Nichterkennens der Entscheidungserheblichkeit einer unionsrechtlichen Frage" kritisch Wißmann, in: FS Kohte, 2016, S. 993 (1002 ff.).

2158 BAG, Urteil vom 19.2.2019, 9 AZR 423/16, Rn.31, 34 - NZA 2019, 977; zustimmend Busch, jurisPR-ArbR 47/2019 Anm. 3 unter C.

2159 BVerfG, Beschluss vom 10.12.2014, 2 BvR 1549/07, Rn. 35 - NZA 2015, 375.

2160 Sagan, NZA 2015, 341 (342). Oetker, EWiR 2015, 193 (194) bezeichnet die Entscheidung des Bundesverfassungsgerichts als „spektakulär“ und angesichts dem BAG zustimmender Stimmen im Schrifttum „übertrieben hart“.

2161 Frantzen, Staatshaftung, 2018, S. 108 im Anschluss an BVerfG, Beschluss vom 10.12.2014, 2 BvR 1549/07 - NZA 2015, 375. 
nicht entgegenstellen ${ }^{2162}$, weswegen es auf mögliche Zeitpunkte, bis zu denen Vertrauen als schutzwürdig erscheint, nicht ankommt. ${ }^{2163}$ Diese Frage hatte in Rechtsprechung und Literatur zuvor Kontroversen ausgelöst. Insoweit waren sowohl der Zeitpunkt des Bekanntwerdens eines Vorabentscheidungsersuchens ${ }^{2164}$ als auch der Ablauf der Umsetzungsfrist einer Richtlinie ${ }^{2165}$ bzw. der Tag der Veröffentlichung der Richtlinie im Amtsblatt ${ }^{2166}$ sowie das Urteil des EuGH selbst ${ }^{2167}$ in Betracht gezogen worden.

Dass auch Entscheidungen des Bundesverfassungsgerichts $\mathrm{zu}$ finden sind, in denen dieses prüft, ob die mit der Verfassungsbeschwerde angegriffenen Entscheidungen des Fachgerichts die Beschwerdeführer dadurch „in Art. 2 I GG in Verbindung mit dem Rechtsstaatsprinzip“ verletzen, dass sie keinen Vertrauensschutz gewährt haben, passt zwar nicht in dieses Bild. ${ }^{2168} \mathrm{Da}$ es in den erwähnten Entscheidungen keinen verfassungsrechtlichen Verstoß erkannt hat und verfassungsrechtlichen Vertrauensschutz den unionsrechtlichen Anforderungen damit nicht entgegengehalten hat, bleibt diese Prüfung aber immerhin folgenlos.

2162 Näher Wißmann, in: FS Kohte, 2016, S. 993 (1000f.), der zutreffend darauf hinweist, dass das Bundesverfassungsgericht in der richtlinienkonformen Auslegung eine „starke Klammer“ zwischen Unions- und nationalem Recht sieht. Schubert, AuR 2015, 233 (234) erkennt zugleich eine Verletzung des Schutzanspruchs des Arbeitnehmers durch das BAG, der in der richtlinienkonformen Auslegung des $₫ 17 \mathrm{KSchG}$ auch in Altfällen bestehe.

2163 Deutlich BAG, Urteil vom 19.2.2019, 9 AZR 423/16, Rn. 35 - NZA 2019, 977.

2164 BAG, Urteil vom 24.3.2009, 9 AZR 983/07, Rn. 74, 76 - BAGE 130, 119. Bereits diesen Zeitpunkt sieht Benecke, RdA 2011, 241 (243) als „recht früh“ an; kritisch auch Gaul/Bonanni/Ludwig, DB 2009, 1013 (1013 f.).

2165 BAG, Urteil vom 23.3.2010, 9 AZR 128/09, Rn. 96, 101 - BAGE 134, 1; BAG, Urteil vom 4.5.2010, 9 AZR 183/09, Rn. 20 - BAGE 134, 196. Zustimmend Koch, SR 2012, 159 (167 f.); ablehnend Besgen, SAE 2010, 201 (203).

2166 Vgl. Höpfner, in: Franzen/Gallner/Oetker (Hrsg.), Arbeitsrecht, 3. Aufl. 2020, Art. 288 AEUV, Rn. 56.

2167 Sedlmeier, EuZA 2010, 88 (97 f.); Krieger/Arnold, NZA 2009, 530 (532); Picker, ZTR 2009, 230 (236); siehe auch Bauer/Arnold, NJW 2009, 631 (634). Zu weiteren Differenzierungsmöglichkeiten Höpfner, in: Franzen/Gallner/Oetker (Hrsg.), Arbeitsrecht, 3. Aufl. 2020, Art. 288 AEUV, Rn. 58.

2168 BVerfG, Beschluss vom 23.5.2016, 1 BvR 2230/15, 1 BvR 2231/15, Rn. 56 f. NJW-RR 2016, 1366. Auf diesen Beschluss weist auch Brams, Impulse, 2019, S. 277 f. hin. Siehe auch den Hinweis von Höpfner, in: Franzen/Gallner/Oetker (Hrsg.), Arbeitsrecht, 3. Aufl. 2020, Art. 288 AEUV, Rn. 54 auf BVerfG, Beschluss vom 26.9.2011, 2 BvR 2216/06, 2 BvR 469/07 - BVerfGK 19, 89 (100 ff., insb. $104 \mathrm{f}$.). 
Vertrauensschutzerwägungen sind nach alledem keine Grenze der Auslegung, sondern der Anwendung des ausgelegten Rechts. Die eigentliche Gesetzesauslegung bzw. -fortbildung einerseits und die Prüfung der Reichweite des Vertrauensgrundsatzes andererseits sind demnach voneinander zu trennen. ${ }^{2169}$ Zwischen Methodenregeln und vertrauensschutzbezogenen Aspekten ist zu unterscheiden. ${ }^{2170}$ Daran ändert nichts, dass aus nationaler Sicht nur eine solche Lösung eines Rechtsstreits „richtig“ ist, die eine zutreffende Auslegung zwar vornimmt, sie im konkreten Fall bei Vorliegen schutzwürdigen Vertrauens aber nicht durchsetzt, sodass Vertrauensschutzerwägungen in die Frage einbezogen werden, wann eine materiell richtige Entscheidung vorliegt.

Als ausschließlich nationale Angelegenheit kann die Berücksichtigung nationaler Vertrauensumstände damit nicht angesehen werden. ${ }^{2171}$ Jedenfalls ist ein Zusammenhang zu verneinen, der daraus, dass die auszulegende Vorschrift eine solche des nationalen Rechts ist, ableiten wollte, dass sich dann auch der Vertrauensschutz nach nationalem Recht richtet. Die Besonderheit liegt ja gerade darin, dass die Auslegung richtlinienkonform zu erfolgen hat. ${ }^{2172}$ Die Frage nach der zeitlichen Reichweite der Pflicht zu richtlinienkonformer Auslegung ist eine solche des Unionsrechts, sodass der EuGH über Vertrauensschutz in richtlinienwidrige höchstrichterliche Rechtsprechung zu entscheiden hat. ${ }^{2173}$

Dass das Unionsrecht es hinnimmt, dass eine richtlinienkonforme Auslegung ausscheidet, setzt nach alledem voraus, dass der ihr entgegenstehende Aspekt Teil des Auslegungsvorgangs ist. Dagegen verhindert das Unionsrecht, dass ein methodisch mögliches richtlinienkonformes Auslegungsergebnis im Anschluss an den Auslegungsvorgang durch Vertrauensschutzüberlegungen nicht zum Tragen kommt. Eine Ergebniskorrektur gestattet das Unionsrecht also nicht.

2169 So auch Rüthers/Höpfner, JZ 2005, 21 (24f.) im Zusammenhang mit ihrem Stufenmodell der Gesetzesanwendung, auf der Grundlage der subjektiven Auslegungsmethode und ihres Spannungsverhältnisses zum Analogieverbot zu Lasten des Täters nach Art. 103 II GG.

2170 Vgl. Rosenkranz, ZESAR 2018, 24 (26) zum deutschen Recht.

2171 So aber noch Lunk, in: FS Reuter, 2010, S. 689 (699); Franzen, RIW 2010, 577 (579); Picker, ZTR 2009, 230 (235); Weber, Grenzen, 2010, S. 181 meint, nationaler Vertrauensschutz sei von demjenigen nach Unionsrecht zu unterscheiden.

2172 Sagan, Jahrbuch Junger Zivilrechtswissenschaftler 2010, 67 (82).

2173 Oetker, EWiR 2015, 193 (194). 
Ein Beispiel für eine vom Unionsrecht anerkannte Methodenregel erblickt Generalanwältin Kokott etwa im verfassungsrechtlichen in dubio mitius-Grundsatz des tschechischen Rechts. Ihm zufolge ist eine steuerrechtliche Vorschrift immer zu Gunsten des Steuerpflichtigen auszulegen, wenn es objektiv mehrere Auslegungsvarianten gibt. Seine Anwendung kann dazu führen, dass zwar ein für den Steuerpflichtigen günstiges und verfassungsrechtlich gefordertes Auslegungsergebnis erzielt wird, das aber nicht richtlinienkonform ist. Mit der Erwägung, dass er die Möglichkeiten der Auslegung auf eine mögliche Auslegung verenge und daher eine Grenze der Konformauslegung darstelle, spricht die Generalanwältin dem in dubio mitius-Grundsatz eine Wirkung zu, wie sie auch anderen Methodenregeln des nationalen Rechts zukommt. Danach könnte er sich der richtlinienkonformen Auslegung entgegenstellen. ${ }^{2174}$

Der Gerichtshof ist diesem Ansatz allerdings nicht gefolgt und verwehrt den nationalen Gerichten, sich auf den in dubio mitius-Grundsatz zu stützen. ${ }^{2175}$ Er ordnet die Anwendung des in dubio mitius-Grundsatzes als Versuch ein, die zeitlichen Wirkungen der vom Gerichtshof vorgenommenen Auslegung des Unionsrechts zu begrenzen ${ }^{2176}$, womit er dieselbe Erwägung wie bereits in seinem DI-Urteil und im Hein-Urteil zum Tragen bringt. $^{2177}$ Aus unionsrechtlicher Perspektive scheiterte eine zeitliche Begrenzung der Wirkung der Auslegung im Sinne der Defrenne-Rechtsprechung an Präklusion. ${ }^{2178}$

Der Ansatz des Gerichtshofs ist insofern nachvollziehbar, als die Anwendung des in dubio mitius-Grundsatzes voraussetzt, dass eine Bestimmung des nationalen Rechts unterschiedlich ausgelegt werden kann. ${ }^{2179}$ Aus der Sicht der Steuerpflichtigen verengt der in dubio mitius-Grundsatz zwar die Möglichkeiten der Auslegung des nationalen Rechts auf eine mögliche

2174 GA Kokott, Schlussanträge vom 3.10.2019 in der Rs. C-401/18 (Herst), Rn.4, 70, 72. Sie zieht einen Vergleich zur Wortlautgrenze.

2175 EuGH, Urteil vom 23.4.2020, Rs. C-401/18 (Herst), Rn. 60.

2176 EuGH, Urteil vom 23.4.2020, Rs. C-401/18 (Herst), Rn. 55.

2177 EuGH, Urteil vom 19.4.2016, Rs. C-441/14 (DI), Rn.39; EuGH, Urteil vom 13.12.2018, Rs. C-385/17 (Hein), Rn. 61. Zum letztgenannten Urteil sogleich näher bei Fn. $2237 \mathrm{ff}$.

2178 EuGH, Urteil vom 23.4.2020, Rs. C-401/18 (Herst), Rn. 56 ff. unter Verweis in Rn. 57 auf EuGH, Urteil vom 6.3.2007, Rs. C-292/04 (Meilicke u.a.), Rn. 37 und EuGH, Urteil vom 23.10.2012, verb. Rs. C-581/10 und C-629/10 (Nelson u.a.), Rn. 91 sowie unter Verweis in Rn. 58 auf die fehlende Begrenzung der zeitlichen Wirkung der Folgen der Auslegung der Mehrwertsteuerrichtlinie in EuGH, Urteil vom 19.12.2018, Rs. C-414/17 (AREX CZ).

2179 Darauf weist Nieskens, UR 2020, 392 (394) zu Recht hin. 
Auslegung. Aus der für den Gerichtshof maßgeblichen Perspektive ist das nach dem in dubio mitius-Grundsatz erzielte Auslegungsergebnis aber nur ein denkbares Ergebnis unter mehreren möglichen Ergebnissen. Die unter Ausblendung des in dubio mitius-Grundsatzes feststellbare Auslegungsoffenheit des tschechischen Rechts zeigt, dass die Erzielung eines richtlinienkonformen Ergebnisses methodisch möglich ist.

Letztlich nimmt der Gerichtshof damit für sich in Anspruch, über die Einordnung eines Aspekts als Teil des Auslegungsvorgangs oder als Instrument der Ergebniskorrektur entscheiden zu können. Generalanwältin Kokott hatte den Mitgliedstaaten hier durch ihren Vergleich des in dubio mitius-Grundsatzes mit der Wortlautgrenze größeren Freiraum gewährt. An dieser Stelle taucht damit die Frage nach der näheren Bestimmung des Begriffs des contra legem-Judizierens wieder auf, derer sich der Gerichtshof zu Lasten der Mitgliedstaaten bemächtigt. Insoweit ist seitens des Gerichtshofs darauf zu achten, dass sich sein Bekenntnis zur contra legem-Grenze nicht in seiner formelhaften Wiederholung erschöpft.

\section{cc) Vertrauensschutz als Reflex der contra legem-Grenze}

Auch wenn Vertrauensschutz nicht als Methodenregel formuliert werden kann, ist die Anerkennung nationaler Methodenregeln durch den EuGH für die Frage des Vertrauensschutzes nicht ohne Bedeutung. Sie führt da$\mathrm{zu}$, dass die Betroffenen darauf vertrauen dürfen, dass eine richtlinienkonforme Auslegung nur unter Wahrung der Methodengrenzen vorgenommen wird, worin sich der vertrauensschutzrelevante Aspekt der contra legem-Grenze zeigt. Die mitgliedstaatlichen Gerichte sind eben nur „so weit wie möglich“ zur Erzielung richtlinienkonformer Ergebnisse verpflichtet. „Nationaler Vertrauensschutz“ stellt sich insoweit als Schutz des Vertrauens in die Grenzen der richtlinienkonformen Auslegung dar. ${ }^{2180} \mathrm{Er}$ ist sozusagen Reflex der Begrenzung auf das methodisch Mögliche.

Sehr umstritten ist allerdings, wie weitreichend der hierdurch gewährte Schutz ist, da zur Wirkungsweise der richtlinienkonformen Auslegung naturgemäß unterschiedliche Ansichten bestehen. ${ }^{2181}$ Ein Blick auf diese

2180 Schmitt, GPR 2019, 249 (251); Rosenkranz, ZESAR 2018, 24 (26); siehe auch Gallner, in: FS Etzel, 2011, S. 155 (170).

2181 Eine ausführliche Darstellung der hier nur überblicksartig vorgestellten Möglichkeiten bietet etwa Baldauf, Richtlinienverstoß, 2013, insb. S. $106 \mathrm{f} ., 116 \mathrm{ff}$., $156 \mathrm{ff}$. Sie selbst spricht sich für eine Anwendung der Methode des Ergebnis- 
Wirkungsweise ist erforderlich, um Entscheidungen aus der Rechtsprechung des BGH untersuchen zu können, in denen sich unter anderem die Frage stellte, ob jedenfalls Vertrauen auf den Bestand einer nationalen Norm geschützt ist, die dann nicht teleologisch auf Null reduziert werden dürfte. Angesprochen ist damit insbesondere auch die richtlinienkonforme Rechtsfortbildung, in deren Rahmen zum Teil eine weitergehende Berücksichtigung nationaler Vertrauensumstände gefordert wird als bei der richtlinienkonformen Auslegung im engeren Sinn. ${ }^{2182}$ Die Entscheidungen des BGH sind in der Literatur zum Teil sehr kritisch aufgenommen worden.

\section{(1) Verpflichtung auch zur Rechtsfortbildung}

Auszugehen ist zunächst davon, dass der EuGH bei der Verwendung des Begriffs der Auslegung nicht von einem deutschen Begriffsverständnis ausgeht, sondern ein autonomes zugrunde legt, das nicht zwischen Auslegung und Rechtsfortbildung unterscheidet. ${ }^{2183}$

Auslegung meint für den EuGH daher jede zulässige Form der Rechtsfindung und damit auch die Rechtsfortbildung. ${ }^{2184}$ Dementsprechend spricht er auch dann von Auslegung, wenn es nach deutschem Verständnis um Rechtsfortbildung geht ${ }^{2185}$, was sich beispielhaft an den Ausführungen des Gerichtshofs in den verbundenen Rechtssachen Brasserie du pêcheur und Factortame zeigt, die die Anerkennung eines unionsrechtli-

vorrangs aus und lehnt damit eine Modifikation nationaler Methoden ab, S. 226. Mit der Wirkungsweise der richtlinienkonformen Auslegung, der er den Begriff der „richtlinienkonformen Rechtsanwendung“ vorzieht, befasst sich auch Reimer, JZ 2015, 910 (913 ff., 919).

2182 Michael, Der Staat 54 (2015), 349 (370) meint, bei Auslegung im engeren Sinne sei Maßstabsbildung auch mit Wirkung für die Vergangenheit legitim. Auch das ArbG Bochum, Urteil vom 17.3.2005, 3 Ca 307/04 - NJOZ 2005, 1804 (1817) hat seine Ablehnung der Gewährung von Vertrauensschutz u.a. damit begründet, dass es in dem von ihm entschiedenen Fall nicht um eine der Rechtsetzung angenäherte Rechtsfortbildung gehe, sondern um eine richtlinienkonforme Auslegung der „schon seit langem geltenden $\$ \mathbb{1 7} 17,18 \mathrm{KSchG}$ “.

2183 Schlachter, EuZA 2015, 1 (7); Riesenhuber, in: Riesenhuber (Hrsg.), Europäische Methodenlehre, 3. Aufl. 2015, $\$ 10$, Rn. 3; Riesenhuber/Domröse, RIW 2005, 47 (50); Canaris, in: FS Bydlinski, 2002, S. 47 (81 f.). Erklären lässt sich dies mit dem Vorbild der französischen Rechtstradition, siehe Levits, SR 2015, 121 (126f.).

2184 Siehe nur Schürnbrand, JZ 2007, 910; Baldauf, Richtlinienverstoß, 2013, S. 83; Mörsdorf, ZIP 2008, 1409 (1415, Fn. 41).

2185 So auch Kroll-Ludwigs/Ludwigs, ZJS 2009, 7 (12). 
chen Staatshaftungsanspruchs als Frage der in die Zuständigkeit des EuGH fallenden Auslegung des Vertrags einordnen. ${ }^{2186}$ Dies allein genügt aber noch nicht zur Bejahung einer Pflicht zur richtlinienkonformen Rechtsfortbildung. Hinzutreten müssen weitere Erwägungen.

Die nationalen Gerichte müssen bei der Auslegung des nationalen Rechts im Hinblick auf Wortlaut und Zweck einer Richtlinie „die diesem Zweck am besten entsprechende Auslegung der nationalen Rechtsvorschriften wählen" (,favouring the interpretation of the national rules which is the most consistent with that purpose“; „en privilégiant l'interprétation des règles nationales la plus conforme à cette finalitéc). ${ }^{2187}$ Trotz der Bezeichnung als richtlinienkonforme Auslegung ist der dem nationalen Recht beizulegende Bedeutungsgehalt damit nicht zwingend vorgegeben. Aus dem Spektrum möglicher Auslegungsergebnisse schließt sie aber bestimmte Bedeutungsgehalte aus, die ihm nicht beigelegt werden dürfen. ${ }^{2188}$

Damit, dass nach seiner Rechtsprechung das Auslegungsergebnis, das mit der Richtlinie vereinbar ist, Vorrang vor anderen möglichen Auslegungsergebnissen hat, lässt der EuGH den Auslegungsvorgang selbst noch unberührt. ${ }^{2189}$ Darauf beschränkt er die richtlinienkonforme Auslegung aber nicht; sie geht darüber hinaus und greift auch in den Auslegungsvorgang selbst ein, was etwa daran deutlich wird, dass der EuGH die mitgliedstaatlichen Gerichte dazu auffordert, bei der Auslegung eines Um-

2186 EuGH, Urteil vom 5.3.1996, verb. Rs. C-46/93 und C-48/93 (Brasserie du pêcheur und Factortame), Rn. 24 ff. Gegen seine Anerkennung durch den Gerichtshof war geltend gemacht worden, dass dies der Zuständigkeitsverteilung zwischen EU und Mitgliedstaaten und dem institutionellen Gleichgewicht auf EU-Ebene widerspreche und er nur im Wege der Gesetzgebung eingeführt werden könne.

2187 EuGH, Urteil vom 4.7.2006, Rs. C-212/04 (Adeneler u.a.), Rn. 124. Ebenso EuGH, Urteil vom 22.12.2008, Rs. C-414/07 (Magoora), Rn. 44; EuGH, Urteil vom 23.12.2009, Rs. C-305/08 (CoNISMa), Rn.50; EuGH, Urteil vom 16.2.2012, Rs. C-594/10 (van Laarhoven), Rn. 37; EuGH, Urteil vom 18.7.2013, Rs. C-124/12 (AES-3C Maritza East 1), Rn. 53. Nach Auffassung des EuGH sind also Abstufungen denkbar, obwohl „Konformität“ eigentlich keine Stufen kennt, vgl. Simon, in: Mélanges Mengozzi, 2013, S. 279 (286f. mit Fn. 742 und 744).

2188 Darauf weist auch Simon, in: Mélanges Mengozzi, 2013, S. 279 (289) hin, wenn er ausführt, es gebe keinen „sens obligatoire“, dafür aber „sens interdits“.

2189 Brenncke, EuR 2015, 440 (446f.). 
setzungsgesetzes davon auszugehen, dass der nationale Gesetzgeber eine richtlinienkonforme Regelung treffen wollte. ${ }^{2190}$

Aufgrund dieser Vermutungsregel ist der Normzweck - jedenfalls, wenn der Gesetzgeber nicht ausdrücklich die Umsetzung verweigert - unter Berücksichtigung des gesetzgeberischen Willens zu bestimmen, die einschlägige Richtlinie korrekt umzusetzen. Diese dient daher gleichzeitig als Maßstab der Lückenfeststellung (als Voraussetzung der Rechtsfortbildung) und der Lückenschließung. ${ }^{2191}$ Als Aspekt der Umsetzungsverpflichtung aus Art. 288 III AEUV genießt das Gebot richtlinienkonformer Auslegung angesichts des Vorrangs des Art. 288 III AEUV selbst Vorrang. ${ }^{2192}$ Die Richtlinie als Maßstab für die Feststellung der Unvollständigkeit des Gesetzes heranzuziehen, ist angesichts der Vorrangwirkung der Umsetzungsverpflichtung gerechtfertigt. ${ }^{2193}$

Die Richtlinie ist damit bereits auf der Ebene der Auslegungsmethoden „maßgeblich und vorrangig“ zu berücksichtigen und nicht erst auf der Ebene des Auslegungsergebnisses. Wenn das nationale Recht „so weit wie möglich“ im Lichte der Richtlinie auszulegen ist, muss auch ein Auslegungsergebnis erreicht werden, das ohne Berücksichtigung der Richtlinie im Auslegungsvorgang nicht hätte erreicht werden können. Voraussetzung ist lediglich, dass es methodisch erzielbar ist. Dies verlangt Art. 288 III AEUV. ${ }^{2194}$ Die fehlende Unterscheidung zwischen Auslegung und Rechts-

2190 Zutreffend Brenncke, EuR 2015, 440 (447 f.). Zur vom Gerichtshof aufgestellten Vermutung siehe EuGH, Urteil vom 5.10.2004, verb. Rs. C-397/01 bis C-403/01 (Pfeiffer u.a.), Rn. 112 unter Verweis auf EuGH, Urteil vom 16.12.1993, Rs. C-334/92 (Wagner Miret), Rn.20. Im letztgenannten Urteil ging es um einen Fall, in dem der Mitgliedstaat sein Recht bereits für richtlinienkonform hielt. Höpfner, Jahrbuch Junger Zivilrechtswissenschaftler 2009, 73 (84) ist dagegen der Auffassung, dass der Auslegungsvorgang von der richtlinienkonformen Auslegung nicht berührt wird.

2191 BVerwG, Urteil vom 31.1.2017, 6 C 2.16, Rn. 29 - BVerwGE 157, 249; BGH, Urteil vom 7.5.2014, IV ZR 76/11, Rn. 23 - BGHZ 201, 101; Mörsdorf, ZIP 2008, 1409 (1415).

2192 Herrmann, Richtlinienumsetzung, 2003, S. 128; Canaris, in: FS Bydlinski, 2002, S. 47 (68 f.); Michael, Der Staat 54 (2015), 349 (364, Fn. 54); siehe auch Franzen, Privatrechtsangleichung, 1999, S. 339.

2193 Kroll-Ludwigs/Ludwigs, ZJS 2009, 123 (125). Zu unterscheiden ist dies von der Frage des Vorrangs der Richtlinie als Rechtsnorm, vgl. Franzen, Privatrechtsangleichung, 1999, S. 260. Siehe auch Baldauf, Richtlinienverstoß, 2013, S. 34 mit Fn. 129 und Kroll-Ludwigs/Ludwigs, ZJS 2009, 123 (126 mit Fn. 49).

2194 Überzeugend Hermann, Richtlinienumsetzung, 2003, S. 132 ff. Reimer, JZ 2015, 910 (914 f., 916, 918) lehnt es dagegen ab, Art. 288 III AEUV Vorgaben für die „Erkenntnis des Regelungsinhalts mitgliedstaatlicher Rechtsakte“ zu 
fortbildung in der Rechtsprechung des EuGH mit der Achtung des Gerichtshofs für die nationale Gewaltenteilung zu erklären ${ }^{2195}$, greift daher zu kurz.

Die contra legem-Grenze spricht nach alledem die „funktionelle“ Kompetenzgrenze zwischen Judikative und Legislative an. ${ }^{2196} \mathrm{Zu}$ den den Gerichten zur Verfügung stehenden Methoden gehört nach deutschem Verständnis etwa auch die teleologische Reduktion einer Norm. ${ }^{2197}$ Da das deutsche Recht der Rechtsfortbildung damit offen gegenübersteht, ist sie im Falle des Vorliegens ihrer Voraussetzungen aufgrund des Äquivalenzgrundsatzes auch in richtliniengeprägten Fallgestaltungen gefordert. ${ }^{2198}$ Unionsrechtlich verlangt die Verpflichtung zu richtlinienkonformer Auslegung also eine Auslegung über den Wortlaut hinaus, wo dies methodisch möglich ist. ${ }^{2199}$ Dieser Ansatz liegt der Rechtsprechung des BGH daher zu Recht zugrunde. ${ }^{2200}$ Entscheidender Bezugspunkt ist deshalb nicht der Wortlaut der nationalen Vorschrift. Das wäre aus unionsrechtlicher Sicht vielmehr ein Rückschritt, wenn die nationale Methodik eine Rechtsfindung über den Wortlaut hinaus zulässt. 2201

entnehmen, sodass nach nationalem Recht bestehende Bindungen des nationalen Gerichts nicht durch das Unionsrecht überwunden werden können. Unionsrechtlich gefordert sei lediglich eine richtlinienkonforme Ausfüllung bestehender Konkretisierungsspielräume; der Umfang der Spielräume werde dagegen nicht beeinflusst.

2195 So Herdegen, WM 2005, 1921 (1926). Nettesheim, AöR 119 (1994), 261 (265 f.) sieht in der Verwendung des Wortes „Auslegung“ den Ausdruck der Hoffnung des Gerichtshofs auf Akzeptanz und Gefolgschaft der Mitgliedstaaten, da dieser Begriff Konfliktpotential verberge und aus mitgliedstaatlicher Sicht unverdächtig erscheine.

2196 Schlachter, EuZA 2015, 1 (9). Deutlich wird damit, dass die contra legem-Grenze Gewaltenteilung zwischen Rechtsprechung und Gesetzgebung voraussetzt, vgl. Brenncke, Statute Law Review 39 (2018), 134 (143). Die Bedeutung des Verhältnisses der Gerichte zum Gesetzgeber heben auch Kroll-Ludwigs/Ludwigs, ZJS 2009, 7 (10) hervor. Nettesheim, AöR 119 (1994), 261 (266) betont die zwischen beiden bestehenden „Konfliktpotentiale“.

2197 BVerfG, Beschluss vom 26.9.2011, 2 BvR 2216/06, 2 BvR 469/07 - BVerfGK 19, 89 (103); BVerfG, Beschluss vom 23.5.2016, 1 BvR 2230/15, 1 BvR 2231/15, Rn. 50 - NJW-RR 2016, 1366.

2198 Darauf weist auch Reimer, JZ 2015, $910(916,919)$ hin.

2199 Kroll-Ludwigs/Ludwigs, ZJS 2009, 7 (12); Gallner, in: FS Etzel, 2011, S. 155 (163 f.) unter Verweis auf EuGH, Urteil vom 5.10.2004, verb. Rs. C-397/01 bis C-403/01 (Pfeiffer u.a.), Rn. 111 f., 115 ff.

2200 BGH, Urteil vom 26.11.2008, VIII ZR 200/05, Rn. 21 - BGHZ 179, 27.

2201 Kainer, GPR 2016, 262 (265). Raff, Jahrbuch Junger Zivilrechtswissenschaftler 2016, 67 (83) meint dagegen, dass die Grenze zwischen richtlinienkonformer 
Damit ist davon auszugehen, dass die Ausführungen des EuGH zur richtlinienkonformen Auslegung (unter Respektierung der nationalen Methodengrenzen) auch die Rechtsfortbildung umfassen. Entscheidend ist dabei weniger, dass der EuGH terminologisch keine Unterscheidung zwischen Auslegung und Rechtsfortbildung trifft, sondern vielmehr, dass die richtlinienkonforme Auslegung über den Umsetzungsbefehl nach Art. 288 III AEUV ein funktionales Verständnis des Auslegungsbegriffs verlangt. Danach kann die Berücksichtigung der Richtlinie bei der Auslegung eine Lücke im nationalen Recht erst schaffen, die mit ihrer Hilfe dann geschlossen wird.

\section{(2) Teleologische Reduktion (auf Null)}

Mit diesem Wissen um die durch die Verpflichtung zu richtlinienkonformer Auslegung gestellten Anforderungen sind die bereits erwähnten Entscheidungen des BGH zu würdigen.

In seinem Urteil zu $\$ 5$ a II 4 VVG a.F. ${ }^{2202}$ hatte der BGH durch teleologische Reduktion (im Rahmen einer gespaltenen Auslegung) erreicht, dass die dort genannte Jahresfrist für die Ausübung des Rechts zum Widerspruch im Anwendungsbereich zweier Lebensversicherungsrichtlinien keine Anwendung fand, sodass bei den erfassten Lebens- und Rentenversicherungen im Falle nicht ordnungsgemäßer Belehrung über das Widerspruchsrecht ein unbefristetes Widerspruchsrecht besteht. ${ }^{2203}$ Die teleologische Reduktion war vom BGH vor dem Hintergrund des Urteils des EuGH in der Rechtssache Endress vorgenommen worden, in dem dieser entschieden hatte, dass die einschlägige Richtlinie $\$ 5$ a II 4 VVG a.F. entgegensteht. ${ }^{2204}$ Die uneingeschränkte Anwendung des $\$ 5$ a II 4 VVG a.F. konnte nach Auffassung des BGH nicht als gesichert angesehen werden, da Stimmen in der Literatur die Vereinbarkeit mit der Richtlinie von Anfang an bezweifelt hatten. Einen Verstoß der von ihm vorgenommenen

Auslegung und Staatshaftung in Deutschland der Wortlaut sei; scheitere eine richtlinienkonforme Auslegung, sei zwar das Ergebnis unionsrechtswidrig, nicht aber die Methode.

2202 „Abweichend von Satz 1 erlischt das Recht zum Widerspruch jedoch ein Jahr nach Zahlung der ersten Prämie."

2203 BGH, Urteil vom 7.5.2014, IV ZR 76/11, Rn. 17 ff. - BGHZ 201, 101.

2204 EuGH, Urteil vom 19.12.2013, Rs. C-209/12 (Endress), Rn. 32. 
gespaltenen Auslegung gegen Art. 20 III GG verneinte der BGH dementsprechend. ${ }^{2205}$

Gegen die Nichtgewährung von Vertrauensschutz durch den BGH wird zum Teil eingewendet, dass den Gerichten nicht mehr erlaubt sein könne als dem Gesetzgeber. Da Vertrauen in den Bestand einer Rechtsnorm geschützt werde und durch rückwirkende richtlinienkonforme Reduktion einer Norm die Anwendung des Gesetzes aufgehoben werde, sollen hier daher Rückwirkungsverbote für die Rechtsprechung Geltung beanspruchen. Grundrechtlich geschütztes subjektives Vertrauen müsse Berücksichtigung finden. ${ }^{2206} \mathrm{Da}$ der BGH das Verbot echter Rückwirkung hinsichtlich der betroffenen Versicherungsunternehmen berühre und durch echte Rechtsfortbildung abstrakt-generelle Maßstäbe setze, seien die für den Gesetzgeber geltenden Schranken zu beachten. ${ }^{2207}$ Das Bundesverfassungsgericht hat sich von diesen Einwänden dagegen unbeeindruckt gezeigt und die BGH-Rechtsprechung einschließlich der Nichtgewährung von Vertrauensschutz aus verfassungsrechtlicher Sicht gebilligt. 2208

In der Tat weist das Bundesverfassungsgericht das Argument der Beschwerdeführerin der Verfassungsbeschwerde, sie habe sich auf den eindeutigen Wortlaut des $\$ 5$ a II 4 VVG a.F. verlassen, zu Recht zurück. Sie bezieht sich damit nämlich nur auf eine Wortlautauslegung und vertraut lediglich auf die Anwendung einer bestimmten Auslegungsmethode, die das Grundgesetz aber nicht vorschreibt. ${ }^{2209} \mathrm{Da}$ die Erzielung des richtlinienkonformen Auslegungsergebnisses demnach methodisch möglich ist ${ }^{2210}$, scheidet eine Ergebniskorrektur durch Vertrauensschutzerwägungen wie gesehen aus. Da die teleologische Reduktion ebenfalls eine anerkannte Me-

2205 BGH, Urteil vom 7.5.2014, IV ZR 76/11, Rn. 32 - BGHZ 201, 101. Siehe auch BGH, a.a.O., Rn. 41 f. zur Ablehnung der Beschränkung der bereicherungsrechtlichen Rechtsfolgen auf eine Wirkung ex nunc ab Zugang des Widerspruchs und Rn. 45 zur Einordnung des erlangten Versicherungsschutzes als Vermögensvorteil mit der Folge der Wertersatzpflicht nach $\$ 818$ II BGB (unter Verweis auf EuGH, Urteil vom 15.4.2010, Rs. C-215/08 (E. Friz), Rn. 48).

2206 Michael, Der Staat 54 (2015), 349 (371 f.).

2207 Michael/Payandeh, NJW 2015, 2392 (2397).

2208 Die Verfassungsbeschwerden richteten sich gegen BGH, Urteil vom 29.7.2015, IV ZR 448/14 - NJW 2015, 3098 und BGH, Urteil vom 29.7.2015, IV ZR 384/14 - WM 2015, 1614.

2209 BVerfG, Beschluss vom 23.5.2016, 1 BvR 2230/15, 1 BvR 2231/15, Rn. 50, 56 ff. - NJW-RR 2016, 1366.

2210 Näher zur Wahrung der verfassungsrechtlichen Grenzen der Rechtsfindung und Gesetzesbindung BVerfG, Beschluss vom 23.5.2016, 1 BvR 2230/15, 1 BvR 2231/15, Rn. 35 ff. - NJW-RR 2016, 1366. 
thode der Gesetzesauslegung ist und die richtlinienkonforme Auslegung daher mehr als bloße Wortlautauslegung verlangt, kann der Wortlaut auch aus unionsrechtlicher Sicht kein tauglicher Anknüpfungspunkt für Vertrauen sein. Dies gilt umso mehr vor dem Hintergrund, dass der EuGH festgestellt hatte, dass hinsichtlich der Tragweite der unionsrechtlichen Bestimmungen keine „,erhebliche objektive Unsicherheit““ bestand, da das nationale Recht „eindeutig“ gegen das Richtlinienziel verstieß. ${ }^{2211}$

Für die Berücksichtigung von Vertrauensschutz kann auch die vom Gerichtshof aufgestellte Vermutung ordnungsgemäßer Richtlinienumsetzung, nach der das nationale Gericht bei der richtlinienkonformen Rechtsfindung davon ausgehen muss, dass der nationale Gesetzgeber lediglich richtlinienkonforme Ziele verfolgt hat ${ }^{2212}$, nicht ins Feld geführt werden. Mit Hilfe dieser Vermutung kann der vom Gesetzgeber mit dem Erlass eines Gesetzes verfolgte Zweck dadurch überspielt werden, dass zu vermuten ist, dass der Gesetzgeber ein richtlinienkonformes Gesetz erlassen wollte. ${ }^{2213}$ Als Anknüpfungspunkt für Vertrauensschutz eignet sie sich dennoch nicht. So ist die Vermutung einerseits nicht allumfassend ${ }^{2214}$ und daher nur in bestimmten Fällen anwendbar, nicht aber etwa bei bewusster Nichtumsetzung der Richtlinie und auch nicht bei bereits bestehendem nationalen Recht, wenn der Gesetzgeber dieses nicht geändert hat und auch nicht davon ausging, dass es der Richtlinie bereits entspreche. Andererseits kann sie durch den Beweis des Gegenteils widerlegt werden. ${ }^{2215}$ Zudem dient sie nicht dazu, eine generelle Vermutung der Unionsrechtskonformität nationalen Rechts aufzustellen, sondern nur dazu, eine gemeinsame Ausrichtung der Regelungsabsichten von nationalem und Unionsgesetzgeber für die Zwecke der Auslegung zu erreichen. Die Aussage, dass sich die Einzelnen auf eine sich als richtlinienwidrig erweisende Norm verlassen können, trifft sie also nicht. Sie ändert daher nichts daran, dass mit einer rückwirkenden richtlinienkonformen Rechtsfortbildung zu rechnen ist.

2211 EuGH, Urteil vom 19.12.2013, Rs. C-209/12 (Endress), Rn. 38 f.

2212 Siehe zu dieser Vermutung bereits oben bei Fn. $2119 \mathrm{f}$.

2213 Schürnbrand, JZ 2007, 910 (912) weist darauf hin, dass „der Gehorsamsvermutung im Zweifel der Vorrang gegenüber sonstigen Sachüberlegungen gebührt".

2214 So aber Baldauf, Richtlinienverstoß, 2013, S. 91, 99.

2215 Überzeugend Brenncke, Statute Law Review 39 (2018), 134 (139ff.). Zu einer vollständigen Überlagerung der nationalen Methodenlehre kommt es damit nicht, vgl. Weber, Grenzen, 2010, S. 99 f., der sonst ein Leerlaufen der contra legem-Grenze befürchtet. 
Damit ist noch der Fall der teleologischen Reduktion auf Null in den Blick zu nehmen. $\mathrm{Zu}$ erwähnen ist an dieser Stelle die Rechtsprechung des BGH zu $₫ 8$ V 4 VVG a.F. ${ }^{2216}$ Der BGH führt aus, dass die Rücktrittserklärung von einem Rentenversicherungsvertrag trotz des Ablaufs der in dieser Vorschrift vorgesehenen Frist wirksam sei, da diese Befristung unwirksam sei, was sich aus einer richtlinienkonformen Auslegung des $\$ 8$ VVG a.F. ergebe. ${ }^{2217}$ Seine Überlegungen zu $\$ 5$ a II 4 VVG a.F. überträgt der BGH auf diesen Fall und meint, dem stünde nicht entgegen, dass die richtlinienkonforme Auslegung hier zum Wegfall der Befristung und damit zur vollständigen Aufhebung der in $₫ 8$ V 4 VVG a.F. getroffenen Regelung führt. Begründet wird dies von ihm damit, dass die Vorschrift im Zusammenhang mit $\mathbb{8}$ IV VVG a.F. zu lesen sei. ${ }^{2218}$ Auch diese Argumentation billigt das Bundesverfassungsgericht. 2219

Die Rechtsfortbildung hat hier also zum vollständigen Funktionsverlust der Norm geführt. Gegen ein solches Ergebnis wird eingewandt, dass diese "faktische Derogation der Norm" mit der Bindung an Recht und Gesetz nach Art. 20 III GG unvereinbar sei.2220 Aus dem Grundsatz der Gewaltenteilung folge, dass die Aufhebung der Norm allein dem Gesetzgeber obliegt. 2221 Zutreffend ist zwar, dass die Nichtanwendung der Norm nicht mit dem Vorrang des Unionsrechts begründet werden kann, da der Richtlinie in dem zugrundeliegenden Horizontalverhältnis mangels unmittelbarer Wirkung kein Anwendungsvorrang zukommt. Die teleologische Reduktion der Norm auf Null ist deswegen aber nicht auf einen

2216 „Unterbleibt die Belehrung, so erlischt das Rücktrittsrecht einen Monat nach Zahlung der ersten Prämie.“"

2217 BGH, Urteil vom 17.12.2014, IV ZR 260/11, Rn. 19f. - NJW 2015, 1023.

2218 BGH, Urteil vom 17.12.2014, IV ZR 260/11, Rn. 23 ff. - NJW 2015, 1023.

2219 BVerfG, Beschluss vom 28.7.2016, 1 BvR 128/16 - WM 2016, 1780. Das Vorbringen der Beschwerdeführerin, die Auslegung des BGH führe zur vollständigen Aufhebung der in $₫ 8 \mathrm{~V} 4 \mathrm{VVG}$ a.F. für Lebensversicherungsverträge getroffenen Regelung, weist das Bundesverfassungsgericht mit dem Argument zurück, dass auch diese teleologische Reduktion die Grenzen der richterlichen Rechtsfortbildung wahrt. Die Begründung des BGH mit einer Zusammenschau von $\$ 8 \mathrm{~V}$ und IV VVG a.F. sei verfassungsrechtlich nicht zu beanstanden. Die Verfassungsbeschwerde richtete sich gegen OLG Frankfurt am Main, Urteil vom 10.12.2015, 3 U 51/15.

2220 Kroll-Ludwigs/Ludwigs, ZJS 2009, 123 (128). Michael/Payandeh, NJW 2015, 2392 (2398) meinen, der Verstoß eines Gesetzes gegen eine Richtlinie sei nicht geeignet, die Gesetzesbindung der Gerichte aufzuheben.

2221 Frantzen, Staatshaftung, 2018, S. 90. 
Vorrang außerhalb des Anwendungsvorrangs zurückzuführen.2222 Sie ist lediglich Folge der angesichts der methodischen Möglichkeiten des nationalen Rechts nach Art. 288 III AEUV geforderten richtlinienkonformen teleologischen Reduktion. Dass der Norm kein Anwendungsbereich verbleibt, ist daher unbedenklich.

\section{(3) Überspielen der Wertentscheidung des Gesetzgebers}

Interesse weckt die Entscheidung des BGH zu $\$ 5$ a II 4 VVG a.F. noch aus einem weiteren Grund. Sie zeichnet sich nämlich durch die zusätzliche Besonderheit aus, dass die Jahresausschlussfrist für einen Widerspruch nach $\$ 5$ a II 4 VVG a.F. durch das Gesetz zur Reform des Versicherungsvertragsrechts ${ }^{2223}$ zum 1.1.2008 abgeschafft worden war, die Jahresfrist für Altverträge über Art. 1 I EGVVG (Einführungsgesetz zum Versicherungsvertragsgesetz) allerdings grundsätzlich weiter Geltung beansprucht hätte.

In der Literatur wird gegen die Rechtsprechung des $\mathrm{BGH}$ daher eingewandt, dass die teleologische Reduktion des $\$ 5$ a II 4 VVG a.F. die Wertentscheidung des Gesetzgebers über den Geltungszeitpunkt der Rechtsänderung ignoriere und die Grenzen verfassungsrechtlich zulässiger Rechtsfortbildung damit übersteige. ${ }^{2224}$ Bei einer gesetzgeberischen Lückenschließung ex nunc, die hier durch das Gesetz zur Reform des Versicherungsvertragsrechts erfolgt sei, sei eine Rechtsfortbildung ex tunc versperrt. ${ }^{2225}$

Gegen diese Argumentation ist mit dem Bundesverfassungsgericht allerdings einzuwenden, dass das Endress-Urteil des EuGH, vor dessen Hintergrund der $\mathrm{BGH}$ die teleologische Reduktion vorgenommen hat, zum Zeitpunkt der vom Gesetzgeber vorgenommenen Gesetzesänderung noch nicht ergangen war. Da sie diesem also bei Verabschiedung des Gesetzes nicht bekannt war, kann nicht angenommen werden, dass er das Gesetz bei Kenntnis der EuGH-Entscheidung unverändert erlassen hätte. ${ }^{2226}$ Dies

2222 Eine solche Ableitung macht Michael, Der Staat 54 (2015), 349 (364f.) dem BGH zum Vorwurf. In eng begrenzten Ausnahmefällen erkennt auch Michael, a.a.O., S. 366 f. eine Normderogation durch Rechtsfortbildung an.

2223 Gesetz zur Reform des Versicherungsvertragsrechts vom 23. November 2007 (BGBl. I vom 29.11.2007, S. 2631).

2224 Frantzen, Staatshaftung, 2018, S. 84.

2225 Michael, Der Staat 54 (2015), 349 (355 f.).

2226 BVerfG, Beschluss vom 23.5.2016, 1 BvR 2230/15, 1 BvR 2231/15, Rn. 54 NJW-RR 2016, 1366. 
wäre ihm im Übrigen unionsrechtlich auch verwehrt gewesen. Eine spezifisch gegen ex tunc wirkende EuGH-Rechtsprechung ${ }^{2227}$ gerichtete Gesetzgebung ist nämlich wie oben gesehen ${ }^{2228}$ nicht zulässig.

\section{(4) Zwischenfazit}

Dem Vertrauen in den Wortlaut und die Regelungsabsicht des Gesetzgebers kommt angesichts der Pflicht zu richtlinienkonformer Auslegung im Ergebnis kaum Bedeutung zu. ${ }^{222}$ Art. 288 III AEUV bewirkt, dass die Richtlinie auch die Methodenanwendung beeinflusst und fordert im Rahmen des methodisch Möglichen eine Rechtsfindung auch über den Wortlaut hinaus. Zu bedenken ist zudem, dass eine Richtlinie auch aus nationaler Perspektive als Bestandteil von Recht und Gesetz nach Art. 20 III GG ${ }^{2230}$ einen Vertrauenstatbestand darstellt, sodass sich der von ihr Begünstigte auf die Durchsetzung seiner durch Unionsrecht eingeräumten Rechtsposition mittels richtlinienkonformer Auslegung des nationalen Rechts verlassen kann. Unter dem Vorbehalt mangelnden Vertrauensschutzes des Anspruchsgegners steht dies nicht, da zwischen der Auslegung an sich und ihrer zeitlichen Dimension zu unterscheiden ist. ${ }^{2231}$ Der Schutz „abstrakten Gesetzesvertrauens“ der Gegenseite scheidet insoweit aus. 2232

2227 Eine Begrenzung der zeitlichen Wirkungen hatte der Gerichtshof ausdrücklich abgelehnt, EuGH, Urteil vom 19.12.2013, Rs. C-209/12 (Endress), Rn. 33 ff.

2228 Siehe bei Fn. 1233.

2229 Frantzen, Staatshaftung, 2018, S. 99 f. mit Fn. 415 zieht die Grenzen daher zu eng, wenn sie bei Rechtsentwicklungen außerhalb des Wortsinns berechtigtes Vertrauen bejaht. Auch die Auffassung von Neuner, in: FS Canaris, 2017, S. 205 (212 ff.), dass eine Rechtslage nach dem Wortlaut und der vom Gesetzgeber kundgetanen Intention klar ist, vermag daher nicht zu überzeugen.

2230 Siehe nur Spelge, FA 2011, 34.

2231 Riesenhuber, AP KSchG $1969 \$ 17$ Nr. 21.

2232 A.A. Frantzen, Staatshaftung, 2018, S. 70 f. im Zusammenhang mit der Problematik der rückwirkenden Richtlinienumsetzung durch den Gesetzgeber. 
dd) Bedeutung der Äußerungen nationaler Gerichte zur contra legemGrenze

Auch wenn ihre Bedeutung für die Berücksichtigung nationaler Vertrauensumstände nach dem bisher Gesagten sehr begrenzt ist, könnte die contra legem-Grenze dennoch für die Frage des Vertrauens in richtlinienwidrige nationale Rechtsprechung insoweit fruchtbar zu machen sein, als Rechtsprechung in Rede steht, die „im Angesicht der Richtlinie“2233 die Möglichkeit richtlinienkonformer Auslegung verneint hat. ${ }^{2234}$ Rechtsprechung, die sich nicht unter Berücksichtigung der Richtlinie entwickelt hat, erscheint demgegenüber von vornherein weniger schutzwürdig, da das Hinzutreten der Richtlinie vertrauenszerstörend wirkt. ${ }^{2235}$

Haben die Äußerungen eines nationalen Gerichts den im Rahmen der richtlinienkonformen Auslegung von Unionsrechts wegen zu beachtenden europäischen Methodenregeln hinreichend Beachtung geschenkt, steht also die Frage im Raum, ob die Betroffenen, wenn sich eine nationale Regelung als richtlinienwidrig erweist, zu der Annahme berechtigt sind, dass sich die Grenze zwischen Rechtsprechung und Gesetzgebung inzwischen nicht verschoben hat, eine richtlinienkonforme Auslegung also weiterhin an der contra legem-Grenze scheitern wird. ${ }^{2236}$

Berührt war diese Frage in der Rechtssache Hein. So hatte das BAG in einem die Kürzung des Urlaubsentgelts bei Saison-Kurzarbeit betreffenden Urteil von 2009, auf das das Arbeitsgericht Verden in seinem Vorlagebeschluss in der Rechtssache Hein auch Bezug nahm, die Möglichkeit einer richtlinienkonformen Auslegung bzw. Fortbildung der Öffnungsklauseln des $\$ 13$ I, II BUrlG verneint, da es an die Grenzen des Art. 20 III GG und Art. 20 II 2 GG stoße. ${ }^{2237}$ Die Öffnungsklauseln gestatten in dem dort vorgesehenen Umfang eine Abweichung von den gesetzlichen Regelungen

2233 Weber, Grenzen, 2010, S. 183.

2234 Maul-Sartori, in: Boecken/Düwell/Diller/Hanau (Hrsg.), Gesamtes Arbeitsrecht, 2016, Art. 153 AEUV, Rn. 64; Gallner, in: FS Etzel, 2011, S. 155 (170 f.); Sagan, Jahrbuch Junger Zivilrechtswissenschaftler 2010, 67 (77).

2235 BAG, Urteil vom 4.5.2010, 9 AZR 183/09, Rn. 20 - BAGE 134, 196; siehe auch Düwell, NZA-Beilage 2011, 133 (141).

2236 Rosenkranz, ZESAR 2018, 24 (27) meint, dass in diesem Fall bei einer Rechtsprechungsänderung der Grund für diese entscheidend sei. Gehe sie auf unionsrechtliche Erwägungen zurück, ließe sich darauf hinweisen, dass bereits vor der Behandlung des Vertrauensschutzes als rein nationale Angelegenheit gewarnt wurde.

2237 BAG, Urteil vom 17.11.2009, 9 AZR 844/08, Rn. 46 - BAGE 132, 247. 
durch Tarifvertrag; von ihnen sieht das BAG die in Rede stehende tarifliche Regelung gedeckt.

Die nationale Regelung, die eine Bestimmung in Tarifverträgen zulässt, wonach durch Kurzarbeit eingetretene Verdienstkürzungen bei der Berechnung der Urlaubsvergütung berücksichtigt werden, erwies sich als unionsrechtswidrig, was der Gerichtshof damit begründet, dass ihr Art. 7 I RL 2003/88/EG und Art. 31 II GRCh entgegenstehen. ${ }^{2238}$ Für die Entscheidung des dem Arbeitsgericht Verden vorliegenden konkreten Rechtsstreits - eines Rechtsstreits zwischen Privatpersonen - verweist der Gerichtshof auf die Pflicht des Arbeitsgerichts zur richtlinienkonformen Auslegung des nationalen Rechts im Einklang mit Art. 7 I RL 2003/88/EG. Der Gerichtshof betont in diesem Zusammenhang auch die gegebenenfalls bestehende Pflicht zur Abänderung einer richtlinienwidrigen gefestigten Rechtsprechung. ${ }^{2239}$

Dieser Ansatz muss überraschen, hatte der Gerichtshof Art. 31 II GRCh doch in seiner Rechtsprechung bereits unmittelbare Wirkung im Privatrechtsverhältnis zuerkannt. Danach ergibt sich die Verpflichtung zur Nichtanwendung einer nicht im Einklang mit Art. 7 RL 2003/88/EG und Art. 31 II GRCh auslegbaren nationalen Regelung gegenüber einem privaten Arbeitgeber aus Art. 31 II GRCh (und im Verhältnis zu einem staatlichen Arbeitgeber aus Art. 7 RL 2003/88/EG und Art. 31 II GRCh). ${ }^{2240}$ Diese Pflicht zur Nichtanwendung spricht der Gerichtshof hier aber nicht an. Obwohl er in seiner Antwort auf die Frage der Unionsrechtswidrigkeit des nationalen Rechts Art. 31 II GRCh mit einbezogen hat, stellt er für die Frage der Entscheidung des konkreten Rechtsstreits nicht auf die unmittelbare Wirkung des Art. 31 II GRCh und die hieraus gegebenenfalls folgende Pflicht zur Nichtanwendung des nationalen Rechts ab, sondern betont lediglich die aus Art. 7 I RL 2003/88/EG fließenden Verpflichtungen.2241

Nachdem er eine Begrenzung der zeitlichen Wirkungen im Sinne der Defrenne-Rechtsprechung aufgrund fehlender Anhaltspunkte in den Akten für das Vorliegen einer Gefahr schwerwiegender wirtschaftlicher Aus-

2238 EuGH, Urteil vom 13.12.2018, Rs. C-385/17 (Hein), Rn. 53.

2239 EuGH, Urteil vom 13.12.2018, Rs. C-385/17 (Hein), Rn. 48 ff., insb. Rn. 51 f.

2240 EuGH, Urteil vom 6.11.2018, verb. Rs. C-569/16 und C-570/16 (Bauer und Willmeroth), Rn. $79 \mathrm{ff}$.

2241 Bayreuther, NZA 2019, 945 (950) findet es „fast überraschend“, dass der Gerichtshof kein „Durchschlagen“ (Anführungszeichen im Original) von Art. 31 II GRCh anordnet und sich lediglich auf das Gebot richtlinienkonformer Auslegung stützt. 
wirkungen abgelehnt hatte ${ }^{2242}$, widmete sich der Gerichtshof der Frage, „ob das Unionsrecht es den nationalen Gerichten gestattet, auf der Grundlage des nationalen Rechts das berechtigte Vertrauen der Arbeitgeber auf den Fortbestand der nationalen höchstrichterlichen Rechtsprechung zu schützen, die die Rechtmäßigkeit der Regelungen des BRTV-Bau [Bundesrahmentarifvertrag für das Baugewerbe, Anmerkung des Verfassers] über den bezahlten Urlaub bestätigt hat“.

Diese Frage verneint er unter Anführung der aus dem Urteil in der Rechtssache DI bereits bekannten Erwägungen, das er auch mehrfach zitiert. Das Unionsrecht hindere die nationalen Gerichte vielmehr an einer derartigen Schutzgewährung. Die Anwendung des Grundsatzes des Vertrauensschutzes in der vom Arbeitsgericht Verden in Betracht gezogenen Weise laufe in Wirklichkeit nämlich darauf hinaus, die zeitlichen Wirkungen der vom Gerichtshof vorgenommenen Auslegung des Unionsrechts zu begrenzen, da diese Auslegung dann im Ausgangsverfahren keine Anwendung fände. Das Vorliegen außergewöhnlicher Umstände sei nicht nachgewiesen - insoweit verweist der Gerichtshof auf den fehlenden Nachweis der Gefahr schwerwiegender wirtschaftlicher Auswirkungen im Sinne der Defrenne-Rechtsprechung -, sodass die Auslegung des EuGH auch auf vor dem Urteil entstandene Rechtsverhältnisse anzuwenden sei. ${ }^{2243}$

Er verweist also auch in einem Fall, in dem das nationale Gericht zum Mittel der richtlinienkonformen Auslegung greifen soll, auf das Urteil in der Rechtssache DI und vergleicht damit das Ergebnis der Gewährung nationalen Vertrauensschutzes und der Ablehnung einer Begrenzung der zeitlichen Wirkungen im Sinne der Defrenne-Rechtsprechung miteinander. Da dies der Vorgehensweise beim unmittelbar anwendbaren Unionsrecht entspricht, scheint Vertrauensschutz im Hinblick auf eine höchstrichterliche Rechtsprechung, die die Rechtmäßigkeit des nationalen Rechts betont hat, ausgeschlossen. Dass die nationale Rechtsprechung von der Vereinbarkeit des Umsetzungsrechts mit der zugrundeliegenden Richtlinie ausgeht, würde danach nicht zur Begründung von Vertrauen genügen. ${ }^{2244}$

Unterschiede in der Behandlung bei der Betroffenheit von unmittelbar und mittelbar wirkendem Unionsrecht lässt der Gerichtshof also nicht

2242 EuGH, Urteil vom 13.12.2018, Rs. C-385/17 (Hein), Rn. 56 ff., insb. Rn. 59.

$2243 \mathrm{EuGH}$, Urteil vom 13.12.2018, Rs. C-385/17 (Hein), Rn. $61 \mathrm{ff}$. unter Verweis auf EuGH, Urteil vom 19.4.2016, Rs. C-441/14 (DI), Rn. 39 und 40.

2244 Frantzen, Staatshaftung, 2018, S. 101 nimmt in diesem Fall dagegen schutzwürdiges Vertrauen an. 
erkennen. Dabei spielt aber sicherlich die Verankerung des Anspruchs auf bezahlten Jahresurlaub in Art.31 II GRCh in seinen Überlegungen eine Rolle, auch wenn er zur Entscheidung des konkreten Rechtsstreits wie gesehen nicht auf sie verwiesen hat. ${ }^{2245}$ Dies zeigt sich in gewisser Weise auch daran, dass er für seine Ausführungen zur Rolle der nationalen Gerichte bzw. für die gegebenenfalls bestehende Pflicht zur Abänderung einer richtlinienwidrigen gefestigten Rechtsprechung auf seine Urteile in den Rechtssachen Kücükdeveci und DI verweist. In Bezug nimmt er damit Urteile zum primärrechtlichen Verbot der Altersdiskriminierung, in denen er bei Scheitern einer richtlinienkonformen Auslegung des nationalen Rechts auf die Pflicht zu dessen Nichtanwendung verwiesen hat. ${ }^{2246}$

Dass er eine endgültige Aussage über die Möglichkeiten nationaler Gerichte zur Berücksichtigung nationaler Vertrauensumstände im Rahmen der richtlinienkonformen Auslegung getroffen hat, ist daher nicht sicher. Verstärkt wird diese Unsicherheit dadurch, dass er sich lediglich zum Schutz des Vertrauens in höchstrichterliche Rechtsprechung ,auf der Grundlage des nationalen Rechts" geäußert hat, was ihre Berücksichtigung in einem unionsrechtlichen Rahmen nicht zwangsläufig ausschließt. Zudem bezieht er sich auf die Bejahung der „Rechtmäßigkeit“ des nationalen Rechts, mit der auch lediglich die Rechtmäßigkeit im Hinblick auf nationales Recht gemeint sein kann, etwa weil der Tarifvertrag die Öffnungsklausel im BUrlG respektiert.

Durch den Bezug lediglich zum Vertrauen auf den Fortbestand der Rechtsprechung, „die die Rechtmäßigkeit“ der entsprechenden tarifvertraglichen Regelungen „bestätigt hat“, äußert sich der Gerichtshof auch nicht ausdrücklich zu Aussagen in der nationalen Rechtsprechung, die betonen, dass eine richtlinienkonforme Auslegung des nationalen Rechts methodisch nicht möglich sei. Durch den Verweis auf das DI-Urteil

2245 So auch Schmitt, GPR 2019, 249 (251) und Zeh, ZESAR 2019, 301 (304f.). Höpfner, in: Franzen/Gallner/Oetker (Hrsg.), Arbeitsrecht, 3. Aufl. 2020, Art. 288 AEUV, Rn. 55 sieht die Betroffenheit von Art. 31 II GRCh als entscheidend dafür an, dass sich die Ablehnung „nationalen Vertrauensschutzes“ durch den EuGH in der Rechtssache Hein „nicht ohne Weiteres“ auf „die ,regulären' Fälle der Richtlinienumsetzung“ übertragen lasse.

2246 Siehe EuGH, Urteil vom 13.12.2018, Rs. C-385/17 (Hein), Rn. 48 unter Verweis auf EuGH, Urteil vom 19.1.2010, Rs. C-555/07 (Kücükdeveci), Rn. 45 und EuGH, Urteil vom 19.4.2016, Rs. C-441/14 (DI), Rn. 29 sowie EuGH, Urteil vom 13.12.2018, Rs. C-385/17 (Hein), Rn. 51 unter Verweis auf EuGH, Urteil vom 19.4.2016, Rs. C-441/14 (DI), Rn. 32 und 33 und die dort angeführte Rechtsprechung. 
scheint er zwar auch insoweit die Begründung von Vertrauen auszuschließen, sodass im Ergebnis der Einzelne - in diesem Fall der Arbeitgeber auch mit einer Verschiebung der contra legem-Grenze rechnen müsste. Überzeugender erscheint es allerdings, in der Betonung der fehlenden richtlinienkonformen Auslegbarkeit eine „Zusicherung"2247 durch das mitgliedstaatliche Gericht zu sehen, der angesichts der unionsrechtlichen Anerkennung der contra legem-Grenze vertrauensschützende Wirkung zukommt. Diese Wirkung kann daher angesichts ihrer unionsrechtlichen Anerkennung auch als Wirkung des unionsrechtlichen Vertrauensschutzgrundsatzes beschrieben werden.

\section{ee) Ergebnis}

Die Anerkennung der contra legem-Grenze bedeutet nicht, dass Vertrauensschutz einfach als Methodenregel formuliert werden kann. Das reflexhaft geschützte Vertrauen darauf, nur innerhalb der Grenzen des methodisch Möglichen belastet zu werden, hat sich als sehr eingeschränkt erwiesen, da die Richtlinie angesichts der Umsetzungsverpflichtung aus Art. 288 III AEUV auch die Methodenanwendung beeinflusst. Sie fordert eine Rechtsfindung auch über den Wortlaut hinaus, wo dies wie im deutschen Recht methodisch möglich ist. Der Wortlaut und die Regelungsabsicht des Gesetzgebers verlieren dadurch an Bedeutung. Zwischen Auslegung und Rechtsfortbildung bestehen daher im Hinblick auf die Berücksichtigung nationaler Vertrauensumstände keine Unterschiede. Lediglich wenn die Rechtsprechung (unter Beachtung der vom Gerichtshof für die richtlinienkonforme Auslegung aufgestellten europäischen Methodenregeln) verneint hat, dass eine nationale Norm mit den Methoden des nationalen Rechts richtlinienkonform auslegbar ist, kommt Vertrauensschutz in Betracht, da dann nicht mehr mit einer Verschiebung der contra legem-Grenze gerechnet werden muss.

2247 Dass eine Zusicherung vertrauensbegründend wirken und der Verpflichtung zur richtlinienkonformen Auslegung entgegenstehen kann, hat der EuGH anerkannt, siehe EuGH, Urteil vom 17.10.2018, Rs. C-167/17 (Klohn), Rn. 51 f. 
e) Berücksichtigung nationaler Vertrauensumstände im Rahmen der Grenze der allgemeinen Rechtsgrundsätze?

Hat sich eine Fruchtbarmachung der contra legem-Grenze als wenig ertragreich erwiesen, ist im Folgenden der Versuch zu unternehmen, die Grenze der allgemeinen Rechtsgrundsätze in den Dienst der Forderung nach Berücksichtigung nationaler Vertrauensumstände zu stellen. ${ }^{2248} \mathrm{Da}$ die allgemeinen Rechtsgrundsätze mit Art.288 III AEUV, auf dem die Pflicht zu richtlinienkonformer Auslegung beruht, auf einer Stufe stehen, sind sie zur Begrenzung dieser Pflicht imstande. 2249

Ihr Inhalt und Umfang bestimmen sich nach Unionsrecht. Die Einordnung der Berücksichtigungsfähigkeit nationaler Vertrauensumstände an dieser Stelle böte daher den Vorteil eines unionsweit einheitlichen Maßstabs $^{2250}$ und machte deutlich, dass die Entscheidung über ihre Berücksichtigung nicht in die Hände mitgliedstaatlicher Gerichte gelegt ist. ${ }^{2251}$

In der Begrenzung der richtlinienkonformen Auslegung durch allgemeine Rechtsgrundsätze, zu denen der Grundsatz der Rechtssicherheit zu zählen ist, eine Ermächtigung der nationalen Gerichte zu sehen, Vertrauensschutz durch eine Anknüpfung an Art. 20 III GG und den dort im Rahmen des Rechtsstaatsprinzips verbürgten Vertrauensschutz zu gewähren, überzeugt daher nicht. ${ }^{2252}$ Die Grenze der Rechtssicherheit stellt keinen Verweis auf das innerstaatliche Rechtsstaatsprinzip dar. ${ }^{2253}$

2248 So etwa Benecke, RdA 2011, 241 (242).

2249 Vgl. Herrmann, Richtlinienumsetzung, 2003, S. 161. Indem der Gerichtshof darauf hinweist, dass die nationalen Gerichte das nationale Recht innerhalb der durch das Unionsrecht gesetzten Grenzen auslegen müssen (EuGH, Urteil vom 7.1.2004, Rs. C-60/02 (X), Rn. 59), zeigt er, dass eine Überschreitung dieser Grenzen unzulässig wäre. Die allgemeinen Rechtsgrundsätze können einem nationalen Gericht daher auch die Erzielung eines Ergebnisses durch Auslegung untersagen. Darauf weist auch Prechal, Directives, 2. Aufl. 2005, S. 208 hin.

2250 Dies ist Temming, ZESAR 2015, 298 (302) ein besonderes Anliegen; siehe auch Sagan, NZA 2015, 341 (342).

2251 A.A. Nicolai, AP KSchG $1969 \$ 17$ Nr. 22.

2252 In diesem Sinne aber Maul-Sartori, in: Boecken/Düwell/Diller/Hanau (Hrsg.), Gesamtes Arbeitsrecht, 2016, Art. 153 AEUV, Rn. 63.

2253 So aber Höpfner, in: Franzen/Gallner/Oetker (Hrsg.), Arbeitsrecht, 3. Aufl. 2020, Art. 288 AEUV, Rn. 55. 
Die Maßstabsbildung obliegt daher dem EuGH.2254 Da er hierzu nur bei entsprechenden Vorlagen mitgliedstaatlicher Gerichte in der Lage ist, ist eine Vorlagepflicht letztinstanzlicher Gerichte zu bejahen. ${ }^{2255}$ Ein Monopol des Gerichtshofs in Bezug auf die Gewährung von Vertrauensschutz wird damit nicht zwingend begründet. Hat der Gerichtshof die Reichweite der Grenze der allgemeinen Rechtsgrundsätze näher bestimmt, kann das nationale Gericht die Vertrauensumstände nämlich im Einzelfall ermitteln und anwenden. ${ }^{2256}$ Dieses kann dann auf der Grundlage dienlicher Hinweise des EuGH eine Verletzung der allgemeinen Rechtsgrundsätze des Unionsrechts im konkreten Fall feststellen ${ }^{2257}$, also eine Prüfung nach den vom EuGH entwickelten Kriterien vornehmen. ${ }^{2258}$

Die allgemeinen Rechtsgrundsätze als Grenze der Pflicht zu richtlinienkonformer Auslegung haben vor allem im Strafrecht Bedeutung, sodass sie insbesondere in diesem Bereich eine eigenständige Ausgestaltung erfahren haben. ${ }^{2259}$ Ihre Bedeutung zeigt sich etwa am Urteil in der Rechtssache Caronna, in dem der entsprechende Abschnitt mit "Zur Verpflichtung einer konformen Auslegung im Bereich des Strafrechts" überschrieben ist. Dort heißt es, dass die Verpflichtung zu richtlinienkonformer Auslegung „im Bereich des Strafrechts“ gewissen Grenzen unterliege, woraufhin der

2254 Vgl. Abele, RdA 2009, 312 (317); siehe auch Gaul/Josten/Strauf, BB 2009, 497 (500). Bauer/Arnold, NJW 2009, 631 (633 f.) sind dagegen der Auffassung, beim Unterbleiben einer zeitlichen Begrenzung durch den EuGH obliege es etwa dem BAG, ,am Maßstab des Grundgesetzes über Vertrauensschutz zu entscheiden“; Tavakoli/Westhauser, DB 2008, 702 (705) möchten die Schutzwürdigkeit des Vertrauens „nach nationalen Grundsätzen“ beurteilen.

2255 Dies forderte bereits Kokott, RdA 2006, Sonderbeilage zu Heft 6, 30 (37 mit Fn. 106); ebenso Preis/Temming, NZA 2010, 185 (188 mit Fn.22). Gallner, in: Franzen/Gallner/Oetker (Hrsg.), Arbeitsrecht, 3. Aufl. 2020, Art. 7 RL 2003/88/EG, Rn. 5 meint daher mit Blick auf Art. 101 I 2 GG, die Gewährung nationalen Vertrauensschutzes sei „gefährlich“.

2256 In diesem Sinne etwa Rosenkranz, ZfPW 2016, 351 (376).

2257 GA Sharpston, Schlussanträge vom 6.12.2018 in der Rs. C-566/17 (Związek Gmin Zagłębia Miedziowego), Rn. 116 unter Verweis auf EuGH, Urteil vom 1.7.2014, Rs. C-573/12 (Ålands Vindkraft), Rn. 126, wo der Gerichtshof ausführt, dass es Sache des vorlegenden Gerichts ist, zu prüfen, ob eine nationale Regelung zur Umsetzung des Unionsrechts mit den allgemeinen Rechtsgrundsätzen vereinbar ist, da der Gerichtshof im Rahmen des Vorabentscheidungsverfahrens darauf beschränkt sei, dem vorlegenden Gericht alle erforderlichen unionsrechtlichen Auslegungshinweise zu geben.

2258 Abele, RdA 2009, 312 (317).

2259 In diesem Sinne auch Grosche/Höft, NJOZ 2009, 2294 (2300, Fn. 35). Siehe zur Begrenzung ihrer Bedeutung in diesem Bereich aber auch bei Fn. 2054. 
Gerichtshof die Grenze der allgemeinen Rechtsgrundsätze, die Bestandteil des Unionsrechts sind, entfaltet. ${ }^{2260} \mathrm{Da}$ dem Vorabentscheidungsersuchen ein Strafverfahren zugrunde lag, kann daraus aber noch nicht geschlossen werden, dass sie in anderen Rechtsbereichen nicht zum Tragen kommen sollen. Der Gerichtshof hat sie wie gesehen dann auch in weiteren Konstellationen fruchtbar gemacht oder jedenfalls angesprochen. ${ }^{2261}$

aa) Ausschluss der Berücksichtigung nationaler Vertrauensumstände im Horizontalverhältnis?

Diese Fallgestaltungen betrafen allerdings keine privatrechtlichen Beziehungen, sodass im Folgenden zu fragen ist, ob eine Begrenzung der Pflicht zu richtlinienkonformer Auslegung durch nationale Vertrauensumstände auch in Horizontalverhältnissen denkbar ist oder ebenso wie bei unmittelbar anwendbarem Recht ausscheiden muss.

Dabei kann angesichts des unionsrechtlichen Rahmens als Ausgangspunkt nicht die Überlegung zugrunde gelegt werden, dass Unions- und nationales Recht gleichermaßen vertrauensbegründend und vertrauenszerstörend wirkten, da sich die eine Partei auf die Richtlinie, die andere auf das nationale Recht verlassen dürfe. ${ }^{2262}$ Über Vertrauensschutz stattdessen unter Heranziehung der Unterscheidung zwischen positiver und negativer Wirkungen der Richtlinie zu entscheiden, muss aber ebenfalls abgelehnt werden, da der Gerichtshof diese Differenzierung wie gesehen nicht vornimmt. 2263

2260 EuGH, Urteil vom 28.6.2012, Rs. C-7/11 (Caronna), Rn. 51 f.

2261 Siehe dazu oben bei Fn. 2056 ff. und Fn. 2067 ff.

2262 Hierfür aber Brechmann, Richtlinienkonforme Auslegung, 1994, S. 279; Rüffler, ÖJZ 1997, 121 (130); Koch, SR 2012, 159 (167). Gegen die Überlegung, die Vertrauensgesichtspunkte höben sich gegenseitig auf, spricht sich wie hier Herrmann, Richtlinienumsetzung, 2003, S. 163 aus. Wie hier kritisch auch Herresthal, Rechtsfortbildung, 2006, S. 303, Fn. 77 und Weber, Grenzen, 2010, S. 144. Siehe in diesem Zusammenhang noch Herdegen, WM 2005, 1921 (1927).

2263 Dafür aber Herrmann, Richtlinienumsetzung, 2003, S. 164. Zur Ablehnung der Unterscheidung zwischen positiven und negativen Richtlinienwirkungen näher oben bei Fn. 1938 ff., insb. bei Fn. 1945 ff. 
(1) Begrenzte Aussagekraft des Urteils in den verbundenen Rechtssachen Gutiérrez Naranjo u.a.

Zur Beantwortung der hier aufgeworfenen Frage ist zunächst das Urteil des Gerichtshofs in den verbundenen Rechtssachen Gutiérrez Naranjo u.a. in den Blick zu nehmen, das dem ersten Anschein nach ein Verständnis nahelegen könnte, wonach eine Berücksichtigung nationaler Vertrauensumstände im Horizontalverhältnis ausgeschlossen ist. Dieses Urteil fand bereits im Rahmen der Erörterung der Abgrenzung zwischen nationalen Verfahrensmodalitäten und einer zeitlichen Begrenzung der Wirkungen des Unionsrechts Erwähnung ${ }^{2264}$, ist an dieser Stelle aber noch einmal näher zu untersuchen.

In den Sachverhalten der Ausgangsverfahren standen von Kreditinstituten mit Verbrauchern geschlossene Hypothekendarlehensverträge in Rede, die in den allgemeinen Geschäftsbedingungen Klauseln enthielten, die eine Mindesthöhe vorsehen, die der variable Zinssatz nicht unterschreiten darf. Diese sogenannten Mindestzinssatzklauseln waren vom spanischen Obersten Gerichtshof, dem Tribunal Supremo, für missbräuchlich befunden und daher für nichtig erklärt worden. Gestützt auf den Grundsatz der Rechtssicherheit - er verwies insbesondere auf die drohenden finanziellen Lasten der die Klausel verwendenden Kreditinstitute - hatte jener allerdings die zeitliche Wirkung der Nichtigerklärung auf den Zeitraum nach Urteilsveröffentlichung beschränkt. Vor dem 9.5.2013 aufgrund der für nichtig erklärten Klauseln erfolgte Zahlungen blieben von der Feststellung der Nichtigkeit danach unberührt; ihre Rückforderung hatte der Oberste Gerichtshof also ausgeschlossen.2265 Das Vorgehen des Tribunal Supremo stufte der EuGH in seinem Urteil als unzulässig ein, da dadurch das Recht der Verbraucher nach Art. 6 I RL 93/13/EWG („Klauselrichtlinie“)2266 in seinem Wesensgehalt beeinträchtigt werde und darin entgegen Art. 7 I der

$2264 \mathrm{Zu}$ dieser Frage siehe oben bei Fn. $1259 \mathrm{ff}$.

2265 EuGH, Urteil vom 21.12.2016, verb. Rs. C-154/15, C-307/15 und C-308/15 (Gutiérrez Naranjo u.a.), Rn. 68.

2266 Richtlinie 93/13/EWG des Rates vom 5. April 1993 über missbräuchliche Klauseln in Verbraucherverträgen, ABl. L 95 vom 21.4.1993, S. 29. Art. 6 I der Richtlinie lautet: „Die Mitgliedstaaten sehen vor, dass missbräuchliche Klauseln in Verträgen, die ein Gewerbetreibender mit einem Verbraucher geschlossen hat, für den Verbraucher unverbindlich sind, und legen die Bedingungen hierfür in ihren innerstaatlichen Rechtsvorschriften fest; sie sehen ferner vor, dass der Vertrag für beide Parteien auf derselben Grundlage bindend bleibt, wenn er ohne die missbräuchlichen Klauseln bestehen kann.“ 
Klauselrichtlinie kein angemessenes und wirksames Mittel gesehen werden könne, um der Verwendung dieser Klauseln ein Ende zu setzen. ${ }^{2267}$

Dadurch, dass er zur Begründung der Unzulässigkeit des Vorgehens des Tribunal Supremo darauf Bezug nimmt, dass nur er die Geltung einer von ihm vorgenommenen Auslegung einer Norm des Unionsrechts in zeitlicher Hinsicht einschränken kann ${ }^{268}$, könnte der Gerichtshof nationalen Vertrauensschutzerwägungen bei der Anwendung von Richtlinien ganz generell eine Absage erteilt haben. Ob dies tatsächlich der Fall ist, kann nur eine Analyse seiner tragenden Erwägungen zeigen.

Art. 6 I der Klauselrichtlinie ist dem Gerichtshof zufolge dahingehend zu verstehen, dass eine für missbräuchlich erklärte Vertragsklausel grundsätzlich als von Anfang an nicht existent anzusehen ist, sodass der Verbraucher in eine Lage zu versetzen ist, in der er sich ohne die Klausel befunden hätte; die damit verbundene Restitutionswirkung entspreche dem von Art. 6 I i.V.m. Art. 7 I der Klauselrichtlinie verfolgten Ziel der Abschreckung vor der Verwendung missbräuchlicher Klauseln. ${ }^{2269}$ Der EuGH erblickt in der „Unverbindlichkeit“ missbräuchlicher Klauseln demnach trotz des Verweises in Art. 6 I der Klauselrichtlinie auf im innerstaatlichen Recht festgelegte Bedingungen kein von den Mitgliedstaaten zu konkretisierendes Konzept, sondern schreibt ihr mit den Elementen der Rück- und Restitutionswirkung unionsautonome Merkmale zu. ${ }^{2270}$

2267 Vgl. EuGH, Urteil vom 21.12.2016, verb. Rs. C-154/15, C-307/15 und C-308/15 (Gutiérrez Naranjo u.a.), Rn. 71 ff. Dass damit im Ergebnis der Klauselverwender das Risiko der rückwirkenden Unwirksamkeit der missbräuchlichen Klausel trägt, ist eine auch in der nationalen Rechtsprechung anzutreffende Lösung, vgl. BGH, Urteil vom 13.5.2014, XI ZR 405/12, Rn. 88 - BGHZ 201, 168; BGH, Urteil vom 5.3.2008, VIII ZR 95/07, Rn.19f. - NJW 2008, 1438; BGH, Urteil vom 18.1.1996, IX ZR 69/95 - BGHZ 132, 6 (11f.). Auf diese Rechtsprechung weist auch Düsterhaus, EuR 2017, 30 (49, Fn. 151) hin. Die Frage des Vertrauensschutzes im Falle einer Rechtsprechungsänderung kann daher, wenn AGB betroffen sind, durchaus nach eigenständigen Maßstäben behandelt werden, siehe Maultzsch, RabelsZ 79 (2015), 323 (358 ff.) und oben bei Fn. 2029. Kritisch insoweit etwa Herdegen, WM 2009, 2202.

2268 EuGH, Urteil vom 21.12.2016, verb. Rs. C-154/15, C-307/15 und C-308/15 (Gutiérrez Naranjo u.a.), Rn. 70 unter Verweis auf EuGH, Urteil vom 2.2.1988, Rs. 309/85 (Barra u.a.), Rn. 13.

2269 EuGH, Urteil vom 21.12.2016, verb. Rs. C-154/15, C-307/15 und C-308/15 (Gutiérrez Naranjo u.a.), Rn. $61 \mathrm{f}$.

2270 Vgl. Leskinen/de Elizalde, CMLRev. 55 (2018), 1595 (1608). Durch die mehrfache Verwendung des Wortes "grundsätzlich“ (EuGH, Urteil vom 21.12.2016, verb. Rs. C-154/15, C-307/15 und C-308/15 (Gutiérrez Naranjo u.a.), Rn. 61 f.) zeigt sich der EuGH vorsichtig und ermöglicht eventuelle zukünftige Ausnah- 
Es verstößt nach Auffassung des Gerichtshofs also gegen Art. 6 I der Klauselrichtlinie, wenn Wirkungen der missbräuchlichen Klauseln durch die zeitliche Begrenzung der Restitutionswirkung noch „überleben“. ${ }^{2271}$ Da die Klauselrichtlinie den Schutz des Verbrauchers im Blick hat und darauf abzielt, der Verwendung missbräuchlicher Klauseln ein Ende zu setzen, ist es nur konsequent, den Verbraucher in eine Lage zu versetzen, in der er sich ohne die Klausel befunden hätte, und die geleisteten Zahlungen in vollem Umfang rückabzuwickeln, um eine Abschwächung des Abschreckungseffekts ${ }^{2272}$ zu vermeiden. ${ }^{273}$ Diese Vorgaben hat das Tribunal Supremo ignoriert, indem es nicht auf eine Ausgewogenheit der Rechte und Pflichten im Einzelfall, sondern auf allgemeine Rechtssicherheitserwägungen und die finanziellen Lasten für die Kreditinstitute und damit die Klauselverwender verwiesen hat. Es ging ihm also nicht um die Aufrechterhaltung des Vertragsgleichgewichts und damit auch nicht um die Interessen beider Vertragsparteien. ${ }^{2274}$ Aus diesem Grund stellen die finanziellen Lasten der Klauselverwender keinen Grund für eine Abweichung von den unionsrechtlichen Vorgaben dar. ${ }^{2275}$ Die Nichtberücksichtigung dieser Lasten ermöglicht effektiven Verbraucherschutz. ${ }^{2276}$

Die Überlegungen des EuGH sind also deutlich erkennbar von den Besonderheiten der in Rede stehenden Bestimmung geprägt. Art. 6 I der Klauselrichtlinie selbst wohnt bereits eine zeitliche Dimension inne, indem er die Wiederherstellung einer Lage verlangt, in der sich die Parteien ohne die missbräuchliche Klausel befunden hätten. Ihm ist daher das

men von der von ihm aufgestellten Grundregel. Dass es hier Ausnahmen geben kann, ist allerdings kaum vorstellbar, so die Einschätzung bei Micklitz, VbR 2017, 80 (83). GA Szpunar, Schlussanträge vom 5.3.2020 in den verb. Rs. C-698/18 und C-699/18 (Raiffeisen Bank u.a.), Rn. 77 hebt diese Einschränkung dagegen besonders hervor.

2271 Vgl. de Elizalde, EuCML 2015, 184 (187).

2272 Hervorgehoben auch von Esposito/Hacker, ERCL 2017, 98 (109 f.).

2273 Siehe dazu auch Ulmer, WuB 2017, 254 (255), der das Urteil des Gerichtshofs als „gut nachvollziehbar und im Ergebnis überzeugend“ bezeichnet.

2274 Vgl. Deinert/Ahnis, IR 2017, 106 (108).

2275 Markert, LMK 2017, 386786, der auch auf die Höhe der möglichen Rückerstattungen von mehr als 4 Milliarden Euro hinweist; Ulmer, WuB 2017, 254 (255).

2276 Der EuGH wehrt sich hier also gegen die Einbeziehung sozioökonomischer Argumente, um die Wirkungen des Unionsrechts zu begrenzen, während er solche zur Verstärkung des Verbraucherschutzes selbst heranzieht, wie etwa in EuGH, Urteil vom 14.3.2013, Rs. C-415/11 (Aziz), Rn.61, wo er auf den verstärkenden Aspekt der Betroffenheit der Wohnung des geschädigten Verbrauchers und seiner Familie Bezug nimmt. Zum Ganzen näher Mak, ELRev. 2018, 447 (452 ff.). 
Verbot der Begrenzung der Restitutionswirkung zu entnehmen. Verstärkend kommt noch hinzu, dass Art. 6 I der Klauselrichtlinie über seine Eigenschaft als nicht dispositive Vorschrift auch ordre public-Charakter zukommt. Deutlich wird dies etwa an der englischen, französischen und italienischen Urteilsfassung, aber auch an der spanischen Sprachfassung als Verfahrenssprache, die zwischen "rules of public policy“ und „mandatory provision" bzw. den diesen Begriffen in den anderen Sprachen entsprechenden Begrifflichkeiten differenzieren, wohingegen in der deutschen Fassung an sämtlichen Stellen einheitlich von „zwingenden Bestimmungen " die Rede ist. ${ }^{2277}$

Damit erweist sich die Argumentation des EuGH mit seiner ausschließlichen Begrenzungsbefugnis insofern als missverständlich, als mit ihr keine Aussage zur Möglichkeit nationaler Vertrauensschutzerwägungen verbunden ist. Sie dient lediglich der Abgrenzung von den den Mitgliedstaaten als Ausfluss ihrer Verfahrensautonomie zur Verfügung stehenden Möglichkeiten. Der Verweis des EuGH auf seine Begrenzungsrechtsprechung dient damit nicht dazu, einen Vergleich zwischen der Wirkung der Berücksichtigung nationaler Vertrauensumstände mit der Defrenne-Rechtsprechung zu fordern, um auf der Grundlage des Ergebnisses dieses Vergleichs darüber zu entscheiden, ob sie Beachtung finden können. ${ }^{2278}$

\section{(2) Deutlicher Hinweis im Urteil in der Rechtssache DI}

Auch wenn vielfach angenommen wird, dass dem Urteil in der Rechtssache DI zur unmittelbaren Wirkung des Verbots der Altersdiskriminierung zwischen Privaten für die hier interessierende Frage noch keine abschlieBende Aussage entnommen werden könne ${ }^{2279}$, so legt es doch zumindest

2277 EuGH, Urteil vom 21.12.2016, verb. Rs. C-154/15, C-307/15 und C-308/15 (Gutiérrez Naranjo u.a.), Rn. 54 (rules of public policy) einerseits und Rn. 55 (mandatory provision) andererseits. Siehe auch bereits EuGH, Urteil vom 6.10.2009, Rs. C-40/08 (Asturcom Telecomunicaciones), Rn. 30, 51 (mandatory provision) einerseits und Rn. $52 \mathrm{ff}$. (rules of public policy) andererseits. Zur Frage der Begründung des ordre public-Charakters siehe EuGH, Urteil vom 6.10.2009, Rs. C-40/08 (Asturcom Telecomunicaciones), Rn. 30, 51 f. und Hilbig, SchiedsVZ 2010, 74 (78f.).

2278 Wohl aus diesem Grund meint Rosenkranz, ZESAR 2018, 24 (26), die Bezugnahme auf seine Begrenzungsrechtsprechung könne eine „bloße Unachtsamkeit" gewesen sein.

2279 Oetker, EWiR 2015, 193 (194); Gallner, FA 2016, 289. Siehe auch Brams, Impulse, 2019, S.278, die die Frage als unbeantwortet ansieht, aber zunächst 
sehr nahe, dass nationale Vertrauensumstände nach Auffassung des Gerichtshofs auch gegen die Verpflichtung zu richtlinienkonformer Auslegung nicht in Stellung gebracht werden können. Der EuGH hält dort nämlich zusammenfassend fest, dass weder die Grundsätze der Rechtssicherheit und des Vertrauensschutzes noch die Möglichkeit eines unionsrechtlichen Staatshaftungsanspruchs des Einzelnen gegen den Mitgliedstaat die Verpflichtung des nationalen Gerichts zur richtlinienkonformen Auslegung bzw. zur Nichtanwendung des nationalen Rechts in Frage stellen können. ${ }^{2280}$ Insbesondere stellt der Tenor Nr. 2 eine Verpflichtung zur richtlinienkonformen Anwendung des nationalen Rechts und nicht nur zu einer entsprechenden Auslegung auf. ${ }^{2281} \mathrm{Da}$ der Gerichtshof offenlässt, ob das unionsrechtskonforme Ergebnis über eine konforme Auslegung des nationalen Rechts oder dessen Nichtanwendung zu erreichen ist, sind seine Aussagen zum Vertrauensschutz nicht auf die Lösung über den Anwendungsvorrang begrenzt.

Dass das Recht des Einzelnen auf Entschädigung nicht dazu führen darf, dass dem Vertrauensschutz des Arbeitgebers, der dem nationalen Recht nachgekommen ist, der Vorrang eingeräumt wird ${ }^{2282}$, überzeugt, da die Möglichkeit von Staatshaftung nicht genügen kann, die direkte Berufung auf Unionsrecht auszuschließen, um der Effektivität des Unionsrechts nicht allzu großen Schaden zuzufügen. ${ }^{2283}$ Ein unionsrechtlicher Staatshaftungsanspruch wäre lediglich „Trostpreis“ für die Nichtdurchsetzung des unionsrechtlichen Rechts auf Primärebene und seiner geschmälerten effektiven Geltendmachung. ${ }^{2284}$

ausführte, das Urteil habe klargestellt, dass das Gebot der richtlinienkonformen Auslegung nicht durch die Gewährung von Vertrauensschutz unterlaufen werden dürfe. Zum DI-Urteil ausführlich bereits oben bei Fn. $1588 \mathrm{ff}$.

2280 EuGH, Urteil vom 19.4.2016, Rs. C-441/14 (DI), Tenor Nr. 2 und Rn. 43 sprechen von "diese“ Verpflichtung; aus dem Zusammenhang ergibt sich, dass damit sowohl die richtlinienkonforme Auslegung als auch die Nichtanwendung des nationalen Rechts gemeint sind. Auch Haket, NtEr 2016, 237 (241) stellt fest, dass im Tenor beide Durchsetzungswege angesprochen sind.

2281 Siehe auch die Ausführungen von Dubout, R.A.E. 2016, 287 (290).

2282 EuGH, Urteil vom 19.4.2016, Rs. C-441/14 (DI), Rn. 42.

2283 Dubout, R.A.E. 2016, 287 (290).

2284 Sowery, CMLRev. 53 (2016), 1705 (1720 ff.) unter Inbezugnahme von EuGH, Urteil vom 6.10.2015, Rs. C-69/14 (Târşia), Rn. 40. Siehe auch Forst, EWiR 2016, 381 (382). 
(3) Rechtssicherheit und Vertrauensschutz

Eine Begrenzung der Pflicht zu richtlinienkonformer Auslegung durch die allgemeinen Rechtsgrundsätze des Unionsrechts setzt wie gesehen eine Maßstabsbildung auf Ebene des Unionsrechts voraus. Hierfür kommen insbesondere die Grundsätze der Rechtssicherheit und des Vertrauensschutzes in Betracht. Ihre Fruchtbarmachung als Grenze der Pflicht zu richtlinienkonformer Auslegung erweist sich allerdings als schwierig, wie die im Folgenden anzustellenden Überlegungen deutlich machen.

\section{(a) Rechtssicherheit}

Der Grundsatz der Rechtssicherheit hat in der Rechtsprechung unterschiedliche Ausprägungen erfahren. Die Verwendung des Begriffs im Zusammenhang mit den Grenzen richtlinienkonformer Auslegung trifft also noch keine Aussage über den zugrundeliegenden inhaltlichen Maßstab.

Überlegt werden könnte zunächst, die auf den Grundsatz der Rechtssicherheit zurückzuführende Defrenne-Rechtsprechung unter den Grundsatz der Rechtssicherheit als Grenze richtlinienkonformer Auslegung zu fassen. ${ }^{2285}$ Auch wenn in diesem Zusammenhang zutreffend darauf hingewiesen wird, dass die Kriterien für die Begrenzung der Wirkung der Auslegung in zeitlicher Hinsicht bei unmittelbar und mittelbar wirkendem Unionsrecht dieselben sind ${ }^{2286}$, würde eine Heranziehung der Defrenne-Rechtsprechung im vorliegenden Zusammenhang nicht recht einleuchten, da die Defrenne-Rechtsprechung ohnehin als Grenze der Wirkung des Unionsrechts in zeitlicher Hinsicht besteht und deswegen nicht noch einmal gesondert betont werden muss. Zudem setzt diese bei der Auslegung des Unionsrechts als solcher an und begrenzt deren Wirkungen. Sie bezieht sich dagegen nicht auf die „Durchsetzungsdimension“ des Unionsrechts, um die es an dieser Stelle geht. ${ }^{2287}$

2285 Hierfür Ebers, Unionsprivatrecht, 2016, S. 409 f.

2286 Herresthal, Rechtsfortbildung, 2006, S. 303 unter Verweis auf EuGH, Urteil vom 13.12.2001, Rs. C-481/99 (Heininger), Rn. 52, die ihrerseits auf EuGH, Urteil vom 28.9.1994, Rs. C-128/93 (Fisscher), Rn. 18 verweist. Dort nimmt der EuGH das Defrenne II-Urteil in Bezug, in dem er die Defrenne-Rechtsprechung vor dem Hintergrund der unmittelbaren Anwendbarkeit des ehemaligen Art. 119 EWG-Vertrag begründet hat.

2287 Im Ergebnis ebenso Rosenkranz, ZfPW 2016, 351 (373). 
Ebenfalls nicht weiter führt letztlich der Hinweis darauf, dass der unionsrechtliche Grundsatz der Rechtssicherheit auch verlangt, dass Rechtsvorschriften klar, bestimmt und in ihren Auswirkungen vorhersehbar sein müssen, da dieser Maßstab auf das Staat-Bürger-Verhältnis zugeschnitten ist, da er dort nachteilige Folgen für Einzelne durch staatliche Maßnahmen verhindern möchte. ${ }^{2288}$

Nicht von vornherein von der Hand zu weisen ist dagegen der Gedanke, die nationalen Gerichte auf die Anwendung des unionsrechtlichen Rückwirkungsverbots zu verpflichten, um so eine Begrenzung der Wirkung des Unionsrechts im Einzelfall zu erreichen. ${ }^{2289}$ Der Grundsatz der Rechtssicherheit lässt eine Rückwirkung nur dann zu, wenn sie durch Allgemeininteressen gerechtfertigt ist und dem berechtigten Vertrauen der Betroffenen hinreichend Rechnung getragen wird. 2290 „Üblicher" Adressat des unionsrechtlichen Rückwirkungsverbots ist der Unionsgesetzgeber. Gerichtet ist der Grundsatz der Rechtssicherheit in dieser Ausprägung aber auch an die mitgliedstaatlichen Gesetzgeber, wenn sie ihnen in Richtlinien eingeräumte Befugnisse ausüben und damit auch, wenn sie ein unter das Unionsrecht fallendes Gesetz erlassen. ${ }^{2291}$

Festzuhalten bleibt zunächst, dass der Gerichtshof damit sowohl die zeitliche Dimension von Rechtsprechung als auch von Rechtsetzung dem Grundsatz der Rechtssicherheit unterworfen hat. Während die Rückwirkung von Normen nur ausnahmsweise zulässig ist, ist im Hinblick auf die Auslegung des Unionsrechts vom Grundsatz der ex tunc-Wirkung auszugehen, die nur ausnahmsweise beschränkt werden kann.2292 Obwohl er sich beide Male auf den Grundsatz der Rechtssicherheit beruft, hat der Gerichtshof diesem demnach einen jeweils unterschiedlichen Gehalt beigelegt.

Angesichts der Bedeutungsoffenheit des Begriffs ist daher nicht auszuschließen, dass der Grundsatz der Rechtssicherheit als Grenze der Pflicht zu richtlinienkonformer Auslegung einer zeitlich nicht begrenzten richtlinienkonformen Auslegung entgegensteht.

2288 Erwähnung gefunden hat dieser Aspekt deshalb in einem ein solches Verhältnis betreffenden Fall, vgl. EuGH, Urteil vom 17.10.2018, Rs. C-167/17 (Klohn), Rn. 50.

2289 Hierfür Latzel, EuR 2015, 415 (429, 436).

2290 EuGH, Urteil vom 26.4.2005, Rs. C-376/02 („Goed Wonen“), Rn. 33. Hierauf verweist GA Kokott, Schlussanträge vom 9.1.2008 in der Rs. C-268/06 (Impact), Rn. 140, als sie sich zur Grenze der allgemeinen Rechtsgrundsätze äußert.

2291 EuGH, Urteil vom 26.4.2005, Rs. C-376/02 („Goed Wonen“), Rn. 32, 34.

2292 Siehe auch Latzel, EuR 2015, 415 (436). 
In seiner Ausprägung als Rückwirkungsverbot hat der Grundsatz der Rechtssicherheit für nationale Gerichte aber jedenfalls bislang keine Bedeutung erlangt. Wegen des deklaratorischen Auslegungsverständnisses des EuGH ist insoweit auch keine Gleichbehandlung zu erwarten. ${ }^{2293}$ Lediglich in Ausnahmefällen wie im besonders sensiblen Bereich des Strafrechts scheint der Gerichtshof für Rechtsetzung und Rechtsprechung einheitliche Maßstäbe anzulegen. ${ }^{2294}$ Verallgemeinern lässt sich dies aber nicht.

\section{(b) Vertrauensschutz}

Wie sich nicht zuletzt in der bislang stets im Rahmen der Defrenne-Rechtsprechung vorgesehenen Rückausnahme für Rechtsbehelfsführer zeigt, stellen Vertrauensschutz und Rechtssicherheit unterschiedliche Aspekte dar. Eine Begrenzung der zeitlichen Wirkungen unter Anordnung einer Rückausnahme berücksichtigt ja die Interessen der Gegenseite im Ausgangsverfahren nicht. ${ }^{2295}$ Daneben zielt die Gewährung von Vertrauensschutz auf den Einzelfall ab und kann daher nicht eine Gefahr schwerwiegender Störungen für ganze Subsysteme zur Voraussetzung haben. ${ }^{2296}$ An diesen Unterschied zwischen dem Maßstab der Defrenne-Rechtsprechung und der Berücksichtigung von Vertrauensumständen im Einzelfall knüpfen zahlreiche Stimmen in der Literatur an, um eine Begrenzung des im Einzelfall durch richtlinienkonforme Auslegung zu erzielenden Ergebnisses in zeitlicher Hinsicht einzufordern. 2297

Der unionsrechtliche Grundsatz des Vertrauensschutzes zum Schutz von Rechtspositionen Einzelner kann hierfür aber nicht herangezogen werden. Ihn hat der Gerichtshof wie gesehen zwar in der Rechtssache Klohn angesprochen. Dort bezog er sich allerdings auf die Sonderkonstellation der „immediate applicability“; auch war kein horizontales Rechtsverhältnis

2293 Rosenkranz, ZfPW 2016, 351 (373).

2294 EuGH, Urteil vom 5.12.2017, Rs. C-42/17 (M.A.S. und M.B.), Rn. 60.

2295 Siehe Koch, SR 2012, 159 (166).

2296 Weber, Grenzen, 2010, S. 146 f.

2297 Siehe etwa Brams, Impulse, 2019, S. 280 f., 283, 285. Sie spricht von einem Alternativverhältnis, in dem nationale Vertrauensschutzerwägungen und Defrenne-Rechtsprechung stünden. Ebenso Gallner, in: FS Etzel, 2011, S. 155 (167). Der unterschiedliche Bezugspunkt der Erwägungen von EuGH und nationalem Gericht überzeugt auch Kamanabrou, SAE 2009, 233 (236). 
betroffen. ${ }^{2298} \mathrm{Da}$ es bei der richtlinienkonformen Auslegung in der Regel nicht um einzelfallbezogene Umstände geht ${ }^{2299}$, steht insoweit keine dem Einzelnen eingeräumte Rechtsposition in Rede. ${ }^{2300}$ Ausgelegt wird nationales Recht aus Anlass eines Rechtsstreits zwischen Privaten. Eine aus verwaltungsrechtlichen Konstellationen bekannte „Zusicherung“ erhalten die Betroffenen hier nicht. ${ }^{2301}$

Ein Anwendungsbeispiel für den unionsrechtlichen Grundsatz des Vertrauensschutzes als Grenze der richtlinienkonformen Auslegung bildet auch nicht das Problem der zu Lasten einer Partei erfolgten Abweichung des EuGH von seinem bisherigen Verständnis einer Richtlinienbestimmung, da dieses eine im Rahmen der Defrenne-Rechtsprechung des EuGH zu behandelnde Frage darstellt. Dass eine Ausweitung der Anforderungen an die richtlinienkonforme Auslegung Vertrauensschutzprobleme aufwerfen kann, erscheint angesichts ihrer bereits jetzt bestehenden "Schärfe“ kaum denkbar, da sie es derzeit schon ermöglicht, mit der unmittelbaren Wirkung vergleichbare Ergebnisse zu erzielen. ${ }^{2302}$

\section{(c) Fazit}

Eine eigenständige Ausfüllung der allgemeinen Rechtsgrundsätze des Unionsrechts im Hinblick auf Horizontalverhältnisse muss daher scheitern. Als Grenze der Pflicht zu richtlinienkonformer Auslegung sind sie auf das Strafrecht und umgekehrt vertikale Verhältnisse beschränkt. ${ }^{2303} \mathrm{Im}$ Rahmen von Horizontalverhältnissen erlangt der Grundsatz der Rechtssi-

2298 Siehe oben bei Fn. $2067 \mathrm{ff}$.

2299 Vgl. Rosenkranz, Beschränkung der Rückwirkung, 2015, S. 486 f. Nach Müller/ Christensen, Juristische Methodik, Band II, 3. Aufl. 2012, Rn. 580 ist „mangels konkret zu entscheidender Fälle" noch offen, ob Vertrauensschutz auch bei der richtlinienkonformen Auslegung eine Rolle spielt.

2300 Die begrenzte Bedeutung des Vertrauensschutzes im vorliegenden Zusammenhang betont auch Dubout, R.A.E. 2016, 287 (292 f.).

2301 Einen Sonderfall bildet die Äußerung eines nationalen Gerichts, die die fehlende richtlinienkonforme Auslegbarkeit des nationalen Rechts betont hat und der daher vertrauensschützende Wirkung zukommt, siehe oben bei Fn. 2247.

2302 Diese Aspekte unter den unionsrechtlichen Vertrauensschutz fassend allerdings Weber, Grenzen, 2010, S. $144 \mathrm{f}$.

2303 Vgl. Dubout, R.A.E. 2016, 287 (296f.). 
cherheit damit lediglich in Gestalt der contra legem-Grenze Bedeutung. ${ }^{2304}$ Dass diese zu beachten ist, ändert nichts daran, dass auch eine gefestigte nationale Rechtsprechung die Erzielung richtlinienkonformer Ergebnisse nicht hindert.

\section{(4) Vergleichbarkeit mit den Erwägungen zum Anwendungsvorrang}

Dadurch dass die allgemeinen Rechtsgrundsätze im richtliniengeprägten Horizontalverhältnis nicht als Grenze der Pflicht zu richtlinienkonformer Auslegung zum Tragen kommen und das DI-Urteil des EuGH einen Ausschluss der Möglichkeit zur Berücksichtigung nationaler Vertrauensumstände nahelegt, zeichnet sich insoweit eine Gleichbehandlung der richtlinienkonformen Auslegung mit dem Anwendungsvorrang ab, wenn man von den über die contra legem-Grenze geschützten Aspekten einmal absieht. Sie erscheint im Ergebnis auch gerechtfertigt.

Dass die richtlinienkonforme Auslegung nach ihrer Konzeption - anders als der Anwendungsvorrang - nationale Normen nicht verdrängt, steht einer Gleichbehandlung für die vorliegenden Zwecke nicht entgegen. Entscheidend ist, dass der Inhalt der nationalen Norm durch die richtlinienkonforme Auslegung (innerhalb der Grenzen des methodisch Möglichen) dadurch im Ergebnis verändert wird, dass diese eigentlich stärkere Auslegungsgesichtspunkte in den Hintergrund treten lässt und der Norm dadurch einen richtlinienkonformen Inhalt verleiht. Die Reichweite richtlinienkonformer Auslegung zeigt sich auch daran, dass sich die mit der unmittelbaren Wirkung und der richtlinienkonformen Auslegung jeweils erzielbaren Ergebnisse kaum voneinander unterscheiden, auch wenn der Gerichtshof sie als unterschiedliche Kategorien konzipiert hat; die Übergänge sind fließend. ${ }^{2305}$ Es ist daher denkbar, dass ein Gericht in einem Rechtsstreit die unmittelbare Wirkung einer Richtlinienbestimmung gegenüber dem Mitgliedstaat bejaht und gegenüber einer anderen

2304 Vgl. EuGH, Urteil vom 5.9.2019, Rs. C-331/18 (Pohotovost'), Rn. 56; EuGH, Urteil vom 5.3.2020, Rs. C-679/18 (OPR-Finance), Rn. 45.

2305 Vgl. GA Bobek, Schlussanträge vom 26.6.2018 in der Rs. C-384/17 (Link Logistik N\&N), Rn. 52 ff. Siehe auch EuGH, Urteil vom 15.3.2018, Rs. C-470/16 (North East Pylon Pressure Campaign und Sheehy), Rn. 58: „Diese Bestimmungen haben keine unmittelbare Wirkung, doch ist es Sache des nationalen Gerichts, das nationale Verfahrensrecht so auszulegen, dass es so weit wie möglich mit diesen im Einklang steht." Auf diese Aussage weist auch GA Bobek, Schlussanträge vom 5.6.2018 in der Rs. C-167/17 (Klohn), Rn. 34 hin. 
privaten Partei ablehnt, dieser dann aber doch im Wege richtlinienkonformer Auslegung dieselbe Verpflichtung auferlegt. ${ }^{2306}$

Auch das Bundesverfassungsgericht zieht in seinem Beschluss zur JunkProblematik eine Parallele zwischen der Unterlassung der richtlinienkonformen Auslegung einer nationalen Norm wegen der Gewährung von Vertrauensschutz ${ }^{2307}$ und der Frage der Gewährung von Vertrauensschutz bei Unvereinbarkeit mit unmittelbar anwendbarem Primärrecht. Dies wird nicht zuletzt an dem Verweis auf seine diesbezüglichen Ausführungen im Honeywell-Beschluss deutlich, der das unmittelbar anwendbare Verbot der Altersdiskriminierung betraf. ${ }^{2308}$ Im Zusammenhang damit steht der Vorwurf des Bundesverfassungsgerichts an das BAG, dass die Begrenzung der praktischen Wirksamkeit der Richtlinie aus Gründen des nationalen Verfassungsrechts im Widerspruch zur Rechtsprechung des Gerichtshofs zum Vorrang des Unionsrechts stehe. ${ }^{2309}$ Ebenso stellt es eine Verbindung zwischen der Beschränkungsrechtsprechung des EuGH und der praktischen Wirksamkeit der Richtlinie her, was an die Erwägungen zur (fehlenden) Möglichkeit der Gewährung „nationalen Vertrauensschutzes“ bei Betroffenheit des Anwendungsvorrangs erinnert. ${ }^{2310}$

2306 GA Bobek, Schlussanträge vom 5.6.2018 in der Rs. C-167/17 (Klohn), Rn. 74 mit Fn. 48 meint dagegen, ein Gericht würde dies nicht tun.

2307 BVerfG, Beschluss vom 10.12.2014, 2 BvR 1549/07, Rn. 40 - NZA 2015, 375.

2308 BVerfG, Beschluss vom 10.12.2014, 2 BvR 1549/07, Rn. 40 - NZA 2015, 375 unter Verweis auf BVerfG, Beschluss vom 6.7.2010, 2 BvR 2661/06 - BVerfGE 126, 286 (314).

2309 BVerfG, Beschluss vom 10.12.2014, 2 BvR 1549/07, Rn. 41 - NZA 2015, 375 unter Verweis auf EuGH, Urteil vom 17.12.1970, Rs. 11/70 (Internationale Handelsgesellschaft), Rn.3, wonach nationales Verfassungsrecht der Geltung von Handlungen der Unionsorgane nicht entgegengehalten werden kann.

2310 BVerfG, Beschluss vom 10.12.2014, 2 BvR 1549/07, Rn. 35 - NZA 2015, 375 zitiert mit EuGH, Urteil vom 27.3.1980, Rs. 61/79 (Denkavit italiana), Rn. $17 \mathrm{f}$. unter Verweis auf EuGH, Urteil vom 8.4.1976, Rs. 43/75 (Defrenne), Rn. 74/75 einerseits Urteile, in denen der Gerichtshof sein Monopol zur Begrenzung der zeitlichen Wirkungen einer von ihm vorgenommenen Auslegung begründet hat, und mit EuGH, Urteil vom 10.4.1984, Rs. 14/83 (von Colson und Kamann), Rn. 26, EuGH, Urteil vom 16.7.2009, Rs. C-12/08 (Mono Car Styling), Rn.60, EuGH, Urteil vom 19.1.2010, Rs. C-555/07 (Kücükdeveci), Rn. 48, EuGH, Urteil vom 15.1.2014, Rs. C-176/12 (Association de médiation sociale), Rn. 38 andererseits Urteile, die sich mit der Reichweite der Pflicht zu richtlinienkonformer Auslegung befassen und die Verpflichtung der nationalen Gerichte aufstellen, das nationale Recht so weit wie möglich an Wortlaut und Zweck der Richtlinie auszurichten, um das darin festgelegte Ergebnis zu erreichen. 
Die Bindung an die Umsetzungspflicht verwehrt es daher den mitgliedstaatlichen Gerichten, die Wirkungen der Richtlinie durch die Gewährung von Vertrauensschutz hinauszuzögern. ${ }^{2311}$ Angesichts der sich aus Art. 288 III AEUV, 4 III EUV ergebenden Verpflichtung zur richtlinienkonformen Auslegung kann nur der EuGH eine zeitliche Begrenzung der Reichweite der Pflicht zur richtlinienkonformen Auslegung anordnen. ${ }^{2312}$ Die zum Teil ins Feld geführte größere Sachnähe der nationalen Gerichte, die in der besseren Position für eine Entscheidung über die zeitlichen Grenzen der richtlinienkonformen Auslegung seien ${ }^{2313}$, ist daher ohne Belang.

Angesichts der Identität der Kriterien für die Begrenzung der Wirkungen der Auslegung in zeitlicher Hinsicht bei unmittelbar und mittelbar wirkendem Unionsrecht kann nicht geltend gemacht werden, dass bei mittelbar wirkendem Unionsrecht anders als bei unmittelbar wirkendem ein Schutzdefizit bestehe, weswegen Vertrauensschutzerwägungen neben der Defrenne-Rechtsprechung zulässig sein müssten. ${ }^{2314}$ Dieses bestünde bei unmittelbar wirkendem Unionsrecht dann gleichermaßen. Dort können auf das Vertrauen auf nationales Recht gestützte Erwägungen neben der Defrenne-Rechtsprechung aber wie gesehen nicht zum Tragen kommen. Gleiches gilt, von den angesichts der Anerkennung der contra legem-Grenze geschützten Aspekten abgesehen, für den Bereich der richtlinienkonformen Auslegung.

bb) Verhältnis zu Art. 53 GRCh

Noch zu klären gilt es das Verhältnis der bisherigen Ausführungen zu Art. 53 GRCh vor dem Hintergrund, dass zum Teil geltend gemacht wird, nationaler Vertrauensschutz dürfe wegen Art. 53 GRCh „durchaus“ weiter gehen als nach Unionsrecht. ${ }^{2315}$

2311 Riesenhuber/Domröse, NZA 2005, 568 (569).

2312 Ähnlich Temming, ZESAR 2015, 298 (300); siehe auch Preis/Temming, NZA 2010, 185 (188).

2313 Höpfner, in: Franzen/Gallner/Oetker (Hrsg.), Arbeitsrecht, 3. Aufl. 2020, Art. 288 AEUV, Rn. 54. Siehe auch Arnold/Schansker, ArbRAktuell 2015, 89 (92), die entscheidend darauf abstellen, dass die Anwendung des Unionsrechts im nationalen Rahmen Sache der nationalen Gerichte sei.

2314 In diese Richtung aber Düsterhaus, YEL 36 (2017), 237 (262).

2315 Michael, Der Staat 54 (2015), 349 (370) im Hinblick auf die richtlinienkonforme Rechtsfortbildung. Siehe auch Kirchhof, NVwZ 2014, 1537 (1538, Fn. 14), 
Zunächst ist davon auszugehen, dass jede Auslegung, Anwendung und Nichtanwendung des Unions- oder nationalen Rechts die allgemeinen Rechtsgrundsätze und Grundrechte des Unionsrechts achten muss, wobei unerheblich ist, ob eine unmittelbar oder mittelbar wirkende Norm des Unionsrechts in Rede steht. Sowohl die Nichtanwendung des nationalen Rechts als auch dessen konforme Auslegung können an allgemeinen Rechtsgrundsätzen des Unionsrechts scheitern. ${ }^{2316}$

Würde die Anwendung einer unionsrechtskonformen Auslegung etwa auf den Sachverhalt des Ausgangsverfahrens einer Vorabentscheidung zur Verletzung der in der Charta verankerten Grundrechte oder der allgemeinen Grundsätze des Unionsrechts führen, besteht keine Verpflichtung zur Vornahme einer solchen Auslegung, auch wenn dadurch die Unvereinbarkeit mit Unionsrecht beseitigt werden könnte. ${ }^{2317}$ Da Gleiches für den Fall der Nichtanwendung des nationalen Rechts gilt, können richtlinienkonforme Auslegung und Vorrang im Hinblick auf ihre Begrenzung durch Grundrechte und allgemeine Rechtsgrundsätze gleichbehandelt werden. Vor dem Hintergrund, dass eine Durchführung des Unionsrechts auch bei der Anwendung der zur Umsetzung einer Richtlinie ergangenen nationalen Rechtsvorschriften und damit auch bei der richtlinienkonformen Auslegung vorliegt ${ }^{2318}$, richtet sich die Zulässigkeit der Anwendung eines höheren nationalen Grundrechtsstandards nach den gleichen Maßstäben.

Damit sind auch hier die den Mitgliedstaaten durch Art. 53 GRCh eröffneten Möglichkeiten unionsrechtlich begrenzt, wie die Rechtsprechung des Gerichtshofs im Grundrechtsbereich zeigt. 2319 Ein auf Art. 53 GRCh gestützter Ansatz muss daher bedenken, dass nationaler Vertrau-

der meint, u.a. an Art. 53 GRCh zeige sich, dass die Vorrangfrage der Grundrechtecharta gegenüber nationalen Grundrechten offengehalten worden sei.

2316 Prechal, in: Barnard (Hrsg.), The Fundamentals of EU Law Revisited, 2007, S. 35 (49 f.); Dougan, CMLRev. 56 (2019), 1459 (1473f.). EuGH, Urteil vom 7.1.2004, Rs. C-60/02 (X), Rn. 62 etwa überträgt „die Erwägungen des Gerichtshofes zu den Richtlinien" auf eine Verordnung.

2317 GA Sharpston, Schlussanträge vom 6.12.2018 in der Rs. C-566/17 (Związek Gmin Zagłębia Miedziowego), Rn.74f. unter Heranziehung verschiedener Urteile des Gerichtshofs.

2318 GA Sharpston, Schlussanträge vom 31.1.2019 in der Rs. C-704/17 (D.H.), Rn. 30 f. Siehe auch EuGH, Urteil vom 5.4.2016, verb. Rs. C-404/15 und C-659/15 PPU (Aranyosi und Căldăraru), Rn. 84 zum Vorliegen einer Durchführung des Unionsrechts bei der Anwendung der zur Umsetzung eines Rahmenbeschlusses ergangenen nationalen Bestimmungen.

2319 EuGH, Urteil vom 26.2.2013, Rs. C-399/11 (Melloni), Rn. 60. Siehe dazu bereits oben bei Fn. $1722 \mathrm{ff}$. und Fn. $1883 \mathrm{ff}$. 
ensschutz als autonome Garantie in den Anwendungsbereich der allgemeinen Rechtsgrundsätze und damit auch den der (unionsrechtlichen) Rechtssicherheit als Grenze der richtlinienkonformen Auslegung fällt. ${ }^{2320}$ Aus diesem Grund kann er grundsätzlich nicht zu einer weitergehenden Begrenzung der Pflicht zu richtlinienkonformer Auslegung führen als in dieser Arbeit bislang angenommen.

Im grundrechtlichen Bereich ist für die Frage der Anwendung nationaler (Grundrechts)maßstäbe eine Unterscheidung danach möglich, ob eine Fallgestaltung durch unionsrechtliche Bestimmungen determiniert ist oder ob es sich um eine solche handelt, die Spielräume für Mitgliedstaaten eröffnet. So kommt die Anwendung nationaler Grundrechtsgewährleistungen nur in Betracht, soweit die Bestimmungen einer Richtlinie keine vollständige Harmonisierung bewirken. Die im nationalen Recht belassenen Umsetzungsspielräume, die eine Anwendung nationaler Grundrechtsstandards ermöglichen, müssen sich daher auf den durch die Richtlinienbestimmungen bewirkten Harmonisierungsgrad beziehen. ${ }^{2321}$ Auch das Bundesverfassungsgericht unterscheidet hinsichtlich des anzuwendenden Grundrechtsmaßstabs zwischen vollständig vereinheitlichtem und gestaltungsoffenem Unionsrecht, wobei sich die Abgrenzung nach einer Auslegung des jeweils anzuwendenden unionsrechtlichen Fachrechts richtet. ${ }^{2322}$

Da sich im Horizontalverhältnis auch zwingende Richtlinienvorgaben nicht immer durchsetzen, wenn man mit dem EuGH davon ausgeht, dass eine unmittelbare Horizontalwirkung ausgeschlossen ist, erscheint die im grundrechtlichen Bereich getroffene Unterscheidung auf den Bereich der richtlinienkonformen Auslegung nicht ohne Weiteres übertragbar. Möchte man dennoch eine Bestimmung eines unionsrechtlich determinierten Bereichs im vorliegenden Zusammenhang versuchen, dann kommen mit der Defrenne-Rechtsprechung und den Grenzen der richtlinienkonformen Auslegung zwei Anknüpfungspunkte in Betracht. Gegen eine Inbezugnahme der Defrenne-Rechtsprechung spricht allerdings, dass es an dieser Stelle um die der Auslegung des Unionsrechts durch den EuGH nachgelagerte Stufe der „Durchsetzung“ des Unionsrechts im konkreten Fall mittels

2320 Siehe in diesem Zusammenhang auch Düsterhaus, YEL 36 (2017), 237 (263 f.). Sein Verweis in Fn. 211 auf EuGH, Urteil vom 26.4.2005, Rs. C-376/02 („Goed Wonen“), Rn. 33 erscheint aber als unpassend, da es dort gerade um den rückwirkenden Rechtsakten gegenüber wirkenden Aspekt des Rechtssicherheitsgrundsatzes geht.

2321 EuGH, Urteil vom 29.7.2019, Rs. C-476/17 (Pelham u.a.), Rn. 81.

2322 Vgl. BVerfG, Beschluss vom 6.11.2019, 1 BvR 276/17, Rn. 77 f. - EuZW 2019, 1035. 
richtlinienkonformer Auslegung geht. Damit können an dieser Stelle nur die Grenzen der richtlinienkonformen Auslegung in den Blick zu nehmen sein. Sie umfassen die allgemeinen Rechtsgrundsätze, die aber wie gesehen im Horizontalverhältnis gerade keinen Raum für eine Berücksichtigung nationaler Vertrauensumstände bieten. Aus diesem Grund muss im Übrigen auch ein grundrechtlicher Ansatz scheitern, der bei Betroffenheit des Anwendungsvorrangs „nationalen Vertrauensschutz“ gewähren will. Insoweit ist die Rechtslage durch die Defrenne-Rechtsprechung determiniert, neben der eine weitergehende Berücksichtigung nationaler Vertrauensumstände nicht möglich ist.

Damit kann eine Anwendung mitgliedstaatlicher Grundrechtsstandards im vorliegenden Zusammenhang nur verfangen, wenn die zugrundeliegende Richtlinienbestimmung in den Blick genommen wird.2323 Diese kann einem Mitgliedstaat mehrere Möglichkeiten zur Umsetzung bieten. In diesem Fall steht es dem Mitgliedstaat frei, sich für eine dieser Möglichkeiten zu entscheiden. Legt ein nationales Gericht das in Ausfüllung des von der Richtlinie gewährten Gestaltungsspielraums gesetzte nationale Recht nun anders als bisher aus, erscheint es nach Auffassung von Düsterhaus als eine Frage des nationalen Rechts, ob die Berufung auf die Neuauslegung auch mit Wirkung für die Vergangenheit möglich ist. ${ }^{2324}$

Zuzustimmen ist dieser Überlegung insoweit, als die Auslegung einer Umsetzungsspielraum gewährenden Vorschrift durch den EuGH zwar an sich verbindlich ist, die mitgliedstaatlichen Spielräume aber nicht zwangsläufig beseitigt. Die Neuauslegung der nationalen Umsetzungsbestimmung durch ein nationales Gericht ist daher solange eine Frage des nationalen Rechts, als sich die Auslegung innerhalb des gewährten Spielraums bewegt. Liegt die Rechtsprechungsänderung dagegen darin begründet, das nationale Recht in Einklang mit der Auslegung der Richtlinie durch den EuGH zu bringen, steht die Verpflichtung auf das von der Richtlinie vorgegebene Ergebnis im Vordergrund. ${ }^{2325}$ An ihr ändert das Bestehen mehrerer Möglichkeiten der Umsetzung nichts, weshalb insoweit

2323 Ebenso Düsterhaus, EuR 2017, 30 (47 f.).

2324 Düsterhaus, YEL 36 (2017), 237 (264).

2325 Diese Anforderung kommt etwa in der englischen und französischen Fassung des Art. 288 III AEUV zum Ausdruck, in denen nicht von „Ziel“, sondern von „result" bzw. „résultat" die Rede ist. Siehe dazu auch Ipsen, in: FS Ophüls, 1965, S. 67 (73f.), der meint, die deutsche Fassung des Art. 288 III AEUV verwende eine „recht eigenwillige“ Formulierung im Vergleich zu den übrigen Sprachfassungen, da „Ziel“ sonst Synonym etwa für „idéal“, „but“, „objectif“, „objet" sei. 
die Anwendung eines mitgliedstaatlichen Grundrechtsmaßstabes ausscheiden muss.

Bei weiten Umsetzungsspielräumen der Mitgliedstaaten sind die Pflicht zur richtlinienkonformen Auslegung und die unionsrechtlichen Grenzen nationalen Vertrauensschutzes daher „relativiert“. ${ }^{2326}$ Insoweit ist der unionsrechtliche Grundsatz der Rechtssicherheit nicht „umfassend und abschließend“2327, sondern gestattet die Anwendung eines nationalen Grundrechtsstandards. Bei bloßer Teilharmonisierung kann das in den einzelnen Mitgliedstaaten jeweils unterschiedliche rechtliche Umfeld einer Regelung daher einen Vertrauenstatbestand begründen.2328

\section{f) Ergebnis}

Da sich das Unionsrecht einer Ergebniskorrektur durch Vertrauensschutzerwägungen entgegenstellt, kommt eine Einschränkung der Pflicht zur richtlinienkonformen Auslegung durch nationale Vertrauensumstände kaum einmal in Betracht. Insbesondere sind im nationalen Recht wurzelnde Belange wie der Vertrauensschutzgedanke, die lediglich eine zeitliche Begrenzung der richtlinienkonformen Auslegung fordern und sich dieser nicht aus grundsätzlich methodischen Erwägungen heraus entgegenstellen, nicht unter die contra legem-Grenze zu fassen. ${ }^{2329}$ Vertrauensschutz kann nicht einfach als Methodenregel formuliert werden.

„Nationaler Vertrauensschutz“ ist als Reflex der Begrenzung auf das methodisch Mögliche zu denken, wobei Vertrauen in den Wortlaut und die Regelungsabsicht des Gesetzgebers allerdings kaum Bedeutung zukommt, während die "Zusicherung" der fehlenden richtlinienkonformen Auslegbarkeit des nationalen Rechts durch ein nationales Gericht vertrauensschützende Wirkung entfalten kann, wenn dieses den bei der richtlinienkonformen Auslegung zu beachtenden europäischen Methodenregeln hinreichend Beachtung geschenkt hat.

Unmittelbar und mittelbar wirkendes Unionsrecht sind damit im Hinblick auf ihre Offenheit gegenüber der Berücksichtigung nationaler Vertrauensumstände im Wesentlichen gleichzubehandeln, wenn man von den durch die Methodenbindung reflexhaft geschützten Umständen einmal ab-

2326 Düsterhaus, EuR 2017, 30 (48).

2327 Anders Latzel, EuR 2015, 415 (437).

2328 Vgl. Brams, Impulse, 2019, S. $281 \mathrm{f}$.

2329 So pointiert auch Frantzen, Staatshaftung, 2018, S. 108. 
sieht. Entscheidend hierfür ist insbesondere die Umsetzungsverpflichtung nach Art. 288 III AEUV. Lediglich bei Umsetzungsspielräumen gewährenden Richtlinienvorgaben ist eine weitergehende Berücksichtigung nationaler Vertrauensumstände möglich.

\section{Zusammenfassung}

Ausgangspunkt der in diesem Kapitel angestellten Überlegungen war die Wirkungsweise von nach traditioneller Vorstellung unmittelbar und mittelbar wirkendem Unionsrecht. Trotz in seiner Rechtsprechung nachweisbarer Ansätze eines „entkoppelten“ Anwendungsvorrangs hat sich letztlich erwiesen, dass die von unionsrechtlichen Vorschriften ausgeübte Verdrängungswirkung nach Auffassung des Gerichtshofs unter der Bedingung unmittelbarer Wirkung steht. Angesichts der Ablehnung der Aufspaltung der Wirkung einer Richtlinie in eine positive Ersetzungs- und eine negative Ausschlusswirkung kann eine Richtlinienbestimmung auch im Horizontalverhältnis zwischen Privaten nicht geltend gemacht werden, um die Nichtanwendung unionsrechtswidrigen nationalen Rechts zu erreichen. Für eine unterschiedliche Beurteilung der Reaktionsmöglichkeiten mitgliedstaatlicher Gerichte im Hinblick auf die zeitliche Dimension der Rechtsprechung des Gerichtshofs, je nachdem ob unmittelbar oder lediglich mittelbar wirkendes Unionsrecht betroffen ist, war damit grundsätzlich Raum geschaffen.

In den Fokus geraten ist vor diesem Hintergrund das Instrument der richtlinienkonformen Auslegung, dessen Reichweite letztlich darüber entscheidet, welche Gesichtspunkte einer Auslegung des nationalen Rechts im Lichte der Richtlinie entgegengehalten werden können. Besonderes Augenmerk war daher auf die vom Gerichtshof anerkannten Grenzen der Pflicht zu richtlinienkonformer Auslegung zu richten und zu überlegen, ob sie für eine Berücksichtigung nationaler Vertrauensumstände fruchtbar gemacht werden können. Insoweit konnte insbesondere ein Interesse daran nachgewiesen werden, eine langjährige gefestigte Rechtsprechung als nationalen Vertrauenstatbestand ins Feld zu führen; daneben konnte gezeigt werden, dass aus Sicht der betroffenen Einzelnen die Erwartung besteht, dass die nationale Rechtsprechung angesichts ihrer Bindung an Recht und Gesetz den durch das Gesetz gesteckten Rahmen nicht verlässt.

$\mathrm{Da}$ die Bedeutung der Grenzen richtlinienkonformer Auslegung, was die Berücksichtigung nationaler Vertrauensumstände anbelangt, in der Rechtsprechung des Gerichtshofs bislang weitgehend offengeblieben ist, 
war es angezeigt, eine nähere Bestimmung des Inhalts der contra legemGrenze und der Grenze der allgemeinen Rechtsgrundsätze vorzunehmen.

Zunächst in den Blick zu nehmen war dabei die contra legem-Grenze, da sie eine Brücke zu den nationalen Methoden der Auslegung und damit zu im nationalen Recht wurzelnden Erwägungen schlägt. Bei genauerem Hinsehen hat sich allerdings der begrenzte Wert einer solchen Anknüpfung gezeigt, da die contra legem-Grenze nicht eigenständig von den mitgliedstaatlichen Gerichten ausgestaltet werden kann, sondern vielmehr weitreichende unionsrechtliche Einflüsse feststellbar sind. So sind mitgliedstaatliche Gerichte etwa dazu verpflichtet, eine richtlinienwidrige nationale Rechtsprechung abzuändern, sodass eine solche nicht angeführt werden kann, um zu begründen, die contra legem-Grenze der Auslegung sei erreicht. Eine Formulierung des Vertrauensschutzes als Methodenregel ist den nationalen Gerichten verwehrt, was sich in das Bild einfügt, dass der Gerichtshof der Anerkennung von Methodenregeln als Grenze der Konformauslegung insgesamt skeptisch gegenübersteht und darin in erster Linie eine Gefahr der Begrenzung der zeitlichen Wirkungen seiner Auslegung sieht.

Ganz ohne Bedeutung zeigte sich die Begrenzung der richtlinienkonformen Auslegung auf das methodisch Mögliche aber nicht. Aus unionsrechtlicher Sicht verlangt ist eine richtlinienkonforme Rechtsfortbildung über den Wortlaut des nationalen Rechts hinaus nur dort, wo dies methodisch möglich ist. Dann kann auch die teleologische Reduktion einer Norm (auf Null) unionsrechtlich geboten sein. Dass einer nationalen Norm in diesem Fall ein geringerer oder kein Anwendungsbereich verbleibt, ist aber letztlich auch Folge der im nationalen Recht eröffneten methodischen Möglichkeiten. Dem nationalen Recht böte die contra legem-Grenze daher durchaus Möglichkeiten, dem Vertrauen auf den Bestand einer Norm größeres Gewicht beizumessen. Das deutsche Recht hat diese angesichts seiner weitreichenden Möglichkeiten zur Rechtsfortbildung aber nicht ergriffen.

Angesichts der nur sehr eingeschränkten Möglichkeiten zur Berücksichtigung nationaler Vertrauensumstände im Rahmen der contra legem-Grenze war noch der Frage nachzugehen, ob dies in weitergehendem Umfang im Rahmen der allgemeinen Rechtsgrundsätze möglich ist. In der Tat hat sich gezeigt, dass sie eine Rolle in straf- und verwaltungsrechtlichen Konstellationen spielen. Im Hinblick auf Horizontalverhältnisse war der Befund dagegen ein anderer. Die verschiedenen Ausprägungen der Grundsätze der Rechtssicherheit und des Vertrauensschutzes ließen sich insoweit sämtlich nicht fruchtbar machen. Letztlich führt dies zu der Feststellung, dass der Grundsatz der Rechtssicherheit im Horizontalverhältnis nur in 
Gestalt der contra legem-Grenze Bedeutung erlangt. An dieser Stelle zeigt sich die enge Verbindung der allgemeinen Rechtsgrundsätze zur contra legem-Grenze, die auch Ausfluss des unionsrechtlichen Rechtssicherheitsgrundsatzes ist. Dass in Äußerungen nationaler Gerichte, die die fehlende Auslegbarkeit einer nationalen Norm betont haben, eine "Zusicherung“ erblickt werden kann, die insoweit Vertrauen begründet, als dann nicht mehr mit einer Verschiebung der contra legem-Grenze gerechnet werden muss, ist Ausdruck der Begrenzung auf das methodisch Mögliche und des unionsrechtlichen Vertrauensschutzgrundsatzes.

Da vor dem Hintergrund ihrer zeitlichen Dimension auch im Rahmen der richtlinienkonformen Auslegung eine Korrektur des von Unionsrechts wegen zu erzielenden Ergebnisses durch nationale Vertrauensschutzerwägungen nicht möglich ist, besteht eine Vergleichbarkeit mit den im Rahmen der Möglichkeiten zur Begrenzung des Anwendungsvorrangs angestellten Erwägungen. Dass den Grenzen der richtlinienkonformen Auslegung vor diesem Hintergrund eine geringere Bedeutung zukommt als es ihre in ständiger Rechtsprechung wiederholte Betonung vermuten ließe, hat sich nicht zuletzt mit Blick auf Art. 288 III AEUV als unbedenklich erwiesen. Die Defrenne-Rechtsprechung entfaltet zwar insoweit keine umfängliche "Sperrwirkung“ als sie eine Berücksichtigung gewisser vertrauensschützender Aspekte wie die fehlende richtlinienkonforme Auslegbarkeit des nationalen Rechts nicht ausschließen kann. Einer weitergehenden Berücksichtigung nationaler Vertrauensumstände steht sie aber, von der Situation bei Umsetzungsspielräumen gewährenden Richtlinienvorschriften abgesehen, entgegen.

\section{E. Verfassungsrechtliche Integrationsgrenzen und zeitliche Dimension der EuGH-Rechtsprechung}

In den vorangegangenen Kapiteln wurde die Frage danach gestellt, ob die Berücksichtigung nationaler Vertrauensumstände als Bestandteil der dem Unionsrecht immanenten Grenzen des Anwendungsvorrangs/der Pflicht zu richtlinienkonformer Auslegung formuliert werden kann. Insoweit hat sich hinsichtlich des Anwendungsvorrangs erwiesen, dass dieser durch eine unionsintern erfolgende Abwägung einer temporären Suspendierung zwar grundsätzlich zugänglich ist, seine vorübergehende Aussetzung durch Erwägungen, die auf das Vertrauen auf die Anwendbarkeit nationalen Rechts gestützt sind, aber ausscheiden muss. Im Hinblick auf die Pflicht zu richtlinienkonformer Auslegung hat sich gezeigt, dass diese 
zwar ihre Schranken in der contra legem-Grenze und den allgemeinen Rechtsgrundsätzen findet, dies aber nichts daran ändert, dass die Berücksichtigung nationaler Vertrauensumstände nur sehr eingeschränkt möglich ist. Vor diesem Hintergrund besteht die Versuchung eines Rückgriffs auf nationales Verfassungsrecht, um der zeitlichen Wirkung der unionsgerichtlichen Rechtsprechung Grenzen zu setzen.

\section{Einführung}

Daher sind die im nationalen Recht im Hinblick auf die europäische Integration und damit gegenüber einer Anwendung von Unionsrecht formulierten Integrationsgrenzen in den Blick zu nehmen. Für den deutschen Rechtsraum sind sie vom Bundesverfassungsgericht näher ausgestaltet worden. Ihre Besonderheit besteht darin, dass es sich bei ihnen um autonome, von den Mitgliedstaaten ins Feld geführte Schranken handelt, die aus diesem Grund nicht notwendigerweise im Einklang mit den vom Unionsrecht selbst anerkannten Grenzen seiner Durchsetzung gebildet wurden. Aus unionsrechtlicher Sicht handelt es sich daher um nicht ohne Weiteres zulässige, wenn nicht sogar unzulässige Grenzen, mit denen der Mitgliedstaat dem aus seiner Sicht unverzichtbaren „letzten Wort der Verfassung“ zur Geltung verhelfen möchte. Auch wenn sich diese mitgliedstaatliche Sichtweise fragen lassen muss, ob sie unionsrechtlichen Besonderheiten hinreichend Rechnung trägt, darf nicht übersehen werden, dass es in diesem Bereich letztlich kein Richtig oder Falsch gibt. ${ }^{2330}$ In seinem EZB-Urteil bringt das Bundesverfassungsgericht diesen Gedanken dadurch zum Ausdruck, dass es von „im Grundsatz unvermeidlichen Spannungslagen“ spricht, da "die verfassungsrechtliche und die unionsrechtliche Perspektive nicht vollständig harmonieren“. ${ }^{2331}$

2330 So auch Thiele, EuR 2017, 367 (369 f.), der meint, die Ansichten des Gerichtshofs und des Bundesverfassungsgerichts zum Vorrang des Unionsrechts seien für sich genommen in sich schlüssig und unversöhnlich.

2331 BVerfG, Urteil vom 5.5.2020, 2 BvR 859/15, 2 BvR 1651/15, 2 BvR 2006/15, 2 BvR 980/16, Rn. 111 - NJW 2020, 1647. 


\section{Verfassungsrechtliche Grenzen des „Anwendungsvorrangs“}

Nach der Rechtsprechung des Bundesverfassungsgerichts unterliegt der Anwendungsvorrang des Unionsrechts verfassungsrechtlichen Schranken. Er ist nach der Formulierung im OMT-Urteil begrenzt durch das im Zustimmungsgesetz zu den Verträgen niedergelegte Integrationsprogramm (Art. 23 I 2 GG) und die durch Art. 23 I 3 i.V.m. Art. 79 III GG für integrationsfest erklärten Grundsätze der Art. 1 und 20 GG. ${ }^{2332}$ Unmittelbar angesprochen sind damit die Ultra-vires- und die Verfassungsidentitätskontrolle. Hinzu kommt der in Art. 23 I 1 GG verankerte ${ }^{2333}$ Vorbehalt hinreichend wirksamen Grundrechtsschutzes im Sinne der Solange II-Rechtsprechung, die das Bundesverfassungsgericht in der wiedergegebenen Urteilspassage zwar nicht ausdrücklich erwähnt, die es aber trotz einiger Ungereimtheiten in seiner neueren Judikatur nicht aufgegeben hat. ${ }^{2334}$ Schlagwortartig zusammengefasst können die verfassungsrechtlichen Grenzen des Anwendungsvorrangs daher als „Schrankentrias“2335 bezeichnet werden. Ihre Aktivierung führt zu einer zeitlich unbefristeten Nichtbefolgung von Unionsrecht.

Maßnahmen von Organen der EU und damit auch Urteile des EuGH sind keine Akte deutscher öffentlicher Gewalt. ${ }^{2336}$ Im Hinblick auf diese ist nur eine mittelbare/inzidente Überprüfung, eine Überprüfung als Vorfrage, soweit sie die Grundrechtsberechtigten in Deutschland betreffen, denkbar, wenn sie Grundlage von Handlungen deutscher Staatsorgane sind oder eine Verletzung der Integrationsverantwortung durch Verfassungsorgane im Raum steht. ${ }^{2337}$ Demnach erfolgt eine mittelbare Überprüfung daraufhin, ob sie durch das Integrationsprogramm (Zustimmungsgesetz nach Art. 23 I 2 GG) gedeckt sind oder gegen sonstige grundgesetzliche Grenzen der europäischen Integration verstoßen.

2332 BVerfG, Urteil vom 21.6.2016, 2 BvR 2728/13 bis 2 BvR 2731/13, 2 BvE 13/13, Rn. 115 - BVerfGE 142, 123.

2333 Thiele, EuR 2017, 367 (372ff.).

$2334 \mathrm{Zu}$ dieser Frage näher unten bei Fn. $2349 \mathrm{ff}$.

2335 Begriff bei Schweitzer/Dederer, Staatsrecht III, 12. Aufl. 2020, Rn. 166 (Anführungszeichen im Original).

2336 BVerfG, Urteil vom 5.5.2020, 2 BvR 859/15, 2 BvR 1651/15, 2 BvR 2006/15, 2 BvR 980/16, Rn. 93 - NJW 2020, 1647.

2337 Vgl. BVerfG, Beschluss vom 28.6.2016, 2 BvR 322/13, Rn. 9 - juris; BVerfG, Beschluss vom 15.5.2017, 2 BvR 865/17, Rn. 8 - juris; BVerfG, Urteil vom 5.5.2020, 2 BvR 859/15, 2 BvR 1651/15, 2 BvR 2006/15, 2 BvR 980/16, Rn. 89 NJW 2020, 1647. 
Anknüpfungspunkt ist damit nicht das Unionsrecht als solches, sondern entweder seine Durchführung durch die deutsche öffentliche Gewalt oder das Unterlassen von durch die Integrationsverantwortung gebotenen Reaktionsmaßnahmen gegen Identitätsverletzungen. ${ }^{2338}$ Im Unterschied zu der im Maastricht-Urteil noch vorgesehenen Möglichkeit ${ }^{2339}$ findet also keine Überprüfung unmittelbar von Unionsrecht statt. Dies wird aber dadurch weitgehend kompensiert, dass das Bundesverfassungsgericht die Integrationsverantwortung als Verfahrensgegenstand anerkannt hat. ${ }^{2340}$

Gegen ein Urteil des EuGH selbst kann demnach nicht verfassungsgerichtlich vorgegangen werden, wohingegen das Urteil eines deutschen Gerichts, das ein gegen die Integrationsgrenzen verstoßendes Urteil des EuGH umsetzt, zum Gegenstand einer verfassungsgerichtlichen Überprüfung gemacht werden kann. Die unionsrechtlich bedingte Versagung von "Vertrauensschutz“ durch ein deutsches Gericht kann daher auf ihren verfassungsrechtlichen Bestand überprüft werden.

Daneben kommt eine Anknüpfung an die Integrationsverantwortung in Betracht. Auch wenn im konkreten Fall keine Verletzung der Integrationsverantwortung gerügt wurde, ist die Anknüpfung an diese doch bereits in einem Fall zur Sprache gekommen, in dem das Bundesverfassungsgericht mit der gegen einen Bußgeldbescheid der Kommission und dessen Bestätigung durch Urteile des EuG und EuGH gerichteten (unzulässigen) Verfassungsbeschwerde befasst war. Zumindest angedacht wurde dort eine Auslösung der Integrationsverantwortung von Bundestag und Bundesregierung vor dem Hintergrund der Auslegung und Anwendung von Art. 23 VO (EG) Nr. 1/2003 durch die Organe der EU. ${ }^{2341}$

In seinem Urteil zum Anleihekaufprogramm der EZB hat das Bundesverfassungsgericht die Überprüfung eines Urteils des Gerichtshofs eingebettet in die Prüfung der Verletzung der Integrationsverantwortung durch das Unterlassen von Bundesregierung und Bundestag, geeignete Schrit-

2338 BVerfG, Urteil vom 21.6.2016, 2 BvR 2728/13 bis 2 BvR 2731/13, 2 BvE 13/13, Rn. 97 ff. - BVerfGE 142, 123.

2339 BVerfG, Urteil vom 12.10.1993, 2 BvR 2134/92, 2 BvR 2159/92 - BVerfGE 89, 155 (175).

2340 Siehe Classen, EuR 2016, 529 (532).

2341 BVerfG, Beschluss vom 19.7.2016, 2 BvR 2752/11, Rn. 20 - NJW 2017, 149. Die Integrationsverantwortung würde Bundestag und Bundesregierung dazu verpflichten, „sich aktiv mit der Frage auseinanderzusetzen“, ob das Verhalten der Unionsorgane die Verfassungsidentität des Grundgesetzes und die Grenzen des Integrationsprogramms wahrt, sowie darüber zu entscheiden, wie die verfassungsrechtlichen Anforderungen gewährleistet werden können. 
te gegen das Überschreiten der währungspolitischen Kompetenz durch die EZB zu unternehmen. Die aus Sicht des Bundesverfassungsgerichts im EuGH-Urteil in der Rechtssache Weiss u.a. ${ }^{2342}$ erfolgte Verkennung von Bedeutung und Tragweite des Verhältnismäßigkeitsgrundsatzes bei der Überprüfung der in Rede stehenden Beschlüsse der EZB führte zur Einordnung des EuGH-Urteils als Ultra-vires-Akt wegen offenkundiger Überschreitung des Mandats des Gerichtshofs nach Art. 19 I UAbs. 1 S. 2 EUV. ${ }^{2343}$ Da eine „offenkundige Außerachtlassung der im europäischen Rechtsraum überkommenen Auslegungsmethoden oder allgemeiner, den Rechtsordnungen der Mitgliedstaaten gemeinsamer Rechtsgrundsätze“ nach Auffassung des Bundesverfassungsgerichts die Grenzen des Art. 19 I UAbs. 1 S. 2 EUV überschreitet ${ }^{2344}$, ist ein entsprechendes Vorgehen des Bundesverfassungsgerichts jedenfalls grundsätzlich auch im Hinblick auf den die zeitliche Dimension der Auslegungszuständigkeit des EuGH prägenden Grundsatz der Rechtssicherheit denkbar.

Eine Aktivierung der Integrationsverantwortung im Angesicht der Auslegung des Unionsrechts durch den EuGH ist demnach nicht ausgeschlossen. Dies kommt sowohl im Hinblick auf eine vom Gerichtshof vorgenommene bzw. bestätigte Auslegung an sich in Betracht als auch hinsichtlich der zeitlichen Dimension einer derartigen Auslegung.

\section{Vorbehalt hinreichend wirksamen Grundrechtsschutzes}

Um der zeitlichen Wirkung der Rechtsprechung des Gerichtshofs Grenzen zu ziehen, ist zunächst an den Vorbehalt hinreichend wirksamen Grundrechtsschutzes im Sinne der Solange II-Rechtsprechung zu denken.

2342 EuGH, Urteil vom 11.11.2018, Rs. C-493/17 (Weiss u.a.).

2343 BVerfG, Urteil vom 5.5.2020, 2 BvR 859/15, 2 BvR 1651/15, 2 BvR 2006/15, 2 BvR 980/16, Rn. 119 - NJW 2020, 1647. Dies eröffnete dem Bundesverfassungsgericht die Möglichkeit zu einer eigenständigen Überprüfung des Handelns der EZB, das es ebenfalls als Ultra-vires-Akt einordnet, vgl. BVerfG, a.a.O., Rn. 164, 178.

2344 BVerfG, Urteil vom 5.5.2020, 2 BvR 859/15, 2 BvR 1651/15, 2 BvR 2006/15, 2 BvR 980/16, Rn. 112 - NJW 2020, 1647. 
a) Schicksal des Solange II-Vorbehalts

Im Solange II-Beschluss führte das Bundesverfassungsgericht aus: „Solange die Europäischen Gemeinschaften, insbesondere die Rechtsprechung des Gerichtshofs der Gemeinschaften einen wirksamen Schutz der Grundrechte gegenüber der Hoheitsgewalt der Gemeinschaften generell gewährleisten, der dem vom Grundgesetz als unabdingbar gebotenen Grundrechtsschutz im wesentlichen gleichzuachten ist, zumal den Wesensgehalt der Grundrechte generell verbürgt, wird das Bundesverfassungsgericht seine Gerichtsbarkeit über die Anwendbarkeit von abgeleitetem Gemeinschaftsrecht, das als Rechtsgrundlage für ein Verhalten deutscher Gerichte und Behörden im Hoheitsbereich der Bundesrepublik Deutschland in Anspruch genommen wird, nicht mehr ausüben und dieses Recht mithin nicht mehr am Maßstab der Grundrechte des Grundgesetzes überprüfen; entsprechende Vorlagen nach Art. 100 Abs. 1 GG sind somit unzulässig." 2345

Im Hinblick auf den Grundrechtsschutz nach dem Grundgesetz gilt im unionsrechtlich determinierten Bereich daher seitdem, dass das Bundesverfassungsgericht lediglich darüber wacht, dass das Unionsrecht den vom Grundgesetz gebotenen Mindeststandard an Grundrechtsschutz nicht verfehlt. Ist dies der Fall, unterbleibt eine Überprüfung der Wirksamkeit unionsrechtlicher Normen selbst sowie deutscher Normen, die zwingendes Unionsrecht innerstaatlich umsetzen, am Maßstab der Grundrechte des Grundgesetzes. ${ }^{2346}$ Der Solange II-Vorbehalt verlangt ein Maß an Grundrechtsschutz, das „nach Konzeption, Inhalt und Wirkungsweise“ dem Grundrechtsstandard des Grundgesetzes „im wesentlichen gleichzuachten“ ist. Im Einzelfall noch bestehende Lücken etwa hinsichtlich der Reichweite eines bestimmten Grundrechts sind dabei unschädlich. ${ }^{2347}$ Erforderlich ist also eine auf das jeweilige Grundrecht bezogene generelle Betrachtung - unabhängig vom Einzelfall muss der Grundrechtsschutz auf EU-Ebene generell ausreichend sein hinsichtlich des jeweils betroffenen Grundrechts. Soll die Reservefunktion der Grundrechte des Grundgesetzes aktiviert

2345 BVerfG, Beschluss vom 22.10.1986, 2 BvR 197/83 - BVerfGE 73, 339 (387). In Rede stand die Ablehnung eines Antrags auf Genehmigung der Einfuhr von Champignonkonserven aus Taiwan durch das Bundesamt für Ernährung und Forstwirtschaft auf der Grundlage einer Verordnung.

2346 Vgl. BVerfG, Beschluss vom 6.11.2019, 1 BvR 276/17, Rn. 51, 89 - EuZW 2019, 1035; Schmahl, in: Breuer (Hrsg.), Principled Resistance, 2019, S. 299 (302).

2347 BVerfG, Beschluss vom 22.10.1986, 2 BvR 197/83 - BVerfGE 73, 339 (378, 383). 
werden, unterliegt dies hohen Substantiierungsanforderungen. ${ }^{2348}$ Eine Einzelfallkontrolle wäre daher nur bei substantiierter Darlegung möglich, dass ein dem Grundgesetz im Wesentlichen entsprechender Grundrechtsschutz in der EU generell nicht mehr gewährleistet ist.

Durch die Möglichkeit der Identitätskontrolle ist die Bedeutung des Solange II-Vorbehalts in der neueren Rechtsprechung des Bundesverfassungsgerichts in Zweifel geraten. ${ }^{2349}$ Das Festhalten an dem Grundsatz, dass durch das Unionsrecht determinierte Akte der deutschen öffentlichen Gewalt von verfassungsgerichtlicher Prüfung ausgeschlossen $\sin ^{2350}$, schließt es nicht aus, diese an den integrationsfesten Grundsätzen des Grundgesetzes (und damit unter anderem dem Menschenwürdekern der Grundrechte) zu messen. Die Prüfung an diesen Grundsätzen beschränkt die Kontrolle derartiger Akte auf den Maßstab des Art. 79 III GG ${ }^{2351}$, sodass zumindest auf den ersten Blick nicht recht einleuchtet, wie sich eine Prüfung am Maßstab sämtlicher Grundrechtsgewährleistungen des Grundgesetzes damit in Einklang bringen lassen sollte. ${ }^{2352}$

Auch wenn die Solange II-Rechtsprechung damit jedenfalls in Einzelfällen zugunsten einer Menschenwürdeprüfung durchbrochen wird ${ }^{2353}$, so ist doch zu bedenken, dass eine Aktivierung der Grundrechtsprüfung nur bei strukturellen Defiziten auf europäischer Ebene erfolgt. Die Menschenwürdeprüfung setzt dagegen kein Absinken des europäischen Grundrechtsschutzniveaus auf ein aus Sicht des Grundgesetzes nicht mehr akzeptables Niveau voraus, sondern ist auch unter Geltung des europäischen Grundrechtsschutzes in seiner jetzigen Form durchzuführen. Erst wenn das akzeptable Niveau unterschritten ist, lebt die vollumfängliche Grundrechtsprüfung wieder auf, sodass auch erst dann eine Unvereinbarkeit der Prüfungsmaßstäbe insoweit anzunehmen ist, als eine auf die Berührung der Verfassungsidentität beschränkte Prüfung nicht mehr angezeigt ist,

2348 BVerfG, Beschluss vom 6.11.2019, 1 BvR 276/17, Rn. 47 f. - EuZW 2019, 1035; siehe auch Ludwigs/Sikora, JuS 2017, 385 (389).

2349 Siehe nur Classen, EuR 2016, 529 (535). Nettesheim, JZ 2016, 424 (428) sieht das „faktische Ende der Solange-Rechtsprechung“, während Ludwigs/Sikora, EWS 2016, 121 (124) „eine konsequente Abschichtung von Grundrechts- und Identitätsvorbehalt" erkennen.

2350 BVerfG, Urteil vom 21.6.2016, 2 BvR 2728/13 bis 2 BvR 2731/13, 2 BvE 13/13, Rn. 115 - BVerfGE 142, 123.

2351 Vgl. BVerfG, Beschluss vom 6.9.2016, 2 BvR 890/16, Rn. 32 - JZ 2016, 1113.

2352 Sauer, EuR 2017, 186 (203) spricht insoweit von einem „Fremdkörper“.

2353 Vgl. Schönberger, JZ 2016, 422 (424). 
sondern vielmehr eine umfassende Grundrechtsprüfung vorgenommen werden kann und vorzunehmen ist.

Dementsprechend misst auch das Bundesverfassungsgericht der Solange II-Rechtsprechung weiterhin Bedeutung bei. In einem neueren Beschluss betont es den Vorbehalt hinreichend wirksamen Grundrechtsschutzes wieder ausdrücklich und nimmt die Ultra-vires-Kontrolle und die Wahrung der Verfassungsidentität daneben als „weitere“ Vorbehalte in Bezug.. 2354 Für die Rechtsprechungstätigkeit des Gerichtshofs bedeutet der Solange IIVorbehalt, dass er bei seiner Auslegung des Unionsrechts den vom Grundgesetz geforderten grundrechtlichen Mindeststandard beachten muss.

\section{b) Ex tunc-Wirkung und Solange II-Rechtsprechung}

Von Interesse ist die Geltendmachung des Solange II-Vorbehalts im vorliegenden Zusammenhang insbesondere im Hinblick auf die Fälle, in denen der EuGH eine Begrenzung der zeitlichen Wirkungen seiner Rechtsprechung ausdrücklich oder stillschweigend abgelehnt hat. Ist auf Ebene des Unionsrechts hinsichtlich der zeitlichen Dimension unionsgerichtlicher Rechtsprechung kein strukturelles Defizit auszumachen, darf keine Überprüfung am Maßstab der Vertrauensschutz verbürgenden verfassungsrechtlichen Gewährleistungen erfolgen, verfassungsrechtlicher Vertrauensschutz also nicht geltend gemacht werden, um ein aus unionsrechtlicher Perspektive in zeitlicher Hinsicht zwingend vorgegebenes Ergebnis zu umgehen. ${ }^{2355}$

In seinem Honeywell-Beschluss hatte das Bundesverfassungsgericht noch eine Verletzung des Art.12 I GG i.V.m. Art. 20 III GG durch das BAG wegen der unterbliebenen Gewährung von Vertrauensschutz geprüft und seine Solange II-Rechtsprechung dabei nicht erwähnt, sondern vielmehr seine Pflicht zur Wahrung des Grundgesetzes auch gegenüber Unionsrecht umsetzenden oder vollziehenden Maßnahmen betont. Dennoch hat es die unionsrechtlichen Vorgaben im Ergebnis akzeptiert und der Ver-

2354 BVerfG, Beschluss vom 6.11.2019, 1 BvR 276/17, Rn. 47, 49 - EuZW 2019, 1035. Zur Diskussion um die Fortführung der Solange II-Rechtsprechung angesichts ihrer nicht ausdrücklichen Nennung in BVerfG, Urteil vom 21.6.2016, 2 BvR 2728/13 bis 2 BvR 2731/13, 2 BvE 13/13, Rn. 115 - BVerfGE 142, 123 im Unterschied zu BVerfG, Beschluss vom 15.12.2015, 2 BvR 2735/14, Rn. 41 - BVerfGE 140, 317 siehe Ludwigs/Sikora, JuS 2017, 385 (389, Fn. 35) und Classen, EuR 2016, 529 (535).

2355 Siehe dazu auch Rosenkranz, Beschränkung der Rückwirkung, 2015, S. 444 f. 
pflichtung zur Nichtanwendung des nationalen Rechts keinen „nationalen Vertrauensschutz" entgegengesetzt. Es hat zwar ausgeführt, dass Fragen des Vertrauensschutzes auch bei der rückwirkenden Nichtanwendung eines nationalen Gesetzes aufgeworfen würden, aber ebenso die unionsrechtliche Vorprägung und Begrenzung der in diesem Bereich bestehenden mitgliedstaatlichen Möglichkeiten anerkannt. ${ }^{2356}$ Obwohl das BAG-Urteil keinen Vertrauensschutz gewährt hat, erblickte das Bundesverfassungsgericht darin keine Grundrechtsverletzung. ${ }^{2357}$ Dass bei der Betroffenheit des Anwendungsvorrangs neben der Defrenne-Rechtsprechung keine Begrenzung durch Vertrauen in nationales Recht in Betracht kommt, hat es damit hingenommen. ${ }^{2358}$

In seinem zur Junk-Problematik ergangenen Beschluss hat das Bundesverfassungsgericht dem BAG sodann vorgeworfen, Bestimmungen des nationalen Verfassungsrechts ins Feld geführt zu haben, um damit in dem von ihm zu entscheidenden Fall die Erzielung eines unionsrechtskonformen Ergebnisses mittels richtlinienkonformer Auslegung zu unterlassen. ${ }^{2359}$ Den gegenüber dem BAG erhobenen Vorwurf eines Verstoßes gegen die Solange II-Rechtsprechung begründet es damit, dass der Rückgriff auf nationales Verfassungsrecht bei der Anwendung von Unionsrecht voraussetze, dass der vom Grundgesetz gebotene Mindeststandard an Grundrechtsschutz durch das Unionsrecht verfehlt wird, was hier nicht der Fall sei und jedenfalls vom Bundesverfassungsgericht festgestellt werden müsste. ${ }^{2360}$

In der Literatur wird zum Teil bezweifelt, dass das Bundesverfassungsgericht hier den zutreffenden Ansatz gewählt hat. In der Tat steht zwar nicht eine inhaltliche Prüfung des Umsetzungsgesetzes in Rede, sondern die Begrenzung der richtlinienkonformen Auslegung im Einzelfall. ${ }^{2361}$ Da die Solange II-Rechtsprechung aber auch für den Fall der konkretisierenden Anwendung der unionsrechtlichen Vorgaben gilt, sind deutsche

2356 BVerfG, Beschluss vom 6.7.2010, 2 BvR 2661/06 - BVerfGE 126, 286 (313 f.).

2357 BVerfG, Beschluss vom 6.7.2010, 2 BvR 2661/06 - BVerfGE 126, 286 (298 f., 313).

2358 Siehe auch Rosenkranz, Beschränkung der Rückwirkung, 2015, S. 450 unter Verweis auf BVerfG, Beschluss vom 6.7.2010, 2 BvR 2661/06 - BVerfGE 126, 286 (314).

2359 Zur vom Bundesverfassungsgericht kritisierten Rechtsprechung des BAG siehe oben bei Fn. $1340 \mathrm{ff}$.

2360 BVerfG, Beschluss vom 10.12.2014, 2 BvR 1549/07, Rn. 41 - NZA 2015, 375.

2361 Dies führt Brams, Impulse, 2019, S. 281 ins Feld. 
Grundrechte auch insoweit nicht anwendbar. ${ }^{2362}$ Der Vorwurf eines unzutreffenden Ausgangspunkts seiner Überlegungen kann dem Bundesverfassungsgericht daher nicht gemacht werden.

Klar geworden ist durch die vorangegangene Überlegung jedoch, dass es bei der Frage, ob nationale Grundrechte Anwendung finden können, in erster Linie um die Frage geht, ob ein nationales Gericht, das die unionsrechtlichen Vorgaben umsetzt - sei es im Wege der rückwirkenden Nichtanwendung des nationalen Rechts oder seiner rückwirkenden richtlinienkonformen Auslegung -, einen grundrechtlichen Vertrauensschutzmaßstab anlegen darf, ohne gegen verfassungsrechtliche Vorgaben zu verstoßen. 2363

Die Solange II-Rechtsprechung befasst sich zwar mit dem grundgesetzlichen Grundrechtsschutz, wohingegen Vertrauensschutz in der Rechtsprechung des Bundesverfassungsgerichts nicht nur in den Grundrechten, sondern auch im Grundsatz der Rechtssicherheit als Ausfluss des Rechtsstaatsprinzips verankert wird. ${ }^{2364}$ Dennoch ist die Solange II-Rechtsprechung auf die in zeitlicher Hinsicht bestehenden unionsrechtlichen Vorgaben übertragbar, da die Verankerung des Vertrauensschutzes auch im Rechtsstaatsprinzip nichts daran ändert, dass dieser vom Individuum her denkt und damit den Einzelnen schützt. ${ }^{2365}$

Aus der Sicht des nationalen Verfassungsrechts ist entscheidend, mit welchen unionsrechtlichen Vorgaben das nationale Gericht konfrontiert ist. Für den Anwendungsvorrang gilt wie gesehen, dass neben der Defrenne-Rechtsprechung keine auf nationales Recht gestützten Vertrauensschutzerwägungen möglich sind. Für die richtlinienkonforme Auslegung ist diese Frage dagegen vom Gerichtshof noch nicht letztendgültig geklärt worden. Dass die Anforderungen richtlinienkonformer Auslegung aus unionsrechtlicher Perspektive einer Berücksichtigung nationaler Vertrauensumstände in sehr weitgehendem Umfang entgegenstehen, hat sich im Rahmen der in dieser Arbeit erfolgten Untersuchung allerdings gezeigt. ${ }^{2366}$ Das Bundesverfassungsgericht jedenfalls sieht in der Pflicht zur richtlinien-

2362 BVerfG, Beschluss vom 6.11.2019, 1 BvR 276/17, Rn. 43 - EuZW 2019, 1035.

2363 Gleiches muss für einfachrechtlichen Vertrauensschutz gelten, wenn mit diesem im Ergebnis die gleiche Wirkung wie bei der Gewährung von Grundrechtsschutz erzielt wird.

2364 Siehe dazu bereits oben bei Fn. $1973 \mathrm{f}$.

2365 Rosenkranz, Beschränkung der Rückwirkung, 2015, S. $446 \mathrm{f}$. spricht von "grundrechtsrelevanten Ausprägungen“ und „individualschützenden Komponenten"; siehe auch Rosenkranz, ZfPW 2016, 351 (371).

2366 Zum Ganzen ausführlich oben bei Fn. 1564 ff. und Fn. 2034 ff. 
konformen Auslegung eine derart „starke Klammer“ zwischen nationalem und Unionsrecht, dass ein Rückgriff auf verfassungsrechtlichen Vertrauensschutz nicht möglich ist. ${ }^{2367}$

Sowohl hinsichtlich des Anwendungsvorrangs als auch der richtlinienkonformen Auslegung ist die Rechtslage also unionsrechtlich determiniert, was grundsätzlich zur Rücknahme des grundgesetzlichen Grundrechtsschutzes führt. Demnach ist sowohl im Hinblick auf den Anwendungsvorrang als auch die richtlinienkonforme Auslegung entscheidend, ob die Defrenne-Rechtsprechung des Gerichtshofs im Ergebnis das vom Grundgesetz geforderte Mindestmaß an Grundrechtsschutz wahrt, da mit ihr die entscheidende Weiche für die in zeitlicher Hinsicht bestehenden unionsrechtlichen Vorgaben gestellt wird.

Wird sie daraufhin untersucht, ob sie den Mindestanforderungen des Grundgesetzes an Vertrauensschutz gerecht wird, ist in Erinnerung zu rufen, dass der Gerichtshof im Unterschied zum Bundesverfassungsgericht etwa eine zeitliche Begrenzung sogar dann in Betracht zieht, wenn er eine Rechtsfrage zum ersten Mal beantwortet. Mit dem guten Glauben hat der EuGH ein Kriterium entwickelt, das zwar einen objektivierten Maßstab zugrunde legt, die Erkenntnismöglichkeiten der Betroffenen aber dadurch berücksichtigt, dass es entscheidend darauf ankommt, welches Verständnis des Unionsrechts diese vernünftigerweise erwarten durften. Dass neben dem guten Glauben kumulativ eine Gefahr schwerwiegender Störungen bestehen muss, ist dem Umstand geschuldet, dass die sich als unzutreffend herausstellende Sichtweise auch tatsächlich weit verbreitet gewesen sein muss, um eine unionsweite Beschränkung rechtfertigen zu können.

Mit dem Erfordernis einheitlicher Anwendung des Unionsrechts ist auch zu begründen, dass eine territoriale Aufspaltung der zeitlichen Dimension der EuGH-Rechtsprechung nicht in Betracht kommt, auch wenn dies zur Wahrung nationaler Besonderheiten zum Teil gefordert wird. ${ }^{2368}$ Dass der Gerichtshof die zeitliche Begrenzung als absolute Ausnahme ansieht, führt zu keiner anderen Bewertung der Defrenne-Rechtsprechung aus grundrechtlicher Perspektive. Wenn etwa im Rahmen der Rückforderung unionsrechtswidriger Beihilfen das öffentliche Interesse der Union an der Durchsetzung des Unionsrechts in die Abwägung eingestellt werden kann $^{2369}$, muss auch im vorliegend interessierenden Zusammenhang

2367 Vgl. Wißmann, in: FS Kohte, 2016, S. 993 (1001).

2368 Siehe hierzu näher oben bei Fn. $1023 \mathrm{ff}$.

2369 BVerfG, Beschluss vom 17.2.2000, 2 BvR 1210/98 - NJW 2000, 2015. 
geltend gemacht werden können, dass sich die zeitliche Begrenzung nur ausnahmsweise der Durchsetzung des Unionsrechts entgegenstellen kann.

In Horizontalverhältnissen besteht zudem die Besonderheit, dass ein Interessenausgleich zwischen den Parteien herzustellen ist. Der größere Schutz der einen Partei ist daher notwendigerweise mit einem geringeren Schutz der anderen Partei verbunden. ${ }^{2370}$ Beruft sich die eine Partei auf ihr Vertrauen auf nationales Recht, die andere dagegen auf ihr durch Unionsrecht begründetes Recht, so mögen Unionsrecht und nationales Recht die betroffenen Interessen zwar anders gewichten. Von einem höheren grundgesetzlichen Schutzniveau, unter das das unionsrechtliche Schutzniveau absinken könnte, ist deswegen aber noch nicht zu sprechen. ${ }^{2371}$

Ein generelles Defizit auf europäischer Ebene besteht demnach nicht. ${ }^{2372}$ Die Bindung des EuGH an den Grundsatz der Rechtssicherheit ist mit der Bindung deutscher Gerichte an Art. 20 III GG vergleichbar. ${ }^{2373}$ Eine Überprüfung der mit der Rechtsprechung des Gerichtshofs verbundenen zeitlichen Vorgaben am nationalen grundrechtlichen Vertrauensschutzmaßstab muss daher nach dem derzeitigen Stand des Unionsrechts ausscheiden.

c) Grundrechtsprüfung durch das Bundesverfassungsgericht

Sind die deutschen Grundrechte verdrängt, kontrolliert das Bundesverfassungsgericht nach seiner neueren Rechtsprechung nun die Anwendung des Unionsrechts durch deutsche Stellen am Maßstab der Unionsgrundrechte. ${ }^{2374}$ Anzusprechen ist dieser neue Ansatz an dieser Stelle vor dem Hintergrund, dass das Bundesverfassungsgericht eine Verdrängung des verfassungsrechtlich verbürgten Vertrauensschutzes sowohl hinsichtlich

2370 Vgl. Koch, SR 2012, 159 (160).

2371 Siehe zu den hier vorgebrachten Argumenten bereits Rosenkranz, Beschränkung der Rückwirkung, 2015, S. 449.

2372 Ebenso Franzen, AP TzBfG $\$ 14$ Nr. 23 unter IV.2.a); Schaer, Grenzen rückwirkender Rechtsprechung, 2010, S. 165; Rosenkranz, Beschränkung der Rückwirkung, 2015, S. 449. Siehe in diesem Zusammenhang auch Bauer/Arnold, NJW 2006, 6 (10) zur Mangold-Entscheidung des EuGH und der Befugnis deutscher Gerichte zur Nichtanwendung formeller deutscher Gesetze vor dem Hintergrund der Solange II-Rechtsprechung.

2373 Rosenkranz, Beschränkung der Rückwirkung, 2015, S. 447.

2374 BVerfG, Beschluss vom 6.11.2019, 1 BvR 276/17, Rn. 50 - EuZW 2019, 1035. Zur Einordnung dieser Rechtsprechung siehe näher Breuer, Verfassungsblog vom 2.12.2019. 
des Anwendungsvorrangs als auch der richtlinienkonformen Auslegung zutreffend anerkannt hat. ${ }^{2375}$

Fragt man, welche unionsrechtlichen Maßstäbe das Bundesverfassungsgericht bei seiner Kontrolle der Fachgerichte im hier interessierenden $\mathrm{Zu}$ sammenhang heranziehen kann, so ist zunächst davon auszugehen, dass das Bundesverfassungsgericht das Monopol des Gerichtshofs im Rahmen der Defrenne-Rechtsprechung zu achten hat. Da nur der EuGH selbst eine zeitliche Begrenzung im Sinne der Defrenne-Rechtsprechung vornehmen kann, ist dem Bundesverfassungsgericht eine Anwendung der Maßstäbe der Defrenne-Rechtsprechung verwehrt.

Da bei unmittelbar anwendbarem Unionsrecht eine Begrenzung des Anwendungsvorrangs mit der Begründung, der Betroffene habe auf die nationale Rechtslage vertraut, ausscheiden muss, ist insoweit von unionsrechtlicher Determinierung auszugehen. Überprüfen kann das Bundesverfassungsgericht dann lediglich, ob die nationalen Gerichte dies bei der Entscheidung des konkreten Falles beachtet haben. Daneben ist im Hinblick auf die Frage der vorübergehenden Aussetzung der Verdrängungswirkung einer unionsrechtlichen Norm zu bedenken, dass lediglich der Gerichtshof dazu berechtigt ist, die Voraussetzungen festzulegen, unter denen eine solche Suspendierung ausnahmsweise in Betracht kommt. Das Bundesverfassungsgericht ist damit von vornherein auf die Überprüfung der Wahrung der vom Gerichtshof aufgestellten Voraussetzungen durch die Fachgerichte beschränkt.

Begrenzen die allgemeinen Rechtsgrundsätze des Unionsrechts die Pflicht zu richtlinienkonformer Auslegung, so kann das Bundesverfassungsgericht in den Bereichen, in denen diese wie etwa im Strafrecht und in umgekehrt vertikalen Konstellationen zum Tragen kommen, über ihre Wahrung wachen. $\mathrm{Zu}$ erfolgen hat dies gegebenenfalls im Dialog mit dem Gerichtshof im Wege des Vorabentscheidungsverfahrens, wozu sich das Bundesverfassungsgericht auch bereit erklärt hat. ${ }^{2376}$ Im Horizontalverhältnis ist insbesondere an eine Überprüfung der Wahrung der unionsrechtlichen Grenzen der contra legem-Grenze zu denken. Ansonsten ist das Bundesverfassungsgericht auch hier darauf beschränkt, zu überprüfen, ob

2375 Siehe einerseits BVerfG, Beschluss vom 6.7.2010, 2 BvR 2661/06 - BVerfGE 126, 286 (314) zum Anwendungsvorrang und andererseits BVerfG, Beschluss vom 10.12.2014, 2 BvR 1549/07, Rn. 34 ff. - NZA 2015, 375 zur richtlinienkonformen Auslegung.

2376 Vgl. BVerfG, Beschluss vom 6.11.2019, 1 BvR 276/17, Rn. 68 ff. - EuZW 2019, 1035 . 
die nationalen Gerichte das Gebot richtlinienkonformer Auslegung nicht in unzulässiger Weise durch verfassungsrechtliche Vertrauensschutzerwägungen begrenzt haben.

Sind die Grundrechte des Grundgesetzes dagegen nicht verdrängt, zieht das Bundesverfassungsgericht diese als Prüfungsmaßstab heran, wobei es sie unter Heranziehung der Grundrechtecharta als Auslegungshilfe im Lichte der Grundrechtecharta auslegt. ${ }^{2377}$ Überlässt eine Richtlinie den Mitgliedstaaten Gestaltungsspielräume und macht damit insoweit keine zwingenden Vorgaben, ist grundsätzlich Raum für die Berücksichtigung nationaler Vertrauensumstände und eine Anwendung deutscher Grundrechte. Da hierbei aber immer auch die allgemeinen Rechtsgrundsätze des Unionsrechts anwendbar sind, sind diese Umstände im Lichte des Unionsrechts zu würdigen, um ein Unterschreiten des durch die allgemeinen Rechtsgrundsätze gebildeten unionsrechtlichen Maßstabs zu verhindern.

\section{Identitäts- und Ultra-vires-Kontrolle}

Die Identitätskontrolle, mit der auch durch das Unionsrecht determinierte Hoheitsakte überprüft werden, setzt anders als der Solange II-Vorbehalt keinen Nachweis eines strukturellen Defizits auf Unionsebene voraus. Vielmehr genügt der Nachweis einer Verletzung der Identitätsgehalte im konkreten Einzelfall. Die Aktivierung der Identitätskontrolle gegenüber zeitlich unbegrenzt wirkender Rechtsprechung ist daher nicht von vornherein ausgeschlossen.

Die Identitätskontrolle beruht auf Art. 23 I 3 GG i.V.m. Art. 79 III GG $^{2378}$ und ermöglicht mit Art. 1 und Art. 20 GG eine Prüfung an den Grenzen des Übertragbaren. ${ }^{2379}$ Mit ihr untersucht das Bundesverfassungsgericht u.a., ob durch eine Maßnahme von Organen, Einrichtungen und sonstigen Stellen der Europäischen Union die in Art. 79 III GG für unantastbar erklärten Grundsätze berührt werden ${ }^{2380}$ - an ihnen hält das Bun-

2377 BVerfG, Beschluss vom 6.11.2019, 1 BvR 16/13, Rn. 60 f. - EuZW 2019, 1021.

2378 BVerfG, Urteil vom 21.6.2016, 2 BvR 2728/13 bis 2 BvR 2731/13, 2 BvE 13/13, Rn. 121 - BVerfGE 142, 123.

2379 Sauer, Staatsrecht III, 5. Aufl. 2018, $\$ 9$, Rn. 41 b.

2380 BVerfG, Urteil vom 21.6.2016, 2 BvR 2728/13 bis 2 BvR 2731/13, 2 BvE 13/13, Rn. 138 - BVerfGE 142, 123; BVerfG, Urteil vom 30.6.2009, 2 BvE 2/08, 2 BvE 5/08, 2 BvR 1010/08, 2 BvR 1022/08, 2 BvR 1259/08, 2 BvR 182/09 - BVerfGE 123, 267 (344, 353 f.); BVerfG, Beschluss vom 6.7.2010, 2 BvR 2661/06 BVerfGE 126, 286 (302); BVerfG, Beschluss vom 19.7.2011, 1 BvR 1916/09 
desverfassungsgericht demnach ohne Einschränkung fest. ${ }^{2381}$ Werden diese Grundsätze berührt, geht die betreffende Maßnahme nach der Rechtsprechung des Bundesverfassungsgerichts über die grundgesetzlichen Grenzen offener Staatlichkeit hinaus. ${ }^{2382}$ Nur die Verfassungsidentität wahrendes Unionsrecht kann danach Vorrang beanspruchen; ihre Berührung führt zur absoluten Unzulässigkeit der betreffenden Maßnahme. ${ }^{2383}$ Deren Ausführung stößt damit an verfassungsrechtliche Grenzen. ${ }^{2384}$

Neben der Identitätskontrolle ist noch kurz die Bedeutung der Ultravires-Kontrolle im Zusammenhang mit der Begrenzungsrechtsprechung des EuGH zu beleuchten. Diese fragt nach einem offensichtlichen und strukturell bedeutsamen Überschreiten des demokratisch legitimierten Integrationsprogramms nach Art. 23 I 2 GG und knüpft damit an das Zustimmungsgesetz an. ${ }^{2385}$ Indem sie die Reichweite der übertragenen Kompetenzen in den Blick nimmt, bestimmt sie die Grenzen des Übertragenen. ${ }^{2386}$

Auch wenn das Bundesverfassungsgericht zu erkennen gibt, dass es die Identitätskontrolle als „Oberkonzept“ ${ }^{\text {“2387 }}$ der verfassungsgerichtlichen Kontrollmöglichkeiten ansieht, indem es die Ultra-vires-Kontrolle als besonderen Anwendungsfall der Identitätskontrolle einordnet ${ }^{2388}$, so liegt den beiden Integrationsschranken damit doch ein unterschiedlicher Ansatz zugrunde. ${ }^{2389}$ Die Verankerung der Ultra-vires-Kontrolle in Art. 79 III GG mit der Begründung, dass eine hinreichend qualifizierte Kompetenzüberschreitung zugleich die Verfassungsidentität berührt, kann nicht

- BVerfGE 129, 78 (100); BVerfG, Beschluss vom 14.1.2014, 2 BvR 2728/13 bis 2 BvR 2731/13, 2 BvE 13/13, Rn. 27 - BVerfGE 134, 366.

2381 Classen, EuR 2016, 304 (312) bezeichnet die Identitätskontrolle daher als „zu fundamentalistisch“. Nach Schönberger, JZ 2016, 422 (423) begründet sie ein „bisher unbekanntes Supergrundrecht auf menschenwürdige Verfassungsidentität".

2382 BVerfG, Urteil vom 21.6.2016, 2 BvR 2728/13 bis 2 BvR 2731/13, 2 BvE 13/13, Rn. 137 - BVerfGE 142, 123.

2383 Sauer, NJW 2016, 1134 (1135) nennt dies „unbedingte[n] Vorrang von Art. 1 I GG vor dem Unionsrecht".

2384 Walter, ZaöRV 72 (2012), 177 (183).

2385 BVerfG, Urteil vom 21.6.2016, 2 BvR 2728/13 bis 2 BvR 2731/13, 2 BvE 13/13, Rn. 121 - BVerfGE 142, 123.

2386 Sauer, Staatsrecht III, 5. Aufl. 2018, \$9, Rn. 41 b.

2387 Sauer, Staatsrecht III, 5. Aufl. 2018, \$9, Rn. 44 b.

2388 BVerfG, Urteil vom 21.6.2016, 2 BvR 2728/13 bis 2 BvR 2731/13, 2 BvE 13/13, Rn. 153 - BVerfGE 142, 123; kritisch etwa Thiele, EuR 2017, 367 (372).

2389 BVerfG, Urteil vom 21.6.2016, 2 BvR 2728/13 bis 2 BvR 2731/13, 2 BvE 13/13, Rn. 153 - BVerfGE 142, 123. 
darüber hinwegtäuschen, dass für sie ein anderer Prüfungsmaßstab als im sonstigen Bereich der Identitätskontrolle heranzuziehen ist. ${ }^{2390}$ Für beide Arten der Kontrolle beansprucht das Bundesverfassungsgericht für sich die ausschließliche Zuständigkeit. ${ }^{2391}$

a) Identitätskontrolle

aa) Ex tunc-Wirkung im Lichte von Art. 1 GG und Art. 20 GG

Legt man die Rechtsprechung des Bundesverfassungsgerichts trotz berechtigter Kritik an ihr ${ }^{2392}$ zugrunde, kommt die Identitätskontrolle im vorliegenden Zusammenhang in mehreren Ausprägungen in Betracht.

\section{(1) Menschenwürde}

Schutz und Achtung der Menschenwürde gehören zu den unantastbaren Grundsätzen des Art. 1 GG. ${ }^{2393}$ Bei einer zeitlich unbegrenzt wirkenden Auslegung des Gerichtshofs, gegen die keine nationalen Vertrauensumstände ins Feld geführt werden können, ist daher in einem Fall, in dem dies zur rückwirkenden Unanwendbarkeit des nationalen Rechts führt, eine Berührung der Menschenwürde des auf das nationale Recht Vertrauenden in Erwägung zu ziehen. Auch wenn die Verletzung der Garantie der Menschenwürde vom Beschwerdeführer substantiiert dargelegt werden muss $^{2394}$, hat die Menschenwürde durchaus Potential zur Begrenzung des Vorrangs. ${ }^{2395}$

Was die Schutzgüter der Verfassungsidentität anbelangt, so spricht das Bundesverfassungsgericht sowohl von den Grundsätzen des Art. 1 GG'2396

2390 Sauer, EuR 2017, 186 (204f.) sieht deshalb zu Recht „erhebliche Risse“ im „Einheitskonzept der Identitätskontrolle“ und spricht davon, dass das „Bündelungskonzept" dadurch „erheblich relativiert" sei.

2391 BVerfG, Urteil vom 21.6.2016, 2 BvR 2728/13 bis 2 BvR 2731/13, 2 BvE 13/13, Rn. 155 - BVerfGE 142, 123.

2392 Siehe insbesondere Sauer, EuR 2017, $186 \mathrm{ff}$.

2393 BVerfG, Urteil vom 3.3.2004, 1 BvR 2378/98, 1 BvR 1084/99 - BVerfGE 109, 279 (310).

2394 BVerfG, Beschluss vom 15.12.2015, 2 BvR 2735/14, Rn. 50 - BVerfGE 140, 317.

2395 Sauer, NJW 2016, 1134 (1136).

2396 BVerfG, Beschluss vom 15.12.2015, 2 BvR 2735/14, Rn. 48 - BVerfGE 140, 317. 
als auch von der Wahrung des Menschenwürdekerns der Grundrechte (Art. $1 \mathrm{GG})^{2397}$. Hinsichtlich des Menschenwürdegehalts der Grundrechte wird zum Teil zwar ein eigenständiger Schutz über Art. 79 III GG verneint und stattdessen die Bindung an Art. 1 I GG betont, die den Schutz der menschenwürdebezogenen Aspekte der Grundrechte ermögliche. ${ }^{2398}$ Im Ausgangspunkt spricht aber nichts dagegen, die Unantastbarkeit des Menschenwürdegehalts in allen Grundrechten garantiert zu sehen, wenn auch in unterschiedlichen Ausprägungen. ${ }^{2399}$ Die Beeinträchtigung eines Grundrechts in seinem Menschenwürdegehalt selbst kann auch Art. 1 GG berühren ${ }^{2400}$, sodass die Konkretisierung der Menschenwürde in den Grundrechten über Art. 79 III GG geschützt ist. An der Beschränkung der Überprüfung auf den Maßstab der Menschenwürde ändert dies nichts. ${ }^{2401}$ Nicht jeder Verstoß gegen ein Grundrecht kann daher unter Berufung auf Art. 1 GG als Verletzung der Menschenwürde aufgefasst werden. Insbesondere darf Art. 1 I GG nicht extensiv ausgelegt werden, um die Beschränkung des Art. 79 III GG auf Art. 1 und 20 GG nicht zu unterlaufen. ${ }^{2402}$ Die Grenzen des Menschenwürdekerns sind grundsätzlich eng zu ziehen. ${ }^{2403}$

2397 BVerfG, Urteil vom 21.6.2016, 2 BvR 2728/13 bis 2 BvR 2731/13, 2 BvE 13/13, Rn. 138 - BVerfGE 142, 123. Sachs, in: Sachs (Hrsg.), GG, 8. Aufl. 2018, Art. 79 GG, Rn. 51 mit Fn. 129 kritisiert diese Bezugnahme und meint, sie sei „missverständlich".

2398 Sachs, in: Sachs (Hrsg.), GG, 8. Aufl. 2018, Art. 79 GG, Rn. 51; Herdegen, in: Maunz/Dürig, GG, Art. 79 GG, Rn. 115 (Stand: Juli 2014).

2399 Sannwald, in: Schmidt-Bleibtreu/Hofmann/Henneke (Hrsg.), GG, 14. Aufl. 2017, Art. 79 GG, Rn. 49. A.A. Herdegen, in: Maunz/Dürig, GG, Art. 79 GG, Rn. 115 (Stand: Juli 2014); Dreier, in: Dreier (Hrsg.), GG, Band II, 3. Aufl. 2015, Art. 79 III GG, Rn. 28 mit Fn. 110, in der er sich kritisch zu in der Tat kaum Erfolg versprechenden Versuchen äußert, Grundrechte zu Gruppen mit unterschiedlich starkem Menschenwürdebezug zuzuordnen; siehe auch Hain, in: von Mangoldt/Klein/Starck, GG, Band 2, 7. Aufl. 2018, Art. 79 Abs. 3 GG, Rn. 67, der Klassifikationsversuchen nur indizielle Bedeutung für die Frage der Berührung der Menschenwürde im Einzelfall zuspricht.

2400 Bryde, in: von Münch/Kunig (Hrsg.), GG, Band 2, 6. Aufl. 2012, Art. 79 GG, Rn. 37 mit der Erwägung, auf diese Weise eine „Inhaltsleere“ des Menschenwürdeschutzes zu vermeiden; siehe auch Pieroth, in: Jarass/Pieroth, GG, 15. Aufl. 2018, Art. 79 GG, Rn. 15; Evers, in: Kahl/Waldhoff/Walter (Hrsg.), Bonner Kommentar, Art. 79 Abs. 3 GG, Rn. 173 f. (Zweitbearbeitung Oktober 1982).

2401 Siehe in diesem Zusammenhang auch Hain, in: von Mangoldt/Klein/Starck, GG, Band 2, 7. Aufl. 2018, Art. 79 Abs. 3 GG, Rn. 67.

2402 Thiele, EuR 2017, 367 (375 ff., siehe auch Fn. 63).

2403 So fällt etwa, um ein Beispiel aus dem sensiblen Bereich des Strafrechts heranzuziehen, nicht jede Ausprägung des Grundsatzes der Selbstbelastungsfreiheit 
Was im Rahmen einzelner Grundrechte zum Gewährleistungsgehalt des Art. 1 I GG gehört, ist durch Auslegung der jeweiligen Grundrechtsnorm eigenständig zu bestimmen. ${ }^{2404}$

Aufgeworfen ist damit letztlich die Frage, ob sich „Vertrauensschutz“ unmittelbar in Art. 1 I GG bzw. im Menschenwürdekern der den Vertrauensschutz bereits eigenständig umfassenden Grundrechte verankern lässt. $^{2405}$ Entscheidend ist also, ob ihm ein Menschenwürdegehalt zuzusprechen ist.

In der Tat ist die freie Gestaltung des Lebensraums des Einzelnen mit dem Begriff der Menschenwürde eng verbunden; auf den freiheitssichernden Aspekt auch des Vertrauensschutzes wurde bereits hingewiesen. ${ }^{2406}$ Wird einer im Vertrauen auf den Freiraum der Lebensgestaltung getroffenen Entscheidung des Individuums keine Beachtung geschenkt, ist daher ein Bezug zur Menschenwürde nicht zu verleugnen. In der Nichtgewährung von Vertrauensschutz eine Verletzung der Menschenwürde zu erblicken, birgt allerdings die Gefahr einer „Überforderung“ ihres Gewährleistungsgehalts. Die Nichtgewährung von Vertrauensschutz ist nicht generell gleichbedeutend mit einer Missachtung des Wertes einer Person. ${ }^{2407}$ Entgegen vereinzelter Stimmen in Rechtsprechung ${ }^{2408}$ und Literatur ${ }^{2409}$, die Vertrauensschutz in der Menschenwürde verankern, kann nicht behauptet werden, dass die Nichtgewährung von Vertrauensschutz stets dazu führe, dass der Mensch zum bloßen Objekt staatlichen Handelns gemacht werde.

unter den Schutz des Art. 1 GG, vgl. BVerfG, Beschluss vom 6.9.2016, 2 BvR 890/16, Rn. 36 - JZ 2016, 1113.

2404 Vgl. BVerfG, Urteil vom 3.3.2004, 1 BvR 2378/98, 1 BvR 1084/99 - BVerfGE 109, 279 (310 f.) für die verfassungsändernde Grundrechtseinschränkung.

2405 So hat „der rechtsstaatliche Grundsatz des Vertrauensschutzes [...] für die vermögenswerten Güter im Eigentumsgrundrecht eine eigene Ausprägung und verfassungsrechtliche Ordnung erfahren“. Der allgemeine Vertrauensgrundsatz hat insoweit keine selbständige Bedeutung, BVerfG, Beschluss vom 15.1.1974, 1 BvL 5/70, 1 BvL 6/70, 1 BvL 9/70 - BVerfGE 36, 281 (293).

2406 Siehe oben bei Fn. 1974.

2407 Schwarz, Vertrauensschutz, 2002, S. 162.

2408 LSG Bremen, Urteil vom 20.2.1957, LV 161/55 - BB 1957, 543.

2409 Zuck, DÖV 1960, 580 (582); Rohwer-Kablmann, NJW 1960, 1641 (1642); Podlech, in: AK-GG, Art. 1 GG, Rn. 63 (Stand: 2001), der eine aus dem Menschenwürdegehalt des Sozialstaatsprinzips und Art. 2 II GG folgende Veränderungssperre hinsichtlich der Verpflichtung der öffentlichen Gewalt auf Sicherung eines menschenwürdigen Existenzminimums des Einzelnen und seiner Familie im engeren Sinn annimmt. 
Da sämtliche vom Individuum getroffene Planungen und von ihm vorgenommene Dispositionen Schutz durch Vertrauensschutz genießen ${ }^{2410}$, ist sein Anwendungsbereich nicht auf den Kernbereich der Persönlichkeit begrenzt. Ein Bezug der Enttäuschung von Vertrauensschutz zur Menschenwürde besteht daher nur ganz ausnahmsweise. Ein allgemeiner Vertrauensschutz lässt sich mit der Menschenwürde daher nicht begründen. ${ }^{2411}$

Art. 1 I GG kann der Betroffene als Grundlage für Vertrauensschutz daher nur heranziehen, wenn der Kernbereich der Persönlichkeit des Einzelnen betroffen ist. ${ }^{2412}$ Auch wenn man an den Menschenwürdegehalt einzelner Grundrechte anknüpft, lässt sich kein weitergehender Schutz begründen. Bei der Beurteilung einer Identitätsverletzung ergeben sich daher keine Unterschiede, je nachdem, ob unmittelbar Art. 1 I GG oder der Menschenwürdekern der Grundrechte als Prüfungsmaßstab herangezogen werden.

In seinem Honeywell-Beschluss, in dem wie gesehen die rückwirkende Unanwendbarkeit des nationalen Rechts aufgrund seiner Unvereinbarkeit mit dem primärrechtlichen Verbot der Altersdiskriminierung betroffen war, hat das Bundesverfassungsgericht die Möglichkeit der Gewährung "primären“ nationalen Vertrauensschutzes verneint, ohne dabei die Menschenwürde in Stellung zu bringen. ${ }^{2413}$ Ins Spiel gebracht hat es dagegen die Möglichkeit der (aus unionsrechtlicher Sicht allerdings umstrittenen) Gewährung von Vertrauensschadensersatz und damit einer Kompensation auf Sekundärebene. Dass es ohne diese Überlegung eine Berührung der Menschenwürde angenommen hätte, muss allerdings bezweifelt werden, da eine Existenzbedrohung auch bei fehlendem Schadensausgleich kaum einmal in Betracht kommt.

Im Rahmen seiner Defrenne-Rechtsprechung prüft und berücksichtigt der EuGH grundsätzlich guten Glauben der Betroffenen. Lehnt der EuGH

2410 Siehe nur Grabitz, DVBl. 1973, 675 (680), wonach die Tatsache, dass der Bürger im Vertrauen auf den Bestand eines Hoheitsakts Dispositionen getroffen hat, entscheidend dafür ist, dass Vertrauensschutz als geboten erscheint.

2411 Weber-Dürler, Vertrauensschutz, 1983, S. 58 zählt die Menschenwürde (neben dem Grundsatz der Freiheit) dagegen zu den „letzten und allgemeinsten Grundlagen" des Vertrauensschutzprinzips (Kursivschrift im Original).

2412 Fuhrmanns, Vertrauensschutz, 2004, S. 20. Siehe zum Ganzen ausführlich Schwarz, Vertrauensschutz, 2002, S. 163 ff., der Fälle unter Art. 1 I GG fasst, in denen die Grenze der materiellen Existenz des Betroffenen unterschritten wird.

2413 BVerfG, Beschluss vom 6.7.2010, 2 BvR 2661/06 - BVerfGE 126, 286 (314). 
eine zeitliche Begrenzung wegen fehlenden guten Glaubens ab, kann also nicht behauptet werden, dass er die von seiner Auslegung in zeitlicher Hinsicht negativ Betroffenen dadurch zum Objekt seines Handelns machen würde. Lehnt der Gerichtshof eine Begrenzung der ex tunc-Wirkung wegen des fehlenden Nachweises des Bestehens einer Gefahr schwerwiegender Störungen ab, so ist dies aus Sicht des Einzelnen schon bedenklicher, da die Vorstellung der Betroffenen vom Inhalt des Unionsrechts für den Gerichtshof dann keine Rolle spielt. Sind die aus der ex tunc-Wirkung zu ziehenden Folgen im Einzelfall derart gravierend, dass Existenzen „zerstört" werden, ist der Kernbereich der Persönlichkeit betroffen und an eine Aktivierung des Menschenwürdeschutzes zu denken. Derartige Fälle sind zwar kaum vorstellbar, aber jedenfalls nicht von vornherein ausgeschlossen. So kann beispielsweise bei einem auf das nationale Recht vertrauenden Unternehmer eine äußerste Grenze des aus Sicht des Identitätsgehalts des Grundgesetzes Hinnehmbaren erreicht sein, wenn er durch die rückwirkende Unanwendbarkeit des nationalen Rechts finanziell so überfordert wird, dass seine Existenz gefährdet ist. ${ }^{2414}$ Da bei der Durchführung des Unionsrechts aber immer auch die Grundrechtecharta zu beachten ist, stößt dieser Fall angesichts der auch in Art. 1 GRCh verbürgten Unantastbarkeit der Menschenwürde bereits an eine unionsrechtliche Grenze. ${ }^{2415}$

\section{(2) Rechtsstaatsprinzip / Gewaltenteilung}

Als Ausprägung des Rechtsstaatsprinzips ist "nationaler Vertrauensschutz“ auch in Art.20 III GG angesiedelt. Dass die Identitätskontrolle neben der Menschenwürde gleichfalls hinsichtlich der übrigen in Art. 79 III GG genannten Grenzen in Betracht kommt, zu denen die Grundsätze, die das

2414 Siehe auch Brams, Impulse, 2019, S. 285 ff., die Vertrauensschutz bei der richtlinienkonformen Auslegung insbesondere dann gewähren möchte, wenn sonst eine Gefährdung der beruflichen oder finanziellen Existenz des Betroffenen droht.

2415 Zur Anwendbarkeit des Art. 1 GRCh siehe etwa Jarass, GRCh-Kommentar, 3. Aufl. 2016, Art. 1 GRCh, Rn.3. Auch das Unionsrecht schützt die Menschenwürde, vgl. Sauer, Verfassungsblog vom 7.4.2016 mit Blick auf EuGH, Urteil vom 5.4.2016, verb. Rs. C-404/15 und C-659/15 (Aranyosi und Căldăraru). Siehe auch Borowsky, in: Meyer/Hölscheidt (Hrsg.), Charta der Grundrechte, 5. Aufl. 2019, Art. 1 GRCh, Rn. 43, 47. 
Rechtsstaatsprinzip prägen, zu zählen sind ${ }^{2416}$, bedeutet allerdings noch nicht, dass „nationaler Vertrauensschutz“ auch insoweit zum unabänderbaren Verfassungskern gerechnet werden kann. Er wird dort nämlich nicht ausdrücklich erwähnt. Vor dem Hintergrund, dass aus Sicht des Bundesverfassungsgerichts nicht jeder aus dem Rechtsstaatsprinzip ableitbare Rechtsgrundsatz unter dem Schutz des Art. 79 III GG steht ${ }^{2417}$, legt dies die Erwägung nahe, dass es sich beim Vertrauensschutz als Ausfluss des Rechtsstaatsprinzips bereits nicht um einen in Art. 20 GG niedergelegten Grundsatz handelt, so wie Art.79 III GG dies verlangt. ${ }^{2418}$ Einen nach Art. 79 III GG geschützten menschenwürdebezogenen Aspekt des Vertrauensschutzes anzuerkennen, seine Verankerung in Art. 20 III GG mit Blick auf Art. 79 III GG dagegen anders zu beurteilen, würde allerdings nicht überzeugen. Die im vorhergehenden Abschnitt getroffenen Aussagen gelten hier daher entsprechend.

Neben der Vertrauensschutzproblematik erscheint der durch die Rechtsprechung des Gerichtshofs hervorgerufene Konflikt mit dem Gewaltenteilungsgrundsatz, Art. 20 II 2 GG, mehr als Reflex. Zwar kann es infolge einer Entscheidung des EuGH zur (rückwirkenden) Unanwendbarkeit ei-

2416 BVerfG, Urteil vom 21.6.2016, 2 BvR 2728/13 bis 2 BvR 2731/13, 2 BvE 13/13, Rn. 138 - BVerfGE 142, 123: „Grundsätze, die das Demokratie-, Rechts-, Sozial- und Bundesstaatsprinzip im Sinne des Art. 20 GG prägen“.

2417 BVerfG, Urteil vom 15.12.1970, 2 BvF 1/69, 2 BvR 629/68, 2 BvR 308/69 - BVerfGE 30, 1 (24f.): „Auch in Art. 20 GG sind mehrere Grundsätze niedergelegt, nicht jedoch ist dort ,niedergelegt ${ }^{\text {' }}$ das ,Rechtsstaatsprinzip', sondern nur ganz bestimmte Grundsätze des Rechtsstaatsprinzips: [...]. Aus dem Rechtsstaatsprinzip lassen sich mehr als die in Art. 79 Abs. 3 GG in Bezug genommenen Rechtsgrundsätze des Art. 20 GG entwickeln und das Bundesverfassungsgericht hat solche Rechtsgrundsätze entwickelt (z.B.: das Verbot rückwirkender belastender Gesetze, [...], die Lösung des Spannungsverhältnisses von Rechtssicherheit und Gerechtigkeit im Einzelfall, [...]).“

2418 Stern, Staatsrecht I, 2. Aufl. 1984, S. 172 f. bejaht eine Unantastbarkeit des Rechtsstaatsprinzips, aber nicht aller seiner „Verästelungen“ (Anführungszeichen im Original). Dietlein, in: Epping/Hillgruber (Hrsg.), BeckOK Grundgesetz, 43. Edition, Stand: 15.05.2020, Art. 79 GG, Rn. 48 meint, die Ausdifferenzierungen u.a. zum Vertrauensschutz oder zum Rückwirkungsverbot seien nicht unantastbar. Dreier, in: Dreier (Hrsg.), GG, Band II, 3. Aufl. 2015, Art. 79 III GG, Rn. 53 ist der Auffassung, diese Elemente seien „gewissen Modifikationen zugänglich“, insbesondere die „richterrechtliche Dogmatik“ zu Vertrauensschutz und Rückwirkungsverbot. Nach Ansicht von Sachs, in: Sachs (Hrsg.), GG, 8. Aufl. 2018, Art. 79 GG, Rn. 78 sind dagegen auch in Art. 20 GG nicht eigens aufgeführte Teilaspekte des Rechtsstaatsprinzips „in ihrer Grundsatzbedeutung" unberührbar, wobei er Rechtssicherheit und Vertrauensschutz nennt. 
nes vom nationalen Gesetzgeber erlassenen Gesetzes kommen, weshalb die Versagung einer Begrenzung der ex tunc-Wirkung und die daraus zu ziehenden Konsequenzen im Grundsatz geeignet sind, eine Identitätsverletzung im Hinblick auf die Gewaltenteilung zu begründen. ${ }^{2419}$ Auch kann die Wahrung der Verfassungsidentität im Rahmen der Identitätskontrolle nicht damit begründet werden, dass der Gerichtshof grundsätzlich bereit ist, die Wirkung seiner Rechtsprechung zeitlich zu begrenzen. ${ }^{2420}$ Die Besonderheit der Identitätskontrolle im Vergleich zur Solange II-Rechtsprechung besteht ja gerade in der Möglichkeit einer Einzelfallkontrolle. Dennoch erscheint die Unanwendbarkeit des nationalen Rechts hier als "gewöhnliche" Folge des Anwendungsvorrangs, den das Grundgesetz als Wesensmerkmal des Unionsrechts grundsätzlich hinnimmt. ${ }^{2421}$ Kommt es bei der richtlinienkonformen Auslegung durch teleologische Reduktion zur Nichtanwendung nationalen Rechts ${ }^{2422}$, ist dies zwar keine Folge des Anwendungsvorrangs, wohl aber einer konsequenten Befolgung der Pflicht zu richtlinienkonformer Auslegung, gegenüber der sich das Grundgesetz ebenfalls offen zeigt. ${ }^{2423}$ Eine abweichende Beurteilung im Vergleich zur Betroffenheit des Anwendungsvorrangs ist daher nicht angezeigt.

Konflikte mit dem mitgliedstaatlichen Gewaltenteilungsgrundsatz sind allerdings nicht ausgeschlossen. Sie können jedoch bereits bei der Formulierung der unionsrechtlichen Anforderungen Beachtung finden und auf diese Weise entschärft werden, um eine Aktivierung der Identitätskontrolle zu vermeiden. So begegnete der Gerichtshof den Bedenken des italienischen Verfassungsgerichtshofs hinsichtlich des ,italienischen“ Gewaltenteilungsgrundsatzes in der Taricco-Konstellation mit einer Rücknahme der unionsrechtlichen Verpflichtungen. Der Verfassungsgerichtshof hatte u.a. die Vereinbarkeit der Taricco-Regel mit dem italienischen Gewaltentei-

2419 Siehe in diesem Zusammenhang auch Beukers, CMLRev. 48 (2011), 1985 (2002 f.) zur Winner Wetten-Problematik.

2420 So aber Rosenkranz, Beschränkung der Rückwirkung, 2015, S. 444. Von einem dogmatischen Gleichlauf des Solange II-Vorbehalts mit den beiden anderen Integrationsschranken kann daher entgegen Rosenkranz, ZfPW 2016, 351 (371) nicht gesprochen werden.

2421 Auch BVerfG, Beschluss vom 6.7.2010, 2 BvR 2661/06 - BVerfGE 126, 286 (315) nimmt es hin, dass nationale Gesetze aufgrund des Anwendungsvorrangs unangewendet bleiben müssen.

2422 Siehe oben bei Fn. 2202 ff. und zur teleologischen Reduktion einer Norm auf Null bei Fn. $2216 \mathrm{ff}$.

2423 Kritisch Michael, Der Staat 54 (2015), 349 (365) hinsichtlich der Reduktion einer Norm auf Null durch den BGH. Michael erkennt hierin zu Unrecht eine dem Unions- und nationalen Recht fremde „Normkategorie“. 
lungsgrundsatz in Zweifel gezogen, da bei ihrer Befolgung die Inanspruchnahme von Befugnissen des Gesetzgebers durch die Gerichte drohe. ${ }^{2424}$

\section{(3) Haushaltspolitische Gesamtverantwortung / Budgetrecht des Deutschen Bundestages}

Mit der Identitätskontrolle kann auch die Wahrung der nach Art.79 III GG geschützten haushaltspolitischen Gesamtverantwortung des Deutschen Bundestages als Teil seines Budgetrechts überprüft werden. ${ }^{2425} \mathrm{Zum}$ Identitätskern des Grundgesetzes gehört diese angesichts der Verankerung des Budgetrechts des Bundestages in Art. 20 I und II GG. ${ }^{2426}$ Mit ihr bezweckt ist der "Schutz von Möglichkeitsräumen zukünftiger Haushaltsgesetzgebung“. ${ }^{2427}$ Auf diese Weise soll verhindert werden, dass die Gestaltungsfreiheit des künftigen Gesetzgebers durch Entscheidungen des heutigen Gesetzgebers verloren geht.

Der Bundestag oder zukünftige Bundestage müssen das Budgetrecht in eigener Verantwortung ausüben können und damit frei von Fremdbestimmung seitens der Organe der EU und anderer Mitgliedstaaten. Der Bundestag muss dauerhaft „Herr seiner Entschlüsse“ bleiben ${ }^{2428}$; er muss der Ort bleiben, in dem eigenverantwortlich über Einnahmen und Ausgaben entschieden wird, auch im Hinblick auf internationale und europäische Verbindlichkeiten. ${ }^{2429}$ Da zur europäischen Integration nach Ansicht des Bundesverfassungsgerichts auch „die Anpassung an Vorgaben und Bin-

2424 Zur Taricco-Problematik ausführlich oben bei Fn. $1685 \mathrm{ff}$.

2425 Siehe nur BVerfG, Beschluss vom 18.7.2017, 2 BvR 859/15, 2 BvR 1651/15, 2 BvR 2006/15, 2 BvR 980/16, Rn. 54 - BVerfGE 146, 216.

2426 BVerfG, Beschluss vom 18.7.2017, 2 BvR 859/15, 2 BvR 1651/15, 2 BvR 2006/15, 2 BvR 980/16, Rn. 128 - BVerfGE 146, 216. Kritisch Nettesheim, in: Brandt (Hrsg.), Verfassung und Krise, 2015, S. 11 (31 f.), der auf den „zutiefst politischen Charakter“ der Frage des Schutzes künftiger Gestaltungsspielräume des Gesetzgebers verweist. Er verweist auch auf die potentielle Grenzenlosigkeit dieses Konzepts, da sich unterschiedlichste Entwicklungen auf künftige Haushaltsgesetzgebung auswirken können, S. $34 \mathrm{f}$.

2427 Nettesheim, in: Brandt (Hrsg.), Verfassung und Krise, 2015, S. 11 (12 f.), Hervorhebung im Original.

2428 BVerfG, Urteil vom 12.9.2012, 2 BvR 1390/12, 2 BvR 1421/12, 2 BvR 1438/12, 2 BvR 1439/12, 2 BvR 1440/12, 2 BvE 6/12, Rn. 106 ff. - BVerfGE 132, 195 (Anführungszeichen im Original).

2429 BVerfG, Urteil vom 7.9.2011, 2 BvR 987/10, 2 BvR 1485/10, 2 BvR 1099/10 BVerfGE 129, 124 (178). 
dungen [gehört], die der Haushaltsgesetzgeber als nicht unmittelbar beeinflussbare Faktoren in die eigene Planung einstellen muss“, gefährdet nicht jede haushaltswirksame europäische oder internationale Verpflichtung die Gestaltungsfähigkeit des Bundestages als Haushaltsgesetzgeber. ${ }^{2430}$

Die Stoßrichtung der vom Bundesverfassungsgericht geforderten ausreichenden politischen Freiräume für die Entscheidung über Einnahmen und Ausgaben wird deutlich, wenn es als Beispiel für einen Verstoß gegen die haushaltspolitische Gesamtverantwortung eine Haftungsübernahme für Willensentscheidungen Dritter mit schwer kalkulierbaren Folgewirkungen nennt. ${ }^{2431}$ Danach darf also ein EU-Organ keine Entscheidungen treffen können, die ohne vorherige konstitutive Zustimmung des Bundestages erhebliche Auswirkungen auf den Haushalt haben. ${ }^{2432}$

Insofern könnte überlegt werden, ob nicht der EuGH, wenn er eine zeitliche Begrenzung der Berufung auf eine von ihm ausgelegte Norm ablehnt, eine derartige haushaltsrelevante Entscheidung trifft. Auch wenn dadurch auf den Haushalt Belastungen in Milliardenhöhe zukommen sollten, ist dieser Fall aber letztlich anders gelagert als ein solcher, vor dem das Konzept der haushaltspolitischen Gesamtverantwortung schützen soll. Durch eine unterbliebene Begrenzung der zeitlichen Wirkungen werden nämlich nicht in der Höhe unbestimmte Verpflichtungen für die Zukunft begründet, sondern vielmehr mitgliedstaatliche Verstöße gegen Unionsrecht in der Vergangenheit bewältigt. Da die haushaltspolitische Gesamtverantwortung des Bundestages daher vorliegend nicht betroffen ist, kann eine genaue Bestimmung des Umfangs ihres Schutzes an dieser Stelle unterbleiben. ${ }^{2433}$

Während die haushaltspolitische Gesamtverantwortung das Budgetrecht mit der staatlichen Unabhängigkeit eines im Staatenverbund eingehegten Gemeinwesens verbindet, zählt das Budgetrecht des Bundestages bereits zum Begriff der Staatlichkeit selbst. ${ }^{2434}$ Dessen Berührung durch ex tunc wirkende Rechtsprechung des Gerichtshofs ist keine ganz fern liegende Möglichkeit.

2430 BVerfG, Urteil vom 30.6.2009, 2 BvE 2/08, 2 BvE 5/08, 2 BvR 1010/08, 2 BvR 1022/08, 2 BvR 1259/08, 2 BvR 182/09 - BVerfGE 123, 267 (361 f.).

2431 BVerfG, Beschluss vom 18.7.2017, 2 BvR 859/15, 2 BvR 1651/15, 2 BvR 2006/15, 2 BvR 980/16, Rn. 129 - BVerfGE 146, 216.

2432 Simon, Grenzen, 2016, S. 280.

2433 Sie bereitet gewisse Schwierigkeiten, siehe näher Nettesheim, in: Brandt (Hrsg.), Verfassung und Krise, 2015, S. 11 (29 f.).

2434 So Anderheiden, in: FS Müller-Graff, 2015, S. 1238 (1244f.). 
Wie bereits erwähnt, wird in der Literatur zum Teil erwogen, eine Ausnahme von der ex tunc-Wirkung einer unionsgerichtlichen Auslegung allein aufgrund finanzieller Folgen bei einer drohenden Funktionsunfähigkeit des Mitgliedstaats bzw. bei einer Aushöhlung des Budgetrechts des nationalen Parlaments zuzulassen und in diesem Fall auf das Kriterium des guten Glaubens zu verzichten. ${ }^{2435}$ Auch wenn dies lediglich in "ganz außergewöhnlichen Fällen“ angedacht wird ${ }^{2436}$, könnte damit eine von den Mitgliedstaaten gebildete Vorstellung vom Inhalt des Unionsrechts Berücksichtigung finden, für die aber aus unionsrechtlicher Sicht kein Anhaltspunkt besteht. Finanzielle Erwägungen allein können eine zeitliche Beschränkung in diesem Fall daher nicht rechtfertigen. ${ }^{2437}$ Am Kumulationserfordernis einer Begrenzung im Sinne der Defrenne-Rechtsprechung, das sowohl das Bestehen einer Gefahr schwerwiegender Störungen als auch von gutem Glauben fordert, ist daher festzuhalten. Die DefrenneRechtsprechung verweigert sich damit einer Begrenzung auch dann, wenn eine Berührung des Budgetrechts des Bundestages im Raum steht. In diesem Fall ist das Bundesverfassungsgericht aufgefordert, im Dialog mit dem EuGH einen möglichst schonenden Ausgleich zu suchen, der einerseits in Rechnung stellt, dass die unionsrechtlichen Vorgaben von der Bundesrepublik ohne unionsrechtliche Veranlassung missachtet wurden, der sich andererseits aber auch für die Überlegung offen zeigt, dass die EU selbst kein Interesse an einem finanziellen Zusammenbruch einer ihrer Mitgliedstaaten hat.

\section{(4) Ergebnis}

Die Verfassungsidentität wird durch die mit der Rechtsprechung des Gerichtshofs in zeitlicher Hinsicht verbundenen Vorgaben in aller Regel nicht berührt, sodass eine Aktivierung des Identitätsvorbehalts lediglich in ganz besonders gelagerten Ausnahmefällen denkbar erscheint. So besteht etwa eine wenn auch nur sehr entfernte Möglichkeit der Berührung des Kernbereichs der Persönlichkeit. Daneben ist an vom EuGH - aus nationaler Perspektive betrachtet - nicht hinreichend berücksichtigte Auswirkun-

2435 Wusterhausen, Wirkungen, 2016, S. $330 \mathrm{ff}$. Siehe hierzu bereits oben bei Fn. $762 \mathrm{ff}$.

2436 GA Wahl, Schlussanträge vom 24.10.2013 in der Rs. C-82/12 (Transportes Jordi Besora), Rn. 58.

2437 Berkemann, DVB1. 2017, 950 (952) meint, diese Frage bleibe „kritisch“. 
gen auf das Budgetrecht des Bundestages zu denken. Diesen Bedenken ist letztlich bereits durch unionsrechtliche Erwägungen zu begegnen, etwa durch Fruchtbarmachung des Art. 1 GRCh oder einen Hinweis auf die finanzielle Leistungsfähigkeit der Mitgliedstaaten als Voraussetzung gelingender europäischer Integration.

\section{bb) Bedeutung für die richtlinienkonforme Auslegung}

Indem das Bundesverfassungsgericht den Begriff des „Anwendungsvorrangs" als Bezugspunkt der Integrationsgrenzen wählt, ist nicht auf den ersten Blick klar, ob sie auf nach traditionellem Verständnis unmittelbar anwendbares/wirkendes Unionsrecht begrenzt sind oder etwa auch Fälle der richtlinienkonformen Auslegung im Horizontalverhältnis erfassen. An dieser Stelle ist daher das bundesverfassungsgerichtliche Verständnis des Vorrangbegriffs kurz zu beleuchten. ${ }^{2438}$

Im Rahmen der Erörterung der Frage, ob nationales Umsetzungsrecht zu einer Richtlinie am Maßstab des Grundgesetzes zu überprüfen ist, hat das Bundesverfassungsgericht vom Begriff des Anwendungsvorrangs als Ausdruck der Eigenschaft unmittelbarer Anwendbarkeit/Wirkung Gebrauch gemacht. Es unterscheidet dabei zwischen dem Anwendungsvorrang einerseits und der Überprüfbarkeit am Maßstab nationalen Verfassungsrechts andererseits und damit zwischen der vorrangigen Anwendung des Unionsrechts auf den konkreten Sachverhalt und der Verdrängung des verfassungsrechtlichen Prüfungsmaßstabs. ${ }^{2439}$ Für den Verzicht auf eine Überprüfung an den Grundrechten des Grundgesetzes bei nach Art. 288 III AEUV umzusetzenden zwingenden Vorgaben des Unionsrechts, die den Mitgliedstaaten keinen Umsetzungsspielraum lassen, ist demnach

2438 Siehe zu einem Sonderfall BVerfG, Beschluss vom 17.11.2017, 2 BvR 1131/16, Rn. 33 f. - NJW-RR 2018, 305, wo das Bundesverfassungsgericht dem BGH ein Vorgehen „in Übereinstimmung mit den unionsrechtlichen Vorgaben“ bescheinigt, obwohl dies insoweit nicht der Fall war, als der BGH trotz des von ihm bejahten Vorliegens eines Horizontalverhältnisses eine negative Richtlinienwirkung angenommen hatte. Zum Vorgehen des BGH näher BGH, Urteil vom 28.10.2015, VIII ZR 158/11, Rn. 33, 35, 65, 66 und 68 - BGHZ 207, 209; hierzu zu Recht kritisch Riesenhuber, LMK 2016, 375867; siehe auch Frantzen, Staatshaftung, 2018, S. $54 \mathrm{f}$.

2439 Siehe auch Mißling, EuR 2007, 261 (264 und Fn. 21), nach dessen Ansicht der Entzug des Unionsrechts vor verfassungsrechtlicher Kontrolle nicht zwingend mit der Vorrangfrage verbunden sei, da sich diese Frage erst im Zusammenhang mit der direkten Anwendung des Unionsrechts stelle. 
nicht entscheidend, ob die „Richtlinie ausnahmsweise wie eine Verordnung unmittelbare Wirkung entfaltet und ihr damit Anwendungsvorrang gegenüber entgegenstehenden mitgliedstaatlichen Normen zukommt“. ${ }^{2440}$ Damit stellt das Bundesverfassungsgericht zu Recht fest, dass die Determinierung nationalen Rechts von der unmittelbaren Wirkung unabhängig ist. ${ }^{2441}$

Die Verwendung des Begriffs des Anwendungsvorrangs in diesem $\mathrm{Zu}$ sammenhang als an die unmittelbare Wirkung gekoppelte Eigenschaft beschränkt die Integrationsgrenzen aber nicht auf Fälle, in denen es um die Verdrängung des nationalen Rechts durch unmittelbar wirkendes Unionsrecht geht. Da eine Überprüfbarkeit des zugrundeliegenden Unionsrechtsakts am Maßstab der Grundrechte bereits deshalb ausscheidet, weil es sich bei diesem nicht um einen Akt deutscher Hoheitsgewalt handelt, geht es dem Bundesverfassungsgericht in seiner Rechtsprechung zur Überprüfbarkeit nationalen Umsetzungsrechts letztlich um eine Rücknahme des grundgesetzlichen Grundrechtsschutzes. Es erkennt damit, wie es selbst formuliert, einen „die Überprüfung an den Grundrechten des Grundgesetzes ausschließenden Anwendungsvorrang des Unionsrechts“ an. ${ }^{2442}$ Die Ablehnung einer Überprüfbarkeit am Maßstab der Grundrechte und damit die Rücknahme des grundgesetzlichen Grundrechtsschutzes erscheinen damit als Folge des Vorrangs des Unionsrechts. ${ }^{2443}$

Mit der Verwendung des Begriffs des Anwendungsvorrangs im $\mathrm{Zu}$ sammenhang mit den Integrationsgrenzen möchte das Bundesverfassungsgericht der unionsrechtlich geforderten Verdrängung verfassungsrechtlicher Prüfungsmaßstäbe seinerseits Grenzen setzen und durch Unionsrecht beeinflusste Fallgestaltungen generell einer Prüfung der Wahrung der Integrationsgrenzen unterwerfen. ${ }^{244}$

2440 BVerfG, Beschluss vom 13.3.2007, 1 BvF 1/05 - BVerfGE 118, 79 (96f.), Hervorhebung nur hier. Kritisch zu dieser Rechtsprechung Funke, Umsetzungsrecht, 2010, S. $171 \mathrm{ff}$. Ein weites Vorrangverständnis zugrunde legend dagegen BVerfG, Beschluss vom 15.12.2015, 2 BvR 2735/14, Rn. 77 - BVerfGE 140, 317: „Am Anwendungsvorrang des Unionsrechts nehmen auch Rahmenbeschlüsse teil."

2441 Funke, Umsetzungsrecht, 2010, S. 183 f.

2442 BVerfG, Beschluss vom 6.11.2019, 1 BvR 276/17, Rn. 47 - EuZW 2019, 1035.

2443 Siehe hierzu bereits Masing, NJW 2006, 264 (265 ff.).

2444 Siehe Sauer, NJW 2016, 1134 (1135) mit Blick auf BVerfG, Beschluss vom 15.12.2015, 2 BvR 2735/14 - BVerfGE 140, 317, der zu Recht hervorhebt, dass in der diesem Beschluss zugrundeliegenden Fallkonstellation gar keine Kollision zwischen unionsrechtlichem Gebot und grundrechtlichem Verbot bestand. Zu Recht kritisch daher auch Schmabl, in: Breuer (Hrsg.), Principled 
Angesichts der vom EuGH gegenüber der richtlinien- bzw. rahmenbeschlusskonformen Auslegung anerkannten contra legem-Grenze ${ }^{2445}$ hätte zwar auf den ersten Blick fraglich erscheinen können, ob es in diesem Bereich einer zusätzlichen verfassungsrechtlichen Überprüfung überhaupt bedarf, da ein Verstoß gegen die Integrationsgrenzen ausgeschlossen erschiene, wenn über die contra legem-Grenze sämtliche verfassungsrechtlichen Bedenken unionsrechtlich geltend gemacht werden könnten. In diesem Sinne wird in der Tat vorgebracht, dass die Wahl eines verfassungswidrigen Auslegungsergebnisses im Wege richtlinienkonformer Auslegung unzulässig sei und die verfassungskonforme Auslegung zum nationalen Methodenkanon gehöre, den das Unionsrecht respektiere. ${ }^{2446}$ Sämtliche grundgesetzlichen Vorgaben können aber nicht als Schranke der richtlinienkonformen Auslegung gedeutet werden, da die Mitgliedstaaten wie gesehen in der Bestimmung der contra legem-Grenze nicht frei sind. So können die nationalen Gerichte etwa eine richtlinienkonforme Auslegung nicht mit dem Argument entgegenstehender höchstrichterlicher Rechtsprechung verweigern; „nationaler Vertrauensschutz“ kann nicht einfach als Methodenregel formuliert werden. ${ }^{2447}$ Die nach ausschließlich nationalem Verständnis erfolgte Einordnung eines Auslegungsergebnisses als contra legem kann daher unionsrechtlich unzulässig sein. In diesem Fall müsste ein deutsches Gericht das deutsche Recht in einer aus dessen Sicht unzulässigen Weise auslegen, um sich unionsrechtskonform zu verhalten. Der damit im Raum stehende Verstoß insbesondere gegen verfassungsrechtlich relevante Vertrauensschutzgesichtspunkte kann das erzielte Auslegungsergebnis aus deutscher Perspektive als identitätswidrig erscheinen lassen. Das Interesse an einem Vorbehalt verfassungsgerichtlicher Überprüfung wird damit verständlich. Darüber hinaus sind an die Grenze der allgemeinen Rechtsgrundsätze unionsrechtliche Maßstäbe anzulegen, sodass ein nationales Gericht sie nicht beliebig eigenständig ausfüllen kann.

Ein sämtliche verfassungsrechtliche Bedenken umfassendes Verständnis der contra legem-Grenze würde zudem die Solange II-Rechtsprechung konterkarieren, die eine Prüfung am Maßstab der deutschen Grundrechte nur bei einem generellen Absinken des Schutzniveaus auf Ebene des

Resistance, 2019, S. 299 (303). Kritisch zum Ansatz des Bundesverfassungsgerichts bereits Schönberger, JZ 2016, 422 (424) und Schmahl, JZ 2016, 921 (924).

$2445 \mathrm{Zu}$ dieser ausführlich oben bei Fn. $2084 \mathrm{ff}$.

2446 Höpfner, Jahrbuch Junger Zivilrechtswissenschaftler 2009, 73 (89).

2447 Siehe dazu näher oben bei Fn. 2124 ff. 
Unionsrechts und nicht in jedem Einzelfall ins Auge fasst. ${ }^{2448}$ Darüber hinaus handelt es sich bei der richtlinienkonformen Auslegung im Falle fehlender oder mangelhafter Umsetzung der Richtlinienvorgaben um „Umsetzungsersatzrecht“. ${ }^{2449}$ Die richtlinienkonforme Auslegung kann die korrekte Richtlinienumsetzung durch den Gesetzgeber zwar insofern nicht ersetzen, als sich ihre Bedeutung insbesondere dann zeigt, wenn das nationale Recht Defizite bei der Richtlinienumsetzung aufweist. Sie ist mit dem Umsetzungsrecht aber insoweit gleichzubehandeln, als auch bei ihr der verfassungsrechtliche Prüfungsmaßstab verdrängt werden kann.

Deutlich geworden ist damit, dass die vom Bundesverfassungsgericht für den Anwendungsvorrang des Unionsrechts formulierten Schranken auch in Fallgestaltungen greifen, in denen es nicht um die „klassische“ Konstellation der Verdrängung des nationalen Rechts durch eine unmittelbar wirkende Bestimmung des Unionsrechts geht, sondern etwa eine richtlinienkonforme Auslegung im Horizontalverhältnis in Rede steht.

\section{b) Ultra-vires-Kontrolle}

Abschließend ist ein Blick auf die Ultra-vires-Kontrolle zu richten. Sie umfasst wie die anderen Integrationsgrenzen - das zeigen etwa der Honeywell-Beschluss ${ }^{2450}$ oder das EZB-Urteil ${ }^{2451}$ des Bundesverfassungsgerichts auch die Rechtsprechung des EuGH und führt bei der Einstufung eines EuGH-Urteils als Ultra-vires-Akt dazu, dass diesem Urteil die Entfaltung einer Bindungswirkung in Deutschland versagt ist.

Ultra vires ergeht eine Maßnahme, wenn sie das Integrationsprogramm in hinreichend qualifizierter Weise überschreitet und ihr in Deutschland daher die demokratische Legitimation fehlt; ebenso verletzt ist dadurch

2448 Siehe auch Rosenkranz, Beschränkung der Rückwirkung, 2015, S. 488 f.

2449 Begriff bei Domröse, Jahrbuch Junger Zivilrechtswissenschaftler 2009, 109 (117), der ihn im Hinblick auf das „autonome Privatrecht“ der Mitgliedstaaten verwendet, das in den Dienst der Erzielung eines richtlinienkonformen Ergebnisses gestellt wird (Hervorhebung im Original).

2450 BVerfG, Beschluss vom 6.7.2010, 2 BvR 2661/06 - BVerfGE 126, 286 (304).

2451 BVerfG, Urteil vom 5.5.2020, 2 BvR 859/15, 2 BvR 1651/15, 2 BvR 2006/15, 2 BvR 980/16, Rn. 118 f., 163 - NJW 2020, 1647. Kritisch zu diesem Urteil Wegener, Verfassungsblog vom 5.5.2020; dem Bundesverfassungsgericht im Ergebnis zustimmend Gärditz, Verfassungsblog vom 21.5.2020. 
das Rechtsstaatsprinzip. ${ }^{2452}$ Erforderlich ist ein offensichtlich kompetenzwidriges Handeln der Unionsgewalt mit der Folge einer „strukturell bedeutsame[n] Verschiebung zulasten mitgliedstaatlicher Kompetenzen “. ${ }^{2453}$

Das Bundesverfassungsgericht selbst spricht verharmlosend von der Notwendigkeit der Koordination der Ultra-vires-Kontrolle mit der Auslegungszuständigkeit des EuGH nach Art. 19 I UAbs. 1 S. 2 EUV, Art. 267 AEUV. ${ }^{2454}$ Dies kann aber nicht darüber hinwegtäuschen, dass sie aus unionsrechtlicher Perspektive unzulässig ist, was sich bereits aus der Missachtung der Bindung mitgliedstaatlicher Gerichte an das Unionsrecht in seiner Auslegung durch den EuGH ergibt. ${ }^{2455}$

Wird die Defrenne-Rechtsprechung des Gerichtshofs, d.h. die Rechtsprechung zur Begrenzung der Berufung auf eine Norm in der von ihm vorgenommenen Auslegung in zeitlicher Hinsicht, daraufhin untersucht, ob sie das Integrationsprogramm in hinreichend qualifizierter Weise überschreitet, so ist festzustellen, dass der Gerichtshof sie mit dem allgemeinen unionsrechtlichen Rechtsgrundsatz der Rechtssicherheit begründet. Im Hinblick auf die ihm nach Art. 19 I UAbs. 1 S. 2 EUV übertragene Aufgabe hat sich diese Verankerung als tragfähig erwiesen. ${ }^{2456}$ Auch in seiner Handhabung des Grundsatzes der Rechtssicherheit überschreitet der

2452 BVerfG, Urteil vom 21.6.2016, 2 BvR 2728/13 bis 2 BvR 2731/13, 2 BvE 13/13, Rn. 143 und 152 - BVerfGE 142, 123. Siehe auch Leitsatz 2 dieses Urteils, wonach eine ultra vires ergangene Maßnahme den zur Verfassungsidentität zählenden (siehe Urteil, Rn. 82) Grundsatz der Volkssouveränität verletzt. In Rn. 162 des Urteils scheint weiterhin die Vorstellung auf, Ultra-vires-Akte seien nicht vom Rechtsanwendungsbefehl des Zustimmungsgesetzes gedeckt, wenn es heißt, sie nähmen nicht am Anwendungsvorrang des Unionsrechts teil und seien in Deutschland unanwendbar.

2453 BVerfG, Urteil vom 5.5.2020, 2 BvR 859/15, 2 BvR 1651/15, 2 BvR 2006/15, 2 BvR 980/16, Rn. 110 - NJW 2020, 1647.

2454 BVerfG, Urteil vom 5.5.2020, 2 BvR 859/15, 2 BvR 1651/15, 2 BvR 2006/15, 2 BvR 980/16, Rn. 111 - NJW 2020, 1647.

2455 Classen, EuR 2015, 477 (478) unter Verweis auf EuGH, Urteil vom 16.6.2015, Rs. C-62/14 (Gauweiler u.a.), Rn. 16 und die dort betonte Bindung der vorlegenden Gerichte an eine Vorabentscheidung; ebenso Epiney, NVwZ 2016, 655 (659 f.), die auf die mit der Ultra-vires-Kontrolle verbundene Aushebelung der Bindungswirkung der EuGH-Urteile hinweist. Siehe auch die im Anschluss an das EZB-Urteil des Bundesverfassungsgerichts herausgegebene Pressemitteilung des EuGH, in der dieser "ganz generell“ auf seine ständige Rechtsprechung zur Bindung des vorlegenden Gerichts an die von ihm getroffene Entscheidung hinweist, Gerichtshof der Europäischen Union, Pressemitteilung Nr. 58/20 vom 8.5.2020. Deutlich auch Kelemen/Eeckbout/Fabbrini/Pech/Uitz, Verfassungsblog vom 26.5.2020.

2456 Siehe oben bei Fn. 392 ff. 
Gerichtshof die Grenze zum Ultra-vires-Handeln nicht; von einer „schlechterdings nicht mehr nachvollziehbaren und daher objektiv willkürlichen Auslegung der Verträge “2457 kann keine Rede sein. Der Gerichtshof wahrt damit im Rahmen seiner Defrenne-Rechtsprechung die ihm aus verfassungsrechtlicher Sicht gezogenen Kompetenzgrenzen. ${ }^{2458}$ Nichts anderes gilt für den vom Gerichtshof aufgestellten Grundsatz der ex tunc-Wirkung der Auslegung. Sie wird vom Rechtsanwendungsbefehl der ausgelegten Norm verlangt. ${ }^{2459}$ Die zeitliche Dimension der unionsgerichtlichen Rechtsprechung „an sich“ ist demnach unbedenklich.

Aus mitgliedstaatlicher Sicht ultra vires erfolgt sein kann dagegen etwa die „Entdeckung“ eines primärrechtlichen Grundsatzes wie etwa des Verbots der Altersdiskriminierung vor dem Inkrafttreten der Grundrechtecharta. ${ }^{2460}$ An dieser mitgliedstaatlichen Einschätzung würde sich durch eine Begrenzung der ex tunc-Wirkung nichts ändern, es sei denn, die zeitliche Begrenzung würde die Berufung auf den vom Gerichtshof entdeckten Rechtsgrundsatz erst zu einem Zeitpunkt ermöglichen, zu dem - etwa durch das Inkrafttreten von Art. 21 GRCh - dessen Existenz als kompetenzgemäß erscheint. ${ }^{2461}$

\section{Ergebnis}

Die Fruchtbarmachung der verfassungsrechtlichen Integrationsgrenzen im Zusammenhang mit der zeitlichen Dimension der Rechtsprechung des EuGH hat ein nur sehr geringes Konfliktpotential zu Tage gefördert.

2457 BVerfG, Urteil vom 5.5.2020, 2 BvR 859/15, 2 BvR 1651/15, 2 BvR 2006/15, 2 BvR 980/16, Rn. 118 - NJW 2020, 1647.

2458 Gleiches gilt für die Rechtsprechung des Gerichtshofs zur Begrenzung der ex tunc-Wirkung der Unwirksamkeitserklärung von Unionsrechtsakten, die sich auf Art. 264 II AEUV und damit auf eine primärrechtliche Grundlage stützen kann. Auch deren Anwendung überschreitet die Kompetenzgrenzen nicht in offensichtlicher bzw. strukturell bedeutsamer Art und Weise.

2459 Siehe oben bei Fn. 191 und Fn. 212.

2460 So ordnet etwa das Højesteret, Urteil vom 6.12.2016, 15/2014, englische Übersetzung, S. $44 \mathrm{ff}$. (zusammenfassend S. 48) den allgemeinen Rechtsgrundsatz des Verbots der Altersdiskriminierung als nicht vom dänischen Zustimmungsgesetz zu den Verträgen umfasst ein. Kritisch hierzu Dubout, RTDEur. 2018, 563 (574). Siehe auch die Kritik oben in Fn. 1593.

2461 Siehe zur Ultra-vires-Kontrolle auch bereits Rosenkranz, Beschränkung der Rückwirkung, 2015, S. 443. 
So ist ein Unterschreiten des nach dem Grundgesetz unabdingbaren grundrechtlichen Schutzniveaus nicht erkennbar. Vor dem Hintergrund, dass sowohl hinsichtlich der Pflicht zur Nichtanwendung des nationalen Rechts als auch hinsichtlich der Pflicht zu seiner richtlinienkonformen Auslegung die Rechtslage im Hinblick auf die Berücksichtigung nationaler Vertrauensumstände unionsrechtlich determiniert ist, führt diese Feststellung zu einer Rücknahme des grundgesetzlichen Grundrechtsschutzes. Eine Überprüfung der mit der Rechtsprechung des Gerichtshofs verbundenen zeitlichen Vorgaben am nationalen grundrechtlichen Vertrauensschutzmaßstab ist daher nicht möglich. Lediglich bei Umsetzungsspielraum gewährenden Bestimmungen ist eine Anwendung deutscher Grundrechte möglich, die dann aber im Lichte des unionsrechtlichen Grundsatzes der Rechtssicherheit zu würdigen sind.

Eine Verletzung der Verfassungsidentität ist lediglich in Ausnahmefällen denkbar. Nicht ausgeschlossen ist, dass im Zusammenhang mit einer zeitlich unbegrenzt wirkenden Rechtsprechung des Gerichtshofs einmal die Berührung des Kernbereichs der Persönlichkeit eines dem Unionsrecht Unterworfenen im Raum steht. Rechnung zu tragen ist dem durch Heranziehung des Gewährleistungsgehalts des Art. 1 GRCh. In Betracht kommt auch eine Aushöhlung des Budgetrechts des Bundestages, wenn aufgrund einer ex tunc wirkenden Auslegung des Gerichtshofs sehr hohe Summen zur Bewältigung der Folgen dieser Auslegung aufzubringen sind. In diesem Fall ist im Dialog von Bundesverfassungsgericht und EuGH ein schonender Ausgleich zwischen Unions- und nationalen Interessen zu suchen.

Ein kompetenzwidriges Verhalten des Gerichtshofs, was spezifisch die zeitliche Dimension seiner Rechtsprechung betrifft, ist nicht festzustellen. Die Ultra-vires-Kontrolle kann insoweit also nicht in Stellung gebracht werden. Denkbar sind allerdings Fallgestaltungen, in denen das Bundesverfassungsgericht das „sonstige“ Handeln des EuGH bei der Auslegung des Unionsrechts als ultra vires beanstandet, was die entsprechende Rechtsprechungstätigkeit des Gerichtshofs - vom Standpunkt des Bundesverfassungsgerichts aus betrachtet - als unverbindlich erscheinen lässt. Dies würde dann auch deren zeitlichen Aspekt erfassen. Dass gegen ein solches Vorgehen des Bundesverfassungsgerichts aus unionsrechtlicher Sicht durchgreifende Bedenken bestehen, ist offenkundig. 


\section{Schlussbetrachtung und Ausblick}

Die in dieser Arbeit angestellten Überlegungen haben im Wesentlichen drei denkbare Anknüpfungspunkte für mitgliedstaatliche Gerichte ergeben, wenn sie eine Begrenzung der mit der Rechtsprechung des Gerichtshofs einhergehenden unionsrechtlichen Vorgaben in zeitlicher Hinsicht in Erwägung ziehen.

Zum einen ist die Winner Wetten-Rechtsprechung mit ihrer Überlegung einer vorübergehenden Suspendierung der Verdrängungswirkung unmittelbar anwendbarer unionsrechtlicher Normen zu nennen. Der Gerichtshof verfährt hier verständlicherweise sehr restriktiv. Erwägungen wie haushalts- und verwaltungstechnische Schwierigkeiten, denen bereits im Rahmen der Defrenne-Rechtsprechung keine Bedeutung beizumessen ist, können auch auf diesem Weg keine Berücksichtigung finden. Ebenso scheidet eine Begrenzung der Durchsetzungsdimension unmittelbar anwendbaren Unionsrechts durch auf das Vertrauen in nationales Recht gestützte Erwägungen aus, da insoweit nur die Maßstäbe der DefrenneRechtsprechung heranzuziehen sind, für deren Anwendung dem Gerichtshof eine ausschließliche Zuständigkeit zusteht. Eine Berücksichtigung auf einen Mitgliedstaat bezogener Erwägungen, die zur Rechtfertigung einer vorübergehenden Aufrechterhaltung einer unionsrechtswidrigen Rechtslage herangezogen werden sollen, ist aber nicht von vornherein ausgeschlossen. Sie kommt in Betracht, wenn diese Erwägungen wie etwa die Stromversorgungssicherheit eines Mitgliedstaats in Art.194 I lit. b AEUV eine unionsrechtliche Anerkennung gefunden haben. Hierbei ist allerdings den im Rahmen des Unionsrechts eröffneten Möglichkeiten, die etwa der Binnenmarkt zur Verfügung stellt, Rechnung zu tragen. Bislang hat der Gerichtshof den mitgliedstaatlichen Gerichten nur hinsichtlich des Umweltschutzes und der Stromversorgungssicherheit eines Mitgliedstaates eine Befugnis zur Aufrechterhaltung bestimmter Wirkungen unionsrechtswidrigen nationalen Rechts zugesprochen, wenn ihnen dies nach ihrem nationalen Recht möglich ist und sie die vom EuGH zum Gebrauchmachen von dieser Befugnis aufgestellten Bedingungen beachten. Im Übrigen ist es dem Gerichtshof vorbehalten, eine vorübergehende Aussetzung der Verdrängungswirkung herbeizuführen, wenn dies aus spezifischen Risiken für die unionsrechtliche Rechtssicherheit erforderlich erscheint. Eine tem- 
poräre Suspendierung kommt daher nur im Rahmen vom EuGH festgelegter Bedingungen in Betracht. ${ }^{2462}$

Im Rahmen der richtlinienkonformen Auslegung nationalen Rechts lassen sich die dieser Verpflichtung gesetzten Grenzen nur sehr eingeschränkt fruchtbar machen. So hat sich eine Verankerung der Berücksichtigung nationaler Vertrauensumstände in der contra legem-Grenze als wenig ergiebig erwiesen. Ebenso ist die Berücksichtigung nationaler Vertrauensumstände im Rahmen der Grenze der allgemeinen Rechtsgrundsätze des Unionsrechts auf Ausnahmefälle begrenzt. Angedeutet hat der Gerichtshof zwar, dass der Vertrauensschutzgrundsatz als Grenze Bedeutung erlangen kann. Begrenzt war dies aber auf den Sonderfall der Anwendbarkeit einer Richtlinie auf die künftigen Auswirkungen in der Vergangenheit begonnener Sachverhalte. Nur für straf- und verwaltungsrechtliche Fallgestaltungen ist eine eigenständige Ausgestaltung der der richtlinienkonformen Auslegung durch die allgemeinen Rechtsgrundsätze gezogenen Grenze festzustellen. Dass der Gerichtshof die richtlinienkonforme Auslegung im Hinblick auf die Berücksichtigung nationaler Vertrauensumstände anders als den Anwendungsvorrang behandeln möchte, hat er bislang nicht erkennen lassen. Vor dem Hintergrund im Ergebnis gleichartiger Wirkungen von Anwendungsvorrang und richtlinienkonformer Auslegung wäre dies auch nicht überzeugend. Neben Vertrauensschutz als Reflex der Begrenzung auf das methodisch Mögliche genießt daher lediglich eine „Zusicherung "der nationalen Rechtsprechung in dem Sinne, dass das nationale Recht nicht richtlinienkonform auslegbar sei, Schutz. ${ }^{2463}$

Die im Taricco II-Urteil durch den EuGH ermöglichte Berücksichtigung des italienischen Verständnisses des Legalitätsgrundsatzes betrifft eine Sonderkonstellation. Sie hat zwar eine temporäre Differenzierung hinsichtlich der Verpflichtung zur Nichtanwendung nationalen Rechts ermöglicht. Trotz ihrer Anknüpfung an allgemeine Rechtsgrundsätze ist diese Entscheidung aber nicht verallgemeinerungsfähig und damit auch nicht auf den Fall der Berücksichtigung nationaler Vertrauensumstände übertragbar. Die Taricco-Konstellation zeigt jedoch, dass in unionsrechtlich nicht harmonisierten Bereichen größerer Spielraum der Mitgliedstaaten besteht, der es mitgliedstaatlichen Gerichten gestattet, auf das nationale Recht ge-

2462 Siehe zu den hier angesprochenen Fragestellungen ausführlich bei Fn. 1375 ff. und Fn. $1564 \mathrm{ff}$.

2463 Zum Ganzen ausführlich bei Fn. 2034 ff. 
stützte Vertrauensschutzerwägungen in größerem Umfang zur Geltung zu bringen. ${ }^{2464}$

Die vorgestellten Anknüpfungspunkte erweisen sich demnach als nur eingeschränkt offen für eine Berücksichtigung nationaler Besonderheiten. Vor diesem Hintergrund sollen abschließend noch einige Ausführungen zum Aspekt der Staatshaftung erfolgen, der dann verstärkt in das Blickfeld des Interesses gerät. Zu unterscheiden sind insoweit verschiedene Konstellationen, da es davon abhängt, ob die mitgliedstaatlichen Gerichte die zeitlichen Vorgaben des Unionsrechts durchgesetzt haben oder nicht, wessen Rechtsposition im Ergebnis auf Primärebene durchgesetzt wurde. Je nachdem, ob dies unter Befolgung oder Missachtung unionsrechtlicher Vorgaben erfolgte, ist die Ausgangslage eine andere. $\mathrm{Zu}$ denken ist in diesem Zusammenhang sowohl an einen Staatshaftungsanspruch wegen Verstoßes gegen Unionsrecht als auch an einen Ausgleich der dem Einzelnen dadurch entstandenen Einbußen, dass das Unionsrecht ohne zeitliche Begrenzung zur Anwendung gekommen ist. ${ }^{2465}$ Aufgeworfen ist dann auch die Frage, auf welcher Grundlage der jeweilige Anspruch gegebenenfalls begründet werden kann, ob auf einer unionsrechtlichen wie bei der mitgliedstaatlichen Staatshaftung nach den Grundsätzen der FrancovichRechtsprechung oder einer nationalrechtlichen. ${ }^{2466}$

Auf dieser Sekundärebene ist als Besonderheit in Rechnung zu stellen, dass das Unionsrecht mit dem Merkmal des hinreichend qualifizierten Verstoßes als Voraussetzung eines unionsrechtlichen Staatshaftungsanspruchs nicht nur nach einem Verstoß gegen Unionsrecht an sich, sondern nach einer besonderen Qualität des unionsrechtswidrigen Verhaltens fragt. So ist ein Verstoß gegen Unionsrecht eindeutig dann hinreichend qualifiziert, wenn er trotz des Erlasses eines Urteils, in dem der zur Last gelegte Verstoß festgestellt wird, eines Urteils im Vorabentscheidungsverfahren oder einer gefestigten einschlägigen Rechtsprechung des Gerichtshofs, woraus sich die Pflichtwidrigkeit des fraglichen Verhaltens ergibt, fortbestanden hat. 2467

Auch wenn die vom EuGH vorgenommene Auslegung auf Primärebene ex tunc wirkt, führt dies also nicht zwangsläufig dazu, vor dem Zeitpunkt

2464 Näher bei Fn. 1685 ff. und Fn. 2315 ff.

2465 Vgl. Kirschnick, Verstoß, 2015, S. 272 f.

2466 Siehe zu dieser Unterscheidung auch Rosenkranz, Beschränkung der Rückwirkung, 2015, S. 498.

2467 EuGH, Urteil vom 13.3.2007, Rs. C-524/04 (Test Claimants in the Thin Cap Group Litigation), Rn. 120. 
eines klärenden EuGH-Urteils auf Sekundärebene einen hinreichend qualifizierten Verstoß des Mitgliedstaats gegen Unionsrecht anzunehmen. Das Vorliegen eines hinreichend qualifizierten Verstoßes kann für die Zeit vor dem Urteil daher anders ausfallen als für die Zeit danach. ${ }^{2468}$

Ist in einem Urteil die Antwort auf eine Frage zwar bereits angedeutet, aber noch nicht gegeben worden, kann vor dem diese Frage eindeutig klärenden nachfolgenden Urteil daher nicht von einem offenkundigen Verkennen der Rechtsprechung des Gerichtshofs und damit auch nicht von einem hinreichend qualifizierten Unionsrechtsverstoß ausgegangen werden. ${ }^{2469}$ Ebenso ist die Verneinung eines hinreichend qualifizierten Verstoßes möglich, wenn eine Richtlinienbestimmung ungenau ist und von einem Mitgliedstaat vertretbar ausgelegt wird, was insbesondere der Fall sein kann, wenn zu der fraglichen Vorschrift EuGH-Rechtsprechung fehlt, aus der sich ergibt, wie diese auszulegen ist und wenn nahezu alle Mitgliedstaaten die gleiche Auslegung zugrunde gelegt haben. ${ }^{2470}$ Ergibt sich allerdings aus einer ohne Weiteres auf vergleichbare Sachverhalte übertragbaren gefestigten Rechtsprechung ein bestimmtes Erfordernis, ist der Einwand abgeschnitten, die Rechtsprechung sei noch nicht eindeutig gefestigt gewesen, sodass es an einem hinreichend qualifizierten Verstoß fehle. ${ }^{2471}$ Ein hinreichend qualifizierter Verstoß ist in diesem Fall deswegen zu bejahen.

Aus dem Vorstehenden ergibt sich, dass die Rechtsprechung des Gerichtshofs einer erst allmählich Kontur gewinnenden Rechtslage durch Verneinung eines hinreichend qualifizierten Verstoßes Rechnung trägt. Ein Automatismus zwischen ex tunc-Wirkung und hinreichend qualifiziertem Unionsrechtsverstoß besteht demnach nicht. Von einer genauen Untersuchung der bisherigen Rechtsprechung, die fragt, welche Aussage ihr

2468 EuGH, Urteil vom 25.4.2013, Rs. C-398/11 (Hogan u.a.), Rn.51f. Seit der Verkündung des klärenden Urteils liegt ein hinreichend qualifizierter Verstoß also vor, vgl. GA Mengozzi, Schlussanträge vom 23.1.2017 in der Rs. C-482/16 (Stollwitzer), Rn. 71. Siehe auch EuGH, Urteil vom 19.6.2014, verb. Rs. C-501/12 bis C-506/12, C-540/12 und C-541/12 (Specht u.a.), Rn. 105.

2469 EuGH, Urteil vom 28.7.2016, Rs. C-168/15 (Tomášová), Rn. 29 f., 33.

2470 EuGH, Urteil vom 26.3.1996, Rs. C-392/93 (British Telecommunications), Rn. 43 ff.; EuGH, Urteil vom 17.10.1996, verb. Rs. C-283/94, C-291/94 und C-292/94 (Denkavit u.a.), Rn. $51 \mathrm{ff}$.

2471 Vgl. EuGH, Urteil vom 30.5.2017, Rs. C-45/15 P (Safa Nicu Sepahan), Rn. $34 \mathrm{ff}$. 
mit hinreichender Deutlichkeit entnommen werden kann, entbindet dies aber natürlich nicht. ${ }^{2472}$

Eine Differenzierung zwischen Primär- und Sekundärebene hat auch das Bundesverfassungsgericht im Blick, wenn es in seinem Honeywell-Beschluss die Auffassung vertritt, in der Rechtsprechung des Gerichtshofs fänden sich keine Anhaltspunkte für einen Ausschluss sekundären Vertrauensschutzes durch Ersatz des Vertrauensschadens. Es erachtet es danach für möglich, zur Sicherung des verfassungsrechtlichen Vertrauensschutzes in Konstellationen der rückwirkenden Nichtanwendbarkeit eines Gesetzes infolge einer Entscheidung des Gerichtshofs innerstaatlich eine Entschädigung dafür zu gewähren, dass ein Betroffener auf die gesetzliche Regelung vertraut und in diesem Vertrauen Dispositionen getroffen hat. Auch das unionsrechtliche Haftungsrecht weise dem Mitgliedstaat die Verantwortung für ein unionsrechtswidriges Gesetz zu und entlaste insoweit den Bürger. ${ }^{2473}$

Das Bundesverfassungsgericht bringt dadurch seinen Wunsch nach erweiterten Möglichkeiten zur Gewährung von Vertrauensschutz auf Primärebene zum Ausdruck. ${ }^{2474}$ Auf den Befund der derzeit insoweit nur sehr eingeschränkt bestehenden Möglichkeiten mit dem Vorschlag der Gewährung von Vertrauensschutz auf Sekundärebene mit Hilfe eines sozusagen „europarechtskonträren“ Anspruchs zu reagieren, erscheint aus unionsrechtlicher Perspektive allerdings nicht unproblematisch. ${ }^{2475}$ Im Vergleich zu der beim „normalen“ unionsrechtlichen Staatshaftungsanspruch anzutreffenden Ausgangslage ist die diesem Anspruch zugrundeliegende nämlich gewissermaßen „invers“2476, da der vom Bundesverfassungsgericht ins Auge gefasste Anspruch letztlich auf die Durchsetzung des unionsrechtswidrigen nationalen Rechts gerichtet ist. Wie ein solcher Ansatz aus dem Blickwinkel unionsrechtlicher Grundsätze zu bewerten ist, bleibt

2472 In diesem Zusammenhang ist auch das Urteil des BGH zur Bedeutung der verfassungsgerichtlichen Übergangsfrist im Sportwetten-Urteil (BVerfG, Urteil vom 28.3.2006, 1 BvR 1054/01 - BVerfGE 115, 276) für die Frage des Vorliegens eines hinreichend qualifizierten Verstoßes zu betrachten und kritisch zu würdigen, BGH, Urteil vom 18.10.2012, III ZR 196/11 - EuZW 2013, 194.

2473 BVerfG, Beschluss vom 6.7.2010, 2 BvR 2661/06 - BVerfGE 126, 286 (314f.). Das Bundesverfassungsgericht lässt offen, ob ein entsprechender Anspruch bereits im bestehenden Staatshaftungssystem angelegt ist.

2474 Zu dieser Einschätzung gelangt auch Giegerich, EuR 2012, 373 (380).

2475 Giegerich, EuR 2012, 373.

2476 Eder, EuR 2015, 746 (759). Von Zöchling-Jud, in: FS Mayer, 2011, S. 871 (879) als „,umgekehrte“ Staatshaftung“ bezeichnet. 
Schlussbetrachtung und Ausblick

einer eigenständigen und eingehenden Untersuchung an anderer Stelle vorbehalten. 


\section{Literaturverzeichnis}

Abele, Roland, Geschwindigkeit ist keine Hexerei - Zur richtlinienkonformen Aus-

legung und Anpassung des deutschen Urlaubsrechts, RdA 2009, S. 312 ff.

Alexander, Willy, The Temporal Effects of Preliminary Rulings, YEL 8 (1988), S. $11 \mathrm{ff}$.

Alexy, Robert, Theorie der Grundrechte, 1. Auflage, Nachdruck, 2006

Althammer, Christoph, Bindungswirkung der Entscheidungen des EuGH, in: Gsell, Beate/Hau, Wolfgang (Hrsg.), Zivilgerichtsbarkeit und Europäisches Justizsystem, Institutionelle und prozedurale Rahmenbedingungen des Vorlageverfahrens nach Art. 267 AEUV auf dem Prüfstand, 2012, S. 37 ff.

Amalfitano, Chiara/Pollicino, Oreste, Two Courts, two Languages? The Taricco Saga Ends on a Worrying Note, Verfassungsblog vom 5.6.2018, abrufbar unter https:/ /verfassungsblog.de

Amoroso, Daniele, To Luxembourg and back: How judicial dialogue avoided a normative clash between the EU and Italian legal orders, IYIL 27 (2018), S. $452 \mathrm{ff}$.

Anderheiden, Michael, Gemeinwohl und nationale Identität, in: Stumpf, Cordula/Kainer, Friedemann/Baldus, Christian (Hrsg.), Privatrecht, Wirtschaftsrecht, Verfassungsrecht, Privatinitiative und Gemeinwohlhorizonte in der europäischen Integration, Festschrift für Peter-Christian Müller-Graff zum 70. Geburtstag am 29. September 2015, 2015, S. 1238 ff.

Annacker, Claudia, Die Inexistenz als Angriffs- und Verteidigungsmittel vor dem EuGH und dem EuG, EuZW 1995, S. 755 ff.

von Arnauld, Andreas, Rechtssicherheit - Perspektivische Annäherungen an eine idée directrice des Rechts, 2006

Arnold, Christian/Schansker, Mareike, Kein Vertrauensschutz ohne EuGH?, ArbRAktuell 2015, S. 89 ff.

Arnull, Anthony, Interpretation and Precedent in European Community Law, in: Andenas, Mads/Jacobs, Francis (Hrsg.), European Community Law in the English Courts, 1998, S. 115 ff.

-, The European Union and its Court of Justice, 2. Auflage 2006

Aubert, Michel/Broussy, Emmanuelle/Donnat, Francis, Chronique de jurisprudence de la CJUE, Pouvoirs des juges nationaux, AJDA 2010, S. 2305 ff.

Avbelj, Matej, Supremacy or Primacy of EU Law - (Why) Does it Matter?, ELJ 17 (2011), S. 744 ff.

Baldauf, Nicole, Richtlinienverstoß und Verschiebung der Contra-legem-Grenze im Privatrechtsverhältnis - Der Konflikt zwischen Richtlinie und nationalem Recht bei der Rechtsanwendung, 2013 
Baldus, Christian/Raff, Thomas, Unionsrechtliche Überformung mitgliedstaatlicher Methodik? Zugleich eine Anmerkung zu den Schlussanträgen von GA Bot in C-441/14 (Dansk Industri/Rasmussen), GPR 2016, S. $71 \mathrm{ff.}$

Balmes, Frank/Ribbrock, Martin, Die Schlussanträge in der Rechtssache Meilicke Vorschlag einer zeitlichen Begrenzung der Wirkung des Urteils „auf Zuruf“ der Mitgliedstaaten?!, BB 2006, S. $17 \mathrm{ff}$.

Barents, René, Remedies and Procedures Before the EU Courts, 2. Auflage 2020

Bassini, Marco/Pollicino, Oreste, Defusing the Taricco Bomb through Fostering Constitutional Tolerance: All Roads Lead to Rome, Verfassungsblog vom 5.12.2017, abrufbar unter https://verfassungsblog.de

Bauer, Jobst-Hubertus/Arnold, Christian, Auf „Junk“ folgt „Mangold“ - Europarecht verdrängt deutsches Arbeitsrecht, NJW 2006, S. 6 ff.

-, Anmerkung, AP BUrlG $\$ 7$ Nr. 39

-, EuGH kippt deutsches Urlaubsrecht - Die Schultz-Hoff-Entscheidung und ihre Folgen, NJW 2009, S. $631 \mathrm{ff}$.

Bayreuther, Frank, Urlaubsrecht - finalisiert, NZA 2019, S. $945 \mathrm{ff}$.

Bebr, Gerhard, Direct and Indirect Judicial Control of Community Acts in Practice: The Relation between Articles 173 and 177 of the EEC Treaty, Michigan Law Review 82 (1984), S. $1229 \mathrm{ff}$.

-, Case 112/83, Société des Produits de Maïs v. Administration des Douanes et Droits Indirects, Judgment of 27 February 1985, CMLRev. 22 (1985), S. $771 \mathrm{ff}$.

Becker, Florian, Application of Community Law by Member States' Public Authorities: Between Autonomy and Effectiveness, CMLRev. 44 (2007), S. 1035 ff.

Beljin, Saša, Wann muss ein Verstoß gegen die Grundfreiheiten beseitigt sein?, NVwZ 2008, S. $156 \mathrm{ff}$.

Benecke, Martina, Urlaub und Urlaubsabgeltung - Besprechung des Urteils BAG v. 4.5.2010 - 9 AZR 183/09, RdA 2011, S. $241 \mathrm{ff}$.

-, Anmerkung, EuZW 2016, S. 469 f.

Berger, Alina, Anwendungsvorrang und nationale Verfassungsgerichte - Ein Vergleich der verfassungsgerichtlichen Rechtsprechung in Deutschland, Frankreich und Spanien im Hinblick auf die Effektivität des unionsrechtlichen Anwendungsvorrangs, 2016

Berkemann, Jörg, Uwe Wusterhausen, Die Wirkungen der Urteile des EuGH in der Zeit, DVBl. 2017, S. $950 \mathrm{ff}$.

Besgen, Nicolai, Urlaubsansprüche bei langandauernder Arbeitsunfähigkeit, SAE 2010, S. $201 \mathrm{ff}$.

Besselink, Leonard F.M., Case C-50/96, Deutsche Telekom AG v. Lilli Schröder, Joined Cases C-234/96 and C-235/96, Deutsche Telekom AG v. Agnes Vick and Ute Conze, Joined Cases C-270/97 and C-271/97, Deutsche Post AG v. Elisabeth Sievers and Brunhilde Schrage, Judgments of the Court of Justice (Sixth Chamber) of 10 February 2000, CMLRev. 38 (2001), S. 437 ff.

-, The parameters of constitutional conflict after Melloni, ELRev. 2014, S. $531 \mathrm{ff}$. 
Bethge, Herbert, Die rechtlichen Konsequenzen der Entscheidung des Bundesverfassungsgerichts vom 28. März 2006 (ODDSET) zur Zulässigkeit gewerblicher Veranstaltung und Vermittlung von Sportwetten in den Ländern, ZfWG 2007, S. $245 \mathrm{ff}$.

Bettermann, Karl August, Richterliche Gesetzesbindung und Normenkontrolle, in: Müller, Georg/Rhinow, René A/Schmid, Gerhard/Wildhaber, Luzius (Hrsg.), Staatsorganisation und Staatsfunktionen im Wandel, Festschrift für Kurt Eichenberger zum 60. Geburtstag, 1982, S. 593 ff.

Beukers, Thomas, Case C-409/06, Winner Wetten GmbH v. Bürgermeisterin der Stadt Bergheim, Judgment of the Court (Grand Chamber) of 8 September 2010, not yet reported, CMLRev. 48 (2011), S. 1985 ff.

Billig, Hildegard, Beschränkung der zeitlichen Wirkung eines Urteils - EuGH-Urteil in Sachen Meilicke, FR 2007, S. 785 ff.

Boecken, Winfried/Düwell, Franz Josef/Diller, Martin/Hanau, Hans (Hrsg.), Gesamtes Arbeitsrecht, Kommentar, 2016 [zitiert als Bearbeiter, in: Boecken/ Düwell/Diller/Hanau (Hrsg.), Gesamtes Arbeitsrecht, 2016]

Borchardt, Klaus-Dieter, Richterrecht durch den Gerichtshof der Europäischen Gemeinschaften, in: Randelzhofer, Albrecht/Scholz, Rupert/Wilke, Dieter (Hrsg.), Gedächtnisschrift für Eberhard Grabitz, 1995, S. 29 ff.

Brams, Isabelle, Unionsrechtliche Impulse für das Recht der Massenentlassung, 2019

Brechmann, Winfried, Die richtlinienkonforme Auslegung - Zugleich ein Beitrag zur Dogmatik der EG-Richtlinie, 1994

Brenncke, Martin, Europäisierung der Methodik richtlinienkonformer Rechtsfindung, EuR 2015, S. 440 ff.

-, Hybrid Methodology for the EU Principle of Consistent Interpretation, Statute Law Review 39 (2018), S. $134 \mathrm{ff}$.

Breuer, Marten, Urteile mitgliedstaatlicher Gerichte als möglicher Gegenstand eines Vertragsverletzungsverfahrens gem. Art. 226 EG?, EuZW 2004, S. 199 ff.

-, Nichtiges Gesetz und vernichtbarer Verwaltungsakt - Überlegungen zur Ratio der Fehlerfolgendifferenzierung bei Norm und Einzelakt -, DVBl. 2008, S. $555 \mathrm{ff}$.

-, Wider das Recht auf Vergessen ... des Bundesverfassungsgerichts!, Verfassungsblog vom 2.12.2019, abrufbar unter https://verfassungsblog.de

van den Brink, Jacobine E./den Ouden, Willemien, Noot, AB Rechtspraak Bestuursrecht 2018, S. $1112 \mathrm{ff}$.

-, Noot, AB Rechtspraak Bestuursrecht 2019, S. 242 ff.

Britz, Gabriele, Grundrechtsschutz durch das Bundesverfassungsgericht und den Europäischen Gerichtshof, EuGRZ 2015, S. 275 ff.

Broberg, Morten/Fenger, Niels, Das Vorabentscheidungsverfahren vor dem Gerichtshof der Europäischen Union, 2014 
Brocker, Lars, Rechtsprechungsänderung und Vertrauensschutz - Staatsfunktionengerechte Auslegung des rechtsstaatlichen Rückwirkungsverbots, NJW 2012, S. $2996 \mathrm{ff}$.

Buckler, Julius, Ein neuer allgemeiner Rechtsgrundsatz: Das unionsrechtliche Missbrauchsverbot - Anmerkung zum Urteil des EuGH v. 22.11.2017, Rs. C-251/16 (Cussens u. a./Brosnan), EuR 2018, S. $371 \mathrm{ff}$.

Budinska, Barbora/Vikarska, Zuzana, Judicial dialogue after Taricco II: who has the last word, in the end?, EU Law Analysis: Criminal law, human rights and constitutional pluralism: two views on Taricco II, Blog vom 7.12.2017, abrufbar unter eulawanalysis.blogspot.com

Burchardt, Dana, Belittling the Primacy of EU Law in Taricco II, Verfassungsblog vom 7.12.2017, abrufbar unter https://verfassungsblog.de

-, Kehrtwende in der Grundrechts- und Vorrangrechtsprechung des EuGH? - Anmerkung zum Urteil des EuGH vom 5.12.2017 in der Rechtssache M.A.S. und M.B. (C-42/17, „Taric co II“), EuR 2018, S. 248 ff.

Busch, Sebastian, Vertrauen auf Fehler der Gerichte? Rechtswidrige Rechtsprechung und Vertrauensschutz, FA 2006, S. 235 ff.

-, Kein Vertrauensschutz für Fortgeltung der veralteten Rechtsprechung zum Verfall von Urlaubsansprüchen, jurisPR-ArbR 47/2019 Anm. 3

Bydlinski, Franz, Gegen die „Zeitzündertheorien“ bei der Rechtsprechungsänderung nach staatlichem und europäischem Recht, JBl. 2001, S. 2 ff.

Calliess, Christian/Ruffert, Matthias (Hrsg.), EUV/AEUV - Das Verfassungsrecht der Europäischen Union mit Europäischer Grundrechtecharta, Kommentar, 5. Auflage 2016 [zitiert als Bearbeiter, in: Calliess/Ruffert (Hrsg.), EUV/AEUV, 5. Aufl. 2016]

Canaris, Claus-Wilhelm, Die Stellung der »UNIDROIT Principles« und der »Principles of European Contract Law « im System der Rechtsquellen, in: Basedow, Jürgen (Hrsg.), Europäische Vertragsrechtsvereinheitlichung und deutsches Recht, 2000, S. $5 \mathrm{ff}$.

-, Die richtlinienkonforme Auslegung und Rechtsfortbildung im System der juristischen Methodenlehre, in: Koziol, Helmut/Rummel, Peter (Hrsg.), Im Dienste der Gerechtigkeit, Festschrift für Franz Bydlinski, 2002, S. 47 ff.

Cassagnabère, Hervé, Le juge du droit de l'Union et la modulation dans le temps, Les nouveaux cahiers du Conseil Constitutionnel 2017, S. $47 \mathrm{ff}$.

Claes, Monica, The Primacy of EU Law in European and National Law, in: Chalmers, Damian/Arnull, Anthony (Hrsg.), The Oxford Handbook of European Union Law, 2015, S. $178 \mathrm{ff}$.

Classen, Claus Dieter, Funktionsadäquate checks and balances statt richterliche Vollkontrolle unter demokratischem Vorwand - Anmerkung zum Urteil des EuGH v. 16.6.2015, Rs. C-62/14 (Peter Gauweiler u.a.), EuR 2015, S. 477 ff.

-, Zu wenig, zu fundamentalistisch - zur grundrechtlichen Kontrolle „unionsrechtlich determinierter" nationaler Hoheitsakte, Anmerkung zum Beschluss des BVerfG vom 15.12.2015, 2 BvR 2735/14, EuR 2016, S. 304 ff. 
-, Europäische Rechtsgemeinschaft à l'allemande? Anmerkung zum Urteil des BVerfG vom 21.6.2016, 2 BvR 2728/13 u.a., EuR 2016, S. $529 \mathrm{ff}$.

Clément-Wilz, Laure, L'office du juge interne pour moduler les effets de l'annulation d'un acte contraire au droit de l'Union. Réflexions sur l'arrêt Association France Nature Environnement du Conseil d'État français, European Papers 2017, S. 259 ff., abrufbar unter www.europeanpapers.eu

Cloer, Adrian, EWS-Kommentar, EWS 2005, S. $213 \mathrm{ff}$.

-, EWS-Kommentar, EWS 2006, S. $36 \mathrm{f}$.

Costa, Marios/Peers, Steve, Steiner \& Woods EU Law, 14. Auflage 2020

Coutron, Laurent, Retour fataliste aux fondements de l'invocabilité des directives Du cartésianisme au pragmatisme, RTDEur. 2015, S. $39 \mathrm{ff}$.

-, Quand la réitération de l'effet direct horizontal du principe de non-discrimination en raison de l'âge passe mal: du rififi avec la Cour suprême danoise!, RTDEur. 2017, S. 389 ff.

-, Limitation des effets dans le temps d'un arrêt préjudiciel: un monopole menacé de la Cour de justice?, RTDEur. 2017, S. $400 \mathrm{ff}$.

Craig, Paul, The legal effect of Directives: policy, rules and exceptions, ELRev. 2009, S. $349 \mathrm{ff}$.

Cross, Rupert/Harris, James W., Precedent in English Law, 4. Auflage 1991

Daig, Hans-Wolfram, Nichtigkeits- und Untätigkeitsklagen im Recht der Europäischen Gemeinschaften - unter besonderer Berücksichtigung der Rechtsprechung des Gerichtshofs der Europäischen Gemeinschaften und der Schlußanträge der Generalanwälte, 1985

von Danwitz, Thomas, Verwaltungsrechtliches System und europäische Integration, 1996

-, Rechtswirkungen von Richtlinien in der neueren Rechtsprechung des EuGH, JZ 2007, S. $697 \mathrm{ff}$.

-, Europäisches Verwaltungsrecht, 2008

Dänzer-Vanotti, Wolfgang, Unzulässige Rechtsfortbildung des Europäischen Gerichtshofs, RIW 1992, S. $733 \mathrm{ff}$.

Dashwood, Alan/Dougan, Michael/Rodger, Barry/Spaventa, Eleanor/Wyatt, Derrick, Wyatt and Dashwood's European Union Law, 6. Auflage 2011

Dauses, Manfred A., Das Vorabentscheidungsverfahren nach Artikel 177 EG-Vertrag, 2. Auflage 1995

Dautzenberg, Norbert, RIW-Kommentar, RIW 2005, S. 959 f.

Dederer, Hans-Georg, Die Grenzen des Vorrangs des Unionsrechts - Zur Vereinheitlichung von Grundrechts-, Ultra-vires- und Identitätskontrolle, JZ 2014, S. $313 \mathrm{ff}$.

Deinert, Antonia/Abnis, Erik, EuGH: Zeitliche Beschränkung der Rechtsfolgen unwirksamer Mindestzinsklauseln in Hypotheken-Darlehensverträgen, IR 2017, S. $106 \mathrm{ff}$. 
Delhomme, Vincent/Larripa, Lucie, C-416/17 Commission v France: failure of a Member State to fulfil its obligations under Article 267(3) TFEU, European Law Blog, Blog vom 22.11.2018, abrufbar unter https://europeanlawblog.eu

Denninger, Erhard/Hoffmann-Riem, Wolfgang/Schneider, Hans-Peter/Stein, Ekkehart (Hrsg.), Kommentar zum Grundgesetz für die Bundesrepublik Deutschland, Alternativ-Kommentar, Loseblatt [zitiert als Bearbeiter, in: AK-GG]

Deutsche Emissionshandelsstelle (DEHSt), Europäischer Gerichtshof zum sektorübergreifenden Korrekturfaktor - Positionspapier der DEHSt, Juni/Juli 2016, abrufbar unter https://www.dehst.de/SharedDocs/Downloads/DE/Rechtsprechu ng/CSCF.pdf?_blob=publicationFile \&v $=1$

Di Francesco Maesa, Costanza, Effectiveness and Primacy of EU Law v. Higher National Protection of Fundamental Rights and National Identity - A Look through the Lens of the Taricco II Judgment, eucrim 2018, S. 50 ff., abrufbar unter https://eucrim.eu

Domahidi, Ákos, Anmerkung, EuZW 2007, S. $127 \mathrm{f}$.

Domröse, Ronny, Der Einfluss des europäischen Gemeinschaftsrechts auf die Anwendung des autonomen Privatrechts der Mitgliedstaaten, in: Busch, Christoph/Kopp, Christina/McGuire, Mary-Rose/Zimmermann, Martin (Hrsg.), Europäische Methodik - Konvergenz und Diskrepanz europäischen und nationalen Privatrechts, Jahrbuch Junger Zivilrechtswissenschaftler 2009, 2010, S. $109 \mathrm{ff}$.

Dörr, Oliver/Lenz, Christofer, Europäischer Verwaltungsrechtsschutz, 2006

Dougan, Michael, When worlds collide! Competing visions of the relationship between direct effect and supremacy, CMLRev. 44 (2007), S. $931 \mathrm{ff}$.

-, Primacy and the remedy of disapplication, CMLRev. 56 (2019), S. $1459 \mathrm{ff}$.

Dreier, Horst (Hrsg.), GG, Grundgesetz Kommentar, Band II, 3. Auflage 2015 [zitiert als Bearbeiter, in: Dreier (Hrsg.), GG, Band II, 3. Aufl. 2015]

Drüen, Klaus-Dieter/Kahler, Björn, Die nationale Steuerhoheit im Prozess der Europäisierung, StuW 2005, S. $171 \mathrm{ff}$.

Dubout, Édouard, Grandeur et décadence de l'obligation d'interprétation conforme aux directives dans les litiges horizontaux, CJUE, gde ch., 19 avril 2016, Dansk Industri (DI) / Succession Rasmussen, aff. C-441/14, EU:C2016:278, R.A.E. 2016, S. $287 \mathrm{ff}$.

-, La primauté du droit de l'Union et le passage au pluralisme constitutionnel, Réflexions autour de l'arrêt M.A.S. et M.B., RTDEur. 2018, S. $563 \mathrm{ff}$.

Düsterhaus, Dominik, Es geht auch ohne Karlsruhe: Für eine rechtsschutzorientierte Bestimmung der zeitlichen Wirkungen von Urteilen im Verfahren nach Art. 234 EG, EuZW 2006, S. 393 ff.

-, Eppur Si Muove! The Past, Present, and (possible) Future of Temporal Limitations in the Preliminary Ruling Procedure, YEL 36 (2017), S. 237 ff.

-, Zwischen Rechts- und Vertrauensschutz: Die zeitlichen Wirkungen von Auslegungsurteilen des EuGH nach Artikel 267 AEUV, EuR 2017, S. 30 ff. 
-, EU Citizenship and Fundamental Rights: Contradictory, Converging or Complementary?, in: Kochenov, Dimitry (Hrsg.), EU Citizenship and Federalism, The Role of Rights, 2017, S. $642 \mathrm{ff}$.

Düwell, Franz-Josef, Urlaubsrecht im Umbruch - Von der freien richterlichen Rechtsschöpfung zu den Problemen im Mehrebenenregelungssystem, NZA-Beilage 2011, S. $133 \mathrm{ff}$.

Ebers, Martin, Rechte, Rechtsbehelfe und Sanktionen im Unionsprivatrecht, 2016

Eder, Julia, Rechtsfolgen des Erlasses technischer Vorschriften ohne vorherige Mitteilung an die Kommission gemäß Art. 8 Richtlinie 98/34/EG - Anmerkung zum Urteil des EuGH vom 11.6.2015, Rs. C-98/14, Berlington, EuR 2015, S. $746 \mathrm{ff}$.

Ehlers, Dirk (Hrsg.), Europäische Grundrechte und Grundfreiheiten, 4. Auflage 2015 [zitiert als Bearbeiter, in: Ehlers (Hrsg.), Europäische Grundrechte und Grundfreiheiten, 4. Aufl. 2015]

Ehlers, Dirk/Eggert, Anke, Zur Zulässigkeit einer zeitlich begrenzten weiteren Anwendung gemeinschaftsrechtswidrigen nationalen Rechts, JZ 2008, S. 585 ff.

Ehricke, Ulrich, Die Bindungswirkung von Urteilen des EuGH im Vorabentscheidungsverfahren nach deutschem Zivilprozeßrecht und nach Gemeinschaftsrecht, Vortrag gehalten am 17. Dezember 1996, in: Ress, Georg/Stein, Torsten (Hrsg.), Vorträge, Reden und Berichte aus dem Europa-Institut, Nr. 364, 1997

Ehrmann, Markus, Anmerkung, NVwZ 2016, S. $1311 \mathrm{f}$.

Eicker, Klaus/Ketteler, Thomas, Die verfahrensrechtliche Durchsetzung von Gemeinschaftsrecht im Steuerrecht am Beispiel der Rs. Manninen und die Frage der Durchbrechung der Bestandskraft, BB 2005, S. $131 \mathrm{ff}$.

de Elizalde, Francisco, The Rain in Spain Does Not Stay in the Plain - Or How the Spanish Supreme Court Ruling of 25 March 2015, on Minimum Interest Rate Clauses, affects European Consumers, EuCML 2015, S. $184 \mathrm{ff}$.

Ellis, Evelyn, The supremacy of Community pensions equality law: a two-edged sword?, ELRev. 2000, S. $564 \mathrm{ff}$.

Epiney, Astrid, Die Rechtsprechung des EuGH im Jahr 2015, Europäisches Verfassungsrecht, NVwZ 2016, S. 655 ff.

Epping, Volker/Hillgruber, Christian (Hrsg.), BeckOK Grundgesetz, 43. Edition, Stand: 15.5.2020 [zitiert als Bearbeiter, in: Epping/Hillgruber (Hrsg.), BeckOK Grundgesetz, 43. Edition, Stand: 15.5.2020]

Erdbrügger, Andreas, Der EuGH versagt dem Finanzsektor die Umsatzsteuerbefreiung für Kostenteilungsgemeinschaften - Welche Auswirkungen ergeben sich für deutsche Banken und Versicherungen?, UR 2018, S. $301 \mathrm{ff}$.

Esposito, Fabrizio/Hacker, Philipp, European Union Litigation, ERCL 2017, S. 98 ff.

Everling, Ulrich, Der Ausschluß der Rückwirkung bei der Feststellung der Ungültigkeit von Verordnungen durch den Gerichtshof der EG, in: Baur, Jürgen F./Müller-Graff, Peter-Christian/Zuleeg, Manfred (Hrsg.), Europarecht, Energierecht, Wirtschaftsrecht, Festschrift für Bodo Börner zum 70. Geburtstag, 1992, S. $57 \mathrm{ff}$. 
-, Richterliche Rechtsfortbildung in der Europäischen Gemeinschaft, JZ 2000, S. $217 \mathrm{ff}$.

Faraguna, Pietro, The Italian Constitutional Court in re Taricco: "Gauweiler in the Roman Campagna”, Verfassungsblog vom 31.1.2017, abrufbar unter https://verf assungsblog.de

Fichera, Massimo, Taricco II: the Italian Constitutional Court raises its voice and the Court of Justice listens, EU Law Analysis: Criminal law, human rights and constitutional pluralism: two views on Taricco II, Blog vom 7.12.2017, abrufbar unter eulawanalysis.blogspot.com

Finke, Thorsten, Rückwirkung und Bestandskraft in der Entwicklung der europäischen Rechtsprechung, IStR 2006, S. 212 ff.

Forst, Gerrit, Geltung des Altersdiskriminierungsverbots auch in Rechtsstreit zwischen Privaten („DI“), EWiR 2016, S. $381 \mathrm{f}$.

Forsthoff, Ulrich, Die Beschränkung der zeitlichen Wirkung von Urteilen des EuGH - Überlegungen zum Fall „Meilicke“, DStR 2005, S. 1840 ff.

Frantzen, Katharina Isabelle, Staatshaftung für das Vertrauen auf unionsrechtswidrige Gesetze, 2018

Franzen, Martin, Privatrechtsangleichung durch die Europäische Gemeinschaft, 1999

-, Anmerkung, AP TzBfG $₫ 14$ Nr. 23

-, Die Umsetzung des EuGH-Urteils „Kücükdeveci“ durch Unanwendbarkeit des $\$ 622$ Abs. 2 Satz 2 BGB, RIW 2010, S. 577 ff.

Franzen, Martin/Gallner, Inken/Oetker, Hartmut (Hrsg.), Kommentar zum europäischen Arbeitsrecht, 3. Auflage 2020 [zitiert als Bearbeiter, in: Franzen/Gallner/Oetker (Hrsg.), Arbeitsrecht, 3. Aufl. 2020]

Franzius, Claudio, Grundrechtsschutz in Europa. Zwischen Selbstbehauptungen und Selbstbeschränkungen der Rechtsordnungen und ihrer Gerichte, ZaöRV 75 (2015), S. $383 \mathrm{ff}$.

Frenz, Walter, Der europäische Grundsatz der Rechtssicherheit und Veröffentlichungspflicht, Anmerkung zu EuGH (Große Kammer), Urteil vom 10.3.2009 C-345/06 - Gottfried Heinrich, DVB1. 2009, S. 590 ff.

-, Handbuch Europarecht, Band 5, Wirkungen und Rechtsschutz, 2010

Frenz, Walter/Kühl, Andrea, Das Vorabentscheidungsurteil und seine Wirkungen, DStZ 2009, S. $432 \mathrm{ff}$.

Fuhrmanns, Achim, Vertrauensschutz im deutschen und österreichischen öffentlichen Recht - Eine rechtsvergleichende Untersuchung unter Berücksichtigung des Vertrauensschutzes im Europäischen Gemeinschaftsrecht, 2004

Funke, Andreas, Der Anwendungsvorrang des Gemeinschaftsrechts - Einige Problemfälle und ein Präzisierungsvorschlag -, DÖV 2007, S. 733 ff.

-, Umsetzungsrecht - Zum Verhältnis von internationaler Sekundärrechtsetzung und deutscher Gesetzgebungsgewalt, 2010 
Gallner, Inken, Im europäisch-deutschen Dreieck: Luxemburg, Karlsruhe, Erfurt Geschichte einer Rezeption des Unionsrechts -, in: Bader, Peter/Lipke, Gert-Albert/Rost, Friedhelm/Weigand, Horst (Hrsg.), Festschrift für Gerhard Etzel zum 75. Geburtstag, 2011, S. $155 \mathrm{ff}$.

-, Der EuGH zeigt die Krallen - Vertrauensschutz nach Dansk Industri, FA 2016, S. 289

Gänswein, Olivier Rolf, Der Grundsatz unionsrechtskonformer Auslegung nationalen Rechts - Erscheinungsformen und dogmatische Grundlage eines Rechtsprinzips des Unionsrechts, 2009

Gärditz, Klaus Ferdinand, Herrschaftslegitimation und implizite Identitätskontrolle, Nachbemerkungen zum PSPP-Urteil des Bundesverfassungsgerichts, Verfassungsblog vom 21.5.2020, abrufbar unter https://verfassungsblog.de

Gaul, Björn/Bonanni, Andrea/Ludwig, Daniel, Urlaubsanspruch trotz Langzeiterkrankung - Handlungsbedarf für die betriebliche Praxis!, DB 2009, S. 1013 ff.

Gaul, Björn/Josten, Daniela/Strauf, Hendrik, EuGH: Urlaubsanspruch trotz Dauerkrankheit, BB 2009, S. 497 ff.

Gazin, Fabienne, 85 Clauses abusives, Note, Europe 2017, S. 39 f.

Gentile, Giulia, Inter-Environnement Expanded: Another Brick Out of the Wall of EU Law Supremacy?, European Papers 2017, S. 321 ff., abrufbar unter www.europeanpapers.eu

Germelmann, Claas Friedrich, Wie weit reicht die Wirkung von Ungültigerklärungen im Vorabentscheidungsverfahren? Zugleich Anmerkung zu dem Beschluss des EuGH vom 8.11.2007, Rs. C-421/06 (Fratelli Martini und Cargill), EuR 2009, S. $254 \mathrm{ff}$.

-, Die Rechtskraft von Gerichtsentscheidungen in der Europäischen Union - Eine Untersuchung vor dem Hintergrund der deutschen, französischen und englischen Rechtskraftlehren, 2009

Giegerich, Thomas, Europarechtskonträre Staatshaftung? - Widerspruchsfreiheit der Rechtsordnung und Pflichtenstellung Privater nach dem Karlsruher HoneywellDictum, EuR 2012, S. $373 \mathrm{ff}$.

Gleiss, Alfred/Kleinmann, Werner, Gestaltungsrecht des Europäischen Gerichtshofes bei Nichtigerklärung einer Verordnung, NJW 1966, S. $1591 \mathrm{ff.}$

Göbel-Zimmermann, Ralph/Kern, Markus, Der Anwendungsvorrang der Antidiskriminierungsrichtlinien bei mangelnder „Normbereinigung“ durch die Landesgesetzgeber, NVwZ 2014, S. $1202 \mathrm{ff}$.

Grabitz, Eberhard, Entscheidungen und Richtlinien als unmittelbar wirksames Gemeinschaftsrecht - Zur Analyse der Leber-Pfennig-Urteile des EuGH, EuR 1971, S. $1 \mathrm{ff}$.

-, Vertrauensschutz als Freiheitsschutz, DVBl. 1973, S. 675 ff.

Grabitz, Eberhard/Hilf, Meinhard/Nettesheim, Martin (Hrsg.), Das Recht der Europäischen Union, Loseblatt [zitiert als Bearbeiter, in: Grabitz/Hilf/Nettesheim (Hrsg.), Recht der EU]

Griller, Stefan, Der Anwendungsvorrang des EG-Rechts, ecolex 1996, S. $639 \mathrm{ff}$. 


\section{Literaturverzeichnis}

von der Groeben, Hans/Schwarze, Jürgen/Hatje, Armin (Hrsg.), Europäisches Unionsrecht, Vertrag über die Europäische Union - Vertrag über die Arbeitsweise der Europäischen Union - Charta der Grundrechte der Europäischen Union, 7. Auflage 2015 [zitiert als Bearbeiter, in: von der Groeben/Schwarze/Hatje (Hrsg.), Unionsrecht. 7. Aufl. 2015]

Grosche, Nils/Höft, Jan, Richtlinienkonforme Rechtsfortbildung ohne Grenzen? - Zugleich Besprechung von BGH, NJW 2009, 427 - Quelle, NJOZ 2009, S. $2294 \mathrm{ff}$.

Gualco, Elena, "Clash of Titans 2.0". From Conflicting EU General Principles to Conflicting Jurisdictional Authorities: The Court of Justice and the Danish Supreme Court in the Dansk Industri Case, European Papers 2017, S. $223 \mathrm{ff}$., abrufbar unter www.europeanpapers.eu

Gualco, Elena/Lourenço, Luísa, "Clash of Titans”. General Principles of EU Law: Balancing and Horizontal Direct Effect, European Papers 2016, S. 643 ff., abrufbar unter www.europeanpapers.eu

Gundel, Jörg, Quersubventionierung durch parafiskalische Abgaben und EG-Beihilfenrecht - Klärungen zu prozessualen und materiellen Fragen. Zugleich Anmerkung zu EuGH, 22.12.2008 - Rs. C-333/07, Régie Networks, EWS 2009, S. 350 ff.

-, Die Begrenzung der zeitlichen Wirkung bei der Feststellung von Verstößen gegen EU-Recht: Neuer allgemeiner Rechtsgrundsatz oder Einfallstor für Einschränkungen des Vorrang-Anspruchs?, in: Hösch, Ulrich (Hrsg.), Zeit und Ungewissheit im Recht, Liber amicorum zum 70. Geburtstag von Herrn Professor Dr. Wilfried Berg, 2011, S. $54 \mathrm{ff}$.

Hailbronner, Kay, Hat der EuGH eine Normverwerfungskompetenz?, NZA 2006, S. $811 \mathrm{ff}$.

Hakenberg, Waltraud, Befolgung und Durchsetzung der Urteile der Gemeinschaftsgerichte, in: Müller-Graff, Peter-Christian/Scheuing, Dieter H. (Hrsg.), Gemeinschaftsgerichtsbarkeit und Rechtsstaatlichkeit, EuR 2008, Beiheft 3, S. $163 \mathrm{ff}$.

Haket, Sim W., Dansk Industri: nadere afbakening grenzen aan richtlijnconforme interpretatie en horizontale werking algemeen Unierechtelijk beginsel?, NtEr 2016, S. 237 ff.

-, Noot, AB Rechtspraak Bestuursrecht 2019, S. 1517 ff.

Hanau, Hans, Unmittelbare Anwendbarkeit und inhaltliche Reichweite der Richtlinie über befristete Arbeitsverträge, Urteil des Europäischen Gerichtshofs vom 15.4.2008 - Rechtssache Impact, EuZA 2009, S. 534 ff.

Haratsch, Andreas, Nationale Identität aus europarechtlicher Sicht, EuR 2016, S. $131 \mathrm{ff}$.

Hay, Peter, European Economic Community - Res Judicata and Precedent in the Court of Justice of the Common Market, 12 AJCL (1963), S. $404 \mathrm{ff}$.

Hein, Daniela, Die Inzidentkontrolle sekundären Gemeinschaftsrechts durch den Europäischen Gerichtshof - Dargestellt am Beispiel der Prüfung von Richtlinien im Vertragsverletzungsverfahren, 2001

Herdegen, Matthias, Richtlinienkonforme Auslegung im Bankrecht: Schranken nach Europa- und Verfassungsrecht, WM 2005, S. $1921 \mathrm{ff}$. 
-, Vertrauensschutz gegenüber rückwirkender Rechtsprechung im Zivilrecht, WM 2009, S. $2202 \mathrm{ff}$.

Herresthal, Carsten, Rechtsfortbildung im europarechtlichen Bezugsrahmen - Methoden, Kompetenzen; Grenzen dargestellt am Beispiel des Privatrechts, 2006

-, Die richtlinienkonforme und die verfassungskonforme Auslegung im Privatrecht, JuS 2014, S. $289 \mathrm{ff}$.

Herrmann, Christoph, Richtlinienumsetzung durch die Rechtsprechung, 2003

-, Die negative unmittelbare Wirkung von Richtlinien in horizontalen Rechtsverhältnissen - Erwiderung auf T. Gas, Gastkommentar Heft 24/2005, S.737., EuZW 2006, S. 69 f.

Heß, Burkhard, Die Einwirkungen des Vorabentscheidungsverfahrens nach Art. 177 EGV auf das deutsche Zivilprozeßrecht, ZZP 108 (1995), S. $59 \mathrm{ff}$.

Heukels, Ton, Intertemporales Gemeinschaftsrecht - Rückwirkung, Sofortwirkung und Rechtsschutz in der Rechtsprechung des Gerichtshofes der Europäischen Gemeinschaften, 1990

Heuschmid, Johannes, Ausschluss rentenberechtigter Arbeitnehmer von einer »Entlassungsabfindung " nach dänischem Recht verstößt gegen Verbot der Altersdiskriminierung, AuR 2016, S. 422 ff.

Hey, Johanna, Rückwirkende Klarstellung und rückwirkende Nichtanwendungsgesetzgebung, Eine Bewertung in vertrauensschutzrechtlicher Hinsicht nach dem Beschluss des BVerfG v. 17.12.2013 - 1 BvL 5/08, JZ 2014, S. $500 \mathrm{ff}$.

Hilbig, Katharina, Absoluter Verbraucherschutz bei unzulässigen AGB-Schiedsvereinbarungen?, SchiedsVZ 2010, S. $74 \mathrm{ff}$.

Hoffmann, Jochen, Die Zukunft geschlechtsspezifischer Versicherungstarife, Zugleich Besprechung EuGH v. 1.3.2010 - Rs C-236/09, ZIP 2011, 1475, ZIP 2011, S. $1445 \mathrm{ff}$.

Holdgaard, Rass/Elkan, Daniella/Krohn Schaldemose, Gustav, From cooperation to collision: The ECJ's Ajos ruling and the Danish Supreme Court's refusal to comply, CMLRev. 55 (2018), S. $17 \mathrm{ff}$.

Honer, Mathias, Fortgeschrittenenhausarbeit - Öffentliches Recht: Europarecht und Grundrechte - Zuckerreiche Ernährung führt zu Übergewicht!, JuS-Extra 2017, S. $21 \mathrm{ff}$.

Höpfner, Clemens, Vertrauensschutz und Richterrecht - Zur Zulässigkeit rückwirkender Rechtsprechungsänderungen im Zivilrecht, RdA 2006, S. $156 \mathrm{ff}$.

-, Die systemkonforme Auslegung - Zur Auflösung einfachgesetzlicher, verfassungsrechtlicher und europarechtlicher Widersprüche im Recht, 2008

-, Voraussetzungen und Grenzen richtlinienkonformer Auslegung und Rechtsfortbildung, in: Busch, Christoph/Kopp, Christina/McGuire, Mary-Rose/Zimmermann, Martin (Hrsg.), Europäische Methodik - Konvergenz und Diskrepanz europäischen und nationalen Privatrechts, Jahrbuch Junger Zivilrechtswissenschaftler 2009, 2010, S. $73 \mathrm{ff}$.

-, Altersdiskriminierung und europäische Grundrechte - Einige methodische Bemerkungen zum Richterrecht des EuGH, ZfA 2010, S. 449 ff. 


\section{Literaturverzeichnis}

-, Das deutsche Urlaubsrecht in Europa - Zwischen Vollharmonisierung und Koexistenz - Teil 1, RdA 2013, S. 16 ff.

Huep, Tobias, Beschränkung einer Rückwirkung neuer richterlicher Erkenntnisse auf ältere Sachverhalte. Am Beispiel der deutschen und europäischen Gleichbehandlungsrechtsprechung zur betrieblichen Altersversorgung, 2001

-, Die zeitliche Reichweite des geschlechtsbezogenen Entgeltgleichheitsgrundsatzes im deutschen und europäischen Arbeitsrecht, RdA 2001, S. $325 \mathrm{ff}$.

Hufen, Friedhelm/Nörr Stiefenhofer Lutz, Beschränkung von Urteilswirkungen im Falle der Feststellung der Verfassungswidrigkeit von Rechtsnormen - Teil 1 - Rechtsgutachten, Rechtsvergleichende Untersuchung über die Rechtslage in den Mitgliedstaaten der Europäischen Union im Auftrag des Bundesministeriums für Finanzen, 2008, ehemals abrufbar unter https://www.bundesfinanzmini sterium.de/Content/DE/Standardartikel/Themen/Europa/RechtsgutachtenTeil 1. pdf?_blob=publicationFile $\& v=3$

van der Hulle, Rob, De voorrang van het Unierecht anno 2016: van een absolute regel naar een zwaarwegend principe?, NtEr 2016, S. $284 \mathrm{ff}$.

van der Hulle, Rob/van der Hulle, Rick, Op weg naar een minder strikte toepassing van de voorrangsregel?, SEW 2012, S. $490 \mathrm{ff}$.

Hüsken, Felix B., Verfassungsgerichtliches Übergangsrecht im Spiegel des Gemeinschaftsrechts, ZfWG 2009, S. $13 \mathrm{ff}$.

Hwang, Shu-Perng, Grundrechte unter Integrationsvorbehalt? Eine rahmenorientierte Überlegung zur Debatte um die Bindung der Mitgliedstaaten an die Unionsgrundrechte, EuR 2014, S. $400 \mathrm{ff}$.

Hyland, Niamb, Temporal limitation of the effects of judgments of the Court of Justice - A review of recent case-law, IJEL 2 (1995), S. $208 \mathrm{ff}$.

Ionescu, Emanuel C., Innerstaatliche Wirkungen des Vertragsverletzungsverfahrens - Die Aufsichtsklage im föderalen Gefüge der Europäischen Union, 2016

Ipsen, Hans Peter, Richtlinien-Ergebnisse, in: Hallstein, Walter/Schlochauer, HansJürgen (Hrsg.), Zur Integration Europas, Festschrift für Carl Friedrich Ophüls aus Anlass seines siebzigsten Geburtstages, 1965, S. $67 \mathrm{ff}$.

Ipsen, Jörn, Rechtsfolgen der Verfassungswidrigkeit von Norm und Einzelakt, 1980

Isaac, Guy, La modulation par la Cour de Justice des Communautés Européennes des effets dans le temps de ses arrêts d'invalidité., C.D.E. 1987, S. $444 \mathrm{ff}$.

Isensee, Josef/Kirchhof, Paul (Hrsg.), Handbuch des Staatsrechts der Bundesrepublik Deutschland

- Band IV, Aufgaben des Staates, 3. Auflage 2006 [zitiert als Bearbeiter, in: Isensee/Kirchhof (Hrsg.), HStR IV, 3. Aufl. 2006]

- Band XII, Normativität und Schutz der Verfassung, 3. Auflage 2014 [zitiert als Bearbeiter, in: Isensee/Kirchhof (Hrsg.), HStR XII, 3. Aufl. 2014]

Ismer, Roland/Piotrowski, Sophia, Erste Einordnung, MwStR 2017, S. 834 ff.

Jarass, Hans D., Zum Verhältnis von Grundrechtecharta und sonstigem Recht, EuR 2013, S. $29 \mathrm{ff}$. 
-, Charta der Grundrechte der Europäischen Union unter Einbeziehung der vom EuGH entwickelten Grundrechte, der Grundrechtsregelungen der Verträge und der EMRK, Kommentar, 3. Auflage 2016 [zitiert als Jarass, GRCh-Kommentar, 3. Aufl. 2016]

Jarass, Hans D./Beljin, Saša, Die Bedeutung von Vorrang und Durchführung des EG-Rechts für die nationale Rechtsetzung und Rechtsanwendung, NVwZ 2004, S. $1 \mathrm{ff}$.

Jarass, Hans D./Pieroth, Bodo, GG, Grundgesetz für die Bundesrepublik Deutschland, Kommentar, 15. Auflage 2018 [zitiert als Bearbeiter, in: Jarass/Pieroth, GG, 15. Aufl. 2018]

Kadelbach, Stefan, Allgemeines Verwaltungsrecht unter europäischem Einfluß, 1999

-, Die Wirkung von im Vorabentscheidungsverfahren ergangenen Urteilen, in: Holoubek, Michael/Lang, Michael (Hrsg.), Das EuGH-Verfahren in Steuersachen, 2000, S. $119 \mathrm{ff}$.

Kahl, Wolfgang/Waldhoff, Christian/Walter, Christian (Hrsg.), Bonner Kommentar zum Grundgesetz, Loseblatt [zitiert als Bearbeiter, in: Kahl/Waldhoff/Walter (Hrsg.), Bonner Kommentar]

Kähler, Lorenz, Strukturen und Methoden der Rechtsprechungsänderung, 2. Auflage 2011

Kainer, Friedemann, Privatrecht zwischen Richtlinien und Grundrechten - Zu den Grenzen richtlinienkonformer Auslegung und horizontalen Richtlinienwirkungen, GPR 2016, S. 262 ff.

-, Rückkehr der unmittelbar-horizontalen Grundrechtswirkung aus Luxemburg?, NZA 2018, S. $894 \mathrm{ff}$.

Kamanabrou, Sudabeh, Urlaubsabgeltung bei krankheitsbedingter Arbeitsunfähigkeit nach der Schultz-Hoff-Entscheidung des EuGH, SAE 2009, S. $233 \mathrm{ff}$.

Karpenstein, Ulrich, Rechtsfolgen der Aufhebung von EG-Recht für die nationalen (Umsetzungs-)Maßnahmen, in: Dolde, Klaus-Peter/Hansmann, Klaus/Paetow, Stefan/Schmidt-Aßmann, Eberhard (Hrsg.), Verfassung - Umwelt - Wirtschaft, Festschrift für Dieter Sellner zum 75. Geburtstag, 2010, S. 125 ff.

Karpenstein, Ulrich/Kuhnert, Kathrin, Anmerkung, DVBl. 2006, S. 1466 f.

Kelemen, R. Daniel/Eeckhout, Piet/Fabbrini, Federico/Pech, Laurent/Uitz, Renáta, National Courts Cannot Override CJEU Judgments - A Joint Statement in Defense of the EU Legal Order, Verfassungsblog vom 26.5.2020, abrufbar unter https://v erfassungsblog.de

von Kielmansegg, Sebastian Graf, Tücken im Dreieck - Die individualbelastende Richtlinienwirkung im Unionsrecht, EuR 2014, S. $30 \mathrm{ff}$.

Kim, Sora/Dübbers, Robert, Behördliche Unterbindung privaten Wettangebots in Deutschland als Auslöser europarechtlich fundierter Staatshaftungsansprüche, ZfWG 2006, S. 107 ff.

Kingreen, Thorsten, Die Grundrechte des Grundgesetzes im europäischen Grundrechtsföderalismus, JZ 2013, S. $801 \mathrm{ff}$. 
Kirchhof, Ferdinand, Nationale Grundrechte und Unionsgrundrechte - Die Wiederkehr der Frage eines Anwendungsvorrangs unter anderer Perspektive, NVwZ 2014, S. 1537 ff.

Kirschnick, Stephan, Der hinreichend qualifizierte Verstoß als Voraussetzung des unionsrechtlichen Staatshaftungsanspruchs, 2015

Klappstein, Verena, Die Rechtsprechungsänderung mit Wirkung für die Zukunft Eine rechtsmethodische und rechtsvergleichende Untersuchung im Zivilrecht, 2009

Klein, Eckart, Unmittelbare Geltung, Anwendbarkeit und Wirkung von europäischem Gemeinschaftsrecht, Vortrag vor dem Europa-Institut der Universität des Saarlandes, in: Ress, Georg/Will, Michael R. (Hrsg.), Vorträge, Reden und Berichte aus dem Europa-Institut / Nr. 119, 1988

Klein, Marvin, Friedensgrüße aus Luxemburg: Neue Entwicklungen im europäischen Grundrechteverbund, DÖV 2018, S. $605 \mathrm{ff}$.

Klein, Oliver, Vertrauensschutz für EU-rechtswidrige Vorschriften? Die Schlussanträge des Generalanwaltes in der Rechtssache Meilicke, IStR 2006, S. $209 \mathrm{ff}$.

Klöpfer, Matthias, Missbrauch im Europäischen Zivilverfahrensrecht, 2016

Koch, Ulrich, Die Berücksichtigung des Vertrauensschutzes im Anwendungsvorrang des Gemeinschaftsrechts, JbArbR 44 (2007), S. $91 \mathrm{ff}$.

-, Die Bewältigung von selbst- und fremdbestimmten Rechtsprechungsänderungen durch das Bundesarbeitsgericht, SR 2012, S. $159 \mathrm{ff}$.

Koenig, Christian, Vorabentscheidungswirkungen erga omnes - die Glücksspielurteile des EuGH als Lehrbuchbeispiele!, EWS 2010, S. 449 ff.

Koenig, Christian/Schreiber, Kristina, Gewährung von Übergangsfristen à la Bundesverfassungsgericht durch den Europäischen Gerichtshof?, DÖV 2008, S. 450 ff.

Kokott, Juliane, Auslegung europäischen oder Anwendung nationalen Rechts?, Grundsätze und Kriterien für die Behandlung arbeitsrechtlicher Streitigkeiten mit europarechtlichem Bezug, RdA 2006, Sonderbeilage zu Heft 6, S. 30 ff.

-, The jurisprudence of the Court of Justice of the European Communities in the area of tax law: the limitation in time of the effects of judgements, Vortrag Florenz 2006, ehemals abrufbar unter http://www.olcilaw.com/pdf/ [44646cd7593ef]Newsletter\%202006-01\%20English.pdf

-, Die Durchsetzung der Normenhierarchie im Gemeinschaftsrecht, in: Müller, Gerda/Osterloh, Eilert/Stein, Torsten (Hrsg.), Festschrift für Günter Hirsch zum 65. Geburtstag, 2008, S. 117 ff.

-, Bedeutung und Wirkungen deutscher und europäischer Grundrechte im Steuerstrafrecht und Steuerstrafverfahren, NZWiSt 2017, S. 409 ff.

Kokott, Juliane/Henze, Thomas, Die Beschränkung der zeitlichen Wirkung von EuGH-Urteilen in Steuersachen, NJW 2006, S. 177 ff.

-, Ist der EuGH - noch - ein Motor für die Konvergenz der Steuersysteme?, BB 2007, S. $913 \mathrm{ff}$. 
Komárek, Jan, Precedent and Judicial Lawmaking in Supreme Courts: The Court of Justice Compared to the US Supreme Court and the French Cour de Cassation, CYELS 11 (2009), S. 399 ff.

Koopmans, Thijmen, Retrospectivity reconsidered, C.L.J. 39 (1980), S. 287 ff.

-, Stare decisis in European Law, in: O'Keeffe, David/Schermers, Henry G. (Hrsg.), Essays in European Law and Integration - To Mark The Silver Jubilee Of The Europa Institute, Leiden 1957-1982, 1982, S. $11 \mathrm{ff}$.

Kovács, Christian, Die temporale Wirkung von Urteilen des EuGH im Vorabentscheidungsverfahren, 2014

Krajewski, Michat, 'Conditional' Primacy of EU Law and Its Deliberative Value: An Imperfect Illustration from Taricco II, European Law Blog, Blog vom 18.12.2017, abrufbar unter https://europeanlawblog.eu

Kreft, Burghard, Die Auslegung europäischen oder die Anwendung nationalen Rechts, Grundsätze und Kriterien für die Behandlung arbeitsrechtlicher Streitigkeiten mit europarechtlichem Bezug, RdA 2006, Sonderbeilage zu Heft 6, S. $38 \mathrm{ff}$.

Krieger, Steffen/Arnold, Christian, Urlaub 1. + 2. Klasse - Das BAG folgt der SchultzHoff-Entscheidung des EuGH, NZA 2009, S. $530 \mathrm{ff}$.

Krois, Christopher, Inhalt und Grenzen des unionsrechtlichen Verbots der Altersdiskriminierung - Zugleich Besprechung von EuGH vom 19.1.2010 - C-555/07 (Kücükdeveci) -, DB 2010, S. 1704 ff.

Kroll-Ludwigs, Kathrin/Ludwigs, Markus, Die richtlinienkonforme Rechtsfortbildung im Gesamtsystem der Richtlinienwirkungen - Zugleich Besprechung von BGH, Urt. v. 26.11.2008 - VIII ZR 200/05 (Quelle), ZJS 2009, S. 7 ff. und S. 123 ff.

Krönke, Christoph, Die Verfahrensautonomie der Mitgliedstaaten der Europäischen Union, 2013

Kruis, Tobias, Anmerkung, EuZW 2006, S. $606 \mathrm{ff}$.

-, Der Anwendungsvorrang des EU-Rechts in Theorie und Praxis - Seine Durchsetzung in Deutschland. Eine theoretische und empirische Untersuchung anhand der Finanz- und Verwaltungsgerichte und Behörden, 2013

Kühling, Jürgen, Die richtlinienkonforme und die verfassungskonforme Auslegung im Öffentlichen Recht, JuS 2014, S. 481 ff.

Küpper, Herbert, Das EU-Sprachenregime und die neuen Mitgliedstaaten - Der Fall Skoma-Lux, JOR 2008, S. $147 \mathrm{ff}$.

Lang, Michael, Limitation of the Temporal Effects of Judgments of the ECJ, Intertax 35 (2007), S. $230 \mathrm{ff}$.

-, Die Beschränkung der zeitlichen Wirkung von EuGH-Urteilen im Lichte des Urteils Meilicke, in diesem Heft S. 247, IStR 2007, S. 235 ff.

-, Limitation of Temporal Effects of CJEU Judgments: Mission Impossible for Governments of EU Member States, in: Popelier, Patricia/Verstraelen, Sarah/ Vanheule, Dirk/Vanlerberghe, Beatrix (Hrsg.), The Effects of Judicial Decisions in Time, 2014, S. $245 \mathrm{ff}$. 
Langenbucher, Katja, Rechtsprechung mit Wirkung für die Zukunft, JZ 2003, S. $1132 \mathrm{ff}$.

Langohr-Plato, Uwe, Gleichbehandlungsgrundsatz und betriebliche Altersversorgung, MDR 1992, S. $838 \mathrm{ff}$.

Lasiński-Sulecki, Krzysztof, Proper Publication of Legal Texts Relevant for Taxation, Tax Aspects of the ECJ Judgment in the Skoma-Lux Case, Intertax 37 (2009), S. $414 \mathrm{ff}$.

Latzel, Clemens, Schutz vor rückwirkendem Recht kraft Unionsrechts, EuR 2015, S. $415 \mathrm{ff}$.

Lenaerts, Koen, The Rule of Law and the Coherence of the Judicial System of the European Union, CMLRev. 44 (2007), S. 1625 ff.

-, National remedies for private parties in the light of the EU law principles of equivalence and effectiveness, 46 Irish Jurist (2011), S. $13 \mathrm{ff}$.

-, Die EU-Grundrechtecharta: Anwendbarkeit und Auslegung, EuR 2012, S. 3 ff.

-, Kooperation und Spannung im Verhältnis von EuGH und nationalen Verfassungsgerichten, EuR 2015, S. 3 ff.

-, The ECHR and the CJEU: Creating Synergies in the Field of Fundamental Rights Protection, in: European Court of Human Rights, Dialogue between judges, 2018, S. 57 ff. [abrufbar unter https://www.echr.coe.int/Documents/Dialogue_20 18_ENG.pdf\#page=29]

Lenaerts, Koen/Arts, Dirk/Maselis, Ignace/Bray, Robert (Hrsg.), Procedural Law of the European Union, 2. Auflage 2006

Lenaerts, Koen/Corthaut, Tim, Of birds and hedges: the role of primacy in invoking norms of EU law, ELRev. 2006, S. $287 \mathrm{ff}$.

Lenaerts, Koen/Gutiérrez-Fons, José A., To Say What the Law of the EU Is: Methods of Interpretation and the European Court of Justice, EUI Working Paper AEL 2013/9, abrufbar unter https://cadmus.eui.eu

Lenaerts, Koen/Maselis, Ignace/Gutman, Kathleen, EU Procedural Law, 2014

Lenz, Carl Otto/Borchardt, Klaus-Dieter (Hrsg.), EU-Verträge Kommentar, EUV, AEUV, GRCh, 6. Auflage 2012 [zitiert als Bearbeiter, in: Lenz/Borchardt (Hrsg.), EU-Verträge, 6. Aufl. 2012]

Leonard, Axel/Szczekalla, Peter, Anwendungsvorrang und Bestandskraft - Eine Bestandsaufnahme aus Anlass der Rechtssache Linneweber -, UR 2005, S. $420 \mathrm{ff}$.

Lepsius, Oliver, Zur Neubegründung des Rückwirkungsverbots aus der Gewaltenteilung, Besprechung von BVerfG, Beschluss v. 17.12.2013 - 1 BvL 5/08, JZ 2014, S. 488 ff.

-, Brauchen wir einen Schutz des abstrakten Vertrauens in die Geltung von Gesetzen? Replik auf Lothar Michael JZ 2015, 425 ff., JZ 2015, S. 435 ff.

-, Kontextualisierung als Aufgabe der Rechtswissenschaft, JZ 2019, S. 793 ff.

Leskinen, Charlotte/de Elizalde, Francisco, The control of terms that define the essential obligations of the parties under the Unfair Contract Terms Directive: Gutiérrez Naranjo, CMLRev. 55 (2018), S. 1595 ff. 
Levits, Egils, Gesetzesbindung und Richterrecht in der Praxis des EuGH, SR 2015, S. $121 \mathrm{ff}$.

Lindemann, Hans/Hackemann, Tim, Die Rückwirkung von EuGH-Urteilen unter besonderer Betrachtung des „Marks \& Spencer“-Falls, IStR 2005, S. 786 ff.

Lock, Tobias, Are there exceptions to a Member State's duty to comply with the requirements of a Directive?: Inter-Environnement Wallonie, CMLRev. 50 (2013), S. $217 \mathrm{ff}$.

Lohse, Eva Julia, Rechtsangleichungsprozesse in der Europäischen Union - Instrumente, Funktionsmechanismen und Wirkparameter effektiver Harmonisierung, 2017

Louven, Christoph, Problematik und Grenzen rückwirkender Rechtsprechung des Bundesarbeitsgerichts, 1996

Ludewig, Philipp, Die zeitliche Beschränkung der Wirkung von Urteilen des EuGH im Vorabentscheidungsverfahren, 2012

Ludwigs, Markus/Sikora, Patrick, Der Vorrang des Unionsrechts unter Kontrollvorbehalt des BVerfG, EWS 2016, S. $121 \mathrm{ff}$.

-, Grundrechtsschutz im Spannungsfeld von Grundgesetz, EMRK und Grundrechtecharta, JuS 2017, S. 385 ff.

Lunk, Stefan, Vertrauensschutz in der Rechtsprechung des Bundesarbeitsgerichts, in: Martinek, Michael/Rawert, Peter/Weitemeyer, Birgit (Hrsg.), Festschrift für Dieter Reuter zum 70. Geburtstag am 16. Oktober 2010, 2010, S. $689 \mathrm{ff}$.

Madsen, Mikael Rask/Olsen, Henrik Palmer/Šadl, Urška, Competing Supremacies and Clashing Institutional Rationalities: the Danish Supreme Court's Decision in the Ajos Case and the National Limits of Judicial Cooperation, ELJ 23 (2017), S. $140 \mathrm{ff}$.

Mak, Chantal, Gutierrez Naranjo: on limits in law and limits of law, ELRev. 2018, S. $447 \mathrm{ff}$.

Mamoudy, Olga, Note, AJDA 2016, S. $2229 \mathrm{ff}$.

von Mangoldt, Hermann/Klein, Friedrich/Starck, Christian/Huber, Peter M./ Voßkuhle, Andreas (Hrsg.), Grundgesetz Kommentar, GG, Band 2, 7. Auflage 2018 [zitiert als Bearbeiter, in: von Mangoldt/Klein/Starck, GG, Band 2, 7. Aufl. 2018]

Manthey, Leslie/Unseld, Christopher, Der Mythos vom contra-legem-Verbot: Vom Umgang des EuGH mit einem Verfassungsprinzip, DÖV 2011, S. $921 \mathrm{ff}$.

Markert, Kurt, Anmerkung, LMK 2017, 386786

Martens, Sebastian A.E., Die Werte des Stare Decisis, JZ 2011, S. 348 ff.

-, Methodenlehre des Unionsrechts, 2013

Masclet, Jean-Claude, Note. - La jurisprudence «Roquette» à l'épreuve des juridictions françaises (Conseil d'État et Cour de Cassation), RTDEur. 1986, S. $161 \mathrm{ff}$.

Masing, Johannes, Vorrang des Europarechts bei umsetzungsgebundenen Rechtsakten, NJW 2006, S. 264 ff.

Maultzsch, Felix, Das Zeitelement in der richterlichen Fortbildung des deutschen Rechts, RabelsZ 79 (2015), S. 322 ff. 
Maunz, Theodor/Dürig, Günter, Grundgesetz, Kommentar, Loseblatt [zitiert als Bearbeiter, in: Maunz/Dürig, GG]

Maunz, Theodor/Schmidt-Bleibtreu, Bruno/Klein, Franz/Bethge, Herbert, Bundesverfassungsgerichtsgesetz, Kommentar, Loseblatt [zitiert als Bearbeiter, in: Maunz/Schmidt-Bleibtreu/Klein/Bethge, BVerfGG]

Mayer, Franz C., Kompetenzüberschreitung und Letztentscheidung - Das Maastricht-Urteil des Bundesverfassungsgerichts und die Letztentscheidung über Ultra vires-Akte in Mehrebenensystemen - Eine rechtsvergleichende Betrachtung von Konflikten zwischen Gerichten am Beispiel der EU und der USA, 2000

Mertens, Karsten, "Bet and lose" oder doch "betandwin"? - Zum anhaltenden Chaos im Recht der Sportwetten -, DVB1. 2006, S. 1564 ff.

Meyer, Frank, Anmerkung, JZ 2018, S. 304 ff.

Meyer, Jürgen/Hölscheidt, Sven (Hrsg.), Charta der Grundrechte der Europäischen Union, 5. Auflage 2019 [zitiert als Bearbeiter, in: Meyer/Hölscheidt (Hrsg.), Charta der Grundrechte, 5. Aufl. 2019]

Michael, Lothar, Das Verbot echter Rückwirkung als Schutz des abstrakten Vertrauens in die Geltung von Gesetzen und eines Kernbereichs der Judikative Zugleich Erwiderung zu Oliver Lepsius JZ 2014, 488 ff., JZ 2015, S. 425 ff.

-, Verfassungsrechtliche Grenzen richtlinienkonformer Rechtsfortbildung, Der Staat 54 (2015), S. 349 ff.

Michael, Lothar/Payandeh, Mehrdad, Richtlinienkonforme Rechtsfortbildung zwischen Unionsrecht und Verfassungsrecht, NJW 2015, S. $2392 \mathrm{ff}$.

Micklitz, Hans-W., Vereinbarkeit von Leistungsfristen in der AGB-Kontrolle mit dem Unionsrecht, VbR 2017, S. 80 ff.

Mißling, Sven, Die bundesverfassungsgerichtliche Kontrolle so gen. umsetzungsgebundener Rechtsakte im Bereich der polizeilichen und justitiellen Zusammenarbeit nach dem EUV, EuR 2007, S. $261 \mathrm{ff}$.

Mörsdorf, Oliver, Verpflichtung des Käufers zur Zahlung eines Nutzungsentgelts im Rahmen der Neulieferung einer mangelhaften Kaufsache - Zugleich Besprechung EuGH v. 17.4.2008 - Rs C-404/06, ZIP 2008, 794 - Quelle, ZIP 2008, S. $1409 \mathrm{ff}$.

Mörth, Philipp, Vorrang und unmittelbare Anwendbarkeit des Unionsrechts. Von einer Bruchlinie in einem zeitgenössischen Verfassungskonflikt, ZöR 70 (2015), S. $33 \mathrm{ff}$.

Müller, Christoph, Die Begrenzung der zeitlichen Wirkungen von EuGH-Entscheidungen, 2009

Müller, Friedrich/Christensen, Ralph, Juristische Methodik, Band II - Europarecht, 3. Auflage 2012

von Münch, Ingo/Kunig, Philip (Hrsg.), Grundgesetz, Kommentar, Band 2, 6. Auflage 2012 [zitiert als Bearbeiter, in: von Münch/Kunig (Hrsg.), GG, Band 2, 6. Aufl. 2012]

Nettesheim, Martin, Auslegung und Fortbildung nationalen Rechts im Lichte des Gemeinschaftsrechts, AöR 119 (1994), S. 261 ff. 
-, Normenhierarchien im EU-Recht, EuR 2006, S. 737 ff.

-, Die „haushaltspolitische Gesamtverantwortung“ in der Rechtsprechung des BVerfG, in: Brandt, Peter (Hrsg.), Verfassung und Krise, Erträge des Symposions des Dimitris-Tsatsos-Instituts für Europäische Verfassungswissenschaften an der FernUniversität in Hagen am 29. und 30. November 2013, 2015, S. 11 ff.

-, Anmerkung, JZ 2016, S. 424 ff.

Neuner, Jörg, Vertrauensschutz durch die Rechtsprechung, in: Auer, Marietta/Grigoleit, Hans Christoph/Hager, Johannes/Herresthal, Carsten/Hey, Felix/Koller, Ingo/Langenbucher, Katja/Neuner, Jörg/Petersen, Jens/Riehm, Thomas/Singer, Reinhard (Hrsg.), Privatrechtsdogmatik im 21. Jahrhundert, Festschrift für Claus-Wilhelm Canaris zum 80. Geburtstag, 2017, S. 205 ff.

Neuschl, Hanna/Schumm, Martin, Die temporäre Durchbrechung des Anwendungsvorrangs im Gemeinschaftsrecht - Dürfen wir Europa für eine Übergangszeit suspendieren?, ZEuS 2008, S. $527 \mathrm{ff}$.

Nicolai, Andrea, Anmerkung, AP KSchG $1969 \$ 17$ Nr. 22

Nicolaysen, Gert, Europarecht I - Die Europäische Integrationsverfassung, 2. Auflage 2002

Nieskens, Hans, Anmerkung, UR 2020, S. 392 ff.

Nirk, Rudolf/Hülsmann, Christoph, Urheberrechtlicher Inlandsschutz aufgrund des gemeinschaftsrechtlichen Diskriminierungsverbotes? Eine kritische Retrospektive auf die „Phil Collins“-Entscheidung des EuGH sowie auf das „Rolling Stones“- und das „Cliff Richard II“-Urteil des BGH, in: Erdmann, Willi/Gloy, Wolfgang/Herber, Rolf (Hrsg.), Festschrift für Henning Piper zum 65. Geburtstag, 1996, S. $725 \mathrm{ff}$.

Oetker, Hartmut, Zur Vorlagepflicht zum EuGH, hier: im Zusammenhang mit der Auslegung der Massenentlassungsrichtlinie, EWiR 2015, S. $193 \mathrm{f}$.

Obler, Christoph, Grundrechtliche Bindungen der Mitgliedstaaten nach Art. 51 GRCh, NVwZ 2013, S. 1433 ff.

Osterloh, Lerke, Die Beschränkung der Urteilswirkungen in der Rechtsprechung des Europäischen Gerichtshofs und des Bundesverfassungsgerichts zum Steuerrecht, in: Herzog, Felix/Neumann, Ulfrid (Hrsg.), Festschrift für Winfried Hassemer, 2010, S. $173 \mathrm{ff}$.

-, Neuere Entwicklungen zum verfassungsrechtlichen Vertrauensschutz im Steuerrecht, StuW 2015, S. $201 \mathrm{ff}$.

Osterlob-Konrad, Christine, "Quelle“ und die Folgen: kein Nutzungsersatz bei Ersatzlieferung, CR 2008, S. $545 \mathrm{ff}$.

Paulus, Andreas, Gesetzliche Regelungslücken nach Entscheidungen von BVerfG und EuGH, NJW 2011, S. 3686 ff.

Payandeh, Mehrdad, Judikative Rechtserzeugung - Theorie, Dogmatik und Methodik der Wirkungen von Präjudizien, 2017

Pechstein, Matthias, EU-Prozessrecht - Mit Aufbaumustern und Prüfungsübersichten, 4. Auflage 2011

Peers, Steve, Social security equality for Turkish nationals, ELRev. 1999, S. $627 \mathrm{ff}$. 
Peristeridou, Christina/Ouwerkerk, Jannemieke, A Bridge over Troubled Water - a Criminal Lawyers' Response to Taricco II, Verfassungsblog vom 12.12.2017, abrufbar unter https://verfassungsblog.de

Pfeiffer, Thomas, Entwicklungen und aktuelle Fragestellungen des AGB-Rechts, NJW 2017, S. 913 ff.

Picker, Christian, Urlaubsanspruch trotz Dauererkrankung: Die Schultz-Hoff-Entscheidung des EuGH und ihre Folgen, ZTR 2009, S. 230 ff.

Piekenbrock, Andreas, Faktische Rechtsänderungen durch Richterspruch als kollisionsrechtliches Problem, ZZP 119 (2006), S. 3 ff.

Pieroth, Bodo/Hartmann, Bernd J., Verfassungsrechtliche Grenzen rückwirkender Rechtsprechungsänderungen, dargestellt am Beispiel der Aufklärung über Provisionen für den Vertrieb geschlossener Fonds, ZIP 2010, S. $753 \mathrm{ff}$.

Pietrek, André U., Verbindlichkeit von Vorabentscheidungen nach Art. 177 EWGV - Rechtswirkungen im Ausgangsverfahren und als Präjudiz im Lichte von Rechtsvergleichung und Rechtsprechung, 1989

Pilz, Stefan, Anmerkung, NJW 2018, S. 221

Plouvier, Liliane, Les décisions de la Cour de Justice des Communautés Européennes et leurs effets juridiques, 1975

Prechal, Sacha, Does Direct Effect Still Matter?, CMLRev. 37 (2000), S. 1047 ff.

-, Directives in EC Law, 2. Auflage 2005

-, Joined Cases C-397/01 to C-403/01, Bernhard Pfeiffer et al., judgment of the Court (Grand Chamber) of 5 October 2004, nyr, CMLRev. 42 (2005), S. 1445 ff.

-, Direct Effect, Indirect Effect, Supremacy and the Evolving Constitution of the European Union, in: Barnard, Catherine (Hrsg.), The Fundamentals of EU Law Revisited: Assessing the Impact of the Constitutional Debate, 2007, S. $35 \mathrm{ff}$.

Preis, Ulrich/Temming, Felipe, Der EuGH, das BVerfG und der Gesetzgeber - Lehren aus Mangold II, NZA 2010, S. $185 \mathrm{ff}$.

Prete, Luca/Smulders, Ben, The Coming of Age of Infringement Proceedings, CMLRev. 47 (2010), S. $9 \mathrm{ff}$.

Raff, Thomas, Gemeinschaftsprivatrecht und Methode - Der Einfluss der Auslegungsmethoden des EuGH auf die nationale Methodenlehre und die Privatrechtsintegration, in: Behme, Caspar/ Fervers, Matthias/ Hofmann, Franz/ Maute, Lena/ Röder, Erik/ Sattler, Andreas/ Schmidt, Patrick/ Seibl, Maximilian (Hrsg.), Perspektiven einer europäischen Privatrechtswissenschaft, Jahrbuch Junger Zivilrechtswissenschaftler 2016, 2017, S. 67 ff.

Rainer, Anno, Die zeitliche Wirkung der Auslegungsurteile des EuGH, IStR 1996, S. $328 \mathrm{f}$.

Rauchegger, Clara, National constitutional rights and the primacy of EU law: M.A.S., CMLRev. 55 (2018), S. $1521 \mathrm{ff}$.

Reimer, Philipp, Richtlinienkonforme Rechtsanwendung: Spielräume und Bindungen nach mitgliedstaatlichem Recht, JZ 2015, S. 910 ff. 
Reiß, Wolfram, Unionsrechtlich gebotene Bestrafung und Besteuerung sine lege und contra legem - Anordnung des EuGH im Bereich des „Mehrwertsteuerbetrugs“ im grenzüberschreitenden Mehrwertsteuerkarussell -, UR 2016, S. 342 ff.

Rengeling, Hans-Werner/Middeke, Andreas/Gellermann, Martin (Hrsg.), Handbuch des Rechtsschutzes in der Europäischen Union, 3. Auflage 2014 [zitiert als Bearbeiter, in: Rengeling/Middeke/Gellermann (Hrsg.), Handbuch des Rechtsschutzes, 3. Aufl. 2014]

Rennert, Klaus, Bestandskraft rechtswidriger Verwaltungsakte und Gemeinschaftsrecht, DVBl. 2007, S. $400 \mathrm{ff}$.

Rieble, Volker, CGZP-Tarifunfähigkeit und Vertrauensschutz, BB 2012, S. 2945 ff.

Riemer, Konrad, Investitionspflichten der Betreiber von Elektrizitätsübertragungsnetzen - Eine energierechtliche und verfassungsrechtliche Untersuchung, 2017

Riesenhuber, Karl, Anmerkung, AP KSchG 1969 \$ 17 Nr. 21

-, (Hrsg.), Europäische Methodenlehre - Handbuch für Ausbildung und Praxis, 3. Auflage 2015 [zitiert als Bearbeiter, in: Riesenhuber (Hrsg.), Europäische Methodenlehre, 3. Aufl. 2015]

-, Anmerkung, LMK 2016, 375867

-, (Hrsg.), European Legal Methodology, 2017 [zitiert als Bearbeiter, in: Riesenhuber (Hrsg.), European Legal Methodology, 2017]

Riesenhuber, Karl/Domröse, Ronny, Richtlinienkonforme Rechtsfindung und nationale Methodenlehre - Zugleich eine Besprechung von EuGH, Urt. v. 5.10.2004 - verb. Rs. C-397/01 bis 403/01 Pfeiffer u.a., RIW 2005, 54 (in diesem Heft), RIW 2005, S. 47 ff.

-, Richtlinienkonforme Auslegung der $\mathbb{S} 17,18 \mathrm{KSchG}$ und Rechtsfolgen fehlerhafter Massenentlassungen, NZA 2005, S. $568 \mathrm{ff}$.

Röhl, Klaus Friedrich/Röhl, Hans Christian, Allgemeine Rechtslehre - Ein Lehrbuch, 3. Auflage 2008

Rohwer-Kahlmann, Harry, Die Einwirkung verfassungsrechtlicher Normen auf das Recht der sozialen Sicherheit, NJW 1960, S. $1641 \mathrm{ff}$.

Rosenkranz, Frank, Die Beschränkung der Rückwirkung von Entscheidungen des Europäischen Gerichtshofs, 2015

-, Gerichtlicher Vertrauensschutz gegen Rechtsprechung: Das Zusammenspiel von Unions- und nationalem Recht, ZfPW 2016, S. $351 \mathrm{ff}$.

-, Anmerkung, ZESAR 2018, S. $24 \mathrm{ff}$.

Rüffler, Friedrich, Richtlinienkonforme Auslegung nationalen Rechts, ÖJZ 1997, S. $121 \mathrm{ff}$.

Rüthers, Bernd/Höpfner, Clemens, Analogieverbot und subjektive Auslegungsmethode, JZ 2005, S. $21 \mathrm{ff}$.

Sachs, Michael (Hrsg.), GG, Grundgesetz, Kommentar, 8. Auflage 2018 [zitiert als Bearbeiter, in: Sachs (Hrsg.), GG, 8. Aufl. 2018] 
Sagan, Adam, Europäischer und nationaler Vertrauensschutz bei Rechtsprechungsänderungen im Arbeits- und allgemeinen Privatrecht, in: Aichberger-Beig, Daphne/Aspöck, Florian/Leupold, Petra/Oelkers, Janine/Perner, Stefan/Ramharter, Martin (Hrsg.), Vertrauen und Kontrolle im Privatrecht, Jahrbuch Junger Zivilrechtswissenschaftler 2010, 2011, S. 67 ff.

-, Nationaler Vertrauensschutz nach Junk: Das Ende eines deutschen Alleingangs, NZA 2015, S. $341 \mathrm{ff}$.

Sarmiento, Daniel, To bow at the rhythm of an Italian tune, Despite our Differences, Blog vom 5.12.2017, abrufbar unter https://despiteourdifferencesblog.wor dpress.com

Sauer, Heiko, „Solange“ geht in Altersteilzeit - Der unbedingte Vorrang der Menschenwürde vor dem Unionsrecht, NJW 2016, S. 1134 ff.

-, Mit den eigenen Waffen geschlagen: Die Reaktion des EuGH auf den unbedingten Vorrang der Menschenwürde vor dem Unionsrecht nach dem BVerfG, Verfassungsblog vom 7.4.2016, abrufbar unter https://verfassungsblog.de

-, Der novellierte Kontrollzugriff des Bundesverfassungsgerichts auf das Unionsrecht, EuR 2017, S. $186 \mathrm{ff}$.

-, Staatsrecht III - Auswärtige Gewalt, Bezüge des Grundgesetzes zu Völker- und Europarecht, 5. Auflage 2018

Schaer, Frank, Rechtssicherheit und Vertrauensschutz als Grenzen rückwirkender Rechtsprechung im europäischen Arbeitsrecht, 2010

Schermers, Henry G./Waelbroeck, Denis F., Judicial Protection in the European Union, 6. Auflage 2001

Schiek, Dagmar, Auslegung von $\$ 17 \mathrm{KSchG}$ im Lichte der Rechtsprechung des EuGH - Aspekte der vor dem BAG schwebenden Verfahren, AuR 2006, S. $41 \mathrm{ff}$.

Schima, Bernhard, Das Vorabentscheidungsverfahren vor dem EuGH - Unter besonderer Berücksichtigung der Rechtslage in Österreich und Deutschland, 2. Auflage 2004

Schlachter, Monika, Methoden der Rechtsgewinnung zwischen EuGH und der Arbeitsgerichtsbarkeit, ZfA 2007, S. 249 ff.

-, Entwicklungen im Individualarbeitsrecht unter dem Einfluss der Rechtsprechung des EuGH - erforderliche und entbehrliche Veränderungen, RdA 2009, Sonderbeilage zu Heft 5, S. 31 ff.

-, Grenzen zulässiger Rechtsfortbildung und Pflicht zur Umsetzung des Unionsrechts, EuZA 2015, S. $1 \mathrm{ff}$.

Schlücke, Katharina, Die Umsetzung von EuGH-Entscheidungen in das deutsche Steuerrecht - Das Beispiel der Betriebsstättenverluste, 2014

Schmahl, Stefanie, Der Beitritt der EU zur Europäischen Menschenrechtskonvention: Wo liegt das Problem?, JZ 2016, S. $921 \mathrm{ff}$.

-, The National Identity Criterion in the Crossfire Between European Integration and the Preservation of National Sovereignty, in: Breuer, Marten (Hrsg.), Principled Resistance to ECtHR Judgments - A New Paradigm?, 2019, S. 299 ff. 
Schmahl, Stefanie/Köber, Michael, Durchbrechung der Rechtskraft nationaler Gerichtsentscheidungen zu Gunsten der Effektivität des Unionsrechts?, EuZW 2010, S. $927 \mathrm{ff}$.

Schmid, Georg, Das Vorgehen gegen illegale Sportwetten in Bayern - Die Rechtslage nach dem Urteil des Bundesverfassungsgerichts vom 28.3.2006, GewArch 2006, S. $177 \mathrm{ff}$.

Schmidt-Bleibtreu, Bruno/Hofmann, Hans/Henneke, Hans-Günter (Hrsg.), GG, Kommentar zum Grundgesetz, 14. Auflage 2017 [zitiert als Bearbeiter, in: Schmidt-Bleibtreu/Hofmann/Henneke (Hrsg.), GG, 14. Aufl. 2017]

Schmitt, Laura, Anmerkung zu EuGH v. 13.12.2018 - C-385/17, Torsten Hein/Albert Holzkamm GmbH \& Co. KG, GPR 2019, S. 249 ff.

Schmitz, Holger/Krasniqi, Shqipe, Die Beschränkung der zeitlichen Wirkung von Urteilen in den Mitgliedstaaten der Europäischen Union - ein allgemeiner Rechtsgrundsatz mit Beachtungspflicht des EuGH in Vorlageverfahren -, EuR 2010, S. $189 \mathrm{ff}$.

Schmitz, Holger/Stammler, Philipp, Mehr Freiheiten für den nationalen Gesetzgeber! Die Rechtsprechung des EuGH und des BVerfG zur zeitlichen Beschränkung von Urteilswirkungen, AöR 136 (2011), S. 479 ff.

Schnapp, Friedrich E., Unbegrenzte Nachbesserung von Gesetzen bei unklarer und verworrener Rechtslage?, JZ 2011, S. 1125 ff.

Schneider, Anne, Die Wiederaufnahme rechtskräftig abgeschlossener nationaler Verfahren nach EuGH-Entscheidungen, EuR 2017, S. 433 ff.

Schönberger, Christoph, Der Rahmenbeschluss - Unionssekundärrecht zwischen Völkerrecht und Gemeinschaftsrecht, ZaöRV 67 (2007), S. $1107 \mathrm{ff}$.

-, Anmerkung, JZ 2016, S. 422 ff.

Schröder, Meinhard, Gesetzesbindung des Richters und Rechtsweggarantie im Mehrebenensystem, 2010

Schroeder, Werner, Grenzen der Rechtsprechungsbefugnis des EuGH, in: Altmeppen, Holger/Fitz, Hanns/Honsell, Heinrich (Hrsg.), Festschrift für Günther H. Roth zum 70. Geburtstag, 2011, S. 735 ff.

Schubert, Michael, Vertrauensschutzrechtsprechung zur Massenentlassung verletzt Recht auf ges. Richter, Anmerkung, AuR 2015, S. 233 ff.

Schürnbrand, Jan, Die Grenzen richtlinienkonformer Rechtsfortbildung im Privatrecht, JZ 2007, S. $910 \mathrm{ff}$.

Schwarz, Kyrill-Alexander, Vertrauensschutz als Verfassungsprinzip - Eine Analyse des nationalen Rechts, des Gemeinschaftsrechts und der Beziehungen zwischen beiden Rechtskreisen, 2002

Schwarze, Jürgen, Der Schutz der Grundrechte durch den EuGH, NJW 2005, S. $3459 \mathrm{ff}$.

Schwarze, Jürgen/Becker, Ulrich/Hatje, Armin/Schoo, Johann (Hrsg.), EU-Kommentar, 4. Auflage 2019 [zitiert als Bearbeiter, in: Schwarze/Becker/Hatje/Schoo (Hrsg.), EU-Kommentar, 4. Aufl. 2019] 


\section{Literaturverzeichnis}

Schweitzer, Michael/Dederer, Hans-Georg, Staatsrecht III, Staatsrecht, Völkerrecht, Europarecht, 12. Auflage 2020

Sedlmeier, Johannes, Urlaubsabgeltung ohne Grenzen?, EuZA 2010, S. $88 \mathrm{ff}$.

Seer, Roman, The Jurisprudence of the European Court of Justice: Limitation of the Legal Consequences?, European Taxation 2006, S. $470 \mathrm{ff}$.

Seer, Roman/Müller, Jörg Peter, Begrenzung der Wirkungen seiner Richtersprüche durch den EuGH, IWB 2008, S. 255 ff. [= Fach 11, Gruppe 2, Europäische Union, S. $851 \mathrm{ff}$.]

-, Begrenzung der Rechtsfolgen von EuGH-Richtersprüchen durch den nationalen Gesetzgeber, IWB 2008, S. $311 \mathrm{ff}$. [= Fach 11, Gruppe 2, Europäische Union, S. 865 ff.]

Seifert, Achim, Das Arbeitsrecht nach der Kücükdeveci-Entscheidung des EuGH und der Honeywell-Entscheidung des BVerfG, JbArbR 48 (2011), S. $119 \mathrm{ff}$.

Sellmann, Christian/Augsberg, Steffen, Entwicklungstendenzen des Vorlageverfahrens nach Art. 234 EGV, DÖV 2006, S. 533 ff.

Sharpston, Eleanor, The Shock Troops Arrive in Force: Horizontal Direct Effect of a Treaty Provision and Temporal Limitation of Judgments Join the Armoury of EC Law, in: Poiares Maduro, Miguel/Azoulai, Loïc (Hrsg.), The Past and Future of EU Law - The Classics of EU Law Revisited on the 50th Anniversary of the Rome Treaty, 2010, S. $251 \mathrm{ff}$.

Silveira, Alessandra/Perez Fernandes, Sophie, Preliminary References, Effective Judicial Protection and State Liability. What if the Ferreira da Silva Judgment had not been delivered?, Revista de Derecho Comunitario Europeo 54 (2016), S. $631 \mathrm{ff}$.

Simon, Denys, L'effet dans le temps des arrêts préjudiciels de la Cour de justice des Communautés européennes: enjeu ou prétexte d'une nouvelle guerre des juges?, in: Capotorti, Francesco/Ehlermann, Claus-Dieter/Frowein, Jochen/Jacobs, Francis G./Joliet, René/Koopmans, Thijmen/Kovar, Robert (Hrsg.), Du droit international au droit de l'intégration, Liber Amicorum Pierre Pescatore, 1987, S. $651 \mathrm{ff}$.

-, La panacée de l'interprétation conforme: injection homéopathique ou thérapie palliative?, in: Kronenberger, Vincent/D'Alessio, Maria Teresa/Placco, Valerio (Hrsg.), De Rome à Lisbonne: les juridictions de l'Union européenne à la croisée des chemins, Mélanges en l'honneur de Paolo Mengozzi, 2013, S. 279 ff.

Simon, Sven, Grenzen des Bundesverfassungsgerichts im europäischen Integrationsprozess, 2016

Smit, Hans/Herzog, Peter (Hrsg.), The Law of The European Economic Community - A Commentary on the EEC Treaty, Volume 4, 1976 (Loseblatt) [zitiert als Bearbeiter, in: Smit/Herzog (Hrsg.), The Law of The European Economic Community, Volume 4, 1976]

Somek, Alexander, Monism: A Tale of the Undead, in: Avbelj, Matej/Komárek, Jan (Hrsg.), Constitutional Pluralism in the European Union and Beyond, 2012, S. $343 \mathrm{ff}$. 
Sowery, Katy, Equivalent treatment of Union rights under national procedural law: Târşia, CMLRev. 53 (2016), S. 1705 ff.

-, Reconciling primacy and environmental protection: Association France Nature Environnement, CMLRev. 54 (2017), S. $1157 \mathrm{ff}$.

Spelge, Karin, Vertrauen in den Vertrauensschutz? - Unionsrecht und Änderung höchstrichterlicher Rechtsprechung, FA 2011, S. 34 ff.

Sperlich, Elisabeth, Der „Anlassfall“ vor dem VfGH und dem EuGH, in: Achatz, Markus/Ehrke-Rabel, Tina/Heinrich, Johannes/Leitner, Roman/Taucher, Otto (Hrsg.), Steuerrecht, Verfassungsrecht, Europarecht, Festschrift für Hans Georg Ruppe, 2007, S. $551 \mathrm{ff}$.

Sprenger, Markus, Kein Schutz des Vertrauens privater Arbeitgeber in die Anwendung altersdiskriminierender Gesetze, EuZA 2016, S. $460 \mathrm{ff}$.

Staffler, Lukas, Verfassungsidentität und strafrechtliche Verjährung - Das (vorläufige) Ende des Konflikts zweier Höchstgerichte in der Rechtssache Taricco, EuGRZ 2018, S. 613 ff.

Starke, Max Fabian, EU-Grundrechte und Vertragsrecht, 2016

Steinberg, Philipp/Bark, Felix, Anmerkung, EuZW 2007, S. 245 ff.

Steiner, Udo, Das Spannungsfeld zwischen europäischem Gemeinschaftsrecht und deutschem Verfassungsrecht, EuZA 2009, S. $140 \mathrm{ff}$.

Stelkens, Ulrich, Schützen deutsche Grundrechte vor deutschen unionsrechtswidrigen Rechtsakten?, in: Jochum, Heike/Elicker, Michael/Lampert, Steffen/Bartone, Roberto (Hrsg.), Freiheit, Gleichheit, Eigentum - Öffentliche Finanzen und Abgaben, Festschrift für Rudolf Wendt zum 70. Geburtstag, 2015, S. 467 ff.

Stern, Klaus, Das Staatsrecht der Bundesrepublik Deutschland, Band 1: Grundbegriffe und Grundlagen des Staatsrechts, Strukturprinzipien der Verfassung, 2. Auflage 1984

van der Stok, Eelco/Thomson, Andrew, Temporal Limitations to Tax Judgments of the European Court of Justice, Intertax 34 (2006), S. $552 \mathrm{ff}$.

Streinz, Rudolf, Die Realität des Anwendungsvorrangs des Gemeinschaftsrechts, EuZ 2006, S. $126 \mathrm{ff}$.

-, (Hrsg.), EUV/AEUV, Vertrag über die Europäische Union, Vertrag über die Arbeitsweise der Europäischen Union, Charta der Grundrechte der Europäischen Union, 3. Auflage 2018 [zitiert als Bearbeiter, in: Streinz (Hrsg.), EUV/AEUV, 3. Aufl. 2018]

Talos, Thomas/Arzt, Markus, The Winner Wetten Case and its Implications on the Primacy of EU Law, ELRep. 2010, S. $172 \mathrm{ff}$.

Tavakoli, Anusch/Westhauser, Martin, Vorlegen oder Durchentscheiden? - Kompetenzüberschreitung nationaler Gerichte bei Berechnung der Kündigungsfrist gem. \622 BGB?, DB 2008, S. $702 \mathrm{ff}$.

Temming, Felipe, Anmerkung, ZESAR 2015, S. $298 \mathrm{ff}$.

Terhechte, Jörg Philipp, Temporäre Durchbrechung des Vorrangs des europäischen Gemeinschaftsrechts beim Vorliegen „inakzeptabler Regelungslücken“?, EuR 2006, S. $828 \mathrm{ff}$. 


\section{Literaturverzeichnis}

Thiele, Alexander, Die Integrationsidentität des Art. 23 Abs. 1 GG als (einzige) Grenze des Vorrangs des Europarechts, EuR 2017, S. $367 \mathrm{ff}$.

Thömmes, Otmar, Zeitliche Wirkung von EuGH-Urteilen - Zugleich Anmerkung zu den Schlussanträgen der Frau Generalanwalt Stix-Hackl vom 14.3.2006 in der Rs. C-475/03, Banca Popolare di Cremona, IWB 2006, S. 375 ff. [= Fach 11A, Rechtsprechung, S. $1013 \mathrm{ff}$.]

-, Anmerkung, IWB 2006, S. 997 ff. [= Fach 11A, Rechtsprechung, S. 1099 ff.]

Thym, Daniel, Die Reichweite der EU-Grundrechte-Charta - Zu viel Grundrechtsschutz?, NVwZ 2013, S. 889 ff.

-, Vereinigt die Grundrechte!, JZ 2015, S. 53 ff.

-, Kommentar zum Verfassungsblogbeitrag „Belittling the Primacy of EU Law in Taricco II“ von Dana Burchardt vom 7.12.2017, abrufbar unter https://verfassun gsblog.de

Tillmanns, Kerstin, Zum Vertrauensschutz im Arbeitsvertragsrecht, in: Bauer, JobstHubertus/Kort, Michael/Möllers, Thomas M.J./Sandmann, Bernd (Hrsg.), Festschrift für Herbert Buchner zum 70. Geburtstag, 2009, S. 885 ff.

Timmerman, Mikhel, Balancing effective criminal sanctions with effective fundamental rights protection in cases of VAT fraud: Taricco, CMLRev. 53 (2016), S. $779 \mathrm{ff}$.

Timmermans, C.W.A., Directives: Their Effect within the National Legal Systems, CMLRev. 16 (1979), S. $533 \mathrm{ff}$.

Tomuschat, Christian, Die gerichtliche Vorabentscheidung nach den Verträgen über die europäischen Gemeinschaften, 1964

Toth, A. G., The Authority of Judgments of the European Court of Justice: Binding Force and Legal Effects, YEL 4 (1984), S. $1 \mathrm{ff}$.

Trabucchi, Alberto, L'effet «erga omnes» des décisions préjudicielles rendues par la Cour de justice des Communautés européennes, RTDEur. 1974, S. 56 ff.

Tridimas, Takis, Precedent and the Court of Justice - A Jurisprudence of Doubt?, in: Dickson, Julie/Eleftheriadis, Pavlos (Hrsg.), Philosophical Foundations of European Union Law, 2012, S. 307 ff.

Uffmann, Katharina, Das Verbot der geltungserhaltenden Reduktion, 2010

Ulmer, Michael J., Anmerkung, WuB 2017, S. $254 \mathrm{f}$.

von Ungern-Sternberg, Antje, Normative Wirkungen von Präjudizien nach der Rechtsprechung des Bundesverfassungsgerichts, AöR 138 (2013), S. 1 ff.

Unterreitmeier, Johannes, Glücksspielanbieter ohne Glück - Kein Schadensersatz trotz rechtswidriger Untersagung von Glücksspielen, NJW 2013, S. 127 ff.

Vandersanden, Georges, Note. De l'autorité de chose jugée des arrêts préjudiciels d'interprétation rendus par la Cour de justice des Communautés européennes, RCJB 1972, S. 508 ff.

Vanistendael, Frans, Consequences of the Acte Clair Doctrine for the National Courts and Temporal Effects of an ECJ Decision, in: Dourado, Ana Paula/da Palma Borges, Ricardo (Hrsg.), The Acte Clair in EC Direct Tax Law, 2008, S. $157 \mathrm{ff}$. 
Verstraelen, Sarah, The Temporal Limitation of Judicial Decisions: The Need for Flexibility Versus the Quest for Uniformity, GLJ 14 (2013), S. $1687 \mathrm{ff}$.

Vogel, Klaus, Der EuGH und die direkten Steuern, StuW 2005, S. $373 \mathrm{ff}$.

Vording, Henk/Lubbers, Allard, The ECJ, retrospectivity and the Member States' tax revenues, B.T.R. 2006, S. $91 \mathrm{ff}$.

Waldhoff, Christian, Die Rückwirkung von EuGH-Entscheidungen - Finanzielle Auswirkungen europäischer Rechtsprechung als Kriterium einer Entscheidungsfolgenabschätzung, EuR 2006, S. 615 ff.

-, Rückwirkung von EuGH-Entscheidungen, Zentrum für Europäisches Wirtschaftsrecht, Vorträge und Berichte, Nr. 155, 2006

Walter, Maja, Integrationsgrenze Verfassungsidentität - Konzept und Kontrolle aus europäischer, deutscher und französischer Perspektive, ZaöRV 72 (2012), S. $177 \mathrm{ff}$.

Weber, Martin, Grenzen EU-rechtskonformer Auslegung und Rechtsfortbildung, 2010

Weber-Dürler, Beatrice, Vertrauensschutz im öffentlichen Recht, 1983

de Weerth, Jan, Rückwirkende EuGH-Urteile und Bestandskraft von Steuerbescheiden, DStR 2008, S. $1669 \mathrm{ff}$.

Wegener, Bernhard, Verschroben verhoben! Traurige Einblicke in Karlsruher Parallelwelten, Verfassungsblog vom 5.5.2020, abrufbar unter https://verfassungsblog .de

Weiler, Frank, Grammatikalische Auslegung des vielsprachigen Unionsrechts, ZEuP 2010, S. $861 \mathrm{ff}$.

Weiß, Wolfgang, Die Einschränkung der zeitlichen Wirkungen von Vorabentscheidungen nach Art. 177 EGV, EuR 1995, S. 377 ff.

-, Bestandskraft nationaler belastender Verwaltungsakte und EG-Recht, DÖV 2008, S. $477 \mathrm{ff}$.

Wendel, Mattias, Kompetenzrechtliche Grenzgänge: Karlsruhes Ultra-vires-Vorlage an den EuGH, ZaöRV 74 (2014), S. 615 ff.

Wendenburg, Albrecht, Anmerkung, EuZW 2016, S. $115 \mathrm{f}$.

Weth, Stephan/Kerwer, Christof, Zur Bindungswirkung der Vorabentscheidungen des EuGH, in: Oetker, Hartmut/Preis, Ulrich/Rieble, Volker (Hrsg.), 50 Jahre Bundesarbeitsgericht, 2004, S. 1383 ff.

Wiedmann, Ariane, Non-retroactive or prospective ruling by the Court of Justice of the European Communities in preliminary rulings according to Article 234 EC, EuLF 2006, S. I-197 ff.

-, Zeitlos wie ungeklärt: Die Beschränkung der zeitlichen Wirkung von Urteilen des EuGH im Vorabentscheidungsverfahren nach Art. 234 EG, EuZW 2007, S. $692 \mathrm{ff}$.

Wildemeersch, Jonathan, Une loi inconstitutionnelle et contraire au droit de l'Union: et alors? Une déférence erronée vis-à-vis du législateur, J.T. 2018, S. 256 f.

Willers, Christian, Verfassungsgerichtliche Übergangsfristen im Mehrebenensystem - Am Beispiel der Sportwetten, 2011 


\section{Literaturverzeichnis}

Winter, J.A., Direct Applicability and Direct Effect - Two Distinct and Different Concepts in Community Law, CMLRev. 9 (1972), S. $425 \mathrm{ff}$.

Winter, Regine, Zur zeitlichen Wirkung von Urteilen des EuGH ("Gavieiro Gavieiro und Iglesias Torres”), jurisPR-ArbR 8/2011 Anm. 6

Wißmann, Hellmut, Vertrauensschutz - europäisch und deutsch, in: Baeck, Ulrich/Hauck, Friedrich/Preis, Ulrich/Rieble, Volker/Röder, Gerhard/Schunder, Achim (Hrsg.), Festschrift für Jobst-Hubertus Bauer zum 65. Geburtstag, 2010, S. $1161 \mathrm{ff}$.

-, Neues aus Karlsruhe zur Vorlagepflicht nach Art. 267 Abs. 3 AEUV, in: Faber, Ulrich/Feldhoff, Kerstin/Nebe, Katja/Schmidt, Kristina/Waßer, Ursula (Hrsg.), Gesellschaftliche Bewegungen - Recht unter Beobachtung und in Aktion, Festschrift für Wolfhard Kohte, 2016, S. $993 \mathrm{ff}$.

Woblfahrt, Christian, Die Vermutung unmittelbarer Wirkung des Unionsrechts Ein Plädoyer für die Aufgabe der Kriterien hinreichender Genauigkeit und Unbedingtheit, 2016

Wölker, Ulrich, Die Normenhierarchie im Unionsrecht in der Praxis, EuR 2007, S. $32 \mathrm{ff}$.

Wollenschläger, Ferdinand, Die Erga-omnes-Wirkung von EuGH-Urteilen in Vorabentscheidungsverfahren und die TK-Verkehrsdatenspeicherung, NJW 2018, S. $2532 \mathrm{ff}$.

Wusterhausen, Uwe, Die Wirkungen der Urteile des EuGH in der Zeit - Ein Beitrag zur Problematik der zeitlichen Beschränkung von Urteilswirkungen durch den Gerichtshof der Europäischen Union, 2016

Zeh, Ricarda, Anmerkung, ZESAR 2019, S. $301 \mathrm{ff}$.

Zöchling-Jud, Brigitta, Überlegungen zur unmittelbaren Wirkung von Unionsrecht, in: Jabloner, Clemens/Kucsko-Stadlmayer, Gabriele/Muzak, Gerhard/PertholdStoitzner, Bettina/Stöger, Karl (Hrsg.), Vom praktischen Wert der Methode, Festschrift Heinz Mayer zum 65. Geburtstag, 2011, S. 871 ff.

Zuck, Rüdiger, Der Schutz der Rechtsstellung der ehrenamtl. Verwaltungsrichter bei den Verwaltungsgerichten, DÖV 1960, S. $580 \mathrm{ff}$. 